Marine Biological Laboratory Library Woods Hole, Massachusetts

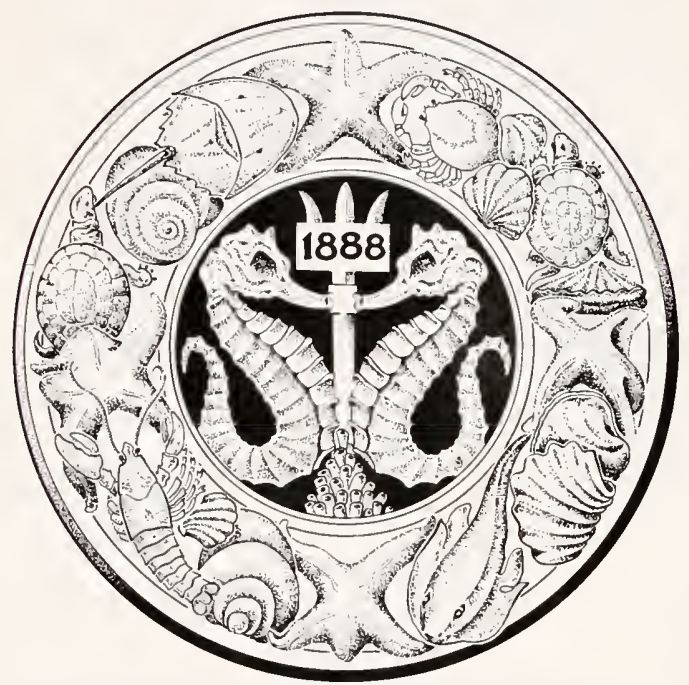

Gift of F.R. Lillie estate - 1on 

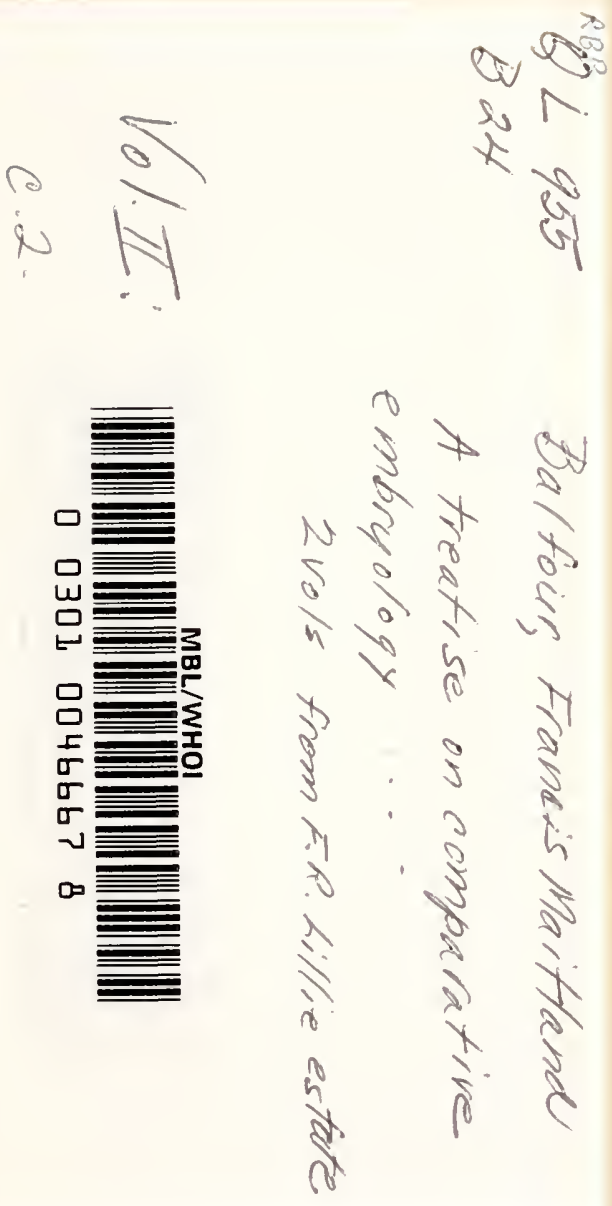





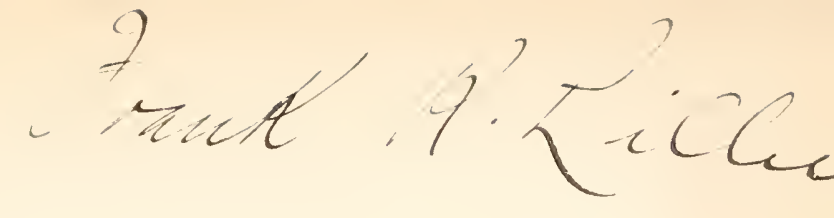

A TREATISE

ox

\section{COMPARATIVE EMBRYOLOGY.}




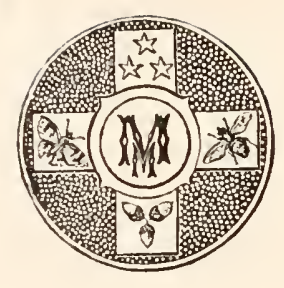




\section{A TREATISE}

ON

\section{COMPARATIVE EMBRYOLOGY}

BY

FRANCIS M. BALFOUR, LL.I., F.R.心., FELLOW AND LECTURET OF TEIXYTY COLLEGE, CAMETIDGE.

IN THO VOLUNESS.

VOL. II.

Zmondon:

MACMILLAN AND CO.

I 88 I

[The Right of Translation is reserved. 


\section{Cambrioge:}

SRIXTED BY C. J. CLAY, M.A. AT THE CXIVERSITY PHESS. 


\section{PREFACE TO VOLUME II.}

'He present volume completes my treatise on Comparative Embryology. The first eleven chapters deal with the developmental history of the Chordata. These are followed by three comparative chapters completing the section of the work deroted to Systematic Embryology. The remainder of the treatise, from Chapter XIV. onwards, is devoted to Organogeny. For the reasons stated in the introduction to this part the organogeny of the Chordata has been treated with much greater fulness than that of the other groups of Metazoa.

My own investigations have covered the ground of the present volume much more completely than they did that of the first volume; a not inconsiderable proportion of the facts recorded having been directly verified by me.

The very great labour of completing this volume has been much lightened by the assistance I have received from my friends and pupils. Had it not been for their co-operaB. E. II. 
tion a large number of the disputed points, which I have been able to investigate during the preparation of the work, must have been left untouched.

My special thanks are due to Mr. Sedgwick, who has not only devoted a very large amount of time and labour to correcting the proofs, but has made for me an index of this volume, and has assisted me in many other ways.

Dr Allen Thomson and Professor Kleinenberg of Messina have undertaken the ungrateful task of looking through my proof-sheets, and have made suggestions which have proved most valuable. To Professors Parker, Turner, and Bridge, I am also greatly indebted for their suggestions with reference to special chapters of the work. 


\section{CONTENTS OF VOLUME II.}

\section{Citapter I. Cepilalocilorda. Pp. $1-7$.}

Segmentation and formation of the layers, pp. 1, 2. Central nervous system, pp. 3, 4. Mesoblast, p. 5. General listory of larra, pp. 5-7.

\section{Chapter II. Urochorda. Pp. 8-32.}

Solitaria, pp. 8-18. Development of embryo, pp. 8-13. Growth and structure of free larva, pp. 13-16. Retrogressive metamorphosis, pp. 16-18. Sedentaria, p. 19. Natantia, pp. 19-23. Doliolide, pp. 23, 24. Salpida, pp. 24-28. Appendicularia, p. 28. Metagenesis, pp. 28-31.

Cimapter III. Elasmobranchil. Pp. 33-54.

Segmentation and formation of the layers, pp. 33-38. Epiblast, pp. 38, 39. Mesoblast, pp. 39-42. Hypoblast and notochord, pp. 42-45. General features of the embryo at successive stages, pp. 4j-51. The yolk-sack, pp. 51-54.

Cilapter IV. Teleostei. PP. 55-67.

Segmentation and formation of the layers, pp. 55-58. General history of the layers, pp. 58-61. General development of the embryo, pp. 61-66.

Chapter V. Ciclostomata. Pp. 68-83.

Segmentation and formation of the layers, pp. 68-71. Mesoblast and notochord, p. 71. General history of the development, pp. 72-80. Metamorphosis, pp. 80-82. Myxine, p. 82 .

Chapter VI. Ganoldei. Pp. 8t-9s.

Acipenser, pp. 81-91. Segmentation and formation of the layers, pp. 84-86. General development of the embryo and larva, pp. 86-91. Lepidusteus, pp. 91 - 98. Segmentation, pp. 91, 92. General development of embryo and larva, pp. 92-98. General observations on the embryology of Ganoids, p. 98.

Chapter VII. Auphibia. Pp. 99-119.

Oviposition and impregnation, pp. 99, 100. Formation of the layers, pp. 100 - 103. Epiblast, pp. 103-105. Mesoblast and notochord, pp. 105, 106. Hypoblast, pp. 107, 108. General growth of the embryo, pp. 108-118. Anura, pp. 108-116. Urodela, pp. 116-118. Gymnophiona, p. 118. 
Chapter VIII. Aves. Pp. 120-166.

Segmentation and formation of the layers, pp. 120-138. General history of the germinal layers, pp. 138-140. General development of the embryo, pp. 140 -150. Fœtal membranes, pp. 154-165. Amnion, pp. 154-158. Allantois, pp. 159, 160. Yolk-sack, pp. 161-165.

Chapter IX. Reptilia. Pp. 167-176.

Lacertilia, pp. 167-173. Segmentation and formation of the layers, pp. 167 -171. General development of the embryo, p. 172. Embryonic membranes and yolk-sack, pp. 172-173. Ophidia, pp. 173, 174. Chelonia, pp. 174, 175.

Chapter $\mathrm{X}$. Mimmala. Pp. 177-228.

Segmentation and formation of the layers, pp. 177-188. General growth of the embryo, pp. 188-192. Embryonic membranes and yolk-sack, pp. 193-198. Comparative history of the Mammalian foetal membranes, pp. 198-215. Comparative histology of the placenta, pp. 215, 216. Evolution of the placenta, pp. 216-218. Development of the Guinea-pig, pp. 218-221. The human embryo, pp. 221-- 226 .

Cinapter XI. Conparison of the formation of the germinal layers AND OF THE EARLY STAGES IN THE DEVELOPHENT OF Vertebrates. P1. 229-257.

Formation of the gastrula, pp. 229-212. The formation of the mesoblast and of the notochord, 1p. 243-249. The epiblast, pp. 249-252. Formation of the central nervous system, pp. 250-252. Formation of the organs of special sense, p. 252. Summary of organs derived from the three germinal layers, pp. 252--254. Growth in length of the Tertebrate embryo, pp. 254-256. The evolution of the allantois and amnion, pp. $256,257$.

Chapter Xil. Obseryations on the ancestral form of tine Ćmordata. $\mathrm{P}_{1}$. $258-273$.

General considerations, pp. 25s-262. The medullary canal, pp. 262, 263. The origin and nature of the month, pp. 263-266. The eranial flexure, pp. 266, 267. The postanal gut and neurenterie eanal, pp. 267-269. The body-cavity and mesoblastic somites, p. 269. The notochord, pp. 269, 270. Gill elefts, pp. 270, 271. Phylogeny of the Chordata, p1. 271-273.

Chapter NiJi. General Conclusions. Pp. $271-319$.

I. Mode of origin and homologies of the germinal layers, pp. $274-$ 297. Formation of the primary germinal layers, pp. 275, 276. Invagination, pp. 276, 277. Delamination, pp. 277-279. Phylogenetic significance of delamination and invagination, pp. 280-285. Homologies of the germinal lavers, pp. 285, 286. The origin of the mesoblast, pp. 286-297.

II. Larval forms: their nature, origin, and affinities. Preliminary considerations, pp. 297-299. Types of larva, pp. 299-316. Phylogenetie eonclusions, pp. 316, 317. General conclusions and summary, pl. 317, 318. 


\section{PART II. ORGANOGENY.}

Introduction. Pp. 323, 324.

Cifapter Xiv. Tile Epidermis and its Derivatives. Pp. 325-329.

Protectire epidermic structures, pp. 325-328. Dermal skeletal structures, p. 328. Glands, pp. 328, 329 .

\section{Chapter XV. The Nervous Systex. Pp. 330-386.}

The origin of the nervous system, pp. 330-335. Nervous system of the Invertebrata, pp. 335-341. Central nervous system of the Vertebrata, pp. 342368. Spinal chord, pp. 342-345. General development of the brain, pp. 345348. Hind-brain, pp. 348-352. Mid-brain, pp. 352, 353. General development of fore-brain, pp. 353, 354. Thalamencephalon, pp. 354-358. Pituitary body, pp. 358-360. Cerebral Hemispheres, pp. 360-366. Olfactory lobes, p. 366. General conclusions as to the central nervous system of the Vertebrata, pp. 366-368. Development of the cranial and spinal nerves, pp. 369-383. Spinal nerves, pp. 369 -374. Cranial nerves, pp. 374-383. Sympathetic nervous system, pp. 384-386.

Chapter XVI. Organs of Vision. Pp. 38 - 421.

Cœlenterata, p. 388. Mollusca, pp. 388-394. Chætopoda, p. 394. Chætognatha, pp. 394, 395. Arthropoda, pp. 395-398. Vertebrata general, pp. 398403. lietina, pp. 404, 405. Optic nerve, pp. 405, 406. Cloroid fissure, p. 406. Lens, pp. 406, 407. Vitreous humour, p. 407. Cornea, pp. 407-409. Aqueous lumour, p. 409. Comparative development of Tertebrate eye, pp. 409-416. Am. mocœte eye, pp. 409, 410. Optic vesicle, p. 410. Lens, p. 410. Cornea, p. 411. Optic nerve and choroid fissure, pp. 411- 416. Iris and ciliary processes, p. 416. Accessory organs connected with the eye, p. 416. Eyelids, pp. 416, 417. Lacrymal glands, p. 417. Lacrymal duct, pp. 417, 418. Fye of the Tunicata, pp. 418420. Accessory eyes in the Vertebrata, p. 420.

\section{C'hapter XVII. Auditory organ, Olfactory organ, and Sense organs} of the Lateral line. P. $422-446$.

Auditory organs, pp. 422-438. General structure of auditory organs, pp. 422-423. Auditory organs of the Coelenterata, pp. 423-424. Auditory organs of the Mollusca, pp. 424-42.5. Auditory organs of the Crustacea, p. 425. Auditory organs of the Tertebrata, pp. 425-436. Auditory vesicle, pp. 425-432. Organ of Corti, pp. 432-43t. Accessory structures connected with the organ of learing of terrestrial vertebrata, pp. 43j-436. Auditory organ of the Tunicata, pp. 436-437. Bibliography of Auditory organs, pp. 437-438.

Olfactory organs, pp. 438-143. Bibliography of Olfactory organs, p. 443. Sense organs of the lateral line, 1p. $413-44.5$. Bibliography of sense organs of lateral line, p. 416 .

Cinapter XVtil. The yotochord, the vertebral coluan, tite ribs, ANd the sterney. Pp. $447-464$.

Introductory' lemarks on the origin of the skeleton, pp. 447-449. Bibliography of the origin of the skeleton, p. 119. The notochord and its cartilaginous sheath 
pp. 449-453. The vertebral arches and the vertebral bodies, pp. 453-461. Cyclostomata, p. 453. Elasmobranchii, pp. 453-455. Ganoidei, p. 456. Teleostei p. 456. Amphibia, pp. 456-458. Reptilia, pp. 458-459. Aves, pp. 459-460. Mammalia, pp. 460-461. Bibliography of the notochord and vertebral column, pp. 461-462. Ribs, pp. 462-463. Sternum, pp. 463-464. Bibliography of the ribs and sternum, p. 464.

Cimapter Xix. Tile skull. Pp. 465-491.

Preliminary remarks, pp. 465-466. The cartilaginous cranium, pp. 466 -471. The parachordals and notochord, pp. 466-468. The trabeculæ, pp. 468471. The sense capsules, p. 471. The branchial skeleton, pp. $471-486$. General structure of, pp. 471-473. Mandibular and hyoid arches, pp. 479-486. Elasmobranchii, pp. 474-476. Teleostei, pp. 476-478. Amphibia, pp. 479483. Sauropsida, pp. 483-484. Mammalia, pp. 484-486. Membrane bones and ossifications of the cranium, pp. 486-490. Membrane bones, pp. 486489. Ossifications of the cartilaginous cranium, pp. 489-490. Labial cartilages, pp. $490-491$. Bibliography of the skull, p. 491.

Chapter XX. Pectoral axd pelyic girdles axd the skeleton of tile LIMBS. Pp. 492-511.

The Pectoral girdle, pp. 492-497. Pisces, pp. 492-493. Amphibia and Amniota, pp. 493-497. Lacertilia, p. 495. Chelonia, p. 495. Aves, pp. 495-496. Manmalia, p. 496. Amplibia, pp. 496-497. Bibliography of Pectoral girdle, p. 497.

The Pelvic girdle, pp. 497-499. Pisces, pp. 497-498. Amphitria and Amniota, 498-499. Amphibia, pp. 498-499. Lacertilia, p. 499. Mammalia, p. 499. Bibliography of Pelvic girdle, p. 499. Comparison of pectoral and pelvic girlles, p. 500 .

Limbs, pp. $500-511$. The piscine fin, $1 p .500$ - 508. The cheiropterygium, pp. 508-511. Biblio

Chapter XXt. Tine body Cavity, the vascular system axd the vasce-

$$
\text { LAR GLAXDS. Pr. 512-549. }
$$

The body cavity, pp. 512 -519. General, pp. 512-513. Chordata, pp. 513 -519. Abdominal pores, pp. 51t-515. Pericardial cavities, pleural cavities and diaphrngm, pp. 515-519. Bibliography of body cavity, p. 519.

The vascular system, pp. 519-517. General, pp. 513-520. The heart, pp. 520-529. Bibliography of the heart, p. 529. Arterial system, pp. 529-535. Bibliography of the arterial system, p. 535. Venous system, pp. 535-517. Bibliography of the venous system, p. 547. Lymphatic system and spleen, p. 547. Bib. liography of spleen, p. 547. Suprarenal bodies, pp. 547-549. Bibliography of suprarenal bodies, p. 549 .

\section{Chapter XXII. The muscular sistem. P1. 550-560.}

Evolution of muscle-cells, p. 550. Toluntary muscular system of the Chordata, pp. 551-560. Muscular fibres, p. 551. Muscular system of the trunk and limbs, pp. 5.51-557. The somites and museular system of the head, pp. 557-560. Bibliography of the muscular system, p. 560. 
Chapter XXiII. Excretory organs. Pp. 561 -609.

Platyelminthes, pp. 561-562. Mollusca, pp. 562-563. Polyzoa, p. 563. Branchiopoda, p. 563. Chætopoda, pp. 563-566. Gephyrea, pp. 566-567. Discophora, p. 567. Arthropoda, pp. 567-568. Nematoda, p. 568. Excretory organs and generative ducts of the Craniata, pp. 568-607. General, pp. 568-569. Elasmobranchii, pp. 569-576. Cyclostomata, pp. 577-578. Teleostei, pp. 578-580. Ganoidei, pp. 580-582. Dipnoi, p. 582. Amphibia, pp. 582-588. Amniota, pp. 589-599. General conclusions and summary, pp. 600-607. Pronephros, pp. 600-601. Mesonephros, pp. 601-603. Genital ducts, pp. 603606. Metanephros, pp. 606-607. Comparison of the excretory organs of the Chordata and Invertebrata, pp. 607-608. Bibliography of Excretory organs, pp. 608609.

Chapter XXiV. Generative organs and genital ducts. Pp. 610-619.

Generative organs, pp. 610-615. Porifera, p. 610. Cœelenterata, pp. 610 -611. Chætopoda and Gephyrea, p. 612. Chætognatha, pp. 612-613. Polyzoa, p. 613. Nematoda, p. 613. Insecta, p. 613. Crustacea, pp. 613-614. Chordata, pp. $614-615$. Bibliography of generative organs, pp. 615-616. Genital ducts, pp. 616-619.

Chapter XXV. The alimentary canal and its appendages, in the Chordata. Pp. 620-643.

Mesenteron, pp. 620-636. Subnotochordal rod, pp. 620-622. Splanchnic, mesoblast and mesentery, pp. 622-623. Respiratory division of the Mesenteron, pp. 623-630. Thyroid body, pp. 624-627. Thymus gland, p. 627. Swimming bladder and lungs, pp. 627-630. The middle division of the IIesenteron, pp. 630634. Cloaca, pp. 630-631. Intestine, pp. 631-632. Liver, pp. 632-633. Pan. creas, pp. 633-631. Postanal section of the Mesenteron, pp. 631-636.

The stomodæum, pp. 636-642. Comparative development of oral cavity, pp. 638-610. Teeth, pp. 610-612.

The proctodæum, pp. 612-643. Bibliography of alimentary canal, p. 613. 



\title{
EMBRYOLOGY.
}

\author{
CHAPTER I.
}

\section{CEPHALOCHORDA.}

THE developmental history of the Chordata has been studied far more completely than that of any of the groups so far considered; and the results which have been arrived at are of striking interest and importance. Three main subdivisions of this group can be recognized: (1) the Cephalochorda containing the single genus Amphioxus; (2) the Urochorda or 'Tunicata; and (3) the Vertebrata'. The members of the second and probably of the first of these groups have undergone degeneration, but at the same time the members of the first group especially undergo a less modified development than that of other Chordata.

\section{Cephalochorda.}

Our knowledge of the development of Amphioxus is mainly due to Kowalevsky (Nos. I and 2). The ripe eggs appear to be dehisced into the branchial or atrial cavity, and to be transported thence through the branchial clefts into the pharynx, and so through the mouth to the exterior. (Kowalevsky, No. I, and Marshall, No. 5.)

When laid the egg is about $0.105 \mathrm{~mm}$. in diameter. It is invested by a delicate membrane, and is somewhat opaque owing to the presence of yolk granules, which are however uniformly distributed through it, and proportionately less numerous than in the ova of most

1 The term Vertebrata is often used to include the Cephalochorda. It is in many ways convenient to restrict its use to the forms which have at any rate some indications of vertebræ; a restriction which has the further convenience of restoring to the term its original limitations. In the first volume of this work the term Craniata was used for the forms which I now propose to call Vertebrata.

B. E. II. 
Chordata. Impregnation is external and the segmentation is nearly regular (fig. 1). A small segmentation cavity is visible at the stage
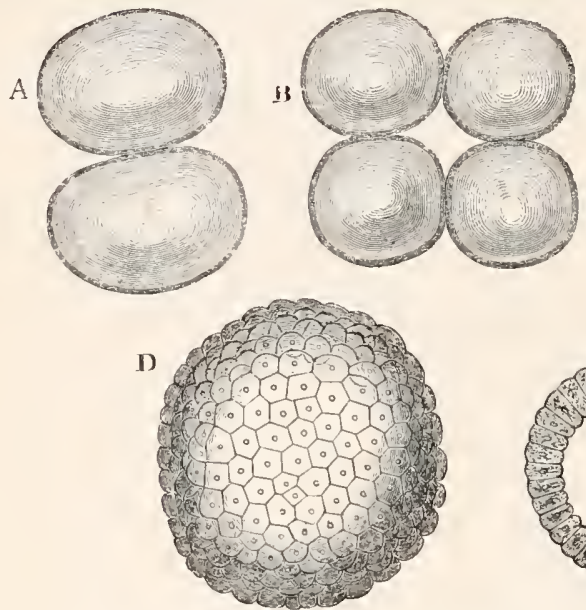

Fig. 1. The Segmentation of Auphioxus.

A. Stage with two equal segments.

B. Stage with four equal segments.

C. Stage after the four segments have become divided by an equatorial furrow into eight equal segments.

D. Stage in which a single layer of cells encloses a central segmentation cavity.

E. Somewhat older stage in optical section.

$s g$. segmentation cavity.

with four segments, and increases during the remainder of the segmentation; till at the close (fig. $1 \mathrm{E}$ ) the embryo consists of a blastosphere formed of a single layer of cells enclosing a large segmentation cavity. One side of the blastosphere next becomes invaginaterl, and during the process the embryo becomes ciliated, and commences to rotate. The cells forming the invaginated layer become gradually more columnar than the remaining cells, and constitute the hypoblast; and a structural distinction between the epiblast and hypoblast is thus established. In the course of the invagination the segmentation cavity becomes gradually obliterated, and the embryo first assumes a cup-shaped form with a wide blastopore, but soon becomes elongated, while the communication of the archenteron, or cavity of invagination, with the exterior is reduced to a small blastopore (fig. $2 \mathrm{~A}$ ), placed at the pole of the long axis which the subsequent development shews to be the hinder end of the embryo. The blastopore is often known in other Chordata as the anus of Rusconi. Before the invagination is completed the larva throws off the egg-membrane, and commences to lead a free existence.

Up to this stage the larva, although it has acquired a cylindrical elongated form, has only the structure of a simple two-layered gastrula; but the clanges which next take place give rise on the one 
hand to the formation of the central nervous system, and on the other to the formation of the notochord and mesoblastic somites ${ }^{2}$. The former structure is developed from the epiblast and the two latter from the hypoblast.

The formation of the central nervous system commences with the flattening of the dorsal surface of the embryo. The flattened area forms a plate (fig. $2 \mathrm{~B}$ and fig. $3 \mathrm{~A}, m p$ ), extending backwards to the blastopore, which has in the meantime passed round to the dorsal surface. The sides of the plate become raised as two folds, which are most prominent posteriorly, and meet behind the blastopore, but shade oif in front. The two folds next unite dorsally, so as to convert the previous groove into a canal² - the neural or medullary canal. They unite first of all over the blastopore, and their line of junction

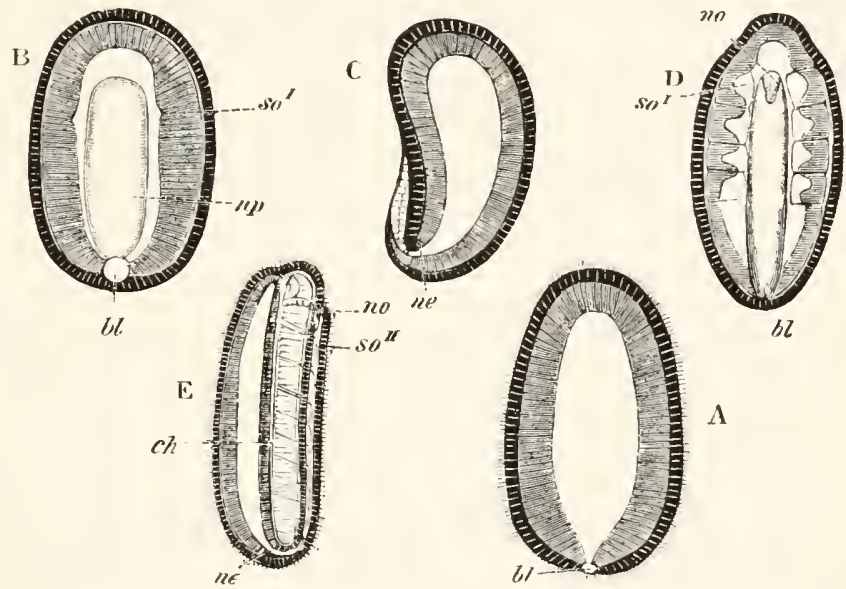

Fig. 2. Eubrios of Amphoxus. (After Kowalevsky.)

The parts in black with white lines are epiblastic; the shaded parts are hypoblastic.

A. Gastrula stage in optical section.

B. Slightly later stage after the neural plate $n p$ has become differentiated, seen as a transparent object from the dorsal side.

C. Lateral view of a slightly older larva in optical section.

D. Dorsal view of an older larva with the neural canal completely closed except for a small pore (no) in front.

E. Older larva seen as a transparent object from the side.

bl. blastopore (which becomes in $\mathrm{D}$ the neurenteric canal); ne. neurenteric canal; $n p$. neural or medullary plate; no. anterior opening of neural canal; ch. notochord; $s o^{\mathrm{I}}, s o^{\mathrm{II}}$. first and second mesoblastic somites.

extends from this point forwards (fig. 2 C, D, E). There is in this way formed a tube on the floor of which the blastopore opens behind, and which is itself open in front. Finally the medullary canal is formed for the whole length of the embryo. 'T'he anterior opening persists however for some time. The communication between the

1 The protovertebra of most embryologists will be spoken of as mesoblastic somites.

" The details of this process are spoken of below. 
neural and alimentary tracts becomes interrupted when the caudal fin appears and the anus is formed. The neural canal then extends round the end of the notochord to the ventral side, but subsequently retreats to the dorsal sile and terminates in a slight dilatation.

In the formation of the medullary canal there are two points deserving notice-viz. (1) the connection with the blastopore; (2) the relation of the walls of the canal to the adjoining epiblast. With reference to the first of these points it is clear that the fact of the blastopore opening on the floor of the neural canal causes a free communication to exist between the archenteron or gastrula cavity and the neural canal; and that, so long as the anterior pore of the neural canal remains open, the archenteron communicates indirectly with the exterior (vide fig. $2 \mathrm{E}$ ). It must not however be supposed (as has been done by some embryologists) that the pore at the front end of the neural canal represents the blastopore carried forwards. It is even probable that what Kowalevsky describes as the carrying of the blastopore to the dorsal side is really the commencement of the formation of the neural canal, the walls of which are continuous with the lips of the blastopore. This interpretation receives support from the fact that at a later stage, when the neural and alimentary canals become separated, the neural canal extends round the posterior end of the notochord to the ventral side. The embryonic communication between the neural and alimentary canals is common to most Chordata; and the tube connecting them will be called the neurenteric canal. It is always formed in fundamentally the same manner as in Amphioxus. With reference to the second point it is to be noted that Amphioxus is exceptional amongst the Chordata in the fact that, before the closure of the neural groove, the layer of cells which will form the neural tube becomes completely separated from the adjoining epiblast (fig. $3 \mathrm{~A}$ ), and forms a structure which may be spoken of as the medullary plate; and that in the closure of the neural canal the lateral epiblast forms a complete
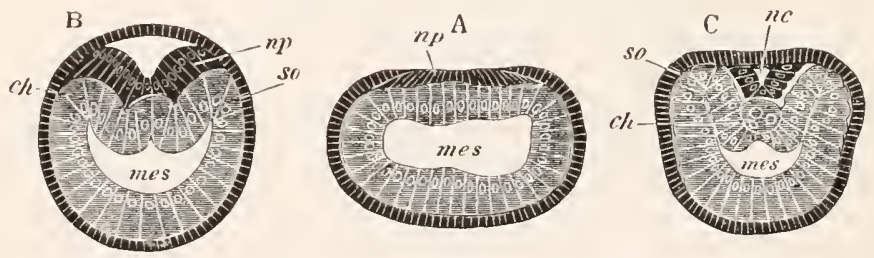

Fig. 3. Sections of an Amphioxus embryo at three stages. (After Kowalevsky.)

A. Section at gastrula stage.

B. Section of an embryo slightly younger than that represented in fig. $2 \mathrm{D}$.

C. Section through the anterior part of an embryo at the stage represented in fig. $2 \mathrm{E}$.

$n p$. newral plate; nc. neural canal; mes. archenteron in $\mathrm{A}$ and $\mathrm{B}$, and mesenteron in C; ch. notochord; so. mesoblastic somite. 
layer above this plate before the plate itself is folded over into a closed canal. This peculiarity will be easily understood from an examination of fig. $3 \mathrm{~A}, \mathrm{~B}$ and $\mathrm{C}$.

The formation of the mesoblastic somites commences, at about the same time as that of the neural canal, as a pair of hollow outgrowths of the walls of the archenteron. These outgrowths, which are shewn in surface view in fig. $2 \mathrm{~B}$ and $\mathrm{D}, s o$, and in section in fig. $3 \mathrm{~B}$ and $\mathrm{C}, s o$, arise near the front end of the body and gradually extend backwards as wing-like diverticula of the archenteric cavity. As they grow backwards their dorsal part becomes divided by transverse constrictions into cubical bodies (fig. $2 \mathrm{D}$ and $\mathrm{E}$ ), which, with the exception of the foremost, soon cease to open into what may now be called the mesenteron, and form the mesoblastic somites. Each mesoblastic somite, after its separation from the mesenteron, is constituted of two layers, an inner one-the splanchnic-and an outer - the somatic, and a cavity between the two which was originally continuous with the cavity of the mesenteron. Eventually the dorsal parts of the outgrowths become separated from the ventral, and form the muscle-plates, while their cavities atrophy. 'The cavity of the ventral part, which is not divided into separate sections by the above described constrictions, remains as the true body cavity. The ventral part of the inner layer of the mesoblastic outgrowths gives rise to the muscular and comnective tissue layers of the alimentary tract, and the dorsal part to a section of the voluntary muscular system. The ventral part of the outer layer gives rise to the somatic mesoblast, and the dorsal to a section of the voluntary muscular system. The anterior mesoblastic somite long retains its communication with the mesenteron, and was described by Max Schultze, and also at first by Kowalevsky, as a glandular organ. While the mesoblastic somites are becoming formed the dorsal wall of the mesenteron develops a median longitudinal fold (fig. $3 \mathrm{~B}, c h$ ), which is gradually separated off from before backwards as a rod (fig. :) C,ch), underlying the central nervous system. This rod is the notochord. After the separation of those parts the remainder of the hypoblast forms the wall of the mesenteron.

With the formation of the central nervous system, the mesoblastic somites, the notochord, and the alimentary tract the main systems of organs are established, and it merely remains briefly to describe the general changes of form which accompany the growth of the larva into the adult. By the time the larva is but wwenty-four hours old there are formed about seventeen mesoblastic somites. The body, during the period in which these are being formed, remains cylindrical, but shortly afterwards it becomes pointed at both ends, and the caudal fin appears. The fine cilia covering the larva also become replaced by long cilia, one to each cell. The mesenterom is still completely closed, but on the right side of the body, at the level of the front end of the mesenteron, the hypoblast and epiblast now grow together, and a perfuration becomes formed through their point 
of contact, which becomes the mouth. The anus is probably formed abont the same time if not somewhat earlier ${ }^{1}$.

Of the subsequent changes the two most important are (1) the formation of the gill slits or clefts; (2) the formation of the peribranchial or atrial cavity.

The formation of the gill slits is, according to Kowalevsky's description, so peculiar that one is almost tempted to suppose that his observations were made on pathological specimens. The following is his account of the process. Shortly after the formation of the mouth there appears on the ventral line a coalescence between the epiblast and hypoblast. Here an opening is formed, and a visceral cleft is thus established, which passes to the left side, viz. the side opposite the month. A second and apparently a third slit are formed in the same way. The stages immediately following were not observed, but in the next stage twelve slits were present, no longer however on the left side, but in the median ventral line. There now appears on the side opposite the mouth, and the same therefore as that originally occupied by the first three clefts, a series of fresh clefts, which in their growth push the original clefts over to the same side as the mouth. Each of the fresh clefts becomes divided into two, which form the permanent clefts of their side.

The gill slits at first open freely to the exterior, but during their formation two lateral folds of the body wall, containing a prolongation of the body cavity, make their appearance (fig. 4 A), and grow downwards over the gill clefts, and finally meet and coalesce along the
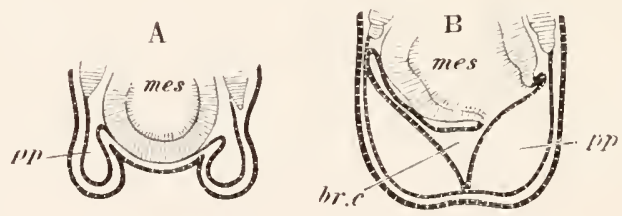

Fit. 4. Sections throvgh two anvanced embryos of Amphioxus to shew the Foriation of the PERIBRANCHIAL CAVity. (After Kowalevsky.)

In $A$ are seen two folds of the body wall with a prolongation of the body cavity. In $B$ the two folds have coalesced ventrally, forming a cavity into which a branchial cleft is seen to open.

mes. mesenteron; br.c. branchial cavity; $p p$. body cavity.

ventral line, leaving a widish cavity between themselves and the body wall. Into this cavity, which is lined by epiblast, the gill clefts open (fig. $4 \mathrm{~B}, b r . c$ ). This cavity - which forms a true peribranchial cavityis completely closed in front, but owing to the folds not uniting completely behind it remains in communication with the exterior by an opening known as the atrial or abdominal pore.

1 The lateral position of the mouth in the embryo Amphioxus has been regarded as proving that the mouth represents a branchial cleft, but the general asymmetry of the organs is such that no great stress can, I think, be laid on the position of the mouth. 
The vascular system of Amphioxus appears at about the same time as the first visceral clefts.

\section{BibliogRaphi.}

(1) A. Kowalevsky. "Entwicklungsgeschichte des Amphioxus lanceolatus." Ilề. Acad. Impér. des Sciences de St Pétèrsbourg, Series vir. Tom. xi. 1867.

(2) A. Kowalevsky. "Weitere Studien iiber die Entwicklungsgeschichte des Amphioxus lanceolatus." Archiv f. mikr. Anat., Vol. xIII. 1877.

(3) Lenckart u. Pagenstecher. "Untersuchungen iber niedere Seethiere." Müller's Archir, 1858.

(t) Max Schultze. "Beobachtung junger Exemplare ron Amphioxus." Zeit. f. wiss. Zool., Bd. III. 1851.

(Б) A. M. Marshall. "On the mode of Oviposition of Amphioxus." Jour. of Anut. and Phys., Vol. x. 1876. 


\section{CHAPTER II.}

\section{UROCHORDA ${ }^{1}$.}

Is the Solitaria, except Cynthia, the eggs are generally laid, and impregnation is effected sometimes before and sometimes after the eggs have left the atrial cavity. In Cynthia and most Caducichordata development takes place within the body of the parent, and in the Salpidxe a vascular connection is established between the parent and the single foetus, forming a structure physiologically comparable with the Mammalian placenta.

Solitaria. The development of the Solitary Ascidians has been more fully studied than that of the other groups, and appears moreover to be the least modified. It has been to a great extent elucidated by the splendid researches of Kowalevsky (Nos. I 8 and 20), whose statements have been in the main followed in the account below. Their truth seems to me to be established, in spite of the scepticism they have met with in some quarters, by the closeness of their correspondence with the developmental phenomena in Amphioxus.

The type most fully investigated by Kowalevsky is Ascidia (Phallusia) mammillata; and the following description must be taken as more especially applying to this type.

The segmentation is complete and regular. A small segmentation cavity appears fairly early, and is surrounded, according to Kowalevsky, by a single layer of cells, though on this point Kupffer (No. 27) and Giard (No. I I) are at variance with him.

1 The following classification of the Urochorda is adopted in the present chapter.

I. Caducichordata.
A. Simplicia
\{Solitaria ex. Ascidia.
\{Socialia ex. Clavellina.
B. Composita (Sedentaria ex. Botryllus C. Conserta iSalpidre.

II Perennichordata. 
The segmentation is followed by an invagination of nearly the same character as in Amphioxus. The blastosphere resulting from the segmentation first becomes flattened on one side, and the cells on the flatter side become more columnar (fig. 8 I.). Very shortly a cup-shaped form is assumed, the concavity of which is lined by the more columnar cells. The mouth of the cup or blastopore next becomes narrowed; while at the same time the embryo becomes oval. The blastopore is situated not quite at a pole of the oval but in a position which subsequent development shews to be on the dorsal side close to the posterior end of the embryo. 'The long axis of the oval corresponds with the long axis of the embryo. At this stage the embryo consists of two layers; a columnar hypoblast lining the central cavity or archenteron, and a thinner epiblastic layer. The dorsal side of the embryo next becomes flattened (fig. S II.), and the epiblast covering it is shortly afterwards marked by an axial groove continued forwards from the blastopore to near the front end of the body (fig. $5, m g$ ). This is the medullary groove, and it soon becomes converted into a closed canal - the medullary or neural canalbelow the external skin (fig. $6, n . c$ ).

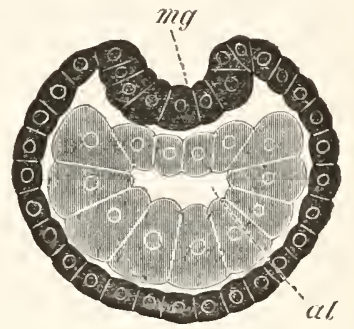

Fig. 5. Transverse section THROUGH THE FRONT END OF AN EMmexo of Phallesia maminllata. (After Kowalevsky.)

The embryo is slightly younger than that represented in fig. 811 .

my. medullary groove; al. alimentary tract.

'The closure is effected by the fulds on each side of the furrow meeting and coalescing dorsally. The original medullary folds fall into one another behind the blastopore, so that the blastopore is situated on the floor of the groove, and, on the conversion of the groove into a canal, the blastopore commects the canal with the archenteric cavity, and forms a short neurenteric canal. The closure of the medullary canal commences at the blastopore and is thence continued forwards, the anterior end of the canal remaining open. The above processes are represented in longitudinal section in fig. 8 III, $n$. When the neural canal is completed for its whole length, it still communicates by a terminal pore with the exterior. In the relation of the medullary canal to the blastopore, as well as in the closure of the medullary groove from behind forwards, the Solitary Ascidians agree closely with Amphioxus.

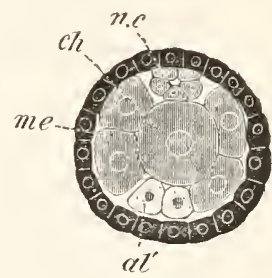

Fig. 6. Transverse opticar SECTION OF THE TAIL OF AN EMbrio of Phallusia mammlifata. (After Kowalevsky.)

The section is from an embryo of the same age as fig. 8 Iv.

ch. notochord; n.c. nellral canal; me. mesoblast; al. hypoblast of tail. 
The cells of the dorsal wall of the archenteron immediately adjoining the front and sides of the blastopore have in the meantime assumed a somewhat different character from the remaining cells of the archenteron, and give rise to a body which, when viewed from the dorsal surface, has somewhat the form of a horseshoe. 'This body was first observed by Metschnikoff. On the elongation of the embryo and the narrowing of the blastopore the cells forming this body arrange themselves as a broad linear cord, two cells wide, underlying about the posterior half of the neural canal (fig. 7, ch). They form the rudiment of the notochord, which, as in Amplioxus, is derived from the dorsal wall of the archenteron. They are seen in longitudinal section in fig. 8 II. and III. ch.

With the formation of the notochord the body of the embryo becomes divided into two distinct regions-a posterior region where the notochord is present, and an anterior region into which it is not prolonged. These two regions correspond with the tail and the trunk of the embryo at a slightly later stage. The section of the archenteric cavity in the trunk dilates and constitutes the permanent mesenteron (figs. 7, $a l$, and 8 III. and IV. $d d$ ). It soon becomes shut off

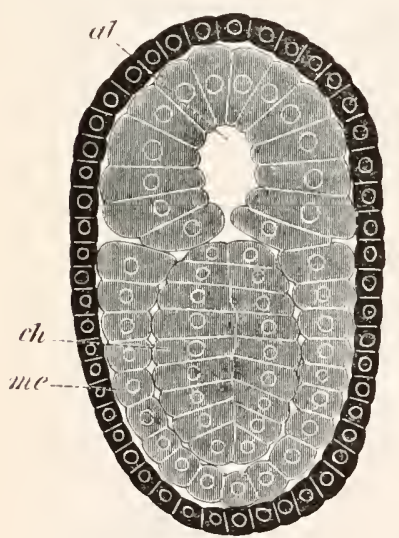

F1g. 7. Optical Section of ay embrio of Phallusia maumillata. (After Kowalevsky.)

The embryo is of the same age as fig. $8 \mathrm{~m}$, but is seen in longitudinal horizontal section.

$a l$. alimentary tract in anterior part of boly; $c h$. notochord; me. inesoblast. attention of other observers. It is stated by Kowalevsky to be eventually transformed into blood corpuscles. 'I'he neurenteric canal leads at first into the narrow space between the above structures, which is the remnant of the posterior part of the lumen of the archenteron. Soon both the neurenteric canal and the candal remnant of the archenteron become obliterated. 


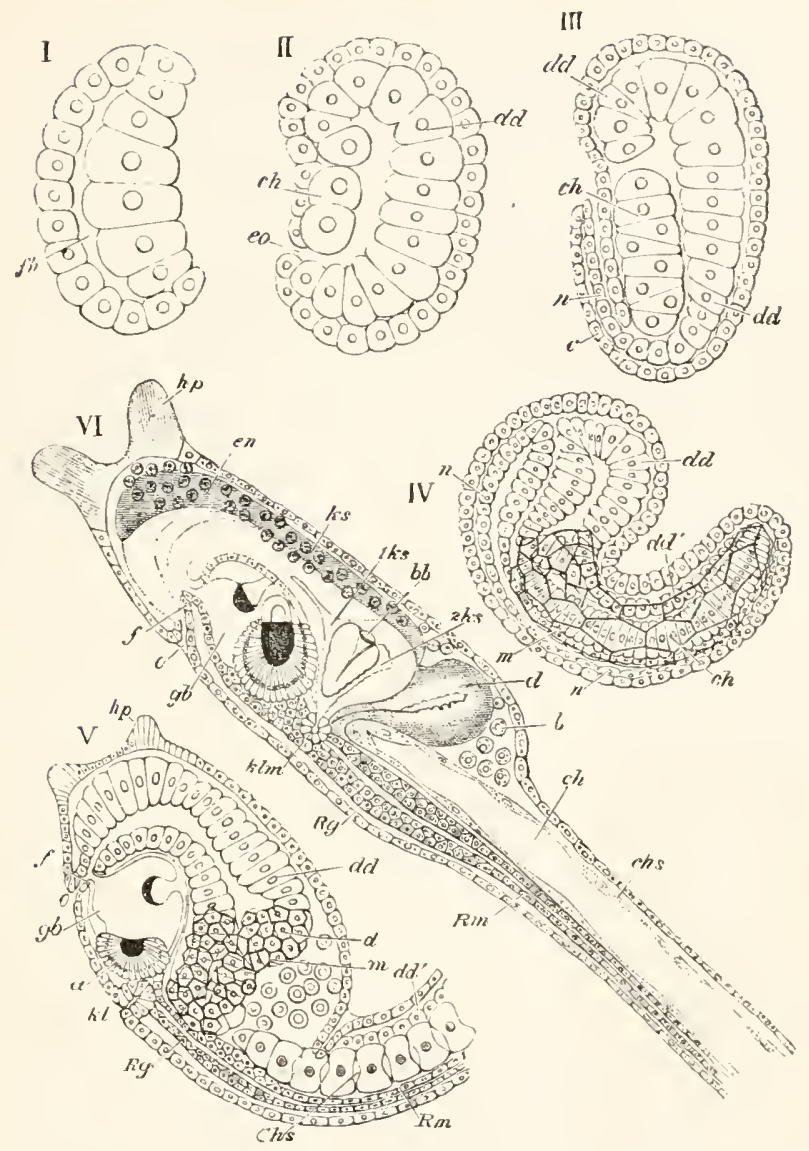

Fig, 8. Variots stages in the developmext of Phallusid mamillata.

(From Huxley; after Kowalevsky.)

The embryos are represented in longitudinal vertical section.

I. Commencing gastrula stage. fh. segmentation cavity.

II. Late gastrula stage with flattened dorsal sufface. eo. blastopore; ch. notochord; $d d$. hypoblast.

III. A more advanced embryo with a partially-formed neural tube. ch. and $d d$. as before; $n$. neural tube; $c$. epiblast.

IV. Older embryo in which the formation of the neural tube is completed. ald. hypoblast enclosing persistent section of alimentary tract; $d d^{\prime}$. hypoblast in the tail; $m$. muscles.

V. Larva just hatched. The end of the tail is not represented. a. eye; gl. dilated extremity of neural tube with otolith projecting into it; $R g$. antcrior swelling of the spinal division of the neural tube; $f$. anterior pore of netral tube; $R m$. posterior part of neural tube; $n$. mouth; Chs. notochord; $k l$. atrial invagination; $d d$. branchial region of alimentary tract; $d$. commeneement of esophagus and stomach; dd'. hypoblast in the tail; $m$. museles; $h p$. papilla for attachment.

VI. Body and anterior part of the tail of a two days' larva. $k \mathrm{~km}$. atrial aperture; $e n$. endostyle; $k s$. branchial sack; $1 \mathrm{ks}, 2 \mathrm{k} s$. branchial slits; $b b$. branchial vessel between them; $c h$. axial portion of notochord; $c h$ s. peripheral layer of cells. Other reference letters as before. 
During the above changes the tail becomes considerably elongated and, owing to the larva being still in the egg-shell, is bent over to the ventral side of the trunk.

The larva at this stage is represented in a side view in fig. 8 IV. The epidermis is formed throughont of a single layer of cells. In the trunk the mesenteron is shewn at $d d$ and the dilated part of the nervous system, no longer communicating with the exterior, at $n$. In the tail the notochord is shewn at $c h$, the muscles at $m$, and the solid remnant of the ventral wall of the archenteron at $d d^{\prime}$. The delicate continuation of the nenral canal in the tail is seen above the notochord at $n$. An optical section of the tail is shewn in fig. (6. It is worthy of notice that the notochord and muscles are formed in the sane manner as in Amphioxus, except that the process is somewhat simplified. The mode of disappearance of the archenteric cavity in the tail, by the employment of the whole of its walls in the formation of various organs, is so peculiar, that I feel some hesitation in accepting Kowalevsky's statements on this head ${ }^{1}$.

The larva continues to grow in length, and the tail becomes further curled round the ventral side of the body within the eggmembrane. Before the tail has nearly reached its full length the test becomes formed as a cuticular deposit of the epiblast cells (O. Hertwig, No. I3, Semper, No. 37). It appears first in the tail and gradually extends till it forms a complete investment round both tail and trunk, and is at first totally devoid of cells. Shortly after the establishment of the test there grow out from the anterior end of the body three peculiar papille, developed as simple thickenings of the epidermis. At a later stage, after the hatching of the larva, these papillw develop glands at their extremities, secreting a kind of glutinous thuid ${ }^{2}$. After these papilla have become formed cells first make their appearance in the test; and there is simultaneously formed a fresh inner cuticular layer of the test, to which at first the cells are confined, though subsequently they are found in the outer layer also. On the appearance of cells in the test the latter must be regarded as a form, though a very abuormal one, of connective tissue. When the tail of the larva has reached a very considerable length the egg-membrane bursts, and the larva becomes free. The hatching takes place in Asc. canina about $4 \$-60$ hours after impregnation. The free larva (fig. 8 v.) has a swollen trunk, and a very long tail, which soon becomes straightened out. It has a striking resemblance to a tadpole (vide tig. 10).

In the free larval condition the Ascidians lave in many respects a higher organization than in the adult state. It is accordingly

1 It is more probable that this part of the alimentary tract is equivalent to the post-anal gut of many Vertebrata, which is at first a complete tube, but disappears later by the simple absorption of the walls.

2 It is probable that these papillix are very primitive organs of the Chordata. Structures, which are probably of the same nature, are fomed behind the mouth in the larve of Amphibia, and in front of the month in the larve of Ganoids (Acipenser, Lepidostens), and are nsed by these larve for attahing themselves. 
convenient to divide the subsequent development into two periods, the first embracing the stages from the condition represented in fig. $8 \mathrm{v}$. up to the full development of the free larva, and the second the period from the full development of the larva to the attainment of the fixed adult condition.

\section{Growite and Structure of the fiee laria.}

The nervous system. The nervous system was left as a closed tube consisting of a dilated anterior division, and a narrow posterior one. The former may be spoken of as the brain, and the latter as the spinal cord; although the homologies of these two parts are quite uncertain. The anterior part of the spinal cord lying within the trunk dilates somewhat (fig. $8 \mathrm{~V}$. and vI. $R g$ ) and there may thus be distinguished a trunk and a caudal section of the spinal cord.

The original single vesicle of the brain becomes divided by the time the larva is hatched into two sections (fig. 9)-(1) an anterior vesicle with, for the most part, thin walls, in which unpaired anditory and optic organs make their appearance, and (2) a posterior nearly solid cephalic ganglion, through which there passes a narrow continuation of the central canal of the nervous system. This ganglion consists of a dorsal section formed of distinct cells, and a ventral section formed of a punctated material with nuclei. The auditory organ ${ }^{1}$ consists of a 'crista acustica' (fig. 9), in the form of a slight prominence of columnar cells on the ventral side of the anterior cerebral vesicle; to the summit of which a spherical otolith is attached by fine hairs. In the crista is a cavity containing clear fluid. The dorsal half of the otolith is pigmented: the ventral half is without pigment. The crista is developed in situ, but the otolith is formed

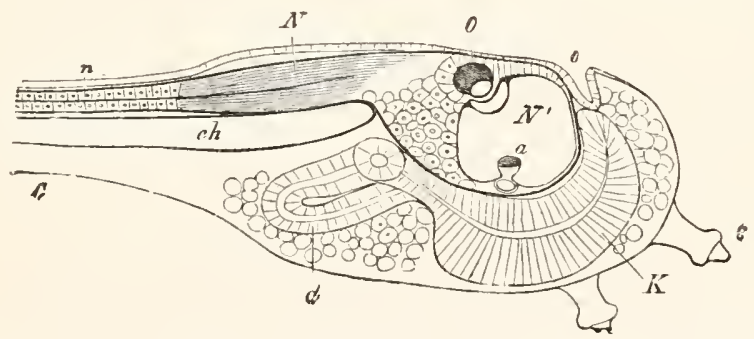

Fig. 9. Lakfa of Ascidia mentula. (From Gegenbaur; after Kupffer.) Only the anterior part of the tail is represented.

$N^{\prime}$. anterior swelling of neural tube; $N$. anterior swelling of spinal portion of nenral tube; $n$. hinder part of neural tube; $c h$. notochord; $\bar{K}$. branchial region of alimentary tract; $d$. œesophageal and gastric region of alimentary tract; 0 . eye; a. otolitb; o. mouth; s. papilla for attachment.

from a single cell on the dorsal side of the cerebral vesicle, which forms a projection into the cavity of the vesicle, and then travels (in

1 For a fuller account of the organs of sense ride the clapters on the eye and ear. 
a manner not clearly made out) round the right side of the vesicle till it comes to the crista; to which it is at first attached by a narrow pedicle. The fully developed eye (figs. 8 vi. and $9, O$ ) consists of a cup-shaped retina, whicl forms a prominence slightly on the right side of the posterior part of the dorsal wall of the anterior cerebral vesicle, and of refractive media. The retina is formed of columnar cells, the inner ends of which are imbedded in pigment. The refractive media of the eye are directed towards the cavity of the cerebral vesicle, and consist of a biconvex lens and a meniscus. Half the lens is imbedded in the cavity of the retina and surrounded by the pigment, and the other half is turned toward a concavo-convex meniscus which corresponds in position with the cornea. The development of the meniscus and lens is unknown, but the retina is formed (fig. $8 \mathrm{v}$. a) as an outgrowth of the wall of the brain. At the inner ends of the cells of this outgrowth a deposit of pigment appears.

The trunk section of the spinal cord (fig. 9, $N$ ) is separated by a sharp constriction from the brain. It is formed of a superficial layer of longitudinal nervous fibres, and a central core of ganglion cells. The layer of fibres diminishes in thickness towards the tail, and finally ceases to be visible. Kupffer detected three pairs of nerves passing off from the spinal cord to the muscles of the tail. The foremost of these arises at the boundary between the trunk and the tail, and the two others at regular intervals behind this point.

The mesoblast and muscular system. It has already been stated that the lateral walls of the archenteron in the tail give rise to muscular cells. These cells lie about three abreast, and appear not to increase in number; so that with the growth of the tail they grow enormously in length, and eventually become imperfectly striated. 'The mesoblast cells at the hinder end of the trunk, close to its junction with the tail, do not become converted into muscle cells, but give rise to blood corpuscles; and the axial remnant of the archenteron undergoes a similar fate. According to Kowalevsky the heart is formed during larval life as an elongated closed sack on the right sile of the endostyle.

The notochord. 'The notochord was left as a rod formed of a single row of cells, or in As. canina and some other forms of two rows, extending from just within the border of the trunk to the end of the tail.

According to Kowalevsky, Kupffer, Giard, etc. the notochord undergoes a further development which finds its only complete parallel amongst Chordata in the doubtful case of Amphioxus.

There appear between the cells peculiar highly refractive dises (fig. $8 \mathrm{v}$. Chs). These become larger and larger, and finally, after pushing the remnants of the cells with their nuclei to the sides, coalesce together to form a continuous axis of hyaline substance. The remnants of the cells with their nuclei form a sheath round the liyaline axis (fig. 8 vi. cl.). Whether the axis is to be regarded as formed of an intercellular substance, or of a differ- 
entiation of parts of the cells is still doubtful. Kupffer inclines to the latter view: the analogy of the notochord of higher types appears to me to tell in favour of the former one.

The alimentary tract. The anterior part of the primitive archenteron alone retains a lumen, and from this part the whole of the permanent alimentary tract (mesenteron) becomes developerl. The anterior part of it grows upwards, and before hatching an involition of the epiblast on the dorsal side, just in front of the anterior extremity of the nervous system, meets and opens into this upgrowth, and gives rise to the permanent mouth (fig. $\$$ V.o).

Kowalevsky states that a prore is formed at the front end of the nervous tube leading into the mouth (tig. 8 v. and VI. $f$ ) which eventually gives rise to the ciliated sack, which lies in the adult at the junction between the month and the branchial sack. Kupffer however was unable to find this opening; but Kowalersky's observations are confirmed by those of Salensky on Salpa.

From the hinder end of the alimentary sack an outgrowth directed dorsalwards makes its appearance (figs. 8 v. and 9, d), from which the asophagus, stomach and intestine become developed. It at first ends blindly. The remainder of the primitive alimentary sack gives rise to the branchial sack of the adult. Just after the larva has become hatched, the outgrowth to form the stomach and œsophagus, etc. bends ventralwards and to the right, and then turns again in a dorsal and left direction till it comes close to the dorsal surface, somewhat to the left of and close to the hinder end of the trunk. The first ventral loop of this part gives rise to the oesophagus, which opens into the stomach; from this again the dorsally directed intestine passes off.

On the ventral wall of the branchial sack there is formed a narrow fold with thickened walls, which forms the endostyle. It ends anteriorly at the stomodxum and posteriorly at the point where the solid remnant of the archenteron in the tail was primitively continuous with the branchial sack. The whole of the alimentary wall is formed of a single layer of hypoblast cells.

A most important organ connected with the alimentary system still remains to be dealt with, viz. the atrial or peribranchial cavity. The first rudiments of it appear at about the time of hatching, in the form of a pair of dorsal epiblastic involutions (fig. $8 \mathrm{v} . k l$ ), at the level of the junction between the brain and the spinal cord. These involutions grow inwards, and meet corresponding outgrowths of the branchial sack, with which they fuse. At the junction between them is formed an elongated ciliated slit, leading from the branchial sack into the atrial cavity of each side. The slits so formed are the first pair of branchial clefts. Belind the first pair of branchial clefts a second pair is formed during larval life by a second outgrowth of the branchial sack meeting the epiblastic atrial involutions (fig. 8 vi. 1ks and 2lis). The intestine at first ends blindly close to the left atrial involntion, but the anus becomes eventually formed by an opening 
being established between the left atrial involution and the intestine.

During the above described processes the test remains quite intact, and is not perforated at the oral or the atrial openings.

\section{The retrogressive metamorphosis of the larva.}

The development of the adult from the larva is, as has already been stated, in the main a retrogressive metamorphosis. The stages in this metamorphosis are diagrammatically shewn in figs. 10 and 11. It commences with the attachment of the larva (fig. $10 \mathrm{~A}$ ) which takes place by one of the three papillse. Simultaneously with the attach-

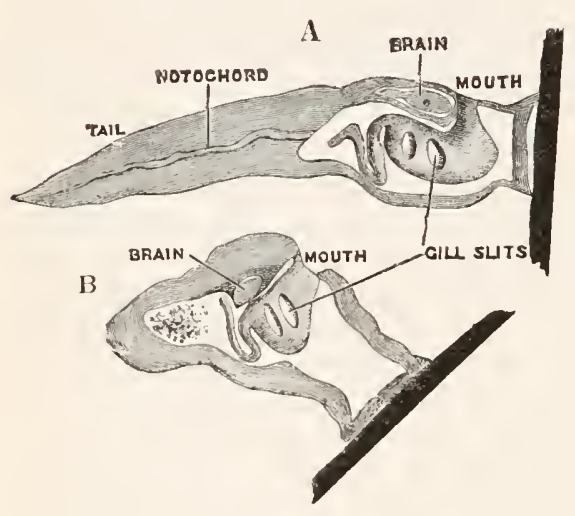

Fig. 10. Diagray Shewixg the hode of ATTACHMENT AND SUBSEQUENT RETROGRESSIVE METAMorpmosis of a Larval Ascidian. (From Tankester.) ment the larval tail undergoes a complete atrophy (fig. $10 \mathrm{~B}$ ), so that nothing is left of it but a mass of fatty cells situated close to the point of the previous insertion of the tail in the trunk.

The nervous system also undergoes a very rapid retrogressive metamorphosis; and the only part of it which persists would seem to be the dilated portion of the spinal cord in the trunk (Kupffer, No. 28).

The three papilla, including that serving for attachment, early disappear, and the larva becomes fixed by a growth of the test to foreign objects.

An opening appears in the test some time after the larva is fixed, leading into the mouth, which then becomes functional. The branchial sack at the same time undergoes important changes. In the larva it is provided with only two ciliated slits, which open into the, at this stage, paired atrial cavity (fig. 10).

The openings of the atrial cavity at first are shut off from communication with the exterior by the test, but not long after the larva becomes fixed, two perforations are formed in tle test, which lead into the openings of the two atrial cavities. At the same time the atrial cavities dilate so as gradually to embrace the whole branchial sack to which their inner walls attach themselves. Shortly after this the branchial clefts rapidly increase in number ${ }^{1}$.

1 The account of the multiplication of the branchial clefts is taken from Krohn's paper on Phallusia mammillata (No. 24), but there is every reason to think that it holds true in the main for simple Ascidians. 
The increase of the branchial clefts is somewhat complicated. Between the two primitive clefts two new ones appear, and then a third appears behind the last cleft. In the interval between each branchial cleft is placed a vaseular branchial vessel (fig. $8 \mathrm{v}$. bb.). Soon a great number of clefts become added in a row on each side of the branchial sack. These clefts are small ciliated openings placed transversely with reference to the long axis of the branchial sack, but only occupying a small part of the breadth of each side. The intervals dorsal and ventral to them are soon filled by series of fresh rows of slits, separated from each other by longitudinal bars. Each side of the branchial sack becomes in this way perforated by a number of small openings arranged in rows, and separated by transverse and longitudinal bars. The whole structure forms the commencement of the

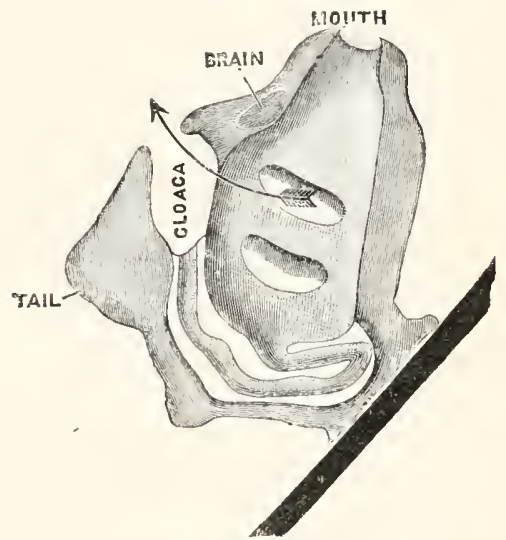

Fig. 11. Diaglam of a verix young Ascioian. (From Lankester.) branchial basketwork of the adult; the arrangement of which differs considerably in structure and origin from the simple system of branchial clefts of normal vertebrate types. At the junction of the transverse and longitudinal bars papillæ are formed projecting into the lumen of the branchial sack.

After the above changes are far advanced towards completion, the openings of the two atrial sacks gradually approximate in the dorsal line, and finally coalesce to form the single atrial opening of the adult. The two atrial cavities at the same time coalesce dorsally to form a single cavity, which is continuous round the branchial sack, except along the ventral line where the endostyle is present. The atrial cavity, from its mode of origin as a pair of epiblastic involutions ${ }^{1}$, is clearly a structure of the same nature as the branchial or atrial cavity of Amphioxus; and has nothing whatever to do with the true body cavity.

It has already been stated that the anus opens into the original left atrial cavity; when the two cavities coalesce the anus opens into the atrial cavity in the median dorsal line.

Two of the most obscure points in the development are the origin of the mesoblast in the trunk, and of the body cavity. Of the former subject we know next to nothing, though it seems that the cells

1 In the asexually produced buds of Ascidians the atrial cavity appears, with the exreption of the external opening, to be formed from the primitive branchial sack. In the buds of Pyrosoma however it arises independently. These peculiarities in the buds cannot weigh against the embryonic evidence that the atrial cavity arises from involutions of the epiblast, and they may perhaps be partially explained by the fact that in the formation of the visceral clefts ontgrowths of the branchial sack meet the atrial involutions. 
resulting from the atrophy of the tail are employed in the nutrition of the mesoblastic structures of the trunk.

The body cavity in the adult is well developed in the region of the intestine, where it forms a wide cavity lined by an epithelioid mesoblastic layer: In the region of the branchial sack it is reduced to the vascular channels in the walls of the sack.

Kowalevsky believes the body cavity to be the original segmentation cavity, but this view can hardly be regarded as admissible in the present state of our knowledge. In some other Ascidian types a few more facts about the mesoblast will be alluded to.

With the above changes the retrogressive metamorphosis is completed; and it only remains to notice the change in position undergone in the attaimment of the adult state. The region by which the larva is attached grows into a long process (fig. $10 \mathrm{~B}$ ), and at the same time the part carrying the mouth is bent upwards so as to be renoved nearly as far as possible from the point of attachment. By this means the condition in the adult (fig. 11) is gradually brought about; the original dorsal surface with the oral and atrial openings becoming the termination of the long axis of the body, and the nervous system being placed between the two openings.

The genus Molgula presents a remarkable exception amongst the simple Ascidians in that, in some if not all the species belonging to it, development takes place (Lacaze Duthiers 29 and 30, Kupffer 28) quite directly and without larval metamorphosis.

The ova are laid either singly or adhering together, and are very opraque. The segmentation (Lacaze Duthiers) commences by the formation of four cqual spheres, after which a number of small clear spheres are firmed which cuvelope the large spheres. The latter give rise to a closed enteric sack, and probably also to a mass of cells situated on the ventral side, which appear to be mesoblastic. The epillast is constituted of a single layer of cclls which completely envelopes the enteric sack and the mesoblast.

While the ovum is still within the chorion five peculiar processes of epiblast grow out; four of which usually lie in the same sectional plane of the embryo. They are contractile and contain prolongations of the borly cavity. Their relative size is very variable.

The nervous system is formed on the dorsal side of the embryo before the above projections make their appearance, but, though it seems probable that it originates in the same manner as in the more normal forms, its development has not been worked out. As soon as it is formed it consists of a nervous ganglion similar to that usually found in the adult. The listory of the mans of mesoblast cells has been inadequately followed, but it continnously disappears as the heart, excretory organs, muscles, etc. become formed. So far as can be determined from Kupffer's descriptions the body cavity is primitively parenchymatous - an indication of an abbreviated development-and does not arise as a definite split in the mesnblast.

The primitive enteric cavity becomes converted into the branchial sack, and from its dorsal and posterior corner the resophagus, stomach and intestine grow out as in the normal forms. The mouth is formerl by the 
invagination of a disc-like thickening of the epidermis in front of the nerrous system on the dorsal side of the body; and the atrial cavity arises behind the nervous system by a similar process at a slightly later period. The gill clefts opening into the atrial cavity are formed as in the type of simple Ascidians described by Krohn.

The embryo becomes hatched not long after the formation of the oral and atrial openings, and the five epiblastic processes undergo atrophy. They are not employed in the attachment of the adult.

The larva when latehed agrees in most important points with the adult; and is without the characteristic provisional larval organs of ordinary forms; neither organs of special sense nor a tail becoming developed. It lias been suggested by Kupffer that the ventrally situated mesoblastic mass is the same structure as the mass of elements which results in ordinary types from the degeneration of the tail. If this suggestion is true it is difficult to believe that this mass has any other than a nutritive function.

The larva of Ascidia ampulloides described by P. ran Beneden is regarded by $\mathrm{Kupffer}$ as intermediate between the Molgula larva and the normal type, in that the larval tail and notochord and a pigment spot are first developed, while after the atrophy of these organs peculiar processes like those of Molgula make their appearance.

Sedentaria. The development of the fixed composite Ascidians is, so far as we know, in the main similar to that of the simple Ascidians. The larve of Botryllus sometimes attain, while still in the free state, a higher stage of development with reference to the number of gill slits, etc. than that reached by the simple A scidians, and in some instances (Botryllus auratus Metschnikoff) eight conical processes are found springing in a ringlike fashion around the trunk. The presence of these processes has led to somewhat remarkable views about the morphology of the group; in that they were regarded by Kölliker, Sars, etc. as separate individuals, and it was supposed that the product of each ovum was not a single individual, but a whole system of individuals with a common cloaca.

The researches of Metschnikoff (No.32), Krohu (No. 25), and Giard (No. 12), etc. demonstrate that this paradoxical view is untenable, and that each ovum only gives rise to a single embryo, while the stellate systems are subsequently formed by budding.

Natantia. Our knowledge of the derelopment of Pyrosoma is mainly due to Huxley (No. I6) and Kowalevsky (No. 22). In each individual of a colony of Pyrosoma only a single egg comes to maturity at one time. 'This egg is contained in a capsule formed of a structureless wall lined by a flattened epithelioid layer. From this capsule a duct passes to the atrial cavity, which, though called the oviduct, functions as an afferent duct for the spermatozoa.

The segmentation is meroblastic, and the germinal disc adjoins the opening of the oviduct. 'The segmentation is very similar to that which occurs in Teleostei, and at its close the germinal dise has the form of a cap of cells, without a trace of stratification or of a segmentation cavity, resting upon the surface of the yolk, which forms the main mass of the ovum.

After segmentation the blastorlerm, as we may call the layer of 
cells derived from the germinal disc, rapidly spreads over the surface of the yolk, and becomes divided into two layers, the epiblast and the hypoblast. At the same time it exhibits a distinction into a central clearer and a peripheral more opaque region. At one end of the blastoderm, which for convenience sake may be spoken of as the posterior end, a dise of epiblast appears, which is the first rudiment of the nervous system, and on each side of the middle of the blastoderm there arises an epiblastic involution. The epiblastic involutions give rise to the atrial cavity.

These involutions rapidly grow in length, and soon form longish tubes, opening at the surface by pores situated not far from the posterior end of the blastoderm.

The blastoderm at this stage, as seen on the surface of the yolk, is shewn in fig. 12 A. It is somewhat broaler than long. The nervous
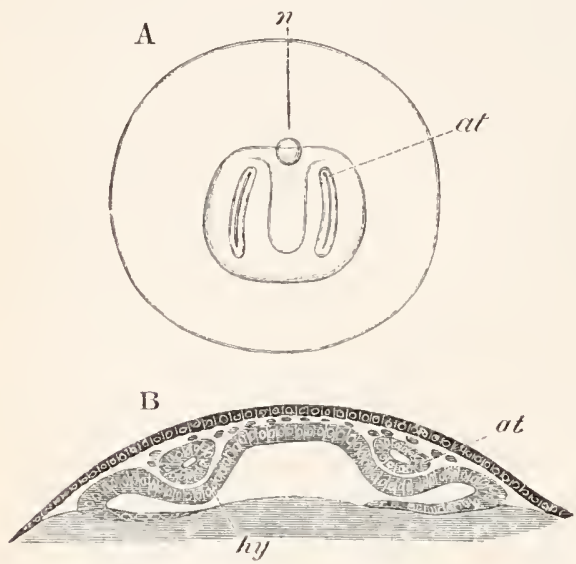

Fig. 12.

A. Surface view of tile ovem of Prrosoma Not FAR ADVANCED IN DEVELOPMENT. The embryonic strnctures are developed from a disc-like blastoderm.

B. Transverse SECTION THROUGH THE MIDDLE PART OF THE SAME BLASTODERM.

at. atrial cavity; hy. hypoblast; $n$. nervous disc in the region of the future Cyathozooid. system is shewn at $n$, and at points to an atrial tube. A transverse section, through about the middle of this blastoderm, is represented in fig. $12 \mathrm{~B}$. The epiblast is seen above. On each side is the section of an atrial tube (at). Below is the hypoblast which is separated from the yolk especially in the middle line; at each side it is beginning to grow in below, on the surface of the yolk. The space below the hypoblast is the alimentary cavity, the ventral wall of which is formed by the cells growing in at the sides. Between the epiblast and hypoblast are placed scattered mesoblast cells, the origin of which bas not been clearly made out.

In a later stage the openings of the two atrial tubes gradually travel backwards, and at the same time approximate, till finally they meet and coalesce at the posterior end of the blastoderm behind the nervous disc (fig. $13, c l$ ). The tubes themselves at the same time become slightly constricted not far from their hinder extremities, and so divided into a posterior region nearly coterminous with the nervous system (fig. 13), and an anterior region. These two regions have very different histories in the subsequent development. 
The nervous disc has during these changes become marked by a median furrow (fig. 13, $\mathrm{ng}$ ), which is soon converted into a canal by the same process as in the simple Ascidians. The closure of the groove commences posteriorly and travels forwards. These processes are clearly of the same nature as those which take place in Chordata generally in the formation of the central nervous system.

In the region of the germinal dise which contains the anterior part of the atrial tubes, the alimentary cavity becomes, by the growth of the layer of cells described in the last stage, a complete canal, on the outer wall of which the endostyle is formed as a median fold. The whole anterior part of the blastoderm becomes at the same time gradually constricted off from the yolk.

The fate of the anterior and posterior parts of the blastoderm is very different. The anterior part becomes segmented into four zooids or individuals, called by Huxley Ascidiozooids, which give rise to a

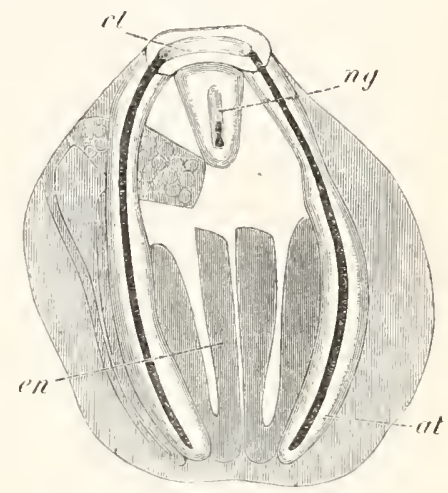

Fig. 13. Blastodera of Prrosona Shortly before its DIVISION INTO CYATHozoold AND Ascidiozooins. (After Kowalevsky.)

$c l$. cloacal (atrial) opening; en. endostyle; at. atrial cavity; ng. nervous groove.

The heart and pericardial cavity are seen to the left. fresh colony of Pyrosoma. The posterior part forms a rulimentary zooid, called by Huxley Cyathozooid, which eventually atrophies. These five zooids are formed by a process of embryonic fission. This fission commences by the appearance of four transverse constrictions in the anterior part of the blastoderm; by which the whole blastoderm becomes imperfectly divided into five regions, fig. $14 \mathrm{~A}$.

The hindermost constriction (uppermost in my figure) lies just in front of the pericardial cavity; and separates the Cyathozooid from the four Ascidiozooids. The three other constrictions mark off the four Ascidiozooids. The Cyathozooid remains for its whole length attached to the blastoderm, which has now nearly enveloped the yolk. It contains the whole of the nervous system ( $n g$ ), which is covered behind by the opening of the atrial tubes $(c l)$. The alimentary tract in the Cyathozooid forms a tube with very delicate walls. The pericardial cavity is completely contained within the Cyathozooid, and the heart itself ( $h t$ ) has become formed by an involution of the walls of the cavity.

The Ascidiozooids are now completely separated from the yolk. They have individually the same structure as the undivided rudiment from which they originated; so that the organs they possess are simply two atrial tubes, an alimentary tract with an endostyle, and undifferentiated mesoblast cells. 
In the following stages the Ascidiozooids grow with great rapidity. They soon cease to lie in a straight line, and eventually form a ring round the Cyathozooid and attached yolk sack.

While these changes are being accomplished in the external form of the colony, both the Cyathozooids and the Ascidiozooids progress considerably in development. In the Cyathozooid the atrial spaces gradually atrophy, with the exception of the external opening, which becomes larger and more conspicuous. The heart at the same time comes into full activity and drives the blood through the whole colony. The yolk becomes more and more enveloped by the Cyathozooid, and is rapilly absorbed; while the nutriment derived from it is transported to the Ascidiozooids by means of the vascular connection. The nervous system retains its previous condition; and round the Cyathozooid is formed the test into which cells migrate, and arrange themselves in very conspicuous hexagonal areas. The delicate alimentary tract of the Cyathozoois is still continuous with that of the first Ascidiozooid. After the Cyathozooid has reached the development just described it commences to atropliy.

The changes in the Ascidiozooids are even more considerable than those in the Cyathozooid. A nervous system appears as a fresh
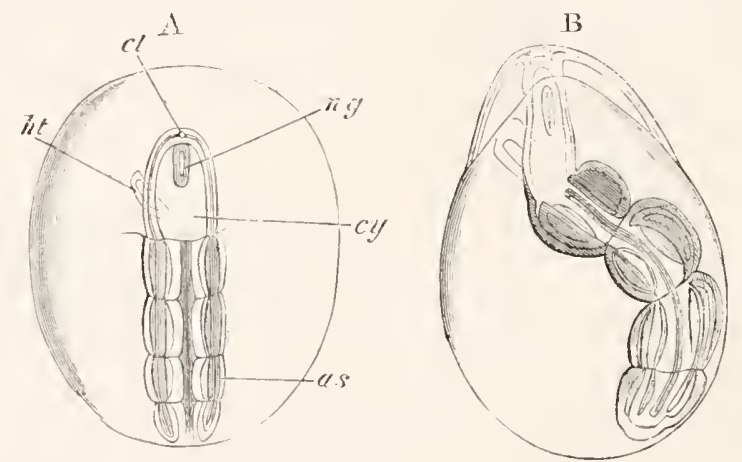

Fig. 14. Two stages in the developient of Proosona in which the Cyathozoony ANi foUr Ascidrozooids AfE ALREADY distinctly formed. (After Kowalevsky.)

cy. cyathozooid; as. ascidiozooid; $n g$. nervous groove; $h t$. heart of cyathozooid; cl. cloacal opening.

formation close to the cnd of each Ascidiozooid turned towards the Cyathozooid. It forms a tube of which the open front end eventually develops into the ciliated pit of the mouth, and the remainder into the actual nervous ganglion. Between the nervous system and the endostyle an involution appears, which gives rise to the mouth. On each side of the primitive alimentary cavity of each Ascidiozooid branchial slits make their appearance, leading into the atrial tubes; so that the primitive alimentary tract becomes converted into the branchial sacks of the Ascidiozooids. The remainder of the alimentary tract of each zooid is formed as a but from the hind end of the 
branchial sack in the usual way. The alimentary tracts of the four Ascidiozooids are at first in free communication by tubes opening from the hinder extremity of one zooid into the dorsal side of the branchial sack of the next zooid. At the hinder end of each Ascidiozooid is developed a mass of fatty cells known as the elroblast, which probably represents a rudiment of the larval tail of simple Ascidians. (Cf. pp. 2.5 and 26.)

The further changes consist in the gradual atrophy of the Cyathozooid, which becomes more and more enclosed within the four Ascidiozooids. These latter become completely enveloped in a common test, and form a ring round the remains of the yolk and of the Cyathozooid, the heart of which continues however to beat vigorously. The cloacal opening of the Cyathozooid persists through all these changes, and, after the Cyathozooid itself has become completely enveloped in the Ascidiozooids and finally absorbed, deepens to form the common cloacal cavity of the Pyrosoma colony.

The main parts of the Ascidiozooids were already formed during the last stage. The zooids long remain connected together, and united by a vascular tube with the Cyathozooid, and these connections are not severed till the latter completely atrophies. Finally, after the absorption of the Cyathozooid, the Ascidiozooids form a rudimentary colony of four individuals enveloped in a common test. The two atrial tubes of each zooid remain separate in front but unite posteriorly. An anus is formed leading from the rectum into the common posterior part of the atrial cavity; and an opening is established between the posterior end of the atrial cavity of each Ascidiozooid and the common axial cloacal carity of the whole colony. The atrial cavities in Pyrosoma are clearly lined by epiblast, just as in simple Ascidians.

When the young colony is ready to become free, it escapes from the atrial cavity of the parent, and increases in size by budding.

Doliolidæ. The sexually developed embryos of Doliolum have been observed by Krohn (No. 23), Gegenbaur (No. 10), and Keferstein and Ehlers (No. I 7); but the details of the development have been very imperfectly investigated.

The youngest embryo observed was enveloped in a large oval transparent covering, the exact nature of which is not clear. It is perhaps a larval rudiment of the test which would seem to be absent in the adult. Within this covering is the larva, the main organs of which are already developed; and which primarily differs from the adult in the possession of a larval tail similar to that of simple Ascidians.

In the body both oral and atrial openings are present, the latter on the dorsal surface; and the alimentary tract is fully established. The endostyle is already formed on the ventral wall of the branchial sack, but the branchial slits are not present. Nine muscular rings are already visible. The tail, though not so developed as in the simple Ascidians, contains an axial notochord of the usual structure, and lateral muscles. It is inserterl on the ventral side, and hy its slow movements the larva progresses. 
In succeeding stages the tail gradually atrophies, and the gill slits, four in number, develop; at the same time a process or stolon, destined to give rise by budding to a second non-sexual generation, makes its appearance on the dorsal side in the seventh inter-muscular space. This stolon is comparable with that which appears in the embryo of Salpa. When the tail completely atrophies the larva leaves its transparent covering, and becomes an asexual Doliolum with a dorsal stolon.

Salpidæ. As is well known the chains of Salpa alone are sexual, and from each individual of the chain only a single embryo is produced. The ovum from which this embryo takes its origin is visible long before the separate Salps of the chain have become completely developed. It is enveloped in a capsule continuous with a duct, which opens into the atrial cavity, and is usually spoken of as the oviduct. The capsule with the orum is enveloped in a maternal blood sinus. Embryonic development commences after the chain has become broken up, and the spermatozoa derived from another individual would seem to be introduced to the ovum through the oviduct.

At the commencement of embryonic development the oviduct and ovicapsule undergo peculiar changes; and in part at least give rise to a structure subservient to the nutrition of the embryo, known as the placenta. These clianges commence with the shortening of the oviduct, and the disappearance of a distinction between oviduct and ovicapsule. The cells lining the innermost end of the capsule, i.e. that at the side of the ovum turned away from the atrial cavity, become at the same time very columnar. The part of the oviduct between the orum and the atrial cavity dilates into a sack, communicating on the one hand with the atrial cavity, and on the other by a very narrow opening with the chamber in which the egg is contained. This sack next becomes a prominence in the atrial cavity, and eventually constitutes a brood-pouch. The prominence it forms is covered by the lining of the atrial cavity, immediately within which is the true wall of the sack. The external opening of the salck becomes gradually narrowed and finally disappears. In the neantime the chamber in which the embryo is at first placed acquires a larger and larger opening into the sack; till finally the two chamber's unite, and a single broor-pouch containing the embryo is thus prorluced. The inner wall of the chamber is formed by the columnar cells already spoken of. They form the rudiment of the placenta. The double wall of the outer prart of the brood-pouch becomes stretched by the growth of the embryo; the inner of its two layers then atrophies. The outer layer subsequently gives way, and becomes rolled back so as to lie at the inner end of the embryo, leaving the latter projecting freely into the atrial cavity.

While these clianges are taking place the placenta becomes fully developed. The first rudiment of it consists, according to Salensky, of the thickened cells of the ovicajsule only, though this view is dissented from by Brooks, Tollitro, etc. Its cells soon divide to form a largish mass, which becomes attached to a part of the epiblast of the embryo.

On the formation of the body cavity of the embryo a central axial portion of the placenta becomes separated from a peripheral layer; and a chamel is left between them which leads fiom a maternal blood sinus into the embryonic body cavity. The peripheral layer of the placenta is formed of cells continuous with the epiblast of the embryo; while the 
axial portion is constituted of a disc of cells adjoining the embryo, with a columm of fibres attached to the maternal side. The fibres of this column are believed by Salensky to be products of the original rudiment of the placenta. The pliventa now assumes a more spherical form, and its cavity becomes shut off from the embryonic body cavity. The fibrous columu breaks up into a number of strands perforating the lumen of the organ, and the cells of the wall become stalked bodies projecting into the lumen.

When the larva is nearly ready to become free the placenta atrophies.

The placenta functions in the nutrition of the embryo in the following way. It projects from its first formation into a maternal blood sinus, and, on the appearance of a cavity in it continuous with the body cavity of the embryo, the blood of the mother fully intermingles with that of the embryo. At a later period the communication with the body cavity of the embryo is shut oft, but the cavity of the placenta is supplied with a continuous stream of maternal blood, which is only separated from the foetal blood by a thin partition.

It is now necessary to turn to the embryonic development about which it is unfortunately not as yet possible to give a completely satisfactory account. The statements of the different investigators contradict each other on most fundamental points. I have followed in the main Salensky (No. 34), but have also called attention to some points where his observations diverge most from those of other writers, or where they seem unsatisfactory.

The development commences at about the period when the brood-pouch is becoming formed; and the ovum passes entirely into the brood-pouch before the segmentation is completed. The segmentation is regular, and the existence of a segmentation cavity is denied by Salensky, though affirmed by Kowalevsky and Todaro'.

At a certain stage in the segmentation the cells of the ovum become divided into two layers, an epiblast investing the whole of the orum with the exception of a small area adjoining the placenta, where the inner layer or hypoblast, which forms the main mass of the orum, projects at the surface. The epiblast soon covers the whole of the hypoblast, so that there would seem (according to Salensky's observations) to be a kind of epibolic invagination: a conclusion supported by Todaro's figures.

At a later stage, on one side of the free apex of the embryo, a mesoblastic layer makes its alpearance between the epiblast and hypoblast. This layer is derivel by Salensky, as it appears to me on insufficient grounds, from the epiblast. Nearly at the same time there arises not far from the same point of the embryo, but on the opposite side, a solid thickening of epiblast which forms the rudiment of the nervons system. The nervous system is placed close to the front end of the body; and nearly at the opposite pole, and therefore at the hind end, there appears immediately below the epiblast a mass of cells forming a provisional organ known as the elreoblast. Todaro regards this organ as mesoblastic in origin, and Salensky as hypoblastic. The organ is situated in the position which would be oceupied by the larval tail were it developed. It may probably be regarded (Salensky) as a disappearing rudiment of the tail, and be

1 From Todaro's latest paper (No. 39) it would seem the segmentation cavity has very peculiar relations. 
compared in this respect with the more or less similar mass of cells described by Kupffer in Molgula, and with the elreoblast in Pyrosoma.

After the differentiation of these organs a cavity makes its appearance between the epiblast and hypoblast, which is regarded by Salensky as the body cavity. It appear's to be equivalent to the segmentation cavity of Todaro. According to Todaro's statements, it is replaced by a second cavity, which appears between the splanchnic and somatic layers of mesoblast, and constitutes the true body cavity. The embryo now begins to elongate, and at the same time a cavity makes its appearance in the centre of the hypoblast cells. This cavity is the rudiment of the branchial and alimentary cavities: on its dorsal wall is a median projection, the rudiment of the socalled gill of Salpa.

At two points this cavity comes into close contact with the external skin. At one of these, sitnated immediately ventral to the nervous system, the mouth becomes formed at a later periorl. At the other, placed on the dorsal surface between the nervous system and the elreoblast, is formed the cloacal aperture.

By the stage muler consideration the more important systems of organs are established, and the remaining embryonic history may be very briefly narrated.

The embryo at this stage is no longer covered by the walls of the lrood-pouch but projects freely into the atrial cavity, and is only attached to its parent by means of the placenta. The epiblast cells soon give rise to a deposit which forms the mantle. The deposit appears lowever to be formed not only on the outer side of the epiblast but also on the inner side; so that the epiblast becomes cemented to the subjacent parts, branchial sack, etc., by an intercellular layer, which would seem to fill up the primitive body cavity with the exception of the vascular channels (Salensky).

The ncrvous system, after its separation from the epiblast, acquires a central cavity, and subserquently becomes divided into three lobes, each with an internal protuberance. At its anterior extremity it opens into the branchial sack; and from this part is developed the eiliated pit of the adult. The nervous ganglion at a later period becomes solid, and a median eye is subsequently formed as an outgrowth from it.

According to Todaro there are further formed two small auditory (? olfactory) sacks on the ventral surface of the brain, each of them placed in communication with the branchial cavity by a narrow canal.

The mesoblast gives rise to the muscles of the branchial sack, to the heart, and to the pericardium. The two latter are situated on the ventral sile of the posterior extremity of the branchial cavity.

Branchial sack and alimentury tract. The first development of the enteric cavity has already been described. The true alimentary tract is formed as a bud from the hinder end of the primitive cavity. The remainder of the primitive cavity gives rise to the branchial sack. The so-called gill has at first the form of a lamella attached dorsally to the walls of the branchial sack; but its attacliment becomes severed except at the two ends, and it then forms a band stretching obliqucly across the branchial cavity, which subsequently becomes hollow and tilled with blood corpuscles. The whole structure is probably homologons with the peculiar fold, usually prolonged into numerous processes, which normally projects from the dorsal wall of the Ascidian branchial sack. 
On the completion of the gill the branchial sack becomes divided into a region dorsal to the gill, and a region ventral to it. Into the former the single atrial invagination opens. No gill slits are formed comparable with those in simple Ascidians, and the only representative of these structures is the simple communication which becomes established between the dorsal division of the branchial sack and the atrial opening. The whole branchial sack of Salpa, including both the dorsal and ventral divisions, corresponds with the branchial sack of simple Ascidians. On its ventral side the endostyle is formed in the normal way. The mouth arises at the point already indicated near the front end of the nervous system ${ }^{1}$.

1 Brooks takes a very different view of the nature of the parts in Salpa. He says, No. 7, p. 322, "The atrium of Salpa, when first observed, was composed of two broad " lateral atria within the body cavity, one on each sicle of the branchial sack, and a very "small mid-atrium... The lateral atria do not however, as in most Tunicata, remain " connected with the mid-atrium, and unite with the wall of the branchial sack to " form the branchial slits, but soon become entirely separated, and the two walls of " each unite so as to form a broad sheet of tissue, which soon splits up to form the " muscular bands of the branchial sack." Again, p. 324, "During the changes which " have been described as taking place in the lateral atria, the mid-atrium has increased . in size... The branchial and atrial tunics now unite upon each side, so that the " sinus is converted into a tube which communicates, at its posterior end, with the " heart and perivisceral sinus, and at the anterior end with the neural sinus. This " tube is the gill.... The centres of the two regions upon the sides of the gill, where " these two tissues hare become united, are now absorbed, so that a single long and " narrow branchial shit is produced on each side of the gill. The branchial earity is "thus thrown into communication with the atrium, and the upper surface of the lat" ter now unites with the outer tunic, and the external atrial opening is formed by "absorption."

The above description would imply that the atrial carity is a space lined by mesoblast, a view which would upset the whole morphology of the Ascidians. Salensky's account, which implies only an inmense reduction in the size of the atrial cavity as compared with other types, appears to me far more probable. The lateral atria of Brooks appear to be simply parts of the body carity, and have certainly no connection with the lateral atria of simple Ascidians or Pyrosoma.

The observations of Todaro upon Salpa $\left(\mathrm{No}_{3} 3^{8)}\right.$ are very remarkable, and illustrated by beautifully engrared plates. His interpretations do not however appear quite satis. factory, The following is a brief statement of some of his results.

During segmentation there arises a layer of small superficial cells (epiblast) and a central layer of larger cells, which becomes separated from the former by a segmentation cavity, except at the pole adjoining the free end of the brood-ponch. At this point the epiblast cells become invaginated into the central cells and form the alimentary tract, while the primitive central cells remain as the mesoblast. A fold arises from the epiblast which Todaro compares to the vertebrate amnion, but the origin of it is unfortunately not satisfactorily described. The folds of the amnion project towards the placenta, and enclose a carity which, as the folds never completely mect, is permanently open to the maternal blood sinus. 'This cavity corresponds with the cavity of the true amnion of higher Vertebrates. It forms the cavity of the placenta already decribed. Between the two folks of the amnion is a cavity corresponding with the rertebrate false amnion. A structure regarded by Todaro as the notochord is formed on the neck, connecting the involution of the alimentary tract with the exterior. It has only a very transitory existence.

In the later stages the segmentation carity disappears and a true body cavity is formed by a split in the mesoblast.

Todaro's interpretations, and in part his descriptions also, both with reference to the notochord and amnion, appear to me quite inadmissible. About some other parts of his descriptions it is not possible to form a satisfactory judgment. He has recently published a short paper on this subject (No. 39) preliminary to a larger memoir, which is very difficult to understand in the absence of plates. He finds liowever in the placenta various parts whici he regards as homologous with the cesilna rera anl leficsa of Mammalia. 
Development of the chain of sexual Salps. My description of the embryonic development of Salpa would not be complete without some reference to the development of the stolon of the solitary generation of Salps by the segmentation of which a chain of sexual Salps originates.

The asexual Salp, the embryonic development of which has just been described, may be compared to the Cyathozooid of Pyrosoma, from which it mainly differs in being fully developed. While still in an embryonic condition it gives rise to a process or stolon, which becomes divided into a number of zooids by transverse constrictions, in the same manner that part of the germ of the ovum of Pyrosoma is divided by transverse constrictions into four Ascidiozooids.

The stolon arises as a projection on the right side of the body of the embryo close to the heart. It is formed (Salensky, No. 35) of an outgrowth of the body wall, into which there grow the following structures:

(1) A central hollow process from the end of the respiratory sack.

(2) A right and left lateral prolongation of the pericardial cavity.

(3) A solid process of cells on the ventral side derived from the same mass of the cells as the elreoblast.

(4) A ventral and a dorsal blood sinus.

Besides these parts there appenrs on the dorsal side a hollow tube, the origin of which is unknown, which gives rise to the nervous system.

The hollow process of the respiratory sack is purely provisional, and disappear's without giving rise to any permanent structure. The right and left prolongations of the pericardial cavity become solid and eventually give origin to the mesoblast. The ventral process of cells is the most important structure in the stolon in that it gives rise both to the alimentary and respiratory sacks, and to the generative organs of the sexual Salps. The stolon containing the organs just enumerated becomes divided by transverse constrictions into a number of rings. These rings do not long remain complete, but become interrupted dorsally and ventrally. The imperfect rings so formed soon overlap, and each of them eventually gives rise to a sexual Salp. Although the stolon arises while the asexual Salp is still in an embryonic condition, it does not become fully developed till long after the asexual Silp has attained maturity.

Appendicularia. Our only knowledge of the development of Appendicularia is derived from Fol's memoir on the group (No. 8). He simply states that it develops, as far as he was able to follow, hike other Ascilians; and that the extremely minute size of the egg prevented him from pursuing the subject. He also states that the pair of pores leading from the lranchial cavity to the exterior is developed from epiblastic iuvolutions meeting outgrowths of the wall of the branchial sack.

\section{Metagenesis.}

One of the most remarkable phenomena in connection with the life history of many Ascidians is the occurrence of an alternation of sexual and gemmiparous generations. This alternation appears to have originated from a complication of the process of reproduction by budding, which is so common in this group. The mode in which this very probably took place will be best understood by tracing a series 
of transitional cases between simple budding and complete alternations of generations.

In the simpler cases, which occur in some Composita Sedentaria, the process of budding commences with an outgrowth of the body wall into the common test, containing a prolongation of part of the alimentary tract ${ }^{1}$.

Between the epiblastic and hypoblastic layers of the bud so formed, a mesoblastic and sometimes a generative outgrowth of the parent also appears.

The systems of organs of the bud are developed from the corresponding layers to those in the embryo". 'The bud eventually becomes detached, and in its turn gives rise to fresh buds. Both the bud and its parent reproduce sexually as well as by budding: the new colonies being derived from sexually produced embryos.

The next stage of complication is that found in Botryllus (Krohn, Nos. 25 and 26). The larva produced sexually gives lise to a bud from the right side of the body close to the heart. On the bud becoming detached the parent dies away without developing sexual vrgans. The bud of the second generation gives rise to two buds, a right one and a left one, and like the larva dies without reaching sexual maturity. The buds of the third generation each produce two buds and then suffer the same fate as their parent.

The buds of the third generation arrange themselves with their cloacal extremities in contact, and in the fourth generation a common cloaca is formed, and so a true radial system of zooids is established; the zooids of which are not however sexual.

The buds of the fourth generation in their turn produce two or three buds and then die away.

Fresh systems become formed by a continuation of the process of budding, but the zooids of the secondary systems so formed are sexual. The ova come to maturity before the spermatozoa, so that cross fertilization takes place.

In Botryllus we have clearly a rudimentary form of alternations

1 It is not within the scope of this work to enter into details with reference to the process of budding. The reader is referred on this head more especially to the papers of Huxley (No. 16) and Kowalevsky (No. 22) on Pyrosoma, of Salensky (No. 35) on Salpa, and Kowalevsky (No. 2I) on Ascidians generally. It is a question of very great interest how budding first arose, and then became so prevalent in these degenerate types of Chordata. It is possible to suppose that budding may have commenced by the division of embryos at an early stage of derelopment, and have gradually been carried onwards by the help of natural selection till late in life. There is perhaps little in the form of budding of the Ascirlians to support this riew-the early budding of Didemmum as described by Gegenbaur being the strongest evidence for it-but it fits in rery well with the division of the embryo in Lumbricus trapezoides deseribed by Kleinenberg, and with the not unfrequent occurrence of double monsters in Vertebrata which may be regarded as a phenomenon of a similar nature (Rauber). The embryonic budding of Pyrosoma, which might perhaps be viewed as supporting the hypothesis, appears to me not really in favour of it; since the Cyathozooid of Pyrosoma is without doubt an extremely modified form of zooid, which has obvionsly been specially developed in connection with the peculiar reproduction of the Pyrosomidæ.

2 The atrial spaces form somewhat doubtful exceptions to the rule. 
of generations, in that the sexually produced larva is asexual, and, after a series of asexual generations, produced gemmiparously, there appear sexual generations, which however continue to reproduce themselves by budding.

The type of alternations of generations observable in Botryllus becomes, as pointed out by Huxley, still more marked in Pyrosoma.

The true product of the ovum is here (vide p. 21) a rudimentary individual called by Huxley the Cyathozooid. This gives rise, while still an embryo, by a process equivalent to budding to four fully developed zooids (Ascidiozooids) similar to the parent form, and itself dies away. The four Ascidiozooids form a fresh colony, and reproduce (1) sexually, whereby fresh colonies are formed, and (2) by ordinary budding, whereby the size of the colony is increased. All the individuals of the colony are sexual.

The alternation of generations in Pyrosoma widely differs from that in Botryllus in the fact of the Cyathozooid differing so markedly in its anatomical characters from the ordinary zooids.

In Salpa the process is slightly different ${ }^{1}$. The sexual forms are now incapable of budding, and, although at first a series of sexual individuals are united together in the form of a chain, so as to form a colony like Pyrosoma or Botryllus, yet they are so loosely connected that they separate in the adult state. As in Botryllus, the ova are ripe before the spermatozoa. Each sexual individual gives rise to a single offspring, which, while still in the embryonic condition, buds out a 'stolon' from its right ventral side. This stolon is divided into a series of lateral buds after the solitary sexual Salp has begun to lead an independent existence. The solitary sexual Salp clearly corresponds with the Cyathozooid of Pyrosoma, though it has not, like the Cyathozooid, undergone a retrogressive metamorphosis.

By far the most complicated form of alternation of generations known amongst the Ascidians is that in Doliolum. The discovery of this metamorphosis was made by Gegenbaur (No. Io). The sexual form of Doliolum is somewhat cask-shaped, with ring-like muscular bands, and the oral and atrial apertures placed at opposite ends of the cask. The number of gill slits varies according to the species. The ovum gives rise, as already described, to a tailed embryo which subsequently develops into a cask-shaped asexual form. On attaining its full size it loses its branchial sack and alimentary tract. While still in the embryonic condition, a stolon grows out from its dorsal side in the seventh intermuscular space. The stolon, like that in Salpa, contains a prolongation of the branchial sack ${ }^{2}$.

On this stolon there develop two entirely different types of buds, (1) lateral buds, (2) dorsal median buds.

1 ride p. 28.

2 I draw this conclusion from Gegenbanr's fig. (No. Io), Pl. xvi., fig. 15. The body $(x)$ in the figure appears to me without doubt the rudiment of the stolon, and not, as believed by Gegenbaur, the larval tail. 
The lateral buds are developed in regular order on the two sides of the stolon, and the most adranced buds are those furthest removed from the base. They give rise to forms with a very different organization to that of the parent. They are compared by Gegenbaur to a spoon, the bowl of which is formed by the branchial sack, and the handle by the stalk attaching the bud to the stolon. The oral opening into the branchial sack is directed upwards: an atrial opening is remarkably enough not mesent. The branchial sack is perforated by numerous openings. It leads into an alimentary tract which opens directly to the exterior by an anus opposite the mouth.

The stalks attaching the more mature buds to the stolon are provided with ventrally directed scales, which completely hide the stolon in a view from the ventral surface.

These buds have, even after their detachment, no trace of generative organs, aud shew no signs of reproducing themselves by budding. Their eventual fate is unknown.

The median dorsal buds have no such regular arrangement as the lateral buds, but arise in irregular bunches, those furthest removed from the base of the stolon being however the oldest. These buds are almost exactly similar to the original sexual form; they do not acquire sexual organs, but are provided with a stulon attached on the ventral sirle, in the sixth inter-muscular space.

This stolon is simply the stalk by which each median bud was primitively attached to the stolon of the first asexual form.

From the stolon of the median buds of the second generation buds are developed which grow into the sexual forms.

The generations of Doliolum may be tabulated in the following' way.

Sexual generation,

1st asexual form with dorsal stolon, I

spoon-like forms developed as 2nd asexual forms developed as

lateral buds (eventual history unknown). median buds with ventral stolon, sexual generation.

\section{Bibliggraphy.}

(6) P. J. van Beneden. "Recherches s. lEmbryogénie, l'Anat. et la Physiol. des Ascidies simples," Mém. Acad. Roy. de Belgique, Tom. xx.

(7) W. K. Brooks. "On the development of Salpa." Bull. of the MIusenm of Comp. Anat. at Harrard College, Cambridge, Mass.

(8) H. Fol. Études sur les Appendicnlaires du détroit de Messine. Genève et Bâle, 1872.

(9) Ganin. "Neue Thatsachen a. d. Entwicklungsgeschichte d. Ascidien." Zeit. f. wiss. Zool., Vol. xx. 1870.

(10) C. Gegenbaur. "Ueber den Entwicklungseyelus von Doliolum nebst Bemerkungen über die Larven dieser Thiere." Zeit.f. wiss. Zool., Bd. vur. 1856.

(II) A. Giard. "Études critiques des travaux d'embryogénie relatifs à la parenté des Vertébrés et des Tunieiers." Archiv. Zool. expériment., Vol. I. 1872. 1872 .

(I 2) A. Giard. "Recherches sur les Synascidies." Archiv. Zool. expér., Vol. ז. 
(13) O. Hertwig. "Untersuchungen üb. d. Bau u. d. Entwicklung des CelluloseMantels d. Tunicaten." Jenaische Zeitschrift, Bd. vir. 1873.

(14) Th. H. Huxley. "Remarks upon Appendicularia and Doliolum." Phil. Trans., 1851.

(15) Th. H. Hnxley. "Observations on the anatomy and physiology of Salpa and Pyrosoma." Phil. Trans., 1851.

(I6) Th. H. Huxley. "Anatomy and development of Pyrosoma." Linnean Trans., 1860 , Vol. xхIII.

(17) Keferstein u. Ehlers. Zoologische Beiträge, 1861. Doliolum.

(18) A. Kowalersky. "Entwicklnngsgeschichte d. einfachen Ascidien." Mém. Aead. Pétersbourg, vil. série, T. х. 1866.

(19) A. Kowalevsky. "Beitrag z. Entwick. d. Tunicaten." Nachrichten d. königl. Gesell. zu Göttingen. 1868.

(20) A. Kowalevsky. "Weitere Studien iib. d. Entwicklung d. einfachen Ascidien." Archiv f. mikr. Anat., Vol. viı. 1871.

(21) A. Kowalevsky. "Ueber Knospung d. Ascidien." Archiv f. mikr. Anat., Vol.x. $187 t$.

(22) A. Kowalevsky. "Ueber die Entwicklungsgeschichte d. Pyrosoma." Archin f. mikr. Anat., Vol. xi. 1875.

(23) A. Krolnn. "Ueber die Gattung Doliolum u. ihre Arten." Archiv $f$. Naturgeschichte, Bd. xvin. 1852.

(24) A. Krohn. "Ueber die Entwicklung d. Ascidien." Miiller"s Archiv, 1852.

(25) A. Krohn. "Ueber die Fortpflanzungsverhältuisse d. Botrylliden." Arehiv f. Naturgeschichte, Vol. xxxv. 1869.

(26) A. Krohn. "Ueber die früheste Bildung d. Botryllenstöcke." Archiv $f$. Naturgeschichte, Vol. xxxv. 1869.

(27) C. Kupffer. "Die Stammverwandschaft zwischen Ascidien u. Wirbelthieren." Archiv t', mikr. Anat., Vol. vi, 1870.

(2S) C. Kupffer. "Zur Entwicklung d. einfachen Ascidien." Arehiv f. mikr. Anat., Vol. vir., 1872.

(29) H. Isacaze Duthiers, "Recherches sur l'organisation et l'Embryogénie des Ascidies (Molgula tubulosa)." Comptes rendus, May 30, 1870, p. 1154.

(30) H. Lacaze Duthiers. "Les Ascidies simples des Côtes de France (Development of Molgula). Archiv. Zool. expér., Vol. III. 1874.

(31) R. Lenckart. "Salpa u. Verwandte." Zoologische Untersuchungen, Heft ir.

(32) E. Metschnikoff. "Observations sur le développement de quelques animaux (Botryllus and Simple Ascidians)." Bull. d. l'Aead. Pétersbourg, Vol. xiı. 1869.

(33) H. Milne-Edwards. "Observations s. l. Ascidies composées des côtes de la Manche." Mémoires l. l'Institut, T. xviı. 1842.

(34) W. Salensky. "Ueber d. embryonale Entwicklungsgeschichte der Salpen." Zeit.f. wiss. Zool., B. xxvir. 1877.

(35) W. Salensky. "Ueber die Knospung d. Salpen." Morphol. Jahrbuch, Bd. III. 1877.

(36) W. Salensky. "Ueber die Entwicklung d. Hoden n. über den Generationswechsel d. Salpen." Z Zeit. f. wiss. Zool., Bd. xxx. Suppl. 1878.

(37) C. Semper. "Ueber die Entstehung d. geschichteten Cellulose-Epidermis d. Ascidien." Arbeit. a. d. zool.-zoot. Instit. W'ürzburg, Vol. 11.1875.

(38) Fr. Todaro. Sopra lo sciluppo e l'anatomia delle Salpe. Roma, 1875.

(39) Fr. Todaro. "Sui primi fenomeni dello sviluppo delle Salpe." Reale Accademia dei Lincei, Vol. Iv. 1880. 


\section{CHAPTER III.}

\section{ELASMIOBRANCHII.}

THE impregnation of the ovum is effected in the oviduct. In most forms the whole of the subsequent development, till the time when the embryo is capable of leading a free existence, takes place in the uterus; but in other cases the egg becomes enveloped, during its passage down the oviduct, first in a layer of fluid albumen, and finally in a dense horny layer, which usually takes the form of a quadrilateral capsule with characters varying according to the species. After the formation of this capsule the egg is laid, and the whole of the development, with the exception of the very first stages, takes place externally.

In many of the viviparous forms (Mustelus, Galens, Carcharias, Sphyrna) the egg is enclosel, during the early stages of development at any rate, in a very delicate shell homologous with that of the oviparous forms; there is usually also a scanty albuminous layer. Both of these are stated by Gerbe (No. 42) to be absent in Squalus spinax.

The following are examples of viviparous genera: Hexanchus, Notidanus, Acanthias, Scymnus, Galens, Squalus, Mustelus, Carcharias, Sphyma, Squatina, Torpedo ; and the following of oviparous genera: Scyllimm, Pristiurus, Cestracion, Raja!.

The ovum at the time of impregnation has the form of a large spherical mass, similar to the yolk of a bird's egg. but without a vitelline membrane. . The greater part of it is formed of peculiar oval spherules of food-yolk, held together by a protoplasmic network. The protoplasm is especially concentrated in a small lens-shaped area, known as the germinal disc, which is not separated by a sharp line from the remainder of the ovum. Yolk spherules are present in this disc as elsewhere, but are much smaller and of a different character. The segmentation has the normal meroblastic character (fig. 15) and is confined to the germinal disc. Before it commences the germinal

1 For further details, vide Mïller (No. $\left.{ }_{4}^{8}\right)$.

2 Trile Vol. ז., p. 50.

B. E. II. 
disc exhibits amoboid movements. During the segmentation nuciei make their appearance spontaneously (?) in the yolk adjoining the germinal disc (fig. 15, $n x^{\prime}$ ), and around them portions of the yolk with its protoplasmic network become segmented off. Cells are thus formed which are added to those resulting from the segmentation proper. Even after the segmentation numerous nuclei are present in the granular matter below the blastoderm (fig. $16 \mathrm{~A}, n^{\prime}$ ); and around

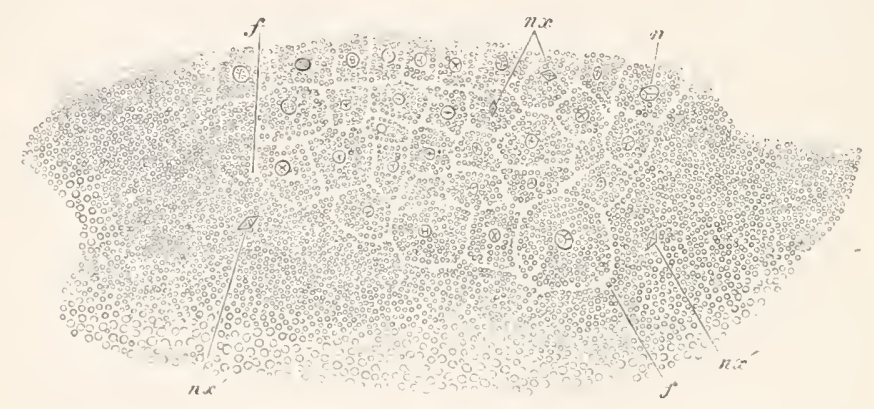

Fig. 15. Section throdgh germinal disc of a Pristiurus embryo during the SEgimentation.

$n$. nuclens; $n x$. nucleus modified prior to division; $n x^{\prime}$. modified nucleus in the yolk; $f$. furrow appearing in the yolk adjacent to the germinal dise.

these cells are being continually formed, which enter the blastoderm, and are more especially destined to give rise to the hypoblast. The special destination of many of these cells is spoken of in detail below.

At the close of segmentation the blastoderm forms a somewhat lens-shaped disc, thicker at one end than at the other; the thicker end being the embryonic end. It is divided into two strata-an upper one, the epiblast-formed of a single row of columnar cells; and a lower one, the primitive liypoblast, consisting of the remaining cells of the blastoderm, and forming a mass several strata deep. These cells will be spoken of as the lower layer cells, to distinguish them from the true hypoblast which is one of their products.

A cavity very soon appears in the lower layer cells, near the nonembryonic end of the blastoderm, but the cells afterwards disappear from the floor of this cavity, which then lies between the yolk and the lower layer cells (fig. $16 \mathrm{~A}, s c$ ). This cavity is the segmentation cavity equivalent to that present in Amphioxus, Amphibia, etc. The chief peculiarity about it is the relatively late period at which it makes its appearance, and the fact that its roof is formed both by the epiblast and by the lower layer cells. Owing to the large size of the segmentation cavity the blastoderm forms a thin layer above the cavity and a thickened ridge round its edge.

The epiblast in the next stage is inflected for a small are at the embryonic end of the blastoderm, where it becomes continuous with 
the lower layer cells; at the same time some of the lower layer cells of the embryonic end of the blastoderm assume a columnar form,
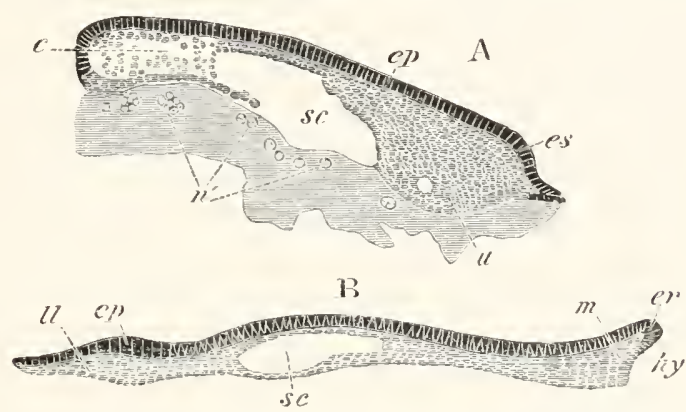

F1g. 16. Two losgitudival sections of the blastodery of a Pristictivs embrio DURING STAGES PRIOR TO THE FORMATION OF THE MEDULLARY GROOTE.

ep. epiblast; $l l$. lower layer cells or primitive hypoblast; $m$. mesoblast; hy. hypoblast; sc. segmentation cavity; es. embryo swelling; $n^{\prime}$. nuclei of yolk; er. embryonic rim. $c$. lotwer layer cells at the non-embryonic end of the blastorterm.

and constitute the true hypoblast. The portion of the blastoderm, where epiblast and liypoblast are continuous, forms a projecting structure which will be called the embryonic rim (fig. $16 \mathrm{~B}$, er).

This rim is a very important structure, since it represents the dorsal portion of the lip of the blastopore of Amphioxus. The space

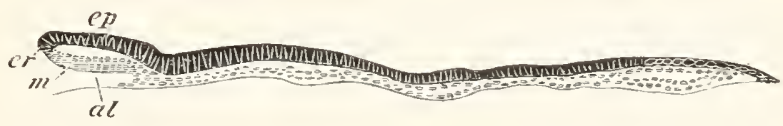

Fig. 17. Loxgitedinal section throcgh the blastonerm of a Pristieres EMbryo OF THE SAME AGE AS Fig. 28 B.

ep. epiblast; $c r$. embryonic rim; $m$. mesoblast; al. mesenteron.

ketween it and the yolk represents the commencing mesenteron, of which the hypoblast on the under side of the lip is the dorsal wall. The ventral wall of the mesenteron is at first formed solely of yolk held together by a protoplasmic network with numerous nuclei. 'The cavity under the lip becomes rapidly larger (fig. 17, al), owing to the continuous conversion of lower layer cells into columnar hypoblast along an axial line passing from the middle of the embryonic rim towards the centre of the blastoderm. The continuous differentiation of the hypoblast towards the centre of the blastoderm corresponds with the invagination in Amphioxus. During the formation of the embryonic rim the blastoderm grows considerably larger, but, with the exception of the formation of the embryonic rim, retains its primitive constitution.

The segmentation cavity undergoes however important changes. There is formed below it a floor of lower layer cells, derived partly from 
an ingrowth from the two sides, but mainly from the formation of cells around the nuclei of the yolk (fig. 16). Shortly after the floor of cells has appeared, the whole segmentation cavity becomes obliterated (fig. 17).

The disappearance of the segmentation cavity corresponds in point of time with the formation of the hypoblast by the pseudo-invagination above described; and is probably due to this pseudo-invagination, in the same way that the disappearance of the segmentation cavity in Amphioxus is due to the true invagination of the hypoblast.

When the embryonic rim first appears there are no external indications of the embryo as distinguished from the blastoderm, but when it has attained to some importance the position of the embryo becomes marked out by the appearance of a shield-like area extending inwards from the edge of the embryonic rim, and formed of two folds with a groove between them (fig. $28 \mathrm{~B}, m g$ ), which is deepest at the edge of the blastoderm, and shallows out as it extends inwards. This groove is the medullary groove; and its termination at the edge of the blastoderm is placed at the hind end of the embryo.

At about the time of its appearance the mesoblast becomes first definitely establisherl.

At the edge of the embryonic rim the epiblast and lower layer cells are continuous. Immediately underneath the medullary groove, as is best seen in transverse section (fig. 18), the whole of the lower layer cells become converted into hypoblast, and along this line the columuar hypoblast is in contact with the epiblast above. At the

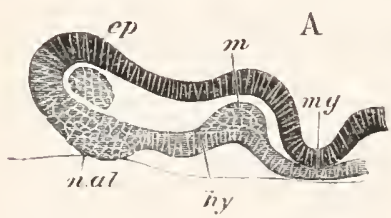

B

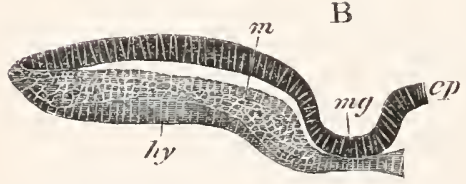

Fug. 18. Two thaxsverse sat toxs OF AN EMBRYO OF THE SAME AGE AS YTA. 17.

A. Anterior section.

B. Posterior section.

$m g$. medullary groove; ep. epiblast; $h y$. hypoblast; n.al. cells formed round the nuclei of the yolk which have entered the hypoblast; $m$. mesoblast.

The sections shew the origin of the mesoblast. sides however this is not the case; but at the junction of the epiblast and lower layer cells the latter remain undifferentiated. A short way from the edge the lower layer cells become divided into two distinct layers, a lower one continuous with the hypoblast in the middle line, and an upper one between this and the epiblast (fig. $18 \mathrm{~B})$. The upper layer is the commencement of the mesoblast (m). The mesoblast thus arises as two independent lateral plates, one on each side of the medullary groove, which are contimuous behind with the undifferentiated lower layer cells at the edge of the embryonic rim. The mesoblast plates are at first very short, and do not extend to the front end of the 
embryo. They soon however grow forwards as twó lateral ridges, attached to the hypoblast, one on each side of the medullary groove (fig. $18 \mathrm{~A}, m$ ). These ridges become separate from the hypoblast, and form two plates, thimner in front than behind; but still continuous at the edge of the blastoderm with the undifferentiated cells of the lip of the blastopore, and laterally with the lower layer cells of the non-embryonic part of the blastoderm. It results from the above mode of development of the mesoblast, that it may be described as arising in the form of a pair of solid outgrowths of the wall of the alimentary tract; which differ from the mesoblastic outgrowths of the wall of the archenteron in Amphioxus in not containing a prolongation of the alimentary cavity.

A greneral idea of the structure of the blastoderm at this stage may be gathered from the diagram representing a longitudinal section through the embryo (fig. $19 \mathrm{~B}$ ). In this figure the epiblast is repre-
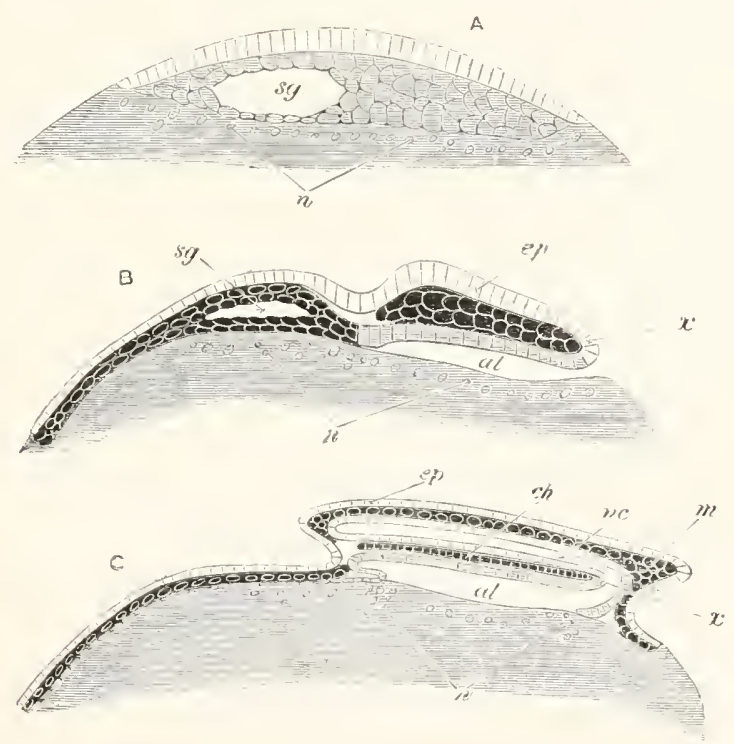

Fig. 19. Diagramatic longitumal sections of ax Elasmobraxch embrio.

Epiblast without shading. Mesoblast black with clear outlines to the cells. Lower layer cells and hypoblast with simple shading.

ep. epiblast; $m$. mesoblast; al. alimentary cavity; $s g$. segmentation cavity; $n$. neural canal; ch. notochord; $x$. point where epiblast and hypoblast become continuous at the posterior end of the embryo; $n$. nuclei of yolk.

A. Section of joung blastoderm, with segmentation cavity enclosed in the lower layer cells.

B. Older blastoderm with embryo in which hypoblast and mesoblast are distinctly formed, and in which the ahmentary slit has appeared. The segmentation cavity is still represented as being present, though by this stage it has in reality disappeared.

c. Older blastoderm with embryo in which the neural canal has become formed, and is continuons posteriorly with the alimentary canal. The notochord, thongh shaded like mesoblast, belongs properly to the hopoblast. 
sented in white and is seen to be continuous at the lip of the blastopore $(x)$ with the shaded hypoblast. Between the epiblast and hypoblast is seen one of the lateral plates of mesoblast, represented by black cells with clear outlines. 'The non-embryonic lower layer cells of the blastoderm are represented in the same manner as the mesoblast of the body. The alimentary cavity is shewn at al, and below it is seen the yolk with nuclei $(n)$. The segmentation cavity is represented as still persisting, though by this stage it would have disappeared.

As to the growth of the blastoderm it may be noted that it has greatly extended itself over the yolk. Its edge in the meantime
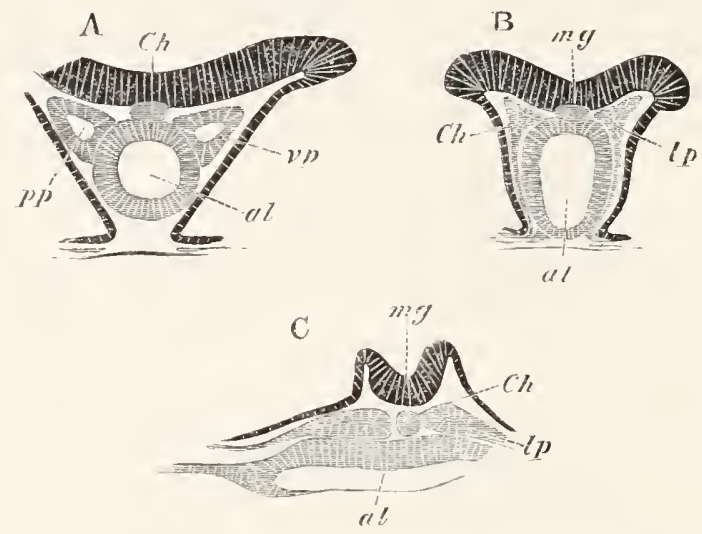

Hig. 20. Three sections throdgh a Pristiures embryo somewhat rodnger THAN FIG. 28 C.

A. Section through the cephalic plate.

B. Section through the posterior part of the cephalic plate.

C. Section through the trunk.

ch. notochord; $m g$. medullary groove; $a$. alimentary tract; $l p$. lateral plate of mesoblast; $p l$. body cavity.

forms a marked ridge, which is due not so much to a thickening as to an arching of the epiblast. This ridge is continuous with the embryonic rim, which gradually concentrates itself into two prominences, one on each sicle of the tail of the embryo, mainly formed of masses of undifferentiated lower layer cells. These prominences will be called the caudal swellings.

By this stage the three layers of the body, the epiblast, mesoblast, and hypoblast, have become definitely established. The further history of these layers may now be briefly traced.

Epiblast. While the greater part of the epiblast becomes converted into the external epidermis, from which involutions give rise to the olfactory and auditory pits, the lens of the eye, the mouth cavity, and anus, the part of it lining the medullary groove becomes converted into the central nervous system and optic cup. The medullary 
groove is at first continued to the front end of the medullary plate; but the anterior part of this plate soon enlarges, and the whole plate assumes a spatula form (fig. $28 \mathrm{C}, h$, and fig. $20 \mathrm{~A}$ and $\mathrm{B}$ ). The enlarged part becomes converted into the brain, and may be called the cephalic plate.

The posterior part of the canal deepens much more rapidly than the rest (fig. $20 \mathrm{C}$ ), and the medullary folds unite dorsally and convert the posterior end of the medullary groove into a closed canal, while the groove is still widely open elsewhere. The medullary canal does not end blindly behind, but simply forms a tube not closed at either extremity. The importance of this fact will appear later.

Shortly after the medullary folds lave met behind the whole canal becomes closed in. This occurs in the usual way by the junction and coalescence of the medullary folds. In the course of the closing of the medullary groove the edges of the cephalic plate, which have at first a ventral curvature, become bent up in the nornial mamer, and enclose the dilated cephalic portion of the medullary canal. The closing of the medullary canal takes place earlier in the head and neck than in the back.

An anterior pore at the front end of the canal, like that in Amphioxus and the Ascidians, is not found. The further differentiation of the central nervous system is described in a special chapter: it may however here be stated that the walls of the medullary canal give rise not only to the central nervous system but to the peripheral also.

Mesoblast. The mesoblast was left as two lateral plates continuons belind with the undifferentiated cells of the caudal swellings.

The cells composing them become arranged in two layers (fig. $20 \mathrm{C},(p)$ ), a splanchnic layer adjoining the hypoblast, and a somatic layer adjoining the epiblast. Between these two layers there is soon developed in the region of the head a well-marked cavity (fig. $20 \mathrm{~A}, p p$ ) which is subsequently continued into the region of the trunk, and forms the primitive body-cavity, equivalent to the cavity originating as an outgrowth of the archenteron in Amphioxus. The body-cavities of the two sides are at first quite independent.

Coincidentally with the appearance of differentiation into somatic and splanchnic layers the mesoblast plates become in the region of the trunk partially split by a

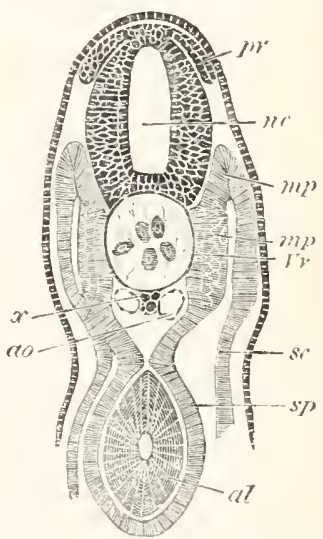

Fig. 21. Trixsterse SECTION THROCGH THE TRUNK OF AN EMBRYO SLIGHTLI OLIER THAN FIG. $28 \mathrm{E}$.

ne. neural eanal; $p v \cdot$ posterior root of spinal nerve; $x$. sulnotochorial rod; ao. aorta; sc. somatic mesoblast; sp. splanchnic mesoblast; mp. muscle-plate; $m p^{\prime}$. portion of muscle-plate converted into muscle; Ire portion of the rertebral plate which will give rise to the vertehral botins: 17 . alimentary tract. 
series of transverse lines of division into mesoblastic somites. Only the dorsal parts of the plates become split in this way, their ventral parts remaining quite intact. As a result of this each plate becomes divided into a dorsal portion adjoining the medullary canal, which is divided into somites, and may be called the vertebral plate, and a ventral portion not so divided, which may be called the lateral plate.

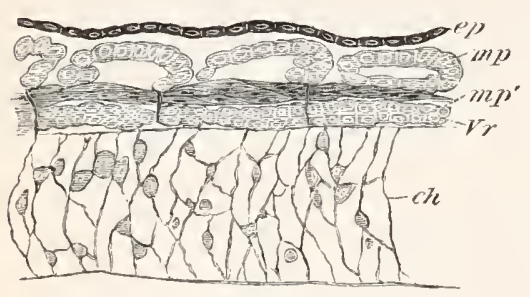

Fig. 22. Horizontal section throvgh

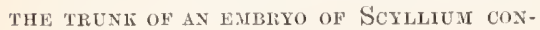
SIDERABLY YOUNGER THAN $28 \mathrm{~F}$.

The section is taken at the level of the notochord, and shews the separation of the cells to form the vertebral bodies from the muscle-plates.

ch. notochord; ep. epiblast; $\boldsymbol{r}_{r}$. rudiment of rertebral body; mp. muscle-plate; $m p^{\prime}$. portion of muscle-plate already differentiated iuto longitudinal muscles. which is the cavity originally continuous with the body-cavity (fig. 23, $m p$ ). The splanchnic layer of the plates buds off cells to form the rudiments of the vertebral bodies which are at first segmented in the same planes as the mesoblastic somites (fig. 22, $\boldsymbol{V}^{\circ} \boldsymbol{r}^{\circ}$. The plates themselves remain as the muscle-plates $(m p)$, and give rise to the whole of the voluntary muscular system of the body. Between the vertebral and lateral plates there is left a connecting isthmus, with a narrow prolongation of the body-cavity (fig. $2.3 \mathrm{~B}, s t$ ), which gives rise (as described in a special chapter) to the segmental tubes and to other parts of the excretory system.

In the meantime the lateral plates of the two sides unite ventrally throughout the intestinal and cardiac regions of the body, and the two primitively isolated cavities contained in them coalesce. In the tail however the plates do not unite ventrally till somewhat later, and their contained cavities remain distinct till eventually obliterated.

At first the pericardial cavity is quite continuous with the bodycavity; but it eventually becomes separated from the body-cavity by the attachment of the liver to the abdominal wall, and by a horizuntal septum in which run the two ductus Cuvieri (fig. $23 \mathrm{~A}, s v$ ). Two perforations in this septum (fig. $23 \mathrm{~A}$ ) leave the cavities in permanent conmmunication. 
'The parts herived from the two layers of the mesoblast (not including special organs or the vascular system) are as follow:-

From the somatic layer are formed

(1) A considerable part of the voluntary muscular system of the body.

(2) The dermis.

(3) A large part of the intermuscular connective tissue.

(4) Part of the peritoneal epithelium.

From the splanchnic layer are formed

(1) A great part of the voluntary muscular system.

(2) Part of the intermusenlar connective tissue.

(3) The axial skeleton and surrounding connective tissue.

(4) The muscular and connective-tissue wall of the alimentary tract.

(5) Part of the peritoneal epithelium.

A.

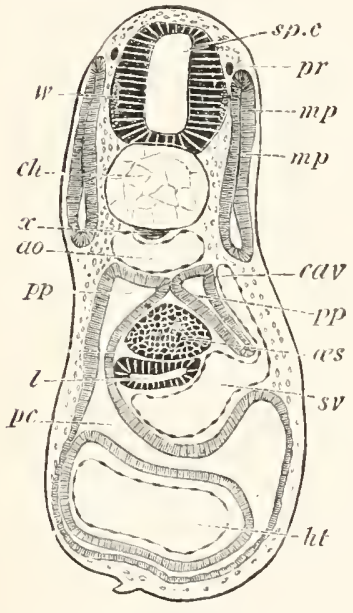

13.

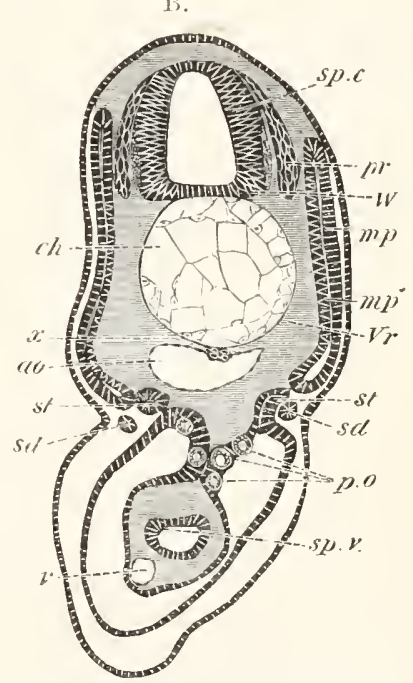

Fig. 23. Sections throvgh the trunk of a Scrlliul embrio shighthy TOUNGER THAN $28 \mathrm{~F}$.

Figure A shews the separation of the body-cavity from the pericardial cavity by a horizontal septum in which runs the ductus Cuvieri; on the left side is seen the narrow passage which remains comnecting the two cavities. Fig. B through a posterior part of the trunk shews the origin of the segmental tubes and of the primitive ora.

sp.c. spinal canal; $\boldsymbol{I r}$. white matter of spinal cord; $p r$. commissure connecting the posterior nerve-roots; $c h$. notochord; $x$. sub-notochordal rod; ao. aorta; st. sinus venosus; cau. cardinal vein; $h t$. heart; $p p$. body-cavity; $p c$. pericarlial carity; $a s$. solid œsophagus; l. liver; $m p$. muscle-plate; $m p^{\prime}$. immer layer of musele-plate; Ir. rudiment of vertebral body; st. segmental tube; sd. segmental duct; sp. $\iota$. spiral valve; $v$. subintestinal vein.

In the region of the head the mesoblast does not at first become livided into somites; but on the formation of the gill clefts a division takes place, which is apparently equivalent to the segmentation 
of the mesoblast in the trunk. This division causes the body-cavity of the head to be divided up into a series of separate segments, one of which is shewn in fig. 24, $\mathrm{pp}$. The walls of the segments eventually give rise to the main

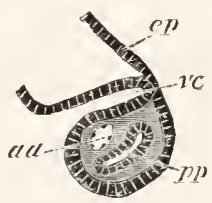

Fig. 24. Horizoxtal Section throvgh THE LAST VISCERAL ARCH BUT ONE OF AN emibryo of Pristiurus.

ep. epiblast; vc. pouch of hypoblast which will form the walls of a visceral cleft; $p p$. segment of body-cavity in visceral arch; ua. aortic arch. splanchnic mesoblast, and the generative system from a portion of the mesoblast of the dorsal part of the body-cavity.

The hypoblast. Very shortly after the formation of the mesoblastic plates as lateral differentiations of the lower layer cells, an axial differentiation of the hypoblast appears, which gives rise to the notochord very much in the same way as in Amphioxus.

At first the hypoblast along the axial line forms a single layer in contact with the epiblast. Along this line a rod-like thickening of the hypoblast very soon appears (fig. $25, \mathrm{~B}$ and $\mathrm{C}, \mathrm{Ch}$ ) at the head end of the embryo, and gradually extends backwards. This is the rudiment of the notochord; it remains attached for some time to the hypoblast, and becomes separated from it first at the hearl end of the embryo (fig. $25 \mathrm{~A}, c h$ ): the separation is then carried backwards.

A series of sections taken throngh an embryo shortly after the first differentiation of the notochord presents the following characters.

In the hindermost sections the hypol,last retains a perfectly normal structure and uniform thickness throughout. In the next few sections (fig. $\left.25 \mathrm{C}, C h^{\prime}\right)$ a slight thickening is to be olsserved in it, immediately below the medullary groove. The layer, which elsewhere is composed of a single row of cells, here becomes two cells deep, but no sign of a division into two layers is exhibited.

In the next few sections the thickening of the hypoblast becomes much more pronounced; we have, in fact, a ridge projecting from the hypoblast towards the epiblast (fig. $25 \mathrm{~B}, C h^{\prime}$ ). This ridge is pressed firmly against the epiblast, and catses in it a slight indentation. The hypoblast in the region of the ridge is formed of two layers of cells, the ridge being entirely due to the uppermost of the two.

In sections in front of this a cylindrical rol, which can at once be recognised as the notochord, and is continuous with the ridge just deseribed, begins to be split off from the liypoblast (fig. $25 \mathrm{~A}, \mathrm{C} h$ ). It is difficult to say at what point the separation of this rod from the lippollast is com- 
pleted, since all intermediate gradations between complete separation and complete attachment are to be seen.

Shortly after the separation takes place, a fairly thick bridge is found connecting the two lateral halves of the hypoblast, but this bridge is anteriorly excessively delicate and thin, and in some cases is barely visible except with high powers. In some sections I have observed possible indications of the process like that described by Calberla for Petronyzon, by which the lateral parts of the hypoblast grow in underneath the axial part, and so isolate it bodily as the notochord.

It is not absolutely clear whether the notochord is to be regarded as an axial differentiation of the hypoblast, or as an axial differentiation of the lower layer cells.

The facts of development both in Amphioxus
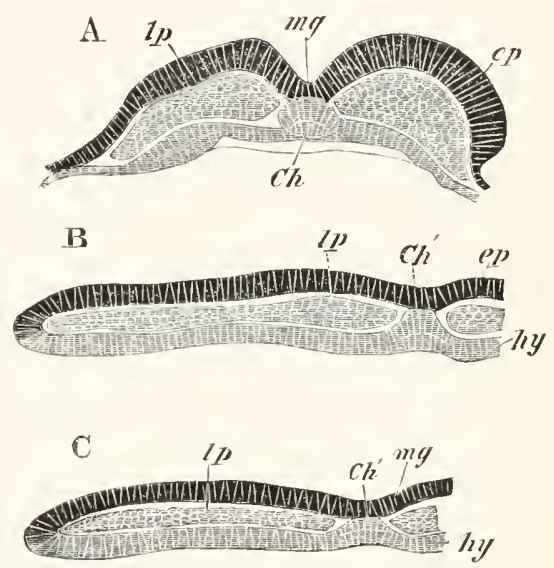

Fig. 25. Timee sections of a Pristicrus EMrRYo SLIGHTLY OLDER THAN Fig, 28 B.

The sections shew the development of the notochord.

$C h$. notochord; $C h^{\prime}$. developing notochord; $m g$. medullary groove; $1 p$. lateral plate of mesoblast; ep. epiblast; hy. hypoblast.

and Elasmobranchii tend towards the former view; but the nearly simultaneous differentiation of the notochord and the mesoblastic plates lends some support to the supposition that the notochord may be merely a median plate of mesoblast developed slightly later than the two lateral plates.

The alimentary canal or mesenteron was left as a space between the liypoblast and the yolk, ending blindly in front, but opening behind by a widish aperture, the blastopore or anus of Rusconi (vide fig. $19 \mathrm{~B})$.

The conversion of this irregular cavity into a closed canal commences first of all at the anterior extremity. In this conversion two distinct processes are concerned. One of these is a process of folding off of the embryo from the blastoderm. The other is a simple growth of cells independent of any fold. To the first of these processes the depth and narrowness of the alimentary cavity is due; the second is concerned in forming its ventral wall. The process of the folding off of the embryo from the blastoderm resembles exactly the similar process in the embryo bird. The fold is a perfectly continuous one round the front end of the embryo, but may be conveniently spoken of as composed of a head-fold and two lateral folds. 
Of far greater interest than the nature of these folds is the formation of the ventral wall of the alimentary canal. This originates in a growth of cells from the two sides to the middle line (fig. 26). The cells for it are not however mainly

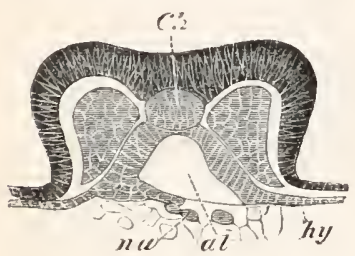

Fig. 26. Section throvgh the anterior part of a Pristiurus EMBRYO TO SHEW THE FORMATION OF THE ALIMENTARY TRACT.

$C h$. notochord; hy. hypoblast al. alimentary tract; na. cells passing in from the yolk to form the ventral wall of the alimentary tract. derived from pre-existing hypoblast cells, but are formed de novo around the nuclei of the yolk which have already been spoken of (fig. 26, na). The ventral wall of the mesenteron is in fact, to a large extent at any rate, formed as a differentiation of the primitive yolk floor.

The folding off and closing of the alimentary canal in the anterior part of the body proceeds rapidly, and not only is a considerable tract of the alimentary canal formed, but a great part of the head is completely folded off from the yolk before the medullary groove is closed.

The posterior part of the alimentary canal retains for a longer time its primitive condition. Finally however it also becomes closed in, by the lips of the blastopore at the hind end of the embryo meeting and uniting. The peculiarity of the closing in of the posterior part of the alimentary canal consists in the fact that a similar continuity to that in Amphioxus obtains between the neural and alimentary canals.

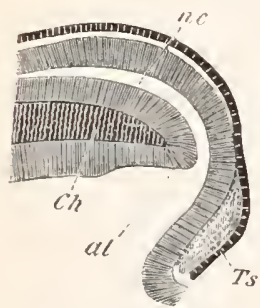

Fig. 27. Loxgitudinat VERTICAL SECTION OF AN EMBRYOSLIGHTLY YOUNGER THAN THAT IN FIG. 26 D.

The section shews the communication which exists between the netural and alimentary canals.

nc. neural canal; al. ali. mentary tract; $C h$. notochord; Ts, tail swelling. This is due to the medullary folds being continuous at the end of the tail with the lips of the blastopore, which close in the hind end of the alimentary canal; so that, when the medullary folds unite to form a canal, this canal becomes continuous witl the alimentary canal, which is closed in at the same time. In other words, the medullary folds assist in enveloping the blastopore which does not therefore become absolutely closed, but opens into the floor of the neural canal. It will afterwards be shewn that it is only the posterior part of the blastopore that becomes closed during the above process, and that the anterior and ventral part long remains open. The general arrangement of the parts, at the time when the hind end of the mesenteron is first closed, is shewn in fig. -27. The same points may be seen in the diagrammatic longitudinal section fig. 19 C:

The middle portion of the alimentary tract is the last to be closed in, since it remains till late in embryonic life as the umbilical or 
vitelline canal, connecting the yolk sack with the alimentary cavity. The umbilical canal falls into the alimentary tract immediately behind the entrance of the hepatic duct.

At a fairly early stage of derelopment a rod is constricted off from the dorsal wall of the alimentary canal (figs. $27^{*}$ and $23 x$ ), which is known as the subnotochordal rol. It is placed immediately below the notochord, and disappears during embryonic life.

\section{General features of the Elasmobranch embryo at successive stages.}

Shortly after the three germinal layers become definitely established, the rudiment of the embryo, as visible from the surface, consists of an oblong plate, which extends inwards from the periphery of the blastoderm, and is bounded on its inner side by a head-fold and two lateral folds (fig. $28 \mathrm{~B}$ ). This plate is the medullary plate; along its axial line is a shallow gloove-the medullary groove $(\mathrm{mg})$. The rudiment of the embryo rapidly increases in length, and takes a spatula-like form (fig. $28 \mathrm{C}$ ). The front part of it, turned away from the edge of the blastoderm, soon becomes dilated into a broad plate,-the cephalic plate $(h)$-while the tail end at the edge of the blastoderm is also enlarged, being formed of a pair of swellingsthe tail swellings $(t s)$-derived from the lateral parts of the original embryonic rim. By this

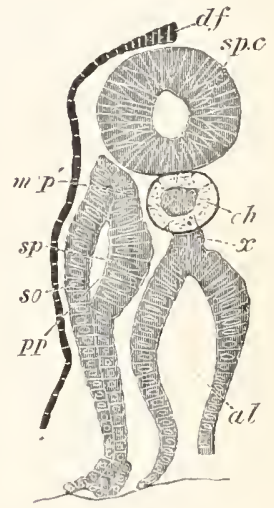

Fig. 27*. TraxsTERSE SECTION THROUGH THE TAIL REGION OF A Pristicres embrto of THE SAME AGE AS FlG. 28 E.

df. dorsal fin; sp.c. spinal cord; pp. bodycavity; sp. splanchnic layer of mesoblast; so. somatic layer of mesoblast; $m p$. commencing differentiation of muscles; $c h$. notochord; $x$. subnotochortal rod arising as an outgrowth of the dorsal wall of the alimentary tract; al. alimentary tract. stage a certain number of mesoblastic somites have become formed but are not shewn in my figure. They are the foremost somites of the trunk, and those behind them continue to be added, like the segments in Chrtopods, between the last formed somite and the end of the body. The increase in length of the body mainly takes place by growth in the region between the last mesoblastic somite and the end of the tail. The anterior part of the body is now completely folded off from the blastoderm, and the medullary groove of the earlier stage has become converted into a closed canal.

By the next stage (fig. 2S D) the embryo has become so much folded off from the yolk both in front and behind that the separate parts of it begin to be easily recognizable.

The embryo is attached to the yolk by a distinct stalk or cord, which in the succeeding stages gradually narrows and elongates, and is known as the umbilical cord (so.s.). The medullary canal has now 
become completely closed. The anterior region constitutes the brain; and in this part slight constrictions, not perceptible in views of the embryo as a transparent object, mark off three vesicles. These vesicles are known as the fore, mid, and hind brain. From the forebrain there is an outgrowth on each side, the first rudiment of the optic vesicles $(o p)$. The tail swellings are still conspicuous.

The tissues of the body have now become fairly transparent, and there may be seen at the sides of the body seventeen mesoblastic
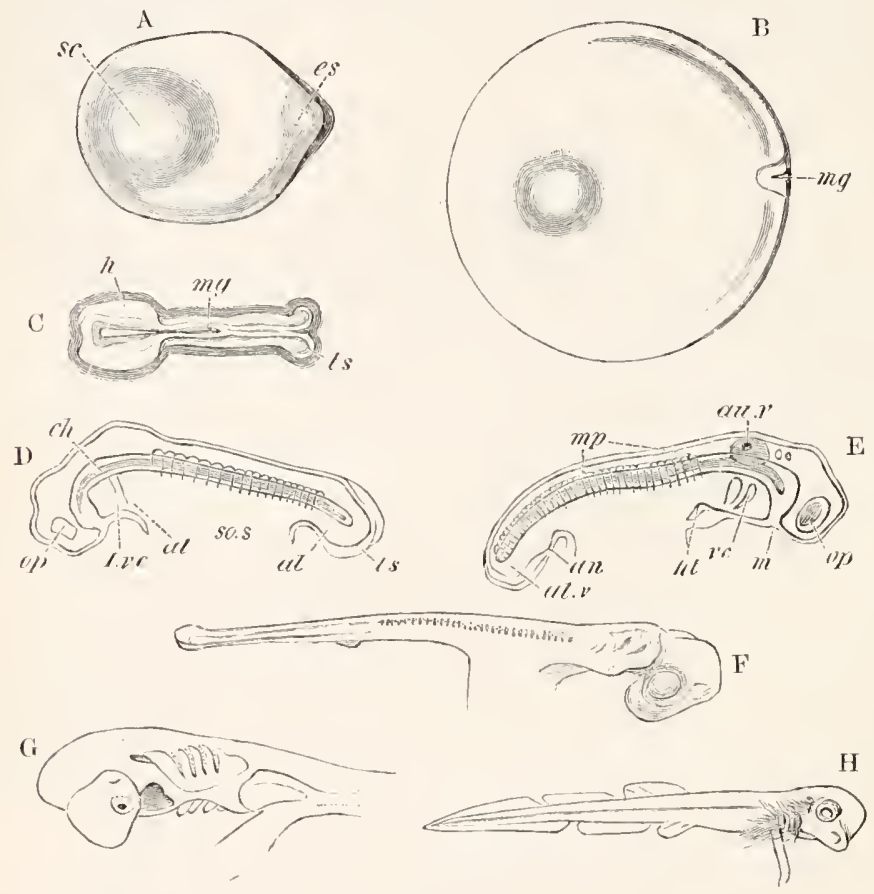

Fig. 28. Views of Elasiobratch embryos.
A-F. Pristiures.
G. and H. Scylliom.

A. A blastoderm before the formation of the medullary plate. sc. segmentation cavity; es, embryonic swelling.

B. A somewhat older blastoderm in which the medullary groove has been established. mg. medullary groove.

C. An embryo from the dorsal surface, as an opaque object, after the medullary groove has become posteriorly converted into a tube. mg. medullary groove: the reference line points very nearly to the junction between the open medullary groove with the medullary tube; $h$. cephalic plate; $t s$. tail swelling.

D. Side view of a somewhat older embryo as a transparent object. ch. notochord; op. optic vesicle; I.v.c. Ist visceral cleft; al. alimentary tract; so.s. stalk connecting the yolk-sack with the embryo.

E. Side view of an older embryo as a transparent object. $m p$. muscle-plates; au. $x$. auditory vesicle; $v c$. visceral cleft; $h t$. heart; $m$. mouth invagination; an. anal diverticulum; al.v. posterior vesicle of post-anal gut.

F. G. H. Older embryos as opaque objects. 
somites. The notochord, which was formed long before the stage represented in figure $28 \mathrm{D}$, is now also distinctly visible. It extends from almost the extreme posterior to the anterior end of the embryo, and lies between the ventral wall of the spinal canal and the dorsal wall of the intestine. Round its posterior end the neural and alimentary tracts become continuous with each other. Anteriorly the termination of the notochord cannot be seen, it can only be traced into a mass of mesoblast at the base of the brain, which there separates the epiblast from the hypoblast. The alimentary canal $(a l)$ is completely closed anteriorly and posteriorly, though still widely open to the yolk-sack in the middle part of its course. In the region of the head it exhibits on each side a slight bulging outwards, the rudiment of the first visceral cleft. This is represented in the figure by two lines (I. v.c.).

The embryo represented in fig. $28 \mathrm{E}$ is far larger than the one just described, but it has not been convenient to represent this increase of size in the figure. Accompanying this increase in size, the folding off from the yolk has considerably progressed, and the stalk which unites the embryo with the yolk is proportionately narrower and longer than before.

The brain is now very distinctly divided into the three lobes, the rudiments of which appeared during the last stage. From the foremost of these the optic resicles now present themselves as wellmarked lateral outgrowths, towards which there has appeared an involution from the external skin (op) to form the lens.

A fresh organ of sense, the auditory sack, now for the first time becomes visible as a shallow pit in the external skin on each side of the hind-brain (au.v). The epiblast which is involuted to form this pit becomes much thickened, and thereby the opacity, indicated in the figure, is produced.

The mesoblastic somites have greatly increased in number by the formation of fresh somites in the tail. Thirty-eight of them were present in the embryo figured. 'The mesoblast at the base of the brain is more bulky, and there is still a mass of unsegmented mesoblast which forms the tail swellings. The first rudiment of the heart $(h t)$ becomes visible during this stage as a cavity between the mesoblast of the splanchnopleure and the hypoblast.

The fore and hind guts are now longer than they were. An invagination from the exterior to form the mouth has appeared $(m)$ on the ventral side of the head close to the base of the thalamencephalon. The upper end of this eventually becomes constricted off as the pituitary body, and an indication of the future position of the anus is afforded by a slight diverticulum of the hind gut towards the exterior, some little distance from the posterior end of the embryo (an). The portion of the alimentary canal behind this point, though at this stage large, and even dilated into a vesicle at its posterior end $(a l . v)$, becomes eventually completely atrophied. It is known as the postanal gut. In the region of the throat the rudiment of a 
second visceral cleft has appeared behind the first; neither of them is as yet open to the exterior.

In a somewhat older embryo the first spontaneous movements take place, and consist in somewhat rapid excursions of the embryo from side to side, produced by a serpentine motion of the body.

A ventral flexure of the preoral part of the head, known as the cranial flexure, which commenced in earlier stages (fig. $28 \mathrm{D}$ and E), has now become very evilent, and the mid-brain ${ }^{1}$ begins to project in the same manner as in the embryo fowl on the third day, and will soon form the anterior termination of the long axis of the embryo. The fore-brain has increased in size and distinctness, and the anterior part of it may now be looked on as the unpaired rudiment of the cerebral hemispheres.

Further changes have taken place in the organs of sense, especially in the eye, in which the involution for the lens has made considerable progress. The number of the muscle-plates has again increased, but there is still a region of unsegmented mesoblast in the tail. The thickened portions of mesoblast, which caused the tail swellings, are
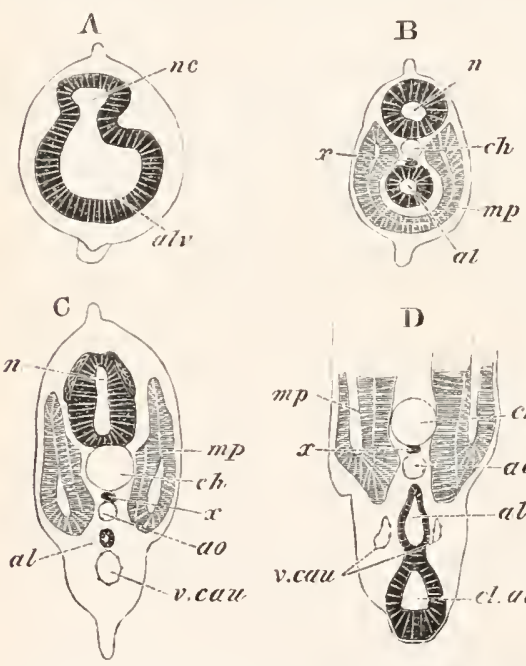

D)

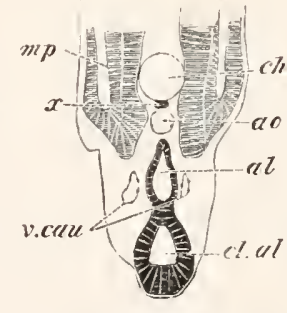

Fig. 28*. Four sections throdgh the postANAL PART OF THE TAIL OF AN EMBRYO OF THE SAME AGE AS FIG. $28 \mathrm{~F}$.

A. is the posterior section.

$n c$. neural canal; al. post-anal gut; alv. caudal resicle of post-anal gut; $x$. subnotochord rod; $m p$. muscle-plate; $c h$. notochord; cl.al. cloaca; $a$. aorta; $v$.cau. caudal vein. still to be seen, and would seem to act as the reserve from which is drawn the matter for the rapid growth of the tail, which occurs soon after this. The mass of the mesoblast at the base of the brain has again increased. No fresh features of interest are to be seen in the notochord. The heart is very much more conspicuous than before, and its commencing flexure is very apparent. It now beats actively. The post-anal gut is much longer than during the last stage; and the point where the anus will appear is very easily detected by a bulging out of the gut towards the external skin. 'The alimentary vesicle at the end of the post-anal gut, first observ-

1 The part of the brain which I have here called mid-brain, and which unquestionably corresponds to the part called mid-brain in the embryos of higher vertebrates, becomes in the adult what Miklucho-Maclay and Gegenbaur called the vesicle of the third ventricle or thalamencephalon. 
able during the last stage, is now a more conspicuous organ. There are three visceral clefts, none of which are as yet open to the exterior.

Figure $28 \mathrm{~F}$ represents a considerably older embryo viewed as an opaque object, and fig. $29 \mathrm{~A}$ is a view of the head as a transparent object. The stalk connecting it with the yolk is now, comparatively speaking, quite narrow, and is of sufficient length to permit the embryo to execute considerable movements.

The tail has grown immensely, but is still dilated terminally. The terminal dilatation is mainly due to the alimentary vesicle (fig. 20* $a l v)$, but the postanal section of the alimentary tract in front of this is now a solid cord of cells. Both the alimentary vesicle and this cort very soon disappear. Their relations are shewn in section in fig. 28\%.

The two pairs of limbs have appeared as differentiations of a continuous but not very conspicuous epiblastic thickening, which is probably the rudiment of a lateral fin. The anterior pair is situated just at the front end of the umbilical stalk; and the posterior pair, which is the later developed and less conspicuous of the two, is situated some little distance behind the stalk.

The cranial Hexure has greatly increased, and the angle between the long axis of the front part of the hear and of the body is less than a right angle. The conspicuous mid-brain $(29 \mathrm{~A}, m b)$ forms the anterior termination of the long axis of the body. The thin roof of the fourth ventricle $(h b)$ may be noticed in the figure behind the mid-brain. The auditory sack $(a u . V)$ is nearly closed, and its opening is not shewn in the figure. In the eye $(o p)$ the lens is completely formed. The olfactory pit $(o l)$ is seen a little in front of the eye.

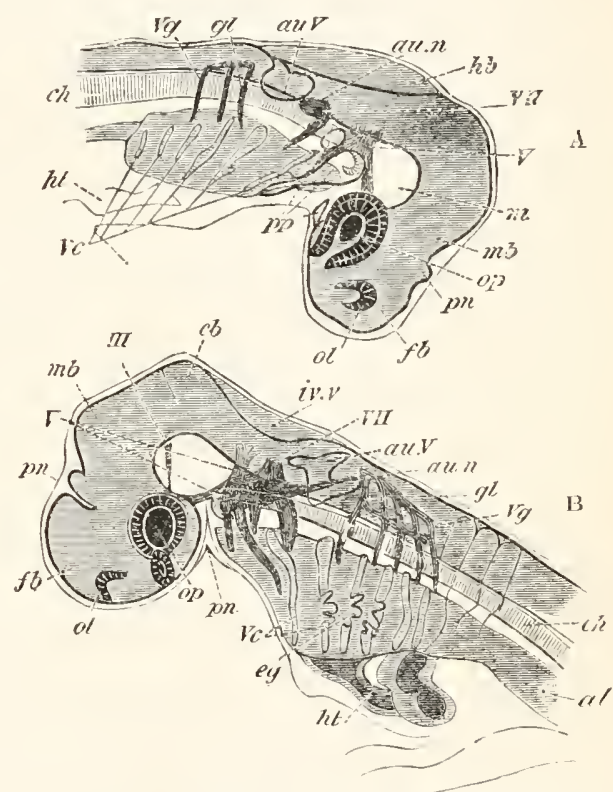

Fig. 29. Views of the head of ElasyoBRAXCH EMBRTOS AT TWO STAGES AS TRANSPAREXT овJECTS.

A. Pristiurus embryo of the same stage as fig. $28 \mathrm{~F}$.

B. Somewhat older Scyllium embryo.

III. third nerve; $V$. fifth nerve; I'II. seventh nerve; au.n. auditory nerve; $g l$. glossopharyugeal nerve; I $g$. vagus nerve; $f b$. fore-brain; $p n$. pineal gland; mb. mid-brain ; $h \dot{b}$. hind-brain; $i x . t$. fourth ventricle; $c b$. cerebellum; ol. olfactory pit; op. eye; au.I. anditory vesicle; $m$. mesoblast at base of brain; $c h$. notochord; ht. heart; Ic. visceral clefts; eq. external gills: $p p$. sections of bodycavity in the head. 
Owing to the opacity of the embryo, the muscle-plates are only indistinctly indicated in fig. $28 \mathrm{~F}$, and no other features of the mesoblast are to be seen.

The mouth is now a deep pit, the hind borders of which are almost completely formed by a thickening in front of the first branchial or visceral cleft, which may be called the first branchial arch or mandibular arch.

Four branchial clefts are now visible, all of which are open to the exterior, but in the embryo, viewed as a transparent object, two more, not open to the exterior, are visible behind the last of these.

Between each of these and bebind the last one there is a thickening of the mesoblast which gives rise to a branchial arch. The arch between the first and second cleft is known as the hyoid arch.

Fig. $29 \mathrm{~B}$ is a representation of the head of a slightly older embryo in which papillw may be seen in the front wall of the second, third, and fourth branchial clefts: these papillæ are the commencements of filiform processes which grow out from the gill-clefts and form external gills. The peculiar ventral curvature of the anterior end of the notochord $(c h)$ botli in this and in the preceding figure deserves notice.

A peculiar feature in the anatomy makes its appearance at this period, viz. the replacement of the original hollow aesophagus by a solid cord of cells (fig. $23 \mathrm{~A}$, ns) in which a lumen does not reappear till very much liter. I have found that in some Teleostei (the Salmon) long after they are hatched a similar solidity in the cesophagus is present. It appears not impossible that this feature in the asophagus may be commected with the fact that in the ancestors of the present types the esophagus was perforated by gill slits; and that in the process of embryonic abbreviation the stage with the perforated osophagus became replaced by a stage with a cord of indifferent cells (the esophagus being in the embryo quite functionless) out of which the non-periorated osophagus was directly formed. Tn the higher types the process of development appears to have become quite direct.

By this stage all the parts of the embryo have become established, and in the succeeding stages the features characteristic of the genus and species are gradually acquired.

Two embryos of Scyllium are represented in fig. $28 \mathrm{G}$ and $\mathrm{H}$, the head and anterior part of the trunk being represented in fig. G, and the whole embryo at a much later stage in fig. $\mathrm{H}$.

In both of these, and especially in the second, an apparent diminution of the cranial flexure is very marked. 'This diminution is due to the increase in the size of the cerebral hemispheres, which grow upwards and forwards, and press the original fore-brain against the mid-brain behind.

In fig. G the rudiments of the nasal sacks are clearly visible as small open pits.

The first cleft is no longer similar to the rest, but by the closure of the lower part has commenced to be metamorphosed into the spiracle. 
Accompanying the change in position of the first cleft, the mandibular arch has begun to bend round so as to enclose the front as well as the sides of the mouth. By this change in the mandibular arch the mouth becomes narrowed in an antero-posterior direction.

In fig. $\mathrm{H}$ are seen the long filiform external gills which now project out from all the visceral clefts, including the spiracle. They are attached to the front wall of the spiracle, to both walls of the next four clefts, and to the front wall of the last cleft. They have very possibly become specially developed to facilitate respiration within the egg; and they disappear before the close of larval life.

When the young of Scyllium and other Sharks are hatched they have all the extemal characters of the adult. In Raja and Torpedo the early stages, up to the acquirement of a shark-like form, are similar to those in the Selachoidei, but during the later embryonic stages the body gradually flattens out, and assumes the adult form, which is thus clearly shewn to be a secondary acquirement.

An embryonic gill-cleft behind the last present in the adult is found (Wyman, No. 54) in the embryo of Raja batis.

The unpaired fins are developed in Elasmobranchs as a fold of skin on the dorsal side, which is continued round the end of the tail along the ventral side to the anus. Local developments of this give rise to the dorsal and anal fins. The caudal fin is at first symmetrical, but a special lower lobe grows out and gives to it a heterocercal character.

\section{Enclosure of the yolk-sack and its relation to the embryo.}

The blastoderm at the stage represented in fig. $28 \mathrm{~A}$ and B forms a small and nearly circular patch on the surface of the yolk, composed of epiblast and lower layer cells. While the body of the embryo is gradually being moulded this patch grows till it envelopes the yolk; the growth is not uniform, but is less rapid in the immediate neighbourhood of the embryonic part, of the blastoderm than elsewhere. As a consequence of this, that part of the edge, to which the embryo is attached, forms a bay in the otherwise regular outline of the edge of the blastoderm, and by the time that about two-thirds of the yolk is enclosed this bay is very conspicuous. It is shewn in fig. $30 \mathrm{~A}$, where $b l$ points to the blastoderm, and $y k$ to the part of the yolk not yet covered by the blastoderm. The embryo at this time is only connected with the yolk-sack by a narrow umbilical cord; but, as shewn in the figure, is still attached to the edge of the blastoderm.

Shortly subsequent to this the bay in the blastoderm, at the head of which the embryo is attached, becomes obliterated by its two sides coming together and coalescing. The embryo then ceases to be attached at the edge of the blastoderm. But a linear streak formed by the coalesced edges of the blastoderm is left connecting the embryo with the edge of the blastoderm. This streak is probably 
analogous to (though not genetically related with) the primitive streak in the Amniota.

This stage is represented in fig. $30 \mathrm{~B}$. In this figure there is

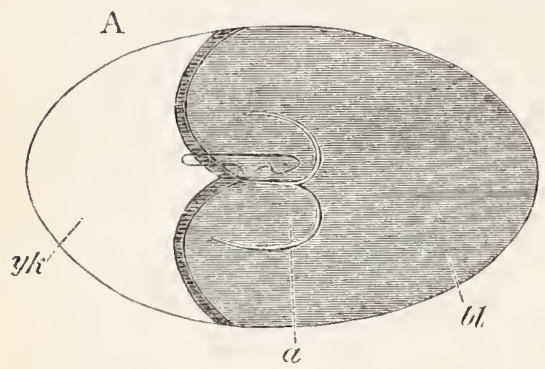
only a small patch of yolk $(y k)$ not yet enclosed, which is situated at some little distance behind the embryo. Throughout all this period the edge of the blastoderm has remained thickened: a feature which persists till the complete investment of the yolk, which takes place shortly after the stage last described. In this thickened

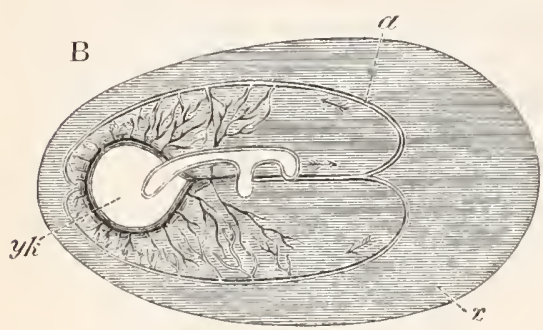
edge a circular vein arises which brings back the blood from the yolk-sack to the embryo. 'The opening in the blastoderm, exposing the portion of the yolk not yet covered, may be conveniently called the yolk blastopore. It is interesting to notice that, owing to the large size of the yolk in

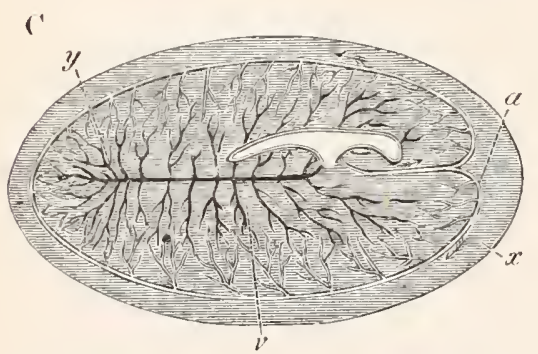

Fig. 30. Three views of the vitellus of aN Elasmobraxch, SHEWLing the eMbrio, the BLASTOUERA, AND THE VESSELS OF THE YOLK-SACK.

The shaded part $(b l)$ is the blastoderm; the white part the uncovered yolk.

A. Young stage with the embryo still attached at the edge of the blastoderm.

B. Older stage with the yolk not quite enclosed by the blastoderm. yolk.

C. Stage after the complete enclosure of the

$y k$. yolk; $6 l$. blastoderm; $\imath$. venous trunks of yolk-sack; $a$. arterial trunks of yolk-sack; $y$. point of closure of the yolk blastopore; $x$. portion of the blastoderm outside the arterial sinus terminalis. Elasmobranchs, the posterior part of the primitive blastopore becomes encircled by the medullary folds and tailswellings, and is so closed long before the anterior and more ventral part, which is represented by the uncovered portion of the yolk. It is also worth remarking that, owing to the embryo becoming removed from the edge of the blastoderm, the final closure of the yolk blastopore takes place at some little distance from the embryo.

The blastoderm enclosing the yolk is formed of an external layer of epiblast, a layer of mesoblast below in which the blood-vessels 
are developed, and within this a layer of hypoblast, which is especially well marked and ciliated (Levdig, No. 46) in the umbilical stalk, where it lines the canal leading from the yolk-sack to the intestine. In the region of the yolk-sack proper the blastoderm is so thin that it is not easy to be quite sure that a layer of hypoblast is throughout distinct. Both the hypoblast and mesoblast of the yolk-sack are formed by a differentiation of the primitive lower layer cells.

Nutriment from the yolk-sack is brought to the embryo partly through the umbilical canal and so into the intestine, and partly by means of blood-vessels in the mesoblast of the sack. The bloodvessels arise before the blastoderm has completely covered the yolk.

Fig. 30 A represents the earliest stage of the circulation of the yolk-sack. At this stage there is visible a single arterial trunk $(a)$ passing forwards from the embryo and dividing into two branches. No venous trunk could be detected with the simple microscope, but probably venous channels were present in the thickened edge of the blastoderm.

In fig. $30 \mathrm{~B}$ the circulation is greatly advanced. The blastoderm has now nearly completely enveloped the yolk, and there remains only a small circular space ( $y k_{i}$ ) not enclosed by it. The arterial trunk is present as before, and divides in front of the embryo into two branches which turn backwards and form a nearly complete ring round the embryo. In general appearance this ring resembles the sinus terminalis of the area vasculosa of the Bird, but in reality bears quite a different relation to the circulation. It gives off branches on its inner side only.

A venous system of returning vessels is now fully developed, and its relations are very remarkable. There is a main venous ring in the thickened edge of the blastoderm, which is connected with the embryo by a single stem rumning along the seam where the edges of the blastoderm have coalesced. Since the venous trunks are only developed behind the embryo, it is only the posterior part of the arterial ring that gives off branches.

The succeeding stage (fig. $30 \mathrm{C}$ ) is also one of considerable interest. The arterial ring has greatly extended, and now embraces nearly half the yolk, and sends off trumks on its inner side along its whole circumference. Hore important changes have taken place in the venous system. The blastoderm has now completely enveloped the yolk, and the venous ring is therefore reduced to a point. The small veins which originally started from it may be observed diverging in a brush-like fashion from the termination of the unpaired trunk, which originally connected the venous ring with the heart.

At a still later stage the arterial ring embraces the whole yolk, and, as a result of this vanishes in its turn, as did the venous ring before it. There is then present a single arterial and a single venous trunk. The arterial trunk is a branch of the dorsal aorta, and the venous trunk originally falls into the heart together with the subintestinal or splanchnic vein. On the formation of the liver the 
proximal end of the subintestinal vein becomes the portal vein, and it is joined just as it enter's the liver by the venous trunk from the yolk-sack. The venous trunk leaves the body on the right side, and the arterial on the left.

The yolk-sack persists during the whole of embryonic life, and in the majority of Elasmobranch embryos there arises within the body walls an outgrowth from the unbilical canal into which a large amount of the yolk passes. This ontgrowth forms an internal yolksack. In Mustelus vulgaris the internal yolk-sack is very small, and in Mustelus lievis it is absent. The latter species, which is one of those in which development takes place within the uterus, presents a remarkable peculiarity in that the vascular surface of the yolk-sack becomes raised into a number of folds, which fit into corresponding depressions in the vascular walls of the uterus. The yolk-sack becomes in this way firmly attached to the walls of the uterus, and the two together constitute a kind of placenta. A similar placenta is found in Carcharias.

After the embryo is hatched or born, as the case may be, the yolksack becomes rapidly absorbed.

\section{Bibliogitapiy.}

(40) F. M. Balfour. "A preliminary account of the development of the Elasmobranch Fishes." Quart. J. of Mirr. Science, Vol. xiv. 1s7t.

(4I) F. Mi. Balfour. "A Monograph on the development of Elasmobranch Fishes." Jondon, 1s78. Reprinted from the Joumal of A nat. and Plysiol. for 1876, 1377 , an 1878 .

(+2) Z. Gerbe. "Recherehes sur la segmentation de la cicatrule et la formation des

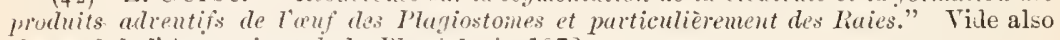
Joumal de l'Anatomie et do la P'hysiologie, 1872.

(t.3) W. His. "Ueb. d. Billung v. Haifischenembryonen." Zeit. für Anat. u. Enticick., Vol. 11. 1877.

(4) A. Kowalevsky. "Development of Acanthias vulgaris and Mustelus lævis." (Rusian.) Trunsactions of the Kiew Society of Naturatists, Vol. 1. Is70.

(45) R. Leuckart. "Ueber die allmählige Bildung d. Körpergestalt bei d. Rochen." Zeit.f. wiss. Zool., Bi. 1., p. 258.

(46) Fr. Leydig. Rochen 1 . Haie. Leipzig, 1852.

$(4)$ A. W. Malm. "Bidrag till kännedom om utvecklingen af Tajæ." Konyl. retenskaps aliademisns firhandlingar. Stockholm, 1876.

(4) Joh. If üller. Glatter IIaie des Aristoteles und aiber die Verschiedenheiten unter den Haifischen und Rochen in der Entwicklung des Eies. Berlin, 1840.

(49) S.. L. Schenk. "Die Eier von Riaja quadrimaculata innerhalb der Eileiter." sitz. der k. Akad. Wien, Vol. txxm11. 1873.

(50) Alex. Schultz. "Zur Entwicklungsgeschichte des Selachiereies." Archiv fïr micro. Auat., Vol. xi. 1875.

(5!) Alex. Schultz. "Beitrag zur Entwicklungsgeschichte d. Knorpelfische." Arclive für micro. Auat., Vol, xin. 1877.

$(, 2)$ C. Semper. "Die Stammesverwandschaft d. Wirbelthiere $u$. Wirbellosen." Arbeit. a. d. zool.-zoot. Instit. Wiirzbur:g, Vol. 1I. 1875.

(53) C. Semper. "Das Urogenitalsystem d. Plagiostomen, etc." Arbeit. a. d. zool.-zoot. Instit. Wiirzburq, Vol. 11. 1875.

(5t) Wyman. "Observations on the Development of Raja batis." Memoirs of the American Academy of Arts and Sciences, Vol. 1x. 1864. 


\section{CHAPTER IV.}

\section{TELEOSTEI.}

THE majority of the Telenstei deposit their eggs before impregnation, but some forms are viviparous, e.g. Blennius viviparus. Not a few carry their eggs about; but this operation is with a few exceptions performed by the male. In Syngnathus the eggs are carried in a brood-pouch of the male situated behind the anus. Amongst the Siluroids the male sometimes carries the eggs in the throat above the gill clefts. Ostegeniosus militaris, Arius falcarius, and Arius fissus have this peculiar habit

The ovum when laid is usually invested in the zona radiata only, though a vitelline membrane is sometimes present in addition, e.g. in the Herring. It is in most cases formed of a central yolk mass, which may either be composed of a single large vitelline sphere, or of distinct yolk spherules. The yolk mass is usually invested by a granular protoplasmic layer, which is especially thickened at one pole to form the germinal disc.

In the Herring's ovum the germinal disc is formed, as in many Crustacea, at impregnation; the protoplasm which was previously diffused through the egg becoming aggregated at the germinal pole and round the periphery.

Impregnation is external, and on its occurrence a contraction of the vitellus takes place, so that a space is formed between the vitellus and the zona radiata, which becomes filled with fluid.

The peculiarities in the development of the Teleostean ovum can best be understood by regarding it as an Elasmobranch ovum very much reduced in size. It seems in fact very probable that the Teleostei are in reality derived from a type of Fish with a much larger ovum. The occurrence of a meroblastic segmentation, in spite of the ovum being usually smaller than that of Amphibia and Acipenser, etc., in which the segmentation is complete, as well as the solid origin of many of the organs, receives its most plausible explanation on this hypothesis.

The proportion of the germinal disc to the whole ovum varies considerably. In very smail eggs, such as those of the Herring, the disc may form as much as a fifth of the whole. 
The segmentation, which is preceded by active movements of the germinal disc, is meroblastic. There is nothing very special to note with reference to its general features, but while in large ova like those of the Salmon the first furrows only penetrate for a certain depth through the germinal disc, in small ova like those of the Herring, they extent through the whole thickness of the disc. During the segmentation a great increase in the bulk of the blastoderm takes place.

In hardened specimens a small cavity amongst the segmentation spheres may be present at any early stage; but it is probably an artificial proluct, and in any case has nothing to do with the true segmentation cavity, which does not appear till near the close of segmentation. The peripheral layer of granular matter, continuous with the gerninal dise, does not undergo division, but it becomes during the segmentation specially thickened and then spreads itself under the edge of the blastodern; and, while remaining thicker in this region, gradually grows inwards so as to form a continuous subblastodermic layer. In this layer nuclei appear, which are equivalent to these in the Elasmobranch ovum. A considerable number of these nuclei often become visible simnltaneously (van Beneden, No. 6o) and they are usually believed to arise spontaneously, though this is still doubtful ${ }^{1}$. Aromb these nuclei portions of protoplasm are segmented offi, and cells are thins formerl, which enter the blastoderm, and lave nearly the same destination as the lomologous cells of the Elasmobranch ortum.

During the later stages of segmentation one end of the blastoderm becomes thickened and forms the embryonic swelling; and a cavity appears betwern the blastorlerm and the yolk which is excentrically situated near the non-embryonic part of the blastoderm. This cavity is the true segmentation cavity. Both the cavity and the embryonic swelling are seen in section in fig. $31 \mathrm{~A}$ and $\mathrm{B}$.

In leucisens rutilus Bambele describes a cavity as appearing in the middle of the hiastolerm during the later stages of segmentation. From lis figures it might be supposed that this cavity was equivalent to the segmentation cavity of Elasmobranchs in its earliest condition, but Bambeke states that it disappears and that it has no connection with the true segmentation cavity. Bambeke and other investigators have failed to recognize the homology of the segmentation cavity in Teleostei with that in Elasmobranchii, Amphiluia, etc.

With the appearance of the segmentation cavity the portion of the blastolerm which forms its roof becomes thinned out, so that the whole blastoderm consists of (1) a thickened edge especially prominent at one point where it forms the embryonic swelling, and (2) a thinner central portion. The changes which now take place result in the differentiation of the embryonic layers, and in the rapid 
extension of the blastoderm round the yolk, accompanied by a diminution in its thickness.
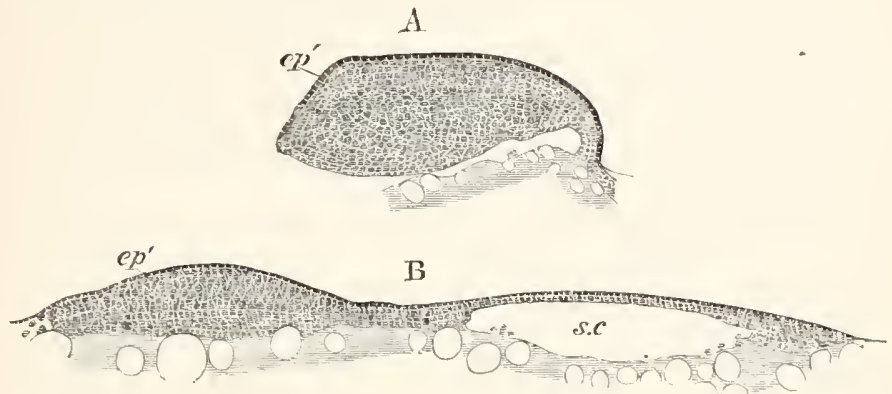

F1g. 31. Loxgitudixal sections throtgh the biastodera of the TroUt AT AN EARLY STAGE OF DEVELOPMENT.

A. at the close of the segmentation; B. after the differentiation of the germinal layers. $e p^{\prime}$. epidermic layer of the epiblast; sc. segmentation cavity.

The first differentiation of the layers consists in a single row of cells on the surface of the blastoderm becoming distinctly marked off as a special layer (fig. $31 \mathrm{~A}$ ); which however does not constitute the whole epriblast but only a small part of it which will be spoken of as the epidermic layer. The complete differentiation of the epiblast is effected by the cells of the thickened edge of the blastoderm becoming divided into two strata (fig. $31 \mathrm{~B}$ ). The upper stratum constitutes the epiblast. It is divided into two layers, viz., the external epidermic layer already mentioned, and an internal layer known as the nervous layer, formed of several rows of vertically arranged cells. According to the unanimous testimony of investigators the roof of the segmentation cavity is formed of epiblast cells only. The lower stratum in the thickened rim of the blastoderm is several rows of cells deep, and corresponds with the lower layer cells or primitive hypoblast in Elasmobranchii. It is continuous at the edge of the blastoderm with the nervous layer of the epiblast.

In smaller Teleostean eggs there is formed, before the blastoderm becomes differentiated into epiblast and lower layer cells, a complete stratum of cells around the nuclei in the granular layer underneath the blastoderm. This layer is the hypoblast; and in these forms the lower layer cells of the blastoderm are stated to become converted into mesoblast only. In the larger Teleostean eggs such as those of the Salmonidæ, the hypoblast, as in Elasmobranchs, appears to be only partially formed from the nuclei of the grantar layer. In these forms however, as in the smaller Teleostean ova and in Elasmobranchii, the cells derived from the granular stratum give rise to a more or less complete cellular floor for the segmentation carity. The segmentation cavity thus becomes enclosed between an hypoblastic floor and an epiblastic roof several cells deep. It becomes obliterated shortly after the appearance of the medullary plate. 
At about the time when the three layers become established the embryonic swelling takes a somewhat shield-like form (fig. $33 \mathrm{~A}$ ). Posteriorly it terminates in a caudal prominence $(t s)$ homologous with the pair of caudal swellings in Elasmobranchs. The homologue of the medullary groove very soon appears as a shallow groove along the axial line of the shield. After these changes there takes place in the embryonic layers a series of differentiations leading to the establishment of the definite organs. These changes are much more difficult to follow in the Teleostei than in the Elasmobranchii, owing partly to the similarity of the cells of the various layers, and partly to the primitive solidity of all the organs.

The first changes in the epiblast give rise to the central nervous system. The epiblast, consisting of the nervous and epidermic strata already indicated, becomes thickened along the axis of the embryo and forms a keel projecting towards the yolk below: so great is the size of this keel in the front part of the embryo that it influences the form of the whole body and causes the outline of the surface adjoining the yolk to form a strong ridge moulded on the keel of the epiblast (fig. 32 A and B). Along the dorsal line of the epiblast keel is placed the shallow medullary groove; and according to Calberla (No. 6I) the keel is formed by the folding together of the two sides of the primitively uniform epiblastic layer. The keel becomes gradually constricted off from the external epiblast and then forms a solid cord below it. Subsequently there appears in this cord a median slit-like canal, which forms the permanent central canal of the cerebrospinal cord. 'The peculiarity in the formation of the central nervous system of Teleostei consists in the fact that it is not formed by the folding over of the siles of the medullary groove into a canal, but by the separation, below the medullary groove, of a solid cord of epiblast in which the central canal is subsequently formed. Various views have been put forward to explain the apparently startling difference between Teleostei, with which Lepidosteus and Petromyzon agree, and other vertebrate forms. The explanations of Götte and Calberla appear to me to contain between them the truth in this matter. The groove above in part represents the medullary groove; but the closure of the groove is represented by the folding together of the lateral parts of the epiblast plate to form the medullary keel.

According to Götte this is the whole explanation, but Calberla states for Syngnathus and Salmo that the epidermic layer of the epiblast is carried down into the keel as a donble layer just as if it had been really folded in. This ingrowth of the epidermic layer is shewn in fig. $32 \mathrm{~A}$ where it is just commencing to pass into the keel; and at a later stage in tig. $32 \mathrm{~B}$ where the keel has reached its greatest depth.

Götte maintains that Calberlat's statements are not to be trusted, and I have myself been unable to confirm them for Teleostei or Lepidostens; but if they could be accepted the difference in the formation of the medullary canal in Teleostei and in other Vertebrata would become 
altogether unimportant and consist simply in the fact that the crdinary "pen medullary groove is in Teleostei obliterated in its inner part by the two sides of the groove coming together. Both layer's of epiblast would thus have a share in the formation of the central nervous system; the epidermic layer giving rise to the lining epithelial celis of the central canal, and the nervous layer to the true nervous tissue.

The separation of the solid nervous system from the epiblast takes place relatively very late; and, before it has been completed, the first traces of the auditory pits, of the optic vesicles, and of the olfactory pits are visible. The auditory pit arises as a solid thickening of the nervous layer of the epiblast at its point of junction with the medullary keel; and the optic vesicles spring as solid outgrowths from part of the keel itself. The olfactory pits are barely indicated as thickenings of the nervous layer of the epiblast.

At this early stage all the organs of special sense are attached to a layer continuous with or forming part of the central nervous system; and this fact has led Götte $\left(\mathrm{No}_{0} \mathrm{G}_{3}\right)$ to speak of a special-sense plate, belonging to the central nervous system and not to the skin, from which all the organs of special sense are developed ; and to conclude that a serial homology exists between these organs in their development. A comparison between Teleostei and other forms shews that this view cannot be upheld ; even in Teleostei the auditory and olfactory rudiments arise rather from the epiblast at the sides of the brain than from the brain itself, while the optic vesicles spring from the first directly from the medullary keel, and are therefore connected with the central nervous system rather than with the external epiblast. In a slightly later stage the different connections of the two sets of sense
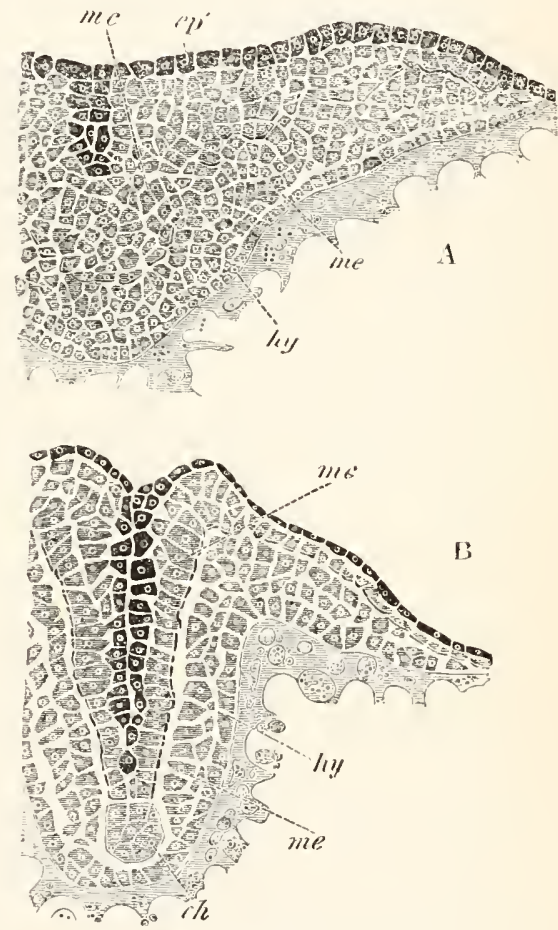

Fig, 32. Two transverse sections of SynGNathus. (After Calberla.)

A. Younger stage before the definite establishment of the notochord.

B. Older stage.

The epidermic layer of the epiblast is represented in black.

$e p$. epidermic layer of epiblast; mc. neural cord; hy. hypoblast; me. mesoblast; ch. notochord.

organs is conclusively shewn by the fact that, on the separation of the central nervons system from the epiblast, the optic vesicles remain attached 
to the former, while the auditory and olfactory vesicles are continuous with the latter.

After its separation from the central nervous system the remainder of the epiblast gives rise to the skin, etc., and most probably the epidermic stratum develops into the outer layer of the epidermis and the nervous stratum into the mucous layer. The parts of the organs of special sense, which arise from the epiblast, are developed from the nervous layer. In the Tront (Oellacher, No. 72) both layers are continued over the yolk-sack; but in Clupeus and Gasterosteus only the epidermic has this extension. According to Götte the distinction between the two layers becomes lost in the later embryonic stages.

Although it is thoroughly established that the mesoblast originates from the lower of the two layers of the thickened embryonic rim, it is nevertheless not quite certain whether it is a continuous layer between the epiblast and hypoblast, or whether it forms two lateral masses as in Elasmobranchs. The majority of observers take the former view, while Calberla is inclined to adopt the latter. In the median line of the embryo undemeath the medullary groove there are undoubtedly from the first certain cells which eventually give rise to the notochord; and it is these cells the nature of which is in doubt. They are certainly at first very indistinctly separated from the mesoblast on the two sides, and Calberla also finds that there is no sharp line separating them from the secondary hypoblast (fig. $32 \mathrm{~A}$ ). Whatever may be, the origin of the notochord the mesoblast very soon forms two lateral pilates, one on each side of the body, and between them is placed the notochord (fig. $32 \mathrm{~B}$ ). The general fate of the two mesoblast plates is the same as in Elasmobranchs. They are at first quite solid and exhibit relatively late a division into splanchnic and somatic layers, between which is placed the primitive body cavity. The dorsal part of the plates becomes transversely segmented in the region of the trunk; and thus gives rise to the mesoblastic somites, from which the muscle plates and the perichordal parts of the vertebral column are developed. The ventral or outer part remains unsegmented. The cavity of the ventral section becomes the permanent body cavity. It is continued forward into the head (Oellacher), and part of it becomes separated off from the remainder as the pericardial cavity.

The hypoblast forms a continuous layer below the mesoblast, and, in liarmony with the generally contined character of the development of the organs in Teleostei, there is $n$ space left between it and the yolk to represent the primitive alimentary carity. The details of the formation of the true alimentary tube have not been made out; it is not however formed by a folling in of the lateral parts of the hypoblast, but arises as a solid or nearly solid cord in the axial line, between the notochord and the yolk, in which a lumen is gradually establisher. 
In the just hatehed larva of an undetermined fresh-water fish with a very small yolk-sack I found that the yolk extended along the ventral side of the embryo from almost the moutl to the end of the gut. The gut had, except in the hinder part, the form of a solid cord resting in a concavity of the yolk. In the hinder part of the gut a lumen was present, and below this part the amount of yolk was small and the yolk nuclei numerous. Near the limit of its posterior extension the yolk broke up into a mass of cells, and the gut ended behind by falling into this mass. These incomplete observations appear to shew that the solid gut owes its origin in a large measure to nuclei derived from the yolk.

When the yolk has become completely enveloped a postanal section of gut undoubterlly becomes formed; and although, owing to the solid condition of the central nervous system, a communication between the neural and alimentary canals cammot at first take place, yet the terminal vesicle of the postanal gut of Elasmobranchii is represented by a large vesicle, originally discovered by Kupffer (No. 68), which can easily be seen in the embryos of most Teleostei, but the relations of which have not been satisfactorily worked out (vide fig. $\left.34, h y x^{\prime}\right)$. As the tail end of the embryo becomes separated off from the yolk the postanal vesicle atrophies.

General development of the Embryo. Attention has already been called to the fact that the embryo first appears as a thickening of the edge of the blastoderm which soon assumes a somewhat shieldlike form (fig. $33 \mathrm{~A}$ ). The hinder end of the embryo, which is placed at the edge of the blastoderm, is somewhat prominent, and forms the caudal swelling $(t s)$. 'The axis of the embryo is marked by a shallow groove.

The body now rapidly elongates, and at the same time becomes

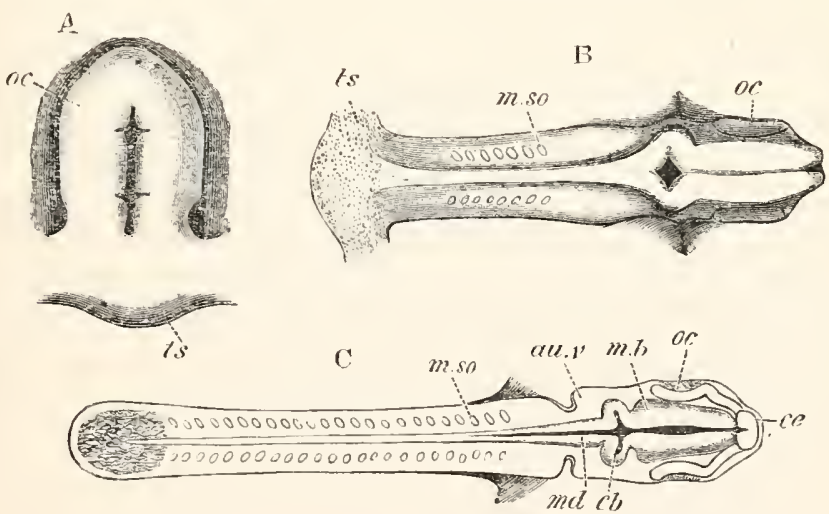

Fig. 33. Three stages in the developirent of the Salion. (After His.)

ts. tail-swelling; au.v. auditory vesicle; oc. optic vesicle; ce. cerebral rudiment; $m . b$. mid-brain; $c b$, cerebellum; md. medulla oblongata; m.so. mesoblastic somite. 
considerably narrower, while the groove along the axis becomes shallower and disappears. The anterior, and at first proportionately a very large part, soon becomes distinguished as the cephalic region (fig. 33 B). The medullary cord in this region becomes very early divided into three indistinctly separated lobes, representing the fore, the mid, and the hind brains : of these the anterior is the smallest. With it are connected the optic vesicles (oc) - solid at first-which are pushed back into the region of the mid-brain.

The trunk grows in the usual way by the addition of fresh somites behind.

After the yolk has become completely enveloped by the blastodern the tail becomes folded off, and the same process takes place at the front end of the embryo. The free tail end of the embryo continues to grow, remaining however closely applied to the yolk-sack, round which it curls itself to an extent varying with the species (vide fig. 3t).

The general growth of the embryo during the later stages pre-

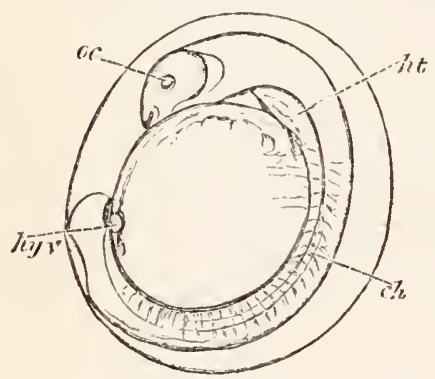

Fig. 34. I IEW of AX advanced EMBRTo OF a HERRING IN THE EGG. (After Kupffer.)

$o c$. eye; $h t$. heart; $h y v$. postanal resicle; $c h$. notochord.

of these appear before hatching.

The first cleft closes up very early (about the time of hatching in the Salmon); and about the same time there springs a membranous fold from the hyoid arch, which gradually grows backwards over the arches following, and gives rise to the operculum. There appear in the Salmon shortly before hatching double rows of papillw on the four anterior arches behind the hyoid. They are the rudiments of the branchiæ. They reach a considerable length before they are covered in by the opercular membrane. In Cobitis (Götte, No. 64) they appear in young larve as filiform processes equivalent to the external gills of Elasmobranchs. The extremities of these processes atrophy; while the basal portions become the permauent gill lamellæ. The general relation of the clefts, after the closure of the hyomandibular, is shewn in fig. 3.5. 
The air-bladder is formed as a dorsal outgrowth of the alinentary tract very slightly in front of the liver. It grows in between the two limbs of the mesentery, in which it extends itself backwards. It appears in the Salmon, Carp, and other types to originate rather on the right side of the median dorsal line, but whether this fact has any special siguificance is rather doubtful. In the Silmon and Trout it is formed considerably later than the liver, but the two are stited by Von Baer to arise in the Carp nearly at the same time. The absence of a pneumatic duct in the Physoclisti is due to a post-larval atrophy. The region of the stomach is reduced almost to nothing in the larva.

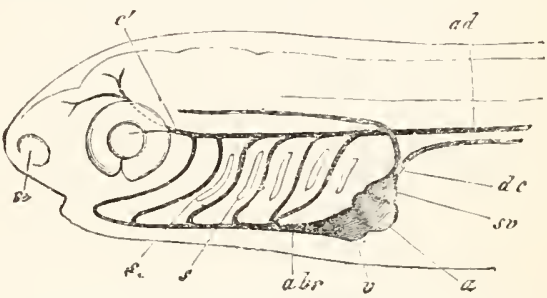

Fig. 35. Diagramatic View of the hein of aN eabryo Teleosteas, with the primetrve vascular trunks. (From Gegenbaur.)

$a$. auricle; $r$. ventricle; $a b r$. branchial artery; $c^{\prime}$. carotid; ad. aorta; $s$. branchial clefts; $s t$. sinus venosus; $d c$. ductus Cuvieri; n. nasal pit.

The osophagus becomes solid, like that of Elasmobranchs, and remains so for a considerable period after hatching.

The liver, in the earliest stage in which I have met with it in the Trout (27 days after impregnation), is a solid ventral diverticulum of the intestine, which in the region of the liver is itself without a lumen.

The excretory system commences with the formation of a segmental duct, formed by a constriction of the parietal wall of the peritoneal cavity. The anterior end remains open to the body cavity, and forms a pronephros (head kidney). On the inner side of and opposite this opening a glomerulus is developed, and the part of the body cavity containing both the glomerulus and the opening of the pronephros becomes shut off from the remainder of the body cavity, and forms a comp?etely closed Malpighian capsule.

The mesonephros (IVolffian body) is late in developing.

The unpaired fins arise as simple folds of the skin along the dorsal and ventral edges, continuous with each other round the end of the tail. The ventral fold ends anteriorly at the anus.

The dorsal and anal fins are developed from this fold by local hypertrophy. The caudal fin ${ }^{1}$, however, undergoes a more complicated metamorphosis. It is at first symmetrical or nearly so on the dorsal and ventral sides of the hinder end of the notochord. This symmetry is not long retained, but very soon the ventral part of the fin with its fin rays becomes much more developed than the dorsal part, and at the same time the posterior part of the notochord bends up towards the dorsal side.

In some few cases, e.g. Gadus, Salmo, owing to the simultaneous appearance of a number of fin rays on the dorsal and ventral side of the notochord the external symmetry of the tail is not interfered with in the above processes. In most instances this is far from being the case.

1 In addition to the paper by Alex. Agassiz (No. 55) vide papers by Huxley, Kölliker, Togt, etc. 
In the Flounder, which may serve as a type, the primitive symmetry is very soon destroyed by the appearance of fin rays on the ventral side. The region where they are present soon forms a lobe; and an externally heterocercal tail is produced (fig. $36 \mathrm{~A}$ ). The ventral lobe with its rays continues to grow more prominent and causes the tail fin to become bilobed (fig. $36 \mathrm{~B}$ ); there being a dorsal embryonic lobe without fin rays $(c)$, which contains the notochord, and a ventral lobe with fin rays, which will form the permanent caudal fin. In this condition the tail fin resembles the usual Elasmobranch

A.

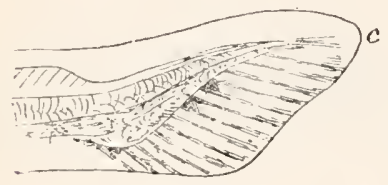

B.

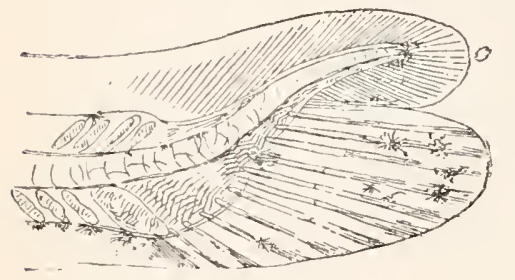

C.

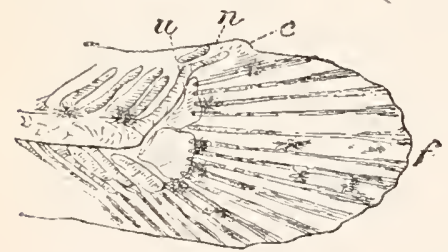

Fig. 36. Three stages in the developuent of the tail of the Flodnder (Pleuronectes). (After Agassiz.)

A. Stage in which the permanent caudal fin has commenced to be visible as an enlargement of the ventral side of the embryonic caudal fin.

B. Ganoid-like stage in which there is a true external heterocercal tail.

C. Stage in which the embryonic caudal fin has almost completely atrophied.

$c$. embryonic caudal fin ; $f$. permanent caudal fin; $n$. notochord; $u$. uro. style.

geon as far as concerns their caudal fin.

form or still more that of some Ganoids, e.g. the Sturgeon. The ventral lobe continues to develop; and soon projects beyond the dorsal, which gradually atrophies together with the notochord contained in it, and finally disappears leaving hardly a trace on the dorsal side of the tail (fig. $36 \mathrm{C}, c)$. In the meantime the fin rays of the ventral lobe gradually become parallel to the axis of the body; and this lobe, together with a few accessory dorsal and ventral fin rays supported by neural and hæmal processes, forms the permanent tail fin, which though internally unsymmetrical, assumes an externally symmetrical form. 'The upturned end of the notochord which was originally continued into the primitive dorsal lobe becomes ensheathed in a bone without a division into separate vertebræ. This bone forms the urostyle (u). The hæmal processes belonging to it are represented by two cartilaginous masses, which subsequently ossify, forming the hypural bones, and supporting the primary fin rays of the tail (fig. $36 \mathrm{C}$ ). 'The ultimate changes of the notochord and urostyle vary very considerably in the different types of Teleostei. Teleostei may fairly be described as passing through an Elasmobranch stage or a stage like that of most pre-jurassic Ganoids or the SturThe anterior paired fins arise before the posterior; and there do 
not appear to be any such indications as in Elasmobranchii of the paired tins arising as parts of a continuous lateral fin.

Most osseous fishes pass through more or less considerable post-embryonic changes, the most remarkable of which are those mulergone by the Pleuronectida ${ }^{1}$. These fishes, which in the adult state have the eves unsymmetrically placed on one sile of the head, leave the egg like normal Teleostei. In the majority of cases as they become older the eye on the side, which in the adult is without an eye, travels a little forward and then grarlually rotates over the dorsal side of the head, till finally it comes to lie on the sanse side as the other eye. During this process the rotating eye always remains at the surface and continues functional; and on the two eyes coming to the same side of the head the side of the horly without an organ of vision loses its pigment cells, and becomes colourless.

The dorsal fin, after the rotation of the eye, grows forward beyond the level of the ejes. In the genus Plagusiat (Steenstrup, Agassiz, No. 56) the dorsal fin grows forward before the rotation of the eye (the right eye in this form), and causes some modifications in the process. The eye in travelling round gradually sinks into the tissues of the head, at the base of the fin above the frontal hone; and in this process the original large opening of the molut becones much reluced. Swon a fresh opening on the opprosite and left side of the dorsal fin is formed; so that the orbit has two external openings one on the left and one on the right side. The original one on the right soon atrophies, and the eye prasses through the tissues at the hase of the dorsal tin completely to the left side. species.

The rotating eye may be either the right or the left according to the

The most remarkable featre in which the young of a large number of Teleostei differ from the adults is the possession of provisional spines, rery often formed as osseous spinous projections the spraces between which become filled up in the adult. 'These processes are probably, as suggested by Güuther, secondary developments acquired, like the Zocea spines of larval C'ustaceans, for purposes of defence.

The yolk-sack varies greatly in size in the different types of Teleostei.

According as it is enclosed within the body-wall, or forms a distinct rentral appendage, it is spoken of by Von Baer as an internal or external yolk-sack. By Von Baer the yolk-sack is stated to remain in communication with the intestine inmediately behind the liver, while Lerebouliet states that there is a vitelline pedicle opening between the stomach and the lirer which persists till the absorption of the yolk-sack. My own observations do not fully contirm either of these statements for the Salmon and Trout. So far as I have been able to make out, all communication between the yolli-sack and the alimentary tract is completely obliteraterl very early. In the Trout the communication between the two is shut off' before hatching, and in the just-hatched Saluon I can find no trace of any vitelline pedicle. 'T he absorption of the yolk would seem therefore to be effected entirely by blood-ressels. 
The yolk-sack persists long after hatching, and is gradually absorbed. There is during the stages either just before hatching or shortly subsequent to hatehing (Cyprinus) a rich vascular development in the mesoblast of the yolk-sack. 'The blood is at first contained in lacunar spaces, but subsequently it becomes confined to definite channels. As to its exact relations to the vascular system of the embryo more observations seem to be required.

The following account is given by Rathke (No. $72^{*}$ ) and Lereboullet (No. 7I). At first a subintestinal vein (vide cliapter on Circulation) falls into the lacunce of the yolk-sack, and the blood from these is brought back direct to the heart. At a later preriod, when the liver is developed, the suhintestinal vessel hreaks up into capillaries in the liver, thence passes into the yolk-sack, and from this to the heat. An artery arising from the aorta penetrates the liver, and there breaks up into capillaries continuous with those of the yolk-sack. This ressel is perhaps the equivalent of the artery which supplies the yolk-sack in Elasmobranchii, but it seems possible that there is some error in the above description.

\section{BIBLIOGRAPHY.}

(55) Al. Agassiz. "On the young Stages of some Osseous Fishes. I. Development of the Tail." Proceedings of the American Acudemy of Arts and Sciences, Vol. xıи. Presented Oct. 11, 1877.

$\left(5^{6}\right)$ Al. Agassiz. "II. Development of the Flomders." Proceedings of the American Aearl. of Atts and Sciences, Vol, xiv. Presented Jume, 1878.

(57) K. E. v. Baex. Lntersuchungen über die Entwicklungsgesehiehte der Fische. Leipzig, 1835.

(58) Ch. van Bambeke. "Premiers effets de la fécondation sur les ceufs de Poissons: sur l'origine et la signification dn fenillet muqueux on glandulaire chez les J'oissons Osseux." Comptes Rendus des Séances de l'Acatémie des Séiences, Tome Lxxiv. 1872.

(59) Ch. van Bambeke. "Recherches sur l'Emlryologie des Poissons Osseux." Mém.eouronnés et Mém. de suvants étrangers de l'Aeudêmie roy. Belgique, Vol. xu. 1875.

(6o) E. v. Beneden. "A contribution to the history of the Embryonic development of the Teleosteans." Quart. J. of Micr. Sci., Vol. xvm. 1878.

(6i) E. Calberla. "Zur Entwicklung des Medullarnolnes u. d. Chorda dorsalis d. T'eleostier u. ג. Petromyzonten." Morphologisehes Jahrbuch, Vol. III. 1877.

(62) A. Götte. "Beiträge zur Entwicklungsgeschichte der Wirbelthiere." Arehiv f. mikr. Anat., Vol. Ix. 1873.

$(63)$ A. Göttc. "Ueber d. Entwicklung d. Central-Nervensystems der Teleostier." Archiof. mikr. Anat., Vol. xr. 1878. 1878.

(64) A. Götte. "Entwick. d. Teleostierkeime." Zoologiseher Anzeiger, No. 3.

$\left(\sigma_{5}\right)$ W. His. "Untersuchungen über die Entwicklung von Knochenfischen, etc." Zeit. f. Anat. u. Enturicklungsgesehichte, Vol. I. 1876.

(66) W. His. "Untersuchungen über die Bildung des Knochenfischembryo (Salmen)." Archiv f. Anat. u. Physiol., 1878.

$\left(\sigma_{7}\right)$ E. Klein. "Observations on the early Development of the Common Trout." Quart. J. of Micr. Scienee, Vol. xvi. 1876.

(68) C. Kupffer. “Beobachtungen über die Entwicklung der Knochenfische." Arehie f. mikr. Anat., Bd. Iv. 1868.

(69) C. Kupffer. Leber Laichen u. Entwicklung des Ostsee-Herings. Berlin, 1878.

(7o) M. Lereboullet. "Recherches sur le développement du brochet de la perche et de l'écrevisse." Amuales des Scienees Nut., Tol. I., Series iv. 1854.

( $;$ ) M. Lereboullet. "Recherches d'Embryologie comparée sur le développement de la Truite." An. Sei. Nat., quatrième série, Vol. xvi. 1861. 
(72) T. Oellacher. "Beiträge zur Entwicklungsgeschichte der Knochenfische nach Beobachtungen am Bachforellenei." Zeit. f. wiss. Zool., Yol. xxII., 1872, and Vol. xxiIr., 1873.

$\left(z^{*}\right)$ H. Rathke. Abh. z. Bildung u. Entwick. d. Henschen u. Thiere. Leipzig, 1832-3. Part II. Blennins.

(73) Rieneck. "Ueber die Schichtung des Forellenkeims." Archiv f. mikr. Anat., Bil. v. 1869.

(74) S. Stricker. "Untersuchungen über die Entwicklung der Bachforelle." Sitzungsberichte der Wiener k. Akad. d. Wiss., 1865. Vol. L. Abth. 2.

(75) Carl Yogt. "Embryologie des Salmones." Histoire Nuturelle des Poissons de l'Europe Centrale. I. Agassiz. 1842.

$\left({ }^{6} 6\right)$ C. Weil. "Beitrïge zur Kenntniss der Knochenfische." Sitzungsber, der Wiener kais. Alad. der Wiss., Bd. Lxv. 1872. 


\section{CHAPTER V.}

\section{CYCLOS'TOMA'TA'.}

Petromyzon is the only type of this degenerated but primitive gronp of Fishes the development of which has been as yet studied ${ }^{2}$.

The development does not however throw any light on the relationships of the group. The similarity of the mouth and other parts of Petromyzon to those of the Tadpole probably indicates that there existed a common ancestral form for the Cyclostomata and Amphibia. Embryology does not however add anything to the anatomical evidence on this subject. The fact of the segmentation being complete was at one time supposed to indicate an affinity between the two groups; but the diseovery that the segmentation is also complete in the Ganoids deprives this feature in the development of any special weight. In the formation of the layers and in most other developmental characters there is nothing to imply a special relationship with the Amphibia, and in the mode of formation of the nervous system Petromyzon exhibits a peculiar modification, otherwise only known to occur in Teleostei and Lepidosteus.

Dohrn $^{3}$ was the first to bring into prominence the degenerate character of the Cyclostomata. I camnot however assent to his view that they are descended from a relatively highly-organized type of Fish. It appears to me almost certain that they belong to a group of fishes in which a true skeleton of branchial bars had not become developed, the branchial skelechapter :

1 The following classification of the Cyclostomata is employed in the present

I. Hyperoartia ex. Petromyzon.

II. Hyperotreta ex. Myxine, Bilcllostoma.

2 The present chapter is in the main founded upon observations which I was able to make in the spring of 1880 upon the development of Petromyzon Planeri. Mr Scott very kindly looked over my proof-sheets and made a number of valuable suggestions, and also sent me an early copy of his preliminary note (No. 87 ), which I lave been able to make use of in correcting my proof-sheets.

${ }^{3}$ Der Ursprung d. Wirbelthiere, etc. Leipzig, 1875. 
ton they possess being simply an extra-branchial system; while I see no reason to suppose that a true hanchial skeleton has disappeared. If the primitive Cyclostomata had not true branchial bars, they could not have had jaws, because jaws are essentially developed from the mandibular branchial bar. These considerations, which are suplorted by numerous other features of their anatomy, such as the character of the axial skeleton, the straightness of the intestinal tube, the presence of at subintestinal vein etc., all tend to prove that these fishes are remnants of a primitive and præguathostomatous group. The few surviving members of the gromp have probably owed their preservation to their parasitic or semiparasitic habits, while the group as a whole probably disappeared on the appearance of gnathostomatous Vertelinata.

'The ripe ovum of Petromyzon Planeri is a slightly oval body of about $1 \mathrm{~mm}$. in liameter. It is mainly formed of an opaque nearly white yolk, invested by a membrane composed of an inner perforated layer, and an outer structureless layer. There appears to be a pore perforating the inner layer at the formative pole, which may be called a micropyle (Kupifer and Benecke, No. 79). Enclosing the egor-membranes there is present a mucous envelope, which causes the egg, when laid, to adhere to stones or other objects.

Impregnation is effected by the male attaching itself by its suctorial month to the female. The attached couple then shake together; and, as they do so, they respectively emit from their abdominal pores ova and spermatozoa which pass into a hole previously made ${ }^{1}$.

The segmentation is total and unequal, and closely resembles that in the Frog's egg (Tol. 1. p. TS). The upper pole is very slightly whiter than the lower. A segmentation cavity is formed very early, and is placed between the small cells of the upper pole and the large cells of the lower pole. It is proportionately larger than in the Frog; and the roof eventually thins out so as to be formed of a single row of small cells. At the sides of the segmentation cavity there are always several rows of small cells, which gradually merge into the larger cells of the lower pole of the egg. The segnuentation is completed in about fifty hours.

The segmentation is fol-

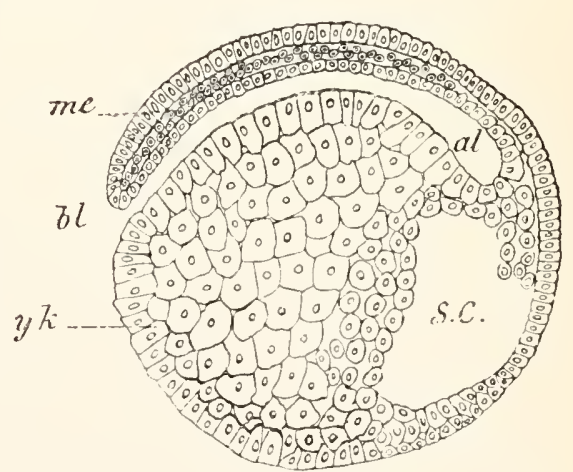

Flit, 37. Loxgitudinal vertical section throdgli an ejebryo of Petromyzon Planelit OF 136 HOURS.

me. mesoblast; $y k$. yolk-cells; al. alimentary tract; $b l$. blastopore; s.c. segmentation cavity.

1 Artiticial inpremation may be effected witlont difficulty by squeezing out into the same vessel the ova and spematozoa of a ripe fenale and male. The fertilized egrs are easily reared. Petromyzon Planeri hreeds during the secund half of Apil. 
lowed by an asymmetrical invagination (fig. 37) which leads to it mode of formation of the liypoblast fundamentally similar to that in the Frog. The process has been in the main correctly described by II. Schultze (No. 8I).

On the border between the large and small cells of the embryo, at a point slightly below the segmentation carity, a small circular pit appears; the roof of which is formed by an infolding of the small cells, while the floor is formed of the large cells. This pit is the commencing mesenteron. It soon grows deeper (fig. 37, al) and extends as a well-defined tube (shewn in transverse section in fig. 3s, al) in the direction of the segmentation cavity. In the course of the

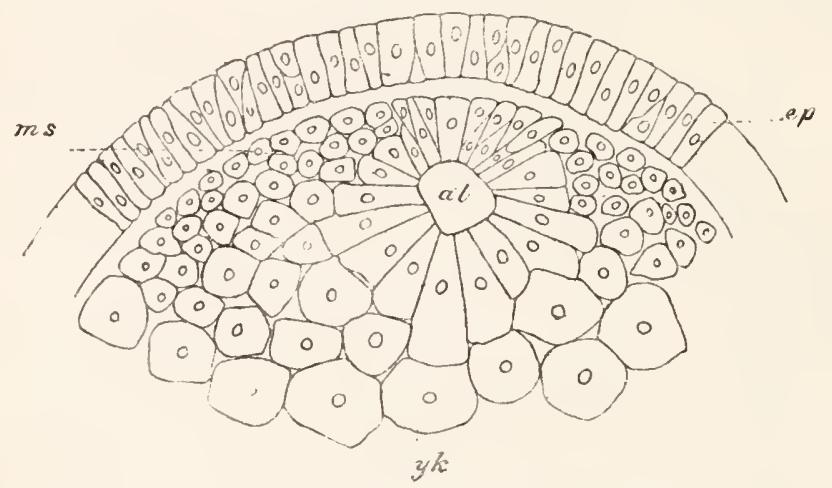

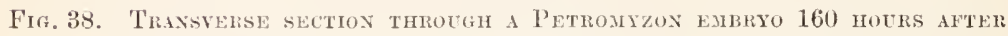
IMPREGNATION.

ep. epiblast; al. mesenteron; yli. yolk-cells; ms. mesollast.

formation of the mesenteron the segmentation cavity gradually becomes smaller, and is finally (about the 200th hour) obliterated. The roof of the mesenteron is formed by the continued invagination of small cells, and its floor is composed of large yolk-cells. The wide external opening is arched over dorsally by a somewhat prominent lip-the honologue of the embryonic rim. The opening persists till nearly the time of liatching; but eventually becomes closed, and is not converted into the permanent anus. On the formation of the mesenteron the hypublast is composer of two groups of cells, (1) the yolk-cells, and (2) the cells forming the roof of the mesenteron.

While the above changes are taking place, the small cells, or as they may now be called the epiblast cells, gradually spread over the large yolk-cells, as in normal types of epribolic invagination. The growth over the yolk-cells is not symmetrical, but is most rapid in the meridian opposite the opening of the alimentary cavity, so that the latter is left in a bay (cf. Elasmobranchiii, p. 51). The epibolic invagination takes place as in Molluses and many other forms, not simply by the division of pre-existing epiblast cells, but by the forma- 
tion of fresh epiblast cells from the yolk cells (fig. 37); and till after the complete enclosure of the yolk cells there is never present a sharp line of demarcation between the two groups of cells. By the time that the segmentation cavity is obliterated the whole yolk is enclosed by the epiblast. The folk cells adjoining the opening of the mesenteron are the latest to be covered in, and on their enclosure this opening constitutes the whole of the blastopore. The epiblast is composed of a single row of columnuar cells.

Mesoblast and notochord. During the above changes the mesoblast becomes established. It arises, as in Elasmobranchs, in the form of two plates derived from the primitive hypoblast. During the invagination to form the mesenteron some of the hypoblast cells on each side of the invaginated layer become smaller, and marked off as two imperfect plates (fig. 39, ms). It is difficult to say whether these plates are entirely derived from invaginated cells, or are in part inectly formed from the pre-cxisting yolk cells, but I am inclined to alopt the latter view; the rentral extension of the mesoblast plates undoubtedly takes place at the expense of the yolk cells. The mesoblast plates soon become more definite, and form (fig. 39 , ms) welllefined structures, triangnlar in section, on the two sides of the middle line.

At the time the mesoblast is first formed the hypoblast cells, which roof the mesenteron, are often imperfectly two layers thick (fig. 38). They soon however become constituted of a single layer only. When the mesoblast is fairly established, the lateral parts of the hypoblast grow inwards underueath the axial part, so that the latten (fig. 39, ch) first becomes isolated as an axial cord, and is next inclosed between the medullary cord (nc) (which has by this time been formed) and a continuous

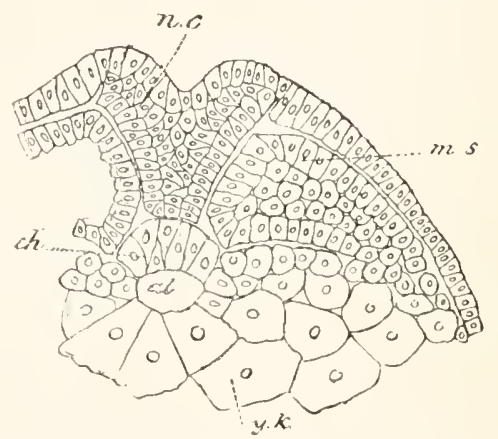

Fig. 39. Transverse section throvith an. embero of Petroaizzon Planeni of 20\$ IFOU1:S.

The figure illustrates the formation of the neural cord and of the notochord.

ms. mesoblast; n.e. neural cord; ch. notochord; $y k$. yolk cells; al, alimentary canal. sheet of hypoblast below (fig. 40). Here its cells divide and it becomes the notochord. The notochord is thus bodily formed out of the axial portion of the primitive hypoblast. Its mode of origin may be compared with that in Amphioxus, in which an axial foll of the archenteric wall is constricted off as the notochord. The above features in the development of the notochord were first established by Ca!berla ${ }^{1}$ (No. $7 S$ ).

IIn Calberla's figure, shewing the development of the notochord, the limits of mesoblast aud hypoblast are wrongly indicated. 
General history of the development. Up to about the time when the enclosure of the hypoblast by the epiblast is completed, no

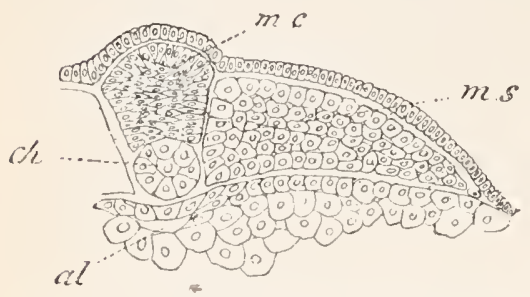

Fig. 40. Transverse section throvgh part of an embrio of Petromyzun P'Laneri of 256 Hours.

m.c. medullary cord; ch. notochord; $a$ l. alimentary caual; ms. mesoblastic plate. extemal traces are visible of any of the organs of the embryo; but about this time, i.e. about 180 hours after impregnation, the rudiment of the medullary plate becomes established, as a linear streak extending forwards from the blastopore over fully one half the circumference of the embryo. 'The medullary plate first contains a shallow median groove, but it is converted into the medullary cord, not in the usual vertebrate fashion, but, as first shewn by Calberla, in a mamner much more closely resembling the formation of the medullary cord in Teleostei. Along the line of the median groove the epiblast becomes thickened and forms a kind of keel projecting inwards towards the hypoblast (fig. 39, nc). This kecl is the rudiment of the medullary cord. It soon becomes more proniment, the median groove in it disappears, and it becomes separated from the epiblast as a solid cord (fig. $40, m c$ ).

By this time the whole embryo has become more elongated, and on the dorsal surface is placed a ridge formed by the projection of the medullary cord. At the lip of the blastopore the medullary cord is continuous with the hypoblast, thus forming the rudiment of a neurenteric canal.

Calberla gives a similar account of the formation of the neural canal to that which he gives for the 'Teleostei (vide p. 59).

He states that the epiblast becomes divided into two layers, of which the outer is involuted into the neural cord, a median slit in the involution representing the neural groove. The evential neural canal is stated to be lined by the involuted cells. Scott (No. 87) fully confirms Calberla on this point, and, although my own sections do not clearly shew an involutim of the outer layer of epillast cells, the testimony of these two olservers must no doubt be accepted on this point.

Shortly after the comp'ete establishment of the neural cord the elongation of the embryo proceeds with great rapidity. The processes in this growth are shewn in fig. $41, \mathrm{~A}, \mathrm{~B}$, and $\mathrm{C}$. The cephalic portion $(\boldsymbol{A}, c)$ tirst becomes tistinct, forming an anterior protuberance tree from yolk. About the time it is formed the mesoblastic plates begin to be divided into somites, but the embryo is so opaque that this process can only be studied in sections. Shortly afterwards an axial lumen appears in the centre of the neural cord, in the same manner as in Teleostei.

The general elongation of the embryo continues rapidly, and, as shewn in my figures, the anterior end is applied to the ventral 
surface or of the yolk (B). With the srowth of the embryo the yolk becomes entirely confined to the posterior purt. This
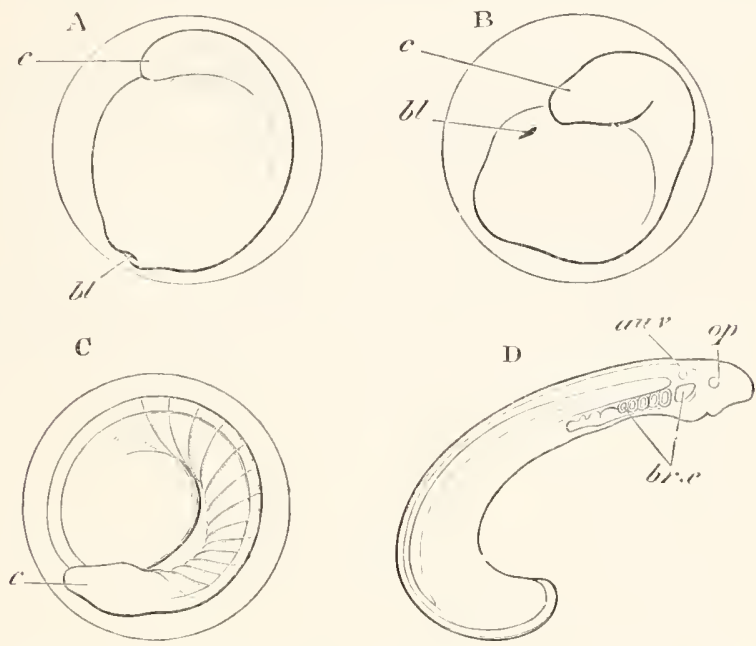

Fig, 11. Foul stages in the developanex of Petrojyzon. (After Owsjamnikoff.)

$c$. cephalic extremity; $u$. blastoporc; op. optic vesicle; $a u . v$. anditory vesicle; br.c. branchial clefts.

part is accordingly greatly dilated, and might easily be mistaken for the head. The position of the yolk gives to the embryo a very peculiar appearance. The apmarent difference between it and the embryos of other Fishes in the position of the yolk is due in the main to the fact that the postanal portion of the tail is late in developing, and always small. As the embryo grows longer it becomes spirally coiled within the egry shell. Before hatching the mesoblastic somites become distinctly marked (C).

The hatching takes place at between 13-21 lays after impregnation; the period varying according to the temperature.

During the above changes in the external form of the embryo, the development of the various organs makes great progress. This is especially the case in the head. The brain becomes distinct from the spinal cord, and the auditory sacks and the optic vesicles of the eye become formed. The branclial region of the mesenteron becomes established, and causes a dilatation of the anterior part of the body, and the branchial pouches grow ont from the throat. The anus becomes formed, and a nemrenteric canal is also established (scott). The nature of these and other changes will best be understood by a description of the structure of the jist-hatched larva. The general appearance of the larva immediately after hateling is shewn in fig. 41, D. The body is somewhat curved; the posterior extremity lueing 
much dilated with yolk, while the anterior is very thin. All the cells still contain yolk particles. which render the embryo very opaque. The larva only exhibits slow movements, and is not capable of swimming about.

The structure of the head is shewn in figs. 42 and $43 . \quad$ Fig. 42 is a section through a very young larva, while fig. 43 is taken from a larva three days after hatching, and shews the parts with considerably greater detail.

On the ventral side of the head is placed the oral opening (fig. $43, m$ ) leading into a large stomodæum which is still without a communication with the mesenteron. Ventrally the stomodrum is prolonged for a considerable distance under the anterior part of the mesenteron. Immediately behind the stomodæum is placed the branchial region of the mesenteron. Laterally it is produeed on each side into seven or perhaps eight branchial pouches (fig. 4.3, br.c), which extend outwarks nearly to the skin but are not yet open. Between the successive pouches are placed mesoblastic segments, of the same natme and structure as the walls of the head cavities in the embryos of Elasmobranchs, and like them enclosing a central cavity. A similar structure is placed belind the last, and two similar structures in front of the first persistent pouch. This pouch is situated in the same verticat line as the auclitory sack (au.v), and would appear therefore to be the hyo-branchial cleft; and this identification is confirmed

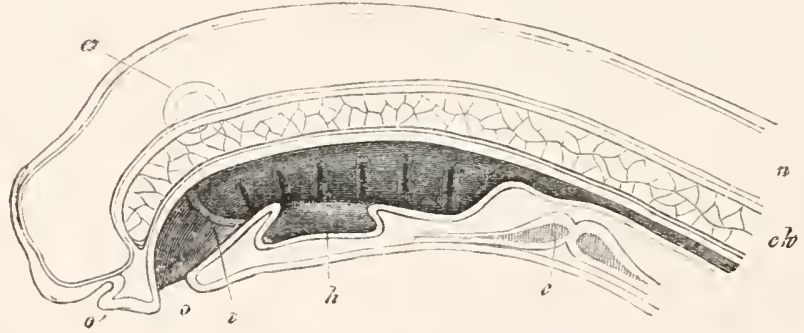

Fil. 12. Dighamiatio vertical section of a just-hatched lakva of Petrosrzos. (From Gegenbaur; after Calberla.)

b. wonth: $o^{\prime}$. olfactory pit; $r$. septum between stomodaun and mesenteron; $h$. thyro:d involution; $n$. spinal corl ; $c h$. notochord; $c$. heart; $a$. auditory vesicle.

by the fact of two heal cavities being present in front of it. At the front end of the branchial region of the mesenteron is placed a thickened ridge of tissue, which, on the opening of the passage between the stomodxum and the mesenteron, forms a partial septum between the two, and is known as the velum (fig. $43, t v$ ).

According to Scott (No. 87) a hyomandibular pouch forming the eighth pouch is formed in front of the pouch alseady defined as the hyobranchial. It disappears early and does not acquire gill folds ${ }^{1}$. The tissue

1 Scott informs me that he has been unalle to find the hyomandibular pouch in larve larger than $4.8 \mathrm{~mm}$. My material of the stages when it should he present is 
forming the line of insertion of the relum appears to me to represent tlie mandibular arch. The grounds for this view are the following :

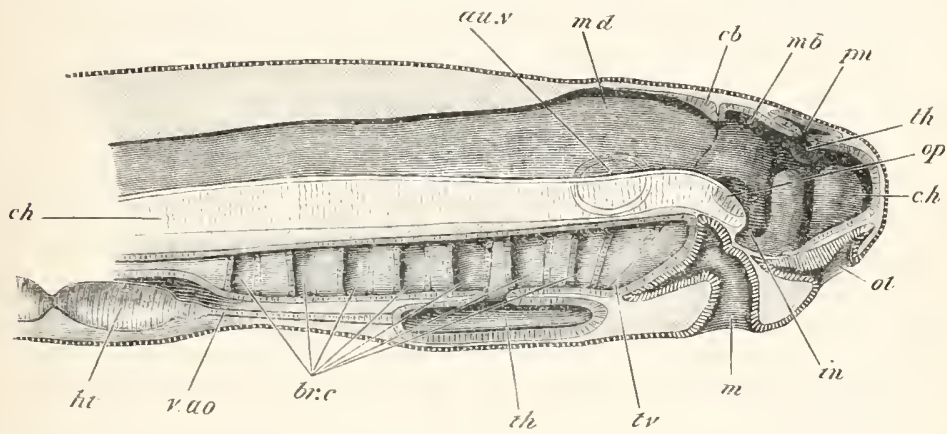

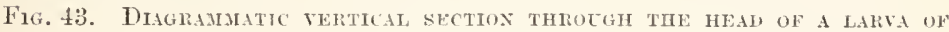
PLTIOAIZON.

The larva had been hatched threc days, and was $4.8 \mathrm{~mm}$. in length. The optic and auditory vesicles are supposed to be seen through the tissues. The letfer to pointing to the base of the relum is where Scott belieres the hyomandibular cleft to be situated.

c.h. cerebral hemisphere; th. optic thalamus; $i n$. infundibulum; $p$. pineal gland; $m b$. mid-brain; $c b$. cerebellum; md. nedulla oblongata; au. $x$. anditory resicle; op. optic resicle; ol. olfactory pit; $m$. wouth; br.c. branchial pouches; th. thyroit involution; r.ao. rentral aorta; ht. ventricle of heart; ch. notochord.

(1) The structure in question las excetly the position usually occupierl by the mandibular areh.

$(2)$ There is present in late larve (about 20 days after hatching) an arterial ressel, continued from the rentral prolongation of the bulbus arteriosus along the insertion of the relum towards the dorsal aorta, which has the relations of a true branchial artery.

On the rentral aspect of the branchial region is placen a sack (figs. $4 \cdot 2, h$, and $4: 3, t h$ ), which extends from the front end of the branchial region to the fourth cleft. At first it constitutes a groove opening into the throat above (fig. 44 ), but soon the opening becomes nairowed to a pore placed between the second and third of the permanent branchial pouches (fig. 4:3, ih). In Ammocoetes ${ }^{1}$ the simple tube becomes divided, and assumes a vely complicated form, though still retaining its opening into the branchial region of the throat. In the alult it forms a glandular mass underneath the branchial region of the throat equivalent to the thyoil gland of higher Tertebrates.

somewhat scanty, but I have as ret. very likely owing to the imperfection of uny material, been umable to find Scott's lyomandibular pouch either in my sections or surface-riews. Huxley describes this poitch as present in the form of a cleft in later stages; I have failed to find lis cleft also. The vessel interpreted below as the branchial artery of the mandibular areh was only inperfectly investigated by me, and I was not sure of my interpretations about it. Scott however informs me by letter that it is undoubtedly present.

i Schneider (No.85) states that in the full-grown Ammocotes the opening is situated between the third and foutl pouches. 'This is certainly not true for the young larva. 
On the ventral aspect of the liead, and immediately in front of the mouth, is placed the olfactory pit (fig. 4:3, ol). It is from the first unpuired, and in just-liatched larvæ simply forms a shallow groove of thickened epiblast at the base of the front of the brain. By the stage represented in fig. 43 the ventral part of the original groove is prolonged into a pit, extending backwards beneath the brain nearly up to the infundibulum.

On the side of the head, nearly on a level with the front end of the notochord, is placed the eye (fig. 43, op). It is constituted (figs. 4.5 and 46) of a very shallow optic cup with a thick outer (retinal) layer, and a thin inner choroid layer. In contact with the retinal layer is placed tne lens. The latter is formed as an invagination of the skin; to which it is still attached in the just-hatched larva (fig. 4.5). 'The eye only differs at this stage from that of other Vertebrata in its
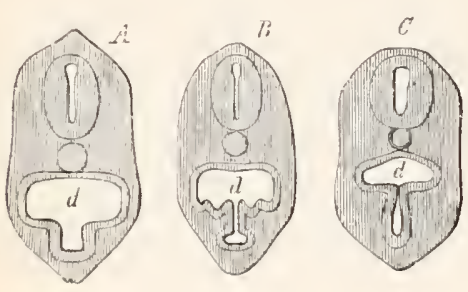

Fig. 44. Diagramatic trinsverse secTIONS THROEGH THE BRANCHLL REGION OF A rousa latid of Petromyzon. (From Gegenbaur; after Calherla.)

d. branchial region of throat. extraordinarily small size, and the rudimentary character of its coustituent parts.

The auditory sack is a large vesicle (fig. 43, (ии...), placed at the side of the brain opposite the first persistent branclial poucl.

The brain is formed of the usual vertebrate parts ${ }^{1}$, but is characterized by the very slight cranial flexure. The fore-brain consists (fig. 43) of a thalamencephalon (thi) and an undivided cerebral rudiment $(c . h)$. To the roof of the thalamencephalon is attached a flattened sack $(\mathrm{m} m)$ which is probably the pineal gland. The floor is prolonged into an infundibulum (in) which contains a prolongation of the third ventricle. 'The lateral walls of the cerebral rudiment are much thickened.

Behind the thalamencephaton follows the mid-brain $(\mathrm{mb})$, the sides of which form the optic lobes, and behind this again the hindbrain $(m d)$; the front border of the roof of which is thickened to form the cerebellum $(c b)$. The medulla passes without any marked line of demarcation into the spinal cord.

The histological differentiation of the brain has already proceeded to some extent; and it lias in the main the same character as the spinal cord. Before the larva has heen hatched very long a lateral investment of white matter is present throughout. The notochord (ch) is continued forwards in the liead to the hinder border of the infundibulum. It is slightly flexed anteriorly.

From the hincler border of the auditory region to the end of the branchial region the mesoblast is dorsally divided into myotomes,

1 Max Schultze's statements as to the structure and histolory of the brain are very inalequate in the present state of our knowledge. 
which nearly, though not quite, correspond in number with the branchial pouches.

The growth of the myotomes would seem, as might be anticipated from their independent innervation, not to be related to that of the branchial pouches, so that there is a want of correspondence between these parts, the extent of which varies at different periods of life. The relation between the two in an old larva is shewn in fig. $4 \pi$.

The head of the larva of Petromyzon differs very strikingly in general appearance from that of the normal Vertebrata. This is at once shewn by a comparison of fig. 4.3 with fig. 29. The most important difference between the two is due to the absence of a pronounced cranial flexure in Petromyzon; an absence which is in its turn probably caused by the small development of the fore-brain.

The stomodxum of Petromyzon is surprisingly large, and its size and structure in this type militate against the view of some embryologists that

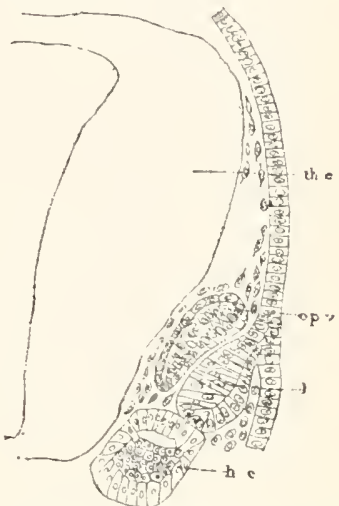

Fig. 45. Horizontal section THROUGH THE HEAD OF A JUST hatched Lafia of Petromizon SHEWIYG THE DEVELOPMENT OF THE LEXS OF THE EYE.

th.c. thalamenceplialon; op.e. optic vesicle; l. lens of eye; h.c. liead earity. the stomodeum originated from the coalescence of a pair of branchial pouches.

In the region of the trunk there is present an uninterrupted dorsal fin continuous with a ventral fin round the end of the tail.

There is a well-dereloped body cavity, which is especially dilated in front, in the part which afterwards becomes the pericardium. In this region is placed the nearly straight heart, divided into an auricle and ventricle (figs. 42 and $4: 3$ ), the latter continued forwards into a bulbus arteriosus.

The myotomes are now very numerous (about $5 \bar{T}$, including those of the head, in a three days' larva). They are separated by septa, but do not fill up the whole space between the septa, and have a peculiar wavy outline. The notochord is provided with a distinct sheath, and below it is placed a subnotochordal rod.

The alimentary canal consists of a narrow anterior section free from yolk, and a posterior region, the walls of which are largely swollen with yolk. The an-

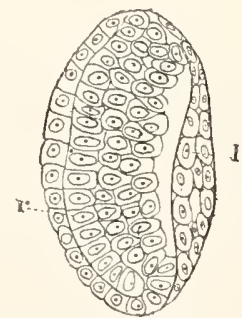

Fig. 46. EYE OF A LARTA OF Petroniyzon nine dats aftur HATCHING.

l. lens; r. retina.

The section passes through one side of the lens. 
terior section corresponds to the region of the asophagus and stomach, but exhibits no distinction of parts. Immediately behind this point the alimentary canal dilates considerably, and on the ventral side is placed the opening of a single large sack, which forms the commencement of the liver. The walls of the hepatic sack are posteriorly united to the yolk-cells. At the region where the hepatic sack opens into the alimentary tract the latter dilates considerably.

The posterior part of the alimentary tract still constitutes a kind of yolk sack, the ventral wall being enormously thick and formed of several layers of yolk-cells. The dorsal wall is very thin.

The excretory system is composed of two segmental ducts, each connected in front with a well-developed pronephros (head-kidney), with about five ciliated funnels opening into the pericardial region of the body cavity. The segmental ducts in the larvæ open behind into the cloacal section of the alimentary tract.

The development of the larva takes place with considerable rapidity. The yolk becomes absorbed and the larva becomes accordingly more transparent. It generally lies upon its side, and resembles in general appearance and habit a minute Amphioxus. It is soon able to swim with vigour, but usually, unless disturbed, is during the day quite quiescent, and chooses by preference the darkest situations. It soon straightens out, and, with the disappearance of the yolk, the tail

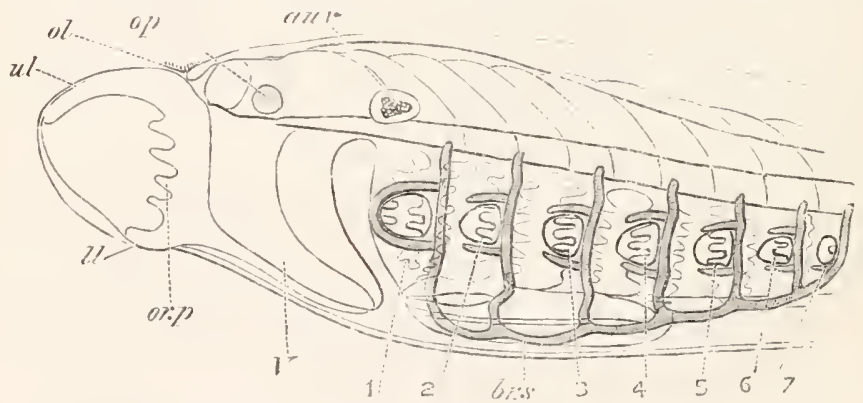

Fig. 47. Head of a rarta of Petrouryon six weeks old.

(Altered from Max Schultze.)

au.r. auditory vesicle; op. optic resicle; ol. olfactory pit; ul. upper lip; 11 . lower lip; or.p. papillæ at side of mouth; $r$. velum; $h r . s$ extra branchial skeleton; 1 - 7 . branrhial clefts.

becomes narrower than the head. A large caudal fin becomes developed.

When the larva is about twenty days old, it bears in most anatomical features a close resemblance to an Ammocotes; though the histological differences between my oldest larva (2? davs) and even rery young Ammocœetes are considerable.

The mouth undergoes important changes. The upper lip becomes much more prominent, forming of itself the anterior end of the body (fig. $47, m l$ ). 
The openin; of the nasal pit is in this way relatively thrown back, and at the same time is caused to assume a clorsal prosition. This will be at once understood by a comparison of fig. 43 with fig. 47 . On the imner side of the oral cavity a ring of papillie is formed (fig. 47, or. $\mu$ ). Dorsally these papillie are continued forward as a linear streak on the under side of the upper lip. A communication between the oral cavity and the branchial sack is very soon established.

The gill pouches gradually hecome enlarged; but it is some time before their small external openings are established. Their walls, which are entirely lined by hypoblast, become raised in folds, forming the branchial lamellet. The walls of the head cavities between them become resolved into the contractor's and dilators of the branchial sacks. The extra-branchial basketwork becomes established very early (it is present in the larvi of 6 millimetres, about 9 days after hatching) and is shewn in an older larva in fig. $4 \pi, b r . s$. It is not so complicated in these young larra as in the Ammoccetes, lut in Max Schultze's figure, which I have reproduced, the dorsal elements of the system are omitted. On the dorsal wall of the branchial region a ciliated ridge is formed, which nray be homologous with the ridge on the dorsal wall of the branchial sack of A scidians. It has been described by schneider in Ammocotes.

With reference to the remainder of the alimentary canal there is but little to notice. The primitive hepatic diverticulum rapilly sprouts out and forms a tubular gland. The opening into the duodenum changes from a ventral to a lateral or even dorsal position. The duct leads into a gallbladder imbeded in the substance of the liver. Ventrally the liver is united with the abdominal wall, but laterally passages are left by which the pericardial and body cavities continue to communicate.

The greater part of the yolk becomes employed in the formation of the intestinal wall. This part of the intestine in a nine days' larva $(6 \cdot 7 \mathrm{~mm}$.) has the form of a cylindrical tube with very thick colummar cells entirely filled with yolk particles. The dorsal wall is no longer appreciably thinner' than the ventral. In the later stages the cells of this part of the intestine become gradually less columnar as the yolk is absorbed.

The fate of the yolk cells in the Lamprey is different from that in most other Vertebrata with an equally large amount of yolk. They no cloubt supjly nutriment for the growth of the embryo, and although in the anterior part of the intestine they become to some extent enclosed in the alimentary tract and break up, yet in the posterior part they become wholly transformed into the regular epithelium of the intestine.

On the ninth day a slight fold filled with mesoblastic tissue is visible on the dorsal wall of the intestine. This fold appears to travel towards the ventral side; at any rate a similar but better-marked fold is visible in a ventro-lateral position at a slightly later period. This fold is the commencement of the fold which in the adult makes a lalf spiral, and is no doubt equivalent to the spiral valve of Elasmobranchs and Gimoids. It contains a prolongation of the coliac artery, which constitutes at first the vitelline ar'tery.

The nervous system does not undergo during the early larval period changes which require a description.

The opening of the olfactory sack becomes narrowed and ciliated (fig. $47, o l$ ). It is curried by the process already mentioned to the dorsal 
surface of the head. The lumen of the sack is well developed; and lies in contact with the base of the fore jart of the brain.

The vascular system presents no very remarkable features. The heart is two-chambered and straight. The ventricle is continued forwards as a bullus arteriosus, which divides into two arteries at the thyroid body. From the bulbus and its continuations eight branches are given off to the gills; and as mentioned above a vessel, probably of the same nature, is given off in the region of the velum. The blood from the branchial sacks is collected into the dorsal aorta. Some of it is transmitter to the lear, but the greater part flows backwards under the notochord.

The venous system consists of the usual anterior and posterior cardinal veins which unite on each sile into a ductus Cuvieri, and of a great sub-intestinal vessel of the same nature as that in embryo Elasmobranclus, which prersists however in the arult. It breaks up into capillaries in the liver, and constitutes therefore the portal vein. From the liver the blood is brought by the hepatic vein into the sinus venosus. In addition to these vessels there is a remarkable unpaired sub-branchial vein, which brings back the blood directly to the heart from the ventral part of the branchial region.

Metamorphosis. The lirva just described does not grow directly into the alult, but first becomes a larval form, known as Ammocnetes, which was supposed to be a distinct species till Aug. Muller (No. 80) made the brilliant discovery of its nature.

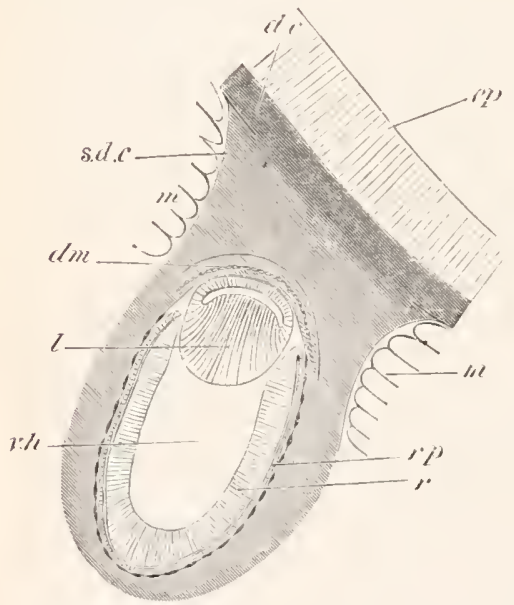

Fig. 48. Eye of ax Amaocetes litig BEXEATH THE SKIN.

ep. epidermis; d.c. dermal comnective tissue continuous with the sub-dermal connective tissue (s.d.c), which is also shaded. 'There is no definite boundary to this tissue where it surrounds the eve.

$m$. muscles; $d m$. membrane of Descemet; l. leus; $r . h$. vitreous humor; $r$. retina; $r p$. retinal pigment.

The Ammocotes does not differ to any marked extent from the larva just described. The histological elements becone more difierentiated, and a few organs reach a fuller development.

The branchial skeleton becomes more developed, and capsules for the olfactory sack and anditory sacks are established.

The olfactory sack is nearly divided inte two by a ventral septum. The eye (fig. 48) is much more fully developed, lut lies a long way helow the surface. The optic eup forms a deep pit, in the mouth of which is placed the lens. The retinal layers are wall developed (ef. Langerhans) and the onter layer of the optic eup or layer of retinal pigment $(r p)$ contains numerous pigment gramules especially on its dorsal side. At the erlge of the optic cup the two layers fall into each other. They 
constitute the commencement of the pigment layer of the iris; but at this stage they are not pigmented. The mesoblast of the iris is hardly differentiated. The lens $(l)$ has the normal structure of the enbryonic lens of Vertebrata. The imner wall is thick and doubly convex, while the outer wall, which will form the anterior epithelium, is very thin. There is a large space between the lens and the retina containing the vitreous humour $(v h)$. 'There is no aqueous humour', and the tissues in front of the lens bear but little resemblance to those in higher. Vertebrata. The cornea is represented by (1) the epidermis (ep); (2) the dermis (d.c); (3) the sub-dermal comnective tissue (s.d.c) which passes without any sharp line of demareation into the dermis; (t) a thick membrane continuous with the choroid which represents Descemet's membrane. The sub-dermal comnective tissue is continued as an investment round the whole eye. There is no specially differentiated sclerotic, and a choroid is only imperfectly indicated ${ }^{1}$. The peculiar features of the eye of the young larva of the Ammocotes are probahly due to degeneration.

In the brain the two cerebral hemispheres lie one on each side of the anterior end of the thalamencephalon. There are well-defined olfactory lobes, and two distinct olfactory nerves are present.

The excretory system has undergone great changes. A series of segmental tubes, which first appear in a larra of about $9 \mathrm{~mm}$, becomes established behind the pronepliros, and in an Ammocotes of $6.5 \mathrm{~mm}$. the pronephros has begun to atrophy. The generative organs are formed in a larva of about $35 \mathrm{~mm}$. Shortly lefore the metamorphosis the portion of the cloaca into which the segmental tubes open becomes separated off as a distinct urinogenital sinus, the walls of which become perforated by the two abdominal pores.

The Ammocates of Petromyzon Planeri lives in the mud in streams. Without undergoing any marked changes in structure it gradually grows larger, and after three or four years undergoes a metamorphosis. The full-grown larva may be as large or even larger than the adult. The metamorphosis takes place from August till January. The breeding season sets in during the second half of April; and shortly after depositing its generative products the Lamprey dies. The changes which take place in the metamorphosis are of a most striking kind.

The dome-shaped mouth of the larva is replaced (fig. $4 \bar{\gamma}$ ) by a more definitely suctorial mouth with horny cuticular teeth (fig. 49). The eyes appear on the surface;

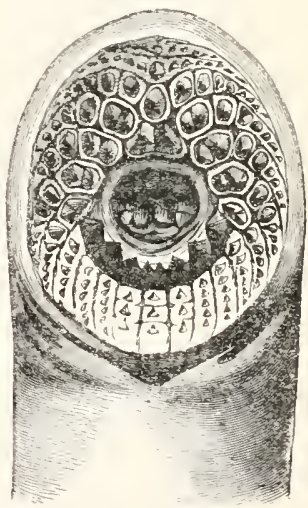

Fig. 19. Moutil of Pl:TROMYZON MARINUS WITH ITS HORNY TEETH. (From Gegenbaur; after Heckel and Kner.)

${ }^{1}$ Langerhans loc, cit. describes the eye of the Ammocoetes in some respects very differently from the above. Very prolably his description applies to an older Ammoccetes. The most important points of difference appear to be (1) that the vitreous humour is all but obliterated; (2) that the iris is much better developed.

B. E. II. 
and the dorsal fin becomes more prominent, and is divided into two parts.

Besides these obvious external changes very great modifications are effected in almost all the organs, which may be very briefly enumerated.

1. Tery profound changes take place in the skeleton. An elaborate system of cartilages is developed in connection with the mouth; the cranium itself undergoes important modifications; and neural arches become formed.

2. Considerable changes are effected in the gill pouches, and, according to Schneider, whose statements must however be received with some caution, the branchial sack becomes detached posteriorly from the asophagus, the cesophagus then sends forwards a prolongation above the branchial sack which is at first solicl. This prolongation forms the anterior part of the asophagus of the alnlt, and joins the primitive oral cavity at the velum. The so-called bronchus of the adult is thus the whole branchial region of the Ammocsetes, and the anterior part of the osoplagus of the adult is an entirely new formation.

3. The posterior part of the alimentary tract of the Ammocœes undergoes partial atrophy. The gall-bladiler of the liver is absorbed; and the liver itself ceases to communicate with the intestine.

4. The eye undergoes important changes in that it travels to the surface, and acquires all the characters of the normal vertebrate eye.

5. The brain becomes relatively larger but more compact, ant the optic lobes (corpora bigemina) become more distinct.

6 . The pericarclial cavity becomes completely separated from the body cavity, and a distinct pericardium is formed.

7. The mesonephros of the larva disappears, and a fresh posterior' part is formed.

Myxine. The ovum of Lyxine when ready to be laid is inclosed, as shewn by Allen 'Thomson ${ }^{1}$, in an oval horny shell in many respects similar to that of Elasmobranchii ; from its ends there project a number of trumpet-shaped tubular processes, which no doubt serve to attach it to marine objects. No observations have been made on the levelopment.

\section{Bibliography.}

(77) E. Calberla. "Der Befruchtungsvorgang beim Petromyzon Planeri." Zcit.,f. wiss. Zool. Vol. xxx. 1877.

(78) E. Calberla. "Ueb. d. Entwicklnng d. Medullarohres u.d. Chorda dorsalis d. Teleostier n. d. Petromyzonten." Morpholog. Jahrbuch, Vol. IIr. 1877.

(79) C. Kupffer и. B. Beneeke. Der Torgang d. Befruchtung am Ei d. Nounaugen. Königsberg, 1878. 1856.

(8o) Aug. Miiller. "Ueber die Entwicklung d. Nemnaugen." Müller's Archiv,

1 Cyelopadia of Anat, and Phys, Article 'Ovum.' 
(8I) Aug. Müller. Beobachtnngen üb. d. Befruchtungserscheinungen im Ei d. Neunangen. Künigsberg, 1864.

(82) W. Miiller. "Das Urogenitalsystem d. Amphioxus u. d. Cyclostomen." Jenaische Zeitschrift, Vol. Ix. 1875.

(83) Ph. Owsjannikoff. "Die Entwick. von d. Flussnemangen." Vorläuf. Vittheilung. Mélanges Biologiques tirés du Bulletin de l'Acad. Imp. St Pétersbourg, Vol. v11. 1870.

(84) Ph. Owsjannikoff. On the development of Petromyzon fluviatilis (Russian).

(85) Anton Schneider. Deitrïge z. vergleich. Anat. u. Entwich.d. Wirbethiere. Quarto. Berlin, 1879.

(86) M. S. Schultze. "Die Entwickl. v. Petromyzon Planeri." Gekronte Preisschrift. Haarlem, 1856.

$\left(8_{i}\right)$ W. B. Scott. "Vorläufige Mittheilung üb. d. Entwicklungsgeschichte ה. Petromyzonten." Zoologischer Anzeiger, Nos, 63 and 64. II. Jahrg. 1880. 


\title{
CHAP'TER VI.
}

\author{
GANOIDEI
}

IT is only within quite recent times that any investigations have been made on the embryology of this heterogeneous, but prinitive group of fishes. Wuch still remains to be done, but we now know the main outlines of the development of Acipenser and Lepidosteus, which are representatives of the two important sub-divisions of the Ganoids. Both types lave a complete segmentation, but Lepidosteus presents in its derelopnent some striking approximations to the 'Teleostei. I have placell at the end of the chapter' a few remarkis with reference to the affinities indicated by the embryology.

\section{ACIPENSER ${ }^{2}$.}

The freshly laid orum is $2 \mathbf{m m}$. in diameter and is invested by a two-layered shell, covered by a cellular layer derived from the follicle? The segmentation, though complete, approaches the meroblastic type more nearly than the segmentation of the frog's egg. The first furrow appears at the formative pole, at which the germinal vesicle was situated. The earlier phases of the segmentation are like those of meroblastic ova, in that the furrows only. penetrate for a certain distance into the egg. Eight vertical furrows appear before the first equatorial furrow; which is somewhat irregular, and situated close to the formative pole.

1 The following classification of the Ganoidei is employed in the present chaptes:

I. Selachoidei. $\left\{\begin{array}{l}\text { Acipenseridie. } \\ \text { Polyodontidie. }\end{array}\right.$

$$
\text { II. Teleostoidei. }\left\{\begin{array}{l}
\text { Polypteridæ. } \\
\text { Amiida. } \\
\text { Lepidosteidx. }
\end{array}\right.
$$

2 Our knowledge of the development of Acipenser is in the main derived from Salensky's valuable observations. His full memoir is unfortunately published in Russian, and I have been obliged to satisfy myself with the abstract (No. 9o), and with what could be gathered from his plates. Prof. Salensky very kindly supplied me with some embryos; and I have therefore been able to some extent to work over the subject myself. This is more especially true for the stages after hatching. The embryos of the earlier stages were not sufficiently well preserved for me to observe more than the external features and a few points with reference to the formation of the layers.

${ }_{3}$ Seven micropylar apertures, six of which form a circle round the seventh, are stated by Kowalersky, Wagner, and Owsjannilioff (No. 89) to be present at one of the poles of the imner egg membrane. They are stated by Salensky to vary in number from five to thin teen. 
In the later stages the vertical furrows extend though the whole egg, and a segmentation cavity appears between the small and the large spheres. The segmentation is thus in the main similar to that of a frog, from which it diverges in the fact that there is a greater difference in size between the small and the large segments.
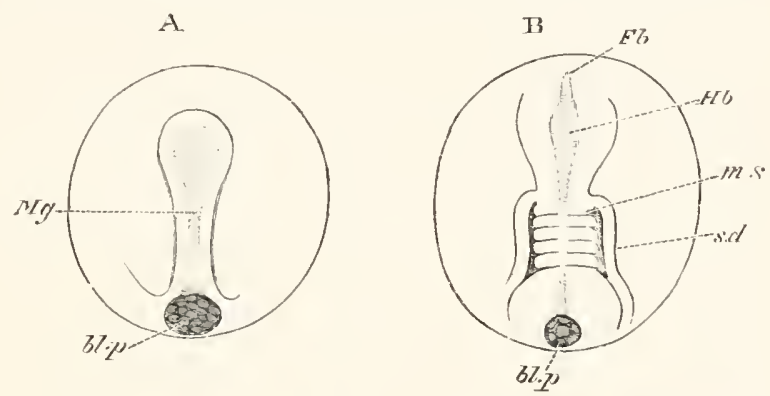

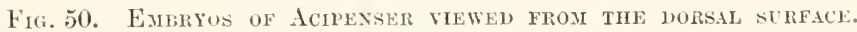
(After Salensky.)

A. Stage before the appearance of the mesoblastie somites.

b. Stage with five somites.

1Iy. meduilary groove; bl.p. blastopore; s.d. segmental duct; $F b$. fore-brain; IIl. hind-brain; m.s. mesoblastic somite.

In the final stages of the segmentation the cells become distinctly divided into two layers. A layer of small cells is placed at the formative pole, and constitutes the epiblast. The cells composing it are divided, like those of Teleostei, etc., into a superficial epidermic and a deeper nervous layer. The remaining cells constitute the primitive hypoblast (the eventual hypoblast and mesoblast); they form a great mass of yolk-cells at the lower pole, and also sprearl along the roof of the segmentation cavity, on the inner side of the epiblast.

A process of unsynmetrical invagination now takes place, which is in its essential features exactly similar to that in the frog or the lamprey, and I must refer the reader for the details of the process to the chapter on the Amphibia. The edge of the cap of epiblast forms an equatorial line. For the greater extent of this line the epiblast cells grow over the hypoblast, as in an epibolic gastrula, but for a small are they are inflected. At the inflected edge an invagination of cells takes place, underneath the epiblast, towards the segmentation cavity, and gives rise to the dorsal wall of the mesenteron and the main part of the dorsal mesoblast. The slit below the invaginated layer gradually dilates to form the alimentary cavity ; the ventral wall of which is at first formed of yolk-cells. The ejiblast along the line of the invaginated cells soon becomes thickened, and forms a medullary plate, which is not very distinet in surface views. The cephalic extremity of this plate, which is furthest renoved from the edge, dilates, and the medullary plate then assumes a spatula form (fig. $50 \mathrm{~A}, \mathrm{Mg}$ ). 
By the continued extension of the epiblast the uneovered part of the hypoblast has in the meantime become reduced to a small circular pore-the blastopore-and in surface views of the embryo has the form represented in fig. $50 \mathrm{~A}, b l . p$. The invagination of the mesenteron has in the meantime extended very far forwards, and the segmentation cavity has become obliterated. The lip of the blastopore has noreover become inflected for its whole circunference.

The invaginated cells forming the dorsal wall of the mesenteron soon become dividerl into a pigmented hypoblastic epithelium adjoining the lumen of the mesenteron (fig. 51, en) and a mesoblastic layer $(S g p)$, between the hypoblast and the epiblast. The mesoblast. is divided into two plates between which is placed the notochord ${ }^{1}(C h)$.

With the completion of the medullary plate and the germinal layers, the first embryonic period may be considered to come to a close. The second period ends with the hatching of the embryo. During it the rudiments of the greater number of organs make their appearance. The general form of the embryo during this period is shewn in figs. $50 \mathrm{~B}$ and $52 \mathrm{~A}$ and $\mathrm{B}$.

One of the first changes to take place is the conversion of the medullary plate into the medullary canal. This, as shewn in fig. 51,

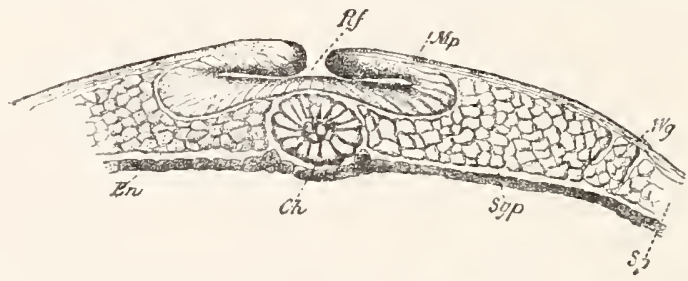

Fia. 51. Transverse section throdgh the anterior part of an Acipenser Eмвкто. (After Salensky.)

If . medullary groove; Mp. medullary plate; Wg. segmental duct; Ch. notochord; En. hypoblast; Sgp. mesoblastic somite; Sp. parietal part of mesoblastic plate.

is effected in the nsual rertebrate fashion, by the establishment of a medullary groove which is then converted into a closed canal by the folding over of the sides.

The uncovererl patch of yolk in the blastoporic area soon becomes closed over; and on the formation of the medullary canal the usual neurenteric canal becomes established.

The further changes which take place are in the main similar to those in other Ichthyopsida, but in some ways the appearance of the embryo is, as may be gathered from fig. 52, rather strange. This is mainly due to the fact that the embryo does not become folded off from the yolk in the manner usual in Vertebrates; and as will be shewn in the sequel, the relation of the yolk to the embryo is unlike that in any other known Vertebrate. The appearance of the embryo

I Salensky believes that the notochord is derivel from the mesolblast. I could not satisfy myself on this point. 
is something like that of an ordinary embryo slit open along the ventral side and then flattened out. Organs which properly belong to the ventral side appear on the lateral parts of the dorsal surface.
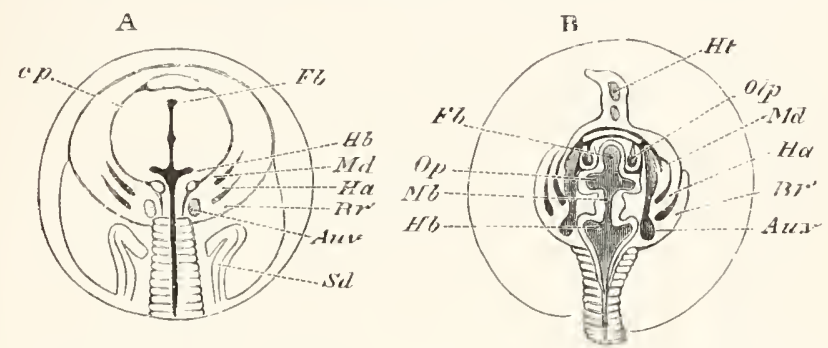

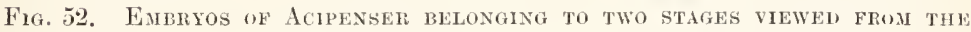
DORSAL SURFACE. (After Salensky.)

Fb. fore-brain; Mb. mid-brain; Hb. hind-brain; $c p$. cephalic plate; Op. optic vesicle; Aur. auditory vesicle; Olp. olfactory pit; 11 . heart; $H d$. mandibular arch ; Ha. hyoid arch; $B r$. first branchial arch; Sd. segmental duct.

Owing to the great forward extension of the yolk the heart (fig. $52 \mathrm{~B}$ ) appears to be placed directly in front of the head.

Even before the formation of the medullary canal the cephalic portion of the nervous system becomes marked out. This part, after the closure of the medullary groove, becomes divided into two (fig. $50 \mathrm{~B}$ ), and then three lobes-the fore-, the mid-, and the hind-brain (fig. 5.2, A and B). From the lateral parts of the at first undivided fore-brain the optic vesicles (fig. $52 \mathrm{~B},(0)$ ) soon sprout out; and in the hind-brain a dilatation to form the fourth ventricle appears in the usual fashion.

The epiblast at the sides of the brain constitutes a more or less well-defined structure, which may be spoken of as a cephalic plate (fig. $52 \mathrm{~A}, c p)$. From this plate are formed the essential parts of the organs of special sense. Anteriorly the olfactory pits arise (fig. 52 B, $\left.O l_{p}\right)$ as invaginations of both layers of the epiblast. The lens of the eye is formed as an ingrowth of the nervous layer only, and opposite the hind-brain the auditory sack (fig. $52 \mathrm{~A}$ and $\mathrm{B}, A u v$ ) is similarly formed from the nervous layer of the epiblast. At the sides of the cephalic plate the visceral arches make their appearance: and in fig. $52 \mathrm{~A}$ and $\mathrm{B}$ there are shewn the mandibular $(M d)$, hyoid $(H a)$ and first branchial $\left(B r^{\prime}\right)$ arches, with the lyomandibular (spiracle) and hyobranchial clefts between them. They constitnte peculiar concentric circles round the cephatic plate; their shape being due to the flattened form of the embryo, already alluded to.

While the above structures are being formed in the head, the changes in the trunk have also been considerable. The mesoblastic plates at the junction of the head and trunk become very early segmented, the segments being formed from before backwards (fig. $50 \mathrm{~B}$ ). With their formation the trunk rapilly increases in 
length. At their outer border the segmental duct (fig. $50 \mathrm{~B}$, and fig. $52 \mathrm{~A}, S(d)$ is very early established. It is formed, as in Elasmobranchs, as a solid outgrowth of the mesoblast (fig. 51, Wg); but its anterior extremity becomes converted into a pronephros (fig. $57, \mathrm{~m} . \mathrm{n}$ ).

Before hatching, the embryo has to a small extent become folded off from the yolk both anteriorly and posteriorly; and has also become to some extent vertically compressed. As a result of these changes, the general form of its body becomes much more like that of an ordinary Teleostean embryo.

The general features of the larva after hatching are illustrated by figs. 5:3, 5 t and 55 . Fig. 53 represents a larva of about $7 \mathrm{~mm}$. and fig. 54 a lateral and fig. 55 a ventral view of the head of a larva of about $11 \mathrm{~mm}$.

There are only a few points which call for special attention in the general form of the borly. In the youngest larva figured the ventral part of the hyomandibular cleft is already closed : the dorsal part of the cleft is destined to form the spiracle $(s p)$. The arch behind is the hyoid: on its posterior border is a membranous ontgrowth,

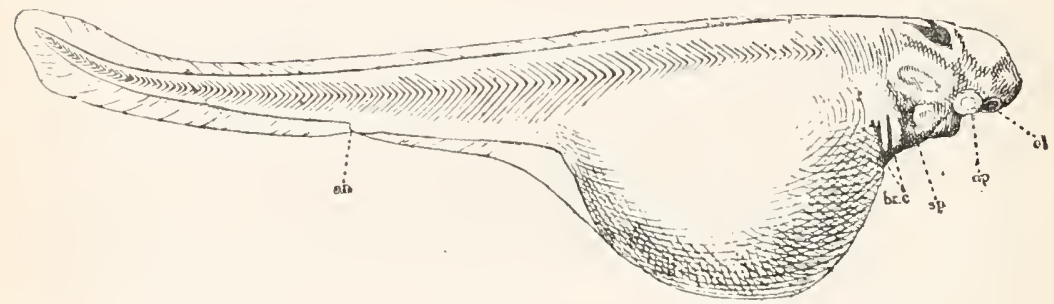

Fiv. 53. Lanva of ACipenser or 7 mir, shortlly after hatching,

ol. olfactory pit; op. optic vesicle; sp. spiracle; br.c. branchial clefts; an. anus.

which will develop into the operculum. In older larvæ, a very rudimentary gill appears to be developed on the front walls of the spiracular cleft (Parker), but I have not succeeded in satisfying myself about its presence; and rows of gill papillie appear on the hyoid and the true branchial arches (figs. 54 and 5.5, g). The biseriallyarranged gill papillie of the true branchial arches are of considerable length, and are not at first covered by the operculum; but they do not form elongated thread-like external gills similar to those of the Elasmobranchii.

The oral cavity is placed on the ventral side of the head. it has at first a more or less rhomboidal form. It soon however (fig. 5.5) becomes narrowed to a slit with projecting lips, and eventually becomes converterl into the suctorial mouth of the adult. The most remarkable feature connected with the mouth is the development of provisional teeth (fig. 55 ) on both jaws.

These teeth were first discorered by Knock (No. 88). They do not appear to be calcitied, and might be supposed to he of the same nature ats the horny teeth of the Lamprey. They are however developed like true teeth, as a 
deposit between a papilla of subepidermic tissuc and an epidermic cap. The substance of which they are formed corresponds morphologically to the enamel of ordinary teeth. As they grow they pierce the epidcrinis, and form bollow spine-like structures with a central axis filled with subepidermic (mesoblastic) cells. They disappear after the third month of larval life.

In front of the mouth two pairs of papilla grow out, which appear to be of the same nature as the papillae on the suctorial dise in the embryo of Lepidosteus (vide 1\%.95). They are very short in the embryo represented in fig. $5: 3$; soon however they grow in length (figs. $5+$ and 5.5, st); and it is probable that they become the barbels, since these occupy a precisely similar position ${ }^{1}$.

The openings of the nasal pits are at first single; but the opening of each becomes gradually divided into two by the growth of a flap on the outer side (fig. $5 t, o l$ ). It is probable that this tlap is equivalent to the fold of the superior maxillary pro-

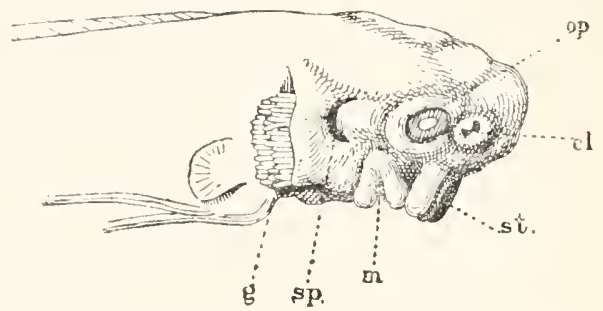

Fit. 54. Side View of a LaRVa of ACIPENSER OF 11 MILLIMETRES.

op. eye; ol. olfactory pit; st. suetorial (?) processes; $m$. mouth; sp. spiracle; 9 . gills.

cess of the Amniota, which by its growth roofs over the open groove which originally leads from the external to the internal nares; so that the two openings of each nasal sack, so established in these and in other fishes, correspond to the external and internal nares of higher Vertebrata.

At the time of hatching there is a continuous dorsoventral fin, which, by atrophy in some parts, and hypertrophy in other parts, gives rise to all the unpaired fins of the adult, except the first lorsal and the abdominal.

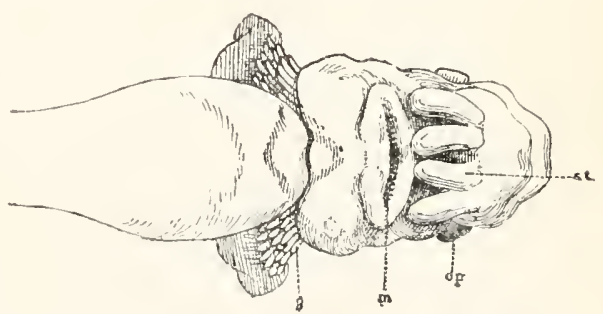

Fig. 55. Vextral VIEW OF a harva of ACIPENSER OF 11 MILLIMETRES.

m. mouth ; st. suctorial (?) processes; op. eye ; \%. gills.

The caudal part of the fin is at first symmetrical, and the heterocercal tail is produced by the special growth of the ventral part of the fin.

Of the internal features of development in the Sturgeon the most important concern the relation of the yolk to the alimentary tract. In

1 If these identifications are correct the barbels of fishes must be phylogenetically derived from the papilla of a suctorial dise adjoining the mouth. 
most Vertebrata the yolk-cells form a protuberance of the part of the

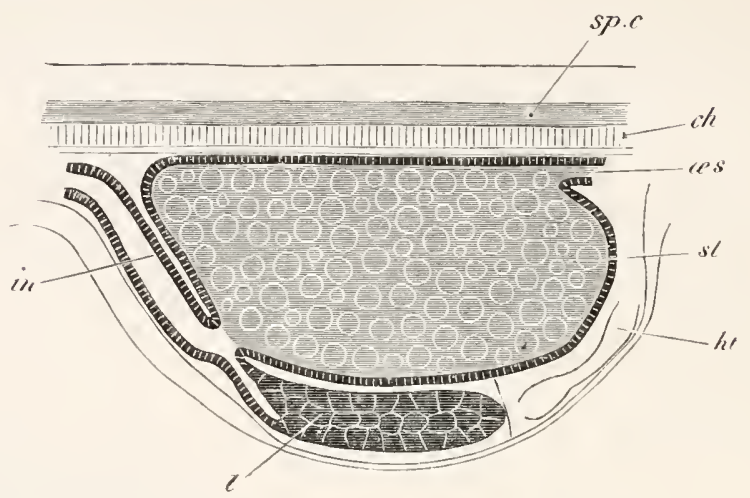

Hig. 56. DIAGRMMATIC LOXgitudiNaL SECTION THROUGH THE ANTERlOR PART OF CHE TRTIK OF A LARVA OF ACIPENSEl TO SHEW THE POSITION OCCUPIED BY THE YOLK.

in. intestine; st. stomach filled with yolk; es. csophagus; l. liver; ht. heart; ch. notochord; sp.c. spinal cord.

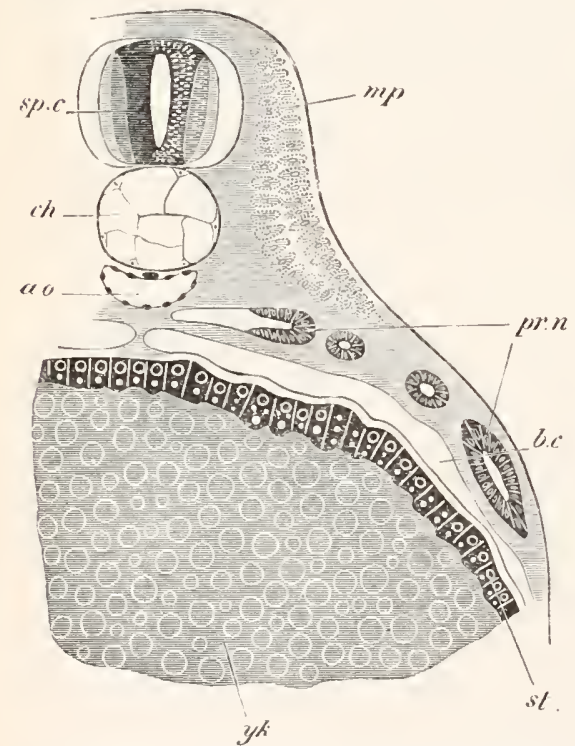

Fig. 57. Transterse section throcgh THE REGION OF THE STOMACH OF A LARVA OF ACipexsler 5 Min. in LeNGth.

st. epithelium of stomach; yl. yolk; $c h$. notochord, below which is a subnotochordal rod; $m$ r.n. promephros; ao. aorta; $m p$. muscleplate formed of large cells, the outer parts of which are differentiated into contractile fibres: sp.c. spiual cord; be. body cavity. alimentary canal, immediately behind the duodenum. The yolk may either, as in the lamprey or frog, form a simple thicken ing of the alimentary wall in this region, or it may constitute a well-developed yolk-sack as in Elasmobranchii and the Amni ota. In either case the liver is placed in front of the yolk. In the Sturgeon on the contrary the yolk is placed almost entirely in front of the liver, and the Stmrgeon appears to be also peculiar in that the yolk, instead of constituting an appendage of the alimentary tract, is eompletely enelosed in a dilated portion of the tratet which becomes the stomach (figs, 56 and 57). It dilates this portion to such extent that it inight be supposed to form a true external yolk-sack. In the stages before hatching the glandular liypoblast, which was established on the dorsal side of the primitive mesenteron, envelops the yolk-cells, which fuse together into a yolk-mass, and lose all trace of their original cellular structure. 
The peenliar flattening out of the embryo over the yolk (vide plp. so and 87) is no doubt comneeted with the mode in whieh the yolk beeomes enveloper by the hypoblast.

As the posterior part of the trunk, eontaining the intestine, beeomes formed, the yolk is gradually confined to the anterior part of the alimentary tract, which, as before stated, beeomes the stomaeh. The epithelial eells of the stomatel, as well as those of the intestine, are enormously dilated with food yolk (fig. 57, st). Behind the stomaeh is formed the liver. The subintestinal vein bringing baek the blood to the liver appears to have the same course as in Teleostei, in that the blood, after passing through the liver, is listributed to the walls of the stomaeh and is again collected into a venous trunk whieh falls into the sinus venosus. As the yolk beeomes absorbed, the liver grows forwards undemeath the stomaeh till it comes in elose eontact with the heart. The relative position of the parts at this stage is shewn diagrammatically in fig. 56. At the eommencement of the intestine there arises in the larva of about $14 \mathrm{~mm}$. a great number of diverticula, which are elestined to form the compaet glandular organ, whieh opens at this spot in the adult. At this stage there is also a fairly well developed pancreas opening into the duodenmm at the same level as the liver.

No trace of the air-bladder was present at the stage in question.

The spiral valve is formed, as in Elasmobranehii, as a simple fold in the wall of the intestine.

There is a well-developed subnotoehordal rod (fig. 57), whieh, aecording to Salensky, becomes the subvertebral ligament of the adult; a statement whieh eonfirms an earlier suggestion of Bridge. The pronephros (headkidney) resembles in the main that of Teleostei (fig. 57); while the front end of the mesonephros, which is developed eonsiderably later than the promephros, is placed some way hehind it. In my oldest larva ( $14 \mathrm{~mm}$.) the mesomephros did not extend backwards into the posterior part of the abdominal cavity.

\section{BibliograpHY.}

(8s) Knock. "Die Beschr. d. Reise z. Wolga Behufs d. Sterlettbefruchtung." Bull. Soc. Nut. Moscow, 1871.

(8g) A. Kowalevsky, Ph. Owsjannikoff, and N. Wagner. "Die Entwick. ג. Störe." Vorläuf. Mittheilung. Málanges Biologiqnes tirés du Bulletin d. l'Acad. Imp. St Pétersbourg, Vol. viI. 1870.

(o) W. Salensky. "Development of the Sterlet (Acipenser ruthenus)." 2 Parts. Proceedings of the Society of Naturalists in the imperial Lnirersity of Kasan. 1878 and 9 (Russian). Part I., abstracted in Hoffmann and Sehwalbe's Julhesbericht for 1878.

(91) W. Salensky. "Znr Embryologie d. Ganoiden (Acipenser)." Zoologiseher Anzeiger, Yol. I., Nos. 11, 12, 13.

\section{LEPIDOSTEUS ${ }^{1}$.}

The ova of Lepidosteus are spherical bodies of about $3 \mathrm{~mm}$. in

1 Alexander Agassiz was fortunate enough to snceed in proeuring and rearing a batch of eggs of this interesting form. He has given an adequate account of the external characters of the post-embryonic stages, and very liberally placed his preserved matcrial of the stages both before and after hatching at Prof. W. K. Parker's and my disposal. The account of the stages prior to hatching is the result of investigations carried on by Professor Parker's son, Mr W. N. Parker, and nysself on the material supplied to us by Agassiz. This material was not very satisfactorily preserved, but I trust that our results are not without sone interest. 
diameter. They are invested by a tough double membrane, composel of (1) an outer layer of somewhat pyriform bodies, radiately arranged, which appear to be the remains of the follicular cells; and (2) of an inner zona radiata, the outer part of which is radiately striated, while the inner part is homogeneous.

The segmentation, as in the Sturgeon, is complete, but approaches closely the meroblastic type. It commences with a vertical furrow at the animal pole, extending through about one-fifth of the circumference. Before this furrow has proceeded further a second furrow is formed at right angles to it. The next stages have not been observed, but on the third day after impregnation (fig. 58), the animal pole is completely divided into small segments, which form a disc similar to the blastoderm of meroblastic ova; while the vegretative pole, which subsequently forms a large yolk-sack, is divided by a few

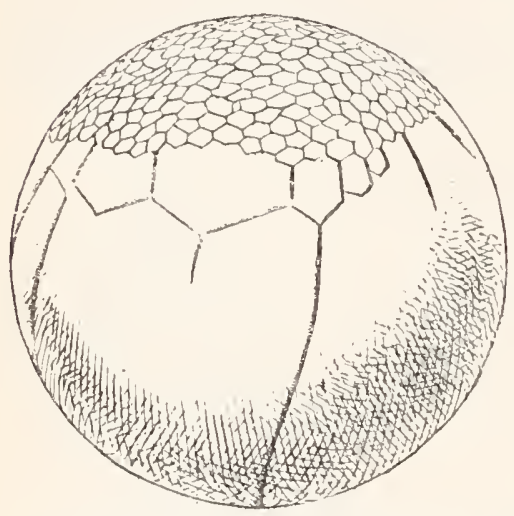

Fig. 58. SURFACE VIEW OF THE OVUM

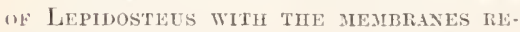
MOVEN ON THE THIRD DAY AFTER IMPTEGNATIOX.

The embryo (fig. 59) has a dumbbell-shaped outline, and is composed of (1) an outer area, with some resemblance to the area pellucida of an avian embryo, forming the lateral part of the body; and (2) a central portion consisting of the vertebral plates and medullary plate. The medullary plate is dilated in front to form the brain $(b r)$. Two lateral swellings in the brain are the commencing optic vesicles. The caudal extremity of the embryo is somewhat swollen.

Sections of this stage (fig. (60) are interesting as shewing a remarkable resemblance between Lepidosteus and Teleostei.

The three layers are fully established. The epiblast $(e p)$ is formed of a thicker inner nervous stratum, and an outer flattened epidermic stratum. Along the axial line there is a solid keel-like thickening of the nervous layer of the epidermis, which projects towards the hypoblast. This thickening $\left(M C^{\circ}\right)$ is the medullary cord; and there is $n 0$ eridence of the epidermic layer being at this or any subsequent perior 
concened in its formation (vide chapter on Teleostei, p. is). In the region of the brain the medullary cord is so thick that it gives rise, as in Teleostei, to a projection of the whole body of the embryo towards the yolk. Posteriorly it is flatter. The mesoblast (Me) in the trunk lias the form of two plates, which thin out laterally. The hypoblast $(h y)$ is a single layer of cells, and is nowhere folded in to form a closer alimentary caual. The hypoblast is separated from the neural cord by the notochord $(C h)$, which throughout the greater part of the embryo is a distinct strueture.

In the region of the tail, the axial part of the hypoblast, the notochord, and the neural cord fuse together, the fused part so formed is the homologue of the

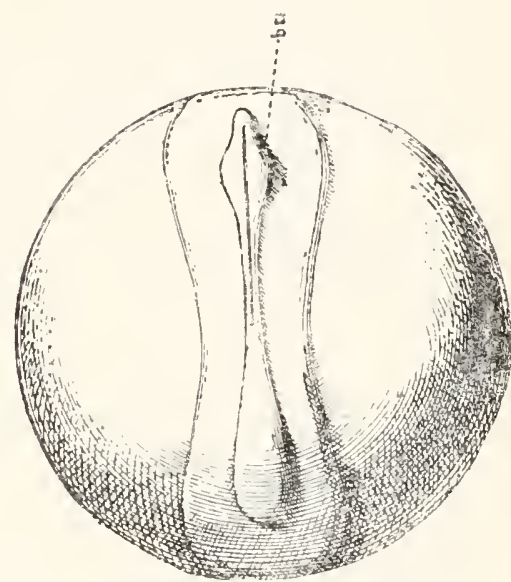

Fig. 59. SURFACE VIET OF A LeyluosTEUS EMBRTO ON THE FIFTH DAY AFTEL IMPREGNATION.

br. dilated extremity of meclullary plate which forms the rudiment of the brain. neurenteric canal of other types. Quite at the hinder end of the embryo the mesoblastic plates cease to be separable from the axial structures between them.

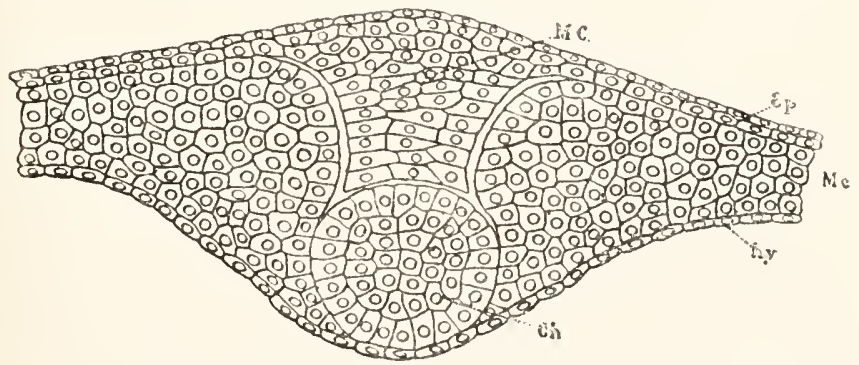

Fig. 60. Section tmrough ax eMmero of Lepmostecs ox the riftir nay AFTER IMPLEGXATION.

MC. medullary cord; Ep. epiblast; Me. mesoblast; hy. hypoblast; Ch. notochort.

In a somewhat later stage the embryo is considerably more elongated, embracing lialf the circumference of the ovum. The brain is divided into three distinct vesicles.

Anteriorly the neural cord has now become separated from the epidermis. The whole of the thickened nervous layer of the epiblast appears to remain united with the cerebro-spinal cord, so that the latter organ is covered dorsally by the epidermic layer of the epiblast 
only. The nervous layer soon however grows in again from the two sides.

Where the nemral cord is separated from the epidermis, it is already provided with a well-developed lumen. Posteriorly it remains in its earlier condition.

In the recrion of the hind-brain traces of the auditory vesicles

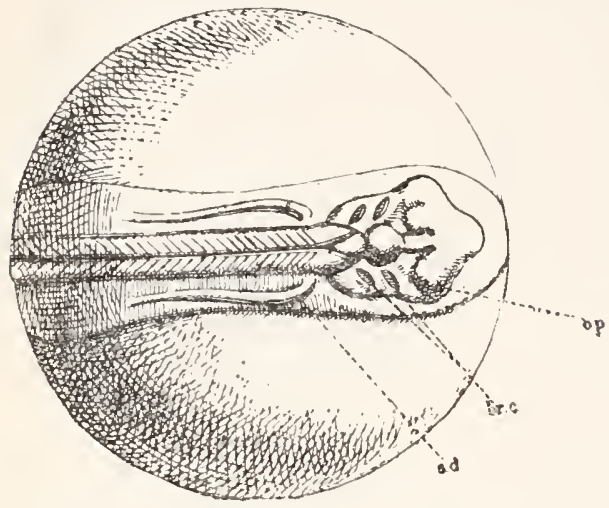

Fig. 61. Embrio of Lepidosteus on the SIXTH DAY AFTER IMPREGATION.

op. optic resicles; br.c. branchial clefts (?); sd. segmental duct.

N.B. The branchial clefts and segmental duct are somewhat too prominent.

rally two streaks are visible (br.c), which, by comparison with the Sturgeon, would seem to be the two first visceral clefts ${ }^{1}$ : they are

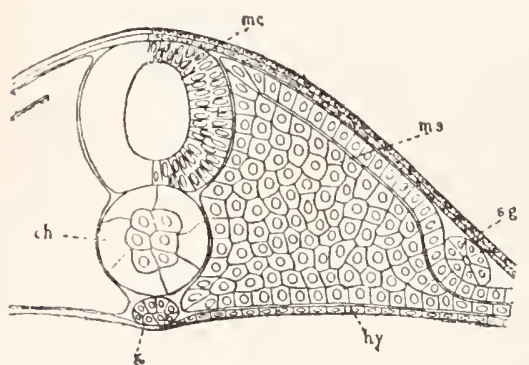

Fig. 62. SEction thIROUGH the tRUNK OF A Lepidosteus EMBRYO ON THE SIXTII DAY AFTER IMPREGNATION.

mc. medullary cord; ms. mesoblast; $s g$. segmental duct; ch. notochord; $x$. sub-notochordal rod; hy. hypoblast. are present in the form of slightly involuted thickenings of the nervous layer of the epidermis.

The mesoblast of the trunk is divided anteriorly into splanchnic and somatic layers.

In the next stage, on the sixth day after impregnation (fig. 61), there is a great advance in development. The embryo is considerably longer, and a great number of mesoblastic somites are visible. The body is now laterally compressed and raised from the yolk.

The region of the head is more distinct, and latenot yet perforated. In the lateral regions of the trunk the two segmental ducts are visible in surface views (fig. (i1, sd) occupying the same situation as in the Sturgeon. Their position in section is shewn in fig. $62, \mathrm{sg}$.

With reference to the features in development, visible in sections, a few points may be alluded to.

The optic vesicies are very prominent outgrowths of the brain, but are still solid, though the anterior cerebral vesicle has a well-developed lumen. The 
auditory vesicles are now deep pits of the nerrous layer of the epillast, the openings of which are covered by the epidermic layer. They are shewn for a slightly later stage in fig. $63(a u . v)$.

There is now present a subnotochordal rod, which develops as in other types from a thickening of the hypoblast (fig. $62, x)$.

In an embryo of the seventh day after impregnation, the features of the preceding stage become generally more pronounced.

The optic resicles are now provided with a lumen (fig. 64 ),

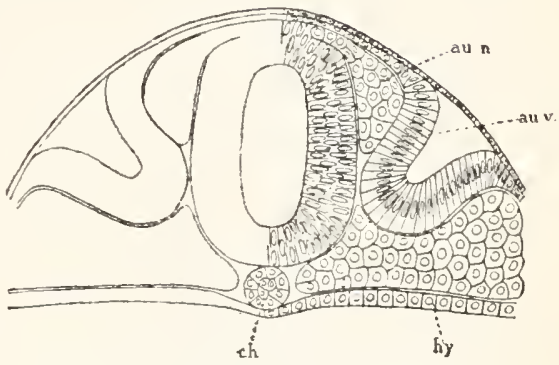

Fig. 63. Section throvgit the head of a Lepidosteus embryo on the sixth DaY AFTER IMPREGNATION.

au.c. auditory resicle; au.n. auditory nerve; $c h$. notochord; hy. hypoblast. and have approached close to the epidermis. Adjoining them a thickening $(l)$ of the nercous lnyer of the epidermis has appeared, which will form the lens. The cephalic extremity of the segmental duct, which, as shewn in fig. 61 , is bent inwards towards the middle line, has now become slightly convoluted, and forms the rudiment of a pronephros (head-kidney).

During the next few days the folding off of the embryo from the yolk commences, and proceeds till the embryo acquires the form represented in fig. 6.5 .

Both the head and tail are quite free from the yolk; and the embryo presents a general resemblance to that of a Teleostean.

On the ventral surface of the front of the head there is a dise (figs. 65, 66, sd), which is beset with a number of processes, formed as thickenings of the epiblast. As shewn by Agassiz, these eventually become short suctorial papillæ ${ }^{1}$. Immediately behind this disc is placed a narrow depression which forms the rudiment of the mouth.

The olfactory pits are now developed, and are placed near the front of the head.

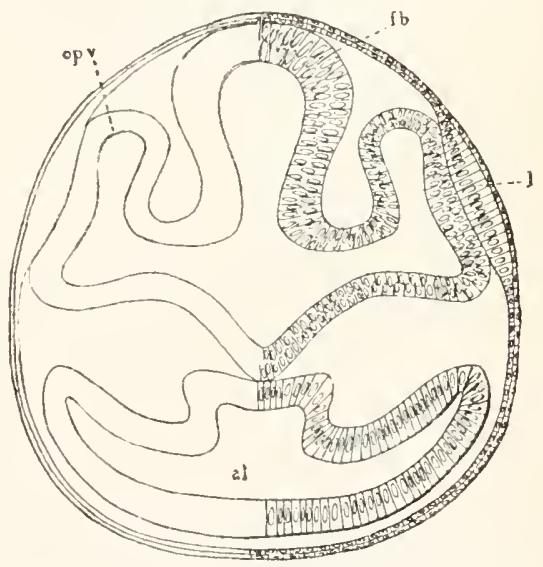

Fig. 64. Section throdgh the rront PART OF THE HEAD OF A Lepidosteds EMBRTO ON THE SEVENTH DAY AFTER IMPREGNATION.

al. alimentary tract; $f b$. thalamencephalon; $l$. lens of eye; op. $v$. optic vesicle. The mesoblast is not represented.

1 These papille are very probably sensitive structures; but I have not yet investigated their histological characters. 
A great advance has taken place in the development of the visceral clefts and arches. The oral region is bounded behind by a wellmarked mandibular arch, which is separated by a shallow depression from a still more prominent hyoid arch $($ fig. $65, h y)$. Between the hyoid and mandibular arches a double lamella of hypoblast, which represents the hyomandibular cleft, is continued from the throat to the external skin, but does not, at this stage at any rate, contain a lumen.

The hyoid arch is prolonged backwards into a considerable opercular fold, which to a great extent overshadows the branchial clefts behind. The hyobranchial cleft is widely open.

Behind the hyobranchial cleft are four pouches of the throat on

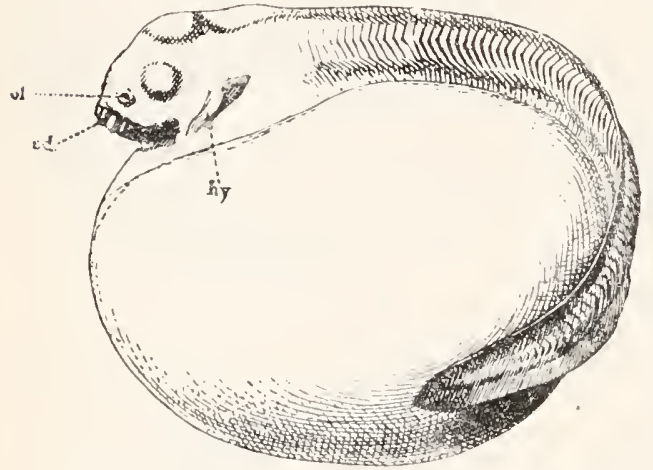

Fig. 65. Limbo of Lepidostees shontuy befolie HATCHING. arch.

ol. olfactory pit; sel. suetorial dise; hy. hyoid each side, not yet open to the exterior. They are the rudiments of the four branchial clefts of the adult.

The trunk has the usual compressed piscine form, and there is a welldeveloped dorsal fin continuous round the end of the tail, with a ventral fin. There is no trace of the paired fins.

The anterior and posterior portions of the alimentary tract are closed in, but the middle region is still open to the yolk. The circulation is now fully established, and the vessels present the usual vertebrate arrangement. There is a large subintestinal vein.

The first of Agassiz embryos was hatched about ten days after impregnation. The young fish on hatching immediately used its suctorial dise to attach itself to the sides of the vessel in which it was placed.

The general form of Lepidosteus shortly after hatching is shewn in tig. 67 . On the ventral part of the front of the head is placed the large suctorial disc. At the side of the head are seen the olfactory pit, the eye and the auditory vesicle; while the projecting vesicle of the mid-brain is very prominent above. Behind the mouth follow the visceral arches. The mandibular arch $(m d)$ is placed on the hinder border of the month, and is separated by a deep groove from the hyoid arch $(h y)$. This groove is connected with the hyomandibular cleft, but I have not determined whether it is now perforated. The posterior border of the hyoid areh is prolonged into an opercular fold. Behind the hyoil arch are seen the true branchial arches. 
There is still a continuous dorso-ventral fin, in which there are as yet no fin-rays, and the anterior paired fins are present.

The yolk-sack is very large, but its communication with the alimentary canal is confined to a narrow vitelline duct, which opens into the commencement of the intestine immediutely behind the duct of the liver, which is now a compact gland. The yolk in Lepidosteus thus behaves very differently from that in the Sturgeon. In the first place it forms a special external yolk-sack, instear of an internal dilatation of part of the alimentary tract; and in the second place it is placed behind instead of in front of

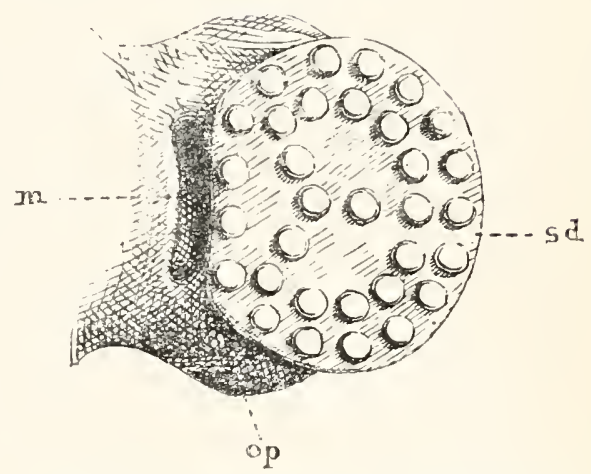

Fig, 66. Vextral view of the heat) OF A LEPIDOSTEUS EMBRTO SHORTLY BEFORE HATCHING, TO SHEW TIE LARGE SUCTORIAL IISC.

m. mouth; op. eye; sd. suctorial dise. the liver.

I failed to find any trace of a pancreas. There is however, opening on the dorsul side of the throut, a well-developed appendage

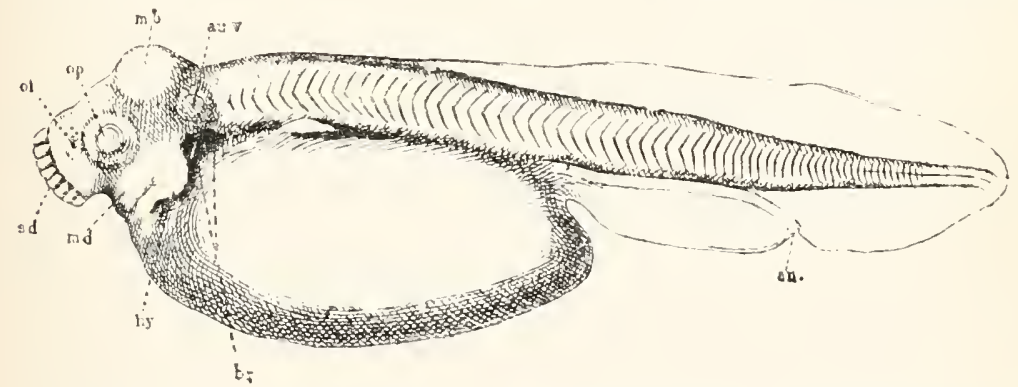

Fig. 67. Larva of Lepidosteys shortly after hatching. (After Parker.)

ol. olfactory pit; op. optic vesicle; au $r$, auditory vesicle; $m b$. mid-brain; sd. suctorial dise; mel. mandibular arelı; hy. hyoid arch with opereulum; br. branchial arches; an. anus.

continued backwards beyond the level of the commencement of the intestine. This appendage is no doubt the air-bladder.

In the course of the further growth of the young Lepidosteus, the yolk-sack is rapidly absorbed, and has all but disappeared after three weeks. A rich development of pigment early takes place; and the pigment is specially deposited on the parts of the embryonic fin which will develop into the permanent fins.

The notochord in the tail bends slightly upwards, and by the special development of a caudal lobe an externally heterocercal tail like that of Acipenser is establisherl. The ventral paired fins are first visible 
after about the end of the third week, and by this time the operculum has grown considerably, and the gills have become well developed.

The most remarkable changes in the later periods are those of the mouth.

The upper and lower jaws become gradually prolonged, till they eventually form a snout; while at the end of the upper jaw is placed the suctorial disc, which is now considerably reduced in size (fig. $68, s d$ ). The "fleshy globular termination of the upper jaw of the adult Lepidosteus is the remnant of this embryonic sucking lisc." (Agassiz, No. 92.)

The fin-rays become formed as in Teleostei, and parts of the cou-

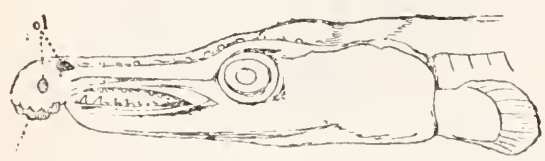

sd

FIf. 69. HEAI OF AN ADVAXCE1 TARTA OF Lepidosteus. (After Parlier.)

ol. openings of the olfactory pit; st. remains of the larval suctorial disc. tiuuous embryonic fin gradually usulergo atrophy. The dorsal limb of the embryonic tail, as has been shewn by Wilder, is absorbed in precisely the same manner as in Teleostei, leaving the ventral lobe to form the whole of the permanent tail-fin.

\section{Biblogiraphy.}

(92) Al. Agassiz. "The derelopment of Lepilostens." Iroc. Amer. Acad. of Arts and Sciences, Vol. xim. 1878.

\section{General observations on the Embryology of the Ganoids.}

The rery heterogeneous character of the Ganoid group is elearly shewn both in its emloryology and its anatony. The two known types of formation of the central nervous system are exemplified in the two species which have been studied, and these two species, though in accord in having a holoblastie segmentation, yet differ in other important features of derelopment, such as the position of the yolk etc. Both types exhibit Teleostean affinities in the character of the pronephros; hut as might have been anticipated Lepidosteus presents in the origin of the nervous system, the relations of the hypoblast, and other characters, eloser approximations to the 'T'eleostei than does Acipenser. There are no very prominent Amphibian characters in the development of either type, other than a general similarity in the segmentation and formation of the layers. In the young of Polypterus an interesting amplibian and dipnoid character is fonnd in the presence of a pair of true external gills covered br epiblast. These gills are attached at the hinder end of the operculum, and receive their blood from the hyoid arterial arch ${ }^{1}$. In the peculiar suctorial disc of Lepidostens, and in the more or less similar structure in the Sturgeon, these fishes retain, I believe, a very prinitive rertehrate organ, which has disappenred in the adult state of almost all the Vertebrata; but it is probable that further investigations will shew that the Teleostei, and especially the Siluroids, are not without traces of a similar structure.

1 Vide Steindachner, Polyptems Lapradei. \&e., and Hyrtl, "Uther d. Blutgefasse, \&c." Sitz. Wiener Aliad., Vol. Lx. 


\title{
CHAPTER VII.
}

\author{
AMPHIBIA
}

THe eggs of most Amphibia ${ }^{2}$ are laid in water. They are smallish nearly spherical bodies, and in the majority of known Anura (all the European species), and in many Urodela (Amblystoma, Axolotl, though not in the common Newt) part of the surface is dark or black, owing to the presence of a superficial layer of pigment, while the remainder is unfigmented. The pigmented part is at the upper pole of the egg, and contains the germinal vesicle till the time of its atrophy; and the yolk-granules in it are smaller than those in the unpigmented part. The ovum is closely surrounded by a vitelline membrane $^{3}$, and receives, in its passage down the oviduct, a gelatinous investment of varying structure.

In the Anura the eggs are fertilized as they leave the oviduct. In some of the Urodela the mode of fertilization is still imperfectly understood. In Salamanders and probably Newts it is internal ${ }^{4}$;

1 The following classification of the Amphibia is employed in the present chapter:

I. Anura.

II. Urodela.

III. Gymnophiona.

2 I am under great obligations to Mr Parker for haring kindly supplied me, in answer to my questions, with a large amount of valuable information on the development of the Amphibia.

3 Within the vitelline membrane there appears to be present, in the Anura at any rate, a very delicate membrane closely applied to the yolk.

4 Allen Thomson informs me that he has watched the process of fertilization in the Newt, and that the male deposits the semen in the water close to the female. From the water it seems to enter the female generative aperture. Ton siebold has shewn that there is present in female Newts and Salamanders a spermatic bursa. In this bursa the spermatozoa long (three months) retain their vitality in some Salamanders. Tarious peculiarities in the gestation are to be explained by this fart. 
but in Amblystoma punctatum (Clark, No. 98), the male deposits the semen in the water. The eggs are laid by the Anura in masses or strings. By Newts they are deposited singly in the angle of a bent blade of grass or leaf of a water-plant, and by Amblystoma punctatum in masses containing from four eggs to two hundred. Salamandra atra and Salamandra maculosa are viviparous. The period of gestation for the latter species lasts a whole year.

A good many exceptions to the above general statements have been recorded ${ }^{1}$.

In Notodelphis ovipara the eggs are transported (by the male?) into a peculiar dorsal ponch of the skin of the female, which has an anterior upening, but is continued b.1ckwands into a pair of diverticula. The eggs are very large, and in this poucl, which they enormously distend, they undergo their development. A more or less similar pouch is found in Nototrema marsupiatum.

In the Surinam toad (Pipa dorsigera) the eggs are placed by the male on the back of the female. A peculiar pocket of skin becomes developed round each egg, the open end of which is covered by a gelatinous opereulum. The larve are hatched, and actually undergo their metamorphosis, in these pockets. The female during this period lives in water. Pipa Americana (if specifically distinct from $\mathrm{P}$. dorsigera) presents nearly the same peculiarities. The female of a tree frog of Ceylon (Polypedates reticulatus) carries the egss attached to the abiomen.

Rhinoderma Darwinii ${ }^{2}$ behaves like some of the Siluroid fishes, in that the male carries the eggs during their development in an enormously developed laryngeal pouch.

Some Anura do not lay their eggs in water. Chiromantis Guineensis attaches them to the leaves of trees; and Cystiguathus mystacius lays them in holes near ponds, which may become filled with water after heavy rains.

The eggs of Hylodes Martinicensis are laid under dead leaves in moist situations.

\section{Formation of the layers.}

Anura. The formation of the germinal layers has so far only been studied in some Anura and in the Newt. The following description applies to the Anura, and I have called attention, at the end of the section, to the points in which the Newt is peculiar.

The segmentation of the Frog's ovum has already been described (Vol. I. p. 78), but 1 may remind the reader that the segmentation (fig. 69) results in the formation of a vesicle, the cavity of which is situated excentrically; the roof of the cavity being much thinner than the Hoor. The cavity is the segmentation cavity. The roof is formed of two or three layers of smallish pigmented cells, and

1 For a summary of these and the literature of the subject vide "Amphibia," by C. K. Hoffmamn, in Brom's Classen und Ordmungen d. Thier-reichs.

2 Vide Spengel, "Die Fortpflanzung des Rhinoderina Darwinii." Zcit.f. wiss. Zool. [3. xxıx., 1577. This paper contains a translation of a note by Jinuinez de la Espada on the derelopment of the species. 
the Hoor of large cells, which form the greater part of the ovum.

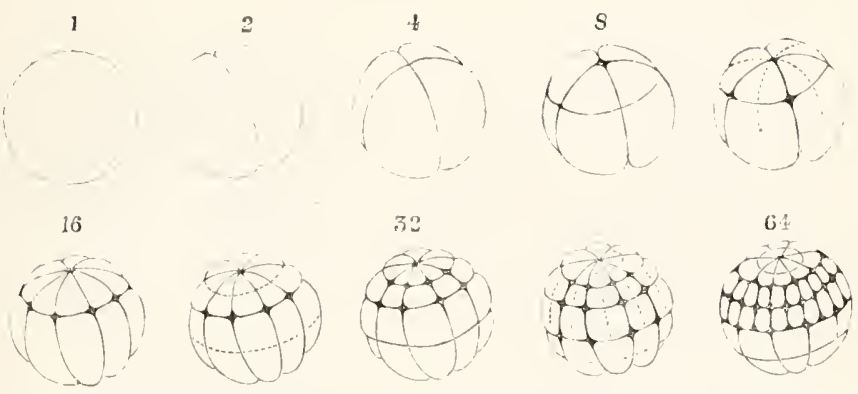

Fia. 69. Segmentation of Common Frog. Rana Temporala. (After Eeker.) The numbers above the figures refer to the number of segments at the stage figured.

These large cells, which are part of the primitive hypoblast, will be spoken of in the sequel as yolk-cells: they are equivalent to the food-yolk of the majority of vertebrate ova.

The cells forming the roof of the cavity pass without any sharp boundary into the yolk-cells, there being at the junction of the two a number of cells of an intermediate character. The cells both of the roof and the floor continue to increase in number, and those of the roof become divided into two distinct strata (fig. 70, ep.).

The upper of these is formed of a single row of somewhat cubical cells, and the lower of several rows of more rounded cells. Both of these strata eventually become the epiblast, of which they form the epidermic and nervous layers. The roof of the segmentation cavity appears therefore to be entirely constituted of epiblast.

The next clianges which take place lead (1) to the formation of the mesenteron ${ }^{1}$, and (2) to the enclosure of the yolk-cells by the epiblast.

The mesenteron is formed as in Petromyzon and Lepidosteus by an unsymmetrical form of invagination. The invagination first commences by an inflection of the epiblast-cells for a small are on the

1 Since the body-cavity is not developed as diverticula from the cavity of invagination, the latter eavity may conveniently be called the mesenteron and not the archenteron. 
equatorial line which marks the junction between the epiblastic cells and the yolk-cells (fig. $70, x$ ).

The inflected cells become continnous with the adjoining cells; and the region where the inflection is formed constitutes a kind of lip, below which a slit-like cavity is soon established. This lip is equivalent to the embryonic rim of the Elasmobranch blastoderm, and the cavity beneath it is the rudiment of the mesenteron.

The inesenteron now rapidly extends by the invagination of the cells on its dorsal side. 'These cells grow inwards towards the segmentation cavity as a layer of cells several rows deep At its inner end, this layer is continuous with the yolk-celts; and is divided into two strata (fig. $71 \mathrm{~A}$ ), viz. (1) a stratum of sereral rows of cells adjoining the epiblast, which becomes the mesoblast $(m)$, and ( 2 ) a stratum of a single row of more colummar cells lining the cavity of the mesenteron, which forms the hypoblast $(h y)$. The growtl inwards of the dorsal wall of the mesenteron is no doubt in part a true invagination, but it seems probable that it is also due in a large measure to an actual differentiation of yolk-cells along the line of growth. T'he mesenteron is at first a simple slit between the yolk and the hypoblast (fig. $71 \mathrm{~A}$ ), but as the involution of the livpoblast and mesoblast extends further inwards, this slit enlarges, espeeially at its inner end, into a considerable cavity; the blind end of which is separated by a narrow layer of yolk-cells from the segmentation-cavity (fig. $71 \mathrm{~B}$ ).

In the conrse of the involution, the segmentation-cavity becomes gradually pushed to one side and finally obliterated. Before obliteration, it appears in some forms (Pelobates fucus) to become completely enchosed in the volk-cells.

While the invagination to form the mesenteron takes place as above described, the enclosure of the yolk has been rapidly proceeding. It is effected by the epiblast growing over the yolk at all points of its ciremmference. The nature of the growth is however very different at the embryonic rim and elsewhere. At the embryonic rim it takes place by the simple growth of the rim. so that the point $i$ in figs. 70 and 71 is carried further and further over the surface of the yolk. Elsewhere the epiblast at first extends over the yolk as in a typical epibolic gastrula, without being inflected to form a definite lip. While a considerable patch of yolk is still left uncovered, the whole of the edge of the epiblast becomes however inflected, as at the embryonic rim (fig. $71 \mathrm{~A}$ ); and a circular blastopore is established, round the whole edge of which the epiblast and intermediate cells are continuous.

From the ventral lip of the blastopore the mesoblast (fig. 71, $m^{\prime}$ ), derived from the small intermediate cells, grows inwards till it comes to the segmentation-cavity; the growth being not so much due to an actual invagination of cells at the lip of the blastopore, as to a differentiation of yolk-cells in situ. Shortly after the stage represented in fig. $71 \mathrm{~B}$, the plug of yolk, which fills up the opening of the blastopore, disappears, and the mesenteron communicates freely 
with the exterior hy a small circular blastopore (fig. 7:3). The position

A.

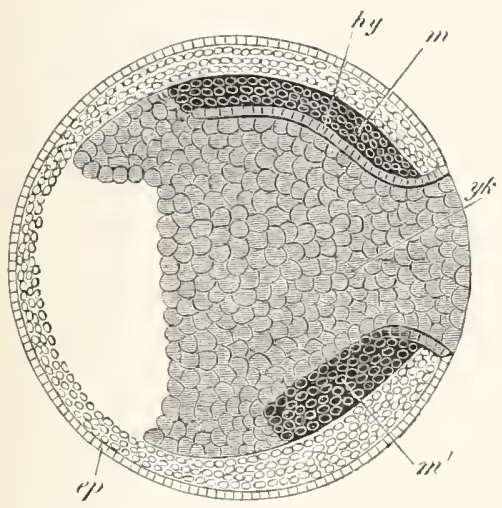

B.

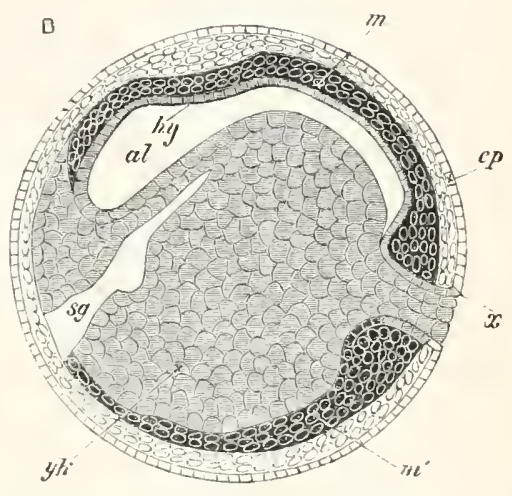

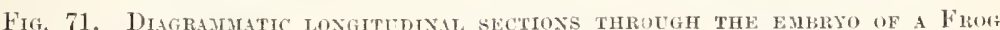
AT TWO STAGES, TO SHEW THE FOMMATION OE THE GERMINAL 1,AYERs. (Modified from (iötte.)

ep. epiblast; $m$. dorsal mesoblast; $m^{\prime}$. ventral mesoblast; hy. hypollast; yl. yolk; x. point of junction of the epiblast and lypoblast at the dorsal side of the blastopore; al. mesenteron; $8 g$. segmentation cavity.

of the blastopore is the same as in other types, viz. at the hinder end of the embryo.

By this stage the three layers of the embryo are definitely established. The epiblast, consisting from the first of two strata, arises from the small cells forming the roof of the segmentation-cavity. It becomes continuous at the lip of the blastopore with cells intermediate in size between the cells of which it is formed and the yolkcells. 'These latter, increasing in number by additions from the yolkcells, give rise to the mesoblast and to part of the hypohlast; while to the latter laver the yolk-cells, as mentioned above, must also be considered as appertaining. Their history will be dealt with in treating of the general fate of the hypoblast.

Urodela. The early stages of the development of the Newt have been adequately investigated hy seott and Osborn (No. I I ). The segmentation and formation of the layers is in the main the same as in the Frog. The ovum is without black pigment There is a typical unsymmetrical invagination, but the dorsal hip of the blastoprose is somewhat thickened. The most striking featme in which the Newt differs from the Frog is the fact that the epiblast is at first constituted of a single layer of cells (tig. $75, e p)$. The roof of the segmentation carity is constituted, during the later stages of the segmentation, of several rows of cell- (Bambeke, No. 95), but subsequently it would appear to be formed of a single row of cells only (Scott and Osborn, No. I 14 ).

\section{General history of the layers.}

Epiblast: Anura. At the completion of the invagination the "piblast forms a continuous layer enclosing the whole ovum, and con- 
stituted throughout of two strata. The formation of the medullary canal commences by the nervous layer along the axial dorsal hine becoming thokened, and giving rise to a somewhat pyriform medullary plate, the sides of which form the projecting medullary folls. (fig. $77 \mathrm{~A}$ ). The mednilary plate is thickened at the two sides, and is crooved in the median line by a delicate furrow (fig. $72, r$ ). The dilated extremity of the medullary plate, situated at the end of the embryo opposite the blastopore, is the cerebral part of the plate, and the remainder the spinal. The mednllary folds bend npwards, and finally meet aloove, enclosing a central cereloro-spinal canal (fig. 74 ). The point at which they first meet is near'y at the junction of the brain and spinal cord, and from this point their junction extends backwarls and forwards; but the whole process is so rapil that the closure of the medullary canal for its whole length is effected nearly sinultaneously. In front the medullary canal ends blindly, but behind it opens freely into the still persisting blastopore, with the lips of which the medullary folls become, as in other types, continuous. Fig. 73 represents a longitudinal section through an embryo, shortly

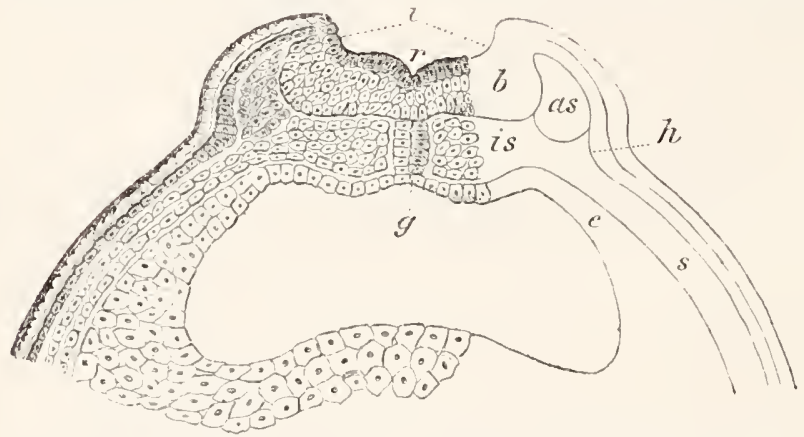

Fig. 72. Thaxsmere secrion throdgh the posterior caphatic region of as EARLy eubrio of Boyminator. (After Götte.)

l. medullary groore; $r$. axial furrow in the medullary groove; $h$. nervous layer of cpidermis; $a s$. outer portion of vertebral plate; $i s$. inner portion of vertebral plate; $\therefore$ lateral plate of mesoblast; $g$. notochord; e. hypoblast.

after the closure of the medullary canal $(n c)$; the opening of which into the blastopore $(x)$ is clearly seen.

On the closure of the medullary canal, its walls become separated from the external epiblast, which extends above it as a continuous layer. In the formation of the central nervous system both strata of the epiblast have a share, thongh the main mass is derived from the nervous layer. After the central nervous tube has becme separated from the external skin, the two layers forming it fuse together; but there can be but little doubt that at a later period the epidermic layer separates itself again as the central epithelium of the nervous system.

Both the nervous and epidermic strata have a share in forming the 
general epiblast; and though eventually they partially fuse together vet the homv layer of the ardult epilermis, where such can be distinguished, is probably derived from the epidernic layer of the embryo, and the mucous layer of the epidermis from the embryonic nervous layer.

In the formation of the organs of sense the nervous layer shews itself throughout is the active layer. The lens of the eye and the anditory sack are derived exclusively from it, the latter having no external opening. The nerrous layer also plays the more important part in the formation of the alfactory sack.

The outer layer of epiblastcells becomes ciliated after the close of the segmentation, but the cilia gradually disappear on the formation of the internal gills. The cilia canse a slow rotatery movement of the embryo within the egg, and probably assist in the respiration after it is hatched. They are especially leveloped on the external gills.

Urodela. In the Nowt (Seott and Oshorn, No. 1 14) the medullary plate becomes established, while the epihlast is still formed of a single row of cells; and it is not till after the closure of the neural groove that any distinction is observable between the epithelium of the central canal, and the remaining cells of the cerebro-spinal cord (tig. 75 ).

Before the closure of the medullary folds the lateral epiblast becomes divided into the two strata present from the first in the Frog; and in the subsequent derelopment the inner layer behaves as the active layer, precisely as in the Anura.

The mesoblast and notochord: Anura. After the disappearance of the segmentation-cavity, the mesollast is described by most observers, including Götte, as forming a continuous sheet round the ovum, underneath the epiblast. The first important differentiations in it take place, as in the case of the epiblast, in the axial dorsal line. Along this line a central cord of the mesoblast becomes separated from the two lateral sheets to form the notochord. Calberla states, however, that when the mesoblast is distinctly separated from the liypoblast it does not form a continuous sheet, but two sheets one on each side, between which is placed a ridge of cells continuons with the hypoblastic sheet. This ridge subsequently hecomes sepa- 
rated from the hypoblast as the notochord. Against this view Götte has recently strongly protested, and given a series of careful representations of his sections which certainly support his original account.

My own observations are in favour of Calberla's statement, and so far as I can determine from my sections the mesoblast never appears as a perfectly continuous sheet, but is always deficient in the dorsal median line. My observations are unfortunately not founded on a sufficient series of sections to settle the point definitely.

After the formation of the notochord (fig. 72), the mesoblast may be regarded as consisting of two lateral plates, continuous ventrally, but separated in the median dorsal line. By the division of the dorsal parts of these plates into segments, which commences in the region of the neck and thence extends backwards, the mesoblast of the

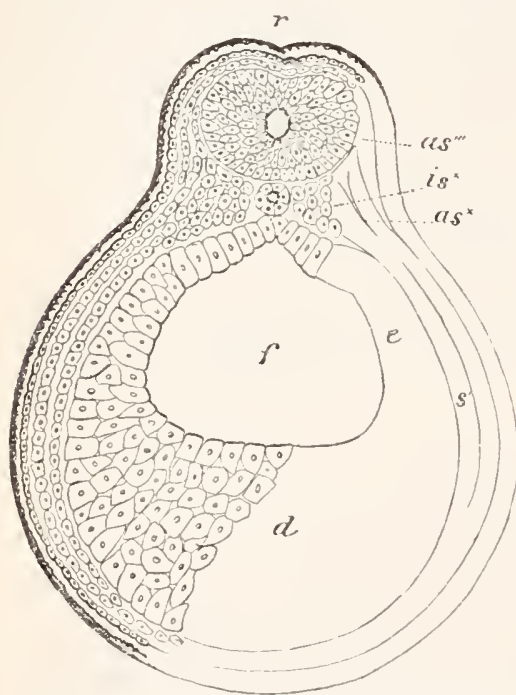

Fig. 7t. Section throvgh the ANTERIOR PALT OF THE TFUXK OF A YOUNG wabryo of Bomisatok. (After Götte.)

$a s^{\prime \prime \prime}$. medulla oblongata; isx. splanchnopleure; $a s^{x}$. somatoplenre in the vertebral part of the mesoblastic plate; s. lateral plate of mesoblast; $f$. throat; $e$. passage of epithelial cells in to yolli-cells; $d$. yolk-cells; $r$ dorsal groove along the lime of junction of the medullary folds.

types already considered (fig. 75). The body-carity is continued into the region of the head; and the mesoblast lining the cephalic section of the body-cavity is divided into the same numler of head-cavities as in Ela-mobranchii, viz. one in front of the montl, and one in the mandibulitr and one in each of the fullowing arches. vertebral portion, cleft into seprate somites, and a lateral unsegmented portion (fig. 74).

The history of these two parts and of the mesoblast is generally the same as in Elasmobranchs.

The mesoblast in the hear becomes, according to Götte, divided into four segments, equivalent to the trunk somites. Owing to a confusion into which Götte has fallen from not recognizing the epiblastic origin of the eranial nerves, his statements on this head must, I think, be accepted with considerable reserve; but some part of liis segments appeats to correspond with the head-carities of Elasunobranchii.

Urodela. Scott and Osborn (No. II.4) have sluewn that in the Newt the mesoblast (tig. 75) is formed of two lateral plates, split off from the hypoblast, and that the rentral growth of these plates is largely effected by the conversion of yolk-cells into mesollast-cells. They lave further shewn that the notochord is formed of an axial portion of the liypoblast, as in the trunk becomes divided into a 
The hypoblast. There are no important points of difference in the relations of the hypoblast between the Anura and Urodela. The mesenteron, at the stage represented in fig. 7:3, forms a wide cavity lined dorsally by a layer of invaginated hypoblast, and ventrally by the yolk-cells. The hypoblast is continuous laterally and in front with the yolk-cells (figs. 72,74 and 75 ). At an earlier stage, when the mesenteron has a less definite form, such a continuity between the true hypoblast and the yolk-cells does not exist at the sides of the cavity.

The definite closing in of the mesenteron by the true hypoblast-cells commences in

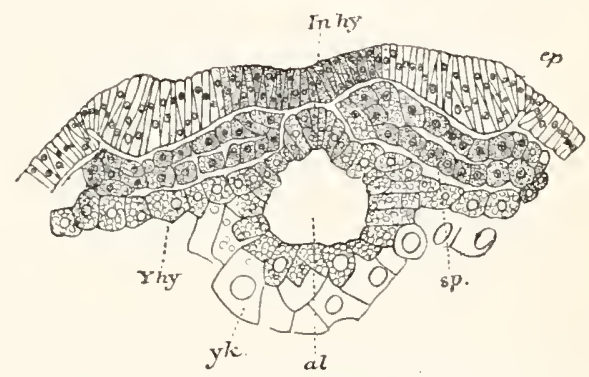

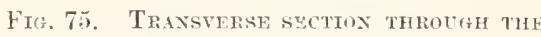

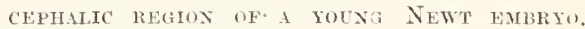
(After Scott and Osborn.)

In.hy. invaginated hypoblast, the dorsal part of which will form the notochord; ep. epiblast of neural plate; sp. splanclmopleure; al. ali mentary tract; $y k$. and $Y h y$. rolk-cells. front and behind, and takes place last of all in the middle (fig. 76 ). In front this process takes place with the greatest rapichity. The cells of the yolk-floor become continuously differentiated into hypoblast-cells, and rery soon the whole of the front end becomes completely lined by true hypoblastic cells, while the yolk-cells become confined to the floor of the middle part.

The front portion of the mesenteron gives rise to the oesophagus, stomach and duodenum. Close to its hinder boundary there appears a ventral outgrowth, which is the commencement of the hepatic diverticulum (fig. $\bar{\tau}(\mathrm{j}, \mathrm{l})$. The yolk is thus posthepatic, as in Vertebrates generally.

The stomodienm is formed comparatively late by an epiblastie invagination (fig. 76 , $m$ ).

It should be noticed that the conversion of the yolk-cells into hypoblast-cells to form the ventral wall of the anterior region of the alimentary tract is a closely similar occurrence to the formation of cells in the

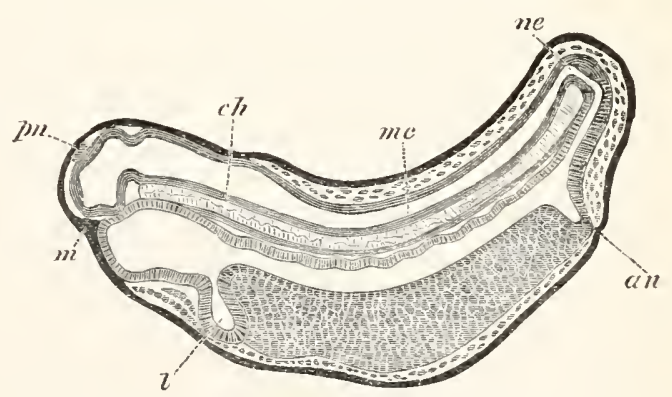

Fiar. 76. Longitedial section throvgh an aljraxced embrio of boubinator. (After Götte.)

$m$. mouth; an. anu;; l. liver; ne. neurenteric canal; me. medullary canal; $c h$. notochord; $\mathrm{m}$. pineal gland. yolk-floor of the anterior part of the alinentary tract in Elasmobranchii. 
This conversion is apparently denied by Götte, but since I find cells in all stages of transition between yolk-cells and hypoblast-cells I cannot doubt the fact of its occurrence.

At first, the mesenteron freely communicates with the exterior by the opening of the blastopore. The lips of the blastopore gradually approximate, and form a narrow passage on the dorsal side of which the neural tube opens, as has already been described (fig. 7:3). 'T'he external opening of this passage finally becomes obliterated, and the passage itself is left as a narrow diverticulum leading from the hind end of the mesenteron into the neural canal (fig. 76). It forms the post-anal gnt, and gradually narrows and finally atrophies. At its front border, on the ventral side, there may be seen a slight ventrally direeter diverticulum of the alimentary tract, which first becomes visible at a somewhat earlier stage ifig. 73). 'This diverticulım becomes longer and meets an invagination of the skin (fig. 76, an), which arises in Rana temporaria at a somewhat earlier period than representerl by Götte in Bombinator. This epiblastic invagination is the proctorlieum, and an anal perforation eventually appears at its upper extremity.

The differentiation of the hinder end of the præanal gut proceeds in the sane fashion as that of the front end, thongh somewhat later. It gives rise to the cloacal and intestinal part of the alimentary tract. From the ventral wall of the eloacal section, there grows out the bifid allantoic bladder, which is probably homologous with the allantois of the higher Vertebrata. After the differentiation of the ventral wall of the fore and hind ends of the alimentary tract has proceeded for a certain distance, the yolk only forms a Hoor for a restricted median region of the alimentary cavity, which corresponds to the umbilical canal of the Amniota. The true hypoblastic epithelium then grows over the onter side of the yolk, which thus constitutes a true, though small, and internal yolk-sack. The yolk-cells enclosed in this sack become gratually absorbed, and the walls of the sack form part of the intestine.

\section{General growth of the Embryo.}

Anura. The pyriform medullary plate, already described, is the first external inlication of the embryo. This plate appears about the stage represented in longitudinal section in fig. 7 ! B. The feature most conspicuous in it at first is the axial groove. It soon becomes more prominent (fig. $77 \mathrm{~A}$ ), and ends behind at the blastopore $(b l)$, the lips of which are continuous with the two medullary folds. As the sides of this plate bend upwards to form the closed medullary canal, the embryo elongates itself and assumes a somewhat oval form. At the sane time the cranial flexure becomes apparent (fig. 73), and the blastopore shortly afterwards becomes shut off from the exterior: The embryo now continnes to grow in length (fig. 77 B), and the mesoblast becomes segmented. The somites are first formed in the neck, and are adderl successively behind in the nusegmented 
posterior region of the embryo. out into a rounded prominence, which rapidly elongates, and becomes a well-marked tail entirely formed by the elongation of the post-anal section of the body. The whole body has a very decided dorsal flexure, the ventral surface being convex. Fig. 78 represents an embryo of Bombinator in side view, with the tail commencing to project. The longitudinal section (fig. 76) is taken through an embryo of about the same age. In the cephalic region important changes have taken place. The cranial flexure has become more marked, but is not so conspicuous a feature in the Amphibia as in most other types, owing to the small size of the cerebral rudiment. The mid-brain is shewn at fig. $78 a$ forming the termination of the long axis of the body, and the optic vesicles $\left(a^{\prime}\right)$ are seen at its sides.

The rudiments of the mandibular $(d)$, hyoid $(e)$, and first branchial $\left(e^{\prime}\right)$ arches project as folds at the side of the hearl, but the

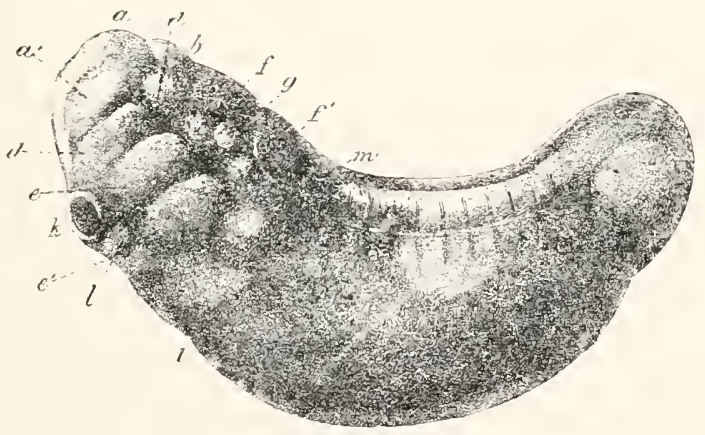

Fig. 78. Lateral view of an adrayced embryo of Bombinator. (After Götte.)

$a$. mid-brain ; $a$. eye; $b$. lind brain; $d$. mandibular arch; $d$. Gasserian ganglion; e. hyoid arch; $e^{\prime}$. first branclial arch; $f$. seventh nel've; $f^{\prime}$. glossopharyngesl and vagus nerve; $g$. anditory vesicle; $i$. boundary between liver and yolk-sack; $k$. suctorial disc; 1 . pericardial prominence; $m$. prominence formed by the pronephros.

visceral clefts are not yet open. Rudiments of the proctodæum and stomodæum have appeared, but neither of them as yet communicates with the mesenteron. Below the hyoid arch is seen a peculiar lise $(k)$ which is an embryonic suctorial organ, formed of a plate of 
thickened epiblast. There is a pair of these discs, one on each side, but only one of them is shewn in the figure. At a later periorl they meet each other in the middle line, though they separate again before their final atrophy. They are found in the majority of the Anura, but are absent according to Parker in the Aglossa (Pipa and Dactylethra (fig. 8:3)). They are probably remnants of the same primitive organs as the suctorial lise of Lepidosteus.

The embryo continues to grow in length, while the tail becomes more and more prominent, and becomes bent round to the side owing to the confinement of the larva within the egg membrane. At the front of the head the olfactory pits become distinct. The stomodrum deepens, though still remaining blind, and three fresh branchial arches become formed; the last two being very imperfectly differentiated, and not visible from the exterior. There are thus six

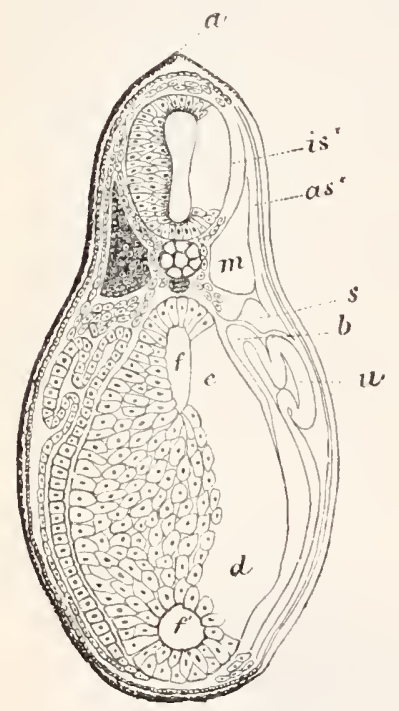

Fig. 79. Transverse secTHON THROUGH A VERT YOTNG TADPOLE OF BoMbinator at THE LEVEL OF THE ANTERIOR EXD OF THE YOLK-SACK. (Afıer Götte.)

a. fold of epiblast continuous with the dorsal fin; $i s^{\mathrm{x}}$. neural cord; $m$. lateral muscle; $a s^{\mathrm{x}}$. outer layer of muscle-plate; s. lateral plate of mesoblast; b. mesentery; $u$. fold of the peritoneal epithelium which forms the segmental duct; $f$. alimentary tract; $f^{\prime}$. ventral diverticulum which becomes the liver; $e$. juuction of yolkcells and hypoblast-cells; $d$. rolk.cells. arches in all, viz. the mandibular, the hyoid and four branchial arches. Between the mandibular and the hyoid, and between each of the following arches, pouches of the mesenteron push their way towards the external skin. Of these pouches there are five, there being no pouch behind the last branchial arch. The first of these will form the liyomandibular cleft, the second the hyobranchial, and the third, fourth and fifth the three branchial clefts.

Although the pouches of the throat meet the extemal skin, an external opening is not formed in them till after the larva is hatched. Before this takes place there grow, in the majority of forms, from the outer side of the first and second branchial arches small processes, each forming the rudiment of an external gill; a similar rudiment is formed, either before or after hatching, on the third arch; but the fourth arch is without it (figs. 80 and 82).

These external gills, which differ fundamentally from the external gills of Elasmobranchii in being covered by epiblast, soon elongate and form branched ciliated processes floating freely in the medium around the embryo (fig. 80 ).

Before hatching the excretory system begins to develop. The segmental duct is formed as a fold of the somatic wall at the dorsal side of the body cavity (fig. $79, u$ ). Its anterior end alone remains open to the bodycavity, and gives rise to a pronephros with 
two or three peritoneal openings, opposite to which a glomerulus is formed.

The mesonephros (permanent kidney of Amphibia) is formed as a series of segmental tubes much later than the pronephros, during late larval life. Its anterior end is situated some distance behind the pronephros, and during its formation the pronephros atrophies.

The period of hatching varies in different larvir, but in most cases, at the time of its occurrence, the mouth has not yet become perforated. The larva, familiarly known as a tadpole, is at first enclosed in the detritus of the gelatinous egg envelopes. The tail, by the development of a dorsal and ventral fin, very soon becomes a powerful swimming organ. Growth, during the period before the larva begins to feed, is no doubt carried on at the expense of the yolk, which is at this time enclosed within the mesenteron.

The mouth and aual perforations are not long in making their. appearance, and the tadpole is then able to feed. The sill slits also become perforated, but the hyomandibular direrticulum in nost species never actually opens to the exterior, and in all cases becomes very soon closed.

There can be but little doubt that the hyomandibular diverticulum gires rise, as in the Amniota, to the Eustachian tube and tympanic carity, except when these are absent (i.e. Bombinatoriare). Gütte holds however that these parts are derived from the liyobranchial cleft, but his statements on this head, which would involve us ingreat morphological diticulties, stand in direct contradiction to the careful researches of Parker.

Shortly after hatching, there grows out from the hyoid arch on each sicle an opercular fold of skin, which gradually covers over the posterior branchial arches and the external gills (fig. $80 d$ ). It fuses with the skin at the upper part of the gill arches, and also with that of the pericardial wall below them; but is free in the middle, and so assists in
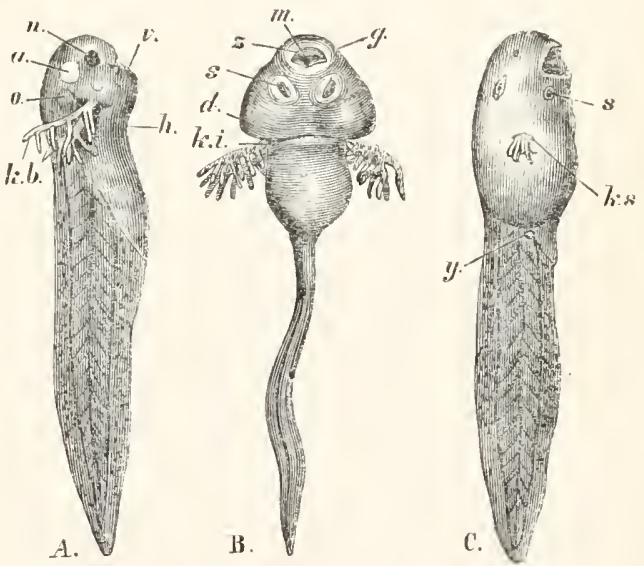

Fif. 80. Tadpoles with external braxchiæ. (From Huxley; after Ecker.)

A. Lateral view of a young tadpole.

B. Tentral view of a somewhat older tadpole.

$k \cdot b$. external branchire; $m$. moutl ; $n$. nasal sack: a. eye; $o$. auditory vesicle; $z$. horny jaws; $s$, ventral sucker; $\boldsymbol{a}$. opereular fold.

C. More advanced larra, in which the opereular fold has nearly corered the branchix.

$s$. ventral sucker; $h s$. external branchix; $y$. rudiment of hind limb. 
forming a cavity, known as the branchial cavity, in which the gills are placed. Each branchial cavity at first opens by a separate widish pore behind (fig. s0), and in Dactylethra both branchial apertures are preserved (Huxley). In the larva of Bombinator, and it would seem also that of Alytes and Pelodytes, the original widish openings of the two branchial chambers meet together in the ventral line,

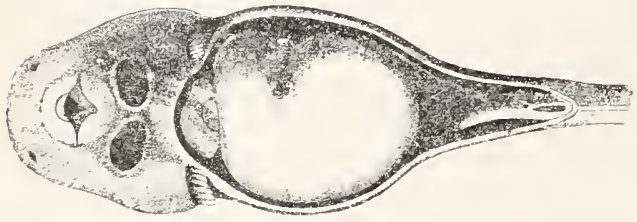

Fig: 81. Tadpole of Bonbinator from thie VENTRAL SIDE, WITH THE ABDOMINAL WALL REMOVED. (After Götte.)

Behind the mouth are placed the two snelers, and behind these are seen the gills projecting through the spiracles. at the mouth, passes through the branchial clefts into the branchial cavities, and is thence carried out by the spiracle.

Immediately after the formation of the branchial cavities, the original external gills atrophy, but in their place fresh gills, usually ealled internal gills, appear on the outer side of the middle region of the four branchial arches.

There is a single row of these on the first and fourth branchial arehes, and two rows on the second and third. In addition to these gills, which are vascular processes of the mesoblast, covered, according to Götte, with an epiblastic (?) epithelium, branchial processes appear on the hypoblastic walls of the three branchial clefts. The last-named branchial processes would appear to be homologous with the gills of Lanpreys. In Dactylethra no other gills but these are formed (Parker).

The mouth, even before the tadpole begins to feed, acquires a transversely oval form (fig. 81), and becomes armed with provisional structures in the form of a horny beak and teeth, which are in use duriug larval life.

The beak is formed of a pair of horny plates moulded on the upper and lower pair's of labial cartilages. The upper valve of the beak is the larger of the two, and covers the lower. The beak is surrounded by a projecting lip formed of a circular fold of slin, the free edge of which is covered by papillar. Between the papillae and the beak rows of horny teeth aro placed on the inner surface of the lip. There are usually two rows of these on the upper side, the imner one not continuous across the middle line, and three or four rows on the lower side, the inner one or two divided into two lateral parts.

As the tadpole attains its full development, the suctorial organs behind the mouth gradually atrophy. The alimentary canal, which is (fig. 81) at first short, rapidly elongates, and fills up with its 
numerous coils the large body cavity. In the meantime, the lungs develop as outgrowths from the osophagus.

Various features in the anatomy of the Tadpole point to its being a repetition of a primitive vertebrate type. The nearest living representative of this type appears to be the Lamprey.

The resemblance botween the mouths of the Tadpole and tamprey is very striking, and many of the peculiarities of the larval skull of the Anmia, especially the position of the Meckelian cartilages and the subocular arch, perhaps find their parallel in the skull of the Lamprey ${ }^{1}$. The internal hypoblastic gill-sacks of the Frog, with their branchial processes, are probably equivalent to the gill-sacks of the Lamprey ${ }^{2}$; and it is not impossible that the common posterior openings of the gill-pouches in Myxine are equivalent to the originally paired openings of the branchial sack of the Tadpole.

The resemblances between the Lamprey and the Tadpole appear to me to be sufficiently striking not to be merely the results of more or less similar habits; but at the same time there are no grounds for supposing that the Lamprey itself is closely related to an ancestral form of the Amphibia. In dealing with the Ganoids and other types arguments have been adduced to shew that there was a primitive vertebrate stock provided witl a perioral suctorial dise; and of this stock the Cyclostomata are the degraded, but at the same time the nearest living representatives. The resemblances between the Tadpole and the Lamprey are probably due to both of them being descended from this stock. The Ganoils, as we have seen, also shew traces of a similar descent; and the resemblance hetween the larva of Dactylethra (fig. 8:3), the Old Red Sandstone Gamoids ${ }^{3}$ and Chimera, probably indicates that an extension of our knowledge will bring to light further affinities between the primitive Ganoid and Holocephalous stocks and the Amphibia.

Metamorphosis. The change undergone by the Tadpole in its passage into the Frog is so considerable as to deserve the name of a metamorphosis. This metamorphosis essentially consists in the reduction and atrophy of a series of provisional embryonic organs, and the appearance of adult organs in their place. The stages of this metamorphosis are shewn in fig. $82,5,6,7, S$.

The two pairs of limbs appear nearly simultaneously as small buds; the himder pair at the junction of the tail and body (fig. 82, 5), and the anterior pair concealed under the opercular membrane. The lungs acquire a greater and greater importance, and both branchial and pulmonary respirations go on together for some time.

When the adult organs are sufficiently developed an ecdysis takes place, in which the gills are completely lost, the provisional horny beak is thrown off, and the mouth loses its suctorial form. The eyes, hitherto concealed under the skin, become exposed on the

3 Vide Huxley, "Craniofacial apparatus of Petromyzon." Journal of Anat. and Phys., Vol. x. 1876. Huxley's views awont the Heckelian arch, etc., are plansible, but it seems probable from Scott's observations that true branchial bars are not developed in the Lamprey. How far this fact necessarily disproves Huxley's views is still doubtful.

¿ Conf. Huxley and Götte.

3 Cf. Parker (No. Io7).

B. E. II. 
surface, and the front limbs appear (fig. 82,6 ). With these external changes important internal modifications of the mouth, the vascular system, and the visceral arches take place.

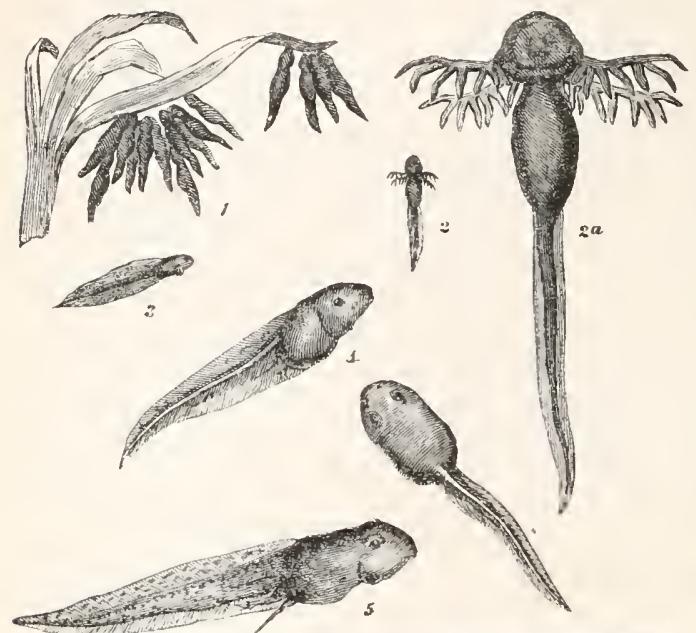

A gradual atrophy of the tail, commencing at the apex, next sets in, and results in the complete absorption of this organ.

The long alimentary canal becomes shortened, and the, in the main, herbivorous Tadpole gradually becomes converted into the carnivorous Frog (fig. 82, 6, 7, 8).

The above description of the metamorphosis of the Frog applies fairly to the majority of the Anura, but it is necessary to notice a few of the more instructive divergences from the general type.

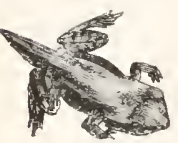

5

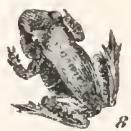

Fig. 82. Tadpoles and young of the comion Frog, (From Mivart.)

1. Recently-hatched Tadpoles twice the natural size. 2. Tadpole with external gills. 2a. Same enlarged. 3 and 4. Later stages after the enclosure of the gills by the opercular membrane. 5. Stage with well-developed hind-limbs visible. 6. Stage after the ecdysis, with both pairs of limbs visible. 7. Stage after partial atrophy of the tail. 8. Young Frog. acquires within the egg a long tail; but while Bavay ${ }^{1}$ states that it is jrovided with external gills, which however are not covered by an operculum, Peters ${ }^{2}$ was unable to see any traces of such structures.

In Pipa Americana, and apparently in Pipa dorsigera also if a distinct species, the larva leaves the cells on the back of the mother in a condition closely resembling the adult. The embryos of both species develop a long tail in the egg, which is absorbed before hatching, and according to WVyman ${ }^{3}$

I Annal. de Sciences Nat., 5th Series, Vol. xviı., 1873.

2 Berlin. Monatsbericht, 1876, p. 703, and Nature, April 5, 1877.

3 Proceed. of Boston Nat. Hist. Society, Vol. v., 1854. 
P. Americana is also temporarily provided with gills, which atrophy early.

The larva of Rhinoderma Darwinii is stated by Jiminez de la Espada to be without external gills, and it appears to be hatched while still in the laryngeal pouch of the male. In Nototrema marsupiatum the larve are also stated to be without external gills.

Amongst the forms with remarkable developments Pseudis paradoxa deserves especial mention, in that the tadpole of this form attains an immensely greater bulk than the adult; a peculiarity which may be simply a question of nutrition, or may perhaps be explained by supposing that the larva resembles a real ancestral form, which was much larger than the existing Frog.

Another form of perhaps still greater morphological interest is the larva of Dactylethra. The ehief peculiarities of this larva (fig. 83) have been summarized by Parker (No. 107, p. 626), from whom I quote the following passage :

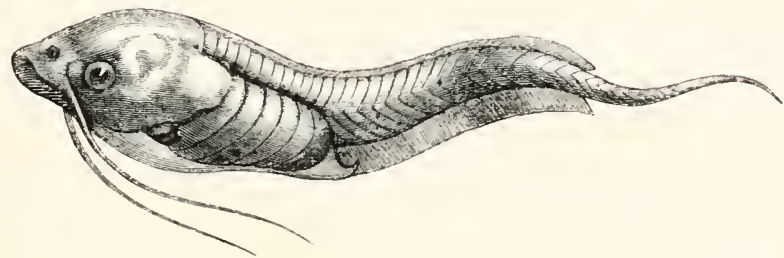

Fig. 83. Larva of Dactylethra. (After Parker.)

a. "The mouth is not inferior in position, suctorial and small, but is very wide like that of the 'Siluroids and Lophius;' has an underhung lower jaw, an immensely long tentacle from each upper lip, and possesses no trace of the primordial horny jaws of the ordinary kind.

b. "In conformity with these characters the hear is extremely flat or depressed, instead of being high and thick.

c. "There are no claspers beneath the chin.

d. "The branchial orifice is not confined to the left side, but exists on the right side also.

e. "The tail, like the skull, is remarkably chimæeroid; it terminates in a long thin pointed lash, and the whole candal region is narrow and elongated as compared with that of our ordinary Batrachian larve.

$f$. "The fore-limbs are not lidden beneath the opercular fold."

Although nost Anurous embryos are not provided with a sufficient amount of yolk to give rise to a yolk-sack as an extemal appendage of the embryo, yet in some forms a yolk-sack, nearly as large as that of 'T'eleostei, is developed. One of these forms, Alytes obstetricans, belongs to a wellknown European genus allied to Pelobates. The embryos of Pipa dorsigera (Parker) are also provided with a very large yolk-sack, round which they are coiled like a Teleostean embryo. A large yolk-sack is also developed in the embryo of Pseudophryne australis.

The actual complexity of the organization of different tadpoles, and their relative size, as compared with the adult, vary considerably. The 
tadpoles of Toads are the smallest, Psendophryne australis excelling in this respect; those of Pseudis are the largest known.

The external gills reach in certain forms, which are hatched in late larval stages, a very great development. It seems however that this development is due to these gills being especially required in the stages before hatching. Thus in Alytes, in which the larva leaves the egg in a stage after the loss of the external gills, these structures reach in the egg a very great development. In Notodelphis ovipara, in which the eggs are carried in a dorsal pouch of the mother, the embryos are provided with long vesicular gills attached to the neck by delicate threads. The fact (if confirmed) that some of the forms which are not hatched till post-larval stages are without external gills, probably indicates that there may be various contrivances for embryonic respiration ${ }^{1}$; and that the external gills only attain a great development in those instances in which respiration is mainly carried on by their means. The external gills of Elasmobranchii are probably, as stated in a previous chapter, examples of secondarily developed structures, which have been produced by the same causes as the enlarged gills of Alytes, Notodelphis, etc.

Urodela. Up to the present time complete observations on the development of the Urodela are confined to the Myctodera2.

The early stages are in the main similar to those of the Anura. The body of the embryo is, as pointed out by Scott and Osborn, ventrally instead of dorsally flexed. 'The metamorphosis is much less complete than in the Anura. The larva of Triton may be taken as typical. At hatching, it is provided with a powerful swimming tail bearing a well-developed fin: there are three pairs of gills placed on the three anterior of the true branchial arches.

Between the hyoid and first branchial arch, and between the other branchial arches, slits are developed, there being four slits in all. At the period just before hatching, only three of these have made their appearance. The hyomandibular cleft is not perforated. Stalked suckers, of the same nature as the suckers of the Anura, are formed on the ventral surface behind the mouth. A small opercular fold, developed from the lower part of the hyoid arch, covers over the bases of the gills. The suctorial mouth and the provisional horny beak of the Anura have no counterpart in these larvæ. 'The skin is ciliated, and the cilia canse a rotation in the egg. Even before hatching, a small rudiment of the anterior pair of limbs is formed, but the hind-limbs are not developed till a later stage, and the limbs do not attain to any size till the larva is well advanced. In the course of the subseguent metamorphosis lungs become developed, and a pulmonary respiration takes the place of the branchial one. The branchial slits at the same time close and the branchiæ atrophy.

${ }_{1}^{1}$ In confirmation of this view it may be mentioned that in Pipa Americana the tail appears to function as a respiratory organ in the later stages of development (Peters).

2 The recent observations on this subject are those of Scott and Osborn (No. II ) on Triton, of Bambeke (No. 95) on various species of Triton and tire Axoloti, and of Clark (No. 98) on Amblystoma punctatum. 

Newt.

The other types of Myctodera, so far investigated, agree fairly with the

The larva of Amblystoma punctatum (fig. 8t) is provided with two very long processes $(s)$, like the suctorial processes in Triton, placed on the throat in firont of the external gills. They are used to support the larva when it sinks to the bottom, and have been called by Clark (No. 98) halancers. On the development of the limbs, these processes drop off. The external gills atrophy about one hundred days after hatching.

It might have been anticipated that the Axolotl, being a larval form of Amblystoma, would agree in development with Amblystoma punctatum. The conspicuous suctorial processes of the latter form are however represented by the merest rudiments in the Axolotl.

The young of Salamandia maculata leave the uterus with external gills, but those of the Alpine Salamander (Salamandra atra) are born in the fully developed condition without gills. In the uterus they pass through a metamorphosis, and are provided (in accordance with the principle already laid down) with rery long gill-filaments ${ }^{1}$.

Salamandra atra has only two embryos, but there are originally a larger number of eggs ( $T$ on Siehold), of which all but two fail to develop, while their remains are nsed as pabulum by the two which survive. Both species of Salamander have a sufficient quantity

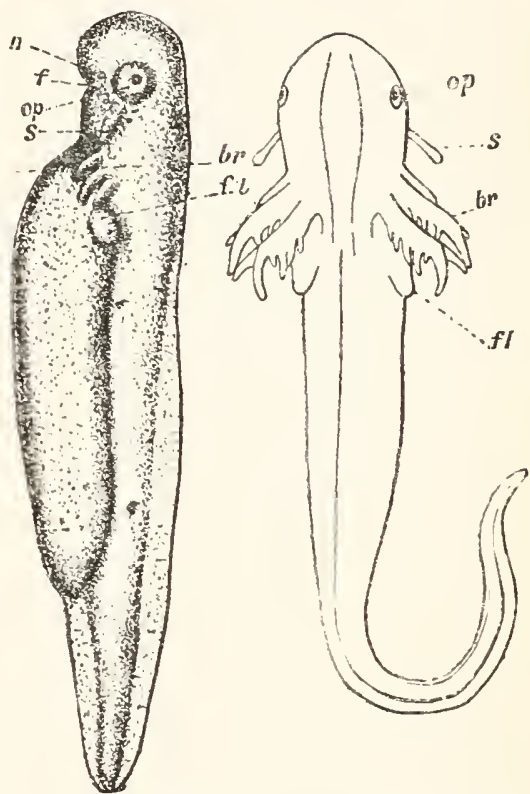

Fig, 8t, Linye of Amblistoma PenctaTux. (After Clark.)

n. nasal pit; $f$. oral invagination; op. eye; $s$. balancers; f.l. front limb; br. branchire. of food-yolk to give rise to a yolk-sack.

Spelerpes only develops three post-hyoid arches, between which slits are formed as in ordinary types. Henobranchus and Proteus agree with Spelerpes in the number of post-hyoid arches.

One of the most remarkable recent discoveries with reference to the metamorphosis of the Urodela was made by Dumeril ${ }^{2}$. He found that some of the larve of the Axolotl, bred in the Jardin des Plantes, left the water, and in the course of about a fortnight underwent a similar metamorphosis to that of the Newt, and became converted into a form agreeing in every particular with the American genus Amblystoma. During this

1 Allen Thomson informs me that the crested Newt, Triton cristatus, is in rare instances viviparous.

" Comptes Rendus, 1870, p. 782. 
metamorphosis a pulmonary respiration takes the place of a branchial one, the gills are lost, and the gill-slits close. The tail loses its fin and becomes rounded, the colour changes, and alterations take place in the gums, teeth, and lower jaw.

Madlame von Chauvin ${ }^{1}$ was able, by gradually accustoming Axolotl larva to breathe, artificially to cullse them to undergo the above metanorphosis.

It seems very possible, as suggested by Weismann ${ }^{2}$, that the existing Axolotls are really descendants of Amblystoma forms, which lave reverted to a lower stage. In favour of this possibility a very interesting discovery of Filippi's ${ }^{3}$ may be cited. He found in a pond in a marsh near Andermat some examples of Triton alpestris, which, though they had become sexually mature, still retained the external gills and the other larval characters. Similar sexually mature larval forms of 'Triton treniatus have been described by Jullien. These discoveries would seem to indicate that it might be possible artificially to cause the Newt to revert to a peremniblanchiate condition.

Gymnophiona. The development of the Gymnophiona is almost unknown, but it is certain that some larval forms are provided with a single gill-cleft. while others have exterual gills.

$\Lambda$ gill-cleft has been noticed in Epicrium glutinosum (Miiller), and in Cocilia oxymra. In Coecilia compressicauda, Peters (No. IO8) was unable to find any trace of a gill-cleft, but he observed in the larva within the uterus two elongated vesicular gills.

\section{Bibliography.}

\section{Amphibia.}

(93) Ch. van Bambeke. "Recherches sur le développement du Pélobate brun." Mémoires couronnés, etc. de l'Acad. roy. de Belgique, 1868.

(94) Ch. van Bambeke. "Recherches sur l'embryologie des Batraciens." Bulletin de l'Acad. roy. de Belgique, 1875.

(95) Ch. van Bambeke. "Nouvelles recherches sur l'embryologie des Batraciens." Archices de Biologie, Vol. 1. 1880.

(96) K. E. von Baer. "Die Metamorphose des Eies der Batrachier." Müller's Archiv, 1834.

(97) B. Benecke. "Ueber die Entwicklung des Erdsalamanders." Zoologischer Anzeiger, 1880.

(๑s) S. F. Clarke. "Development of Amblystoma punctatum," Part I., External. Studies from the Biological Laboratory of the Johns Hopkins University, No. 11. 1880.

(99) H. Cramer. "Bemerkungen üb. d. Zellenleben in d. Entwick. d. Froscheies." Müller's Archiv, 1848.

(100) A. Ecker. Icónes Plysiolog. 1851-1859.

(ror) A. Götte. Die Entwicklungsgeschichte der Unke. Leipzig, 1875.

(102) C. K. Hoffmann. "Amphibia." Klassen u. Ordnungen d. Thierreich", $1873-1879$.

(103) T. H. Huxley. Article "Amphibia" in the Encyclopadia Britannica.

(ro+) A. Moquin-Tandon. "Déreloppement des Batraciens anures." Annales des Sciences Naturelles, 11J. 1875.

1 Zeit.f. uiss. Zool., Bd. xxvir., 1876.

2 Zeit.f. wiss. Zool., Bd. xxv., sup. 1875.

a Archivio per la Zoologia, l' dnatomia e la Fisiologia, Vol. 1. Genoa, 1861. Conf. also Von Siebold, "Ueber die geschlechtliche Entwicklung d. Urodelen-Larven." Zeit.f. wiss. Zool., Bd, xxv111, 1877. 
(105) G. Newport. "On the impregnation of the Ovum in Amphibia" (three memoirs). Phil. Trans. 1851, 1853, and 185t.

(106) W. K. Parker. "On the structure and development of the Skull of the common Frog." Plil. Trans., cuxi. 1871.

( $\left.\mathrm{IO}_{7}\right)$ W. K. Parker. "On the structure and development of the Skull of the Batracbia." Phil. Trens., Vol. cxuvi., Part 2. 1876.

(ro8) W. C. H. Peters. "Ueber die Entwicklung der Coecilien und besonders von Coecilia compressicauda." Berlin. Monatsbericht, p. 40, 1874.

(rog) TV. C. H. Peters. "Ueber die Entwicklung der Coecilien." Berl. Monatsbericht, p. $483,1875$.

(гіо) J. L. Frevost and J. B. Dumas. "Deuxième Mém. s. l. génération. Développement de l'ouf d. Batraciens." A $\mathrm{mm}$. Sci. Nut. II. $182 t$.

(I1I) R. Remak. Untersuehungen über die Entwieklung der Wirbelthiere, 18501858 .

(II2) Mr. Rusconi. Développenent de la grenonille eommune depuis le moment de sa naisáance jusqu'í son état parfait, 1826 .

(rз) MI. Rusconi. Histoire naturelle, développement et métamorphosc de la Salamandre terrestre, 1854.

(I 4 ) W. B. Scott and H. F. Osborn. "On the early development of the common Newt." Quart. J. of Hier. Scienee, Vol. xxix. 1879.

(1 I5) S. Stricker. "Entwicklungsgeschichte ron Bufo einereus." Sitzb. der kaiserl. Acad. zu Wien, 1860.

(I16) S. Stricker. "Untersuchungen über die ersten Anlagen in BatrachierEiern." Zeitschrift f. wiss. Zoologie, Bd. xI. 1861. 


\section{CHAP'TER VIII.}

AVES.

INTRODUCTION.

The variations in the character of the embryonic development of the Amniota are far less important than in the case of the Ichthyopsida. There are, it is true, some very special features in the early developmental history of the Mammalia, but apart from these there is such a striking uniformity in the embryos of all the groups that it woukl, in many cases, be difficult to assign a young embryo to its proper class.

Amongst the Sauropsida the Aves have for obvious reasons received a far fuller share of attention than any other group; and an account of their embryology forms a suitable introduction to this part of our subject. For the convenience of the student many parts of their developmental history will be dealt with at greater length than in the case of the previous groups.

\section{The development of the Aves.}

Comparatively few types of Birds have been studied embryologically. The common Fowl has received a disproportionately large share of attention; although within quite recent times the Duck, the

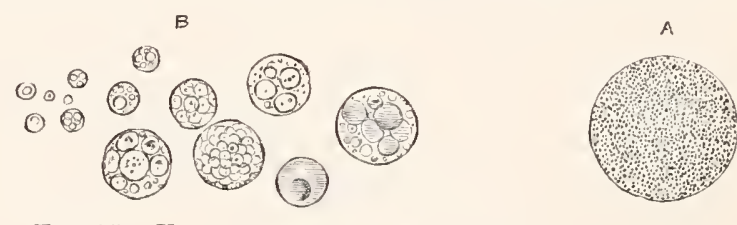

Fic. 85. Yolk elements from the egti of the Fowl.

A. Yellow yolk. B. White yolk.

Goose, the Pigeon, the Starling, and a Parrot (Melopsittacus undulatus) have also been studied. The result of these investigations has been to shew that the variations in the early development of different Birds are comparatively unimportant. In the serquel the common 
Fowl will be employed as type, attention being called when necessary to the development of the other forms.

The ovum of the Fowl, at the time when it is clasped by the expanded extremity of the oviduct, is a large yellow body enclosed in a vitelline membrane. It is mainly formed of spherules of food-yolk. Of these there are two varieties; one known as yellow yolk, and the other as white. The white yolk spherules form a small mass at the centre of the ovum, which is continued to the surface by a narrow stalk, and there expands into a somewhat fumnel-shaped disc, the edges of which are continued over the surface of the ovum as a delicate layer. The major part of the ovum is formed of yellow yolk. The yellow yolk consists of large delicate spheres, filled with small granules (fig. 8.5 A); while the white yolk is formed of vesicles of a smaller size than the yellow yolk spheres, in which are a variable number of higbly refractive bodies (fig. $85 \mathrm{~B}$ ).

In addition to the yolk there is present in the ovum a small protoplasmic region, containing the remains of the germinal vesicle, which forms the germinal disc (fig. 86). It overlies the funnel-shaped disc

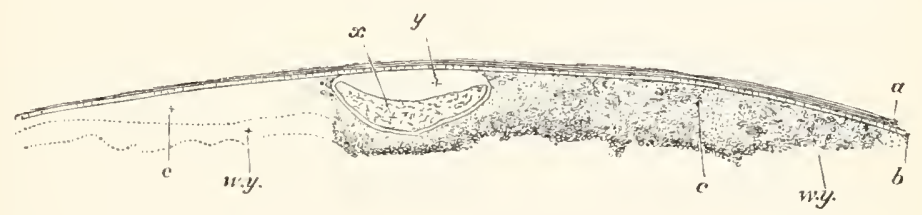

Fig. 86. Section throvgh the germinal disc of the mipe ovarian ovum of a FOWL WHILE YET ENCLOSED IN ITS CAPSULE.

a. Connective-tissue capsule of the ovum; $b$. epithelium of the capsule, at the surface of which nearest the ovum lies the vitelline membrane; $c$. granular material of the germinal dise, which becomes converted into the blastoderm. (This is not very well represented in the woodeut. In sections which have been hardened in chromic acid it consists of fine granules.) w. w. white yolk, which passes insensibly into the fine granular material of the disc; $x$. germinal vesicle enclosed in a distinct membrane, but shrivelled up; $\%$. space originally completely filled up by the germinal vesicle, before the latter was shivelled up.

of white yolk, into which it is continued without any marked line of demarcation. It contains numerous minute spherules of the same nature as the smallest white yolk spherules.

Impregnation takes place at the upper extremity of the oviduct.

In its passage outwards the ovum gradually receives its accessory coverings in the form of albumen, shell-membrane, and shell (fig. 87).

The segmentation commences in the lower part of the oviduct, shortly before the shell has begun to be formed. It is meroblastic, being confined to the germinal disc, through the full depth of which however the earlier furrows do not extend. It is mainly remarkable for being constantly somewhat unsymmetrical (Kölliker) -a feature which is not represented in fig. 88, copied from Coste. 
Owing to the absence of symmetry the cells at one side of the ger-

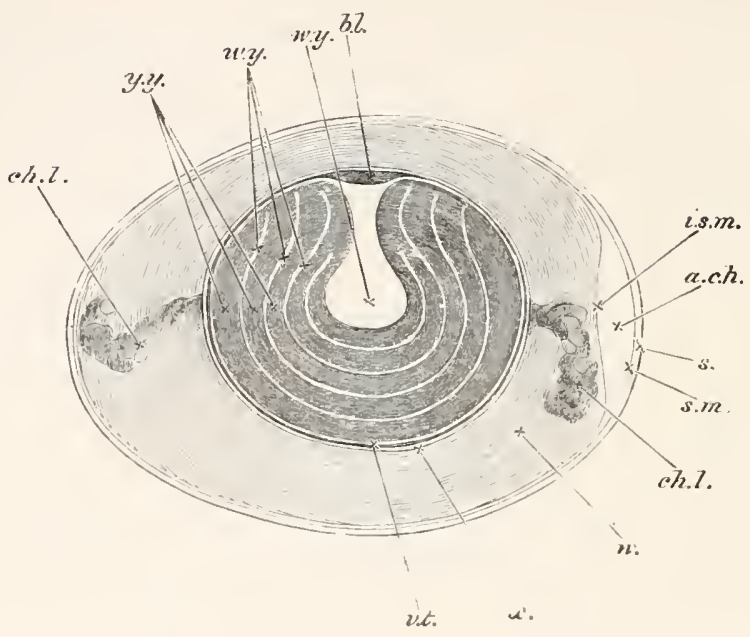

Fig. 87. Diagramiatic section of an enincubated Fowl's ege.

(Modified from Allen Thomson.)

bl. blastoderm; $w . y$. white yolk. This consists of a central flask-shaped mass and a number of layers concentrically arranged around it. y.y. yellow yolk; v.t. vitelline membrane; $x$. layer of more fluid albumen immediately surrounding the yolk; w. albumen consisting of alternate denser and more fluid layers; ch.l. chalaza; a.ch. air-chamber at the broad end of the egg. This chamber is merely a space left between the two layers of the shell-membrane. i.s.m. internal layer of shell-membrane; $s . m$. external layer of shell-membrane; $s$. shell.

minal disc are larger than those at the other, but the relations between

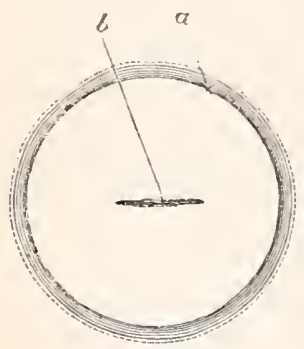

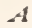

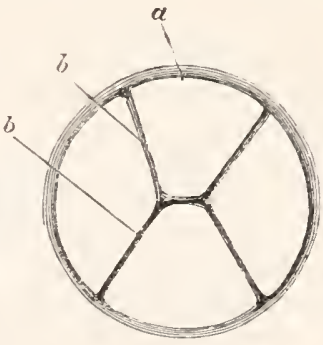

B

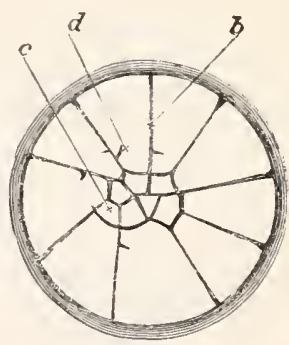

C

Fig. 88. Surface views of the early stages of the segmentation in a Fowl's egg. (After Coste.)

$a$. edge of germinal disc; $b$. vertical furrow; $c$. small central segment; $d$. larger peripheral segment.

the disc and the axis of the embryo are not known. During the later stages the segmentation is irregular, and not confined to the surface; and towards its close the germinal disc becomes somewhat lenticular 
in shape; and is formed of segments, which are smallest in the centre and increase in size towards the periphery (fig. 89 and 90$)$. The superficial segments in the centre of the germinal disc are moreover smaller than those below, and more or less separated as a distinct layer (fig. 90). As development proceers the segmentation reaches its linits in the centre, but continues at the periphery; and thus eventually the masses at the periphery become of the same size as those at the centre. At the time when the ovum is laid (fig. 91) the uppermost layer of segments has given rise to a distinct membrane, the epiblast, formed of a
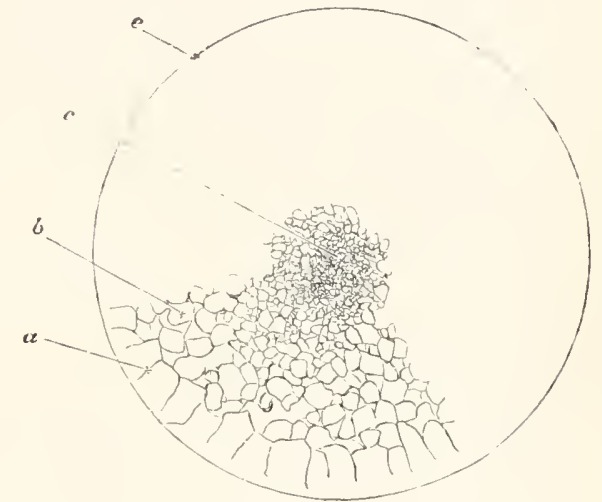

Fig. 89. SURFACE VIEW OF the GERMINAL DISC of Fowl's EgG DURiNg a Late Stage of the SEgIENTATION.

$c$. small central segmentation spheres; $b$. larger segments outside these; $a$. large, imperfectly circumscribed, marginal segments; $e$. margin of germinal dise.

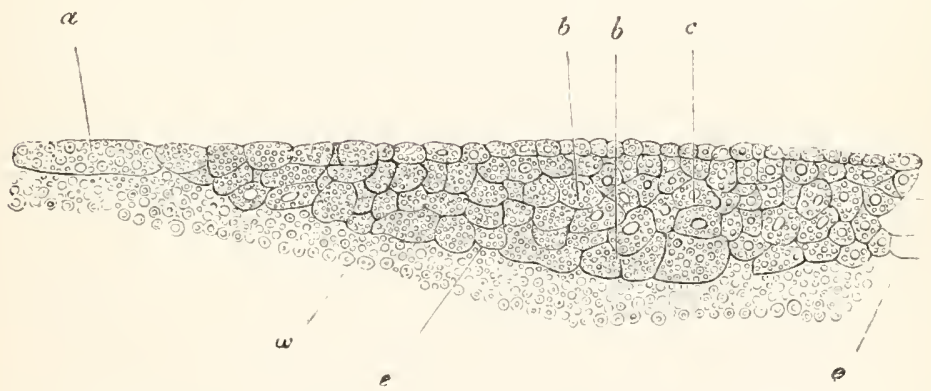

Fig. 90. Section of the germinal disc of a Fow derivg the later stages OF SEgMeNTation.

The section, which represents rather more than half the breadth of the blastoderm (the midlle line being shewn at $c$ ), shews that the upper and central parts of the disc segment faster than those below and towards the periphery. At the periphery the segments are still very large. One of the larger segments is shewn at $a$. In the majority of segments a nucleus can be seen; and it seems probable that the nucleus is present in them all. Most of the segments are filled with highly refracting spherules, but these are more numerous in some cells (especially the larger cells near the yolk) than in others. In the ceutral part of the blastoderm the upper cells have commenced to form a distinct layer. No segmentation cavity is present.

a. large peripheral cell; $b$. larger cells of the lower parts of the blastoderm; c. middle line of blastoderm; $e$. edge of the blastoderm adjoining the white yolk; $w$. white yolk. 
single row of columnar cells $(e p)$. The lower or hypoblast segments are larger, in some cases very much larger, than those of the epiblast, and are so granular that their nuclei can only with difficulty be seen. They form a somewhat irregular mass, several layers deep, and thicker at the periphery than at the centre: they rest on a bed of white yolk, from which they are in parts separated by a more or less developed cavity, which is probably filled with fluid yolk matter about to be absorbed. In the bed of white yolk nuclei are present, which are of the same character, and have the same general fate, as

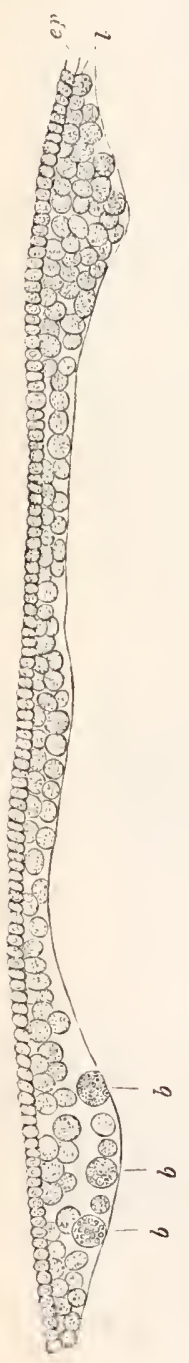

Fig. 91. Section of a blastoderi of a Fowl's egg at the COMMENCEMENT OF INCUBATION.

The thin epiblast ep composed of columnar cells rests on the incomplete lower layer $l$, composed of larger and more granular hypoblast cells. The lower layer is thicker in some places than in others, and is especially thick at the periphery. The line below the under layer marks the upper surface of the white yolk. The larger so-called formative cells are seen at $b$, lying on the white yolk. The figure does not take in quite the whole breadth of the blastoderm; but the reader must understand that both to the right hand and to the left $e p$ is continued farther than $l$, so that at the extreme edge it rests directly on the white yolk.

those in Elasmobranchii. They are generally more numerous in the neighbourhood of the thickened periphery of the blastoderm than elsewhere. Peculiar large spherical bodies are to be found amongst the lower layer cells, which superficially resemble the larger cells around them, and have been called formative cells [vide Foster and Balfour (No. I26)]. Their real nature is still very doubtful, and though some are no doubt true cells, others are perhaps only nutritive masses of yolk. In a surface view the blastoderm, as the segmented germinal lisc may now be called, appears as a circular disc; the central part of which is distinguished from the peripheral by its greater transparency, and forms what is known in the later stages as the area pellucida. The narrow darker ring of blastoderm, outside the area pellucida, is the commencing area opaca.

As a result of incubation the blastoderm undergoes a series of changes, which end in the definite furmation of three germinal layers, and in the establishment of the chief systems of organs of the embryo. The more important of these changes are accomplished in the case of the common Fowl during the first day and the early part of the second day of incubation.

There is hardly any question in development which has been the subject of so much controversy as the mode of formation of the germinal layers in the common Fowl. The differences in the views of authors have been caused to a 
large extent by the difficulties of the investigation, but perhaps still more by the fact that many of the observations were made at a time when the methods of making sections were very inferior to those of the present day. The snbject itself is by no means of an importance commensurate with the attention it has received. The character's which belong to the formation of the layers in the Samropsida are secondarily derived from those in the Ichthyopsida, and are of but little importance for the general questions which concern the nature and origin of the germinal layers. In the account in the sequel I have aroided as much as possible discussion of controverted points. My statements are founded in the main on my own observations, more especially on a recent investigation carried on in conjunction with my pupil, $M_{r}$ Deighton. It is to Killiker (No. I3.5), and to Gasser (No. I 27 ) that the most important of the nore recent alvances in our knowledge are due. Kölliker, in his great work on Embryology. definitely established the essential connection between the primitive streak and the formation of the mesoblast; but while contiming lis statement on this head, I am obliged to differ from him with reference to some other points.

Gasser's work, especially that part of it which relates to the passages leading from the neural to the alimentary canal, which he was the first to discover, is very valuable.

The blastoderm gradually grows in size, and extends itself over the yolk; the growth over the yolk being very largely effected by an increase in the size of the area opaca, which during this process becomes more distinctly marked off from the area pellucida. The area pellucida gradually assumes an oval form, and at the same time becomes divided into a posterior opaque region and an anterior transparent region. The posterior opacity is named by some authors the embryonic shield.

During these changes the epiblast (fig. 92) becomes two layers deep over the greater part of the area pellucida, though still only one cell deep in the area opaca. The irregular hypoblast spheres of the unincubated blastoderm flatten themselves out, and mite into a definite hypoblastic membrane (fig. 92). Between this membrane
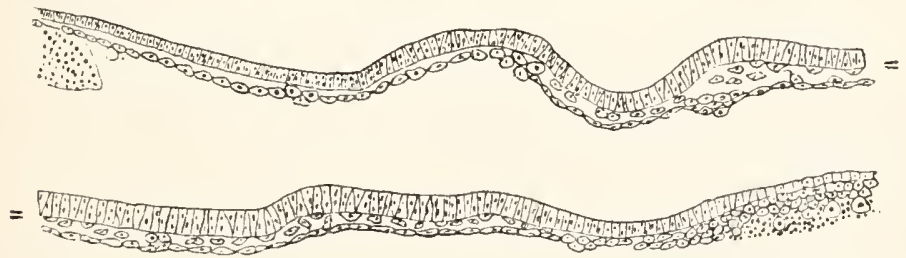

Fia. 92. Transverse section throcgh the buastoderis OF a CHICK Before THE APPEARANCE OF THE PRIMTIVE STREAK.

The epiblast is represented somewhat diagrammatically. The hyphens shew the points of junction of the two halves of the section.

and the epiblast there remain a number of scattered cells (fig. 92) which cannot however be said to form a definite layer altogether distinct from the hypoblast. 'They are almost entirely confined to 
the pusterior part of the area pellucida, and give rise to the opacity of that part.

At the edge of the area pellucida the hypoblast becomes continuous with a thickened rim of material, underlying the epiblast, and derived from the orginal thickened edge of the blastoderm and the subjacent yolk. It is mainly formed of yolk granules, with a varying number of cells and nuclei imbedded in it. It is known as the germinal wall, and is spoken of more in detail on pp. 132 and 133 .

The changes which next take place result in the complete differentiation of the embryonic layers, a process which is intimately con-

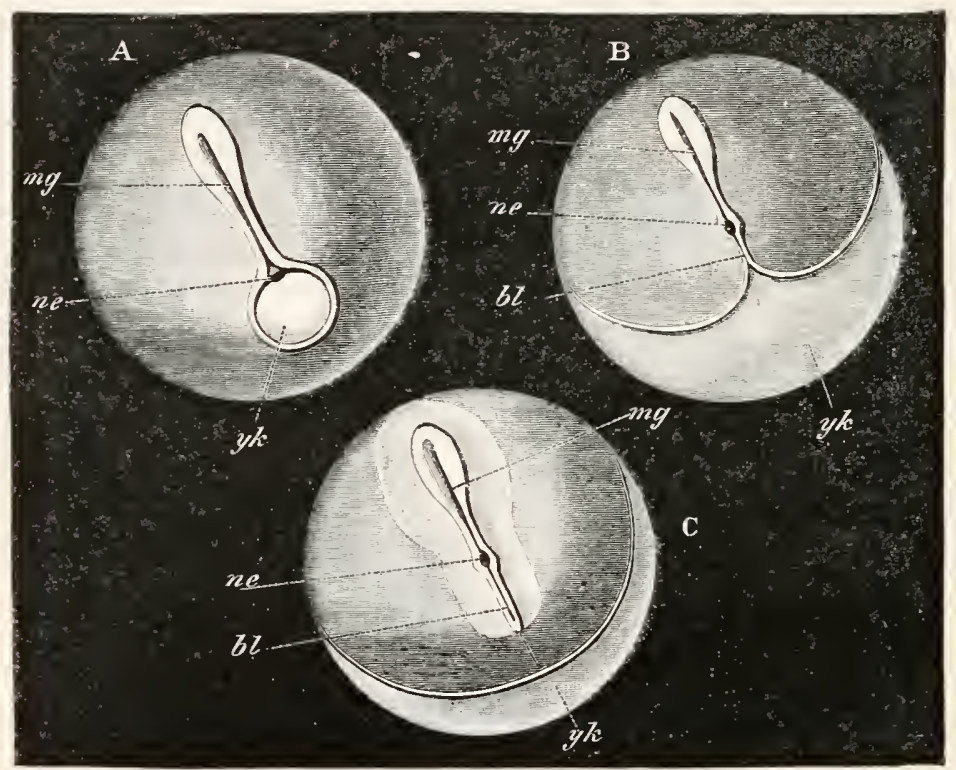

Fig. 93. Diagrams illestrating the position of the blastopore, and the relation OF THE EMBRYO TO THE YOLK IN VARIOUS MEROBLASTIC VERTEBRATE OVA.

A. Type of Frog. B. Elasmobranch type. C. Amniotic Vertebrate.

$m g$. medullary plate; ne. neurenteric canal; $b l$. portion of blastopore adjoining the neurenteric canal. In B this part of the blastopore is formed by the edges of the blastoderm meeting and forming a linear streak behind the embryo; and in $\mathrm{C}$ it forms the structure known as the primitive streak. $y k$. part of yolk not yet enclosed by the blastoderm.

nected with the formation of the structure known as the primitive streak. The meaning of the latter structure, and its relation to the embryo, can only be understood by comparison with the derelopment of the forms already considered. The most striking peculiarity in the first formation of the embryo Bird, as also in that of the embryos of all Amniota, consists in the fact that they do not occupy a position at the edge of the blastoderm, but are placed near its centre. Behind the embryo there is however a peculiar structure-the primitive streak above men- 
tioned-which is a linear body placed in the posterior region of the blastoderm. This body, the nature of which will be more fully explained in the chapter on the comparative development of Vertebrates, is really a rudimentary part of the blastopore, of the same nature as the linear streak behind the embryo in Elasmobranchii formed by the concrescence of the edges of the blastoderm (vide p. 52); although there is no ontogenetic process in the Amniota, like the concrescence in Elasmobranchii. The relations of the blastopore in Elasmobranchii and Aves is shewn in figs. $\mathrm{B}$ and $\mathrm{C}$ of the diagram (fig. 9:3).

In describing in detail the succeeding changes we may at first confine our attention to the area pellucida. As this gradually assumes an oval form the posterior opacity becomes replaced by a very dark median streak, which extends forwards some distance from the posterior border of the area (fig. 94). This is the first rudiment of the primitive streak. In the region in front of it the blastoderm is still formed of two layers only, but in the region of the streak itself the structure of the blastoderm is greatly altered.

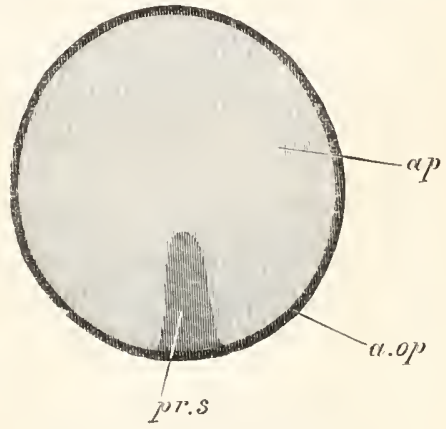

Fig. 94. Area pellucida of a VERY YOUNG BLASTODERM OF A CHICK, SHEWING THE PRIMHTIVE STREAK AT ITS FIRST APPEARANCE.

pr.s. primitive streak; ap. area pellucida; a.op. area opaca. The most important features in it are

represented in fig. 9.5. This figure shews that the median portion of the blastoderm has become very much thickened (thus producing the opacity of the primitive streak), and that this thickening is caused

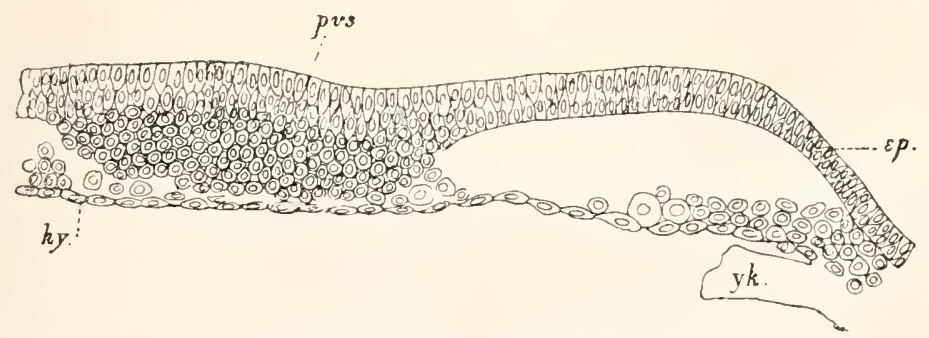

Fig. 95. Transverse section throdgh a blastoderm of about the age represented IN FIG. 94, SHEWING THE FIRST DIFFERENTIATION OF THE PRIMITIVE STREAK.

The section passes through about the middle of the primitive streak. pvs. primitive streak; $e p$. epiblast; $h y$. hypoblast; $y k$. yolk of the germinal wall.

by a proliferation of rounded cells from the epiblast. In the very young primitive streak, of which fig. 95 is a section, the rounded cells are still continuous throughout with the epiblast, but they form nevertheless the rudiment of the greater part of a sheet of mesoblast, which will soon arise in this region. 
In addition to the cells clearly derived from the epiblast, there are certain other cells (vide fig. 95), closely adjoining the hypoblast, which appear to me to be the derivatives of the cells interposed between the epiblast and hypoblast, which gave rise to the posterior opacity in the blastoderm during the previous stage. In my opinion these cells also have a share in forming the future mesoblast.

The number and distribution of these cells is subject to not inconsiderable variations. In a fair number of cases they are entirely congregated along the line of the primitive streak, leaving the sides of the blastoderm quite free. They then form a linyer, which can ouly with difficulty be distinguished from the cells derived from the epiblast by slight peculiarities of staining, and by the presence of a considerable proportion of large granular cells. It is, I believe, by the study of such blastoderms that Kölliker has been led to deny to the intermediate cells of the previons stage any share in the formation of the mesolbast. In other instances, of which fig. 95 is a fairly typical example, they are more widely scattered. To follow with absolute certainty the listory of these cells, and to prove that they join the mesoblast is not, I believe, possible by means of sections,

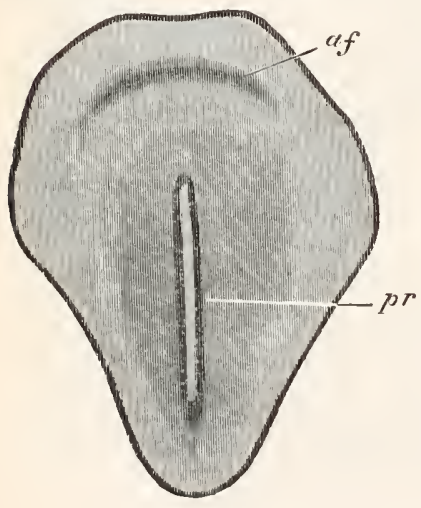

Fig. 96. Surface view of The AREA PEILUCIDA OF A CHACK'S RLASTO. DERM SIORTLY AFTER THE FORALATON OF THE PRIMITIVE GROOVE.

$p r$ primitive streak with primitive groove; af. amniotic fold.

The darker shading round the primitive streak shews the extension of the mesoblast. and I must leave the reader to judge how far the evidence given in the sequel is sufficient to justify my opinions on this subject.

In the course of further growth the area pellucida soon becomes pyriform, the narrower extremity being the posterior. The primitive streak (fig. 96) elongates considerably, so as to occupy about two-thirds of the length of the blastoderm; but its hinder end in many instances does not extend to the posterior border of the area pellucida. The median line of the primitive streak becomes marked by a shallow groove, known as the primitive groove.

During these changes in extemal appearance there grow from the sides of the primitive streak two lateral wings of mesoblast cells, which gradually extend till they reach the sides of the area pellucida (fig. 97). The mesoblast still remains attached to the epiblast along the line of the primitive streak. During this extension many sections through the primitive streak give an impression of the mesoblast being involuted at the lips of a fold, and so support the view above propounded, that the primitive streak is the rudiment of the coalesced lips of the blastopore. The hypoblast below the primitive streak is always quite independent of the mesoblast above, though much more closely attached to it in the median line than at 
the sides. The part of the mesoblast, which I believe to be deriverl

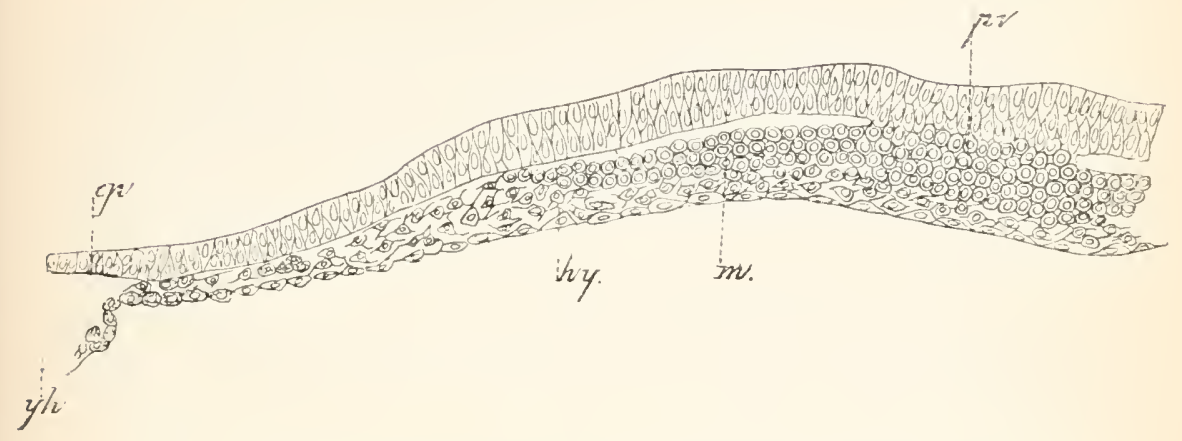

Fig. 97. Transverse gection throvgh the front end of the prinitive STREAK OF A BLASTODERM OF TIIE SAME AGE AS FIG. 96.

$p r$. primitive groove; $m$. mesoblast; $p p$. epiblast; hy. hypoblast; $y h$. yolk of germinal wall.

from the primitive hypoblast, can generally be distinetly traced. In many cases, especially at the front end of the primitive streak, it forms, as in fig. 97, a distinct layer of stellate cells, quite unlike the rounded cells of the mesoblastic involution of the primitive streak.

In the region in front of the primitive streak, where the first trace of the embryo will shortly appear, the layers at first undergo no important changes, except that the hypoblast becomes somewhat thicker. Soon, however, as shewn in longitudinal section in fig. 98. the hypoblast along the axial line becomes eontinuous behind with the front end of the primitive streak. Thus at this point, which is the future hind pr: $s$

$c p$

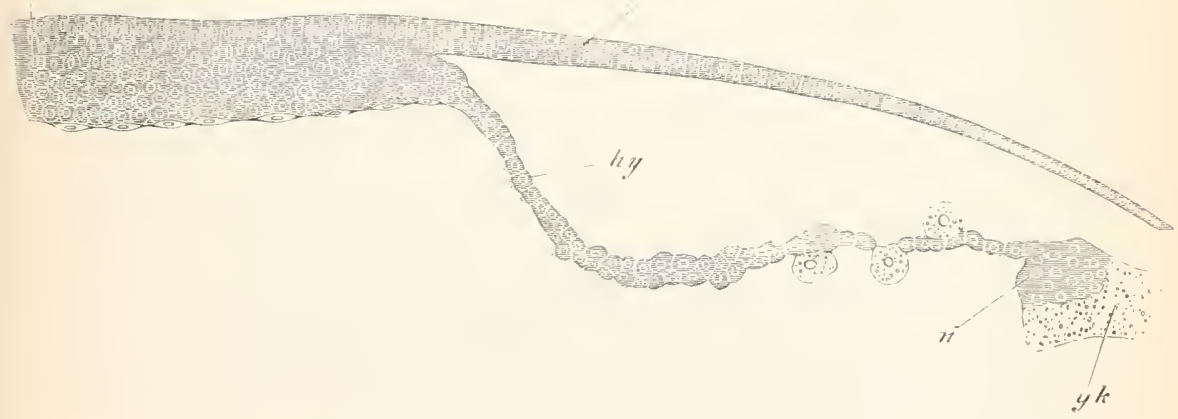

Fig. 98. Longitudinal section throtgh the axial line of the primtive STREAK, AND THE PART OF THE BLASTODERM IN FRONT OF IT, OF AN EMBRYO CHICK SOMEWHAT YOUNGER THAN FIG. 99.

$p r . s$. primitive streak; ep. epiblast; $h y$. hypoblast of region in front of primitive streak; $n$. nuclei; $y k$. yoik of germinal wall.

B. E. II. 
end of the embryo, the mesoblast, the epiblast, and the hypoblast all unite together ; just as they do in all the types of Ichthyopsida.

Shortly afterwards, at a slightly later stage than that represented in fig. 96, an important change takes place in the constitution of the hypoblast in front of the prinitive streak. The rounded cells, of which it is at first composed (fig. 9S), break up into (1) a layer formed of a single row of more or less flattened elements below-the hypoblastand (2) into a layer formed of several rows of stellate elements, between the hypoblast and the epiblast-the mesoblast (fig. 99). A separation between these two layers is at first hardly apparent, and before it has become at all well marked, especially in the median line, an axial opaque line makes its appearance in surface views, continued forwards from the front end of the primitive streak, but stopping short at a

in

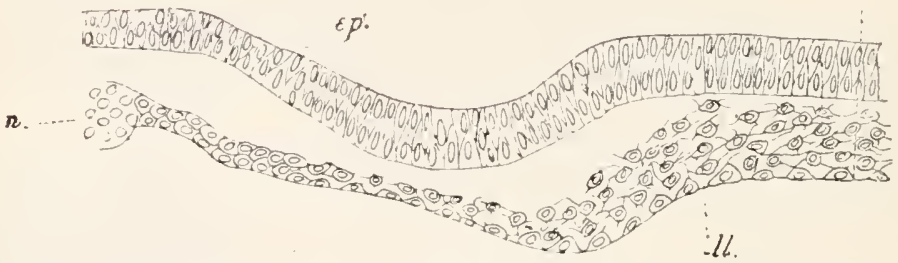

Fig. 99. Transverse section tmovor the embryonic region of the blastoDERA OF A CHICK SHORTLY PRIOR TO THE FORMATION OF THE MEDULLARY GROOVE ANI NOTOCHORD.

$m$. median line of the section; ep. epiblast; 1.I. lower layer cells (primitive hypoblast) not yet completely differentiated into mesoblast and hypoblast; n. nuclei of germinal wall.

semicircular fold-the future head-fold-near the frout end of the area pellucida. In section (fig. 100) this opaque line is seen to be due to a special concentration of cells in the form of a cord. This cord is the commencement of the notochord $(c h)$. In some instances the conmencing notochord remains attached to the hypoblast, while the mesoblast is laterally quite distinct (vide fig. 100), and is therefore formed in the same manner as in most Ichthyopsida; while in other instances, and always apparently in the Goose (Gasser, No. 127), the notochord appear's to become differentiated in the already separated layer of mesoblast. In all cases the notochord and the hypoblast below it unite with the front end of the primitive streak; with which also the two lateral plates of mesoblast become continuous.

From what has just been said it is clear that in the region of the embryo the mesoblast originates as two lateral plates split off from the hypoblast, and that the notochord originates as a median plate, simultaneously with the mesoblast, with which it may sometimes be at first continuous.

Kölliker holds that the mesoblast of the region of the embryo is derived from a forward growth from the primitive streak. There is no theoretical objection to this view, and 1 think it would be impossible to 
shew for certain by sections whether or not there is a growth snch as he

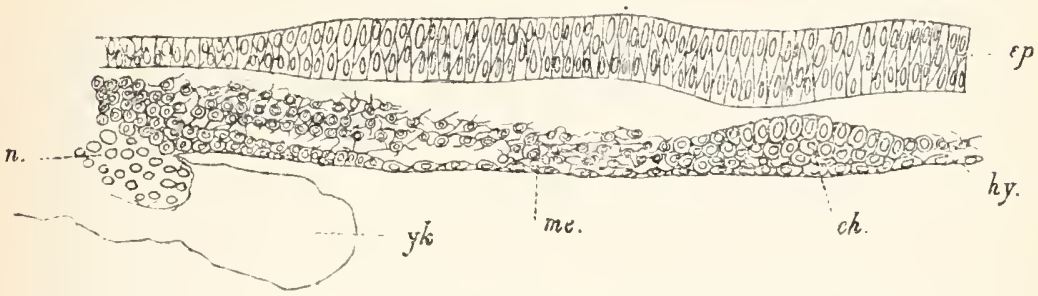

Fig. 100. Transverse SECIION THRoUgh THE FMBRLONIC REglON OF THE BLASTODERM OF A CHICK AT THE TIME OF TIE FORMATION OF THE NOTOCHORD, BUT BEFORE TIIE, APPEARANCE OF THE MEDTLLARY GROOVE.

ep. epiblast; hy. hypoblast; ch. notochord; me. mesoliast; $n$. nuelei of the genninal wall $y k$.

describes; lnt such sections as that represented in fig. 99 (and I lave series of similar sections from several embryos) appear to me to be conclu. sive in favour of the view that the mesoblast of the region of the embyo is to a large extent derived fiom a diflerentiation of the primitive hypoliant. I an however inclined to believe that some of the mesoblast cells of the embryonic region have the derivation which Kolliker ascribes to all of then.

As regards the mesollast of the primitive streak, in a purely objective description like that given above, the greater part of it may fairly be described as being derived from the epiblast. But if it is granted that the primitive streak corresponds with the blastopore, it is obrious to the com. parative embryologist that the mesoblast derived from it really originates from the lips of the blastopore, as in so many other cases; and that to describe it, witlout explanation, as arising from the epiblast, wonld give an erroneous impression of the real uature of the process.

'The differentiation of the embryo may be said to commence with the formation of the notochord and the lateral plates of mesoblast. Very shortly after the formation of these structures the axial part of the epiblast, above the notochord and in front of the primitive streak, which is somewhat thicker than the lateral parts, becomes differentiated into a distinct medullary plate, the sides of which form two

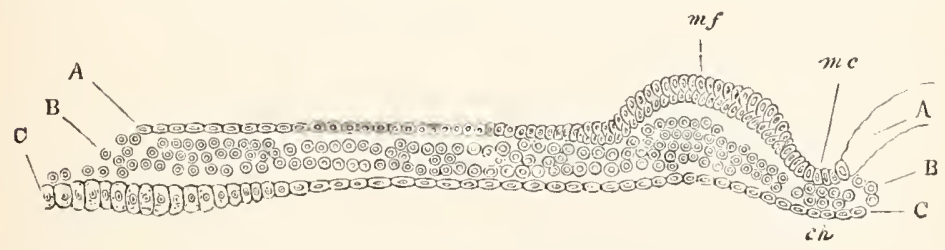

Fig. 101. Thansterse sectiun OF a blastoderd ixcubated fol 18 hodrs.

The section passes through the medullary groove me, at some distance behind its front end.

A. epiblast. B. mesoblast. C. hypoblast.

m.c. medullary groove; m.f. medullary fold; ch. notochord. 
fulds-the medullary folds-enclosing between them a medullary groove (fig. 101).

In front the two medullary folds meet, while posteriorly they thin out and envelop between them the front end of the primitive streak. On the formation of the medullary folds the embryo assumes a form not unlike that of the embryos of many Ichthyopsida at a corresponding stage. The appearance of the embryo, and its relation to the surrounding parts is sonewhat diagrammatically represented in

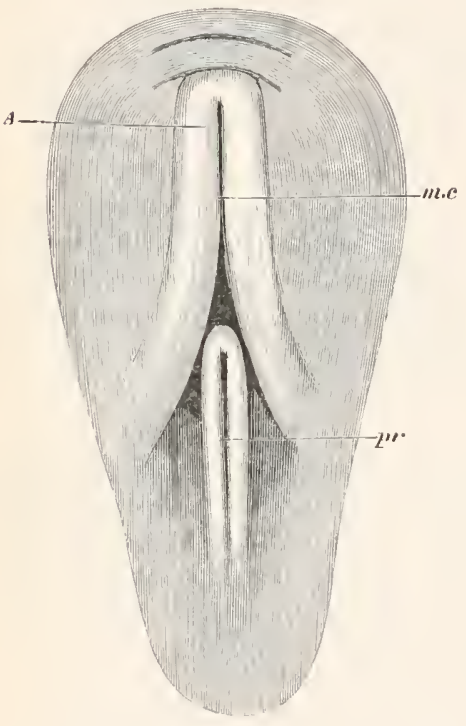

F1g. 102. Strface V1EW OF THE PELIUCID AREA OF A MLASTODERM OF 18 HONRS.

None of the opaque area is shewn, the pear-shaped outline indicating the limits of the pellucid area.

At the hinder part of the area is seen the primitive groove $p r$, with its nearly parallel walls, fading away behind, but curving round and meeting in front so as to form a distinct anterior termination to the groove, about halfway up the pellucid area.

Above the primitive groove is seen the mednllary groove m.c., with the melullary folds $\mathrm{A}$. These, diverging behind, shope away on either side of the primitive groove, while in front they curve round and meet each other close upon a curved line which represents the headfold.

The second curred line in frout of and coneentric witl the first is the commencing fold of the amnion. fig. 102. The prinitive streak now ends with an anterior swelling (not represented in the figure), and is usually somewhat unsymmetrical. In most cases its axis is more nearly continuous with the left, or sometimes the right, nedullary fold than with the medullary groove. In sections its front end appears as a ridge on one side or on the middle of the floor of the widened end of the medullary groove.

The mesoblast and hypoblast, within the area pellucida, do not give rise to the whole of these two layers in the surrounding area opaca; but the whole of the hypoblast of the area opaca, and a large portion of the mesoblast, and possibly even some of the epiblast, take their origin from the peculiar material already spoken of, which forms the germinal wall, and is continuous with the hypoblast at the edge of the area opaca (vide figs. 91, 94, 97, 98, 99, 100).

The exact nature of this material las been the subject of many controversies. Into these controversies it is not my purpose to enter, but subjoined are the results of my own examination. The germinal wall first consists, as already mentioned, of the lower cells of the thickened edge of the blastoderm, and of the subjacent yolk material with nuclei. During the period before the formation of the primitive streak the epiblast extenrls itself over the yolk, partly, it appears, at the expense of the cells of the 
germinal wall, and possibly even of cells formed aromul the nuclei in this part. 'This mode of growth of the epiblast is rery similar to that in the epibolic gastrulas of many Invertebrata, of the Lamprey, etc; but how far this process is continued in the subsequent extension of the epiblast I an unable to say. The cells of the germinal wall, which are at first well separated from the yolk below, become gradually absorbed in the growth of the hypoblast, and the remaining cells and yolk then become mingled together, and constitute a compound structmre, continuous at its inner border with the hypoblast. This structure is the germinal wall nsually so described. It is mainly formed of yolk grannles with numerous muclei, and a sumewhat variable number of largish cells imbedded annongst them. The nuclei typically form a special layer immerliately below the epiblast, some of which are probably enclosed by a definite cell-body. A special mass of nuclei (vide figs. 98 and $100, n$ ) is ustully present at the junction of the hypoblast with the germinal wall.

The germinal wall at this stage corresponds in many respects with the granular material, forming a ring below the edge of the blastorlem in Teleostei.

It retains the characters above enumerated till near the close of the first day of incubation, i.e. till several mesoblastic somites hare hecome established. It then becomes more distinctly separated from the subjacent yolk, and its component parts change very considerably in character. The whole wall becomes much less granular. It is then mainly formed of large vesicles, which often assume a palisade-like arrangement, and contain granular balls, spherules of white yolk, and in an early stage a gool deal of granular matter (vile fig. 115). These bolies have some resemblance to cells, and have been regarded as such by Kölliker (No. I 35) and Virchow (No. I50) : they contain however nothing which can he considered as a nucleus. Between them however nuclei may easily be seen in specimens hardened in picric acid, and stained with hamatoxylin (these nuclei are not shewn in fig. 115). These nuclei are about the same size as those of the hypoblast cells, and are surrounded by a thin layer of granulat protoplasm, which is continuous with a meshwork of granular protoplism enveloping the above described vesicles. The germinal wall is still continuous with the hypoblast at its edge; and close to the junction of the two the hypoblast at first forms a layer of moderately columnar cells, one or two deep and directly continuons with the germinal wall, and at a later period usually consists of a mass of romiler cells lying above the sonewhit abrupt inner edge of the germinal wall.

The germinal wall certainly gives rise to the hypoblast cells, which mainly grow at its expense. They arise at the edge of the area pellucida, and when first formed are markedly columnar, and cnclose in their protoplasm one of the smaller vesicles of the germinal wall.

In the later stages (fomth day and onwarts) the whole germinal wall is stated to break "1p into columnar hypolblast cells, each of them mainly formed of onc of the vesicles just spoken of. After the commencing formation of the embryo the mesoblast liecomes estalilished at the inner edre of the area opaca, between the germinal wall and the epiblast; and

I The presence of numerous nuclei in the germinal wall was, I believe, first clearly proved by His (No. 132). I camnot however accept the greater number of his interpretations. 
gives rise to the tissue which eventually forms the area vasculusa. It seems pobable that the mesoblast in this situation is manly derived from cells formed aromul the nuclei of the germinal wall, which are usually specially agcregated rlose below the epiblast. Disse (No. 122) has especially brought evidence in favom of this view, and my own observations also smpport it.

The mesoblastic somites begin to be formed in the lateral plates of the mesoblast before the chosure of the medullary folds. The first somite arises close to the foremost extremity of the primitive struak, but the next is stated to arise in front of this, so that the first formed somite corresponds to the second permanent vertebra ${ }^{2}$. The region of the embryo in front of the seennd formed somite-at first the largest part of the embryo-is the ceplalic region. The somites following the second are formed in the regular manner, from before backwards, ont of the musegmunted posterior part of the cubryo. which rapilly grows in length to supply the necessary material (fig. 10:3). As the somites retain during the early stages of development an approximately constant breadth, their number is a fair test of the lenoth of the trunk. With the growth of the embryo the primitive streak is eontinually carried back, the length. ening of the embryo always taking place between the front end of the primitive streak and the last somite; and during this process

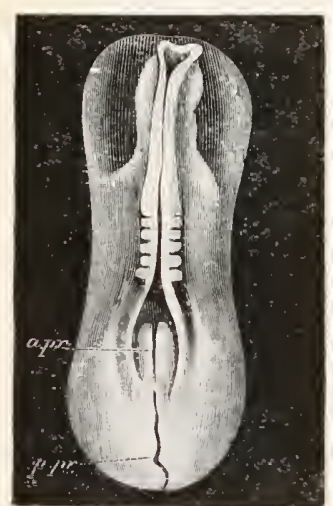

Fig. 10:3. DoIsAL VISW OF THE HARDENED BLASTODEKM OF A CHICK WITH F1VE MESOELASTIC SOMITIS. THE MEDTLLAFY FOLDS HAIE MET FOR PART OF THEIR EXTENT, BUT HAVE NOT UNITED.

a.pr. auterior part of the primitive streak; $p \cdot p r$. posterior part of the primitive streak. the primitive streak undergoes important clanges both in itself and in its relation to the embryo. Its anterior thicker part, which is enveloped in the diverging medullary folds, soon becomes distinguished in structure from the part behind this, and placed symmetrically in relation to the axis of the embryo (fig. 103, $(t . p)^{\circ}$ ), and at the same time the nedullary folds, which at first simply diverge on each sile of the primitive streak, bend in again and meet behind so as completely to enclose the front part of the primitive streak. The region of the embryo bird, where the medullary folds diverge, is known as the sinus rhomboidalis, thongh it las no connection with the similarly named structure in the adult. By the time that ten somites are formed the sinus rhomboida! is is completelyestablished, and the medullary groove has become converter into a tube till close up to the front end of the simus. In the following stages the closmre of the medullary canal extends to the sinns rhomboidalis, and the folding

1 Further investigatious in confirmation of this widcly accepted statement are very revirable. 
off of the hind end of the embryo from the yolk commences. Coincidently with the last-named changes the sides of the front part of the primitive streak become thickened, and give rise to conspicuous caudal swellings; in which the layers of the embryo are indistinguishably fused. The apparently hinder part of the primitive streak becomes, as more particularly explained in the seyuel, folded downwards and forwards on the ventral side.

This is a convenient place to notice remarkahle appearances which present themselves close to the junction of the neural plate and the primitive streak. These are temporary passages leading from the hinder end of the neural tube into the alimentary canal. They vary somewhat in different species of birds, and it appears that in the same species there may be several openiugs of the kind, which appear one after the other and then close again. They were first discoreled by Gasser (No. 127). In all cases ${ }^{1}$ they lead round the posterior end of the notochord, or through the point where the notochord falls into the primitive streak.

If the primitive streak is, as I believe, formed of the lips of the blastopore, there can be but little doubt that these structures are disappearing, and functionless rudiments of the opening of the blastopore, and they thus lend sujport to my view as to the nature of the primitive streak. That, in part, they correspond with the nementeric canal of the Ichthyopsida is clear from the detailed statements helow. Till their relations have been more fully worked ont it is not possible to give a more definite explanation of them.

According to Praun (No. I 20) three independent conmunications are to be distinguished in Birds. These are hest developed in the Duck. 'The first of these is a small fummel-shaped diverticulum leading from the neural groove through the lypoblast. It is visible when eight mesoblastic somites are present, and soon disappears. The second, which is the only one I have myself investigated, is present in the embryo duck with twenty-six mesoblastic somites, and is represented in the series of sections (fig. 104). The passage leads obliquely backwards and ventralwards from the hind end of the neural tube into the notochord, where the latter joins the prinitive streak (B). A narrow diverticulum from this passage is continued forwards for a short distance along the axis of the notochord $(\mathrm{A}, c h)$. After traversing the notochord, the passage is continued into a hypoblastic diverticulum, which opens ventrally into the future lumen of the alimentary tract $(\mathrm{C})$. Shortly behind the point where the neurenteric passage communicates with the neural tube the latter strncture opens dorsally, and a groove on the surface of the primitive streak is continmed backwards fiom it for a short distance (C). The first part of this passage to appear is the hypoblastic diverticulum above mentioned.

This passage does not long remain open, but after its closure, when the tail-end of the embryo has become folded off from the yolk, a third passage is established, and leads round the end of the notochord from the closed medullary canal into the post-anal gut. It is shewn diagrammatically in fig. 106, ne, and, as may be gathered from that figure, has the same relations as the nementeric canal of the Ichthyopsida.

1 This does not appear to be the ease with the anterior opening in Melop:ittacus monlatus, though its relations are not clear from Braun's description (No. 120). 
In the goose a passige has been described by Gasser, which alpears when about fourtern or fifteen somites are present, and lasts till twenty-
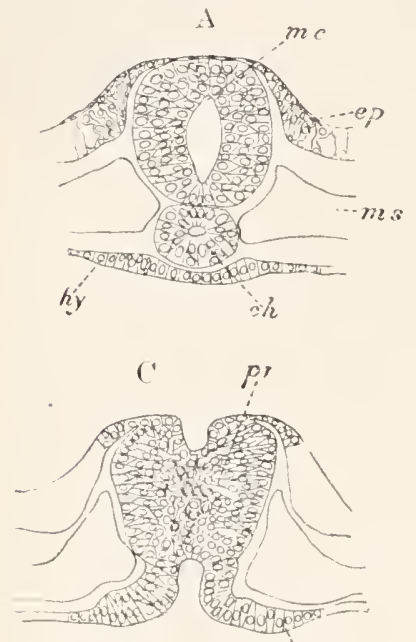

hy
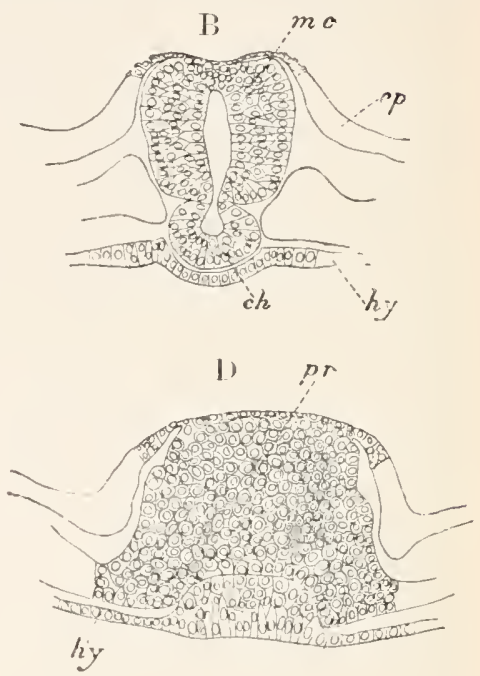

Fig. 104. Fuer transperse sections throdgh the neurentelic passage aNi, ADJOINING PARTS IN A DUCK EMBRYO WITH TWENTY-SIX MESOBLASTIC SOMITES.

A. Section in front of the neurenteric canal shewing a lumen in the notochord.

B. Section through the passage from the medullary eanal into the notochord.

C. Section shewing the luypoblastic opening of the neurenteric canal, and the groove on the surface of the primitive streak, which opens in front into the medullary canal.

1. Primitive streak immediately belind the opening of the neurenteric passage.

me. medullary canal; ep. epiblast; hy. hypoblast; ch. notochord; pr. primitive streak.

three are formed. Behind its opening the medullary canal is continued back as a small diverticulum, which follows the course of the primitive groove and is apparently formed hy the conversion of this groove into a canal. It is at first open to the exterior, but soon becomes closed, and then atroplies.

In the chick there is a perforation on the floor of the neural canal, which is not so marked as those in the goose or duck, and never results in a complete continuity between the neural and alimentary tracts; but simply leads from the floor of the neural canal into the tissues of the tail-swelling, and thence into a cavity in the posterior part of the notochord. The hinder diverticulum of the neural canal along the line of the primitive groove is, moreover, very considerable in the chick, and is not so soon obliterated as in the goose. The incomplete passage in the click arises when about twelve somites are present. It is regarded by Braun as equivalent to the first formed passage in the duck, but I very nuch doubt whether there is a very exact equivalence between the openings in different types, and think it more probable that they are variable remmants of a primitive neureuteric canal, which in the ancestors of those forms persisted 
through the whole period of the early development. The third passage is formed in the chick (Kupfter) during the third day of incubation. In Melopsittacus undulatus the two first communications are stated by Braun (No. I 20) to be present at the same time, the one in front of the other.

It is probable, from the above clescription, that the front portion of the primitive streak in the bird corresponds with that part of the lips of the blastopore in Elasmobruuchii which becomes converted into the tail-swelling and the lining of the neurenteric canal; while the original groove of the front part of the primitive streak aplears to be converted into the posterior. diverticulum of the neural canal. The hinder part of the primitive streak of the bird corresponds, in a very general way, with the part of the blastopore in Elasmobranchii, which shuts off the embryo firom the erge of the blastoderm (vide P. 5.2), though there is of course no genetic relation between the two structures. When the anterior part of the streak is becoming converted into the tail-swelling, the groove of the posterior part gradnally shallows and finally disappears. The hinder part itself atrophies from behind forwarks, and in the couse of the folding off of the embryo from the yolk the part of the blastoderm where it was placed becomes folded in, so as to form part of the ventral wall of the embryo. 'The apparent hinder. part of the primitive streak is therefore in reality the ventral and anterior. jart'.

It has generally been maintained that the prinitive streak aud groove become wholly converted into the dorsal portion of the trunk of the embryo, i.e. into the posterior part of the medullary plate and subjacent struetures. This view appears to me mntenable in itself, and quite ineompatible with the interpretation of the primitive streak given above. To shew how inmobable it is, apart from any theoretical considerations, I have compiled two tables of the relative lengths of the primitive streak and the body of the embryo, measured by the number of sections made throngh them, in a series of examples from the lata in Gasser's important memoir (No. 1 27 ). In these tables cach horizontal line relates to a single embryo. The first coluron shews the number of somites, and the second the number of sections through the primitive streak. Where the primitive streak becomes divided into two parts the sections thongh the two parts are given separately: the left colum (A) referring to the anterior part of the streak; the right column $(\mathrm{P})$ to the posterior part. The third colmmn gives the number of sections through the embryo. The first table is for fowl embryos, the second for goose embryos.

1 This nomenclature may seem a little paradoxical. But on reflection it will appear that so long as the embryo is simply extented on the yolk-sphere, the point where the ventral surface begins has to be decided on purely morphological grounds. That point may fairly be considered to be close to the junction of the medullary plate and primitive streak. To use a mathematical expression the sign will change when we pass from the dorsal to the ventral surface, so that in strict nomenclature we ought in contimuing round the egg in the same direction to sjeak of passing backwards along the medullary, but forwarts along the primitive streak. Thus the apparent hind end of the primitive streak is really the front end, and vice versa. I have avoided using this nomenclature to simplify nin description, but it is of the utmost importance that the morphological fact should be grasped. If any reader fails to understand my point, a reference to fig. 52 $\mathrm{B}$ will, I trust, make everything quite clear. The heart of Acipenser $(h t)$ is there seen apparently in front of the head. It is of course really ventral, and its apparent position is due to the extension of the embryo on a sphere. The apparent front end of the heart is really the hild end, and rice versa. 


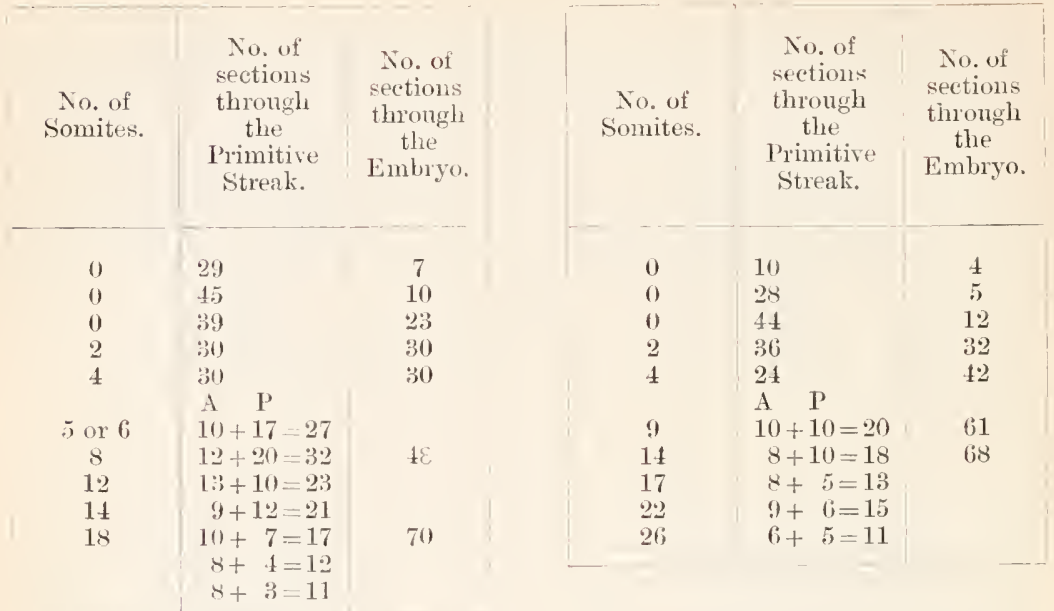

An inspection of these two tables sliews that an actual diminution in the length of the primitive strak takes place just abont the time when the first somites are being formed, but there is 110 ground for thinking that the primitive streak hecomes then converted into the medullary plate. Subsequently the primitive streak does not for a considerable time become markedly shorter, and certainly its curtailment is not really sufficient to accomt for the increased length of the embryo-an increase in length, which (with the exception of the head) takes place entirely by additions at the lind 'nd. At the stage with fourtcen somites the primitive streak is still petty long. In the later stages, as is clearly demonstrated by the tables, the diminution in the length of the primitive streak mainly concerns the posterior part and not that adjoining the embryo.

\section{General history of the germinal layers.}

The epiblast. The epiblast of the body of the embryo, though several rows of cells deep, does not become divided into two strata till late in embryonic life; so that the organs of sense formed from the epiblast, which are the same as in the types alrearly described, are not specially formed from an inner nervous stratum. The medullary canal in closed in the sane manner as in Elasmobranchii, the Frog, ete., by the simple conversion of an open groove into a closed canal. The closire conmences first of all in the region of the mid-brain, and extends rapidly backwards and more slowly forwards. It is completed in the Fowl by about the time that twelve mesoblastic somites are formed.

The mesoblast. The general clanges of this layer do not exlibit any features of special interest-the division into lateral and vertebual plates, etc, being nearly the same as in the lower forms.

The hypoblast. 'The clusure of the alimentary canal is entirely uffected by a process of tucking in or folding off of the embryo from the 
yolk-sack. The general nature of the poocess is seen in the liagrams figs. 10.5 and 1:21. The folds by which it is effected are usually distinguished as the head-, the tail- and the lateral folds. The head-fold (fig. 105) is the first to appear ; and in combination with the lateral folds gives rise to the anterior part of the mesenteron $(D)$ (including the oesophagns, stomach and duodenum), which by its mode of formation clearly ends blndly in front. 'The tail-fold, in combination with the two lateral folds, gives rise to the hinder part of the alimentary tract, including the cluaca, which is a true part of the mesenteron. At the junction between the two folds there is present a circular opening leading into the yolk-sack, which becomes gradually narrowed as development proceeds. The opening is completely closed long before the embryo is hatcher. Certain peculiarities in reference to the structure of the tail-fold are caused by the formation of the allantois, and are describer with the embryonic appendages. 'The stomodium and

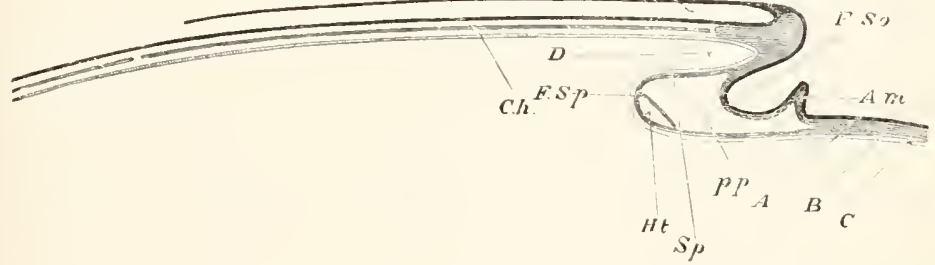

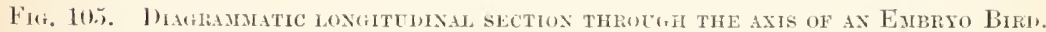

The section is supposed to be makle at a time when the head-fold has commenced but the tail-folit has not ret appearril.

F.So. head-fold of the somatopleme. F.sp. head-fold of the splanchnoplemre.

$p p$. pleuroperitoneal cavity ; $A m$. commencing (head-) foll of the amnion; $D$. alimentary tract; $N . C$. newal canal ; $C h$. notochort; A. epiblast; $B$. mesoblast ; $C$. liypoblast.

proctodxum are formed by epiblastic invaginations. The communication between the stomodxem and the mesenteron is effected comparatively early (on the 4th dar in the chick), while that between the proctodisum and mesenteron does not take place till very late (15th day in the chick). The proctodienm gives rise to the bursa Fabricii, as well as to the anus. Although the opening of the amos is so late in being formed, the proctodium itself is very early apparent. Soon after the hinder part of the primitive streak becomes tucked in on the ventral side of the embryo, an invagination may be noticed where the tail of the embryo is folded off. This gradually becomes deeper, and finally comes into contact with the hypoblast at the front (primitively the apparent hind) border of the posterior section of the prinitive streak. An early stage in the invagination is shewn in the diagram (fig. 106, (m). It deserves to be noted that the anus lies some way in front of the blind end of the mesenteron, so that there 
is in fact a well-developed post-anal section of the gut (fig. $106, p . u \cdot g$ ),

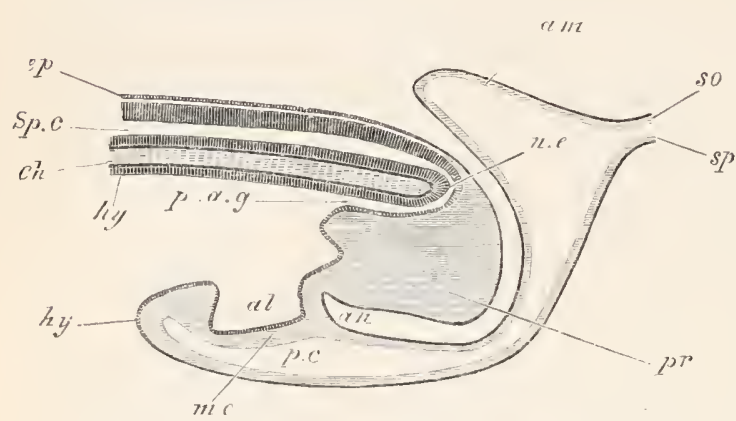

Fig, 106. DIAGRAMITATIC LOXGITUDINAL SECTION THROVGH THE POSTERIOR END OF AN EUBRYO BIRD AT THE TIME OF TIIE FORMATION OF THE ALLANTOTS.

ep. epiblast; Sp.c. spinal canal; ch. notochord; u.e. neurentuic canal; $h y$. hypolsast; $p . a \cdot f$. post-anal gut; $p$. remains of primitive streak folded in on the ventral side; 11. allantois; me. Inesoblast; an. point where anus will he formed; p.c. perivisceral eavity: am. ammion; so. somatopleure; sp. sjiauchnopleure. which corresponds with that in the Tchithyopsida. For a short period, as mentioned above (1. 135). a neurenteric canal is present connecting the post-anal gut with the medullary tube in the duck, fowl, and other birds. On the ventral wall of the post-anal gut there are at first two prominences. The posterior of these is formed of part of the tailswelling, and is therefore derives

firm the apparent anterior part of the primitive streak. The anterior is formed from what was originally the apparent posterior part of the primitive streak. The post-anal gut becomes gradually less and less prominent, and finally atrophies.

\section{General development of the Embiryo.}

It will be convenient to take the Fowl as a type for the general development of the Sauropsida.

The embryo occupies a fairly constant position with reference to the egg-shell. Its long axis is placel at right angles to that of the egg, and the brod end of the egg is on the left side of the embryo. The general history of the embryo has alreaty been traced up to the formation of the first formed mesoblastic somites (fig. 107). 'This stage is usually reached at abont the close of the first day. After this stage the embryo rapidly grows in length, and becomes, especially in front and to the sides, more and more definitely folded off from the yolk-sack.

The general appearance of the embryo between the 30th and 40th hours of incubation is shewn in fig. 108 fiom the upper surface, and in fig. 109 from the lower. The outlines of the embryo are far bolder than during the earlier stages. Fig. 109 shews the natme of the folding, by which the embryo is constricted off from the yolk-sack. The folds are complicated by the fact that the mesoblast has already become split into two layers-a splanchnic layer adjoining the hypoblast and a somatic layer adjoining the epiblast-and that the body- 
cavity between these two laycrs has already become pretty wide in the lateral parts of the body of the embryo and the area pellucida. The fold by which the embryo is constricted off from the yolksack is in consequence a double one, formed of two limbs or lamina. an inner limb constitnted by the splanclmopleure, and an outer limbi by the somatopleure. The relation of these two limbs is shewn in the diagrammatic longitudinal section (fig. 10.5), and in the surface view (fig. 109) the splanchnic limb being shewn at sf and the somatic at so. Between the two limbs, and closely adjoining the splanchnoplene. is seen the heart $(h t)$. At the stage figmed the head is well marked off from the trunk, but the first separation between the two regions was effected at an earlier period, on the appearance of the foremost somite (fic. 107). Tery shortly after the cephalic region is established, and before the closure of the medullary folds. the anterior part of the neural canal becomes enlarged to form the first cerebral resicle, from which two lateral diverticula-rudiments of the optic lobes-are almost at once given off

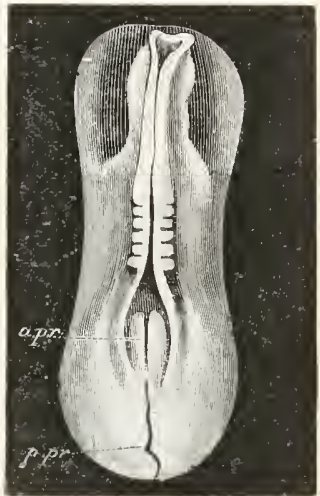

Fig, 107. Dorsal VIEW of THE MARDENED BLASTOLERM OF A CHICK WITH FIVE MESORLASTIC SOMITFS, THE MEIULLARY FOLDS IIAVE HET FOR PART OF THEIR EXTENT, BUT IIAVE NOT UNITED.

a.pr. anterior part of the primitive streak; $p \cdot p r$. posterior part of the primitive streak.

(fig. 108, op.v). By the stage figured the cephalic part of the nemral canal has become distinctly differentiated into a fore- ( $f . b)$, a mid- $(m . b)$ and a hind-brain $(h . b)$ : and the hind-brain is often subdivided into successive lobes. In the region of the hind-brain two shallow epiblastic invaginations form the rudiments of the auditory pits ( $a$ u. $p$ ).

A section rhrough the posterior part of the head of an embryo of 30 homrs is represented in fig. 110. The enlarged part of the newral tube, forming the hind-brain, is shewn at $(h b)$. It is still connected with the epidermis, and at its dorsal border an outgrowth on each side forming the root of the vagus nerve is present ( $g)$. The notochord $(c h)$ is seen below the hrain, and below this again the crescentic foregut $(a l)$. The commencing heart $(h t)$, formed at this stage of two listinct tubes, is attached to the ventral side of the foregut.

On the dorsal side of the foregut immediately below the notochord is seen a small body $(x)$ formed as a thickening of the hypoblast. This may possibly he a rudiment of the subnotochordal rod of the Ichthyopsida.

In the trunk (fig. 108) the chief point to be noticed is the complete closure of the neural canal, though in the posterior part, where the open sinus rhomboidalis was situated at an earlier stage, there may still be seen a dilatation of the canal (fig. 108, s.r), ou each vide of which are the tail-swellings; while the mesoblastic somites 
stop short somewhat in front of it. Underneath the neural canal may be seen the notochord (fig. 109, ch) extending into the head, as far as the base of the mid-brain. At the sides of the trunk are seen the mesoblastic somites $(p v)$, the outer edges of which mark the boundary between the vertebral and lateral plates. A fainter line can be seen marking off the part of the lateral plates which will become part of the body-wall, from that which pertains to the yolk-sack.

During the latter half of the second day, and during the third lay, great progress is made in the folding off of the embryo. Both the head-and tail-ends of the embryo become quite distinct, and the side-folds make such conisilerable progress that the embryo is only connected with the yolk by a broad stalk. This stalk is double, and consists of an inner splanchnic stalk, continuous with the walls of the alimentary canal, and an outer somatic stalk, continuous with the body-walls of the embryo. The somatic stalk is very much wider than the splanchnic. (Compare fig. $121 \mathrm{E}$ and $\mathrm{F}$, which may be taken as diagrammatic longitudinal and transverse sections of the embryo on the third day.) A change also takes place in the position

Fig. 108. EyBryo of THE

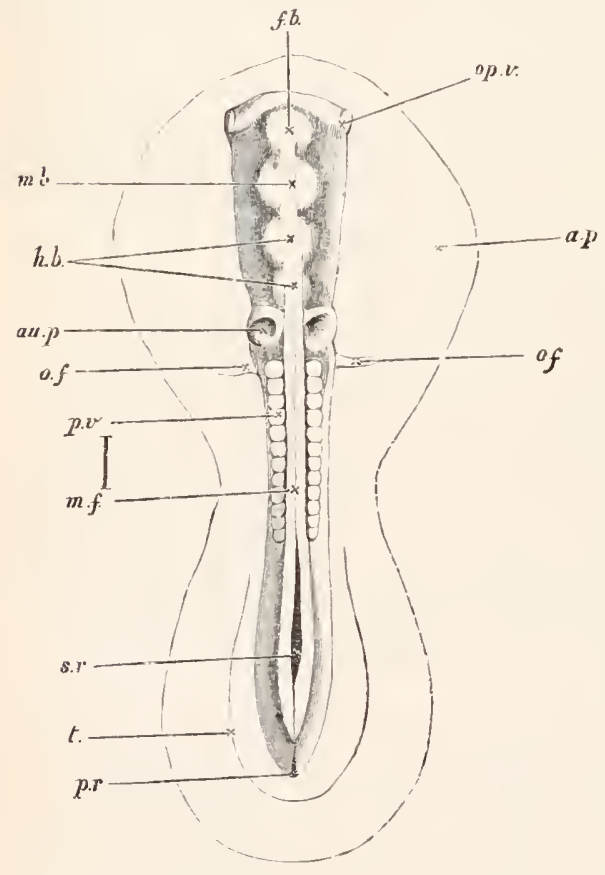
CHICK BETWEEN 30 AND 36 HOURS VIEWED FHOM ABOVE AS AN OPAQUE овљест. (Chromic acid preparation.)

f.b. front-brain; m.b. midbrain; h.b. hind-brain; op.v. optic vesicle; au.p. auditory pit; o.f. vitclline vein; $p \cdot r$. mesoblastic somite; $m . f$. line of junction of the medullary folds above the medullary canal; s.r. sinus rhomboidalis; $t$. tail-fold ; p.r. remains of primitive groove (not satisfactorily represented); a.p. area pellucida.

The line to the side between $p . r$. and $m . f$. represents the true length of the embryo.

The fiddle-shaped outline indicates the margin of the pellucid area. The head, which reaches as far back as o.f., is distinctly marked off; but neither the somatopleuic nor splanchnopleuric folds are shewn in the figure; the latter diverge at the level of o.t., the former considerably nearer the front, somewhere between the lines $m . b$. and $h . b$. The optic vesicles op.r. are seen bulging out beneath the superficial epiblast. The heart lying underneath the opaque body cannot be seen. The tail-fold $t$. is just indicated; no distinct lateral folds are as yet visible in the region midway between head and tail. At m. $f$. the line of junction between the medullary folds is still visible, being lost forwards over the cerebral vesicles, while behind may be seen the remains of the sinus rhomboidalis, $s, r$. 
Fig. 109. Ax exbryo chlch of ABout thintYSIX HOCRS VIEWED FROM BELOW AS A TRANSPARENT OBJECT.

FB. the fore-brain or first cerebral resicle, projecting from the sides of which are seen the optic resicles op. A definite head is now con. stituted, the backward limit of the somatopleure fold being indicated by the faint line s.o. Around the hearl are seen the two limbs of the amniotic head-fold: one, the true amnion a, closely enreloping the liead, the other, the false amnion $a^{\prime}$, at some distance from it. The head is seen to project beyond the anterior limit of the pellncid area.

The splanchnopleure fold extends as far back as $s p$. Along its diverging limbs are seen the conspicuous renous roots of the vitelline veins, uniting to form the heart $h$, already established by the coalescence of two lateral halyes which, continuing forward as the bulbus arteriosus $b . u$, is lost in the substance of the llead just in front of the somatopleure foll.

$H B$. hind-brain; MT. mid-brain; p.r. and $r . p l$. mesoblastic somites; ch. front end of notochord; me. posterior part of notocherd; $e$. parietal mesoblast; $p l$. outline of area pellucida; $p$. primitive streak.

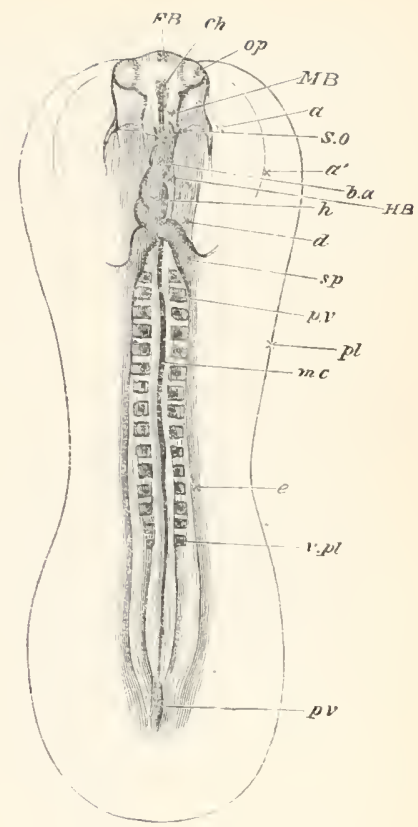

of the embryo. Up to the thind day it is placed sy $111 \mathrm{metrical-}$ ly, on the yolk, with its ventral face downwards. During this day it tumns so as partially to lie on its left side. This rotation affects first the head (fig. 111), but in tlie course of the fourth day gradually extends to the rest of the body (fig. 118). Coincidently with this change in position the whole

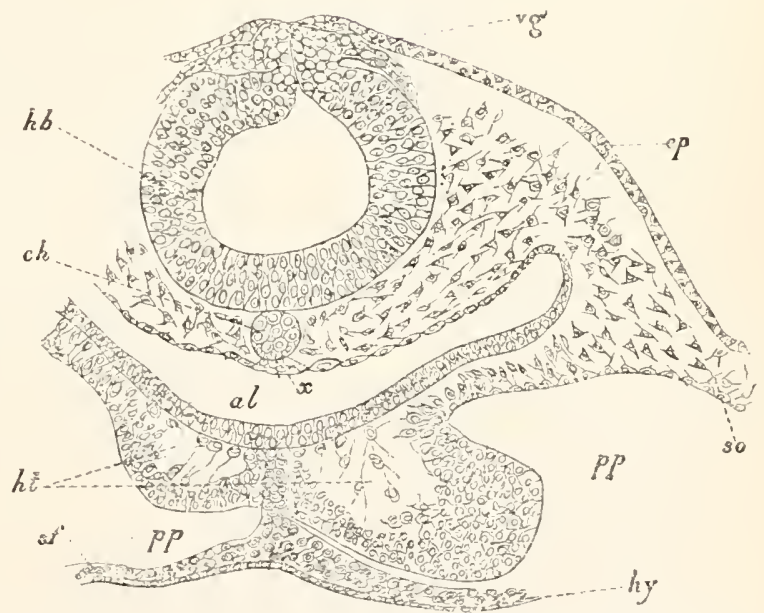

Fig. 110. Transverse section throdgh the posterior PART OF THE HEAJ OF AN EMIBRYO CHICK OF THIRTY HOURS.

$h b$. hind-brain; $v y$. vagus nerve; ep. epiblast; ch. notochord; $x$. thickening of hypoblast (possibly a rudiment of the subnotochordal rod); al. throat; ht. heart; $p p$. body-carity; so. somatic mesoblast; sf. splanchnic mesoblast; hy. lyppoblast.

embryo undergoes a ventral and somewhat spiral Hexure. 
Durng the latter part of the second day and during the thirl day important changes take place in the head. One of these is the cranial flexure. This, which must not be confounded with the curvature of the body just referred to, comnences by the bending downwards of the front part of the head round a point which may be considered as the extreme end either of the notochord or of the alimentary caral.

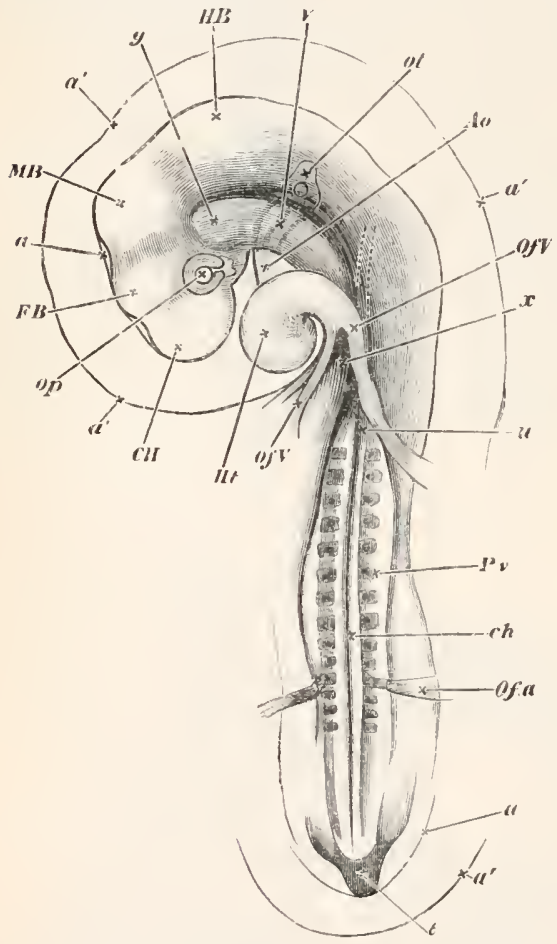

Fit, 111. Сमіск OF THE TH1RD DAY (54 HOURS) VIEWED FROM UNDERNEATH AS A TRANSPARENT OBJECT.

$a^{\prime}$. the onter amniotic fold or false amnion. This is very conspicuous around the head, but may also be seen at the tail.

$a$. the true amnion, very closely enveloping the liead, and liere seen only between the projections of the several cerebral vesicles. It may also be traced at the tail, $t$.

In the embryo of which this is a drawing the head-fold of the amnion reacheil a little farther backward than the reference $u$, but its limit cannot be distinctly seen through the body of the embryo.

C.II. cerebral hemisphere; $\boldsymbol{F} . \boldsymbol{B}$. vesicle of the third ventricle; M.L: mid-brain; H.B. hind-brain; Op. eye; $O t$, auditory vesiclc.

of $\mathrm{T}^{\mathrm{T}}$. vitelline veins forming the venous roots of the lieart. The trunk on the right hand (left trunk when the embryo is viewed in its natural position from above) receives a large branclı, shewn by dotted lines, coming from the anterior portion of the sinus terminalis. Ht. the heart, now completely twisted on itself. $A o$. the bulbus arteriosus, the threc aortic arches being dimly seen stretching from it across the throat, and uniting into the aorta, still more dimly seen as a curved dark line running along the boly. The other curved dark line by its side, cnding near the reference $y$, is the notochord $c h$.

Abont opposite the line of reference $x$ the aorta divides into two trunks, which running in the linc of the somewhat opaque somites on either side, are not clearly seen. Their branches however, $O f . \alpha$, the vitelline arteries, are conspicuous and are seen to curve round the commencing side-folds.

Pv. mesoblastic somites.

$x$ is placed at the "point of divergence" of the splanchnopleure folds. The blind foregut begins here and extends about up to near $y$, the more transparent space marked by that letter is however mainly due to the presence there of investing ntass at the base of the brain. $x$ marks the hind limit of the splanchnopleure folds. The limit of the more transparent somatopleure folds cannot be seen.

It will be of course understood that all the boly of the embryo above the level of the reference $x$, is seen throngli the portion of the yolk-sac (vascular and pellucid area), which has been removed with the embryo from the egg, as well as through the double amniotic fold.

The view being from below, whatever is described in the natural position as being to the right appears here to the left, and vice versu. 
The cranial flexure progresses rapidly, the front-brain being more and more folded down till, at the end of the third day, it is no longer the first vesicle or fore-brain, but the second cerebral vesicle or midbrain, which occupies the extreme front of the long axis of the embryo. In fact a straight line through the long axis of the embryo would now pass through the mid-brain instead of, as at the beginning of the second day, through the fore-brain, so completely has the front end of the nemral canal been folded over the end of the notochord. The commencement of this cranial flexure gives the body of an embryo of the third day somewhat the appearance of a chemist's retort, the head of the embryo corresponding to the bulb. On the fourth day the flexure is still greater than on the third, but on the fifth and succeeding days it becomes less obvious.

The anterior part of the fore-brain has now become greatly dilated, and may be distinguished from the posterior part as the impaired rudiment of the cerebral hemispheres. It soon bulges out laterally into two lobes, which do not however become separated by a median partition till a much later period.

Owing to the development of the cerebral rudiment the posterior part of the fore-brain no longer occupies the front position (fig. 111, and $112 F^{\prime} B$ ), and ceases to be the conspicuous object that it was. Inasmuch as its walls will hereafter be developed into the parts surrounding the so-called third ventricle of the brain, it is known as the vesicle of the third ventricle, or the thalamencephalon.

On the summit of the thalamencephalon there may now be seen a small conical projection, the rudiment of the pineal gland, while the centre of the floor is produced into a funnel-shaped process, the infundibulum, which, stretching towards the extreme end of the alimentary canal, joins the pituitary body.

Beyond an increase in size, which it

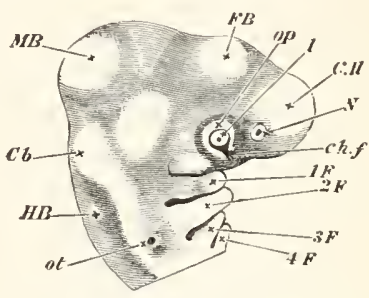

F19. 112. Side rieW of THE HEAD of AN Emrryo Chick of the THIRD DAY AS AY OPAQTE OBJECT. (Chromic acid preparation.)

CH. Cerebral hemispheres; F.B. Vesicle of third ventricle; II.B. Mid-brain; Clb. Cerebellum; H.B. Medulla oblongata: N. Nasal pit: ot. auditory vesicle in the stage of a pit with the opening not yet closed up; op. Optic vesicle, with 7. lens and ch.f. choroidal fissure. The choroidal fissure, though formed entirely underneath the superficial epiblast, is distinctly visible from the outside.

$1 \mathrm{~F}$. The first visceral fold: above it is seen a slight indication of the stperior maxillary process.

$2,3,4 \mathrm{~F}$. Second, third and fourth visceral folds, with the visceral clefts between them. shares with nearly all parts of the embryo, and the change of position which has already been referred to, the mid-brain undergoes no great alterations during the third day. Its sides will ultimately become developed into the corpora bigemina or optic lobes, its floor will form the crura cerebri, and its cavity will be reduced to the narrow canal known as the iter a tertio ad quartum ventriculum and two diverticula leading from this into the optic lobes. 
In the hind-brain, or third cerebral vesicle, the roof of the part which lies nearest to the mid-brain, becomes during the third day marked off from the rest by a slight constriction. This distinction, which becomes much more evident later on by a thickening of the walls and roof of the front portion, separates the hind-brain into the cerebellum and the medulla oblongata (fig. $112 \mathrm{Cb}$ and $I I B$ ). While the walls of the cerebellar portion of the hind-brain become very much thickened as well at the roof as at the sides, the roof of the posterior portion or medulla oblongata thins out into a mere membrane, forming a delicate covering to the cavity of the vesicle (fig. 114 $I V$ ), which here becoming broad and shallow with greatly thickened floor and sides, is known as the fourth ventricle, subsequently overhung by the largely-developed posterior portion of the cerebellum.

The third day, therefore, marks the distinct differentiation of the brain into five distinct parts: the cerebral hemispheres, the central masses round the third ventricle, the corpora bigemina, the cerebellum and the medulla oblongata; the original cavity of the neural canal at the same time passing from its temporary division of three single cavities into the permanent arrangement of a series of connected ventricles, viz. the lateral ventricles, the third ventricle, the iter (with a prolongation into the optic lobe on each side), and the fourth ventricle.

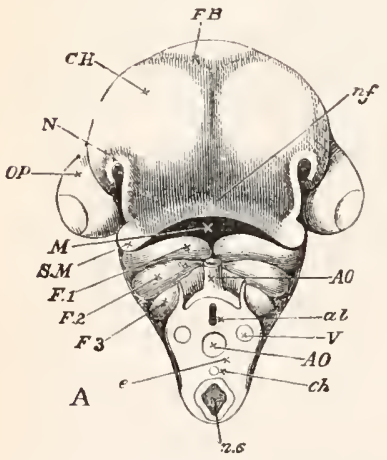

Fig. 113. Head of an Embryo Chick of the fourth day NIEWED AS AN OPAQUE OBJECT: FROM THE FRONT IN A, AND FROM THE SIDE IN B. (Chromic acid preparation.)

$C I I$. cerebral hemispheres; $F B$. vesicle of the third ventricle; $O p$. eyeball; $n f$. naso-frontal process; $M$. cavity of mouth; $S .1$, superior maxillary process of $F .1$, the first visceral fold (inferior maxillary process); $F .2, F .3$, second and third visceral folds; $N$. nasal pit; ot. otic vesicle.

In order to gain the view here given the neck was cut across between the thind and fourth visceral folds. In the section $e$ thus made, are seen the alimentary canal $a l$, the neural caual n.c., the notochord $c h$, the dorsal aorta $A O$, and the vertebral veins $T^{r}$.
By the third day the lens of the eye has become formed by an invagination of the epiblast, and other changes in the eye have taken place. The external opening of the auditory pit is closed before the completion of the third day (fig. $114, R L)$; and the rudiments of the external parts of the organ of smell have become formed as small pits on the under surface of the fore-brain (fig. 112, $N$ ). Like the lens and the labyrinth of the ear, they are form- 
ed as invaginations of the external epiblast; unlike them they are never closed up.

During the second and third days there are formed the visceral or branchial clefts, homologous with those of the Ichthyopsida, though never developing branchial processes from their walls.

They are however real clefts or slits passing right through the walls of the throat, and are placed in series on either side across the axis of the alimentary canal, lying not quite at right angles to that axis nor parallel to each other, but converging somewhat to the middle of the throat in front, (fig. 112 and fig. 113).

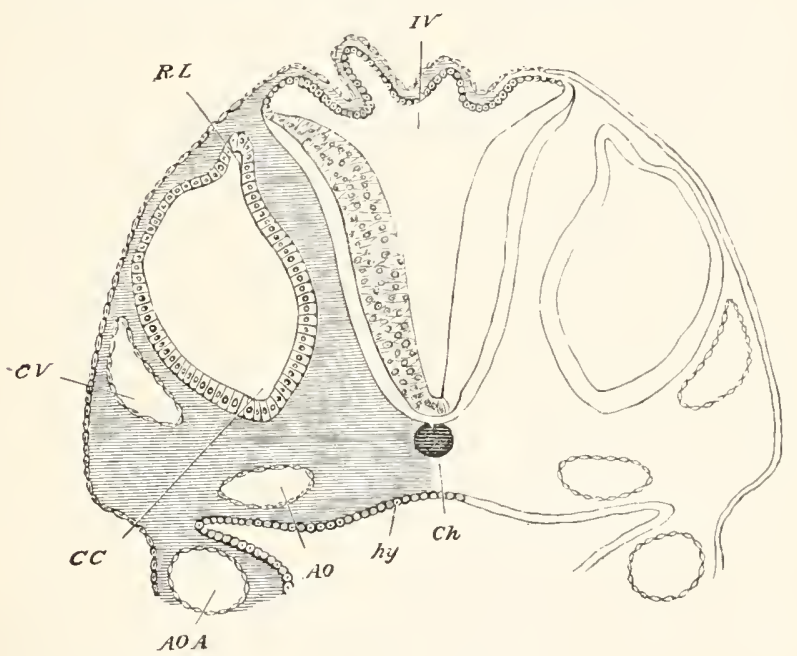

Fig, 114. Section throdgh the hisd-braix of a Chick at the end of the THIRD DAY OF INCEBATION.

$I V$. Fourth ventricle. The section shews the very thin roof and thicker sides of the ventricle. $C h$. Notochord; $C V$. Anterior cardinal vein; $C C$. Involuted auditory vesicle; $C C$ points to the end which will form the cochlear canal; $R L$. Recessus labyrinthi (lemains of passage comnecting the vesicle with the exterior); hy. Hypoblast lining the alimentary canal; $A O ., A O A$. Aorta, and aortic areh.

Four in number on either side, the anterior is the first to be formed, the other three following in succession. They originate as pouches of the hypoblast, which meet the epiblast. At the junction of the epiblast and hypoblast an absorption of the tissue is effected, placing the pouches in communication with the exterior.

No sooner has a cleft been formed than its anterior border (i.e. the border nearer the head) becomes raised into a thick lip or fold, the visceral or branchial fold. Each cleft has its own fold on its anterior border, and in addition the posterior border of the fourth or last visceral cleft is raised into a similar fold. There are thus five visceral folds to four visceral clefts (figs. 112 and 113). The last two folds however, and especially the last, are not nearly so thick and prominent as the other three, the second being the broadest and most conspicuous 
of all. The first fold meets, or nearly meets, its fellow in the middle line in front, but the second falls short of reaching the middle line, and the third, fourth and fifth do so in an increasing degree. Thus in front views of the neck a triangular space with its apex directed towards the head is observed between the ends of the several folds (fig. 113 A).

Into this space the pleuroperitoneal cavity extends, the somatopleure separating from the splanchnopleure along the ends of the folds ; and it is here that the aorta plunges into the mesoblast of the body.

The history of these most important visceral folds and clefts will be dealt with in detail hereafter; meanwhile I may say that in the chick and higher Vertebrates the first three pairs of folds are those which call for most notice.

The first fold on either side, increasing rapidly in size and prominence, does not, like the others, remain single, but sends off in the course of the third day a branch or bud-like process from its upper edge (fig. 113). This branch, starting from near the outer end of the fold, runs forwards and upwards in front of the stomodwum, tending to meet the corresponding branch from the fold on the other side, at a point in the middle line nearer the frout of the head than the junction of the main folds (fig. 11:3 sm). The two branches do not quite meet, being separated by a median process, which at the same time grows down from the extreme front of the head, and against

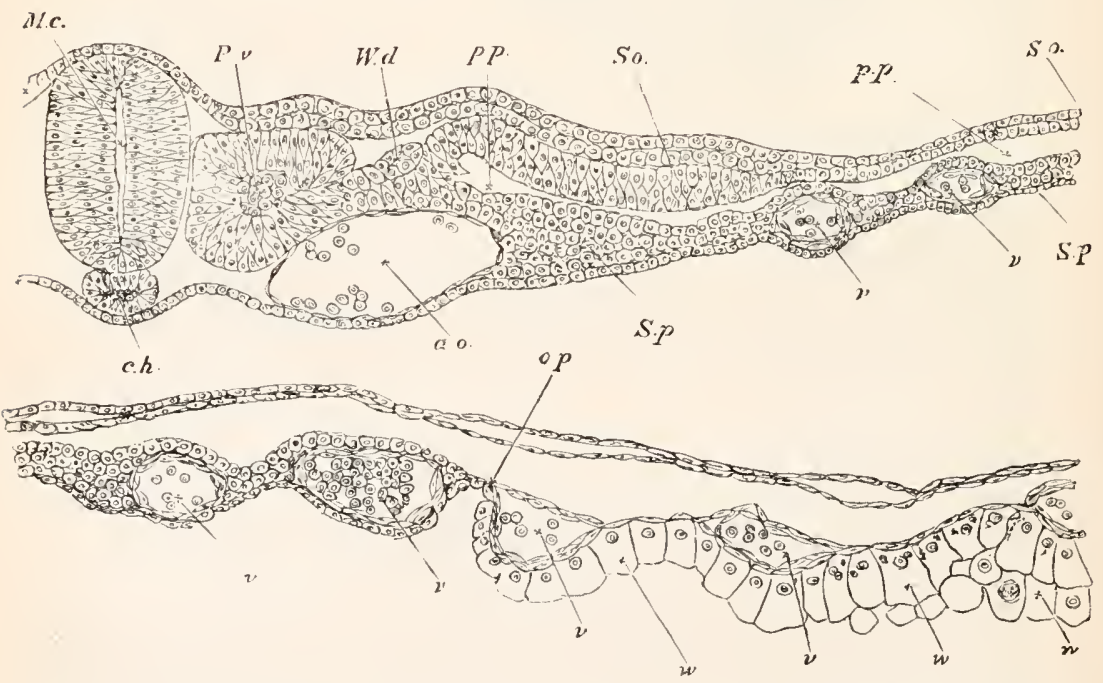

Fig. 115. Transverse section throvgh the dorsal region of an Eibryo Chick of 45 HоURs.

M.c. medullary eanal; P.v. mesoblastic somite; W.d. Wolffian duct; So. Somatopleure; S.p. Splanchnopleure; $p . p$. pleuroperitoneal cavity; $a$. aorta; $v$. bloodressels; w. germinal wall; $c h$. notochord; op. junction between area opaca and area pellucida. 
which they abut (fig. $120 \mathrm{k}$ ). Between the main folds, which are directed somewhat downwards and their branches which slant upwards, the somewhat lozenge-shaped stomodxum is placed, which, as the folds become more and more prominent, grows deeper and deeper (fig. $120 \mathrm{~A}$ ). The main folds form the mandibular arch, and their branches the maxillary processes, and the descending process which helps to complete the anterior margin of the stomodieum or oral cavity is called, from the parts which will be formed out of it, the fronto-nasul process.

In two succeeding pairs of visceral folds, which correspond with the hyoid and first branchial arches of the Ichthyopsida, are developed the parts of the hyoid bone, which will be best considered in connection with the development of the skull. The last two disappear in the chick without giving rise to any permanent structures. The external opening of the first visceral i.e. hyomandibular cleft becomes closed', but the inner part of the cleft, opening into the mouth, gives rise to the Eustachian tube and the tympanic cavity, the latter being formed as a special diverticulum.

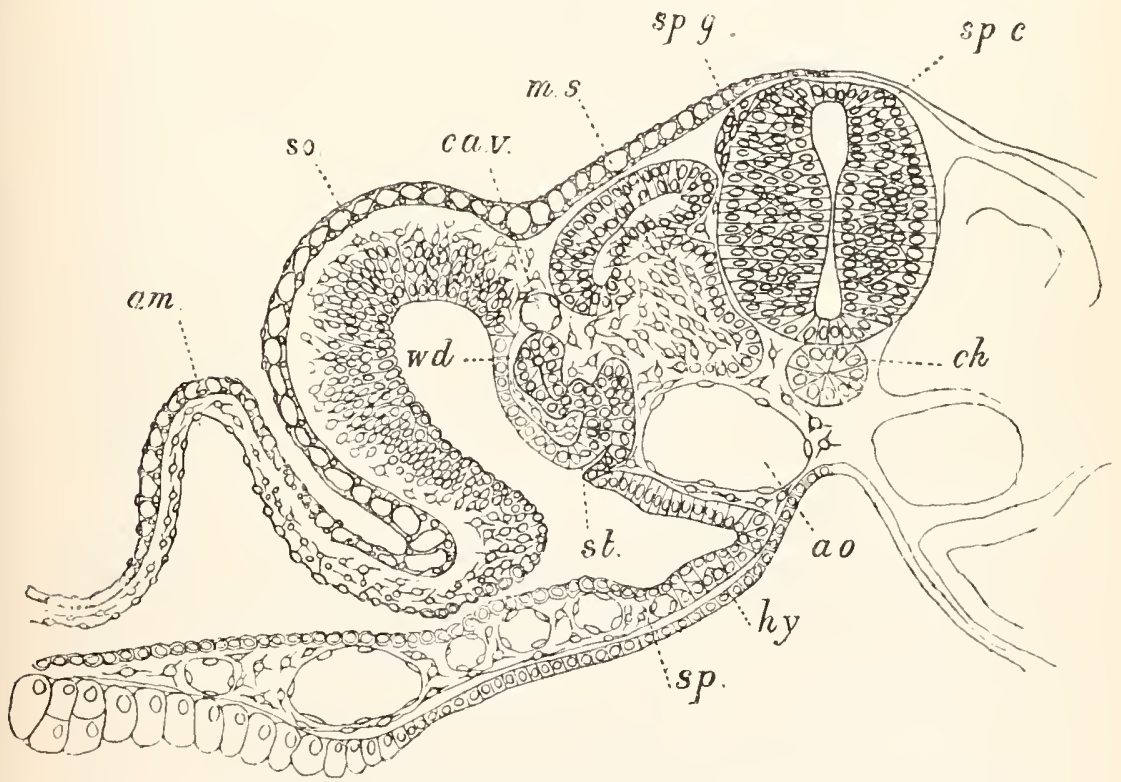

Fig. 116. Transperse section throvgh the trenk of a Duck Embiro with abovi TWENTY-FOUR MESOBLASTIC SOMITES.

am. amnion; so. somatopleure; $s p$. splanchnopleure; wd. Wolffian duct; st. segmental tube; ca.v. cardinal vein; ms. muscle-plate; sp.g. spinal ganglion; sp.c. spinal cord; ch. notochord; ao. aorta; hy. hypoblast.

1 Vide Moldenhauer, "Die Entwicklung des mittleren und des äusseren Ohres." Horphologisches Jahrbuch, Vol. III. 1877. 
Part of the membranous mandibular and hyoid arches form a wall round the dorsal part of the original opening of this cleft, and so give rise to the

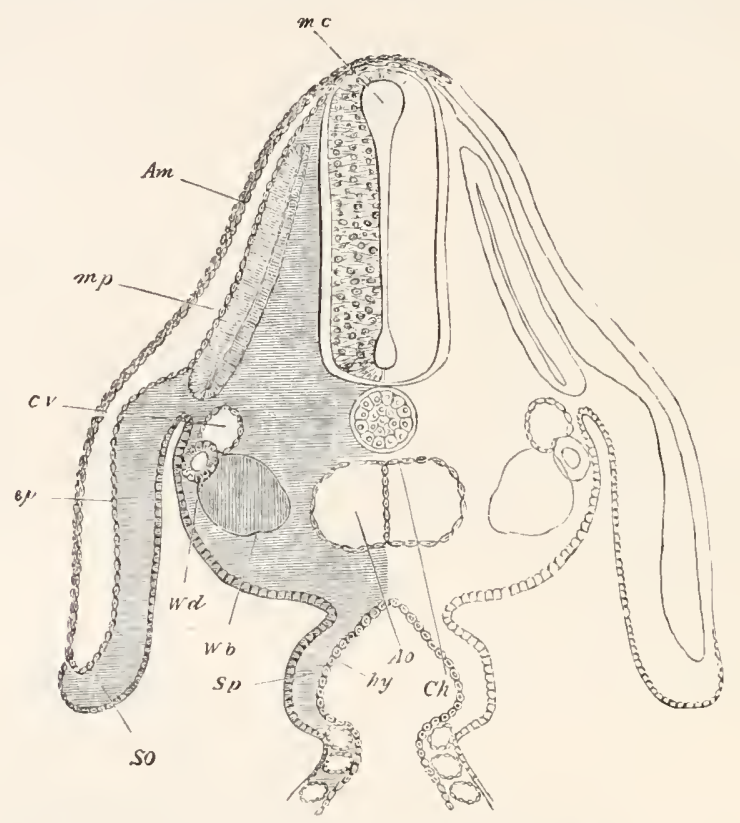

Fig. 117. Section throdgh the dorsal region of an Embryo Chick at the end OF THE THIRD DAY.

Am. amnion; m.p. muscle-plate. C.I. cardinal vein. Ao. dorsal aorta. The section passes through the point where the dorsal aorta is just commencing to divide into two branches. Ch. notochord; W.d. Wolffian duct; W.b. commencing differentiation of the mesoblast cells to form the Wolffian borly; ep. epiblast; So. somatopleure; Sp. splanchnopleure; hy. hypoblast. The section passes through the point where the digestive canal communicates with the yolk-sack, and is consequently still open below.

meatus auditorius externus. At the bottom of this is placed the tympanic membrane, which is probably derived from the tissne which grows over the dorsal part of the opening of the first cleft. It is formed of an external epiblastic epithelium, a middle layer of mesoblast, and an internal hypoblastic epithelium.

The general nature of the changes, which take place in the trunk between the commencement of the second half of the second day and the end of the third day, is illustrated by the sections figs. 115, 116, 117.

In the earliest of these sections there is not a trace of a folding off of the embryo from the yolk, and the body walls are quite horizontal. In the second section (fig. 116), from an embryo of about two days, the body walls are already partially inclined, and the splanchnopleure is very distinctly fohled inwards. There is a con- 


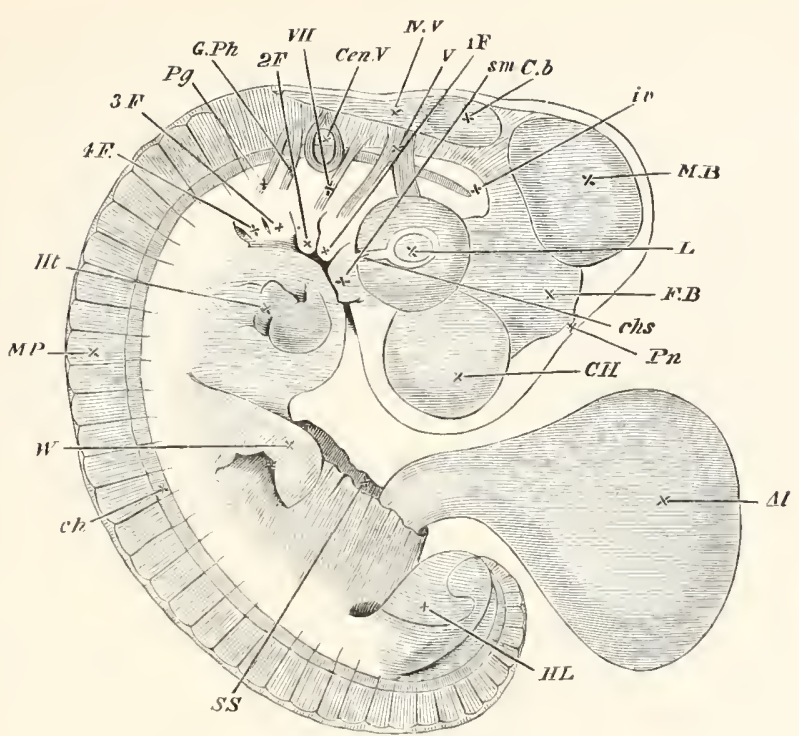

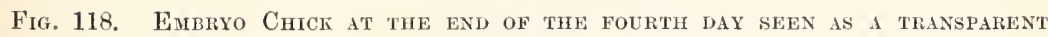
OBJECT.

The amnion has been completely removed, the eut end of the somatic stalk is shewn at S.S. with the allantois $(A l)$ protruding from it.

C.H. cerebral hemisphere; F.B. vesicle of the third ventricle with the pineal gland $(P n)$ projecting from its summit; II.B. mid-brain; $C b$. cerebellum. $I V$. $V$. fourth ventricle; $L$. lens; ch.s. choroid slit. Owing to the growth of the optic cup the two layers of which it is composed cannot any longer be seen from the surface, but the retinal surface of the layer alone is visible. Cen. $V$. auditory vesicle; s.m. superior maxillary process; $1 F, 2 F$. etc. first, second, third and fourth visceral arches; $V$. fifth nerve sending one branch to the eye, the ophthalmic branch, and another to the first visceral arch; $Y I I$. seventh nerve passing to the second visceral arch; G.Ph. glossopharyngeal nerve passing towards the third visceral arch; $P g$. pneumogastric nerve passing towards the fourth visceral arch; $i$. investing mass. No attempt has been made in the figure to indicate the position of the dorsal wall of the throat, which cannot be easily made out in the living embryo; $c h$. notochord. The front end of this camnot be seen in the living embryo. It does not enrl however as shewn in the figure, but takes a sudden bend downwards and then terminates in a point. IIt . heart seen through the walls of the chest; M.P. muscle-plates. $W$. wing; H.L. hind limb. Beneath the hind limb is seen the curved tail.

siderable space between the notochord and the hypoblast, which forms the rudiment of the mesentery.

In the third section (fig. 117) the body walls have become nearly vertical, the folding of the splanchnopleure is nearly completed, and it is only for a small region that the alimentary tract is open, by the vitelline duct, to the yolk sack.

These three sections further illustrate (1) the gradual differentiation of the mesoblastic somites (fig. $115 \mathrm{P.v}$ ) into $(\alpha)$ the muscle-plates (figs. $116 \mathrm{~ms}$ and $117 \mathrm{mp}$ ), and $(b)$ the tissue to form the vertebral bodies and adjacent connective tissue; (2) the formation of a mass of tissue 
between the lateral plates and the mesoblastic somites (fig. 115), known as the intermediate cell mass, on the dorsal side of which the Wolffian duct is formed, while the intermediate cell mass itself breaks up into the segmental tubes (fig. $116 \mathrm{st}$ ) and connective tissue of the Wolffian body.

Various other features in the development of the vascular system, general mesoblast, etc., are also represented in these sections. It may more especially be noted that there are at first two widely separated dorsal aorta, which gradually approach (fig. 115 and 116); and meeting first of all in front finally coalesce (fig. $117 \& 119$ ) for their whole length.

The general appearance of the embryo of the fourth day may be gathered from fig. 118.

The changes which have taken place consist for the most part in the further development of the parts already present, and do not need to be specified in detail. The most important event of the day is

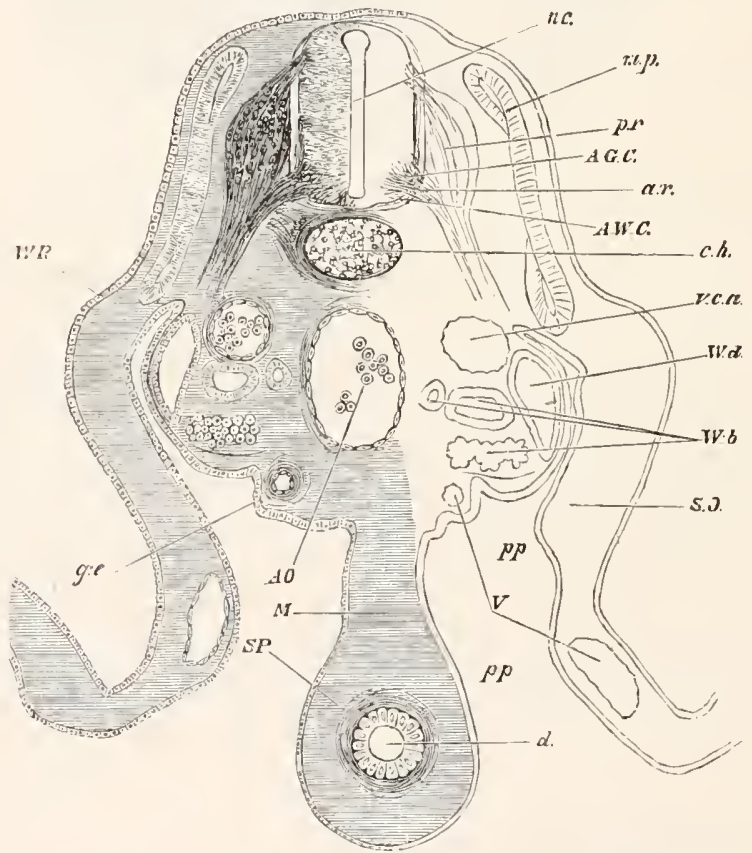

Fit. 119. Section through the lumbar region of an Eibryo Chick at the enil OF THE FOURTH DAT.

n.c. neural canal; p.r. posterior root of spinal nerve with ganglion; a.r. anterior root of spinal nerve; A.G.C. anterior grey column of spinal cord; A.W.C. anterior white column of spinal cord just conmencing to be formed, and not very distinctly marked in the figure; m.p. muscle-plate; ch. notochord; W.R. Wolffian ridge. A.O. dorsal aorta; V.e.a. posterior cardinal vein; W.d. Wolffian duct; W.b. Wolftian body, consisting of tubules and Malpighian bodies; g.e. germinal epithelium; d. alimentary caval; $I$. commencing mesentery; SO. somatopleure; ST. splanchnopleure; $r$. blool-vessels; $p p$. plemroperitoneal carity. 
perhaps the formation of the limbs. They appear as outgrowths from a slightly marked lateral ridge (fig. $119 \mathrm{WR}$ ), which runs on the

A.

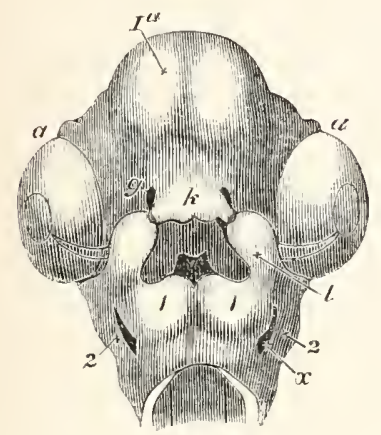

B.

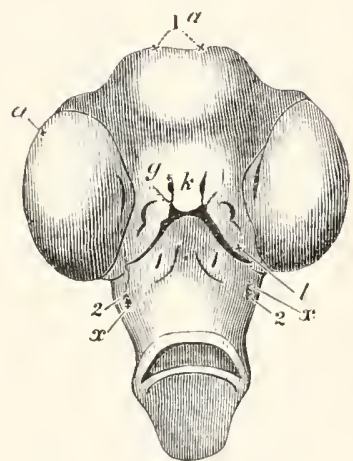

Fig. 120. Head of a Chick from below on the sixti and seventh days of incubation. (From Huxley.)

I $a$. cerebral vesicles; $a$. eye, in which the remains of the choroid slit can still be seen in $\mathrm{A} ; g$. nasal pits; $k$. fronto-nasal process; $l$. superior maxillary process; 1. inferior maxillary process or first visceral arch; 2 . second visceral arch; $x$. first visceral cleft.

In A the cavity of the mouth is seen enclosed by the fronto-nasal process, the superior maxillary processes and the first pair of visceral arches. At the back of it is seen the opening leading into the throat. The nasal grooves leading from the nasal pits to the mouth are already closed over and converted into canals.

In $\mathrm{B}$ the external opening of the mouth has become nuch constricted, but it is still enclosed by the fronto-nasal process and superior maxillary processes above, and by the inferior maxillary processes (first pair of visceral arches) below.

The superior maxillary processes have united with the fronto-nasal process, along nearly the whole length of the latter.

level of the lower end of the muscle plates for nearly the whole length of the trunk. This ridge is known as the Wolffian ridge. The first trace of the limbs can be seen towards the end of the third day; and their appearance at the end of the fourth day is shewn in fig. $118 \mathrm{~W}$ and $H L$.

A section through the trunk of the embryo on the fourth day is represented in fig. 119. The section passes through the region of the trunk behind the vitelline duct. The mesentery $(M)$ is very much deeper and thinner than on the previous day. The notochord has become invested by a conclensed mesoblastic tissue, which will give rise to the vertebral column. The two dorsal aortæ have now completely coalesced into the single dorsal aorta, and the Wolffian body has reached a far more complete development.

In the course of the fifth day the face begins to assume a less embryonic character, and by the sixth and succeeding days presents distinctive avian characters.

The general changes which take place between the sixth day and the time of hatching do not require to be specified in detail. 


\section{Fatal Membranes.}

The Reptilia, Aves and Mammalia are distinguished from the Ichthyopsida by the possession of certain provisional foetal membranes, known as the amnion and allantois.

As the mode of development of these membranes may be most conveniently studied in the chick, I have selected this type for their detailed description.

The Amnion. The amnion is a peculiar sack which envelopes, and protects the embryo.

At the end of the first day of incubation, when the cleavage of the mesoblast has somewhat advanced, there appears, a little way in front of the semilumar head-fold, a second fold (fig. 102, also fig. 121, C, of and fig. $122 \mathrm{Am}$ ), running more or less parallel or rather concentric with the first and not unlike it in general appearance, though differing widely from it in nature. This second fold gives rise to the amnion, and is limited entirely to the somatopleure. Rising up as a semilunar fold with its concavity directed towards the embryo (fig. $121 \mathrm{C}$, af ), as it increases in height it is gradually
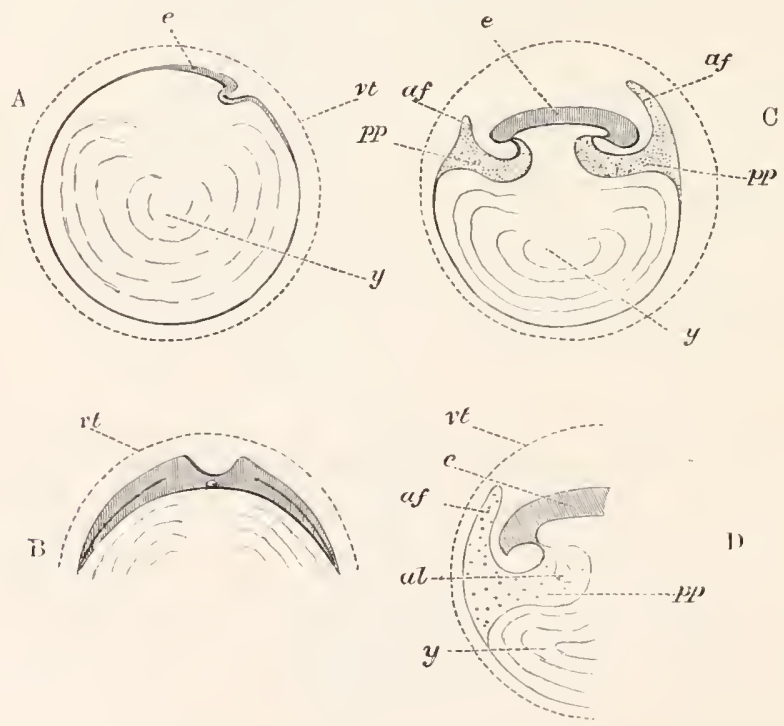

Frg. 121.

Hig. 121 A to $\mathrm{N}$ forms a series of purely diagrammatic representations introdnced to facilitate the comprehension of the manner in which the body of the embryo is formed, and of the various relations of the yolk-sack, amnion, and allantois.

In all $v t$ is the vitelline membrane, placed, for convenience sake, at some distance from its contents, and represented as persisting in the later stages; in reality it is in direct contact with the blastoderm or yolk, and early ceases to have a separate existence. In all $e$ indicates the embryo proper; $p p$ the general pleuro-peritoneal space with its extension betwcen the membranes; $a f$ the folds of the amnion; $a$ the 
anınion proper; ae or ac the carity lolding the liquor amnii; al the allantois; $a^{\prime}$ the alimentary canal; $y$ or $y$ s the yolk or yolk-sack.

A, which may be considered as a rertical section taken longitudinally along the axis of the embryo, represents the relations of the parts of the egg at the time of the first appearance of the head-fold, seen on the right-hand side of the embryo $e$. The blastodcrm is spreading both behind (to the left hand in the figure), and in front (to right hand) of the head fold, its limits being indicated by the shading and thickening for a certain distance of the margin of the yolk $y$. As yet there is no fold on the left side of $e$ corresponding to the head-fold on the right.

$B$ is a vertical transverse section of the same period drawn for convenience sake on a larger scale (it should have been made flatter and less curved). It shews that the blastoderm (vertically shaded) is extending laterally as well as fore and aft, in fact in all directions; but there are no lateral folds, and therefore no lateral himits to the body of the embryo as distinguished from the blastoderm.

Incidentally it shews the formation of the medullary groove by the rising up of the laminæ dorsales. Beneath the section of the groove is seen the rudiment of the notochord. On either side a line indicates the cleavage of the mesoblast just commencing.

In $\mathrm{C}$, which represents a vertical longitudinal section of later date, both head-fold (on the right) and tail-fold (on the left) have adranced considerably. The alimentary canal is therefore closed in, both in front and behind, but is in the middle still widely open to the yolk $y$ below. Though the axial parts of the embryo have become thickened by growth, the body-walls are still thin; in them however is seen the cleavage of the mesoblast, and thedivergence of the somatopleure and splanchnopleure. The splanchnopleure both at the head and at the tail is folded in to a greater extent than the somatopleure, and forms
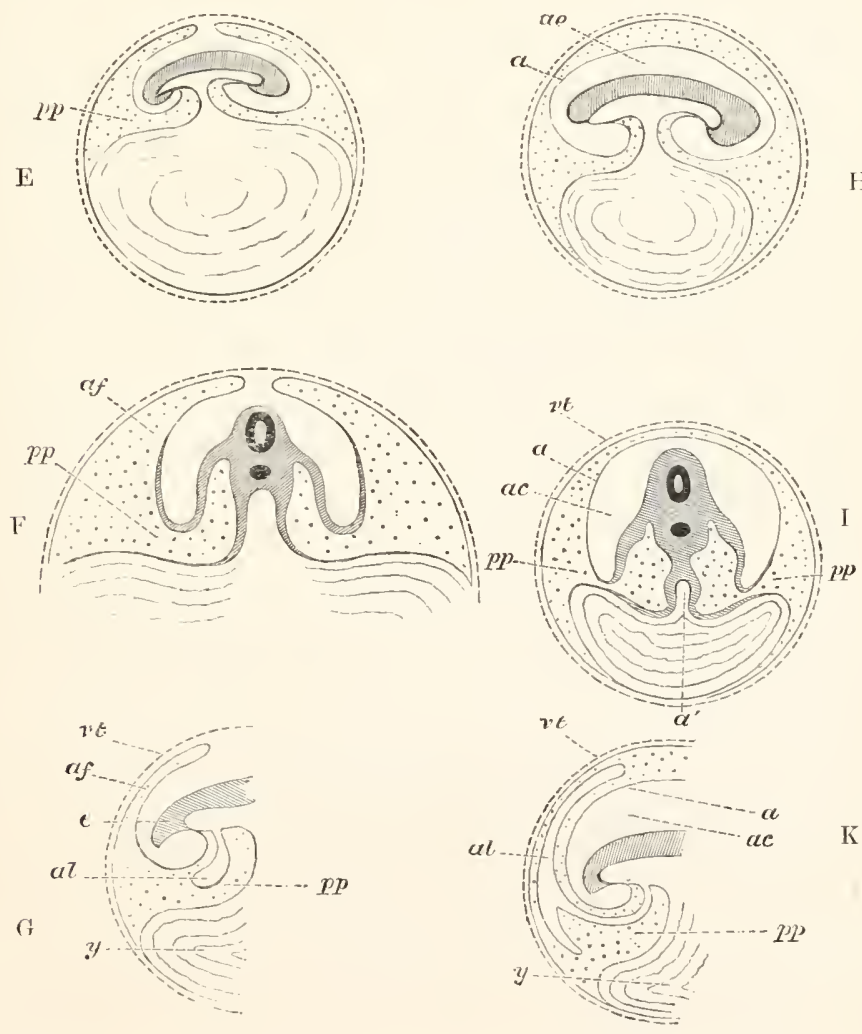
the still wide splanchnic stalk. At the end of the stalk, which is as yet short, it bends outwards again and spreads over the surface of the yolk. The somatopleure, folded in less than the splanchnopleure to form the wider somatic stalk, sooner bends round and runs outwards again. At a little distance from both the head and the tail it is raised up into a fold, af, af, that in front of the head being the highest. These are the amniotic folds. Descending from either fold, it speedily joins the splanchnopleure again, and the two, once more united into an uncleft membrane, extend some way downwards over the yolk, the limit or outer margin of the opaque area not being shewn. All the space between the somatopleure and the splanchnopleure is shaded with dots, $p p$. Close to the body this space may be called the pleuroperitoneal cavity; but outside the body it runs up into either amniotic fold, and also extends some little way over the yolk.

$D$ represents the tail-end at abont the same stage on a more enlarged scale, in order to illustrate the position of the allantois al (which was for the sake of simplicity omitted in C), shewn as a bud from the splanchnopleure, stretching downwards in to the pleuroperitoneal cavity $\mathrm{pp}$. The dotted area representing as before the whole space between the splanchnopleture and the somatopleme, it is evident that a way is open for the allantois to extend from its present position into the space between the two limbs of the amniotic fold $a f$.

E, also a longitudinal section, represents a stage still farther advanced. Both splanchnic and somatic stalks are much narrowed, especially the former, the cavity of the alimentary canal being now connected with the cavity of the yolk by a mere canal. The folds of the amnion are spreading over the top of the embryo and nearly meet. Each fold consists of two walls or limbs, the space between which (dotted) is as before merely a part of the space between the somatopleure and splanchnopleure. Between these arched ammiotic folds and the body of the embryo is a space not as yet entirely closed in.

$\mathrm{F}$ represents on a different scale a transverse section of $\mathrm{E}$ taken throngh the middle of the splanchmic stalk. The dark ring in the body of the embryo shews the position of the neural canal, below which is a black spot, marking the notochord. On either side of the notochord the divergence of somatopleure and splanchnopleure is obvious. The splanchnopleure, more or less thickened, is somewhat bent in towards the middle line, but the two sides do not unite, the alimentary canal being as yet open below at this spot; after converging somewhat they diverge again and run outwards over the yolk. The somatopleure, folded in to some extent to form the body-walls, soon bends outwards again, and is almost immediately raised up into the lateral folds of the amnion af. The continuity of the pleuroperitoneal cavity, within the body, with the interior of the amniotic fold, outside the body, is evident; both cavities are dotted.

$G$, which corresponds to $D$ at a later stage, is introduced to shew the manner in which the allantois, now a considerable hollow body, whose cavity is continuous with that of the alimentary canal, becomes directed towards the amniotic fold.

In $\mathrm{H}$ a longitudinal, and $\mathrm{I}$ a transverse section of later date, great changes have taken place. The several folds of the amnion have met and coalesced above the body of the embryo. The inner limbs of the several folds have united into a single membrane (a), which encloses a space (ae) round the embryo. This membrane $a$ is the amnion proper, and the cavity within it, i.e. between it and the embryo, is the cavity of the ammion cortaining the liquor amnii. The allantois is omitted for the sake of simplicity.

It will be seen that the amnion a now forms in every direction the termination of the somatopleure; the peripheral portions of the somatopleure, the mited outer or descending limbs of the folds af in C, D, F, G having been eut adrift, and now forming an independent continuous membrane, the serous membrane, immediately underneath the vitelline membrane.

In I the splanchnopleure is seen converging to complete the closure of the alimentary canal $a^{\prime}$ even at the stalk (elsewhere the canal has of conrse long been closed in), and then spreading ontwards as before over the yolk. The point at which it rnites with the somatopleure, marking the extreme limit of the cleavage of the mesoblast, is now much nearer the lower pole of the diminished yolk.

As a result of these several changes, a great increase in the dotted space has taken place. It is now possible to pass from the actual peritoneal cavity within the body, on the one hand round a great portion of the circumference of the yolk, and on the other hand above the amnion $a$, in the space between it and the serous envelope.

Into this space the allantois is seen spreading in $\mathrm{K}$ at $a l$.

In I the splanchnopleure has completely invested the yolk-sack, but at the lower pole of the yolk is still continuous with that peripheral remnant of the somatopleure 
now called the serous membrane. In other words, cleavage of the mesoblast has been carried all round the yolk (ys) except at the very lower pole.
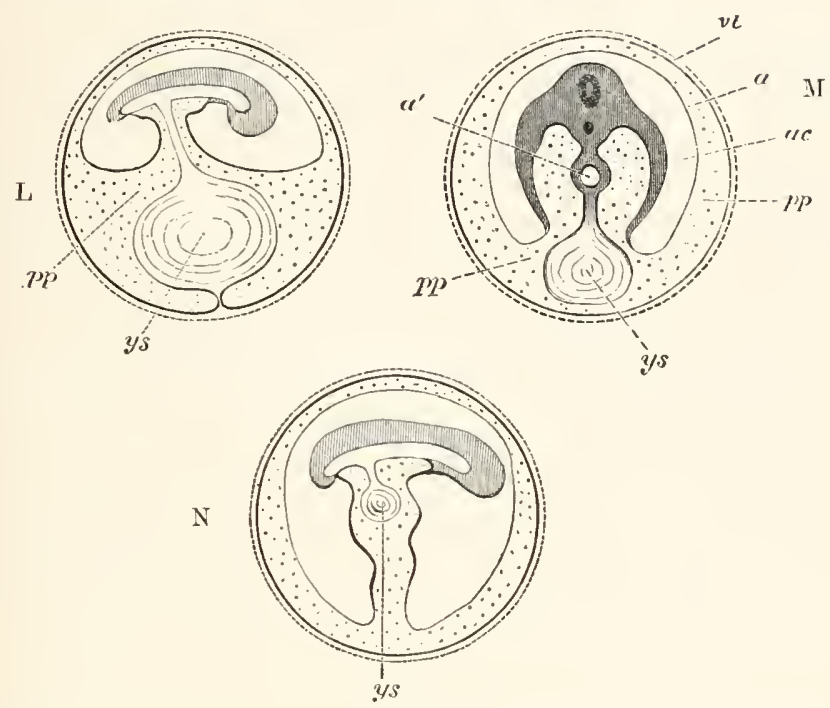

In $\mathrm{M}$ the cleavage has been carried through the pole itself; the peripheral portion of the splanchnopleure forms a complete investment of the yolk quite uneonnected with the peripheral portion of the somatopleure, which now exists as a continuous membrane lining the interior of the shell. The yolk-sack $(y s)$ is therefore quite loose in the pleuroperitoneal cavity, being connected only with the alimentary canal $\left(a^{\prime}\right)$ by a solid pedicle.

Lastly, in $\mathrm{N}$ the yolk-sack $(y s)$ is shewn being withdrawn into the cavity of the body of the embryo. The allantois is as before, for the sake of simplicity, omitted; its pedicle would of course lie by the side of $y s$ in the somatic stalk marked by the usual dotted shading.

It may be repeated that the above are diagrams, the various spaces being shewn distended, whereas in many of them in the actual egg the walls have collapsed, and are in near juxtaposition.

drawn backwards over the developing head of the embryo. The fold thus covering the head is in due time accompanied by similar folds of somatopleure, starting at some little distance behind the tail, and at some little distance from the side (fig. 121, C, D, E, F and $116 \mathrm{~cm}$ ). In this way the embryo becomes surrounded by a series of folds of thin somatopleure, which form a continuous wall all round it. All are drawn gradually over the body of the embryo, and at last meet and completely coalesce (fig. 121, H, I and $117 \mathrm{Am}$ ), all traces of their junction being removed. Beneath these united folds there is therefore a cavity, within which the embryo lies (fig. 121, $\mathrm{H}$ ae). This cavity is the cavity of the amnion.

Each fold is necessarily formed of two limbs, both limbs consisting of epiblast and a very thin layer of mesoblast; but in one limb the epiblast looks towards the embryo, while in the other it 
looks away from it. The space between the two limbs of the fold, as can easily be seen in fig. 121, is really part of the space between the somatopleure and splanchnopleure; it is therefore continuous with the general space, part of which afterwards becomes the pleuroperitoneal cavity of the body, shaded with dots in the figure and marked $\left(\begin{array}{ll}p & p\end{array}\right)$; so that it is possible to pass from the cavity between the two limbs of the amniotic folds into the cavity which surrounds the alimentary canal. When the several folds meet and coalesce together above the embryo, they unite in such a way that all their inner limbs unite to form a continuous inner membrane or sack, and all their outer limbs a similarly continuous outer membrane or sack. The inner membrane thus built up forms a completely closed sack round the body of the embryo, and is called the amniotic sack, or amnion proper (fig. 121, H, I, \&c. a), and the fluid which it afterwards contains is called the amniotic fluid, or liquor amnii. The space between the inner and outer sack is, from the mode of its formation, simply a part of the general cavity found everywhere between somatopleure and splanchnopleure. The outer sack over the embryo lies close under the vitelline membrane, and the cavity between it and the true amnion is gradually extended over the whole yolk sack.

The actual manner in which the amniotic folds meet is somewhat peculiar (His and Kölliker). The head fold of the amnion is the earliest

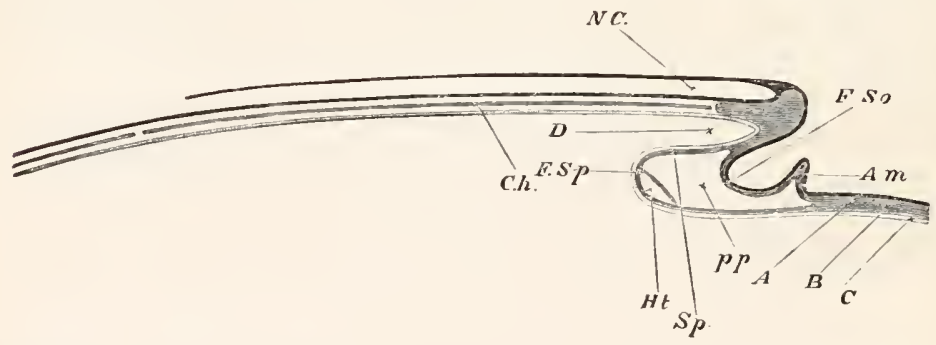

Fig. 122. Diagramatic longltudinal section throdgli the axis of an Embryo.

The section is supposed to be made at a time when the head-fold has commenced but the tail-fold has not yet appeared.

F.So, fold of the somatopleure. F.SP. fold of the splanchnopleure ; D. fore-gut.

$\mathrm{pp}$. pleuroperitoneal cavity between somatopleure and splanchnopleure; $\mathrm{Am}$. commencing (head) fold of the amnion. For remaining reference letters vide p. 139.

formed, and completely covers over the head before the end of the second day. The side and tail folds are later in developing. The side folds finally meet in the dorsal line, and their coalescence proceeds backwards from the head fold in a linear direction, till there is only a small opening left over the tail. This also becomes closed early on the third day. 
The allantois ${ }^{1}$ is essentially a diverticulum of the alimentary tract into which it opens immediately in front of the anus. Its walls are formed of splanchnic mesoblast with blood-vessels, within which is a lining of liypoblast. It becomes a conspicuous object on the third day of incubation, but its first development takes place at an earlier period, and is intimately connected with the formation of the posterior section of the gut.

At the time of the folding in of the hinder end of the mesenteron the splitting of the mesoblast into somatopleure and splanchnopleure has extended up to the border of the hinder division of the primitive streak. As has been already mentioned, the ventral wall of the postanal section of the alimentary tract is formed by the primitive streak. Immediately in front of this is the involution which forms the proctodxum; while the wall of the hindgut in front of the anus owes its origin to a folding in of the splanchnopleure.

The allantois first appears as a protuberance of the splanchnopleure just in front of the anus. This protuberance arises, however, before the splanchnopleure has begun to be tucked in so as to form the ventral wall of the hindgut; and it then forms a diverticulum (fig. $123 \mathrm{~A}, \mathrm{All}$ ) the open end of which is directed forward, while its blind end points somewhat upwards and towards the peritoneal space behind the embryo.

A.

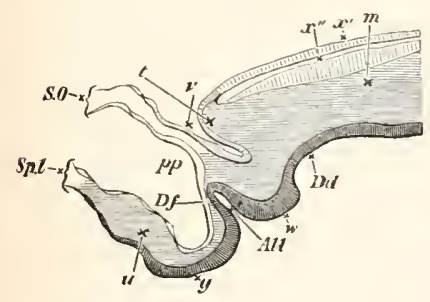

B.

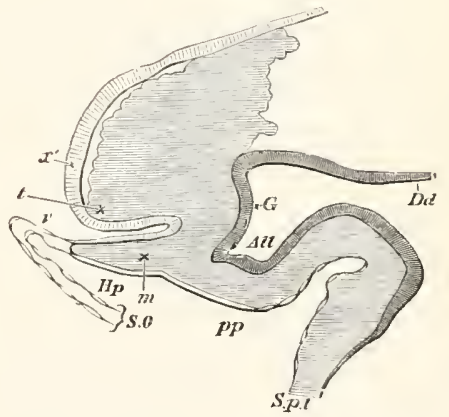

Fig. 123. Two longitudinat sections of the tail-end of an Embryo Chick to

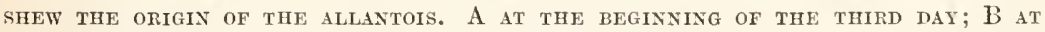
THE MIDDLE OF THE THIRD DAY. (After Dobrynin.)

$t$. the tail; $m$. the mesoblast of the body, about to form the mesoblastic somites; $x^{\prime}$. the roof of $x^{\prime \prime}$. the neural canal; $D d$. the hind end of the hindgut; So. somato. pleure; Spl. splanchnopleure; $u$. the mesoblast of the splanchnopleure carrying the vessels of the yolk-sack; $p p$. pleuroperitoneal cavity; $D f$. the epithelium lining the pleuroperitoneal cavity; All. the commencing allantois; $u$. projection formed by anterior and posterior divisions of the primitive streak; $y$. hypoblast which will form the rentral wall of the hindgut; $v$. anal invagination; $G$. eloaca.

${ }^{1}$ For details on the development of the allantois the reader is referred to the works of Kölliker (No. I35), Gasser (No. I27), and for a peculiar view on the subject Kupffer (No. I36). In addition to these works he may refer to Dobrynin "Ueber die erste Anlage der Allantois." Sitz. der k. Akad. Wien, Bd. 64, 1871. E. Gasser, Reiträge zur Entwicklungsgeschichte d. Allantois, ete. 
As the hindgut becomes folded in the allantois shifts its position, and forms (figs. $123 \mathrm{~B}$ and 124 ) a rather wide vesicle lying immediately below the hind end of the digestive canal, with which it communicates freely by a still considerable opening; its blind end projects into the pleuroperitoneal cavity below.

Still later the allantois grows forward, and becomes a large spherical vesicle, still however remaining connected with the cloaca by a narrow canal which forms its neck or stalk (fig. $121 \mathrm{G}, a l$ ). From the first the allantois lies in the pleuroperitoneal cavity. In

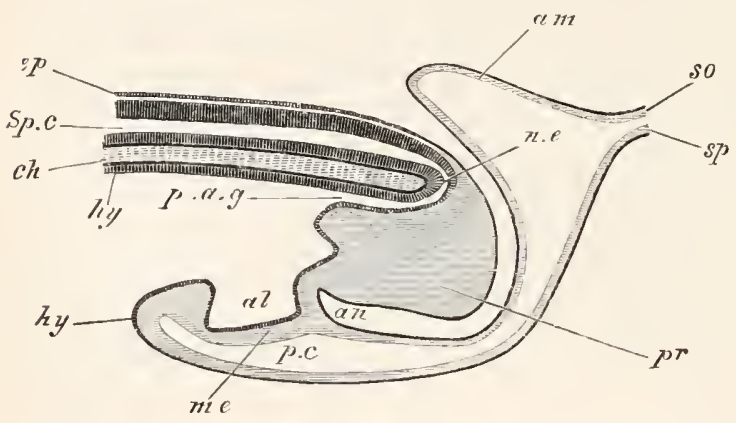

Fig. 124. Diagramatic longitudinal section throdgh the posterior END OF AN Eurryo Bird at the time of the formation of the Allantois.

ep. epiblast; Sp.c. spinal canal; ch. notochord; n.e. neurenteric canal; hy. hypoblast; p.a.g. postanal gut; pr. remains of primitive streak folded in on the ventral side; al. allantois; me. mesoblast; an. point where anus will be formed; p.c. perivisceral cavity; am. amnion; so. somatopleure; sp. splanchnopleure. this cavity it grows forwards till it reaches the front limit of the hindgut, where the splanchnopleure turns back to enclose the yolk-sack. It does not during the third day project beyond this point; but on the fourth day begins to pass out beyond the body of the chick, along the as yet wide space between the splanchnic and somatic stalks of the embryo, on its way to the space between the external and internal folds of the amnion, which it will be remembered is directly continuous with the pleuroperitoneal cavity (fig. $121 \mathrm{~K}$ ). In this space it eventually spreads out over the whole body of the chick. On the first half of the fourth day the vesicle is still very small, and its grow th is not very rapid. Its mesoblast wall still remains very thick. In the latter half of the day its growth becomes very rapid, and it forms a very conspicuous object in a chick of that date (fig. 118, $A l$ ). At the same time its bloodvessels become important. It receives its supply of blood from two branches of the iliac arteries known as the allantoic arteries ${ }^{1}$, and the blood is brought back from it by two allantoic veins which run along in the body walls (fig. 119) and after uniting into a single trunk fall into the vitelline vein close behind the liver.

Before dealing with the later history of the fœtal membranes, it will be convenient to complete the history of the yolk sack.

1 I propose to call these arteries and the corresponding veins the allantoic arteries and veins, instead of using the confusing term 'umbilical.' 
Yolk-Sack. The origin of the area opaca has already been described. It rapidly extends over the yolk underneath the vitelline membrane; and is composed of epiblast and of the hypoblast of the geminal wall continuous with that of the area pellucida, which on the fourth day takes the form of a more or less complete layer of columnar cells ${ }^{1}$. Between the epiblast and hypoblast there is a layer of mesoblast, which does not extend as far as the two other layers. The yolk is completely surrounded by the seventh day.

T'owards the end of the first day blood-vessels begin to be developed in the inner part of the mesoblast of the area opaca. Their development is completed on the second day; and the region through which they extend is known as the area vasculosa. The area

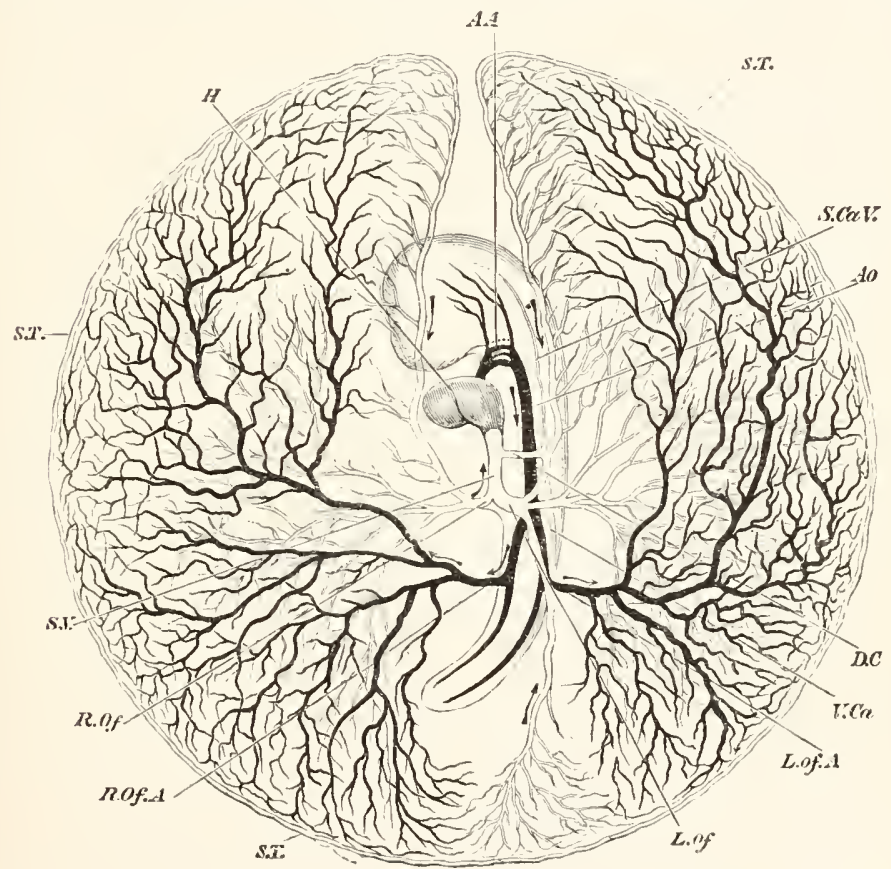

Fig. 125. Diagram of the circulation of the Yolk-Sack at the end of the third DaY OF INCUBation.

$H$. heart; $A A$. the second, third and fourth aortic arches; the first has become obliterated in its median portion, but is continued at its proximal end as the external carotid, and at its distal end as the internal carotid ; $A O$. dorsal a.orta ; L.Of.A. left vitelline artery; R.Of.A. right vitelline artery; S.T. sinus terminalis; L.Of. left vitelline vein; R.Of. right vitelline vein; S.V. sinus venosus; D.C. ductus Cuvieri ; S.Ca.V. superior cardinal vein ; V.Ca. inferior cardinal vein. The veins are marked in ontline and the arteries are black. The whole blastoderm has been removed from the egg and is supposed to be viewed from below. Hence the left is seen on the right, and vice versa.

1 Further investigations are required as to the character of this layer.

B. F. II. 
vasculosa also grows round the yolk, and completely encloses it not long after the area opaca. The part of the blastoderm which thus encloses the yolk forms the yolk-sack. The splitting of the mesoblast gradually extends to the mesoblast of the yolk-sack, and eventually the somatopleure of the sack, which is continuous, it will be remembered, with the outer limb of the amnion, separates completely from the splanchnopleure; and between the two the allantois inserts itself. These features are represented in fig. $121 \mathrm{E}, \mathrm{K}$, and L.

The circulation of the yolk-sack is most important during the third day of incubation. The arrangement of the vessels during that day is shewn in fig. 125.

The blood leaving the body of the embryo by the vitelline arteries (fig. 125, R.Of.A, L.Of.A), which are branches of the dorsal aorta, is carried to the small vessels and capillaries of the vascular area, a small portion only being appropriated by the pellucid area.

From the vascular area part of the blood retums directly to the sinus venosus by the main lateral trunks of the vitelline veins (R.Of., L.Of), and so to the heart. During the second day these venous trunks join the body of the embryo considerably in front of, that is nearer, the head than the corresponding arterial ones. Towards the end of the third day, owing to the continued lengthening of the heart, the veins and arteries run not only parallel to each other, but almost in the same line, the points at which they respectively join and leave the body being nearly at the same distance from the head.

The rest of the blood brought by the vitelline arteries finds its way into the lateral portions of a venous trunk bounding the vascular area, which is known as the sinus terminalis, S.T., and there divides on each side into two streams. Of these, the two which, one on either side, flow backward, meet at a point about opposite to the tail of the embryo, and are conveyed along a distinct vein which, ruming straight forward parallel to the axis of the embryo, empties itself into the left vitelline vein. The two forward streams reaching a gap in the front part of the sinus terminalis fall into either one, or in some cases two veins, which run straight backwards parallel to the axis of the embryo, and so reach the roots of the heart. When one such vein only is present it joins the left vitelline trunk; where there are two they join the left and right vitelline trunks respectively. The left vein is always considerably larger than the right; and the latter when present rapidly gets smaller and speedily disappears. After the third day, although the vascular area goes on increasing in size until it finally all but encompasses the yolk, the prominence of the sinus terminalis becomes less and less.

The foetal membranes and the yolk-sack may conveniently be treated of together in the description of their later changes and final fate.

On the sixth and seventh days they exhibit changes of great importance. 
The ammion, at its complete closure on the fourth day, very closely invested the body of the chick: the true cavity of the ammion was then therefore very small. On the fifth day fluid hegins to collect in the cavity, and raises the membrane of the amnion to some distance from the embryo. The cavity becomes still larger by the sixth day, and on the seventh day is of very considerable dimensions, the fluid increasing with it. On the sixth day Von Baer observed movements of the embryo, chiefly of the limbs; he attributes them to the stimulation of the cold air on opening the egg. By the seventh day very obvious movements begin to appear in the amnion itself; slow vermicular contractions creeping rhythmically over it. The amnion in fact begins to pulsate slowly and rhythmically, and by its pulsation the embryo is rocked to and fro in the egg. This pulsation is probably due to the contraction of involuntary muscular fibres, which seem to be present in the attenuated portion of the mesoblast, forming part of the amniotic fold. Similar movements are also seen in the allantois at a considerably later period.

The growth of the allantois has been very rapid, and it forms a flattened bag, covering the right side of the embryo, and rapidly spreading ont in all directions between the primitive folds of the amnion, that is, between the amnion proper and the false amnion or serous envelope. It is filled with fluid, so that in spite of its flattened form its opposite walls are distinctly separated from each other.

The vascular area has become still further extended than on the fifth day, but with a corresponding loss in the definite character of its blood-vessels. The sinus terminalis has indeed by the end of the seventh day lost all its previous distinctness; and the vessels which brought back the blood from it to the heart are no longer to be seen.

Both the vitelline arteries and veins now pass to and from the body of the chick as single trunks, assuming more and more the appearance of being merely branches of the mesenteric vessels.

'The yolk is still more fluid than on the previous day, and its bulk has (according to Von Baer) increased. This can only be due to its absorbing the white of the egg, which indeed is diminishing rapiilly.

During the eighth, ninth, and tenth days, the amnion does not undergo any very important changes. Its cavity is still filled with fluid, and on the eighth day its pulsations are at their height, henceforward diminishing in intensity.

The splitting of the mesoblast has now exterded to the outer limit of the vascular area, i.e. over about three-quarters of the yolk-sack. 'The somatopleure at this point is continuous (as can be easily seen by reference to fig. 121) with the original outer fold of the amnion. It thus comes about that the further splitting of the mesoblast merely enlarges the cavity in which the allantois lies. The growth of this organ keeps pace with that of the cavity in which it is placer. Spread out over the greater part of the yolk-sack as a 
flattened bag filled with fluid, it now serves as the chief organ of respiration. It is indeed very vascular and a marked difference may be observed between the colour of the blood in the outgoing and the returning vessels.

The yolk now begins to diminish rapidly in bulk. The yolk-sack becomes flaccid, and on the eleventh day is thrown into a series of internal folds, abundantly supplied by large venous trunks. By this means the surface of absorption is largely increased, and the yolk is more and more rapidly taken up by the blood-vessels, and in a partially assimilated condition transferred to the body of the embryo ${ }^{1}$.

By the eleventh day the abdominal parietes, though still much looser and less firm than the walls of the ehest, may be said to be definitely established; and the loops of intestine, which have hitherto been hanging down into the somatic stalk, are henceforward confined within the cavity of the abdomen. The body of the embryo is therefore completed; but it still remains connected with its various appendages by a narrow somatic umbilicus, in which run the stalk of the allantois and the solid cord suspending the yolk sack.

The cleavage of the mesoblast is still progressing, and the yolk is completely invested by a splanchnopleural sack.

T'he allantois meanwhile spreads out rapidly, and lies over the embryo close under the shell, being separated from the shell membrane by nothing more than the attenuated serous envelope, formed out of the outer primitive fold of the ammion and the remains of the vitelline membrane. With this membrane the allantois partially coalesces, and in opening an egg at the later stages of incubation, unless care be taken, the allantois is in danger of being torn in the removal of the shell-membrane. As the allantois increases in size and inportance, the allantoic vessels are correspondingly developed.

On about the sixteenth day, the white having entirely disappeared, the cleavage of the mesoblast is carried right over the pole of the yolk opposite the embryo, and is thus completed (fig. 121). The yolksack now, like the allantois which closely wraps it all round, lies loose in a space bounded ontside the body by the serous membrane, and continuous with the pleuroperitoneal cavity of the body of the embryo. Deposits of urates now become abundant in the allantoic fluid.

The loose and flaccid walls of the abdomen enclose a space which the empty intestines are far from filling, and on the nineteenth day the yolk-sack. diminished greatly in bulk but still of some considerable size, is withdrawn through the somatic stalk into the abdominal cavity, which it largely distends. Outside the embryo there now remains nothing but the highly vascular allantois and the bloodless serous membrane and amnion. The amnion, whose fluid during the later days of incubation rapidly diminishes, is continnous at the umbilicus with the body-walls of the embryo. The serous membrane (or outer primitive amniotic fold) is, by the completion of the cleavage

${ }^{1}$ For details on this subject vide A. Conrty, "Structure des Appendices Vitellins chez le Ponlet." An. Sci. Nat. Ser. III. Vol. rx. 1848. 
of the mesoblast and the withdrawal of the yolk-sack, entirely separated from the embryo. The cavity of the allantois, by means of its stalk passing through the umbilicus, is of course continuous with the cloaca.

When the chick is about to be hatched it thrusts its beak through the egg-membranes and begins to breathe the air contained in the air chamber. Thereupon the pulmonary circulation becomes functionally actire, and at the same time blood ceases to flow through the allantoic arteries. The allantois shrivels up, the umbilicus becomes completely closed, and the chick, piercing the shell at the broar end of the egg with repeated blows of its beak, casts off the dried remains of allantois, amnion and serous membrane, and steps out into the world.

\section{Bibliography.}

( 17 ) K. E. ron Baer. "Ueb. Entwicklungsgeschichte d. Thiere." Königsherg, $1828-1837$.

(iIs) F. M. Balfour. "The development and growth of the lavers of the Blastoderm," ant "On the disappearance of the Primitive Groove in the Embryo Chick." Quart. J. of Micros. Science, Yol. xir. 1873.

(гі) M. Brann. "Die Entwieklung d. Wellenpapagei's." Part I. Arbeit. $d$. zool. -zoot. Instit. Ḧ̈̈rzurg, Vol. v. 1879.

( 120$)$ M. Braun. "Aus d. Entwick. d. Papageien; I. Rüickenmark; II. Entwicklung d. Nesolerms; III. Die Verbindungen zwischen Rückenmark u. Darm bei Vögeln." Verh. d. phys,-med. Ges. zu W"ïrzburg. N. F. Bd. xıv, and x₹. 1879 an 11880 .

(I21) J. Disse. "Die Entwicklung des mittleren Keimblattes im Hülnerei." Archiv fiir mike. Anat., Vol. xv. 1878.

(1 22 ) J. Disse. "Die Entstehung d. Blutes 11. d. ersten Gefässe im Hiihnerei." Archiv fo mikr. Anat., Tol. xvi. 1879.

(I23) Fr. Durante. "Sulla struttura della macula germinativa delle nova di Gallina." Ricerche nel Laboratorio di Anatomia lella R. Universitì di Roma.

(124) E. Dursy. Der, Primitivatreif des Hïlnchens. 1867.

(125) II. Duval. "Etude sur la lime primitive de l'embryon de Poulet." Annales des Sciences Naturelles, Vol. vin. 1879.

( 26$)$ M. Foster and F. M. Balfour. Elements of Embryology. Part I. London, 1874.

(I27) Gasser. "Der Primitivstreifen bei Vogelembryonen." Schriften $d$. Gesell. zur Beförd. d. gesammten Naturwiss. zu Marburg, Vol. II. Supplement I. 1879.

(I28) A. Götte. "Beiträge zur Entwicklungsgeschichte d. Wirbelthiere. II. Die Bildung d. Keimblatter u. d. Blutes im Huihnerei." Archiv fiir mikr. Anat., Vol, $x$. 1874 .

(г 29) V. Hensen. "Embryol. Mitth." Arehir f. mikr. Anat., Vol. III. 1867. 1868.

(เzo) W. His. Untersuch. üb. d. erste Anlage d. Wirbelthierleibes. Leipzig,

(izI) W. His. Unsere Körperform und das physiol. Problem ihrer Entstehung. Leipzig, 1875 .

(132) W. His. " Der Keimwall des Hïhnereies u. d. Entstehung d. parablastisehen Zellen." Zeit. f. Anut. u. Entwicklungsgeschichte. Bi. 1. 1876.

(133) W. His. "Neue Untersuchungen üb. die Bildung des Hühnerembryo I." Archiv f. Auat. u. Plyys. 1877.

(I34) E. Klein. "Das mittlere Keimblatt in seiner Bezieh. z. Entwick, d. ers. Blutgefässe und Blutkörp. im Hühnerembryo." Sitzungsber. Wien. Aliad., Vol. Lxnr. 1871 .

(I35) A. Kölliker. Entwichlungsgeschichte d. Menschen u. d. hïheren Thiere. Leipzig, 1879. 
(136) C. Kupffer, "Die Entsteh. d. Allantois u. d. Gastrula d. Wirbelth.' Zoolog. Anzeiger, Vol. I1. 1879, pp. 520, 593, 612.

(r37) C. Kupffer and B. Benecke. "Photogramme z. Ontogenie d. Vögel.' Nov. det. d. k. Leop.-Carol.-Dentsehen Akad. d. Naturforseher, Vol, xul. 1879.

(138) J. Oellacher. "Untersuchungen über die Furchung u. Blatterbildung im Hühnerei." Stricker's Studien. 1870. 1817.

(139) C. H. Pander. Beiträge z. Entwiek, d. Hünehens in Eie. Würzburg,

( 1 fo) A. Rauber. "Ueber die Embryonalanlage des Hiihnchens." Centralblatt fiir d. medie. Wissensehaften. 1874-75.

(141) A. Rauber. Ueber die Stellung des Hühnehens im Entwicklungsplan. 1876.

$(\mathrm{I}+2)$ A. Rauber. "Primitivrinne und Urmund. Beiträge zur Entwicklungsgeschichte des Hiihnehens." IForphol. Jahrbuch, B. 11. 1876.

$(1+3)$ A. Rauber. Primitivstreifen und Neurula der Wirbelthiere in normaler und pathologiseher Beziehnng. 1877.

$\left({ }_{1}+4\right)$ R. Remak. Untersneh. ïb. d. Entwieklung d. Wirbelthiere. Berlin, 1850_55.

$(\mathrm{I}+5)$ S. L. Schenk. "Beiträge z. Lehre v. d. Organanlage im motorischen Keimblatt." Sitz. Wien. Akad., Vol. Lv11. 1860.

$(1+6)$ S. L. Schenk. "Beiträge z. Lehre v, Amnion." Archiv f. mikr. Anat., Vol. vil. 1871 .

$(\mathrm{I}+7)$ S. L. Schenk. Lehrbueh d. vergleieh. Embryol. d. Wirbelthiere. Wien, 1874.

(148) S. Stricker. "Mittheil. üb. d. selbstständigen Bewegungen embryonaler Zellen." Sitz. ITien. Akad., Vol. xum. 1864.

$(1+9)$ S. Stricker. "Beiträge zur Kenntniss des Hühnereies." Wiener Sitzungsber., Vol. Liv. 1866.

(i 50$)$ H. Virchow. Ueber d. Epithel d. Dottersaekes im Hüherei. Inaug. Diss. Berlin, 1875.

(I, I) W. Waldeyer. "Ueber die Keimblätter und den Primitivstreifen bei der Entwicklung des Hiihuerembryo." Zeitsehrift fïr rationelle Mediein. 1869.

(I52) C. F. Wolff. Theoria generationis. Halæ, 1759 .

(153) C. F. Wolff. Ueb. d. Bildung d. Darmeanals im bebrüteten Hünehen. Halle, 1812. 


\title{
CHAP'TER IX.
}

\author{
REPTILIA.
}

'THe formation of the germinal layers in the Reptilia is very imperfectly known. The Lizard has been studied in this respect more completely than other types, and there are a few scattered observations on Turtles and Snakes.

The ovum has in all Reptilia a very similar structure to that in Birds. Impregnation is effected in the upper part of the oviduct, and the early stages of development invariably take place in the oviduct. A few forms are viviparous, viz. some of the blindworms amongst Lizards (Anguis, Seps), and some of the Viperide and Hydrophidx amongst the Serpents. In the majority of cases, however, the eggs are laid in moist earth, sand, \&c. Around the true ovum an egg shell (of the same general nature as that in birds, though usually soft), and a variable quantity of albumen, are deposited in the oviduct. The extent to which development has proceeded in the oviparous forms before the eggs are laid varies greatly in different species.

The general features of the development (for a knowledge of which we are mainly indebted to Rathke's beautiful memoirs), the structure of the amnion and allantois, \&c. are very much the same as in Birds.

The Lizards will be taken as type of the class, and a few noteworthy points in the development of other groups will be dealt with at the close of the Chapter. The following description, taken in the main from my own observations, applies to Lacerta muralis.

The segmentation is meroblastic, and similar to that in Birds. At its close the resulting blastoderm becomes divided into two layers, a superficial epiblast formed of a single row of cells, and a laver below this several rows deep. Below this layer fresh segments continue for some time to be added to the blastoderm from the subjacent yolk.

The blastoderm, which is thickened at its edge, spreads rapidly over the yolk. Shortly before the yolk is half enclosed a small embryonic shield (area pellucida) nakes its appearance near the centre 
of the blastoderm. The embryonic shield is mainly distinguished from the remainder of the blastoderm by the more columnar character of its constituent epiblast cells. It is somewhat pyriform in shape, the narrower end corresponding with the future posterior end of the embryo. At the lind end of the shield a somewhat triangular primitive streak is formed, consisting of epiblast continuous below with a great mass of rounded mesoblast cells, probably mainly formed, as in the bird, by a proliferation of the epiblast. To this mass of cells the hypollast is also partially adherent. At the front end of the streak an epiblastic involution appears, which soon becomes extended into a passage open at both extremities, leading obliquely forwards throngh the epiblast to the space below

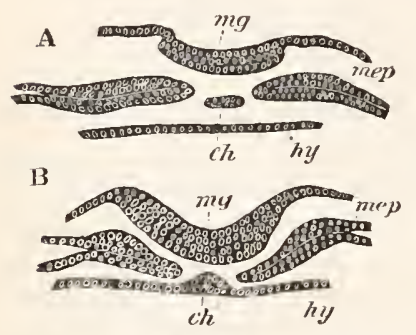
the liypoblast. The walls of the passage are formed of a layer of columnar cells continuous both with epiblast and liypoblast. In front of the primitive streak the body of the embryo becomes first differentiated by the formation of a medullary plate; and at the same time there grows out from the primitive streak a layer of mesoblast, which spreads out in all directions between the epiblast and hypoblast. In the region of the
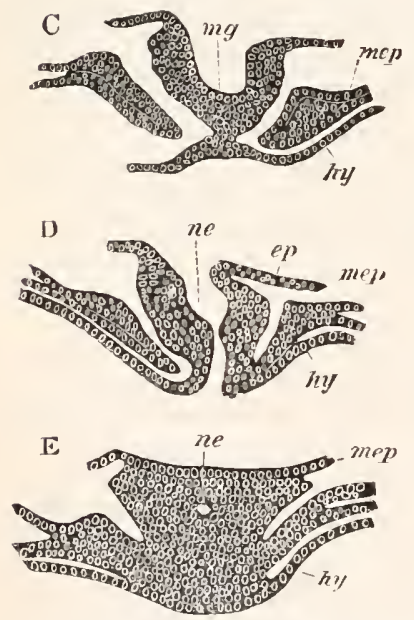

Fig. 126. Sections through AN EMBRTO OF LACERTA MUtialis LIEPRESENTED IN FIG. 129.

m.g. medullary groove; mep. mesoblastic plate; $c p$. epiblast; hy. hypoblast; ch'. notochordal thickening of hypoblast; ch. notochord; ne. neurenteric caual (blastopore). In E. ne points a diverticulum of the neurenteric canal into the primitive streak. embryo the mesoblast plate is stated by Kupffer and Benecke to be continuous across the middle line, but this appears very improbable. In a shightly later stage the medullary plate becomes marked by a shallow groove, and the mesoblast of the embryo is then undoubtedly constituted of two lateral plates, one on each side of the median line. In the median line the notochord arises as a ridge-like thickening of the hypoblast, which is continued posteriorly into the front wall of the passage mentionerl above.

The notochord does not long remain attached to the hypoblast, and the separation between the two is already effected for the greater part of the length of the embryo by the stage represented in fig. 129. Fig. 126 represents a series of sections through this embryo.

In a section (A) through the trunk of the embryo a short way in front of the primitive streak, there is a medullary 
plate with a shallow groove $(\mathrm{mg})$, well-developed mesoblastic plates $(m e p)$, already divided into somatic and splanchnic layers, and a completely formed notochord independent of the hypoblast $(h y)$. In the next section (B), taken just in front of the primitive streak, the notochord is attached to the hypoblast, and the medullary groove is deeper; while in the section following (C), which passes through the front border of the primitive streak, the notochord and hypoblast have become fused with the epiblast. The section behind (D) shews the neurenteric passage leading through the floor of the medullary groove and through the liypoblast (ne). On the right side the mesoblastic plate has become continuous with the walls of the passage. The last section (E) passes through the front part of the primitive streak behind the passage. The mesoblast, epiblast, and to some extent the hypoblast, are now fused together in the axial line, and in the middle of the fused mass is seen a narrow diverticulum (ne) which is probably equivalent to the posterior diverticulum of the neural canal in Birds (vide p. 136).

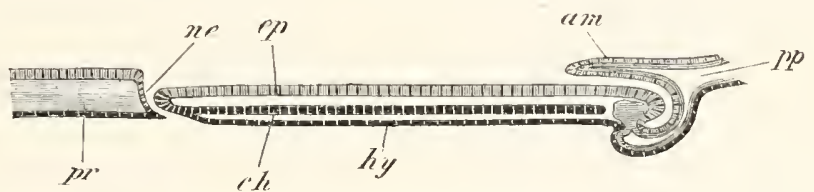

Fig. 127. Diagramatic longitudinal section of an embryo of Lacerta.

$p p$. body eavity; am. amnion; ne. neurenteric canal; $c h$. notochord; $h y$. hypoblast; $e p$. epiblast of the medullary plate; $p r$. primitive streak. In the primitive streak all the layers are partially fuseil.

The general features of the stage will best be understood by an examination of the diagrammatic longitudinal section represented in fig. 127. In front is shewn the amnion $(\mathrm{am})$, growing over the head of the embryo. The notochord $(c h)$ is seen as an independent cord for the greater part of the length of the embryo, but falls into the hypoblast shortly in front of the neurenteric passage. The neurenteric passage is shewn at ne, and behind it is the front part of the primitive streak.

It is interesting to notice the remarkable relations of the notochord to the walls of the neurenteric passage. More or less similar relations are also well marked in the case of the goose and the fowl, and support the conclusion, deducible from the lower forms of Vertebrata, that the notochord is essentially hypoblastic.

The passage at the front end of the primitive streak forms the posterior boundary of the medullary plate, though the medullary groove is not at first continued back to it. The anterior wall of this passage connects together the medullary plate and the notochordal ridge of the hypoblast. In the stage represented in fig. 126 and 129 the medullary groove has become continued back to the opening of the passage, which thus becomes enclosed in the medullary folds, and forms a true neurenteric passage ${ }^{1}$.

${ }^{1}$ Kupffer and Benecke (No, 154) give a very different account from the above of 
It will be convenient at this point to say a few words as to what is known of the further fate of the neurenteric canal, and the early development of the allantois. According to Strahl, who las worked on Lacerta vivipara, the canal grarlually closes from below upwards, and is obliterated before the completion of the neural canal. The hind end of the alimentary tract appears also to become a closed canal before this stage.

In Lacerta muralis the history appears to be somewhat different, and it is more especially to be noticed that in this species the hindgut loes not become closed till considerably after the completion of the neural canal. In a stage shortly after that last described, the neurenteric passage becomes narlower. The next stage which I have observed is considcrably later. The neural canal has become completely closed, and the flexure of the embryo has already made its appearance. There is still a well-developed, though somewhat slit-like, neurenteric passage, but from the analogy of birds, it is not impossible that it may have in the meantime closed up and opened again. It has, in any case, the same relations as in the previous stage.

It leads from the end of the medullary canal (at the point where its walls are continuous with the cells of the primitive streak) round the end of the notochord, which here becomes continuous with the medullary cord, and so through the hypoblast. The latter layer is still a flat sheet without any lateral infolding; but it gives rise, behind the neurenteric passage, to a blind posteriorly directed diverticulum, placed in the body cavity behind the embryo, and opening at the ventral face of the apparent hind end of the primitive streak. There is very little doubt that this diverticulum is the commencing allantois.

At a somewhat later stage the arrangement of these parts has undergone some changes. Their relations are shewn in the sections represented in fig. 128 .

The foremost section (A) passes through the alimentary opcning of the neurenteric passage $(n e)$. Above this opening the section passes through the prinitive streak $\left(m^{\circ}\right)$ close to its junction with the walls of the medullary canal. The hypoblast is folded in laterally, but the gut is still open below. The amnion is completely established. In the next section figured (B), the fourth of my series, the gut is completely closed in; and the mesoblast has united laterally with the axial tissue of the primitive streak. Vessels to supply the allantois are shewn at $v$.

The thrce following sections are not figured, but they present the same features as B, except that the primitive strcak gets rapidly smaller, and the lumen of the gut narrower. The section following (C) represents, I believe, only the stalk of the allantoic diverticulum. This diverticulum appears

the carly Lacertilian development, more especially in what concerns the so-called neurenteric passage. They believe this strncture to be closed below, and to form therefore a blind sack open externally. The open end of this sack they regard as the blastopore-an interpretation which accords with my own, but they regard the sack as the rudiment of the allantois, and hold that it is equivalent to the invaginated arehenteron of Amphioxus. I need searcely say that I believe Kupffer and Benceke to have made a mistake in denying the existence of the ventral opening of this organ. Kupffer in a subsequent paper (No. 155) states that my deseriptions of the structure of this organ do not correspond with the fact. I have perfect confidence in leaving the decision of this point to future observers, and may say that my observations have already been fully confirmed by Strahl (No. I60), who has also added some observations on the later stages to which I shall hereafter have occasion to allude. 
to be formed as usual of liypoblast (hy) enveloped by splanchnic mesoblast (me), and projects into the section of the body cavity present behind the embryo. Its position in the body cavity is the cause of its somewhat peculiar appearance in the figure. Had the whole section been represented the allantois would have been enclosed in a space between the serous membrane (se) and a layer of splanchnic mesoblast below which has also been omitted in fig. $\mathrm{B}^{1}$. It still points directly backwards, as it primitively does in the ehick, vide fig. $123 \mathrm{~A}$, and Gasser, No. 127, Pl. v. figs. 1 and 2. I do not understand the apparently double character of the lumen of the allantois. In the next section (not figured) the lumen of the allantoic stalk is larger, but still apparently double, while in the last section (D) the lumen is considerably enlarged and single. The neurenteric canal appears to close shortly after the stage last deseribed, though its further history has not been followed in detail.
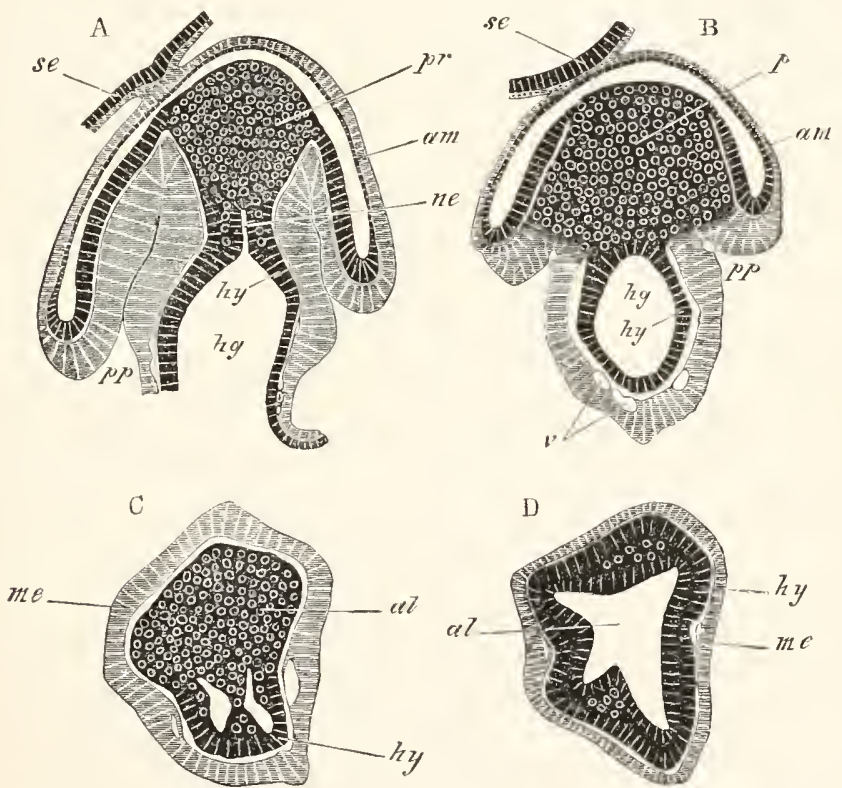

Fig, 128. Four transyerse sections through the hinder end of a young EMBRYO OF LACERTA MURALIS.

Sections A and B pass through the whole embryo, while C and D only pass through the allantois, which at this stage projects backwards into the section of the body eavity behind the primitive streak.

ne. neurenteric canal; $p r$. primitive streak; hg. hindgut; hy. hypoblast; $p p$. body cavity; am. amnion; se. serous envelope (outer limb of the amnion fold not yet separated from the inner limb or true amnion); al. allantois; me. mesoblastic wall of the allantois ; $v$. vessels passing to the allantois.

1 Owing to the difficulty of procuring material I have ouly been able to prepare the two sets of sections just described, and in the absence of a fuller series there are some points in the interpretation of the sections which must remain doubtful. 


\section{General development of the Embryo.}

The formation of the embryo commences with the appearance of

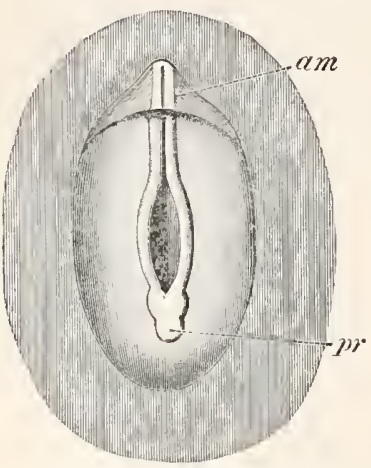

Fig. 129. Surface view of A Young enbrio of Lacerta MUTaLIS. streak. the medullary plate, the sides of which soon grow up to form the medullary folds. The medullary groove is developed anteriorly before any trace of it is visible behind. In a general way the closure of the groove takes place as in Birds, but the auterior part of the body is very early folded off, sinks into the yolk, and becomes covered over by the amnion as by a hood (figs. 127 and 129). All this takes place before the closure of the medullary canal; and the changes of this part are quite concealed from view.

The closure of the medullary canal commences in the neck, and extends forwards and backwards; and the whole region of the brain becomes closed in, while the groove is still largely open behind.

'The later stages in the development of the Lacertilian embryo do not require a detailed description, as they present the closest analogy with those already described for Aves. The embryo soon turns on to its left side; and then, becoming continuously folded off from the yolk, passes through the series of changes of form with which the reader is already familiar. An advanced embryo is represented in fig. 130. The early development and great length of the tail, which is spirally coiled on the ventral surface, is a special feature to which the attention of the reader may be caller.

\section{Embryonic Membranes and Toll-Sack.}

The early development of the cephalic portion of the amnion las already been alluded to. The first traces of it become apparent while the medullary groove is still extremely shallow. The medullary plate in the region of the head forms an axial strip of a thickish plate of epiblast. The elge of this plate coincides with the line of the amniotic fold, and as this fold rises up the two sides of the plate become bent over the embryo and give rise to the inner limb of the amnion or amnion proper. The section (fig. 127), representing the origin of the amniotic hood of the head, shews very well how the space between the two limbs of the amnion is continuous with the body cavity. The amnion very early completely encloses the embryo (fig. $128 \mathrm{~A}$ and B), and its external limb or serous membrane, after separating from the true amnion, soon approaches and fuses with the vitelline membrane.

The first development of the allantois as a diverticulum of the hypoblast covered by splanchnic mesoblast, at the apparent posterior 
end of the primitive streak, has been described on pp. 170-171. The allantois continues for some time to point directly backwards; but gradually assumes a more vent ral direction; and, as it increases in size, extends into the space between the serous nembrane and amnion, eventually to form a large, lighly vascular, flattened sack immediately below the serous membrane.

The Yolk-Sack. The blastoderm spreads in the Lizard with very great rapidity over the yolk to form the yolk sack. The early appearance of the area pellucida, or as it has been called by Kupffer and Benecke the embryonic shield, has already been noted. Outside this a vascular area, which has the same function as in the chick, is not long in making its ap-

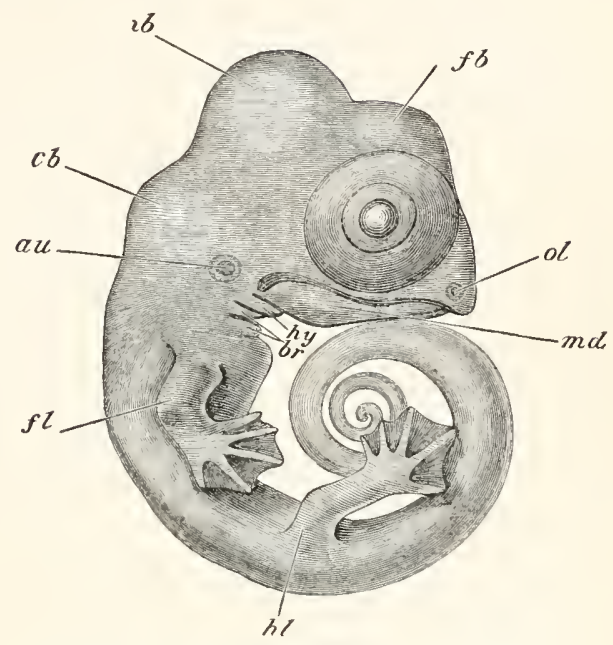

Frg, 130. Adfanced embrio of Lacerta nuRALIS AS AN OPAQUE OBJECT ${ }^{1}$.

The embryo was $7 \mathrm{~mm}$. in length in the curled up state.

$f b$. fore-brain ; $m b$. mid.brain ; $c b$. cerebellum; au. auditory vesicle (closed); ol. olfactory pit; $m d$. mandible; $h y$. hyoid arch; br. branchial arches; $f l$. fore-limb; $h l$. hind-limb. pearance. In all Reptilia the vascular channels which arise in the vascular area, and the vessels carrying the blood to and from the vascular area, are very similar to those in the chick. In the Snake the sinus terminalis never attains so conspicuous a development and in Chelonia the stage with a pair of vitelline arteries is preceded by a stage in which the vascular area is supplied, as it permanently is in many Mammals, by numerous transverse arterial trunks, coming off from the dorsal aorta (Agassiz, No. I64). The vascular area gradually envelopes the whole yolk, although it does so considerably more slowly than the general blastoderm.

Ophidia. There is, as might have been anticipated, a very close correspondence in general development between the Lacertilia and Ophidia. The embryos of all the Amniota are, during part of their development, more or less spirally coiled about their long axis. This is well marked in the chick of the third day; it is still more pronounced in the Lizard (fig. 1:30); but it reaches its maximum in the Snake. The whole Snake embryo has at the time when most coiled (Dutrochet, Rathke) somewhat the form of a Trochus. The base of the spiral is formed by the head, while the 'majority of

1 This figure was drawn for me by Professor Haddon. 
the coils are supplied by the tail. There are in all at this stage seven coils, and the spiral is right-handed.

Another point, which deserves notice in the Snake, is the absence in the embryo of all external trace of the limbs. It might have been anticipated, on the analogy of the branchial arches, that rudiments of the limbs would be preserved in the embryo even when limbs were absent in the adult. Such, however, is not the case. It is however very possible that rudiments of the branchial arches and clefts have been preserved because these structures were functional in the larva (Amphibia) after they ceased to have any importance in the adult; and that the limbs have disappeared even in the embryo because in the course of their gradual atrophy there was no advantage to the organism in their being specially preserved at any period of life ${ }^{1}$.

Chelonia ${ }^{2}$. In their early development the Chelonia resemble, so far as is known, the Lacertilia. The amnion arises early, and soon forms a great cephalic hood. Before development has proceeded very far the embryo turns over on to its left side. The tail in many species attains a very considerable development (fig. 133). The chief peculiarity in the form of the embryo (figs. 131, 132, and 133) is caused by the development of the carapace. The first rudiment of the carapace appears in the form of two longitudinal folds, extending above the line of insertion of the fore- and hind-limbs, which have already made their appearance (fig. 131). These folds are sub-

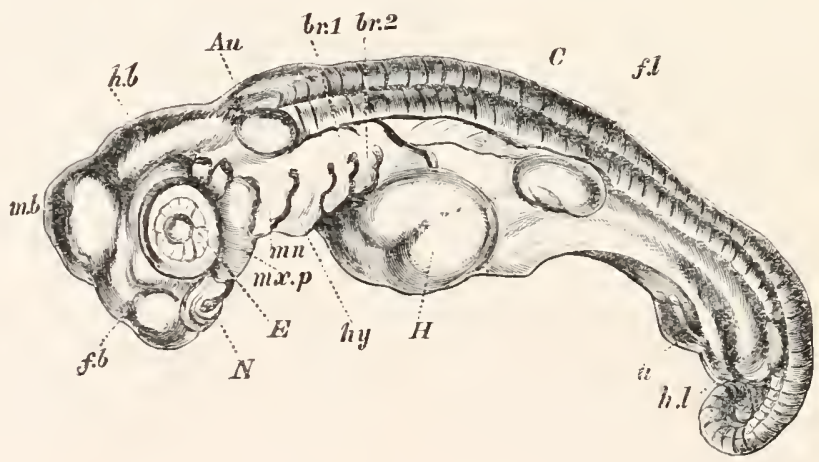

Fig. 131. Chelone midas, first stage.

$A$. auditory capsule; br. 1 and 2 , branchial arches; C. carapace; E. eye; f.b. fore-brain; f.l. fore-limb; $H$. heart; h.b. hind-brain; h.l. hind-limb; hy. hyoid; m.b. mil-brain; m.., mandible; mx.p. maxillo-palatine; N. nostril; $u$. umbilicus.

sequently prolonged so as to mark out the area of the carapace on the dorsal surface. On the surface of this area there are formed the

1 It is very probable that in those Ophidia in which traces of limbs are still preserved, that more conspicuous traces would be found in the embryos than in the adults.

2 Vide Agassiz (No. 164). Kupffer and Benecke (No. 154), and Parker (No. 165). 
horny plates (tortoise shell), and in the mesoblast below the bony elements of the carapace (figs. 132 and 133).

Immediately after hatching the yolk-sack becomes withdrawn into the body; while the external part of the allantois shrivels up.

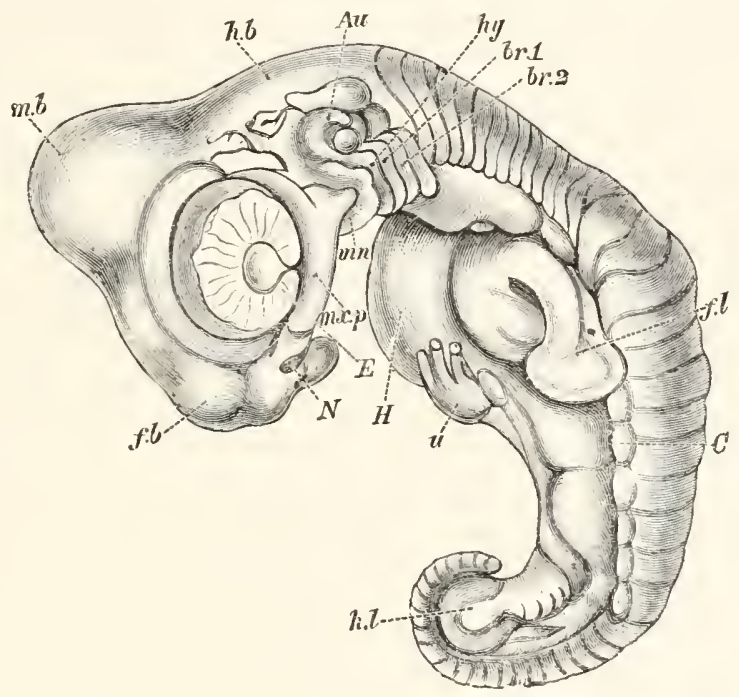

Fig. 132. Chelone midas, second stage.

Letters as in fig. 131.

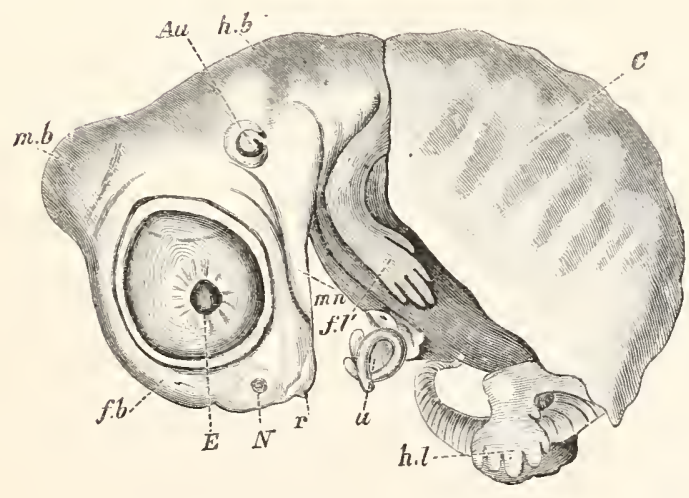

Fir. 133. Chelone mis, timin stare.

Letters as in fig. $131 . \quad r$, rostrum. 


\section{Bibliography.}

\section{General.}

(154) C. Kupffer and Benecke. Die erste Entwicklung am Ei d. Reptilien. Königsberg, 1878.

(155) C. K upffer. "Die Entstehung d. Allantois u. d. Gastrula d. Wirbelthiere." Zoologischer Anzeiger, Vol. II. 1879, pp. 520, 593, 612.

\section{Lacertilia.}

(156) F. M. Balfour. "On the early Development of the Lacertilia, together with some observations, ete." Quart. J. of Micr. Science, Vol. xIx, 1879.

(157) Emmert u. Hochstetter. "Untersuchung üb. d. Entwick. d. Eidechsen in ihren Eiern." Reil's Archiv, Vol. x. 1811.

( 5 58) M. Le reboullet. "Développement de la Truite, du Lézard et du Limnée. II. Embryologie du Lézard." An. Sci. Nat., Ser. IV., Vol. xxvir. 1862.

( 159$)$ W. K. Parker. "Structure and Devel. of the Skull in Lacertilia." Phil. Trans., Vol. 170, p. 2. 1879.

(i6o) H. Strahl. "Ueb. d. Canalis myeloentericus d. Eidechse." Schrift. d. Gesell. z. Beför. d. gesam. Naturwiss. Marburg. July 23, 1880.

\section{Ophidia.}

(161) H. Dutrochet. "Recherches s. 1. enveloppes du foetus." Mém.d. Soc. Méd. d'Emulation, Paris, Vol. vin. 1816.

(162) W. K. Parker. "On the skull of the common Snake." Phil. Trans., Vol, 169, Part II. 1878.

(163) H. Rathke. Entwick. d. Natter. Königsberg, 1839.

\section{Chelonia.}

(164) I. Agassiz. Contributions to the Natural II istory of the United States, Vol. 11, 1857. Embryology of the Turtle.

(16z) W. K. Parker. "On the development of the skull and nerves in the green Turtle." Proc, of the Roy. Soc., Vol. xxvin, 1879. Vide also Nature April 14, 1879, and Challenger Reports, Vol. I. 1880.

(166) H. Rathke. Ueb. d. Entwicklung d. Schildkröten. Braunschweig, 1848.

\section{Crocodilia.}

(167) H. Rathke. Ueber die Entwicklung d. Krokodile. Braunschweig, 1866. 


\title{
CHAPTER X.
}

\author{
MAMMALIA.
}

THE classical researches of Bischoff on the embryology of several mammalian types, as well as those of other observers, have made us acquainted with the general form of the embryos of the Placentalia, and have shewn that, except in the earliest stages of development, there is a close agreement between them. More recently Hensen, Schäfer, Kölliker, Van Beneden and Lieberkühn have sherl a large amount of light on the obscurer points of the earliest developmental periods, especially in the rabbit. For the early stages the rabbit necessarily serves as type; but there are grounds for thinking that not inconsiderable rariations are likely to he met with in other species, and it is not at present easy to asrign to some of the developmental features their true value. We have no knowledge of the early development of the Ornithodelphia or Marsupialia.

The ovum on leaving the ovary is received by the fimbriated extremity of the Fallopian tube, down which it slowly travels. It is still invested by the zona radiata, and in the rabbit an albuminous envelope is formed around it in its passage downwards. Impregnation takes place in the upper part of the Fallopian tube, and is shortly followed by the segmentation, which is remarkable amongst the Amniota for being complete.

Although this process (the details of which have beeu made known by the brilliant researches of Ed. van Benerlen) has alrealy been shortly dealt with as it occurs in the rabbit (Vol. I. p. 80) it will be convenient to describe it again with somewhat greater detail.

The ovum first divides into two nearly equal spheres, of which one is slightly larger and more transparent than the other. The larger sphere and its products will be spoken of as the epiblastic spheres, and the smaller one and its products as the hypoblastic spheres, in accordance with their different destinations.

Both the spheres are soon divided into two, and each of the four so formed into two again; and thus a stage with eight spheres ensues.

B. E. II. 
At the moment of their first separation these spheres are spherical, and arranged in two layers, one of them formed of the four epiblastic spheres, and the other of the four hypoblastic. This position is not long retained, but one of the hypoblastic spheres passes to the centre; and the whole ovum again takes a spherical form.

In the next phase of segmentation each of the four epiblastic spheres divides into two, and the ovum thus becomes constituted of twelve splieres, eight epiblastic and four hypoblastic. The epiblastic spheres have now become markedly smaller than the hypoblastic.

The four hypoblastic spheres next divide, giving rise, together with the eight epiblastic spheres, to sixteen spheres in all; which are nearly uniform in size. Of the eight hypoblastic spheres four soon pass to the centre, while the eight superficial epiblastic spheres form a kind of cup partially enclosing the hypoblastic spheres. The epiblastic spheres now divide in their turn, giving rise to sixteen spheres which largely enclose the hypoblastic spheres. The segmentation of both epiblastic and hypoblastic spheres continues, and in the course of it the epiblastic spheres spread further and further

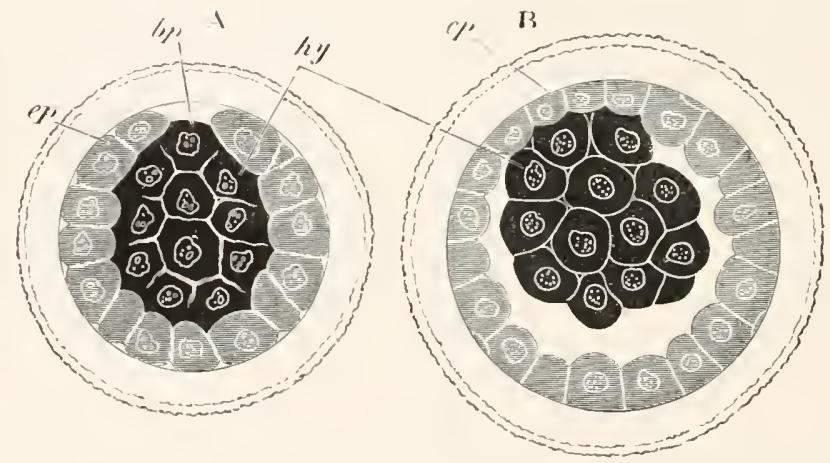

Frg, 134. Optical sections of a Rabrit's ovull at tWo stages closely Following upon the segmextation. (After E. van Beneden.)

ep. epiblast; hy. primary hypoblast; $b$. . Van Beneden's blastopore.

The shading of the epiblast and hypoblast is diagrammatic.

over the hypoblastic, so that at the close of segmentation the hypoblastic splieres constitute a central solid mass almost entirely surrounded by the epiblastic spheres. In a small circular area however the hypoblastic spheres remain for some time exposed at the surface (fig. 134 A).

The whole process of segmentation is completed in the rabbit about seventy hours after impregnation. At its close the epiblast cells, as they may now be called, are clear, and have an irregularly cubical form; while the hypoblast cells are polygonal and granular, and somewhat larger than the epiblast cells.

The opening in the epiblastic layer where the hypoblast cells are exposed on the surface may for convenience be called with Van 
Befieden the blastopore, though it is highly improbable that it in any way corresponds with the blastopore of other vertebrate ova ${ }^{1}$.

After its segmentation the ovum passes into the uterus. The epiblast cells soon grow over the blastopore and thus form a conplete superficial layer. A series of changes next take place which result in the formation of what las been called the blastodermic vesicle. To Ed. van Beneden we owe the fullest account of these changes; to Hensen and Kölliker however we are also indebted for valuable observations, especially on the later stages in the development of this vesicle.

The succeeding changes commence with the appearance of a narrow cavity between the epiblast and hypoblast, which extends so as completely to separate these two layers except in the region adjoining the original site of the blastopore (fig. 13+ B)" The cavity so formed rapidly enlarges, and with it the ovum also; which soon takes the form of a thin-walled vesicle with a large central cavity. This vesicle is the blastodermic vesicle. The greater part of its walls are formed of a single row of flattened epiblast cells; while the hypoblast cells form a small lens-shaped mass attached to the inner side of the epiblast cells (fig. 135).

In the Vespertilionidse

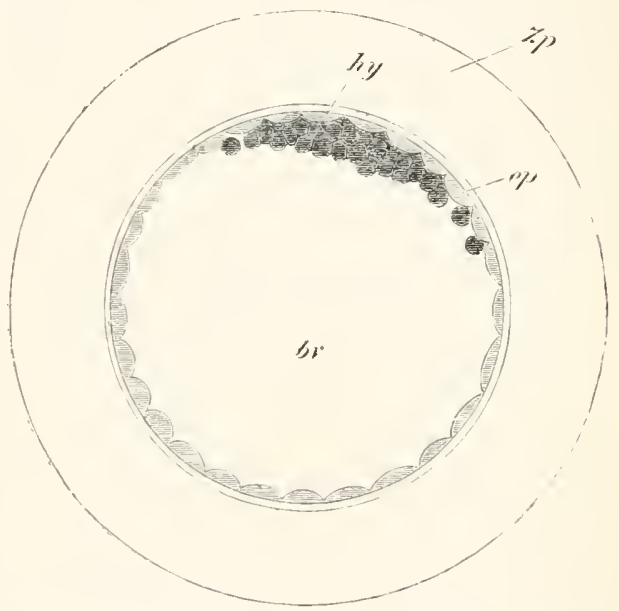

Fig. 135. RiABEIT'S OVIM BeTweEN 70- (N) HOCRS AFTER MPREgNATION. (After E. van Beneden.)

bv. cavity of blastodermic vesicle (yolk-sack); ep. epiblast; hy. primitive hypoblast; Z.p. mucous envelope (zona pellucida). Van Beneden and Julin have shewn that the ovum undergoes at the elose of segmentation changes of a more or less similar nature to those in the rabbit; the llastopore would however appear to be wider, and to persist even after the cavity of the blastodermic vesicle has commenced to be developed.

Although by this stage, which occurs in the rabbit between seventy and ninety hours after impregnatiou, the blastodermic vesicle

1 It is stated by Bischoff that shortly after impregnation, and before the commencement of the segmentation, the ova of the rabbit and guinea-pig are covered with cilia and exhibit the phenomenon of rotation. This has not been noticed by other observers.

2 Van Beneden regards it as probable that the blastopore is situated somewhat excentrically in relation to the area of attachment of the hypoblastic mass to the epiblast. 
has by no means attained its greatest dimensions, it has nevertheless grown from about $0.09 \mathrm{~mm}$. - the size of the orum at the close of segmentation-to about $0 \cdot 25$. It is enclosed by a membrane formed from the zona radiata and the mucous layer around it. The blastodermic vesicle continues to enlarge rapidly, and during the process the hypoblastic mass undergoes important changes. It spreads out on the inner side of the epiblast and at the same time loses its lens-like form and becomes flattened. The central part of it remains however thicker, and is constituted of two rows of cells, while the peripheral part, the outer boundary of which is irregular, is formed of an imperfect layer of anoboid cells which continually spread further and further within the epiblast. The central thickening of the hypoblast forms an opaque circular spot on the blastoderm, which constitutes the commencement of the embryonic area.

The history of the stages immediately following, from about the commencement of the fifth day to the seventh day, when a primitive streak makes its appearance, is imperfectly understood, and has been interpreterl very differently by Van Beneden (No. I7I) on the one hand and by Kölliker (I84), Rauber (187) and Lieberkiihn (I86) on the other. I have myself in conjunction with my pupil, Mr Heape, also conducted some investigations on these stages, which have unfortunately not as yet led me to a completely satisfactory reconciliation of the opposing views.

Van Benerlen states that abont five days after impregnation the hypoblast cells in the embryonic area become divided into two distinet stratak, an ulper stratum of sniall cells adjoining the epiblast and a lower stratum of flattencd cells which form the true hypoblast. At the edge of the embryonic area the lyypoblast is continuous with a peripheral ring of the amorboid cells of the earlier stage, which now form, except at the edge of the ring, a continuous layer of flattened cells in contact with the epiblast. During the sixth day the flattened epiblast cells are believed by Van Beneden to become columnar. The enbryonic area gradually extends itself, and as it does so becomes oval. A central lighter portion next becomes apprarent, which gradually spreads. till eventually the darker part of the embryonic area forms a cresecnt at the posterior part of the now somewhat pyriform embryonic arca. The lighter part is formed of columnar epiblast and lypoblast only, while in the clarker area a layer of the mesoblast, derived from the intermediate layer of the fiftlı clay, is also found. In this darker area the primitive streak originates early on the seventh day.

Kölliker, following the lines originally laic down by Rauber, has arrived at very different results. He starts from the three-layered condition described by Van Beneden for the fifth day, but does not give any investigations of his own as to the origin of the middle layer. He holds the onter layer to be a provisional layer of protective cells, forming part of the wall of the original vesicle, the middle layer he regards as the true epiblast and the inner laver as the hypobiast.

During the sixtl day he finds that the cells of the outer laycr gradually cease to form a continuous layer and finally disappear; while the cells of 
the middle layer become columnar, and form the colummar epiblist present in the embyonic area at the end of the sixth day. The mecoblast first takes its origin in the region and on the formation of the prinitive streak.

The investigations of Heape and myself do not extend to the first formation of the intermediate layer found on the fifth day. We find on the sixth day in germinal vesicles of about $2.2-9.5$ millimetres in diameter with embryonic areas of about $8 \mathrm{~mm}$. that the embryonic area (tig. 136) is throughout composed of

(1) A layer of Hattened hypoblast cells;

(2) A somewhat irregular layer of more columnar elements, in some places only a single row deep and in other places two or more rows deep.

(3) Flat elements on the surface, which do not, however, form a continuous layer, and are intimately attached to the columnar cells below.

Our results as to the strueture of the blastoder'm at this stage closely correspond therefore with those of Kölliker, but on one important point we have arrived at a different conclusion. Köliker states that he has never found the flattened elements in the act of becoming columnar. We believe that we have in many instances been able to trace them in the act of undergoing this change, and have attempted to shew this in our figure.

Our next oldest embryonic areas were somewhat pyriform measuring about $1.19 \mathrm{~mm}$. in length and .85 in breadth. Of these we have several, some from a rabbit in which we also met with younger still nearly circular areas. All of them had a distinctly marked posterior opacity forming a commencing primitive streak, thongh decidedly less adranced than in the blastoderm represented in fig. 140. In the younger specinnens the epiblast in firout of the primitive streak was formed of a single row of columnar cells (fig. $138 \mathrm{~A})$, no mesoblast was present and the hypoblast formed a layer of flattened cells. In the region immediately in front of the primitive streak, an irregular layer of mesoblast cells was interposed between the epiblast and hypoblast. In the anterior part of the primitive streak itself (fig. 13\& B) there was a layer of mesoblast with a consilerable lateral extension, while in the median line there was a distinct mesoblastic proliferation of epiblast cells. In the posterior sections the lateral extension of the mesoblast was less, but the mesoblast cells formed a thicker cord in the axial line.

Owing to the unsatisfactory character of our data the following attempt to fill in the history of the fifth and sixth days must be regarded as tentative ${ }^{1}$. At the commencement of the fifth day the central thickening, of what has been called above the primitive hypoblast, becomes divided into two layers: the lower of these is continuous with the peripheral hypoblast and is formed of flattened cells, while the upper one is formed of small rounded elements. The superficial epiblast again is formed of flattened cells.

During the fifth day remarkable changes take place in the epiblast of the embryonic area. It is probable that its constituent cells

1 The attempt made below to frame a consecutive history out of the contradictory data at my disposal is not entirely satisfactory. Should Kolliker's view turn out to be quite correct, the origin of the middle layer of the fifth day, which Kölliker believes to become the permanent epiblast, will have to be worked out again, in order to determine whether it really comes, as it is stated by Tan Benerlen to do, from the primitive hypoblast. 
increase in number and become one by one columnar; and that in the process they press against the layer of rounded elements

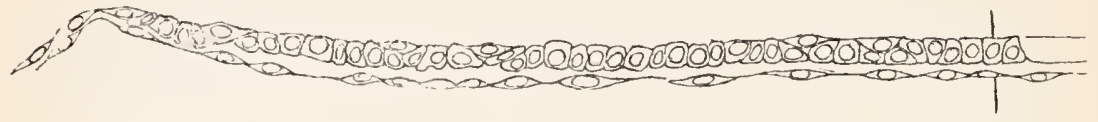

Fiti. 136. Seclion throtgh the nearly circular embryoxic area of a Rabir's OVIM OF SIX DAYS, NINE HOURS and 8 MM. IN DHAMETER.

The section shews the peculiar character of the upper layer with a certain number of super ficial tlattened cells; and represents about half the brearth of the area.

below them, so that the two layers cease to be distinguishable, and the whole embryonic area acquires in section the characters represented in fig. $1366^{1}$. 'Towards the end of the sixth day the embryonic area becomes oval, but the changes which next take place are not understood. In the front part of the area only two layers of cells are found, (1) an liypoblast, and (2) an epiblast of columnar cells probably derived from the flattened epiblast cells of the earlier stages. In the posterior part of the blastoderm a middle layer is present (Van Beneden) in addition to the two other layers; and this layer probably originates from the midlle layer which extended throughout the area at the beginning of the fitth lay, and then became fuserl with the epiblast. The middle layer does not give rise to the whole of the cventual mesoblast, but only to part of it. From its origin it may be called the hypoblastic mesoblast, and it is probably equivalent to the

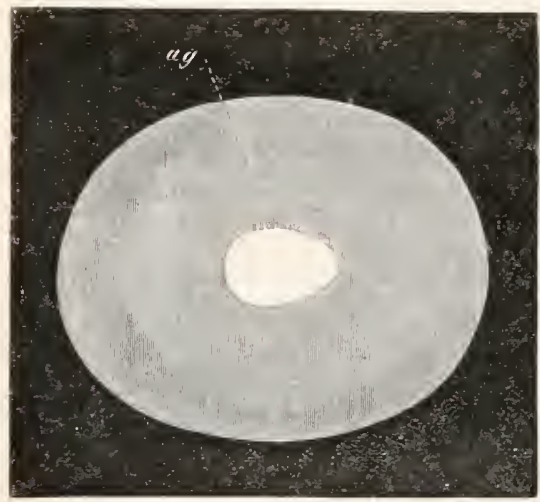

A.

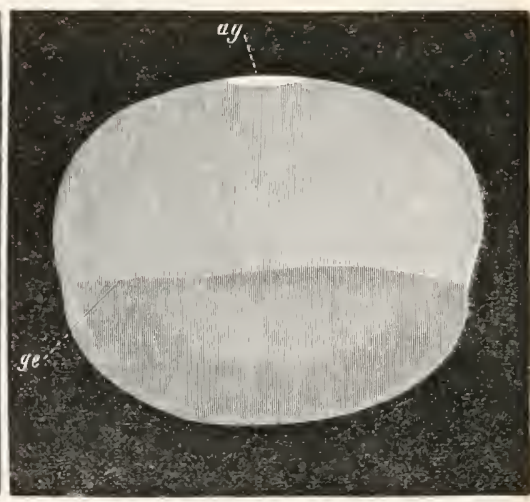

B.

Fig. 137. Views of the blastodendic vesicle of a liabeit on the seventh Dar Without the zoNA. A. from above, B. from the side. (From Kölliker.)

ag. embryonic area; ge. boundary of the hypoblast.

1 The section figured may perhaps hardly appear to justify this view; the examination of a larger number of sections is, howerer, more favourable to it, but it must be admitted that the interpretation is by no means thoroughly satisfactory. 
hypoblastic mesoblast alrearly described in the chick (p. 128 and 129). The stage just described has only been met with by Van Beneden ${ }^{1}$.

A diagrammatic view of the whole blastodermic vesicle at about the beginning of the seventh day is given in fig. 137. The embryonic area is represented in white. The line ge in B shews the

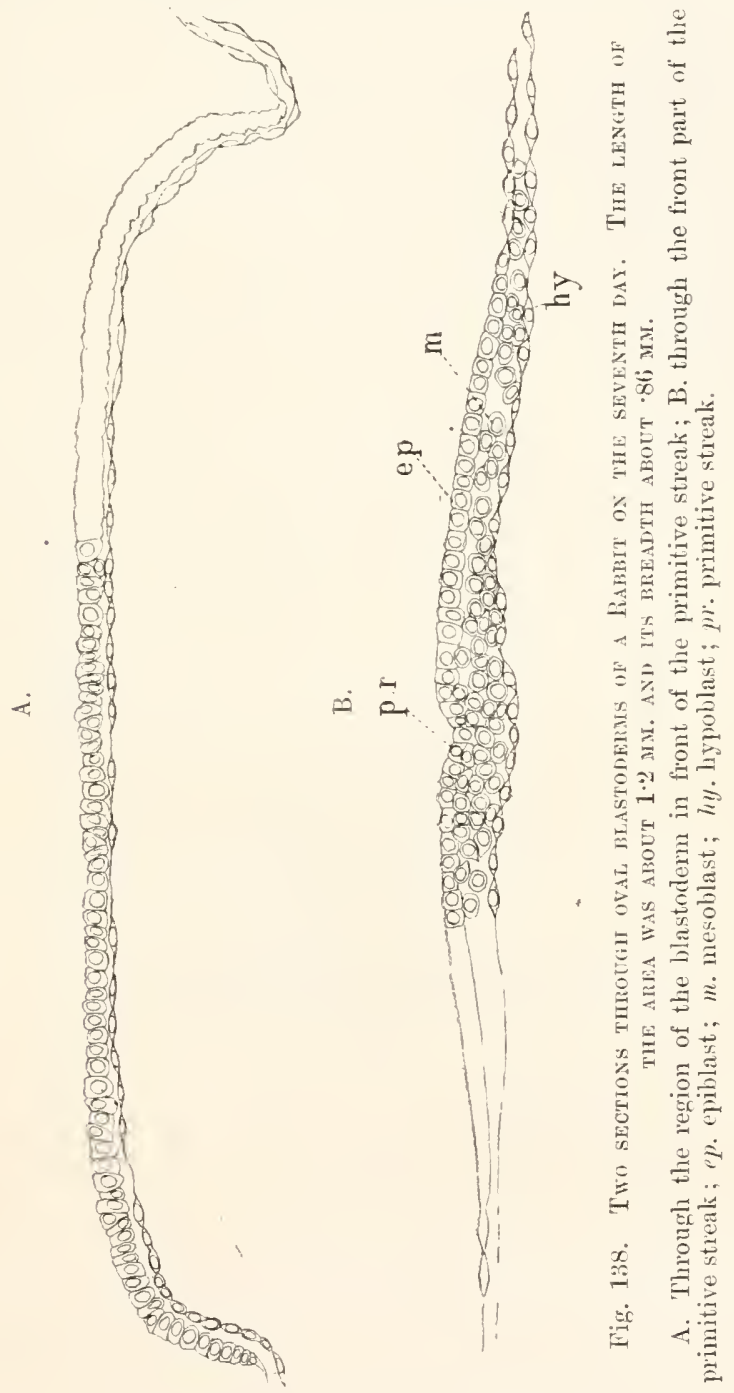

1 Kölliker does not believe in the existence of this stage, having nerer met witl it himself. It appears to me, however, more probable that Koblliker has failed to obtain it, than that Van Beneden has been guilty of such an extraordinary blunder as to have describel a stage which has no existence. 
extension of the hypoblast round the inner side of the vesicle. The blastodermic vesicle is therefore formed of three areas, (1) the embryonic area with three layers: this area is placed where the blastopore was originally situated. (2) The ring around the embryonic area where the walls of the vesicle are formed of epiblast and hypoblast. (3) The area beyond this again where the vesicle is formed of epiblast only ${ }^{1}$.

The changes which next take place begin with the formation of a primitive streak, homologous with, and in most respects similar to, the primitive streak in Birds. The formation of the streak is preceded by that of a clear spot near the middle of the blastoderm, forming the nodal point of Hensen. This spot subsequently constitutes the front end of the primitive streak.

The history of the primitive streak was first worked out in a satisfactory manner by Hensen (No. IS2), from whom however I differ in admitting the existence of a certain part of the mesoblast before its appearance.

Early on the seventh clay the embryonic area becomes pyriform, and at its posterior and narrower end a primitive streak makes its appearance, which is due to a proliferation of rounded cells from the epiblast. At the time when this proliferation commences the layer of hypoblastic mesoblast is present, especially just in front of, and at the sides of, the anterior part of the streak; but no mesoblast is found in the anterior part of the embryonic area. These features are shewn in fig. 138 A and B. The mesoblast derived from the Iroliferation of the epiblast soon joins the mesoblast already present; though in many sections it seems possible to trace a separation between the two parts (fig. $139 \mathrm{~B}$ ) of the mesoblast.

During the seventh day the primitive streak becomes a more pronounced structure, the mesoblast in its neighbourhood increases in quantity, while an axial groove-the primitive groove-is formed

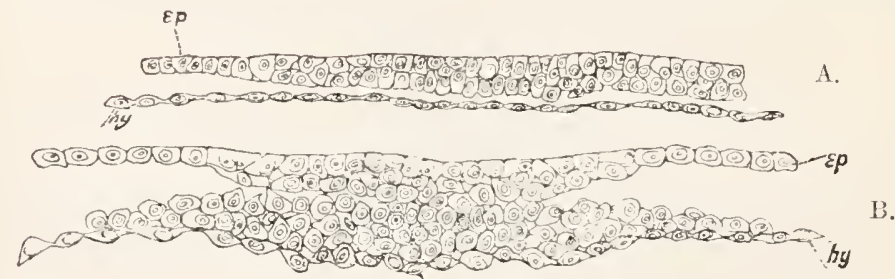

F1g. 139. Two transterse sections throdgh the EMbryonic area of aN EMBRYO RABBIT OF SEVEN DATS.

The embryo has nearly the structure represented in fig. 140.

A. is taken through the anterior part of the embryonic area. It represents about half the breadth of the area, and there is no trace of a medullary groove or of the mesoblast.

B. is taken through the posterior part of the primitive streak. ep. epiblast; hy. hypoblast.

1 Schifer lescribes the blastodermic vesicle of the cat as being throughout in a biliminar condition before the formation of a definite primitive streak or of the mesoblast. 
on its upper surface. The mesoblastic layer in front of the primitive streak becomes thicker, and, in the two-layered region in front, the epiblast becomes several rows deep (fig. $139 \mathrm{~A}$ ).

In the part of the embryonic area in front of the primitive streak there arise during the eighth day two folds bounding a shatlow median groove, which meet in front, but diverge behind, and enclose between them the foremost end of the primitive streak (fig. 1+1). These folds are the medullary folds and they constitute the first definite traces of the embryo. The medullary plate bounded by them rapidly grows in length, the primitive streak always remaining at its hinder end. While the lateral epiblast is formed of several rows of cells, that of the medullary plate is at first formed of but a single row (fig. $1+2 \mathrm{mg}$ ). The mesoblast, which appears to grow forward from the primitive streak, is stated to be at first a continuous sheet between the epiblast and hypoblast (Hensen). The evidence on this point does not however

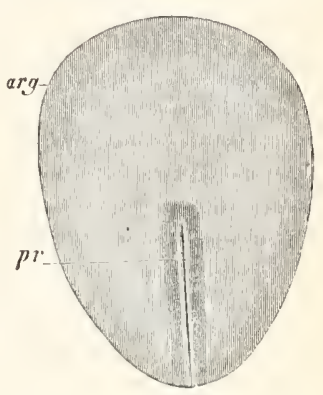

Fig. 140. EMrrionic are.t OF AN EIGHT DAYs' RABBit. (After Kölliker.)

arg. embryonic area; $p r$. primitive streak. appear to me to be quite conclusive. In any case, as soon as ever

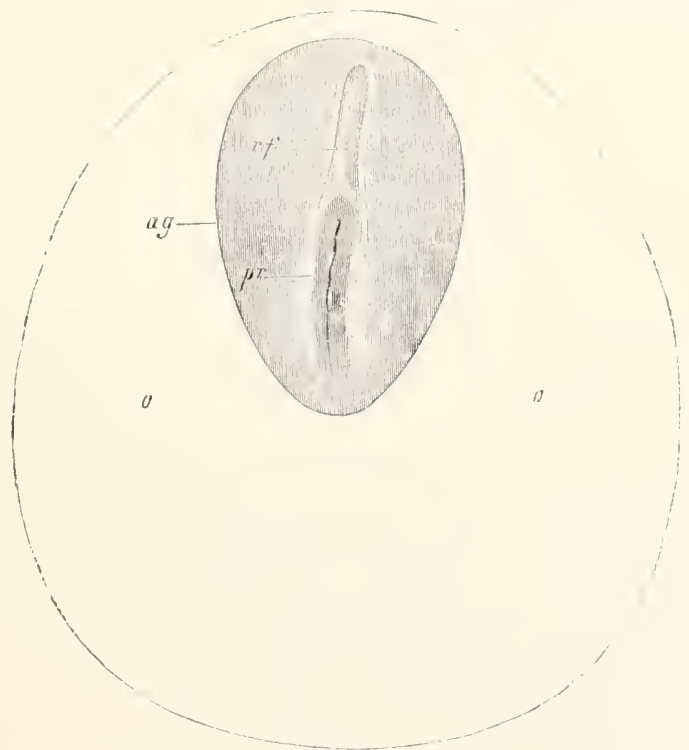

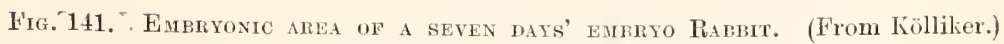

$o$. place of future area vaseulosa; $r f$. medullary groove; $p r$. primitive streak; ag. embryonic area. 
the medullary groove is formed, the mesoblast becomes divided, exactly as in Lacerta and Elasmobranchii, into two independent lateral plates, which are not continuous across the middle line (fig. 142 me). The hypoblast cells are flattened laterally, but become columnar beneath the medullary plate (fig. 142).

In tracing the changes which take place in the relations of the layers, in passing from the region of the embryo to that of the primitive streak, it will be convenient to follow the account given by Schäfer for the guinea-pig (No. 190), which on this point is far fuller and more satisfactory than that of other observers. In doing so I shall leave out of consideration the fact (fully dealt with later in this chapter) that the layers in the guinea-pig are inverted. Fig. 143 represents a series of sections through this part in the guinea-pig. The anterior section (D) passes through the medullary groove near its linder end. The commencement of the primitive streak is marked by a slight prominence on the floor of the medullary groove between the two diverging medullary folds (fig. $143 \mathrm{C}$, ae). Where this prominence becomes first apparent the epiblast and liypoblast

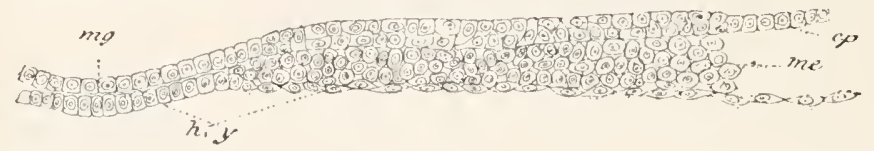

lig. 142. Transerse section throvgh ax embero Rabitit of eight pays.

cp. epiblast; me. mesoblast; hy. hypollast; mg. medullary groove.

are united together. The mesoblast plates at the two sides remain in the meantime quite free. Slightly further back, but before the primitive groove is reached, the epiblast and hypoblast are connecterl together by a cord of cells (fig. 143 B, f), which in the section next following becomes detached from the hypoblast and forms a solid keel projecting from the epiblast. In the following section the hitherto independent mesoblast plates become united with this keel (fig. $143 \mathrm{~A}$ ); and in the posterior sections, throngh the part of the primitive streak with the primitive groove, the epiblast and mesoblast continue to be united in the axial line, but the hypohlast remains distinct. These peculiar relations may shortly be deseribed by saying that in the axial line the hypoblast becomes united with the epiblast at the posterior end of the embryo; and that the cells which connect the hypoblast and epiblast are posteriorly continuous with the fused epiblast and mesoblast of the primitive streak, the hypoblast in the region of the primitive streak having becone distinct from the other layers.

The peculiar relations just described, which hold also for the rabbit, receive their full explanation by a comparison of the Hammal with the Bird and the Lizard, but before entering into this comparisou, it will be well to describe the next stage in the rabbit, which is in many respects very instructive. In this stage the thickenet axial portion of the hypoblast in the region of the embryo becomes sepa- 
rated from the lateral parts as the notochord. Tery shortly after the formation of the notochord, the hypoblast grows in from the two siles, and becomes quite continuous across the micllle line. The formation of the notochord takes place from before backwards; and at the hinder end of the embryo the notochord is continued into the mass of cells which forms the axis of the primitive streak, beconning therefore at this point continuous with the epilblast. The notochord in fact behaves exactly as did the axial hypoblast in the earlier stage.

In comparison with Lacerta (p. 168 \& 169) it is obvious that the axial hypothlast and the notochord derived from it lave exactly the same relations in Mammalia and Lacertilia. In both they are continuerl at the hind end of the embryo into the epiblast; and close to where they join it, the mesoblast and epiblast fuse together to form the primitive streak. The difference between the two types consists in the fact that in Reptilia there is formed at prsage connecting the neural and alimentary canials, the front wall of which is constituted by the cells which form the above junction between the notrohord and epiblast; and that in Mammalia this passage - which is only a rudimentary structure in Rep-
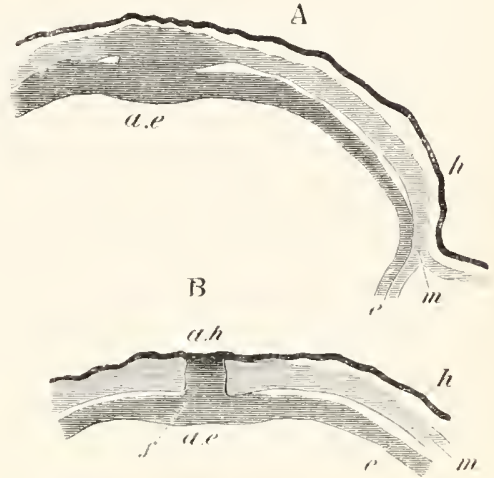

$(+$
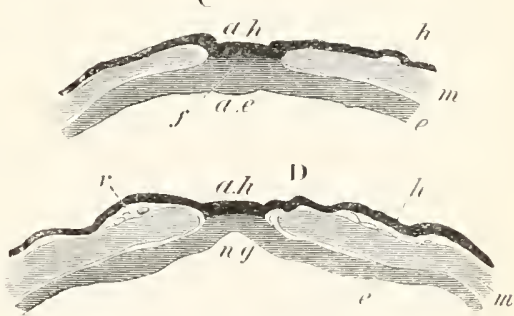

Fic. 143. A sertes of traxsterse secTIOXS THROUGH THE JUXCTION OF THE PRMMTIVE STREAK AND MEIULLARX GROOVE OF A TOUNG Girnea-pig. (After Schäfer.)

A. is the posterior section.

e. epiblast; $m$. mesoblast; h. hypolslast; ae. axial epiblast of the primitive streak; ah. axial hypoblast attached in B. and C. to the epiblast at the rudimentary blastopore; $n g$. medullary groove; $f$. rudimentary blastopore.

tilia-bas either heen overlooked or else is absent. In any case the axial junction of the epiblast and hypoblast in Mammalia is shewn by the above comparison with J acertilia to represent the dorsal lip of the true rertebrate bla-topore. The presence of this hastopore serms to render it clear that the blastopore discovered by Eil. van Beneden cannot have the meaning he assigned to it in comparing it with the blastopore of the frog.

Kölliker adduces the fact that the notsehord is continuous with the axial cells of the pimitive streak as an argument against its hypoblastic origin. The above emmarison with Lacertilia altogether deprives this arguinent of any force.

At the stage we have now reashed the thee layers are definitoly 
establisherl. The epiblast (on the view adopted above) clearly originates from epiblastic segmentation cells. The hypoblast without doubt originates from the hypoblastic segmentation spheres which give rise to the lenticular mass within the epiblast on the appearance of the cavity of the blastodermic vesicle; while, thongh the history of the mesoblast is still obscure, part of it appears to originate from the hypoblastic mass, and part is undoubtedly formed from the epiblast of the primitive streak.

While these changes have been taking place the rudiments of a vascular area become formed, and it is very possible that part of the hypoblastic mesoblast passes in between the epiblast and hypoblast, immediately around the embryonic area, to give rise to the area vasculosa. From Hensen's observation it seems at any rate clear that the mesoblast of the vascular area arises independently of the primitive streak: an observation which is borne out by the analogy of Birds.

\section{General growth of the Embryo.}

We have seen that the blastodermic vesicle becomes divided at an early stage of development into an embryonic area, and a nonembryonic portion. The embryonic area gives rise to the whole of the body of the cmbryo, while the non-embryonic part forms an appenlage, known as the umbilical vesicle, which becomes gradually filded off from the embryo, and has precisely the relations of the yolk-sack of the Sauropsida. It is almost certain that the Placentalia are clescended from ancestors, the embryos of which had large yolksacks, but that the yolk has become reduced in quantity owing to the nutriment received from the wall of the uterus taking the place of that originally supplied by the yolk. A rudiment of the yolksack being retained in the umbilical vesicle, this structure may be called indifferently umbilical vesicle or yolk-sack.

The yolk which fills the yolk-sack in Birds is replaced in Mammals by a coagulable fluid; while the gradual exteusion of the hypoblast round the wall of the blastodermic vesicle, which has already been described, is of the same nature as the growth of the hypoblast round the yolk-sack in Birds.

The whole embryonic area would seem to be employed in the formation of the buily of the embryo. Its long axis has no very definite relation to that of the blastodermic vesicle. The first external trace of the embryo to appear is the medullary plate, bounded by the meilullary folds, and occupying at first the anterior half of the embryonic area (fig. 141). The two medullary folds diverge behind and enclose the front end of the primitive streak. As the embryo elongates, the medullary folds nearly meet behind and so cut off the front portion of the primitive streak, which then appears as a projection in the hind end of the medullary groove. In an embryo rabbit, eight days after impregnation, the medullary groove is about $1.80 \mathrm{~mm}$. in length. At this stage a division may be clearly 
seen in the lateral plates of mesoblast into a vertebral zone adjoining the embryo and a more peripheral lateral zone; and in the vertebral zone indications of two somites, about $0.37 \mathrm{~mm}$. from the linder end of the embryo, become apparent. 'The foremost of these somites marks the junction, or very nearly so, of the cephalic region and trunk. The small size of the latter as compared with the former is very striking, but is characteristic of Vertebrates generally. The trunk gradually elongates relatively to the head, by the addition behind of fresh somites. 'The embryo has not yet begun to be folded off from the yolk-sack. In a slightly older embryo of nine days there appears (Hensen, Kölliker) round the embryonic area a delicate clear ring which is narrower in front than behind (fig. 1t+ A. ap). This ring is regarded by these authors as representing the peripheral part of the area pellucida of Birds, which does not

A.

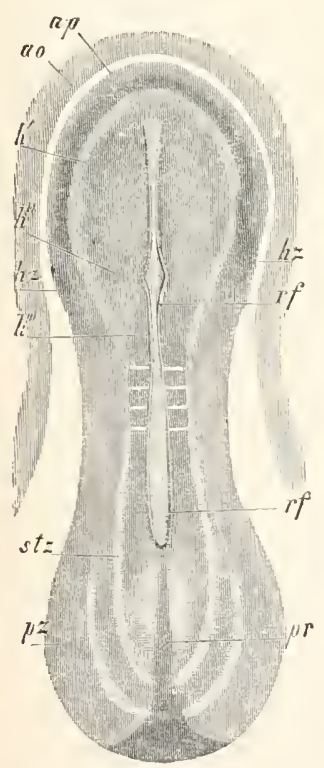

B.

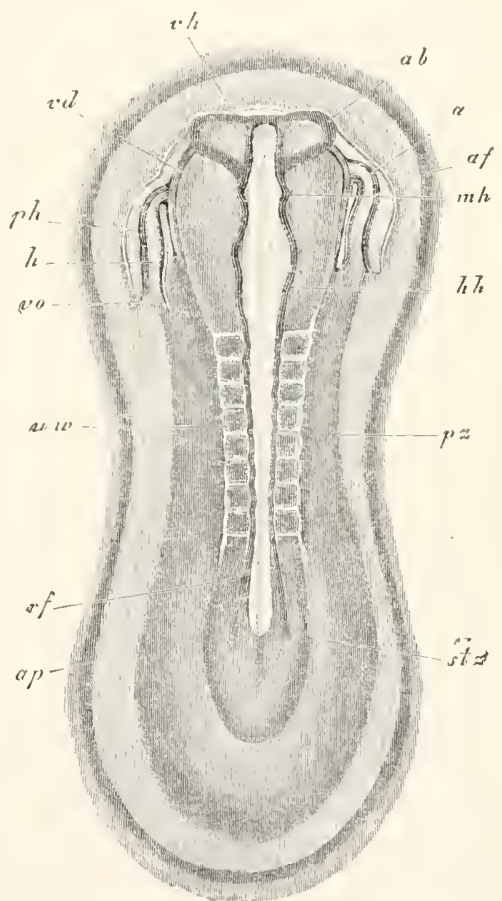

Fig. 144. Embrio Rabbits of arodt yixe dass from the norsal side. (From Kölliker.)

A. magnified 22 times, and B. 21 times.

ap. area pellucida; $r f$. medullary groove; $h^{\prime}$. medullary plate in the region of the future fore-brain; $h^{\prime \prime}$. medullary plate in the region of the future mid-brain; $v h$. forebrain; $a b$. optic vesicle; $m h$. nid-brain; $h h$. and $h^{\prime \prime \prime}$. hind-brain; $u x$. mesoblastic somite; st $z$. vertebral zone; $p z$. lateral zone; $h z$ and $h$. heart; $p h$. pericardial section of body-cavity; $v_{0}$, vitelline vein; af. ammion fold. 
become converted into the body of the embryo. Outside the area pellucida, an area vasculosa has become very well definerl. In the embryo itself (fig. 1+t A) the dispioportion between head and trunk is less marked than before; the medullary plate dilates anteriorly to form a spatula-shaped cephalic enlargement; aud three or four somites are established. In the lateral parts of the mesoblast of the head there may be seen on each side a tube-like structure ( $h z$ ). Each of these is part of the heart, which arises as two independent tubes. The remains of the primitive streak $(\mathrm{pr})$ are still present behind the medullary groove.

In somewhat older embryos (fig. 14t B) with about eight somites, in which the trunk considerably exceeds the head in length, the first distinct traces of the folding-off of the head end of the embryo become apparent, and somewhat later a fold also appears at the hind end. In the formation of the hind end of the embryo the primitive streak gives rise to a tail swelling and to part of the ventral wall of the post-anal gut. In the region of the heal the rudiments of the heart $(h)$ are far more definite. The medullary groove is still open for its whole length, but in the head it exhibits a series of well-marked dilatations. 'The foremost of these $(v h)$ is the rudiment of the fore-brain, from the sides of which there project the two optic vesicles $(a b)$; the next is the midl-brain ( $m h$ ), and the last is the hind-brain $(h h)$, which is again divided into smaller lobes by successive constrictions. The medullary groove behind the region of the somites dilates into an embryonic sinus rhomboidalis like that of the Bird. Traces of the amnion (af) are now apparent both in front of and behind the embryo.

The structure of the head and the formation of the heart at this age are illustrated in fig. 14.5. The widely-open medullary groove $(r f)$ is shewn in the centre. Below it the liypoblast is thickened to form the notochord $d d^{\prime}$; and at the sides are seen the two tubes, which, on the folding-in of the fore-gut, give rise to the unpaired heart. Each of these is formed of an outer muscular tube of splanchnic mesoblast $(a h h)$, not quite closed towards the hypoblast, and an inner epithelioid layer $(i h h)$; and is placed in a special section of the bodycavity $(p h)$, which afterwards forms the pericardial cavity.

Before the ninth day is completed great external changes are usually effected. The medullary groove becomes closed for its whole length with the exception of a small posterior portion. The closure commences, as in Birds, in the region of the mid-brain. Anteriorly the folding-off of the embryo proceerls so far that the head becomes quite free, and a considerable portion of the throat, ending blindly in front, becomes established. In the course of this folding the, at first widely separated, halves of the heart are brought together, coalesce on the rentral side of the throat, and so give rise to a median undivided heart. The fold at the tail end of the embryo progresses considerably, and during its advance the allantois is formed in the same way as in Birds. The somites increase in 
number to about twelve. The amniotic folds nearly meet above the embryo.
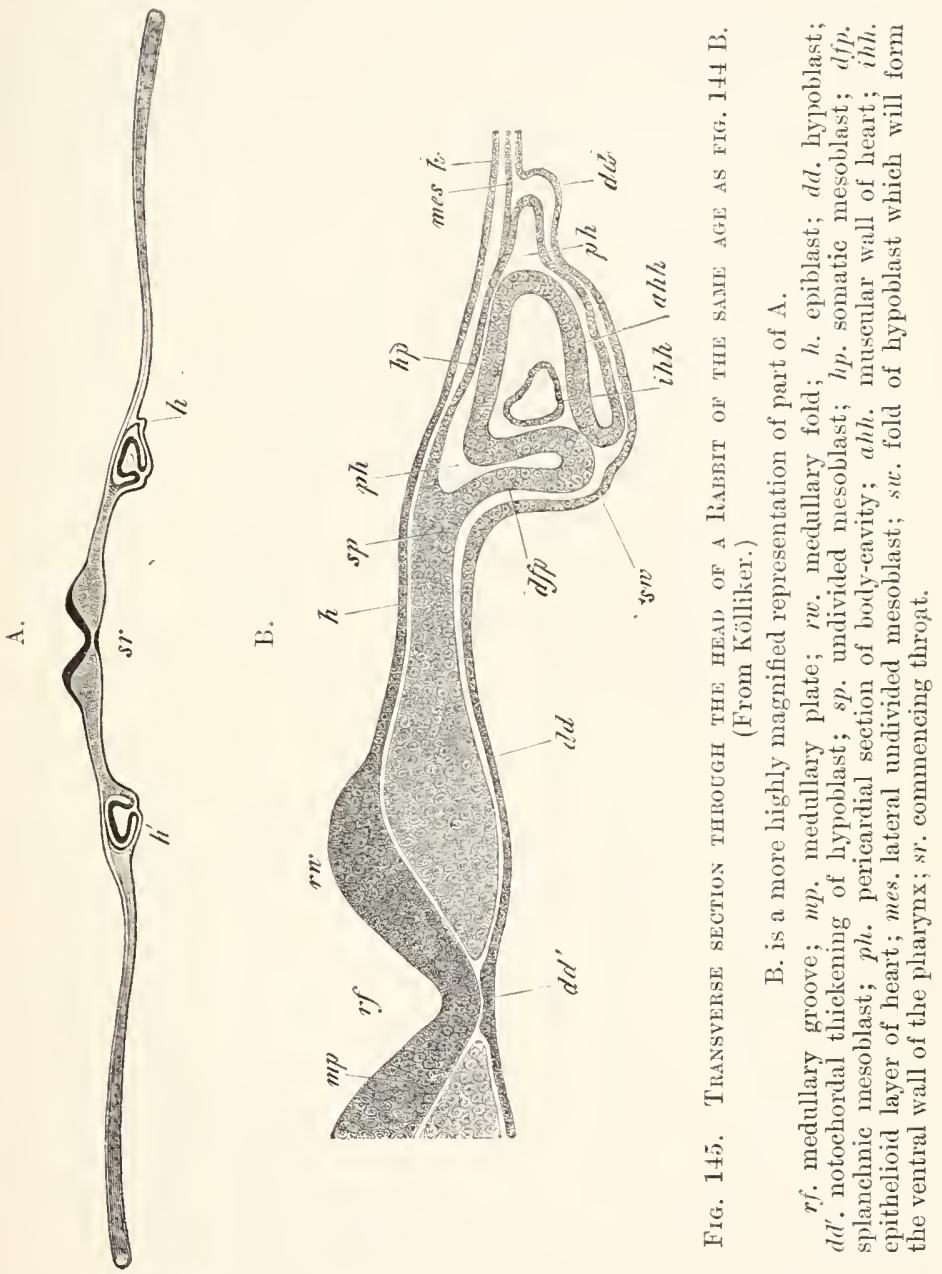

The later stages in the development proceed in the main in the same manner as in the Bird. The cranial flexure soon becomes very marked, the mid-brain forming the end of the long axis of the embryo (fig. 146). The sense organs have the usual development. Under the fore-brain appears an epiblastic involution giving rise both to the mouth and to the pituitary body. Behind the mouth are three wellmarked pairs of visceral arehes. The first of these is the mandibular arch (fig. $146 \mathrm{md}$ ), which meets its fellow in the midtlle line, and forms 
the posterior boundary of the mouth. It sends forward on each sile a superior maxillary process $(m x)$ which partially forms the anterior margin of the mouth. Behind the mandibular arch are present a well-developed hyoid $(h y)$ and a first branchial arch (not shewn in fig. 146). There are four clefts, as in other Amniota, but the fourth is not bounded behind by a definite arch. Only the first of these clefts persists as the tympanic cavity and Eustachian tube.

At the time when the cranial flexure appears, the body also

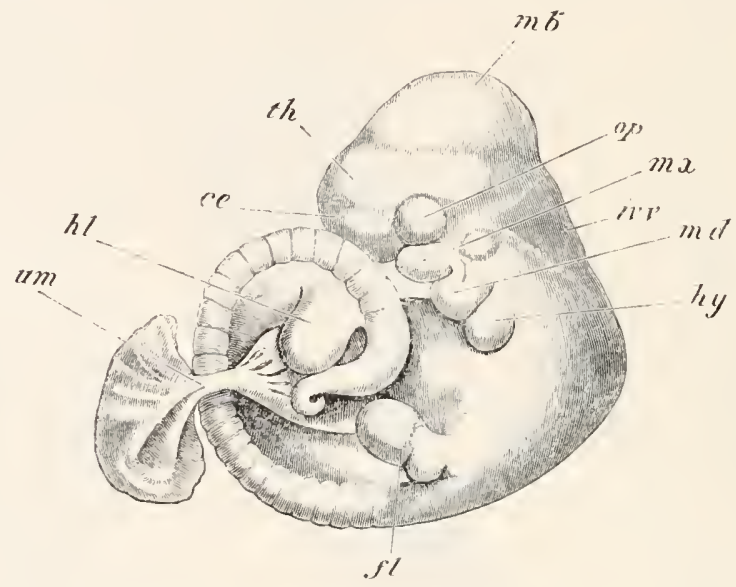

Fig. 146. Aivanced embrio of a Rabit (about twelve days) ${ }^{1}$.

$m b$. mid-brain; th. thalamencephalon; $c e$. cerebral hemisphere; op. eye; $i v \cdot v$. fourth ventricle; mx. maxillary process; md. mandibular arch; hy. hyoid arch; fl. fore-limb; $h$. hind-limb; $u$ m. umbilical stalk.

develops a sharp flexure immediately behind the head, which is thus bent forwards upon the posterior straight part of the body (fig. 146). The amount of this flexure varies somewhat in different forms. It is very marked in the $\log$ (Bischoff). At a later period, and in some species even before the stage figured. the tail end of the borly also becomes bent (fig. 146), so that the whole dorsal side assumes a convex curvature, and the head and tail become closely approximated. In most cases the embryo, on the development of the tail, assumes a more or less definite spiral curvature (fig. 146); which however never becomes nearly so marked a feature as it commonty is in Lacertilia and Ophidia. With the more complete development of the lower wall of the body the ventral Hexure partially disappears, but remains more or less persistent till near the close of intra-uterine life. The limbs are formed as simple buds in the same mamner as in Birds. The buds of the hind-limbs are directed somewhat forwards, and those of the fore-limb backwards.

1 This figure was drawn for me by my pupil, Mr Wheldon. 


\section{E'mbryonic membranes and yolk-sach.}

The early stages in the development of the embryonic membranes are nearly the same as in Aves; but during the later stages in the Placentalia the allantois enters into peculiar relations with the uterine walls, and the two, together with the interposed portion of the subzonal membrane or false amnion, give rise to a very characteristic Mammalian organ-the placenta-into the structure of which it will be necessary to enter at some length. The embryonic membranes vary so considerably in the different forms that it will be advantageons to commence with a description of their development in an ideal case.

We may commence with a blastodermic vesicle, elosely invested by the delicate remnant of the zona racliata, at the stage in which the medullary groove is already established. Around the embryonic area a layer of mesoblast would have extended for a certain distance; so as to give rise to an area vasculosa, in which however the bloodvessels would not have become definitely established. Such a vesicle is represented diagrammatically in fig. 147, I. Somewhat later the embryo begins to be folded off, first in front and then behind (fig. $147,2)$. These folds result in a constriction separating the embryo and the yolk-sack $(d s)$, or as it is known in Mammalian embryology, the umbilical vesicle. The splitting of the mesoblast into a splanchnic and a somatic layer has taken place, and at the front and lind end of the embryo a fold (lis) of the somatic mesoblast and epiblast begins to rise up and grow over the head and tail of the embryo. These two folds form the commencement of the amnion. The head and tail folds of the amnion are continued round the two sides of the embryo, till they meet and unite into a continuous fold. This fold grows gradually upwards, but before it has completely enveloped the embryo, the blood-vessels of the area vasculosa become fully developed. They are arranged in a manner not very different from that in the chick.

The following is a brief account of their arrangement in the Rabbit :-

The outer boundary of the area, which is continually extending further and further round the umbilical vesicle, is marked by a venous sinus terminalis (fig. $147, s t$ ). The area is not, as in the chick, a nearly complete circle, hut is in front divided by a deep indentation extending inwards to the level of the heart. In consequence of this indentation the sinus terminalis ends in front in two branches, which bend inwards and fall directly into the main vitelline veins. The blood is brought from the dorsal aorte by a series of lateral vitelline arteries, and not by a single pair as in the chick. These arteries break up into a more deeply situated arterial network, from which the blood is continued partly into the sinus terminalis, and partly into a superficial venous network. The hinder end of the heart is continued into two vitelline veins, each of which divides into an anterior and a posterior branch. The anterior branch is a limb

B. E. II. 

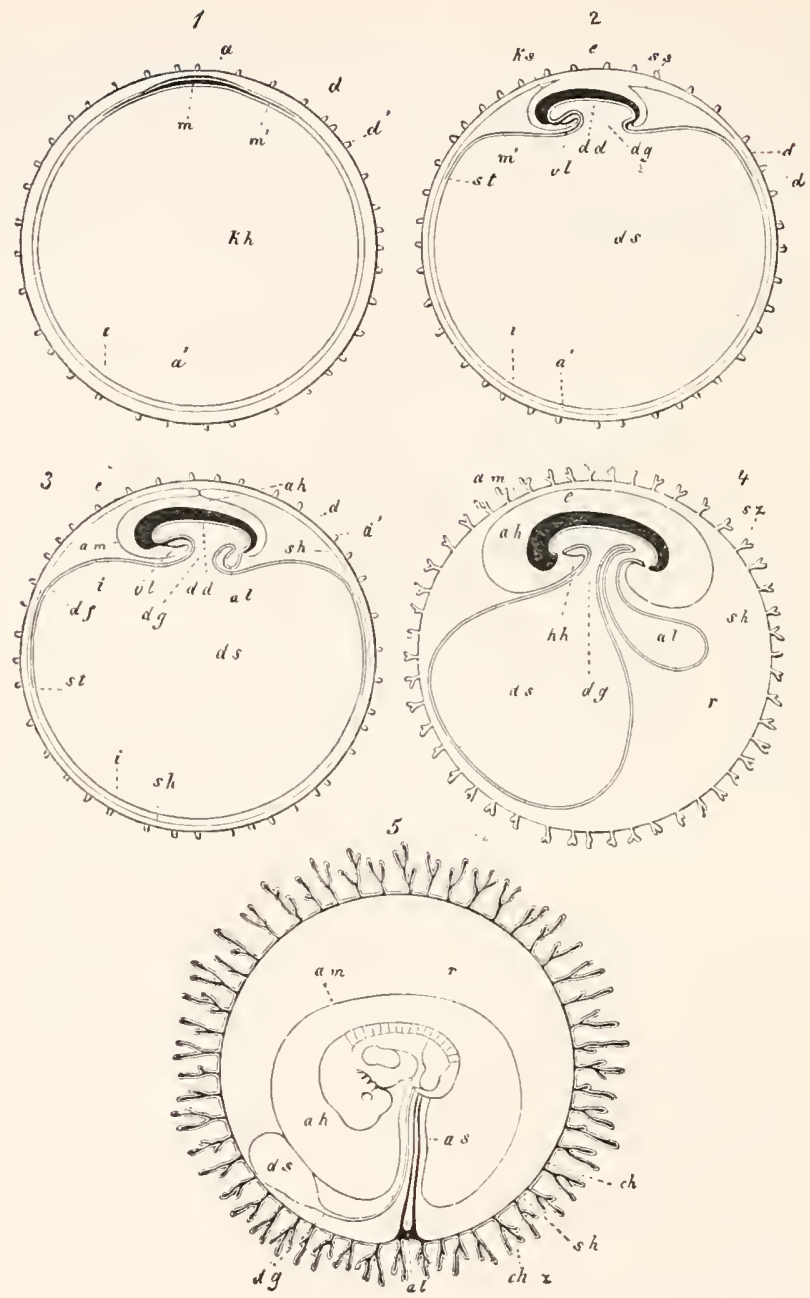

Fig. 147. Five digramiatic figures iluestrating the formation of the Fetal MeMbranes of a Mamal. (From Kölliker.)

In $1,2,3,4$ the embryo is represented in longitudinal section.

1. Orum with zona pellucida, blastodermic vesicle, and embryonic area.

2. Orum with commencing formation of umbilical vesicle and amnion.

3. Ovum with amnion about to close, and commeneing allantois.

4. Orum with rillous subzonal membrane, larger allantois, and mouth and anus.

5. Ovum in which the mesoblast of the allantois has extended round the inner surface of the subzonal membrane and united with it to form the chorion. The cavity of the allantois is aborted. This fig. is a diagram of an early human ovum.

d. zona radiata; $d$ '. processes of zona; sh. subzonal membrane; ch. chorion; ch.z. chorionic villi; am. amnion; $k$ s. head-fold of amnion; ss.tail-fold of amnion; a. epiblast of embryo; $a^{\prime}$. epiblast of non-embryonic part of the blastodermic vesicle; 
m. embryonic mesoblast; $m^{\prime}$. nou-embryonic mesoblast; $d f$. area vasculosa; st. sinus terminalis: $d d$. embryonic hypoblast; $i$. non-embryonic hypoblast; $k h$. cavity of blastodermic resicle, the greater part of which becomes the cavity of the umbilical vesicle $d s$; : dg. stalk of umbilical resicle; $a l$. allantois; $e$. embryo; $r$. space hetween chorion and amnion containing albuminous fluid; $v l$. ventral body wall; hlt. pericardial cavity.

of the sinus terminalis, and the posterior and smaller branch is continued towards the hind part of the sinus, near which it ends. On its way it receives, on its outer side, numerous hranches from the venous network, which connect by their anastomoses the posterior branch of the vitelline vein and the sinus terminalis.

While the above changes have been taking place the whole blastodermic vesicle, still enclosed in the zona, has become attached to the walls of the uterus. In the case of the typical uterus with two tubular horns, the position of each embryo, when there are several, is marked by a swelling in the walls of the uterus, preparatory to the changes which take place on the formation of the placenta. In the region of each swelling the zona around the blastodermic vesicle is closely embraced. in a ring-like fashion, by the epithelium of the uterine wall. The whole vesicle assumes an oval form, and it lies in the uterus with its two ends fiee. The embryonic area is placed close to the mesometric attachment of the uterus. In many cases peculiar processes or villi grow out from the ovum (fig. $1+7,4, s z)$, which fit into the folds of the uterine epithelium. The nature of these processes requires further elucidation, but in some instances they appear to proceed from the zona (the Rabbit) and in other instances from the subzonal membrane (the Dog). In any case the attachment between the blastodermic vesicle and the uterine wall becomes so close at the time when the body of the embryo is first formed out of the embryonic area, that it is hardly possible to separate them without laceration; and at this period-fiom the 8th to the 9th day in the Rabbit-it requires the greatest care to remove the ovum from the uterus without injury. It will be understood of course that the attachment above described is at first purely superficial and not vascular.

Shortly after the establishment of the circulation of the yolk-sack the folds of the amnion meet and coalesce above the embryo (fig. 147 , 3 and $4, a m)$. After this the inner or true amnion becomes severed from the outer or false amnion, though the two sometimes remain comnected by a narrow stalk. Between the true and false amnion is a continuation of the body-cavity. The true amnion consists of a layer of epiblastic epithelium and generally also of somatic mesoblast, while the false amnion consists, as a rule, of epiblast only; though it is possible that in some cases (the Rabbit?) the mesoblast may be contimued along its inner face.

Before the two limbs of the amuion are completely severed, the epiblast of the nmbilical vesicle becomes separated from the mesoblast and hypoblast of the vesicle (fig. 147, 3), and, together with the false amnion $(s h)$, with which it is continuous, forms a complete lining 
for the inner face of the zona radiata. The space between this membrane and the umbilical vesicle with the attached embryo is obviously continuous with the body cavity (vide figs. 147,4 and $147^{*}$ ). 'Io this membrane Turner has given the appropriate name of subzonal membrane: by Von Baer it was called the serous envelope. It soon fuses with the zona rarliata, or at any rate the zona ceases to be distinguishable.

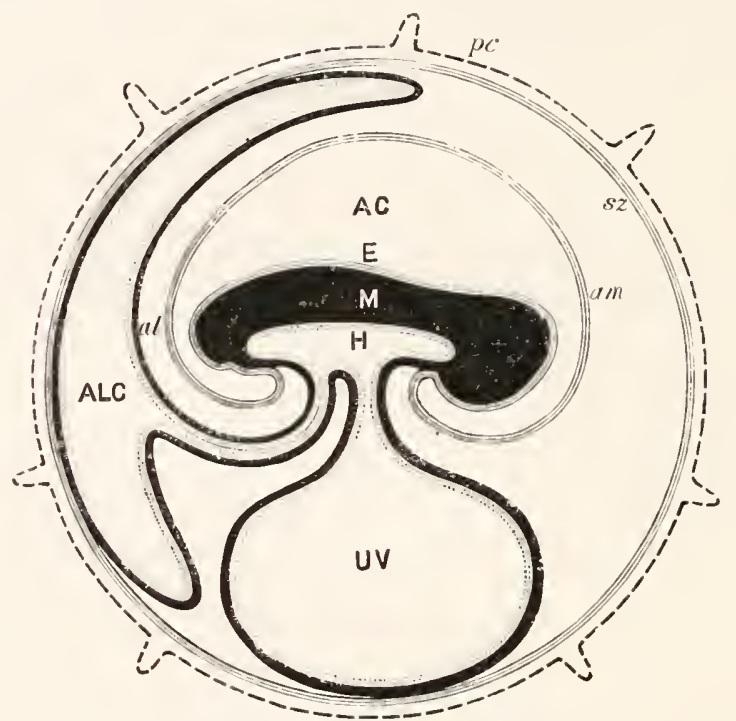

Fig. 147*. Diagram of the fotal membianes of a Mammal. (From Turner.)

Structures which either are or have been at an earlier period of development continuous with each other are represented by the same character of shading.

$p c$. zona with villi; sz. subzonal membrane; $E$. epiblast of embryo; am. amnion; $A C$. amniotic cavity; $I F$. mesoblast of embryo; $H$. hypoblast of embryo; $U \mathrm{~T}$. umbilical vesicle; al. allantois; $A L C$. allantoic cavity.

While the above changes are taking place in the amnion, the allantois grows out from the hind-gut as a vesicle linerl by hypoblast, but covered externally by a layer of splanchnic mesoblast (fig. 147,3 and $4, a l)^{1}$. The allantois soon becomes a flat sack, projecting into the now largely developed space between the subzonal membrane and the ammion, on the dorsal sile of the embryo (fig. 147*, $A L C$ ). In some cases it extends so as to cover the whole imner surface of the subzonal membrane; in other cases again its extension is much more Jimited. Its lumen may be retained or may become nearly or wholly aborted. A fusion takes place between the subzonal membrane and the adjoining mesoblastic wall of the allantois, and the two together give rise

I The hypoblastic element in the allantois is sometimes rery much reduced, so that the allantois may be mainly formed of a vascular layer of mesoblast. 
to a secondary membrane round the ovum, known as the chorion. Since however the allantois does not always come in contact with the whole inner surface of the subzonal membrane, the term chorion is apt to be somewhat rague; and in the rabbit, for instance, a considerable part of the so-called chorion is formed by a fusion of the wall of the yolk-sack with the subzonal inembrane (fig. 1+S). The placental region of the chorion may in such cases be distinguished as the true chorion, from the remaining part which will be called the false chorion.

The mesoblast of the allantois, especially that part of it which assists in forming the chorion, becomes lighly vascular; the blood being brought to it by two allantoic arteries continued from the terminal bifurcation of the dorsal aorta, and returned to the body by one, or rarely two, allantoic veins, which join the vitelline veins from the yolk-sack. From the outer surface of the true chorion (fig. 1+7, $5, d, 148$ ) villi grow out and fit into crypts or depressions which have in the meantime made their appearance in the walls of the uterus ${ }^{1}$. The villi of the chorion are covered by an epithelium derived from the subzonal membrane, and are provided with a connective tissue core containing an artery and vein and a capillary plexus connecting them. In most cases they assume a more or less arborescent form, and have a distribution on the surface of the chorion varying characteristically in different species. The walls of the crypts into which the villi are fitted also become lighly vascular, and a nutritive fluid passes from the maternal vessels of the placenta to the fuetal vessels by a process of diffusion; while there is probably also a secretion by the epithelial lining of the walls of the crypts, which becomes absorbed by the vessels of the foetal villi. The above maternal and foetal structures constitute together the organ known as the placenta. The maternal portion consists essentially of the vascular crypts in the uterine walls, and the fuetal portion of more or less arborescent villi of the true chorion fitting into these crypts.

While the placenta is being developed, the folding-off of the embryo from the yolk-sack becomes more complete; and the yolksack remains connected with the ileal region of the intestine by a narrow stalk, the vitelline duct (fig. $1+7,4$ and 5 and fig. $147^{*}$ ), consisting of the same tissues as the yolk-sack, viz. hypoblast and splanchnic mesoblast. While the true splanchnic stalk of the yolksack is becoming narrow, a somatic stalk connecting the amnion with the walls of the embryo is also formed, and closely envelops the stalk both of the allantois and the yolk-sack. The somatic stalk together with its contents is known as the umbilical cord. The mesoblast of the somatopleuric layer of the cord develops into a kind of gelatinous tissue, which cements together the whole of the contents. The

1 These crypts have no comection with the openings of glands in the walls of the uterus. They are behieved by Ercolani to be formed to a large extent by a regeneration of the lining tissue of the uterine walls. 
allantoic arteries in the cord wind in a spiral manner round the allantoic vein. The yolk-sack in many cases atroplies completely before the close of intra-uterine life, but in other cases it is only removed with the other embryonic membranes at birth. The intraembryonic portion of the allantoic stalk gives rise to two structures, viz. to (1) the urinary bladder formed by a dilatation of its proximal extremity, and to (2) a cord known as the urachus connecting the bladker with the wall of the borly at the umbilicus. The urachus, in cases where the cavity of the allantois persists till birth, remains as an open passage connecting the intra- and extra-embryonic parts of the allantois. In other cases it gradually closes, and becomes wearly solid before birth, though a delicate but interrupted lumen would appear to persist in it It eventually gives rise to the ligamentum vesica medium.

At birth the fotal membranes, incluking the foetal portion of the placenta, are shed; but in many forms the interlocking of the foetal villi with the uterine crypts is so close that the uterine mucous membrane is carried away with the foutal part of the placenta. It thus comes about that in some placenta the maternal and foetal parts simply seprarate from each other at birth, and in others the two remain intimately locked together, and both are shed together as the after-birth. These two forms of placenta are distinguished as non-deciduate and deciduate, but it has been shewn by Ercolani and Turner that 110 sharp line can be drawn between the two types; noreover, a larger part of the uterine nucous membrane than that forming the maternal part of the placenta is often shed in the deciduate Mammalia, and in the non-deciduate Mammalia it is probable that the mucous membrane (not including vascular parts) of the matornal placenta either peels or is absorbed.

\section{Comparatice history of the Mammaliun fatal membranes.}

'Two groups of Mammalia-the Monotremata and the Marsmpialia -are believed not to be provided with a true placenta.

The nature of the foetal membranes in the Monotrenata is not known. Ova, presumably in an early stage of development, liave been found free in the uterus of Ornithorhyneus by Owen. The lining membrane of the uterus was thickened and highly vascular. The females in which these were found were killed early in October .

Marsupialia. Our knowledge of the foetal membranes of the Marsupialia is almost entirely due to Owen. In Macropus major he found that birth took place thirty-eight clays after impregnation. A

1 The following is Uwen's account of the young after birth (Cump. Anat. of I'rtebutes, Tol. nI. p. 717): "On the eighth of December Dr Bennet discovered in "the subterranean nest of Ornithorhyncus three living young, naked, not quite two "inches in length." On the 12th of August, 1861, "a female Echidua hystrix was " captured... having a young one with its head buried in a mammary or marsupial

" fossa. This young one was naked, of a bright red colour, and one inch two lines in

- lensth. 
fœetus at the twentieth day of gestation measured eight lines from the mouth to the root of the tail. The fotus was enveloped in a large subzonal membrane, with folds fitting into uterine furrows, but not adhering to the werns, and without villi. The embryo was enveloped in an amnion reftected over the stalk of the yolk-sack, which was attached by a filanentary pedicle to near the end of the ileum. The yolk-sack was large and vascular, and was comected with the futal vaseular system by a vitelline artery and two veins. The yolk-sack was partially allherent, especially at one part, to the subzonal membrane. No allantois was observed. In a somewhat older foutus of ten lines in length there was a small allantois supplied by two allantoic arteries and one vein. The allantois was quite free and not attached to the subzonal membrane. The yolk-sack was more closely attached to the subzonal membrane than in the younger embryo'.

All Nammalia, other than the Monotremata and Marsupialia, have a true allantoic placenta. The placenta presents a great variety of forms, and it will perhaps be most couvenient first to treat these varieties in succession, and then to give a general exposition of their mutual affinities ${ }^{2}$.

Amongst the existing Mammals provided with a true placenta, the most primitive type is probably retained by those forms in which the placental part of the chorion is confined to a comparatively restricted area on the dorsal side of the embryo; while the false chorion is formed by the vascular yolk sack fusing with the remainder of the subzonal membrane. In all the existing forms with this arrangement of futal membranes, the placenta is deciduate. This, however, was probably not the case in more frimitive forms from which these are descended ${ }^{3}$. The placenta would appear from Ercolani's deseription to be simpler in the mole (Talpa) than in other species. The Insectivora, Cheiroptera, and Rodentia are the groups with this type of placenta; and since the rabbit, amongst the latter, has been more fully worked ont than other species, we may take it first.

The Rabbit. In the pregnant female Rabbit several ova are generally found in each horn of the uterus. The general condition of the egg-membranes at the time of their full development is shewn in fig. 148 .

The embryo is surrounded by the amnion, which is comparatively small. The yolk-sack $(d s)$ is large and attached to the embryo by a long stalk. It has the form of a flattened sack closely applied to about two-thirds of the surface of the sulzonal membrane. The outer wall of this sack, arljoining

1 Owen quotes in the Anatomy of Tertebrates, Vol. III. p. 721, a description from Rengger of the development of Didelphis azara, which would seem to imply that a vascular athesion arises between the uterine walls and the subzonal membrane, but the description is too vague to be of any value in determining the nature of the fortal membranes.

2 Numerous contributions to our knowledge of the various types of placenta have been made during the last few years, amongst which those of Turner and Ercolani may be singled out, both from the variety of forms with which they deal, and the important light they have thrown on the structure of the placenta.

3 Tide Ercolani, No. I97, and Harting, No. 201, and also Von Baer, Entuicklungsgeschichte table on $\mathrm{p} .225$, part $\mathrm{I}_{\text {. }}$, where the importance of the limited area of attachment of the allautois as compared with the yolk-sack is distinctly recognised. 
the subzonal membrane, is formed of hypoblast only; but the inner wall is

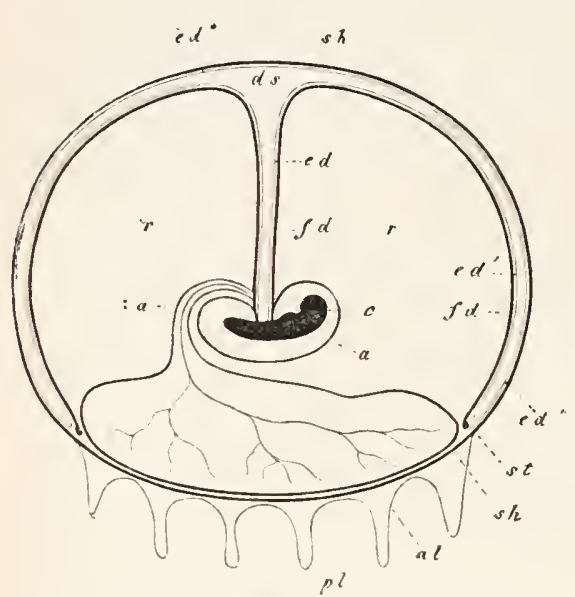

Fig. 148. I)tagramatic LoNgitudinal secTION OF a RiBbit's OVUM at ax ADVANCED STAGE OF PREGAANCY: (From Kölliker after Bischoff.)

e. embryo; a. amnion ; $a$. urachus ; al. allan. tois with blood-vessels; $s h$. sub-zonal membrane; ll. placental villi; $j d$. vascular layer of yolk-sack; ed. hypoblastic layer of yolk-sack; $e d^{\prime}$. inner portion of hypoblast, and ed". onter portion of hypoblast lining the compressed cavity of the yolksack; $d s$. carity of yolk-sack; st. sinus terminalis; $r$. space filled with fluid between the amnion, the allantois and the yolk-sack.

and Kölliker's olservations, that the subzonal memliane in the area of the placenta becomes attached to the uterine wall, by means of villi, even beforc its fusion with the allantois. In the later periods of gestation the intermingling of the maternal and foetal parts of the placenta becomes very close, and the placenta is truly deciduate. The cavity of the allantois persists till birtl. Between the yolk-sack, the allantois, and the embryo, there is left a large cavity filled with an albuminous fluid.

The Hare does not materially differ in the arrangement of its foetal membranes from the Rabbit.

In the Rat (Mus decumanus) (fig. 149) the sack of the allantois conpletely atroplies before the close of foetal life ${ }^{1}$, and there is developed, at the junction of the maternal part of the placenta and the unaltered mucous membrane of the uterus, a fold of the mucous membrane which completely encapsules the whole chorion, and forms a separate chamber for it, distinct from the general lumen of the uterus. Folds of this nature, which are specially developed in Man and Apes, are known as a decidua reflexa. I The decidua reflexa of the Rat is reduced to extreme tenuity, or even vanishes before the close of gestation.

1 This is denied by Nasse; ride Kölliker, No. 183, p. 361. 
Guinea-pig. The development of the Guinea-pig is dealt with elsewhere, but, so fur as its peculiarities permit a comparison with the Rabbit, the agreement between the two types appears to be fairly close.

The blastodermic vesicle of the Guineapig becomes completely enveloped in a eapsule of the uterine wall (decidua-reflexa) (fig. 150). The epithelium of the blastodermic vesicle in contact with the uterine wall is not epiblastic, but corresponels with the hypoblast of the volk-sack of other forms, and the meso. hlast of the greater part of the imner side

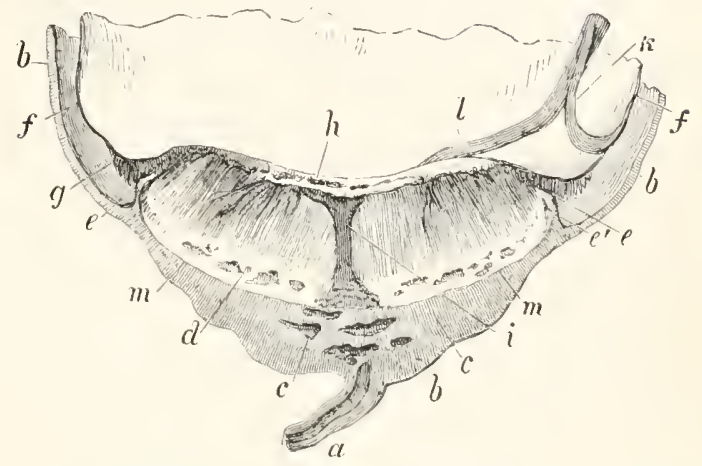

Flg, 149. SECTION THROCGH THE PLACENTA AND ADJACENT parts of a Rat ONE tach aND a QUARTER LONG. (From Huxley.)

a. uterine vein ; $b$. uterine wall $; c$. carernons portion of uterine wall ; $\boldsymbol{l}$. deciduous portion of uterus with eavernous structure; $i$. large vein passing to the foetal portion of the placenta; $f$. false chorion supplied by vitelline vessels; $l$. vitelline ressel ; $l$. allantoic vessel; $g$. boundary of true p'acenta; $e, m, m, e$. line of junction of the deciduate and non-deciduate parts of the uterine wall. of this becomes richly rascular $(y k)$; the vascular area being bounded by a sinus terminalis.

The blastodermic vesicle is so situated within its uterine capsule that the embryo is attached to the part of it aljoining the free side of the uterus. From the opposite side of the uterms, viz. that to which the mesometrium is attacherl, there grow into the wall of the blastodermic vesicle numerous vascular processes of the uterine wall, which establish at this point an organic connection between the two $(p l)$. The bloodvessels of the blastodermic resicle (yolk-sack) stop short immediately around the area of attachment to the uterus; but at a late period the allantois grows towarrs, and fuses with this area. The blood-vessels of the allantois and of the nterus become intertwined, and a disclike placenta more or less similar to that in the Rabbit beromes formed $(p /)$. The eavity

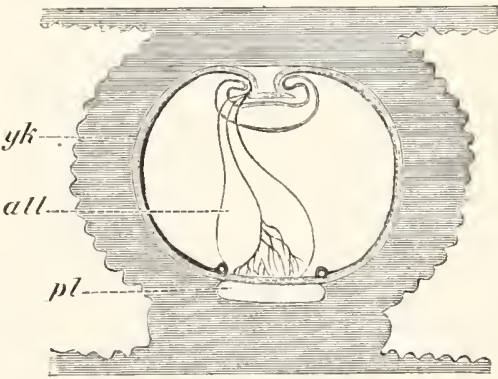

Fig. 150. DIagramiatic loxgituminal secTION OF AN OVUM OF A GUINEA-PIG AND THE ADIACENT CTERINE WALLS AT AN ADVANCED STAGE OF PREGNANCr. (After Bischoff.)

$y k$. yolk-sack (nmbilical vesicle) formed of an external hypollastic layer (shaded) and an internal mesoblastic rascnlar layer (black). At the end of this layer is placed the sinus termiualis; all. allantois ; $p l$. placenta. walls.

The external shaded parts are the uterine of the allantois, if developed, vanishes completely. 
In all the Rodentia the placenta appears to be situated on the mesometric side of the uter'us.

Insectivora. In the Mole (Talpa) and the Shrew (Sorex), the fotal membranes are in the main similar to those in the rabbit, and a deciduate discoidal placenta is always present. It may be situated anywhere in the circumference of the uterine tube. The allantoic cavity persists (Owen), but the allantois only corers the placentat area of the chorion. The yolk-sack is persistent, and fuses with the non-allant:ic part of the subzonal membrane; which is rendered vascular by its blood-vessels. There would seem to be (Owen) a small decidua reflexa. A similat arrangement is found in the Hedgehog (Erinacens Europrus) (Rolleston), in which the placenta occupies the typical dorsal position. It is not clear from Rolleston's description whether the rolk-sitck persists till the close of foetal life, but it seems probable that it does so. There is a considerable reflexa which does not, however, cover the whole chorion. In the Tenrec (Centetes) the yolk-sack and non-placental part of the chorion ate described by Rolleston as being absent, but it seems not impossible that this may have been owing to the barl state of preservation of the specimen. The ammion is large. In the Cheiroptera (Tespertilio and Pteropus', the yolk-sack is large, and coalesces with part of the chorion. The large yolk sack has been observed in Pteropus by Rolleston, and in Vespertilio by Oweu. The allantoic vessels supply the placenta only. The Cheiroptera are usually uniparous.

Simiadæ and Anthropidæ. The foetal membranes of Apes and Man, though in their origin unlike those of the Rodentia and Insectivora, are in their ultimate form sinilar to them, and may be conveniently dealt with here. 'The early stages in the derelopment of these membranes in the hunan embryo have not been satisfactorily observed; but it is known that the ovmm, shortly after its entrance into the uterus, becomes attacherl to the uterine wall, which in the meantime las undergone considerable preparatory changes. A fold of the uterine wall appears to grow round the blastodermic vesicle, and to form a complete capsule for it, but the exact mode of formation of this capsule is a matter of inference and not of observation. During the first fortuight of pregnancy villi grow ont, according to Alten Thomson over its whole surface, but according to Reichert in a ring-like fashion round the edge of the somewhat flattened ovum, and attach it to the uterus. The further history of the early stages is extremely obscure, and to a large extent a matter of speculation: what is known with reference to it will be found in a special section, but I shall here take up the history at about the fourth week.

At this stage a complete chorion has become formed, and is probably derived firom a growth of the mesoblast of the allantois (unacempranied by the liypoblast) round the whole inner surface of the subzonal membrane. From the whole surface of the chorion there project branched vascular processes, covered by an epithelium. The allantois is without a cavity, but a hypoblastic epithelium is present in the allantoic stalk, through which it does not, howerer, form a continuous tube. The blood-ressels of the chorion are derived from the usual allantoic arteries and vein. The general condition of the embryo and of its memhranes at this period is shewn diagrammatically in fig. 147, 5. Around the embryo is seen the amnion, already separated by a considerable interval from the embryo. The yolk-sack is shewn at $d s$. Relatively to the other parts it is considerably smaller than 
it was at an earlier' stage. The allantoic stalk is shewn at al. Both it and the stalk of the yolk-sack are enveloped by the amnion (am). The chorion with its vasenlar processes surrounds the whole embryo.

It may be noted that the condition of the chorion at this stage is very similar to that of the normal diffused type of placenta, desccibed in the sequel.

While the alove changes are taking place in the embryonic nembranes, the blastodermic vesicle greatly increases in size, and forms a considerable projection from the upjer wall of the uterus. Three regions of the uterine wall, in relation to the blastodermic vesicle, are usually distinguished; and since the superficial parts of all of these are thrown off with the afterbirth, each of them is called a decidua. They are represented at a somewhat later stage in fig. 151. There is (1) the part of the wall reflected over the blastodermic vesicle, called the decidua reflexa $\left(d_{i}\right)$; (2) the part of the wall forming the area round which the reflexa is inserted, called the decidua serotima (ds); (3) the general wall of the uterus, not related to the embryo, called the decidua vera (du).

The decidua reflexa and serotina together envelop the chorion, the processes of which tit iuto erypts in them. At this period botl of then are highly and nearly miformly vascular. The general cavity of the uterus is to a large extent obliterated by the ovum, but still persists as a

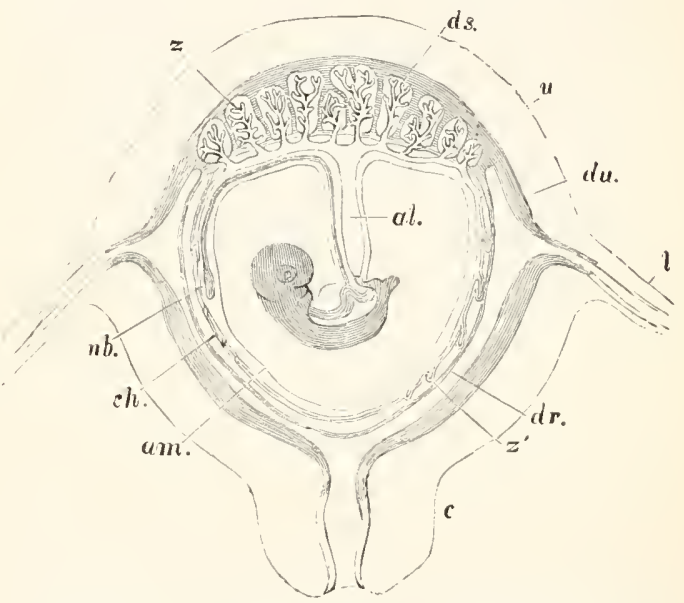

Fig, 151. Diagramatic section of peegnant homan utenus with contained Fetes. (From Huxley after Longet.)

al. allantoic stalk; $n b$. umbilical vesicle; $a m$. amnion; ch. chorion; $d s$. decidua serotina: $d u$. decidua vera; $d r$. decidua reflexa; $\boldsymbol{l}$. Fallopian tube; $c$. cervix uteri; $\boldsymbol{u}$. uterus; z. fotal villi of true placenta; $z^{\prime}$. villi of non-placental part of chorion. space filled with mitcus, between the decidua reflexa and the deciciua vera.

The changes which ensue from this period onwards are fully known. The amnion continues to dilate (its cavity being tensely filled with ammiotie fluid) till it comes very close to the chorion (fig. $151, \mathrm{~cm}$ ); from which, however, it remains separated by a layer of gelatinous tissue. The villi of the chorion in the region covered by the decidua reflexa, gradually cease to be vascular, and partially atrophy, but in the region in contact with the decidua serotina increase and become more vascular and more arborescent (tig. 151, z). The former region becomes known as the chorion lave, and the latter as the chorion frondosun. The chorion frondosum, torgether with the decidua serotinu, gives rise to the placenta. 
Although the vasenlar supply is cut off from the chorion lave, the processes on its surface do not conipletely ahort. It becomes, as the time of birth approaches, more and more closely united with the reflexa, till the uniom between the two is so close that their exact boundaries cannot be made ont. The rmbilical vesicle (fig. 151, $n b$ ), although it becomes greatly reduced in size and flattened, persists in a recognisable form till the time of birth.

As the embryo enlarges, the space between the decidua vera and decidua reflexa becomes reduced, and finally the two parts unite together. The decidua vera is mainly characterised by the presence of peculiar roundish cells in its subepithelial tissue, and hy the disappearance of a distinct lining of epithelial cells. Dnring the whole of pregnancy it remains highly vascular. The decichua reflexa, on the disappearance of the vessels in the clorion lave, becomes nou-vascular. Its tissue undergoes changes in the main similar to those of the decilua vera, and as has been already mentioned, it fuses on the one hand with the chorion, and on the other with the decidua vera. The membrane resulting from its fusion with the latter strncture hecomes thinner and thinner as pregnancy advances, and is reduced to a thin layer at the time of birth.

The placenta las a somewhat discoidal form, with a slightly convex nterine surface and a concave enbryonic surface. At its edge it is continuous both with the decidua reflexa and decidua vera. Near the centre of the embryonic surface is implanted the nmbilical cord. As las aheady been mentioned, the placenta is formed of the decidua serotina and the fietal villi of the chorion frondosum. The foetal and maternal tissnes are fir more closely nuited (fig. 152) than in the forms described above. The villi of the chorion, which were originally comparatively simple, become more and more complicaterl, and assume an extremely arboreseent form. Each of them contains in vein and an artery, which sublivide to enter the complicated ramitications; and are connected together by a rich anastomosis. The villi are formed mainly of comnective tissne, but are covered by an epithelial layer generatly believed to be derivet from the subzonal membrane; bnt, as was first stated by Goodsir, and has since been more fully shewn by Ercolani and Turner, this epithelial layer is really a part of the cellular lecidua serotina of the uterine wall, which has become adherent to the villi in the development of the placenta (fig. 161, g). The placenta is divided into a number of lobes, usually called cotyledons, by septa which pass towards the chorion. These sejta, which belong to the serotina, lie between the arborescent villi of the chorion. The cotyledous themselves consist of a network of tissue permeated by large vascular spaces, formed by the dilatation of the maternal blood-vessels of the serotina, into which the ramitications of the foetal villi project. In these spaces they partly float freely, and partly are attaclied to delicate trabeculae of the maternal tissue (fig. 161, G). They are, of course, separated from the maternal blood by the uterine epithelial layer before mentioned. The blood is brought to the maternal part of the placenta by spirally coiled arteries, which do not divide into capillaries, but open into the large blood-spaces already spoken of. From these spaces there pass off oblique utero-placental veins, which pierce the serotina, and form a system of large venous sintses in the aljoining uterine wall (fig. $35.2, F$ ), and eventually fall into the general uterine vemous system. At birth the whole placenta, together with the 
fused decidua vera, and reflexa, with which it is continuous, is shed; and the blood vessels thins ruptured are closed by the contraction of the nterine wall.

The foetal membranes and the placenta of the Simiala ('Turner, No. 225) are in most respects closely similar to those in Man; but the pla centa is, in most cases, livided into two lobes, though in the Chimpanzee, Cynocephalus, and the Apes of the New World, it appears to be single.

The typres of decilluate placentia so far described, are usually classified by anatomists as discoidal placentre, although it must be borne in mind that they differ very widely. In the Rolentia, Insecti-

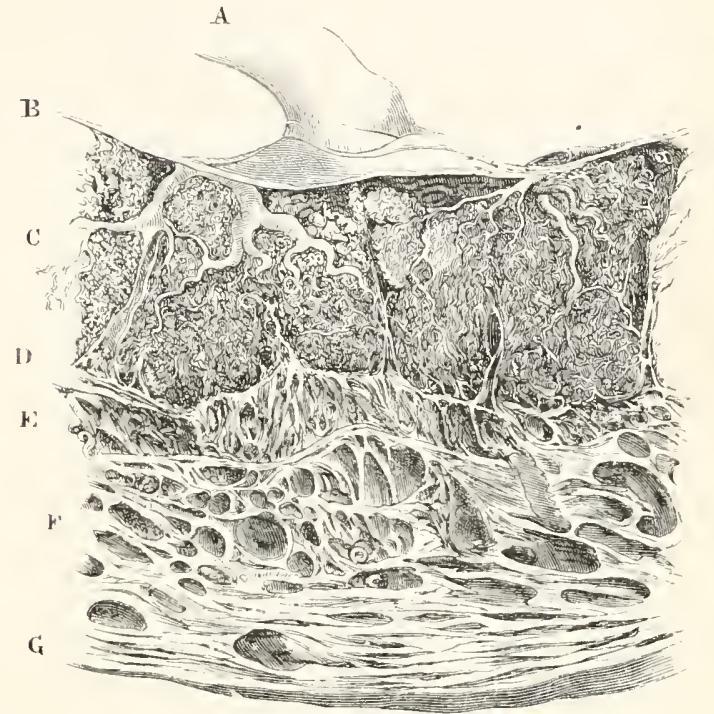

Fi(r. 152. Section of the huMAN UTERUS AND PLACENTA IT THE THIRTIETH WEEK OF PREGNANCY. (From Huxley, after Ecker.)

A. umbilical cord; $B$. chorion : $C$. foetal villi separated by processes of the decidua serotina, $D ; E, F, C_{\text {r }}$ walls of uterus. vora, and Cheiroptera there is a (usually) dorsal placenta, which is co-extensive with the area of contact between the allantois and the subzonal membrane, while the yolksrck adheres to a large part of the subzonal membrane. In Apes and Man the allantois spreads over the whole inner surface of the subzonal membrane; the placenta is on the rentral side of the embryo, and oceupies only a small part of the surface of the allantois. The placenta of Apes and Man might be called metadiscoidal, in orter to distinguish it from the primitive discoidal placenta of the Rodentia and Insectivora.

In the Armadilloes (Dasypus) the placenta is truly discoidal and deciduate (Owen and Kölliker). Alf. Milne Edwards states that in Dasypus novemeinctus the placenta is zonary, and both Kölliker and he found four embryos in the uterus, each with its own amnion, but the placenta of all fon united together; and all four enclosed in a common chorion. A reflexa does not appear to be present. In the Sloths the placenta approaches the discoidal type (Turner, No. 2 I 8 ). It occupies in Chalopus Hoffinami about four-fifths of the surface of the chorion, and is composed of about thirty-four discoid lobes. It is truly deciduate, and the maternal capillaries are replaced by a system of sinmses (fig. 161). The amnion is close to the inner surface of the chorion. A dome-shajed placenta is also found amongst the Edentata in Myrmecophaga and Tamandua (Milne Edwards, No. 208). 
Zonary Placenta. Another form of deciduate placenta is known as the zonary. This form of placenta occupies a broad zone of the chorion, leaving the two poles free. It is found in the Carnivora, Hyrax, Elephas, and Orycteropus.

It is easy to understand how the zonary placenta may be derived fiom the primitive arrangement of the membranes (vide p. 199) by the extension of a discoidal placental area to a zonary area, but it is possible that some of the types of zonary placenta may have been evolved from the concentration of a diffused placenta (ivile p. 217) to a zonary area. The absence of the placenta at the extreme poles of the chorion is explained by the fact of their not being covered by a reflection of the uterine mucons. membrane. In the later periods of pregnancy the placental area becomes, however, in most forms much more restricted than the area of contact between the uterus and chorion.

In the Dog ${ }^{1}$, which may be taken as type, there is a large vascular yolk-sack formed in the usual way, which does not however fuse with the chorion. It extends at first quite to the end of the citron-shaped ovum, and persists till birth. The allantois first grows out on the dorsal side of the embryo, where it coalesces with the subzonal membrane, over a small discoidal area.

Before the fusion of the allantois with the subzonal membrane, there grow out from the whole surface of the external covering of the ovum, except the poles, numerous non-vaseular villi, which fit into uterine crypts. When the allantois atheres to the subzonal membrane vaseular processes grow out from it into these villi. The vascular villi so formed are of course at first confined to the disc-shaped area of adhesion between the allantois and the subzonal menbrane; and there is thus formed a rudimentary discoidul placenta, closely resembling that of the Rodentia. The view previously stater, that the zonary placenta is derived from the discoidal one, receives from this fact a strong support.

The cavity of the allantois is large, and its inner part is in contact with the amnion. The area of adhesion between the outer part of the allantois and subzonal membrane graduatly spreads over the whole interior of the subzonal membrane, and vascular villi are formed orer the whole area of adhesion except at the two extreme poles of the egg. The last part to be covered is the ventral side where the yolk-sack adjoins the subzonal membrane.

During the extension of the allantois its cavity persists, and its inner part covers not only the amnion, but also the yolk-sack. It adheres to the amnion and smpplies it with blood-vessels (Bischoff).

With the full growth of the allantois there is formed a broad placental zone, with numerous branched villi, fitting into corresponding pits which become developed in the uterine walls. The maternal and fotal structures become closely interlocked and highly vascular; and at birth a large part of the maternal part is carried away with the placenta; some of it however still remains attached to the muscular wall of the uterus. The villi of the chorion do not fit into nterine glands. The zone of the placenta diminishes greatly in proportion to the chorion as the latter elongates: and at the full time the breadth of the zone is not more than about onefifth of the whole length of the chorion.

$$
1 \text { Tide Bischoff, No. } 175 .
$$


At the edge of the placental zone there is a very small portion of the? uterine mucous membrane reflected over the non-placental part of the chorion, which forms a small reflexa analogous with the reflexa in Man.

The Carnivora generally closely resemble the Dog, but in the Cat the whole of the maternal part of the placenta is carried away with the foetal parts, so that the placenta is more completely deciduate than in the Dog. In the Grey seal (IIalichorus grypleus, Turner, No, 2 I9) the general arrangement of the fotal membranes is the same as in the other groups of the Carnivora, but there is a considerable reflexa developed at the edge of the placenta. The foetal part of the placenta is divided by a series of primary fissures which give off secondary and tertiary fissures. Into the fissures there pass vascular lamine of the uterine wall. The generai surface of the fotal part of the placenta between the fissures is covered by a greyish membrane former of the coalesced terminations of the fotal villi.

The structure of the placenta in Hyrax is stated by Turner (No. 22r) to be very similar to that in the Felidre. The allantoic sack is large, and covers the whole surface of the subzonal membrane. The ammion is also large, but the yolk-sack would seem to disappear at an early stage, instead of persisting, as in the Cirnivora, till the close of fetal life.

The Elephant (Owen, Turner, Chapman) is provicled with a zonary decidnate placenta, though a villous patch is present near each pole of the chorion.

Turner (No. 220) has shewn that in Orycteropus there is present a zonary placenta, which differs lrowever in several particulars from the normal zonary placenta of the Carnivora; and it is even doubtful whether it is truly deciduate. There is a single embryo, which fills up the body of the uterus and also projects into only one of the horns. The placenta forms a broad median zone, leaving the two poles free. The breadtl of the zone is considerably greater than is usual in Carnivora, one-half or more of the whole longitudinal diameter of the chorion being occupied by the placenta. The chorionic villi are arborescent, and diffusely scattered, and thongh the maternal and foetal parts are closely interwoven, it has not been ascertained whether the adhesion between them is sufficient to cause tle maternal subepithelial tissue to be carried away with the foetal part of the placenta at birth. The allantois is adherent to the whole chorion, the nonplacental parts of which are vascular. In the umbilical cord a remnant of the allantoic vesicle was present in the embryos observed by 'Turner, but in the absence of a large allantoic cavity the Cape Ant-eater differs greatly from the Carnivora. The amnion and allantois were in contact, but no yolk-sack was observed.

Non-deciduate placenta. The remaining Mammalia are characterized by a non-deciduate placenta ; $\mathrm{ol}^{\prime}$ at least by a placenta in which only parts of the maternal epithelium and no vascular maternal structures are carried away at parturition. The non-deciduate placentre are divided into two groups: (1) The polycotyledonary placenta, characteristic of the true Ruminautia (Cervidx, Antilopidæ, Bovidæ, Camelopardalidæ); (2) the diffused placenta found in the other non-deciduate Mammalia, viz, the Perissodactyla, the Suidæ, the Hippopotamidre, the Tylopoda, the Tragulidx, the Sirenia, the Cetacea, Manis amongst the Fidentata, and the Lemuridie. The polycotyledonary form is the most differentiated; and is probably a modification of the diffused form. The riffused non-deciduate placenta is very easily 
derived from the primitive type (p. 199) by an extension of the allantric portion of the chorion; and the exchsion of the yolk-sack from any participation in forming the chorion.

The possession in eommon of a diffused type of plaeenta is by no means to be regarded as a necessary proof of affinity between two groups, and there are often, even amongst animals possessing a diffused form of plaeenta, eonsiderabie differenees in the general arrangement of the embryonic membranes.

Ungulata. Although the Ungulata inchude forms with both eotyledonary and diffused placentre, the general arrangement of the embryonie membranes is so similar throughout the group, that it will be eonvenient to commence with a deseription of them, which will fairly apply both to the Ruminantia and to the other forms.

The blastodermie vesicle during the early stages of development lies frealy in the uterus; and no non-vaseular villi, similar to those of the Dog or the Ribbit, are formed before the appearanee of the allantois. The blastodermie vesiele has at first the usual spherieal form, but it grows out at an early period, and with prodigious rapidity, into two immensely long horns; which in eases where there is only one embryo are eventually prolonged for the whole length of the two horns of the uterus. The embryonic area is formed in the usual way, and its long axis is placed at

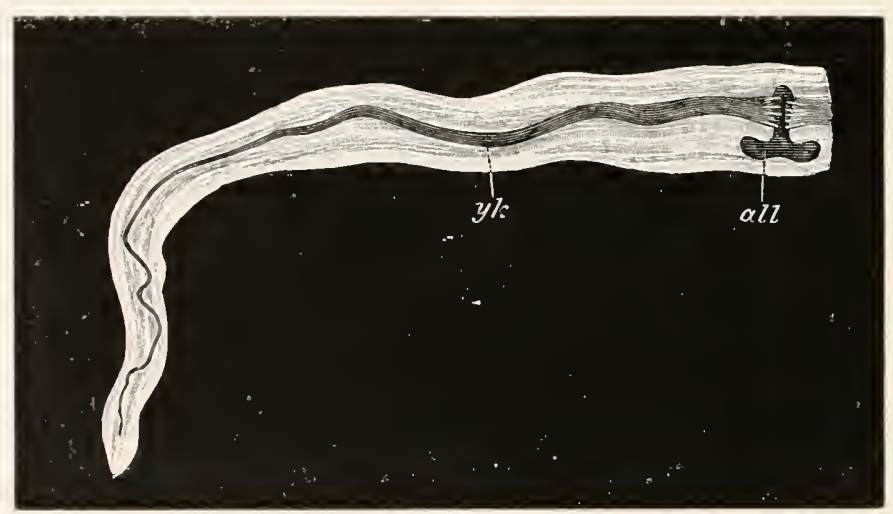

Fig. 153. Eabrixo and fetal membranes of a young embrio Roe-deer. (After Bischoff.)

$y k$. yolk-sack; all. allantois just spronting as a bilobed sack.

right angles to that of the resicle. On the formation of an amnion there is formed the usual subzonal membrame, whieh soon beeones separated by a eonsiderable space from the yolk-sack (fig. 153). The yolk-saek is, however, continued into two elongater proeesses $(y k)$, whieh pass to the two extremities of the subzonal membrane. It is supplied with the normal blood-ressels. As soon as the allantois appears (fig. 153 all), it grows out into a right and a left process, which rapidly fill the whole free space within the subzonal membrane and in many cases, e.\%. the Pig (Von Baer), break throngh the ends of the membrane, from which they projeet as the diver- 
ticula allantoidis. The eavity of the allantois remains large, but the lining of hypoblast becomes separated from the mesollast, owing to the more lapid growth of the latter. The nesoblast of the allantois applies itself externally to the subzonil membrane to form the chorion ${ }^{2}$, and in. termally to the amnion, the cavity of which remains very small. The chorionic portion of the allantoic mesoblast is very vascular, and that applier to the ammion also becomes vascular in the latel developmental periorls.

The horns of the yolk-sack gradually atrophy, and the whole yolksick disappear's some time before birth.

Where two or more embryos are present in the uterus, the chorions of the several embryos may unite where they are in contact.

From the chorion there grow out numerous vascular villi, which fit into morresponding pits in the uterine walis. Accorling to the listribution of these villi, the allantois is either diffused or polycotyledonary.

The jig presents the simplest type of diffused placenta. 'The villi of the surface of the chorion cover a broad zone, leaving onty the two poles free; their arrangement differs therefore from that iu a zonary placenta in the greater breath of the zone covereil by them. The villi have the form of simple papillae, arranged on a series of ridges, which are highly vascular as compared with the intervening valleys. If an injected chorion is examined (fig. 15t), certain clear non-vascular spots are to be seen (b), from

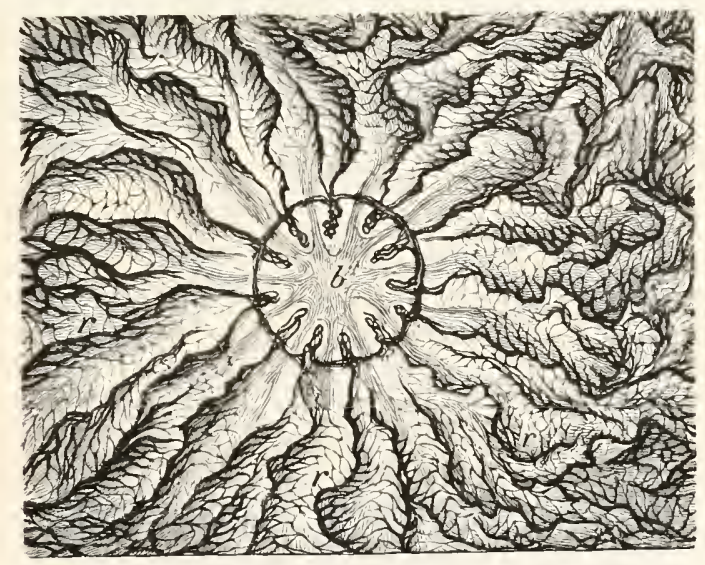

Fir. 154. Portion of the nijected chorion of a Pig, slightly magnified. (From Turner.)

The figure shews a minute circular spot $(b)$ (enclosed by a vascular ring) from which villous ridges $(r)$ radiate.

which the ridges of villi radiate. The surface of the uterus ardapts itself exactly to the elevations of the chorion; and the furrows which receive the chorionic risges are highly vascular (fig. 15.5). On the other hant, there are non-vascular circulir depressions corresponding to the nonvascular areas on the chorion; and in these areas, and in these alone, the

1 According to Bischoff the subzonal membrane atrophies, leaving the allantoic mesoblast to constitute the whole chorion.

b. E. II. 
glands of the uterus open (fig. $15.5 \mathrm{~g}$ ) (T'morer). The maternal and fortal parts of the placenta in the pig separate with very great ease.

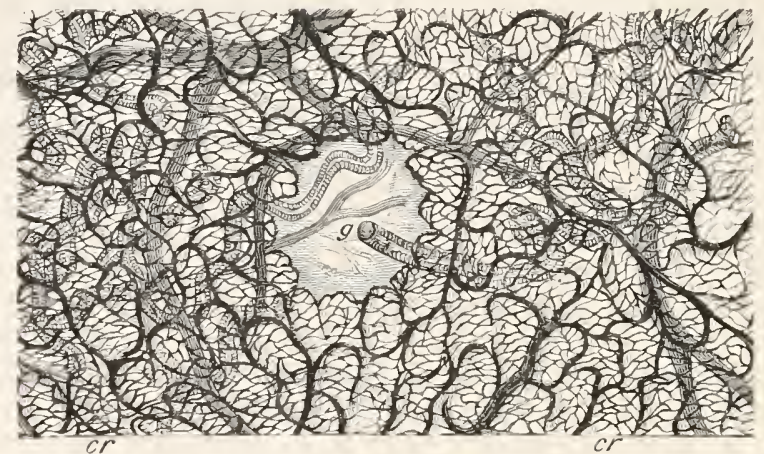

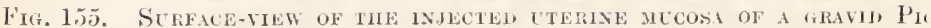

\section{Turner.)}

(Fiom

The fig. shews a circular non-vascular spot where a gland opens (g) surrounded by numerous vascular errpts $(\mathrm{cr})$.

In the mare (Turner), the foetal villi are arranged in a less clefinite zonary band than in the pig, though still absent for a rery small area at hoth poles of the chorion, and also opposite the os uteri. The filiform villi, though to the naked ere miformly scattered, are, when magnified, found to be clustered together in minute cotyledons, which fit into corresponding nterine erypts (fig. 156). Surounding the uterine crypts are reticulate

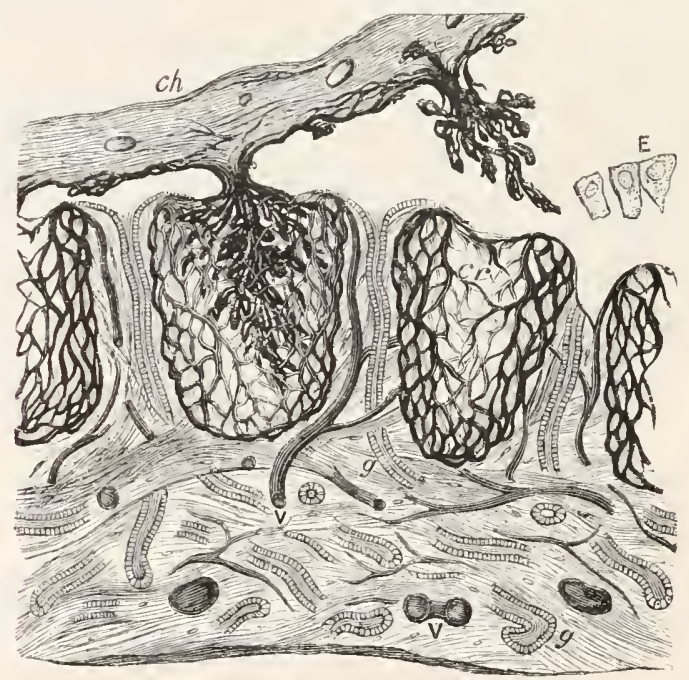

Fig. 156. Vertical section throtgh the injected placenta of a Mare.

(From Turner.)

ch. chorion with its villi partly in situ and partly drawn out of the crypts $(c r)$; $E$. loose epithelial cells which formed the lining of the crypt; $g$. uterine glands: $v$. blood-vessels. 
ridges on which are placed the openings of the uterine glands. The remaining Ungulata with diffused placentse do not differ in any important pirticulars from those already described.

The polycotyledonary form of placenta is found in the Ruminantia alone. Its essential claracter consists in the fotal villi not being miformly distributed, but collected into patches or cotyledons which form as it were so many small placentre (fig. 15\%). The fotal villi of these patches

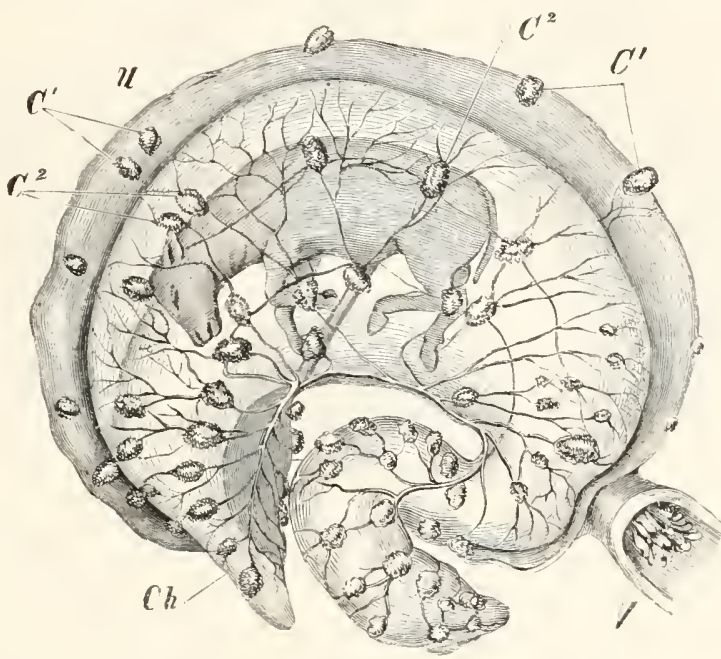

Fig. 157. Uteres of a Cow in the Middee of pregrancr laid opex. (From Huxley after Colin.)

$r$ ragina ; $C$. uterus; $C h$. chorion; $C^{1}$. uterine cotyledons ; $C$. fortal cotyledons.

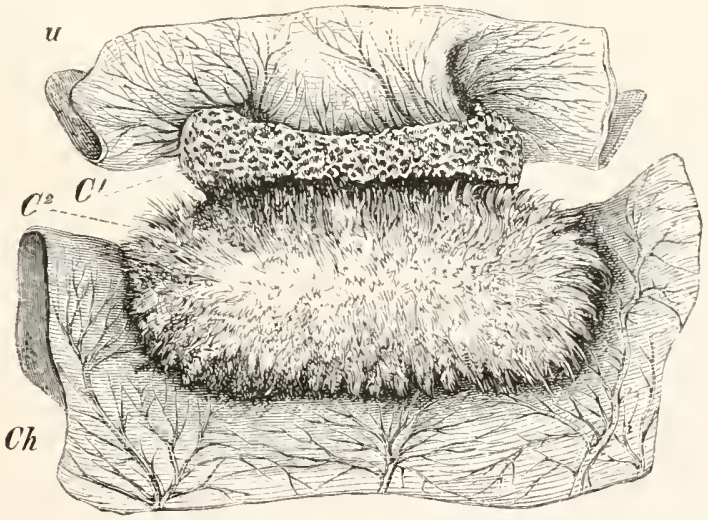

Fig. 158. Cotyledon of a Cow, the fetal axd materval parts half separated. (From Huxley after Colin.)

u. uterus; $C h$, chorion; $C^{1}$. maternal part of cotyledon ; $C^{2}$. futal part. 
fit into corresponding pits in thickened patches of the wall of the uterus (figs. 158 and 159). In many cases (Turner), the interlocking of the maternal aud fotal structures is so close that large parts of the maternal epithelium are carried away when the fotal villi are separated from the

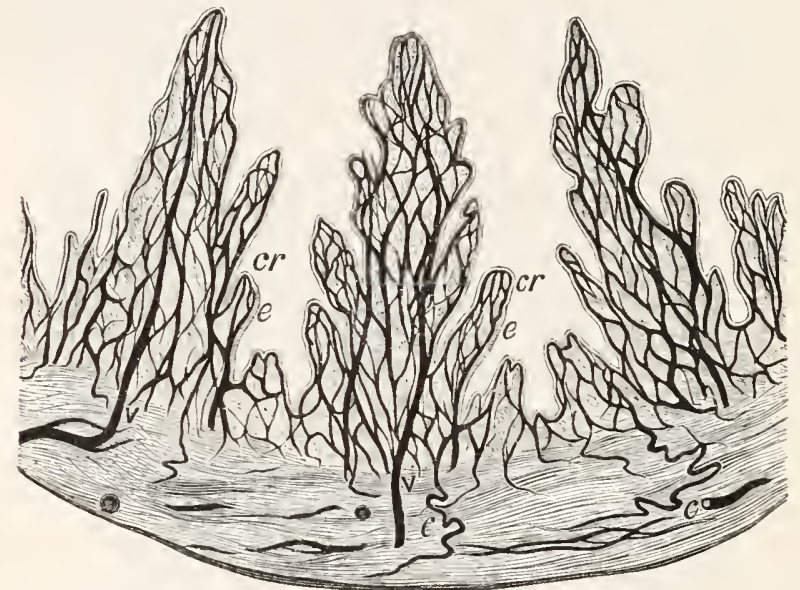

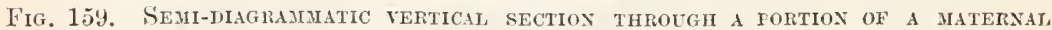
COTYledox of A SHEeP. (From Tumer.)

$c r$. crypts; $e$. epithelial lining of crypts; $r$. veins and $c$. curling arteries of sub. cpithelial connective tissuc.

uterus. The glands of the utelus open in the intervals between the cotyledons. The character of the cotyledons differs greatly in clifferent types. The materual parts are cup-shaped in the sheep, and mushroomshaped in the cow. There are from 60-100 in the cow and sheep, but only about five or six in the Roe-deer. In the Giraffe there are, in addition to larger and smaller cotyledons, rows and clusters of short villi, so that the placenta is more or less intermediate between the polycotyledonary and diffused types (Turner). A similarly intermediate type of placenta is found in Cervns mexicanus (Turner).

The groups not belonging to the Ungulata which are characterized by the posspssion of a diffused placenta are the Sirenia, the Cetacea, Manis, and the Lemuridie.

Sirenia. Of the Sirenia, the placentation of the Dugong is known from some observations of Harting (No. 20I).

It is provided with a diffuse and non-deciduate placenta ; with the villi generally scattered except at the poles. The umbilical vesicle vanishes early.

Cetacea. In the Cetacea, if we may generalize from Turner's observations on Orca Gladiator and the Narwhal, and those of Anderson (No. I9 I) on Platanista and Orcella, the blastodermic vesicle is very much elongated, and prolonged unsymmetrically into two horns. The mesoblast (fig. 160) of the allantois would appear to grow round the whole inuer surface of the subzonal membrane, but the cavity of the allantois only persists as a widisl sack on the ventral aspect of the embryo (al). The amnion $(a m)$ is enor- 
mous, and is dorsally in apposition with, and apparently coalesces with the chorion, and ventrally coveis the inner wall of the persistent allantoic

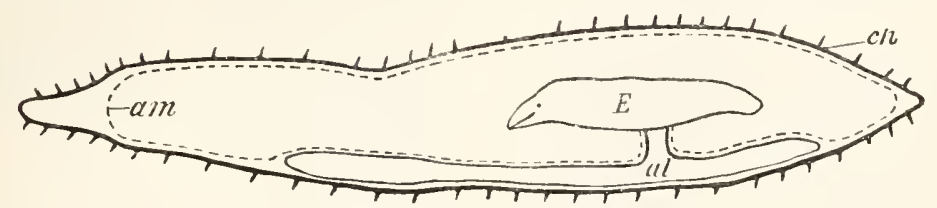

F1g. 160. Diagray of the feetal membranes in Orca ghadrator. (From Turner.) $c h$. chorion; am. amnion ; al. allantois ; $E$. embryo.

sack. The chorion, except for a small area at the two poles and opposite the os nteri, is nearly uniformly covered with villi, which are more numerous than in fig. 160. In the large size of the amnion, and small dimensions of the persistent allantoic sack, the Cetacea difter considerably from the Ungulata.

Manis. Manis amongst the Edentata presents a type of diffused placenta ${ }^{1}$. The villi are arranged in ridges which radiate from a non-villous longitudinal strip on the concave surface of the chorion.

Manis presents us with the third type of placenta found amongst the Edentata. On this subject, I may quote the following stntence from Tnrner (Journal of Anat. and Phys., vol. x., p. 706).

"The Armadillos (Dasypus), according to Professor Owen, possess it single, thin, oblong, disc-sliaped placenta; a specimen, probably Jasypus gymumins, recently described by Kibliker ${ }^{2}$, had a transversely oval placenta, which occupied the upper ards of the uterus. In Manis, as Dr. Sliarpey has shewn, the placenta is diffused over the surfaces of the chorion and uterine mucosa. In Mrrmecophaga and Tamandua, as MM. Milne Edwards have pointed out, the placenta is set on the chorion in a clomelike manner. In the Sloths, as I have elsewhere described, the placenta is dome-like in its general form, and consists of a number of aggregated, discoid lobes. In Orycteropus, as I have now shewn, the placenta is broadly zonular."

Lemuridæ. The Lemurs in spite of their affinities with the Primates and Insectivora have, as has been shewn by Hihe Edwards and Turner, an apparently very different form of placenta. There is only one enbryo, which occupies the body. and one of the comua of the utems. The yolk-sack disappears early, and the allantois (Turner) bulges out into a right and left lobe, which meet above the back of the embryo. The cavity of the allantois persists, and the mesoblast of the outer wall fuses with the subzonal membrane (the hypoblastic epithelium remaining distinct) to give rise to the chorion.

On the surfice of the chorion are numerous vascular villi, which fit into uterine crypts. They are generally distributed, though absent at the two ends of the chorion and opposite the os uteri. Their distribution

1 The observations on this head were made by Sharpey, and are quoted by Huxley (No. 202) and with additional observations by Turner in his Memoir on the placentation of the Sloths. Anderson (No. I9) has also recently confirmed Sharpey's account of the diffused cliaracter of the placenta of Manis.

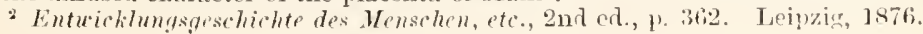




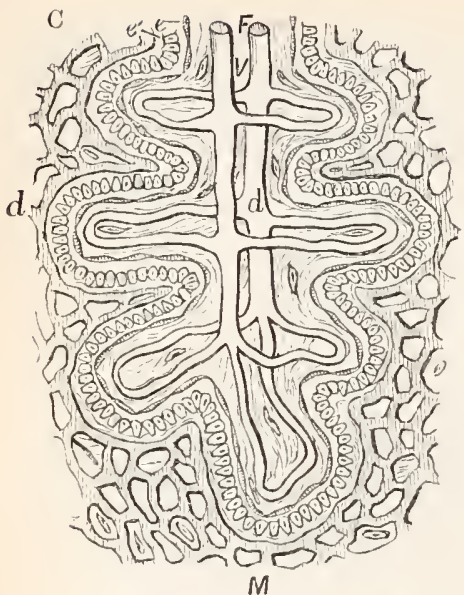

F

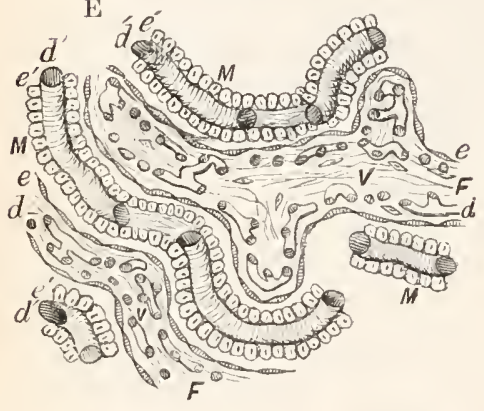

$\mathbf{I}^{1}$

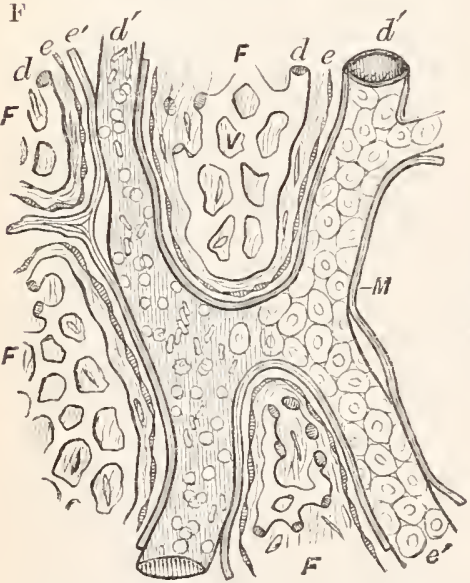

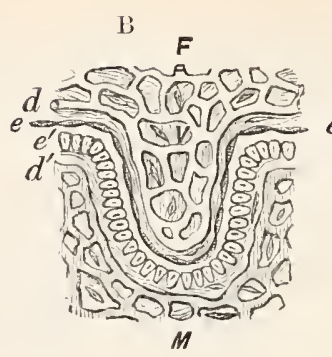
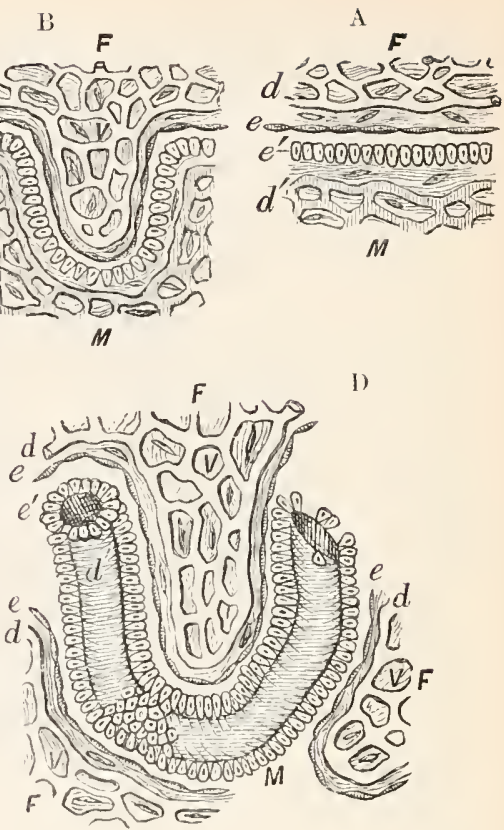

(

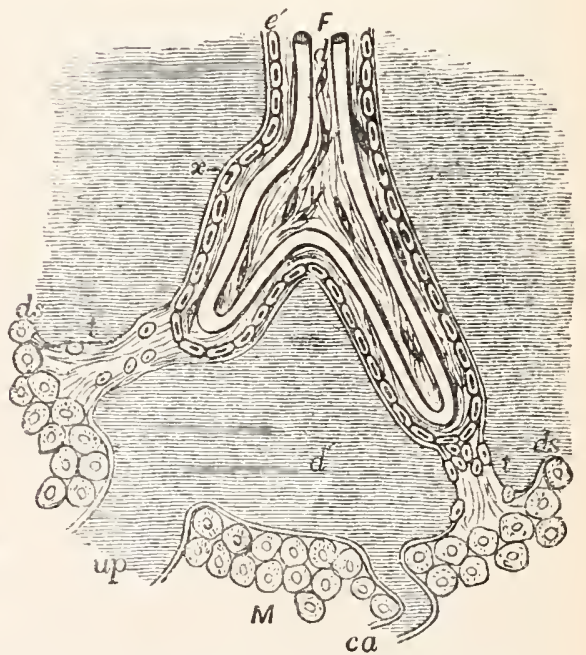

Fig. 161. Diagramatic representations of the minute structule of the Placenta. (From Turner.)

$F$. the fuetal; .7 . the maternal placenta; $e$. epithelium of chorion; $e^{\prime}$. epithelium of maternal placenta; $d$. fotal blood-ressels; $d$. maternal blood-vessels; $v$. villus. 
A. Placenta in its most generalized form.

B. Structure of placenta of a Pig.

C. Structure of placenta of a Cow.

D. Structure of placenta of a Fox.

E. Structure of placenta of a Cat.

F. Structure of placenta of a Sloth. On the right side of the figure the flat maternal epithelial cells are shewn in sitn. On the left side they are removed, and the dilated maternal vessel with it: blood-corpuscles is exposed.

G. Structure of Human placenta. In addition to the letters already referred to, $d s$, ds. represents the decidua serotina of the placcnta; $t, t$. trabecule of serotina passing to the fotal villi; ca. curling artery; up. utero-placental vein; $x$. a prolongation of maternal tissue on the exterior of the villus outside the cellular layer $e^{\prime}$, which may represent either the endothelium of the maternal blook-vessel or delicate connective tissue belonging to the selotina, o1 both. The layer $c^{\prime}$ represents maternal cells derived from the serotina. The layer of fietal epithelium cannot be seen on the villi of the fully-formed human placenti.

accords with Turner's diffused type. Patches bare of villi correspond with smooth areas on the surface of the nterine mucosa in which numerous utricular glands open. There is no reflexa.

Although the Lemurian type of placenta undoubtedly differs from that of the Primates, it must be borne in mind that the placenta of the Primates may easily be conceived to be derived from a Lemurian form of placenta. It will be remembered that in Man, before the true placenta becones developed, there is a condition with simple vascular villi scattered over the chorion. It seems very probable that this is a repetition of the condition of the placenta of the ancestors of the Primates which has probahly been more or less retained by the Lemurs. It was nentioned above that the resemblance between the metadiscoidal placenta of Man and that of the Cheiroptera. Insectivora and Rodentia is rather physiological than morphological.

\section{C'omparative listology of the Placentu.}

It does not fall within the province of this work to treat fiom a histological standpoint the changes which take place in the nterine walls huring pregnancy. It will, however, be convenient to place before the reader a short statement of the relitions between the maternal and foetal tissues in the different varieties of placenta. This sulject has been adınirably dealt with by Turner (No. 222), from whose paper tig. 161 illustrating this smbject is taken.

The simplest known condition of the placenta is that found in the pig (B). The papilla-like fotal villi fit into the maternal crypts. The villi $(v)$ are formed of a connective tissue cone with capillaries, and are covered by a layer of very flat epithelium (e) derived from the subzonal membrane. The maternal crypts are lined by the uterine epithelium (é), immediately below which is a capillary flexus. The maternal and foetal ressels are here separated by a duuble epithelial layer. The same general arrangement holds good in the diffused placenta of other forms, and in the polycotyledonary placenta of the Ruminantia, but the fotal villi (C) in the latter acquire an arborescent form. The maternal vessels retain the form of capillaries.

In the decirluate placenta a considerably more complicated arrangement is usually found. In the typical zonary placenta of the fox and cat (J) and E), the maternal tissue is broken up into a complete trabecular. 
meshwork, and in the interior of the trabecule there run dilated materral capillaries $\left(d^{\prime}\right)$. The trabeculie are covered by a more or less columnar uterine epithelium $\left(e^{\prime}\right)$, and are in contact on every side with fotal villi. The capillaries of the foetal villi preserve their normal size, and the villi are covered by a flat epithelial layer $(e)$.

In the sloth (F) the maternal capillaries become still more dilated, and the epithelium covering them is formed of very flat polygonal cells.

In the human placenta $(G)$, as in that of Apes, the greatest modification is found in that the maternal vessels have completely lost their capillary form, and have become expanded into large freely commuuicating sinuses $\left(l^{\prime}\right)$. In these simuses the fotal villi hang for the most part freely, though occasionally attached to their walls $(t)$. In the late stages of fould life there is only one epithelial layer ( $e^{\prime}$ ) hetween the maternal and foetal vessels, which closely invests the foetal villi, but, as shewn by Turner and Ercolani, is part of the uterine tissue. In the foetal villi the vessels retain their capillary form.

\section{Evolution of the Placentu.}

From Owen's observations on the Marsupials it is clear that the yolk-sack in this group plays an important, if not the most important part, in absorbing the matemal nutriment destined for the foutus. 'The fact that in Marsupials both the yolk-sack and the allantois are functional in rendering the chorion vascular makes it i priori probable that this was also the case in the prinitive types of the Placentalia, and this deduction is supported by the fact that in the Rodentia, Insectivora and Cheiroptera this peculiarity of the fietal membrames is actually found. In the prinitive Placentalia there was probably present a discoidal allantoic region of the chorion, from which simple foetal villi, like those of the pig (fig. $161 \mathrm{~B}$ ), projected into uterine crypts; but it is not certain how far the umbilical part of the chorion, which was no doubt vascular, may also have been villous. From such a primitive type of tout membranes divergences in various directions have given rise to the types of foetal membranes now existing.

In a general way it may be laid down that variations in any direction which tended to increase the absorbing capacities of the chorion would be advantageous. 'There are two obvious ways in which this might be clone, viz. (1) by increasing the complexity of

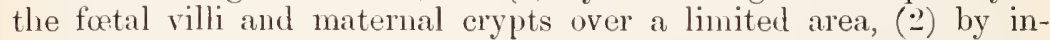
creasing the area of the part of the chorion covered by placental villi. $V$ arious combinations of the two processes would also of course be adrantageous.

The most fundamental change which has taken place in all the existing Placentalia is the exclusion of the umbilical vesicle from any important function in the nutrition of the foetus.

The arrangement of the fotal parts in the Rodentia, Insectivora and Cheiroptera may be directly derived from the primitive form by supposing the villi of the discoidal placental area to have become more complex, so as to form a deciducte riscoidal placenta; while the 
yolk-sack still plays a part, thouglı physiologically an unimportant part, in rendering the chorion vascular.

In the Carnivora again we have to start from the discoidal placenta, as shewn by the fact that the allantoic region of the placenta is at first discoidal (p. 206). A zonary deciduate placenta indicates an increase both in area and in complexity. The relative diminution of the brealth of the placental zone in late foetal hife in the zonary placenta of the Carnivora is probably due to its being on the whole advantageous to secure the nutrition of the foetus by insuring a more intimate relation between the fotal and maternal parts, than by increasing their area of contact. The reason of this is not obvious, but as mentioned below, there are other cases where it can be shewn that a diminution in the area of the placenta has taken place, accompanied by an increase in the complexity of its villi.

The second type of differentiation from the prinitive form of discoidal placenta is illustrated by the Lemuridx, the Suidre, and Manis. In all these cases the area of the placental villi appears to have increased so as to cover nearly the whole subzonal membrane, without the villi increasing to any great extent in complexity. From the diffused placenta covering the whole surface of the chorion, differentiations appear to have taken place in varions lirections. The metadiscoidul placenta of Man and Apes, from its mode of ontogeny (1. 20:3), is clearly derived from a diffused placenta-very probably similar to that of Lemurs-by a concentration of the foetal villi, which are originally spread over the whole chorion, to a disc-shaped area, and by an increase in their arborescence.

The polycotyledonary forms of placenta are due to similar concentrations of the foetal villi of an originally diffused placenta.

In the Edentata we have a group with very varying types of p'acenta. Very probably these may all be differentiations within the group itself from a diffused placenta, such as that found in Manis. The zonary placenta of Orycteropus is capable of being easily derived from that of Manis, by the disappearance of the fuetal villi at the two poles of the ovun. The small size of the umbilical vesicle in Orycteropus indicates that its discoidal placenta is not, like that in Carnivora, directly derived from a type with both allantoic and umbilical vascularization of the chorion. The discoidal and dome-shaped placentie of the Armadilloes, Myrmecophaga, and the Sloths may easily have been formed from a diffinsed placenta, just as the discoidal placenta of the Simiade and Anthropide appears to have been formed from a diffused placenta like that of the Lemurirle.

The presence of zonary placentæ in Hyrax and Elephas does not necessarily afford any proof of aftinity of these types with the Carnivora. A zonary placenta may quite easily be derived from a ditfused placenta; and the presence of two villous patches at the poles of the chorion in Elephas indicates that this was very probably the case with the placenta of this form.

Althongh it is clear from the above considerations that the 
placenta is capable of being used to some extent in classification, yet at the sane time the striking resemblances which can exist between such essentially different forms of placenta, as for instance those of Man and the Rodentia, are likely to prevent it being employed, except in conjunction with other characters.

\section{Special types of development.}

The Guinea-pig, Cavia cobaya. Nany years ago Bischoff (No. 176) sliewed that the development of the guinea-pig was strikingly different from that of other Mammalia. His statements, which were at first received with some doubt, have been in the main fully confirmed by Hensen (No. I S2) and Schäfer (No, r9o), but we are still as far as ever from explaining the mystery of the phenomenon.

The ovmu, enclosed by the zona racliata, passes into the Fallopian tube and undergoes a segmentation whith has not been studied with great detail. On the close of segmentation, about six days after impregnation, it assmmes (Hensen) a vesicular form not unlike that of other Mammalia. To the inner side of one wall of this resicle is attached a mass of granular cells similar to the hypoblastic mass in the blastodermie vesicle of the rabbit. The ecgr still lies freety in the uterus, and is invested by its zona radiata. The changes which next take place are in spite of Bischoff's, Reichert's (No. r 88) and Hensen's observations still involver in great obscurity. It is certain, however, that during the course of the seventh day a ring-like thickening of the utcrine mucous membrane, ou the free side of the uterus, gives rise to a kind of diverticulum of the uterine cavity, in which the ovum hecomes lodged. Opposite the diverticulum the nucous membrane of the mesometric side of the uterus also becomes thickened, and this thickening very soon (shortly after the seventh day) unites with the wall of the diverticulum, and completely shuts off the ovum in a tosed capsule.

'The history of the ovum during the earlier period of its inclusion in the diverticulum of the uterine wall is not satisfactorily elucidated. There appears in the diverticulum during the eighth and succeeding days a cylindrical body, one end of which is attached to the uterine walls at the mouth of the diverticulum. The opposite end of the cylinder is free, and contains a solid borly.

With reference to the nature of this eylinder two views have been put forward. Reichert and Hensen regard it as an outgrowth of the uterine wall, while the body within its free apex is regarded as the orum. Bischoff and Schäfer maintain that the cylinder itself is the ovum attached to the uterine wall. The observations of the latter authors, and especially those of Schäfur, appear to me to speak for the correctness of their view ${ }^{1}$.

The cylinder gradually elongates $u$, to the twelfth day. Before this period it becomes attached by its base to the mesometric thickening of the uterus, and enters into vascular connection with it. During its elongation it becomes hollow, and is filled with a fluid not coagulable in alcohol, while the body within its apex remains unaltered till the tenth day.

1 Schüfer's and Hensen's statements are in more or less direct contradiction as to the structure of the ovum after the formation of the embryo; and it is not possible to decide between the two views about the ovum till these points of difference have been cleared up. 
On this day a cavity develops in the interior of this body which at the same time enlarges itself. The greater part of its wall next attaches itself to the free end of the cylinder, and becomes considerably thickened. The remainder of the wall adjoining the cavity of the cylinder becomes a comparatively thin membraue. At the free end of the cylinder there appears on the thirteenth day an embryonic area similar to that of other Mammalia. It is at first round but soon becomes pyriform, and in it there appear a primitive streak and groove; and on their. alpearance it becomes ohvious that the outer layer of the cylinder is the hypoblast', instead of, as in all other. Mammatia, the epiblast; and that the epiblast is formed by the wall of the inner resicle, i.e. the original solid body placed at the end of the cylinder. Thus the dorsal surface of the embryo is turned inwards, and the ventral surface outwards, and the ordinary position of the layers is completely

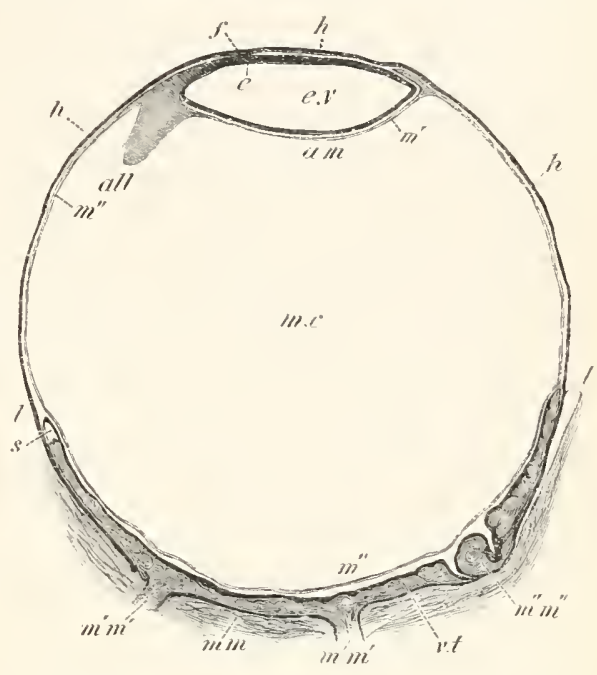

Fig. 162. Diagramatic InxGitudixal SEctios THROUGH THE EMERYo OF A (iUNEA-PIG W1TH 1TS menbraxes. (After Schäter.)

$e$. epiblast; $h$. hypoblast; $m^{\prime}$. amniotic mesoblast ; $m$ ". splanchnic mesoblast; am. amnion; $c r$. cavity of amnion: all. allantois; $f$. rudimentary blastopore; $m c$. cavity of resicle continuons with body-cavity; $m m$. mucous membrane of uterus; $m^{\prime} m^{\prime}$. parts where vascular uterine tissue perforates hypoblast of blastodermic vesicle; $v t$, uterine vascular tissue; $l$. limits of uterine tissue. inverted.

The previously cylindrical egg next assumes a spherical form, and the mesoblast arises in connection with the primitive streak in the manner already described. A splanchnic layer of mesoblast attaches itself to the inner side of the outer hypoblastic wall of the egg, a srmatic layer to the cpiblast of the inner vesicle, and a mass of mesoblast grows out into the cavity of the larger vesicle forming the commencement of the allantois. The general structure of the ovm at this stage is represented on fig. $16 \%$, copied from Schäfer; and the condition of the whole ovum will best be understood by a description of this figure.

It is seen to consist of two vesicles, (1) an outer larger one $(h)$-the original egg-cylinrier-united to the mesometric wall of the uterus by a vascular connection at $m^{\prime} m^{\prime}$, and (2) an inner smaller one $(e v)$ - the originally solid body at the free end of the egg-cylinder. The onter vesicle is formed of (1) an external lining of columnar hylmblast $(h)$ which is either pierced or

1 According to Hensen the hypoblast grows round the inside of the wall of the cylinder from the hody which he regards as the orum. The original wall of the cylinder persists as a very thin layer separated from the hypoblast by a membrane. 
invaginated at the area of vascular connection with the uterus, and (2) of an inner layer of splanchnic mesolblast $\left(m^{\prime \prime}\right)$ which covers without a break the vascular uterine growth. At the upper pole of the orum is placed the smaller epiblastic vesicle, and where the two vesicles come together is situated the embryonic area with the primitive streak $(f)$, and the medullary plate seen in longitudinal section. The thinner wall of the inner vesicle is formed of epiblast and somatic mesoblast, and covers over the dorsal face of the embryo just like the ammion. It is in fact usually spoken of as the ammion. The large cavity of the outer vesicle is continuous with the body cavity, and into it projects the solid mesoblastic allantois (all), so fal witlout hypoblast ${ }^{1}$.

The outer vesicle corresponds exactly with the yolk-sack, and its mesoblastic layer receives the ordinary vascular supply.

The embryo becomes folded off from the yolk-sack in the usual way, but comes to lie not outside it as in the ordinary form, but in its interior, and is connectel with it by an umbilical stalk. The yolk-sack forms the substitnte for part of the subzonal membrane of other Mammalia. The so-called amnion appears to me from its development and position rather to correspond with the non-embryonic part of the epiblastic wall (true sulzonal membrane) of the hlastodermic vesicle of the ordinary mannalian forms than with the true amnion; and a true amnion would seem not to he developed.

The allantois meets the yolk-sack on about the seventeenth day at the region, of its vascular connection with the uterine wall, and gives rise to

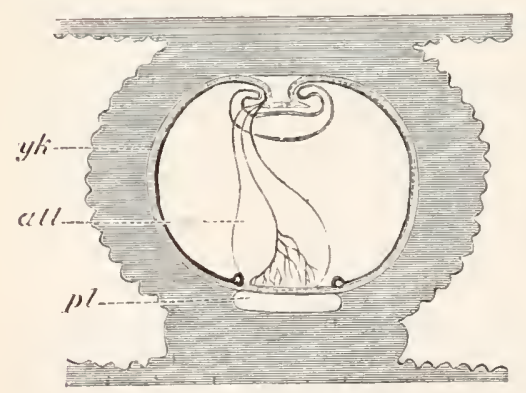

Fig. 163. 1)lag RaMMATIC LONGITUDINAL SECTION OF AN ONUM OF A GUINEA PIG AND THE ADJACENT TTERINE WALLS AT AN ADVANCED STAGE of Pregrancy. (After Bischoff.)

$y k$. inverted yolk-sack (umbilical vesicle) formed of an exterual hypoblastic layer (shaded) and an intemal raseular layer (black). At the end of this layer is placed the sinus terminalis; all. allantois; $p l$. placenta. walls.

The external shaded parts are the uterine

1 Hensen states that the hypoblast never gkows into the allantois; while Bischoff, though not very precise on the point, implies that it does; he states however that it soon disappears. the placenta. A diagrammatic representation of the structure of the embryo at this stage is given in fig. 163 .

The peculiar inversion of the layers in the Guinea-pig has naturally excited the curiosity of embryologists, but as yet no satisfactory explanation has been offered of it.

At the time when the ovmm first becomes fixed it will be renembered that it resembles the early blastodermic vesicle of the Rabbit, and it is natural to suppose that the apparently hypoblastic mass attached to the inner wall of the vesicle becomes the solil body at the end of the escy-cylinder. This appears to be Bischoff"'s view, but as shewn above, the solid mass is really the epiblast! Is it conceivable that the hypoblast in one species 
becomes the epiblast in a closely allicd species? 'To ny mind it is not conceivahle, and I am reduced to the hypothcsis, put forward hy Hensen, that in the comse of the attachment of the orum to the wall of the uterus a rupture of walls of the blastodermic vesicle takes place, and that they become completely turned inside out. It must be admitted, lowever, that in the present state of our knowledge of the development of the ovum on the sereuth and cighth lays it is not possible to frame a satisfactory explanation how such an inversion can take place.

The Human Embryo. Our knowledge as to the carly development of the human embryo is in an unsatisfactory state. The positive facts we know are comparatively few, and it is not possible to construct from them a listory of the development which is capable of satisfactory comparison with that in other forms, unless all the early embryos known are to be regarded as abnormal. The most remarkable feature in the development, which was first clearly brought to light by Allen Thomson in 1839 , is the very early appearance of branched villi. In the last few years several ova, even younger than those described by Allen Thomson, have been met with, which exhibit this peculiarity.

The best-preserved of these ova is one described by Reichert (No.237). This ovum, though probably not more than thirteen days old, was completely enclosed by a decidua reflexa. It had (fig. 164 A and B) a flattened oval form, measuring in its two diameters $5.5 \mathrm{~mm}$. and $3.5 \mathrm{~mm}$. The edge was covered with branched villi, while in the centre of each of the flattened surfaces there was a spot free from villi. On the surface
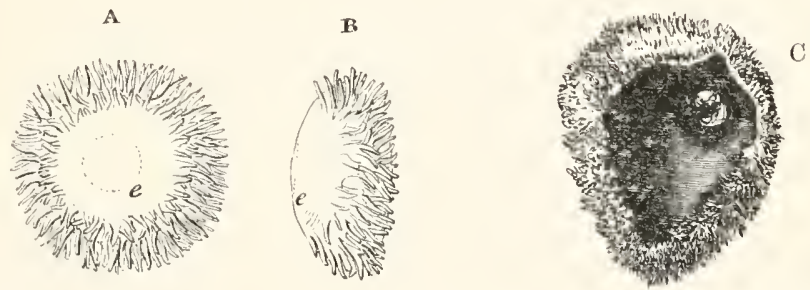

Fig. 164. The human ova derixg early stages of Developyext.

(From Quain's Anatomy.)

A. ant B. Front and side view of an ovum figured by Reichert, supposed to be about thirteen days. e. embryonic area.

C. An ovum of about four or five weeks shewing the general structure of the orum before the formation of the placenta. Part of the wall of the ovum is removed to shew the embryo in situ. (After Allen Thomson.)

arljoining the uterine wall was a darker area $(e)$ formed of two layers of cells, which is interpreted by Reichert as the embryonic area, while the membrane forming the remainder of the ovum, including the branched villi, was stated by Reichert to be composed of a single row of epithelial cells.

Whether or no Reichert is correct in identifying his darker spot as the embryonic area, it is fairly certain from the later observations of Beigel and Löwe (No. 228), Ahlfeld (No. 227), and Kollmann (No. 234) on ova nearly as young as that of Reichert, that the wall of very young ova 
has a more complicated structure than Reichert is willing to almit. These authors do not however agree amongst themselves, but from Kollmann's
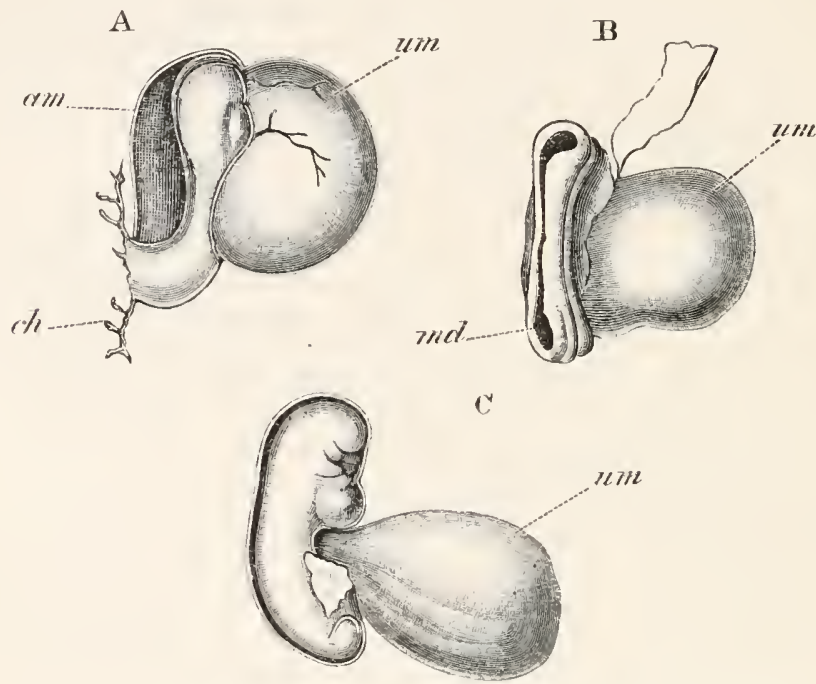

Fig. 165. Three earis human embrios. (Copied from His.)

A. An early embryo described by His from the side. am. amnion; um. umbilical resicle; ch. chorion, to which the embryo is attached by a stalk.

B. Embryo described by Allen Thomson about 12-14 days. um. umbilical resicle; $m d$. medullary groove.

C. Young embryo described by His. $u m$. umbilical vesicle.

description, which appears to me the most satisfactory, it is probable that it is composed of an outer epithelial layer, and an inner layer of connective tissue, and that the comnective tissue extends at a very early period into the villi; so that the latter are not hollow, as Reichert supposed them to be.

The villi, which at first leave the flattened poles free, seem soon to extend first orer one of the fiat sides, and finally over the whole ovum (tig. $16+\mathrm{C}$ ).

Unless the two-layered region of Reichert's ovum is the embryonic area, nothing which can clearly be identified as an embryo has been detected in these early ova. In an ovum described by Breus (No. 228), and in one described long ago by Wharton-Jones a mass found in the interior of the egg may perhaps be interpreted (His) as the remains of the yolk. It is, however, rery probable that all the early ova so far discovered are more or less pathological.

The youngest ovum with a distinct embryo is one described by His (No. 232). This ovum, which is diagrammatically represented in fig. 168 in longitudinal section, had the form of an oval vesicle completely covered by villi, and about $8.5 \mathrm{~mm}$. and $5.5 \mathrm{~mm}$. in its two diameters, and flatter on one side than on the other. An embryo with a yolk-sack was attached to the inner side of the flatter wall of the vesicle by a stalk, 
which must be regarded as the allantoic stalk ${ }^{1}$, and the embryo and yolksack filled up but a very small part of the whole cavity of the vesicle.

The embryo, which was probably not quite normal (fig. 165 A), was very imperfectly developed; a medullary plate was hardly inclicated, and, though the mesoblast was unsegmented, the head fold, separating the embryo from the yolk-sack ( $1 \mathrm{~m}$ ), was already indicated. The amnion $(a m)$ was completely formed, and vitelline ressels had made their appearance.

Two embryos described by Allen Thomson (No. 239) are but slightly older than the above embry os of His. Both of them probally belong to the first fortnight of pregnancy. In both cases the embryo was more or less folded off from the yolk-sack, and in one of them the medullary groove was still widely open, except in the region of the neck (fig. $165 \mathrm{~B}$ ). The allantoic stalk, if present, was not clearly made out, and the condition of the amnion was also not fully studied. The smaller of the two ova was just $6 \mathrm{~mm}$. in its largest diameter, and was nearly completely covered with simple villi, more developed on one side than on the other.

In a somewhat later period, about the stage of at chick at the end of the second day, the medullary folds are completely closed, the region of the brain already marked, and the cranial flexure commencing. The mesoblast is divided up into numerous somites, and the mandibular and first two branchial arches are indicated. The embryo is still but incompletely folded off from the yolk-sack below.

In a still older stage the cranial flexure becomes still more pronounced, placing the mid-brain at the end of the long axis of the body. The body also begins to be ventrally curved (ig. $16.5 \mathrm{C}$ ).

Externally human embryos at this age are characterized by the small size of the anterior end of the head.

The flexure goes on gralually increasing, and in the third week of pregnancy in embryos of about $4 \mathrm{~mm}$. the limbs make their appearance.
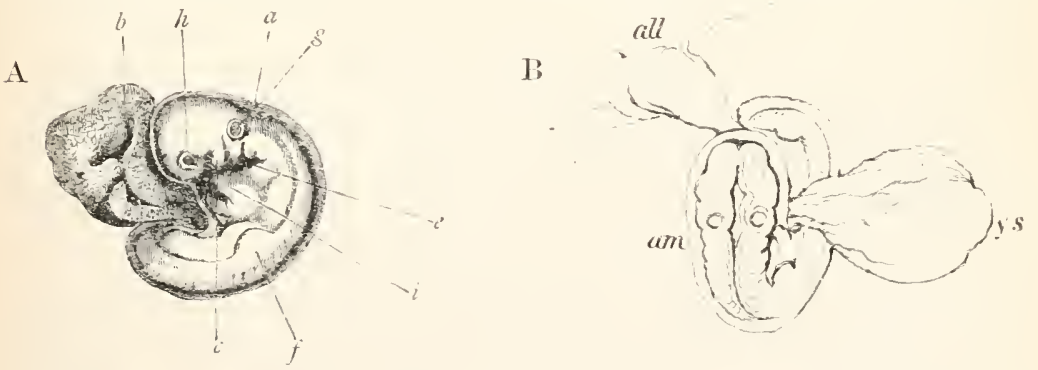

Fig. 169. TWO VIEWS OF A HUMAN EMBRYO OF BETWEEN THE THIRD ANI FOCFTH WEEK.

A. Side view. (From Külliker; after Allen Thomson.) a. amnion; $b$. umbilical resicle; $c$. mandibular areh; $e$. hyoid arch; $f$. commencing anterior limb; g. primitive auditory resicle; $h$. eye; $i$. heart.

B. Dorsal view to shew the attachment of the dilated allantoic stalk to the chorion. (From a sketch by Allen Thomson.) am. ammion; all. allantois; ys. yolk-sack.

1 Allen Thomson informs me that he is rery confident that such a form of attach. ment between the hind end of the embryo and the wall of the vesicle, as that described and figured by His in this embryo, did not exist in any of the younger embryos examined by him. 
The embryo at this stage (fig. 166), which is about equivalent to that of a chick on the fourth clay, resembles in alnost every respect the normal embryos of the Amuiota. The cranial flexure is as pronouncel as usual, and the cerebral region has now fully the normal size. The whole body soou becomes flexed ventrally, and also somewhat spirally. The yolksack (b) forms a small spherical aplendage with a long wide stalk, and the embryo (B) is attached by an allantoic stalk with a slight swelling (all), pobably indicating the presence of a small hypoblastic diverticulum, to the inner face of the chorion.

A remarkable exception to the embryos generally observed is afforded by an embryo which has been described by Krause (No. 235). In this embryo, which probably helongs to the third week of pregnancy, the limbs were just commencing to be indicated, and the embryo was completely covered by an amnion, but instead of being attached to the chorion by an allantoic cord, it was quite free, and was provided with a small spherical sack-like allantois, viry similar to that of a fourth-rlay chick, projected from its hind enel,

A

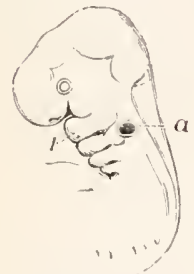

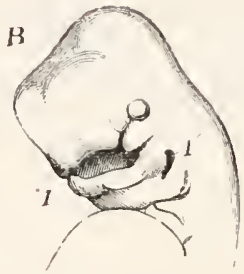

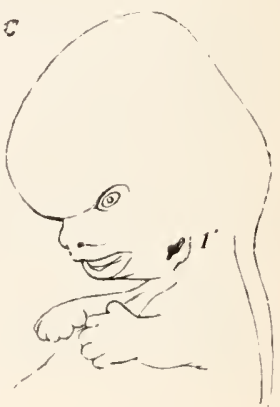

Fig, 167. Figures SHEWING THE EAILX CHANGES IN THE FORM OF THE HUMAN IIEAD. (From Quain's Anatomy.)

A. Head of an embryo of about four weeks. (After Allen Thomson.)

B. Head of an embryo of about six weeks. (After Ecker.)

C. Head of an embryo of about nine weeks.

1. mandibular arch; 1 '. persistent part of byomandibular cleft; $a$. auditory vesicle.

No details are given as to the structure of the chorion or the presence of villi upon it. The presence of such an allantois at this stage in a human embryo is so unlike what is usually found that Krause's statements have been received with considerable scejticism. His even holds that the embryo is a chick embryo, and not a human one; while Kïlliker regards Krause's allantois as a pathological structure. The signiticance to be attached to this embryo is dealt with below.

A detailed listory of the further development of the human embryo does not fall within the province of this work; while the later clanges in the embryonic membranes have already been dealt with (pp. 202-205).

For the changes which take place on the formation of the face I may refer the reader to fig. 167 .

The most obscure point comnected with the early history of the human orum concerns the first formation of the allantois, and the nature of the villi 
covering the surface of the ovmm. The villi, if really former of mesoblast covered by epiblast, liave the true structure of chorionic villi; and can hardly be compared to the early villi of the dog which are derived from the subzonal membrane, and still less to those of the rabbit formed from the zona radiata.

Unless all the early ova so far deseribed are pathological, it seems to follow that the mesoblast of the chorion is formed before the embryo is defuitely established, and even if the pathological character of these ova is admitted, it is nevertheless probable (leaving Krause's embryo out of account), as shewn by the early embryos of Allen Thomson and His, that it is formed before the closnre of the medullary groove. In order to meet this difficulty $H$ is supposes that the embryo never separates from the blastodermic vesicle, but that the allantoic stalk of the youngest embryo (fig. i6s) represents the persistent attachment hetween the two ${ }^{1}$. His' view has a good deal to be said for it. I would venture, however, to suggest that Reichert's emhryonic area is probably not in the twolayered stage, but that a mesoblast has already become established, and that it has grown round the inner face of the blastorlermic resicle from the (apparent) posterior end of the primitive streak. This growth I regard as a precocious formertion of the mesolulast of the allemtois - an exaggeration of the early formation

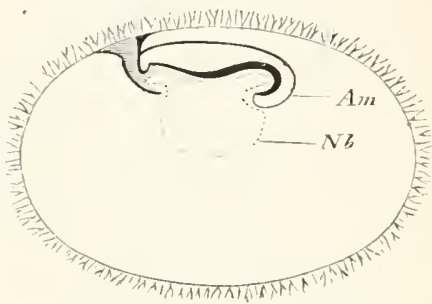

Fig. 168. Diagramate moxglTEDINAL SECTION OF THE OVUM TO WHICH THE EMBRYO (FIG. $16.5 \mathrm{~A}$ ) BELOXGED. (After His.)

Am. amnion; Nb. umbilical vesicle. of the allautoic mesoblast which is characteristic of the Guinea-pig (vide p. 220). This mesoblast, together with the epiblast, forms a true chorion, so that in tig. 168, and probably also in fig. $16+\mathrm{A}$ and $\mathrm{B}$, a true chorion has already become established. The stalk connecting the embryo with the chorion in His' earliest embryo (fig. 168) is therefore a true allantoic stalk into which the hypoblastic allantoic diverticulum grows in for some distance. How the yolk-sack (umbilical resicle) is formed is not clear. Perhaps, as snggested by His, it arises from the conversion of a solid mass of primitive hypoblast directly into a yolk-sack. The amnion is probably formed as a fold over the liead end of the embryo in the mamner indicated in His' diagram (fig. $168 \mathrm{Am}$ ).

These speculations have so far left Krause's embryo out of account. How is this embryo to he treated? Krause maintains that all the other embryos shewing an allantoic stalk at an early age are pathological. This, though not impossible, appear's to me, to say the least of it, improbable; especially when it is borne in mind that embryos, which have every appearance of being normal, of about the sane age and yomnger than Krause's, have been freqnently observed, and have always been found attached to the chorion by an allantoic stalk.

We are thus provisionally reduced to suppose either that the structure figured by Krause is not the allantois, or that it is a very abnorm:1 allantois. It is perhaps just possible that it may be an abnormally

1 For a fuller explanation of His' views I must refer the reacer to his Memoir (No. 232), pp. 170, 171, and to the diagrams contained in it. 
developed hypolastic vesicle of the allantois artificially detached from the mesoblastic layes, - the latter having given rise to the chorion at an earlier date.

\section{Bibitugrapity.}

\section{Gienertel.} 1837.

(168) K. E. von Baer. Teb. Entwicklungsgeschichte d. Thiere. Königsberg, 1828-

(169) Barry. "Researches on Embryology." First Series. Philosophical Transartions, 1838, Part II. Second Series, Ibid. 1839, Part II. Third Series, Ibid. 1810.

(i 70$)$ Ed. van Beneden. La unaturatiou de locuf, la fécondation et les premières phases du déreloppement enbryonaire d. Mammifères. Bruxelles, 1875.

(171) Ed. van Beneden. "Recherches sur l'embryologie des Manmifères." Arrhices de Biologie, Vol. 1. 1880.

(172) Ed, v. Beneden and Ch. Julin. "Observations sur la maturation ete. de l'œuf chez les Cheiroptères." Archives de Biologie, Vol. 1. 1880.

(173) Th. L. W. Bisch off.' Entwickhngsgeschichted. Simgethiere u. des Mensehen. Leipzig, 1812 .

$(174)$ Th. L. W. Bischoff. Entuichlungsgeschichte des Kanincheneies. Bramschweig, 1812 .

(I 75$)$ Th. L. W. Bischoff. Eutwickluugsyeschichte des Hundecies. Braunschweig, 1845 . 1852.

(176) Th. L. W. Bischoff. Entwickhngsgeschichte des Meerschweinchens. Giessen.

(17z) Th. L. W. Bischoff. Entwicklungsgeschichte des Rehes. Giessen, 1854.

(i 7 S) Th. L. W. Bischoff. "Neue Beobachtungen z. Entwicklungsgesch. des Meerschweinchens." Abh. d. bayr. Akud., Cl. 11. Vol. x. 1866.

(179) Th. I. Wr. Bischoff. Mistorisch-kritische Bemerkungen z. d. ucuesten Wittheihungen $2 i b$. d. erste Eutwick. d. Sïugethieveier. Niünchen, 1877.

(iso) M. Coste. Eubryogénie compatée. Paris, 1837. 1874 .

(18r) E. Haeckel. Anthropogenie, Entwicklungsgeschichte des Meuschen. Leipzig,

(I82) V. Hensen. "Beobachtungen ïb. d. Befrucht. u. Entwick d. Kaninchens u. Meerschweinchens." Zeit.f. Anat. u. Eutuick., Vol, 1. 1876.

$(183)$ A. Kölliker. Eutwichlungsgeschichte d. Menschen u. d. hïheren Thiere. I.eipzig, 1879.

(18+) A. Kölliker. "Die Entwick. d. Keimblätter des Kaninchens." Zoologischer" Anzeiger, Nos. 61, 62, Tol. 111. 1880.

(IS,) N. Lieberkiihn. Ueber d. Keimblätter d. Süngethiere. Doctor-Jubelfeier d. Heriu H. Nusse. Marburg, 1879.

(186) N. Lieberkühn. "Z. Lehre von d. Keimblittern d. Säugethiere." Sitz.d. Gesell. z. Befïrd. 1. gesem. Naturwiss. Marburg, No. 3. 1880.

(187) Rauber. "Die erste Entwicklung d. Kaninchens." Sitzungsber. d. naturfor. Gesell. z. Leipziq. 1875.

(188) C. B. Reichert. "Entwicklung des Neerschweinchens." Abh. der Ber\%. Akad. 1862 .

(189) E. A. Schäfer. "Description of a Manmalian ovum in an early condition of development." Proc. Roy. Soc., No, 168.1876.

(190) E. A. Schäfer. "A contribution to the history of development of the guinea-pig." Jourual of Auat. and Phys., Tol x. and xi. 1876 and 1877.

\section{Fotal Membranes and Placentt.}

(191) John Anderson. Anatomical and Zoological researches in Western Yunuan. London, 1878.

(19z) K. E. von Baer. Untersuchungen über die Gefissverbindung zrischen Mutter und Frneht, 182s. 
(193) ('. (i. Carus. Trabulne anatomiam comparativom illustrantes. 1831, 1840. (19+) H. (. Chapman. "The placenta and generative apparatus of the Elephant," Journ. Acat. Tat. Sc., Philadelphia. Tol. rrm. 1880.

(195) C. Creighton. "On the formation of the placenta in the guinea-pig." Journal of Anzt. and Phys., Vol. xir. 1878.

(196) Ecker. Icones Physiologicue. $1852-1859$.

(г97) G. B. Ercolani. The utricular glands of the vierus, etc., translated from the Italian under the direction of H. O. Marcy. Boston, 18s0. Contains translations of memoirs published in the Mem. dell Accad. d. Scienze d. Bologno, and additional matter written specially for the translation.

(198) G. B. Ercolani. Nuove ricerehe sulla placenta nei pesci cartilaginosi e nei nammiferi. Bologna, 1880 .

(199) Eschricht. De organis quae respirationi et untritioni fotns Mammalinm inservint. Hafniae, 1837.

(200) A. H. Garrod and W. Turner. "The gravid uterus and placenta of Hyomoschus aquaticus." Proc. Zool. Soc., London, 1878.

(20r) P. Harting. Ilet ei en de plaeenta van Halicore Dugong. Inang. diss. Itrecht. "On the orum and placenta of the Dugong." Abstract by Prof. Turner. Joirmal of Anot. and Phys., Vol. sill.

(202) Th. H. Huxley. The Elements of Gomparative Anatomy. Iondon, 1864.

(203) A. Kölliker. "Ueber die Placenta der Gattungr Tragulus." Verh. der Wiirzb. phys.-med. Gesellschott, Bil. x.

$\left(20_{+}\right)$C. D. Meigs. "On the reproduction of the Opossum (Didelphis Virginiana)." Amer. Phil. Soc. Trans., Tol. x. 18.53.

(205) H. Milne-Edwards. "Sur la Classification Naturelle." Am. Seienees Nat., Sér. 3, Tol. r. $184 t$.

(206) Alf. Milne-Edwards. "Recherches sur la famille des Chevrotains." Amm. des Seienees Not., Series v., Vol. II. 1864.

$(207)$ Alf. Milne-Edwards. "Olıservations sur" quelques points de l'Embryulogie res Lemuriens, ete." Ann. Sci. Nat., Ser. r., Vol. xv. 1,72.

(208) Alf. Milne-Edwards. "Sur la conformation du placenta chez le Tamantua." Anm. des Se. Nat., xv. 187.2.

(209) Alf. Milne-Edwards. "Recherehes s. l. enveloppes fietales du Tatou à neuf bandes." Amn. Sici. Not., Ser. vi., Vol. vir. 1878.

(210) R. Owen. "On the generation of Mrsupial animals, with a description of the impregnated uterus of the Kangaroo." Phil. Trans., 1834.

(2II) R. Owen. "Description of the membranes of the uterine foetus of the Kangaroo." Mag. Nat. Hist., Vol. r. 1837.

(2 г 2) R. Owen. "On the existence of an Allantois in a fuetal liangaroo (Nacropus major)." Zool. Śoc. Proc., v. 1837.

(213) R. Owen. "Description of the fotal membranes and placenta of the Elepliant." Phil. Trans., 1857.

(2I + ) R. Owen. On the Anatomy of Vertebrates, Vol. nix. Inndon, 1868.

(2I G) G. Rolleston. "Placental structure of the Tenrec, ete." Tronsactions of the Zoological Society. Vol. v. 1866.

(2I0) W. T'urner. "Observations on the structure of the human placenta." Journal of Anat. and Phys., Tol. vir. 1868.

(2I7) WT. Turner. "On the placentation of the Cetacea." Trans. Roy. Soc. Edimb., Tol. xxvi. 1872.

(2 IS) W. Turner. "On the placentation of Sloths (Choløpus Hoffmanni)." Trans. of R. Society of Ediuburgh, Tol. xлт1т. 1875.

(2 r9) WT. Turner. "On the placentation of Seals (Halichcrus gryphus)." Trans. of R. Soeiety of Edinburqh, Vol. xxvir. 1875.

(220) W. Turner." "On the placentation of the Cape Ant-eater (Orycteropus capensis)." Jourmal of Anat. and Plyss., V'ol. x. 1876.

(22I) IV. Turner. Leetures on the Amatomy of the Placenta. First Series. Edinburgh, 1876.

(222) W. Turner. "Some general observations on the placenta, with special reference to the theory of Evolution." Journal of Anat. and Phys., Vol. xı. 1877.

(223) VI. Turner. "On the placentation of the Lemurs." Phil. Trans., Vol. 166, p. 2. 1877.

(224) W. Turner. "On the placentation of Apes." Phil. Trans., 1878.

$(225)$ W. Turner. "The cotyledonary and diffused placenta of the Mexican deer (Cervus Anerieanus)." Joumul of Anat. and Plys., Vol. xilr. 1879. 


\section{Humeen Embryo.}

(226) Fried. Ahlfeld. "Beschreibung eines sehr kleineu mensehliehen Eies," Archiv f. Gynackologie, Bd. x111. 1878.

(227) Herm. Beigel und Ludwig Loewe. "Beschreibung eines menschlichen Eichens ans der zweiten bis dritten Woche der Schwangersehaft." A rehiv f. Gynaekologie, Bd. х11. 1877.

$(228)$ K. Breus. "Ueber ein menschliches Ei aus der zweiten Woche der Gravidität." Wriener medicinische Wochenschrift, 1877.

(229) M. Coste. Histoire génèrale et particnlière du dêvcloppement des corps organisés, 1847-59.

(230) A. Ecker. Icones Physiologicae. Leipzig, 1851-1859.

(23I) V. Hensen. "Beitray z. Morphologie d. Körperform u. d. Gehirns d. menschliehen Embryos." Archiv f. Auat. ". Phys., 1877.

(232) W. His. Anatomie menschlicher Embryomen, Part I. Embryonen d. eraten Monats. Leipzig, 1880.

(233) J. Kollmann. "Die menşhlichen Eier von 6 MM. Grösse." Archir , Anat. und Phys., 1879. 1875 .

(234) W. Krause. "Ueber d. Allantois d. Mensehen." Archir, Anat. mol Phys.,

(2.35) W. Krause. "Ueber zwei frühzeitige mensehliche Embryonen." Zeit. it. mis.: Zool., Vol. xxxv. 1880.

$\left(23^{6}\right)$ L. Loewe. "Im Saehen der Eihäute jüngster mensehlicher Eier." Archir fiir Gymackologie, Bd. xıv. 187!).

(237) C. B. Reiehert. "Beschreibung einer frïhzeitigen menschlichen Frucht im blïschenförmigen Bildungszustande (sackförmiger Keim von Bacr) nebst vergleichenden Untersuchungen über die bläschenfömigen Früchte der Säugethiere und des Mensehen." Abhandlnngen der kïnigl. Akad. d. Wiss. zn Berlin, 1873.

(238) Allen Thomson. "Contributions to the history of the structure of the human ovum and cmbryo before the third week after conception; with a deseription of some early ova." Edinlmrgh IIed. Surg. Jonrmal, Vol. L11. 1839. 


\section{(HAP'TER XI.}

\section{COMPARISON OF THE FORIIATION OF THE GERMINAL LAYERS AND OF THE EARLY S'TAGES IN THE DEVELOPMENT OH VERTEBRATES.}

Although the preceding chapters of this volume contain a fiarly detailed account of the early developmental stages of different groups of the Chordata, it will nevertheless be advantageons to give at this place a short comprarative review of the whole subject.

In this review only the most important points will be dwelt upon, and the reader is referred fir the letails of the processes to the sections on the derelopment of the individual groups.

The subject may conveniently be treated under three heads.

(1) The formation of the gastrula and behaviour of the blastopore: together with the origin of the hypoblast.

(2) The mesoblast and notuchurd.

(3) The epiblast.

At the close of the chapter is a short summary of the organs derived from the several layers, together with some remarks on the growth in length of the vertebrate embryo, and some suggestions as to the origin of the allantois and amnion.

Formation of the gastrula. Amphioxus is the type in which the developmental phenomena are least interfered with by the presence of food-yolk.

In this form the segmentation results in a uniform, or nearly miform, blastosphere, one wall of which soon becomes thjekened and invaginated, giving rise to the hypoblast; while the larva takes the form of a gastrula, with an archenteric cavity opening by a blastopore. The blastopore rapidly narrows, while the enbryo assumes an elongated cylindrical form with the blastopore at its hinder extremity (fig. $169 \mathrm{~A}$ ). The blastopore now passes to the dorsal surface, and by the flattening of this surface a medullary plate is formed extending forwards from the blastopore (fig. 169 13). On the formation of the medullary groove and its conversion into a canal, the blastopore cpens intu this canal, and gives rise to a neurenteric passage, leading 
fiom the nemal canal into the alimentary tract (fig. 169 ( and $E$ ).

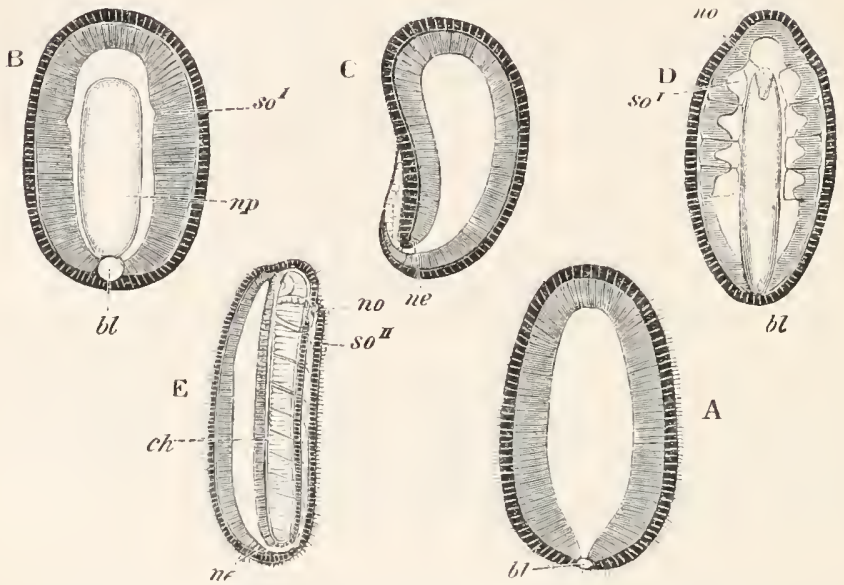

Fig. 169. Embryos of Amphioxus. (After Kowalevsky.)

'l'he parts in black with white lines are epiblastic; the shaded parts are hypoblastic.

A. Gastrula stage in optical section.

B. Slightly later stage after the neural plate $n p$ has become differentiated, seen as a transparent object from the dorsal side.

C. Lateral view of a slightly oleter larra in optical section.

1. Dorsal view of an older larva with the neural canal completely closed cxcept for a small pore $(n o)$ in front.

E. Older larra seen as a transparent object from the side.

bl. blastopore (which becomes in D the neurenteric canal); ne. nenrenteric canal; np. neural or mednllary plate; no. anterior opening of nenral canal; ch. notochord; $s 0^{1}, s 0^{11}$. first and second mesoblastic somites.

At a later perind this canal closes, and the nemral and alimentary canals become separaterl.

Such is the simple history of the layers in Amphioxus. In the simplest types of Ascidians the series of phenomena is almost the same, but the blastopore assumes a more definitely dorsal position.

Here also the blastopore lies at the hinder end of the medullary groove, and on the closure of the groove becomes converted into a neurenteric passage.

In the true Vertebrates the types which most approach Amphioxus are the Amphibia, Acipenser and Petromyzon. We may take the first of these as typical (though Petromyzon is perhaps still more so) and fig. $170 \mathrm{~A}$ B C D represents four diagrammatic longitudinal vertical sections through a form belonging to this group (Bombinator). The food-yolk is here concentrated in what I shall call the lower pole of the egg, which becomes the ventral aspect of the future embryo. The part of the egg containing the stored-up food-yolk is, as has already been explained in the chapter on segmentation (Vol. 1. pp. 75 and 78), to be regarder as cquivalent to part of those eggs which do not contain food-yolk; a fact which requires to be borne in mind in any attempt 
to deal comparatively with the formation of the layers in the Vertebrata. It may be laid down as a general law, which holds very accurately for the Vertebrata, that in eggs in which the distribution of food-yolk is not uniform, the size of the cells resulting from segmentation is proportional to the quantity of food-material they contain. In accordance with this law the cells of the Amphibian ovum are of unequal size even at the close of segmentation. They may roughly be divided into two categories, viz. the smaller cells of the upper pole and the larger of the lower (fig. $170 \mathrm{~A}$ ). The segmentation cavity $(s g)$ lies between the two, but is mnsmmetrically placed near the upper pole of the egg, owing to the large bulk of the ventrally placed yolk-segments. In the inequality of the cells at the close of segmentation the Amphibia stand in contrast with Amphioxus. The

A

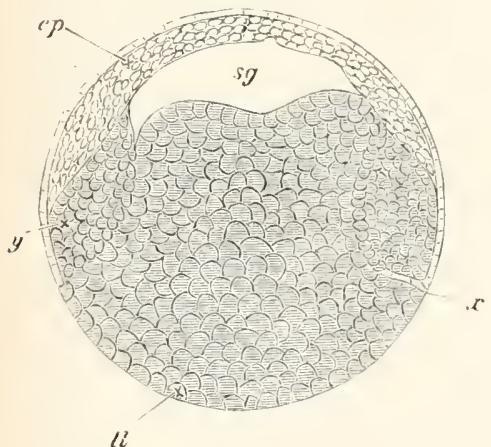

B

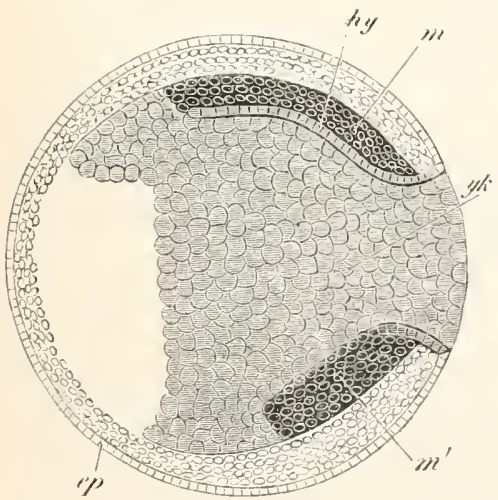

(

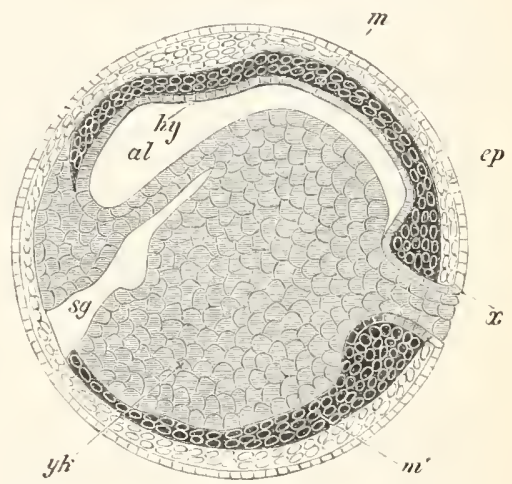

1)

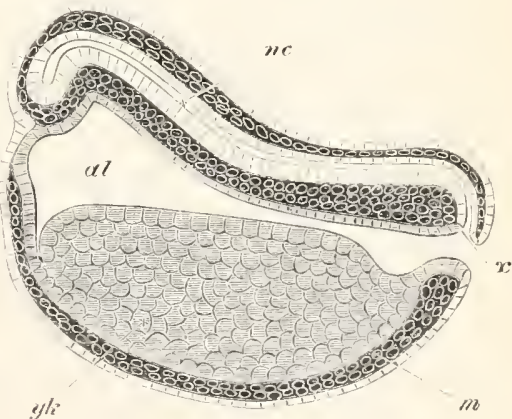

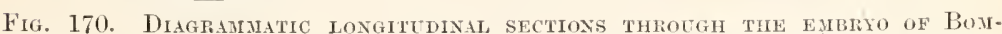
BINATOR AT TWO STAGES, TO SHEW THE FORMATION OF THE GERMINAL LAYERS. (Modified from Götte.)

$c p$. epiblast; $m$. dor'sal mesollast; $m^{\prime}$. ventral mesoblast; $h y$. hypoblast; $y k$. yolk; r. point of junction of the epiblast and hypohlast at the dorsal sice of the blastopore; al. mesenteron; sq. segmentation cavity. 
upper ce!ls are mainly destined to for'm the epiblast, and the lower the hypoblast and mesoliast.

The next change which takes place is an invagination, the earliest traces of which are observable in fig. 170 A. The invagination is not however so simple as in Amphioxus. Owing in fact to the presence of the food-yolk it is a mixture of invagination by epibole and by embole.

At the point marked $x$ in fig. $170 \mathrm{~A}$, which corresponds with the future lind end of the emlryo, and is placed on the equatorial line marking the junction of the large and small cells, there takes place a normal invagination, which gives lise solely to the hypoblast of the dorsal wall of the alimentary tract and to part of the dorsal mesoblast. The invaginated layer grows inwards from the point $x$ along what becomes the dorsal side of the embryo; and between it and the yolk-eells below is formed a shit-like space (fig. $170 \mathrm{~B}$ and C). This space is the mesenteron. It is even better shewn in fig. 171 representing the process of invagination in Petromyzon. The point $x$ in tig. 170 where epiblast, mesoblast and hypoblast are continuous, is homologous with the dorsal lip of the blastupore in Anphioxus. In the course of the invagination the segnentation cavity, as in Amphiuxus, beconses obliterated.

While the above invagination has been taking place, the epiblast cells lave been simply growing in an epibolic fashion round the yolk; and by the stage represented in fig. 170 ( $\mathrm{C}$ and $\mathrm{D})$ the exposed surface of yolk has becone greatly diminished; and an obvions blastopore is thus established. Along the line of the growth a layer of mesoblast cells $\left(\mathrm{m}^{\prime}\right)$, contimuos at the sides with the invaginaterl mesoblast layer, has becone differentiaten from the snall cells (fig. 170 A) intermediate between the epib'ast cel!s and the yolk.

Owing to the nature of the above process of invagination the mesentern is at first only provided with an epithelial wall on its dorsal side, its veutral wall being formed of yolk-cells (fig. 170). At a later period some of the yolk-cells becone transformed intu the epithelial cells of the ventral wall, while the remainder become enclosed in the alimentary cavity and enployed as pabulum. The whole of the yolk-cells, after the separation of the mesoblast, are however norphologically part of the hypoblast.

'The final fate of the blastopore is nearly the same as in Amphioxus. It gradually narrows, and the yolk-cells which at first plug it up disappear (fig. 170 C and D). The neural groove, which becomes firmed on the dorsal surface of the embryo, is continued forwards fiom the point $x$ in fig. 170 (: On the conversion of this groove into a canal the canal freely opens behind into the blastopore; and a condition is reached in which the blastupore still opens to the exterior and also into the nenral canal tio. $170 \mathrm{D}$. In a later stage (fig. 17.) the exterual opening of the blastopore becomes closed by the nedullary folds meeting behind it, but the passage connceting the neural and alinentary canals is left. There is one 
small difference between the Frog and Amphioxus in the relation of the neural canal to the blastopore. In both types the medullary folds embrace and meet behind it, so that it comes to vecupy a position at the hinil extremity of the medullary groove. In Amplioxus the closure of the medullary folds commences behind, so that the external opening of the blastopore is obliterated simultaneously with the commencing formation of the medullary canal; but in the Frog the closure of the medullary folds commences anteriorly and proceeds backwards, so that the obliteration of the extermal opening of the blastopore is a late event in the formation of the medullary canal.

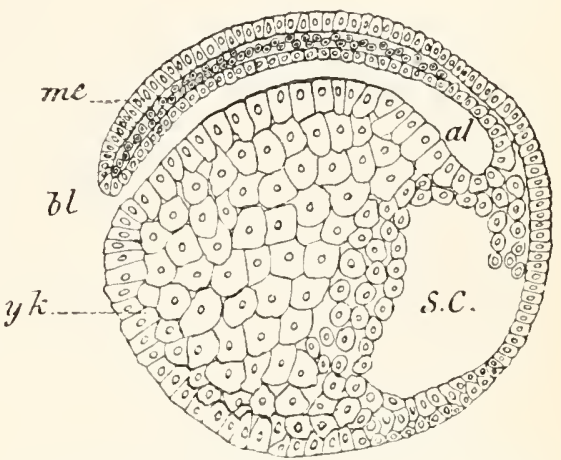

Fiti. 171. Longitedeinal vertical, secrion througir an embryo of Petromyzon of 136 HOURS.

me. mesoblast; $y k$. yolk-cells; al. alimentary tract; $b l$, blastopore; s.e. segmentation eavity.

The anus is formed (vide fig. 172) some way in front of the blastopore, and a post-anal gut, continuous with the neurenteric canal, is thus established. Both the post-anal gut and the neurenteric caual eventualty disappear.

The two other types classed above with the Amphibia, viz. Petroinyzon and Acipenser, agree sufficiently closely with them to require no special mention; but with reference to both types it may be pointed out that the ovum contains relatively more

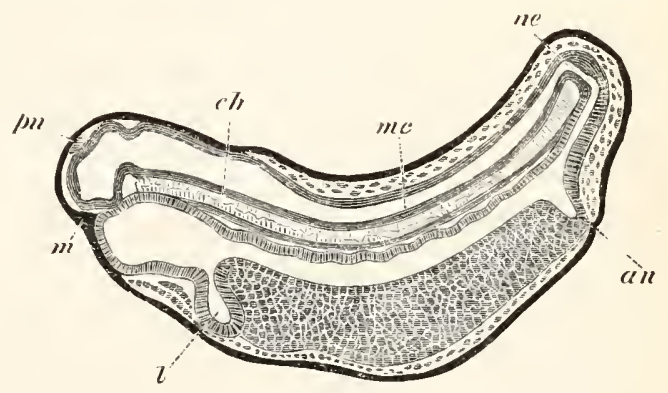

Fig. 17: Longtetixal SECTION THRovgh AN AI vaNCED EMmio of Bombinatol. (After Götte.)

$m$. mouth; $a n$. anus; $l$. liver; ne. neurenteric canal; me. medullary canal; ch. notochord; $p n$. pineal gland. food-yolk than that of the Amphibian type just deseribed, and that this leads amongst other things to the lower layer cells extending up the sides of the segmentation cavity, and assisting in forming its root.

The next type to be considered is that of Elasuobranchii. 'The yolk in the ovum of these forms is enormonsly bulky, and the segmentation is in consequence a partial one. At first sight the differences between their development and that of Amphibia would appear to be very great. In orrler fully to bridge over the gulf 
which separates them I have given three diagrammatic longitudinal sections of an ideal form intermediate between Amphibia and Elasmobranchii, which differs however mainly from the latter in the smaller amount of food-yolk; and by their aid I trust it will be made clear that the differences between the Amphibia and Elasmobranchii are of an insignificant character. In fig. $17+\mathrm{A} \mathrm{B} \mathrm{C}$ are represented three diagrammatic longitudinal sections of Elasmobranch embryos, and in fig. 17:3 A B C three longitudinal sections of the ideal intermediate form. The diagrams correspond with the Amphibian diagrams already described (fig. 170). In the first stage figured there is present in all of these forms a segmentation cavity $(s g)$ situated not centrally but near the surface of the egg. The roof of the cavity is thin, being composed in the Amphibian embryo of epiblast alone, and in the Elasmobrauch of epiblast and lower layer cells. The floor of the cavity is formed of so-called yolk, which forms the main mass of the embryo. In Amphibia the yolk is segmented. In Elasmobranchii there is at first a layer of primitive hypoblast cells separating the segmentation cavity from the yolk proper; this however soon disappears, and an unsegmented yolk with firee muclei fills the place of the segmented yolk of the Amphibia. The small cells at the sides of the segmentation cavity in Amphibia correspond exactly in function and position with the lower layer cells of the Elasmobranch blastoderm.

The relation of the yolk to the blastoderm in the Elasmobranch embryo at this stage of development very well suits the view of its homology with the yolk-cells of the Amphibian embryo. The only essential difference between the two embryos arises from the roof of the segmentation cavity being formed in the Elasmobranch embryo of lower layer cells, which are absent in the Amphibian embryo. This difference no doubt depends upon the greater quantity of yolk in the Elasmobranch ovum, and a similar distribution of the lower layer cells is found in Acipenser and in Petromyzon.

In the next stage for the Elasmobranch (fig. 173 and $17+\mathrm{B}$ ) and for the Amphibian (fig. 170 C) or better still Petromyzon (fig. 171) the agreement between the three types is again very close. For a small are $(x)$ of the edge of the blastoderm the epiblast and hypoblast become continuous, while at all other parts the epiblast, accompanied by lower layer cells, grows round the yolk or round the large cells which correspond to it. The yolk-cells of the Amphibian embryo form a comparatively small mass, and are therefore rapidty enveloped; while in the case of the Elasmobranch embryo, owing to the greater mass of the yolk, the same process occupies a long period. 'The portion of the blastoderm, where epiblast and hypoblast become continuous, forms the dorsal lip of an opening-the blastoporewhich leads into the alimentary cavity. 'This cavity has the same relation in all the three cases. It is linerl dorsally by lower layer cells, and ventrally by yolk-cells or what corresponds with yolk-cells; a large part of the ventral epithelinm of the alimentary canal being in both cases eventrally derived from thr yolk. In Amphibia this 
epithelium is formed directly from the existing cells, while in Elasmobranchii it is derived from cells formed around the nuclei of the yolk.
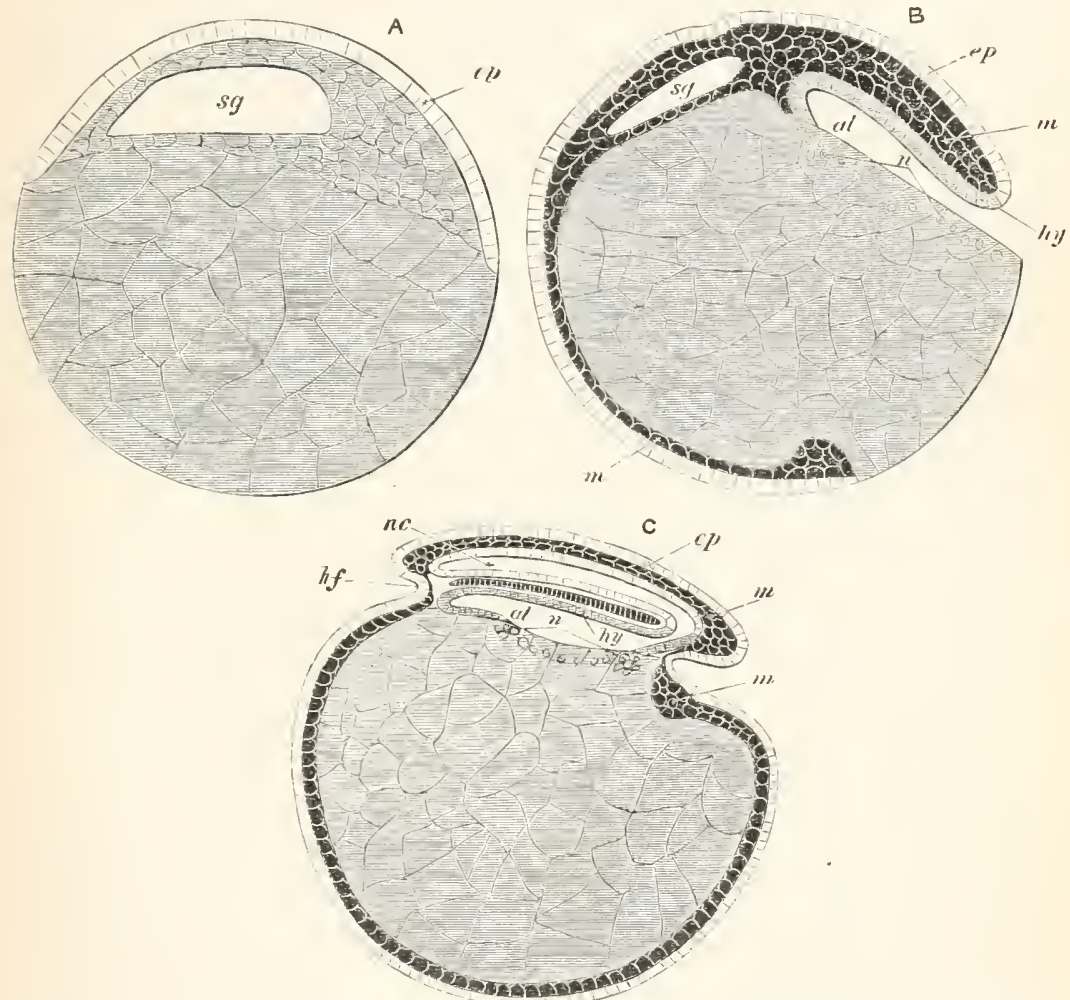

Fig. 173. Three diaratratic loxgltudixal sections through an ideaL trpe

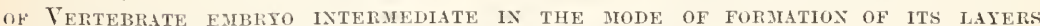
betwees A vphibia or Petromtzon axd Elasiobranchis.

sq. segmentation cavity; ep. epiblast; $m$. mesoblast; $h y$. hypoblast; nc. neural cinal; al. mesenteron; $n$. nuclei of the yolk.

As in the earlier stage, so in the present one, the anatomical relations of the yolk to the blastoderm in the one case (Elasmobranchii) are nearly identical with those of the yolk-cells to the blastoderm in the other (Amphibia).

The main features in which the two embryos differ, during the stage under consideration, arise from the same cause as the solitary point of difference during the preceding stage.

In Amphibia the alimentary cavity is formed coincidently with a true ingrowth of cells from the point where epiblast and hypoblast become continuous; and from this ingrowth the dorsal wall of the alimentary cavity is formed. The same ingrowth canses the obliteration of the segmentation cavity. 
In Elasmobranchs, owing probably to the larger bulk of the luwer layer cells, the prinitive hypoblast cells arrange themselves in their final position during segmentation, and no room is left for a true invagination; but instead of this there is formed a simple space between the blastoderm and the yolk. The homology of this space with the primitive invagination cavity is nevertheless proved by the survival of a number of features belonging to the ancestral condition in which a true invagination was present. Amongst the more important of these are the following:-(1) The contimuity of epiblast and hypoblast at the dorsal lip of the blastopore. (2) The continuous conversion of primitive hypoblast cells into permanent hypoblast, which gradually extends inwards towards the segmentation cavity, and exactly represents the course of the invagination whereby in Amphibia the dor:al wall of the alimentary cavity is formed. (3) The obliteration of the segmentation carity during the period when the psendo-invagination is occurring.

In the next stage there appear nore inportant lifferences between the two types than in the preceding stages, though here again the points of resemblance predominate.

Figs. $170 \mathrm{D}$ and $174 \mathrm{C}$ represent longitudinal sections through embryos after the closure of the medullary canal. The neurenteric canal is established; and in front and behind the epithelium of the ventral wall of the mesenteron has begun to be formed.

The mesoblast is represented as having grown in between the medullary canal and the superjacent epiblast.

There are at this stage two points in which the embryo Elasmobranch differs from the corresponding Anphibian entbryo. (1) In the formation of the neurenteric canal, there is no free passage leading into the mesenteron from the exterior as in Amphibia (fig. $170 \mathrm{D}$ ). (?) The whole yolk is not enclosed by the epiblast, and therefore part of the blastopore is still open.

The difference between Amphibia and Elasmobranchii in the first of these points is due to the fact that in Elasmobranchii, as in Amphioxus, the neural canal becomes first closed behind; and simultaneously with its closure the lateral parts of the lips of the blastopore, which are continuous with the medullary folds, meet together and shut in the hindmost part of the alimentary tract.

'The second point is of some importance for understanding the relations of the formation of the layers in the amniotic and the nonammiotic Vertebrates. Owing to its large size the whole of the yolk in Elasnobranchii is not enclosed by the epiblast at the time when the neurenteric canal is established; in other words a small posterior and dorsal portion of the blastopore is shut off in the formation of the neurenteric canal. The remaining ventral portion becomes closed at a later period. Its closure takes place in a linear fashion, commencing at the hind end of the embryo, and proceeding apparently backwards; though, as this part eventually becomes folded in to form the ventral wall of the embryo, the closure of it really 
travels forwards. The process causes however the embryo to cease to lie at the edge of the blastoderm, and while situated at some
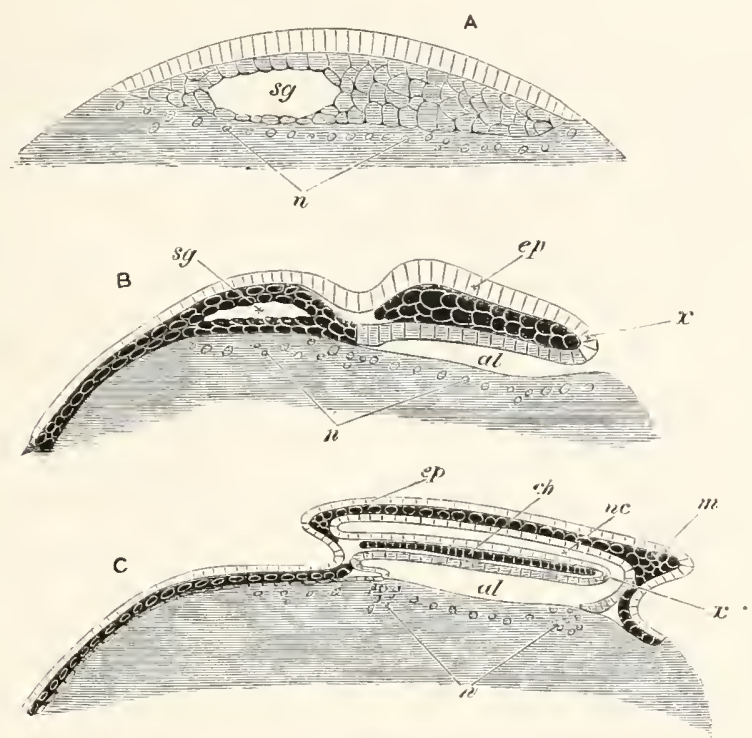

Fig. 17t. Diagramatic loxgituminal sections of ais Elasmobranch embrio.

Epiblast without shading. Mesoblast black with clear outlines to the cells. Lourr layer cells and hypoblast with simple shading.

ep. epiblast; m. mesoblast; al. alimentary cavity; sg. segmentation carity; $n c$. neural canal; $c h$. notochord; $x$. point where epiblast and hypoblast become continuous at the posterior end of the embryo; $n$. nuclei of yolk.

A. Section of young blastodem, with the segmentation cavity enclosed in the lower layer cells (primitive hypoblast).

B. Older blastoderm wilh embryo in which hypoblast and mesoblast are distinctly formed, and in which the alimentary cavity has appeared. The segmentation cavity is still represented, though by this stage it has in reality disappeared.

C. Older blastoderm with embryo in which the neural canal is formed, and is continuous posteriorly with the alinentary canal. The notochord, though shaded like mesoblast, belongs properly to the hypoblast.

distance from the alge, to be connected with it by a linear streak, representing the coalesced hips of the blastopore. The above process is diagrammatically represented in fig. $17.5 \mathrm{~B}$; while as it actually occurs it is shewn in fig. $30,0.52$. The whole closure of the blastopore in Elasmobranchii is altogether unlike what takes place in Amphibia, where the blastopore remains as a circular opening which gradually narrows till it becomes completely enveloped in the medullary folds (fig. $175 \mathrm{~A}$ ).

On the formation of the neurenteric canal the body of the embryo Elasmobranch becomes gradually folded off from the yolk, which, owing to its great size, forms a large sack appended to the ventral side of the body. The part of the somatoplemre, which grows rom 
it, is to be regarded as a modified portion of the ventral wall of the body. The splanchnoplenre also envelopes it, so that, morphologically speaking, the yolk lies within the mesenteron.

The Teleostei, so far as the first formation of the layers is concerned, resemble in all essential features the Elasmobranchii, but the neurenteric canal is apparently not developed (?), owing to the obliteration of the neural canal; and the roof of the segmentation cavity is formed of epiblast only.

In the preceling pages I have attempterl to shew that the Amphibia, Acipenser, Petromyzon, the Elasmobranchii and the Teleostei agree very closely in the mode of formation of the gastrula. The unsymmetrical gastrula or pseudo-gastrula which is common to them all is, 1 believe, to be explained by the form of the vertebrate body. In Amphioxus, where the small anomnt of food-yolk present is distributed uniformly, there is no reason why the iuvagination and resulting gastrula should not be symmetrical. In true Vertebrates, where more food-yolk is present, the shape and structure of the body render it necessary for the food-yolk to be stored away on the ventral side of the alimentary canal. It is this fact which causes the asymmetry of the gastrula, since it is not possible for the part of the ovum, which will become the ventral wall of the alinentary tract, and which is loaded with food-yolk, to be invaginated in the same fashion as the rorsal wall.

Sauropsida. The comparison of the different types of the Ichthyopsida is fairly simple, but the comparison of the Sauropsida with the Ichthyopsida is a far more difficult matter. In all the Sauropsida there is a large food-yolk, and the segmentation agrees closely with that in the Elasmobranchii. It might have becn anticipated that the resemblance would continue in the subsequent development. This however is far from being the case. The medullary plate, instead of lying at the elge of the blastoderm, lies in the centre, and its formation is preceded by that of a peculiar structure, the primitive streak, which, on the formation of the medullary plate, is found to lie at the hinder end of the latter and to connect it with the edge of the blastoderm.

The possibility of a comparison between the Sauropsida and the Elasmobranchii depents upon the explanation being possible of (1) the position of the embryo near the centre of the blastoderm, and $(\boldsymbol{\theta})$ the nature of the primitive streak.

The answers to these two questions are, according to my view, intimately bound together.

I consider that the embryos of the San ropsida have come to occupy a central position in the blastoderm owing to the abbreviation of a process similar to that by which, in Elasmobranchii, the embryo is removed from the edge of the blastoderm; and that the primitive streak represents the linear streak connecting the Elasmobranch embryo with the erlge of the blastoderm after it has become removerl from its previous 
peripheral position, as well as the true nenrenteric part of the Elasmobranch blastopore.

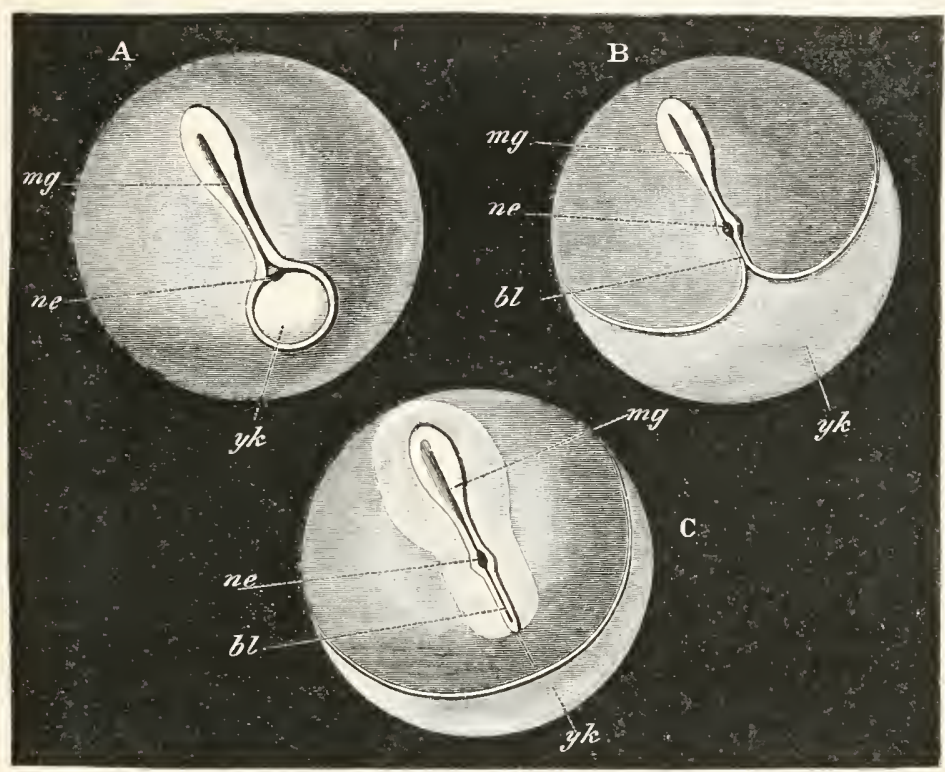

F19. 175. Diagams illustratixa the position of the blastopore, and the relation OF THE EMBRTO tO THE YOLK IN VARIOUS Meroblastic Vertebrate OVA.
A. Type of Frog.
B. Elasmobranch type.
C. Amniotic Vertebrate.

$m g$. medullary plate; ne. neurenteric canal; $b l$. portion of blastopore adjoining the neurenteric eanal. In B this part of the blastopore is formed by the edges of the blastoderm meeting and forming a linear streak behind the embryo; and in $\mathrm{C}$ it forms the structure known as the primitive streak. ylk part of the yolk not yet enclosed by the blastorlerm.

This view of the nature of the primitive streak, which is diagrammatically illustrated in fig. 175 , will be rendered more clear by a brief review of the early developmental processes in the Sauropsila.

After segmentation the blastoderm becomes divided, as in Elasmobranchii, into two layers. It is doubtful whether there is any true representative of the segmentation cavity. The first structure to appear in the blastoderm is a linear streak placed at the hind end of the blastolerm, known as the primitive streak (fige. $175 \mathrm{C}, b l$ and 176 $p r)$. At the front end of the primitive streak the epiblast and hypoblast become continuous, just as they do at the dorsal lip of the blastopore in Elasmobranchii. Continued back from this point is a streak of fused mesoblast and epiblast to the under side of which a linear thin layer of hypoblast is more or less definitely attached.

A further structure, best developed in the Lacertilia, appears in 
the form of a circular passage perforating the blastorlerm at the front end of the primitive streak (fig. $176 \mathrm{ne}$ ). This passage is bounded anteriorly by the layer of cells forming the continuation of the hypoblast into the epiblast.

In the next stage the medullary plate becomes formed in front of the primitive streak (fig. 17.5 C), and the merlullary folds are continued backwards so as to enclose the upper opening of the passage through the blastoderm. On the closure of the medullary canal (fig. 177) this passage leads from the medullary canal into the alimentary tract, and is therefore the neurenteric canal; and a post-anal gut also becomes formed. The latter part of the above description applies especially to the Lizard: but in (helonia and most Birds distinct remnants (vide pp. 1:5.5 and 1:36) of the nenrenteric canal are developer.

On the hypothesis that the Sauropsidan embryos have come to occupy their central position, owing to an abbreviation of a process analogons to the linear closing of the blastopore belind the embryos of Elasmobranchii, all the appearances above described receive a satisfactory explanation. The passage at the front end of the primitive streak is the dorsal part of the blastopore, which in Elasmobranchii becomes converted into the neurenteric canal. The remainder of the primitive streak represents, in a rulimentary form, the linear streak in Elasmobranchii, formed by the coalesced edges of the blastoderm, which connects the hinder end of the embryo with the still open yolk blastopore. That it is in later stages not continued to the erlge of the blastoderm, as in Elasmobranchii, is due to its being a rudimentary organ. The more or less complete fusion of the layers in the primitive streak is simply to be explained by this structure representing the coalesced edges of the blastopore; and the growth outwards from it of the mesoblast is probably a remmant of a primitive dorsal invagination of the mesoblast and hypoblast like that in the Frog.

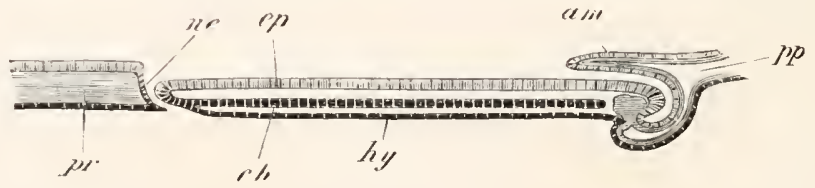

Fig. 176. Dhagamatic losgitedisal section of an embrio of Lacerta. $m p$. body-carity ; am. amnion; ne. nementeric canal; ch. nctochord; hy. hypoblast; ep. epiblast; $m$. primitive streak. In the primitive streak all the layers are partially fused.

The final enclosure of the yolk in the Sauropsida takes place at the pole of the yolk-sack opposite the embryo, so that the blastopore is formed of three parts, (1) the neurenteric canal, (2) the primitive streak behind this, (3) the blastopore at the pole of the yolksack opposite the embryo.

Mammalia. The features of the development of the placental Mammalia receive their most satisfactory explanation on the hypothesis that their ancestors were provided with a large-yolked ovum 
like that of the Sauropsida. The food-yolk must be supposed to have ceased to be developed on the establishment of a maternal nutrition through the uterus.

On this hypothesis all the derelopmental phenomena subsequently to the formation of the blastodermic vesicle receive a satisfactory explanation.

The whole of the blastodermic vesicle, except the embryonic area, represents the yolksack, and the

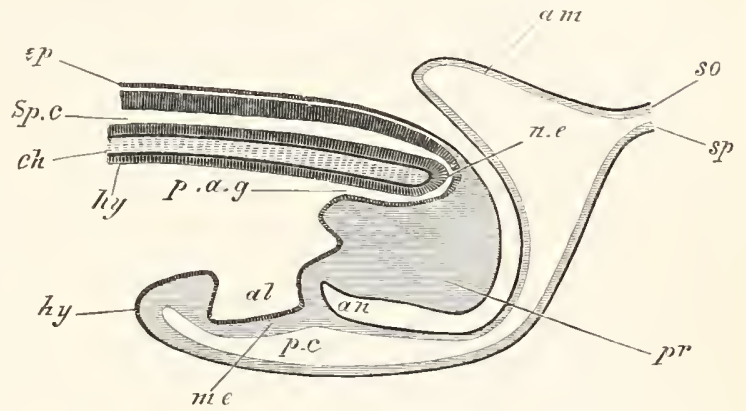

Fig. 177. Diagramiate Loxgitudiral sectiox thlodgh THE POSTERIOR END OF AN EMPRTO BIRD AT THE TIME OF THE Formation of THE AlLantors.

ep. epiblast; Sp.c. spinal canal; ch. notochord; n.e. neurenteric canal; $h y$. hypoblast; $p . a . q$. postanal gut; $p r$. remains of primitive streak folded in on the rentral side; al. allantois; me. mesoblast; an. point where anus will be formed; p.c. perivisceral carity; am. amnion; so. somatopleure; $s p$. splanchnopleure. growth of the hy-

poblast and then of the mesoblast round its inner wall represents the corresponding growths in the Sauropsida. As in the Samropsida it becomes constricted off from the embryo, and the splanchnopleuric stalk of the sack opens into the ileum in the usual way.

In the formation of the embryo out of the embryonic area the phenomena which distinguish the Sauropsida from the Ichthyopsida are repeated. The embryo lies in the centre of the area; and before it is formed there appears a primitive streak, from which there

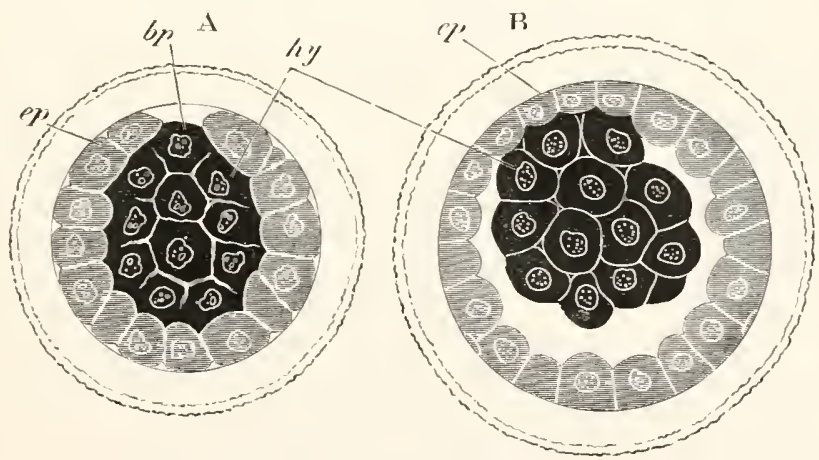

Fig. 178. Optical sections of a Rabbit's oveji at two stages closelt Following upon the segmentation. (After E. van Beneden.)

$e p$. epiblast; $h y$. primary hypoblast; $b p$. Van Beneden's so-called blastopore. The shading of the epiblast and hypoblast is diagrammatic.

b. E. II. 
grows out the greater part of the mesoblast. At the front end of the primitive streak the hypoblast and epiblast become continuous, though a perforated neurenteric blastopore has not yet been detected.

All these Sauropsidan features are so obvious that they need not be insisted on further. The embryonic evidence of the common origin of Mammalia and Sauropsida, both as concerns the formation of the layers and of the embryonic membranes, is as clear as it can be. The only difficulty about the early development of Mammalia is presented by the epibolic gastrula and the formation of the blastodermic vesicle (figs. 178 and 179). That the segmentation is a conplete one is no doubt a direct consequence of the reduction of the food-yolk, but the growth of the epiblast cells round the hypoblast

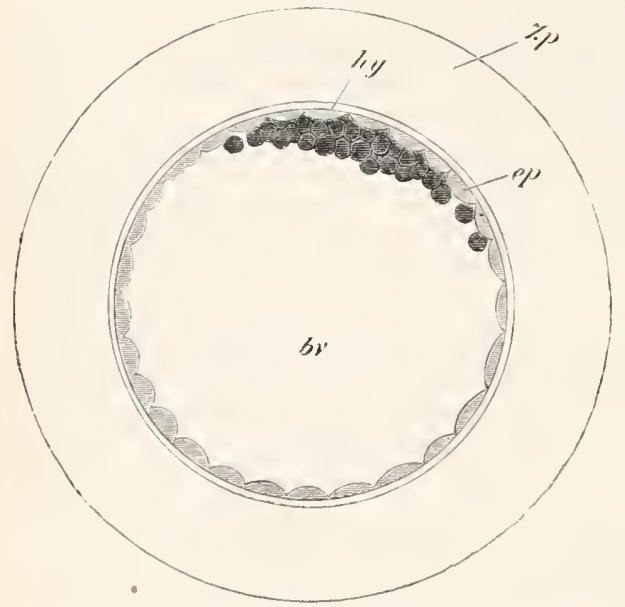

Fig. 179. RabBlt's ovUM Between 70-90 hours AFTER IMPREgNation. (After E. van Beneden.)

$b v$. cavity of blastodermic vesicle (yolk-sack); ep. epiblast; $h y$. primitive hypoblast; $Z / p$. mucous envelope.

position previously adopted about the primitive streak is to be maintained, Van Beneden's view must be abandoned. No satisfactory phylogenetic explanation of the Mammalian gastrula by epibole has in my opinion as yet been offered.

The formation of the blastodermic vesicle may perhaps be explained on the view that in the Proto-mammalia the yolk-sack was large, and that its blood-vessels took the place of the placenta of higher forms. On this view a reduction in the bulk of the ovarian ovum might easily have taken place at the same time that the presence of a large yolk-sack was still necessary for the purpose of affording surface of contact with the uterus. 


\section{The formation of the Mesoblast and of the Notochord.}

Amphioxus. The mesoblast originates in Amphioxus, as in several primitive invertebrate types, from a pair of lateral divertieula, constricted off from the archenteron (fig. 180). Their formation commences at the front end of the body and is thence carried backwards, and each diverticulum contains a prolongation of the cavity of the archenteron. After their separation from the archenteron the dorsal
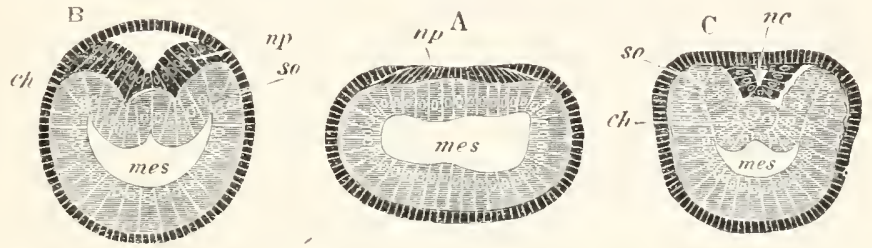

Fig. 180. Sectioxs of ax Amphoxes exbryo at thine stafies. (After Kowalessky.)

A. Section at gastrula stage.

B. Section of an embryo slightly younger than that represented in fig. $169 \mathrm{D}$.

C. Section through the anterior part of an embryo at the stage represented in fig. $169 \mathrm{E}$.

$n$. neural plate; $n$. neural canal; mes. archenteron in $\mathbf{A}$ and $\mathbf{B}$, and mesenteron in $\mathrm{C}$; $c h$. notochord; so. mesollastic somite.

parts of these diverticula become divided by transverse septa into successive somites, the cavities of which eventually disappear; while the walls become mainly converted into the muscle-plates, but also into the tissue around the notochord which corresponds with the vertebral tissue of the higher Chordata.

The ventral part of each diverticulum, which is prolonged so as to meet its fellow in the middle ventral line, does not become divided into somites, but contains a continuous cavity, which becomes the body eavity of the adult. The inner layer of this part forms the splanchnic mesoblast, and the outer layer the somatic mesoblast.

The notochord would almost appear to arise as a third inedian and dorsal diverticulum of the archenteron (fig. 180 ch). At any rate it arises as a central fold of the wall of this cavity, which is gradually constricted off from before backwards.

Urochorda. In simple Ascidians the above processes undergo a slight modification, which is mainly due (1) to a general simplification of the organization, and (2) to the non-continuation of the notochord into the trunk.

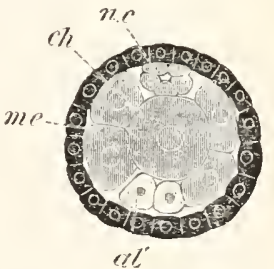

Fif. 181. Traxstemse optical SECTION OF THE TAIL OF AN EMbrio of Phallesia mamalllat. (After Kowalersky.)

The section is from an embryo of the same age as fig. 8 Iv.

ch. notochord; n.c. neural canal; me. mesoblast; al'. hypoblast of tail. 
The whole dorsal wall of the posterior part of the archenteron is converted into the notochord (fig. $181 \mathrm{ch}$ ), and the lateral walls into the mesoblast (me); so that the original lumen of the posterior part of the archenteron ceases to be bounded by hypoblast cells, and disappears as such. Part of the ventral wall remains as a solid cord of cells $\left(a l^{\prime}\right)$. The anterior part of the archenteron in front of the notochord passes wholly into the permanent alimentary tract.

The derivation of the mesoblast from the lateral walls of the posterior part of the archenteron is clearly comparable with the analogous process in Amphioxus.

Vertebrata. In turning from Amphioxus to the true Vertebrata. we find no form in which diverticula of the primitive alimentary tract give rise to the mesoblast. There is reason to think that the type presented by the Elasmobranchii in the formation of the mesoliast is as primitive as that of any otber group. In this group the

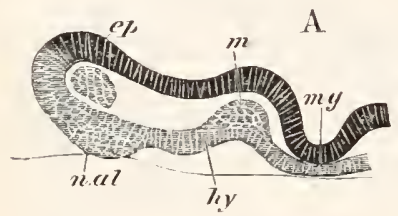

B

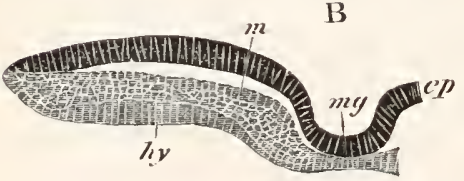

Fig. 182. Two transverse Sections of an embrio Pristiures of the same age as FIG. 17.

A. Anterior section.

B. Posterior section.

$m q$. medullary groove; ep. epiblast; $h y$. hypoblast; n.al. cells formed round the nuclei of the yolk which have entered the hypoblast; $m$. mesoblast.

The sections shew the origin of the mesoblast. mesoblast is formed, nearly coincidently with the hypoblast of the dorsal wall of the mesenteron, as two lateral sheets, one on each side of the middle line (fig. 182 $m$ ). These two sheets are at first solid masses; and their differentiation commences in front and is continued backwards. After their formation the notochord arises from the axial portion of the hypoblast (which had no share in giving rise to the two mesoblast plates) as a solid thickening (fig. $183 \mathrm{ch}^{\prime}$ ), which is separated from it as a circular rod. Its differentiation, like that of the mesoblastic plates, commences in front. The mesoblast plates subsequently become divided for their whole length into two layers, between which a cavity is developed (fig. 184). The dorsal parts of the plates become divided by transverse partitions into somites, and these somites with their contained cavities are next separated from the more ventral parts of the plates (fig. $185 \mathrm{mp}$ ). In the somites the cavities become eventually obliterated, and from their inner sides plates of tissue for the vertebral bodies (fig. $186 \mathrm{Vr}$ ) are separated; while the outer parts, consisting of two sheets, containing the remains of the original cavity, form the muscleplates $(m p)$.

The undivided rentral portion gives rise to the general somatic 
and splanchnic mesoblast (fig. 185), and the cavity between its two layers constitutes the body cavity. The originally separate halves of the body cavity eventually meet and unite in the ventral median line throughout the greater part of the body, though in the tail they remain distinct and are finally obliterated. Dorsally they are separated by the mesentery. From the mesoblast at the junction of the dorsal and ventral parts of the primitive plates is formed the urinogenital system.

That the above mode of origin of the mesoblast and notochord is to be regarded as a modification of that observable in Amphioxus seems probable from the following considerations :-

In the first place, the mesoblast is split off from the hypoblast not as a single mass but as a pair of distinct masses, comparable with the paired diverticula in Amphioxus. Secondly, the body cavity, when it appears in the mesoblast plates, does not arise as a single cavity, but as a pair of cavities, one for each plate of mesoblast; and these cavities remain permanently distinct in some parts of the body, and nowhere unite till a comparatively late period. Thirdly, the primitive body cavity of the embryo is
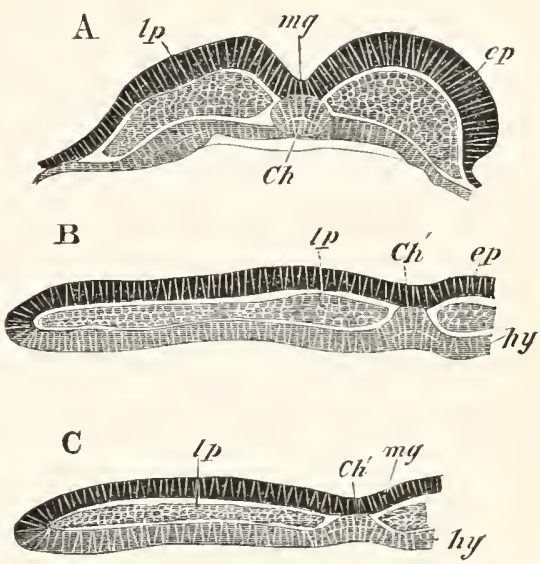

Fig. 183. Three sections of a Pristiurus EMBRYO SLIGHTLI OLDER THAN FIG, $2 Y$ B.

The sections shew the development of the notochord.

$C h$. notochord; $C h$ '. developing notochord; $m y$. medullary groore; $l p$. lateral plate of mesoblast; ep. epiblast; hy. hypoblast.

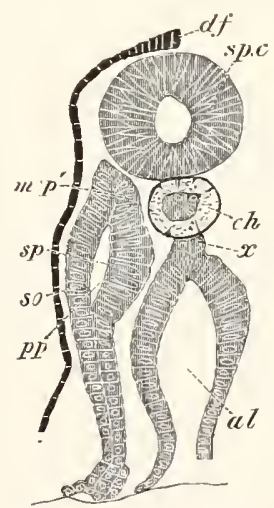

Fig. 184. Transverse section throdgh the tail-region of a Pristiorus embrio of the same AGE AS FIG. $28 \mathrm{E}$.

df. dorsal fin; sp.c. spinal cord; $p p$. bodycavity; sp. splanchnic layer of mesoblast; so. somatic layer of mesoblast; $m p^{\prime}$. commencing differentiation of muscles; ch. notochord ; $x$. subnotochordal rod arising as an ontgrowth of the dorsal wall of the alimentary tract; al. alimentary tract. 
not confined to the region in which a body cavity exists in the adult, but extends to the summit of the muscle-plutes, at first separating parts which become completely fused in the adult to form the great lateral muscles of the borly.

It is difficult to understand how the body carity could thus extend into the muscle-plates on the supposition that it lepresents a primitive split in the mesoblast between the wall of the gut and the body-wall; but its extension to this part is quite intelligible, on the hypothesis that it represents the cavities of two diverticula of the alimentary tract, from the muscular walls of which the voluntary muscular system has been derived; and it may be pointed out that the derivation of part of the muscular system from what is apparently splanchnic mesoblast is easily explained on the above hypothesis, but not, so far as I see, on any other.

Such are the main features, presented by the mesoblast in Elasmobranchii, which favour the view of its having originally formed the walls of the alimentary diverticnla. Against this view of its inature are the facts (1) of the mesoblast plates being at first solid, and $(\cdot)$ of the borly cavity as a consequence of this never communicating with the alimentary canal. These points, in view of our knowledge of embryological modifications, cannot be regarded as great difficulties in my hypothesis. We have many exanples of organs, which, though in most cases arising as involutions, yet appear in other cases as solid ingrowths. Such examples are atforded by the optic vesicle, auditory vesicle, and probably also by the central nervous system of Osseous Fishes. In most Vertebrates these orgaus are former as hollow in-

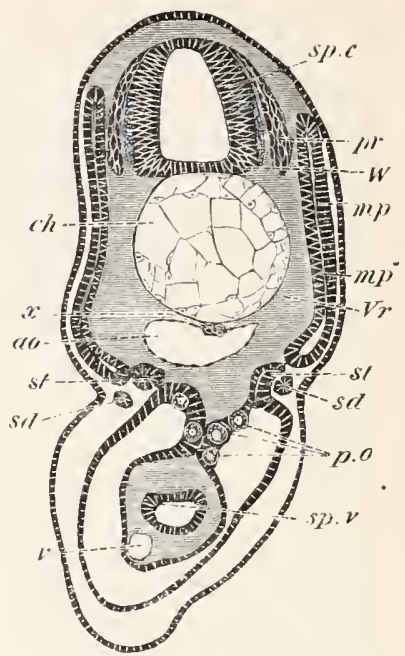

Fic. 18.5. Section THROtgh THE TRUNK OF A SCYLLIUM EMBRYO SLIGHTLY YUUNGER THAN $28 \mathrm{~F}$.

sp.c. spinal canal; $W$. white matter of spinal cord; $\mu r$ r. posterior nerve-roots; $c h$. notochord; .r. sub-notochordal rod; ao. aorta; $m p$. muscle-plate; mp'. inner layer of muscle-plate already converted into muscles; $V r$. rudiment of vertebral body; st. segmental tube; sd. segmental duct; sp.e. spiral valve; $r$. subintestinal rein; p.o. primitive generative cells.

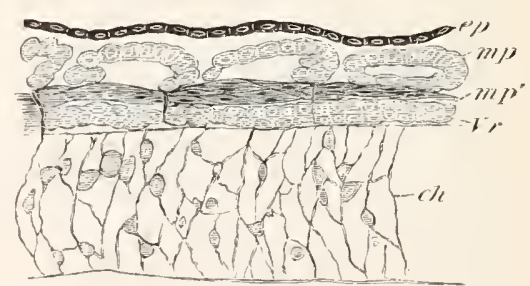

FIr. 186. HoRIZOXTAL SECTION THROUGH THE TLUNK OF AN EMBRYO OF SCYLLIUM CONSIDERABLY YOUNGER THAX $28 \mathrm{~F}$.

The section is taken at the level of the notochord, and shews the separation of the cells to form the vertebral bodies from the muscle-plates.

ch. notochord; ep.epiblast; Irr. rudiment of vertebral body; mp. muscle-plate; $m p^{\prime}$. portion of muscle-plate already differentiated into longitudinal muscles. 
volutions from the exterior; in Osseous Fishes, llowever, as solid involutions, in which a cavity is secondarily established.

There are strong grounds for thinking that in all Vertebrates the mesoblast plates on each side of the notochord originate independently, much as in Elasmobranchii, and that the notochord is derived from the axial hypoblast; but there are some difficulties in the application of this general statement to all cases. In Amphibia, Ganoids, and Petromyzon, where the dorsal hypoblast is formed by a process of invagination as in Amphioxus, the dorsal mesoblast also owes its origin to this invagination, in that the indifferent invaginated layer becomes divided into hypoblast and mesoblast. Amongst these forms the mesoblast sheet, when separated from the hypoblast, is certainly not continuous across the mildle line in Petromyzon (Calberla) and the Newt (Scott and Osborm), and cloubtfully so in the other forms. It arises, in fact, as in Elasmobranchii, as two independent plates. The fact of these plates originating from an invaginater layer can omly be regarded in the light of an approximation to the primitive type found in Amplioxus.

In Petromyzon and the Newt the whole axial plate of dorsal hypoblast becomes separated off from the rest of the hypoblast as the notochord, and this mode of origin for the notochord resembles more closely that in Amphioxus than the mode of origin in Elasmobranchii.

In Teleostei, there is reason to think that the processes in the formation of the mesoblast accord closely with what has been describerl as typical for the Ichthyopsida, but there are still some points involved in obscurity.

Leaving the Ichthyopsida, we may pass to the consideration of the Sauropsida and Mammalia. In both of these types there is evidence to shew that a part of the mesoblast is formed in situ at the same time as the hypoblast, from the lower strata of segmentation spheres. This mesoblast is absent in the front part of the area pellucida, and on the formation of the primitive streak (blastopore), an outgrowth of mesoblast arises from it as in Amphibia, etc. From this region the mesoblast spreads as a continuous sheet to the sides and posterior part of the blastoderm. In the region of the embryo,

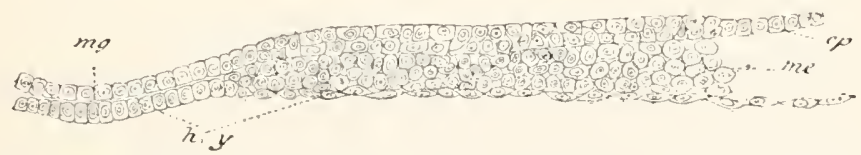

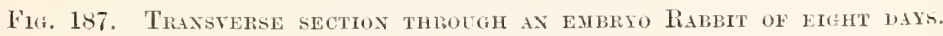
ep. epiblast; me. mesoblast; hy. hypoblast; mg. medullary groove.

its exact behaviour lats not in some cases been quite satisfactorily marle out. There are reasons for thinking that it appears as two sheets not united in the axial line in both Lacertilia (fig. 1:6) and Mammalia (fig. 187), and this to some extrut holds true for Aves (ride p. 1:30). 
In Lacertilia (fig. 188) and Nammalia, the axial hypoblast becomes wholly converted into the notochord, which at the posterior end of the body is continued into the epiblast at the dorsal lip of the blastopore; while in Birds the notochord is formed by a very similar (fig. $189 \mathrm{ch}$ ) process.

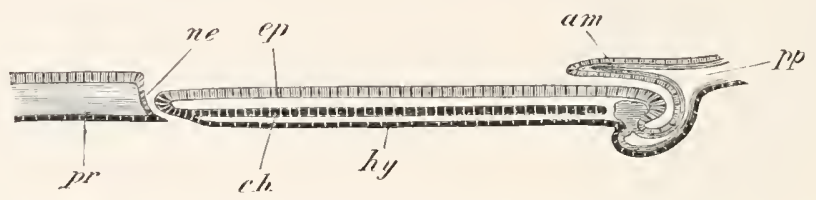

Fig. 188. Diagranjatic longitudinal section through ax ejbryo Lizard to shew

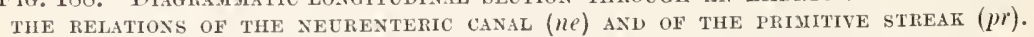

am. amnion; ep. epiblast; hy. hypoblast; $c h$. notochord; $p p$. body cavity; ne. neurenteric canal; $r$. primitive streak.

The above processes in the formation of the mesoblast are for the most part easily explained by a comparison with the lower types. The outgrowth of the mesoblast from the sides of the primitive streak is a rudiment of the dorsal invagination of hypoblast and mesoblast found in Amphibia; and the apparent outgrowth of the mesoblast from the epiblast in the primitive streak is no more to be taken as a proof of the epiblastic origin of the mesoblast, than the continuity of the epiblast with the invaginated hypoblast and meso-

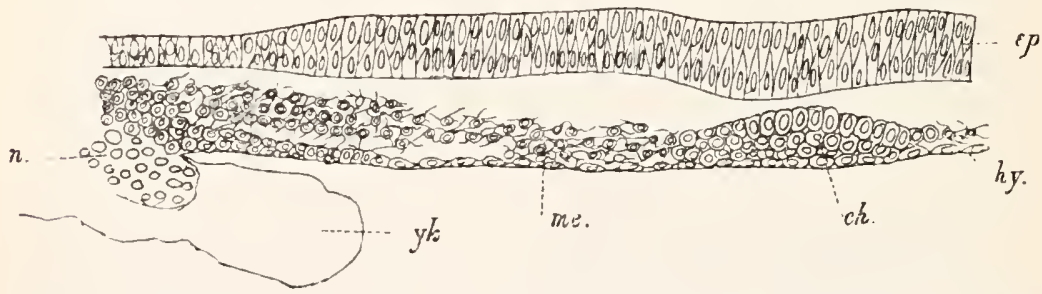

Fig. 189. Transterse section through the embryonic region of the Bhastodery of A CHICK AT THE TIJIE OF THE FORMATION OF THE Notochord, BUT BEFORE THE APPEARANCE OF THE MEDULLARY GROOVE.

ep. epiblast; hy. hypoblast; $c h$. notochord; me. mesoblast; $n$. nuelei in the yolk of the germinal wall $y l$.

blast at the lips of the blastopore in the Frog of the derivation of these layers from the epiblast in this type.

The division of the mesoblast into two plates along the dorsal line of the embryo, and the fomation of the notochord from the axial hypoblast, are intelligible without further explanation. The appearance of part of the mesoblast before the formation of the primitive streak is a process of the same nature as the differentiation of hypoblast and nesoblast in Elasmobranchii without an invagination. 
In the Sauropsida, some of the mesoblast of the vascular area would appear to be formed in situ out of the germinal wall, by a process of cell-formation similar to that which takes place in the yolk adjoining the blastoderm in Elasmobranchii and Teleostei. The mesoblast so formed is to be compared with that which arises on the ventral sile of the embryo in the Frog, by a direct differentiation of the yolk-cells.

What was stated for the Elasmobranchii with reference to the general fate of the mesoblast holds approximately for all the other forms.

\section{The Epiblast.}

The epiblast in a large number of Chordata arises as a single row of more or less columnar cells. Since the epiclermis, into which it becomes converted, is formed of two more or less distinct strata in all Chordata except Amplioxus and Ascidians, the primitive row of epiblast cells, when single, necessarily becomes divided in the course of development into two layers.

In some of the Yertebrata, viz. the Anurous Amphibia, Teleostei, Acipenser, and Lepidosteus, the epiblast is from the first formed of two distinct strata. The upper of these, formed of a single row of cells, is known as the epidermic stratum, and the lower, formed of sereral rows, as the nervous stratum. In these cases the two original strata of the epiblast are equivalent to those which appear at a later period in the other forms. Thus Vertebrates may be divided into groups according to the primitive condition of their epiblast, viz. a larger group with but a single stratum of cells at first; and a smaller group with two strata.

While there is no great difficulty in determining the equivalent parts of the epidermis in these two groups, it still remains an open question in which of them the epiblast retains its primitive condition.

Though it is not easy to bring conclusive proofs on the one side or the other, the balance of argument appears to me to be decidedly in favour of regarding the condition of the epiblast in the larger group as primitive, and its condition in the smaller group as secondary, and due to the throwing back of the differentiation of the epiblast to a very early period of development.

In favour of this view may be urged (1) the fact that the simple condition is retained in Amphioxus through life. (2) The correlation in Amphibia, and the other forms belonging to this group, between a closed autitory pit and the early division of the epiblast into two strata; there being no doubt that the auditory pit was at first permanently open, a condition of the epiblast which necessitates its never having an externat opening must elearly be secondary. (3) It appears more likely that a particular genetic feature should be thrown back in development, than that such an important feature, as a distinction between two primary layers, should be absolutely lost during an early period of development, and then re-appear in later stages. 
The fact of the epiblast of the nenral canal being divided, like the remainder of the layer, into nervous and epidermic parts, cannot, I think, be used as an argument in favour of the opposite view to that here maintained. It seens probable that the central canal of the nervous system arose phylogenetically as an involution from the exterior, and that the epidermis lining it is merely part of the original epidermis, which has retained its primitive structure as a simple stratum, but is naturally distinguishable from the nervous structures adjacent to it.

Where the epiblast is divided at an early period into two strata, the nervous stratum is always the active one, and takes the main share in forming all the organs deriver from the layer.

Formation of the central nervous system. In all Chordata an axial strip of the dorsal epiblast, extending from the lip of the blastopore to the anterior extremity of the head, and known as the
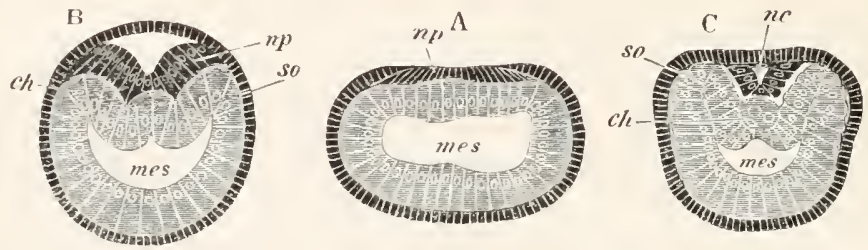

Fig. 190. Sections of an Amphioxus embryo at three stages. (After Kowalevsky.)

A. Section at gastrula stage.

B. Section of an embryo slightly younger than that represented in fig. $169 \mathrm{D}$.

C. Section through the anterior part of an embryo at the stage represented in fig. $169 \mathrm{E}$.

$n p$. neural plate; ne. neural canal; mes. archenteron in $\mathrm{A}$ and $\mathrm{B}$, and mesenteron in $\mathrm{C}$; ch. notochord; so. mesoblastic somite.

medullary plate, becomes isolated from the remainder of the layer to give rise to the central nervous axis.

According to the manner in which this takes place, three types may, however, be distinguished. In Amphioxus the axial strip becomes first detached from the adjoining epiblast, which then meets and forms a continuous layer above it (fig. $190 \mathrm{~A}$ and $\mathrm{B} m p$ ). The sides of the medullary plate, which is thus shut off from the surface, bend over and meet so as to convert the plate into a canal (fig. $190 \mathrm{C}$ $n c)$. In the second and ordinary type the sides of the medullary plate fold over and meet so as to form a canal before the plate becomes isolated from the external epiblast.

The third type is characteristic of Lepidosteus, Teleostei, and Petromyzon. Here the axial plate becomes narrowed in such a way that it forms a solid keel-like projection towards the ventral surface (fig. $191 / / c$ ). This keel subsequently becomes separated from the remainder of the epidemis, and a central canal is afterwards developed in it. Calberla and Scott hold that the epilermic laver of the skin is involuted into this keel in Petromyzon, am 
Calberla maintains the same view for Teleostei (fig. 32), but further observations on this subject are required. In the Teleostei a very shallow depression along the axis of the keel is the only indication of the medullary groove of other forms.

In Amphioxus (fig. 180), the Tunicata, Petromyzon (?), Elasmobranchii (fig. 182), the Urodela and Mammalia (fig. 187), the epiblast of the medullary plate is only formed of a single row of cells at the time when the formation of the central nervous system commences; but, except in Amphioxus and the Tunicata, it becomes several cells deep before the completion of the process. In other types the epiblast is several cells deep even before the differentiation of a medullary plate. In the Anura, the nervous layer of the epidermis alone

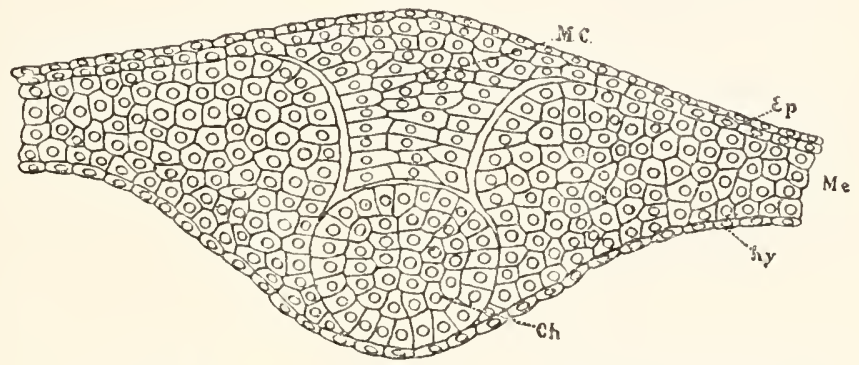

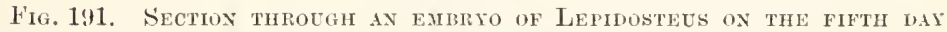
AFTEIR IMPREGNATION.

MC. medullary cord; Ep. epiblast; Me. mesollast; hy. hypoblast; Ch. notochord.

is thickened in the formation of the central nervous system (fig. 72); and after the closure of the medullary canal, the epidermic layer fuses for a period with the nervous layer, though on the subsequent formation of the central epithelium of the nervous canal, there can be little doubt that it becomes again distinct.

It seems almost certain that the formation of the central nervous system from a solid keel-like thickening of the epidermis is a derived and secondary mode; and that the folding of the medullary plate into a canal is primitive. Apart from its greater frequency the latter mode of formation of the central nervous system is shewn to be the primitive type by the fact that it offers a simple explanation of the presence of the central canal of the nervous system; while the existence of such a canal cannot easily be explained on the assumption that the central nervous system was originally developed as a kectlike thickening of the epiblast.

It is remarkable that the primitive medullary plate rarely exhibits any indication of being formed of two symmetrical halves. Such indications are, however, found in the Amphibia (fig. 192 and fig. 72 ) ; and, since in the adult state the nervous cord exhibits nearly as distinct traces of being formed of two united strands as does the ventral nerve-cord of many Chetopurs, it is quite possible that the 
structure of the medullary plate in Amphibia may be more primitive than that in other types ${ }^{1}$.

Formation of the organs of special sense. The more important parts of the organs of smell, sight, and hearing are derived from the epiblast; and it has been as-

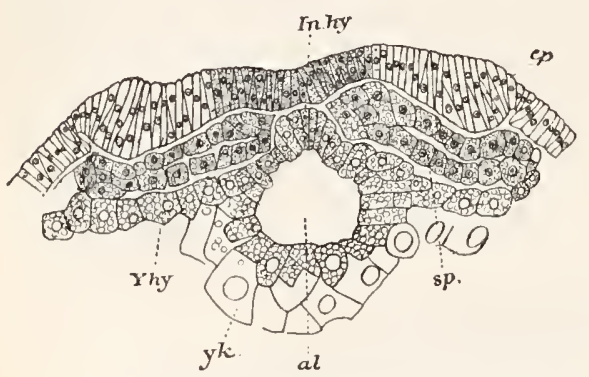

Fig. 192. Transterse section throdgh the CEPHALIC REgION OF A YoUxG NEWT EMBRYo. (After Scott and Osborn.)

In.hy. invaginated hypoblast, the dorsal part of which will form the notochord; ep. epiblast of neural plate; sp. splanchnopleure; al. alimentary tract; $y k$. and $Y h y$. yolk-cells. serted that the olfactory pit, optic vesicles and auditory pit take their origin from a special sense plate, continuous at first with this medullary plate. In my opinion this view cannot be maintained.

In the case of the group of forms in which the epiblast is early divided into nervous and epidermic layers, the former layer alone becomes involuted in the formation of the auditory pit and the lens, the external openings of which are never developed, while it is also mainly concerned in the formation of the olfactory pit.

Summary of the more important Organs derived from the three germinal layers.

The epiblast primarily gives origin to two very important parts of the body, viz. the central nervous system and the epidermis.

It is from the involuted epiblast of the neural tube that the whole of the grey and white matter of the brain and spinal cord appear to be developed, the simple columnar cells of the epiblast being directly transformed into the characteristic multipolar nerve cells. The whole of the sympathetic nervous system and the peripheral nervous elements of the body, including both the spinal and the cranial nerves and ganglia, are epiblastic in origin.

The epithelium (ciliated in the young animal) lining the canalis centralis of the spinal cord, together with that lining the ventricles of the brain, is the undifferentiated remnant of the primitive epiblast.

The epiblast also forms the epidermis; not however the dermis, which is of mesoblastic origin. The line of junction between the

1 A parallel to the unpaired medullary plate of most Chordata is supplied by the embryologically unpaired ventral cord of most Gephyrea and some Crustacea. In these forms there can be little doubt that the ventral cord has arisen from the fusion of two originally independent strands, so that it is not an extremely improbable hypothesis to suppose that the same may have been the case in the Chordata. 
epiblast and the mesoblast coincides with that between the epidermis and the dermis. From the epiblast are formed all such tegumentary organs or parts of organs as are epidermic in nature.

In addition to the above, the epiblast plays an important part in the formation of the organs of special sense.

According to their mode of formation, these organs may be arranged into two divisions. In the first come the organs where the sensory expansion is derived from the involuted epiblast of the medullary canal. To this class belongs the retina, including the pigment epithelium of the choroid, which is formed from the original optic vesicle budded out from the fore-brain.

To the second class belong the epithelial expansions of the membranous labyrinth of the ear, and the cavity of the nose, which are formed by an involution of the epiblast covering the external surface of the embryo. These accordingly have no primary connection with the brain. 'Taste bulbs' and other terminal nervous organs, such as those of the lateral line in fishes, are also structures formed from the external epiblast.

In addition to these we have the crystalline lens formed of involuted epiblast as well as the cavity of the month and anus, and the glands derived from them. The pituitary body is also epiblastic in origin.

From the hypoblast are derived the epithelium of the digestive canal, the epithelium of the trachea, bronchial tubes and air cells, the cylindrical epithelium of the ducts of the liver, pancreas, thyroid body, and other glands of the alimentary canal, as well as the hepatic cells constituting the parenchyma of the liver, developed from the hypoblast cylinders given off around the primary hepatic diverticula.

Homologous probably with the hepatic cells, and equally of hypoblastic origin, are the spheroidal 'secreting cells' of the pancreas and other glands. The epithelium of the salivary glands, though these so closely resemble the pancreas, is probably of epiblastic origin, inasmuch as the cavity of the mouth is entirely lined by epiblast.

The hypoblast also lines the allantois. To these parts must be added the notochord and subnotochordal rod. From the mesoblast are formed all the remaining parts of the body. The muscles, the bones, the connective tissue and the vessels, both arteries, veins, capillaries and lymphatics with their appropriate epithelium, are entirely formed from the mesoblast.

The generative and urinary organs are entirely derived from the mesoblast. It is worthy of notice that the epithelium of the urinary glands, though resembling the hypoblastic epithelium of the alimentary canal, is undoubtedly mesoblastic.

From the mesoblast are lastly derived all the muscular, comnective tissue, and vascular elements, as well of the alimentary canal and its appendages as of the skin and the tegumentary organs. Just as it is only the epidernic moiety of the latter which is derived from the 
epiblast, so it is only the epithelium of the former which comes from the hypoblast.

\section{Girowth in length of the Vertebrate Embryo.}

With reference to the formation and growth in length of the boty of the Vertebrate embryo two different riews have been put forward, which can be best explained by taking the Elasmobranch embryo as onr type. One of these views, generally held by embryologists and adopted in the previous pages, is that the Elasmobranch embryo arises from a differentiation of the erlge of the blastoderm; which extends inwards from the edge for some little distance. This differentiation is supposed to contain within itself the rudiments of the whole of the embryo with the exception of the yolk-sack; and the hinder extremity of it, at the elge of the blastoderm, is regarderl as corresponding with the hind end of the body of the adult. The growth in length takes place by a process of intussusception, and, till there are formed the full number of mesoblastic somites, it is effected, as in Chrotopods, by the continual addition of firesh somites between the last-formed somite and the hind end of the body.

A second and somewhat paradoxical view has been recently bronght into prominence by His and Rauber. This view has moreover since been taken up by many embryologists, and has led to strange comparisous between the formation of the mesoblastic plates of the Chrotopods and the medullary folds of Vertebrata. According to this riew the embryo grows in length by the coalescence of the two halves of the thickened edges of the blastoderm in the dorsal median line. The groove between the coalescing edges is the medullary groore, which increases in length by the continued coalescence of fresh portions of the edge of the blastoderm.

The following is His" own statement of his view: "I have slewn that the embryo of Osseous Fishes grows together in length from two symmetrically-placed structures in the thickened edge of the blastorlerm. Only the foremost end of the head and the hindermost end of the tail undergo no concrescence, since they are formed out of that part of the edge of the blastoderm which, together with the two lateral halves, completes the ring. The whole edge of the blastoderm is used in the formation of the embryo."

The edges of the blastoderm which meet to form the body of the embryo are regarded as the blastopore, so that, on this view, the blastopore prinitively extends for the whole length of the dorsal side of the embryo, and the groove between the coalesced lips becomes the medullary groove.

It is not possible for me to enter at any great length into the arguments used to support this position.

They may be summarised as (1) The general appearance; i.e. that the thickened edge of the blastoderm is continuous with the mednllary fold.

(2) Certain measurements (His) which mainly appear to me to prove that the growth takes place by the addition of fresh somites between that last formed and the end of the body.

(3) Some of the phenomena of double monsters (Ranber).

None of these arguments appear to be very forcible, but as the view of His and Rauber, if true, would certainly be important, I shall attempt shortly to state the argnments against it, employing as my type the Elasmobranchii, ly the development of which, according to His, the view 
which he adopts is more conclusively proved than hy that of any other groul?.

(1) The general appearance of the thickened edge of the blastoderm becoming continuous with the medullary folds has been userl as an argument for the medullary folds being merely the coalesced thickened edges of the blastoderm. Since, however, the medullary folds are merely parts of the medullary plate, and since the medullary plate is continuous with the adjoining epiblast of the embryonic rim, the latter structure must be continuous with the medullary folds however they are formed, and the mere fact of their being so continuous camnot be used as an argmment either way. Moreover, were the concrescence theory true, the coalescing edges of the blastoderin might be expected to form an acute angle with each other, which they are far from doing.

$(2)$ The medullary groove becomes closed behind earlic than in front, and the closure commences while the embryo is still quite short, and hefore the hind end has bequn to project over the yoll: After the medullary canal beeomes closed, and is continued behind into the alimentary canal by the neurenteric passage, it is clearly impossible for any further incrcase in length to take place by concrescence. If therefore His' and Pauber's view is accepted, it will liave to he maintained that only a small part of the body is formed by concrescence, while the larger posterior part grows by intussusception. The difticulty involved in this supposition is much increased by the fact that long after the growth by concrescence must have ceased the yolk blastopore still remains open, and the embryo is still attached to the edge of the blastoderm; so that it cannot be maintained that the growth by concrescence has come to an end becanse the thickened edges of the blastoderm have completely coalesced.

The above are arguments derived simply from a consirleration of the growth of the embryo; and they prove (1) that the points adduced by His and Rauber are not at all conclusive; (ㄹ) that the growth in length of the greater part of the boly takes place by the addition of fresh somites behind, as in Chrtopods, and it would therefore be extremely surprising that a small middle part of the borly should grow in quite a different way.

Many minor arguments nsed by His might be replied to, but it is hardly necessary to do so, and some of them depend upon erroneous views as to the course of development, such as an argument about the notochord, which depends for its validity upon the assumption that the notochord ridge appears at the same time as the medullary plate, while, as a matter of fact, the ridge does not appear till considerably later. In addition to the arguments of the class hitherto used, there may be brought against the HisRauber view a series of arguments from comparative embryology.

(1) Were the vertebrate blastopore to be co-extensive with the dorsal surface, as His and Rauber maintain, clear evidence of this ought to be apparent in Amphioxus. In Amphioxus, however, the blastopore is at first placed exactly at the hind end of the hody, though later it passes up just on to the dorsal side (vide p. 3). It nearly closes before the appearance of the medullary groove or mesoblastic somites; and the medullary folds have nothing to do with its lips, except in so far as they are continuous with them behind, just as in Elasmobranchii.

(2) The food-yolk in the Vertehrata is placed on the ventral sirle of the body, and becomes enveloped by the blastoderm; so that in all large-yolked 
Vertebrates the ventral walls of the body are obviously completed by the closure of the lips of the blastopore, on the ventral side.

If His and Rauber are right the dorsal walls are also completed by the closure of the blastopore, so that the whole of the dorsit, as well as of the ventral wall of the embryo, must be formed by the concrescence of the lips of the blastopore; which is clearly a reductio ad absurdum of the whole theory. To my own arguments on the subject I may add those of Kupffer, who has very justly criticised His' statements, and has shewn that growtl of the blastoderm in Chupea and Gasterosteus is absolutely inconsistent with the concrescence theory.

The more the theory of His and Rauber is examined by the light of comparative embryology, the more does it appear quite untenable; and it may be laid down as a safe conclusion from a comparative study of vertebrate embryology that the blastopore of Vertebrates is primitively situated at the hind end of the body, but that, owing to the development of a large food-yolk, it also extends, in most cases, over a larger or smaller part of the ventral side.

\section{The origin of the Allantois and Ammion.}

The development and structure of the allantois and amnion have already been dealt with at sufficient length in the chapter's on Aves and Mammalia; but a few worls as to the origin of these parts will not be out of place here.

The Allantois. The relations of the allantois to the arjoining organs, anci the conversion of its stalk into the bladder, afford ample evidence that it has taken its origin from a urinary bladder such as is found in Amphibia. We have in tracing the origin of the allantois to deal with a case of what Dohrn would call 'change of function.' The allantois is in fact a urinary bladder which, mecociously developed and enormously extended in the embryo, has acquired respiratory (Sauropsida) and nutritive (Mammalia) functions. No form is kuown to have been preserved with the allantois in a transitional state between an ordinary bladder and a large vascular sack.

The advantige of secondary respiratory or'gans duriug fotal life, in addition to the yolk-sack, is evinced by the fact that such organs are very widely developed in the Ichthyopsida. Thus in Elasmobranchii we have the external gills (ef. p. 51). Amongst Amphibia we have the tail modified to be a respiratory organ in Pipa Americana; and in Notodelphis, Alytes, and Cacilia compressicanda the external gills are modified and enlarged for respiratory purposes within the egg (cf. pp. 116 and 118).

The Amnion. The origin of the amnion is more difficult to explain than that of the allantois; and it does not seem possible to derive it from any pre-existing organ.

It appears to me, however, very probable that it was evolved preri passu with the allantois, as a simple fold of the somatopleure round the embryo, into which the allantois extended itself as it increased in size and became a respiratory organ. It would be obviously advantageous for such a fold, having once started, to become larger and larger in order to give more and more room for the allantois to spread into.

The continued increase of this fold wonld lead to its edges meeting on the dorsal side of the embryo, and it is easy to conceive that they might then coalesce. 
To afford room for the allantois close to the surface of the egg, where respiration conld most alrantageously be carried on, it would be convenient that the two laminse of the amnion-the true and false amnion-should then separate and leave a free space above the embryo, and thus it may have come about that a separation finally takes place between the true and false amnion.

This explanation of the origin of the amnion, though of course hypothetical, has the alvantage of suiting itself in most points to the actual ontogeny of the organ. The mian difficulty is the early development of the head-fold of the ammion, since, from the position of the allantois, it might have been anticipated that the tail-fold would be the first formed and most important fold of the annuion.

\section{BIBLIOGRAPHT.}

(230) F. M. Balfour. "A comparison of the early stages in the development of Vertebrates." Quart. J. of Micr. Science, Vol. xv. 1875 .

$(240)$ F. M. Balfour. "A monograph on the derelopment of Elasmobranch Fishes." London, 1878.

$(2+1)$ F. M. Balfour. "On the early development of the Lacertilia together with some observations, ete." Quart. J. of Micr. Science, Vol. xux. 1879.

$(2+2)$ A. Götte. Die Entwicklungsgeschichte d. Unke. Leipzig, 1875.

$(2+3)$ W. His. "Ueb. d. Bildung d. Haitischembryonen." Zeit. f. Anat. u. Entwick., Yol. 11. 1877. Cf. also His' papers on Teleostei, Nos. 65 and 66.

(2+4) A. Kowalevsky. "Entwick. d. Amphioxus lanceolatus." Mém. Acad. des Sciences St Pétersbourg, Ser. vir. Tom. XI. 1867.

$(2+5)$ A. Kowalersky. "Weitere Studien äb. d. Entwick. d. Amphioxus lan. ceolatus." Archiv f. mikr. Anat., Vol. xm1. 1877.

$(2+6)$ C. Kupfer. "Die Entstehung d. Allantois u. d. Gastrula d. Wirbelthiere." Zool. Anzeiger, Vol. II. 1879 , pp. $520,593,612$.

$(2+7)$ R. Remak. Untersuchungen iib. d. Entucickhng d. Wirbelthiere, 1850-1858.

(248) A. Rauber. Primiticstreifen u. Neurula d. Wirbethiere. Leipzig, 1877. 


\section{CHAPTER XII.}

\section{(OBSERTATIONS ON THE ANCESTRAL FORII OH THE CHORDATA.}

THE present section of this work would not be complete withont some attempt to reconstruct, from the materials recorded in the previous chapters, and from those supplied by comparative anatomy, the character's of the ancestors of the Chordata; and to trace as far as possible from what invertebrate stock this ancestor was derived.

The second of these questions has been recently dealt with in a very suggestive mamner by both Dohrn (No. 250) and Semper (Nos. 255 and 256), but it is still so obsenre that I shall refrain from any detailed discussion of it.

While differing very widely in many points both Dohrn and semper. have arrived at the view, already tentatively put forward by arlier inatomists, that the nearest allies of the Chordata are to be sought for amongst the Chretoprala, and that the dorsal surface of the Chordata with the spinal cord corresponds morphologically with the ventral surfire of the Chetoporls with the ventral ganghion chain. In discussing this subject some time ago' I suggested that we must look for the ancestors of the Chordata, not in allies of tle present chetomoda, but in a stock of segmenterl forms descended from the same unsegmented types as the Chetopoda, but in which two lateral nerve-corls, like those of Nimertines, enaleseed dorsally, instead of ventrally to firm a median nervons cord. This group of forms, if my suggestion as to its existence is well founded, appears now to have perished. The recent researches of Hubrecht on the anatomy of the Nemertines ${ }^{2}$ hare, however, adled somewhat to the probalbility of my riews, in that they shew that in some existing Nemertines the nerve-cords approach each other very closely in the dorsal line.

With reference to the characters of the ancestor of the Chordata the following pages contain a few tentative suggestions rather than

- Monograph on the development of Elasmobranch Fishes, pp. 170-173.

" Hubrecht, "Zur Anat. u. Phys. d. Nervensystems der Nemertinen." Krin. d lar. Iiss. Amsterlam: and "liesearches on the Nervous System of Nemertines." Quat. Joxin. of Hicr. Science, $18 \$ 0$. 
an attempt to deal with the whole subject; while the origin of certain of the organs is dealt with in a more special manner in the chapters on organogeny which form the second part of this work.

Before entering upon the more special sulject of this chapter, it will be convenient to clear the ground by insisting on a few morphological conchusions to be drawn from the study of Anplioxus, - a form which, although probably in some respects degenerate, is nevertheless capable of furnishing on certain points very valuable evidence.

(1) In the first place it is clear from Amphioxus that the ancestors of the Chordata were segmented, and that their mesoblast was divided into myotomes which extended even into the region in front of the mouth. The mesoblast of the greater part of what is called the hear in the Vertebrata proper was therefore segmented like that of the trunk.

(2) The only interual skeleton present was the unsegmented notochord-a fact which demonstrates that the skeleton is of conparatively little importance for the solution of a large number of fundamental questions, as for example the point which has been mooted recently as to whether gill-clefts existed at one time in front of the present mouth; and for this reason:-that from the evidence of Amphioxus and the lower Vertebrata ${ }^{1}$ it is clear that such clefts, if they ever existed, had atrophied completely before the formation of cartilaginous branchial bars; so that any skeletal structures in front of the mouth, which have been interpreted by morphologists as branchial bars, can never have acted in supporting the walls of branchial clefts.

(3) The region which, in the Vertebrata, forms the osophagus and stomach, was, in the ancestors of the Chordata, perforated by gillclefts. This fact, which has been clearly pointed out by Gegenbaur, is demonstrated by the arrangement of the gill-clefts in Amphioxus,

1 The greater part of the branchial skeleton of Petromyzon appears clearly to belong to an extra-branchial systcm innch more superficially situated than the true branchial bars of the higher forms. At the same time there is no doubt that cer tain parts of the skeleton of the adult Lamprey lave, as pointed out by Huxley, striking points of resemblance to parts of a true mandibular and hyoid arches. Further embryological evidence is required on the subject, but the statements on this head on p. 69 ought to be qualified.

Should Huxley's views on this subject be finally proved correct, it is probable that, taking into consideration the resemblance of these skeletal parts in the Tadpole to those in the Lamprey, the cartilaginous mandibular bar, before bcing in any way modified to form true jaws, became secondarily adapted to sulport a suctorial mouth, and that it subsequently became converted into the true jaws. Thus the evolution of this bar in the Frog would be a true repetition of the ancestral history, while its ontogeny in Elasmobranchii and other types would be much abbreviated. For a fuller statement on this point I must refer the reader to the chapter on the skull.

It is difficult to believe that the posterior branchial bar's could have coexisted with such a highly developed branchial skeleton as that in Petromyzon, so that the absence of the posterior branchial bars in Petromyzon receives ly far its nosit plansible explanation on the supposition that Petromyzon is descended fiom a vertebrate stock in which true branchial hars had not been evolved. 
and by the distribution of the vagus nerve in the Vertebrata ${ }^{1}$. On the other hand the insertion of the liver, which was probably a very primitive organ, appears to indicate with approximate certainty the posterior limit of the branchial clefts.

With these few preliminary observations we may pass to the main subject of this section. A fundamental question which presents itself on the threshold of our enquiries is the differentiation of the head.

In the Chatopoda the head is formed of a praoral lobe and of the oral segment; while in Arthropods a somewhat variable number of segments are added behind to this primitive head, and form with it what may be called a secondary compound head. It is fairly clear tbat the section of the trunk, which, in Amphioxus, is perforated by the visceral clefts, has become the head in the Vertebrates proper, so that the latter forms are provided with a secondary head like that of Arthropods. There remain however difficult questions (1) as to the elements of which this hear is composed, and $(2)$ as to the extent of its differentiation in the ancestors of the Chordata.

In Arthropods and Chetopods there is a very distinct element in the head known as the procephalic lobe in the case of Arthropods, and the preora! lobe in that of Chrtopods; and this lobe is especially characterized by the fact that the supraœsophageal gangha and optic organs are formed as differentiations of part of the epiblast covering it. Is such an element to be recognized in the head of the Chordata? From a superficial examination of Amplioxus the answer would undoubtedly be no; but then it has to be borne in mind that Amphioxus, in correlation with its habit of burying itself in sand, is especially degenerate in the development of its sense-organs; so that it is not difficult to believe that its preoral lobe may have become so reduced as not to be recognizable. In the true Vertebrata there is a portion of the hear which has undoubtedly many features of the praoral lobe in the types already alluded to, viz. the part containing the cerebral hemispheres and the thalamencephalon. If there is any part of the brain homologous with the supraœsophageal ganglia of the Invertebrates, and it is difficult to believe there is not such a part, it nust be part of, or contain, the fore-brain. The fore-brain resembles the supranesophageal ganglia in being intimately connected in its development with the optic organs, and in supplying with nerves only organs of sense. Its comection with the olfactory organs is an argument in the same direction. Even in Amphioxus there is a small bulb at the end of the nervous tube supplying what is very

I The extension forwards in the Tertebrata of an unintermpted body-cavity into the region previonsly occupied by visceral clefts presents no diffienlty. In Amphioxus the true body-cavity extends forwards, more or less divicled by the branchial clefts, for the whole length of the branchial region, and in embryos of the lower Vertebrata there is a section of the body-cavity-the so-called head-cavities-between each pair of pouches. On the disappearance of the ponches all these parts would naturally coalesce into a continuous whole. 
probably the homologue of the olfactory organ of the Vertebrata; and it is quite possible that this bulb is the reduced rudiment of what forms the fore-brain in the Vertebrata.

The evidence at our disposal appears to me to indicate that the third nerve belongs to the cranio-spinal series of segmental nerves, while the optic and olfactory nerves appear to me equally clearly not to belong to this series". The mid-brain, as giving origin to the third nerve, would appear not to have been part of the ganglion of the preoral lobe.

'These considerations indicate with fair probability that the part of the hear containing the fore-brain is the equivalent of the pritoral lobe of many Invertebrate forms; and the primitive position of the Vertebrate mouth on the ventral side of the head affords a distinct support for this view. It must however be armitted that this part of the head is not sharply seprarated in development from that behind; and, though the fore-brain is usually differentiated very early as a distinct lobe of the primitive nerrous tube, yet that such differentiation is hardly more marked than in the other parts of the brain. 'The termination of the notochord immediately behind the fore-brain is, however, an argument in favour of the morphological distinctness of the latter structure.

The evidence at our disposal appears to indicate that the posterior part of the hear was not differentiated from the trunk in lower Chordata ; but that, as the Chordata rose in the scale of development, more and more centralizing work became thrown on the anterior part of the nervous cord, and pari passu this part became differentiated into the mid- and hind-brain. An analogy for such a differentiation is supplied in the compound suboesophageal ganglion of many Arthropods; and, as will be shewn in the chapter on the nervous system, there is strong embryological evidence that the mid- and hini-brains had primitively the same structure as the spinal cord. The head appears however to have suffered in the course of its differentiation a great concentration in its posterior part, which becomes progressively more marked, even within the limits of the surviving Vertebrata. This concentration is especially shewn in the structure of the vagus nerve, which, as first pointed out by Gegenbaur, bears evidence of having been originally composed of a great series of nerves, each supplying a visceral cleft. Rudiments of the posterior nerves still remain as the branches to the osoplagus and stomach".

The atrophy of the posterior visceral clefts seems to have taken place simultaneously with the concentration of the neural part of the head; but the former process did not proceed so rapidly as the latter,

1 Marshall, in his raluable paper on the derelopment of the olfactory organ, takes a very different view of this subject. For a discussion of this view I must refer the reader to the chapter on the nervous system.

2 The lateral branch of the vagus nerre probably became differentiated in connection with the lateral line, which seems to have been first formed in the head, and subsequently to have extended into the trunk (vide section on Lateral Line). 
so that the visceral region of the hean is longer in the lower Vertebrata than the neural region, and is dorsally overlapped by the anterior part of the spinal cord and the anterior muscle-plates (vide fig. 47 ).

On the above view the posterior part of the hear must have been originally eomposed of a series of sonites like those of the trunk, but in existing Vertebrata all trace of these, except in so far as they are indicated by the visceral clefts, has vanished in the adult. The cranial nerves however, especially in the embryo, still indicate the number of anterior somites; and an embryonic segmentation of the mesollast has also been fomnd in many lower forms in the region of the head, giving rise to a series of cavities known as head-cavities, enclosed by mesoblastic walls which afterwards break up into muscles. These cavities correspond with the nerves, and it appears that there is a præmandibular cavity corresponding with the third nerve (fig. 19:3, $1 p p$ )

anil a mandibular cavity $(2 p P)$ and a

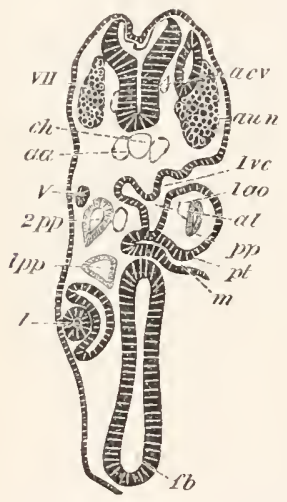

Fif. 193. Transterse section THROCHH THE, FRONT PART OF THE Head of a yoling Pristiurts embryo.

The section, owing to the cranial flexure, cuts both the fore- and the hind-brain. It shews the pramandibular and mandibular head-cavities $1 p p$ and $2 p p$, ete.

$f b$. fore-brain; $l$. lens of eye; $m$. mouth; $p t$. upper end of mouth, forming pituitary involution; 1 ao. mandibular aortic arch; $1 \mathrm{pp}$. and $2 p p$. first and second head-cavities; $1 \mathrm{rc}$. first visceral cleft; $\mathrm{T}$. fifth nerve; aun. ganglion of auditory nerve; III. seventh nerve; an. dorsal aorta; acr. anterior cardinal vein; ch. notochord. the posterior roots arising from the extreme dorsal line (fig. 194), a position which can most easily be explained on the supposition that the two sides of the plate, from which the nerves originally 
proceeded have been folded up so as to meet ach other in the median dorsal line?

The medullary plate, before becoming folder to form the medullary groove, is (except in Amphibia) without any indication of being composed of two halves. In both the embryo and adult the walls of the tube have lowerer a structure which points to their having arisen from the coalescence of two lateral, and most probably at one time independent, cords; and as already indicated this is the view I an mycolf inclined to adopt; vede pp. 2.51 aud 2.52.

The origin and nature of the mouth. The most obvious point connecterl with the development of the month is the fact that in all vertebrate embryos it is placerl ventrally, at some little distance from the front end of the body. This feature is retained in the adult stage in Elasmoloranchii, the Myxinoids, and some Ganoids, but is lost in other vertebrate forms. A mouth, situated as is the embryonic vertebrate mouth, is very ill adapted for biting; and though it acquires in this position a ristinctly bitiug character in the Elasmobranchii, yet it is almost certain that it had not such a character in the ancestral Chordata, and that its terminal position in higher types indicates a step

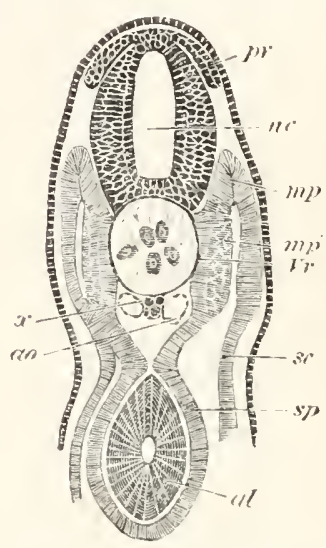

Fif. 104. Transverse secTION THROT(IH THF TRENK OF AN EMBRFO SIIGITLY OLDER TH N FIt. $28 \mathrm{E}$.

ne. neural canal; pr. postei iur root of spinal nerve; $x$. subnotochordal rod: (10), aorta; sc. somatic mesoblast; sp. splanchnis mesoblast; mp. muscle-plate; $m y^{\prime}$. portion of muscle-plate conrerted into muscle; $T r$. portion of the rertebral plate which will give rise to the rertebral bodies; al. alimentary tract. in alvance of the Elasmobranchii.

On the structure of the primitive mouth there appears to me to be some interesting embryological evidence, to which attention lias already been called in the precerling chapters. In a large number of the larva or embryos of the lower Vertebrates the mouth has a more or less distinctly suctorial character, and is comnected with suctorial organs which nuay be placed either in front of or behind it. The more important instances of this kind are (1) the Tadpoles of the Anura, with their posteriorly placed suctorial disc, (2) Lepidosteus Iarva (fig. 195) with its anteriorly placed suctorial disc, (3) the adhesive papillæ of the larve of the Tunicata. To these mav be adder the suctorial mouth of the Mrxinoid fishes ${ }^{2}$.

1 Iide for further details the chapter on the nerrous system.

2 The existing Myxinoid Fishes are no donbt degenerate types, as was first clearly pointed out by Dohrn; but at the same time (although Dohrn does not share this view) it appears to me almost certain that they are the remuants of a large and very primitive group, which have very likely been preserved owing to their parasitic or 
All these considerations point to the conclusion that in the ancestral Chordata the mouth had a more or less definitely suctorial character ${ }^{1}$, and was placed on the ventral surface immediately belind the praeoral lobe; and that this mouth has become in the higher types gradually modified for biting purposes, and has been carried to the front end of the head.

The mouth in Elasmobranchii and other Vertebrates is originally a wide somewhat rhomboidal cavity (fig. 노 G); on the development of the mandibular and its maxillary (pterygo-quadrate) process the opening of the mouth becomes narrowed to a slit. The wide condition of the month may not improbably be interpreted as a remnant of the suctorial state. The fact that no more definite remnants of the suctorial mouth are found in so primitive a group as the Elasmobranchii is probably to be explained by the fact that the members of this group undergo an abbreviated development within the egg.

While the enl,ryological data appear to me to point to the existence of a primitive suctorial mouth, very different conchsions have been put forward by other embryologists, more especially by Dohrn, which are sufficiently striking and suggestive to merit a further discussion.

As mentioned above, both Dohrn and Semper hold that the Vertebrata

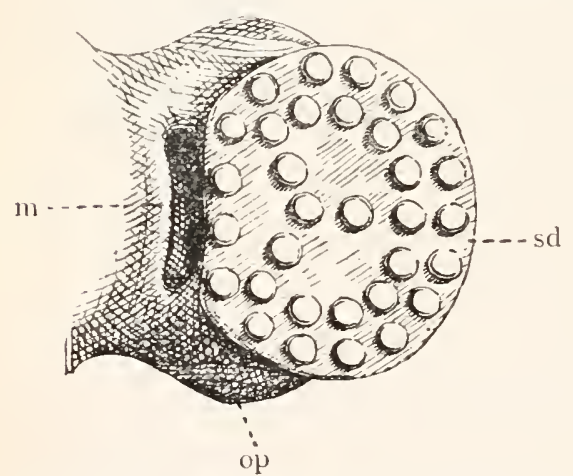

F1g. 195. Vevtral VIET OF THE head OF a LEPIDOSTEUS EMIBRTO SHORTLY BEFORE HATCHING, TO SHEW THE LARGE SCCTORIAL DISC.

m. mouth; op. eye; sd. suctorial disc. are descended from Chretopodlike forms, in which the ventral surface has become the dorsal. In consequence of this view Dohrn has arrived at the following conchusions: (1) that primitively the alimentary canal perforated the nervons system in the region of the original resophageal nerve-ring; (2) that there was therefore an original dorsal mouth (the present ventral mouth of the Chretopora); and (3) that the present mouth was secondary and derived from two visceral clefts which have ventrally coalesced.

A full discussion of these views $^{2}$ is not within the scope

semiparasitic habits; much in the same way as many of the Insectivora have been preserved owing to their subterranean habits. I am acquainted with no evidence, embryological or otherwise, that they are degraded gnathostomatous forms, and the group probably disappeared as a whole from its incapacity to compete successfully with Vertebrata in which true jaws had become developed.

I I do not conceive that the existence of suctorial structures necessarily implies parasitic habits. They might be used for various purposes, especially by predaceous forms not provided with jaws.

2 For a partial discussion of this subject I would refer the reader to my Monograph on Elasmolianch Fishes, pp. 165-172. 
of this work; but, while recognizing that there is much to be said in favour of the interchange of the dorsal and ventral surfaces, I am still inclined to hold that the difficulties involved in this view are so great that it must, provisionally at least, be rejected; and that there are therefore no reasons against supposing the presenc rertebrate mouth to be the primitive mouth. There is no embryological evidence in fuvour of the riew adopted by Dolim that the present mouth was formed by the coalescence of two clefts.

If it is once admitted that the present mouth is the primitive mouth, and is more or less nearly in its original situation, very strong evidence will be required to shew that any structures originally situated in front of it are the remnants of risceral clefts; and if it should be proved that such remnants of visceral clefts were present, the views so far arrived at in this section woukl, I think, have to be to a large extent reconsidered.

The nasal pits have been supposed by Dohru to be remnants of visceral clefts, and this view has been maintained in a very able manner by Marshall. The arguments of Marshall do not, however, appear to me to have any great weight unless it is previously granted that there is an antecedent probubility in favour of the presence of a pair of gill-clefts in the position of the nasal pits; and even then the development of the nasal pits as epiblastic involutions, insteal of lypoblastic outgrowths, is a serious difficulty which has not in my opinion been successfully met. A further argument of Marshall from the supposed segmental nature of the olfactory nerve has already been spoken of.

While most of the structures supposed to be remains of gill-clefts in front of the mouth do not appear to me to be of this nature, there is one organ which stands in a more doubtful category. This organ is the socalled choroid gland. The similarity of this organ to the psendo-branch of the mandibular or hyoid arele was pointed out to ne by Dohrn, and the suggestion was made by him that it is the remmant of a pramandibular gill which has been retained owing to its functional connection with the eye'. Admitting this explanation to be true (which however is by no means certain) are we necessarily compelled to hold that the choroid gland is the remmant of a gill-cleft originally situated in front of the mouth ? I believe not. It is easy to conceive that there may originally have been a premandibular eleft behind the suctorial mouth, but that this

1 The probability of the choroid gland haring the meaning attributed to it by Dohrn is strengthened by the existence of a præmandibular segment as evidenced by the presence of a premandibular head-carity, the walls of which as shewn by Marshall and myself give rise to the majority of the eye-muscles and of a nerve (the third nerre, cf. Marshall) corresponding to it; so that these parts together with the choroid gland may be rudiments belonging to the same segment. On the other hand the absence of the choroid gland in Ganoidei and Elasmobranchii, where a mandibular pseudo-branch is present, coupled with the absence of a mandibular psendo-branch in Teleostei where alone a choroid gland is present, renders the above view about the choroid gland somewhat doubtful. A thorough investigation of the ontogeny of the choroid gland might throw further light on this interesting question, but $I$ think it not impossible that the choroid gland may be nothing else but the modified mandibular pseudo-branch, a view which fits in very well with the relations of the vessels of the Elasmobranch mandibular psendo-branch to the choroid. For the relations and structure of the choroid gland vide F. Müller, Vergl. Anat. Myxinoiden, Part n11. p. 8*2.

It is possible that the fourth nerve and the superior oblique muscle of the ere which it supplies may be the last remaining remnants of a second promandibular segment originally situated between the segment of the third nerve and that of the fifth nerve (mandibular segment). 
cleft graduilly atrophied (for the same reasons that the mandibular cleft shews a tendency to atrophy in existing tishes, drc.), the rudiment of the gill (choroid gland) alone remaining to mark its situation. After the disappearance of this cleft the suctorial mouth may have become relatively shifted backwards. In the meantime the hranchial bars became developed, and as the mouth was changed into a biting one, the bar (the mandiluular arch) supporting the then firnt cleft became gradually modified and converted into a snpporting apparatus for the mouth, and finally formed the skeleton of the jirws. In the hyostylic Vertebrata the liyoid arch also became modified in comnection with the formation of the jaws.

The conchusions arrived at may be summed up as follows:

The relations which exist in all jaw-bearing Vertebrates between the mandibular arch and the oral aperture are secondary, and arose

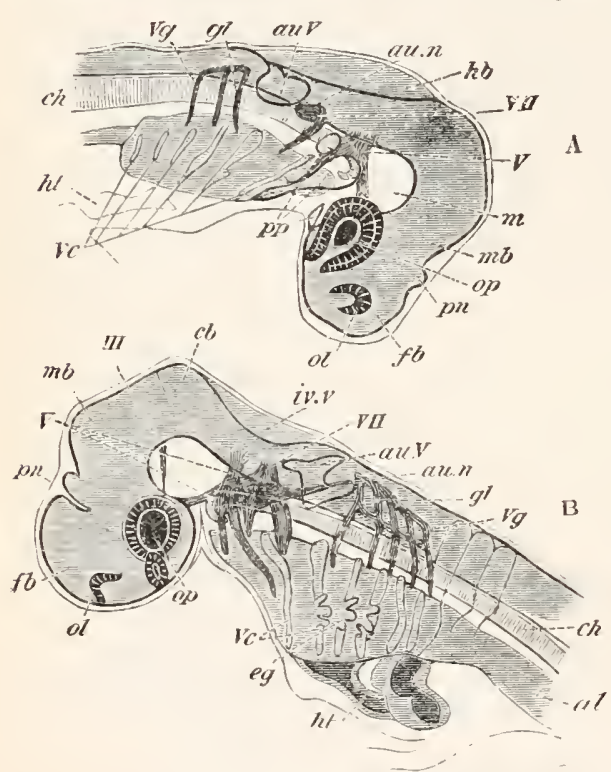

Fig. 196. The heads of Elasmobraxch emBRYOS AT TWO STAGES VIEWED AS TRANSPARENT OBJECTS.

A. Pristiurus embryo of the same stage as fig. 28 F. B. Somewhat older Scyllium embryo.

III. third nerve; $I$. fifth nerve; III. seventh nerve; $u u_{. n}$. auditory nerve; $g l$. glossopharyngeal nerve; $\mathrm{I} g$. vagus nerve; $f b$. fore-brain; $m$. pineal gland; $m b$. mid-brain: $h$ \% hind-brain ; $i v \cdot v$. fourth ventricle; $c b$. cerebellum; ol. olfactory pit; op. eye; $a u . l$. auditory vesicle; $m$. mesoblast at base of brain; $c h$. notochord; $h t$. heart; $T^{\prime}$. risceral clefts; e $g$. external gills; $p p$. sections of bodycavity in the head. pari passu with the evolution of the jaws ${ }^{\text {. }}$.

\section{The cranial flexure and the form of the head in vertebrate embryos.} All emhryologists who liave studied the embryos of the various verteliate groups have been struck with the remarkable similarity which exists between them, more especially as concerns the form of the head. This similarity is closest between the members of the Amniota, but there is also a very narked resemblance between the Amniota and the Elasmobranchii. The peculiarity in question, which is characteristically shewn in fig. 196 , consists in the cerebral henispheres and thalamencephalon being ventrally flexed to such an extent that the midbrain forms the termination of the long axis of the body. At a later period in development the cerebral hemispheres come to be placed at the front end of the head; but the original nick or bend of the floor of the hrain is never got rid of.

It is obvious that in dealing with the light thrown

I I do not mean to exclude the possibility of the mandibular arch having supported a suctorial mouth before it became converted into a pair of jaws. 
by embryology on the ancestral form of the Chordata the significance of this peculiar character of the head of many vertebrate embryos must be discussed. Is the constancy of this claracter to be explained by supposing that at one period vertebrate ancestors had a head with the same features as the embryonic head of existing Vertebrata?

This is the most obvious explanation, but it does not at the same time appear to me satisfactory. In the first place the month is so situated at the time of the maximum cranial flexure that it could harlly lave been functional; so that it is almost impossible to believe that an animal with a head such as that of these embryos can have existed.

Then again, this type of embryonic head is especially characteristic of the Ammiota, all of which are developed in the egg. It is not generally so marked in the Ichthyopsida. In Amphibia, Teleostei, Ganoidse and Petromyzontidre, the head never completely acquires the peculiar characteristic form of the head of the Amniota, and all these forms are hatched at a relatively much earlier phase of development, so that they are leading a free existence at a stage when the embryos of the Amniota are not yet hatched. The only Ichthyopsidan type with a head like that of the Amniota is the Elasmobranchii, and the Elasmobranchii are the only Ichthyopsida which undergo the major part of their development within the exgs.

These considerations appear to shew that the peculiar characters of the embryonic head above alluded to are in some way connected with an embryonic as opposed to a larval development; and for reasons which are explained in the section on larval forms, it is probable that a larval development is a more faithful record of ancestral history than an embryonic development. The flexure at the base of the brain appears however to be a typical rertebrate claracter, but this flexure never led to a conformation of the head in the adult state similar to that of the embryos of the Amniota. The form of the head in these embryos is probably to be explained by supposing that some advantage is gained hy a relatively early development of the brain, which appears to be its proximate canse; and since these embryos had not to lead a free existence (for which such a form of the head would have been unsuiterl) there was nothing to interfere with the action of natural selection in bringing about this form of hearl during fœetal life.

\section{Post-anal gut and neurenteric canal.} One of the most remarkable structures in the trunk is the postanal gut (fig. 197). Its structure is fully dealt with in the chapter on thealimentary tract,but attention may here be called to the light which it appears to throw on the characters of theancestor of the Chordata.

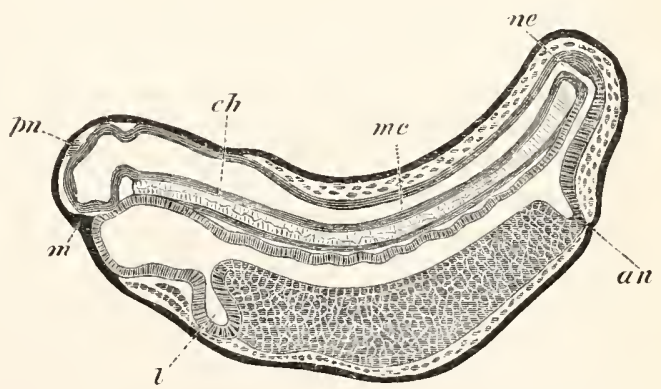

Fig. 197. Longitudinal SECtion throvgir aN AD" VANCED EMBRYo of Bombinator. (After Götte.)

$m$. mouth; an. anus; l. liver; ne. neurenteric canal; mc. medullary canal; $c h$. notochord; $p n$. pineal gland. 
In face of the facts which are known with reference to the post-anal section of the alimentary tract, it can hardly be doubted that this portion of the alimentary tract must have been at one time functional. This seems to me to be shewn (1) by the constancy and persistence of this obviously now functionless rudiment, (2) by its greater development in the lower than in the higher forms, (3) by its relation to the formation of the notochord and subnotochordal rod.

If the above position be admitted, it is not permissible to shirk the conchusions which seem necessarily to follow, however great the difficulties may be which are involved in their acceptance. These conclusious have in part already been dealt with by Dohrn in his suggestive tract $\left(N_{0} .250\right)$. In the first place the alimentary canal must prinitively have been continued to the end of the tail; and if so, it is lardly credible that the existing anus can have been the original one. Although, therefore, it is far from easy, on the physiological principles involved in the Darwinian theory, to understand the formation of a new anus ${ }^{1}$; it is nevertheless necessary to believe that the present vertebrate anus is a formation acquired within the group of the Chordata, and not inherited from some older group. This involves a series of further consequences. The opening of the urinogenital ducts into the cloaca must also be secondary, and it is probable that the segmental tubes were primitively continued along the whole post-anal region of the vertebrate tail, opening into the body-cavity which embryology proves to have been originally present there. They are in fact continued in many existing forms for some distance behind the present anus. If the present anus is secondary, there must have been a primitive anus, which was probably situated behind the post-anal vesicle; and therefore in the region of the netrrenteric canal. The neurenteric canal is, however, the remnant of the blastopore (vide p. 230). It follows, therefore, that the vertebrate blastopore is probably almost, if not exactly identical in position with the primitive anus. This consideration may assist in explaining the remarkable phenomenon of the existence of the neurenteric canal. The attempt has already been made to shew that the central canal of the nervous system is really a groove converted into a tube and lined by the external epidermis. This tube (as may be concluded from embryological considerations) was probably at first open posteriorly, and no doubt terminated at the primitive anus. On the closure of the primitive anal opening, the terminal portions of the post-anal gut and the neural tube, may conreivably have been so placed that both of them opened into a common cavity, which previously had communication with the exterior by the anus. Such an arrangement would necessarly result in the formation of a neurenteric canal. It seems not impossible that a dilated vesicle, often present at the end of the

1 Dohrn (No. 250, p. 25) gives an explanation of the origin of the new anus which does not apjear to me quite satisfactory. 
post-anal gut (vide fig. 28*, p. 48), may have been the common cavity into which both neural and alimentary tubes opened'. Till further light is thrown by fresh discoveries upon the primitive condition of the posterior continuation of the vertebrate alimentary tract, it is perhaps fruitless to attempt to work out more in detail the above speculation.

Body-cavity and mesoblastic somites. The Chordata, or at least the most primitive existing members of the group, are characterized by the faet that the body-cavity arises as a pair of outgrowths of the archenteric cavity. This feature ${ }^{2}$ in the development is a nearly certain indication that the Chordata are a very primitive stock. The most remarkable point with reference to the development of the two outgrowths is, howerer, the fact that the dorsal part of each outgrowth becomes separated from the ventral. Its walls becone segmented and form the mesoblastic somites, which eventually, on the obliteration of their cavity, give rise to the muscle-plates and to the tissue surrounding the notochord. It is not easy to understand the full significance of the processes concerned in the formation of the mesoblastic somites (vide p. 246 ). The mesoblastic somites have no doubt a striking resemblance to the mesoblastic somites of the Chrtopods, and most probably the segmentation of the mesoblast in the two groups is a phenomenon of the same nature; but the difference in origin letween the two types of mesoblastic somites is so striking, and the development of the muscular system from them is so dissimilar in the two groups, as to render a direct descent of the Chordata from the Chatopoda very improbable. The ventral parts of the original outgrow th give rise to the permanent body-cavity, which appears originally to have been divided into two parts by a dorsal and a ventral mesentery.

The notochord. The most characteristic organ of the Chordata is without doubt the notochord. The ontogenetic development of this organ probably indicates that it arose as a differentiation of the dorsal wall of the archenteron; at the same time it is not perhaps safe to lay too much stress upon its mode of development. Embryological and anatomical evidence demonstrate, however, in the clearest manner that the early Chordata were provided with this organ as their sole axial skeleton; and no invertebrate group can fairly be regarded as genetically related to the Chordata till it ean be shewn to possess some organ either derived from a notochord, or capable of having

1 As pointed out in Vol. I. p. 211, there is a striking similarity between the history of the neurenteric canal in Vertebrates, and the history of the blastopore and rentral groove as described by Kowalevsky in the larva of Chiton. Mr A. Sedgrick has pointed out to me that the ciliated rentral groove in Protoneomenia, which contains the anus, is mobably the homologue of the groove found in the larva of Chiton, and not, as nsualiy supposed, simply the foot. Were this groove to be converted into a canal, on the sides of which were placed the nervous cords, there would be formed a precisely similar nemrenteric canal to that in Vertebrata, though I do not mean to suggest that there is any homology between the two (vide Hubecht, Zool. Anzeiger, 1850, P. 589).

I File the chapter on the Germinal Iayers. 
become developed into a notochord. No stlch organ has as yet beeu reeognized in any invertebrate group ${ }^{1}$.

Gill-clefts. The gill-clefts, which are essentially pouches of the throat opening externally, constitute extremely characteristic organs of the Chordata, and have always been taken into consideration in any comparison between the Chordata and the Invertebrata.

Amongst the Invertebrata organs of undoubtedly the same nature are, so far as I know, only found in Balanoglossus, where they were discovered by Kowalevsky. The resemblance in this case is very striking; but althongh it is quite possible that the gill-clefts in Balanoglossus are genetically connected with those of the Chordata, yet the organization of Balanoglossus is as a whole so different from that of the Chordata that no comparison can be instituted between the two groups in the present state of our knowledge.

Other organs of the Invertebrata lave some resemblance to the gill-clefts. The lateral pits of the Nemertines, which appear to grow out as a pair of assophageal diverticula, which are eventually placed in communication with the exterior by a pair of ciliated canals (vide Vol. I. 11. 164 and 166), are such organs.

S'mper (No. 256) has made the interesting discovery that in the budding of Nais and Chretugaster two lateral masses of cells, in each of which a lumen may be formed, unite with the oral invagination and primitive alimentary canal to form the permanent cephalic gut. The lateral masses of cells are regarded by lim as branchial passages lomologons in sone way with those in the Chordata. The somewhat scanty ohservations on this sulject which he has recorded do not appear to me to lend much support to this interpretation.

It is probable that the part of the alimentary tract in which gill-clefts are present was originally in simple unperforated tube provided with highly vascular walls; and that respiration was carried on in it by the alternate introduction and expulsion of sea water. A more or less similar mode of respiration has been recently shewn by Eisigg ${ }^{2}$ to take place in the fore part of the alimentary tract of many Chetopods. This part of the alimentary tract was probalily provicied with paired cacal pouches with their blind ends in contiguity with the skin.

Perforations placing these pouches in communication with the exterior must be supposed to have been formed; and the existence of openings into the alimentaly tract at the end of the tentacles of many A ctinise and of the hepatic diverticula of some nudibranchiate Molluses (Eolis, itc. ${ }^{3}$ ) shews that such perforations may easily he made. On the formation of such perforations the water taken in at the mouth would pass out by them ; and the respiration would be localized in the walls of the pouches leading to

1 In the Chatopods various organs have been interpreted as rudiments of a notochord, but none of these interpretations will be ar examination.

" "Ueb. d. Vorkommen eines scinwimmblasenibnlichen Orgaus bei Anmeliden." Iittheil. a. d. zool. Station zu Nerpel, Vol. Ir. 1881.

3 The openiugs of the hepatic diverticula through the sacks linel with thread cells are descibed by Hancock and Embleton, Anu. and Mu! of Nat. History, Vol. xv. 1845, p. 82. Ton Jhering has also recently cescribed these openings (Zool. Anzeiger", No. 23) and apparently attributes their discovery to himselt. 
them, and thus the typical mode of respiration of the Chordata would be estalblished.

Phylogeny of the Chordata. It may be convenient to slew in a definite way the bearing of the above speculations on the phylogeny of the Chordata. For this purpose, I lave drawn up the subjoined table, which exhibits what I believe to be the relationships of the existing gromps of the Chordatia. Such a table camot of course be constructed from embryological data alone, and it does not fall within the scope of this work to defend its parts in detail.

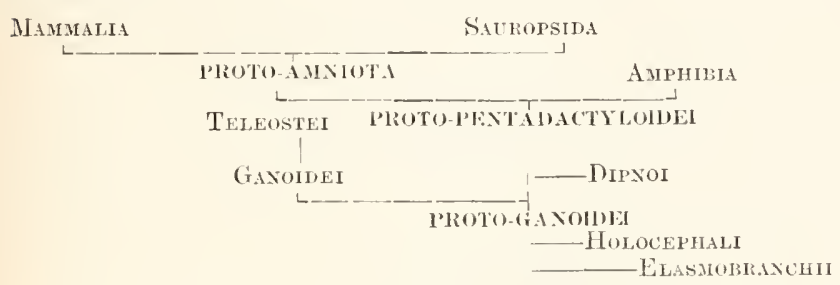

P'RUTU-(IXNTHOSTUMATA

Cyclostomiate PROTO-VIRTEBHATA

\begin{tabular}{|c|c|}
\hline$\Gamma-$ & \\
\hline
\end{tabular}

In the above table the names printed in large capitals are hypothetical groups. The other groups are all in existence at the present day, but those printed in Italics are probably degenerate.

The ancestral forms of the Chordata, which may be called the Protochordata, must be supposed to have had (1) a uotochord as their sole axial skeleton, (2) a ventral mouth, surrounded by suctorial structures, and (:3) very nmmerous gill-slits. Two degenerate iffshomts of this stock still persist in Amphioxus (Cephalochorda), and the Ascidians (Urochorda).

The direct descendants of the ancestral Chodata, were probably a group which may be called the Proto-vertebrata, of which there is no persisting representative. In this group, imperfect neural arches were probably present; and a ventral suctorial month without a maudible and maxillix was still persistent. The branchial clefts had, however, become reduced in number, and were provided with gill-folds; and a secondary head (vide p. -260), with brain and organs of sense like those of the higher Vertebrata, had become formed.

The Cyclostomata are probably a degenerate offshoot of this group.

With the development of the branchial bars, and the conversion of the mandibular bar into the slicleton of the jaws, we cone to the Protognathostomata. The nearest living representatives of this group are the Elasmobranchii, which still reain in the adult state the rentrally 
placed mouth. Owing to the development of food-yolk in the Elasmobranch ovum the early stages of development are to some extent abbreviated, and almost all trace of a stage with a suctorial mouth has become lost.

We next come to an hypothetical group which we may call the Proto-ganoidei. Bridge, in his Memoir on Polyodon ${ }^{1}$, which contains some very interesting speculations on the affinities of the Ganoids, has called this group the Pneumatocela, from the fact that we find for the first time a full development of the air-bladder, though it is possible that a rudiment of this organ, in the form of a pouch opening on the dorsal side of the stomachic extremity of the oesophagus, was present in the earlier type.

Existing Ganoids are descendants of the Proto-ganoidei. Some of them at all events retain in larval life the suctorial mouth of the Proto-vertebrata; and the mode of formation of their germinal layers, resembling as it does that in the Lamprey and the Amphibia, probably indicates that they are not lescended from forms with a large foodyolk like that of Elasmobranchii, and that the latter group is therefore a lateral offshoot from the main line of descent.

Of the two groups into which the Ganoidei may be divided it is clear that certain members of the one (Teleostoidei), viz. Lepidosteus and Amia, shew approximations to the Teleostei, which no doult originated from the Ganoids; while the other (Selachoidei or Sturiones) is more nearly related to the Dipnoi. Polypterus las also marked affinities in this direction, e.g. the external gills of the larva (vide p. 98).

The Teleostei, which have in common a meroblastic segmentation, had probably a Ganoid ancestor, the ova of which were provided with a large amount of food-yolk. In most existing Teleostei, the ovum has become again reduced in size, but the meroblastic segmentation has been preserved. It is quite possible that Amia may also be a descendant of the Ganoil ancestor of the Teleostei; but Lepidosteus, as shewn by its complete segmentation, is clearly not so.

The Dipnoi as well as all the higher Vertebrata are descendants of the Proto-ganoidei.

The character of the limbs of higher Vertebrata indicates that there was an ancestral group, which may be called the Proto-pentadactyloidei, in which the pentadactyle limb became established; and that to this group the common ancestor of the Amphibia and Amniota belonged.

It is possible that the Plesiosauri and Ichthyosauri of Mesozoic times nay have been more nearly related to this group than either to the Amniota or the Antphibia. The Proto-pentarlactyloirlei were probably much more closely related to the Amphibia than to the Amniota. They certainly must have been capable of living in water as well as on land, and had of course persistent branchial clefts. 
It is also fairly certain that they were not provided with large-yolked ova, otherwise the mole of formation of the layers in Amphibia could not be easily explained.

The Mammalia and Sauropsida are probably independent offshoots from a common stem which may be called the Proto-amniota.

\section{Bibltography.}

(249) F. M. Balfour. A Monograph on the development of Eilasmobranch Fishes, London, 1878.

(250) A. Dohrn. Der Ursprung d. Nirbelthiere und d. I'rincip. d. Functionswechsel. Leipzig, 1875.

(25工) E. Haeckel. Schöptungsgeschichte. Leipzig. Tide also Translation. The Ilistory of Creation. King and Co., London. 1876.

$(2,52)$ F. Haeckel. Anthopoyenie. Leipzig. Tide also Translation. Anthropogeny. Kegan Paul and Co., Jondon, 1878.

$(253)$ A. Kowalevsky. "Entwicklungsgeschichte d. Amphioxus lanceolatus." Mém. Arad. d. Scien. St Pétersbourg, Ser. VII. Tom. xi. 1867, and drehiv f. mikr. Anat., Vol. xili. 1877.

$(2,+4)$ A. Kowalevsky. "Weitere Stud. iib. d. Fntwick. d. einfachen Ascidien." Archinf. mikr. Anat., Tol. vil. 1871.

$\left.(25)^{\circ}\right)$ C. Semper. "Die Stammesverwand schaft ג. Wirbelthiere u. Wirbellosen." Arbeit. a. d. zool.-zoot. Instit. Niirzhurg, Vol. Ir. 1875.

(256) C. Semper. "Die Verwandschaltbeziehungen d. gegliederten Thiere." Arbeit. a. d. zool.zoot. Instit. I1 iirzbury, Vol. III. 1876-1877. 


\title{
CHAP'TER XIII.
}

\author{
GENERAL CONCLUSIONS.
}

\section{THE MODE OF ORIGLN AND HONOLOGES OF THE GERMINAL, LAYERS.}

IT has already been shewn in the earlier chapters of the work that during the first phases of development the history of all the Metazoa is the same. They all originate from the coalescence of two cells, the ovum and spermatozoon. The coalesced product of these cells - the fertilized ovum-then undergoes a process known as the segmentation, in the course of which it becomes divided in typical cases into a number of uniform cells. An attempt was made from the point of view of evolution to explain these processes. The ovim and spermatozoon were regarded as representing phylogenetically two physiolugically differentiated forms of a Protozoon; their coalescence was equivalent to conjugation : the subsequent segmentation of the fertilized ovum was the multiplication by division of the organism resulting from the conjugation ; the resulting organisms, remaining, however, united to form a fresh organism in a higher state of aggregation.

In the systematic section of this work the embryological history of the Metazoa has been treated. The present chapter contains a review of the cardinal features of the various histories, together with an attempt to determine how far there are any points common to the whole of these histories; and the phylogenetic interpretation to be given to such points.

Some years ago it appeared probable that a definite answer wonkl be given to the questions which must necessarily be raised in the present chapter; but the results of the extended investigations made during the last few years have shewn that these expectations were premature, and in spite of the numerous recent valuable contributions to this branch of Embryology, amongst which special attention may be called to those of Kowalevsky (No. 277), Lankester (Nos. 27S and 279), and Haeckel (No. 266), there are few embryologists 
who would venture to assert that any answers which can be given are more than tentative gropings towards the truth.

In the following pages I aim more at summarising the facts, and critically examining the different theories which can be held, than at dogmatically supporting any definite views of my own.

In all the Metazoa, the development of which lias been investigated, the first process of differentiation, which follows upon the segmentation, consists in the cells of the organism becoming divided into two groups or layers, known respectively as epiblast and hypoblast.

These two lavers were first discovered in the voung enbryos of vertel,rated animals by Pander and Von Baer, and have been since known as the germinal layers, though their cellular nature was not at first recognised. They were shewn, together with a third layer, or mesollast, which subsequently appears between them, to bear throughont the Vertebrata constant relations to the organs which beeame developed from them. A very great step was sulseguently made by Remak (No. 287), who successfully worked out the problem of rertebrate embryology wh the cellular theory.

Rathke in his memoir on the development of Astacus (No. 286) attempted at a very early period to extend the doctrine of the derivation of the organs from the germinal layers to the Invertebrata. In 1859 Huxley made an important step towards the explanation of the nature of these layers by comparing them with the ectoderm and endoderm of the Hydrozoa; while the brilliant researches of Kowaless a great variety of invertebrate forms formed the starting point of the current views on this sulject.

The differentiation of the epiblast and hypoblast may commence during the later phases of the segmentation, but is generally not completed till after its termination. Not only do the cells of the blastoderm become differentiated into two layers, but these two layers, in the case of a very large number of ova with but little foodyolk, constitute a double- walled sack - the gastrulia (fig. 198) - the characters of which are too well known to require further description. Following the lines of phylogenetic speculation above indicated, it may be concluded that the two-layered condition of the organism represents in a general way the passage from the protozoon to the metazoon coudition. It is probable that we may safely go further, and assert that the gastrula reproduces, with more or less fidelity, a stage in the evolution of the Netazoa, permanent in the simpler Hydrozoa, during which the organism was provided with (1) a fully developed digestive cavity

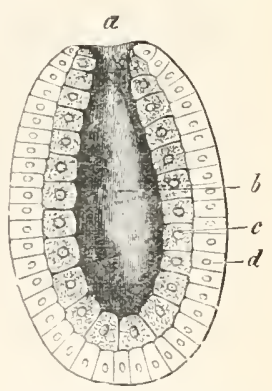

Fig. 198. Diagrair of a Gastrula. (From Gegenbaur.)

a. mouth; b. ar. chenteron; c. hypoblast; $d$. epiblast. (fig. 198 b) lined by the hypoblast with digestive and assimilative functions, (2) an oral opening (1), and (3) a super- 
ficial epiblast $(d)$. These generalisations, which are now widely accepted, are no dumbt very valuable, but they leave unanswered the following important questions :

(1) By what steps did the compound Protozoon become differentiated into a Metazoon?

(2) Are there any grounds for thinking that there is more than one line along which the Metazoa have become independently evolved from the Protuzoa?

(3) 'To what extent is there a eomplete homology between the two primary germinal layers throughout the Metazoa?

Ontogenetically there is a great variety of processes by which the passage from the segmented ovum to the two-layered or diploblastic condition is arrived at.

These processes may be grouperl under the following heads:

1. Invagination. Under this term a considerable number of closely comnected processes are included. When the segmentation results in the formation of a blastospliere, one half of the blastosphere may be pushed in towards the opposite balf, and a gastrula be thus producer (fig. 199, A and B). This process is known as embolic

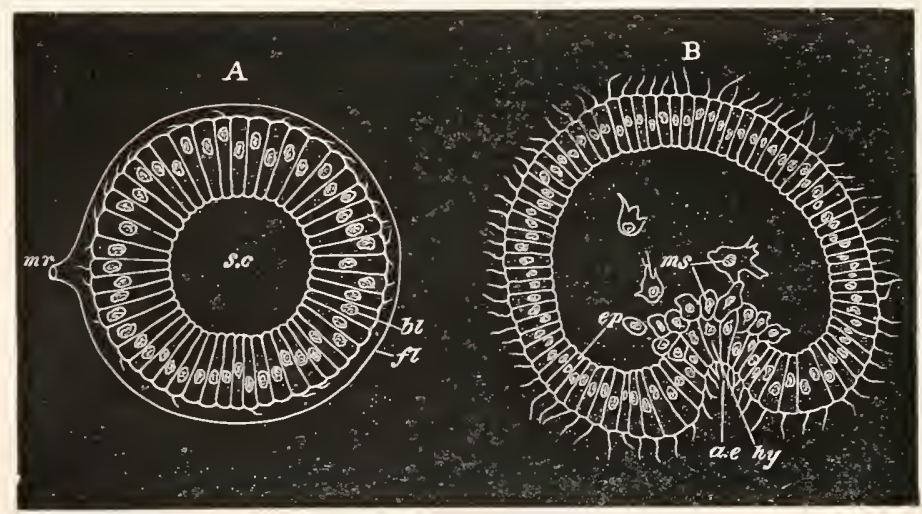

Fig. 199. 'Two stages in the DeVelopment of Holothuria tubulosa, viewei IN optical section. (After Selenka.)

A. Stage at the close of the segmentation. B. Gastrula stage.

$m r$. micropyle ; $t$. chorion; s.c. segmentation cavity; bl. blastoderm; $e p$. epi. blast; hy. hypoblast; ms. amoboid cells derived from hypoblast; a.e. archenteron.

invagination. Another process, known as epibolic invagination, consists in epiblast cells growing round and enclosing the hypoblast (fig. 200). This process replaces the former process when the hypoblast cells are so bulky from being distended by food-yolk that their invagination is mechanically impossible.

There are various peculiar molitications of invagination which camnot be dealt with in letail. 
Invagination in one form or other oceurs in some or all the members of the following groups :

The Dicyemidæ, Calcispongize (after the amphiblastula stage) and Silicispongixe, Coelenterata, Turbellaria, Nemertea, Rotifera, Mollusca, Polyzoa, Brachiopoda, Chætopoda, Discophora, Gephyrea, Cliatognatha, Nematehminthes, Crustacea, Echinodermata, ancl Chordata.

The gastrula of the Crustacca is peculiar, as is also that of many of the Chordata (Reptilia, Aves, Mammalia), but there is every reason to suppose that the gastrulæe of these groups are simply modifications of the normal type.

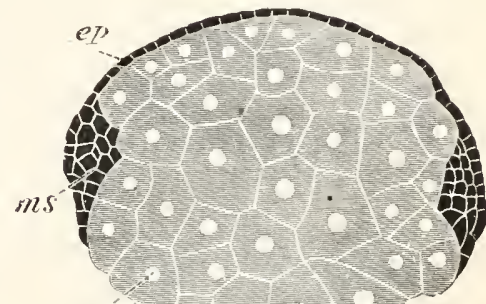

$7 y$.

F1g. 200. Transverse section THROUGH THE OVUM OF EUAXFS DURING AN EARLY STAGE OF DEVELOPMENT, TO SHEW THE NATURE OF EPIBOLIC INVAGINATIov. (After Kowalevsky.)

e). epiblast; ms. mesoblastic band; hy. hypoblast.

2. Delamination. Three types of delamination may be distinguished:

a. Delamination where the cells of a solid morula become divided into a superficial epiblast, and a central solid mass in which the digestive cavity is subsequently hollowed out (fig. 201).

b. Delamination where the segmented ovum has the form of a blastosphere, the cells of which give rise by budding to scattered cells in the interior of the vesicle, which, though they may at first form a solid mass, finally arrange themselves in the form of a definite layer around a central digestive cavity (fig. 202).

c. Delamination where the segmented ovum has the form of a blastosphere in the cells of which the protoplasm is differentiated into an inner and an outer part. By a subsequent process the inner parts of the cells become separated from the outer, and

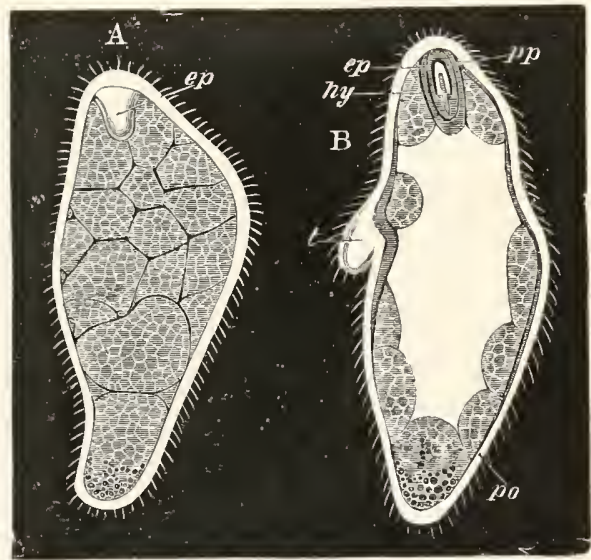

Fig. 201. Two stages in the development

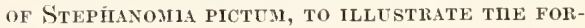
MATION OF THE LAYERS BY DELAMINATION. (After Metschnikoff.)

A. Stage after the delamination; ep. epiblastic invagination to form pneumatocyst.

B. Later stage after the formation of the gastric cavity in the solid hypoblast. po. polypite; $t$. tentacle; $p p$. pnemmatocyst; $e p$. epiblast of pneumatocyst; hy. hypoblast surrounding pneumatocyst. 
the walls of the blastosphere are so divided into two distinct layers (fig. 205).

Although the thind of these processes is usually regarded as the type of delamination, it does not, so far as I know, occur in nature, but is most nearly approached in Geryonia (fig. 20:3).

The first type of delanimation is found in the Ceratospongix, some Silicispongice (?), and in many Hydrozoa and Actinozoa, and in Nemertea and Nematelminthes (Gordiondea?). The second type occurs in many Porifera [Calcispongice (Ascetta), Myxospongice], and in some Coelenterata, and Brachiopoda (Thecidium).

Delanination and invagination are undoubtedly the two most
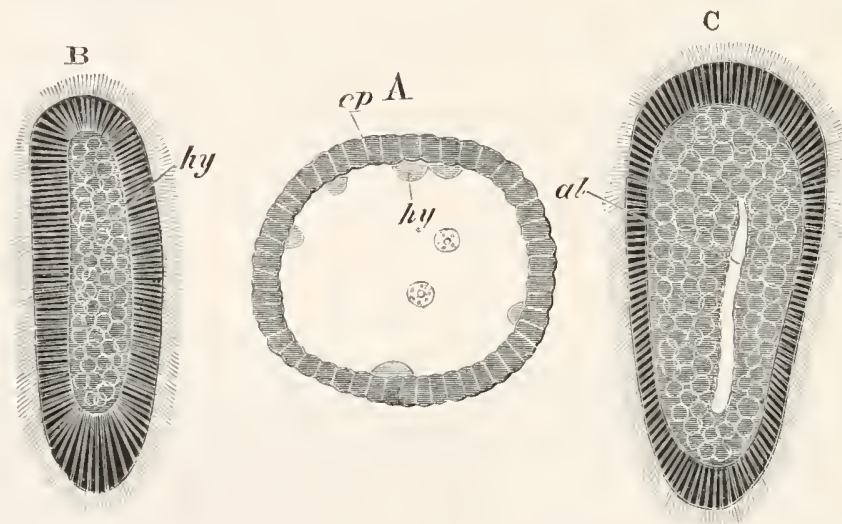

Fig. 202. 'Three lakval stages of Eucope polystrla. (After lowalevsky.)

A. Blastosphere stage with hypoblast spheres becoming budded off into central cavity. B. Plannla stage with solid hypoblast. C. Planula stage with a gastric cavity. ep. epiblast; hy. hypoblast; al. gastric eavity.

frequent modes in which the layers are differentiated, but there are in addition several others. In the first place the whole of the Tracheata (with the apparent exception of the Scorpion) develop, so far as is known, on a plan peculiar to them, which approaches delannination. This consists in the appearance of a superficial layer of cells enclosing a central yolk nilass, which corresponds to the hypoblast (figs. 204 and 214). This mode of development might be classed under delamination, were it not for the fact that the early development of many Crustacea is almost the same, but is subsequently followed by an invagination (fig. 208), which apparently corresponds to the normal invagination of other types. There are strong grounds for thinking that the tracheate type of formation of the epiblast and hypoblast is a secondury modification of an invaginate type (vide Vol. I. p. 378).

The type of some Turbellaria (Styluchopsis ponticus) and that of Nephelis amongst the Discophora is not capable of being rednced to the invaginate type. 
The development of almost all the parasitic groups, i.e. the Trematoda, the Cestoda, the Acanthocephala, and the Linguatulida, and also

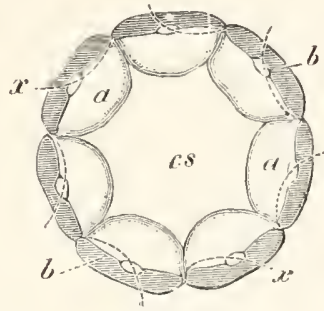

A.

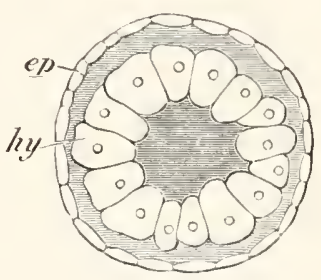

B.

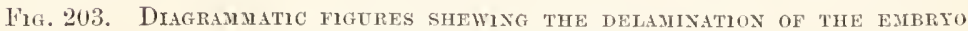
of Gerionia. (After Fol.)

A. Stage at the commencement of the delamination; the dotted lines $x$ shew the course of the next planes of division. 13. Stage at the close of the delamination.

$c s$. segmentation carity; $a$. endoplasm; $b$. ectoplasm; ep. epiblast; hy. hypoblast.

of the Tardigrada, Pycnogonida, and other minor groups, is too imperfectly known to be classed with either the delaminate or invaginate types.

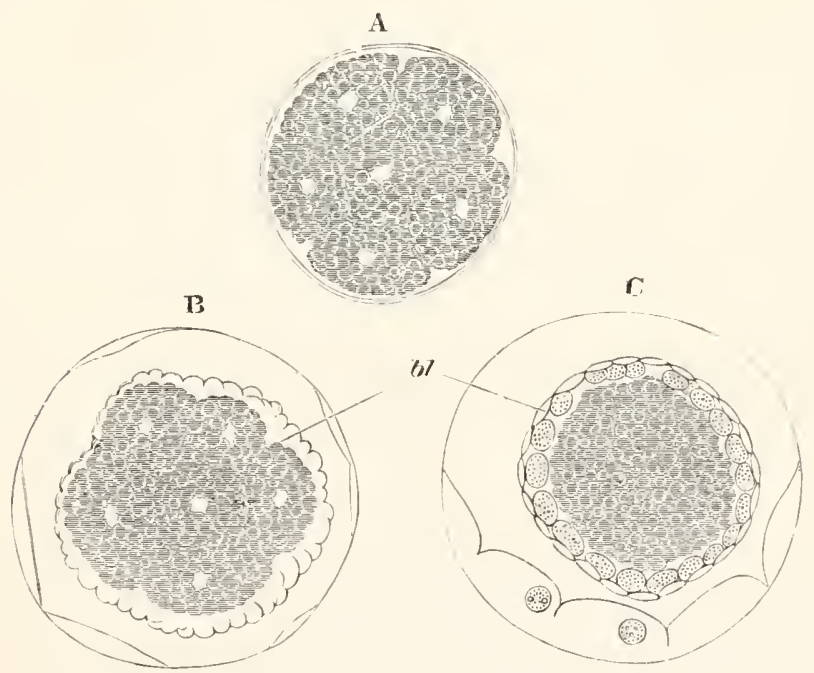

Hig. 204. Segmentation and formation of the BLAstoderm ix Chelifer. (After Metschnikoff.)

In A the ovum is divided into a number of separate segments. In $\mathrm{B}$ a number of small cells have appeared $(b l)$ which form a blastoderm enveloping the large yolkspheres. In $\mathrm{C}$ the blastoderm has become divided into two layers. 
It will, I think, be conceded on all sides that, if any of the ontogenetic processes by which a gastrula form is reached are repetitions of the process by which a simple two-layered gastrula was actually evolved from a compound Protozoon, these processes are most probably of the nature either of invagination or of delamination.

The much disputed questions which have been raised about the gastrula and planula theories, originally put forward by Haeckel and Lankester, resolve themselves then into the simple question, whether any, and if so which, of the ontogenetic processes by which the gastrula is formed are repetitions of the phylogenetic origin of the gastrula.

It is very difficult to bring forward arguments of a conclusive kiud in favour of either of these processes. The fact that delaminate and invaginate gastrulw are in several instances found coexisting in the same group renders it certain that there are not two independent pliyla of the Metazoa, derived respectively from an invaginate and a delaminate gastrula ${ }^{1}$.

'The four most important cases in which the two processes coexist are the Porifera, the Coelenterata, the Nemertea, and the Brachiopoda. In the cases of the Porifera and Cotenterata, there do not appenr to me to be any means of deciding which of these processes is derived from the other; but in the Nemertea and the Brachiopoda the case is different. In all the types of Nemertea in which the development is relatively not abbreviated there is an invaginate gastrula, while in the types with a greatly abbreviated development there is a delaminate gastrula. It would seem to follow from this that a delaminate gastrula las here been a secondary result of an abbreviation in the development. In the Brachiopoda, again, the majority of types develop by a process of invagination, while Thecidiun appears to develop by delamination; here also the delaminate type would appear to be secondarily derived from the invaginate.

If these considerations are justified, delamination must be in sone instances secondarily derived from invagination; and this fact is so far an argument in favour of the more primitive nature of invagination; though it by no means follows that in the invaginate process the steps by which the Metazoa were derived from the Protozoa are preserved.

It does not, therefore, seem possible to decide conclusively in

1 It is not difficult to picture a possible derivation of delamination from invagination; while a comparison of the formation of the inner layers (mesoblast and hypoblast) in Ascetta (amongst the Sponges), and in the Echinodermata, shews a very simple way in which it is possible to conceive of a passage of delamination into invagination. In Ascetta the cells, which give rise to the mesoblast and hypoblast, are budded off from the inner wall of the blastosphere, especially at one point; while in Echinodermata (fig. 199) there is a small invaginated sack which gives rise to the hypoblast, while from the walls of this sack amoboid cells are budded off which give rise to a large part of the mesoblast. If we suppose the hypoblast cells budded off at one point in Ascetta gradually to form an invaginated sack, while the mesoblast cells continued to be budded off as before, we should pass from the delaminate type of Ascetta to the invaginate type of an Echinoderm. 
favour of either of these processes by a comparison of the cases where they ocem in the sime groups.

The relative frequency of the two processes supplies us with another possible means for deciling between them; and there is no doubt that here again the scale inclines towards invagination. It must, however, be bone in mind that the fiequency of the process of invagination almits of another possible explanation. 'There is a contimual tendency for the processes of development to be abbreviated and simplified, and it is quite possible that the frequent occurence of invagination is lue to the fact of its being, in most cases, the simplest means by which the two-layered condition can be reached. But this argument can have but little weight until it can be shewn in each case that invagination is a simpler process than delannination; and it is rendered improbable by the cases already mentioned in which delamination has been secondarily derived from invagination.

If it were the case that the blastopore had in all types the same relation to the adult mouth, there would be strong grounds for regarding the invaginate gastrula as an ancestral form; but the fact that this is by no means so is an argument of great weight in favour of some other explanation of the frequency of invagination.

The force of this consideration can best be displayed by a short simmmary of the fate of the blastopore in different forms.

The fate of the blastopore is so variable that it is difficult even to classify the cases which have been described.

(1) It becomes the permanent mouth in the following forms ${ }^{1}$ : Colenteristu.-Pelagia, Cereantluus.

Turbellaria.-Leptoplana (?), Thrsanozoon.

Nemertea.-Pilitium, larva of the type ot Desor.

Mollusca. In numerous examples of most Mollusean groups, except the Cephalopoda.

Chetopoda.-Most Oligochæta, and probably many Polychata.

Gepluyrer.-Pluascolosoma, Phoronis.

Nemritelminthes._Cucullanus.

(2) It closes in the position where the mouth is subsequently formed. Corlenteruta.-Ctenophora (?).

Molluscu. - In numerous examples of most Mollusean groups, except the Cephalopoda.

Crustucea.-Cirripedia (?), some Cladocera (Moina) (?).

(3) It becomes the permanent anus.

Mollusca.-Paludiua.

Chotopodu.- Serpula and some other types.

Echinodermata.-Almost universally, except amongst the Crinoidea.

(4) It closes in the position where the anus is subsequently formed. Echinodermata.-Crinoidea.

(5) It closes in a position which does not correspond or is not known to correspond ${ }^{2}$ either with the future mouth or anus.-Porfera-Sycandia. Corlenterata-Chrysaora*, Anrelia*. Nemertea ${ }^{*}$-Some larva which develop without

1 The above list is somewhat tentatire; and future investigations will probably shew that many of the statements at present current about the position of the blastopore are inaccurate.

2 The forms in which the position of the blastopore in relation to the month or anus is not known arc marked with an asterisk. 
a metamorphosis. Rotifere* ${ }^{*}$ Mollusca-Cephalopoda. Polyzod* Brachiopoda-Argiope, Terebratula, Terebratulina. Chotopoda-Euaxes. Discophora -Clepsine. Gephyrea-Bone!lia*. Chotognatha. Crustacea-Decapoda. Chordata.

The forms which have been classed together under the last heading vary considerably in the character of the blastopore. In some cases the fact of its not coinciding either with the mouth or anus appears to be due simply to the presence of a large amount of foodyolk. The cases of the Ceplialopoda, of Euaxes, and perhaps of Clepsine and Bonellia, are to be explained in this way: in the case of all these forms, except Bonellia, the blastopore has the form of an elongated slit along the ventral surface. This type of blastopore is characteristic of the Mollusca generally, of the Polyzoa, of the Nematelminthes, and very possibly of the Chrtopoda and Discophora. In the Chretognatha (fig. 209 13) the blastopore is situated, so far as can be determined, behind the future anus. In many Decapoda the blastopore is placed behind, but not far from, the anus. In the Chordata it is also placed posteriorly to the anus, and, remarkably enough, remains, in a large number of forms, for some time in connection with the neural tube by a neurenteric canal.

The great variations in the character of the gastrula, indicated in the above summary, go far to shew that if the gastrulx, as we find them in most types, have any ancestral characters, these characters can only be of the most general kind. This may best be shewn by the consideration of a few striking instances. The blastopore in Mollusca lias an elongated slit-like form, extending along the ventral surface from the mouth to the ants. In Echinodermata it is a narrow pore, remaining as the anus. In most Chetopoda it is a pore remaining as the month, but in some as the anus. In Chordata it is a posteriorly-placed pore, opening into both the archenteron and the neural canal.

It is clearly out of the question to explain all these differences as having connection with the characters of ancestral forms. Many of them can only be accounted for as secondary adaptations for the convenience of development.

The epibolic gastrula of Mammalia (vide pp. 178 and 242) is a still more striking case of a secondary enbryonic process, and is not directly derived from the gastrula of the lower Chordata. It probably originated in connection with the loss of food-yolk which took place on the establishment of a placental nutrition for the fotus. The epibolic gastrula of the Scorpion, of Isopods, and of other Arthropoda, seems also to be a derived gastrula. These instances of secondary gastrula are very probably by no means isolated, and should serve as a warning against laying too much stress upon the frequency of the occurrence of invagination. The great influence of the food-volk upon the early development might be illustrated by numerous examples, especially amongst the Chordata (vide Chapter XI.).

If the descendants of a form with a large amount of food-yolk in 
its ova were to prouluce ova with but little fool-yolk, the type of formation of the germinal lavers which would thereby result would be by no means the same as that of the ancestors of the forms with much food-yolk, but would mobably be something very different, as in the case of Mammalia. Yet amongst the comntless generations of ancestors of most existing forms, such oscillations in the amount of the fool-yolk must have occurred in a large number of instances.

The whole of the above considerations point towards the view that the formation of the hypoblast by invagination, as it occurs in most forms at the present day, can have in many instances no special phylogenetic significance, and that the argument from frequency, in favour of invagination as opposed to delamination, is not of prime importance.

A third possible method of deciding between delamination and invagination is to be fonnd in the consideration as to which of these processes occurs in the most primitive forms. If there were any agreement amongst primitive forms as to the type of their development this argunent might have some weight. On the whole, delamination is, no doubt, characteristic of many primitive types, but the not infrequent occurrence of invagination in both the Coelenterata and the Porifera-the two groups which would on all hands be admitted to be amongst the most primitive-deprives this argument of much of the value it might otherwise have.

'T'o sum up-considering the alnost indisputable fitct that both the processes above dealt with have in many instances had a purely secondary origin, no valid arguments can be produced to shew that either of them reproduces the mode of passage between the Protozoa and the ancestral two-layered Metazoa. These conclusions do not, however, throw any doubt upon the fact that the gastrula, however evolved, was a primitive form of the Metazoa; since this conclusion is founded upon the actual existence of adult gastrula forms independently of their occurrence in development.

Though embryology does not at present furnish us with a definite answer to the question how the Metazoa lecame developed fiom the Protozoa, it is nevertheless worth while reviewing some of the processes by which this can be conceived to lawve oceurred.

On purely ì miori grounds there is in my opinion more to be said for invagination than for any other view.

On this view we may suppose that the colony of Protozoa in the course of conversion into Metazoa had the form of a blastospliere; and that at one pole of this a depression appeared. The cells lining this depression we may suppose to have been amoeboid, and to have arried on the work of digestion; while the remaining cells were probably ciliated. The digestion may be supposed to have heen at first carried on in the interior of the cells, as in the Protozoa; but, as the depression became deeper (in order to increase the area of nutritive cells and to retain the food) a digestive secretion probably became poured out from the cells lining it, and the mode of digestion generally characteristic of the Metazoa was thereby 
inaugurated. It may be noted that an intracellular protozoon type of digestion persists in the Porifera, and appears also to oceur in many Celenterata, Turbellaria, dc., though in most of thesc cases both kinds of digestion probably go on simultaneously".

Another hypothetical mode of passage, which fits in with delamination, has been put forward by Lankester, and is illustrated by fig. 205. He supposes that at the blastosphere stage the fluid in the centre of the colony acquired special digestive properties; the inner ends of the cells having at this stage somewhat different properties from the outer, and the food being still incepted hy the surface of the cells (fig. 205, 3). In a later stage of the lrocess the inner portions of the cells became separated off as the hypoblast; while the food, though still ingested in the form of solir particles by the superficial cells, was carricd through the protoplasm into the central digestive cavity. Later (fig. 205, 4), the point where the food entered became localised, and eventually a mouth became formed at this point.

The main oljection which can he raised against Lankester's view is that it presupposes a type of dclamination which does not occur in nature except in Geryonia.

Metschnikoff has propounded a third view with reference to delamination. He starts as before with a ciliated blastosphere. He next supposes the cells from the walls of this to become buclded off into the central
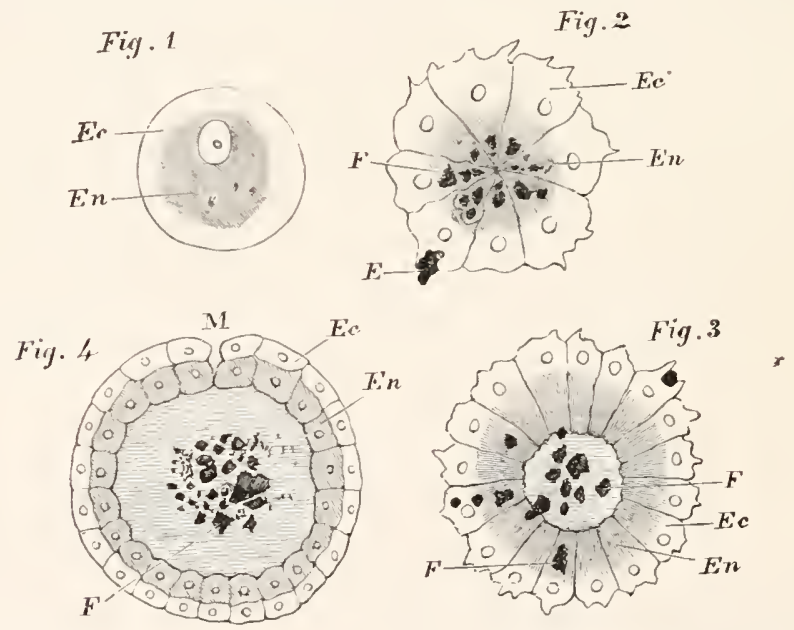

Fig. 205. Diagray shewixg the formation of a Gastrula by delamination. (From Lankester.)

Fig. 1, ovmm; fig. 2, stage in segmentation; fig. 3, commencennent of delamination after the appearance of a central cavity; fig. 4 , delamination completed, mouth form. ing at $M$. In figs. 1,2 , and $3, E c$. is ectoplasm, and $E n$. is endoplasm. In fig. 4, Ec. is epiblast, and Eu, hypoblast. $E$. and $F$. food particles.

I J. Parker, "On the Histology of Hydra fusca," Quart. Journ. Micr. Science, vol. xx. 1880; and El. Metschnikoff, "Ueb. die intracelluläre Verdauung bei Cœelenteraten," Zoologischer Anzeiger, No. 5f, vol. III. 1880 and Lankester, "On the intracellular digestion and endoderm of Limnocodium," Quart. Journ. Nicr. Science, vol. xx1. 1881 . 
cavity, as in Eucope (fig. 202), and to lose their cilia. These cells give rise to an internal parenchyma, which carries on an intracellular digestion. At a later stage a central digestire carity is supposed to be formerl. This view of the passage from the protozoon to the metazoon state, though to my mind improbable in itself, tits in very well with the ontogreny of the lower Hycliozoa.

Another view has been put forward by myself in the chapter on the Porifera', to the effect that the amphiblastula larva of Calcispongia may be a transitional form between the Protozoa and the Metazoa, composed of a hemisphere of nutritive amoboid cells, and a hemisphere of ciliated cells. The absence of such a larval form in the Colenterata and higher Metazoa is opposed, howerer, to this latra being regarded as a transitional form, except for the Porifera.

It is obvious that so long as there is complete uncertainty as to the value to be attached to the early developmental processes, it is not possible to decide from these processes whether there is only a single metazoon phylum or whether there may not be two or more such phyla. At the same time there appear to be strong arguments for regarding the Porifera as a phylum of the Metazoa derived independently from the Protozoa. This seems to me to be shewn (1) by the striking larval peculiarities of the Porifera; (2) by the early development of the mesoblast in the Porifera, which stinds in strong contrast to the absence of this layer in the embryos of most Coelenterata; and above all, (3) by the remarkable characters of the system of digestive chamnels. A further argument in the same direction is supplied by the fact that the germinal layers of the Sponges very probably do not correspond physiologically to the germinal layers of other types. The embryological evidence is insufficient to decide whether the amphiblastula larva is, as suggested above, to be regarded as the larval ancestor of the Porifera.

Homologies of the germinal layers. The question as to how far there is a complete homology between the two primary germinal layers throughout the Metazoa was the third of the questions proposed to be discussed here.

Since there are some Metazoa with only two geminal layers, and other Metazoa with three, and since, as is shewn in the following section, the third layer or mesoblast can only be regarderl as a derivative of one or both the primary layers, it is clear that a complete homology between the two primary germinal layers does not exist.

That there is a general homology appears on the other hand hardly open to doubt.

The primary layers are usually continuous with each other, near one or both (when both are present) the openings of the alimentary tract.

As a rule an oral and anal section of the alimentary tract -the stommlium and proctodidum-are derived fiom the ejiblast; 
but the limits of both these sections are so variable, sometimes even in closely allied forms, that it is difficult to avoid the conclusion that there is a border-land between the epiblast and hypoblast, which appears by its development to belong in some forms to the epiblast and in other forms to the hypoblast. If this is not the case it is necessary to admit that there are instances in which a very large portion of the alimentary canal is phylogenetically an epiblastic structure. In some of the Isopods, for example, the stomodieun and proctodxum give rise to almost the whole of the alimentary canal with its appendages, except the liver.

The origin of the Mesoblast. A diploblastic condition of the organism precerterl, as we have seen, the triploblastic. The epiblast during the diploblastic condition was, as appears from such forms as Hydra, especially the sensory and protective layer, while the hypoblast was the secretory and assimilating layer; both layers giving rise to muscular elements. It must not, however, be supposed that in the early diploblastic ancestor's there was a complete differentiation of function, but there is reason to think that both the primary layers retained an indefinite capacity for developing into any form of tissue". The fact of the triploblastic condition being later than the diploblastic proves in a conclusive way that the mesoblast is a derivative of one or both the primary layers. In the Ccelenterata ive can study the actual origin from the two primary layers of various forms of tissue which in the higher types are derived from the mesoblast ${ }^{2}$. This fact, as well as general it miori considerations, conchusively prove that the mesoblast did not at first originate as a mass of independent cells between the two primary layers, but that in the first instance it gradually arose as differentiations of the two layers, and that its condition in the embryo as an independent layer of undifferentiated cells is a secondary condition, hrought about by the general tendency towards a simplification of development, and a retardation of histological differentiation ${ }^{3}$.

1 The Hertwigs (No. 2;0) have for instanee shewn that nerrous struetures are developed in the hypoblast in the Actinozoa and other Ccelenterata.

2 There is considerable confusion in the use of the names for the embryonie layers. In some eases various tissues formed by differentiations of the primary layers have been called mesoblast. Sehultze, and more recently the Hertwigs, have pointerl out the inconvenience of this nomenelature. In the ease of the Coelenterata it is difficult to decile in certain instances (e. $g$. Sympodium) whether the cells which give rise to a particular tissue of the adult are to be regarded as forming a mesollast, i.e. a middle undifferentiated laver of cells, or whether they arise as already histologically differentiated elements from one of the primary layers. The attempt to distingnish hy a special nomenclature the epiblast and hypoblast after and before the separation of the mesoblast, which has been marle by Allen Thomson (No. I), appears incapable of being consistently applied. though it is convenient to distinguish a primary and a secondary hypoblast. A proposal of the Hertwigs to alopt special names for the outer and inner limiting membranes of the adult, and for the interposed mass of organs, appears to me unnecessarr.

3 The eauses which give rise to a retarlation of histologieal differentiation will be dealt with in the second part of thi chapter which deals with larval charactcrs and larval forms. 
The Hertwigs have recently attempted (No. 27I) to distinguish two types of differentiation of the mesoblast, viz. (1) a direct differentiation from the primitive epithelial cells; () a differentiation from primitively indifferent cells budded off into the gelatinous matter between the two primary layers.

It is quite possible that this distinction may be well-fomnled, but no conclusive evidence of the occurrence of the second process hats yet been ahlinced. The Ctenophora are the type upon which special stress is laid, but the early passage of amoboid cells into the gelatinous tissue, which sulsequently become muscular, is rery probally an embryonic abbreviation; and it is quite possible that these cells may phylogenetically have originated from epithelial cells proviled with contractile processes passing through the gelatinous tissue.

The conversion of non-embryonic connective-tissue cells into muscle cells in the higher types has been described, but very much more evidence is required before it can be accepted as a common occurrence.

In addition to the probably degraded Dicyemidie and Orthonectidæ, the Coelenterata are the only group in which a true mesoblast is not always present. In other words, the Cœlenterata are the only group in which there is not found in the embryo an undifferentiated group of cells from which the majority of the organs situated between the epidermis and the alimentary epithelium are developed.

The organs invariably derived, in the triploblastic forms, from the mesoblist, are the rascular and lymphatic systems, the muscular system, and the greater part of the connective tissue and the excretory and gen rative (?) systems. On the other hand, the nervous systems (with a few possible exceptions) and organs of sense, the epithelium of most glands, and a few exceptional connective-tissue organs, as for example the notochord, are developed from the two primary layers.

The fact of the first named set of organs being invariably derived from the mesoblast points to the establishment of the two following propositions:-(1) That with the differentiation of the mesoblast as a distinct layer by the process already explained, the two primary layers lost for the most part the capacity they primitively possessed of giving rise to muscular and connective-tissue differentiations ${ }^{1}$, to the epithelium of the excretory organs, and to generative cells. (2) That the mesoblast throughout the triploblastic Hetazoa. in so far as these forms have sprung from a common triploblastic ancestor. is an homologous structure.

The second proposition follows from the first. The mesoblast can only have ceased to be homologous throughout the triploblastica by additions from the two primary layers, and the existence of such additions is negatived by the first proposition.

1 The connective-tissne test of the Tunicata, though denived from the epiblast, is not really an example of such a differentiation. 
These two propositions, which hang together, are possibly only approximately true, since it is quite possible that future investigations may shew that differentiations of the two primary layers are not so rare as has been hitherto imagined.

Ranvier ${ }^{1}$ finds that the muscles of the sweat-glinds are developed from the inner part of the layer of epiblast cells, inviginated to form these glands.

Götte describes the epiblast cells of the larra of Comatula as being at a certain stage eontractile and compares them with the epithelio-muscular cells of Hydra. These cells would appear subsequently to be converted into a simple cuticular structure.

It is moreover quite possible that fresh differentiations from the two primary layers may have arisen after the triploblastic condition hat been establisher, and by the process of simplification of development and precocious segregation, as Lankester calls it, have become indistinguishable from the normal mesoblast. In spite of these exceptions it is probahle that the major part of the muscular system of all existing triploblastic forms has been differentiated from the muscular system of the ancestor or ancestors (if there is more than one phylum) of the triploblastica. In the case of other tissues there are a few instances which might be regarded as examples of an organ primitively developed in one of the two primary layers having become secondarily carried into the mesoblast. The notochord has sometimes been cited as such an organ, but, as indicated in a previous chapter, it is probable that its hypoblastic origin can always be demonstrated.
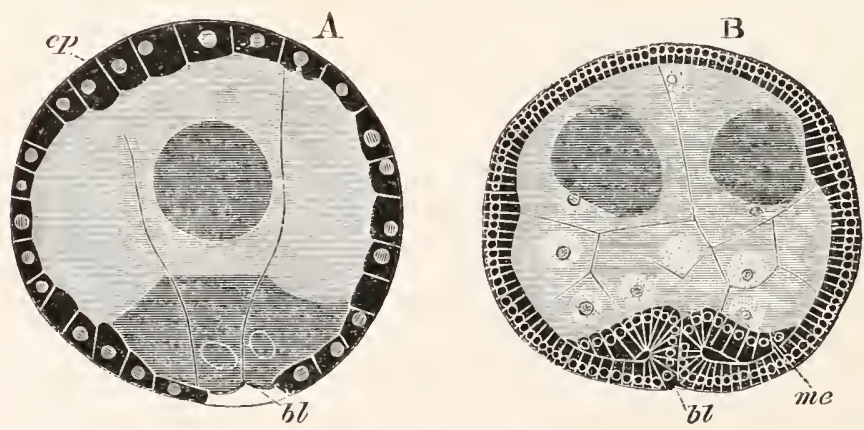

Fig. 206. Eptbolic gastrula of Boxella. (After spengel.)

A. Stage when the four hrpohlast cells are nearly enclosed.

B. Stage after the formation of the mesoblast has commenced by an infulding of the lips of the blastopore.

ep. epiblast; me. mesoblast; Ml. blastopore.

1 M. L. lianvier, "Sur la strincture des glaudes sudonipares." C"muptes Lrrudus, 1)ee. 29,1879 .

$=$ A. (ritte. "Vergleich. Entwick. 1. Comatula mediterraned." frohr I. mikr. Aluat. vol. xir. p. 597. 
The nervous system, although imbedded in mesoblastic derivates in the adults of all the higher triploblastica, retains with marvellous constancy its epiblastic origin (though it is usually separated from the epiblast prior to its histogenic differentiation); yet in the Cephalopoda, and some other Mollusca, the evidence is in favour of its developing in the mesoblast. Should future investigations confirm these conclusions, a good example will be afforded of an organ changing the layer from which it usually develops ${ }^{1}$. The explanation of such a change would be precisely the same as that already given for the mesoblast as a whole.

The actual mode of origin of various tissues, which in the true triploblastic forms arise in mesoblast, can be traced in the Cnelenterata $^{2}$. In this group the epiblast and hypoblast both give rise to muscular and connective-tissue elements; and although the main part of the nervous system is formed in the epiblast, it seems certain that in some types nerves may be derived from the hypoblast $^{3}$. These facts are extremely interesting, but it is by no means
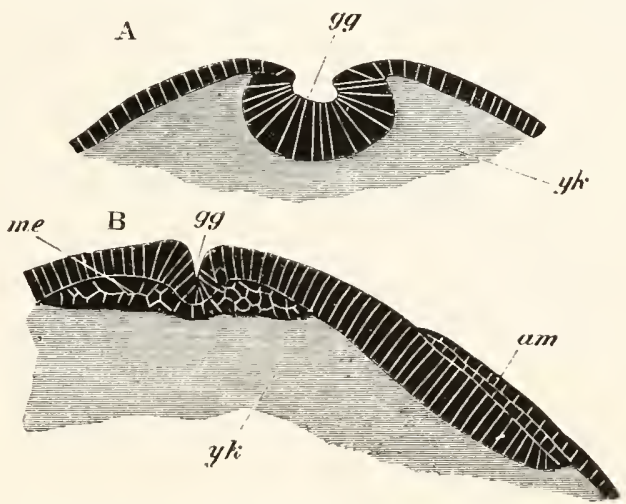

Fic. 207. Two transterse sections throvgh embros of Hyidophilus piceus.

(After Kowalevsky.)

A. Section through an embryo at the point where the two germinal folds most approximate.

B. Section through an embryo, in the anterior region where the folds of the amnion have not united.

gg. germinal groove; me. mesoblast; am. amnion; $y k$. yolk.

1 The Hertwigs hold that there is a distinct part of the nervous system which was at first differentiated in the mesoblast in many types, amongst others the Mollusea. The evidence in favour of this view is extremely scanty and the view itself appears to me highly improbable.

2 The reader is referred for this subject to the valuable memoirs which have been recently published by the Hertwigs, especially to No. 270. He will find a general account of the subject written before the appearance of the Hertwigs' memoir in pp. 149 and 150 of Volume $\mathrm{r}$. of this treatise.

3 It would be interesting to know the history of the various nervous structures found in the walls of the alimentary tract in the higher forms. I have shewn (Development of Elasmobranch Fishes, p. 172) that the central part of the sympathetic system is derived from the epiblast. It would however be well to work over the development of Auerbach's plexus.

B. E. II. 
certain that any conclusions can be directly drawn from them as to

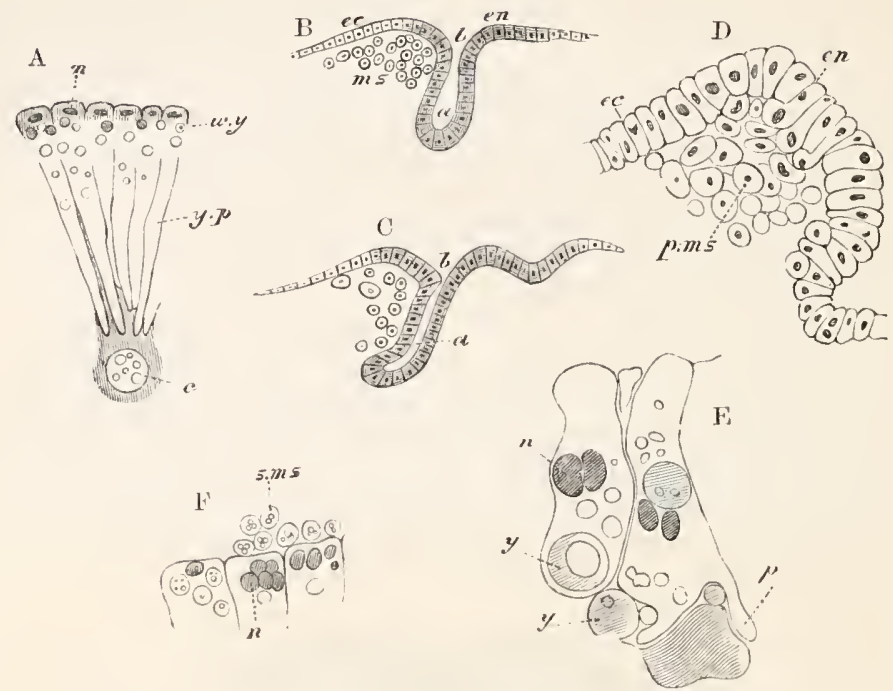

F1g. 208. Figures lluestrativg the developiest of Astacts.

(From Parker; after Reichenbach.)

A. Section through part of the ovum during segmentation. n. nuclei; $u \cdot y$. white yolk; $y \cdot p$. yolk pyramirls; $c$. central yolk mass.

B. and C. Longitudinal sections of the gastrula stage. $a$. archenteron; $b$. blastopore; $m s$. mesoblast; $c c$. epiblast; $e n$. hypoblast, distinguished from epiblast by shading.

D. Highly magnified view of anterior lip of blastopore, to shew the origin of the primary mesoblast from the wall of the arehenteron. p.ms. primary mesoblast; $e c$. epiblast; $e n$. hypoblast.

E. Two hypoblast cells to shew the amoba-like absorption of yolk spheres. $y$. yolk; $n$. nucleus; $p$. pseudopodial process.

F. Hypoblast cells giving rise endogenously to the secondary mesoblast (s.ms.); n. nuclens.

the actual origin of the mesoblast in the triploblastic forms, till we know from what diploblastic forms the triploblastica originated. All that they shew is that any of the constituents of the mesoblast may have originated from either of the primitive layers.

For further light as to the origin of the mesoblast, it is necessary to turn to its actual development.

The following summary illustrates the more important modes in which the mesoblast originates.

1. It grows inwards from the lips of the blastopore as a pair of bands. In these cases it may originate $(\alpha)$ from cells which are clearly hypoblastic, (b) from cells which are clearly epiblastic, (c) from cells which cannot be regarded as belonging to either layer.

Mollusca.-.Gasteropoda, Cephalopoda, and Lamellibranchiata. In Gasteropoda and Lamellibranchiata the mesoblast sometimes originates from a pair of cells at the lips of the blastopore, though very probably 
some of the elements subsequently come from the epiblast; and in Cephanlopoda it begins as a ring of cells round the edge of the blastoderm.

Polyzoa Entoprocta.- It originates from a pair of cells at the lips of the blastopore.

Chætopoda.-Euaxes. It arises as a ridge of cells at the lips of the blastopore (fig. 200).

Gephyrea.-Bonellia. It arises (fig. 206) as an infolding of the epiblastic lips of the blastopore.

Nematelminthes-Cucullanus. It grows backwards from the hypoblast cells at the persistent oral opening of the blastopore.

Tracheata.-Insecta. It grows inwards from the lips of the germinal groove (fig. 207), which probably represent the remains of a blastopore. Part of the mesoblast is probably also derived from the yolk-cells. A similar though more modified development of the mesoblast occur's in the Alaneinat (fig. 214).

Crustacea.-Decapoda. It partly grows in from the hypoblastic lips of the blastopore, and is partly derived from the yolk-cells (fig. 208).

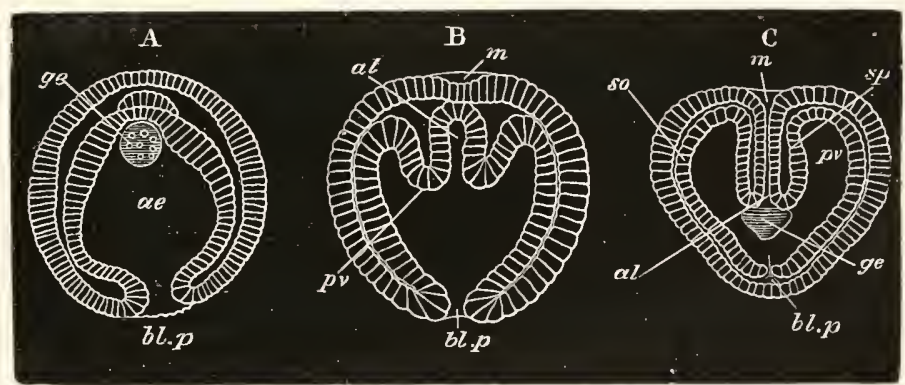

Fic. 209. Three stages in the developuent of Sagitta. (A. and C. after Bütschli, and B. after Kowalevsky.)

The three embryos are represented in the same positions.

A. Represents the gastrula stage.

B. Represents a succeeding stage, in which the primitive archenteron is commencing to be divided into three.

C. Represents a later stage, in which the mouth involution $(m)$ has become continuous with the alimentary tract, and the blastopore has become closed.

$m$. mouth; al. alimentary canal; ae. archenteron; $b l . p$. blastopore; $p v$. perivisceral cavity; $s p$. splanchnic mesoblast; so. somatic mesoblast; ge. generative organs.

2. The mesoblast is developed from the walls of hollow outgrowths of the archenteron, the cavities of which become the body cavity.

Brachiopoda.-The walls of a pair of outgrowths form the whole of the mesoblast.

Chætognatha. - The mesollast arises in the same manner as in the Brachiopoda (fig. 209).

Echinodermata.-The lining of the peritoneal cavity is developed from the walls of outgrowths of the archenteron, but the greater part of the mesoblast is derived from the amneboid cells budded off from the walls of the archenteron (fig. 210). 
Enteropneusta (Balanoglossus).-The hody cavity is derived from two pairs of alimentary diverticula, the walls of which give rise to the greater lart of the mesoblast.

Chordata. - Paired arehenteric outgrowths give rise to the whole mesoblast in Amphioxus (fig. 211), and the mode of formation of the mesoblast in other Chordata is probably secondarily derived from this.

3. The cells which will form the mesoblast become marked out very early, and cannot be regarded as definitely springing from either of the primary layers.

Turbellaria. - Leptoplana (fig. 212), Planaria polychroa (?).

Chætopoda.-Lumbricus, de.

Discophora.

It is very possible that the cases quoted under this hearl ought more properly to belong to group 1.

4. The mesoblast cells are split off from the epiblast.

Nemertea.--Larva of Desor. The mesoblast is stated to be split off from the four invaginated dises.

5. The mesoblast is split off from the hypoblast.

Nemertea...Some of the types without a metamorphosis.

Mollusca.-Scaphopoda. It is derived from the lateral and ventral cells of the hypoblast.

Gephyrea.-Phaseolosoma.

Vertebrata.-In most of the Ichthyopsida the mesoblast is derived from the hypoblast (fig. 213). In some types (i.e. most of the Amniota) the mesoblast might be described as originating at the lips of the blastopore (primitive streak).

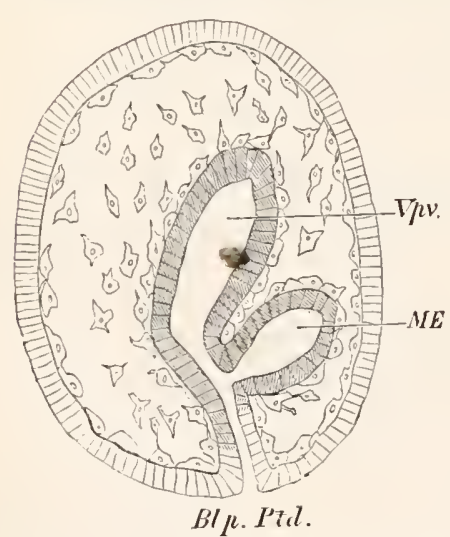

Fig. 210. Longitudinal Section THROUGH AN EMBRYO OF CUCUMARIA DOLIOLUM AT THE END OF THE FOURTH DAY.

$V p v$, raso-peritoneal vesicle; $M E$. mesenteron; Blp., Ptd. blastopore, proe. todæum.
6. The mesoblast is derived from both germinal layers.

Tracheata.-Araneina (fig. 214). It is derived partly from cells split off from the epiblast and partly from the yolk-cells; but it is probable that the statement that the mesoblast is derived from both the germinal layers is only formally accurate; and that the derivation of part of the mesoblast from the yolk-cells is not to be interpreted as a derivation from the hypoblast.

Amniota.-The derivation of the mesoblast of the Amuiota from both the primary germinal layers is without doubt a secondary process.

The conclusions to be drawn from the above summary are by no meaus such as might have been anticipated. The analigy of the 
Coelenterata would lead us to expect that the mesoblast would be derived partly from the epiblast and partly from the hypoblast.
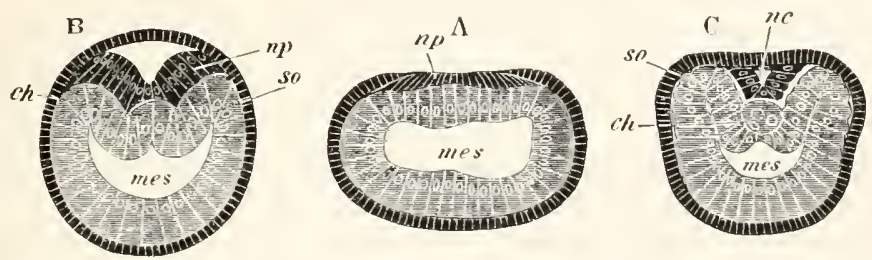

Fig. 211. Sections of an Auphioxus embrio at thize stages. (After Kowalersky.)

A. Section at gastrula stage.

B. Section of a somewhat older embryo.

C. Section through the anterior part of still older embryo.

np. neural plate; ne. nemral canal; mes. archenteron in $\mathrm{A}$, and mesenteron in $\mathrm{B}$ and $\mathrm{C}$; ch. notochord; so. mesoblastic somite.

Such, however, is not for the most part the case, though more complete investigations may shew that there are a greater number of instances in which the mesoblast has a mixed origin than might be supposed from the above summary.

I have attempted to reduce the types of development of the mesoblast to six; but owing to the nature of the case it is not. always easy to distinguish the first of these from the last four. Of the six types the second will on most hands be admitted to be the most remarkable. The formation of hollow outgrowths of the archenteron, the cavities of which give rise to the body cavity, can only be explained on the supposition that the body cavity of the types in which such outgrowths occur is derived from diverticuli cut off from the alimentary tract. The lining epithelium of the diverticula - the peritoneal epithelium-is clearly part of the primitive hypoblast, and this part of the mesoblast is clearly hypoblastic in origin.
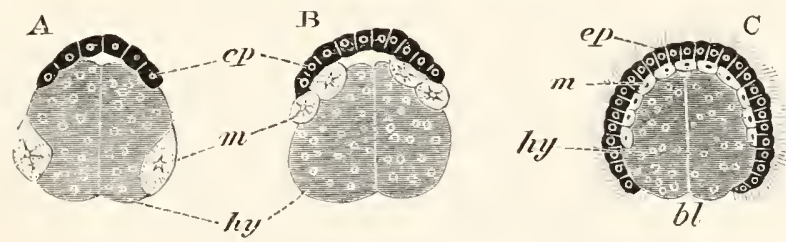

Fig. 212. Sectioxs throcgh the oven of Leptoplaxa tremellatis ix three staGes of DEvelopuext. (After Hallez.)

ep. epiblast; $m$. mesoblast; hy. yolk-cells (hypoblast); bl. blastopore.

In the case of the Chrtognatha (Sagitta), Brachiopoda, and Amphioxus, the whole of the mesoblast originates from the walls of the diverticula; while in the Echinodermata the walls of the diverticula only give rise to the vaso-peritoneal epithelium, the remainder 
of the mesoblast being derived from amoboid cells which spring from the walls of the archenteron before the origin of the vasoperitoneal outgrowths (figs. 199 and 210).

Reserving for the moment the question as to what conclusions can be deduced from the above facts as to the origin of the mesoblast, it is important to determine how far the facts of embryology warrant us in supposing that in the whole of the triploblastic forms the body cavity originated from the alimentary diverticula. There can be but little doubt that the mode of origin of the mesoblast in many Vertebrata, as two solid plates split off from the hypoblast, in

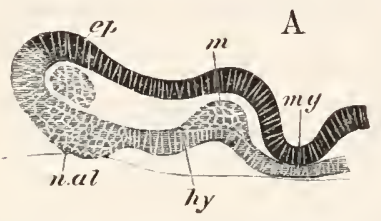

B

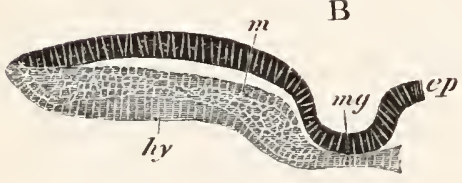

Fig. 213. Two sections of a young Elasmobrancli eMbryo, to SHEW the ME. SOBLAST SPLIT OFF AS TWO LATERAL MASSES FIROM THF HYYOBLAST.

$m g$. medullary groove; ep. epiblast; $m$. mesoblast; hy. hypoblast; n.al. cells formed around the nuclei of the yolk which have entered the hypoblast. have originated from a pair of enteric diverticula in the case of the forms where a body cavity is present, there is a considerable difficulty in holding this view, for forms in which there is no body cavity distinct from the alimentary diverticula.

Of these types the Platyelminthes are the most striking. It is, no doubt, possible that a body cavity may have existed in the Platyelninthes, and become lost; and the case of the Discophora, which in their muscular

1 The wide occurrence of this process was first pointed out by Rabl. He holds, however, a peculiar modification of the gastraa theory, for which I must refer the reader to his paper $\left(\mathrm{No}_{2} 8_{4}\right)$; according to this theory the mesoblast has sprung from a zone of cells of the blastosphere, at the junction between the cells which will be invaginated and the epiblast cells. In the bilateral blastosphere, from which he holds that all the higher forms (Bilateralia) have originated, these cells had a bilateral arrangement, and thus the bilateral origin of the mesoblast is explained. The origin of the mesoblast from the lips of the blastopore is explained by the position of its mother-cells in the blastosphere. It need scarcely be said that the views already put forward as to the probable mode of origin of the mesoblast, founded on the analogy of the Coelenterata, are quite incompatible with Rabl's theories. 
and connective tissue systems as well as in the absence of a body cavity resemble the Platyelminthes, may be cited in favour of this view, in that, being closely related to the Chretopoda, they are almost certainly descended from ancestors with a true body cavity. The usual view of the primitive character of the Platyelminthes, which has much to support it, is, however, opposed to the idea that the body cavity has disappeared.

If Kowalevsky ${ }^{\prime}$ is right in stating that he has found a form intermediate between the Culenterata and the Platyelninthes, there will be strong grounds for holding that the Platyelminthes are, like the Cuelenterata, for'ms the ancestors of which were not provided with a body eavity.

Perhaps the triploblastica are composed of two groups, viz. (1) a more ancestral group (the Platyelminthes), in which there is no body cavity as distinct from the alimentary, and (2) a group descended from these, in which two of the alimentary diverticula have become separated from the alimentary tract to form a body cavity (remaining triploblastica). However this may be, the above considerationsaresufficient to shew how much there is that is

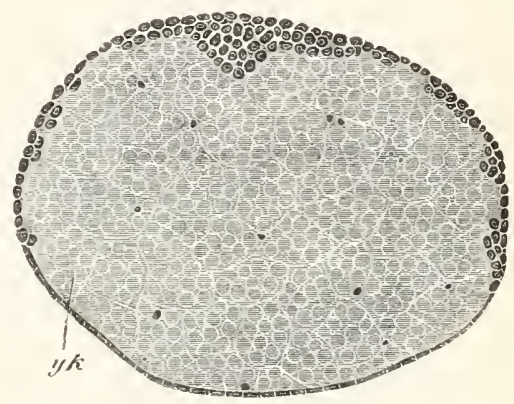

Fig. 214. SECTION THROTGH AN EMbiro of Agelena labrrintilca.

The section is represented with the rentral plate upwards. In the rentral plate is seen a keel-like thickening, which gires rise to the main mass of the mesoblast.

$y k$. yolk divided into large polygonal cells, in several of which are nuclei. still obscure witl reference even to the body carity.

If embryology gives no certain sound as to the questions just raised with reference to the body cavity, still less is it to be hoped that the remaining questions with reference to the origin of the mesoblast can be satisfactorily answered. It is clear, in the first place, from an inspection of the summary given above, that the process of development of the mesoblast is, in all the higher forms, very much abbreviated and modified. Not only is its differentiation relatively deferred, but it does not in most cases originate, as it must have done to start with, as a more or less continuous sheet, split off from parts of one or both the primary layers. It originates in most cases from the hypoblast, and although the considerations already urged preclude us from laying very great stress on this mode of origin, yet the derivation of the mesoblast from the walls of archenteric outgrowths suggests the view that the whole, or at any rate the greater part, of the mesoblast primitively arose by a process of histogenic differentiation from the walls of the archenteron or rather from diverticula

1 Zoologischer Anzeiger, No. 52, 1. 140. This form has been named by Kowalevsky Caloplana Metschnikowii. Kowalevsky's description appears, however, to be quite compatible with the view that this form is a creeping Ctenophor, in no way related to the Turbellarians. 
of these walls. 'This view, which was originally put forward by myself (No. 260), appears at first sight very improbable, but if the statement of the Hertwigs ( $\mathrm{N}_{0} .270$ ), that there is a large development of a hypoblastic muscular system in the Actinozoa, is well founded, it cannot be rejected as impossible. Lankester (No. 279), on the other hand, has urged that the mode of origin of the mesoblast in the Echinodermata is more primitive; and that the amoboid cells which here give rise to the muscular and connective tissues ref resent cells which originally arose from the whole immer surface of the epiblast. It is, however, to be noted that even in the Echinodermata the amœboid cells actnally arise from the hypoblast, and their mode of origin may, therefore, be used to support the view that the main part of the muscular system of higher types is derived from the primitive hypoblast.

The great changes which have taken place in the development of the mesoblast would be more intelligible on this view than on the view that the major part of the mesoblast primitively originated from the epiblast. 'The presence of food-yolk is nuch more frequent in the hypoblast than in the epiblast; and it is well known that a large number of the changes in early development are caused by food-yolk. If, therefore, the mesoblast has been derived from the hypoblast, many more changes might be expected to have been introduced into its early development than if it had been derived from the epiblast. At the same time the hypoblastic origin of the mesoblast would assist in exp'aining how it has come about that the development of the nervous system is almost always much less modified than that of the mesoblast, and that the nervous system is not, as might, on the grounds of analngy, have been anticipated, as a rule secondarily developed in the mesoblast.

The Hertwigs have recently suggested in their very interesting memoir (No. 27 I) that the Triploblastica are to be divided into two phyli, (1) the Enterocola, and (2) the Pseudocola; the former group containing the Chetopoda, Gephyrea, Brachiopoda, Nematoda, Arthropoda, Echinodermata, Enteropmensta and Chordata; and the latter the Mollusca, Polyzoa, the Rotifera, and Platyelminthes.

The Enterocula are forms in which the primitive alimentary diverticula have given origin to the borly cavity, while the major part of the muscular system has originated from the epithelial walls of these diverticula, part however being in many eases also derived from the amoboid cells, called by them mesenchyme, hy the second process of mesoblastic differentiation mentioned on $\mathrm{p}$. $28 \mathrm{i}$.

In the Psendocoela the muscular system has become differentiated from mesenchyme cells; while the borly cavitr, where it exists, is merely a split in the mesenchyme.

It is impossible for me to attempt in this place to state fully, or do justice to, the original and suggestive views contained in this paper. The general conclusion I cannot however accept. The views of the Hertwigs depend to a large extent npon the supposition that it is possible to distingnish histologieally muscle cells derived from epithelial cells, from those 
derived from mesenchyme cells. That in many cases, and strikingly so in the Chordata, the muscle cells retain clear indications of their primitive origin from epithelial cells, I freely admit; but I do not believe either that its histological character can ever be conclusive as to the nonepithelial origin of a muscle cell, or that its derivation in the embryo from an indifferent amoboid cell is any proof that it did not, to start with, originate from an epithelial cell.

I hold, as is clear from the preceling statements, that such immense secondary modifications have taken place in the development of the mesoblast, that no such definite conclusions can be decluced from its mode of (levelopment as the Hertwigs suppose.

In support of the view that the early character of embryonic cells is no safe index as to their phylogenetic origin, I would point to the few following facts.

(1) In the Porifera and many of the Coelenterata (Eucope polystylat, Geryonia, dc.) the hypoblast (endoderm) originates from cells, which according to the Hertwigs' views onght to be classed as mesenchyme.

(2) In numerous instances muscles which have, phylogenetically, an undoubted epithelial origin, are ontogenetically derived nom cells which onght to be classed as mesenchyme. The muscles of the head in all the higher Vertebrata, in which the head cavities have disappeared, are examples of this kind; the muscles of many of the Tracheati, notably the Araneina, must alvo be placed in the same category.

(3) The Mollusca are considered by the Hertwigs to be typical Pseudocola. A critical examination of the early development of the mesolulast in these forms demonstrates howerer that with reference to the mesoblast they must be classed in the same group as the Chretopoda. The mesoblast ( $T$ ol. I. p. 18S) clearly originates as two bands of cells which grow inwards from the blastopore, and in some forms (Paludina, Vol. I. fig. 107 ) become divided into a splanchnic and somatic layer, with a body cavity between them. All these processes are such as are, in other instances, admitted to indicate Enterocelous affinities.

The subsequent conversion of the mesublast elements into amœboid cells, out of which branched muscles are tormed, is in my opinion simply due to the envelopment of the soft Molluscan body within a hard shell.

In addition to these instances I may point out that the distinction between the Pseudocola and Enterocala utterly breaks down in the case of the Discophor:t, and the Hertwigs have made no serious attempt to discuss the characters of this group in the light of their theory, and that the derivation of the Echinoderm muscles from mesenchyme cells is a difficulty which is very slightly treated.

\section{LARVAL FORMS: THEIR NATURE, ORIGIN AND AFFINITIES.}

Preliminary considerations. In a general way two types of development may be distinguished, viz. a foetal type and a larval type. In the fotal type animals undergo the whole or nearly the whole of their development within the egrg or within the body of the parent, and are hatched in a condition closely resembling the adult; and in the larval type they are born at an earlier stage of development, in a condition differing to a greater or less extent from the 
adult, and reach the adult state either by a series of small steps, or by a more or less considerable metamorphosis.

The satisfactory application of embryological data to morphology depends upon a knowledge of the extent to which the record of ancestral history has been preserved in development. Unless secondary changes intervened this record would be complete; it becomes therefore of the first importance to the embryologist to study the nature and extent of the secondary changes likely to occur in the foetal or the larval state.

The principles which govern the perpetuation of variations which occur in either the larval or the foetal state are the same as those for the adult condition. Variations favourable to the survival of the species are equally likely to be perpetuated, at whatever period of life they occur, prior to the loss of the reproductive powers. The possible nature and extent of the secondary changes which may have occurred in the developmental history of forms, which have either a long larval existence, or which are born in a nearly complete condition, is primarily determined by the nature of the favourable variations which can occur in each case.

Where the development is a fretal one, the favourable variations which can most easily occur are-(1) abbreviations, (2) an increase in the amount of food-yolk stored up for the use of the developing embryo. Abbreviations take place because direct development is always simpler, and therefore more advantageous; and, owing to the fact of the foetus not being required to lead an independent existence till birth, and of its being in the meantime nourished by food-yolk, or directly by the parent, there are no physiological causes to prevent the characters of any stage of the development, which are of functional importance during a fiee but not during a foetal existence, from disappearing from the developmental history. All organs of locomotion and nutrition not required by the adult will, for this reasou, obviously have a tendency to disappear or to be reduced in fotal developments; and a little consideration will shew that the ancestral stages in the development of the nervous and muscular systems, organs of sense, and digestive system will be liable to drop out or be modified, when a simplification can thereby be effected. The circulatory and excretory systems will not be modified to the same extent, because both of them are usually functional during foetal life.

The mechanical effects of food-yolk are very considerable, and numerous instances of its influence will be found in the earlier chapters of this work ${ }^{1}$. It mainly affects the early stages of development, i.e. the form of the gastrula, \&c.

The favourable variations which may occur in the free larva are much less limited than those which can occur in the foetus. Secondary characters are therefore very numerous in larvæ, and there may even be larva with secondary characters only, as, for instance, the larve of Insects.

3 For numerou instances of this kind, vide Chapter xi. of Vol. II. 
In spite of the liability of larve to acquire secondary characters, there is a powerful counter-balancing influence tending towards the preservation of ancestral characters, in that larve are necessarily compelled at all stages of their growth to retain in a functional state such systems of organs, at any rate, as are essential for a free and inclependent exislence. It thus comes about that, in spite of the many canses tending to produce secondary changes in larvæ, there is always a better chance of larve repeating, in an unabbreviated form, their ancestral history, than is the case with embryos, which undergo their development within the egg.

It may be further noted as a fact which favours the relative retention by larva of ancestral characters, that a secondary larval stage is less likely to be repeated in development than an ancestral stage, because there is always a strong tendency for the former, which is a secondarily intercalated link in the chain of development, to drop out by the occurrence of a reversion to the original type of development.

The relative chances of the ancestral history being preserved in the fœtus or the larva may be summed up in the following way:There is a greater chance of the ancestral history being lost in forms which develop in the egg; and of its being masked in those which are hatched as larvæ.

The evidence from existing forms undoubtedly confirms the " priori considerations just urged". This is well shewn by a study of the development of Echinodermata, Nemertea, Molhusea, Crustacea, and Tunicata. The free larve of the four first groups are more similar amongst themselves than the embryos which develop directly, and since this similarity cannot be supposed to be due to the larvæ having been modified by living under precisely similar conditions, it must be due to their retaining common ancestral characters. In the case of the Tunicata the free larve retain much more completely than the embryos certain characters such as the notvchord, the cerebrospinal canal, etc., which are known to be ancestral.

Types of Larvæ.-Although there is no reason to suppose that all larval forms are ancestral, yet it seems reasonable to anticipate that a certain number of the known types of larva would retain the characters of the ancestors of the more important phyla of the animal kingdom.

Before examining in detail the claims of various larvæ to such a character, it is necessary to consider somewhat more at length the kind of variations which are most likely to occur in larval forms.

1 It has long been known that land and freshwater forms develop withont a metamorphosis much more frequently than marine forms. This is probably to be explained by the fact that there is not the same possibility of a land or freshwater species extending itself over a wide area by the agency of free larvæ, and there is, therefore, much less advantage in the existence of such larvæ; while the fact of such larvæ being more liable to be preyed upon than eggs, which are either concealed, or carried about by the parent, might render a larval stage absolutely disadvantageous. 
It is probable a priori that there are two kinds of larvæ, which may be distinguished as primary and secondary larvie. Primary larvæ are more or less modified ancestral forms, which have continued uninterruptedly to develop as free larvæ from the time when they constituted the adult form of the species. Secondary larvæ are those which have become introduced into the ontogeny of species, the young of which were originally hatched with all the characters of the iulult; such secondary larve may have originated from a diminution of food-yolk in the egg and a consequently earlier commencement of a free existence, or from a simple adaptive modification in the just hatched young. Secondary larval forms may resemble the primary larval forms in cases where the ancestral characters were retained by the embryo in its development within the egg; but in other instances their characters are probably entirely adaptive.

Causes tending to produce secondary changes in larve.--The modes of action of natural selection on larva may probably be divided more or less artificially in to two classes.

1. The changes in development directly produced by the existence of a larval stage.

2. The adaptive changes in a larva acquired in the ordinary course of the struggle for existence.

The changes which come under the first head consist essentially in a displacement in the order of development of certain organs. There is always a tendency in development to throw back the differentiation of the embryonic cells into definite tissues to as late a date as possible. This takes place in order to enable the changes of form, which every organ undergoes, in repeating even in an abbreviated way its phylogenetic history, to be effecterl with the least expenditure of energy. Owing to this tendency it comes about that when an organism is hatched as a larva many of the organs are still in an undifferentiated state, although the ancestral form which this larva represents liad all its organs fully differentiated. In order, however, that the larva may be enabled to exist as an independent organism, certain sets of organs, e.\% the muscular, nervous, and digestive systems, have to be histologically differentiated. If the period of foetal life is shortened, an earlier differentiation of certain organs is a necessary consequence; and in ahnost all cases the existence of a larval stage causes a displacement in order of development of organs, the complete differentiation of many organs being retarded relatively to the muscular, nervous, and digestive systems.

The possible changes under the second head appear to be unlimited. There is, so far as I see, no possible reason why an indefinite number of organs should not be developed in larva to protect them from their enemies, and to enable them to compete with larva of other species, and so on. The only limit to such development appears $t o$ be the shortness of larval life, which is not likely to be 
prolonged, since, ceteris paribus, the more quickly maturity is reached the better it is for the species.

A very superficial examination of marine larva shews that there are certain peculiarities common to most of them, and it is important to determine how far such peculiarities are to be regarded as adaptive. Almost all marine larva are provided with well-developed organs of locomotion, and transparent bodies. These two features are precisely those which it is most essential for such larva to have. Organs of locomotion are important, in order that larvæ may be scattered as widely as possible, and so disseminate the species; and transparency is very important in rendering larve invisible, and so less liable to be preyed upon by their numerous enemies ${ }^{1}$.

These considerations, coupled with the fact that almost all free-swimming animals, which have not other special means of protection, are transparent, seem to shew that the transparency of larve at all events is adaptive; and it is probable that organs of locomotion are in many cases specially developed, and not ancestral.

Various spinous processes on the larve of Crustacea and Teleostei are also examples of secondarily acquired protective organs.

These general considerations are sufficient to form a basis for the discussion of the characters of the known types of larva.

The following table contains a list of the more important of such larval forms :

Dicyenidæ.-The Infusoriform larva (vol. 1. fig. 62).

Porifera. - (a) The Amphiblastula larra (fig. 215), with one-half of the body ciliated, and the other half without cilia; $(b)$ an oval uniformly ciliated larva, which may be either solid or have the form of a vesicle.

Colenterata. - The planula (fig. 216).

Turbellaria - - (a) The eight-lobed larva of Müller (fig. 222); (b) the larvæ of Götte and Ietschnikoff, with some Pilidium characters.

Nemertea. - The Pilidium (fig. 221).

Trejatoda.-The Cercaria.

Rotifera. - The Trochosphere-like larvæ of Brachionus (fig. 217) and Lacinularia.

Mollusca.-The Trochosphere larva (fig. 218), and the subsequent Veliger larva (fig. 219).

Brachopona.--The three-lobed larva, with a postoral ring of eilia (fig. 220).

PoLrzos.-A larval form with a single ciliated ring surrounding the mouth, and an aboral ciliated ring or dise (fig. 228).

ChжтоPODA.- Various larval forms with many characters like those of the molluscan Trochosphere, frequently with distinct transverse bands of cilia. They are classified as Atrochæ, Mesotrochæ, Telotrochæ (fig. $225 \mathrm{~A}$ and fig. 226), Polytrochæ, and Monotroche (fig. $225 \mathrm{~B})$.

Gephyrea Nuda.-Larval forms like those of preceding groups. A specially characteristic larva is that of Echiurus (fig. 227).

Gephyrea Tubicola. - Actinotrocha (fig. 230), with a postoral ciliated ring of arms.

Irriapoda.-A functionally hexapodous larval form is common to all the Chilognatha (vol. I. fig. 174).

INSECTA. - Various secondary larval forms.

Crustacea, - The Nauplius (vol. I. fig. 208) and the Zora (vol. I. fig. 210).

1 The phosphorescence of many larvæ is very peculiar. I should have anticipated that phosphorescence would have rendered them much more liable to be captured by the forms which feed upon them; and it is difficult to see of what advantage it can be to them. 
Echinoderumta.-The Auricularia (fig. 223 A), the Bipinnaria (fig. 223 B), and the Pluteus (fig. 224), and the transversely-ringed larva of Crinoidea (vol. I. fig. 268). The three first of which can be reduced to a common type (fig. $231 \mathrm{c}$ ).

Enteropneusta.-Tornaria (fig. 229).

Unochorda (Tonicata). - The tadpole-like larva (vol. ir. fig. 8).

Ganolder.-A larva with a dise with adhesive papillæ in front of the mouth (vol. II. fig. 67).

Anurods Amphibia. - The tadpole (vol. II. fig. 80).

Of the larval forms included in the above list a certain number are probably without affinities outside the group to which they belong. This is the case with the larve of the Myriapoda, the Crustacean larvæ, and with the larval forms of the Chordata. I shall leave these forms out of consideration.

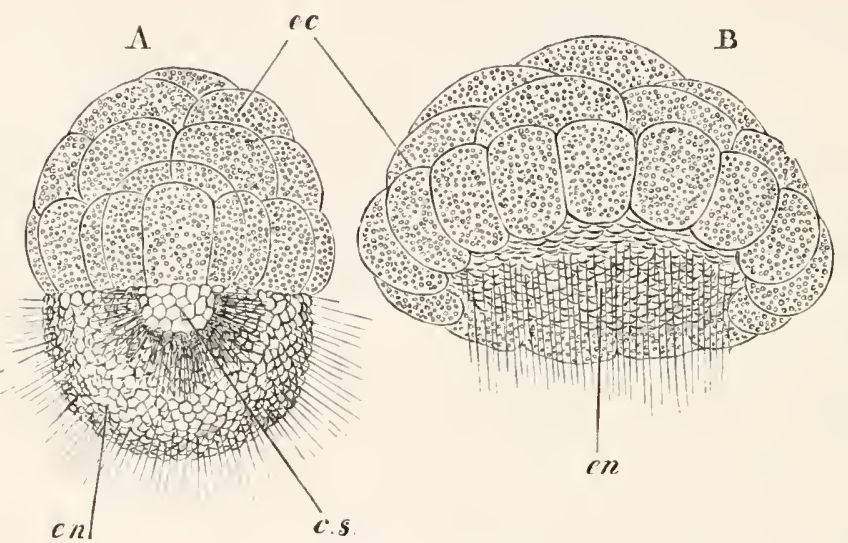

Fig. 215. Two free stages in the Development of Sycandra faphayug. (After Schultze.)

A. Amphiblastula stage.

B. Stage after the ciliated cells have commenced to be invaginated.

c.s. segmentation cavity; ec. granular epiblast cells; en. ciliated hypoblast cells.

There are, again, some larval forms which may possibly turn out hereafter to be of importance, but from which, in the present state of our knowledge, we cannot draw any conclusions. The infusoriform larva of the Dicyemidæ, and the Cercaria of the Trematodes, are such forms.

Excluding these and certain other forms, we have finally left for consideration the larve of the Cœlenterata, the Turbellaria, the Rotifera, the Nemertea, the Mollusca, the Polyzoa, the Brachiopoda, the Chrtopoda, the Gephyrea, the Echinodermata, and the Enteropneusta.

The larve of these forms can be divided into two groups. The one group contains the larva of the Colenterata or Planula, the other group the larve of all the other forms. 
The Planula (fig. 216) is characterised by its extreme simplicity.

B

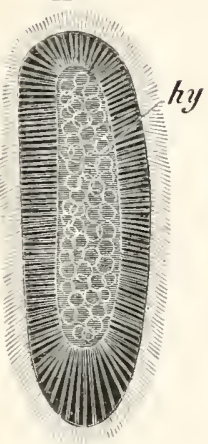

C

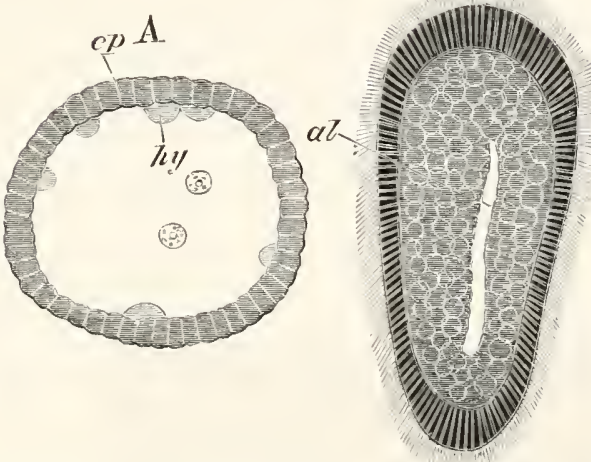

Fig. 216. Three larval stages of Eucore polystrla. (After Kowalersky.)

A. Blastosphere stage with hypoblast spheres becoming budded into the central eavity.

B. Planula stage with solid hypoblast.

C. Planula stage with a gastric earity.

ep. epiblast; hy. hypoblast; al. gastric cavity.

It is a two-layered organism, with a form varying from eylintrical to oval, and usually a radial symmetry. So long as it remains free it is not usually provided with a mouth, and it is as yet uncertain whether or 110 the absence of a mouth is to be regarded as an ancestral character. The Planula is very probably the ancestral form of the Coelenterata.

The larva of almost all the other groups, although they may be subdivided into a series of very distinct types, yet agree in the possession of certain common characters'. 'There is a more or less dome-shaped dorsal surface, and a flattened or concave ventral surface, containing the opening of the mouth, and usually extending posteriorly to the opening of the anus, when such is present.

The dorsal dome is continued in front of the mouth to form a large preoral lobe.

1 The larva of the Brachiopoda does not possess most of the characters mentioned below. It is probably, all the same, a highly differentiated larval form belonging to this group.

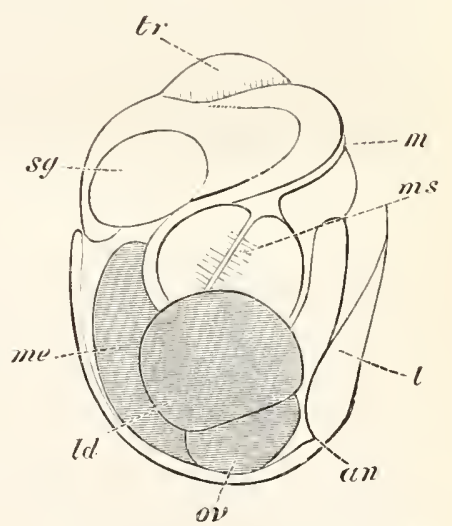

Fig. 217. Evbryo of Brachioxus URCEOLARIS, SHORTLT BEFORE IT IS Hatchen. (After Salensky.)

$m$. mouth; ms. masticatory apparatus; me. mesenteron; an. anus: ld. lateral gland; ov. ovary; $t$. tail (foot); $t r$. trochal dise; $s g$. supracesophageal ganglion. 
There is usually present at first an uniform covering of cilia; but in the later larval stages there are almost always formed definite bands or rings of long cilia, by which locomotion is effected. These bands are often produced into arm-like processes.

The alimentary canal has, typically, the form of a bent tube with a ventral concavity, constituted (when an anus is present) of three sections, viz. an oesophagus, a stomach, and a rectum. The cesophagus and sometimes the rectum are epiblastic in origin, while the stomach always and the rectum usually are derived from the hypoblast ${ }^{1}$.

To the above characters may be added a glass-like transpareney;

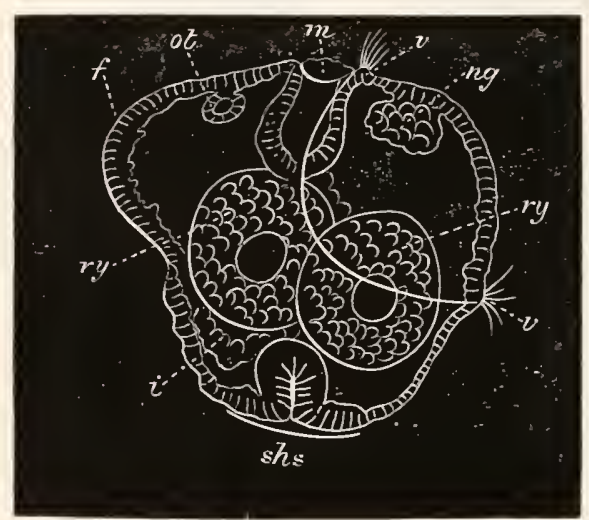

Fig. 218. Diagram of an embryo of PleuroBranchidiuy. (From Lankester.)

$f$. foot; ot. otocyst; $m$. mouth; $r$. velum; $n g$. nerve ganglion; ry. residual yolk spheres; shs. shell-gland; $i$. intestine.
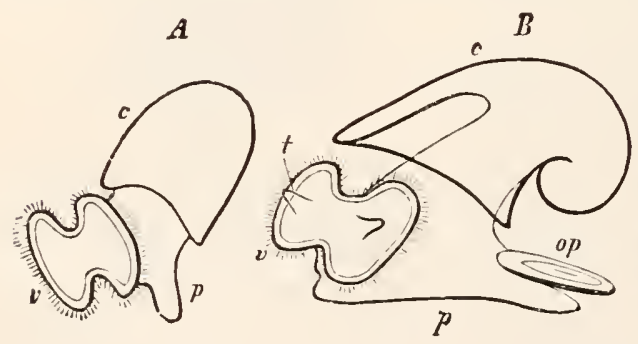
and the presence of a widish space possibly filled with gelatinous tissue, and often traversed by contractile cells, between the alimentary tract aud the body wall.

Considering the very profound differences which exist between many of these larvæ, it may seem that the characters just enumerated are hardly sufficient to justify my grouping them together. It is, however, to be borne in mind that my grounds for doing so depend quite as much upon the fact that they constitute a series

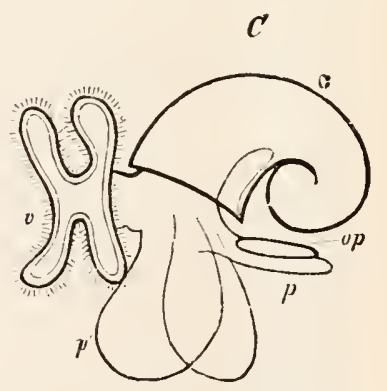

F1g. 219. Larve of Cepifalophorous Mollesca in the veliter stage. (From Gegenbaur.)

A. and B. Earlier and later stage of Gasteropod. C. Pteropod (Cymbulia). $v$. velum; $c$. shell; $p$. foot; op. operculum; $t$. tentacle.

1 There is some uncertainty as to the development of the cesophagus in the Echinodermata, but recent researches appear to indicate that it is developed from the hypoblast. 
without any great breaks in it, as upon the existence of characters common to the whole of them. It is alsu worth noting that most of the characters which have been enumerated as common to the whole of these larva are not such secondary characters as (in accorlance with the considerations used above) might be expected to arise from the fact of their being subjected to nearly similar conditions of life. Their transparency is, no doubt, such a secondary character, and it is not impossible that the existence of ciliated bands may be so atso; but it is quite possible that if, as I suppose, these larve reproduce the characters of some ancestral form, this form may have existed at a time when all marine animals were free-swimming, and that it may, therefore, have been provided with at least one ciliated band.

The detailed consideration of the characters of these larva, given below, supports this view.

This great class of larva may, as already

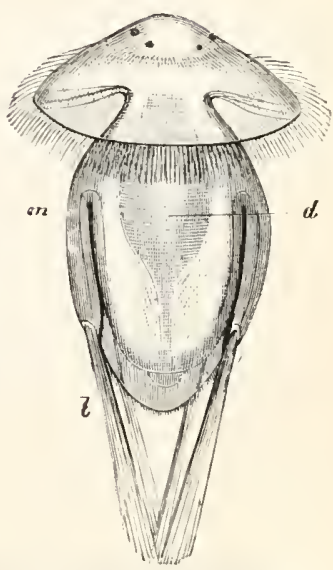

Fig. 220. Larva of ArGIOPE. (From Gezenbaur; after Kowalevsky.)

m. mantle; $b$. setx; d. archenteron. stated, be divided into a series of minor subdivisions. These suhdivisions are the following:

1. The Pilidium Group.-This group is characterised by the mouth being situated nearly in the centre of the ventral surface, and by the absence of an anus. It includes the Pilidium of the Nemer-

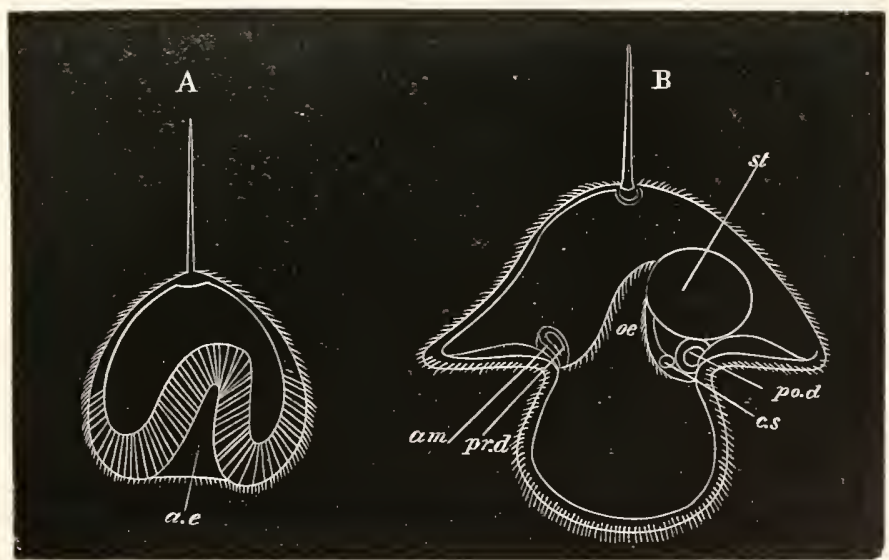

Fin. 221. Two stages in the development of Pilidiox. (After Metschnikoff.) ae. archenteron; oe. osophagus; st. stomach; am. amnion; pr.d. prostomial disc; po.d. metastomial disc; $c . s$. cephalic sack (lateral pit).

l3. E. II. 
tines (fig. 221), and the various larvæ of marine Dendrocœla (fig. 222). At the apex of the prooral lobe a thickening of epiblast may be present, from which (fig. 232 ) a contractile cord sometimes passes to the œesophagus.

2. The Echinoderm Group.-This group (figs. 223, 224 and $281 \mathrm{C}$ ) is characterised by the presence of a longitudinal postoral band of cilia, by the absence of special sense organs in the preoral region, and by the development of the body-cavity as an outgrowth of the alimentary tract. The three typical divisions of the alimentary tract are present, and there is a more or less developed preoral lobe. This group only inchudes the larvet of the Echinodermata.

3. The Trochosphere Group.-This group (figs. 225, 226) is characterised by the presence of a praoral ring of long cilia, the region in front of which forms a great part of the præoral lobe. The mouth opens immediately behind the pracoral ring of cilia, and there

A.

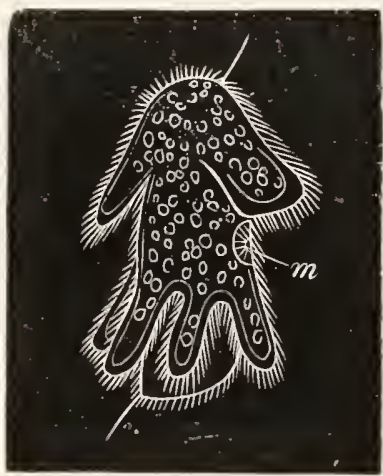

B.

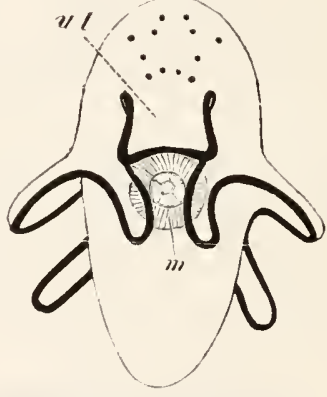

Fig, 22.2. A. Larva of Eurylepta auriculata mimeditely after hatching. Viewed from the side. (After Hallez.) $m$. mouth.

B. Mülaler's Trrbellarian larva (probably Thysayozoon). Viewed from thF ventral strpace. (After Müller.) The ciliated band is represented by the black line. m. mouth; u.l. upper lip.

is very often a second ring of short cilia parallel to the main ring, immediately behind the mouth. The function of the ring of short cilia is nutritive, in that its cilia are employed in bringing food to the mouth; while the function of the main ring is locomotive. A perianal patch or ring of cilia is often present (fig. $225 \mathrm{~A}$ ), and in many forms intermediate rings are developed between the præoral and perianal rings.

The praoral lobe is usually the seat of a special thickening of epiblast, which gives rise to the supra-nosophageal ganghion of the adult. On this lobe optic organs are very often developed in connection with the supra-cesophageal ganglion, and a contractile band fiequently passes from this region to the cesophagus. 
The alimentary tract is formed of the three typical divisions.

The body cavity is not developed directly as an outgrowth of the alimentary tract, though the process by which it originates is very probably secondarily modified from a pair of alimentary outgrowths.

Paired excretory organs, opening to the exterior and into the body cavity, are often present (fig. $226 \mathrm{nph}$ ).

This type of larva is found in the Rotifera (fig. 217) (in which it is preserved in the adult state), the Chropoda (figs. 2.2.5 and 226), the Mollusca (tig. 218), the Gephyrea nuda (fig. 227), and the Polyzoa (fig. 228$)^{1}$.

4. Tornaria.-This larva (fig. 2.29) is intermediate in most of its characters between the larva of the Echinodermata (more especially the Bipinnaria) and the Trochosphere. It resembles Echinoderm larvæ in the possession of a longitudinal ciliated band (divided into a præoral and a postoral ring), and in the derivation of the body cavity and water-vascular vesicle from alimentary diverticula; and it resembles the Trochosphere in the presence of sense organs on the præoral lobe, in the existence of a perianal ring of cilia, and in the possession of a contractile band passing from the praoral lobe to the œsophagus.

5. Actinotrocha. - The remarkable larva of Phoronis (fig. 230), known as Actinotrocha, is characterised by the presence of $(\mathbf{1})$ a postoral and somewhat longitudinal ciliated ring produced into tentacles, and (2) a perianal ring. It is provided with a præoral lobe, and a terminal or somewhat dorsal anus.

\section{The larva of the Brachio-} poda articulata (fig. 220).

The relationships of the six types of larval forms thus briefly characterised have been the subject of a considerable amount of controversy, and the following suggestions on their affinities must be viewed as somewhat speculative. The Pilidium type of

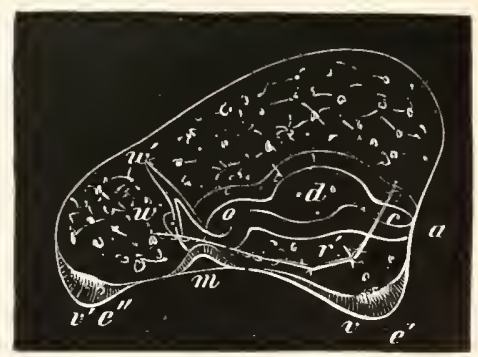

Hig, 224. A LARVA OF STRONGYLocentrus. (From Agassiz.)

$m$. mouth; a. anus; o. œesophagus; $d$. stomach; $c$, intestine; $v^{\prime}$. and $v$. ciliated ridges; $u$. water-vascular tube; $r$. ealcareous rods.

1 For a diseussion as to the structure of the Polyzoon larva, vide Vol. 1. p. 253. 
larva is in some important respects less highly differentiated than the larvæ of the five other groups. It is, in the first place, without an anus; and there aré no grounds for supposing that the anus has become lost by retrogressive changes. If for the moment it is granted that the Pilidium larva represents more nearly than the larve of the other groups the ancestral type of larva, what characters are we led to assign to the ancestral form which this larva repeats?

In the first place, this ancestral form, of which fig. 2:31 A is an ideal representation, would appear to have had a dome-shaped body, with a flattened oral surface and a rounded aboral surface. Its symmetry was radial, and in the centre of the flattened oral surface was placed the mouth, and round its edge was a ring of cilia. The passage of a Pilidium-like larva into the vermiform bilateral Platyelminth form, and therefore it may be presumed of the ancestral form which this larva repeats, is effected by the larva becoming
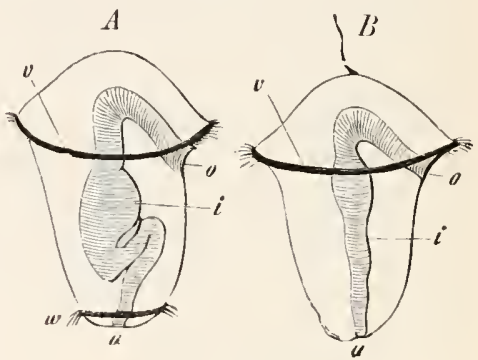

Fig. 225. Two Chetopod LARVA. (From Gegenbaur.)

o. mouth; $i$. intestine; $a$. anus; $v$. praroral ciliated band; $v$. perianal ciliated band. more elongated, and by the region between the mouth and one end of the body becoming the præoral region, aud by an outgrowth between the month and the opposite end developing into the trunk, an anus becoming placed at its extremity in the higher forms.

If what has been so far postulated is correct, it is clear that this primitive larval form bears a very close resemblance to a simplified free-swimming Coelenterate (Medusa), and that the conversion of such a radiate form into the bilateral took place, not by the elongation of the aboral surface, and the formation of an anus there, but by the unequal elongation of the oral face, an anterior part, together with the dome above it, forming a preoral lobe, and a posterior outgrowth the trunk (figs. 226 and 233); while the aboral surface became

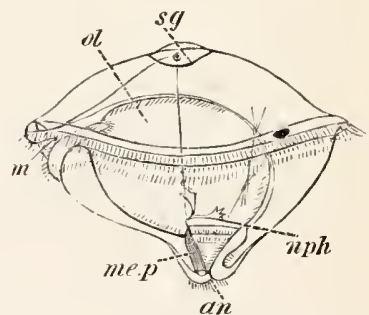

Fig, 226. Polygordus LARva. (After Hatschek.)

m. mouth; sg. supra-cesophageal ganglion; nph. nephridion; me.p. mesoblastic band; an. anus; ol. stomach. the dorsat surface.

This view fits in very well with the anatomical resemblances between the Colenterata and the Turbellaria ${ }^{1}$, and shews, if true,

1 Vide Vol. I. pp. 148 and 158. In this connection attention may be called to Geloplana Metschnikowei, a form described by Kowalevsky, Zoologischer Anzeiger, No. 
that the ventral and median position of the mouth in many Turbellaria is the primitive one.

The above suggestion as to the morle of passage from the radial into the bilateral form differs largely from that usually held. Lankester ${ }^{1}$, for instance, gives the following account of this passage:

"It has been recognised by various writers, but notably by Gegenbaur and Haeckel, that a condition of radiate symmetry must have preceded the condition of bilateral symmetry in animal evolution. The Diblastula may be conceived to have been at first absolutely spherical with spherical symmetry. The establishment of a mouth led necessarily to the establishment of a structural axis passing throngh the mouth, around which axis the body was arranged with radial symmetry. This condition is more or less perfectly

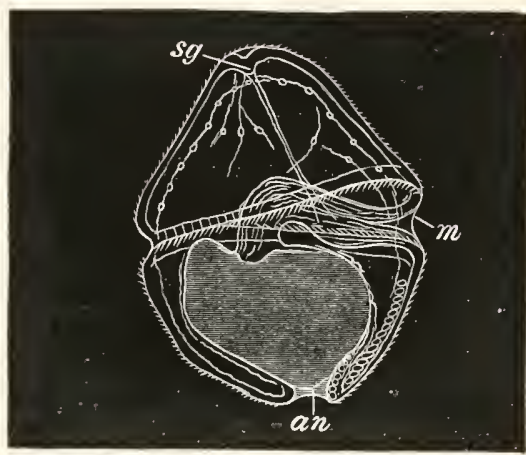

Fig. 227. Larva of Echiurus. (After Salensky.)

$m$. mouth; an. anus; sg. supra-cesophageal ganglion (?).

maintained by many Ccelenterates, and is reassumed by degradation of higher forms (Echinoderms, some Cirrhipedes, some Tunicates). The next step is the differentiation of an uper and a lower surface in relation to the horizontal position, with mouth placed anteriorly, assumed by the organism in locomotion. With the differentiation of a superior and inferior surface, a right and a left side, complementary onc to the other, are necessarily also differentiatcd. 'Thus the organism becomes bilaterally symmetrical. The Coelentera are not wanting in indications of this bilateral symmetry, but for all other higher groups of animals it is a fundamental character. Prolably the development of a region in frout of, and dorsal to the mouth, forming the Prostomium, was accomplisbed pari passu with the levelopment of lilateral symmetry. In the radially symmetrical Coelentera we find very commonly a series of lobes of the body-wall or tentacles produced equally - with radial symmetry, that is to say-all round the mouth, the mouth terminating the main axis of the body-that is to say, the organism being 'telostomiate.' The later fundamental form, common to all animals above the Celentcra, is attained by shifting what was the main axis of the body-so that it may be

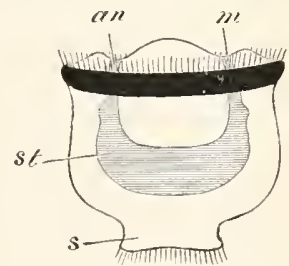

Fig. 228. Diagram of a LARYa of the Polyzod.

$m$. moutl ; an. anus; st. stomach; $s$. ciliated disc.

52, p. 140, as being intermediate between the Ctenophora and the Turbellaria. As already mentioned, there does not appear to me to be sufficient evidence to prove that this form is not merely a creeping Ctenophor.

1 Quart. Journ. of Hicr. Science, Vol. xviI. pp. 422-3. 
described now as the 'enteric 'axis; whilst the new main axis, that parallel with the plane of progression, passes through the dorsil region of the borly rumning obliquely in relation to the enteric axis. Only one lobe or outgrowth of those radially disposed in the telostomiate organisms now persists. This lobe lies dorsally to the mouth, and through it runs the new main axis. This lobe is the Prostominm, and all the organisms which thus develop a new main axis, oblique to the old main axis, may be called prostomiate."

It will be seen from this quotation that the aboral part of the body is supposed to elongate to form the trunk, while the præoral region is derived from one of the tentacles.

Before proceeding to further considerations as to the origin of the Bilateralia, suggested by the Pilidium type of larva, it is necesssary to enter into a more detailed comparison between our larval forms.

A very superficial consideration of the characters of these forms brings to light two important features in which they differ, viz. : lobe.

(1) In the presence or absence of sense organs on the præoral

(2) In the presence or absence of outgrowths from the alimentary tract to form the body cavity.

The larve of the Echinodermata and Actinotrocha (?) are without sense organs on the praoral lobe, while the other types of larva are providert with them. Alimentary diverticula are characteristic of the larva of the Echinodernata and of 'Tornaria.

If the conclusion already arrived at to the effect that the prototype of the six larval groups was descended from a radiate ancestor is correct, it appears to follow that the nervous system, in so far as it was differentiated, had primitively a radiate form; and it is also probably true that there were alimentary diverticula in the form of radial pouches, two of which may have given origin to the paired diverticula which become the body cavity in such types as the Echinoder-
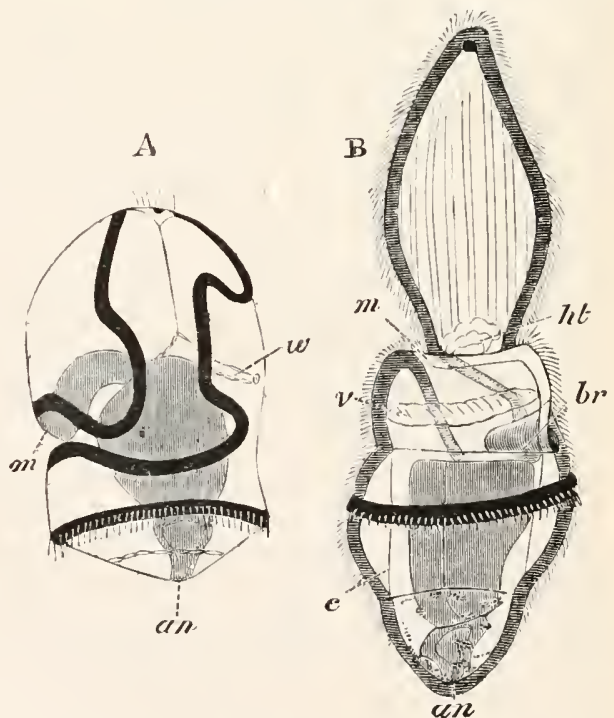

Fig. 229. TWO STAGES IN THE DEVELOPMENT of Torvaria. (After Metschnikoff.)

The black lines represent the ciliated bands.

$m$. mouth; an. anus; $b r$. branchial cleft; $h t$. heart; $c$. body cavity between splanchnic and somatic mesoblast layers; $w$. so-called water-vascular vesicle; $r$. circular blood-vessel. 
mata, Sagitta, etc. If these two points are granted, the further conclusions seem to follow - 1 1) that the ganglion and sense organs of the preoral lobe were secondary structures, which arose (perhaps as differentiations of an original circular nerve ring) after the assumption of a bilateral form; and (2) that the absence of these organs in the larvæ of the Echinodermata and Actinotrocha (?) implies that these larvæ retain, so far, more primitive characters than the Pilidium. The same may be said of the alimentary diverticula. There are thus indications that in two important points the Echinoderm larvæ are nore primitive than the Pilidium.

The above conchusions with reference to the Pilidiun and Echinoderm larva involve some not inconsiderable difficulties, and suggest certain points for further discussion.

In the first place it is to be noted that the above speculations render it

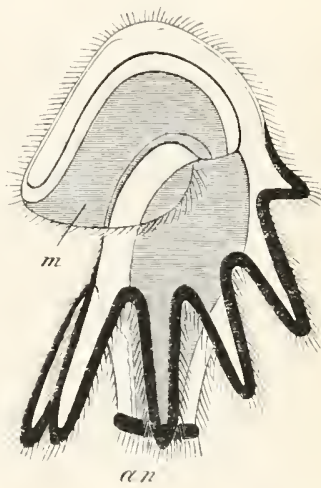

Fig. 230. Actinotroch. (After Metschnikoff.)

$m$. mouth; an. anus. probable that the type of nervous system from which that found in the adults of the Echinodermata, Platyelminthes, Chatopoda, Mollusca, etc., is derived, was a circumoral ring, like that of Medusæ,

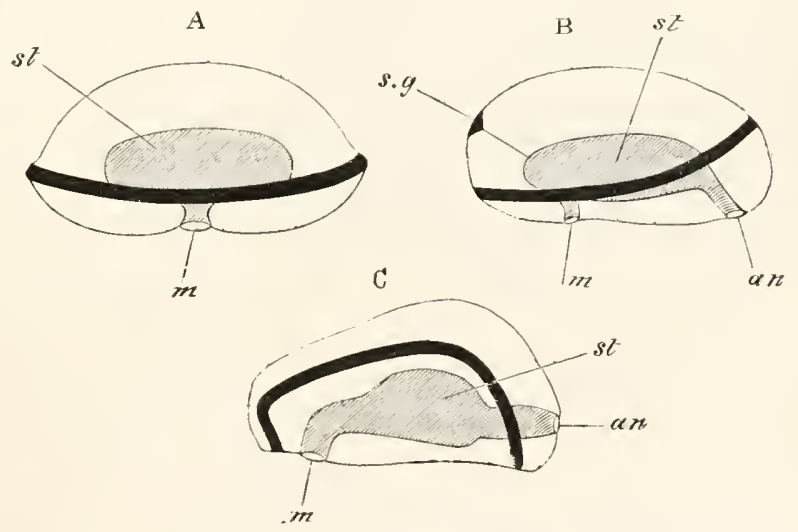

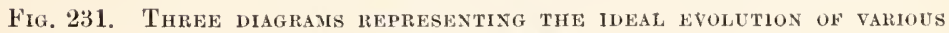
LARVAL FORMS.

A. Ideal ancestral larval form.

B. Larval form from which the Trochosphere larva may have been derived.

C. Larval form from which the typical Echinoderm larva may have been derived. m. mouth; an. anus; st. stomach; s.g. supra-cesophageal ganglion.

The black lines represent the ciliated bands. 
with which radially arranged sense organs may have been connected; and that in the Echinodermata this form of nervous system has been retained, while in the other types it has been modified. Its anterior part may have given rise to supra-œsophageal ganglia and organs of vision; these being developed on the assumption of a bilaterally symmetrical form, and the consequent necessity arising for the sense organs to be situated at the anterior end of the body. If this view is correct, the question presents itself as to how far the posterior part of the nervous system of the Bilateralia can be regarded as derived from the primitive radiate ring.

A circumoral nerve-ring, if longitudinally extended, might give rise to a pair of nerve-cords united in front and behind-exactly such a nervous system, in fact, as is present in many Nemertines ${ }^{1}$ (the Enopla and Pelagonemertes), in Peripatus ${ }^{2}$, and in primitive molluscan types (Chiton, Fissurella, etc.). From the lateral parts of this ring it would be easy to derive the ventral cord of the Chrotopoda and Arthropoda. It is especially leserving of notice in connection with the nervous system of the aliove-mentioned Nemertines and Peripatus, that the commissure connecting the two nerve-cords behind is placed on the dorsal side of the intestine. As is at once obvious, by referring to the diagran (fig. $2: 31$ l3), this is the position this commissure ought, undoubtedly, to occupy if derived from part of a nerve-ring which originally followed more or less closely the ciliated edge of the body of the supposed radiate ancestor.

The fact of this arrangement of the nervous system being found in so primitive a type as the Nemertines tends to establish the views for which I am arguing; the absence or imperfect development of the two longitudinal cords in Turbellarians may very probably be due to the posterior part of the nerve-ring having atrophied in this group.

It is by no means certain that this arrangement of the nervous system in some Moliusca and in Peripatus is primitive, though it may be so.

In the larve of the Turbellaria the development of sense organs in the præoral region is very clear (fig. $222 \mathrm{~B}$ ); but this is by no means so obvious in the case of the true Pilidium. There is in Pilidium (fig. 232 A) a thickening of epiblast at the summit of the dorsal dome, which night seem, from the analogy of Mitraria, ete. (fig. 233), to correspond to the thickening of the prieoral lobe, which gives rise to the supra-cesophageal ganglion; but, as a matter of fact, this part of the larva does not apparently enter into the formation of the young Nemertine (tig. 232). The peculiar metamorphosis, which takes place in the development of the Nemertine out of the Pilidium ${ }^{3}$, may, perhaps, eventually supply an explanation of this fact; but at present it remains as a still unsolved dithiculty.

1 Vide Hubrecht, "Zur Anat. und Phys. d. Nerven-System. d. Nemertinen," Kön. Akud. Wiss., Amsterdam; and "Researches on the Nervous System of Nemertines," Quart. Journ. of Hicr. Science, 1880.

2 Vide F. M. Balfour, "On some points in the Anat. of Peripatus capensis," Quart. . Hum. of Nier. Srience, Vol. xix. 1879.

3 Vide Vol. 1. p. 169. 
The position of the flagellum in Pilidium, and of the supra-cosophageal ganglion in Mitrariat, suggests a different view of the origin of the supracesophageal ganglion from that adopted above. The position of the ganglion in Mitraria corresponds closely with that of the auditory organ in Ctenophora; and it is not impossible that the two structures may have had a common origin. If this view is correct, we must suppose that the apex of the aboral lobe has become the centre of the prooral field of the $\mathrm{Pi}$ idium and Trochosphere larval forms ${ }^{2}$ - a view which fits in very well with their structure (figs. 226 and 233). The whole of the questions concerning the nervous system are still very obscure, and until further facts are brought to light no definite conclusions can be arrived at.

The absence of sense organs on the præoral lobe of larval Echinodermata, coupled with the structure of the nervous system of the adult, points to the conclusion that the adult Echinodermata have retained, and not, as is now usually held, secondarily acquired, their radial symmetry; and if this is admitted it follows that the obvious bilateral symmetry of Echinoderm

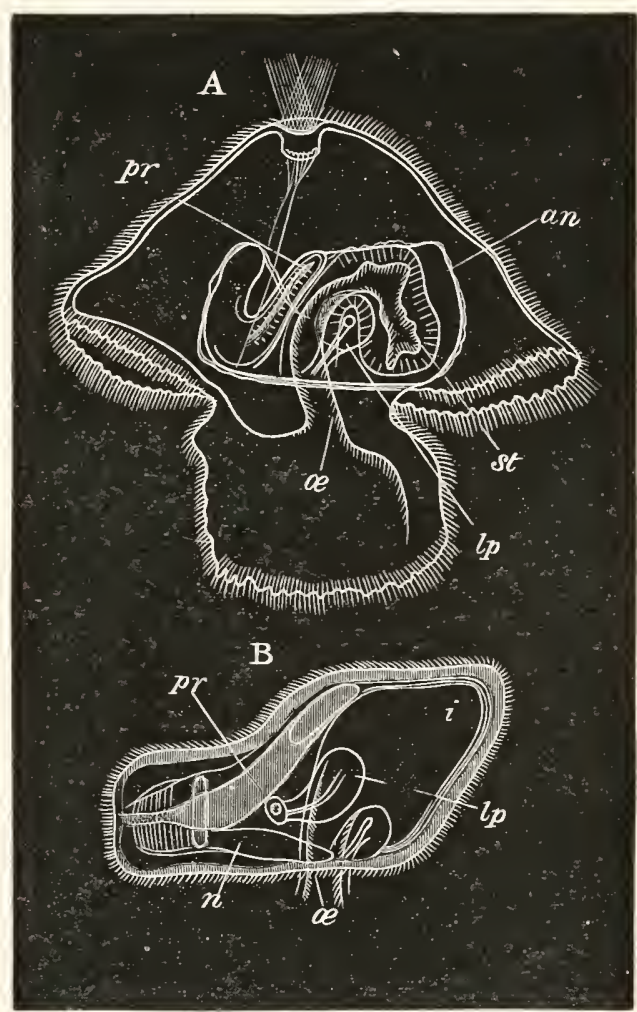

Fig. 232. A. Pilidicu with an advanced Nemertise Woru. B. Ripe embryo of Nemertes in the position it occupies in Pilidiun. (Both after Bütschli.)

$a$. oesophagus; st. stomach; $i$. intestine; $p r$. proboseis; $l p$. lateral pit (cephalic sack); an. amnion; $n$. nervous system. larvi is a secondary character.

The bilateral symmetry of many Coelenterate larva (the larva of Eginopsis, of many Acraspeda, of Actinia, \&c.), coupled with the fact that a bilateral symmetry is obviously advantageous to a free-swimuning form, is sufficient to shew that this supposition is by no means extravagant; while the presence of only two alimentary

1 The indepen lent development of the supra-œsophageal ganglion and ventral nerve-cord in Chatopoda (vide Kleinenberg, Development of Lumbricus trapezoides) agrees very satisfactorily with this view. 
diverticula in Echinoderm larvie is quite in accord with the presence of a single pair of perigastric chambers in the early larva of Actinia, though it must be admitted that the derivation of the water-vascular system from the left diverticulum is not easy to understand on this view.

A difficulty in the above speculation is presented by the fact of the anus of the Echinodermata being the permanent blastopore, and arising prior to the mouth. If this fact has any special significance, it becomes difficult to regard the larva of Echinoderms and that of the other types as in any way related; but if the views already urged, in a previous section on the germinal layer's, as to the mimportance of the blastopore, are admitted, the fact of the anus coinciding with the blastopore ceases to be a difficulty. As may be scen, by referring to fig. $231 \mathrm{C}$, the anus is placed on the dorsal side of the ciliated band. This position for the anns adapts itself to the view that the Echinoderm larva had originally a radial symmetry, with the anus placed at the aboral apex, and that, with the elongation of the larva on the attainment of a bilateral symmetry, the aboral apex became shifted to the present position of the anus.

It may he noticed that the obseure points comnected with the absence of a body eavity in most adult Platvelminthes, which have ahrealy been dealt with in the section of this clrapter devoted to the germinal layers, present themselves again here; and that it is necessary to assume either that alimentary diverticula, like those in the Echinodermata, were primitively present in the Platyehninthes, but have now disappeared from the ontogeny of this group, or that the alimentary diverticula have not become separated from the alimentary tract.

So far the conclusion has been reached that the archetype of the six types of larvie had a radiate form, and that amongst existing larve it is most nearly approached in general shape and in the form of the alimentary canal by the Pilidium group, and in certain other particulars by the Echinoderm larve.

The edge of the oral dise of the larval archetype was probably armed with a ciliated ring, from which the ciliated ring of the Pilidium type and of the Echinodermata was most likely derived. The ciliated riug of the Pilidium varies greatly in its characters, and has not always the form of a eomplete ring. In Pilidium proper (fig. 232 A) it is a simple ring surrounding the edge of the oral disc. In Miiller's larva of Thysanozoon (fig. $2 \cdot 2 \mathrm{~B}$ ) it is inclined at an axis to the oral disc, and might be called præoral, but such a term cannot be properly used in the absence of an anus.

The Echinodem ring is oblique to the axis of the borly, and, owing to the fact of its passing ventrally in front of the anus, must be called postoral.

The next point to be considered is that of the affinities of the other larval types to these two types.

The most important of all the larval types is the Trochosphere, and this type is undoubterly more closely related to the Pilidinm 
than to the Echinoderm larva. Mitraria annougst the Chetopods

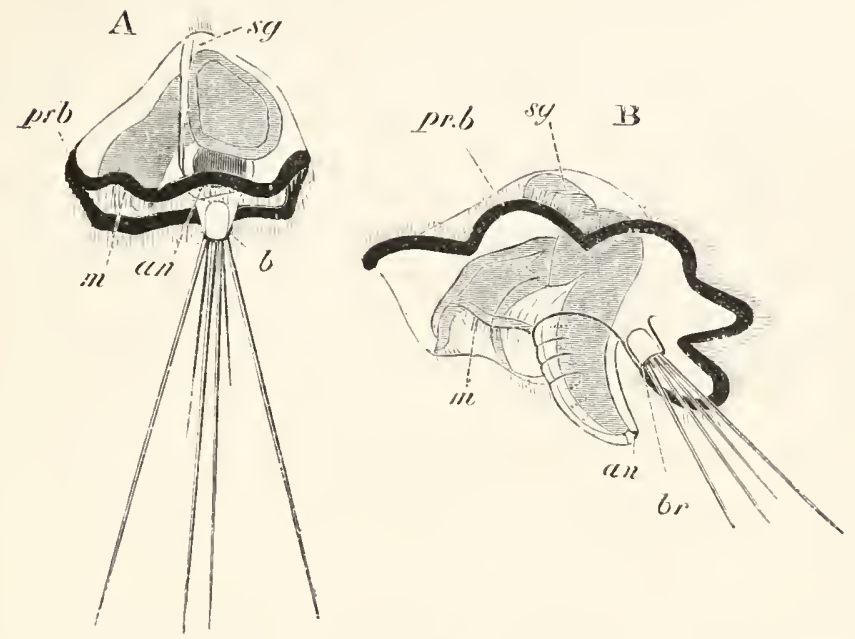

Fig. 233. Two stages in the inevelopient of Mitraris. (After Metschnikoti.) $m$. mouth; an. anus; sg. supra-cesophageal ganglion; $b r$. and $b$. provisional bristles; $m \cdot b$. præoral ciliated band.

(fig. 2:3:3) has, indeed, nearly the form of a Pilidium, and mainly duffers from a Pilidium in the possession of an anus and of provisional bristles; the same may be said of Cyphonautes (fig. 2:34) amongst the Polyzon.

The existence of these two forms appears to shew that the præoral ciliated ring of the Trochosphere mily very probably be derived directly from the circumoral ciliated ring of the Pililium; the other ciliated rings or patches of the Trochosphere having a secondary origin.

The larva of the Brachiopoda (fig. 2.20 ), in spite of its peculiar characters, is, in all probability, more closely related to the Chatopod Trochosphere than to any other larval type. The most conspicuous point of agreement between them is, lowever, the possession in common of provisional setre.

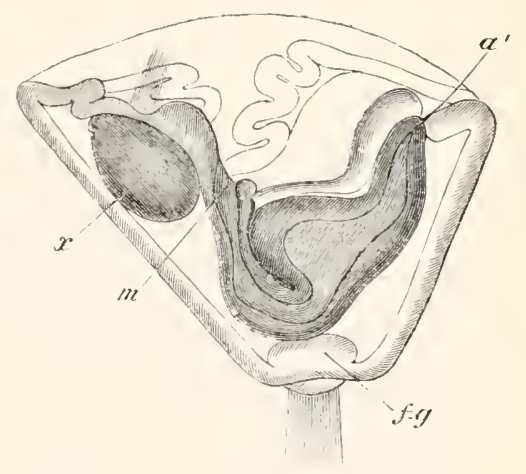

Fig. 234. Crphonates (Laliva of MemishNIPORA). (After Hatschek.)

m. mouth; $a^{\prime}$. anus; $f . g$. foot gland; $x$. problematical body (probably a bud).

The aboral apex is turned downwards. 
Echinoderm larvæ differ from the Trochosphere, not only in the points already alluded to, but in the character of the ciliated band. The Echinoderm band is longitudinal and postoral. As just stated, there is reason to think that the præoral band of the Trochosphere and the postoral band of the Echinoderm larva are both derived from a ciliated ring surrounding the oral disc of the prototype of these larvæ (ride fig. 2:31). In the case of the Echinodermata the anus must have been formed on the dorsal side of this ring, and in the case of the Trochosphere on the ventral side; and so the difference in position between the two rings was brought about. Another view with reference to these rings has been put forward by Gegenbaur and Lankester, to the effect that the prreoral ring of the Trochosphere is derived from the breaking up of the single band of most Echinoderm larvæ into the two bands found in Bipinnaria (vide fig. 223) and the atrophy of the posterior band. There is no doubt a good deal to be said for this origin of the præoral ring, and it is strengthened by the case of 'Tornaria; but the view adopted above appears to me more probable.

Actinotrocha (fig. 2:30) undoubtedly resembles more closely Echinoderm larva than the Trochosphere. Its ciliated ring has Echinoderm characters, and the growth along the line of the ciliated ring of a series of arms is very similar to what takes place in many Echinoderms. It also agrees with the Echinoderm larvæ in the absence of sense organs on the prizoral lobe.

Tornaria (fig. 229) cannot be definitely united either with the Trochosphere or with the Echinoderm larval type. It has important characters in common with both of these groups, and the mixture of these characters renders it a very striking and well-defined larval form.

Phylogenetic conclusions. The phylogenetic conclusions which follow from the above views remain to be dealt with. The fact that all the larvæ of the groups above the Coelenterata can be reduced to a common type seems to indicate that all the higher groups are descended from a single stem.

Considering that the larvæ of comparatively few groups have persisted, no conclusions as to affinities can be drawn from the absence of a larva in any group; and the presence in two groups of a common larval form may be taken as proving a comnon descent, but does not necessarily shew any chose aftinity.

There is every reason to believe that the types with a Trochosphere larva, viz. the Rotifera, the Mollusca, the Chætopoda, the Gephyrea, and the Polyzoa, are descended from a common ancestral form; and it is also fairly certain there was a remote ancestor common to these forms and to the Platyelminthes. A general affinity of the Brachiopoda with the Chatopoda is more than probable. All these types, together with various other types which are nearly related to them, but have not preserved an early larval form, are descended from a bilateral ancestor. The Echinodermata, on the other hand, are probably directly descended from a radial ancestor, and have more or less 
completely retained their radial symmetry. How far Actinotrocha ${ }^{1}$ is related to the Echinoderm larve cammot be settled. Its characters may possibly be secondary, like those of the mesotrochal larva of Chrtopods, or they may be due to its having branched off very early from the stock common to the whole of the forms above the Colenterata. The position of Tornaria is still more obscure. It is difficult, in the face of the peculiar water-vascular vesicle with a dorsal pore, to avoid the conclusion that it has some affinities with the Echinoderm larve. Snch affinities wonld seem, on the lines of speculation adopted in this section, to prove that its affinities to the Trochosphere, striking as they appear to be, are secondary and adaptive. From this conclusion, if justitied, it would follow that the Echinodermata and Enteropneusta have a remote aucestor in common, but not that the two groups are in any other way related.

General conclusions and summary. Starting from the demonstrated fact that the larval forms of a number of widely separaterl types above the Coelenterata have certain characters in common, it has been provisionally assumed that the characters have been inherited from a common ancestor; and an attempt has been made to determine (1) the characters of the prototype of all these larva, and (2) the mutual relations of the larval forms in question. This attempt started with certain more or less plausible suggestions, the truth of which can only be tested by the colnerence of the results which follow from them, and their capacity to explain all the facts.

The results arrived at may be summarised as follows:

1. The larval forms above the Colenterata may be divided into six groups euumerated on pages 305 to 307 .

2 . The prototype of all these groups was an organism something like a Medusa, with a radial symmetry. The mouth was placed in the centre of a flattened ventral surface. The aboral surface was domeshaped. Round the elge of the oral surface was a ciliated ring, and probally a nervous ring provided with sense organs. The alimentary canal was prolonged into two or more diverticula, and there was no anus.

3. The bilaterally symmetrical types were derived from this larval form by the larva becoming oval, and the region in front of the mouth forming a preoral lobe, and that behind the mouth growing out to form the trunk. The aboral dome became the dorsal surface.

On the establishment of a bilateral symmetry the anterior part of the nervous ring gave rise (?) to the supra-osophageal ganglia, and the optic organs connected with them; while the posterior part of the nerve-ring formed (?) the ventral nerve-cords. The body cavity was developed from two of the primitive alimentary diverticula.

The usual view that radiate forms have become bilateral by the elongation of the aboral dome into the trunk is probably erroneous.

4. Pilidium is the larval form which most nearly reproduces

1 It is quite possible that Phoronis is in no way related to the other Gephyrea. 
the characters of the larval prototype in the course of its conversion into a bilateral form.

5. The Trochosphere is a completely differentiated bilateral for'm, in which an anus has become developed. The præoral ciliated ring of the Trochosphere is probably directly derived from the ciliated ring of Pilidium, which is itself the original ring of the prototype of all these larval forms.

6. Echinoderm larvæ, in the absence of a nerve-ganglion or special organs of sense on the præoral lobe, and in the presence of alimentary diverticula, which give rise to the body cavity, retain some characters of the prototype larva which have been lost in Pilidium. The ciliated ring of Echinoderm larvæ is probably derived directly from that of the prototype by the formation of an anus on the lorsal side of the ring. The anus was very probably originally sitnated at the aboral apex.

Adult Echinoderms have probably retained the radial symmetry of the forms from which they are descended, their nervons ring being directly derived from the circular nervous ring of their ancestors. They have not, as is usually supposed, secondarily acquired their radial symmetry. The bilateral symmetry of the larva is, on this view, secondary, like that of so many Coelenterate larvæ.

7. The points of similarity between Tornaria and (1) the Trochosphere and ( $(2)$ the Echinoderm larva are probably adaptive in the one case or the other; and, while there is no difficulty in believing that those to the Trochosphere are adaptive, the presence of a water-vascular vesicle with a dorsal pore renders probable a real affinity with Echinoderm larva.

8. It is not possible in the present state of our knowledge to decide how far the resemblances between Actinotrocha and Echinoderm larva are adaptive or primary.

\section{BiBLIOGRAPHY.}

(257) Allen Thomson. British Association Address, 1877.

(258) A. Agassiz. "Embryology of the Ctenophoræ." Mem. Amer. Acad. of Arts and Sciences, Vol. x. 1874.

(259) K. E. ron Baer. Ueb. Entwicklungsgcschichte d. Thierc. Königsberg, $182-1837$.

(260) F. M. Balfour. "A Comparison of the Early Stages in the Development of Tertebrates." Quart. Journ. of Vicr. Sci., Vol. xv. 1875.

(261) C. Claus. Die Typentehre u. E Haeckel's sy. Gastrantheorie. Wien, 1874 .

(262) C. Claus. Grundzïge d. Zoologie. Marburg und Leipzig, 1879.

(263) A. Dohrn. Der Ursprung d. Wirbelthiere $u$. d. Princip des Functionswechsels. Leipzig, 1875 .

(264) C. Gegenbanr. Geundriss d. vergleicheuden Anatomic. Leipzig, 1878.

ride also Transiotion. Elements of Comparatice Anutomy. Nacmillan \& Co. 1878.

(265) A. Götte. Entwicklungsgeschichte d. Unkc. Leipzig, 1874.

(266) E. Haeckel. Studien $z$. Gastratheorie, Jena, 1877; and also Jenaische Zsitschrift, Vols. vin. and Ix. 1874-5.

(267) E. Haeckel. Schöpfungsgeschichte. Leipzig. Vide also Translation. The Histery of Creation. King \& Co., London, $187 \mathrm{~s}$. 
(268) E. Haeckel. Anthropogenie. Leipzig. Fide also Translation. Anthropogeny. Kegan Paul \& Co., London, 1878.

(269) B. Hat schek. "Studien üb. Entwicklungsgeschichte d. Anneliden." Arbeit. a. d. zool. Instit. d. Univer. Wien. 1878.

(270) O. and R. Hertwig. "Die Actinien." Jenaische Zeitschrift, Vols. xmI. and XIv. 1879.

(27I) O. and R. Hertwig. Die Colomtheorie. Jena, $1881^{1}$.

$(272)$ O. Hertwig. Die Chetognathen. Jena, 1880.

(273) R. Hertwig. Veb. d. Ban d. Ctemophorem. Jena, 1880.

(27t) T. H. Huxley. The Amatomy of Imertebrated Animals. Churehill, 1877.

$\left(27 t^{*}\right)$ T. H. Huxley. "On the Classification of the Animal Kingdom." Qnart.

J. of Hicr. Science, Vol. xv. 1875.

(275) N. Kleinenberg. Iydra, eine anatomisch-entwicklungsgeschichte Untorsuchung. Leipzig, 187:2.

$(2-6)$ A. Kölliker. Entwicklungsgeschichte d. Henschen $u$. d. hoh. Thiere. Leipzig, 1879 .

(277) A. Kowalevsky. "Embryologische Studien an Wïrmeru u. Arthropoden." Mém. Acad. Pétersonra, Series viI. Vol. xvi. 1871.

$(278)$ E. R. Lankester. "On the Germinal Layers of the Embryo as the Basis of the Genealogical Classification of Animals." A mu. and Mag. of Nat. Hist. 1873.

(279) E. R. Lankester. "Notes on Embryology and Classification." Quart. Jomrn. of Hicr. Sei., Vol. xvir. 1877.

(280) E. Metschnikoff. "Zur Lntwicklungsgeschichte d. Kalkschwämme." Zeit. f. wiss. Zool., Vol. xxiv. 1874.

(2SI) F. Metsehnikoff. "Spongiologische Studien." Zeit. f. Uiss. Zool., Vol. xxxiI. 1879 .

(282) A. S. P. Packard. Life Histories of Animals, incluting Man, or Ontlines of Comparative Embryology. Holt and Co., New York, 1876.

$(283)$ C. Rabl. "Uéb. d. Entwick. d. Malermuschel." "tenaische Zeitsch., Vol. x. $187 \%$.

$\left(28_{4}\right)$ C. Rabl. "Ueb. d. Entwicklung. a. Tellerschneke (Planorbis)." Morph. Jahrbnch, Vol. v. 1879.

(285) H. Rathke. Abhandlunyen z. Bildnng und Eutwicklmngsgesch. d. Menschen u. d. Thieve. Leipzig, 18:33.

(286) H. Rathke. Leber die Bildmng n. Entuicklnngs. d. Flusskrebses. Leipzig, 1829.

$(287)$ I. Remak. Untersnch. ̈̈b. d. Entwich. d. Wirbelthiere. Berliu, 1855.

(288) Salensky. "Bemerkangen ib. Haeckels Gastrae-theorie." Archir" $f$. Natwrgeschichte, $187 \dot{4}$.

(289) F. Schäfer. "Some Teachings of Development." Quart. Journ. of Mier. Science, Vol. xx. 1880.

(290) C. Semper. "Die Verwandtschaftbeziehungen d. gegliederten Thiere." Arbeiten a. al. zool.-zoot. Instit. Wrïzbnrg, Tol. II. 1876-7.

1 'This important memoir only came into my hands after this chapter' was already in type. 



\section{PAR'T II.}

\section{URGANOGEIY.}





\section{PART II.}

\section{ORGANOGENY.}

\section{INTRODUCTION.}

Oun knowledge of the development of the organs in most of the Invertebrate groups is so meagre that it would not be profitable to attempt to treat systematically the organogeny of the whole animal kinglom.

For this reason the plan adopted in this section of the work has been to treat somewhat fully the organogeny of the Chorlata, which is comparatively well known; and merely to indicate a few salient facts with reference to the organogeny of other groups. In the case of the nervous system, and of some other organs which especially lend themselves to this treatment, such as the organs of special sense and the excretory system, a wider view of the subject has been taken; and certain general principles underlying the development of other organs have also been noticed.

The classification of the organs is a matter of some difficulty. Considering the character of this treatise it seemed desirable to arrange the organs according to the layers from which they are developed. The compound nature of many organs, e.g. the eye and ear, renders it, however, impossible to carry out consistently such a mode of treatment. I have accordingly adopted a rough classification of the organs according to the layers, dropping the principle where convenient, as, for instance, in the case of the stomodaum and proctodieum.

The organs which may be regarder as mainly derived from the epiblast are (1) the skin; (2) the nervous system; (3) the organs of special sense.

Those from the mesoblast are (1) the general connective tissue and skeleton ; (2) the vascular system and body cavity; (3) the muscular system ; (4) the urinogenital system. 
Those from the hypoblast are the alimentary tract and its derivates; with which the stomodæum and proctodæum and their respective derivates are also dealt with.

\section{BIBLIOGRAPHY.}

General works dealing with the develomment of the organs of the Chordate.

(291) K. E. von Baer. Veber Entricklungsgexchichte d. Thiere. Königsberg, $1828-1837$.

(292) I. M. Balfour. A Monograph on the development of Elasmolranch Fishes. London, 1878.

(29.3) Th. C. W. Bisch of f. Entwicklungsgesch. d. Säugethiere u. d. Menschen. Leipzig, 1842.

(294) C. Gegenbaur. Grmdioss d. vergleichenden. Anatomie. Leipzig, 1878. Vide also English translation, Elements of Comp. Anutomy. London, 1878.

(295) M. Foster and F. M. Balfour. The Elements of Embryology. Part I. Loudon, 1874.

(296) Alex. Götte. Entwicklungsgeschichte d. Vnke. Leipzig, 1875. 1868.

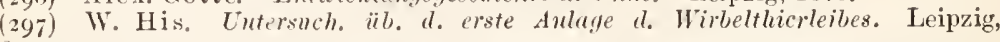

(298) A. Kölliker. Entwicklmngggeschichte d. Menschen u. der höheren Thiere. Leipzig, 1879 .

(299) H. Rathke. Abhandlungen ï. Bildung und Entuicklongsgeschichte d. Menschen $и$. d. Thiere. Leipzig, 1838.

(300) H. Rathke. Entwiclilungs. d. Natter. Königsberg, 1839.

(3०г) H. Rathke. Entuicklungs.d. Hirbelthere. Leipzig, 1861.

(302) R. Remak. Untcrsuchungen ïl. A. Entuicklung d. Wirbelthiere. Berlin, $1850-1855$. 1874 .

(3०3) S. L. Schenk. Lebrbuch d. vergleich. Embryologie d. Wirbelthiere. IVien, 


\section{CHAP'TER XIT.}

\section{THE EPIDERMIS AND ITS DERIVATIVES.}

Is many of the Coelenterata the outermost layer of the blastoderm is converted as a whole into the skin or ectoderm. The cells composing it become no doubt in part differentiated into muscular elements and in part into nervous elements. \&e.; but still it may remain through life as a simple extemal membrane. This membrane contains in itself indefinite potentialities for developing into varions organs, and in all the true Triploblastica these potentialities are more or less realized. The embryonic epiblast ceases in fact, in the higher forms, to become converted as a whole into the epidermis, but first gives rise to parts of the nervous system, organs of special sense, and other parts.

After the formation of these parts the remnant of the epiblast gives rise to the epidermis, and often unites more or less iutimately with a subjacent layer of mesoblast, known as the dermis, to form with it the skin.

Varions differentiations may arise in the epidermis forming protective or skeletal structures, terminal sense organs, or glands. The structure of the epidermis itself varies greatly, and for Vertebrates its general modifications have been already sufficiently dealt with in chapter xiI. Of its special differentiations those of a protective or skeletal nature and those of a glandular nature may be considered in this place.

Protective epidermal structures. These structures constitute a general cuticle or an exoskeleton of scales, hairs, feathers, nails, hoofs, \&c. They may be entirely formed from the epidermis either as (1) a cuticular deposit, or as (2) a chitinization, a cornification, or calcification of its constituent cells. These two processes rum into each other, and are in many cases not easily distinguished. The protective structures of the epidermis may be divided into two groups according as they are formed on the outer or the inner side of the epidermis. Dermal skeletal structures are in many cases added to them. Amongst the Invertebrata the most widely distributed type 
of exoskeleton is a cuticle formed on the outer surface of the epidermis, which reaches its highest development in the Arthropoda. In the same elass with this cuticle must be placed the molluscan and brachiopod shells, which are developed as cuticular plates on special regions of the epidermis. They differ, however, from the more usual form of cuticle in their slighter adhesion to the subjacent epidermis, and in their more complicated structure. The test of Ascidians is an abnormal form of exoskeleton belonging to this type. It is originally formed (Hertwig and Semper) as a cuticle on the surface of the epidermis; but subsequently epidermic cells migrate into it, and it then constitutes a tissue similar to connective tissue, but differing from ordinary epidermic cuticles in that the cells which deposit it do so over their whole surface, instead of one surface, as is usually the case with epithelial cells.

In the Vertebrata the two types of exoskeleton mentioned above are both found, but that developed on the inner surface of the epidermis is always associated with a dermal skeleton, and that on the outer side frequently so. The type of exoskeleton developed on the inner side of the general epidermis is confined to the Pisces, where it appears as the scales; but a primitive form of these structures persists as the teeth in the Amphibia and Amniota. The type developed on the outer side of the epidermis is almost entirely ${ }^{1}$ confined to the Amphibia and Amniota, where it appears as scales, feathers, hairs, claws, nails, de. For the histological details as to the formation of these various organs I must refer the reader to treatises on listology, confining iny attention here to the general embryological processes which take place in their development.

The most primitive form of the first type of dermal structures is that of the placoid scales of Elasmobranchii ${ }^{2}$. These consist, when fully formed, of a plate bearing a spinous projection. They are constituted of an outer enamel layer on the projecting part, developed as a cuticular deposit of the epidermis (epiblast), and an underlying basis of dentine (the lower part of which may be osseous) with a vascular pulp in its axis. 'The development (fig. 2:35) is as follows (Hertwig, No. 306). A papilla of the dermis makes its appearance, the outer layer of which gradually calcifies to form the dentine and osseous tissue. This papilla is covered by the columnar mucous layer of the epidermis (e), from which it is separated by a basement membrane, itself a product of the epidermis. This membrane gradually thickens and calcifies, and so gives rise to the enamel cap $(0)$. The spinous point gradually forces its way through the epidermis, so as to project freely at the surface.

The scales of other forms of fishes are to be derived from those of Elasmobranchii. The great dermal plates of many fishes have been

1 The horny teeth of the Cyclostomata are structures belonging to this group.

2 For the most important contributions on this subject from which the facts and views here expressed are largely derived, vide O. Hertwig, Nos. 306-308. 
furmed by the concrescence of groups of such scales. The dentine in many cases partially or completely atrophies, leaving the major part of the scale formed of osseous tissue; such plates often become parts of the intermal skeleton.

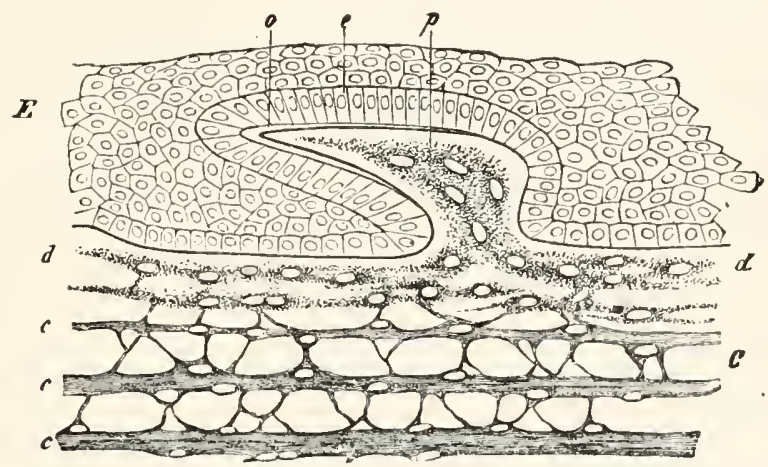

Fig. 235. Verticar section throvgh the sin of an embrionic Shark, to shew A Developing Placoid scale. (From Gegenbaur; after O. Hertwig.)

$E$. epidermis; $C$. layers of dermis; $d$. uppermost layer of dermis; $p$. papilla of dermis; $e$. mucous layer of epidermis; o. enamel layer.

The teeth, as will be more particularly described in the section on the alimentary tract, are formed by a moditication of the same process as the placoid scales, in which a ridge of the epithelium grows inwards to meet a comective tissne papilla, so that the development of the teeth takes place entirely below the superficial layer of epidermis.

In most Teleostei the enamel and dentine layers have disappeared, and the scales are entirely formed of a peculiar calcified tissue developed in the dermis.

The cuticle covering the scales of Reptiles is the simplest type of protective structure formed on the outer surface of the epidermis. The scales consist of papillae of the dermis and epidermis; and are covered by a thickened portion of a two-layered cuticle, formed over the whole surface of the body from a cornification of the superticial part of the epidermis. Dermal osseous plates may be formed in connection with these scales, but are never of course united with the superficial cuticle.

Feathers are probably special modifications of such scales. They arise from an induration of the epidermis of papillæe containing a vascular core. The provisional down, usually present at the time of hatching, is formed by the cornitication of longitudinal ridges of the mucous layer of the epidermis of the papillæ; each cornified ridge giving rise to a barb of the feather. The horny layer of the epidermis forms a provisional sheath for the developing feather below. When the barbs are fully formed this sheath is thrown off, the vascular core dries up, and the barbs become free except at their base.

Without entering into the somewhat complicated details of the formation of the permanent feathers, it may be mentioned that the ealamus or 
yuill is formed by a cornification in the form of a tube of hoth layers of the epidermis at the base of the papilla. The quill is open at both ends, and to it is attached the vexillum or plume of the feather. In a typical feather this is formed at the apex of the papilla from ridge-like thickenings of the mucous layer of the epidermis, arranged in the form of a longitudinal axis, continuous with the connitied mucous layer of the quill, and from lateral ridges. These subsequently become converted into the axis and barbs of the plume. The external epidermic layer becomes converted into a provisional horny shrath for the true feather beneath.

On the completion of the phume of the feather the external sheath is thrown off; leaving it quite free, and the vascular core belonging to it shrivels up. The papilla in which the feather is formed bccomes at a very early period secondurily enveloped in a pit or follicle which gradually deepens as the developnent of the feather is continuerl.

Hairs (Kölliker, No. 298) are formel in solid processes of the mucous layer of the epidermis, which project into the subjacent dermis. The hair itself arises from a cornification of the cells of the axis of one of the above processes; and is invested by a sheath similarly formed from the more superficial epidermic cells. A small papilla of the dermis grows into the imner end of the epidermic process when the hair is first formed. 'The first trace of the hair appears close to this papilla, but soon increases in length, and when the end of the hair projects from the surface, the original solid process of the epidermis becomes converted into an open pit, the lumen of which is filled by the root of the hair. Hairs differ in their mode of formation from scales in a mannel analogous to that in which the teeth differ from ordinary placoid scales; $i . e$. they are formed in inwardly directed projections of the epidermis instead of upon free papilla at the surfice.

Nails (Kïlliker, No 208) are developed on special regions of the epidermis, known as the primitive nail berks. 'They are formed by the cornification of a layer of cells which makes its appearance between the horny and mucons layers of the epidermis. The distal border of the nail som becomes free, and the further growth is effected by additions to the under side and attached extremity of the nail.

Although the nail at first arises in the interior of the epidermis, ret its position on the outer side of the mucous layer elearly indicates with which group of epidemic structures it should be classitied.

Dermal skeletal structures. We have seen that in the Chordata skeletal structures, which were primitively formed of both an epidermic and dermic element, may lose the former element and be entirely developed in the dermis. Amongst the Invertebrata there are certain dermal skeletal structures which are evolved wholly independently of the epilermis. The most important of these structures are the skeletal plates of the Echinodermata.

Glands. 'The secretory part of the various glandular structures belonging to the skin is invariably formed from the epidermis. In Mammalia it appears that these glands are always formed as solid in- 
growths of the mucous layer (Kölliker, No. 298). The ends of these ingrowths dilate to form the true glandular part of the organs, while the stalks comnecting the glandular portions with the surface form the ducts. In the case of the sweat-glands the lumen of the duct becomez first established. Its formation is inangurated by the appearance of the cuticle, and appears first at the inner end of the dnet and thence extends outwards (Ranvier, No. 3II). In the sebaceous glands the first secretion is formed by a fatty modification of the whole of the central cells of the gland.

The muscular layer of the secreting part of the sweat-glands is formed. according to Ranvier (No. 3II), from a moditication of the deeper layer of the epidermic cells.

The Mammary Glands arise in essentially the same manner as the other glands of the skin ${ }^{1}$. 'The glands of each side are formed as a solid bud of the mucous laver of the epidermis. From this bud processes sprout out, each of which gives rise to one of the numerous glands of which the whole organ is formed. Two very distinct types in the relation of the ducts of the glands to the nipple are found (Cegenbaur, No. 3I3).

\section{Biblography OF EpIDERMIS.}

\section{Generul.}

$\left(30_{+}\right)$T. H. Huxley. "Tegumentary orgaus." Todd's Cyclopadia of Anat. and Physiol.

(305) P. Z. Unna. "Histol. u. Entwick. d. Oberliant." Archir f. mikr. Anat. Vol. xv. 1876. Tide also Kölliker (No. 298).

\section{Scules of the Pisces.}

(305) O. Hertwig. "Leber Bau u. Entwicklung d. Placoidschuppen u. d. Zälne d. Selachier." Jenaische Zeitsehrift, Vol. vin. 1874.

(307) O. Hertwig. "Yeber d. Hautskelet d. Fische." Norphol. Jahrbuch, Vol. rr. 1876. (Siluroiden u. Acipenseridx.)

(3c8) O. Hertwig. "Ceber d. Hautskelet d. Fische (Lepidosteus u. Polypterus)." Morph. Jahrbuch, Tol. v. 1879.

\section{Feathers.}

(309) Th. Studer. Die Entwick. d. Federn. Inaug. Diss. Bern, 1873.

(3í) Th. Studer. "Beiträge z. Entwick. d. Feler." Zeit. f. wiss. Zool., Vol. $\mathrm{xxx} .1878$.

\section{Siveut-glands.}

(3II) M. S. Ranvier. "Sur la structure des glandes suloripares." Comptes Rendus, Dec. 29, 1879.

\section{Mammary glands.}

(3i 2) C. Creighton. "On the devel. of the Mamma and the Mammary fuuction." Jour, of Anat. and Phys., Vol. xi. 1877.

(313) C. Gegenbaur. "Bemerkungen iib. d. Milehdriisen-Papillen d. Säugethiere." Jenaische Zeit., Vol. vir. 1873.

(314) M. Huss. "Beitr. z. Entwick. d. Milchdriisen b. Menschen u. b. Wiederkäuern." Jenaische Zeit., Vol. vir. 1873.

(315) C. Langer. "Ueber d. Bau u. d. Entwicklung d. Milchdriisen." Inenk. d. k. Akud. Wiss. Wien, Vol. n. 18.51.

1 For a very different view on this subject vid, Creighton (No. 312). 


\section{CHAPTER XV.}

\section{NERVOUS SYSTEM.}

\section{Origin of the Nervous System.}

ONE of the most important recent embryological discoveries is the fact that the central nervous system, in all the Metazoa in which it is fully established, is (with a few doubtful exceptions) derived from the primitive epiblast ${ }^{1}$. As we have already seen that the epiblast represents to a large extent the primitive epidermis, the fact of the nervous system being derivel from the epiblast implies that the functions of the central nervous system, which were originally taken by the whole skin, became gradually concentrated in a special part of the skin which was step by step removed from the surface, and has finally become in the higher types a well-defined organ imbedded in the subdermal tissues.

Before considering in detail the comparative development of the nervous system, it will be convenient shortly to review the present state of our knowledge on the general process of its evolution.

This process may be studied either embryologically, or by a comparison of the various stages in its evolution preserved in living forms. Both the methods have led to important results.

The embryological evidence shews that the ganglion-cells of the central part of the nervous system are originally derived from the simple undifferentiated epithelial cells of the surface of the body, while the central nervous system itself has arisen from the concentration of such cells in special tracts. In the Chordata at any rate the nerves arise as outgrowths of the central organ.

Another important fact shewn by embryology is that the central nervous system, and percipient portions of the organs of special sense,

1 Whether there is any part of it in many types not so derived requires further investigation, now that it has been shewn by the Hertwigs that part of the system derelops from the endoderm in some Cœlenterata. O. Hertwig holds that part of it has a mesoblastic origin in Sagitta, but his observations on this point appear to me very inconclusive. It would be very advantageous to investigate the origin of Auerbach's plexus in Mammalia. 
especially of optic organs, are often formed from the same part of the primitive epidermis. Thus the retina of the Vertebrate eye is formed from the two lateral lobes of the primitive fore-brain.

The same is true for the compound eyes of some Crustacea. The supracsophageal ganglia of these animals are formed in the embryo from two thickened patches of the epiblast of the procephalic lobes. These thickened patches become gradually detached from the surface, remaining covered by a layer of epidermis. They then constitute the supracesophageal ganglia; but they form not only the ganglia, but also the retinulie of the eye-the parts in fact which correspond to the rods and cones in our own retina. The accessory parts of these organs of special sense, viz. the crystalline lens of the Vertebrate eye, and the corneal lenses and crystalline cones of the Crustacean eye, are independently formed from the epiblast after the separation of the part which becomes the central nervous system.

In the Acraspedote Medusæ the rudimentary central nervous system has the form of isolated rings, composed of sense-cells prolonged into nervous fibres, surrounding the stalks of tentacle-like organs, at the ends of which are placed the sense-organs.

This close connection between certain organs of special sense and ganglia is probably to be explained by supposing that the two sets of structures actually originated pari passu.

We may picture the process as being somewhat as follows:-

It is probable that in simple ancestral organisms the whole body was sensitive to light, but that with the appearance of pigment-cells in certain parts of the body, the sensitiveness to light became localised to the areas where the pigment-cells were present. Since, however, it was necessary that stimuli received by such organs should be communicated to other parts of the body, some of the epidermic cells in the neighloourhood of the pigment-spots, which were at first only sensitive in the same manner as other cells of the epidermis, became gradually differentiated into special nerve-cells. As to the details of this differentiation embryology does not as yet throw any great light; but from the study of comparative anatomy there are grounds for thinking that it was somewhat as follows:-Cells placed on the surface sent protoplasmic processes of a nervous nature inwards, which came into connection with nervous processes from similar cells placed in other parts of the borly. The cells with such processes then became removed from the surface, forming a deeper layer of the cpidermis below the sensitive cells of the organ of vision. With the latter cells they remained connected by protoplasmic filaments, and thus they came to form a thickening of the epidermis mnderneath the organ of vision, the cells of which received their stimuli from those of the organ of vision, and transmitted the stimuli so received to other parts of the body. Such a thickening would obviously be the rudiment of a central nervous system, and is in fact very similar to the rudimentary ganglia of the Acraspeda mentioned above. It is easy to see by what steps it might bccome larger and more important, and miglit gradually travel inwards, remaining connected with the sense-organ at the surface by protoplasmic filaments, which would then constitute nerves. The rudimentary eye would at first merely consist of 
cells sensitive to light, and of ganglion-cells connected with them; while at a later period optical structures, constituting a lens capable of throwing an image of external objects upon it, would be developed, and so convert the whole structure into a true organ of vision. It lias thus come about that, in the development of the individual, the retina is often first formed in connection with the central nervous system, while the lenses of the eye are independently evolved from the epidermis at a later perior.

A series of forms of the Colenterata and Platyelminthes affords us examples of various stages in the differentiation of a central nervons system ${ }^{1}$.

In sea-anemones (Hertwigs, No. 32 I) there are, for instance, no organs of special sense, and no definite central nervous system. There are, however, scattered throughout the skm, and also throughout the lining of the digestive tract, a number of specially moditied epithelial cells, which are no doubt delicate orgaus of sense. They are provided at their free extremity with a long hair, and are prolonged on their inner side into fine processes which penetrate into the deeper part of the epithelial layer of the skin or rligestive wall. 'They eventually join a fine network of protoplasmic tibres which forms a special layer immediately within the epithelimm. The fibres of this

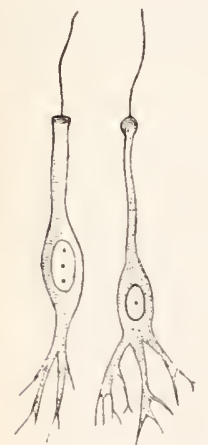

Fig. 236. NeuroEPITHELIAL SENSECELLS OF AtrELIA AUrita. (From Lanliester; after Schäfer.) hair at their free extremity, and a nervous prolongation at the opposite end, which joins the nerve-fibres of the ring. Between such cells and true ganglion-cells an intermediate type of cell has been found (fig. 237 B) which sends a process npwards amongst the epithelial cells, but does not reach the surface. Such cells, as the Hertwigs have pointed out, are clearly sense-cells partially transformed into ganglion-cells.

A still higher type of nervous svstem has been met with amongst some primitive Nemertines (Hubrecht, No. 323), consisting of a pair of large

1 Our knowledge on this subject is especially due to the brothers Hertwig (Nos. 320 and 321 ), Eimer (No. 318), Claus (No.317), Schäfer (No. 326), and Hubrecht (No. 323). 
cephatic ganglia, and two well-developed lateral ganglionic cords placed close beneath the epidermis. These cords, instead of giving off definite nerves, as in animals with a fully differentiated nervous system, are connected with a continuons subdermal nervous plexus.

'The features of the embryology and the anatomy of the nervous system, to which attention has just been called, point to the following general couclusions as to the evolution of the nervous system.

(1) The nervous system of the higher Metazoa appears to have been evolved in the course of a long series of generations from a

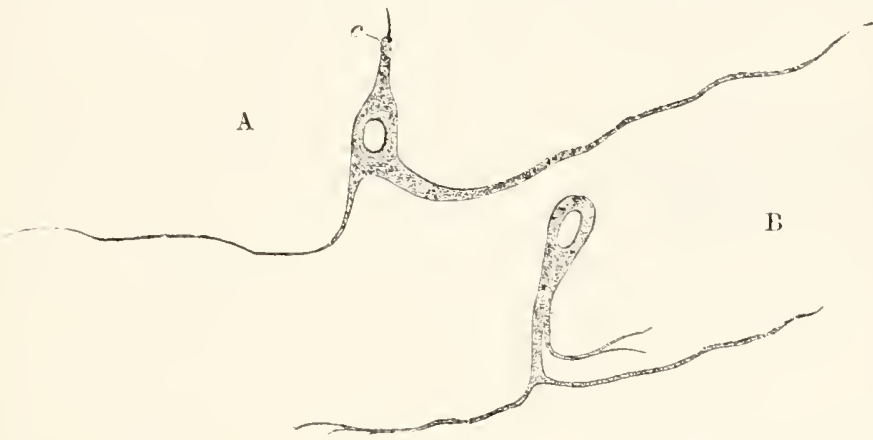

Fiti. 237. Isolated cells beloxging to the tpper xerve-mivg of Carmalisa hastata. (After O. and R. Hertwig.)

A. Nemro-epithelial sense-cell. c. sense-hair.

B. Transitional cell between a neuro-epithelial cell and a ganglion-cell.

differentiation of some of the superficial epithelial cells of the body, though it is possible that some parts of the system may have been formed by a differentiation of the alimentary epithelium.

(2) An early feature in the differentiation consisted in the growth of a series of delicate processes of the inner ends of certain epithelial cells, which became at the same time specially differentiated as sensecells (figs. 2:36 and $2: 37$ ).

(3) These processes gave rise to a subepithelial nervous plexus, in which ganglion-cells, formed from sense-cells which travelled inwards and lost their epithelial character (fig. $2: 37 \mathrm{~B}$ ), soon formed an important part.

(4) Local differentiations of the nervous network, which was no doubt distributed over the whole body, took place partly in the formation of organs of special sense, and partly in other ways, and such differentiations gave rise to a central nervous system. The central nervous system was at first continuous with the epidermis, but became separated from it and travelled inwards.

(5) Nerves, such as we find them in the higher types, originated from special differentiations of the nervous network, radiating from the parts of the central nervous system.

The following points anongst other's are still very obscure :-

(1) The steps by which the protoplasmic processes from the primitive 
epidermic cells became united together so as to form a network of nervefibres, placing the various parts of the body in nervous communication.

(2) The process by which nerves became connected with muscles, so that a stimulus received by a nerve-cell could be communicated to and cause a contraction in a muscle.

It is probable, as stated in the above summary, that the nervous network took its origin from processes of the sense-cells. The processes of the different cells probably first met and then fused together, and, becoming more arborescent, tinally gave rise to a complicated network.

The primitive relations between the nervous network and the muscular system are matters of pure speculation. The primitive muscular cells consist of epithelial cells with muscular processes (fig. 238), but the

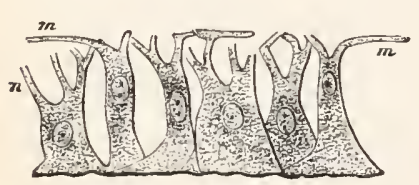

Fig. 238. MYo-epitheliaL celis of Hrdra. (From Gegenbaur; after Kleinenberg.)

$m$. contractile fibres; processes of cells. branches of the nervous network have not been traced into connection with the muscles in any Colenterata except the Ctenophora. In the higher types a continuity between nerves and muscles in the form of motorial end plates has been widely observed. Even in the case of the Coelen. terata it is quite clear from Romanes' experiments that stimuli received by the nerves are capable of being transmitted to the muscles, and that there must therefore be some connection between nerves and muscles. How did this connection originate?

Epithelial cells with muscular processes (fig. 238) were discovered by Kleinenberg (No. 324) in Hydra before epithelial cells with nervous processes were known, and Kleinenherg pointed ont that Hydra shewed the possibility of nervous and muscular tissues existing without a central nervons system, and suggester that the epithelial part of the myo-epithelial cclls was a sense-organ, and that the connecting lart between this and the contractile processes was a rudimentary nerve. He further supposed that in the subsequent evolution of these elements the epithelial part of the cell became a ganglion-cell, while the part connecting this with the muscular tail became prolonged so as to form a true nerve. The discovery of neuroepithelial cells existing side by side with nyo-epithelial cells demonstrates that this theory must in part be abandoned, and that some other explanation must be given of the continuity between nerves and muscles. The hypothetical explanation which most obviously suggests itself is that of fusion.

It seems quite possible that many of the cpithelial cells of the epidermis and walls of the alimentary tract were originally provided with processes, the protoplasm of which, like that of the Protozoa, carried on the functions of nerves and muscles at the same time, and that these processes united amongst themselves into a network. Such cells would be very similar to Kleinenberg's neuro-muscular cells. By at subserquent differentiation some of the cells forming this network may have become specially contractile, the epithelial parts of the cells ceasing to have a nervous function, and other cells may have lost their contractility and become solely nervous. In this way we should get neuro-epithelial cells and nyo-epithelial cells both differentiated from the primitive network, and the connection between the two would also be explained. This hypo- 
thesis fits in moreover very well with the condition of the neuro-muscular system as we find it in the Colenterata.

\section{Bibliography.}

\section{Origin of the Nervous System.}

(3I6) F. M. Balfour. "Address to the Department of Anat. and Physiol. of the British Association." 1880.

$\left(3^{17}\right)$ C. Claus. "Studien üb. Polypen u. Quallen d. Adria. I. Acalephen, Discomedusen." Denk. d. math.-naturwiss. Classe d. k. Akad. W'iss. I'ien, Vol. xxxvin. 1877.

(3I8) Th. Eimer. Zoologische Studien a. Capri. I. Ueber Beroë ovatus. Ein Beitrag z. Anat. d. Rippenquallen. Leipzig, 1873.

(319) V. Hensen. "Zur Entwicklung d. Nervensystems." Virchow's Archiv, Vol. $\mathrm{xxx}, 1864$.

(320) O. and R. Hertwig. Das Nervensystem u. d. Sinnesorgane d. Medusen. Leipzig, 1878.

(321) O. and R. Hertwig. "Die Actinien anat. u. histol. mit besond. Berück. sichtigung d. Nervenmuskelsystem untersucht." Jenaische Zeit., Vol. xin. 1879.

(322) R. Hertwig. "Ueb. d. Bau d. Ctenophoren." Jenaische Zeitschrift, Vol. xIV. 1880 .

$(323)$ A. W. Hubrecht. "The Peripheral Nervous System in Palæo- and Schizonemertini, one of the layers of the body-wall." Quart. J. of Micr. Science, Vol. xx. 1880 .

(324) N. Kleinenberg. Hydra, eine anatomisch-entwicklungsgeschichtliche $U_{u-}$ tersuchung. Leipzig, 1872.

(325) A. Kowalersky. "Embryologische Studien an Würmern u. Arthropoden." Mêm. Acad. Péterstourg, Series viı., Vol. xvi. 1871.

(326) E. A. Schäfer. "Observations on the nerrous system of Aurelia aurita." Phil. Trans. 1878.

Nervous system of the Invertebrata. Our knowledge of the development of the central nervous system is still very imperfect in the case of many Invertebrate groups. In the Echinodermata and some of the Chætopoda it is never detached from the epidermis, and in such cases its origin is clear without embryological evidence.

In the majority of groups the central nervous system may be reduced to the type of a pair of cephalic ganglia, continued posteriorly into two cords provided with nerve-cells, which may coalesce ventrally or be more or less widely separated, and be unsegmented or segmented. Various additional visceral ganglia may be added, and in different instances parts of the system may be much reduced, or peculiarly modified. The nervous system of the Platyelminthes (when present), of the Rotifera, Brachiopoda, Polyzoa (?), the Mollusea, the Chætopoda, the Discophora, the Gephyrea, the Tracheata, and the Crustacea, the various small Arthropodan phyla (Pceciloporla, Pycnognida, Tardigrada, \&c.), the Chætognatha (?), and the Myzostomea, probably belongs to this type.

The nervous system of the Echinodermata cannot be reduced to this form; nor in the present state of our knowledge can that of the Nematelminthes or Enteropneusta.

It is only in the case of members of the former set of groups that any adequate observations have yet been made on the development of the nervous system, and even in the case of these groups observations which have any claim to completeness are confined to certain 
members of the Chretopoda, the Arthropoda and the Mollusca. An account of imperfect observations on other forms, where such have been made, will be found in the systematic part of this work.

Chætopoda. We are indebted to Kleinenberg (No. 329) for the most detailed account which we have of the development of the central nervous system in the Clinetopodia.

The supraresophageal ganglion with the asophageal commissure developes independently of the ventral cord. It arises as an unpaired thickening of the epiblast, close to the dorsal side of the cosophagus at the front end of the head (fig. 239), which becomres separated from

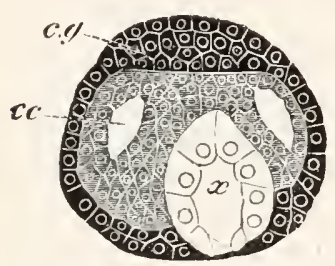

Fig. 23!). SEctrox throvih THE HEAD OF A YOUNG EMBRYO OF Lumbricus trapezoldes. (After Kleinenberg.)

c.g. cephalic ganglion; $c c$. cephalic portion of the body cavity; $x$. cesophagus. the epiblast, and exteuds obliquely backwards and downwards in a somewhat arched form ; its lower extremities being somewhat swollen. The inner portion of this curved rudiment becomes converted into comnissural nerve-fibres, while the cells of the outer and upper portion assume the characters of ganglion-cells. The commissural fibres are continued downwards to meet the ventral cord, but their junction with the latter structure is not effected till late i1) embryonic life.

The ventral cord is formed by the coalescence of a pair of linear cords, the development of which takes place from before backwards, so that when their anterior part is well developed their posterior part is hardly differentiated. These cords arise, one on each side of a ventral ciliated furrow, first as a single row of epiblast cells, and subseruently as several rows (fig. $240,1 \mathrm{~g}$ ). While still united to the

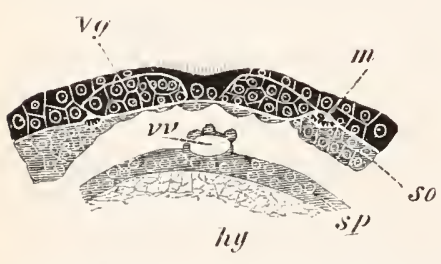

Fig. 240 . Section throegh part OF THE VENTRAL WALL OF THE TRUNK OF AN EMBRYO OF LUMBRICUS TRAPEzoIDEs. (After Kleinenberg.)

$m$. lougitudinal museles; so. somatic mesoblast; sp. splanchnic mesoblast; $h y$. hypoblast; I' $/$. ventral nerve-cord; $v v$. ventral ressel. external epiblast, they extend themselves below the cells lining the ventral furrow, and unite into a single nervous band, which however exhibits its double, origin by its bilobed section. Before the two cords unite, the groove between them becomes somewhat deep, but subsequently shallows out and lisappears. The nervous band, before separating from the epiblast, exhibits, in correspondence with the mesoblastic segments, alternate swellings and constrictions. The former become the ganglia, and the latter the connecting trunks.

As soon as the cord becomes free from the epiblast, it becomes surrounded by a sheath, formed of somatic mesoblast. In each of the ganglionie enlargements there next appears on the dorsal surface a 
pair of areas of punctiform material, the substance of which swon differentiates itself into nerve-fibres. These areas, hy uniting from side to side, give rise to the transverse commissnres, and also by a linear coalescence to the longitudinal commissures of the cord. The cellular parts of the band surrounding them become converted into a ganglionic covering of the cord.

In each ganglion the cells of this ganglionic investment penetrate as a median septum into the cord. A fissure is next formed, dividing this septum into two; it is subsequently continued for the whole length of the cord.

Arthropoda. In the Tracheata and the Crinstacea the develupment of the ventral cord is in the main similar to that in the Chætopods, while that of the supracesophageal ganglia is as a rule somewhat more complicated. No such clear evidence of an independent development of these two parts, as in the case of the Chatopods, has as yet been produced.

The most primitive type of nervous system anongst the Tracheata is that of Peripatis, where it consists of large supraoesophageal ganglia, continuous with a pair of widely separated but large ventral cords united posteriorly above the anus. These cords have an investment of ganglion-cells for their whole length, and are imperfectly divided into ganglia corresponding in number with the feet.

The ventral cordsareformed

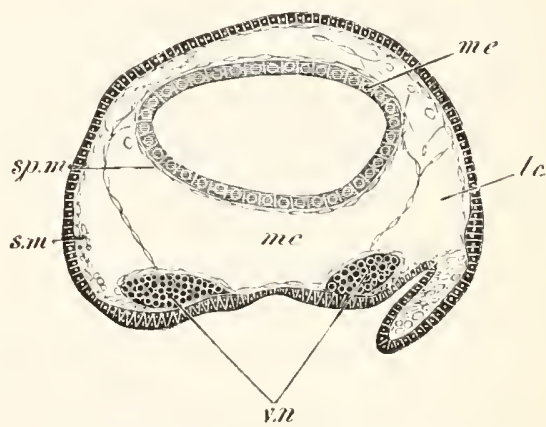

Fig, 241. Section through the trunk of an embrio of Perilatus, The embryo from which the section is taken was somewhat younger than that of fig. 212 .

sp.m. splanchnic mesoblast; s.m. somatic mesoblast; mc. median section of body cavity; $l c$. lateral section of body eavity; $v \cdot n$. ventral nerve cord; me. mesenteron.

as two separate epiblastic ridges (fig. 241,v.n), continued in front into a pair of thickenings of the procephalic lobes, which are at first independent of each other, and from which a large part of the supraœsophageal ganglia takes its origin. After the latter have become separated from the epiblast an invagination of the epiblast covering them grows into each lobe (fig. 242), and becoming constricted from the superficial epiblast, which remains as the epidermis, forms a not unimportant part of the permanent supraœesophageal ganglia.

In the Arachnida the mode of development of the nervous system is essentially the same, and the reader will find a detailed account of it for Spiders in Vol I. pp. 370-373. The ventral cords are here formed as independent and at first widely separated strands (fig. 243, $v n$ ), which for a long time remain far apart; they are subsequently divided into gangha and become united by transverse commissures. 
The supraøesophageal ganglia are formed as two independent thickenings of the procephalic

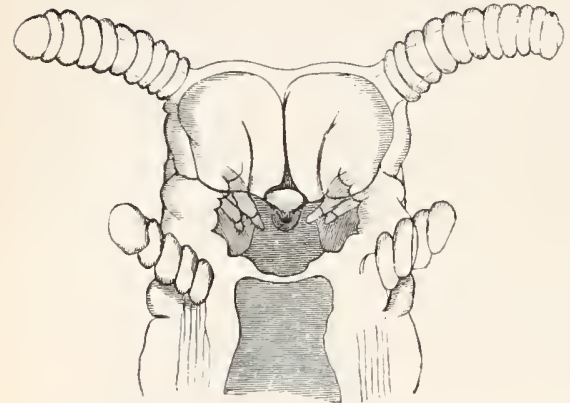

Fig. 242. Heal of an EMBrigo Peripates. (From Moseley.)

The figure shews the jaws (mandibles), and close to them epiblastic inrolutions, which grow into the supracesophageal ganglia. The antemnat, oral cavity, and oral papille are also shewn. has in Lepidoptera (Hatschek) the form of a pit on the dorsal border of the antenne.

Hatschek states that there takes place an invagination of a median part of the skin between the two ventral cords, for the details of which I immst refer the reader to Vol. I. 1. 340. He has made more or less similar statements for the earthworm, but his observations in both instances are open to serious doul,t.

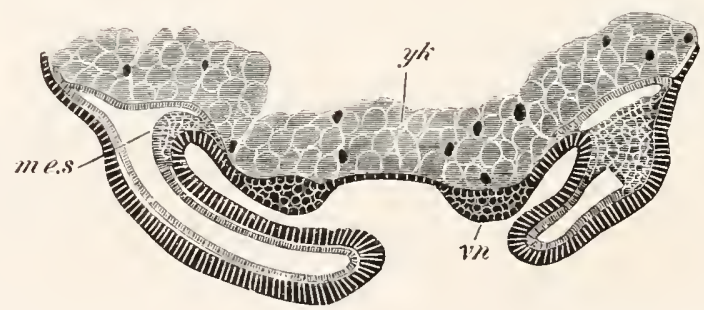

Fig. 243. Transterse section throvgh the ventral plate of Agelena labyinthica.

The ventral cords have begun to be formed as thickenings of the epiblast, and the limbs are established.

me.s. mesoblastic somite; $r$. ventral nerve-cord; $y k$. yolk.

Full details as to the development of the nervous system in the Crustacea are still wanting; a fairly complete account of what is known on the subject is given in Vol. I. pp. 433-4. It appears that the ventral corl may either arise as an unpaires thickening of the epiblast (Isopoda), marked howover by a shallow median furrow, or 
from two cords which eventually coalesce ${ }^{1}$. It is not certain how far the supracesophageal ganglia are usually in the first instance continuous

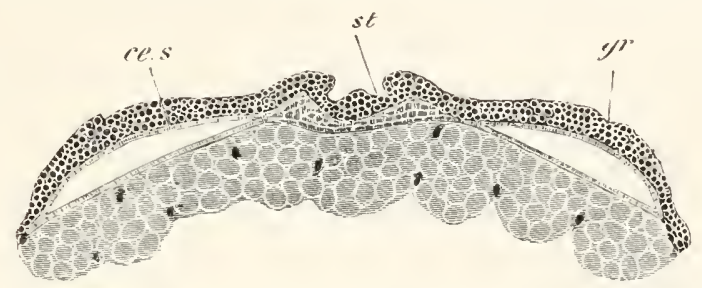

Fig, 24t. Section throdgh the procephalic lobes of an EMBrio of Agelexa Labirixthica.

st. stomadæum; gr. section through semi-circular groove in procephalic lobe; ce.s. cephalic section of body cavity.

with the ventral cord. In Astacis, the early stages of which have been elaborately investigated by Reichenbach (No.33I), they are stated to be so; the supranesophageal ganglia are moreover described by this author as having a somewhat complicated origin. Five elements enter into their composition. There is first formed a pair of pits on the procephalic lobes, which become very deep
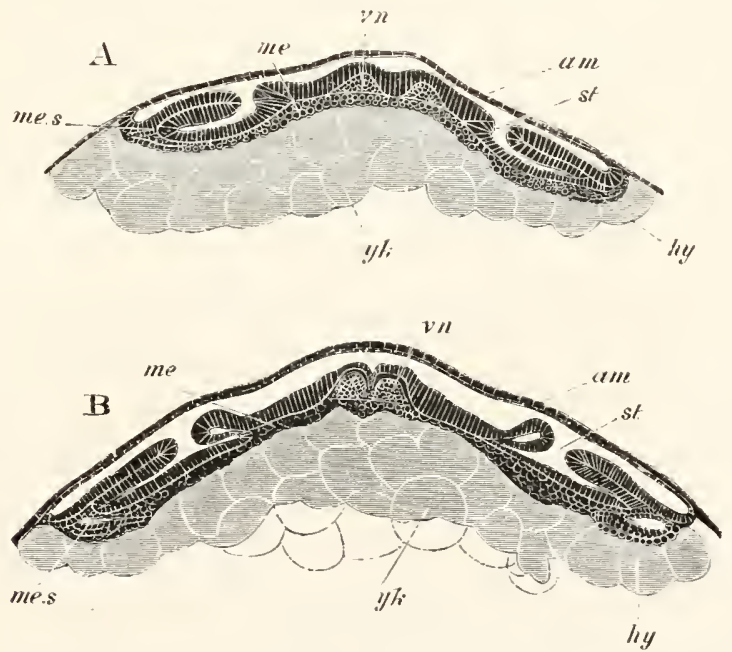

Fig, 245. Two transverse sections throtgh the embryo of Hribrophilus. (After Kowalevsky.)

A. Transverse section through an embryo in the region of one of the stigmata.

B. Transverse section through an older embryo.

$v n$. ventral nerve-cord; am. amnion and serous membrane; me. mesoblast; me.s. somatic mesoblast; $h y$. hypoblast (?); $y k$. yolk-cells (true hypoblast); st. stigma of trachea.

1 Reichenbach (No. 3.3 ) holds that the walls of the groove between the two strands of the ventral cords become invaginated and assist in the formation of the ventral cord. 
during the Nauplins stage, and are continuons with a pair of epiblastic ridges which pass round the mouth, and join the ventral cords just described. T'he walls of the pits are believed to form a part of the embryonic ganglia which gives rise to the retina as well as to the optic ganglia. The ridges form the remainder of the ganglia and the oesophageal commissures; while the fifth element is supplied by a median invagination in front of the mouth, which appears at a much later date than the other parts.

In the Isopoda supracesophageal ganglia are stated to arise as thickenings of the procephalic lubes, which become eventually detached from the epidermis.

The ventral cord is at first unsegmented, but soon becomes partially divided by a series of constrictions into a number of ganglia, corresponding with the segments. The development of the commissural and ganglionic portions takes place much as in the Chretopoda.

The Gephyrea approach closely the types so far dealt with, but the ventral corel in the Inermia is formed as an unpaired thickening of the epiblast. In Echiurus, as has been shewn by Hatschek in an interesting paper on the larva of this species, published since the appearance of the first volume, there is a pair of ventral cords ${ }^{1}$. In correspondence with a general segmentation of the body, which is sulssequently lost, these cords become segmented. The two cords unite in the median line, and Hat-chek, in accordance with his general view on this subject, states that their junction is effected by means of a median cord of invaginated epilblast. The segmentation of the cords subseqnently becomes lost. The suprracesophageal ganglia arise as an unpaired median thickening of the procephalic lobe. No traces of segmentation in the rentral cord have been observed by Spengel in Bonellia, and the supracesophageal ganglion is formed in this genus as an unpaired band.

In all the groups above consilered the nervous system clearly presents the same type of development with various modifications.

It is formed of two parts, viz. (1) the supranesophageal ganglia, and (2) the ventral cord.

In the simpler forms, Chretopoda and Gephyrea, the supraœsophageal ganglia are usually stated to be formed as an unpaired thickening at the apex of the preoral lobe, which in most cases becomes subsequently bilobed.

In the Arthropoda the unpaired præoral lobe of the Chxtopoda is replaced by the so-called procephalic lobes, which are themselves bilobed; and the supracsophageal ganglia are formed of two independent halves; further complications in development are also generally found.

There is not as yet sufficient evidence to decide whether the supranesophageal ganglia were primitively developed continuously with, or independently of, the ventral cords.

The ventral cord appears in the embryo as two independent un-

I "Ueber Entwichlungsgeschichte d. Echiurus." Arbeit. a. d. zool. Instit. Wien, Vol. III. 1880 . 
segmented strands, although in a few cases (some Crustacea and Gephyrea) these cords, by an abbreviation in development, arise as an unpaired median thickening of the epiblast.

The form of nervous system of the Chrotopoda, Arthropoda, and Gephyrea is clearly therefore to be lerived, as was first pointed out by Gegenbaur, from a more or less similar type to that now found in the Nemertines; and as suggested in the ehapter on larval forms (vide p. :31.2) may perhaps be derived from the elongation of a circular ring, of which the anterior end has become developed into the supraosophageal ganglia, the lateral parts into the two lateral strands, while the posterior part persists in some forms in the junction of the ventral cords above the anus (Enopla and Peripatus).

Mollusca. While study of the anatomy of the nerrons system of the Mollusea, especially of certain primitive genera (Chiton, Haliotis, Fissurellit, sc.) leaves little doubt that it is formed on the same type as that of the groups just spoken of, the development, so fir as our imperfect knowledge enables us to make definite statements on the subject, is somewhat abnormal'.

In the Gasteropoda and Pteropoda the suprawsophageal ganglia appear most probably to be developed either as paired thickenings of the epiblast of the relar area, or as invaginated pits of the velar area, which hecome detached from the surface, and then become solid (Hyaleacea and Limax). In either case the supraosophageal ganglia appear to be cleveloped quite independently of the pedal ganglia. The latter, as might be anticipated, are earlier in their development and more constant than the various visceral ganglia; and, if the views above expressed are correct, are homologous with the ventral cord of the Chretopods and Arthropods. Their actual development is very imperfectly known.

The most precise statements on the sulject, viz. those of Bobretzky and Fol, would lead us to suppose that they arise in the mesollast, hut it seems more probable that they are formed as thickenings of the sides of the foot.

In the Cephalopods all the ganglia are stated to be differentiated in the mesoblast (Lankester, Bobretzky).

Hatschek ${ }^{2}$ has recently given a detailed description of the development of the supracsophageal and pedal ganglia of Teredo. He finds that the former ganglia arise as an unpaired thickening of the epiblast in the centre of the velar area, and the latter as an unpaired thickeuing of the epiblast of the ventral side of the body between the mouth and the anus. The two ganglia woukd thus seem to be discomnected with each other in their development.

(327) F. M. Balfour. "Notes on the development of the Araneina." Quart.J.of Micr. Science, Vol. xx. 1880.

(328) B. Hatschek. "Beitr. z. Entwicklung d. Lepidopteren." Jcnaische Zeitschrift, Vol. xI. 1877.

(329) N. Kleinenberg. "The development of the Earthworm, Lumbricus Trapezoides." Quart. J, of Micr. Sicience, Vol. XIx. 1879.

1 Tide Tol. I., pp. 226, 227.

" "Ueber Entwicklungsgeschichte von 'T'eredo." Arbeit. "d. zool. Instit. Wien, Vol. 1II. 1880. 
(330) A. Kowalersky. "Embryologische Studien an Wuirmern u. Arthropoden." Mêm. Acad. Pétersbonr!, Series vin., Vol. xvi. 1871.

(3.3) H. Reichenbach. "Die Embryonalanlage u. erste Entwick. d. Fluss. lirebses." Zeit. f. wiss. Zool., Vol. xxix. 1877.

\section{The Cextral Nervous System of the Vertebrata ${ }^{1}$.}

The formation of the cerebro-spinal axis of the Chordata from the medullary plate has already been treated at length (pp. 250-252). Before entering into the consideration of the morphological value of the various parts of this corl, it will be convenient to describe the more important features of its ontogeny. For this purpose the two parts into which the nervous axis becones at an early period divided, viz. the spinal cord and the brain, may be dealt with separately.

The Spinal Cord, shortly after the closure of the medullary canal, has, in all the true Vertebrata, the form of an oval tube; the walls of which are of a fairly uniform thickness, and are composed of several rows of elongated cells. This cord, as development proceeds, usually becomes vertically prolonged in transverse section, and the central canal which it contains also becomes vertically elongated. The variations in shape of the spinal canal are very great at different periods and in different parts of the body, and an attempt to chronicle them would appear, in the present state of our knowledge, to be quite valueless". Fig. 117, in which the spinal cord of the chick of the third day is shewn in transverse section, ilhustrates the character of the cord at the stage just described. Up to this time the walls of the spinal canal have exhibited an uniform structure. A series of changes now however takes place, which results in the differentiation (1) of the epithelium of the central canal, $(2)$ of the grey matter of the cord, and $(: 3)$ of the external coating of white matter.

'The relative time at which each of these parts becomes developed is not constant in the different forms.

The white matter is apparently the result of a differentiation of the outermost parts of the superficial cells of the cord into longitudinal nerve-fibres, which remain for a long period without a medullary sheath. These fibres appear in transvere sections as small dots. The white matter forms a transparent investment of the grey matter and would seem to contain neither nuclei nor cells ${ }^{3}$. The white matter nay from the first form only two masses, one on each side, forming

1 For the development of the central nervous system in Amphioxus and the Tunicata the reader is referred to the chapters dealing with those two groups.

${ }^{2}$ Löwe $\left(N_{0} .3+1\right)$ holds that at an early stage of development three regions can always le distinguished in any section of the central canal, viz. (1) a ventral narrow slit, (2) a median enlargement, and (3) a dorsal slit. Such a form can no donbt often be observed, but my own observations do not leas me to attach any special importance to it.

3 This holds true at first for Elasmobranchii, but at a later stage there are present numerous nerve-cells in the white matter, so that the distinction between the white and grey matter becomes much less marked than in higher types; in this respect Elas. mobranchii present an approximation to Amphioxus. 
a layer on the ventral and lateral parts of the spinal cord but not extending to the dorsal surface (Elasmobranchii, tig. 18.5, IF); or it may form four patches, viz. an anterior and a posterior white column on each side, which lie on a level with the origin of the anterior and posterior nerve-roots (tle Fowl, Human embryo, etc.). In whichever of these forms the white matter appears, it is always, at first, a layer of extreme temity, which rapidly increases in thickuess in the subseyuent stages, and extends so as gradually to eover the whole cord (tig. 쑤).

The anterior white commissure is formed very shortly after the first appearance of the white matter. The grey matter and the central epithelium are formed by a differentiation of the main mass of the spinal cord. The onter cells lose their epithelial-like arrangenent, and, becoming prolonged into fibres, give rise to the grey matter, while the immermost cells retain their primitive arrangement, and constitute the epithelium of the canal. 'The process of formation of the grey matter would appear to proceed from without inwards, so that some of the cells, which have, on the formation of the grey matter, an epithelial-like arrangement, subsequently becone converted intu true verve-cells.

As has already been mentioned, the central epithelium of the nervous system probably corresponds with the so-called epidermic layer of the epiblast.

The grey matter soon beeomes prolonged dorsally and ventrally into the posterior and anterior horns. Its fibres may especially be traced in two directions:(1) round the anterior end of the spinal canal, imme. diately outside its epithelium and so to the grey matter on the opposite side, forming in this way an anterior grey commissure, through which a decussation of the fibres from the opposite sides is effected: (2) dorsalwards along the outside of the lateral walls of the canal.

There is at this period no trace of the ventral $\sigma^{\circ}$ dorsal fissure, and the slape

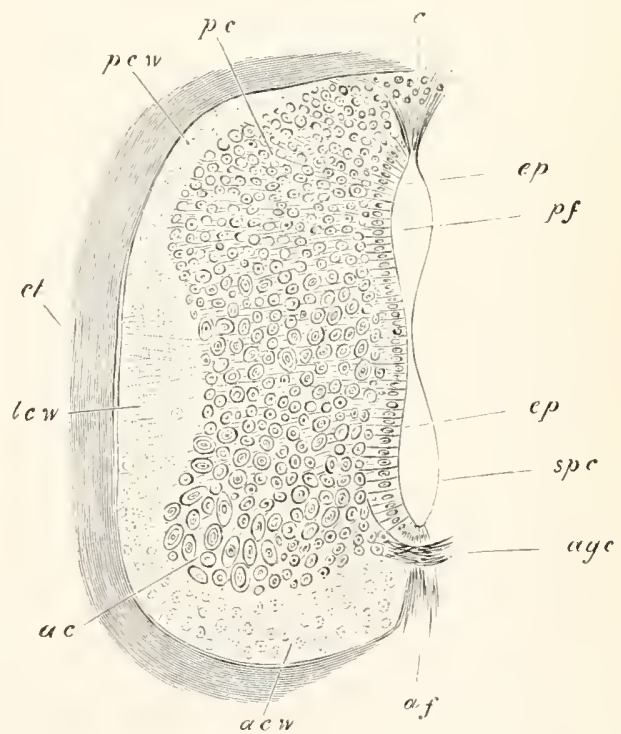

Fir. 246. SEction 'THROGgh THE SPINAL CORD oF A SEven DAYS' CHгќ.

pew. dorsal white column; l'w. lateral white column; acw. ventral white columm; $c$. dorsal tissue filling up the part where the dorsal fissure will be formed; $p c$. dorsal grey cormu; ac. anterior grey coruu; ep. epithelial cells; agc. anterior com. missure; $p f$. dorsal part of spinal canal; spe. ventral part of spinal cumal; at. anterior fissue. 
of the central canal is not very different to what it was at an earlier period. This condition of the spinal cord is especially instructive, as it is very nearly that which is permanent in Amphioxus.

The next event of importance is the formation of the ventral or anterior fissure. This owes its origin to a downgrowth of the anterior horns of the cord on each side of the middle line. The two downgrowths enclose between them a somewhat linear space-the auterior tissure - which increases in depth in the succeeding stages (fig. 246, af ).

The dorsal or posterior fissure is formed at a later period than the anterior, and accompanies the atrophy of the dorsal section of the embryonically large canal of the spinal cord.

The exact mode of its formation appears to me to be still involved in some obscurity.

In the Elements of Embryology the development of the posterior fissure was described in the following way:

"On the seventh day the most important event is the formation of the posterior fissure.

"This is brought about by the absorption of the roof of the posterior of the two parts into which the neural canal has become divided.

"Between the posterior horms of the cord, the epithelium forming the roof of the, so to speak, posterior canal is along the middle line covered neither by grey nor by white matter, and on the seventh day is partially absorbed, thus transforming the canal into a werlge-shaped tissure, whose mouth however is seen in section to be partially closed by a triangular clump of elongated cells (tig. $246, c)$. Below this mass of cells the fissure is open. It is separated from the 'true spinal caual' by a very narrow space along which the side walls have coalesced. In the lumbar and sacral regions the two still communicate.

"We thus find, as was first pointed out by Lockhart Clarke, that the anterior and posterior fissures of the spinal cord are, morphologically speaking, entirely different. The anterior fissure is merely the space left between two lateral downward growths of the cord, while the posterior fissure is part of the original neural canal separated from the rest of the cavity (which goes to form the true spinal caual) by a median coalescence of the side walls."

I confess that I have some doubts as to the complete accuracy of the above statement.

Kölliker gives a full account of the gradual atrophy of the central canal; but I do not fully understand his statements with reference to the formation of the posterior fissure, which in fact appears to be only incidentally mentioned. It would seem foom his account that a shallow and somewhat wide dorsal fissure is formed to start with, in the human embryo, by two projections of the posterior white homs. On the atrophy of the central canal this furrow becomes narrowed, but Kölliker does not definitely state how it becomes dee jeupd so as to give rise to the permanent dorsal fissure.

It seems to me probable, though further investigations on the point are still required, that the dorsal fissure is a direct result of the atrophy of the dorsal part of the central canal of the spinal cord. 
'The walls of the canal coalesce dorsally, and the coalescence gradually extends ventralwards, so as finally to reduce the central canal to a minute tube, formed of the ventral part of the original canal. The epithelial wall formed by the coalesced walls on the dorsal side of the canal is gradually absorbed.

The epithelium of the central canal, at the period when its atrophy commences, is not covered dorsal'y either by grey or white matter, so that, with the gradual reduction of the dorsal part of the canal, and the absorption of the epithelial wall formed by the fusion of its two sides, a fissure between the two halves of the spinal cord becomes formed. This fissure is the posterior or dorsal fissure. In the process of its formation the white matter of the dorsal horns becomes prolonged so as to line its walls; and shortly after its formation the dorsal grey commissure makes its appearance, which is not improbably derived from part of the epithelium of the original central canal.

\section{Development of the Brin.}

The brain is formed from the anterior portion of the medullary plate. When the medullary plate first becomes differentiated it is not possible to distinguish between the region of the brain and that of the spinal cord. The brain region is however usually very eas ly indicated by a widening of the medullary plate, but does not become sharply marked off from the region of the spinal curd. In many Ichthyopsida (Elasmobranchii (fig. 28, C) and Amphibia (fig: 77, A)) the anterior dilatation gives to the medullary plate, before its sides neet to form a eanal, a spatula-like form; which is either not present or less marked in Reptilia, Aves and Mammalia.

The lengtl of the brain as compared to the spinal cord is always very great in the embryo, and in the earliest developmental periods the disproportion in the size of the brain is specially marked, owing to the full number of the somites of the trunk not having been formed. In Elasmobranchii the brain is about one-third of the whole length of the embryo at the stage immediately following the closure of the medullary canal.

The first differentiation of the brain into distinct parts is a very early occurrence, and may take place before (Mammatia) or during the closure of the medullary folds. The brain first becomes divided into two successive lobes or vesicles by a single transverse constriction, and subsequently the posterior of these again becomes divider into two, so that three lobes are formed-known as the fore- the mid- and the hind-brain; of these the hind-brain is usually the longest. In some instances a bilobed stage can hardly be recognised. This primitive division of the brain is shewn in many of the figures already given. The reader may perhaps best refer to fig. 108. On the closure of the medullary groove the hmen of the medullary canal is continued uninterruptedly through the brain, but dilates considerably in each of the cerebral vesicles. 
The anterior lobe of the brain becomes converted into the cerebral hemispheres, the thalamencephalon, the primary optic vesicles, and the parts connected with them. The middle lobe becomes the optic lobes (corpora bigemina or corpora quadrigemina in Mammalia) and the crura cerebri; while the posterior lobe becomes converted into the cerebelhum and medulla oblongata.

Before describing in detail the changes by which the primary vesicles of the brain become converted into the above parts, it will be convenient to say a few words about the general development of the brain.

The most striking peculiarity with reference to the general development of the brain is a curvature which appears in its axis, known as the cranial flexure. The flexure takes place throngh the mid-brain, and canses the fore-brain to be gradually bent downwards so that the axis of its floor forms, first, a right angle with that of the hinder part of the brain, and subsequently, as a rule, an acute angle.

During these changes the brain, in most Amniota at any rate, becomes in the first instance retort-shaped, the cerebral vesicle forming the swollen part of the retort, but subsequently the retort-shape is lost owing to the great development of the vesicle of the midbrain, which forms the termination of the long axis of the embryo. Figs. 29,76 , and 118 , are representative figures of embryos of various vertebrate forms at a period when the mid-brain forms the termination of the long axis of the body.

It is generally stated that the cranial flexure is at its maximum at the stage represented in these figures, and there can be no doubt that viewed from the exterior the cranial flexure ceases to be so

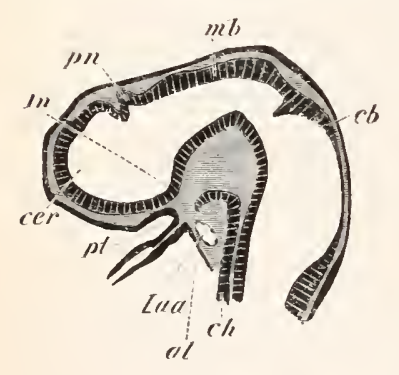

Fig. 247. Longittdinal SecTION THROUGH THE BRAIN OF A youva Pristictes embryo.

cer. commencement of the cerebral hemisphere; $p n$. pineal gland; $I n$. infundibulum; $p t$. ingrowth from mouth to form the pituitary body; mb. mid-brain; cb. cerebellum; ch. notochord; al. alimentary tract; Iaa. artery of mandibular areh. marked a feature, and finally disappears as the embryo gradually grows older; but though the mid-brain ceases to form the termination of the long axis of the embryo, the flexure of the brain becomes in many forms absolutely more marked; while in other forms, though stated to diminish, it does not entirely vanish.

The general nature of the changes which take place will perhaps best be understood by a comparison of figs. 247 and $2+8$ representing longitudinal sections at two stages through the brain of an embryo Elasmobranch. 'The actual cranial flexure, i.e. Hlexure of the floor of the brain, is obviously greater in the older of the two brains, though viewed from the exterior the axis of this brain appears to be quite straight. In the younger stage, fig. 247 , the mid-brain $(m b)$ forms the end of the long axis of 
the body, while in the older one the cerebral hemispheres (cer) have grown very greatly, especially forwards and dorsalwarls. They have thus come to lie in front of the midbrain, and to form the end of the long axis of the borly, and have at the same time compressed the originally large thalamencephalon against the mid-brain. The same general features may be seen in fig. 2.50 representing a longitudinal section of the brain of an embryo fowl, and fig. 25.5 representing a longitudinal section of the brain of a Mammal.

'The infundibulum or perhaps rather the point of origin of the optic nerves is to be regarded as the anterior termination of the axis of the base of the brain.

The cranial flexure is least marked in Cyclostomata (fig. 253), Teleostei, Ganoidei, and Amphibia, while it is very pronounced in Elasmobranchii, Reptilia, Ares, and Mammalia. In Teleostei, and still more in Cyclostomata, it permanently remains slight, owing to the small development of the

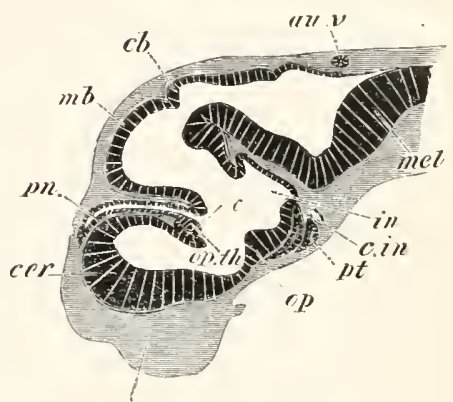

Fig. 248. Loxgitudinal Section THROEGII THE BRAIN OF SCYLLITII CANICULA AT AN ADVANCED STAGE OF DEVELOPIEXT.

cer. cerebral hemisphere; $m$. pineal gland; op.th. optic thalamus, connected with its fellow by a commissure (the middle commissure). In front of it is seen a fold of the roof of the forebram, which is comnected with the choroid plexus of the third ventricle; op. optic cliasma; $p t$. pituitary body; $i n$. infundibulum; $c b$. cerebellum; au.r. passage leadiug from the anditory resicle to the exterior; mel. medulla oblongata; C.in. internal carotid artery. cerebral hemispheres.

In addition to the cranial flexures. two other flexures make their appearance in the base of the brain. A posterior at the junction of the brain and spinal cord, and an anterior at the boundary between the cerebellum and medulla oblongata, just at the point where the pons Varolii is formed in Mammalia. The anterior of these is the most marked and constant; it is shewn in fig. 250. It arises considerably later than the main cranial flexure, and since it is turned the oplosite way it assists to a considerable extent in causing the apparent straightening of the cranial axis.

Histogenetic changes ${ }^{1}$. The walls of the brain are at first very thin and, like those of the spinal cord, are formed of a number of ranges of spindle-shaped cells. The processes of each of these cells are stated to be continued through the whole thickness of the wall. In the floor of the hind-and mid-brain a superficial layer of delicate nerve-fibres is formed at an early period. 'This layer appears in the first instance on the floor and sides of the hind-brain, and very slightly, if at all, later on the floor and the sides of the nuid-brain. The cells internal to the nerve-fibres become differentiated into an

$1 \mathrm{It}$ is not within the scope of this work to give an account of the histogenesis of the brain; in the statement in the text only a few points, of some morphological importance, are touched on. 
immermost epithelial layer lining the cavities of the ventricles, and an outer layer of grey matter.

The similarity of the primitive arrangement and histological character of the parts of the brain behind the cerebral hemispheres to that of the spinal cord is very conclusively shewn by the examination of any good series of sections. In both brain and spinal cord the white matter forms a cap on the ventral and lateral parts consilerably before it extends to the dorsal surface. In the medulla the white matter does not eventually extend to the roof owing to the peculiar degeneration which that part undergoes.

Ln the case of the fore-brain the earliest histological changes, except possibly in Mammals, take place on the same general plan as those of the remainder of the central nervous system ${ }^{1}$; but though the general plan is the same, yet the early histological distinction hetween the fore-brain, and the mid-and hind-brain is more marked than the distinction between the latter and the spinal cord.

On the floor and sides of the thalamencephalon, and apparently the whole of the hemisplieres of the lower types, there is formed, somewhat later than in the remainder of the brain, a very delicate layer of white matter. The inner part of the wall, which still remains comparatively thin, is not at first clearly divided into an epithelial and nervous layer. This distinction soon however becomes more or less apparent, though it is not so marked as in most other parts of the brain; and it appears that in the subsequent grow th the greater part of the original epithelial layer becomes comverted into nervous tissue.

In Mammals the same plan of differentiation would seem to be followed, though somewhat less obviously than in the lower types. The walls of the hemispheres become first divided (Kölliker) into a superficial thimner layer of rounded elements, and a deeper and thicker epithelial layer, and between these the fibres of the crura cerebri soon interpose themselves. At a slightly later period a thin superficial layer of white matter, homologous with that of the remainder of the brain, becomes established.

The inner layer, together with the fibres from the crura cerebri, gives rise to the major part of the white matter of the hemispheres and to the epithelium lining the lateral ventricles.

The outer layer of rounded cells becomes divided into (1) a superficial part with comparatively few cells, which, together with its coating of white matter, forms the cortical part of the grey matter, and (2) a deeper layer with numerous cells which forms the main mass of the grey matter of the hemispheres.

The development of the several parts of the brain will now be described.

The hind-brain. The hind-brain is at first an elongated, funnel-

"I have worked out these changes in Elasmobranchii, Amphibia (Salamandra) and Ares. 
shaped tube the walls of which are of a nearly miform thickness, though the roof and floor are somewhat thinuer than the sides. It forms a direct continuation of the spinal corl, into which it passes without any sharp line of demarcation. The ventricle it contains is known as the fourth ventricle.

The sides becrme in the chick marked by a series of transverse constrictions, dividing it into lobes, which are somewhat indefinite in number. The first of these remains permanent, and its roof gives rise to the cerebellum. It is uncertain whether the other constrictions have any morphological significatuce. More or less similar constrictions are present in Teleostei. In Elasmobranchii the medulla presents on its inner face at a late period a series of lobes corresponding with the roots of the vagus and glossopharyngeal nerves, and it is possible that the earlier constrictions may potentially correspond to so many nerve-roots.

Throughout the Vertebrata an anterior lobe of the hind-brain becomes very early marked off, so that the primitive hind-brain becomes divided into two regions which may be conveniently spoken of as the cerebellum (figs. $2+7$ and $248, c b$ ) and medulla oblongata. The floor of these regions is quite continuous and is also prolonged without any break into the floor of the mid-brain.

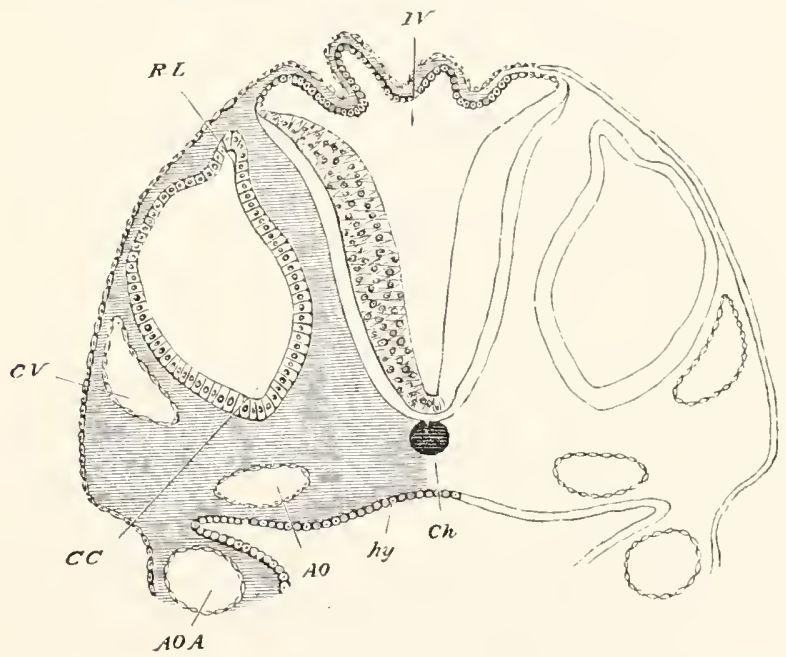

Fig, 249. Section throdgh the hind-bealy of a Chick at the exd of thF THIRD DAT OF INCUBATION.

$I V$. Fourth ventricle. The section shews the very thin roof and thicker sides of the ventricle. $C h$. Notochord; $C V$. Anterior cardinal vein; $C C$. Involuted auditory vesicle; $C C$ points to the end which will form the cochlear canal; $R L$. Recessus labyrinthi (remains of passage comnecting the vesicle with the exterior); $h y$. Hypoblast lining the alimentary canal; $A O ., A O A$. Aorta, and aortic arch.

The posterior section of the hind-brain, which forms the medulla, undergoes changes of a somewhat complicated character. In the first 
place its roof becomes in front very much extended and thinned out. At the raphe, where the two lateral halves of the brain originally united, a separation, as it were, takes place, and the two sides of the brain become pushed apart, remaining united by only a very thin layer of nervous matter, consisting of a single row of flattened cells (fig. 249). As a result of this peculiar growth in the brain, the roots of the nerves of the two sides, which were originally in contact at the dorsal summit of the brain, become carried away from one another, and appear to arise at the sides of the brain.

The thin roof of the fututh ventricle is triangular, or, in Mammalia, somewhat rhomboidal in shape. The apex of the triangle is directed backwards.

At a later period the blood-vessels of the pia mater form a rich plexus over the anterior part of the thin roof of the medulla, which becomes at the same time somewliat folded. The whole structure is known as the tela vasculosa, or choroid plexus of the fourth ventricle (fig. 250, chd 4). The floor of the whole hind-brain becomes thickened, and there very soon appears on its outer surface a layer of non-medullated nerve-fibres, similar to those which first appear on the spinal cord. They are continuous with a similar layer of fibres on the floor of the mid-brain, where they constitute the crura cerebri. On the ventral floor of the medulla is a shallow continuation of the anterior fissure of the spinal cord.

In Elasmobranchii and many Teleostei the restiform tracts are well developed, and are anteriorly continued into the cerebellum, of which they form the peduncles. Near their junction with the cerebellum they form prominent bodies, which are regarded by Miklucho-Maclay as representing the true cerebellmm of Elasmobranchii.

In Elasmobranchii a dorsal pair of ridges projects into the cavity of the fourth ventricle, corresponding alparently with the fasciculi teretes of the Mammalia.

In Mammalia there develop, subsequently to the longitudinal fibres already spoken of, first the olivary bodies of the ventral side of the medulla, and at a still later period the pyramids. The fasciculi teretes in the cavity of the fourth ventricle are developed shortly before the pyranids.

When the hind-brain becomes divided into two regions the roof of the anterior part does not become thinned out like that of the posterior, but on the contrary, becomes somewhat thickened and forms a band-like structure roofing over the anterior part of the fourth ventricle (fig. 247 and fig. $253, c b$ ).

This is a rudiment of the cerebellum, and in all Craniate Vertebrates it at first presents this simple structure and insignificant size. In Cyclostomata, Amphibia and many Reptilia this condition is permanent. In Elasmobranchii, on the other hand, the cerebellum assumes in the course of development a greater and greater prominence (fig. $248, c b$ ), and eventually overlaps both the optic lobes in front and the medulla behind. In the later embryonic stages it exhibits in surface-views the appearance of a median constriction, and 
the portion of the rentricle contained in it is prolonged into two lateral outgrowths.

Miklucho-Maclay, from his observations on the brains of adult Elasmobranchii, was led to regard what is here called the cerehellum as identical with the mid-brain, and the true mid-brain as part of the thalamencephalon. Miklucho-Maclay was no doubt misled by the large size of the cerebellum, but, as we have seen, this body does not begin to be conspicuous till late in embryonic life.

The mid-brain and thalamencephalon (according to the ordinary interpretations) have in the embryo of Elasmobranchs exactly the same relations as in the embryos of other. Tertebrates; so that the embryological evidence appears to me to be conchusive against Miklucho-Maclay's view.

In Birds the cerebellum attains a very considerable development (fig. $25(0, c b l)$, consisting of a folded central lobe with an arbor vita, into which the fourth rentricle is prolonged. There are two small lateral lobes, apparently equivalent to the floceuli. Anteriorly the

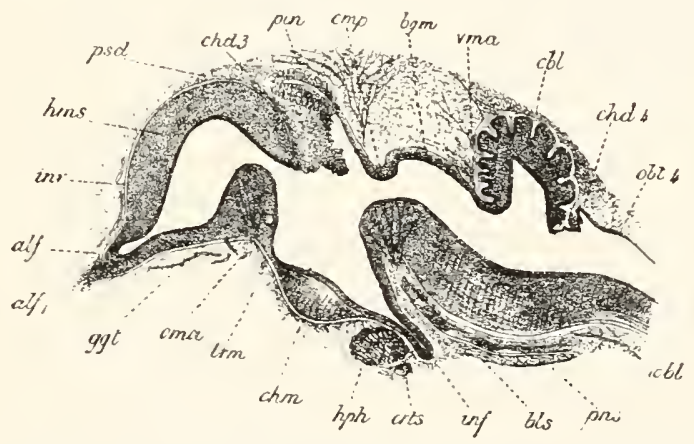

Fig. 250. Losgltudixal section thlodgh the bRaly of a Chick of tex Dass. (After Mihalkovics.)

Ims. cerebral hemispheres; alf. olfactory lobe; alf . olfactory nerve; gyt. corpus striatum; oma. anterior commissure; chd 3. choroid plexus of the third ventricle; pin. pineal gland; cmp. posterior commissure; trm. lamina terminalis; chm. optic chiasma; inf. infundibulum; $h p h$. pituitary body; $b g m$. commissurc of Sylvius (roof of iter a tertio ad quartum ventriculum); ‘ma. velum medulle anterius (valve of Vieussens); cbl. cerebellum; chd 4. choroid plexus of the fourth ventricle; obt 4 . roof of fourth ventricle; obl. medulla oblongata; pns. commissural part of medulla; ine. sheath of brain; bls. basilar artery; crts. internal carotid.

cerebellum is connected with the roof of the mid-brain by a delicate membrane, the velum medullie anterius, or valve of Vieussens (fig. 250,vma). The pons Varolii of Mammalia is represented by a small number of transverse fibres on the Hoor of the hind-brain immediately below the cerebellum.

In Mammalia the cerebellum attains a still greater development. The median lobe or vermiform process is first developed. In the higher Mammalia the lateral parts forming the hemispheres of the cerebellum become formed as swellings at the sides at a considerably 
later period, and are hardly developed in the Monotremata and Marsupialia.

The cerebellum is connected with the roof of the mid-brain in front and with the choroid plexus of the fourth ventricle behind by delicate membranous structures, known as the velum medullae anterius (valve of Vieussens) and the velum medullae posterius.

The pons Varolii is formed on the ventral side of the flool of the cerebellar region as a bundle of transverse fibres at about the same time as the olivary bodies.

The mid-brain. The changes undergone by the mid-brain are simpler than those of any other part of the brain. We have already seen that the mid-brain, on the appearance of the cranial flexure, forms an unpaired vesicle with a vaulted roof and curved floor, at the front end of the long axis of the body (fig. 118, MB). It is at this period in most Vertebrates relatively much larger than in the adult; and it is only in the Teleostei that it more or less retains in the adult its embryonic proportions.

The cavity of the mid-brain, greatly reduced in size in the higher forms, is known as the iter a tertio ad quartum ventriculum, or aqueductus Sylvii.

The roof of the mid-brain is sharply constricted off from the divisions of the brain in front of and behind it, but these constrictions do not extend to the floor.

In some Vertebrates the region of the mid-brain is stated to undergo hardly any further development. In the Axolotl it remains according to Stieda ${ }^{1}$ as a simple tube with nearly uniformly thick walls. In the majority of forms it undergoes, however, a more complicated development.

In Elasmobranclis the sides become thickened to form the optic lobes, which are soon separated by a median longitudinal groove. The floor becomes thickened to form the crura cerebri. The primitive simple median cavity becomes imperfectly divided into a median portion below, and two lateral diverticula in the optic lobes.

In Teleostei the changes, resulting in the formation of (1) a pair of longitudinal ridges projecting from the roof into the cavity of the iter, constituting the fornix of Gottsche, and $(2)$ of the two swellings on the floor, forming the tori semicirculares, are more complicated, but have not been satisfactorily worked out. In Bumbinator and the Anura generally the changes are of the same nature as those in Elasmobranchii, except that the prolongations of the ventricle into the optic lobes are still further constricted off from the median portion, which forms the true iter.

In Reptilia and Aves the development of the mid-brain takes place on the same type as in Elasmobranchii and the Anura. In Birds the optic lobes are pushed very much aside, and the roof of the iter is greatly thinned out. In Mammalia the sides of the mid-brain give rise to two pairs of prominences - the corpora quadrigemina-instead of the two optic lobes of

1 "Ueb. d. Bau d. centralen Nervensystem d. Axolotl." Zeit. f. wiss. Zoool., Vol, xxv. 1875. 
other Vertebrata. The prominences, which lo not contain prolongations of the iter, become first visible on the appearance of an oblique transverse furrow, while the anterior pair alone are separated by a longitudinal furrow. In the later stages of development the longitudinal furrow is continued so as to bisect the posterior pair.

The floor, which is bounded posteriorly by the pons Varolii, becomes the crura cerebri. The corpora geniculata interna also belong to this division of the brain.

Fore-brain. In its earliest condition the fore-lurain forms a single vesicle without a trace of separate divisions, but very early it buils off' the optic vesicles, whose history is described with that of the eye.

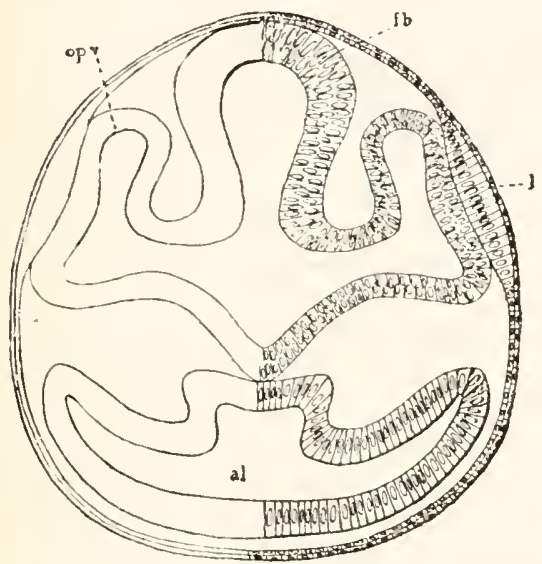

Fig. 251. Section throdgh the froNt PaRT OF THE head OF a Lepidosteus eMbryo ON THE SEVENTH DAY AFTER IMPREGNATION.

$a l$. alimentary tract; $f b$. thalamencephalon; $l$. lens of eye; op. $v$. optic vesicle. The mesoblast is not represented.

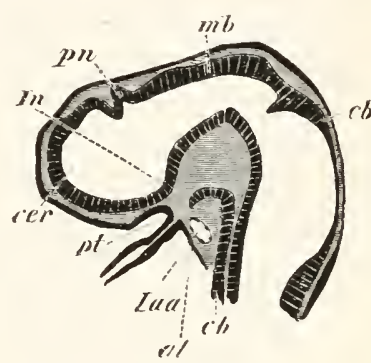

Fig. 252. LoxgITTIINAL SECTIOX THROCGH THE BRAIX OF A Yousg Pristichu's embiro.

cer. commencement of cerebral hemisphere; $3 n$. pineal gland; $I n$. infundibulum; $p t$. ingrowth of mouth to form the pituitary body; $m b$. mid-brain; $e b$. cerebellum; $c h$. notochord; $u l$. alimentary tract; Iaa. artery of mandibular arch.

The optic vesicles become gradually constricted off from the forebrain in a direction obliquely back wards and down wards. They remain, however, attached to it at the anterior extrenity of the base of the fore-brain (fig. $2.51 \mathrm{op} . v$.). While the above changes are taking place in the optic vesicles the anterior part of the fore-brain becomes prolonged, and at the same time somewhat dilated. At first there is no sharp boundary between the primitive fore-brain and its anterior prolongation, but there shortly appears a constriction which passes from above obliquely forwards and downwards. This constriction is shallow at first, but soon becomes much deeper, leaving however the cavities of the two divisions of the fore-brain united ventrally by a somewhat wide canal (fig. 252).

Of these two divisions the posterior becomes the thalamencephalon, while the anterior and larger division (cer) forms the rudiment of the cerebrai hemispheres and olfactory lobes. For a con-

B. E. II. 
siderable period this rudinent remains perfectly simple, and exhibits no signs, either extemally or internally, of a longitudinal constriction dividing it into two lobes.

From the above description it may be conchded that the rudiment of the cerebral hemispheres is contained in the original fore-brain. In spite however of their great importance in all the Craniata, it is probable that the hemispheres were either not present as distinct structnres, or only imperfectly separated from the thalamencephalon, in the primitive rertebrate stock.

The thalamencephalon. The thalamencephalon varies so slightly in structure throughout the Vertebrate series that a general description will suffice for all the types.

It forms at first a simple vesicle, the walls of which are of a nearly uniform thickness and formed of the usual spindle-shaped cells.

The cavity it contains is known as the thirel ventricle. Anteriorly it opens widely into the cerebral rudiment, and posteriorly into the ventricle of the mid-brain. 'The opening into the cerebral rudiment becomes the foramen of Dunro.

For convenience of description I shall divide it in to three regions, viz. (1) the floor, (2) the sides, and (3) the roof:

The floor becomes divided into two parts, an anterior part, giving origin to the optic nerves, in which is formed the optic chiasma; and a posterior part, which becomes produced into an at first inconspicuous prominence-the rudiment of the infundibulum (fig. 252 In). This comes in contact with an involution from the month,

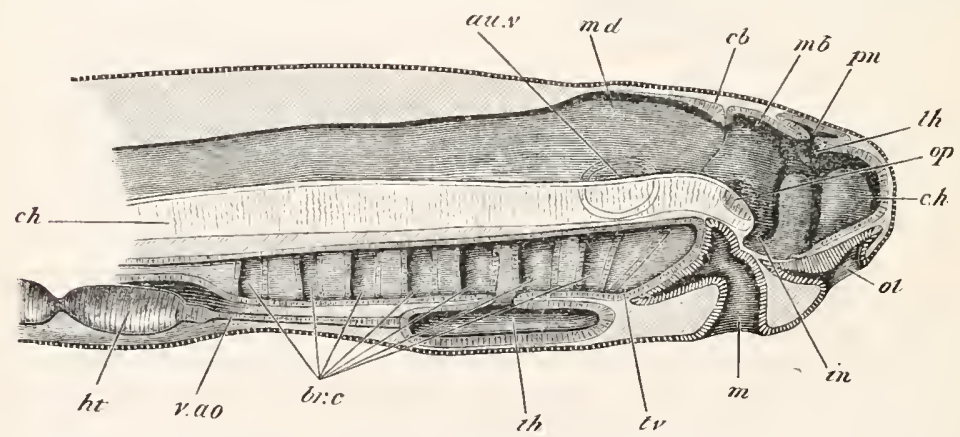

Fig. 25:3. Diagramatic vertical section through the head of a laria of Petromizon.

The larra had been hatched three days, and was $4.8 \mathrm{~mm}$. in length. The optic and auditory resicles are supposed to be seen through the tissues.

c.h. cerebral hemisphere; th. optic thalamus; $i n$. infundibulum; $p n$. pineal gland; $m b$. mid-brain; $c b$. cerebellum; md. medulla oblongata; $a u . x$. auditory vesicle; $o p$. optic vesicle; ol. olfactory pit; $m$. mouth; $b \% . c$. branchial pouches; th. thyroid involution; r.ao. ventral aorta; ht. ventricle of heart; $c h$. notochord.

which gives rise to the pituitary body (fig. $252 p t$ ), the development of which will be dealt with separately.

In the later stages of development the infundibulum becomes 
gradually prolonged, and forms an elongated diverticulum of the third rentricle, the apex of which is in contact with the pituitary body (higs. $2.50,25 t$ in, and figs. 250 and 2.5 inf $f^{\circ}$.

Along the siles of the infundibulum run the commissural fibres comnecting the floor of the mil-brain with the cerebrum.

In its later stages the infundibular region presents consiclerable variations in the different vertebrate types. In Fishes it generally remains very lirge, and permanently forms a marked diverticulum of the floor of the thalamenceplalon. In Elamobranchii the distal end becomes divided into three lobes-a median and two lateral. The lateral lobes apjear to become the sacei vasculosi of the adult.

In Teleostei peculiar bodies known as the lobi inferiores (liypoaria) make their appeance at the sides of the infundibulum. They appar to correspond in position witl the tuber cineremm of Mammalia'. In Birds, Reptiles, and Amphibia the lower part of the embryonic infundibulum becomes atrophied and reduced to a mere fingerlike process-the processus infundibuli.

In Mammalia the posterior part of the primitive infundibulum becomes the corpus albicans, which is double in Man and the higher Apes; the ventral part of the posterior wall forms the tuber cinereum. Laterally, at the junction of the optic thalimi and infundibulum, there are placed the fibres of the crura cerebri, which are probably derived from the walls of the infundibulum. A special process grows out from the base of the infundibulum, which undergoes peculiar chinges, and becomes intimately united with the pituitary body; in which connection it will be more fully described.

The sides of the thalamencephalon become very early thickened to form the optic thalami, which constitute the most important section of the thalamencephalon. 'They are

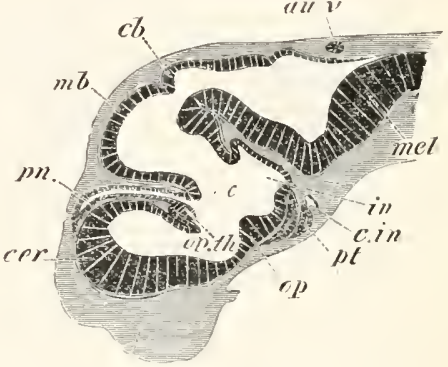

F16. 254. Loxeltumal sectios THROUgH THE BRAlN OF SCYLJIUA CAN1CULA AT AN ADVANCED STAGE OF DEVELOPMENT.

cer. cerebral hemisphere; $p n$. pineal gland; op.th. optic thalamus, connected with its fellow by a commissure (the midile commissure). In front of it is seen a fold of the roof of the fore. brain, which is the choroid plexus of the third ventric'e; op. optic chiasma; pt. pituitary body; in. infundibulum ; cb. cerebellum; au.l passage leading from the auditory resicle to the exterior; mel. medulla oblongata; C.in. internal carotid artery. separated, in Mammalia at all events, on their inner aspect from the infundibular region by a somewhat S-shaped groove, known as the sulcus of Mumro, which ends in the foramen of Munro. They also become in Mammalia secondarily united by a transverse conmissure, the grey or middle commissure, which passes across the cavity of the third ventricle.

1 For the relations of these bodies, ride L. Stieda, "Stud. iib. d. centrale Nervensystem d. Knochentische." Zeit. f. wiss. Zool. Vol. xvin. 1868. 
'This commissure is probably homologous with, and derived from, a conmissural band in the roof of the thalamencephalon, placed immediately in front of the pineal gland which is well developed in Elasmobranchii (fig. 254).

The roof undergoes more complieated changes. It becomes divided, on the appearance of the pineal gland as a small papilliform outgrowth (the development of which is dealt with separately), into two regions-a longer anterior in front of the pineal gland and a shorter posterior. The anterior region becomes at an early period excessively thin, and at a later period, when the roof of the thalamencephalon is shortened by the approach of the cerebral hemispheres to the mid-brain, it becomes (vide figs. 250 and 255 chd 3 and 2.54 ) considerably folded, while at the sane time a vascular plexus is formed in the pia mater above it. On the accomplishment of these changes it is known as the tela chorordea of the thiml ventricle.

In the roof of the third ventricle belind the pineal gland there appear in Elasmobranchii, the Sauropsida and Mammalia transverse commissural fibres, forming a structure known as the posterior commissure, which comects together the two optic thalami.

'The most remarkable organ in the rouf of the thalamencephalon is the pineal gland, which is developed in most Vertebrates as a simple papilliform outgrowth of the root, and is at first composed of cells similar to those of the other parts of the central nervous system (figs. 2.50, 25.2, 2.54 and 2.5. $\mathrm{mm}$ or $\mathrm{pin}$ ). In the lower Vertebrata it is directed forwards, but in Mammalia, and to some extent in Aves, it is directed backwards.

In Amplibia it is deseribed by Gü̈tte (No, 296) as being a product of the point where the roof of the brain remains latest attached to the external skin.

The figure which Götte gives to prove this does not appear to me fully to bear out his conclusion; which if true is very important. Although I directed my attention specially to this point, I could find no indication in Elasmobranchii of a process similar to that described by Gütte, and his observations have not as yet been confirmed for other Vertebrates. Götte compares the pineal gland to the long-persisting pore which leads into the cavity of the brain in the embryo of Amphioxus, and we might add the Ascidians, and, should his facts be contirmed, the conclusion he draws from them would appear to be well founded.

The later stages in the development of the pineal gland in different Vertebrates have not in all cases been fully worked out'.

In Elasmobranchii the pineal gland becomes in time very long, and extends far forwards over the roof of the cerebral hemispheres (fig. $254 \mathrm{~mm}$ ). Its distal extremity dilates somewhat, and in the adult the whole organ forms (Ehlers, No. 337) an elongated tube, enlarged at its free extremity, and opening at its base into the brain. The enlarged extremity may either be lodged in a cavity in the

${ }^{1}$ For a full account of this subject vide Ehlers (No. 33i). 
cartilage of the cranium (Acanthias), or be placed outside the cranium (Raja).

In Petromyzon its form is very different. It arises (fig. $253 \mathrm{~mm}$ ) as a sack-like diverticulum of the thalamencephalon extendins at first both backwards and forwards. In the Ammocote the watls of this sack are deeply infolded.

The embryonic form of the pineal gland in Amphibia is very much like that which remains permanent in Elasmobranchii; the stalk connecting the enlarged terminal portion with the brain soon however becomes solirl and very thin except at its proximal extremity. The enlarged portion also becomes solid, and is placed in the adult externally to the skıll, where it forms a mass originally described by Stieda as the cerebral gland.

In Birls the primitive outgrowth to form the pineal gland becomes, according to Mihalkovics, deeply indented by vascular connective tissue ingrowths, so that it assumes a dendritic structure (fig. $250 \mathrm{pin}$ ).

The proximal extremityattached to the roof of the thalamencephalon forms a special section, known as the infra-pineal process. The central humen of the free part of the gland finally atrophies, but the

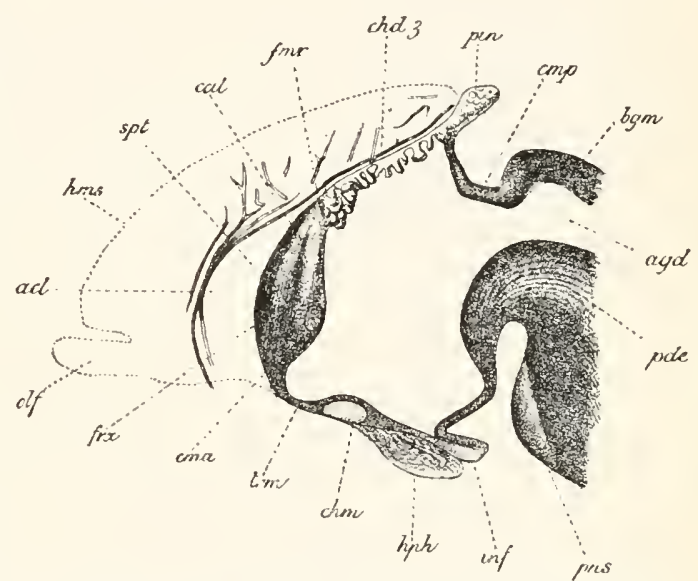

Fi(. 255. LoxGITUDMNAL VERTICAL SECTION THIOUGH THE ANTELIOR PART OF THE BRAIN OF AN EMBRTO RABBIT of forr centmetres. (After Mihalkovics.)

The section passes through the median line so that the cerebral hemispheres are not cut; their position is however indicated in outline.

spt. septum lucidum formed by the coalescence of the inner walls of part of the cerebral hemispheres; cha. anterior commissure; trix. vertical pillars of the fornix; cal. genn of corpus callosum; trm. lamina terminalis; $l \mathrm{lms}$. cerebral hemispheres; ol $f$. olfactory lobes; acl. artery of corpus callosim; fmr. position of foramen of Innro; chd 3 . choroid plexus of third rentricle; pin. pineal gland; cmp. posterior commissure; bgm. lauina miting the lobes of the mid-brain; chm. optic chiasma; $h p h$. pituitary body; inf. infundibulum; pns. pons Varolii; $p d e$. cerebral peduncles; agd. iter. branches still remain

hollow. The infra-pineal process becomes reduced to a narrow statk, comnecting the branched portion of the body with the brain. The branched terminal portion and the stalk obviously correspond with the vesicle and distal part of the stalk of the types alreaty described. In Mammalia the development of the pineal gland is, according to Mibalkovies, generally similar to that of Birds. The original outgrowth becomes branched, but the follicles or lobes to which the 
branthing gives rise eventually become solid (fig. 9.5.5 pin). An infrapineal process is developed comparatively late, and is not sharply separated from the roof of the brain.

No satisfactory suggestions have yet been offered as to the nature of the pineal gland, unless the view of Gotte be regarded as such. It appears to possess in all forms an epithelial structure, but, except at the base of the stalk (infra-pineal process) in Mammalia, in the wall of which there are nerve-fibres, no nervous structures are present in it in the alult state.

The pituitary body. Although the pituitary borly is not properly a nervous structure, yet from its intimate connection with the brain it will be convenient to describe its development here. The pituitary body is in fact an organ derived from the epiblast of the stomodreum. This fact has been demonstrated for Mlammalia, Aves, Amphibia and Elasmobranchii. and may be accepted as bolding good for all the Craniata ${ }^{1}$. The epiblast in the angle formed by the cranial flexure becomes involuted to form the cavity of the mouth. This cavity is bordered on its posterior surface by the front wall of the alimentary tract, and on its anterior by the base of the fore-brain. Its uppermost end does not at first beconne markedly constricted off from the remainder, but is nevertheless the ruliment of the pitnitary body.

Fig. 2.56 represents a transverse section through the head of an Elasmobranch embryo, in which, owing to the cranial flexure, the fore part of the head is cut longitudinally and horizonta!ly, and the section passes throngh both the fore-brain $\left(f^{\prime} b\right)$ and the hind-brain. Close to the base of the fore-brain are seen the mouth $(m)$, and the pituitary involution from this $(p t)$. In contact with the pituitary involution is the blind anterior termination of the throat $(a l)$ which a little way back opens to the exterior by the first visceral cleft (I $x . c$ ). This figure alone suffices to demonstrate the correctness of the above aceount of the pituitary body; but its truth is still further confirmed by fig. 2.5. ; in which the mouth involution $(p t)$ is in contact with, but still separated from, the front end of the alimentary tract. Very shortly after the septum between the mouth and throat becomes pierced, and the two are placed in communication, the pituitary iuvolution becomes very partially constricted off from the mouth involution, though still in direct communication with it. In later stages the pituitary involution becomes longer and is dilated terminally; while the passage connecting it with the mouth becomes narrower and narrower, and is finally reduced to a solid cord, which in its turn disappears.

Before the connection between the pituitary vesicle and the mouth

1 Scott states that in the larva of Petromyzon the pituitary body is derived from the walls of the nasal pit; Quart. J. of Vicr. Science, Vol, xxI. p. 750. I have not myself completely followed its development in Petromyzon, but I have observed a slight diverticulum of the stomodrum which I believe gives origin to it. Fuller details are in any case required before we can admit so great a divergence from the normal development as is indicated by Scott's statements. 
is obliterated the cartilaginous eranimn becomes developed, and it may then be seen that the infundibulum projects throngh the pituitary space to come into close juxtaposition with the pituitary bodr.

After the piturtary resicle has lost its comnection with the mouth it lies just in frout of the infundibulum (figs. 2.50 and .05 .5 hph and fig. $25 \mathrm{t}(\mathrm{t})$; and soon becomes surrounded by vasenlar mesoblast, which grows in and divides it into a number of branching tubes. In many forms the cavity of the resicie completely hisappears, and the branches become for the most part solid [C'yclostomata ancl some Mammalia (the rabbit), Elasmobranchii, 'Telenstei and Anphibia]. In Reptilia, Aves and most Mammalia the lumen of the organ is more or less retained (IT. Miiller, No. 344).

Although in the majority of the Vertebrata there is a close connection between the pituitary body and the infundibulum, there is no actual fusion between the two. In Mammalia the case is different. The part of the infundibulum which lies at the hinder end of the pituitary looly is at first a simple finger-like process of the brain (fig. 2.5 inf), but its end becomes swollen, and the lumen in this part becomes obliterated. Its cells, origirally similar to those of the other parts of the nerrous system and even (Kölliker) containing differentiater nerve-fibres, partly atrophy, and patly assume an indifferent form, while at the same time there grow in amongst

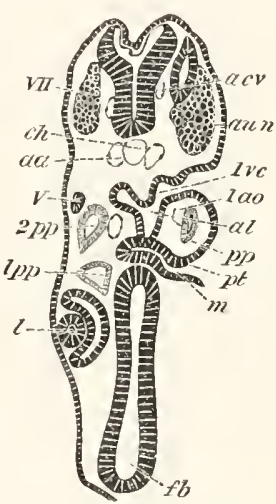

Fig. 256. Traxsterse SECTION THROUGH THE FRONT PART OF THE HEAD OF A YOT'Xi P'RISTICRL' EMBRYo.

The section, owing to the cranial Hexure, cuts both the fore- and the hind-brain. It shews the premandibular and mandibular head cavities $1 p p$ and $2 p p$, etc. The section is moreover somewhat oblique from side to sicle.

$f b$. fore-hrain; $l$. lens of eye; $m$. mouth; pt. upper end of mouth, torming pituitary involution; 1at. mandibular aortic arch; 1 pp. and 2pp. first and second head cavities: lic. first visceral cleft; $T$. fiftl nerve; ann. anditory nerve; $\mathbf{I I}$. seventh nerve; aa. roots of dorsal aorta; acr. anterior cardinal ven; ch. notochord. them numeruus vascular and connec-

tive-tissue elements. The process of the infundibulum thus metanorphosed becomes inseparably commected with the true pituitary body, of which it is usually described as the posterior lobe. The part of the infundibulum which undergoes this change is very probably homologous with the saceus vasculosus of Fishes.

The true nature of the pituitary lody las not yet been marle out. It is clearly a rulimentary organ in existing praniate Vertebrates, and its development iudicates that when functional it was probably a sense organ opening into the month, its blind end reaching to the base of the hrain. No similar organ has as yet been found in Amphioxus, but it seems posible

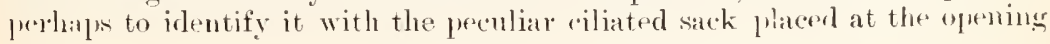


of the pharynx in the Tunicata, the development of which was described at $p .15$. If the suggestion is correct, the division of the body into lobes in existing Vertebrata must be regarded as a step towards a retrogressive metamorphosis.

Another possible view is to regard the pituitary body as a glandular structure which originally opened into the mouth in the lower Chordata, but which has in all existing forms ceased to be functional. The intimate relation of the organ to the brain appears to me opposed to this view of its nature, while on the other hand its permanent structure is more easily explained on this view than on that previously stated. In the Aseidians a glandular organ has been described hy Lacaze Duthiers' ${ }^{1}$ in juxtaposition to the ciliated sack, and it is possible that this organ as well as the ciliated sack may be related to the pituitary boty. In view of this possibility further investigations ought to be carried out in order to determine whether the whole pituitary body is derivel from the oral involution, or whether there may not be a nervous part and in glanclular part of the organ.

The Cerebral Hemispheres. It will be convenient to treat separately the development of the cerebral hemispheres proper, and that of the olfactory lobes.

Although the cerebral hemispheres vary more than any other part of the brain, they are nevertheless developed from the unpaired cercbrat rudiment in a nearly similar manner throughout the series of Vertebrata.

In the cerebral rudiment two parts may be distinguished, viz, the Hoor and the roof. The former gives rise to the ganglia at the base of the hemispheres-corpora striata, etc.-the latter to the hemispheres proper.

The first change which takes place consists in the roof growing out into two lobes, between which a shallow median constriction nakes its appearance (fig. 257). The two lobes thus formed are the rudi-

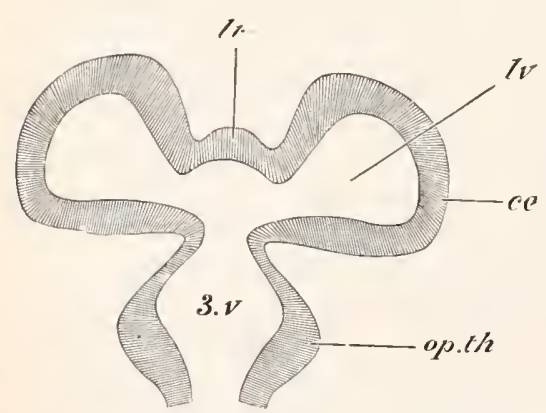

Fig. 257. DiagramMatic LOXgITUDINaL HORIZONTAL SECTION THROTGH THE FOREBRAIX.

$3 . v$. third ventricle; $l$. lateral ventricle; tt. lamina terminalis; ce. cerebral hemisphere; op.th. optic thalamus. ments of the two hemispheres. The cavity of each of them opens by a widish aperture into the vestibule at the base of the cerebral rudiment, which again opens directly into the cavity of the third ventricle $(3 v)$. The Y-shaped aperture thus formed, which leads from the cerebral hemispheres into the third ventricle, is the foramen of Munro. The cavity $(l v)$ in each of the rudimentary hemispheres is a lateral ventricle. The part of the cerebrum which lies between the two hemispheres, and passes forwards from the roof of the

1 "Les Ascidies simples des Côtes de France." Archives de Biologie expér. et générale, Vol. III. 1A74, 1. 329 . 
third ventricle round the end of the brain to the optic chiasma, is the rudiment of the lamina terminalis (figs. $257 \mathrm{lt}$ and $255 \mathrm{tr} \mathrm{m}$ ). Up to this point the development of the cerebrum is similar in all Vertebrata, but in some forms it practically does not proceed much further.

In Elasmobranchii, althongh the cerebrum reaches a considerable size (fig. $254 \mathrm{cer}$ ), and grows some way backwards over the thalamencephalon, yet it is not in many forms divided into two distinct lobes, but its paired nature is only marked by a shallow constriction on the surface. The lamina terminalis in the later stages of development grows backwards as a thick median septum which completely separates the two lateral ventricles ${ }^{1}$ (fig. 263).

There are, it may be mentioned, considerable variations in the structure of the cerebrum in Elasmobranchii into which it is not however within the scope of this work to enter.

In the Teleostei the vesicles of the cerebral hemispheres appear at first to have a wide lnmen, but it subsequently becomes almost or quite obliterated, and the cerebral rudiment forms a small bilobed nearly solid body. In Petromyzon (fig. $2.53 \mathrm{ch}$ ) the cerebral rudiment is at first an unpaired anterior vesicle, which subsequently becomes bilobed in the normal manner. The walls of the hemispheres become much thickened, but the lateral ventricles persist.

In all the higher Vertebrates the division of the cerebral rudiment into two distinct hemispheres is quite complete, and with the deepening of the furrow between the two hemispheres the lamina terminalis is carried backwards till it forms a thin layer bounding the third ventricle anteriorly, while the lateral ventricles open directly into the third ventricle.

In Amphibians the two hemispheres become united together immediately in front of the lamina terminalis by commissural fibres, forming the anterior commissure. They also send out anteriorly two solid prolongations, usually spoken of as the olfactory lobes, which subsequently fuse together.

In all Reptilia and Aves there is formed an anterior commissure, and in the ligher members of the gronp, especially Aves (fig. 250), the hemispheres may obtain a considerable development. 'Their onter walls are much thickened, while their inner walls become very thin; and a well-developed ganglionic mass, equivalent to the corpus striatum, is formed at their base.

The cerebral hemispheres undergo in Mammalia the most complicated development. The primitive unpaired cerebral rudiment becomes, as in lower Vertebrates, bilobed, and at the same time divided' by the ingrowtl of a septum of connective tissue into two distinct hemispheres (figs. 260 and $261 f$ and 258 I). From this septum is formed the falx cerebri and other parts.

1 A comparison of the mode of development of this septum with that of the septum lucidum with its contained commissures in Mammalia clearly shews that the two structures are not homologous, and that Miklucho. Naclay is in error in attempting to treat them as being so. 
The hemispheres contain at first very large cavities, communicating

.

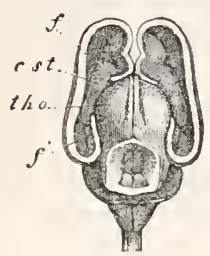

2.

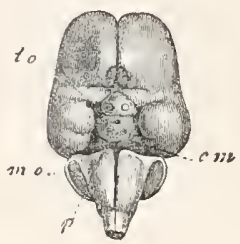

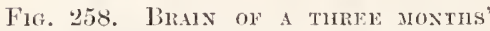
huMAN EMBlyo: NaTfral size. (From liölliker.)

1. From above with the dorsal part of hemispheres and mid-brain removed: 2. From below. $f$. ant rior part of eut wall of the hemisphere; $f^{\prime \prime}$. cormu ammonis; tho. optic thalamus: ist. corpus striatum; to. optic tract; cm. corporil mammillaria; p. pons Varolii.

of which constitute the permanent anterior and lescending tornua of the lateral ventricles (fig. 26.2 st).

With the further growth of the hemisphere the corpus striatum

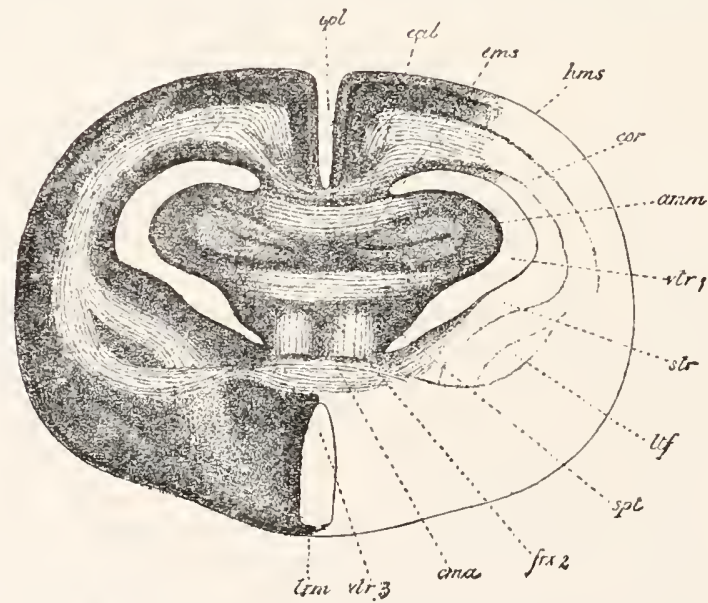

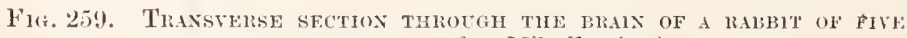
CENTHATRES. (After Mihalkovies.)

The section passes through nearly the posterior border of the septum lucilum, immediately in fiont of the foramen of Mumro.

lims. cerebral hemispheres; cul. corpus callosum; amm. cornu ammonis (hippocampus major); cm.. superior commissure of the cornua ammonis; spt. septum lucidum; frx 2 . vertical tibres of the fornix; cma. anterior commissure: trm. lamina terminalis; str. corpus striatum; ltf. uncleus lenticulari; of corpus striatum; rf 1 . lateral renticle; rtr3. thiod ventricle: $i p /$ slit between cerebral hemispheres. 
loses its primitive relations to the descending cornu. The reduction in size of the foramen of Mumro above mentioned is, to a large extent, caused by the growth of the corpora striata.

The corpora striata are united at their posterior border with the optic thalami. In the later stages of development the area of contact bet:veen these two pairs of ganglia increases to an immense extent (fig. 261), and the boundary between them beenmes somewhat obscure, so that the sharp distinction which exists in the embryo between the thalamencephalon and cerebral hemispheres becomes lost. This change is usually (Mlihalkovics, Kïlliker) attributed to a finsion between the corpora striata and optic thalami, but it has recently heen attributed by Schwalbe (No. 349), with more probability, to a growth of the original surface of contact, and an accompanying change in the relations of the parts.

The onter wall of the hemispheres gradnally thickens, white the immer wall becones thimner. In the latter, two eurved folds, projecting towards the interior of the lateral ventricle, become formed. These folds extend from the foramen of 11 umro aloug nearly the whole of what afterwards becomes the descending cornu of the lateral ventricle.

The upper fold becomes the hippocampus najor (cornu ammonis) (figs. $259 \mathrm{cmm}, 260$ and $291 \mathrm{~h}$, and $262 \mathrm{~cm}$ ). When the rudiment

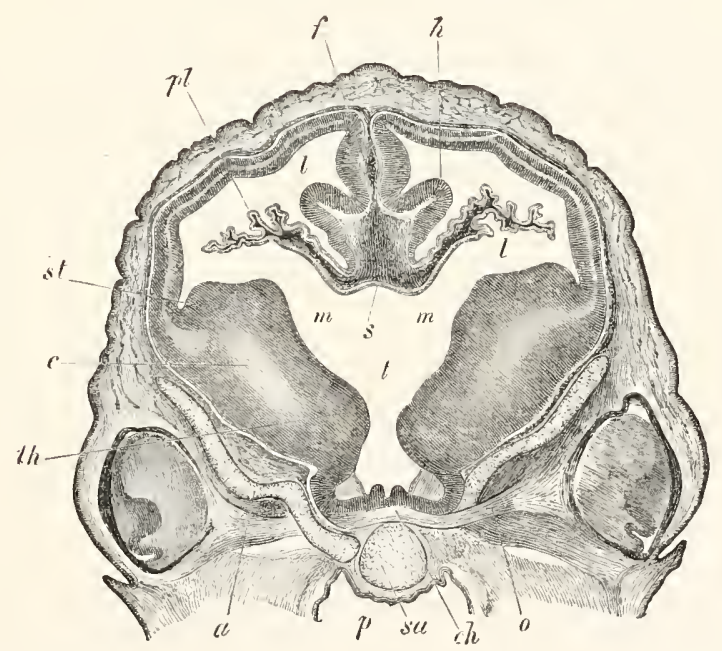

Fir. 260. Transverse section throtgh the prain of a sheer's embryo OF $2 \cdot 7$ CM. IN LEXGTH. (From Kolliker.)

The section passes through the level of the foramen of Mumro.

st. corpus striatum; $m$. foramen of Nunro; $t$. third ventricle; $p l$. choroid plexus of lateral ventricle; $f$. falx cerebri; th. anterior part of optic thalamus; ch. optic chiasma; $\sigma$ optic nerve; $c$. fibres of the cerebral peduncles; $h$. cornu anmonis; p. pharynx; sa. pre-sphenoid bone; a. orbito-sphenoid bone; s. points to part of the roof of the brain at the junction between the loof of the third rentricle and the lamina terminalis; l, lateral ventricle. 
of the descending cornu has become transformed into a simple

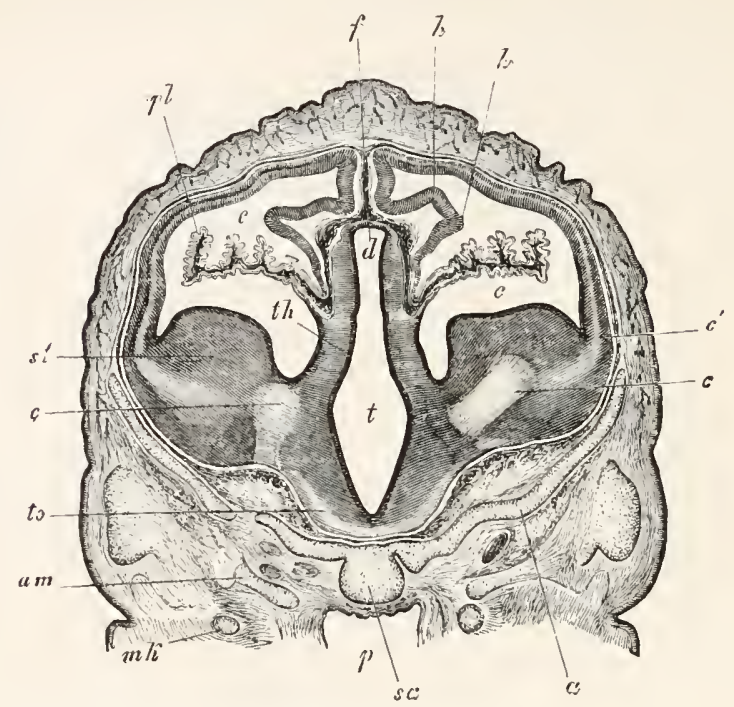

F'1. 231. 'Thansverse section through the maln of a shegp's embryo of $2 \cdot 7$ CMr. Ix LExgTH. (From Kölliker.)

The section is taken a short distance behind the section represented in fig. 260 , and passes through the posterior part of the hemispheres and the third ventricle.

st. corpus striatum; th. optic thalamus; to. optic tract; $t$. third ventricle; $d$. roof of third ventricle; $c$. fibres of cerebral peduncles; $c^{\prime}$. divergence of these fibres into the walls of the hemispheres; $e$. lateral ventricle with choroid plexus $p l$; $h$. cornu ammonis; $f$. primitive falx; $a m$. alisphenoid; $a$. orbito-sphenoid; sa. presphenoid; $p$. pharynx; $m k$. Meckel's cartilage.

process of the lateral ventricle the hippocampus major forms a prominence upon its floor.

'The wall of the lower fold becomes very thin, and a vascular plexus, derived from the connective-tissue septum between the hemispheres, and similar to that of the roof of the third ventricle, is formed outside it. It constitutes a fold projecting far into the cavity of the lateral ventricle, and together with the vascular connective tissue in it gives rise to the choroid plexus of the lateral ventricle (figs. 260 and $261 p l)$.

It is clear from the above description that a marginal fissure leading into the cavity of the lateral ventricle does not exist in the sense often implied in works on human anatomy, in that the epithelium covening the choroid plexus, which forms the true wall of the brain, is a continnous membrane. The epithelium of the choroid plexus of the lateral ventricle is quite independent of that of the chorvid plexus of the third ventricle, though at the foramen of Mnnro the roof of the third ventricle is of course continuous with the inner wall of the lateral ventricle (fig. $260 \mathrm{~s}$ ). The rascular elements of the two plexuses form however a contimuns structure. 
The most characteristic parts of the Mammalian cerebrum are the commissures connecting the two hemispheres. These commissures are (1) the anterior commissure, (2) the fornix, and (3) the corpus callosum, the two latter being peculiar to Mammalia.

By the fusion of the inner walls of the hemispheres in front of the lamina terminalis a solid septum is formed, known as the septum lucidum, continuous behind with the lamina terminalis, and below with the corpora striata (figs. 255 and $259 \mathrm{spt}$ ). It is by a series of differentiations within this septum that the above commissures originate. In Man there is a closed cavity left in the septum known as the fifth ventricle, which has however no communication with the true ventricles of the brain.

In the septum lucidum there become first formed, below, the transverse fibres of the anterior commissure (fig. 2.5.5 and fig. $259 \mathrm{cma}$ ), and in the upper part the vertical fibres of the fornix (fig. 2.55 and tig. 2.59 fix 2). The vertical fibres meet above the foramen of Munro, and thence diverge backwards, as the posterior pillars, to lose themselves in the cornu ammonis (fig. 259 amm). Ventrally they are continued, as the descending or anterior pillars of the formix, into the corpus albicans, and thence into the optic thalami.

The corpus callosum is not formed till after the anterior commissure and fornix. It arises in the upper part of the region (septum lucidum) formed by the fusion of the lateral

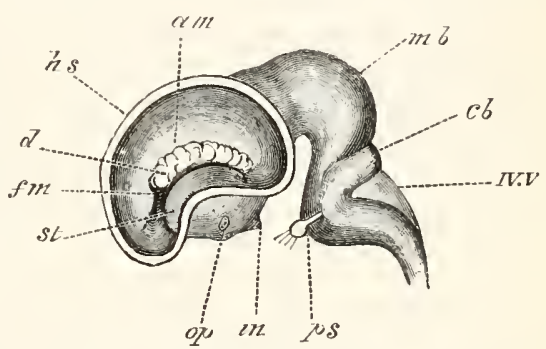

Fić. 262. Lateral view of the brain of a calf Embrio of 5 cr. (After Mihalkovies.)

The outer wall of the hemisphere is removed, so as to give a view of the interior of the left lateral ventricle.

hs. cut wall of hemisphere; st. corpus striatum ; am. hippocampus major (cornu ammonis); d. choroid plexus of lateral ventricle; $\mathrm{im}$. foramen of Munro; op. optic tract; in. infundibulum; mb. mid-brain; $c b$. cerebellum; $I T . V$. roof of fourth ventricle; $p s$. pons Varolii, close to which is the fifth nerve with Gasserian ganglion. walls of the hemispheres (figs.

2.55 and $259 \mathrm{cal}$ ), and at first only its curved anterior portionthe genu or rostrum-is developed. This portion is alone found in Monotremes and Marsupials. The posterior portion, which is present in all the Monodelphia, is gradually formed as the hemispheres are prolonged further backwards.

Primitively the Mammalian cerebrum, like that of the lower Vertebrata, is quite smooth. In many of the Mammalia, Monotremata, Insectivora, etc., this condition is nearly retained through life, while in the majority of Mammalia a more or less complicated system of fissures is developed on the surface. The most important, and first formed, of these is the Sylvian fissure. It arises at the time when the hemispheres, owing to their growth in front of and behind the 
corpora striata, have assumed a somewhat bean-shaped form. At the

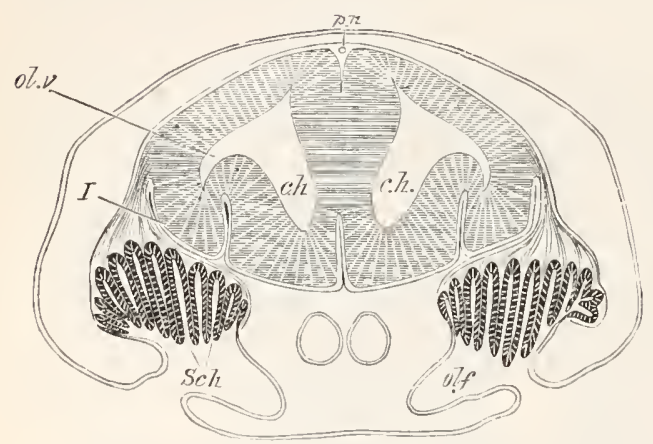

Fig. 263. SEctiox THRotgil THE IRAIX ANI) OL-

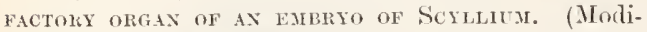
fied from figures by Marshall and myself.)

$c h$. cerebral hemispheres; ol.v. olfactory vesicle; olf. olfactory pit; Sch. Schneiderian folds; $I$. olfactory nerve. The reference line has leen accidentally taken througl the nerve to the brain; $\mu$. anterior prolongation of piueal glaud. root of the hemispheres -the hilus of the bean -there is formed a shallow depression, which constitutes the first trace of the Sylvian fissure. The part of the brain lying in this fissure is known as the island of Reil.

\section{The olfactory lobes.} The olfactory lobes, or 1.hinencephala, are secondary outgrowths of the cerebralhemispheres, and contain prolongations of the lateral ventiicles, but may however be solit in the alult state. According to Marshall they develop in Birds and Elasmobranchs and presumably other forms later than the olfactory nerves, so that the olfactory region of the hemispheres is indicated before the appearance of the oltactory lobes.

In most l'ertebrates the olfactory lobes arise at a fairly early stage of development from the under and anterior part of the henispheres (fig. 2.50 olf'). In Elasmobranchs they arise, not from the base, but from the lateral parts of the brain (fig. 263), and become subsequently divided into a bulbons portion and a stalk. They vary considerably in their structure in the adult.

In Amphibia the solid anterior prolongations of the cerebral hemispheres already spoken of are usually regarded as the olfactory lobes, but according to Götte, whose view appears to me well founded, small papilla, situated at the base of these prolongations, from which olfactory nerves spring, and which contain a process of the lateral ventricle, should properly be regarded as the olfactory lobes. These papilla arise prior to the solid anterior prolongations of the hemispheres.

In Birds the olfactory lobes are small. In the chick they arice (Marshajl) on the seventh day of incubation.

\section{General conchusions as to the Central Nernous System.}

It has been shewn above that both the brain and spinal cord are primitively composed of a uniform wall of epithelial cells, and that the first differentiation results in the formation of an external layer of white matter, a middle layer of grey matter (ganglion cells), and an immer epithelial layer. This primitive histological arrangement, 
which in many parts of the brain at any rate, is only to be observed in the early levelopmental stages, has a simple phylogenetic explanation.

As has been already explained in an earlier part of this chapter the central nervous system was originally a differentiated part of the superticial epidermis.

This differentiation (as may be concluded from the character of the nervous system in the Coelenterata and Echinodermata) consisted in the conversion of the inner ends of the epithelial cells into nervefibres; that is to say, that the first ditferentiation resulted in the formation of a layer of white matter on the inner side of the epilermis. 'The next stage was the separation of a deeper layer of the epiciermis as a layer of ganglion cells from the superficial epithelial layer, i.e. the formation of a middle layer of ganghion cells and an outer epithelial layer. Thus, phylogenetically, the same thee layers as those which first make their appearance in the ontogeny of the vertebrate nervous system became successively differentiated, and in both cases they are clearly placed in the same positions, because the central canal of the rertebrate nervous system, as formed by an involution, is at the true outer surface, and the extcrual part of the cord is at the true inner surface.

It is probable that a very sharp distinction between the white and grey matter is a feature acyured in the higher Vertebrata, since in Amphioxus there is no such sham separation; though the nervefibres are nainly sitnated externally and the nerve-ceils internally.

As already stated in Chapter xir. the primitive livision of the nervous axis was probably not into brain and spinal cord, but into (1) a fore-brain, representing the ganglion of the prixoral lobe, and (๖) the posterior part of the nervons axis, consisting of the midand hind-brains and the spinal cord. 'This view of the division of the central nervous system fits in fairly satisfactorily with the facts of development. The fore-brain is, histologically, nore distinct from the posterior part of the nervous system than the posterior parts are from each other ; the front end of the notochord forns the boundary between these two parts of the central nervous system (cide fig. 25:3), ending as it does at the front termination of the Hoor of the midbrain, and finally, the nerves of the fore-brain have a different character to those of the mid-and hind-brain.

This primitive division of the central nervous systen is lost in all the true Vertebrata, and in its place there is a secomblary divisioncorresponding with the secondary vertebrate hear-into a brain and spinal cord. The brain, as it is established in these forms, is again divided into a fore-brain, a nid-brain and a hind-brain. The forebrain is, as we have already seen, the original gangtion of the praeoral lobe. The mid-brain appears to be the lobe, or ginglion, of the third pair of nerves (first pair of segmental nerves), while the hind-brain is a more complex structure, each section of which (perhaps indicated by the constrictions which often appear at an early stage of develop- 
ment) giving rise to a pair of segmental nerves is, roughly speaking, homologous with the whole nid-brain.

The type of differentiation of each of the primitively simple vesicles forming the fore-, the mid-and the hind-brains is very uniform throughout the Vertebrate series, but it is highly instructive to notice the great variations in the relative importance of the parts of the brain in the different types. This is especially striking in the case of the fore-brain, where the cerebral hemispheres, which on embryological grounds we may conchde to have been hardly differentiated as distinct parts of the fore-brain in the most primitive types now extinct, gradually become more and more prominent, till in the highest Mammalia they constitute a more important section of the brain than the whole of the remaining parts put together.

The little that is known with reference to the significance of the more or less corresponding outgrowths of the floor and roof of the thalamencephalon, constituting the infundibulum and pineal gland, has already been mentioned in connection with the development of these parts.

\section{BibliogRAPHY.} 1814 .

(332) C. J. Carus. Versuch einer Darstellung d. Nerrensystems, etc. Leipzig,

(333) J.L. Clark. "Researches on the development of the spinal cord in Man, Mammalia and Birds." Phit. Trans., 1862.

(334) E. Dursy. "Beiträge zur Entwicklungsgeschichte des Hirnanhanges." Centralblatt f. $d$, med. Wissenschaften, 1868. Nr. 8.

(335) E. Dursy. Zur Lintuich-hngsgeschichte des Kopfes des Menschen und der höheren Wirbelthiere. Tübingen, 1869.

(3.36) A. Ecker. "Zux Entwicklungsgeschichte der Furchen und Windungen der Grosshirn-Hemisphären im Foetus des Menschen." Archir $f$. Anthropologie, v. Ecker und Lindenschmidt. Vol. III. 1868.

(337) E. Ehlers. "Die Epiphyse am Gehirn d. Plagiostomen." Zeit. f. wiss. Zool. Vol. xxx., suppl. 1878.

(338) P. Flechsig. Die Leitungsbahnen im Gehirn und Rüchenmark des Menschen. Auf Grund entwicklungsgeschichtlicher. Untersuchungen. Leipzig, 1876.

(339) V. Hensen. "Zur Entwicklung des Nervensystems." Tirchow's Archir, Bd. xxx. 1864 .

(3+0) L. Löwe. "Beiträge z. Anat. u. z. Entwick. d. Nerrensystems d. Säugethiere u. d. Menschen." Berlin, 1880.

(34 I) L. Löwe. "Beiträge z, vergleich. Morphogenesis d. centralen Nervensystems d. Wirbelthiere." Wittheit. a. d. embryol. Instit. Wien, Vol. 11. 1880.

$\left(34^{2}\right)$ A. M. Marshall. "The Morphology of the Vertebrate Olfactory organ." Quart. J. of Micr. Science, Vol. xix. 1879.

$(3+3)$ V. v. Mihalkovics. Entwicklungsgeschichte d. Gehirns. Leipzig, 1877.

(344) W. Miiller. "Ueber Entwicklung und Bau der Hypophysis und des Processus infundibuli cerebri." Jenaische Zeitschrift. Bd. vi. 1871.

(3+5) H. Rahl-R ii ckhard. "Die gegenseitigen Verhältnisse d. Chorda, Hypo. physis ete. bei Haifischembryonen, nebst Bemerkungen uib. d. Deutung d. einzelnen Sheile d. Fisehgehirns." Morphol. Jahrbuch, Vol. vi. 1880.

$(3+6)$ H. Ratlike. "Ueber die Entstehung der glandula pituitaria." Mïller's Archir $f$. Anat. und Physiol., Bd. v. 1838. 1861 .

$(3+7)$ C. B. Reichert. Der Bau des menschlichen Gehins. Leipzig, 1859 u.

$\left(34^{8}\right)$ F. Schmidt. "Beiträge zur Entwicklungsgeschichte des Gehirns." Zeitschrift f. wiss. Zoologie, 1862. Bd. xI. 
(.349) ('. Schwalbe. "Beitrag z. Entwick. d. Zwischenhinns." Sitz. d. Jenuisch"n Gesell. f. Med. u. Naturuiss. Jan. 23, 1880.

(350) Fried. Tiedemann. Anutomie und Bildungsgesohichte des Gehirm im Foptus des Menschen. Nürnberg, 1816.

\section{The developaext of the Cranial and Sifin Neries ${ }^{1}$.}

All the nerves are outgrowths of the central nervous system, but the differences in development between the cranial and spinal nerves are sufficiently great to make it convenient to treat them separately.

Spinal nerves. The posterior roots of the spinal nerves, as well as certain of the cranial nerves, arise in the same manner, and from the same structure, and are formed considerably before the anterior roots. Elasmobranch fishes may be taken as the type to illustrate the mode of formation of the spinal nerves.

The whole of the nerres in question arise as outgrowths of a median ridge of cells, which makes its appearance on the dorsal side of the spinal cord (fig. 26t $\mathrm{A}, \mathrm{pr}^{\circ}$ ). This ridge has been called by Marshall the neural crest. At each point, where a pair of nerves will be formed, two pear-shaped outgrowths project from it, one on each side; and apply themselves closely to the walls of the spinal cord (fig. $26+\mathrm{B}, p r)$. 'These outgrowths are the rulliments of the posterior'

${ }^{1}$ Remak derived the posterior ganglia from the tissue of the mesoblastic somites, aur following in Remak's steps most author's believed the peripheral vervous system to have a mesoblastic origin. This view, which had lowerer been rejected on theoretical grounds by Hensen and others, was finally attacked on the ground of observation by His $\left(N_{0}, 29 i\right)$. His (No. 352, 1. 45s) found that in the Fowl "the spinal ganglia of the head and trumk arose frow a small band of matter which is placed between the mednllary plate and epiblast, and the material of which he called the "intermediate cord'." He further states that: "Before the closure of the medullary tube this band forms a special groove-the 'intermediate groove'-placed close to the border of the medullary plate. As the closure of the medullary plate into a tube is completed, the earlier intermediate groove becomes a compact cord. In the head of the embryo a longitudinal ridge arises in this way, which separates the suture of the brain from that of the epiblast. In the parts of the neck and in the remaining region of the neck the intermediate cord does not lie over the line of junction of the medullary tube, but laterally from this and forms a ridge, triangular in section, with a slight indrawing." This intermediate ridge gives rise to four ganglia in the head, viz. the g. trigemini, g. acousticum, g. glossopharyngei, and g. vagi, and in the trunk to the spinal ganglia. In botl cases it muites first with the spinal cord.

I have given in the above account, as far as possible, a literal translation of His' own words, because the reader will thus be enabled fairly to appreciate his meaning.

Subsequently to His' memoir (No. 29i) I gave an account of some researches of my own on this subject (No, 35I), stating the whole of the nerves to be formed as cellular out-growths of the spinal cord. I failed fully to appreciate that some of the stages I spoke of had been already accurately described by His, though interpreted by him very differently. Marshall, and afterwards Kölliker, arrived at results in the main similar to my own, and Hensen, independently of and rearly simultaneously with myself, published biefly some observations on the nerves of Hammals in harmony with my results.

His has since worked over the subject again (No.352), and has reaffirmed as a result of his work his original statements. I cannot, however, accept his interpretations on the subject, and must refer the reader who is anxions to study them more fully, to His' own paper.

B. E. II. 


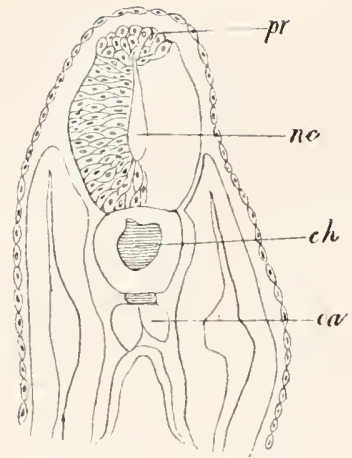

Fig. 264 A. Transverse sectron throvgh a Pristiches emBRTO SHEWIXG THE PROLIFERATION OF CELLS TO FORM THE NEULAL, EREST.

pr. neural crest; $n c$. neural canal; ch. notochord; ao. aorta.

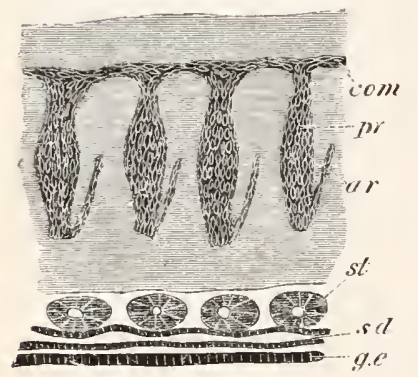

Fig. 265. Vertical, LOxGltTDiNal SECTION THROUGH PART OF THE TRINK of a young Scrlliu embrto.

com. commissure uniting the dorsal ends of the posterior nerve-roots: $p r$. ganglia of posterior roots; $a r$. anterior roots; st. segmental tubes; sil. segmental duct; g.e. epithelium lining the body cavity in the region of the future germinal ridge.

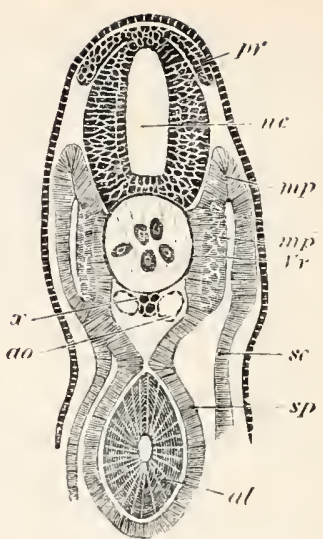

Fig. 264 B. Transverse SECTION THROUGH THE TRUNK OF AN EMBRYO SIIGHTLY OLDER THAN F1G. $28 \mathrm{E}$.

nc. neural canal; pr. posterior root of spinal nerve; $x$. subnotochordal rod; ao, aorta: sc. somatic mesoblast; sp. splanchnic mesoblast; $m p$. muscle-plate; $m p^{\prime}$. portion of muscle-plate converted into muscle; Tro. portion of the vertebral plate which will give rise to the vertebral bodips; $a$. alimentary tract.

nerves. While still remaining attached to the dorsal snmmit of the neural cort they grow to a considerable size (fig. $26+\mathrm{B}, \mathrm{m}^{\circ}$ ).

The attachment to the dorsal summit is not permanent, but before describing the further fate of the nerve-rudiments it is necessary to say a few words as to the neural crest. At the period when the nerves have begun to shift their attachment to the spinal cord, there makes its appearance, in Flasmobranchii, a longitudinal commissure connecting the dorsal ends of all the spinal nerves (figs. 26.5, $266 \mathrm{com}$ ), as well as those of the vagus and glossopharyngeal nerves. 'This commissure has as yet only been found in a complete form in Elasmobranchii; 
but it is nevertheless to be regarded as a very important morphological structure.

A

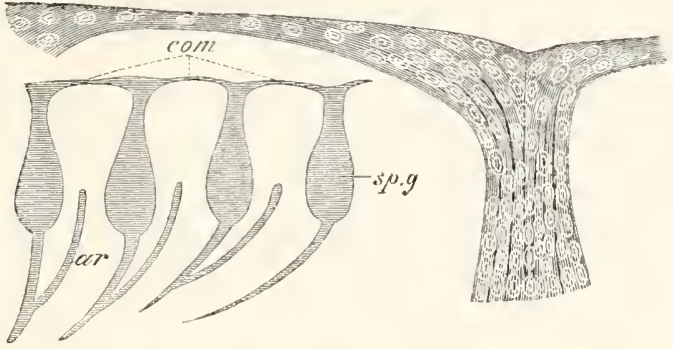

13

Fig. 266. Spinal xerves of Sexllita iN Loxgitudixal section to shew THE COMMSSERE CONNECTING THEM.

A. Section through a series of nerves.

B. Highly magnified view of the dorsal part of a single nerve, and of the com. missure connected with it.

com. commissure; sp.g. ganglion of posterior root; ar. anterior root.

It is probable, though the point has not yet been definitely made out, that this commissure is derived from the neural crest, which appear's therefore to separate into two cords, one comnected with each set of dorsal roots.

Returning to the original attachment of the nerve-rudiments to the medullary wall, it has been already stated that this attachment is not permanent. It becomes, in fact, at about the time of the appearance of the above commissure, either extremely delicate or absolutely interrupted.

The nerve-rudiment now becomes divided into three parts (figs. 267 and 26S), (1) a proximal rounded portion, to which is attached the longitudinal commissure $(p r)$; (2) an enlarged portion, forming the rudiment of a ganglion $(g$ and $s p g)$; (3) a distal portion, forming the commencement of the nerve $(n)$. The proximal portion may very soon be observed to be united with the side of the spinal cord at a

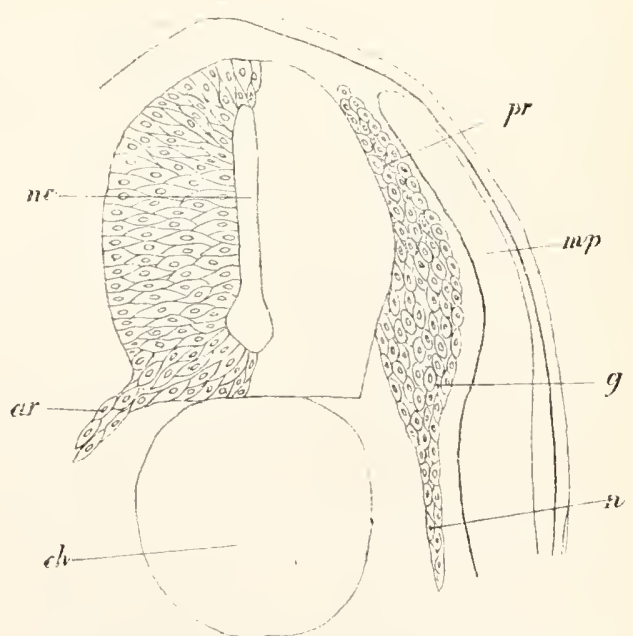

Fig. 267. Section through the torsal part OF THE TRUNK OF a TORPEDO EMBRYo.

$p r$. posterior root of spinal nerve; $g$. spinal ganglion; $n$. nerve; ar. anterior root of spinal nerve; $c h$. notochord; $n c$. neural canal; mp. muscle-plate. 
very considerable distance from its original point of attachment. Horeover the proximal portion of the nerve is attached, not by its extremity, but by its side, to the spinal cord (fig. $268 x$ ). The dorsal extremities of the posterior roots are therefore fiee.

This attachment of the posterior nerve-root to the spinal cord is, on account of its small size, very difficult to observe. In favourable specimens there may however be seen a distinct cellular prominence from the spinal cord, which becomes continuous with a surall prominence on the lateral border of the nerve-root near its proximal extremity. The proximal extremity of the nerve is composed of cells, which, by their small size and circular form, are casily distinguished from those which form the succeeding or ganglionic portion of the nerve. This part has a swollen configuration, and is composed of large elongated cells with oval nuclei. The remainder of the rudiment forms the commencement of the true nerve. This also is, at first, composed of elongated cells '.

It is extremely difficult to decide whether the permanent attachment of the posterior nerve-ronts to the spinal cord is entirely a new formation, or merely due to the shifting of the original proint of attachment. I am inclined to adopt the former view, which is also held by Marshall and Mis, but may refer to fig. 269, shewing the roots after they have become attached to the side, as distinct evidence in favour of the view that the attachment simply becomes shifted, a process which might perhaps be explained by a growth of the dorsal part of the spinal cord. The change of position in the case of some of the cranial nenves is, however, so great that I do not think that it is possible to account for it without admitting the formation of a new attachment.

The anterior roots of the spinal nerves appear somewhat later than the posterior roots, but while the latter are still quite small. Each of them (fig. 269 ar) arises as a small but distinct conical outgrowth from a ventral corner of the spinal cord, before the latter has acquired its covering of white matter. From the very first the rudiments of the anterior roots have a somewhat fibrous appearance and an indistinct form of peripheral termination, while the protoplasm of which they are composed becomes attennated towards its

1 The cellular structure of embryonic nerves is a point on which I should have anticipated that a difference of opinion was impossible, had it not been for the fact that His and Kölliker, following Remak aud other older embryologists, absolutely deny the fact. I feel quite sure that no one studying the development of the nerves in Elasmobranchii with well-preserved specimens could for a moment be doubtful on this point, and I can only explain His' denial on the supposition that his specimens were utterly unsuited to the investigation of the nerves. I do not propose in this work entering into the histogenesis of nerves, but may say that for the earlier stages of their growth, at any rate, iny observations have led me in many respects to the same results as Götte (Entwick. d. Cnke, pp. 482-483), except that I hold that adequate proof is supplied by my inrestigations to demonstrate that the nerves are for their whole length originally formed as outgrowths of the central nervous system. As the nerve-fibres become differentiated from the primitive spindle-shaped cells, the nuclei become relatively more sparse, and this fact has probably misled Kölliker. Löwe, while admitting the existence of nuclei in the nerves, states that they belong to mesollastic cells which have wandered iuto the nerves. This is a purely gratuitous assumption, not supported by observation of the development. 
end. They differ from the posterior roots in never shifting their point of attachment to the spinal cord, in not being united with each other by a commissure, and in never developing a ganglion.

The anterior roots grow rapidly, and soon form elongated cords of spindle-shaped cells with wide attachments to the spinal cord (fig. 267). At first they pass obliquely and nearly horizontally outwards, but, before reaching the muscle-plates, they take a bend downwards.

One feature of some interest with reference to the anterior roots is the fact that they arise not vertically below, but alternately with the posterior roots: a condition which persists in the adult.

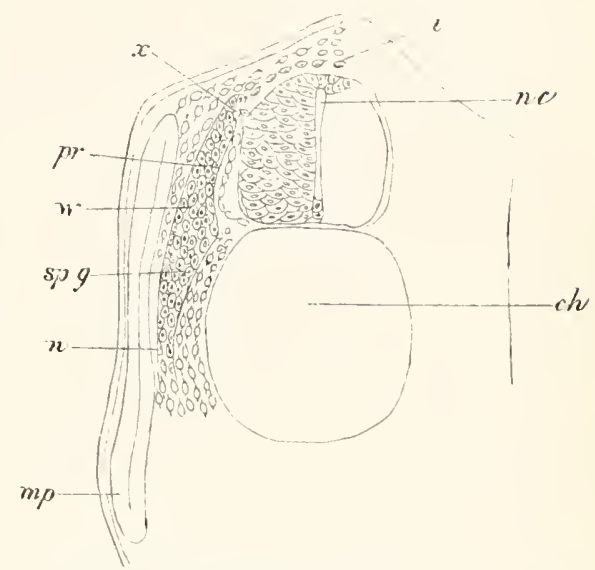

Fig. 268. Section throvgh the norsal region of a Pristumes embryo.

$m$. posterior root; sp.q. spinal ganglion; $n$. nerve; $x$. attachment of ganglion to spinal cord; nc. neural canal; mp. muscle-plate; ch. notochord; $i$. investment of spinal cord.

They are at first quite separate from the posterior roots; but about the stage represented in fig. 267 a junction is effected between each posterior root and the corresponding anterior root. The anterior root joins the posterior at some little distance below its ganglion (figs. 265 and $\left.266^{\circ}\right)$.

Although I have made some efforts to determine the eventual fate of the conmissure uniting the dorsal roots, I have not hitherto met with success. It grows thinner and thinner, becoming at the same time composed of fibrous protoplasm with inbedrled nuclei, and finally ceases to be recognisable. I can only conclude that it gradually atrophies, and ultimately vanislies.

After the junction of the posterior and anterior roots the compound nerve extents downwards, and may easily be traced for a considerable distance. A special dorsal branch is given off from the ganglion on the posterior root (fig. 275 du). Accorling to Lijwe the fibres of the anterior and posterior roots can easily be distinguished in the higher types by their structure and beliaviour towards colouring reagents, and can be separately traced in the compound nerve.

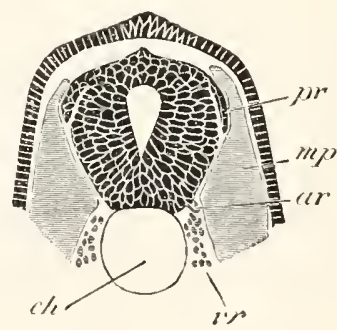

Fig. 269. T'ransverse secTION THROUGH TIIE DORSAL RFGION OF a YOUNG TORPEDo EMBRYo to SHEW THE ORIGLN OF TUE ANTERTOR AND POSTERIOR IROOTS OF THE SPINAL NERYES.

$p r$ posterior root of spinal nerve; $a s$. anterior root of spinal nerve; $m p$. muscle-plate; $c h$. notochord; $r$. mesoblast celle which will form the rertebral hodies. 
So far as has been made out, the development of the spinal nerves of other Vertebrates agrees in the main with that in Elasinobranchii, but no dorsal commissure has yet been discovered. except in the case of the first two or three spinal nerves of the Chick.

In the Chick (Marshall, No. 353) the posterior roots, during their early stages, closely resemble those in Elasmobranchii, though their relatively smaller size makes them difficult to observe. 'They at first extend more or' less horizontally ontwards above the muscle-plates (as a few of the nerves also do to some extent in Elismobranchii), but subsequently lie close to the sides of the neural canal. They are shewn in this position in fig. 116 sp.y. There does not appear to be a continuous crest comnecting the roots of the posterior nerves. The later stages of the development are precisely like those in Elasmobranchii.

The anterior roots have not been so satisfactorily investigated as the posterior; but they grow out, possibly by several roots for each nerve, from the ventral corners of the spinal cord, and subseyuently become attached to the posterior nerves.

I have observed the development of the posterior roots in Lepidostens, in which they appear as projections from the dorsal angles of the spinal cord, extending laterally outwards and, at first, having their extremities placed dor'sally to the muscle-plates.

The cranial nerves ${ }^{1}$. The earliest stages in the development of the cranial nerves have been most satisfactorily studied, especialiy by Marshall (No. 354), in the Chick, while the later stages have been more fully worked out in Elasmobranchii, where, moreover, they present a very primitive arrangement. In the Chick certain of the cranial nerves arise before the complete closure of the nemral groove. These nerves are formed as paired outgrowths of a continuous band composed of two laninx, connecting the dorsal end of the incompletely elosed medullary canal with the extermal epiblast. This mode of development will best be understood by an examination of fig. 270 , where the two roots of the vagus nerve ( $r g$ ) are shewn growing out from the neural band. Shortly after this stage the neural band, becoming separated from the epiblast, constitutes a crest attached to the roof of the brain, while its two lamine become fused. The relation of the cranial nerves to the brain then becomes exactly the same as that of the posterior roots of the spinal nerves to the spinal cord.

It does not appear possible to decide whether the mode of development of the cranial nerves in the Chick, or that of the posterior roots of the spinal nerves, is the more primitive. The difference in development between the two sets of nerves probably depends upon the relative time of the closure of the neural canal. The neural crest clearly belongs to the brain, from the fact of its remaining connected with the latter when the medullary tube separates from the external epiblast.

1 The optic nerves are for obvious reasons dealt with in connection with the development of the eve. 
It is not known whether the cranial nerves originate before the closure of the neural canal in other forms besides the Chick.

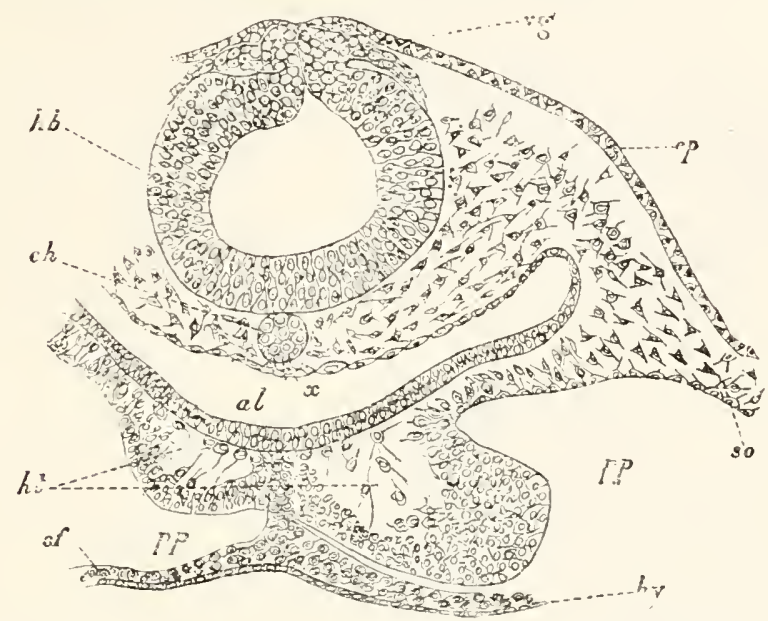

Fiti. 270. Trassverse sectrox throtgh the posterior part of the HEAD OF AN EMBRYO CHICK OF THIRTY HOURS.

$h b$. hind-brain; $r g$. vagus nerve; $\mathrm{ep}$. epiblast: ch. notochord; $x$. thickening of hypoblast (possibly a rudiment of the subnotochordal rod); al. throat; ht. heart; $p p$. body cavity; so. somatic mesoblast; $s f$. splanchnic mesoblast; hy. hypoblast.

The neural crest of the brain is continuons with that of the spinal cord, and on its separation from the central nervons axis forms on each side a commissure, uniting the posterior cranial nerves with the spinal nerves, and continuous with the commissure connecting together the latter nerves.

Anteriorly, the neural crest extends as far as the roof of the midbrain . The pairs of nerves which undoubtedly grow out from it are the third pair (Marshall), the fifth, the seventh and auditory (as a single root), the glossopharyngeal, and the various elements of the vagus (as separate roots in Elasmobranchii, but as a single root in Aves). Iarshall holds that the olfactory nerve probably also originates from this crest. It will howerer be convenient to deal separately with this nerve, after treating of the other nerves which undonbtedly arise from the neural crest.

The cranial nerres just enumerated present in their further developinent many points of similarity; and the glossopharyngeal nerve, as it develops in Elasmobranchii, may perhaps be taken as typical.

1 Marshall holds that the neural crest extends in front of the region of the optic vesicle. I have been unable completely to satisfy miself of the correctness of this statement. In my specimens the epiblast along the line of infolding of this part of the roof of the brain is much thickened, but what IIarshall represents as a pair of outgrowths from it like those of a true nerve (No. $3 z_{+}$, Pl. 11. fig. b) appears to me in my specimens to be part of the external epiblast; and I believe that they remai I connected with the external epiblast on the complete separation of the brain from it. 
This nerve is conneeted by a commissure with those behind, but this fact may for the moment be left out of consideration. Springing at first from the dorsal line of the hind-brain immediately behind the level of the auditory capsule, it apparently loses this primitive attachment and acquires a secondary attachment about half-way down the side of the hind-brain. The primitive undifferentiated rudiment soon becomes divided, exactly like a true posterior root of a spinal nerve, into a root, a ganglion and a nerve. The main branch of the nerve passes ventral wards, and supplies the first branchial arch (fig. $271 \mathrm{gl}$ ). Shortly afterwards it sends forwards a smaller branch, which passes to the hyoid arch in front; so that the nerve forks over the hyobranchial cleft. A typical cranial nerve appears therefore, except as concerns its relations to the clefts, to develop precisely like the posterior root of the spinal nerve.

Most of the cranial nerves of the above group, in correlation with the highly differentiated character of the head, acquire secondary differentiations, and render necessary a brief description of what is known with reference to their individual development.

The Glossopharyngeal and Vagus Nerves. Behind the ear there are formed, in scyllinm, a series of five nerves which pass down to respectively the first, second, third, fourth and fifth branchial arches.

For each arch there is thus one nerve, whose course lies close to the posterior nargin of the preceding cleft; a second anterior branch, forking over the cleft and passing to the arch in front, being developerl later. These nerves are connected with the brain by roots at first attached to the dorsal summit, but eventually situated about half-way down the sides. The foremost of them is the glossopharyngeal. The next four are, as has been shewn by Gegenbaur ${ }^{1}$, equivalent to four independent nerves, but form together a compound nerve, which we may briefly call the vagus.

This compound nerve together with the glossopharyngeal soon attains a very complicated structure, and presents several remarkable teatures. There are present five branches (tig. $271 \mathrm{~B}$ ), viz. the glossopharyngeal $(g l)$ and four branches of the vagus, the latter probal,ly arising by a considerably greatter number of strands from the brain'. All the strands from the brain are united together by a thin commissure (iig. $271 \mathrm{~B}, v g$ ), continuous with the commissure of the posterior roots of the spinal nerves, and from this commissure the tive branches are contimed obliqnely ventralwards and backwards, and each of them dilates into a youglionic swelling. They all become again nuited together by a second thick commissure, which is continued backwards as the intestinal hranch of the vagus nerve. The nerves, however, are continued ventralwards each to its respective arch. From the lower commissure springs the lateral nerve, at a point whose relations to the branches of the vagus I have not certainly determined.

With refercnce to the dorsal commissure, which is almost certainly derived from the original neural crest, it is to he noted that there is a longish stretch of it between the last branch of the vagus and the first spinal

1 "Ueber d. Kopfnerven von Hexanchus," etc., Jenaische Zeitschrift, Vol. vi. 1871. 
nerve, which is probably the remains of a part of the commissure which commected the posterior branches of the vagus, at a stacre in the evolution of the Vertebrata, when the posterior visceral clefts were still present. These branches of the vagus are probably partially preserved in the ramifications of the intestinal stem of the vagus (Gegenbanr). The origin of the rentral commissure, contimued as the intestinal branch of the vagus, has not been embryologically worked out.

The lateral nerve may very probably be a dorsal sensory branch of the vagus, whose extension in to the posterior part of the trunk has been due to the gradual backward elongation of the lateral line", causing the nerve supplying it to elongate at the same time (vicle section on lateral line).

In the Chick the common rudiment for the vagus and glossopharyngeal neives (Marshall), which has alrearly been spoken of, subsequently divides into two parts, an anterior forming the glossopharyngeal nerve, and a posterior forming the vagus nerve.

\section{The seventh and au-} ditory nerves. As shewn by Marshall's and my own observations there is a com-

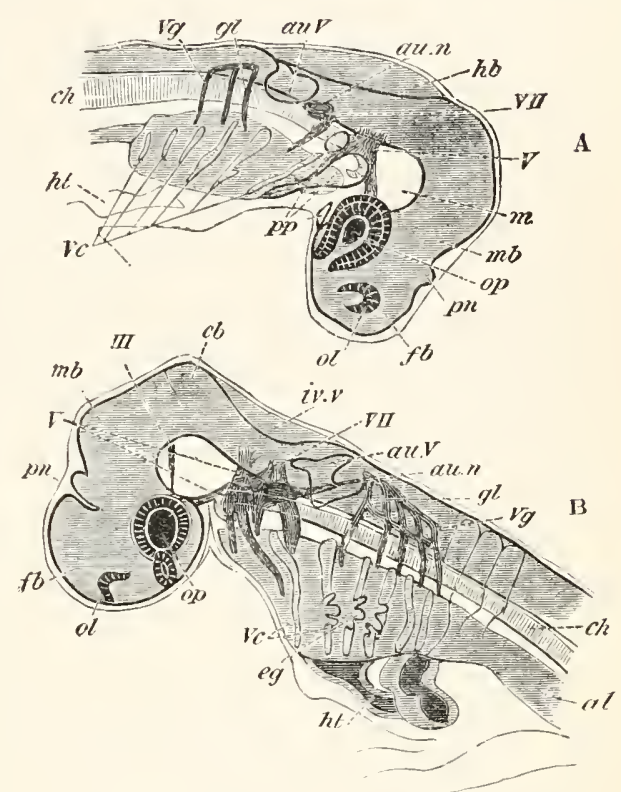

Fig. 271. Views of the head of ElasmoBraNeH EMBRYOS at TWO STAGES as TRANSPARENT OBJECTS.

A. Pristiurus embryo of the same stage as figr. $28 \mathrm{~F}$.

B. Somewhat older Scyllium embryo.

III. third nerve; $V$. fiftl nerve; VII. seventh nerve; au.n. anditory nerve; $g l$. glossopharyngeal nerve; $T_{y}$. vagus nerve; $f b$. fore-brain; $m$. pineal gland; $m b$. mid-brain; $h b$. hind-brain ; iv.v. fourth ventricle; $c \dot{b}$. cerelellum; ol. olfactory pit; $o p$. eye; $а и . V$. anditory vesicle; $m$. mesoblast at base of brain; $c h$. notochord; $h t$. heart; $V c$. visceral clefts; eq. external gills; $p p$. sections of body cavity in the heal. mon rudiment for the seventh and auditory nerres. This rudiment divides almost at once into two branches. The anterior of these pursues a straight course to the hyoid arch (fig. $271 \mathrm{~A}, V I I$.) and forms the rudiment of the facial nerve; the second of the two (fig. $271 \mathrm{~A}$, au.n), which is the rudiment of the anditory nerve, develops a ganglionic enlargement and, turning backwards, closely hugs the ventral wall of the auditory involution (fig. 272).

The seventh or facial nerve soon becomes more complicated. It early develops, like the glossopharyngeal and vagus nerves, a branch, which

1 The peeuliar distribution of branches of the fifth and seventh nerves to the lateral line, which is not uncommon, is to be explained in the same nammer. 
forks over the cleft in front (spiracle), and supplies the namblibular areh (fig. $271 \mathrm{~B}$ ). This brancli forms the prespriracular nerve of the adult, and is liomologous with the chorda tympani of Mammalia. Besides however giving rise to this typieal branch it gives origin, at a very early period, to two other rather remarkable brauches; one of these, arising from its dorsal anterior border, passes forwards to the front part of the head, inmediately dorsal to the ophthalmic branch of the fith to be described directly. This nerve is the portio major or superficialis of the nerve usually known as the ramus ophtinalmicus supel ticlalis in the arlult?

The other hranch of the seventh is the palatine branch-superficial petrowal of Manmalia-the course of which lias been nore fully investigated by Marshall than by myself. He has shewn that it arises "just below the root of the ophthalmic branch," and "runs downwards and forwards, lying parallel and immediately superticial to the maxillary branch of the fifth nerve." "This branch of the seventh nerve appears to bear the same sont of relation to the superior maxillary branch of the fifth nerve, that the oplithahmic branch of the seventh does to the ophthatmic branch of the tifth.

Both the root of the seventh and its main branches are gangliaterl.

The auditory nere is probably to be regarded as a specially differentiated part of a dorwal branch of the seventh, while the op,hthaluic branch may not improbably be a dorsal branch comparable to a dorsal branch of one of the spinal nerves.

The fifth nerve. Shortly after its development the root of the fifth nerve shifts so as to be attached about half-way lown the side of the brain. A large ganglion becomes developed close to the root, which forms the rudiment of the Gasserian ganglion. The main branch of the nerve grows into the mandibular arch (fig. $271 \mathrm{~A}, V$ ), maintaining towads it similar relations to those of the posterior nerves to their respective arehes.

Two other branches very soun become developed, which were not properly distinguished in my original acenunt. The dorsal one takes a course parallel to the ophthalmic branch of the seventh nerve, and forms, according to the nomenclature already alopted, the portio profunda of the ophthalmicus superticialis of the adult.

T!!e second nerve (fig. 27l A) passes forwards, above the mandibular head eavity, and is directed straight towards the eye, near which it meets ond anites with the third nerve, where the ciliary ganglion is developer (Marshatl). This branch is usually called the ophthalmic branch of the tiftl nerve, but Marshall rightly prefers to call it the communicating branch between the tifth and third nerves ${ }^{2}$.

Later than these two branches there is developerl a third branch, passing to the firont of the mouth, and forming the superior maxillary branch of the aclult (fig. $271 \mathrm{~B}$ ).

of the branches of the fifth nerve the main mandibular branch is

1 The two branches of the ramus ophthalmicus superticialis were spoken of as the ram. ophth. superficialis and ram. opth. profundus in my Monograph on Elasmobranch Fishes. The nomenclature in the text is Schwalbe's, which is probably more correct than mine.

2 Marshall thinks that this nerve may be the remains of the commissure originally romnecting the roots of the third and fifth nerres. This suggestion can only be tested hy further observation: 
obviously comparable to the main branch of the posterior nerves. The superficial ophthalmic branch is clearly equivalent to the ophthalmic branch of the seventh. The superior maxillary is usually held to be equivalent to that branch of the posterior nerves which forms the anterior limb of the fork over a cleft. The similarity between the course of this nerve and that of the palatine branch of the seventh, resembling as it does the similar conse of the ophthahmic hranches of the two nerves, suggests that it may perhaps really be the homologue of the palatine branch of the seventh, there being no homologne of the typical anterior branch of the other cranial nerves.

The third nerve. Our knowledge of the development of the third nerve is entircly due to Marshatl. He has shewn that in the Chick there is developed from the neural erest, on the roof of the mid-brain, an outgrowth on each side, very similar to the rudiment of the posterior nerves. This outgrowth, the presence of which I can confirm, he believes to be the thind nerve, hut although he is probably right in this view, it must be borne in mind that there is no lirect evirlence on the point, the fate of the outgrowth in question not having been satisfactorily followed.

At a very considerably later period a nerve may be found springing from the floos of the mid-brain, which is moloubtedly the third nerve, and which Marshall supposes to be the above rudiment, which has shifted its position. It is shewn in seyllium in tig. $271 \mathrm{~B}, I I I$. A few intermediate stages between this and the earliest condition of the nerve have been imperfectly traced by Marshall.

The nerve at the stage represented in fig. $271 \mathrm{~B}$ arises from a ganglionic root, and "runs as a long slender stem almost horizontally backwards, then turns slightly outwards to reach the interval between the dor sal ends of the first and second head cavities, where it expands into a small ganglion." This ganglion, as first suggested hy Schwalbe (No. 359), and subseqnently proved embryologically by Marshall, is the ciliary ganglion. From the ciliary ganglion two branches arise; one branch continuing the main stem of the nerve, and obriously homologous with the main branch of the other nerves, and the other passing directly forwards "along the top of the first head cavity, then along the inmer side of the eye, and finally terminating at the anterior extremity of the head, just dorsal of the olfactory pit."

The partial separation, in many forms, of the ciliary ganglion from the stem of the third nerve has led to the erroneous view (disproved by the researches of Marshall and Schwalhe) that the ciliary ganglion belongs to the fifth nerve. The connecting branch of the fifth nerve often becomes directly continuous with the anterior branch of the third nerve, and the two together probably constitute the nerve known as the ramus ophthalmicus pofundus (Marshall). Further embryological investigations will be required to shew whether this nerve is homologous with the nasal branch of the fifth nerve in Manmalia.

Relations of the nerves to the head-cavities. The cranial nerves, whose development has just been given, bear certain very definite relations to the mesoblastic structures in the hearl, of the nature of somites, which, are known as the head-cavities. Each cranial nerve is typically placed immediately behind the heal-cavity of its somite. Thus the main branch of the fifth nerve lies in contact with the posterior wall of the manclibular cavity, as shewn in section in fig. $272 V .2 p p$ and in suface view in tig. 271 ; the liain branch of the seventh nerve occupies a similar position in relation 
to the hyoid cavity; and, as Marshall has recently shewu, the main branch of the thind nerve adjoins the posterior border of the front cavity, described

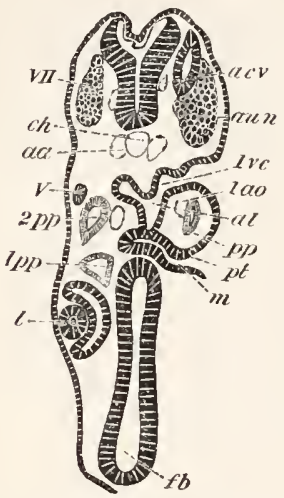

F1g. 272. Transterse Section THROUGH THE FRONT PART OF THE head of a young Pristiurus embiro.

The section, owing to the cranial llexure, cuts both the fore- and the hind-brain. It shews the premandibular and mandibular head cavities $1 p p$ and $2 p p$, etc.

fb. fore-brain; 1 . lens of eye; $m$. mouth; pt. upper end of mouth, forming pituitary involution; $\mathbf{1}$ ao. mandibular aortic arch; $1 \mathrm{pp}$. and $2 p p$. first and second head cavities; 1vc. first visceral cleft; $I$. fifth nerve; aun. ganglion of auditory nerve; I"II. seventh nerve; aa. dorsal aorta ; $a c r$. anterior cardinal vein; ch. notochord. hy me as the premandibular cavity. Owing to the early conversion of the walls of the posterior head-cavities into muscles, their relations to the nerves are not quite so clear as in the case of the anterior cavities, thongh, as far as is known, they are precisely the same.

\section{Anterior nerve-roots in the brain.}

During my investigations on the development of the cranial nerves I was unable to find any roots comparable with the anterior roots of the spinal nerves, and propounded an hypothesis (suggested by the absence of anterior spinal roots in Amphioxus ${ }^{1}$ ) that the head and trunk had hecome differentiated from each other at a stage when mixed motor and sensory posterior roots were the only roots present, and I supposed the cranial and spinal nerves to have been independently erolved from a conmon ground form, the resulting types of uerves being so different that no roots strictly compatrable with the anterior roots of spinal nerves were to be found in the cranial nerves.

The views jut forward by me on this subject, though accepted by sichwalbe (No. 357), have in other quarters not met with uuch favour. Wiedershein holds that it is impossible to believe that the cranial nerves are simpler than the spinal nerves. Such simplicity, which is clearly not found. I have never asserted to exist; I have only stated that the cranial nerves, in acquiring the complicated character they have in the adult, do not develop anterior roots comparable with those of the spinal nerves. Marshall also strongly objects to my views, and has made some observations for the purpose of testing them, learling to some very interesting results, which I proceed to state, and I wili then explain my opinion concerning them.

The most important observation of Marshall on this subject concerus the sixth nerve. In both the Chick and Scyllium he has detected a nerve (the first development of which has unfortunately not been made out) arising by a series of roots from the base of the hind-brain. By tracing this nerve to the external rectus muscle of the eye he has siatisfactorily identified it as the sixth nerve. "Neither in the nerve nor in its roots are there any ganglion cells." This nerve he finds to be pliced vertically below

1 schneider holds that anterior roots are present in Amphioxus, but I have been unable to satisfy myself of their presence. 
the roots of the seventh nerve; and it is not visible till much later than the cranial nerves above describer.

In addition to this nerve Marshall has found, both in the thind nerve and in the fifth nerve, a series of non-gangliated roots, which arise in a manner not yet satisfactorily elucidated, considerably later than, and in front of the main roots. These roots join the ganghiated roots on the proximal side of the ganglion or in the ganglion'; and Marshall believes them to be homologous with the anterior roots of spinal nerves, while he holds the sixth nerve to be an anterior root of the seventh nerve.

In addition to these nerves Marshall holds certain ventral roots, which occur in Elasmobranclis close to the boundary of the spinal cord and medulla, and which probal,ly form the hypoglossal nerve of higher types, to be anterior roots of the vagus. It is very difficult to prove anything definitely abont these nerves, hut, for reasons stated in my work on Elasmobranch. Fishes, I am inclined to regard them as anterjor roots of one or more spinal nerves.

Before attempting to decide how far Marshall's views about the so-called anterior roots of the seventh, the fifth and the third nerves are well founded it will conduce to clearness to statc the characters and relations of the two roots of spinal nerves.

The posterior root is (1) always murely sensory; (2) it always develops a ganglion. The anterior root is (1) always purely motor; $(2)$ it always joins the posterior root belom the ganglion, except in Petromyzon (though not in Myxine) where the two roots are stated to be independent.

How far do Marshall's anterior and posterior roots of the cranial nerves exhibit these respective peculiarities?

With reference to the sixth and seventh nerves he states "we must regard the sixth nerve as having the same relation to the seventh that the anterior root of a spinal nerve has to the posterior root." On this I would remark (1) that the posterior root of this nerve is a mixed sensory and motor nerve and therefore differs in a very fundamental point from that of a spinal nerve; (2) the sixth nerve though resembling the anterior root of a spinal nerve in being motor and without a ganglion, differs from the nearly universal arrangement of spinal nerves in not uniting with the seventh.

With reference to the fifth nerve it is to be observed that it is by 110 means certain that the whole of the motor fibres are supplied by the so-called anterior roots, and that these roots differ again in the most marked manner from the anterior roots of spinal nerves in joining the main root of the nerve above (nearer the brain), and not as in a spinal nerve below the ganglion. The gangliated ront of the thind nerve is purely motor ${ }^{2}$, and its so-called anterior roots again differ from the anterior roots of spinal nerves, in the same mamner as those of the fifth nerve.

With reference to the glossopharyngeal and vagus nerves I would merely remark that no anterior root has even been suggested for the glossopharyngeal nerve and that the posterior roots of both these nerves contain a mixture of sensory and motor fibres.

1 These non-gangliated roots of the fifth nerve are not to be confounded with the motor root of the fifth nerve in higher types. They appear to form the anterior root of the adult which gives origin to the ramus ophthalmicus.

${ }^{2}$ If Marshall's view abont the ramus ophthalmicus profundus (p. 37?) is correct, the third must still be, as it no doubt was primitively, a mixed motor and sensory nerve. 
In view of these facts, my original hypothesis appears to me to be confirmed by Marshall's observations.

The fact of all the posterior roots of the ahove cranial nerves (except the third which may be purely motor) being mixed motor and sensory roots appears to me to demonstrate that the starting-point of their differentiation was a mixed nerve with a single dorsal root; and that they did not therefore become differentiated from nerves built on the same type as the spinal nerves with dorsal sensory and ventral motor roots. The presence of such nongangliated roots as those of the third and fifth nerves is not a dificulty to this view. Con-idering that the cranial nerves are more highly differentiated than the spinal nerves, and have more complicated functions to perform, it would be surprising if there hard not been developed non-ganglionated roots analogous to, hut not of course homologous with, the anterior roots of the spinal nerves ${ }^{1}$.

As to the sixth nerve further embryological investigations are requisite before its true position in the series can be determined; but it appars to me rery probable that it is a product of the differentiation of the seventh nerve.

The fourth nerve. No embryological investigations have been made with reference to the fourth nerve. It is possible that it is a segmental nerve comparable with the third nerve, and that the only remnant still left of the segment to which it belongs is the superior oblique muscle of the eye. If this is the case there must have been two pramandibular segments, viz. that belonging to the third nerve, and that belonging to the fourth nerve. Against this view of the fourth nerve is the fact, urged with great force by Marshall, that the superior oblique muscle is in firont of the other eye muscles, and that the fourth nerve therefore crosses the third nerve to reach its destination.

The 0lfactory nerve. It was shewn in my monograph on Elasmobranch fishes that the olfactory nerve grew out from the brain in the same manner as other nerves; and Marshall (No. 355), to whom we are indebted for the greater part of our knowiedge on the development of this nerve, has proved that it arises prior to the lifferentiation of the olfactory lobes.

The earliest stages in the devclopment of the nerve lave not been made out. Marshall, as already stated, finds that in the Chick the neural crest is continued in front of the optic resicles, and holds that this fact is strong a priori eridence in favour of the nerve growing out from it. As mentioned above, note on P. 375 , I cannot without further evidence accept Marshall's statements on this point. In any case Marshall has not yet been able again to find an olfactory nerve till long after the disappearance of the neural crest. The olfactory nerve at the next stage observed forms an ontgrowth of fusiform cells springing on either side from neas. the summit of the fore-brain; and at fifty hours it ends close to a slight thickening of the epiblast forming the first rudiment of the olfactory pit, with the walls of which it soon becomes united.

1 In the higher types, as is well known, the fifth nerve has its roots formed on the same type as a spinal nerve. The fact that this is not the case in the lower types, either in the embryo or the adult, is a clear indieation, to my mind, that the mammalian arrangement of the roots of the fifth nerve has been secondarily acquired, a fact which is a most striking confirmation of my views as to the difierences between the cranial and spinal nerves. 
The growth of the cerebral hemispheres causes its point of insertion in the brain to be relatively shifted; and on the development of the olfactory lobes (vide p. 366) it arises from then (fig. 273). In Elasmolranchs there is a large development of ganglion cells near its root. From Marshall's figures these appear also to be present in the Chick, but they do not seem to hare been found in other forms. In both Teleostei and Anphibia the olfactory nerves are at first extremely short.

Marshall holds that the olfactory nerve is a segmental nerve equivalent to the third, fifth, serenth ete. nerves. It has been already stated that in ny opinion the origin of the olfactory nerves from the fore-brain, which I hold to be the ganglion of the prreoral lobe, negatives this view. The mere fact of

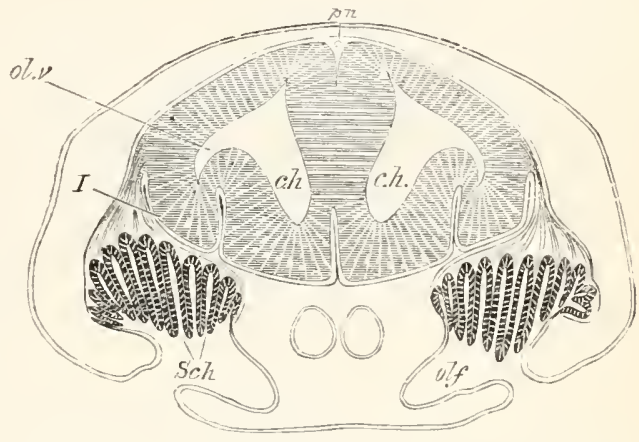

Fig. 273. Section throtgit the brain and oL-

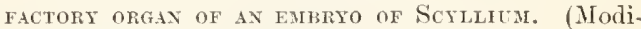
fied from figures by Marshall and myself.)

$c h$. cerebral hemispheres; ol.v. olfactory vesicle; olf. olfactory pit; Sch. Schneiderian folds; $I$. olfactory nerve. The reference line has been accidentally taken timrongh the nerve to the lrain; $m$. pineal glant. these nerves originating as an outgrowth from the central nervous system is no argument in favour of Marshatl's riew of their nature; and even if Marshall's opinion that they arise from the nemral crest should turn ont to be well founded, this fact would not prove their segmental nature, hecause their origin from this crest would, as indicated in the next paragraph, merely seem to imply that they primitively arose from the lateral borders of the nerve-plate from which the cerebro-spinal tube has been formed.

Situation of the dorsal roots of the cranial and spinal nerves. The probable explanation of the origin of nerves from the neural crest lias already been briefly given ( 7.262 ). It is that the nemral crest represents the original lateral borders of the nerrous plate, and that, in the mechanical folding of the nervous plate to form the cerebro-spinal canal, its two lateral borders have become approximated in the median dorsal line to form the neural crest. The suhsequent shifting of the nerves I am mable to explain, and the meaning of the transient longitudinal commissure connecting the nerves is alno unknown. The folding of the neural plate must have extended to the region of the origin of the olfactory nerves, so that, as just stated, there would be no special probability of the olfactory nerves belonging to the same category as the other dorsal nerves from the fact of their springing from the nenral erest. 


\section{Bibliography of the Peripheral Nervols System.}

(351) F. M. Balfour. "On the development of the spinal nerves in Elasmobranch Fishes." Philosophical Transactions, Vol. cLxv1. 1876; vide also, A monograph on the derelopment of Elasmobranch Fishes. London, 1878, pp. 191-216.

(352) W. His. "Ueb. d. Anfänge d. peripherischen Nervensystems." Archiv ff. Anat. u. Physsiol., 1879.

(353) A. M. Marshall. "On the early stages of development of the nerves in Birds." Journal of Anot. and Phys., Vol. x1. 1877.

(.354) A. M. Marshall. "The development of the cranial nerves in the Chick." Quart. J. of Hirr. Science, Vol. xv11. 1878.

(35.) A. M. Marshall. "The morphology of the vertebrate olfactory orgau." Quart. J. of Micr. Science, Vol. xix. 1879.

(356) A. M. Marshall. "On the head-cavities and associated nerves in Elasmobranchs." Quart. J. of Hier. Science, Vol. xxi. 1881.

(357) C. Schwalbe. "Das Ganglion oculomotorii." Jenaische Zeitschrift, Vol. xi1. 1879 .

\section{Sympathetic nervous system.}

The discovery that the spinal and cranial nerves together with their ganghia were formed from the epiblast was shortly afterwards extended to the sympathetic nervous system, which has now been shewn to arise in connection with the spinal and cranial nerves. The earliest observations on this subject were those contained in my Monograph on Elasmobranch Fishes (p. 173), while Schenk and Birdsell (No. 36r) have since arrived at the same result for Aves and Mammalia.

In my account of the development of these ganglia, it is stated that they were first met with as small masses situated at the ends of short branches of the spinal nerves (fig. 27.5 sy.g). More recent investigations have shewn me that the sympathetic ganglia are at first simply swellings on the main branches of the spinal nerves some way below the ganglia. Their situation may be

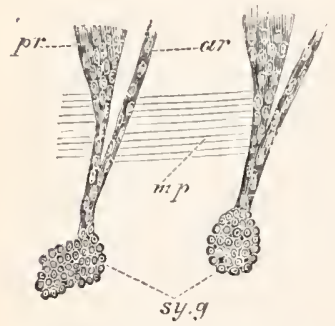

Fig. 274. LongitudisaL VERTICAL SECTION THROCGH PART OF THE BODY WALL OF ax Elasmobraxch Embrio SHEWING PART OF TWO SPINAL NERVES AND THE SYMPATHETIC GANGLIA BELONGING TO THEM.

ar. anterior root; pr. posterior root; $s y . g$. sympathetic ganglion; mp. part of muscle-plate. understood from fig. $27+s y \cdot g$, which belongs however to a somewhat later stage. Subsequently the sympathetic ganglia become removed from the main stem of their respective nerves, remaining however connected with those stems by a short branch (fig. $275 s y \cdot g$ ). I have been unable to find a longitudinal commissure connecting them in their early stages; and I presume that they are at tirst independent, and become subsequently united into a continuous cork on each side.

The observations of Schenk and Birdsell on the Mammalia seem to indicate that the main parts of the sympathetic system arise in continuity with the posterior spinal ganglia: they also shew that in the neck and other parts the sympathetic cords arise as a continuous ganglionic chain. The observa- 
tions on the topographical features of the development of the sympathetic system in higher types are however as yet very imperfect.

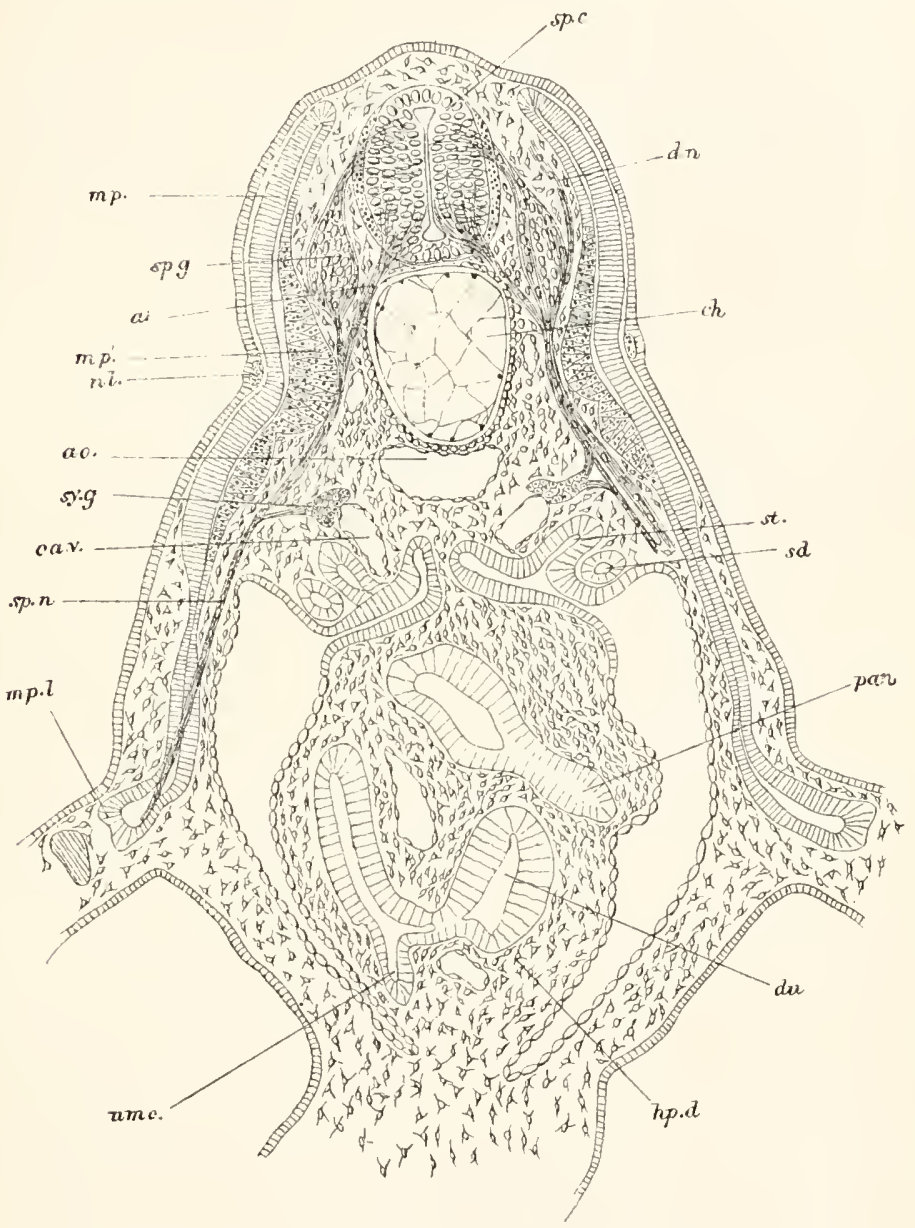

Fig. 275. Transverse section throvgh the anterion part of the trunk of aN EMbRYo of SCyllidi SLightLy OLDER THAN Fig, $29 \mathrm{~B}$.

The section is diagrammatic in the fact that the anterior nerve-roots have been inserted for their whole length; whereas they join the spinal cord half-way between two posterior roots.

sp.c. spinal cord; sp.g. ganglion of posterior root; ar. anterior root; $d n$. dorsally directed nerve springing from posterior root; $m p$. muscle plate; $m p^{\prime}$. part of muscle plate already converted into muscles; mp.l. part of muscle plate which gives rise to the muscles of the limbs; $n l$. nervus lateralis; ao. aorta ; $c h$. notochord; $s y . g . s y m$. pathetic ganglion; ca.v. cardinal vein; sp.n. spinal nerve; sd. segmental (archinephric) duct; st. segmental tube; $d u$. duodenum; pan. pancreas; $h p . d$. point of junction of hepatic duct with duodenum; umc. umbilical canal.

B. E. II. 
The later history of the sympathetic ganglia is intimately bound up with that of the so-called supra-renal bodies, which are dealt with in another chapter.

\section{Bibliography of the Sympathetic Nervous System.}

(360) F. M. Balfour. Monograph on the development of Elasmobranch Fishes. London, 1878, p. 173.

(36I) S. L. Schenk and W. R. Birdsell. "Ueb. d. Lehre von d. Entwicklung d.

Ganglien d. Sympatheticus." Mittheil. a. d. embryologischen Instit. Wien. Heft 11 . 1879 . 


\section{CHAPTER XVI.}

\section{ORGANS OF VISION.}

In the lowest forms of animal life the whole surface is sensitive to light, and organs of vision have no doubt arisen in the first instance from limited areas becoming especially sensitive to light in conjunction with a deposit of pigment. Lens-like structures, formed either as a thickening of the cuticle, or as a mass of cells, were sub. sequently formed ; but their function was not, in the first instance, to throw an image of external objects on the perceptive part of the eye, but to concentrate the light on it. From such a simple form of visual organ it is easy to pass by a series of steps to an eye capable of true vision.

There are but few groups of the Metazoa which are not provided with optic organs of greater or lesser complexity.

In a large number of instances these organs are placed on the anterior part of the head, and are innervated from the anterior ganglia. It is possible that many of the eyes so situated may be modifications of a common prototype. In other instances organs of vision are situated in different regions of the body, and it is clear that such eyes have been independently evolved in each instance.

The percipient elements of the eye would invariably appear to be cells, one end of each of which is continuous with a nerve, while the other terminates in a cuticular structure, or indurated part of the cell forming what is known as the rod or cone.

The presence of such percipient elements in various eyes is therefore no proof of genetic relationship between these eyes, but merely of similarity of function.

Embryological data as to the development of the eye do not exist except in the case of the Arthropoda, Mollusca and Chordata. From such data as there are, combined with study of the adult structure of the eye, it can be shewn that two types of development are found. In one of these the percipient elements are formed from the central nervous system, in the other from the epidermis. The former may be called cerebral eyes. It is probable however that this distinction is not, in all cases at any rate, so fundamental as might be 
supposed; but that in both instances the eye may have taken its origin from the epidermis. In the eyes in which the retina is continuous with the central nervons system, these two organs were probably evolved simultaneously as differentiations of the epidermis, and continue to develop together in the ontogenetic growth of the eye.

Some of the eyes in which the retina is formed from the epidermis have also probably arisen simultaner usly with part of the central nervous system, while in other instances they have arisen as later formations subsequently to the complete establishment of a central nervous system.

Cœlenterata. The actual evolution of the eye is best shewn in the Hydrozoa. The simplest types are those found in Oceania and Lizzia ${ }^{2}$. In Lizzia the eye is placed at the base of a tentacle and consists of (fig. 276) a lens (l) and a percipient bulb (oc). The lens is a simple thickening of the cuticle, while the percipient part of the eye is formed

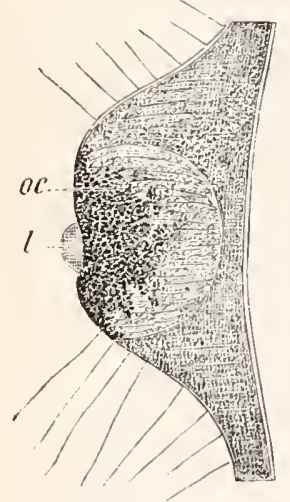

FIG. 276. EYE oF Lizzia KoelLiKeri. (From Lankester; after Hertwig.)

1. lens; oc. perceptive part of eye. of three kinds of elements:-(1) pigment cells; (2) sense cells, forming the true retinal elements, and consisting of a central swelling with the nucleus, a peripheral process representing a hardly differentiated rod, and a central process continuous with (3) ganglion cells at the base of the eye. In this eye there is present a commeneing differentiation of a ganglion as well as of a retina.

The eye of Oceania is simpler than that of Lizzia in the absence of a lens. Claus has shewn that in Charybdea amongst the Acraspeda a more highly lifferentiated eye is present, with a lens formed of cells like the vertebrate eye.

Mollusca. In a large number of the odontophorous Mollusca eyes, imnervated by the supracesophageal ganglia, are present on the dorsal side of the head. These eyes exhibit very various degrees of complexity, but are shewn both by their structure and development to be modifications of a common prototype.

The simplest type of eye is that found in the Nautilus, and although the possibility of this eye being degenerated must be borne in mind, it is at the same time very interesting to note (Hensen) that it retains permanently the early embryonic structure of the eyes of the other groups.

It has (fig. 277 A) the form of a vesicle, with a small opening in the outer wall, placing the cavity of the vesicle in free communication 1878 .

1 o. and R. Hertwig. Das Nerrensystem u. Sinnesorgane d. Medusen. Leipzig, 
with the exterior. The cells lining the posterior face of the vesicle form a retina $(i)$; and are continuous with the fibres of the optic

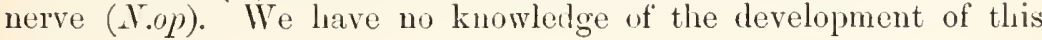
eye.

In the Gasteropods the eye (fig 277 B) has the form of a closed vesicle: the cells lining the imner sile form the retina, while the outer wall of the vesicle constitutes the cornea. A cuticular lens is placed in the cavity, on the side adjoining the comea. 'This eye originates from the ectoderm, within the velar area, and close to the supra-ceso phageal gauglia, usually at the base of the tentacles. According to Rabl (Vol. I. No. 268) it is formed as an invagination, the openirg of which soon closes; while according to Bobretsky (Vol. I. No. 242) and Fol it arises as a thickening of the epiblast, which becoming detached takes the form of a vesicle. It is quite possible that both types of development may ocenr, the second being no doubt abbreviated. The vesicle, however formerl, soon acquires a covering of pigment, except for a small area of its outer wall, where the lens becomes formed as a small body projecting into the lumen of the vesicle. The lens seems to commence as a cuticular deposit, and to grow by the addition of concentric layers. The inner wall of the vesicle gives rise to the retina.

The most highly differentiated molluscan eye is that of the Dibranchiate Cephaloporda, which is in fact more highly organized than any other invertebrate eye.

A brief description of its adult structure ${ }^{1}$ will perlapss render more clear ny account of the development. The most important features of the eye are shewn in fig. $277 \mathrm{C}$. 'The ontermost layer' of the optic bulh, forms a kind

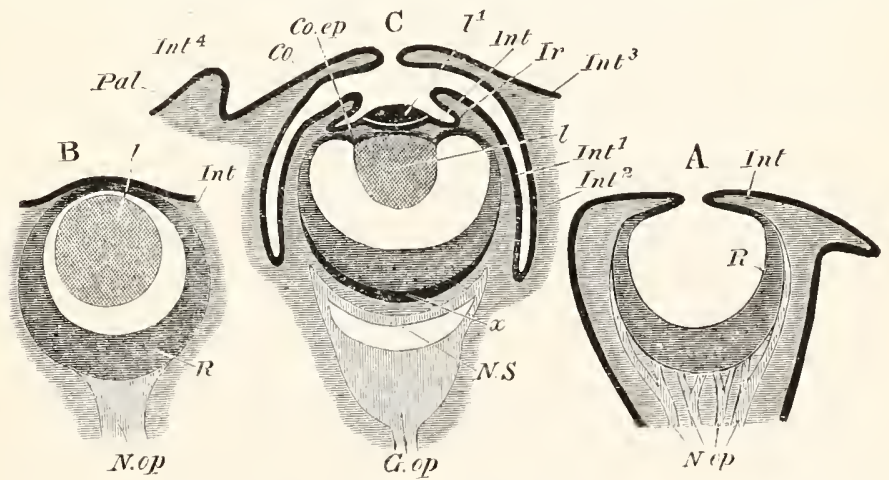

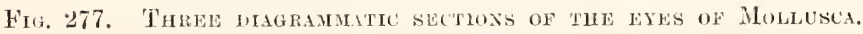
(After Grenacher.)

A. Nautilus. B. Gasteropod (Limax or Helix). C. Dibranchiate Cephalopod.

Pal. eyelid; Co. cornea; Co.ep. epithelium of ciliary body; $I P$. iris; Int, $I n t^{1}$ Int $t^{4}$. different parts of the integument; l. lens; $l^{l}$. outer segment of lens; $R$. retina; N.op. optic nerve; G.op. optic ganglion; $x$. inner layer of retina; N.S. nel vous stratum of retina.

1 Tide Hensen, Zeit. $f$. wiss. Zool. Bd. xv. 
of capsule, which may be called the sclerotic. Posteriorly the selerotic abuts on the cartilaginous orbit, which encloses the optic ganglion $(G . o p)$; and in front it becomes transparent and forms the cornea $\mathrm{Co}$, which may be either completely elosed, or (as represented in the diagram) perforated by a larger or smaller opening. Behind the cornea is a cliamber known as the anterior optic chamber. This chamber is continued back on each side round a great part of the circumference of the eye, and separates the sclerotic from a layer internal to it.

In the anterior optic chamber there are placed (1) the anterior part of the lens $\left(l^{1}\right)$ and (2) the folds of the iris $(I r)$. The wlole chamber, except the part formed by the lens, is lined by the epidermis (Int 1 and Int 2). Bonnding the inner side of the anterior optic chamber is a layer which is called the choroid ( $\operatorname{lnt} 1$ ) which is continued anteriorly into the fold of the iris (Ir). The most superficial layer of the choroid is the epithelium already mentioned, next comes a layer of obliquely placed plates known as the argentea externa, then a layer of muscles, and finally the argentea interna. The argentea interna abuts on a cartilaginous capsule, which completely invests the inner part of the eyc.

The lens is a nearly spherical body composed of concentric latmellie of a structureless material. It is formed of a small outer $\left(l^{1}\right)$ and large inner (l) segrnent, the two being separated by a thin membrane. It is supported by a peculiar projection of the wall of the optic eup, known as the ciliary body $\left(C^{\prime}(0 . e p)\right.$, inserted at the base of the iris, aud mainly formed of a continuation of the retina. This borly is however muscular, and presents a series of folds on its outer and inner surfices, which are especially developed on the latter.

The membrane dividing the lens into two parts is continuous with the ciliary body. Within the lens is the inner optic ehamber, bounded in front by the lens and the ciliary body, and behind by the retina.

The retina is formed of two main divisions, an anterior division adjoining the inner optic chamber, and a posterior division (N.S') adjoining the cartilage of the choroid. The two layer's are separaterl by a membrane. Passing from within outwards the following layers in the retina may be distinguished :

(1) Homogeneous membrane.

(2) Layer of rods.

(3) Layer of granules imbedded in pigment.

Anterior division of retina.

(t) Cellular layer.

(5) Connective tissue layer. Posterior layer of retina.

(6) Layer of nerve-fibres.

At the side of the optic ganglion is a peculiar body, known as the white body (not shewn in the figure), which has the histological characters of glandular tissue.

The first satisfactory account of the development of the eye is due to Lankester (No, 365). The more important features in it were also independently worked out by Grenacher (No. 363), and are beautifully illustrated in Bobretzky's paper (No. 362). The eye first appears as an oval pit of the epiblast, the edge of which is formed by a projecting rim (fig. $278 \mathrm{~A}$ ). The epiblast layer lining the floor of the pit soon becomes considerably thickened. By the 
growtl inwards of the rim the mouth of the pit is gradually narrowed (fig. $278 \mathrm{~B}$ ), resembling at this stage the eye of Nautilus, and finally closed. There is thus formed a flattened sack, lined by epiblast, which may be called the primary optic vesicle. Its cavity eventually forms the inner optic chamber. The anterior wall of the sack is lined by a much less columnar layer than the posterior, the former giving rise to the epithelium on the inner side of the ciliary processes, the latter to the retina.

The cavity of the sack rapidly enlarges, and assumes a spherical form. At the same time a layer of mesoblast grows in between the walls of the sack and the external epiblast. Two new structures soon arise nearly simultaneously (fig. 279), -which become in the adult

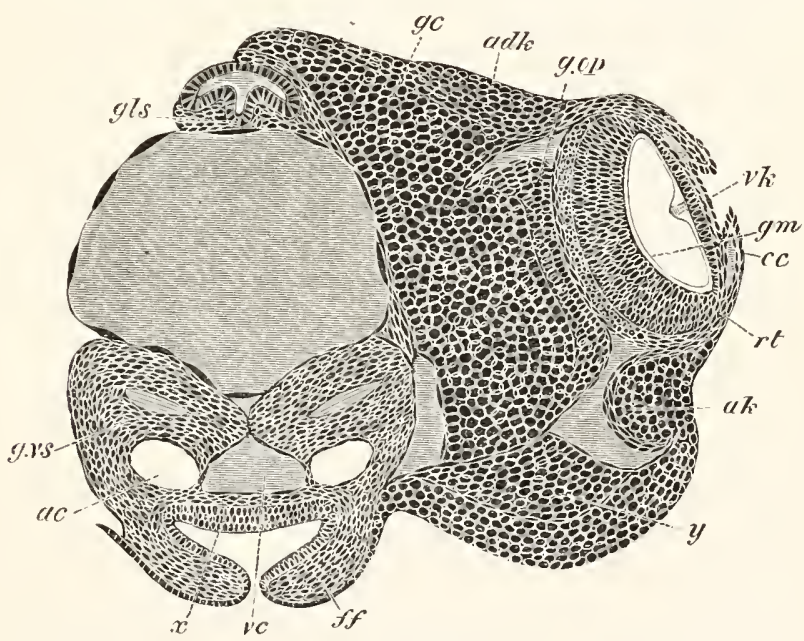

F1g. 279. Transverse Section throdgh the head of aN advanced EMBrio of Loligo. (After Bobretzky.)

gls. salivary gland; g.rs. visceral ganglion; gc. cerebral ganglion; g.op. optic ganglion; $a d k$. optic cartilage; $a k$. and $y$. lateral eartilage or (?) white body; $r t$. retina $g m$. limiting membrane of retina; $i k$. ciliary region of eye; $c c$. iris; $a c$. auditory sack (the epithelium lining the anditory sacks is not represented); $v$. vena cava; $f f$. folds of funnel; $x$. epithelium of funnel.

eye the iris (cc) and the posterior segment of the lens. The iris is formed as a circular fold of the skin in front of the optic vesicle. It consists both of epiblast and mesoblast, and gives rise to a pit lined 
by epiblast. The posterior segment of the lens arises as a structureless rod-like body, which is shewn in fig. 279 depending from the inner side of the anterior wall of the optic vesicle. Its exact mode of origin is somewhat obscure. The following is Lankester's account of it ${ }^{1}$ : "It is formed entirely within the primitive optic chamber, and at first depends as a short cylindrical rod from the middle point of the anterior wall of that chamber, that is to say, from the point at which the chamber finally closed up. It grows subsequently by the deposition of concentric layers of a horny material round this cone. No cells appear to be immediately concerned in affecting the deposition, and it must be looked upon as an organic concretion, formed from the liquid contained in the primitive optic chamber."

The lens would thus appear to be a cuticular structure. It gradually assunies a nearly spherical form; and is then composed of concentrically arranged layers (fig. $280 \mathrm{hl}$ ).

While the lens is being formed, the ciliary epithelium of the optic vesicle becomes divided into two layers, an outer layer of large cells and an inner of small cells. Both layers are at first continuous across the anterior wall of the optic chamber in front of the lens, but soon become confined to the sides (fig. $280 \mathrm{~A}, c c$ and $g z$ ). The inner layer is stated by Lankester to give rise to the muscles present in the adult. The mesoblast cells also disappear from the region in front of the lens, and the outer epithelium is converted into a kind of cuticular membrane. By these changes the original layers of cells in front of the lens become reduced to mere membranes,-a change which appears to be preparatory to the appearance of the anterior segment of the lens. The formation of the latter has not been fully followed out by any investigator except Bobretzky. His figures would seem to indicate that it is formed as a cuticular deposit in front of the membrane already spoken of (fig. $280 \mathrm{~B}, v l$ ). The two segments of the lens appear at any rate to be separated by a membrane continuous with the ciliary region of the optic vesicle.

Grenacher believes that the front prart of the lens is formed in a pocketlike depression of the epiblastic hyer covering the outer side of the optic cup; and Lankester thinks that the lens "pushes its way through the median anterior area of the primitive optic chamber, and projects into the second or anterior optic chamber where the iridian folds lie closely upon it."

While the lens is attaining its complete development there appears a fresh fold round the circumference of the eye, which gradually grows inwards so as to form a chamber outside the parts already present. This chamber is the anterior optic chamber of the adult. In most Cephalopods (fig. $277 \mathrm{c}$ ) the edges of the fold do not. quite meet, but leave a larger or smaller aperture leading into the chamber containing the iris, outer segment of the lens, etc. In some forms however they meet and coalesce, and so shut off this chamber

1 “Devel. of Cephalopoda." Q. J. Micro. Scien. 1875, p. 44. 
from conmunication with the exterior. The edge of the fold constitutes the cornea while the remainder of it gives rise to the sclerotic.

'The retina is at first a thick layer of numerous rows of oval cells (fig. 279). When the inmer segment of the lens is far advauced towards its complete formation pigment becomes deposited in the anterior part of the retina, and a layer of rods grows out from the surface turned towards the cavity of the optic vesicle (fig. $280 \mathrm{~A}$, st). At a slightly later stage the retina becomes divided into two layers (Bobretzky), a thicker anterior layer, and a thimmer posterior layer (fig. ¿su $r t$ and $\left.r t^{\prime \prime}\right)$. The former is composed of two strata, (1) the rools and (2) a stratum with numerous rows of nuclei which becomes in the adult the granular layer with its pigment. 'The posterior la yer' gives rise to the cellular part of the posterior division of the retina, while layers of connective tissue around it give rise to the comnective tissue of this portion of the retina (layer 6 in the scheme on p. 390). 'The nervous layer is derived from the optic ganglion which attaches itself to the inner side of the connective tissue layer.

The greater part of the choroid is formed from the mesoblast adjoining the retina, but the epithelium covering its outer wall is of epi-

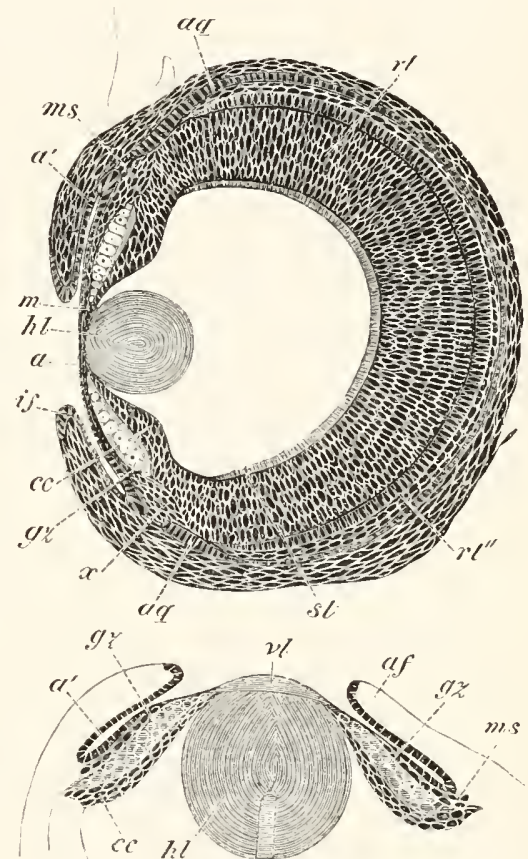

A.

13.

Fig. 280. Sections throtgr the DeVELOPLNG ETE OF LOLlgo at two stages. (After Bobretzky.)

$h$. inner segment of lens: $r l$. outer segment of lens; $a$ and $a^{\prime}$. epithelium lining the anterior optic chamber; $g z$. large epiblast cells of ciliary body; $c c$. sinall epiblast cells of ciliary body; ms. layer of mesoblast between the two epiblastic layers of the eiliary boly ; $a f$. and if. fold of iris; $r t$. retina; $r t^{\prime \prime}$. inner liayer of retina; st. rods; aq. cartilage of the choroid. blastic origin.

It is difficult to decide from development whether the Molluscan eyes, so far dealt with, originated in the first instance pari passu with the supra-cesophageal ganglia or independently at a later period. On purely à priori ground I should be inclined to adopt the former alternative.

In addition to the above eyes there ocen amongst Mollusea highly complicated eyes, of a very different kind, in two wirlely separaterl groups, 
viz. certain species of a genus of slug (Onchidium), and certain Lamellibranchiata. These eyes, though they liave no doubt been evolved independently of each other; present certain remarkable points of agreement. In both of them the rods of the retina are turned away from the surface, and the nerve-fibres are placed, as in the Vertebrate eye, on the side of the retina which faces outwards.

The peculiar eyes of Onchidium, investigated by Semper ${ }^{1}$, are scattered on the dorsal surface, there being normal eyes in the usual situation on the head. The eyes on the dorsal surface are formed of a cornea, a lens composed of $1-7$ cells, and a retina surrounded by pigment; which is perforated in the centre by an optic nerve, the retinal elements being in the inverted position above mentioned.

The development of these eyes has been somewhat imperfectly studied in the adult, in which they continue to be formed anew. They arise by a differentiation of the epidermis at the end of a papilla. At first a few glandular cells appear in the epidermis in the situation where an eye is about to be formed. Then, by a further process of growth, an irregular mass of epidermic cells becomes developed, which pushes the glandular cells to one side, and constitutes the rudiment of the eye. This mass, becoming surrounded by pigment, unites with the optic nerve, and its cells then differentiate themselves, in situ, into the various elements of the eye. No explanation is offered by Semper of the inverted position of the rods, nor is any suggested by his account of the development. As pointed out by Semper these eyes are no doubt modifications of the sensory epithelium of the papilla.

The eyes of Pecten and Spondylus ${ }^{2}$ are piaced on short stalks at the edge of the mantle, and are probably moditications of the tentacular processes of the mantle edge. They are provided with a connea, a cellular lens, a vitreous chamber, and a retina. The retinal elements are inverted, and the optic nerve passes in at the side, but occupies, in reference to its ramifications, the same relative situation as the optic nerve in the Vertebrate eye. The development has unfortunately not yet been studied.

Our knowledge of the structure or still more of the development of the organ of vision of the Platyelminthes, Rotifera, and Echinodermata is too scanty to be of any general interest.

Chætopoda. Amongst the Chrtopoda the cephalic eyes of Alciope (fig. 281) have been adequately investigated as to their anatomy by Greeft. These are provided with a large cuticular lens $(l)$, separated from the retina by a wide cavity containing the vitreous humour. The retina is formed of a single row of cells, with rouls at their free extremities, continuous at their opposite ends with nerve-fibres. The development of this eye has not been worked out. Eyes not situated on the head are found in Polyophthatmus, and have probably been evolved from the more indifferent type of sense-organ found by Eisig in the allied Capitellidx.

Chætognatha ${ }^{3}$. The paired cephalic eyes of Sagitta are spherical bodies imbedded in the epidermis. They are formed of a central mass

1 Ueber Sehorgane von Typus d. Wirbelthieraugen, ete., Wiesbarlen, 1877, and Archiv f. mikr. Anat. Vol. xiv. pl. 118-122.

2 Vide Hensen (No. $36_{4}$ ) and S. J. Hickson, "The Eve of Pecten," Quart. J. of Micr. Science, Vol. xx. 1880.

3 O. Hertwig. "Die Chætognathen." Jenaische Zeitschrift, Vol. xiv, 1880. 
of pigment with three lenses partially imbedded in it. The outer covering of the eye is the retina, which is mainly composed of rod-bearing cells; the rods being placed in contact with the outer surface of each of the lenses. In the presence of three lenses the eye of Sagitta approaches in some respects the eye of the Arthropodit.

Arthropodan eye. A satisfactory elucidation of the phylogeny of Arthropodan eyes has not yet been given.

All the types of eyes found in the group (with exception of that of Peripatus) ${ }^{1}$ present marked features of similarity, but I am inclined to view this similarity as due rather to the character of the exoskeleton modifying in a more or less similar way all the forms of visual organs, than to the descent of all these eyes from a common prototype. In none of these eyes is there present a chamber filled with fluid between the lens and the retina, but the space in question is filled with cells. This character sharply distinguishes them from such eyes as those of Alciope (fig. 281). The types of eyes which are found in the Arthropoda are brietly the following:

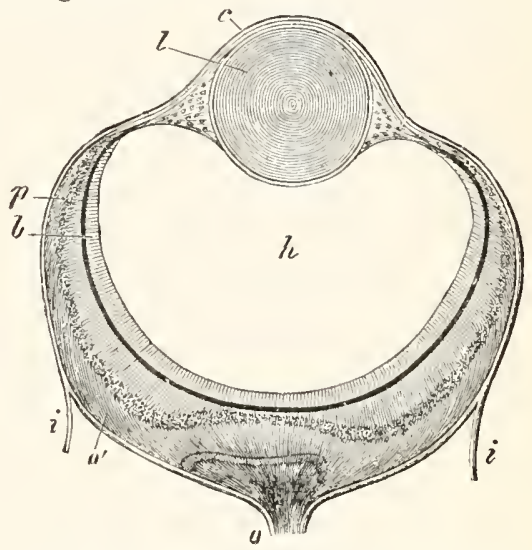

Fig. 281. Eye of an Alcropid (NeoPHANTA CELOX). (From Gegenbaur; after Greef.)

$i$. cuticle; $c$. continuation of cuticle in front of eye; $l$. lens; $h$. vitreous humour; $o$. optic nerve; $o^{\prime}$. expansion of the optic nerve; $b$. layer of rods; $p$. pigment layer.

(1) Simple eyes. In all simple eyes the corneal lens is formed by a thickening of the cuticle. Such eyes are confined to the Tracheata.

There are three types of simple eyes. (a) A type in which the retinal cells are placed immediately belind the lens, foumd (Lowne) in the larve of some Diptera (Eristalis), and also in some Chilognatha.

(b) A type of simple eye found in some Chilopoda, and in some Insect larva (Dytiscus, etc.) (fig. 282), the parts of which are entirely derived from the epidermis. There is present a lens $(l)$ formed as a thickening of the cuticle, a so-called vitreous humour $(g l)$ formed of modified hypodermis cells, and a retina $(r)$ derived from the same

1 The eye of Peripatus is similar neither to the eye of the Arthropoda, nor to that of the Chrtopoda, but resembles much more closely the Molluscan eye. The hypodermis and cuticle form together a highly convex cornea, within which is a large optic chamber, the posterior wall of which is formed by the retina. The optic cliamber would appear to contain a structureless lens, but it is possible that what I regard as a lens may, on fuller investigation, turn out to be only a coagulum. 
source. The outer ends of the retinal cells terminate in rods, and their inner ends are continuous with nerve-fibres.

(c) A type of simple eye found in the Arachnida, and apparently some Chilopoda, and forming the simple eyes of most Insects, which differs from type $(a)$ in the cells of the retina forming a distinct layer beneath the hypodermis; the latter only obviously giving rise to the vitreous humour.

The development of the simple eyes has not yet been studied.

The simple eyes so far described are atways placed on the head, and are usially rather numerous.

(2) Compound eyes. Compound eyes are almost always present in the Crustacea, and are usually found in adult Insects. In both groups they are paired, though in the Crustacea a median much simplified componnd eye may either take the place of the paired eyes in the Nauplius larva and lower forms, or be present together with them during a period in the development of higher forms.

The typical compcund eye is formed (fig. 28:3) of a series of corneal lenses (c) developed from the cuticle; below which are placed bodies known as the crystalline cones, one to each corneal lens; and below the crystalline cones are placed bodies known as the retinula $(r)$ constituting the percipient elements of the eye, each of them being formed of an axial rod, the rhabdom, and a number of cells surrounding it.

The crystalline cones are formed from the coalescence of cuticular deposits in several cells, the nuclei of which usually remain as Semper's nuclei. These cells

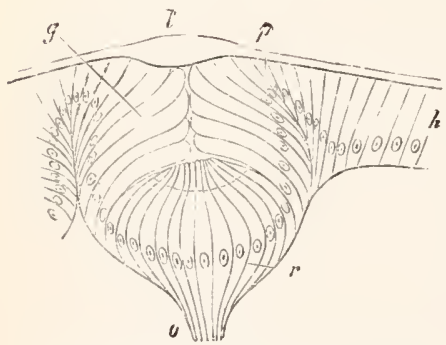

Fig, 282. SECTION THROVGH THE SIMPLE ETE OF A YOUNG DYTISCUS LARva. (From Gegenbaur; after Grenacher.)

l. corneal lens; $g$. vitreous humour; $r$ retina; $u$ optic nerve; $h$. hypodermis.

eyes of the 'Tipulide.

The development of the compound eye has so far only been satisfactorily studied in some Crustacea by Bobretzky (No. 367); by whom it has been worked out in Paliemon and Astacus, but more fully in the latter, to which the following accomnt refers: 
'T'he eye of Astacus takes its origin from two distinct parts, (1) the external epidermis of the procephalic lobes which will be spoken of as the epidermic layer of the eye, (2) a portion of the supra-œsophageal ganglia, which will be spoken of as the neural layer of the eye. The mesoblast is moreover the source of some of the pigment between the two above layers. The epitermic layer gives rise to the comeal lenses, the erystalline cones, and the pigment around the latter. The neural laver on the other hand seems to give rise to the retinulæ with their rhabdoms, and to the optic ganghion.

After the separation of the supracesophageal ganglia from the superticial cpiblast, the cells of the epirlermis in the region of the future eye become columnar, and so form the ahove-mentioned epidermic layer of the eve. This layer soon becomes two or three cells deef. At the same time the most superficial part of the adjoining supra-tesophageal ganglion beeomes partially constricted off from the remainder as the neural layer of the eye, but is separated by a small space from the thickened patch of epidermis. Into this space some mesollast cells penetrate at a slightly later period. Both the epidermic and neural layers next become divided into two strata. The outer stratum of the epidernic layer gives rise to the crystalline cones and Semper's nuclei; each crystalline cone heing formed from four coalesced rods, developed as cuticular differentiations of four cells, the nuclei of which may be seen in the embryo on its onter silie. The lower ends of the cones pass through the inner stratum of the epidermic disc, the cells of which become pigmented, and constitute the pigment cells surrounding the lower part of the crystalline cones in the adult. The outer end of each of the crystalline cones is surrounded by four cells, believed by Bobretzky to be identical with Semper's nuclei ${ }^{1}$. These cells give rise in a later stage (not worked out in Astacus) to the cuticular corneal lenses.

Of the two strata of the neural layer the outer is several cells deep, while the inner is formed of elongated rod-like cells. Unfortuuately however the fate of the two neural layers has not heen workel out, though there can be but little doubt that the retinulie originate from the outer layer.

The mesoblast which grows in between the neural and epidermic layers becomes a pigment layer, and probably also forms the perforated membrane hetween the erystalline cones and the retinulee.

The above observations of Bobretzky would appear to indicate that the paired compound eyes of Crustacea belong to the type of

1 There would appear to be some confusion as to the nomenclature of these parts in Bobretzky's account. 
cerebral eyes. How far this is also the case with the compound eyes of Insects is uncertain, in that it is quite possible that the latter eyes may have had an independent origin.

The relation between the paired and median eye of the Crustacea is also uncertain.

In the genus Euphausia amongst the Schizopods there is present a series of eyes placed on the sides of some of the thoracic legs and on the sides of the abdomen. The structure of these eyes, though not as yet satisfactorily made out, would appear to be very different from that of other Arthropodan visual organs.

The Eye of the Vertebrata. In view of the various structures which unite to form it, the eye is undoubtedly the most complicated organ of the Vertebrata; and though its mode of development is fairly constant throughout the group, it will be convenient shortly to describe what may be regarded as its typical development, and then to proceed to a comparative view of the origin of its various parts, and to enter into greater detail with reference to some of them. At the end of the section there is an account of the accessory structures connected with the eye.

'The formation of the eye commences with the appearance of a pair of hollow outgrowths from the anterior cerebral vesicle or thatamencephalon, which arise in many instances, even before the closure of the medullary canal. 'These outgrowths, known as the optic vesicles, at first open freely into the cavity of the anterior cerebral vesicle. From this they soon however become partially constricted, and form resicles (fig. 284 $a$ ), united to the base of the brain by

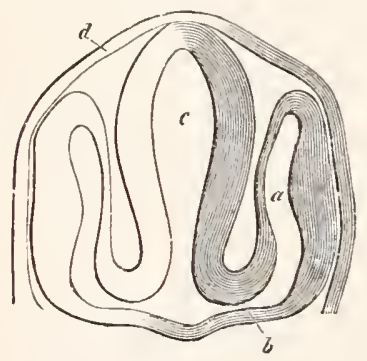

Fig. 284. Section throdgh the inead of an embryo Teleostean, to SHEW THE FORMATION OF THE OPTIC VESICLES, ETC. (From Gegenbaur; after Schenk.)

$c$. fore-brain; $a$. optic vesicle; $b$. stalk of optic vesicle; $d$. epidermis. comparatively narrow hollow stalks, the rudiments of the optic nerves. The constriction to which the stalk or optic nerve is due takes place obliquely downwards and backwards, so that the optic nerves open into the base of the front part of the thalamencephalon (fig. 28+ $b$ ).

After the establishment of the optic nerves, there take place (1) the formation of the lens, and (2) the formation of the optic cup from the walls of the primary optic vesicle.

The external or superficial epiblast which covers, and is in most forms in immediate contact with, the most projecting portion of the optic vesicle, becomes thickened. This thickened portion is then driven inwards in the form of a shallow open pit with thick walls (fig. $285 \mathrm{~A}, 0$ ), carrying before it the front wall $(r)$ of the optic vesicle. 'To such an extent does this involution of the 
superficial epiblast take place, that the front wall of the optic vesicle is pushed close up to the hind wall, and the cavity of the vesicle becomes almost obliterated (fig. 285 B).

The bulb of the optic vesicle is thus converted into a cup with double walls, containing in its cavity the portion of involuted epiblast. This cup, in order to distinguish its cavity from that of the original optic vesicle, is generally called the secondary optic vesicle. We may, for the sake of brevity, speak of it as the optic cup; in reality it never is a vesicle, since it always remains widely open in front. Of its double walls the inner or anterior (fig. $285 \mathrm{~B}, r$ ) is formed from the front portion, the outer or posterior (fig. $285 \mathrm{~B}, u$ ) from the hind portion of the wall of the primary optic vesicle. The inner or anterior $(r)$, which very speedily becomes thicker than the other, is converted into the retina: in the outer or posterior $(u)$, which remains thin, pigment is eventually deposited, and it ultimately becomes the tesselaterl pigment-layer of the choroid.

By the closure of its mouth the pit of the involuted epiblast becomes a completely closed sac with thick walls and a small central cavity (fig. $285 \mathrm{~B}, l$ ). At the same time it breaks away from the external epiblast, which forms a continuous layer in front of it, all traces of the original opening being lost. There is thus left lying in the cup of the secondary optic vesicle, an isolated elliptical mass of epiblast. This is the rudiment of the lens. The small cavity within it speedily becomes still less by the thickening of the walls, especially of the hinder one.

At its first appearance the lens is in immediate contact with the anterior wall of the secondary optic vesicle (fig. $285 \mathrm{~B}$ ). In a short time however, the lens is seen to lie in the mouth of the cup (fig. 285 D), a space ( $v h$ ) (which is occupied by the vitreous humour) making its appearance between the lens and anterior wall of the vesicle.

In order to understand how this space is developed, the position of the optic vesicle and the relations of its stalk must be borne in mind.

The vesicle lies at the side of the head, and its stakk is directed downwards, inwards and backwards. The stalk in fact slants away 
from the vesicle. Hence, when the involution of the lens takes place, the direction in which the front wall of the vesicle is pushed in is not in a line with the axis of the stalk, as for simplicity's sake has been represented in the diagram (fig. 285), but forms an obtuse angle with that axis, after the manner of fig. 286 , where $s^{\prime}$ represents the cavity of the stalk leading away from the almost obliterated cavity of the primary vesicle.

Fig. 286 represents the early stage at which the lens fills the whole cup of the secondary vesicle. The subsequent condition is brought about throngh the rapid growth of the walls of the cup. This growth however does not take place

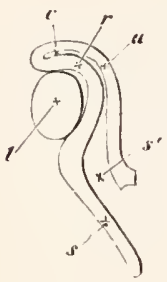

Fig. 286. Diagramuatic SECTION OF THE EYE AND THE OPTIC NERVE AT AN EARLY staGe. (From Lieberkiihn.)

To shew the lens $l$ occupying the whole hollow of the optic cup, the inclination of the stalk $s$ to the optic cup, and the continuity of the cavity of the stalk $s^{\prime}$ with that of the primary vesicle $c$; $r$. anterior, $u$. posterior wall of the optic cup. equally in all parts of the cup. The walls of the cup rise up all round except that point of the circumference of the cup which adjoins the stalk. While elsewhere the walls increase rapidly in height, carrying so to speak the lens with them, at this spot, which in the natural position of the eye is on its under surface, there is no growth: the wall is here imperfect, and a gap is left. 'Through this gap, which afterwards receives the name of the choroidal fissure, a way is open from the mesoblastic tissue surrounding the optic vesicle and stalk into the interior of the cavity of the cup.

From the manner of its formation the gap or fissure is evidently in a line with the axis of the optic stalk, and in order to be seen must be looked for on the under surface of the optic vesicle. In this position it is readily recognised in the embryo seen as a transparent object (fig. $118 \mathrm{chs}$ ).

Bearing in mind these relations of the gap to the optic stalk, the reader will understand how sections of the optic vesicle at this stage present very different appearances according to the plane in which the sections are taken.

When the head is viewed from underneath as a transparent object the eye presents very much the appearance representer in the diagram (fig. 287).

A section of such an eye taken along the line $y$, perpendicular to the plane of the paper, would give a figure corresponding to that of fig. $288 \mathrm{D}$. The lens, the cavity and double walls of the secondary vesicle, the remains of the primary cavity, would all be represented (the superficial epiblast of the head would also be shewn); but there would be nothing seen of either the stalk or the fissure. If on the other hand the section were taken in a plane parallel to the plane of the paper, at some distance above the level of the stalk, some such figure would be obtained as that shewn in fig. $288 \mathrm{E}$. Here the 
fissure $f$ is obvious, and the communication of the cavity $v$ h of the secundary vesicle with the outside of the eye evident; the section of course would not go through the superficial epiblast. Lastly, a section, taken perpendicular to the plane of the paper along the line z, i.e. through the tissure itself, would present the appearances of fig. $258 \mathrm{~F}$, where the wall of the vesicle is entirely wanting in the region of the fissure markerl by the position of the letter $f$. The external epiblast has been omitted in this figure.

With reference to the ahove description, taken witl very slight alterations from the Elements of Embryoloyy, Pt. I., two points require to be noticed. Firstly it is extremely doubtful whether the invagination of the secondary optic vesicle is to be viewed as an actual mechanical result of the ingrowth of the lens. Secondly it seems probable that the choroid tissure is not simply due to an inequality in the growtl of the walls of the secondary optic cup, but is partly due to a doubling up of the primary resicle from the side along the line of the fissure, at the same time that the lens is being thrust in in front. In Mammalia, the doubling up involves the optic stalk, which becomes flattened (whereby its original cavity is obliterated) and then folded in on itself, so as to embrace a new central cavity continuous with the cavity of the vitreous lumour. And in other forms a partial phenomenon of the same kind is usually observable, as is more particularly deserilied in the sequel.

Before describing the development

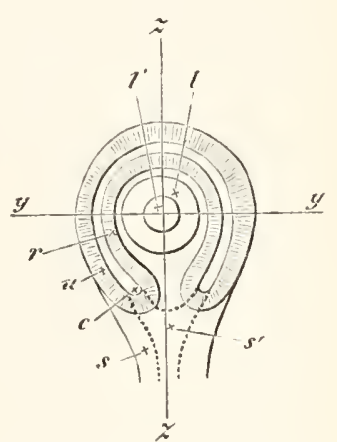

Fic, 287. Diagamatic RePRESENTATION OF THE EYE OF THE CHICK OF ABOUT THE THIRD DAY AS SEEN WHEN THE HEAD IS VIEWED FROM UNDERNEATH AS A TRANSPARENT OBJECT.

l. the lens; $l^{\prime}$. the eavity of the lens, lying in the hollow of the optic cup; $r$. the anterior, $u$. the posterior wall of the optic eup; $c$. the cavity of the primary optic vesicle, now nearly obliterated. By inadvertence $u$ has been drawn in some places thicker than $r$, it should have been thinner throughont. $s$. the stalk of the optie eup with $s^{\prime}$ its eavity, at a lower level than the eup itself and therefore out of focus; the dotted line in. dicates the continuity of the cavity of the stalk with that of the primary resicle.

The line $z z$, through which the section shewn in fig. $288 \mathrm{~F}$ is supposed to be taken, passes through the choroidal fissure. of the cornea, aqueous humour, ete. we may consider the further growth of the parts, whose first development has just been described, commencing with the optic cup.

During the above changes the mesoblast surrounding the optic cup assumes the character of a distinct investment, whereby the outline of the eye-ball is definitely formed. The internal portions of this investment, nearest to the retina, become the choroid (i.e. the choriocapillaris, and the lamina fusca; the pigment epithelium, as we have seen, being derived from the epiblastic optic cup), and pigment is subsequently deposited in it. The remaining external portion of the investment forms the sclerotic.

B. E. II. 
The complete differentiation of these two coats of the eye does not however take place till a late period.

The cavity of the original optic vesicle was left as a nearly obliterated space between the two walls of the optic cup. By the end of the third day the obliteration is complete, and the two walls are in immediate contact.

The inner or anterior wall is, from the first, thicker than the outer or posterior; and over the greater part of the cup this contrast increases with the growth of the eye, the anterior wall becoming markedly thicker and undergoing changes of which we shall have to speak directly (fig. 289).

In the front portion however, along, so to speak, the lip of the cup, anterior to a line which afterwards becomes the ora serrata, both layers cease to take part in the increased thickening, accompanied by peculiar histological changes, which the rest of the cup is undergoing. Thus a hind portion or true retina is marked off from a front portion.

The front portion, accompanied by the mesoblast which immediately overlies it, is behind the lens thrown into folds, the ciliary ridges; while further forward it bends in between the lens and the cornea to form the iris. The original wide opening of the optic cup is thus narrowed to a smaller orifice, the pupil; and the lens, which before lay in the open mouth of the cup, is now inclosed in its cavity. White in the hind portion of the rup or retina proper no deposit of
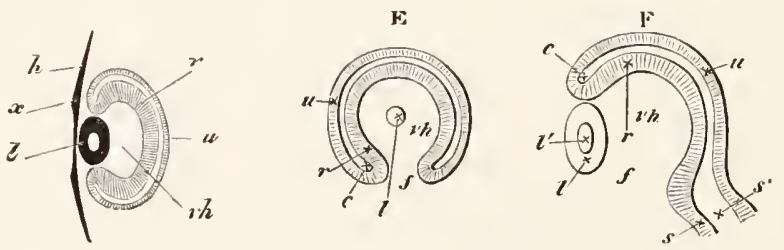

FIG. 288.

D. Diagrammatic section taken perpendicular to the plane of the paper, along the line $y y$, fig. 287. The stalk is not seen, the section falling quite out of its region. $v h$. hollow of optic cup filled with vitreous humour; other letters as in fig. 285 B. (After Remak.)

E. Section taken parallel to the plane of the paper through fig. 287 , so far behind the front surface of the eye as to shave off a small portion of the posterior surface of the lens $l$, but not so far behind as to be carried at all through the stalk. Letters as before; $f$, the choroidal fissure.

F. Section along the line $z z$, perpendicular to the plane of the paper, to sliew the choroidal fissure $f$, and the continuity of the cavity of the optic stalk with that of the primary optic vesicle. Had this section been taken a little to one side of the line $z z$, the wall of the optic cup would have extended up to the lens below as well as above. Letters as before. The external epiblast is omitted in this section.

black pigment takes place in the layer formed out of the inner or anterior wall of the vesicle; in the front portion forming the region of the iris, pigment is largely deposited throughout both layers, though first of all in the outer one, so that eventually this portion 
seems to becone nothing more than a forward prolongation of the pigment epithelium of the choroid.

Thus, while the hind moiety of the optic cup becomes the retina proper, including the choroid-pigment in which the rods and cones

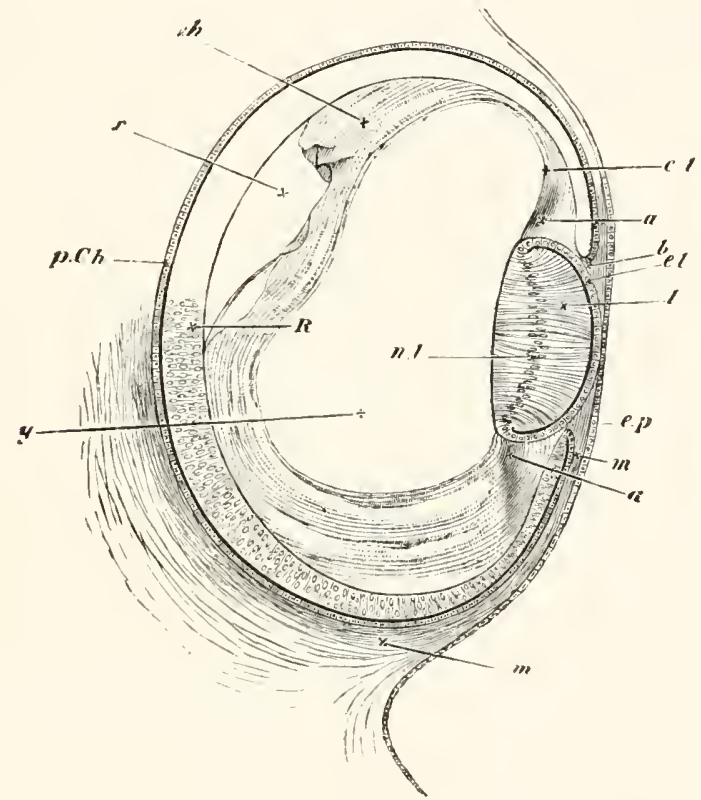

Fig. 289. Section of the Eye of Chick at THE Fovrth D.Y.

e.p. superficial epiblast of the side of the head; $R$. true retina: anterior wall of the optic cup; $p . C \%$. pigment-epithelium of the choroid: posterior wall of the optic cup. $b$ is placed at the extreme lip of the optic cup at what will become the margin of the iris. $l$, the lens. The hind wall, the nuclei of whose elongated cells are shewn at $n l$, now forms nearly the whole mass of the lens, the front wall being reduced to a layer of flattened cells $\mathrm{el}$. $\mathrm{m}$. the mesoblast surrounding the optic cup and about to form the clioroid and sclerotic. It is seen to pass forward between the lip of the optic cup and the superficial epiblast.

Filling up a large part of the hollow of the optic cup is seen a hyaline mass, the rudiment of the hyaloid membrane, and of the coagulum of the vitreous humour, $y$. In the neighbourhood of the lens it seems to be continuous as at $c l$ with the tissue $a$, which appears to be the rudiment of the capsule of the lens and suspensory ligament.

are imbedded, the front moiety is converted into the ciliary portion of the retina, covering the ciliary processes, and into the uvea of the iris; the bodies of the ciliary processes and the substance of the iris, their vessels, muscles, connective tissue and ramified pigment, being derived from the mesoblastic choroid. The margin of the pupil marks the extreme lip of the optic vesicle, where the outer or posterior wall turns round to join the inner or anterior.

The ciliary muscle and the ligamentum pectinatum are both derived from the mesoblast between the cornea and the iris. 
The Retina. At first the two walls of the optic cup do not greatly differ in thickness. On the third day the outer or posterior becomes much thinner than the inner or anterior, and by the middle of the fourth day is reduced to a single layer of flattened cells (fig. 289 p.Ch). At about the soth hour its cells commence to receive a deposit of pigment, and eventually form the so-called pigmentary epithelimm of the choroid; from them no part of the true retina (or no other part of the retina, if the pigment-laver in question be supposed to belong more truly to the retina than to the choroid) is derived.

On the fourth day, the inner (anterior) wall of the optic cup (fig. $289 R$ ) has a perfectly uniform structure, being composed of elongated somewhat spindle-shaped cells. with distinct nuclei. On its external (posterior) surface a distinct cnticular membrane, the membrana limitans externa, early appears.

As the wall increases in thickness, its cells multiply rapidly, so that it soon becomes several cells thick: each cell being however probably continued through the whole thickness of the layer. The wall at this stage corresponds closely in its structure with the brain, of which it may properly be looked upon as part. According to the usual view, which is not however fully supported by the development, the retina becomes divided in the subsequent growth into (1) an outer part, corresponding morphologically to the epithehial lining of the cerehro-spinal canal, composed of what may be called the visual cells of the eye, i.e. the cells forming the outer gramular (nuclear) layer and the rods and cones attached to them; and (2) an inner portion consisting of the inner granular (nuclear) layer, the inner molecular layer, the ganglionic layer and the layer of nerve-fibres corresponding morphologically to the walls of the brain. According to Löwe, however, only the outer limbs of the rods and cones, which he holds to be metamorphosed cells, correspond to the epithelial layer of the brain.

The actual development of the retina is not thoroughly understood. According to the usuat statements (Kölliker, No. 298, 1. 693) the layer of ganglion cells and the inner molecular layer are tirst differentiated, while the remaining cells give rise to the rest of the retina proper, and are bunnded externally by the membrana limitans externa. On the inner side of the ganglionic layer the stratum of nerve-tibres is also very early established. The rorls and cones are formed as prolongations (Kölliker, Babuchin), or cuticularizations (Schultze, W. Miiller) of the cells which eventually form the outer grauular layer. The layer of cells external to the molecular layer is not divided till comparatively late into the inner and outer gramular (nuclear) layers, and the interposed outer molecular layer.

Löwe's account of the development of the retina in the Rabbit is in many points different from the above. He finds that three stages in the differentiation of the layers of the retina may be distinguished.

In the first stage, in an embryo of four or five millimetres, the following layers are present, commencing at the outer side, adjoining the external wall of the secondary optic cup. 
(1) A membrane, which does not however, as usually believed, become the membrana limitans externa.

(2) A layer of clear elements, derived from metamorphosel cells, constituting the outer limbs of the rods and cones.

(3) A layer of dark rounded elements.

(t) An indistinctly striated layer, the future layer of nerve-fibres.

The third of these lavers gives rise to all the eventual strata of the retina proper, except the outer limbs of the ruls and cones.

In the next stage, when the embryo has reached a length of $2 \mathrm{~cm}$., this layer becomes divided intu three strata: viz. an outer and inner layer of dark elements and a middle one of clearer elements. The two immer of these layers hecome respectively the inner molecular layer and the layer of gauglion cells, while the outer layer gives rise to the parts of the retina external to the immer molecular layer.

In the newly born animal the outer darker layer of the previous stage has become considerally subdiviled. Its onternost part forms a stratum of darkly colonred elements, which develop into the inner limbs of the rods and cones. It is bounded internally by a menbrane-the troue membrama elastica externa. The part of the layer within this is soon divided into the outer and inner granular layers, separated from each other by the delicate outer molecular linger. Thus, shortly after birth, all the layers of the retina are established in the Rabbit. It is important to notice that, according to Löwe's views, the outer and inner limbs of the rols and cones are metamorphosed cells. The outer limbs at tirst form a contiuuous layer, in which separate elements cannot be recognised.

At a very early period there alpears a membrane on the side of the retina aljoining the vitreous lumour. This membrane is the hyaloid membrane. The mvestigations of Kessler and nuself lead to the conclusion that it may be formed at a time when there is no trace of mesoblastic structures in the cavity of the vitreous humour, and that it is therefore necessarily developed as a cuticular deposit of the cells of the optic cup. Lieberkinh, Arnold, Liiwe, and other authors regard it howerel as a mesoblastic: product; and Köliker believes that a primitive membrane is developed from the cells of the optic eup, and thit a true hyaloid membrane is developed much later as a product of the mesoblast.

For fuller information on this subject the roader is referred to the authors quoted above.

The optic nerve. The optic nerves are derived, as we have said, from the at first hollow stalks of the optic vesicles. Their cavities gradually become obliterated by a thickening of the walls, the obliteration proceeding from the retinal end inwards towards the brain. While the proximal ends of the optie stalks are still hollow the rudiments of the optic chiasma are formed from fibres at the roots of the stalks, the fibres of the one stalk growing over into the attachment of the other. The decissation of the fibres wonld appear to be complete. The fibres arise in the remainder of the nerves somewhat later. At first the optic nerve is equally continuous with both walls of the optic cup; as must of necessity be the case, since the interval which primarily exists between the two 
walls is continuous with the cavity of the stalk. When the cavity within the optic nerve vanishes, and the fibres of the optic nerve appear, all connection is ruptured between the outer wall of the optic cup and the optic nerve, and the optic nerve simply perforates the outer wall, and becomes continuous with the inner one.

There does not appear to me any ground for doubting (as has been done by His and Kölliker) that the fibres of the optic nerve are deriver from a differentiation of the epithelial cells of which the nerve is at first formed.

Choroid Fissure. With reference to the choroid fissure we may state that its behaviour varies somewhat in the different types. It becomes for the greater part of its extent closed, though its proximal end is always perforated by the optic nerve, and in many forms by a mesoblastic process also.

The lens when first formed is an oval vesicle with a small central cavity, the front and hind walls being of nearly equal thickness, and each consisting of a single layer of elongated columnar cells. In the subsequent stagres the mode of growth of the lind wall is of precisely an opposite character to that of the front wall. The hind wall becomes much thicker, and tends to obliterate the central cavity by beconing convex on its front surface. At the same time its cells, still remaining as a single layer, become elongated and fibre-like. 'The front wall on the contrary becomes thimmer and thinner and its cells flattened.

These modes of growth continne until, as shewn in fig. 289 , the hind wall $l$ is in absolute contact with the front wall el, and the cavity thus becomes entirely obliterated. The cells of the hind wall bave by this time become veritable fibres, which, when seen in section, appear to be arranged nearly parallel to the optic axis, their nuclei $n l$ being seen in a row along their mildle. The front wall, somewhat thickened at either side where it becomes continuous with the hind wall, is now a single layer of flattened cells separating the hind wall of the lens, or as we may now say the lens itself, from the front limb of the lens-capsule; of the latter it becomes the epithelium.

'The subsequent changes undergone consist chiefly in the continued elongation and multiplication of the lens-fibres, with the partial disappearance of their nuclei.

During their multiplication they become arranged in the manner characteristic of the adult lens of the various forms. The lens-capsule, as was originally stated by Kölliker, appears to be formed as a cuticular membrane deposited by the epithelial cells of the lens.

The views of Lieberkühn, Arnoll, Löwe and others, according to which the lens-capsule is a mesoblastic structure, do not appear to be well founded. The contrary view, held by Kölliker, Kessler, etc., is supported mainly by the fact that at the time when the lens-capsule first appears there are no mesoblast cells to give rise to it. It should however be stated that W. Mïller has actually found cellular elements in what he believes to be the lens-capsule of the Ammocote lens. Considering the degraded 
character of the Ammocute eve, evidence derived from its structure must be accepted with caution.

The vitreous humour. The vitreous humour is derived (except in Cyclostomata) from a vascular ingrowth, which differs considerably in different types, through the choroid slit. Its real nature is very much disputed. According to Kessler's view, it is of the nature of a Huid transudation, but the occasional presence in it of ordiuary em. bryonic mesoblast cells, in addition to more numerous blood-corpuscles, gives it a claim to be regarded as intercellular substance. The number of cells in it is however at best extremely small and in many cases there is no trace of them. In Manmals there appear to be some mesoblast cells invaginated with the lens, which are not improbably employed in the formation of the vessels of the so-called membrana capsulo-pupillaris. In the Ammocœte the vitreous humour originates from a distinct mesoblastic ingrowth, though the cells which give rise to it subsequently disappear.

The development of the zonula of Zinu in Mammalia, which onglit to throw some light on the natmre of the vitreous humour, has not been fully investigated. According to Lieberkïhn (No. 373, p. 43), this structure appears in half-grown embryos of the sheep and calf.

He says "At the point where the ciliary processes and the ciliary part of the retina are entirely removed, one sees in the meridian bundles of fine fibres, which correspond to the valleys between the ciliary processes and fill them; also between these bundles there extend, as at thin layer, similar finely striated masses, and these would have been on the top of the ciliary processes." He further states that these fibres may be traced to the anterior and posterior limb of the lens-capsule, and that atmongst them are numerous cells. Kölliker confirms Lieberkühn's statements. There can be little doubt that the fibres of the zonula are of the nature of connective tissue : they are stated to he elastic. By Lïwe they are believed to be developed out of the substance of the vitreous humour, but this does not alpear to me to follow from the observations hitherto made. It seems quite possible that they arise from mesoblast cells which have grown into the cavity of the vitreous hmour, solely in connection with their production.

The integral parts of the eye in front of the lens are the cornea, the aqueous humour, and the iris. The development of the latter lias already been described, and there remain to be dealt with the cornea, and the cavity containing the aqueous humour.

The cornea. The cornea is formed by the coalescence of two structures, viz. the epithelium of the cornea and the cornea proper. The former is directly derived from the external epiblast, which covers the eye after the invagination of the lens. The latter is formed in a somewhat remarkable manner, first clearly made out by Kessler.

When the lens is completely separated from the epidermis its outer wall is directly in contact with the external epiblast (future corneal epithelium). At its edge there is a small ring-shaped space bounded 
by the outer skin, the lens and the edge of the optic cup. In the chick, which we may take as typical, there appears at abont the time when the cavity of the lens is completely obliterated a structureless layer external to the above ring-like space and immediately adjoining the inner face of the epiblast. This layer, which forms the commencement of the cornea proper, at first only forms a ring at the border of the lens, thickest at its outer edge, and gradually thimning off to nothing towards the centre. It soon however becomes broader, and finally forms a continuous stratum of considerable thickness, interposed between the external skin and the lens. As soon as this stratum has reached a certain thickness, a layer of flattened cells grows in along its inner side from the mesoblast surrounding the optic cup (fig. $290, d m$ ). This layer is the epithelioid layer of the

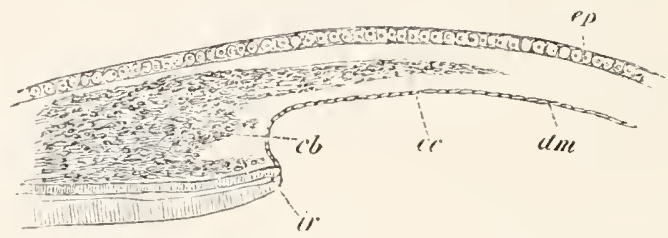

Fig, 290. Section throdgh the eye of a Fow on the eighth day of Develol. mext, TO SHEW THE IRIS AND CORNEA IN the plocess of fonmation. (After Kessler.)

ep. epiblastic epithelium of colnea; cc. corneal corpuscles growing into the structureless matrix of the cornea; $d m$. Descemet's membrane; $i r$. iris; $c b$. mesoblast of the iris (this reference letter points a little too high).

The space between the layers $d m$. and $e p$. is filled with the structureless matrix of the cornea.

membrane of Descemet. After it ${ }^{1}$ has become completely established, the mesoblast around the edge of the cornea becomes divided into two strata; an inner one (fig. $290(b)$ destined to form the mesoblastic tissue of the iris already described, and an outer one (fig. $290 \mathrm{cc}$ ) adjoining the epidermis. The outer stratum gives rise to the corneal corpuseles, which are the only constituents of the comea not yet developed. The corneal corpuscles make their way through the structureless corneal layer, and divide it into two strata, one adjoining the epiblast, and the other adjoining the inner epithelium. The two strata become gradually thinner as the corpuscles invade a larger and larger portion of their substance, and finally the outermost portion of them alone remains as the membrana elastica anterior and posterior (Descemet's membrane) of the cornea. The corneal corpuscles, which have grown in from the sides, thus form a layer which becomes continually thicker, and gives rise to the main substance of the cornea.

1 It appears to me possible that Licberkihn nay be right in stating that the epithelium of Descemet's membrane grows in between the lens and the epiblast before the formation of the cornea proper, and that Kessler's account, given above, may on this point require correction. From the structure of the eye in the Ammoccete it seems probable that Descemet's membrane is continuous with the choroid. 
Whether the increase in the thickness of the layer is due to the immigration of fresh corpuscles, or to the division of those already there, is not clear. After the cellular elements have made their way into the comea, the latter becomes continuous at its edge with the mesoblast which forms the sclerotic.

The derivation of the original structureless layer of the cornea is still uncertain. Kessler derives it from the epiblast, but it appears to me more probable that Kölliker is right in regarling it as derived from the mesoblast. The grounds for this view are, (1) the fact of its growth inwards from the border of the mesoblast round the edge of the eve, $\left({ }^{2}\right)$ the peculiar relations between it and the corneal corpuseles at a later period. This view would receive still further support if a layer of mesollast between the lens and the epiblast were really present as believed by Lieberkiihn. It must however be admitted that the objections to Kessler's view of its epiblastic nature are rather " priori than founded on definite observation.

The observations of Kessler, which have been mainly followed in the ahove account, are strongly opposed by Lieberkühn (No. 374) and Amold (No. 370), and are not entirely accepted by kolliker. It is especially on the development of these parts in Mammalia (to be spoken of in the sequel) that the above anthors foumd their oljections. I have had though Kessler's kindness an opportunity of looking througl some of his heautiful preparations, and have no hesitation in generally accep,ting his conclusions, though as mentioned ahove I cannot agree with all his interpretations.

The aqueous humour. The carity for the aqueous humour has its origin in the ring-shaped space romnd the front of the lens, which, as already mentioned, is bounled by the external skin, the edge of the optic cup, and the lens. By the formation of the cornea this space is shut off from the external skin, and on the appearance of the epithelioid layer of Descemet's membrane a continuous cavity is developed between the cornea and the lens. This cavity enlarges and receives its firal form on the full development of the iris.

\section{Comparative view of the development of the Vertebrate Eye.}

The organ of rision, when not stcondarity abortert, contains in all Vertebrata the essential parts abore described. The most interesting cases of partial degeneration are those of Mysine and the Ammocete. The derelopment of such aborted eyes has as yet been studied only in the Ammocete 1 , in which it restmbles in most importane features that of other Vertebrata.

Eye of Ammocœtes. The optic vesicle arises as an outgrowth of the fore-brain, but the secondary optic cup, is remarkable in the young larva for its small size (fig. $291 \mathrm{opc}$ ). The thicker outer wall gives rise to the retina, and the thinner inner wall to the ehoroid pigment. The lens is formed as an invagination of the single-layered epidermis (fig. 291 l). As develop ment proceeds the parts of the eye gradually enlarge, and the mesoblast around the hinder and dowal part of the optic cup becomes pigmented. There is at first no cavity for the vitreous humour, but erentually the

1 The most detailed account is that of W. Mäller (No. 37-). 
growth of the optic cup gives rise to a space, into which a cellular process of mesoblast grows at a slight notch in the ventral edge of the optic cup (W. Müller, No. 377). This notch is the only rudiment of the choroid fissure of other types. The mesoblastic

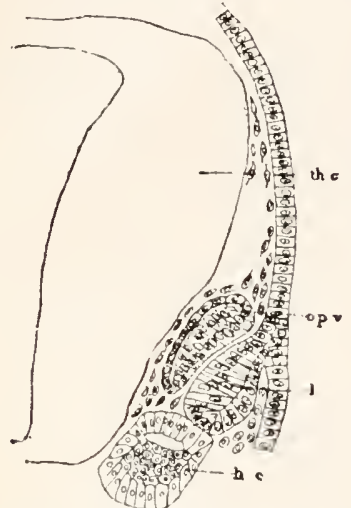

Fig. 291. Horizontal section THROUGH THE HEAD OF A JEST hatched LARVA OF PETROMYZON SHEWING THE DEVELOPMENT OF THE LENS OF TIIE EYE.

th.c. thalamencephalon; op.r. optic vesicle; l. lens of eye; h.c. head cavity.

fectly sepiarated from the remainder of the optic cup; and a mesoblastic element of the iris, distinct from Descemet's membrane ( $(\mathrm{m})$ ), can hardly be spoken of.

There is no cavity for the aqueous humour in front of the lens; and there is no cornea as distinct from the epidermis and subepidermic tissues. The elements in front of the lens are (1) the epidermis $(e p) ;(2)$ the dermis (dc); (3) the subdermal comnective tissue $(s d c)$ which passes without any sharp line of demarcation into the dermis; (4) a thick membrane, continuous with the mesoblastic part of the choroid, which appears to represent Descemet's membrane. 'The sublermal connective tissue is continued as an investment round the whole eye; and there is no differentiated sclerotic and only an imperfect chorvid.

In a still later stage a distinct mesoblastic element for the iris is formed. When the Ammocete is becoming a Lamprey, the eye approaches the surface; an anterior chamber is established; and the eye differs from that of the higher tyles mainly in the fact that the cornea is hardly distinguished from the remainder of the skin, and that a sclerotic is very imperfectly represented.

Optic vesicles. The development of the primitive optic vesicles, so far as is known, is very constant throughout the Vertebrata. In Teleostei and Lepidosteus alone is there an important deviation from the ordinary type, dependent however upon the mode of formation of the medullary keel, the optic vesicles arising while the medullary keel is still solid, and being at first also solid. They subsequently acquire a lumen and undergo the ordinary changes. 
The lens. In the majority of groups, viz. Elasmobranchii, Reptilia, Aves, and Mammalia, the lens is formed by an open invagination of the epiblist, but in Amphibia, Teleostei and Lepidosteus, where the nervous layer of the skin is early established, this layer alone takes part in the formation of the lens (tig. $293 l$ ). The lens is however formed even in these types as a hollow body by an invagination; lut its opening remains permanently shut off from communication with the exterior by the epidermic layer of the epiblast. Gutte describes the lens as formed by a solid thickening of the nervous laver in Bombinator. This is probahly a mistake.

The cornea. The mode of formation of the cornea already described appears to be characteristic of most Vertebrata except the Ammocoete. It has been found by Kessler in Aves, Reptilia and Amphibia, and probably also occurs in Pisces. In Mammals it is not however so easy to establish. There are at first no mesoblast cells between the lens and the epiblast (fig. 295) but in many Mammals (vide Kessler, No. 372, pp. 91-94) a layer of rounded mesoblast cells, which forms Descemet's nembrane, grows in between the two, at a time when it is not easy to recognise a comeal lamina, as distinct from a simple coagulum.

After the formation of this layer the mesoblast cells arow into the corneal lamina firom the sides, and becoming flattened arrange themselves in rows between the lamine of the cornea. The cornea continues to increase in thickness by the aldition of lamine on the side adjoining the epiblast.

We have already seen that in the Lamprey the cornea is nothing else but the slightly modified and more transprarent epilermis and dermis.

The optic nerve and the choroid fissure. It will be convenient to consider together the above structures, and with them the vascular and other processes which pass into the cavity of the optic cup through the choroid fissure. These parts present on the whole a greater amount of variation than any other parts of the eye.

I commence with the Fowl which is both a very convenient general type for comparison, and also that in which these structures have been must fully worked out.

During the third day of incubation there passes in through the choroid slit a vascular loop, which no doubt supplies the transuded material for the growth of the vitreous humour. Up to the fifth day this vasular 
loop is the only structure passing through the choroid slit. On this day however a new structure appears, which remains permanently through litis, and is known as the pecten. It consists of a lamellar process of the mesoblast cells round the eye, passing through the choroid slit near the optic nerve, and enveloping part of the afferent branch of the vascular loop above mentioned. The proximal part of the free edge of the pecten is somewhat swollen, and sections throngh this part have a elub-shaped form. On the sixth day the choroid slit becomes ripliclly closed, so that at the end of the sixth day it is rerluced to a mere seam. There are however two parts of this seam where the erlges of the optic cup have not cralesced. The proximal of these arljoins the optic nerve, and permits the passage of the pecten and at a later period of the optic nerve; and the second or distal one is placed near the ciliary erge of the slit, and is traversed by the efferent branch of the above-mentioned vascular loop. This ressel soon atrophies, and with it the distal opening in the choroid slit completely vanishes, In some varieties of domestic Fowl (Lieberkithn) the opening however persists. The seam which mitrs the original site of the choroid slit is at first conspicuous by the absence of pigment, and at a later period by the deep colour of its pigment. Finally, a little after the ninth day, no trace of it is to be seen.

$\mathrm{Up}$ to the eighth day the pecten remains as a simple lamina; by the tenth or twelfth day it begins to be folded or ather puckered, and

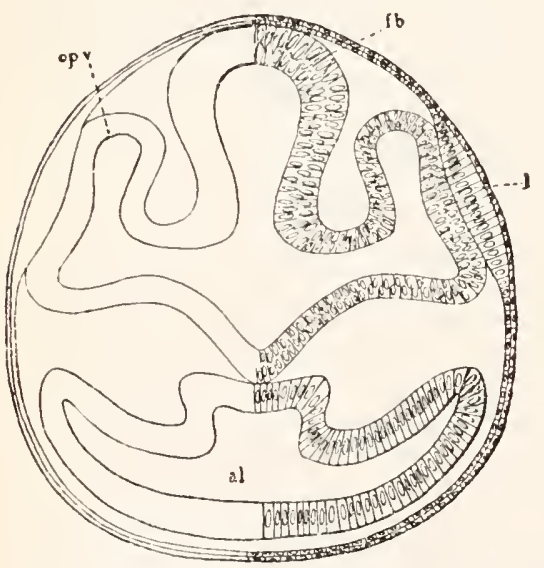

Fig, 293. SECTION THROUGH THE Froxt PART OF THE HEAD OF A LEPIDOSTEUS EMBRIO ON THE SEVENTH DAY AFTER MPREGNATION.

al. alimentary tract; $f b$, thalamencephalon; . lens of eye; op.t. optic vesicle. The mesoblast is not represented. the optic nerve, which is in immcliate proximity with the artery of the pecten, becontes folded. The permanent opening in the choroid fissure for the pecten is intimately related to the entrance of the optic nerve into the eyeball; the tibres of the optic nerve passing in at the inner border of the pecten, coursing along its sides to its outer border, and radiating from it as from a centre to all parts of the retina. day it is richly pigmented and the puckerings havebecome nearly as mumerous as in the adult, there being in all seventeen or eighteen. The pecten is almost entirely composed of vascular coils, which are supported by a sparse pigmented connective tissue; and in the adult the pecten is still extremely vascular. The original artery which became enveloped at the formation of the pecten continues, when the latter becomes vascular, to supply it with blood. The vein is practically a fresh development after the atrophy of the distal portion of the primitive vascular loop of the vitreous humour.

There are no true retinal blook-vessels. In the formation of the optic
cup the extreme peripheral part of hy the seventeenth or eighte'nth 
In the Lizard the choroid slit closes considerably earlier than in the Fowl. The vascular loop in the vitreous humour is however more dereloped. The pecten long remains without ressels, and does not in fact become at all vascular till after the very late disappearance of the distal part of the vascular loop of the vitreous liumour.

The arrangement of the ingrowth through the choroid slit in Elasmomanchii (Scyllium) has been partially worked out, and so far as is at present known the agreement between the Avian and Elasmobranch type is fairly close.

At the time when the cavity between the lens and the secondary optic cup is just commencing to be formed, a process of mesoblast accompanied by a viscular loop passes into the vitreous humour, through the choroid slit, close to the optic nelve. The vessel in this process is no doubt equivalent to the vascular loop in the Avian eyc, but I have not made ont that it projects beyond the mesoblastic process accompanying it. As the cavity of the vitreons humour enlarges and the choroid slit clongates, the process through it takes the form of a lamina with a somewhat swollen border, and projects for some distance into the cavity of the vitreous humour.

At a later stage, after the outer layer of the optic cup lias become pigmented, the distal part of the cloroid slit adjoining the horrler of the lens closes up; but along the line where it was present the walls of the optic cup remain very thin and are thrown into three folds, two lateral and one median, projecting into the cavity of the vitreous humour. The median fold is in contact with the lens, and the vascular mesoblast surrounding the eye projects into the sprace between the two laminæ of which it is formed. In passing from the region of the lens to that of the optic nerve the lateral folls of the optic cup disappear, and the median fold forms a considerable projection into the cavity of the vitreous humour. It consists of a core of mesoblast covered by a delicate layer derived from both strata of the optic cup. Still nearer the optic nerve the cloroid slit is no longer closed, and the mesoblast, which in the neighbourhood of the leus only extended into the folds of the wall of the optic cup, now projects freely into the cavity of the vitrcous humour, and forms the lamina already described. It is not rery vaseular, but close to the optic nerve there prasses into it a considerable artery.

In the young animal the choroid slit is no longer perforated by a mesoblastic lamina. At its inner end it remains open to allow of the passage of the optic nerve. The line of the slit can easily be tracer along the lowcr side of the retina; and close to the lens the retinal wall continues, as in the embryo, to be raised into a projecting fold. Traces of these structures are visible even in the fully grown cxanples of Scylium.

As has been pointed out by Bergmeister the mesoblastic lamina projecting into the vitreous humour resembles the pecten at an early stage of development, and is without doubt homologons with it. The artery which supplies it is certainly equivalent to the artery of the pecten.

There can be no doubt that the mesoblastic lamina projecting into the vitreons hmmour is equivalent to the processus falciformis of Teleostei, and it seems probable that the whole of it, including the free part as well as that covered hy epiblast, onght to be spoken of under this title. The optic nerve in Elasmobranchii is not inchuded in the folding to which the secondary optic vesicle owes its origin, and would seen to perforate 
the walls of the optic cup only at the distal end of the processus falciformis.

In Teleostei there is at first a vascular loop like that in Birds, passing through the choroid fissure. This has been noticed by Kessler in the Pike, and by Schenk in the Trout. At a later period a mesoblastic ingrowth with a blood-vessel makes its way in many forms into the cavity of the vitreous humour, accompanied by two folds in the walls of the free edges of the choroid fissure (fig. 294). These structures, which constitute the processus falciformis, clearly resemble very

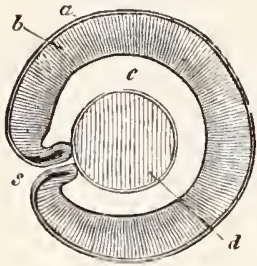

Fig. 294. Horizontal SECTION THROUGH THE EYE OF a Teleostean emibro. (From Gregenbaur; after Schenl.)

s. choroid fissure, with two folds forming part of the processus falciformis; $a$. choroid layer of optic eup; $b$. retinal layer of optic eup; $c$. cavity of vitreous humour; $d$. lens.

represented by a slight notch on the ventrat the choroid slit in most types is represented by a large cellular process, from which the vitreous humour would appear to be derived.

Mammalia differ from all the types aheady described in the immense fotal development of the blood-vessels of the vitreous humour. There are however some points in connection with the development of these vessels which are still uncertain. The most important of these points concerns the presence of a prolongation of the mesoblast around the eye into the cavity of the vitreous humour. It is maintained by Lieberkühn, Arnold, Köliker, etc., that in the invagination of the lens a thin layer of mesoblast is carried before it; and is thus transported into the cavity of the vitreous humour. This is denied by Kessler, but the layer is so clearly figured by thie above cmbryologists, that the existence of it in some Mammalia (the Rabbit, etc.) must I think be accepted.

In the folding in of the optic vesicle, which accompanies the formation of the lens, the optic nerve becomes included, and on the development of the cavity of the vitreous humour an artery, rumning in the fold of the optic nerve, passes through the choroid slit into the cavity of the vitreous humour (fig. $295 \mathrm{acr}$ ). The sides of the optic nerve subsequently bend over, and completely envelope this artery, which at a later period gives off branches to the retina, and becomes known as the arteria centralis retina. It is homologous with the arterial limb of the vascular loop projecting into the vitreous humour in Birds, Lizards, Teleostei, ctc.

Before becoming enveloped in the optic nerve this artery is continued 
through the vitreous humour (fig. 295), and when it comes in close

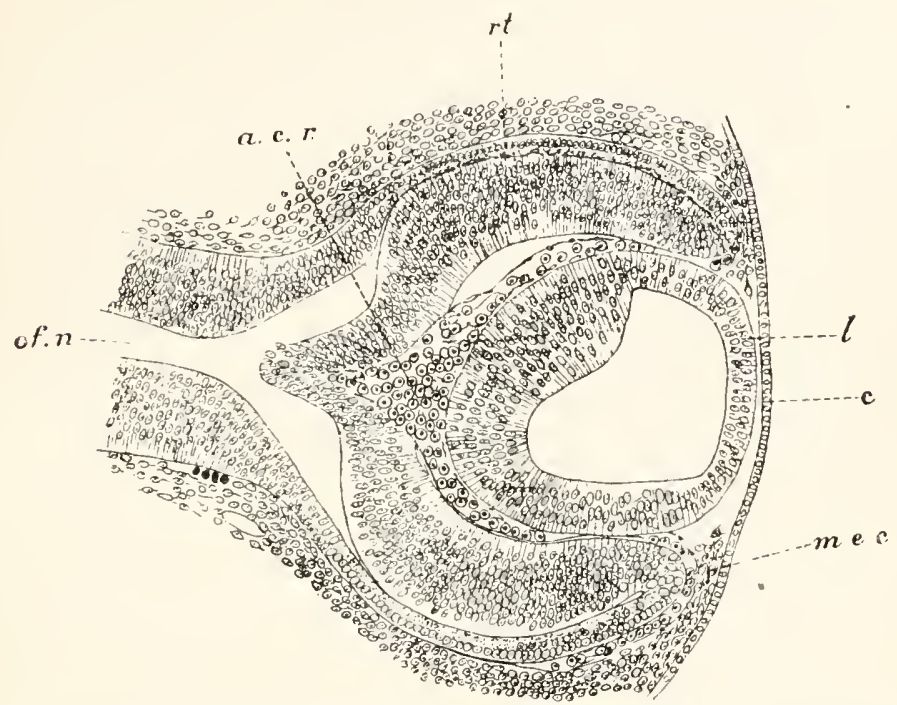

Fig. 295. Section throvgh the eye of a Rabbit embryo of about twelve days.

c. epithelium of cornea; $l$. lens; mec. mesoblast growing in from the side to form the cornea; rt. retina; a.c.r. arteria centralis retine; of.n. optic nerve.

The figure shews (1) the absence at this stage of mesoblast between the lens and the epiblast: the interval between the two has however been made too great; (2) the arteria centralis retine forming the vascular capsule of the lens and continuous with vascular structures round the edges of the optic cup.

proximity to the lens it divides into a number of radiating branches, which pass round the edge of the lens, and form a vascular sheath which is prolonged so as to cover the anterior wall of the lens. In front of the lens they anastomose with vessels, coming from the iris, many of which are venous (fig. 295) - and the whole of the blood from the arteria centralis is carried away by these veins. The vascular sheath surrounding the lens receives the name of the membrana capsulo-pupillaris. The posterior part of it appears (Kessler, No. 372) to be formed of vessels without the addition of any other structures, and is either formed simply by branches of the arteria centralis, or out of the mesoblast cells involuted with the lens. The anterior part of the vascular sheath is however inclosed in a very delicate membrane, the membrana pupillaris, continuous at the sides with the epithelium of Descemet's membrane. On the formation of the iris this membrane lies superficially to it, and forms a kind of continuation of the mesoblast of the iris over the front of the lens.

The origin of this membrane is much disputed. By Kessler, whose statements have been in the main followed, it is believed to appear comparatively late as an ingrowth of the stroma of the iris; while Kölliker believes it to be derived from a mesoblastic ingrowth between the front wall of the lens and the epiblast. According to Kolliker this ingrowth subsequently becomess split into two lamine, one of which forms the cornea, 
and the other the anterior part of the vascular sheath of the lens with its membrana pupillaris. Between the two appears the aqueous hmmour.

The membrana capsulo-pupillaris is simply a provisional embryonic structure, subserving the nutrition of the lens. The time of its disappearance varies somewhat for the different Mammalia in which this point has been investigated. In the human embryo it lasts from the second to the seventh month and sometimes longer. As a rule it is completely absorbel at the tine of birth. The absorption of the anterior part commences in the centre and proceeds outwards.

In addition to the vessels of the vascular caljsule round the lens, there arise from the arteria centralis retine, just after its exit from the optic nerve, in many forms (Dog, Cat, Calf, Sheep, Rahbit, Man) provisional vaseular buanches which extend themselves in the posterior part of the vitreous humour. Near the ciliary end of the vitreous humour they anastomose with the vesvels of the membrana capsulo-pupillaris.

In Mammals the choroid slit closes very early, and is not perforated by any structure lomologous with the pecten. The only part of the slit which remains open is that perforated by the optic nerve; and in the centre of the latter is situated the arteria centralis retina as explained above. From this artery there grow out the vessels to supply the retina, which have however nothing to do with the provisional vessels of the vitreous humour just described (Kessler). On the atrophy of the provisional vessels the whole of the blood of the arteria centralis passes into the retina.

It is interesting to notice (Kesier, $\mathrm{N}(1.372, \mathrm{P} .78$ ) that there seems to be a blood-vessel smplying the vitreous humour in the embryos of nearly all vatebrate types, which is lomologous throughout the Vertebrata. This vessel often exhibits a persisting and a provisional part. The latter in Mammalia is the membrana capsulo-pupillaris and other vessels of the vitreous humour; i:l Birds and Lizards it is the prart of the original vascular loop, not includerl in the pecten, and in Osseous Fishes that part (?) not involved in the processus falciformis. The permanent part is formed by the retinal vessels of Mammalia, by the vessels of the pecten in Birds and Lizards, and by those of the processus falciformis in Fishes.

The Iris and Ciliary processes. The walls of the edge of the optic cup become rery much thinner than those of the true retinal part. In many Vertebrates (Mammalia, Aves, Reptilia, Elasmobranchii, etc.) the thinner part, together with the mesoblast covering it, becomes divided into two regions, iz. that of the iris, and that of the ciliary processes. In the Newt and Lamprey this differentiation does not take place, but the part in question simply becomes the iris.

\section{Accessory Organs connected with the Eye.}

Eyelids. The most importiut accessory structures connected with the eye are the eyelids. They are developed as simple folds of the integument with a mesoblastic prolongation between their two lamine. They may be three in number, viz. an upper and hower, and a lateral one-the nictitating membrane-springing from the imner or anterior border of the eye. Their inner face is lined by a prolongation of enjunctiva, which is the modified "piblast covering the cornea and part of the sclerotic. 
In 'Teleontei and Ganoilei evelids are either not pesent or at most very rudimentary. In Elasmobranchii they are better developed, and the nictitating nembrane is frequently present. The latter is also usually found in Amplibia. In the Samopsida all three eyelids are usually present, but in Mammalia the nictitating membrane is rudimentary.

In many Mammalia the two eyelids meet together during a period of embryonic life, and unite in front of the eye. A similar arrangement. is permanent through life in Ophirlia and some Latcertilia; and there is a chamber formed between the coalesced eyelids and the surfice of the cornea, into which the lacrymal ducts open.

Lacrymal glands. Lacrymal glinds are found in the Siutopisida and Mammalia. They arise (Remak, Kölliker) as solid ingrowths of the conjunctival epithelium. They appear in the chick on the eighth day.

Lacrymal duct. The lacrymal duct tirst appears in Amphibia, and is present in all the higher Vertebrates. Is mode of development in the Amphibia, Lacertilia and Aves has recently been very thoroughly worked out by Born (Nos. 3 So and $3 S_{1}$ ).

In Amphibia lie tiuds that the lacrymal duct arises as a solid ridge of the mucous layer of the epidermis, continued from the external opening of the nasal cavity backwards towards the eye. It usually appears at about the time when the nasal capsule is beginning to be chondritied. As this ridge is gradually prolonged backwards towards the eye its anterior. end becones separated from the epidermis, and grows inwards in the. mesoblast to become continuous with the posterior jatrt of the nasal sack. The posterior end which joins the eye becomes divided into the two collecting branches of the adult. Finally the whole structure becomes separated from the skin except at the external opening, and hevelops a hmen.

In Lacertilia the lacrymal duct arises rery much in the same manner as in Amphibia, though its subsequent growth is somewhat different. It appears as an internal ridge of the epithelium, at the junction of the superior maxillary process and the fold which gives rise to the lower eyelid. A solit process of this ridge makes its way through the mesoblast on the upper border of the maxillary process till it meets the wall of the nasal cavity, with the epithelium of which it becomes continuous. At a subsequent stage a second solid growth from the upper part of the epithelial ridge makes its way through the lower eyelid, and unites with the inner epithelium of the eyelid; and at a still later date a third growth from the lower part of the structure forms a second junction with the epithelium of the eyelid. The two latter outgrowths form the two npper branches of the duct. The ridge now loses its comnection with the external skin, and, becoming hollow, forms the lacrymal duct. It opens at two points on the inner surface of the eyelid, and terminates at its opposite extremity by opening into the nasal cavity. It is remarkable, as pointed out by Born, that the original epithelial ridge gives rise directly to a comparatively small part of the whole duct.

In the Fowl the lacrymat duct is formed as a solid ridge of the epidermis, extending along the line of the so-called lacrymal groove fiom the eye to the nasal pit (fig. 120). At the end of the sixth day it begins to be separated from the epidemis, remaining however united with it on the inner sile of the lower eyclid. After its separation from the epidermis it forms a solid cord, the lower end of which unites with the wall of the

B. E. II. 
nasal cavity. The cord so formed gives rise to the whole of the duct proper and to the lower branch of the collecting tube. The upper branch of the collecting tube is formed as an outgrowth from this cord. A lumen begins to be formed on the twelfth day of incubation, and first appears at the nasal end. It arises by the formation of a space between the cells of the cord, and not by an absorption of the central cells.

In Mammalia Kölliker states that he has been unable to observe anything similar to that described by Born in the Sauropsida and Amphibia, and holds to the old view, originally put forward by Coste, that the duct is formed by the closure of a groove leading from the eye to the nose between the outer nasal process and the superior maxillary process. The upper extremity of the duct dilates to form a sack, from which two branches pass off to open on the lacrymal papillæ. In view of Born's discoveries Kölliker's statements must be received with some cantion.

\section{The Eye of the Tunicata.}

The unpaired eye of the larva of simple Ascidians is situated somewhat to the right side of the posterior part of the dorsal wall of the anterior cephalic vesicle (fig. 296,0 ). It consists of a refractive portion, turned towards the cavity of the vesicle of the brain, and a retinal portion forming part of the wall of the brain. The refractive parts consist of a convex-concave meniscus in front, and a spherical lens behind, adjoining the concave side of the meniscus. The posterior part of this lens is imbedded in a layer of pigment. 'The retina is formed of columnar cells, with their inner ends imbedded in the pigment

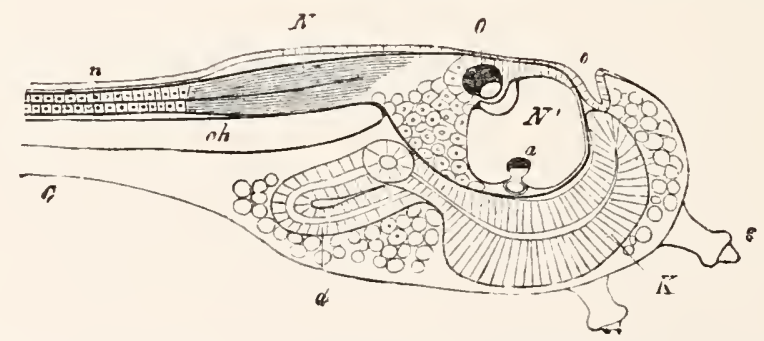

Fig. 296. Larva of Ascidia mentula. (From Gegenbaur; after Kupffer.) Only the anterior part of the tail is represented.

$N^{\prime}$. anterior swelling of neural tube; $N$. anterior swelling of spinal portion of neural tube; $n$. hinder part of neural tube; $c h$. notochord; $K$. branchial region of alimentary tract; $d$. œsophageal and gastric region of alimentary tract; $O$. eye ; a. otolith; o. mouth; s. papilla for attachment.

which encloses the posterior part of the lens. The retinal part of the eye arises in the first instance as a prominence of the wall of the cerebral vesicle: its cells become very columnar and pigmented at their inner extremities (fig. $8 V, a$ ). The lens is developed at a later period, after the larva has become hatched, but the mode of its formation has not been made ont. 


\section{General considerations on the Eye of the Chordatu.}

There can be but little doubt that the eye of the Tunicata belongs to the same phylum as that of the true Vertebrata, different as the two eves are. The same may also be said with reference to the degenerate and very rudimentary eye of Amphioxus.

The peculiarity of the eye of all the Chordata consists in the retini being developed from part of the wall of the brain. How is this remarkable feature of the eye of the Chordata to be explained?

Lankester, interpreting the eye in the light of the Tunicata, has made the interesting suggestion "that the original Vertebrate must have been a transparent animal, and had an eye or pair of eyes inside the brain, like that of the Ascidian Tadpole."

T'lis explanation may possibly be correct, but another explanation appears to me possible, and I am inclined to think that the vertebrate eyes liave not been drrived from eyes like those of Ascidians, but that the latter is a degenerate form of vertebrate eye.

The fact of the retina being derived from the fore-brain may perhaps be explained in the same way as has already been attempted in the case of the retina of the Crustacea; i.e. by supposing that the eye was evolved simultaneously with the fore pitrt of the brain.

The peculiar processes which occur in the formation of the optic vesicle are more difficult to elucidate; and I can only suggest that the development of a primary optic vesicle, and its conversion into an optic cup, is due to the retinal part of the eye having been involved in the infolding which gave rise to the canal of the central nervous system. The position of the rods and cones on the posterior side of the retina is satisfactorily explained by this hypothesis, because, as may be easily seen from figure 285 , the posterior face of the retina is the original external surface of the epidermis, which is infolded in the formation of the brain; so that the rods and cones are, as might be anticipated, situated on what is morphologically the exterual surface of the epiblast of the retina.

The difficulty of this view arises in attempting to make out how the eye can have continued to be employed during the gradual change of position which the retina must have undergone in being infolded with the rrain in the manner suggested. If however the successive steps in this infolding were sufficiently small, it seems to me not impossible that the eye might have continued to be used throughout the whole period of change, and a transparency of the tissues, such as Lankester suggests, may have assisted in rendering this possible.

The difficulty of the eye continning to be in use when undergoing striking changes in form is also involved in Lankester's view, in that if, as I suppose, he starts from the eye of the Ascidian Tadpole with its lenses tmmed towards the cavity of the brain; it is nectssary for him to admit that a fresh lens and other optical parts of the eye became developed on the opposite side of the eye to the original lens; and it is difficult to understand such a change, unless we can believe that the refractive media on the two sides were in operation simultaneously. It may be noted that the same difficulty is involved in supposing, as I have done, that the eye of the Ascidian Tadpole was developed from that of a Vertebrate. I sloould

1 Degeneration, London, 1880, p. 49. 
however be inclined to suggest that the eye had in this case ceased for a period to be employed; and that it has been re-developed again in some of the larval forms. Its characters in the Tunicata are by no means constant.

\section{Accessory eyes in the Vertebrata.}

In addition to the paired eyes of the Vertebrata certain organs are found in the skin of a few Teleostei living in very deep water, which, though clearly not orgars of true vision, yet present characters which indicate that they may be used in the perception of light. The most important of such organs are those found in Clatuliodns, Stomias, etc., the significance of which was first pointed out by Leuckart, while the details of their structure have been recently worked ont by Leydig and Ussow. They are distributed not only in the skin, but are also present in the mouth and respiratory cavity, a fact which appears to indicate that their main function must be something else than the perception of light. It has been suggested that they have the function of producing phosphorescence.

Another organ, probably of the same nature, is found on the head of Scopelus.

The organs in Chatuliodus are spherical or nearly spherical bodies inrested in a special tunic. The larger of them, which alone ean have any relation to vision, are covered with pigment except on their outer surface. The interior is filled with two masses, nlamed by Lenckart the lens and vitreous humour. According to Leydig each of them is cellular and receives a nerve, the ultimate destination of which has not however been made out. According to Ussow the anterior mass is structureless, but serves to support a lens, placed in the centre of the eye, and formed of a series of crystalline cones prolonged into tibres, which in the posterior part of the eye diverge and terminate by uniting with the processes of multipolar cells, placed near the pigmented sheath. These cells, together with the fibres of the crystalline cones which pass to them, are held by Ussow to constitute a retina.

\section{Eye of the Mollusca.}

(362) N. Bobretzky. "Observations on the development of the Cephalopoda" (Russian). Nachrichten d. Kaiserlichen Gesell. d. Freunde der Nuturuiss. Anthropolog. Ethnogr. bei d. Unirersität Moskau.

(363) H. Grenacher. "Zur Entwicklungsgeschichte d. Cephalopoden." Zeit.f. wiss. Zool., Bd. xxıv. 1874.

$\left(3_{4}\right)$ V. Hensen. "Ueber d. Auge einiger Cephalopoden." Zeit. f. wiss. Zool., Vol. xv. 1865.

(365) E. R. Lankester. "Observations on the development of the Cephalojoda." Quart. J. of Micr. Science, Vol. xv. 1875. 1877 .

(366) C. Semper, Ueber Sehorgane von Typus d. Wirbelthieraugen. Wiesbades,

1 F. Leydig. "Ueber Nebenaugen d. Chauliodus Sloani." Archiv f. Anat. und Phys., 1879. M. Ussow. "Ueb. d. Bau d. augenähnlichen Fiłcken einiger Knochenfische." Bul. d. la Soc. d. Nuturalistes de Moscou, Vol. Liv. 1879. Vide for general description and further literature, Giinther, The Study of Fishes, Edinburgh, 1880. 


\section{Eige of the Arthropoda}

(36-) N. Bobretzky. Development of Astacus and Pulaemon. Kiew, 1873.

(3,s) A. Dohrn. "Untersuchungen üb. Bau u. Fntwicklung d. Arthropoden. I'alinurus und Seyllarus." Zeit.f. wiss. Zool., Bd. xx. 1870, p. 264 et seq.

(369) E. Claparède. "Miorphologie d. zusanmengesetzten Auges bei den Arthropoden." Zeit.f. wiss. Zool., Bd. x. 1860.

(370) H. Grenacher. Untersuchungen üb. d. Sehorgane d. Arthropoden. Göttingen, 1879.

\section{l'ertebrate Eye.} $187 \pm$

(37r) J. Arnold. Beitrïge zur Entwickhunasgeschichte des Auges. Heidelberg,

(3;2) Babuchin. "Beiträge zur Entwicklungsgeschichte des Auges." Würzburger naturwissenschaftliche Zeitschrift, Bd. 8.

(373) L. Kessler. Zur Entriclilung d. Auges d. Wirbelthiere. Leipzig, 1877.

$\left(37 t^{)}\right.$N. Lieberkïlın. Ueber das Auge des Iriblthierembryo." Cassel, 1872.

$(375)$ N. Lieberkühn. "Beitrüge z. Anat. d. embryonalen Auges." Archiv f. Anat. und Pliys., 1879 .

(376) L. Löwe. "Beiträge zur Anatomie des Auges" and "Die Histogenese der Retina." Archin $f$ mikr. Anat., Vol. xv. 1878.

(377) V. MiLalkowies. "Untersuchungen ïber den Kamm des Vogelauges." Archir f. mikr. Anat., Vol. Ix. 1873.

$(378)$ W. Miiller. "Ueber die Stammesentwickelung des Sehorgans der Wir. belthiere." Festgabe Carl Ludwig. Leipzig, 1874.

(.379) S. L. Schenk. "Zur Entwickelungsgeschichte des Auges der Fische." Wiener Sitzungsberichte, Bd. Lv. 1867.

\section{Accessory organs of the Vertebrate Eye.}

(380) (G. Born. "Die Nasenhöhlen u. d. Thränennasengang d. Amphibien." Morphologisches fahrbuch, Bd. I1. 1876.

(.81) G. Born. "Die Nasenhöhlen u. d. Thränennasengang d. amnioten Wirbelthiere. I. Lacertilia, II. Aves." Morthologisches Jahrbuch, Bd. v. 1879.

\section{Eye of the Tunicutu.}

$\left({ }_{i} S_{2}\right)$ A. Kowalevsky. "Weitere Studien iib. d. Entwicklung d. einfachen Ascidien." Arehiv f. mikr. Amat, Vol. vir. 1871.

(383) C. Knpffer. "Zur Entwicklung d. einfachen Ascidien." Arehiv f. mikr. Anat., Vol. v11. 1872. 


\section{('HAP'IER XVII.}

\section{AUDITORY ORGAN, OLFAC'TORY ORGAN AND SENSE ORGANS OF THE LATERAL LINE.}

\section{Auditory Uigans.}

A (iREAT variety of organs, very widely distributed amongst aquatic forms, and also found, though less universally, in land forms, are usually classed together as auditory organs.

In the case of all aquatic forms, or of forms which have directly inherited their auditory organs from aquatic forms, these organs are built upon a common type; although in the majority of instances the auditory organs of the several groups have no genetic relations. All the organs have their origin in specialized portions of the epidermis. Some of the cells of a special region become provided at their free extremities with peculiar hairs, known as auditory hairs; while in other cells concretions, known as otoliths, are formed, which appear often to be sufficiently free to be acted upon by vibrations of the surrounding medium, and to be so placed as to be able in their turn to transmit their vibrations to the cells with auditory hairs". The auditory regions of the epidermis are usually shut off from the surface in special sacks.

The actual function of these organs is no doubt correctly described, in the majority of instances, as being auditory; but it appears to me very possible that in some cases their function may be to enable the animals provided with them to detect the presence of other animals in their neighbourhood, through the undulatory movements in the water, caused by the swimming of the latter.

Auditory organs with the above characters, sometimes freely open to the external medium, but more often closed, are found in various Coelenterata, Vermes and Crustacea, and universally or all but iniversally in the Mollusca and Vertebrata.

1 The function of the otoliths is not always clear. There is evidence to shew that they sometimes act as dampers. 
In many terrestrial Insects a different type of auditory organ has been met with, consisting of a portion of the integument modified to form a tympanum or clrum, and supported at its edge by a chitinous ring. The vibrations set $11 \mathrm{p}$ in the membranous tympanum stimulate terminal nerve organs at the ends of chitinous processes, placed in a cavity bounded externally by the tympanic membrane.

The tympanum of Amphibia and Amniota is an accessory organ added, in terrestrial Vertebrata, to an organ of hearing primitively alapted to an aquatic mode of life; and it is interesting to notice the presence of a more or less similar membrane in the two great groups of terrestrial forms, i.e. terrestrial Vertehrata and Insecta.

Nothing is known with reference to the mode of development or evolution of the tympanic type of auditory organ fonnd in Insects, and, except in the case of Vertebrates, but little is known with reference to the development of what may be called the vesicular type of auditory organ found in aquatic forms. Some very interesting facts with reference to the evolution of such organs have however been brought to light by the brothers Hertwig in their investigations on the Cielenterata; and I propose to commence my account of the development of the anditory organs in the animal kingdom by a short statement of the results of their researches.

Colenterata. 'Three distinct types of auditory organ have been recognised in the Medusæ; two of them resulting from the differentiation of a tentacle-like organ, and une from ectorlerm cells on the under surface of the velum. We may commence with the latter as the simplest. It is found in the Neduse known as the Vesiculata. The least differentiated form of this organ, so far lis. covered, is present in Mitrotrocha, 'Tiaropsis and other genera. It has the form of an open pit; and a series of such organs are situated along the attached elge of the velum with their apertures directed downwards. The majority of the cells lining the outer, i.e peripheral side of the pit, contain an otolith, while a row of the cells on the inner, i.e. central side are moditied as auditory cells. The auditory cells are somewhat strap-shaped, their inner ends being continuous with the fibres

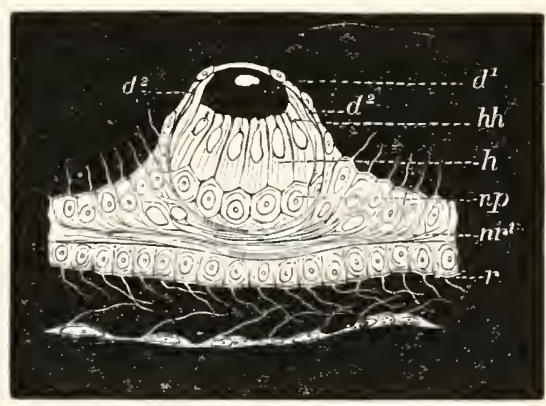

Fig. 297. Auntury vesicle of Phialidiem after TreatMeNT With DILCte OSMC ACid. (From Lankester; after $\mathrm{O}$. and R. Hertwig.)

$d^{2}$. epithelium of the upper surface of the velum; $d^{2}$. epithelium of the under surface of the velum; $r$. circular canal at the ellge of the velum; $n r^{-1}$. upper nerve-ring; $h$. auditory cells; $h$. auditory hairs; $n p$. nervous eushion formed of a prolongation of the lower nerve-ring. Close to the nerve-ring is seen a cell, shewn as black, containing an otolith. 
of the lower nerve-ring, and their free ends being provided with bent anditory hairs, which lie in contact with the convex surfaces of the cells containing the otoliths.

By the conversion of such open pits into closed sacks a more complicated type of auditury organ, which is present in many of the Vesiculata, viz. Aqquorea, Octorchis, Phialidium, \&c., is produced. A closed vesicle of this type is shewn in fig. 297. Such organs form projections on the upper surface of the velum. They are covered by a layer of the epithelium $\left(d^{1}\right)$ of the upper surface of the velum, bnt the lining of the vesicle $\left(d^{2}\right)$ is derived from what was originally part of the epithelium of the lower surface of the rehm, homologous with that lining the open pits in the type already described. The general arrangement of the cells lining such vesicles is the same as that of the cells lining the open pits.

A second type of anditory organ, found in the Trachymeduse, appears in its simplest condition as a modified tentacle. It is formed of a basal portion, covered

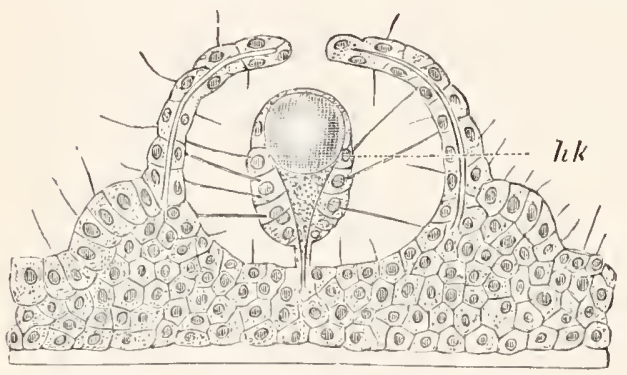

Fic. 29. Audtori organ of Rhopalonema,

(From Lankester; after O. and R. Hertwig.)

The organ consists of a molified tentacle ( $h k$ ) with auditory cells and concretions, partially enclosed in a eup. by auditory cells with long stiff auditory hairs, supporting at its apex a club-shaped borly, attached to it by a delicate stalk. An endodermal axis is continued through the whole structure, and in one or more of the endoderm cells of the chub-shaped body otoliths are always present. The tails of the auditory cells are directly continued into the upper nerve-ring.

In more complicaterl forms of this organ the tentacle becomes enclosed in a kind of cup, by a wall-like mpgrowth of the surrounding parts (fig. 298); and iu some forms, e.g. Geryonia, by the closure of the cup, the whole structure takes the form of a completely closed vesicle, in the cavity of which the original tentacle forms an otolith-bearing projection.

The anditory organs found in the Acraspedote Medusæ approach in many respects to the type of organ found in the Trachymedusæ. They consist of tentacular organs placed in grooves on the under surface of the disc. They have a swollen extrenity, and are provided with an endodermal axis for half the length of which there is a diverticulum of the gastro-vascular canal system. The terminal portion of the entoderm is solid, and contains calcareous concretions. The ectorlermal cells at the base of these organs have the form of auditury cells.

Mollusca. Anlitory resicles are fomnd in almost all Mollusca on 
the ventral side of the body in close juxtaposition to the pedal ganglia. Except possibly in some Cephalopods, these vesicles are closed. They are provicled with free otoliths, supported by the cilia of the walls of the sack, but in addition some of the ce!ls of the sack are provided with stiff auditory hairs.

In many forms these sacks have been observed to originate by an invagination of the epiblast of the foot (Paludina, Nassa, Heteropode, Limax, Clio, Cephalopoda and Lamellibranchiata). In other instances (some Pteropods, Lymmæus, \&c.) they appear, by a secondary modification in the development, to originate by a differentiation of a solid mass of epiblast.

According to Fol the otocysts in Gasteropods are formed by cells of the wall of the auditory sacks; and the same appears to hold good for Cephalopoda (Grenacher)' shewing that free otoliths have in these instances originated from otoliths originally placed in cells.

Crustacea. In the decapodous Crustricea organs, which have been experimentally proved to be true organs of hearing, are usually present on the basal joint of the anterior antennæ. They may have (Hensen, No. $3{ }_{4}$ ) the form either of closed or of open sacks, lincel by an invagination of the epidermis. They are provided with chitinons auditory hairs and free otoliths. In the case of the open sacks the otoliths appear to be simply stones transported into the interior of the sacks, lut in the closed sacks the otoliths, though free, are no drubt developed within the sacks.

The Schizopods, which, as mentioned in the last chapter, are remarkahle as containing a genus (Euphausia) with abnormally situated eyes, distinguish themselves again with reference to their auditory organs, in that another genus (Mysis) is characterized by the presence of a pair of anditory sacks in the inner plates of the tail. These sacks have curved auditory hairs supporting an otolith at their extremity.

The development of the auditory organs in the Crustacea has not been investigated

The Vertebrata. The Cephalochorda are without organs of hearing, and the anditory rrgan of the Urochorda is constructed on a special type of its own. The primitive aurlitny organs of the true Vertebrata lave the same fundamental characters as those of the majority of aquatic invertebrate forms. They consist of a vesicle, formed by the invagination of a patch of epiblast, and usually shut off from the exterior, but occasionally (Elasmobranchii) remainiug open. The walls of this vesicle are always much complicated and otoliths of various forms are present in its cavity. To this vesicle accessory structures, derived from the walls of the hyomandibular cleft, are added in the majority of terrestrial Vertebrata.

The development of the true auditory vesicle will be considered separately from that of the accessury structures derived from the hyomandibular cleft.

1 For the somewhat complicated details as to the development of the auditory sacks of Cephalopots I must refer the reader to Vol. I., 1.p. 230, 231, and to (irenacher (Vol. 1., No. 280). 
In all Vertebrata the development of the auditory vesicle commences with the formation of a thickened patch of epiblast, at the sile of the hind-brain, on the level of

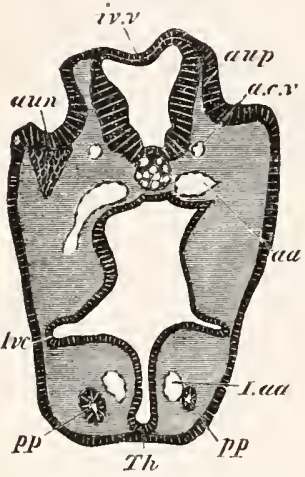

Hig. 299. SECTiON THROUGH THE HEAD OF AN ELASMOBRANCH EMBRYO, AT THE LEVEL OF THE ACDITORY IXYOLUTION.

amp. auditory pit; aun. ganglion of auditory nerve; iv.r. roof of fourth rentricle; a.c.r. anterior cardinal rein; aa. aorta; I.a . aortic trunk of mandibular arch: $p p$. head cavity of mandibular arch; Ivc. alimentary pouch which will form the first visceral cleft; $T h$. rudiment of thyroid body. the second visceral cleft. 'This patch soon becomes invaginated in the form of a pit (fig. 29.9 (uxp), to the imner side of which the ganglion of the auditory nerve (aun), which as shewn in a previous chapter is primitively a branch of the seventh nerve, closely applies itself.

In those Vertebrata (viz. Teleostei, Lepidosteus and Amphibia) in which the epiblast is early divided into a nervous and epidermic stratum, the anditory pit arises as an invagination of the nervous stratum only, and the mouth of the auditory pit is always closed (fig. 300) by the epidermic stratum of the skin. Since the opening of the pit is retained through life in Elasmobranchii the closed form of pit in the above forms is clearly secondary.

In Teleostei the auditory pit arises as a solid invagination of the epiblast.

The mouth of the auditory vesicle gradually narrows, and in most forms soon becomes closed, though in Elasmobranchii it remains permanently open. In any case the vesicle is gradually removed from the sulface, remaining connecterl with it by an elongated duct, either opening on the dorsal aspect of the head (Elasmobranchii), or ending blindly close beneath the skin.

In all Vertebrata the anditory vesicle undergoes further changes

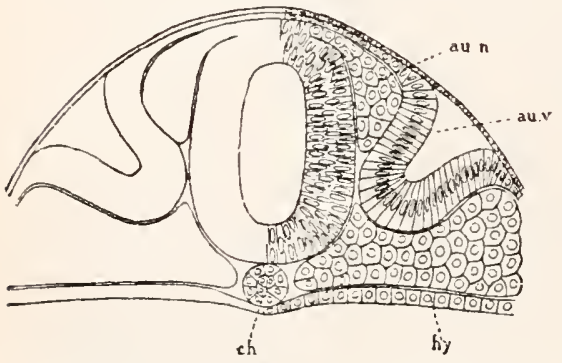

Fig. 300. Section throvgh the he.d of A Lepidosteus EMeryo on the S1XTh DAY AFTER IMPREGNATION.

au.c. auditory vesicle; au.n. auditory nerre; ch. notochorl; hy. hrpoblast. of a complicated kind. In the Cyclostomata these changes are less complicated than in other forms, though whether this is due to degeneration, or to the retention of a primitive state of the auditory organ, is not known. In the Lamprey the auditory vesicle is formed in the usual way by an invagination of the epiblast, which soon becomes vesicular, and for a considerable period retains a simple character. As pointerl out by Max Schultze, 
a number of otoliths appears in the vesicle during larval life, and, although such otoliths are stated by J. Miiller to be absent both in

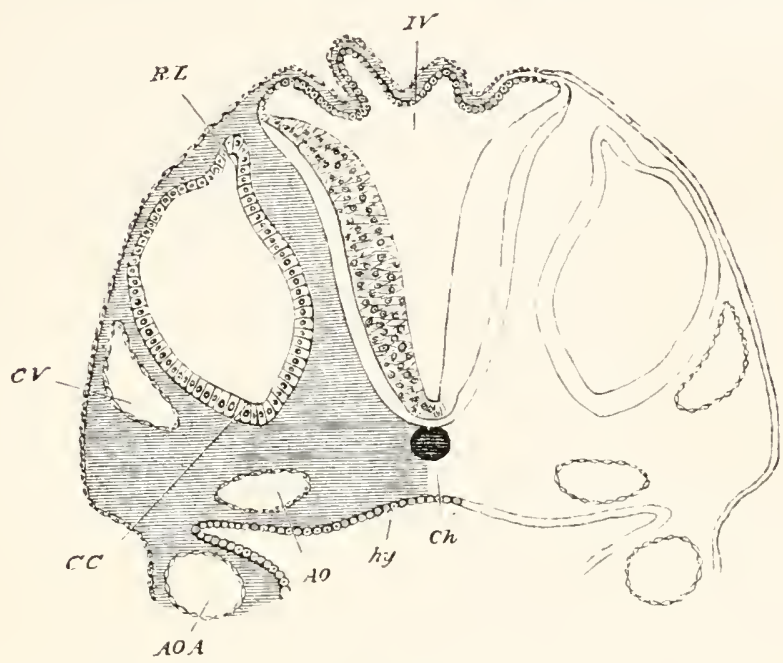

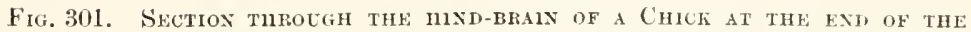
THIRD DAY OF IXCCBATION.

$I V^{*}$. fourth ventricle. The section shews the very thin roof and thicker sides of the ventricle. $C h$. notochord; $C \mathrm{~V}$. anterior cardinal vein; $C C$. involuted auditory vesicle ( $C C$ points to the end which will form the cochlear canal); $R L$. recessus labyrinthi (remaius of passage connecting the vesicle with the exterior); $h y$. hypoblast lining the alimentary canal; $A O ., A O . A$. aorta, and aortic arch.

the full-grown Ammocote and in the adult, they have since been found by Ketel (No. 387). The formation of the two semicircular canals has not been investigated.

In all the higher Vertebrates the changes of the auditory sacks are more complicated. The ventral end of the sack is produced into a short process (fig. 301, CC); while at the dorsal end there is the canal-like prolongation of the lumen of the sack $(R L)$, derived from the duct which primitively opened to the exterior, and which in most cases persists as a blind diverticulum of the auditory sack, known as the recessus labyrinthi or aqueductus vestibuli. The parts thus indicated give rise to the whole of the membranous labyrinth of the ear. 'The main body of the vesicle becomes the utriculns and semicircular canals, while the ventral process forms the sacculus hemisphericus and cochlear canal.

The growth of these parts has been most fully studied in Mammalia, where they reach their greatest complexity, and it will be convenient to describe their development in this group, pointing out how they present, during some of the stages in their growth, a form permanently retained in lower types.

The anditory vesicle in Mammalia is at first nearly spherical, and 
is imbedded in the mesoblast at the side of the hind-brain. It soon becomes triangular in section, with the apex of the triangle pointing inwards and downwards. This apex gradnally elongates to form the rudiment of the cochlear cabal and sacculus hemisphericus (fig. 302, $C C$ ). At the same time the recessus labyrinthi (R.L) becomes distinctly marked, and the outer wall of the main body of the vesicle grows out into two protuberances, which form the rudiments of the vertical semicircular canals (I.B). In the lower forms (fig. 305) the cochlear process of the vestibule hardly reaches a higher stage of development than that found at this stage in Mammalia.

The parts of the auditory labyrinth thus established soon increase in distinctness (fig. 303); the cochlear canal ( $C C$ ) becomes longer and curved; its inner and concave surface being lined by a thick layer of columnar epiblast. The recessus labyrinthi also increases in length, and just below the point where the bulgings to form the vertical semicircular canals are situated, there is formed a fresh protuberance for the borizontal semicircular canal. At the same time the central

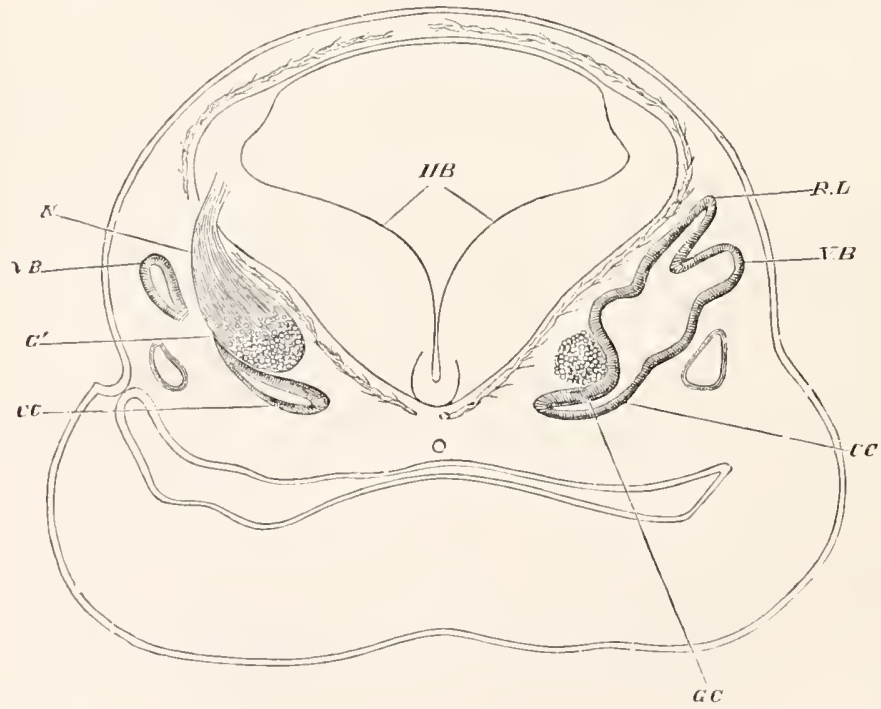

F1g. 302. Transverse section of the head of a fietal Sheep (16 ma. in LENGTH) IN THE REGION OF THE HIND-BRAiN. (After Bötteher.)

IIB. the hind-brain.

The section is somewhat oblique, hence while on the right side the connections of the recessus vestibuli R.L., and of the commencing vertical semicircular canal $V . B$., and of the ductus cochlearis $C C$, with the cavity of the primary otic vesicle are seen: on the left side, only the extreme end of the ductus cochlearis $C C$, and of the semieircular canal V.B. are shewn.

Lying close to the inner side of the otic vesicle is seen the cochlear ganglion $G C$; on the left side the auditory nerve $G$ and its connection $N$ with the hind-brain are also shewn.

Below the otic vesicle on either side lies the jugular vein. 
parts of the walls of the flat bulgings of the vertical canals grow together, obliterating this part of the lumen, but leaving a canal round the periphery; and, on the absorption of their central parts, each of the original simple bulgings of the wall of the vesicle becomes converted into a true semicircular canal, opening at its two extremities into the auditory vesicle. The vertical canals are first established and then the horizontal canal.

Shortly after the formation of the rudiment of the horizontal semicircular canal a slight protuberatuce becomes apparent on the inuer

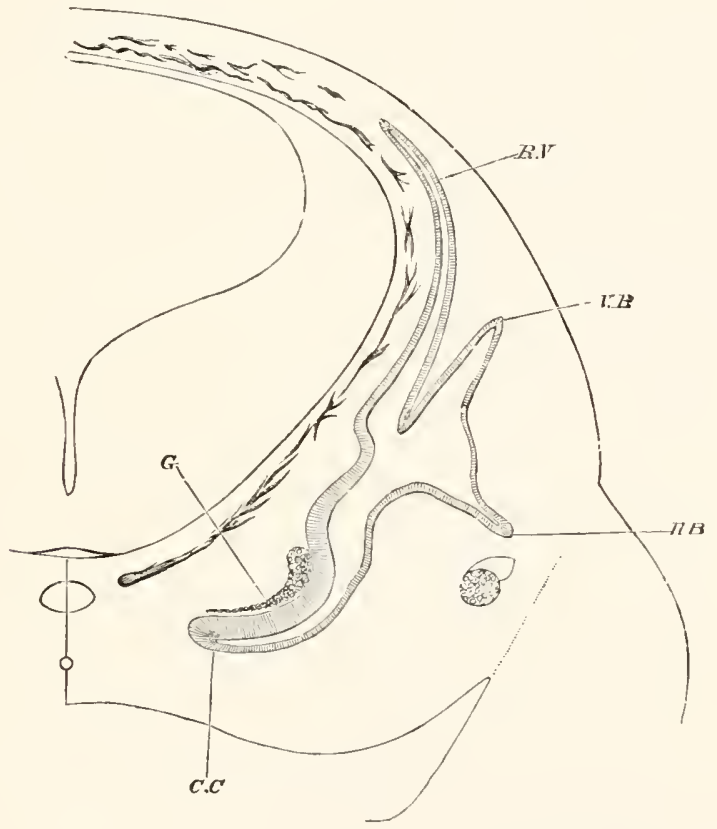

Fig. 303. Section of the hfad of a fetal Sheep 20 mis. in Lexgth. (After Böttcher.)

R.V. recessus labyrinthi; I.B. vertical semicircular canal; $H B$. horizontal semicircular canal; C.C. cochlear canal; $G$. cochlear ganglion.

commencement of the cochlear canal. A constriction arises on each side of the protuberance, converting it into a prominent hemispherical projection, the sacculus hemisphericus (fig. 304, S.R).

The constrictions are so deep that the sacculus is only connected with the cochlear canal on the one hand, and with the general cavity of the auditory vesicle on the other, by, in each case, a narrow though short canal.

The former of these canals (fig. 304,b) is known as the canalis reuniens. At this stage we may call the remaining cavity of the 
original otic vesicle, into which all the above parts open, the utriculus.

Soon after the formation of the sacculus hemisphericus, the cochlear canal and the semicircular canals become invested with cartilage. The recessus labyrinthi remains however still enclosed in undifferentiater mesoblast.

Between the cartilage and the parts which it surrounds there remains a certain amonnt of indifferent connective tissue, which is more abundaut around the cochlear canal than around the semicircular canals.

As soon as they have acquired a distinct connective-tissue coat, the semicircular canals begin to be dilated at one of their terminations to form the ampullw. At about the same time a constriction appears opposite the mouth of the recessus labyrinthi, which causes its opening to be divided into two branches-one towards the utriculus and the other towards the sacculus hemisphericus; and the relations of the parts become so altered that commmication between the sacculus and utriculus can only take place through the mouth of the recessus labyrinthi (fig. 30.5 ).

When the coclilear canal has come to consist of two and a half coils, the thickened epithelium which lines the lower surface of the canal forms a double ridge from which the organ of Corti is subsequently developed. Above the rilge there appears a delicate cuticular membrane, the membrane of Corti or membrana tectoria.

The epithelial wa'ls of the utricle, the recessus labyrinthi, the semicircular canals, and the cochlear canal constitute together the highly complicated product of the original auditory vesicle. The whole structure forms a closed cavity, the various parts of which are in free communication. In the adult the fluid present in this cavity is known as the endolymph.

In the mesoblast lying between these parts and the cartilage, which at this period envelopes them, lymphatic spaces become established, which are partially developed in the Sauropsida, but become in Mammals very important structures.

They consist in Mammals partly of a space surrounding the utricle and semicircular canals, and partly of two very definite channels, which largely embrace between them the cochlear canal. The latter channels form the scala vestibuli on the upper side of the cochlear canal and the scala tympani on the lower. The scala vestibuli is in free communication with the lymphatic cavity surrounding the vestibule, and opens at the apex of the cochlea into the scala tympani. The latter ends blindly at the fenestra rotunda.

The fluid contained in the two scalæ, and in the remaining lymphatic cavities of the auditory labyrinth, is known as perilymph.

The cavities just spoken of are formed by an absorption of parts of the embryonic mucous tissue between the perichondrium and the walls of the membranous labyrinth. 
The scala vestibuli is formed before the scala tympani, and both scalx begin to be developed at the basal end of the cochlea: the cavity of each is continually being carried forwards towards the apex of the cochlear canal by a progressive absorption of the mesoblast. At first both scalæ are somewhat narrow, but they soon increase in size and distinctness.

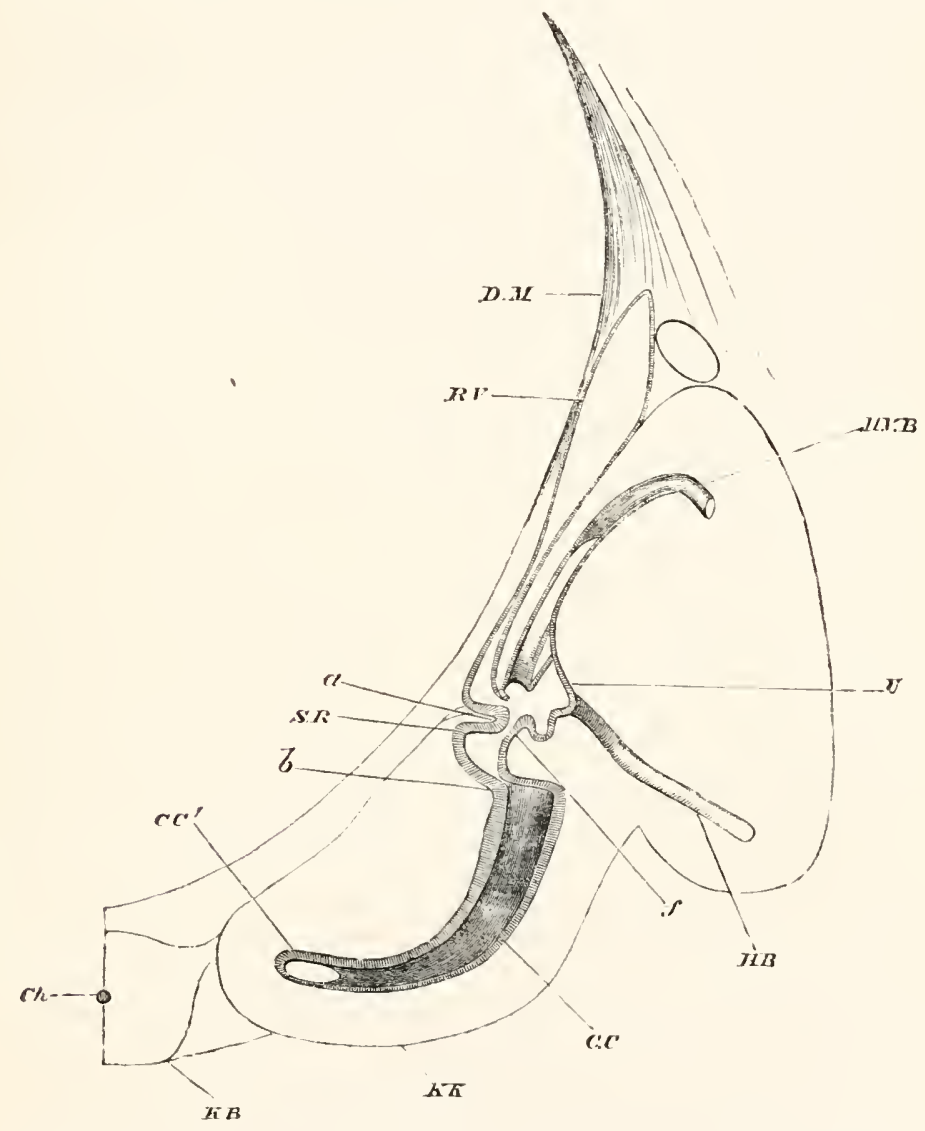

Fig. 304. Section throdgh the internal ear of an embryonic Sheep 28 M. IN LENGTH. (After Böttcher.)

D.M. dura mater; R.V. recessus labyrinthi; II.I.B. posterior vertical semicircular canal; $U$. utriculus; H.B. horizontal semicirenlar canal; $b$. canalis reuniens; $a$. constriction by means of which the sacculus hemisphericus S.R. is formed; $f$. narrowed opening between sacculus hemisphericus and utriculus; C.C. cochlea; $C . C^{\prime}$. Iumen of cochlea; K.K. cartilaginous capsule of cochlea; K.B. basilar plate; Ch. notochord.

The cochlear canal, which is often known as the scala media of the cochlea, becomes compressed on the formation of the scalæ so as to 
be triangular in section, with the base of the triangle outwards. 'This base is only separated from the surrounding cartilage by a narrow strip of firm mesoblast, which becomes the stria vascularis, etc. At the angle opposite the base the canal is joined to the cartilage by a narrow isthmus of firm material, which contains nerves and vessels. This isthmus subsequently forms the lamina spiralis, separating the scala vestibuli from the scala tympani.

The scala vestibuli lies on the upper border of the cocnlear canal, and is separated from it by a very thin layer of mesoblast, bordered on the cochlear aspect by flat epiblast cells. 'This nembrane is ealled the menbraue of Reissner. The scala tympani is separated from the cochlear canal by a thicker sheet of mesoblast, called the basilar membrane, which supports the organ of Corti and the epithelium arljoining it. The upper extrenity of the cochlear canal ends in a blind extremity called the cupola, to which the two scalex do not for some time extend. This condition is permanent in Birds, where the cupola is represented by a structure known as the lagena (fig. 30.5, II. L). Subsequently the two scale join at the extremity of the cochlear canal; the point of the cupola still however remains in contact with the bone, which has now replaced the cartilage, but at a still later period the scala vestibuli, growing further round, separates the cupola from the arljuining osseous tissue.

The ossification around the internal ear is at first confined to the cartilage, but afterwards extends into the thick periostem between the cartilage and the internal ear, and thus eventually makes its way into the lamina spiralis, etc.

The organ of Corti. In Mammalia there is formed from the epithelium of the cochlear canal a very remarkable organ known as the organ of Corti, the development of which is of sufficient importance to merit a brief description. A short account of this organ in the adult state may facilitate the understanding of its development.

The cochlear canal is hounded by three walls, the outer one being the osseous wall of the cochlea. The membrane of Reissner hounds it towards the scala vestibuli, and the basilar membrane towards the scala tympari. This membrane stretches from the margin of the lamina spiralis to the ligamentum spirale; the latter being merely an expanded portion of the connective tissue lining the osseous cochlea.

The lamina spiralis is produced into two lips, called respectively the labium tympanicum and labium restibulare; it is to the former and longer of these that the bisilar mentrane is attached. At the margin of the junction of the lahium tympanicum with the basilar membrane the former is perforated for the passage of the nervous tibres, and this region is called the habenula perforata.

The labium vestibulare, so called from its position, is shorter than the labium tympanicum and is raised above into numerous blunt teeth. Partly springing out from the labium vestibulare, and passing from near the inner attachment of the membrane of Reissner towards the outer wall of the cochlea, is an elastic membrane, the membrana tectoria. Resting on the basilar membrane is the organ of Corti. 
Consillering for the moment that a transverse section of the cochlear canal only one cell deep is being dealt witl, the orgain of Corti will be funnel to consist of a central part composed of two peculiarly shaped rods
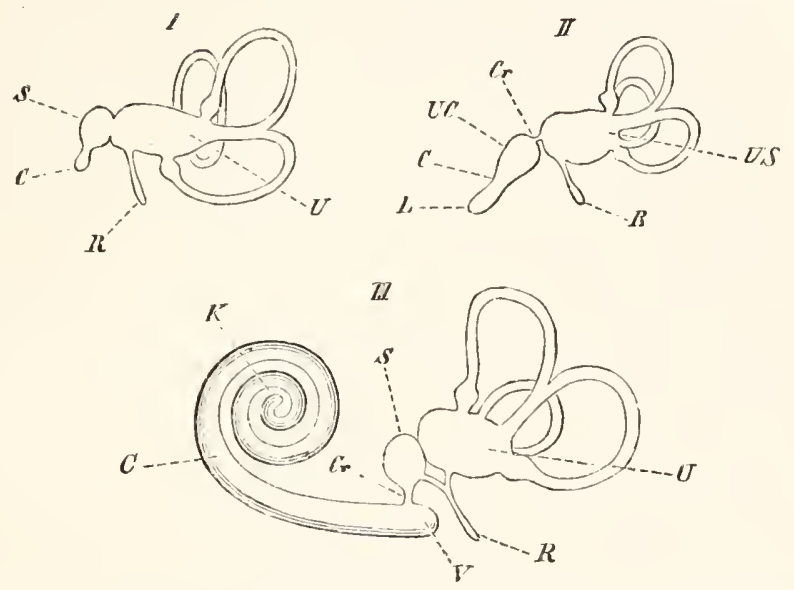

Fig. 305. Diagrais of the Membraxous labrinth. (From Gegenbaur.)
1. Fish.
II. Bird.
III. Mammal.

L. utriculus; S. saceulus; $L S$. utriculus and sacculus; $C r$ canalis reuniens; R. recessus labrinthi; $I^{\top} C$. commencement of cochlea; $C$. cochlear canal; $L$. lagena; $K$. cupola at apex of cochlear canal; $I$. cæeal sack of the vestibulum of the cochlear canal.

widely separated below, but in contact abore. These are the rods or fibres of Corti. On their outa side, i.p. on the side towards the osseons wall of the canal, is a reticulate membrane which passes from the inner rod of Corti towards the osseons wall of the canal. With their mpper extremities fixed in that membrane, and their lower resting on the basilar membrane are thee (fonn in man) cells with anditory hairs known as the outer 'hail' cells,' which alternate with three other cells known as Deiter's' cells. Between these and the outer attachment of the basilar membrane is a series of cells gradually diminishing in leight in parsing outwards. On the inner side of the rods of Corti is one hair cell, and then a number of peculinly nodified cells which fill up the space between the two lips of the lamina spiralis.

It will not he necessary to say much in reference to the development of the labium tympanicun and the labium vestibulare.

The labium vestibulare is formed by a growtl of the connective tissue which fuses with and passes up between the epithelial cells. 'The epithelial cells which line its upper (restibular) border become modified, and remain as its teeth.

The labium tympanicun is formed by the coalescence of the comnective tissue layer separating the scald tympan frou the cochlear canal with part of the commective tissue of the lamina spiralis. At first these two layers are separate, and the nerve fibres to the organ of Corti pars between them. Subsequently however they coalesce, and the region where they are penetrated by the nervous fines becomes the habenula ferforata.

1.. E. II. 
The organ of Corti itself is derived from the epiblast cells lining the cochlear canal, and consists in the first instance of two epithelial ridges or projections. The larger of them forms the cells on the inner side of the organ of Corti, and the smaller the rods of Corti together with the inner and outer hair cells and Deiters' cells.

At first both these ridges are composed of simple elongated epithelial cells one row deep. The smaller ridge is the first to shew any change. The cells adjoining the larger ridge acquire auditory liairs at their free extremities, and form the row of inner laair cells; the next row of cells acquires a broad attachment to the basilar membrane, and gives origin to the inner and outer rods of Corti.

Outside the latter come several rows of cells adhering together so as to form a compact mass which is quadrilateral in section. This mass is composed of three upper cells with nuclei at the same-level, which form the outer hair cells, each of them ending above in auditory hairs, and three lower cells which form the cells of Deiters. Beyond this the cells gradually pass into ordinary cubical epithelial cells.

As just mentioned, the cells of the second row, resting with their broad bases on the basilar nembrane, give rise to the rods of Corti. The breadth of the bases of these cells rapidly increases, and important clanges take place in the structure of the cells themselves.

The nncleus of each cell divides; so that there come to be two nuclei or sometimes three which lie close together near the base of the cell. Outside the nuclei on each side a fibrous cuticular band appears. The two bands pass from the base of the cell to its apex, and there meet though widely separated below. The remaining contents of the cell, hetween the two fibrous bands, become granular, and are soon to a great extent absorbed; leaving at first a round, and then a triaugular space between the two fibres. The two nuclei, suromnded by a small amount of granular matter, come to lie, each at one of the angles between the filrous bands and the basilar membrane.

The two fibrous bands become, by changes which need not be described in detail, converted into the rods of Corti-each of their upper ends growing outwards into the processes which the adult rods possess.

Each pair of rods of Corti is thus (Böttcher') to be considered as the product of one cell; and the nuclei imberded in the granular mass between them are merely the remains of the two nuclei formed by the division of the original nucleus of that cell ${ }^{1}$. The larger ridge is for the most part not permanent, and from being the most conspicuous part of the organ of Corti comes to be far less important than the smaller ridge. Its cells undergo a partial degeneration; so that the epithelium in the hollow between the two lips of the lamina spiralis, which is derived from the larger lidge, comes to be composed of a single row of short and broad cells. In the immediate neighbourhood however of the inner hair cell, one or two of the cells derived from the larger ridge are very much elongated.

The membrana reticularis is a cuticular structure derived from the parts to which it is attached.

1 It is not clear from Böttcher's description how it comes about that the imner rods of Corti are more numerous than the outer. 


\section{Accessory structures connected with the orgun of having in Terrestrial Vertebrata.}

In a!l the Amphibia, Sauropsida and Mammalia, except the Urodela and a few Anura and Reptilia, the first visceral or hyo. nandibular cleft enters into intimate relations with the organs of hearing, and from it and the adjoining parts are formed the tympanic cavity, the Eustachian tube, the tympanic membrane and the meatus auditorius externus. The tympanic membrane serves to receive from the air the sound vibrations, which are communicated to Huids contained in the true andiory labyrinth by one ossicle or by a chain of auditory ossicles.

The addition to the organ of hearing of a tympanic membrane to receive aerial sound vibrations is an interesting case of the adaptation of a structure, originally required for hearius in water, to serve for hearing in air; and as already pointed out, the similurity of this membrane to the tympanic membrane of some Insects is also striking.

There is much that is obscure with reference to the actual development of the above parts of the ear, which has moreover only been carefully studied in Birds and Mammals.

The Eustachian tube and tympanic cavity seem to be derived from the inner part of the first visceral or hyomandibular cleft, the external opening of which becomes soon obliterated. Kölliker holds that the tympanic cavity is simply a dorsally and posteriorly directed outgrowth of the median part of the inner section of this cleft; while Moldenhauer (No. 392) holds, if I understand him rightly, that it is formed as an outgrowth of a cavity called by him the sulcus tubo-tympanicus, derived from the inner aperture of the first visceral cleft together with the groove of the pharynx into which it opens; and Moldenhaner is of opinion that the greater part of the original cleft atrophies.

The meatus anditorius externus is formed at the region of a shallow depression where the closure of the first visceral cleft takes place. It is in part formed by the tissue surrounding this depression growing up in the form of a wall, and Moldenhaner believes that this is the whole process. Kölliker states however that the blind end of the meatus becomes actually pushed in towards the tympanic cavity.

The tympanic membrane is derived from the tissue which separates the meatus auditorius externus from the tympanic cavity. This tissue is obviously constituted of an hypoblastic epithelium on its inner aspect, an epiblastic epithelinm on its outer aspect, and a layer of mesoblast between them, and these three layers give rise to the three layers of which this membrane is formed in the adult. During the greater part of foetal life it is relatively very thick, and presents a structure bearing but little resemblance to that in the adult.

A proliferation of the connective tissue-cells in the vicinity of 
the tympanic cavity canses in Mammalia the complete or nearly complete obliteration of the cavity during fotal life.

'The tympanic cavity is bounded on its inner aspect by the osseous investment of the internal ear, but at one point, known as the fenestra ovalis, the bone is deficient in the Amphibia, Sauropsida and Mammalia, and its place is taken by a membrane; while in Mammalia and Sauropsida a second opening, the fenestra rotunda, is also present.

'These two fenestræ appear early, but whether they are formed by an absorption of the cartilage, or by the nonchondrification of a small area, is not certainly known. The upper of the two, or fenestra ovalis, contains the base of a bne, known in the Sauropsirla and Amphibia as the columella. The main part of the columella is formed of a stalk which is held by Parker to be derived from part of the skeleton of the visceral arches, but its nature is discnssed in connection with the skeleton, while the base, forming the stapes, appears to be derived from the wall of the periotic cartilage.

In all Amphibia and Sauropsida with a tympanic cavity, the stalk of the columella extends to the tympanic membrane; its outer and becoming imbedded in this membrane, and serving to transmit the vibrations of the membrane to the fluid in the internal ear. In Mammalia there is a stapes not directly attached to the tympanic membrane by a stalk, and two arditional auditory ossicles, deriver from parts of the skeleton of the visceral arches, are placed between the stapes and the tympanic membrane. These ossicles are known as the malleus and incus, and the chain of the three ossicles replaces pliysiologically the single ossicle of the lower forms.

These ossicles are at first imbedded in the connective tissue in the neighbourhood of the tympanic cavity, but on the full development of this cavity, become apparently placed within it; though really enveloped in the mucous membrane lining it.

The fenestra ovalis is in immediate contiguity with the walls of the utricle, while the fenestra rotunda adjoins the scala tympani.

Hunt (No. 39r) holds, from his investigations on the embryology of the pig, that "the Eustachian tube is an involution of the pharyngeal mucous membrane;" and that "the meatus is an involntion of the integument" while "the drum is formed by the Eustachian tube orerlapping the extremity of the meatus." Urbantechitsch also holds that the first risceral cleft has nothing to do with the formation of the tympanic cavity and Eustachian tubc, and that these parts are derived from lateral outgrowths of the oral cavity.

The evolution of the accessory prarts of the ar wonld he very difficult to explain on Darwinian principles if the views of Hunt and Urlantschitsch were correct; and the accepted doctrine, originally proposed by Huschke (No. $3^{89}$ ), according to which these stmetnres have originated ly a 'change of function' of the parts of the first risceral cleft, may fairly be held till more conclusive evidence has heen brought against it than has yet been done.

Tunicata. The auditory organ of the 'Tumicata (fig. 306i) is 
placed on the under surface of the anterior vesicle of the brain.

It

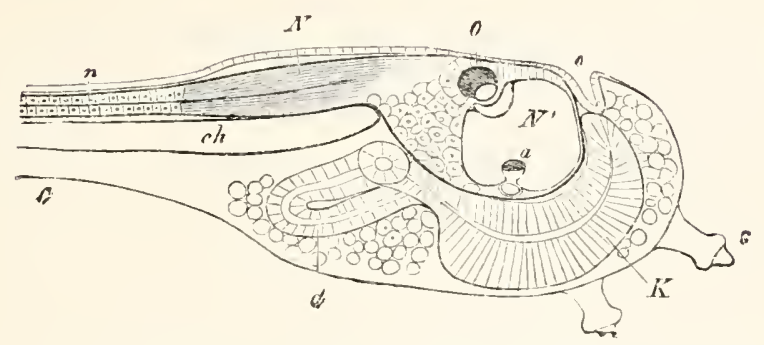

Fig. 306. Larva of Ascidia amentula. (From Gegenbaur; after Kupfter.) Only the anterior part of the tail is represented.

$N^{\prime}$. anterior swelling of neural tube; $N$. anterior swelling of spimal portion of neural tube; $n$. hinder part of neural tube; $c h$. notochord; $K$. branchial region of alimentary tract; $d$. cesophageal and gastric region of alimentary tract; $O$. eye : a. otolith; o. mouth; s. papilla for attachment.

consists of two parts (1) a prominence of the cells of the floor of the brain forming a crista acustica, and $(2)$ an otolith projecting into the cavity of the brain, and attached to the crista by delicate hairs.

The crista acustica is formed of very delicate cylindrical cells, and in its most projecting part is placed a vesicle with clear contents. The otolith is an oval body with its dorsal half pigmented, and its ventral half clear and highly refractive. It is balanced on the highest point of the crista.

The erista acustica would seem to be developed from the cells of the lower part of the front vesiche of the brain. The otolith however is developed from a single cell on the dorsal and right side of the brain. This cell commences to project into the cavity of the brain and its free end becomes pigmented. It gradually grows inwards till it, forms a spherical prominence in the cavity of the brain, to the wall of which it is attached by a stalk. At the same time it travels round the right side of the vesiche of the brain (in a way not fully explained) till it reaches the summit of the erista, which has become in the meantime established.

The auditory organ of the simple Ascidians can hardly be brought into relation with that of the other Chordata, and has nost probably been evolved within the Tunicate phylum.

\section{Bibliograyhy.}

\section{Invertelrutu.}

$\left(3^{8}+\right)$ V. Hensen. "Studien ỉb. d. Gehörorgan d. Decapoden." Zeit. t. wiss. Zool., Vol. xir. 1863 .

(385) O. and R. Hertwig. Das Nerensystem u. d. Sinnesorgane d. Medusen. Leipzig, 1878. 


\section{Vertebrata.}

(386) A. Boettcher. "Bau u. Entwicklung d. Schnecke." Denkschriften $d$. kaiserl. Leop. Carol. Akad. d. Wissens hajt., Vol. xxxv.

$\left(3_{7}\right)$ C. Hasse. Die vergleich. Morphologie n. Histologie d. häutigen Gehörorgane d. Wirbelthiere. Leipzig, 1873.

(38s) V. Henseu. "Zur Morphologie d. Schnecke." Zeit. f. wiss. Zonl., Tol. xIII. 1863.

(389) E. Huschke. "Ueb. d. crste Bildungsgeschichte d. Auges u. Ohres beim bcbrüteten Kï̈chlein." Isis ron Oken, 1831, and Meckel's Archiv, Vol. vi.

(390) Reissuer. De Auris internce formatione. Inang. Diss. Dorpat, 1851.

\section{Accessory parts of Vertebrate Ear.}

(391) David Hunt. "A comparative sketch of the development of the ear and eye in the Pig." Transactions of the International Otological Congress, 1876.

(392) W. Moldenhauer. "Zur Entwick. d. mittleren u. äusseren Ohres." Morphol. Jahrbuch, Vol. in. 1877.

(393) V. Urbantschitsch. "Ueb. d. erste Allage d. Mittelohres u. d. Trommelfelles." Mittheit. a. d. embryol. Instit. Wien, Heft I. 1877.

\section{Olfactory organ.}

Amongst the Invertebrata numerous sense organs have been described under the title of olfactory organs. In aquatic animals they often have the form of ciliated pits or grooves, while in the Insects and Crustacea delicate hairs and other structures present on the antennis are usually believed to be organs of smell. Our knowledge of all these organs is lowever so vague that it would not be profitable to deal with them more fully in this place. Amongst the Chordata there are usually well developed olfactory organs.

Amongst the Urochorda (Tunicata) it is still uncertain what organs (if any) deserve this appellation. The organ on the dorsal side of the opening of the respiratory pharynx may very possibly lave an olfactory function, but it is certainly not homologous with the olfactory pits of the true Vertebrata, and as mentioned above (pp. 359 and 360), may perhaps be homologous with the pituitary body.

In the Cephalochorda (Amphioxus) there is a shallow ciliated pit, discovered by Kölliker, which is situated on the left side of the head, and is closely comnected with a special process of the front end of the brain. It is most probably the homologue of the olfactory pits of the true Vertebrata.

In the true Vertebrata the olfactory organ has usua!ly the form of a pair of pits, though in the Cyclostonata the organ is umpaired.

In all the Vertebrata with two olfactory pits these organs are formed from a pair of thickened patches of the epiblast, on the under side of the fore-brain, immediately in front of the mouth (fig. $307, o l$ ). Each thickened patch of epiblast soon becomes involuted as a pit (fig. 30S, $N$ ), the lining cells of which become the olfactory or Schneiderian epithelium. The surface of this epithelium is usually mnch increased by various foldings, which in the Elasmobranchii arise very early, and are bilaterally symmetrical, diverging on each side like the barbs of a feather from the median line. They subsequently 
become very pronounced (fig. 309), serving greatly to increase the surface of the olfactory epithelium. At a very early stage the olfactory nerve attaches itself to the olfactory epithelium.

In Petromyzon the olfactory organ arises as an umpaired thickening of the epiblast, which in the just hatched larva forms a shallow pit, on the ventral side of the head, immediately in front of the moutl. This pit rapidly deepens, and soon extends itself backwards nearly as far as the infundibulum (fig. 310, ol). By the development of the upper lip the opening of the olfactory pit is gradually carried to the dorsal surface of the head, and becomes at the same time narrowed and ciliated (fig. $47, o l$ ). The whole organ forms an elongated sack, and in later stages becomes nearly divided by a median fold into two halves.

It is probable that the unpaired condition of the olfactory organ in the Lamprey has arisen from the fusion of two pits into one; there is however no evidence of this in the early development; but the division of the sack into two halves by

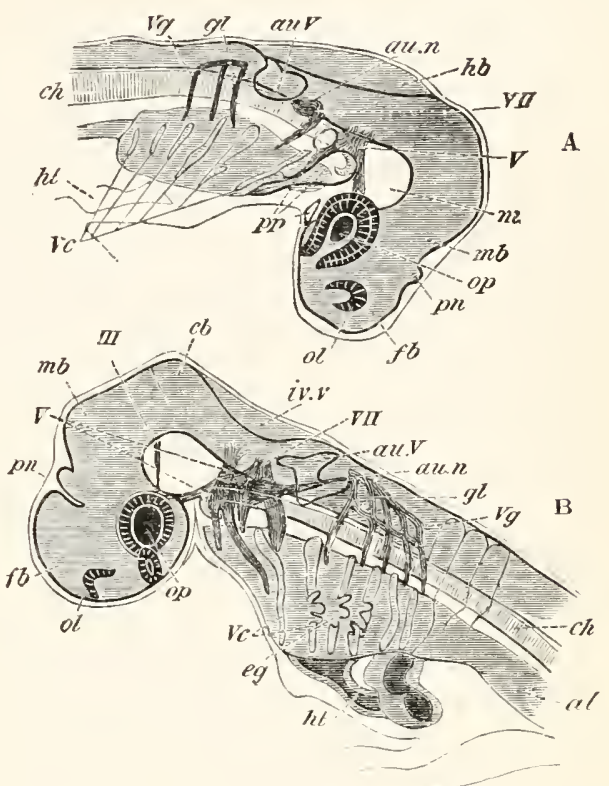

Fig. 307. Thews of the head of ElasiroBRANCH EMBRYOS AT TWO STAGES AS TRANSPARENT OBJECTS. $28 \mathrm{~F}$

A. Pristiurus embryo of the same stage as fig.

B. Somewhat older Scyllium embryo.

III. third nerve; $I$. fifth nerve; VII. seventh nerve; $a u . n$. auditory nerve; $g l$. glossopharyngeal nerve; $I^{\prime} g$. vagus nerve; $f b$. fore-brain; $p n$. pineal gland; mb. mid-brain; $h b$. hind-brain; $i v . l$. fourth ventricle; $c b$. cerebellum; ol. olfactory pit; op. eye; $a u, J$. auditory vesicle; $m$. mesoblast at base of brain ; $c h$. notochord; $h t$. heart; $I c$. visceral clefts; eq. external gills; $p p$. sections of bodycavity in the hear. a median fold may be regarded as an indication of such a paired character in the later stages.

In Myxine the olfactory organ communicates with the mouth through the palate, but the meaning of this communication, which does not appear to be of the same nature as the communication between the olfactory pits and the mouth by the posterior nares in the higher types, is not known.

The opening of the olfactory pit does not retain its embryonic characters. In Elasmobranchii and Chimæra it becomes enclosed by a wall of integument, often deficient on the side of the mouth, so that there is formed a groove leading from the nasal pit towards the angle of the mouth. This groove is usually constricted in the middle, and the 
original single opening of the nasal sack thus becomes nearly divided into two. In Teleostei and Ganoids the division of the nasal opening into two parts becomes complete, but the ventral opening is generally carried off some distance from the mouth, and placed, by the growth of the snout, on the upper surface of the head (tigs. 54 and 68 ). In all these instances it is probable that the dorsal opening of the nasal sack is homologous with the external nares, and the ventral opening with the posterior nares of higher types. 'Thus the posterior nares would in fact seem to be represented in all Fishes by a ventral part of the opening of the original nasal pit which either adjoins the border of the mouth (many Elasnobranchii) or is quite separate from the mouth (Teleostei and Ganoidei). In the Dipnoi, Amphibia and all the higher types the oral region becomes exteruded so as to enclose the posterior nares, and then each nasal pit acquires two openings; viz. one outside the mouth, the external nares, and one within the mouth, the internal or posterior nares.

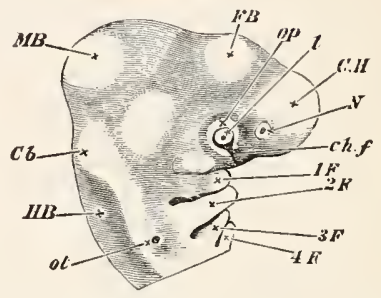

Fig. 368. Side view of the HEAD OF AN EMBRio CHICK OF THE THIRI DAY AS AN OPAQUE OBJECT. (Chromic acit preparation.)

C.II. cerebral hemispheres: $F . B$. vesicle of third ventricle; WIB. mid-brain; $C b$. cerebellum; Ii B. medulla ollongata; N. nasal pit; ot. auditory vesicle in the stage of a pit with the opening not yet closed up; op. optic vesicle, with $l$. lens and $c h . f$. choroidal fissure.

$1 F$. The first visceral fold; above it is seen the superior maxillary process.

$2,3, \pm F$. Second, third and fourth visceral folds, with the visceral clefts between them. In the Dipnoi the two nasal openings are very similar to those in Ganoidei and Teleostei, but both are placed on the under surface of the head, the inner one being within the mouth, and the external one is so close to the outer border of the upper lip that it also has been considered by some auatomists to lie within the mouth.

In all the hioher types the nasal pits have origrinally only a single opening, and the outogenetic process by which the posterior nasal opening is formed has been studied in the Amniota and Amphibia. Amongst the Amniota we may take the Chick as repre-

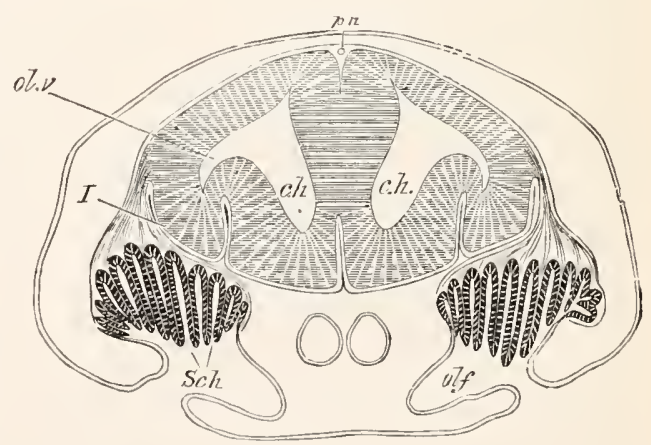

F1g. 309. SEction throvgh the bialn AND OLFACTORY ORGAN OF AN EMBRYo OF Soxllital. (Modified from figures by Marshall and myself.)

c.h. cerebral hemispheres; ol.x. olfactory vesicle; olf. olfactory pit; $s c h$. Schneiderian folds; $I$. olfactory nerve. 'The reference line has been accidentally taken through the neve to the brain. 
senting the process in a very simple form. The general history of the process was first male out by Kölliker.

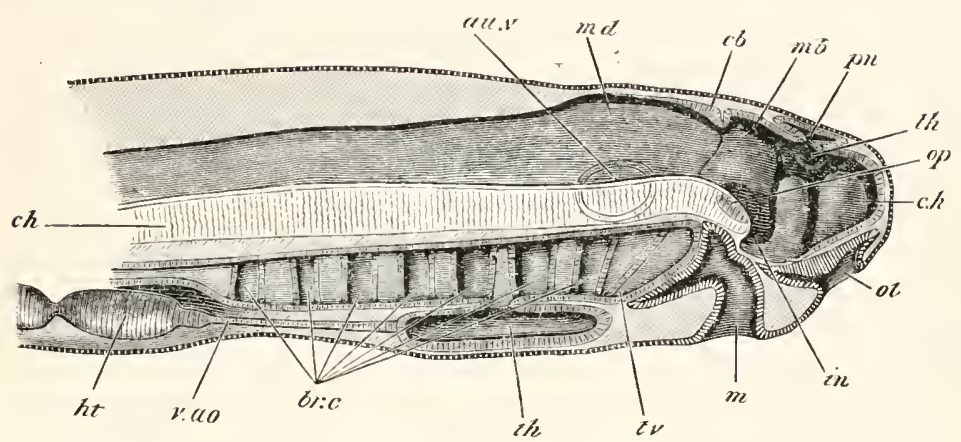

Fig. 310. DIAgramatic Vertical, SECTION THROUgh THE HEAD OF A LARVA OF Petrouyzon.

The larva had been hatched three days, and was $4.8 \mathrm{~mm}$. in length. The optic and auditory vesicles are supposed to be seen through the tissues.

c.h. cerebral hemisphere; th. optic thalamus; in. infundibulum; pn. pineal glant; $m b$. mid-brain; $c b$. cerebellum; $m l$. medulla oblongata ; uu.v. alulitory vesicle; $o p$. optic vesicle; ol. olfactory pit; $m$. month; br.c. branchial pouches; th. thyroid involution; v.uo. ventral aorta; ht. ventricle of heart; ch. notochorl.

The opening of the nasal pit becomes surrounded by a ridge except on its oral side. The deficiency of this ridge on the side of the mouth gives rise to a kind of shallow groove leading from the nasal pit to the mouth. The ridge enveloping the opening of the nasal pit next becomes prolonged along the sides of this groove, especially on its inner one; and at the same time the superin maxillary process grows forwards so as to bound the lower part of its onter side. 'The inner' and outer ridges, together with the superior maxillary procens, enclose a deep groove, connecting the original opening of the masal pit with the mouth. The process just described is illustrated by fig. :311 A, and it nay be seen that the ridge on the inner side of the groove forms the edge of the fronto-nasal process $\left(7_{i}\right)$.

On the sixth day (Born, 394) the sides of this groove unite together in the middle, and convert it into a canal open at both ends-the ventral openings of the canals of the two sides being placed just within the border of the mouth, and forming the posterior nares; while the external openings form the anterior nares. The upper part of the canal, together with the original nasal pit, is alone lined by olfactory epithelium; the remaining epithelium of the nasal cavity being indifferent epiblastic epithelium. Further changes subsequently take place in connection with the posterior nares, but these are described in the section dealing with the mouth.

In Mammalia the general formation of the aliterior and posterior nares is the same as in Birds; but, as shewn by Dursy and Kölliker, an outgrowth from the inner side of the canal between the two open- 
ings arises at an early period; and becoming separate from the posterior nares and provided with a special opening into the mouth, forms the organ of Jacobson. The general relations of this organ when fully formed are shewn in fig. 312.

In Lacertilia the formation of the posterior nares differs in some particulars from that in Birds (Born). A groove is formed leading from the primitive nasal pit to the mouth, bordered on its inner side liy the swollen edge of the fronto-nasal process, and on its outer by an outernasal process; while the superior maxillary process does not assist in

A

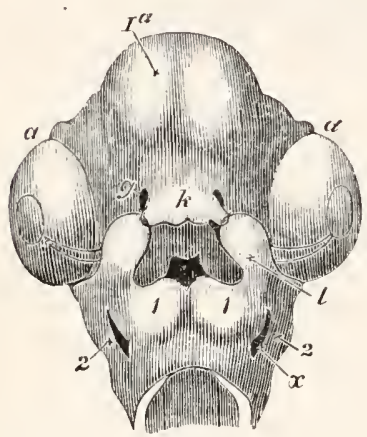

B

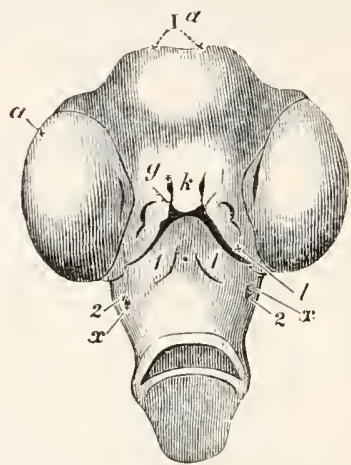

Fig. 311. Head of a Chick froji below on the sixth and seventh days of incubatron. (From Huxley.)

$I^{a}$. cerebral vesicles; $a_{0}$ eye, in which the remains of the choroid slit can still be seen in $A ; g$. nasal pits; $k$. fronto-nasal process; $l$. superior maxillary process; 1. inferior maxillary process or first visceral arch; 2 . second visceral arch; $x$. first visceral cleft.

In $A$ the cavity of the mouth is seen enclosed by the fronto-nasal process, the superior maxillary processes and the first pair of visceral arches. At the back of it is seen the opening leading into the throat. The nasal grooves leading from the nasal pits to the mouth are already closed over.

In $\mathrm{B}$ the external opening of the mouth has become much constricted, but it is still enclosed by the fronto-nasal process and superior maxillary processes above, and by the inferior maxillary processes (first pair of visceral arches) below.

The snperior maxillary processes have united with the fronto nasal process, along nearly the whole length of the latter.

bounding it. On the inner side of the narrowest part of this groove there is formed a large lateral diverticulum, which is lined by a continuation of the Schneiderian epithelium, and forms the rudiment of Jacobson's organ. The nasal groove continues to grow in length, but soon becomes converted into a canal by the junction of the outer-nasal process with the fronto-nasal process. This canal is open at both ends: at its dorsal end is placed the original opening of the nasal pit, and its ventral opening is situated within the cavity of the mouth. The latter forms the primitive posterior nares. The superior maxillary process soon grows inwarels on the under side of the posterior part of the nasal passage, 
and assists in forming its under wall. This ingrowth of the superior maxillary process is the rudiment of the hard palate.

On the conversion of the nasal groove into a closed passage, the opening of Jacobson's organ into the groove becomes concealed; and at a later period Jacobson's organ becomes completely shut off from the nasal carity, and opeus into the mouth at the front end of an elongated groove leading back to the posterior mares.

In Amphibia the posterior nares are formed in a manner very different from that of the Ammiota. At an early stage a shallow groove is formed leading from the nasal pit to the mouth; but this groove instead of forming the posterior nares soon vanishes, and by the growth of the front of the hearl the nasal pits are carried farther away from the moutl.

The actual posterior nares are formed by a perforation in the palate, opening into the blind end of the original nasal pit.

Considering that the various stages in the formation of the posterior nares of the Anniota are so many repetitions of the adult states of lower forms, it may probably be

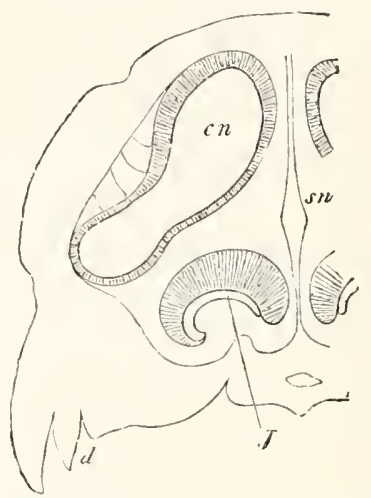

Fig. 312. Section throvgh THE Nasar Cavity aND JaCoBson's oRgan. (From Gegenbaur.)

sn. septum nasi; $c n$. nasal cavity ; J. Jacolson's organ ; $d$. edge of upper jaw. assumed that the mode of formation of the posterior nares in Amphibia is secondary, as compared with that in the Amniota.

A diverticulum of the front part of the nasal cavity of the Anura is probably to be regarded as a rudimentary form of Jacobson's organ.

\section{Bibliograpily.}

(394) G. Born. "Die Nasenhöhlen u. d. Thränennasengang d. amnioten Wirbelthiere." Parts I. and I. Morphologisches Jahrbuch, Bd. v., 1879.

(395) A. Kölliker, "Ueber die Jacobson'schen Organe des Menschen." Festschrift f. Rienecler, 1877.

(396) A. M. Marshall. "Morphology of the Vertebrate Olfactory Organ." Quart. Journ. of Micr. Science, Vol. xIx., 1879.

\section{Sense organs of the lateral line.}

Although I do not propose dealing with the general development of various sense organs of the skin, there is one set of organs, viz. that of the lateral line, which, both from its wide extension amongst the Jehthyopsida and from the similarity of some of its parts to certain organs found amongst the Chretopoda ${ }^{1}$, has a great morphological importance.

1 The organs which resemble those of the lateral line are the remarkable sense organs found by Eisig in the Capitellida (Mitheil. a. d. Zool. Station zu Nerepel, Vol. I.); but I am not inclined to think that there is a true homology between these organs and the lateral line of Vertebrata. It seems to me probable that the segmentally arranged optic organs of Polyophthalmus are a special modification of the more indifferent sense organs of the Capitellide. The close affinity of these two types of Chatopods is favourable to this view. 
The organs of the latercal line consist as a rule of canals, partly situater in the head, and partly in the trunk. These canals open at intervals on the surface, and their walls contain a series of nerve-endings. The branches of the canal in the head are innervated for the most part by the fifth pair, and those of the trunk by the nervus lateralis of the vagus nerve. There is typically but a single canal in the trunk, the openings and nerve-endings of which are segmentally arranged.

Two types of development of these organs liave been found. One of these is characteristic of Teleostei ; the other of Elasmobranchii.

In just hatched 'Teleostei, Schulze (No. 402) foumd that instead of the normal cauals there was present a series of senve bulbs, projecting freely on the surfice and partly composed of cells with stiff hairs. In most cases each buth is enclosed in a delicate tube op at its free extrenity; while the bulbs emrespond in number with the myotomes. In some Teleostei (Gobius, Esox, etc.) such sense orgams persist through lite; in most forms however each organ becomes covered by a pair of lobes of the adjacent tissue, one formed above and the other below it. The two lobes of each pair then unite and torn a tube open at hoth ends. The linear series of tubes so formed is the conmencenent of the adult canal ; while the primitive sense bulbs form the sensory organs of the tubes. The adjacent tubes partially nnite into a continuous canal, but at their points of apposition pores are left, which place the canal in communication with the exterior.

Besides these parts, I have f'ound that there is present in the just hatched Salmon a linear streak of moditied epidermis on the level of the lateral nerve, and from the analogy of the process described helow for Elasmobrinchii it appears to me probable that these streaks play some part in the formation of the canal of the lateral line.

In Elasmotnanchii (Scyllium) the lateral line is formed as a linea. thickening of the mucous layer of the epidermis. This thickening is at first very short, but graclually grows backwards, its hinder end forming a kind of enlarged growing point. The lateral nerve is formed shortly after the lateral line, and by the time that the lateral line has reached the level of the anus the lateral nerve las grown back for about two-thirds of that distance. The lateral nerve would seem to be formed as a branch of the vagns, but is at first half enclosed in the modified cells of the lateral line $(\text { fig. } 275, n l)^{1}$, thongh it soon assmmes a deeper position.

A permanent stage, more or less corresponding to the stage just described in Elasmobranchii, is retained in Chimera, and Echinorhinus spinosus, where the lateral line las the form of an open groove (Solger, No. 404).

The epidermic thickening, which forms the lateral line, is converted into a canal, not as in Teleostei by the folding over of the sides, but by the formation of a cavity between the mucous and epidermic layers of the epiblast, and the subsequent enclosure of this cavity by the modified cells of the mucous layer of the epiblast which constitute the lateral line. The cavity first appears at the hind end of the organ, and thence extends forwarls.

1 Gotte and Semper both hold that the lateral nerve, instea 7 of growing in a centrifugal mamner like other nerves, is directly del ived from the epiblast of the lateral line. For the reasons which prevent me accepting this view I must refer the reader to my ITonograph on Elasmobranch Fishes, pp. 141-14fi. 
After its conversion into a canal the lateral line gradually recedes from the snrface; remaining howerer commected with the epidermis at a series of points corresponding with the segments, and at these points perforations are prentually formed to constitnte the segmental apertmes of the sy-tem.

The mamner in which the lumen of the canal is formed in Elasmohranchs bears the same relation to the ordinary process of conversion of a groove into a eanal that the formation of the anditory involution in Amplibia does to the same process in Birds. In loth Elasmoliranchii and Amplibia the nucous layer of the epiblast behares exactly as does the whole criblast in the otlier types, but is shut off from the surface hy the passive epidermic layer of the ejiblast.

The mucous canils of the head and the ampulle are formed from the mneous layer of the epilernis in a namner very similar to the lateral line; but the nerves to then arise as simple hanclies of the fiftl and seventh nerves, whieh mite with them at a series of points, but do not follow their course like the lateral nerve.

It is clear that the canal of the lateral line is secondary, as comprated with the open groove of Chimara or the segmentally arranged sense bulbs of young feleostri; and it is alsu clear that the phylugenetic mole of formation of the eanal consisted in the closure of a primitively open groove. The ahbreviation of this process in Elasmobranchii was probahly acpured after the alpiearance of frod-yolk in the egg, and the comsequent disappearance of a fice larral stage.

While the above points are fairly obvious it does not seem easy to decide ì minri whether a eontinuous sense groove or isolated sense bulls were the primitive structures firm which the canals of the lateral line took their nrigin. It is equally easy to picture the evolution of the camal of the lateral line either from (1) a continuous unsegmented sense line, certain prints of which became segmentally difierentiated into special sense bullos, while the whole subsequently formed a groove and then a canal; or from (2) a series of isolated sense lulls, for eaeh of which a protective groove was dereloperl; and from the linear fusion of which a continnous canal became formed.

From the presence howerer of a linear streak of modified epidernis in larral Teleostei, as well as in Elasmobranchii, it aplears to me more probable that a linear sense streak was the primitive structure from whieh all the modifications of the lateral line took their origin, and that the segmentally arranged sense bulbs of Teleostei are secondary diflerentiations of this primitive structure.

The, at first sight remarkable, distribution of the vagus neve to the lateral line is probably to he explained in comnection with the erolution of this organ. As is indicatel both hy its innervation from the vagus, as also from the regim where it first hecomes developed, the lateral line was probably originally restricted to the anterior part of the body. As it became prolonged backwards it naturally carried with it the vagus nerve, and thus a sensory branch of this nerve has come to innervate a region which is far beyond the limits of its original distribution. 


\section{BibLiography.}

(397) F. M. Balfour. A Monograph on the development of Elasmobranch Fishes, pp. 141-146. London, 1878.

(39) H. Eisig. "Die Segmentalorgane d. Capitelliden." Mittheil. a. d. zool. Station zu Neapel, Vol. I. 1879.

(399) A. Götte. Entwicklungsgeschichte d. Unke. Leipzig, 1875. 1857.

(†०) F'r. Leydig. Lehrbuch d. Histologie des Menschen u. d. Thiere. Hamm.

(401) Fr. Leydig. Nene Beiträge $z$, anat. Kenntniss d. Hautdecke n. Hantsimesorgane d. Fische. Halle, 1879.

(402) F'. E. Schulze. "Ueb. d. Sinnesorgane d. Seitenlinie bei Fischen und Amphibien." Arehiv f. mikr. Anat., Vol. vi. 1870.

$(+03)$ C. Semper. "Das Urogenitalsystem d. Selachier." Arbeit.a.d. zool.zoot. Instit. Wïrzburg, Vol. II.

$\left({ }_{4} 0_{4}\right)$ B. Solger. "Neue Untersuchungen zur Anat. d. Seitenorgane d. Fische." Archiv f. mikr. Anat., Vol. xvir. and xvur. 1879 and 1880. 


\section{CHAP'TER XVIII.}

\section{THE NOTOCHORD, THE VERTEBRAL COLUMN, THE RIBS AND 'THE STERNUII.}

\section{INTRODUCTION.}

Ayongst the products of that part of the mesoblast which constitutes the connective tissue of the body special prominence must be given to the skeleton of the Vertebrata, from its importance in relation to numerous phylogenetic and morphological problems.

The development of the skeleton is however so large a subject that it cannot be satisfactorily dealt with except in a special treatise devoted to it; and the following description must be regarded as a mere sketch, from which detail has been as far as possible excluded.

In the lowest Chordata the sole structure present, which deserves to be called a skeleton, is the notochord. Although the notochord often persists as an important organ in the true Vertebrata, yet there are always added to it various skeletal structures developed in the mesoblast. Before entering into a systematic description of these, it will be convenient to say a few words as to the general characters of the skeleton.

Two elements, distiuct both in their genesis and structure, are to be recognized in the skeleton. The one, forming the true primitive internal skeleton or endoskeleton, is imbedded within the inuscles and is originally formed in cartilage. In many instances it retains a cartilaginous consistency through life, but in the majority of cases it becomes gradually ossified, and converted into true bone. Bones so formerl are known as cartilage bones.

The other element is originally formed by the fusion of the ossified bases of the dermal placoid scales already described in Chapter XIV., or by the fusion of the ossified bases of teeth situated in the mucous membrane of the mouth. In both instances the plates of bone so formed may lose the teeth or spines with which they were in the first instance covered, either by absorption in the individual, or phylogenetically by their gradually ceasing to be developed. The plates of bone, which originated by the above process, become in higher types directly developed in the connective tissue beneath the skin; 
and gradually acquire a deeper situation, and are finally so intimately interlocked with parts of the true internal skeleton, that the two sets of elements can only be distinguished by the fact of the one set ossifying in cartilage and the other in membrane.

It seems probable that in the Reptilia, and possibly the extinct Amphibia, dermal bones have originated in the skin without the intervention of superjacent spinous structures.

In cases where a membrane bone, as the dermal ossifications are usually called, overlies a part of the cartilage, it may set n' ossification in the latter, and the cartilage bone and membrane bone may become so intimately fused as to be quite inseparable. It seems probable that in cases of this kind the compound bone may in the course of further evolution entirely lose either its cartilaginous element or its membranous element; so that cases occasionally occur where the development of a bone ceases to be an absolutely safe guide to its evolntion.

As to the processes which take place in the ossification of cartilage there is still mnch to be made out. 'Two processes are often distinguished, viz. (1) a process known as ectostosis, in which the ossification takes place in the perichondrinm, and either simply surrounds or gradually replaces the cartilage, and (2) a process known as endostosis, where the ossification actually takes place between the cartilage cells. It seems probahle lowever (Gegenbaur, Vrolik) that there is no sharp line to be drawn between these two processes; but that the ossification almost always starts from the perichondrimm. In the ligher types. as a rule, the vessels of the perichondrium extend into the cartilage, and the ossification takes place around these vessels within the cartilage; but in the lower types (Pisces, Amphibia) ossification is often entirely confined to the perichondrium; and the cartilage is simply absorbel.

The regions where ossification first sets in are known as centres of ossification; and from these centres the ossification spreads ontwards. There may be one or more centres for a bone.

The actual causes which in the first instance gave rise to particular centres of ossification, or t the ossification of particular parts of the cartilage, are but little understool; nor have we as yet any satisfactory criterion for deternining the value to be attached to the number and position of centres of ossification. In some instances such centres appear to have an important morphological significance, and in other instances they would seem to be determined by the size of the cartilage about to be onsified.

There is no doubt that the membrane bones and cartilage bones can as a rule be easily distinguished by their mode of development; but it is by no means certain that this is always the case. It is necessarily very diffisult to estahlish the homology between bones, which develop in one type from membrane and in mother type from cartilage; but there are without doul, certin instances in which the homology hetween two hones would be unhesitatingly adnitted were it not for the difference in their 
development. The most difticult cases of this kind are connected with the shoulder-girdle.

The possible sources of confusion in the development of bones are olviously two. (1) A cartilage bone by origin may directly ossify in membrane, without the previous development of cartilage, and (2) a membrane bone may in the first instance be formed in cartilage.

The occurrence of the first of these is much more easy to admit than that of the second; and there can be little doubt that it sometimes takes place. In a large number of cases it would moreover cause no serious dificulty to the morphologist.

\section{Biblography of the origin of the Skeleton.}

(405) C. Gegenbaur. "Ueb. primïre u, secundäre Knochenbildung mit besonderer Beziehung auf d. Lehre von dem Primordialcranimm." Jenuische Zeitschrift. Tol. III. 1867.

(406) O. Hertwig. "Ueber Bau u. Entwicklung d. Placoidschuppen u. d. Zähme d. Selachier." Jenaische Zeitschrift, Vol. vin. 1874.

$(40 ;)$ O. Hertwig. "Ueb. d. Zahnsystem d. Amphibien u. seine Bedentung f. d. Genese d. Skelets d. Mundhöhle." Archiv j.mikr. Anat., Vol. xi. Supplementheft, 1874 .

(408) O. Hertwig. "Ueber d. Hautskelet d. Fische." Morphol. Jahrunch, Vol. II. 1876. (Siluroiden u. Acipenseriden.)

(409) O. Hertwig. "Ueber d. Hautskelet d. Fische (Lepidosteus u. Polypterus)." Morph. Jahrbuch, Vol. v. 1879.

(4 Io) A. Kölliker. "Allgemeine Betrachtungen üb. die Entstehung d. knöchernen Schädels d. Wirbelthiere." Berichte v. d. k̈̈nigl.zoot. Anstalt z. W"iirzburg, 1849.

(4II) Fr. Leydig. "Histologische Bemerkungen üb. d. Polypterus bichir." Zeit.f. wiss. Zool., Vol. v. 1858.

(412) H. Miiller. "Ueber d. Entwick. d. Knochensubstanz nebst Bemerkungen, etc." Zeit. f. wiss. Zool., Vol. 1x. 1859.

(413) Williamson." "On the structure and derelopment of the Scales and Bones of Fishes." Phil. Trans., 1851.

(4I4) Vrolik. "Studien üb. d. Verknöcherung u. die Fnochen d. Schädels d. Teleostier." Niederländisches Archiv $j$. Zoologie, Vol. I.

\section{Notochord and Vertebral column.}

The primitive axial skeleton of the Chordata consists of the notochord and its sheath. It persists as such in the adult in Amphioxus, and constitutes, in embryos of all Vertebrata, for a considerable period of their early embryonic life, the sole representative of the axial skeleton.

The Notochord. The early formation of the notochord has already been described in detail (pp. 243-249). It is developed, in most if not all cases, as an axial differentiation of the hypoblast, and forms at first a solid cord of cells, without a sheath, placed between the nervous system and the dorsal wall of the alimentary tract, and extending from the base of the front of the mid-brain to the end of the tail. The section in the region of the brain will be dealt with by itself. That in the trunk forms the basis round which the vertebral column is moulded.

The early histological changes in the cells of the notochord are approximately the same in all the Craniata. There is formed by the superficial cells of the notochord a delicate sheath, which soon

13. E. II. 
thickens, and beromes a well-defined structure. Vacnoles (nne or more to each cell) are formed in the cells of the notochord,

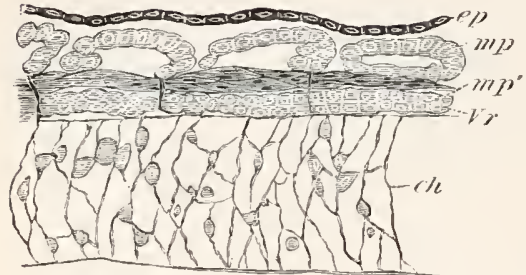

Fig, 313. HoRIZONTAL SECTION THFoLGII THE TRENK OF AN EMBRYO OF SCYLLITM CONSIDERABLY YOCNGER THAN F IN Fl', 2:?.

The section is taken at the level of the notochord, anil shews the separation of the cells to form the vertebral bodies frum the muscle-plates.

ch. notochord; $e p$. epiblast; $\mathrm{I}^{r}$. ruliment of vertebral body; mp. muscle-plate; mp'. portion of muscle-plate already differentiated into longitudinal muscles. distribution of the nuclei in the spaces of the mesh-work remains fairly uniform.

In the early stages of development the spaces in the notochordal sponge-

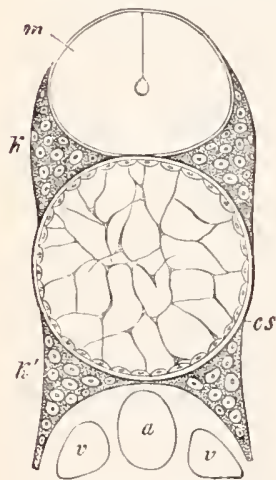

Fit. 314, SEction THROUGH THE SPINAL COLUMA OF A YOTNG Silsos. (From Gegenbaur.)

cs. sheath of noto. chord; $h$, neural areh $k^{\prime}$. hremal arch; $m$. spinal cord; $a$. dorsal aorta; $\iota$ cardiual veins. which enlarge till the whole notochord becomes almost entirely formed of large vacuoles separated by membranous septa wheh form a complete spongelike reticnlum (tig. :31:3). In the Ichthyopsida most of the protoplasm with the nuclei is carried to the periphery, where it forms a special nucleater layer sometimes divided into definite epithelial-like cell's (fig. 314), whi'e in the meshes of the reticulum a few molei surrounded by a little protoplasm still remain In the Amniotic Vertebrati, probably owing to the early atrophy of the notochord, the work, each containing a nucleus and protoplasm, probably represent cells. In the types in which the notochoril persists in the adult the mesh work becomes highly complicated, and then forms a peculiar reticulum tilled with gelatinons material, the spaces in which do not indicate the outlines of definite cells (figs. 315 and 318 ).

Around the sheath of the notochord there is formed in the Cyclostomati, Ganoidei, Elasmobranchii and Teleostei an elastic membrane usually known as the membrana elastica externa.

In most Vertebrates the notochord and its sheath either atrophy completely or become a relatively unimportant part of the axial skeleton; but in the Cyclostomata (fig. 315) and in the Selachioidean Ganoids (Acipenser, etc.) they persist as the sole representative of the true vertebral axis. The sheath becomes very much thickened; and on the membrana elastica covering it the vertebral arches directly rest. In Elasmobranchii the sheath of the notochord undergoes a more complicated series of changes, which result first of all in the formation of a definite 
msegmented cartilaginous tube ${ }^{1}$ romml the notochord, and subsequently (in most forms) in the formation of true vertebral bodies.

Between the membrana elastica externa and the sheath of the notochord a layer of cells becomes interposer (fig. :316, n), which lie in a matrix not sharply separated from the sheath of the notochord. The cells which form this layer appear to be derived from a special investment of the notochord, and to have penetrated through the membrana elastica externa to reach their final situation. 'The layer with these cells soon increases in thickness, and forms a continuous unsegmented tube of fibrous tissue with flattened concentrically arranged nuclei (fig. $\mathbf{3} 17, V b)$. Extenally is placed the membrana clastica externa (mel), while within is the cuticular sheath of the notochord. This tube is the cartilaginous tube spoken of above, and is known as the cartilaginous sheath of the notochord.

'The exact origin of the cartilaginous tube just described is a question of fundamental importance with reference to the origin of the vertebral coiumn and the homologies of its constituent parts; but is ly no means easy to settle. In the account of the subject in my memoir on Elcesmobranch Fishes I held with Gegenbaur that it arose from a layer of cells outside the sheath of the notochord, on the exterior of which the membrana elastica externa was subsequently formed. To this view Gütte (No. 4I9) also gave his adhesion. Schneider lias since (No. 429) stated that this is not the case, but that, as described above, the membrana elastica externa is formed before the layer of cartilage. I have since worked over this subject again, and am on the whole inclined to adopt S'chneider's correction.

It follows from the above description that the cartilaginous tube in

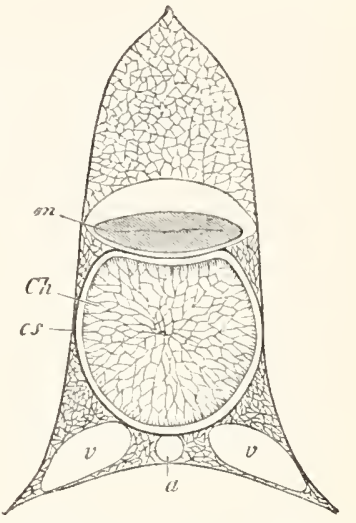

Fig. 315. Section through THE VERTEBRAL COLUMN OF AMMoC(ETEs. (From Gegenbaur.)

Ch. notochord; es. notochordal sheath; m. spinal cord; $a$. aorta; $i$. cardinal reins. question is an essential part of the sheath of the notochord, and that it is to some extent homologous with the notochordal sheath of the Sturgeon and the Lamprey, and not an entirely new formation.

1 This tube consists of a peculiar form of fibrous tissue rather than true cartilage, though part of it subsequently becomes hyaline cartilage. 
This sheath forms the basis of the centra of the future vertebræ. In a few adult forms, i.e. Chimera and the Dipuoi, it retains its primi-

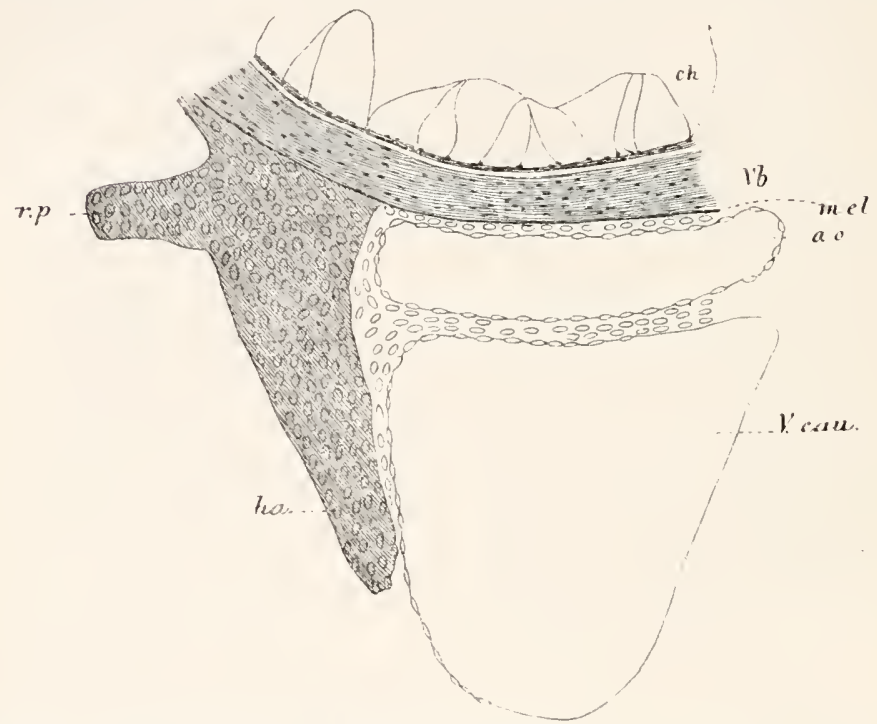

Fig. 317. Thassverse SeCtion through the VENTRAL Part of the Notochord ANJ ADJOINIXG STRUCTURES OF AN ADVANCED SCYlLIUM EMBISO AT TIE ROOT OF THE TAIL.

$7 b$. cartilaginous sheath of the notochord; ha. hrmal arch; $v p$. process to which the rib is articulated; mel. membrana elastica externa; ch. notochord; ao. aorta; l.cau. caudal vein.

tive condition, except that in Chimara there are present delicate ossified rings more numerous than the arches; while in the Notidani, Lxmargi and Echinorhini the indications of vertebræ are imperfectly marked out. The further history of this sheath in the forms in which true vertebra are formed can only be dealt with in connection with the formation of the vertebral arches.

In Teleostei there is present, as in Elasmobranchii, an elastica externa, and an imer notoshordal sheath. The elastica externa contains, according to Gütte, cells. These cells, if present, are however very difficult to make out, but in any case the so-called elastica externa appears to correspond with the cartilaginous sheath of Elasmobranchii together with its enveloping elastica, since ossification, when it sets in, occurs in this layer. The sheath within becomes unusually thick.

In the Amphibia and in the Amniota no membrane is present which can be identified with the membrana elastica externa of the Elasmobranchii, Teleostei, etc. In Amphibia (Gotte) there is formed round the notochord a cellular sheath, which has very much the relations of the cartilaginous tube around the notochord of Elasmobranchii, and is developed in the same way from the perichordal connective tissue cells. It is only necessary to suppose that the membrana elastica externa has ceased to be developed (which in 
view of its extreme delicacy and unimportant function in Elasmobranchii is not difficult to do) and this cellular sheath would then obviously be homologous with the cartilaginous tube in question. In the Amniota an external sheath of the notochord camot be tracel as a distinct structure, but the comective tissue surrounding the notochord and spinal cord is simply differentiated into the vertebral bodies and vertebral arches.

\section{Tertebral arches and Tertebral bodies.}

Cyclostomata. The Cyclostomata are the most primitive forms in which true vertebral arches are present. Their ontogeny in this group has not been satisfactorily worked out. It is however noticeable in connection with them that they form for the most part isolated pieces of cartilage, the segmental arrangement of which is only imperfect.

Elasmobranchii. In the Elasmobranchii the cells forming the vertebral arches are derived from the splanchnic layer of the mesoblastic somites. They have at first the same seg'mentation as the somites (fig. 313, $\mathrm{Vr}$ ), but this segmentation is soon lost, and there is formed round the notochord a continuous sheath of embryonic connective tissue cells, which gives rise to the arches of the vertebræ, the tissue forming the dura mater, the perichondrium, and the general investing comnective tissue.

The changes which next follow result in what has been known since Remak as the secondary segmentation of the vertebral column. This segmentation, which occurs in all Vertebrata with true vertebre, is essentially the segmentation of the continuous investment of the notochord and spinal cord into vertebral bodies and vertebral arches. It does not however follow the lines of the segmentation of the muscle-plates, but is so effected that the centres of the vertebral bodies are opposite the septa between the muscle-plates.

The explanation of this character in the segmentation is not difficult to find. The primary segmentation of the body is that of the muscle-plates, which were present in the primitive forms in which vertcbre had not appeared. As soon however as the notochordal sheath was required to be strong as well as flexible, it necessarily became divided into a series of segments.

The condition under which the lateral muscles can best cause the flexure of the vertebral column is clearly that each myotome shall be capable of acting on two vertebre ; and this condition can only be fulfilled when the myotomes are opposite the intervals between the vertebre. For this reason, when the vertebre becane formed, their centres were opposite not the middle of the myotomes but the inter-muscular septa.

These considerations fully explain the characters of the secondary segmentation of the vertebral columu. On the other hand the primary segmentation (tig. 313) of the vertebral rudiments is clearly a remnaut of a condition when no vertebral bodies were present; and has no greater morphological significance than the fact that the cells of the vertebra 
were derived from the segmented muscle-plates, and then became fused into a continuous sheath around the notochord and nervous axis; till finally they became in still higher forms differentiated into vertebra and their arches.

During the stage represented in fig. $28 \%$, and somewhat before the cartilaginous sheath of the notochord is formed, there appear four special concentrations of the mesoblastic tissue adjoining the notochord, two of them dorsal (nemal) and two of them ventral (hamal). They are not segmented, and form four ridges, seated on the sides of the notochord. They are mited with each other by a delicate layer of tissue, and constitute the substance in which the neural and hemal arches subsequently become differentiated.

At about the time when the first traces of the cartilaginous sheath of the notochort arise, differentiations take place in the neual and hamal rickes. In the neural ridge two sets of arches are formed for each myotome, one resting on the cartilaginous sheath of the notochord in the region which will afterwards form the centrum of a vertebra, and constituting a true neural arch; and a second separate from the cartilaginous sheath, forming an intercalated piece'. Both of them soon become hyaline cartilage.

There is a considerable portion of the original tissue of the neural ridge, especially in the immediate neighbourhood of the notochord, which is not employed in the formation of the neural arches. This tissue has a fibrous character and becomes converted into the perichondrium and other parts.

The hremal arches are formerl fron the hamal ridge in precisely the same way as the neural arches, but interhamal intercalated pieces are often present. In the region of the tail the hromal arches are continued into ventral processes which meet below, enclosing the aorta and caudal veins.

Since primitively the postanal gut was placed between the aorta and the caudal vein, the handal arches potentially invest a caulal section of the body cavity. In the trunk region they do not meet rentrally, but give support to the ribs. The structures just described are shewn in section in fig. 318, in which the nemal (na) and hamal (ha) arches are shewn resting upon the cartilaginous sheath of the notochord.

While these changes are being effecter in the arches the cartilaginous sheath of the notuchord undergoes important differentiations. In the vertebral regions opposite the origin of the neural and hamal arches (fig. :31s) its outer part becomes hyaline cartilage, while the inner parts adjoining the notochord undergo a somewhat different development, the notochord in this part becomes at the same time

1 The presence of intercalated pieces in the netral arch system of Elasmolranchii, Chimæra, etc. is probably not the indication of an highly differentiated type of neural areh, but of a transitional type between an imperfect investment of the spinal cord by isolated cartilaginous hars, and a complete system of neural arches like that in the higher Vertebrata. 
somewhat constricted. In the intervertebral regions the cartilaginous sheath of the notochord becomes more definitely fibrous, while the notochord is in no way constricted. A diagrammatic longitudinal section through the vertebral colmmn, while these changes are being effected, is shewn in fig. $320 \mathrm{~B}$.

These processes are suon carried finther. The notochord within the vertebral body becomes gralually constricted, especially in the median plane, till it is here rerluced to a tibrous band, which gralually enlarges in either direction till it reaches its maximum thickness in the unedian plane of the intervertebral region. 'I'he hyaline cartilage of the vertebral region foms a vertebral body in which caleification may to some extent take place. The eartilage of the base of the arches gradually spreads over it, and on the absorption of the membrana elastica externa which usually takes p'ace long before the adult state is reached the areh tissue becomes indistingnishably firsed with that of the vertebral borkes, so that the latter are compomil struetures, partly formed of the pamitive cartilaginons sheath, and partly of the tissue of the bases of the nenral and hemal arches. Owing to the beader structure of the notochord the vertebra! bodlies take of necessity a biconcave hourglass-shaped form.

The intervertebral regions of the primitive sheath of the notsehord fin tibrous intervertebral liganents enclosing the unconstricted intervertebral suctions of the notochord.

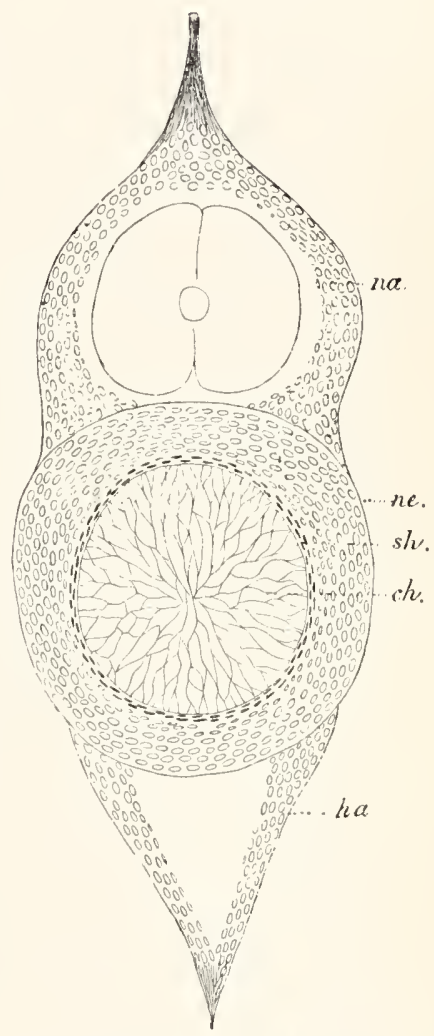

Frg, 31:, DECTION THROLGH THE VERTEBRA COLUMN OF AN AD-

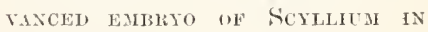
THZ REGION OF IHE TAH.

na. neural areh; ha. hrmal a"ch; ch. notochord; sh. immer s'eath of notoc. ord; ne. membraua clastica externa.

A freculiar fact may here be noticed with reference to the formation of the vertebral bodies in the tail of Seyllium, Raja, and possilly other forms, viz. that there we double as many vertebral bodirs as there are myotomes and spinal nerves. This is not due to a secondary segmentation of the verteblate but, as I have satintied myself by a stuly of the levelopment, takes flace when the vertehral bodies first hecome differentiated. The possibility of such a relation of parts is probably to $\mathrm{l} x$. explained by the filct that the segmentation of the vertebral column arose subsequently to that of the nerves and myotomes. 
Ganoidei. In Acipenser and other cartilaginous Ganoids the hwmal and neural arches are formed as in Elasmobranchii, and rest 11 won the outer sheath of the notochord. Since however the sheath of the notochord is never differentiated into distinct vertebre, this primitive condition is retained through life.

Teleostei. In Teleostei the formation of the rertebral arehes and hordirs takes place in a manner, which can be reduced, except in certain minor points, to the same type as that of Elasmobranchii.

There are early formed (fig. $314 k$ and $k^{\prime}$ ) neural and hemal arches resting unon the outer sheath of the notochord. The litter structure, which, as mentioned on p. 452, corresponds to the cartilaginous sheath of the notochord of Elatsmolnanchii, soon becomes divided into vertebral and intervertebral regions. In the former ossification directly sets in without the sheath acquiring the character of hyaline cartilage (Götte, 4 I 9). The latter forms the fibrons intervertebral ligaments. The notochord (xhibits vertelinal constrictions.

The ossitied outer sheath of the notochord forms but a small part of the permanent vertubre. The remainder is derived partly from an ossification of the connective tissue surrounding the sheath, and partly from the bases of the arches, which do not spread round the primitive vertebral hodies as in Elasmolranchii. The ossifications in the tissue surrounding the sheath usmilly (fig. 319) take the form of a cross, while the bases of the arches $\left(k\right.$ and $\left.l^{\prime}\right)$ remain as four cartilaginous radii between the limbs of the ossenus cross. In some instinces the bases of the arches also become ossified, and are then with difficulty distinguishable from the other parts of the secondary rortebral body. The parts of the arches outsicle the vertebral bodies are for the most part ossified (fig. 319). In correlation with the vertebral constrictions of the notochorl the vertebral bodies are biconcave.

Amphibia. Of the forms of Amplibia so far studied embryologically the Salanantridae present the most primitive type of formation of the rertebrat column.

It has alrearly been stated that in Amphibia there is present around the notochord a eellular sheath, equivalent to the cartilaginous sheath of Elasmobranchii. In the tissue on the dorsal side of this sheath a series of cartilaginous proeesses becomes formed. These processes are the emmmencing nenral arches; and they rest on the cellulitr sheath of the notochord opposite the middle of the vertebral regiuns.

A superficial osseons laver becones very early formed in each vertebral region of the cellular sheath; while in each of the intervertebral regions, which are considerably shorter than the vertebral, there is developed a ring-like cartilaginons thickening of the sheath, which projects inwards so as to constrict the notochord. At a period before this thickening has attained considerable dimensions the notoword becomes sufficiently constricted in the centre of each vertebral region to give a biconcave form to the vertebra for a very short perioxl of fortal life. 
The stage with biconcave vertebre is retained through life in the Peremibranchiata and Gymmophiona.

The chief peculiarity which distinguishes the later history of their vertebral column from that of fishes consists in the immense development of the intervertebral thickenings just mentioned, which increase to such an extent as to reduce the notochord, where it passes through them, to a mere band; while the cartilage of which they are composed becomes differentiated into two regions, one belouging to the vertebra in front, the other to that behind, the hinder one being convex, and the anterior concave. The two parts are not howevel absolutely separated from each other.

By these changes each vertebra comes to be composed of (1) a thin osseous somewhat hourglass-shaped cylinder with a dilated portion of the notochord in its centre, and (2 and 3 ) of two halves of two interverteloral cartilages, viz. an anterior convex half and a posterior concave half. The vertebræ thus come to be

A

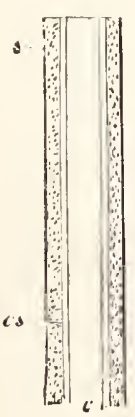

B

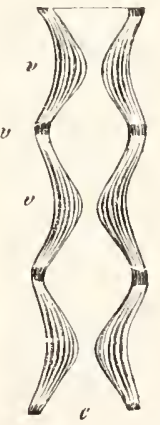

c

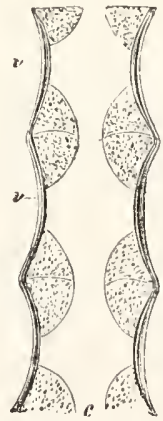

1)

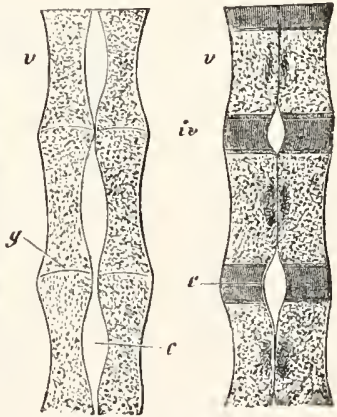

Fig. 320. Diagray representing the hone of Develophent of the vertebre IN THE DIFFERENT TYPES. (From Gegenbaur.)

A. Ideal type in which distinct vertebræ are not established.

B. Type of Pisces with vertebral constrictions of the notochord.

C. Amphibian type, with intervertebral constrictions of the notochord by the intervertebral parts of the cellular sheath.

D. Intervertebral constriction of the notochord as effected in Reptilia and Aves.

E. Vertebral constriction of the notochord as effected in Mammalia, the intervertebral parts of the cartilaginous sheath being converted into intervertcbral ligaments.

$c$. notochord; $c s$. cuticular sheath of notochord ; $s$. cartilaginous sheath; $v$. vertebral regions; $i v$. intervertebral regions ; g. intervertebral joints. 
opisthocoelous. A longitudinal section through the vertebral column at this stage is diagrammatically shewn in fig. $320 \mathrm{C}$.

To the centre of each of these vertebre the neural arches, the origin of which was described ahove, become in the meantime firmly attached; ancl grow obliquely upwards and backwards, so as to meet and unite above the spinal cort. The transverse processes of the vertebre would seem (Fick) to be developed independently of the arches, though they very soon fuse with them. According to Götte the transverse processes are double in the trunk, there being two pairs, one vertically above the other for each vertebra. The pair on each side eventually fuse together.

In the tail hemal arches are formed, which are similar in their mode of development to the neural arches.

The unconstricted portion of the notochord, which persists in each vertebra, becones in part converted into cartilage.

Anura. In the Anura the process of formation of the vertebral column is essentially the same as that in the Salatuandridre. Two types may however be olserved. (One of these occurs in the majority of the Anura, and mainly differs from that in Salamandra in (1) the eal lior fusion of the arehes with the cellular sheath of the notochord; (2) the more rapich growth of the intervertebral thickenings of the cellular sheath, which results in the early and complete obliteration of the intervertebral parts of the notochord; (3) the complete division of these intervertehral thickenings into anterior and posterior portions, which unite with and form the articular surtaces of two contiguous vertebre. The vertebre are moreover procelous instead of being opistliocelous.

The unconstricted vertebral sections of the notochord al ways persist till the ossitication of the vertebre has taken place. In some forms they remain through life (Rana), while in other cases they eventually either wholly or partially disappear.

The second type of vertehral development is found in Bombinator, Pseudis, Pipa, and Pelobates. In these genera the formation of the vertehra takes plice almost entirely on the dorsal side of the notuchord; so that the latter forms a band on the ventral side of the vertebral columm. In other respects the history of the vertebral column is the same in the two casses; the vertebral unconstricted parts of the notochord appear however to become in part converted into cartilage. The type of formation of the vertehral column in these genera has been distinguished as epichordal in contradistinction to the more nownal or perichordal type.

Amniota. In the Ammiota all trace of a distinction between a cellular notochord sheath and an arch tissue is lost, and the two are developed together as a continuous whole forming an unsegmented tube ronul the notochord, with a neural ridge which does not at first near'y invest the neural cord. This tube becomes differentiated, in the namner already described for other types, into (1) vertebral regions with true arches, and (2) intervertebral regions.

Reptilia. In Reptilia (Gegenbaur, No. 4I6) a cartilaginous tube is formed romed the notochord, which is contimous with the carti- 
laginous neural arches. The latter are placed in the vertebral regions, and in these regions ossification very early sets in, while the notochord remains relatively unconstricted. In the intervertebral regions the cartilage becomes thickened, as in Amphibia, and gradually constricts the notochord. The cartilage in each of the intervertebral regions soon becomes dividerh into two parts which form the articular faces of two contiguous vertebra.

The general character of the vertebral column on the completion of these changes is shewn in fig. $320 \mathrm{D}$. The later changes are relatively unimportant. The constricted intervertebral sections of the notochord rapidiy disappear, while the vertebral sections become partially converted into cartilage, and only cease to be distingnishable at a considerably later period.

The ussification extends from the bodies of the vertebre into the arches and into the articular surfaces, so that the whole vertebre eventually become ossified.

The Ascalabota (Geckos) present an exceptional type of vertebral column which has many of the characters of a dere'opmental stage in other Lizands. The borly of the vertehra is formed of a slightly hourglassshaped osseons tube, united with adjoining vertebre by a short intervertehnal cartilage. There is a persistent and continuous notochord which, owing to the small development of the intrvertebral cartilages, is narrower in the vertebral than in the intervertebral regions.

Aves. In Birds the cellular tube formed round the notochord is far thicker than in the Reptilia. It is continuous in the regions of the future vertebre with nemial arches, which do not at first nearly enclose the spinal cord.

On about the fifth day, in the case of the chick, it becomes differentiated into vertebral regions opposite the attachments of the neural arches, and intervertebral regions between them; the two sets of regions being only distinguished by their histological characters. Very shortly afterwards each intervertebral region becomes segmented into two parts, which respectively attach themselves to the contiguous vertebral regions. A part of each intervertebral region, immediately adjoining the notochord, does not however undergo this division, and afterwarls gives rise to the ligamentum suspensorium.

The notochord during these changes at first remains indifferent, but subsequently, on about the seventh day in the chick, a shight constriction of each rertebral region takes place; so that the vertebræ have temporarily, as they have also in Amphibia, a biconcave form which repeats the permanent condition of most fishes. By the ninth and tenth days, however, this condition has completely cisappeared, and in all the intervertebral portions the notochurd has become distinctly constricted, and at the same time in each vertebral portion there have also appeared two constrictions of the notochord giving rise to a central and to two terminal enlargements.

On the twelfth day the ossification of the cartilaginous centra commences. 
The first vertebra to ossify is the second or third cervical, and the ossification gradually extends to those behind. It does not commence in the arches till somewhat later than in the bodies. For each arch there are two centres of ossification, one on each side.

The notochord persists for the greater part of foetal life and even into post-foetal life. The larger vertebral portions are often the first completely to vanish. They would seem in many cases at any rate (Gegenbaur) to be converted into cartilage, and so form an integral part of the permanent vertebræ. Ru-

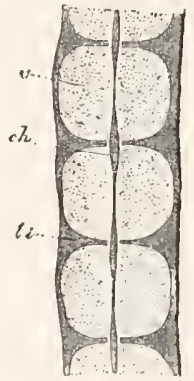

Fig. 321. LoNgitedinal Sec. TION THROUGH THE VERTEBRAL COLUMN OF AN EIGHT WEEKS' HUMAN EMBRYO IN THE THORACIC REGION. (From Kölliker.)

$v$. cartilaginous vertebral body; li. intervertebral ligament; ch. notochord. the same in Mammals as in Birds. The differentiation into vertebral and intervertebral regions is the same in both groups; but instead of becoming divided as in Reptilia and Birds into two segments attached to two adjoining vertebræ, the intervertebral regions become in Mammals wholly converted into the intervertebral ligaments (fig. 322 li). There are three centres of ossifications for each vertebra, two in the arch and one in the centrum.

The fate of the notochord is in important respects different from that in Birds. It is first constricted in the centre of the vertebre (figs. $320 \mathrm{E}$ and 321) and disappears there shortly after the ossification; while in the intervertebral regions it remains relatively unconstricted (figs. 320 E, 321 and $32 \cdot 2$ ) and after undergoing certain histological changes remains through life as part of the mucleus pulposus in the axis of the invertebral ligaments ${ }^{1}$. There is also a slight swelling of the notochord near the two extremities of each vertebra (fig. 322 $c^{\prime}$ and $\left.c^{\prime \prime}\right)$. In the persistent vertebral constriction of the notochord

1 This view was first put forward by Lushka, and his surmises have been confirmed by Kölliker and other embryologists. Leboncq $\left(\right.$ No. $\left._{4} 2_{4}\right)$ however holds that the cells of the notochord in the intervertebral regions fuse with those of the adjoining tissue; and Dursy and others deny that the nucleus pulposus is derived from the notochord. 
Mammals retain a more primitive and piscine mode of formation of

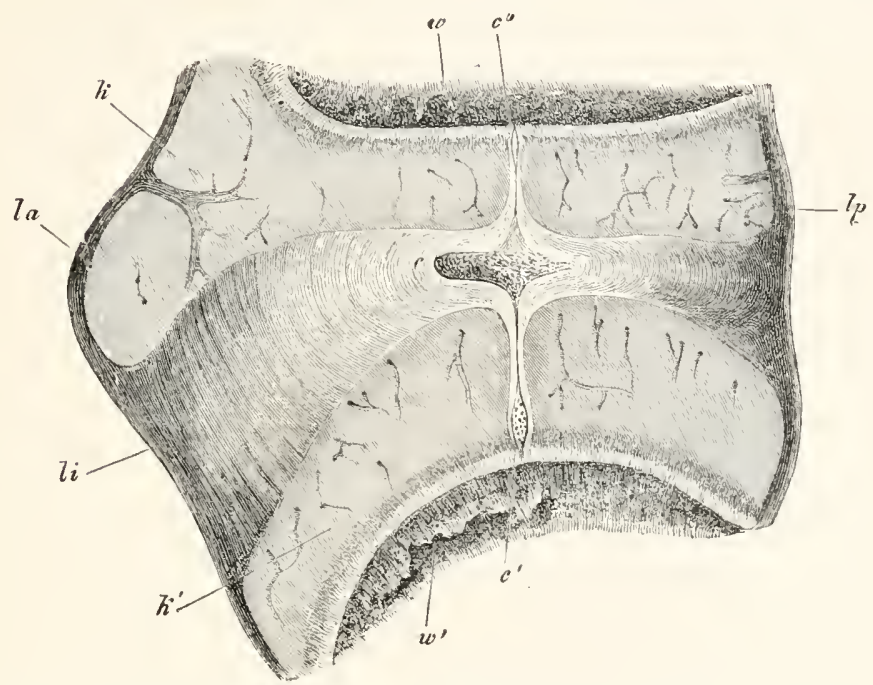

F1G. 322. Loxgltudinal Section throvgh the 1Ntervertebral Liganent and apJACENT PARTS OF TWO VERTEBRæ FROM THE THORACIC REGHON OF AN ALVANCED EMERYO OF A S̆HEeP. (From Kölliker.)

la. ligamentum longitudinale anterius; lp. ligamentum long. posterius; hi. ligamentum intervertebrale $; k, k^{\prime}$. epiphysis of vertebra; $w$. and $u^{\prime}$. anterior and posterior vertebre; $c$. intervertebral dilatation of notochord; $c^{\prime}$. and $c^{\prime \prime}$. vertebral dilatation of notochord.

the vertebral column than the majority either of the Reptiliat or Amphibia.

\section{Bibliography of Notochord and Vertebral column.}

(415) Cartier. "Beiträge zur Entwicklungsgeschichte der Wirbelsäule." Zeitschrift fiir uiss. Zool., Bd. xxv. Suppl. 1875.

(46) C. Gegenbaur. Untersuchungen zur vergleichenden Anatomie der Hirbelsänle der Amphibien und Reptilien. Leipzig, 1862.

$(+17)$ C. Gegenbaur. "Ueber die Entwickelung der Wirbelsäule des Lepidosteus mit vergleichend anatomischen Bemerkungen." Jenaische Zeitschrift, Bd. 111. 1863.

(+I8) C. Gegenbaur. "Ueb. d. Skeletgewebe d. Cyclostomen." Jenaische Zeitschifif, Vol. v. 1870.

(+19) Al. Götte. "Beiträge zur vergleich. Morphol. des Skeletsystems d. Wirbelthiere." II. "Die Wirbelsänle u. ilne Anhänge." Archiv f. mikr. Anat., Vol. xv. 1878 (Cyclostomen, Ganoiden, Plagiostomen, Chimaera), and Vol. xv1. 1879 (Teleostier).

$(+20)$ Hasse und Schwarck. "Studien zur vergleichenden Anatomie der Wirbelsäule u. s. w." Hasse, Anatomische Studien, 1872.

$(+2 \mathrm{I})$ C. Hasse. Das natïrliche System d. Elasmobranchier anf Grandlage d. Bau. u. d. Entıick. ihrer Wirbelsäule. Jena, 1879.

( +22 ) A. Kölliker. "Ueber die Beziehungen der Chorda dorsalis zur Bildung der Wirbel der Selachier und einiger anderen Fische." Terhandlungen der physical.

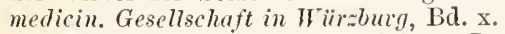

$(+23)$ A. Kölliker. "Weitere Beobachtungen über die Wirbel der Selachier insbesondere iiber die Wirbel der Lamnoidei." Abhuudlungeu der senkenbergischen naturiorschenten Gesellschurt in Frankifurt, Bd. v. 
$\left(t^{2}+\right)$ H. Leboncq. "Recherches s. 1. mode de disparition de la corde dorsale chez lés vertébrés supérieurs." Archires de Biologie, Vol. 1. 1880.

$(+25)$ Fr. Leydig. Anatomisch-histologische Untersuchngen ïber Fische und lieptilien. Berlin, 1853.

(426) Aug. Mïller. "Beobachtungen zur vergleichenden Anatomie der Wirbelsaiile." Miiller's Archir. 1853.

$(427)$ J. Miiller. "Vergleichende Anatomie der Myxinoiden u. der Cyllostomen init durchbohrtem Gaumen, I. Usteologie und Myologie." Abhandlungen der kïniglichen Akademie der Hissunschaten zu Berlin. 1834.

$(+28)$ W. Müller. "Beobachtumgen des pathologischen Instituts zu Jena, I. Ueber den Bau der Chorda dorsalis." Jenuische Zeitschrift, Bd. vr. 1871.

(429) A. Schneider, Beiträge z. vergleich. Anat. u. Entuick. d. Wirbelthier. Berlin, 1879 .

\section{Libs and Sternum.}

Ribs. Embryolugical evidence on the development of the ribs, though somewinat inarlequate, indicates that they arise as cartilaginous bars in the comnective tissuc of the intermuscular septa, and that they are placed (in the Ichthyopsida at any rate) on the level of division between the dorso-lateral and ventro-lateral divisions of the muscle-plates. They may be attached either to the hremal (Pisces) or neural (Amphibia and Ammiota) arches. The connective tissue from which they are formed is continuous with the processes of the vertebre to which they are attached; but the conversion of the tissue into cartilage takes place more or less independently of that of the arches, although in many cases the cartilage of the two becomes continuous, the separation of the ribs being then effected by a subsequent process of segmentation.(Fick, No. 43I). It is possible that the ribs of Pisces may not be homologous with those of Amphibia and the Amniota, but till the reverse can be proved it is more convenient to assume that the ribs are homologons structures throughout the vertebrate series.

In Elasmobranchii the ribs are relatively of less importance in the adult than in the embryo. By a careful examination of their early derelopment, I have satisfied myself that the differentiation of the ribs is imdependent of that of the hemal processes to which they are attached, althougl, the differentiation proceeds in such a mamner that, when both are converted into cartilage, they are quite continuous. Subsequently the rilsi become segmented off from the hemal processes. At the junction of the tail and trunk, where the hiemal processes conmence to be ventrally prolonged, eventually to unite in the region of the tail below the caudal vein, the ribs are attached to short processes which sping from the sides of the hemal arehes (fig. 317). The ventral hremal arches of these fishes are therefore clearly in no part formed by the ribs.

In Ganoidei and Teleostei there is very great difficulty in determining the homologies of the ribs.

In the cartilaginous Ganoidei there are well developed rib-like structures, which might be regarded as homologous with Elasmolranch ribs, and indeed probably are so ; but at the same time their relations are in some respects very different from those of Elasmobranch ribs in the caudal region. In Ganoids the ribs, in approaching the tail, become shorter and then fuse with the euds of the hemal processes, and finally in the caudal region 
form together with the hamal anches at chesed hamal camal which superficially resembles that in Elasmobranchii.

In Lepidostens and Amia, especially the former, the same phenomenon is still more marked; and in Lepillosteus it is easy, in passing backwards, to trace the ribs bending rentral-wards, and uniting ventrally in the caudal region to form, with the hemal processes, a complete hemal canal.

It might have been anticipated that the Teleostean Ganoiels would resemble the 'Teleostei, but, from an examination of adult Telerstei, it would seem to be clear that the relations of the prarts are the same as in Elasmobranchii, i.e. that the ribs lave no share in forming the hemal caul in the tail. Aug. Müller and Gotte have however brought embryological evidence (though not of a conclusive character'), to shew that in the embryo the ribs really fuse with the hemal processes in the tail, and so assist, as in the Ganoids, in forming the hemal canal. Götte moreover holds that the ribs in Elasmobranchii are not homologous with those of Teleostei and Ganoids; but that the hrmal arches in the tail are homologous in the three groups.

Without necessarily following Gütte in these views it is worth pointing ont that the unloubtedly close afhinity between the bony Ganoids and the Telcostei is in farour of the view on the hiemal arches of Teleostei at which he has arrived on embryological grounds.

In Amphibia the formation of the ribs from the connective tissue of the intermuscular septa, their secondary attachment to the transverse processes of the neural arches, and their subsequent separation was first clearly established by Fick (No. 43I), whose statements hatre since been confirmed by Hasse, Born, de., and in part by Götte, who holds however that, though converted into cartilage independently of the transverse processes, they are formed in membrane as outgrowths of these processes.

Iu the Amniotat the ribs are also indeprendently established (Hasse and Born), though they subseqnently become united to the transverse processes and to the bodies of the vertebre, or to the transverse processes only. This junction is however stated by the majority of anthorities, never to be effected by the fusion of the cartilage of the two parts, but always by fibrous tissue; though Hoffiman (No. 435) takes a different view on this subject, holding that the ribs are at first continuons with the intervertelral regions of the primitive cartilaginous tube surrounding the notochord.

Sternum. In dealing with the development of the sternum it will be convenient to leave out of consideration the interclavicle or episternum which is, properly speaking, only part of the shouldergirdle and to confine my statements to the sternum proper.

This structure is found in all the Amniota except the Ophidia, Chelonia, and some of the Amphisbænæ.

From the older researches of Rathke, and from the newer ones of Götte, etc., it appears that the sternum is always formed from the fusion of the ventral extremities of a certain number of ribs. The extremities of the ribs unte with each other from before backwards, and thus give rise to two cartilaginous bands. These bands become segmented off from the ribs with which they are at first continuous, and subsequently fuse in the median ventral line to form an unpaired sternum. The Mammalian presternum (manubrium stemi) and 
xiphosternum have the same origin as the main body of the sternum (Ruge, No. 438).

In the Amphibia there is no structure which admits from its mode of development of a complete comparison with the sternum of the Amniota ; and it must for this reason be considered doubtful whether the median structure placed behind the coracoids in the Anura, which is usually known as the sternum, is really homologous with the stermum of the Amniota ${ }^{1}$. sternum.

The remaining Ichthyopsida are undoubtedly not provided with a

\section{Bibliography of Ribs and Sternum.}

(430) C. Claus. "Beiträge z. vergleich. Osteol. d. Vertebraten. I. Rippen u. unteres Bogensystem." Sitz. d. kaiserl. Akad. Wiss. Wien, Vol. LxxIv. 1876.

(43 I) A. E. Fick. "Zur Entwicklungsgeschichte d. Rippen und Querfortsätze." Archiv $f$. Anat. und Physiol. 1879.

(+32) C. Gegenbaur. "Zur Entwick. d. Wirbelsäule des Lepidosteus mit vergleich. anat. Bemerk." Jenaische Zeit., Vol. III. 1867.

(433) A. Götte. "Beiträge $z$. vergleich. Morphol. d. Skeletsystems d. Wirbelthiere Brustbein u. Schultergürtel." Archiv f. mikr. Anat., Vol. xiv. 1877.

$(434)$ C. Hasse u. G. Born. "Bemerkungen iib. d. Morphologie d. Rippen." Zoologischer Anzeiger, 1879.

(435) C. K. Hoffmann. "Beiträge z. vergl. Anat. d. Wirbelthiere." Niederländ. Archiv Zool., Vol. Iv. 1878.

(45) W. K. Parker. "A monograph on the structure and development of the shoulder-girdle and sternum." Ray Soc. 1867.

(437) H. Rathke. Ueb. d. Bau u. d. Entwicklung d. Brustbeins d. Saurier. 1853.

$\left(43^{8}\right)$ G. Iuge. "Untersuch. ïb. Entwick, am Brustbeine d. Menschen." Morphol. Jahrbuch., Vol. vi. 1880.

1 The so-called sternum of the Amphibia develops in proximity with certain rudimentary abdominal ribs, and Ruge has with some force urged (against Götte) that it may be for this reason a rudimentary structure of the same nature as the sternum of the higher types. 


\title{
CHAPTER XIX.
}

\author{
THE SKULL.
}

Three distinct sets of elements may enter into the composition of the skull. These are (1) the cranium proper, composed of true enduskeletal elements originally formed in cartilage, to which are usually added exoskeletal osseous elements, formerl in the manner already described p. $\mathbf{4 + 7}$, and known in the higher types as nembran. bones. (2) The visceral arches formed primitively as cartilaginous bars, but in the higher types largely supplemented or even replaced by exoskeletal elements. (3) The labial cartilages.

These parts present themselves in the most various forms, and their study constitutes one of the most important departments of vertebrate morphology, and one which has always been a favourite subject of study with anatomists. At the end of the last century and during the tirst half of the present century the morphology of the skull was handled from the point of view of the adult anatomy by Goethe, Oken, Cuvier, Owen, and many other anatomists, while Dugés and, nearer to our own time, Ratlike, laid the foundation of an embryological study of its morphology. A new era in the study of the skull was inaugurated by Huxley in his Croonian lecture in 1858, and in his lectures on Comparative Anatomy subsequently delivered before the Royal College of Surgeons. In these lectures Huxley disproved the then widely accepted view that the skull was composed of four vertebre; and laid the foundation of a more satisfactory method of dealing with the homologies of its constituent parts. Since then the knowledge of the development of the skull has made great progress. In this country a number of very interesting memoirs have been published on the subject by Parker, which together constitute a most striking contribution to our knowledge of the ontogeny of the skull in a series of types; and in Germany Gegenbaur's monograph on the cephalic skeleton of Elasmobranchii has greatly promoted a scientific appreciation of the nature of the skull.

In the present chapter only the most important features in the development of the skull will be tornched on.

B. E. II. 
It will be convenient to describe, in the first instance, the development of the cartilaginous elements of the skull.

The Cranium. The brain is at first enveloped in a continuons layer of mesoblast known as the membranous cranium, into the base of which the anterior part of the notochorel is prolonger for some distance. The primitive cartilaginous cranium is formed by a differentiation within the membranous cranium, and is always compused of the following parts (fig. 32:3):

(1) A pair of cartilaginous plates on eash side of the cephalic section of the notochord, known

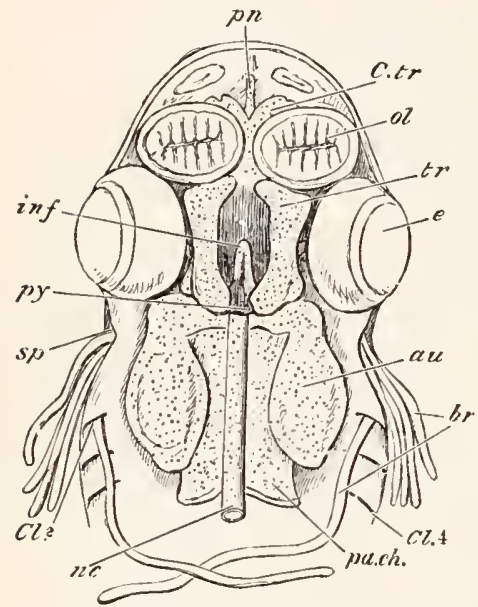

F1g. 323. Head of embiyo Dogresh, SECOND STAGE; BASAL VIEW OF ClAANIUM FLOII ABOVE, THE CONTENTS HAVINGG BEEN REMOVED. (From Parker.)

ol. olfactory sacs; au. auditory capsule; nc. notochord; py. pituitary body; pa.ch. parachordal cartilage; $t r$. trabecula; inf. infundibulum; C.tr. cornua trabecule; $p m$. prenasal element; sp. spiracular cleft; $b r$. external branchia; $C l .2,4$. visceral clefts. as the parachordals (pa. ch). These plates together with the notochord (nc) enclosed between them form a floor for the hindand mill-brain. 'The continuous plate, formed by them and the notochord, is known as the basilar plate.

(2) A pair of bars forming the floor for the fore-brain, known as the trabecula $(t \cdot)$. These bars are continued forward from the parachordials. They meet behind and embrace the front end of the notochord; and after separating for some distance bend in again in such a way as to enclose a space-the pituitary space. In front of this space they remain in contact and generally unite. They extend forwards into the nasal region $(p n)$.

(3) The cartilaginous capsules of the sense organs. Of these the auditory (au) and olfactory capsules $(o l)$ unite more or less intimately with the cranial walls; while the optic capsules, forming the usually cartilaginous sclerotics, remain distinct.

The parachordals and notochord. The first of these sets of elements, viz. the parachordals and notochord, forming together the basilar plate, is always an unsegmented continuation of the axial tissue of the vertebral column. It forms the floor for that section of the brain which belongs to the primitive postoral part of the head (vide p. 261), and its extension is roughly that of the basioccipital of the adult skull. Its mode of development is almost identical with that of the vertebral column, excep, that the notochord, even in many forms where it persists in the vertebral column, disappears in the 
basilar plate; though in a certain number of cases remnants of it are found in the adult state.

It will be convenient to say a few words here with reference to the notochord in the head. It always extends along the floor of the midand hind-brains, but ends immediately behind the infundibulum. The timits of its anterior extension are clearly shewn in tig. 43. The front end of the notochord often becomes more or less ventrally flexed in correspondence with the cranial flexure; its anterior end being in some instances (Elasmobranchii) almost bent backwards (fig. 32t).

Kölliker has shewn that in the Rabbit ${ }^{1}$, and I believe that a more or less similar phenomenon may also be observer in Birds, the anterior end of the notochord is united to the hypoblast of the throat in inmediate contiguity with the opening of the pituitary body ; but it is not clear whether this is to be looked upon as the remnant of a primitive attachment of the notochord to the hyloblest, or as a secondary attachment.

Before the parachordals are formed the anterior end of the notochord has usually undergone a partial atrophy ; and its front end often becomes somewhat dorsally flexed. Within the basilar plate it often exhibits two or more dilatations, which have been regarded by Parker and Kölliker as indicative of a segmentation of this plate; but they hardly appear to me to be capable of this interpretation.

In Elasmobranchs where, as shewn above, a very primitive type of development of the vertebral column is re-

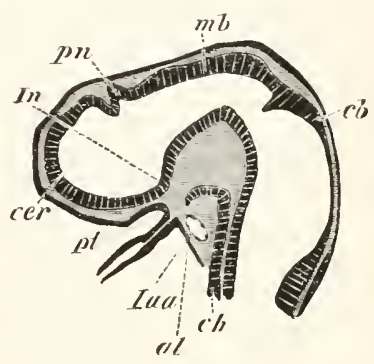

Fig. 324. Loxgitedixal SECTION THROUGH THE BHAN OF A yousg Pristictes emisiro.

cer. commencement of the cerebral hemisphere; $p n$. pineal gland; In.infundibulum; $p t$. ingrowth f om month to form the pituitary body; $m b$. mid-brain; $c b$. cerebellum; $c h$. notochord; $a$. alimentary tract; Laa. artery of mandibular arch. tained, we find that the basilar plate is at first formed of (1) the notochord invested by its cartilaginous sheath, and (2) of lateral masses of cartilage, the parachordals, homologous with the arch tissue of the vertebral columm. This development probably indicates that the basilar plate contains in itself the same elements as those from which the neural arches and the centra of the vertebral column are formed; but that it never passes beyond the unsegmented stage at first characteristic of the vertebral column. The linder end of each parachordal forms a condyle articulating with the first vertebra; so that in the cartilaginous skull there are always two occipital condyles. 'The basilar plate always grows up behind (fig. 320, so), and gives rise to a complete cartilaginous ring enveloping the medulla oblongata, in the same mamer that the neural arches envelope the spinal cord. This ring forms an occipital cartilaginous ring; in front of it the basilar plate becomes laterally continuous

1 "Embryologische Mittheilungen." Festschrift d. Naturjor. Gesell., Halle, 1,79. 
with the periotic cartilaginous capsules, and the occipital ring above usualy spreads forward to form a roof for the part of the brain between these capsules. In the higher Vertebrates the periotic cartilages may be developed continuously with the basilar plate (fig. 325).

The trabeculæ. The trabecule, so far as their mere anatomical relations are concerued, play the same part in forming the floor for the front cerebral vesicle as the parachordals for the mid-and hindbrains. They differ however from the parachordals in one important feature, viz. that, except at their hinder end (fig. 32:3), they do not embrace between them the notochord.

The notochord constitutes, as we have seen, the primitive axial skeleton of the body, and its absence in the greater part of the region of the trabeculie wonld probably seem to indicate, as pointed out by Gegenbaur, that these parts, in spite of their similarity to

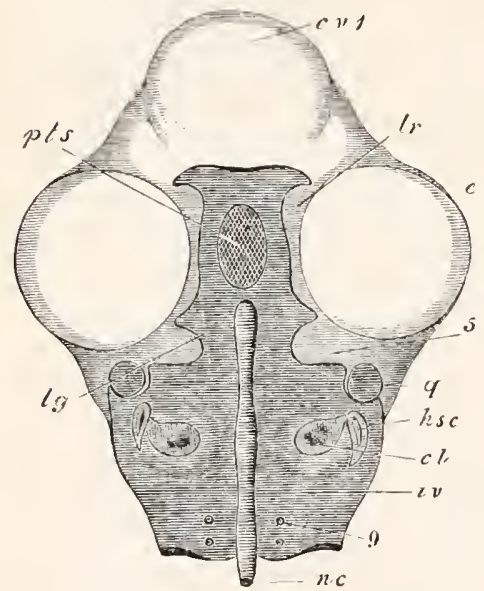

F19. 325. T1EW FroM ABOFE OF THE INVESTING MASS AND OF THE TRABECLLE OF A CHICK ON THE FOUR'TH DAY OF INCUBATIOX. (After Parker.)

In order to shew this, the whole of the upper portion of the head has been sliced away. The cartilaginous portions of the skull are marked with the dark horizontal shading.

$c v$ 1. cerebral vesicle (sliced off); $e$. eye; $n c$. notochord; $i x$. investing mass; 9 . foramen for the exit of the ninth nerve; cl. cochlea; hsc. horizontal semicireular canal; $q$. quadrate; 5 . notch for the passage of the fifth nerve; $l g$. expanled anterior end of the investing mass; $p$ ts. pituitary space; $t r$. trabeculæ. The reference line $t r$. has been accidentally made to end a little short of the cartilage. the parachordals, have not the same morphological significance.

The nature of the trabecule has been much disputed by morphologists. The view that they cannot be regarded as the anterior section of the vertebral axis is supported by the consideration that the forward limit of the primitive skeletal axis, as marked by the notochord, eoincicles exactly with the distinction we have found it necessary to recognise, on entirely independent grounds, between the fore-brain, and the remainder of the nervous axis. But while this distinction between the parachordals and the trabeculie must I think be admitted, I see no reason against supposing that the trabecula may be plates developed to support the floor of the forebrain, for the same physiological reasons that the parachordals have become formed at the sides of the notochord to support the floor of the hind-brain. By some anatomists the trabecula have been held to be a pair of branchial bars; but this view has now heen generally given up. They have also been regarded as equivalent to a complete pair of neural arches enveloping the front end of the brain. The primitive extension of the base of the forebrain through the pituitary space is 
an argument, not without force, which has been appealed to in support of this view.

In the majority of the lower forms the trabecule arise quite independently of the parichordals, though the two sets of elements soon unite; while in Birds (fig. 32.5) and Mammals the parachordals and trabeculie are formed as a continuous whole. The junction between the trabecula and parachordals becomes marked by a cartilaginous rilge known as the posterior clinoid.

The trabeculie are nsually somewhat lyre-shaped, meeting in front and behind, and leaving a large pituitary space between their mildle parts (figs. 3:2:3 and :32.5). Into this space there prinitively projects

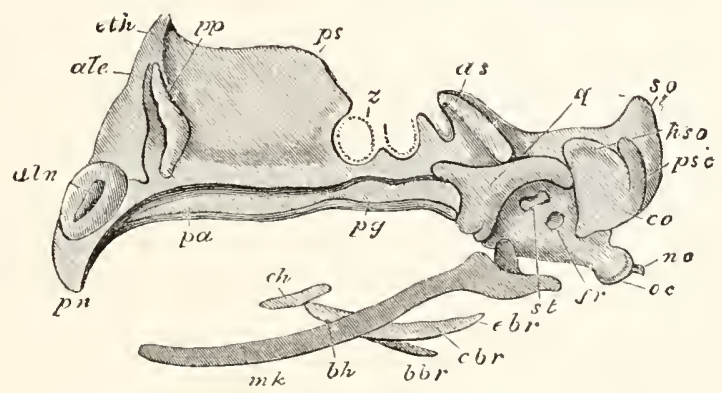

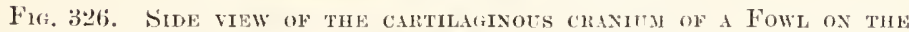
Sevexth day of ixcubation. (After Parker.)

$l^{\prime \prime \prime}$. prenasal cartilage; $a n$. alinasal cartilage; ale. aliethmoid; immediately below this is the aliseptal cartilage. eth. ethmoid; $p p$. pars plana; $p s$. presphenoid or interorbital; $p a$. palatine; $p g$. pterygoid; $z$. optic nerve; $\iota s$. alisphenoid; q. quadrate; st. stapes; fir. fenestra rotunda; hso. horizontal semicircular canal; psc. posterior vertical semicircular canal : both the anterior and the prosterior semicircular canals are seen shining through the cartilage. so. supraoceipital; $\epsilon$. exoccipital; oc. occipital condyle; ne. notochord; ml. Meckel's cartilage; ch. cerato-hyal; bh. basi-hyal; clm. and elr. cerato-branchial; blr. basibranchial.

the whole base of the fore-brain, but the space itself gralnally becomes narrowed, till it usually contains omly the pituitary body. The carotid arteries always pass through it in the embryo; but in the higher forms it ceases to be perforated in the adult. The trabecula soon unite trgether both in front and behind and form a complete plate underneath the fore-brain, and extending into the nasal region ${ }^{1}$. A special vertica! growth of this plate in the region of the orbit forms the interorbital plate of Telenstei, Lacertilia and Aves (fir. $3: 0, p s$. on the upper surface of which the front part of the brain rests. The trabecular floor of the brain does not long remain simple. Its sides grow vertically upwards, forming a lateral+wall for the brain, in which in the higher types two regions may be distinguished, viz. an alisphenoidal region (fis. 326 , as) behind, growing out from what is known as the basisphenoidal region of the

1 In Man (Kolliker) the traherulis form from the first a contimmous plate in front of the pituitary space, an 1 the latter very early acquires a cartilarinons floor. 
primitive trabeculix, and an orbitosphenoidal region in front growing out from the presphenoidal region of the trabeculie. These plates form at first a continuous lateral wall of the cranium. At the front end of the brain they are continued inwards, and more or less completely separate the true cranial cavity from the nasal region in front. The region of the cartilage forming the anterior boundary of the cranial cavity is known as the lateral ethmoid region, and it is always perforated for the passage of the olfactory nerves.

The cartilaginous walls which grow up from the trabecular floor of the cranium generally extend upwards so as to form a roof, though almost always an imperfect roof, for the cranial cavity. In the higher types, in Mammals more especially, this roof can hardly be said to be formed at all. The region of the trabecula in front of the brain is the ethmoid region. The basal part of this region forms an internasal plate, from which an internasal septum may grow up (fig. 326). To its sides the olfactory capsules are attached, and there are usually lateral outgrowths in front forming the trabecular cornua, while from the posterior part of the ethmoidal plate, forming the anterior boundary of the cranial cavity, there often grows out a prefiontal or lateral ethmoidal process.

These and other processes growing out from the trabeculæ have oceasionally been regarded as rudimentary preoral branchial arches. I have already stated it as my view that the existence of branchial arches in this region is highly improbable, and I may add that the development of these structures as ontgrowtls of the skull is in it-elf to my mind a nearly

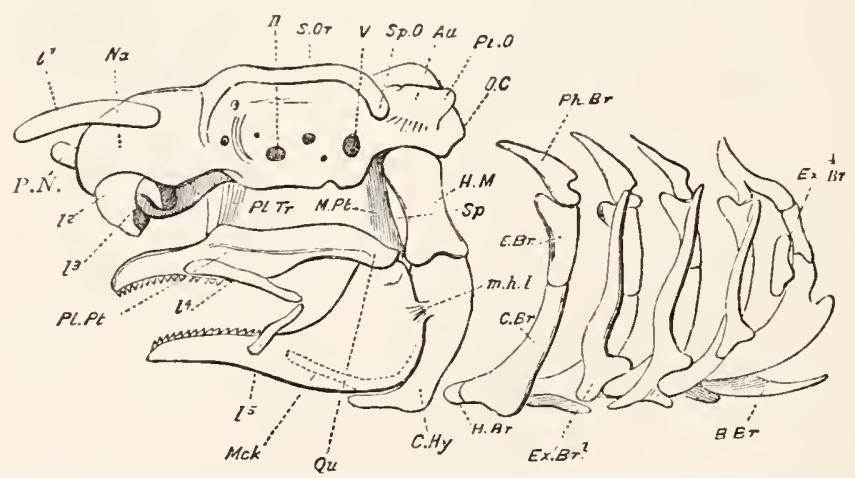

Fig. 327. Skull of adult Dogfish, side view. (From Parker.)

O.C. Occipital condyle; Au. periotic capsule; Pt.O. pterotic ridge; Sp.O. sphenotic process; S.Or. supraorbital ridge; Na. naral capsule; P.N. prenasal cartilage; $I I$. optic foramen; $V$. trigeminal foramen; Pl.Pt., Qu. pterygo-quadrate areade; H.Pt. metapterygoid ligament (including a small cartilage); Pl.Tr. ethmo-palatine or palato-trabecular ligament; Mck. lower jaw; Sp. spiracle; H.M. hyomandibular; C.Hy. ceratohyal; in.h.l. mandibulo-hyoid ligament; $I^{\prime} h . B^{\prime} r$. pharyngobranchial ; E.Br. epibranchial; C.br. ceratobranchial; $I I . B r$. hypobranchial ; B.Br. basibranchial ; Ex.Br. extrabranchial ; $l i, ", 3,4,5$. labial cartilages; the dotted lines within $11 \mathrm{ck}$. indicate the basihyal. 
conchsive argument against their heing branchial arches, in that true branchial arches hatly ever or perhaps never arise in this way.

The sense capsules. The most important of these is the auditory capsule, which, as we have seen, fuses intimately with the lateral walls of the skull. In front there is usua!ly a cleft separating it from the alisphenoid region of the skull, through which the third division of the fifth nerve passes out. This cleft becomes narrowed to a small firranen (fig. $327, V$ ). The sclerotic cartilage is always free, but profound'y modities the region of the cranium near which it is placed. The nasal investment forms in Elasmobranchs (fig. 327, $\mathrm{Na}$ ) a capsule open below, and continuons with the ethmoid region of the trabeculie. In most types however it becomes more closely united with the ethmoid region and the accessory parts belonging to it.

The cartiaginous cranium, the development of which has been thus briefly traced, persists in the adult without even the addition of membrane bones in the Cyclostomata, Elasmobranchii (fig. 327) and Holocephali. In the Selachioid Ganoids it is also found in the adult, but is covered over by membrane bones. In all other types it is invariably present in the enibryo, but becomes in the adult more or less replaced by osseous tissue.

\section{Branchial skieleton.}

The most primitive type of branchial skeleton in any existing form would appear to be that of the Petromyzonide, which is developed in a superficial subdermal tissne, and consists of a series of bars united by transverse pieces, so as to form a basket-work. It is known as an extra-branchial system, and an early stage of its development in the Lamprey is shewn in fig. 47. In the higher forms this system is replaced by a series of bars, known as the branchial bars, so situated as to afford support to the successive branchial pouches. Outside these bars there may be preent in some primitive forms (Elasmobranchii) cartilaginous elements, which are supposed to be remnants of the extra-branchial system (fig. $327, E x . B r$ ) ; while a series of membrane bones is also usually added to them, which will be deatt with in a separate section. The branchial bar's are developed as simple cartilaginous rods in the deeper parts of the mesoblast which constitutes the primitive branchial arches.

The position of the branchial hars in relation to the somatopleure and splanchnoplenre can be determined from their relation to the so-called head cavities. These cavities atrophy before the formation of the cortilaginons Iranclial bars, but it will be observed (fig. 328), that the artery of each arch $(a \alpha)$ is placed on the imner side of the head cavity $(2 p)$. The cartilitginous bar arises at a later period on the inner side of the artery, and therefore on the inner sile of the section of the body cavity primitively present in the arches.

An anterior arch, known as the mandibular areh, placed in front of the liyo-mandibular eleft, and a second arch, known as the hyoid a:ch, placed in front of the hyo-branchial cleft, are developed in aij 
types. The succeeding arches are known as the true branchial a:ches, and are only fully developed in the Ichthyopsida.

In some Sharks (Notidani) seven branchial arches may be present (not including the hyoid and mandibular). In other Jchthyopsilla five are usually present, in the embryo at any rate, while in the Amniota there are usually two or three post-hyoid membranous arches, in the interior of which a carti-

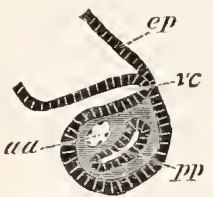

1416. 328. Honizontal secTION THROUGH THE PENTLTIMATE VISCERAL ARCUI OF AN EMbryo of Pristiunts.

ep. epiblast; $v c$. pouch of hypoblast which will form the walls of a visceral cleft; pp. segment of body-cavity in visceral arch; a a. aortic arch. laginous bar is usually formed. The general form of these bars at an early stage of development is shewn in the (log-fish (Scyllium) in fig. 329.

'The simple condition of these bars in the embryo renders it highly probable that forms existed at one time with a simple branchial skeleton of this kind: at the present day however such forms no longer exist. The first arch has in all cases changed its function and has become converted into a supporting skeleton for the mouth; the hyoid arch, though retaining in some forms its branchial function, has in most acquired additional functions and has undergone in consequence various peculiar modifications. The true branchial arches retain their branchial functions in Pisces and

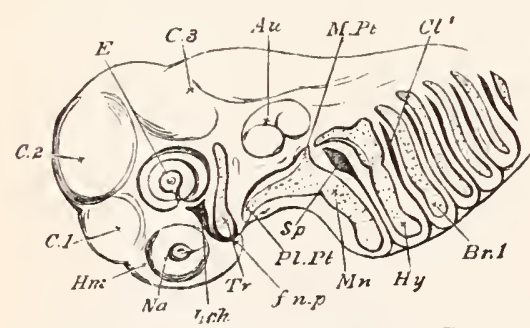

Fig. 329. Head of endiso Dogfish, 11 Lines LoNG. (From Parker.)

Tr. trabecula ; Pl.Pt. pterygo quadrate; 1/.Pt. metapteryoid region; $1 \mathrm{n}$. mandibular cartilage; $H y$. hyoid arch; $B$ r.1. first branchial arch ; Sp. mandibulo-hyoid cleft ; $\mathrm{Cl}^{1}$. hyo-branchial eleft; Lch. groove below the eye; $N a$. olfactory rudiment; $E$. eyeball; $A$ u. auditory mass; $C 1,2,3$, cerebral vesieles; Hm. hemispheres; f.n.p. nasofrontal process.

terior branchial pouches, which commenced at a stage in the evolution of the Chordata long prior to the appearance of cartilaginous or osseous branchial bars, and reaches its climax in the Amniota.

In a fully developed branchial bar the primitively simple rou of arily modified and largely aborted in the abranchiate forms. Since the changes undergone by the true branchial bar's are far less complicated than those of the hyoid and mandibular bars it will be convenient to treat of them in the first instance.

'These bars are, as already mentioned, most numerous in certain very primitive forms (seven in Notidanus), while as we ascend the series there is a gradual tendency for the posterior of them to disappear. This tendency is the result of a gradual atrophy of the possome Amphibia, but are second- 
cartilage becomes divided into a series of segments, usually four, articnlated so as to be more or less mobile: and either remaining eartilaginous or becoming partially or wholly ossified. Each har (fig. 327 ) forms a somewhat curved structure, embracing the pharynx. The dorsal and somewhat horizontally placed segment is known as the pharyngobranchial $(P h . B r \cdot$, the next two as the epibranchial (E.Br) and ceratobranchial $(C \cdot B r)$, and the ventral segment as the hypobranchial $(H . B r)$. There is also typically present a basal unpaired segment, miting the bars of the two sides, known as the basibranchial $(B . B r)$. The arches often bear cartilaginous rays which support the gill lamellæ.

In Teleostei dental plates are usually developed as an exoskeletal covering on parts of the branchial arches.

In the Amphibia four or three branchial arches are present in the embryo. These parts are more or less completely retained in the Perennibranchiata and Caducibranchiata, but in the Myctodera and Anura they become largely reduced, and entirely connected with the hyoid.

In the Anura they never reach any considerable development, and are soon reduced to a plate (fig. 330) - the coalesced basihyal and basi-branchial plate-the posterior processes of which represent the remuants of the branchial arches.

According to Parker the posterior process of this plate in the adult is a remnant of the fourth hranchial bar; the next one is the third branchial bar, while the anterior lamina behind the hyoid is stated by him (though this is somewhat doubtful) to be a remnant of the first two bars.

In the Amniota, the lranchial arches become still more degenerated, in correlation with the total disappearance of a branchial respiration at all periods of life. Their remnants Lecone more or less important. parts of the hyoid bone, and are solely employed in sipport of the tongue. Their basal portions are best preserved, forming parts of the body of the liyvid. The posterior (thyroid) cornua of the lyyoid are remnants of the true irches. Of these there are two in the Chelonia and Lacertilia, and "ne in the Aves and Mammalia. In Aves the cornu formed from the first branchial areh (fig. $3: 31 c^{b} r$ ) is always larger thin that of the true hyoid areh $(x h)$. 
Mandibular and Hyoid arches. The adaptations of both the

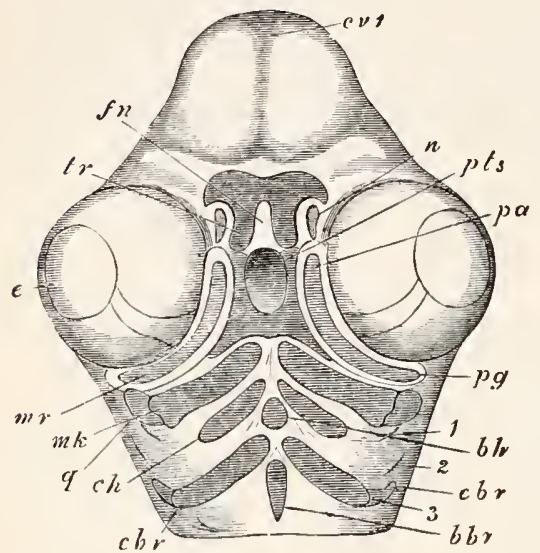

Fig. 331. View From below of the branCHIAL SKELETON OF THE SKULL OF A FOWL ON THe fovrtir day of incubation. (After Parker.)

$c v$ 1. cerebral vesicles; $e$. eye; $f n$. frontonasal process; $n$. nasal pit; $t r$. trabeculis; $p t s$. pituitary space; mer. superior unaxillary process; p\%. pterygoid; pa. palatine; \%. quadrate; $m k$. Neckel's cartilage; $c h$. cerato-hyal; bh. basi-hyal; cbr. cerato-branchial; $c^{\prime} \cdot r$. proximal portion of the cartilage in the third vi iceral (first branchial) areh; $b \iota r$. basibranchial ; 1. first visceral cleft ; 2. second visceral cleft; 3 . third visceral arch.

to the hyo-mandibular cleft (the spiracle).

Elasmobranchii. In Scyllium the hyoid and mandibular arches are at first very similar to those which follow. Soon however each of them sends an anteriorly directed dorsal process (fig. 329)). The regions which may be distinguished owing to the growth of these processes have received names from essifications in them which are found in other types. The anterior process of the mandibular arch is known as the pterygo-yuadrate bar $(P l . P t)$; the dorsal end of the primitive bar from which it starts (M.Pt) is known as the metapterygoid process; while the ventral end of the bar forms the Ileckelian cartilage. The upper end of the hyoid arch is known as the hyomandibular.

In a somewhat later stage changes take place which cause these parts practica'ly to assume the adult form (fig. 327 ). The mandibular arch becomes segmented at its bend into (1) a pterygo-quadrate bar (I'l.Pt) which grows forwards in front of the month, and forms an upper jaw, and $(2)$ a Heckelian cartilage $(M c k)$ which is placed behind the mouth, and forms a lower jaw. T'he two jaws are articulated 
together, and the cartilages of the two sides composing them meet each other distally.

At the articulation of the Meckelian cartilage with the quadrate part of the pterygo-quadrate is situated a ligament (M.Pt), which takes the place of the metapterygoid process of the previous stage, and passes up on the anterior side of the spiracle, to be attached to the cranium in the front part of the anditory region. This ligament, which is supplemented by a second ligament the ethmopalatine ligament, passing from the pterygo-quadrate bar to the antorbital region of the skull, is not the most important support of the jaw. The main support is, on the contrary, given by the hyoid arch; the hyomandibular segment of which $(I I . M)$ as well as the adjoining segment (ceratihyoid $C . H y$ ) are fimly attached by ligament to the mandibular arch. The hyomandibular is articulated with the cranium beneath the pterotic ridge ( $\mathrm{Pt}$.O $\mathrm{O}$.

In the type just described, the hyoid and mandibular arches nndergo less modification than in almost any other case. The hyoid arch has altered its form, but retains its respiratory function. It has however acquired the secondary function of supporting the mandibular arch. The mandibular arch is divider into two elements, which form respectively the upper and lower jaws. It is not directly articulated with the skull, and its mode of support by the hyoid arch has been called by Huxley (No. 445) li yostylic.

'The development of the hyoid and mandibular arches in the Skate is characterised by a few important features (fig. 33:3). The anterior element of the hyoid arch, which forms the hyomandibular $(I . M)$, becomes entirely separate from the posterior part of the arch, and only serves to support the jaws. The posterior part of the arch $(H y)$ carries on the respiratory functions of the hyoid, aud is closely comnected with the first branchial arch. The upper or metapterygoid element of the mandibular arch (M.Pt) has a considerable development, and, becoming separated from the remainder of the arch, forms a iuass of cartilage with one $\mathrm{or}^{\circ}$ two branchial rays, in the front wall of the spiracle, and constitutes a section of the mandibular arch still retaining traces of its primitive function in supporting the wall of a branchial putich.

Although the development of other Elasmobranch types is not 
known, it is necessary to call attention to the mode of support of the mandibular arch in certain forms, notably Notidanus, Hexanchus and Cestracion, where the pterygo-quadrate region of the mandibular arch is directly articulated to the cranium between the optic and trigeminal foramina. In the two former genera the metapterygoid region of the arch is moreover contimuous with the pterygo-qualrate, and articulates with the post-orbital process of the auditory region of the skull. In spite of these attachments the mandibular arch continnes to be partially supported by the hyomandibular. The skulls in which the mandibular arch has this double form of support have been callerl by Huxley amplistylic.

Cousidering the in many respects prinitive characters of the forms with amphistylic skulls it seems not

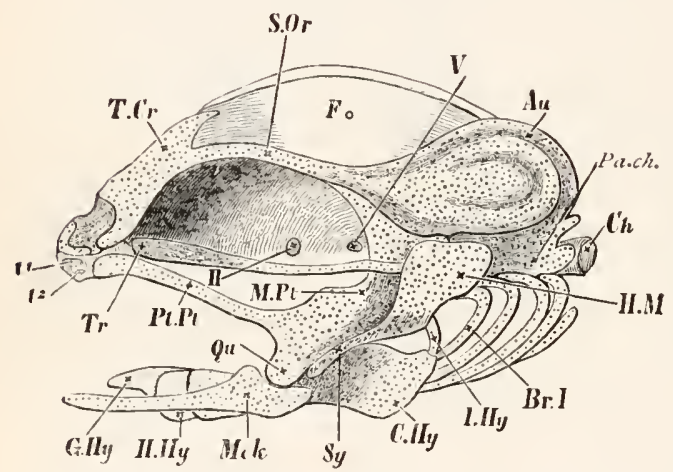

Fig. 334. Cranial skeletox of a Salion fry, seconi) WEEK AFTER HATCHING; MEMBIANF BONES, EXEBALLS, AND Nasal sacs liemoveb. (From Parker.)

T.Cr. tegmen cranii; S.Or. stupraorbital band; Fo. superior fontanelle; Au. auditory capsule; Pa.ch. parachordal cartilage; $C h$. notochord; $T r$. trabecula; above the trabecula, the interorbital septum is seen, passing into the cranial wall above and reaching the supraorbital band; $I I$. optic foramen; $I$. trigeminal formen; $l^{1}, l^{2}$. labial cartilages; $P l . P t$. palatopterygoid bar ; M.Pt. metapterygoid tract; Qu. quadrate region; I ck. Meckelian cartilage; H.M. hyomandibular cartilage; Sy. srmplectic tract; $1 . H y$. interhyal; C.IIy. ceratohyal ; $H .11 y$. hypohyal; G.Hy. glossohyal ; Br. 1 . first branchial arch.

cephala, Dipnoi, Amphibia and the Amniota.

Teleostei. In addition to that of Elasmobranchii, the skull of the Salmon is the only hyostylic skull in which, by the admirable investigation of Parker (No.45I), the ontogeny of the hyoid and mandibular bars has been satisfactorily worked out. Apart from the presence of a series of membrane bones, the development of these bars agrees on the whole with the types a'ready describer.

The hyoil arch, thongh largely ossified, undergoes a process of 
development very similar to that in Raja. It is formol as a sinple cartilaginous bar, which soon becomes segmented longitudinally into an anterior and a posterior part (fig. 33 $\mathrm{w}$ ). The former constitutes the hyomandibular $(M . M)$, while the latter, becoming more and more separated from the hyomandibular, constitutes the hyoid arch proper; owing to the disappearance of the hyobranchial cleft, it loses its primitive function, and serves on the one hand to support the operculum covering the gills, and on the other to support the tongue. It becomes segmented into a series of parts which are ossified (fig. 335 ) as the epiceratohyal (ep.h) above. then a large ceratohyal (ch), followed by a hypohyal (hh), while the median ventral element forms the basi- or glossohyal $(g \cdot h)$.

The hyomandibular itself is articulated with the skull below the pterotic process (fig. $3: 34, H . M)$. Its upper element ossifies as the hyomandibular(fig.3:35, h.m), while its lower part (fig. $33+, S y$ ), which is firmly comnected with the mandibular arch, ossifies as the symplectic (fig. 335, sy). A connecting element between the two parts of the hyoid har forms an interhyal $(i h)$.

There are more important differences in the development of the mandibular arch in Elasmobranchii and the Salmon than in that of the hyoid arch, in that, instead of the whole arcale of the upper jaw being formed from the mandibular arch, a fresh element, in the form of an independently developed bar of cartilage, completes the upper arcade in front; but even with this bar the two halves of the upper branch of

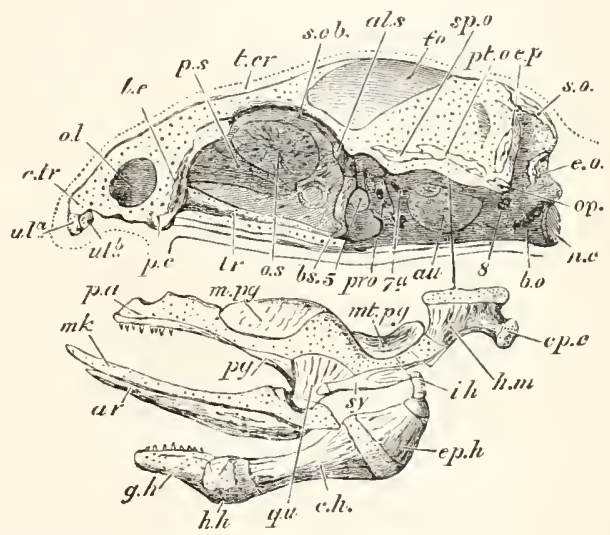

Fig. 335. Yocxig Siluon of the first sumer, ABOUT 2 IXCHES LONG; SIDE VIEW OF SKULL, EXCLUINA Blixenr.s arehes. (From Parker.)

The palato-mandibular and hyoid tracts are detached from their proper situations, a line indicating the position where the hyomandibular is articulated beneath the pterotic ridge.

ol. olfactory fossa; $c, t r$. trabecular cornu; $u l^{\mathrm{a}}$. $u l^{\mathrm{b}}$. upper labial cartilages; p.s. presphenoid tract; t.cr. tegmen cranii; s.o.b. supraorbital band; fo. superior fontanelle; n.c. notochord; b.o. basilar cartilage; $t r$. trabecula; p.c. condyle for palatine cartilage; 5 . trigeminal foramen; $7 u$. facial foramen; 8. foramen for glossopharyngeal and vagus nerves; $m k$. Meckelian cartilage; op.c. operenlar condyle.

Bones: e.o. exoccipital; s.o. supraoceipital; e.p. epiotic; pt.o. pterotic; sp.o. sphenotic; op. opisthotic; pro. prootic; b.s. basisphenoid; al.s. alisphenoid; o.s. orbitosphenoid; l.e. ectethmoid or lateral ethmoid; pa. palatine; $p g$. pterygoid; m.pg. mesopterygoid; mt.py. metapterygoid; qu. quadrate; ar. articular; h.m. hyomandibular; sy. symplectic; i.h. interhyal; ep.h. epiceratohyal; c.h. ceratolyyal; h.h. liypohyal; y.h. glosso- or basihyal. 
the arch do not meet anteriorly, but are separated by the ends of the trabeculæ.

The anterior bar of the upper arcade is known as the palatine; but it appars to me as yet uncertain how far it is to be regarded as an element, primitively be!onging to the upper arcade of the mandibular arch, which has become secondarily independent in its development; or as an entirely distinct structure which has no counterpart in the Elasnobranch npper jaw. The latter view is arlopted by Parker and Bridge, and a cartilage attached to the hinder wall of the nasal capsule of many Elasmobranchii is identitied by them with the palatine rod of the Teleostei.

The arch itself is at first very similar to the succeeding arches; its dorsal extremity soon however becomes broadened, and provided with an anteriorly directed process. This part (fig. 334, $M$. Pt and $Q u$ ) is then segmented from the lower region, and forms what may be called the pterygo-quadrate cartilage, though not completely homologous with the similarly named cartilage in Elasmobranchs; while the lower region forms the Meckelian cartilage (Mck), which has alrealy grown inwards, so as to meet its fellow ventrally below the mouth. The whole arch becomes at the same time widely separated from the axial parts of the skull.

Nearly simultaneously with the first differentiation of the mandibular arch, a bar of cartilage-the palatine bar already spoken of-is formed on each side, below the eye, in front of the mouth. The dilated anterior extremity of this bar soon comes in contact with an anterior process of the trabeculie, known as the ethmopalatine process.

In a later stage the pterygoid end of the pterygo-quadrate cartilage unites with the distal end of the palatine bar (fig. $334, P l . P t$ ), and there is then formed a continuous cartilaginous arcade for the upper jaw, which is strikingly similar to the cartilaginous upper jaw of Elasmobranchii.

A large dorsal process of the primitive pterygo-quadrate now forms a large metapterygoid tract (II.Pt); while the whole arch becomes firmly bo un t to the hyomandibular $(H . M)$.

In the later stages the parts formed in cartilage become ossified (fig. 335). The palatine is first ossified, the pterygoid region of the pterygo-quadrate is next ossified as a dorsal mesopterygoid ( $m \cdot p g)$ and a ventral pterygoid proper $(p g)$. The quadrate region, articulating with the Meckelian cartilage, becomes ossified as a distinct quadrate $(q u)$, while the dorsal region becomes also ossified as a metapterygoid $(m t p g)$.

In the Meckelian cartilage a superficial ossification of the ventral edge and inner surface forms an articulare $(a r)$; but the greater part of the cartilage persists through life.

Some of the above ossifications, at any rate those of the palatine and pterygoil, seem to be started by dental osseous plates adjoining the cartilage. They will be spoken of further in the section dealing with the membrane bones. 
Amphibia. The development of the autostylic piscine skulls has unfortunately not yet been stulied; and the most primitive autostylic types whose development we are acquainted with are those of the Amphibia; on which a large amount of light lias been shed by the researches of Huxley and Parker.

'The modifications of the hyoid arch are comparatively simple and uniform. It forms a rod of cartilage, which soon articulates in front with the quadrate element of the mandibular arch, and is subsequently attached by ligaments both to the quadrate and to the cranium. In those Amphibia in which external gills and gill clefts are lost, it fuses with the basal element of the hyoid (fig. 3:30), which, together with the basal portions of the following arches, forms a continuous cartilaginous plate. On the completion of these changes the paired parts of the hyoid arch have the form of two elongated rods, known as the anterior cornua of the hyoid, which attach the basilyal plate to the cranium belind the anditory capsule.

It is still uncertain whether there is any distinct element corresponding to the liyomandibulin of fishes.

Parker loolds that the columella auris of the Anura is the liomologue of the lyomandibular. The columella develops comparatively late and independently of the remainder of the hyoil arch, but the similarity between its relations to the nerves and those of the hyomandibular is put forward by Parker as an argument in favour of his view. The early ligamentons connection between the quadrate aul the upper end of the primitive hyoid is however an argument in farour of regarding the upper end of the primitive hyoid as the hyomandibulin element, not separated from the remainder of the arch.

The history of the mandibular arch is more complicated than that of the hyoid. The part of it which corresponds with the upper jaw of Elasmobranchii exhibits most striking variations in development; so striking indeed as to suggest that the secondary modifications it has undergone are sufficiently considerable to render great caution necessary in drawing morphological conclusions from the processes which are in some instances observable. A more satisfactory judgment on this point will be possible after the publication of a memoir with which Parker is now engaged on the skulls of the different Anura.

The membrane bones applying themselves to the sides of the mandibular arch are relatively far more important than in the lower types. This is especially the case with the upper jaw where the maxillary and premaxillary bones functionally replace the primitive cartilaginous jaw; while membranous pterygoids and palatines apply themselves to, and largely take the place of, the cartiaginous palatine and pterygoid bar's.

'Two types worked out by Parker, viz. the Axolotl and the common Frog, may be selected to illustrate the development of the mandibular arch.

In the Axolotl, which may be taken as the type for the Trorlela, 
the mandibular arch is constituted at a very early stage of (1) an enlarged dorsal clement, corresponding with the pterygo-quadrate of

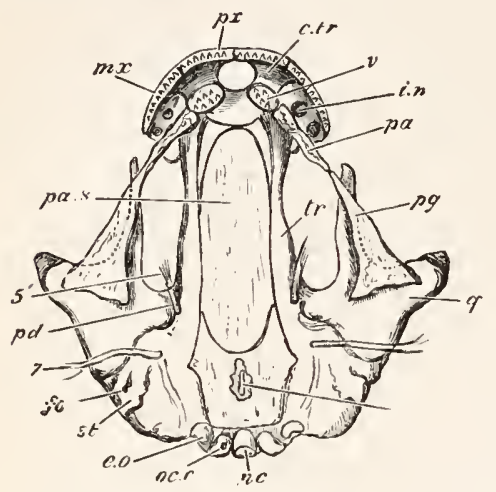

Fig. 336. Young Axolote, $2+$ inches LONG ; UNDER VIEW OF SKULL, DISSECTED, THE LOWER JAW AND GILL ARCHES HAVING BEEN REMOVED. (From Parker.)

nc. notochord; oc.c. occipital condyle; f.o. fenestra oralis; st. stapes; $t r$. trabecular cartilage ; $i . n$. internal nares; c.tr. cornu trabecula; $p d$. pedicle of quadrate; $q$. quadrate; $p \%$. outline of pterygoid cartilage; 5 . orbito-nasal nerve; 7 . facial nerve.

Bones: pa.s. parasphenoid ; c.o. exoccipital; $v$. vomer; $p x$. premaxillary ; $m . x$. maxillary; pa. palatine; pg. pterygoid.

the lower types, but usially known as the quadrate; and (丷) a ventral or Meckelian element. The Meckelian bar very early acquires its investing bones, while the dorsal part of the quadrate becomes divided into two characteristic processes, viz. an auterisr rorsal process which grows towards and soon permanently fuses with the trabecular crest, and a posterior process known as the otic process, which applies itself to the outer side of the auditory region. The anterior of these processes, as pointed ont by Huxley, is probably homologous with the anterior process of the pterygo-quadrate bar in Notidanus, which articulates with the trabecular region of the cranium, while the otic process is homologous with the metapterygoid process. Hardly any trace is present of an anterior process to form a pterygoid bar, but dentigerous
ygoid bar have already appeared.

At a somewhat later stage a fresh process, called by Huxley the pedicle, grows out from the quadrate, and articulates with the ventral side of the auditory region (fig. $336, p d$ ). Shortly afterwards a rod

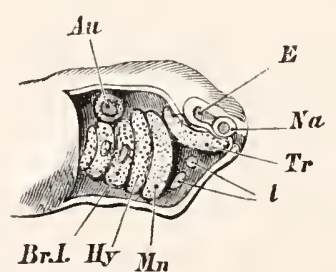

Fig, 337. Eubryo Frog, Just before HATCHING; SIDE VIEW OF HEAD, WITH SKIN REMTOVED. (From Parker.)

$N a$. olfactory sack; $E$. involution for eyeball; $A u$. auditory sack; Tr. trabecula; In. mandibular; $H y$. hyoid; Br.I. first branchial arch; the gill-buds are seen oir the first two branchial arches; 1 . labial cartilages. of cartilage grows forward from the quadrate under the membranous pterygoid $(p g)$, which corresponds with the cartilaginous pterygoid bar of other types (fig. 336), and an independent palatine bar, arising even before the pterygoid process, is formed immediately dorsal to the dentigerous palatine plate $(p t)$, and is attached to the trabecula. These two bar's eventually meet, but never become firmly united to the more important membrane bones placed superficially to them.

The mandibular arch in the 
Frog stands, so far as development is concerned, in striking contrast to the mandibular arch of the Axolotl, in spite of the obvious similarity in the arrangement of the achul parts in the two types.

In the earliest stage it forms a simple bar in the membranous mandibular arch, parallel to and very similar to the hyoid bar behind (fig. 337, Mn). In the next stage observed, that is to say in 'Tadpoles of four, five, to six lines long, an astonishing transformation has taken place. The mandibular areh (fig. 3:3S) is turned directly forwards parallel to the trabecula, to which it is attached in fiont $(p \cdot p q)$ and behind $(p d)$. The proximal part of the arch thus forms a subocular har, and the space between it and the trabecula a subocular fenestra. In front of the auterior attachment it is continued forwards for a short distance, and to the free end of this projecting part is articulated a small Meckelian cartilage directed upwards ( $m k$ ). 'The Meckelian cartilage is at this stage placed in flont of the nasal sacks, in the lower lip of the snctorial mouth. The greater part of the arch, parallel with the trabeculie, is equivalent to what has been called in the Axolotl the quadrate, while its anterior attachment to the trabeculae is the rudiment of the palato-pterygoid cartilage. The posterior attachment is known as the peticle.

The condition of the mandiluular arch during this and the next stage (fig. 339) is very perplexing. Its

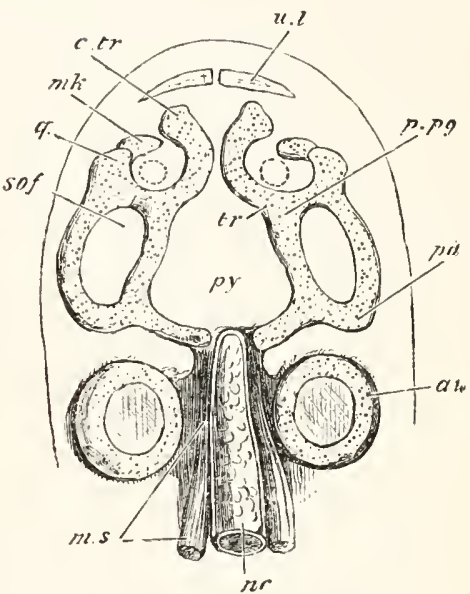

Fig. 33. Tadrole of Common Toan, ONE-THIRD OF AN INCH LONG; CRANIAI ANI MANDIBULAR CARTILAGES SEEN FROM ABONE; THE PARACHORDAL CARTILAGES ARE NOT YET hefinite, (From Parker.)

nc. notochord; ms. muscular segments; au. auditory capsule; py. region of pituitary body; tr. trabecula; $c . t r$. cornu trabeculse; p.pq. palatopterygoid bar; pd. pedicle; q. quadrate condyle; $m k$. Meckelian piece of mandibular arch; s.o.i. subocular fenestra; u.l. upper labial cartilage. The dotted circle within the qua drate region indicates the position of the intermal nostril. structure appears adapted in some way to supjort the suctorial mouth of the Tadpole.

Reasons have been offered in a previous part of this volume for supposing that the snctorial mouth of the Tadpole is probably not simply a structure secondarily acquired by this larva, but is an organ iuherited from an ancestor provided through life with a suctorial mouth.

The question thus arises, is the peculiar noditication of the mandibular arch of the Tadpole an inherited or an acquired feature?

If the first alternative is accepted we should have to admit that the mandibular arch became first of all modified in connection with the suctorial mouth, before it was converted into tho jaws of the Guatho- 
stomata: and that the peculiar listory of this arel in the 'ladpole is a more or less true record of its pliylugenetic clevelnpment. In favour of this view is the striking similarity which Huxley has pointed out between the oral skeleton of the Lamprey and that of the Tadpole; and certain peculiarities of the mandibular arch of Chimara and the Lipnoi can perhaps best be explained on the supposition that the oral skeleton of these forms has arisen in a manner somewlat similar to that in the Frog; though witl reference to this point further developmental data are much required.

On the other hand the above supprositions would necessitate our armitting that a great abbreviation has occmled in the development of the mamdibular arch of the otherwise nore primitive Urodela; aud that the simple mode of growtl of the jaws in Elasmobranchii, from the primitive mandihular areh, is phylogenetically a much abbreviated and norlified process, instead of being, as usually supposed, a true record of ancestral history.

If the view is accepted that the characters of the mandibular arch of the Tarlpole are secondary, it will be necessary to admit that the adaptatiom of the mandibular arch to the suctorial mouth took place after the suctorial mouth hat come to be merely a larval organ.

In view of our imperfect knowlerge of the development of most Piscine skulls I would refoain from expressing a decided opinion in favour of eitler of these alternatives.

As the tail of the Tarpole gradually disappears, and the metamorphosis into the Frog becomes accomplished, the

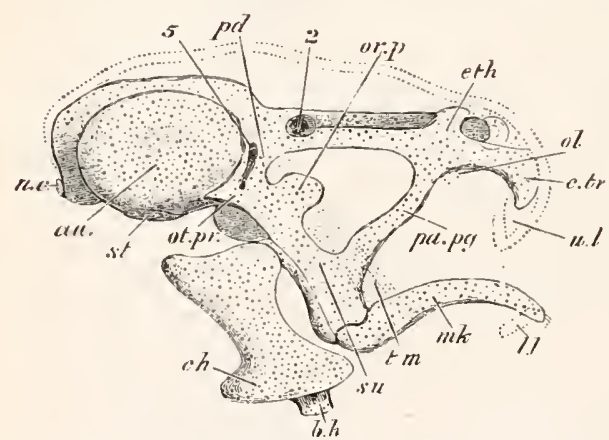

Fig. 339. Tampole with tall beginnisg to SHRINK ; SITE VIEW OF STULL WITHOCT THE BRANchial arches. (From Paiker.)

n.c notochord; au. aulitory capsule; between it and $e t h$. the low cranial side wall is seen; pth. ethmoidal region; st. stapes; 5 . trigeminal foramen; 2. optic foramen; ol. olfactory capsules, both seen owing to slight tilting of the sliull ; c.tr. cornu trabeculx; u.l. npper labial, in outline; su. suspensorium (quadrate); $p d$. its pedicle; ot.pr. its otic process; or.p. its or bitar process; t.m. temporal muscle, indicated by dotted lines passing beneath the orbitar process; pa.pg. palatopterygoid bar; $m k$. Meckelian cartilage; l.l. lower labial, in ontline; c.h. ceratohyal; b.h. basihyal. The upper outline of the head is shew by dotted lines. mandibulararch undergoes important changes (fig. :3:39): the palato-pterygoid attachment (pa.pg) of the quadrate subocular bar becomes gradually elongated; and, as it is so, the front end of the subocular bar (su) rotates outwards and backwards, and soon forms a very considerable angle with the trabeculie. The Meckelian cartilage $(m k)$ at its free end becomes at the same time considerably elongated. These processes of growth continue till (fig. 330) the palato-pterygoid bar $(P t)$ forms a subocular bar, and is considerably longer than the original subocular region of the quadrate; while the Meckelian cartilage $(1 / c k)$ has 
assumed its permanent position on the hinder borter of the no longer suctorial mouth, and has grown forwards so as nearly to meet its fellow in the median line.

The metapterygoid region of the quadrate gives rise to a posterior and dorsal process (fig. 339, ot $\mathrm{pr}$ ), the end of which is constricted off as the tympanic anmulus (fig. 340 , a.t); while the proximal part of the process remains as the otic (metapterygoid) process, articulating with the auditory cartilage.

The pedicte $(p d)$ retains its orginal attachment to the skull.

The palato-pterygoid soon becomes segmented into a transversely placed palatine, and a longitudinally placed pterygoid (fig. 340). With the exception of a few ossifications, which present no features of special interest, the parts of the mandibular arch lave now reached their final condition, which is not very different from that in the Axolotl.

Sauropsida. In the Sauropsida the modifications of the hyoid and mandibular arches are fairly uniform.

The lower part of the hyoid arch, including the

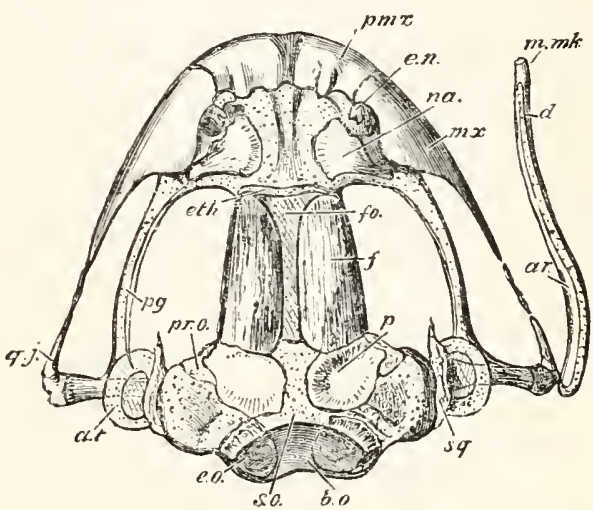

Fig. 340. Tousg Frog, NeAr ExD OF First SEMMER; UPPER VIEW OF SKULL, WITH LEFT MAXIHBLE REMOVED, AXD THE RIGHT EXTENDED OUTWARDS. (From Parker.)

b.o. basioccipital tract; s.o. supraoccipital tract; fo. frontal fontanelle; e.u. exterual nostril ; intermal to it, internasal plate; u.t. tympanic annulus.

Bones: e.o. exoccipital; pr.o. prootic, partly overlapped by $p$. parietal; $f$. frontal; eth. rudiment of sphenethmoid; $n a$. nasal; pm.x. premaxillary; m. maxillary; p!. pterygoid, partly ensheathing the reduced cartilage ; $1 . j$. quadratojugal ; $s q$. squamosal; ar. articular; $d$. dentary; m.mli. mento-Meckelian. basilhyoid, unites with the remuants of the arches behind to form the hyoid bone, to which it contributes the anterior cornu and anterior part of the body.

The columella is betieved by Huxley and Parker to represent, as in the Anura, the independently developed dorsal (hyomandibular) element of the liyoid, together with the stapes with which it has become united ${ }^{1}$.

1 The strongest evidence in favour of Huxley's and Parker's view of the nature of the columella is the fusion in the adult Sphenodon of the upper end of the hyoid with the columella (vide Huxley, No. 445). From an examination of a specimen in the Cambridge museum I do not feel satisfied that the fusion is not secondary, but have not been able to examine the junction of the hyoid and columella in section. For a different view to that of Huxley ride Peters, "Ueb. d. Gehörknochelehen u. ihr Verhältniss zu. Zungenbeinbogen b. Sphenodon." Berlin Monatsberichte, 1874. 
The membranous mandibular arch gives off in the embryos of all the Sauropsida an obvious bud to form the superior maxillary process, and the formation of this bud appears to represent the growth forwards of the pterygoid process in Elasmobranchii, which is indeed accompanied by the formation of a similar bud; but the skeletal rod, which appears in the axis of this bud, is as a rule independent of that in the true arch (fig. 3:31, $p a, p g$ ). The former is the pterygopalatine bar; the latter the Meckelian and quadrate cartilages.

The pterygo-palatime bar is usually if not always ossified directly, without the intervention of cartilage.

Born has recently shewn that Parker was mistalken in supposing that the palato-pterygoid bone is cartilaginous in Birds. In the Turtle a short cartilaginous p,terygoid process of the quadrate would seem to be present (Parker, No. 458).

The quadrate and Neckelian cartilages are either from the first separate, or very early become so.

The quadrate cartilage ossifies as the qualrate bone, and supplies the permanent articulation for the lower jaw. Its upper end exhibits a tendency to divide into two processes, corresponding with the pedicle anil otic processes of the Amphibia. The Neckelian cartilage becomes soon covered by investing bones, and its proximal end ossifies as the articulare. The remainder of the cartilage usually disappears.

Mammalia. The most extraordinary metanorphosis of the hyoid and mandibular arches occurs in the Nammalia, and has been in part known since the publication of the memoir of Reichert (No. 46 I).

Both the hyoid and mandibular arches develop at first more completely than in any of the other types above Fishes; and are articulated to each other above, while the pterygo-palatine bar is quite distinct. The main features of the subsequent development are undisputed, with the exception of that of the upper end of the hyoid, which is still controverted. 'The following is Parker's (No. 452) account for the Pig, which confirms in the main the view originally put forward by Huxley (No. .145).

The mandibular and hyoid arches are at first very similar (fig. 341 $m n$ and $h y$ ), their dorsal ends being somewhat incurved, and articulating together.

In a somewhat later stage (fig. 342 ) the upper end of the mandibular bar $(m b)$, without becoming segmented from the ventral part, becomes distinctly swollen, and clearly corresponds to the quadrate region of other types. The ventral part of the bar constitutes the Meckelian cartilage $(m k)$.

The hyoid arch has in the meantime become segmented into two parts, an upper part $(i)$, which eventually becomes one of the small bones of the ear-the incns-and a lower rart which remains permanently as the anterior cornu of the hyoid (st.h). The two parts continne to be connecterl by a ligament. 
The incus is articulated with the quadrate end of the mandibular arch, and its rounded head comes in contact with the stapes (fig. :342, st) which is segmented from the fenestia vvalis.

The main arch of the hyoid becomes divided into, a hypohyal $(h . / \ell)$ below and a stylohyal (st $h$ ) above, and alsig becomes articulated with the basal element of the arch behina $(b h)$.

In the course of further development the Meckelian part of the mandibular arch becomes enveloped in a superficial ossification forming the dentary. Its upper end, adjoining the quarlrate region, becomes calcified and then absorbed, and its lower, with the exception of the extreme point, is ossified and subsequently incorporated in the dentary.

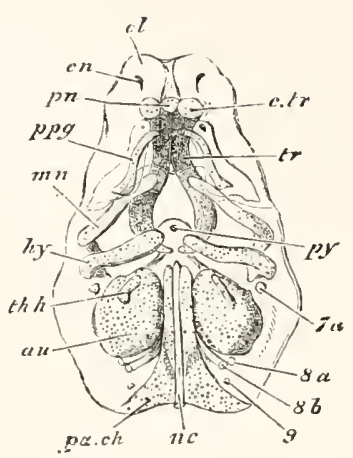

Fig. 341. Embryo Pig, two-thirds of ax INCH LOXG; ELEMENTS OF THE SKULL SEEN SOMEWHAT DIAGRAMUATICALLY FROM BELOW. (From Parker.)

pa.ch. parachordal cartilage; nc. notochord; $a u$. anditory capsule; $p y$. pituitary body; $t r$. tra. beculæ; c.tr. trabecular cornu; prn. prenasal cartilage; e.n. external nasal opening; ol. nasal capsule; p.pg. palatopterygoid tract enclosed in the maxillopalatine process; $m$. mandibular arch; hy. hyoid arch; th.h. first branchial arch; $7 a$. facial nerve; $8 a$. glossopharyngeal; $8 b$. ragus; 9. livpoglossal.

The quadrate region remains relatively stationary in growth as compared with the adjacent parts of the skull, and finally ossifies to form the malleus bone of the ear. The processus gracilis of the malleus is the primitive continuation into Heckel's cartilage.

The malleus and incus are at first embedded in the connective tissue adjoining the tympanic cavity (hyomandibular cleft, vide 1. 43.5); and externally to them a bone known as the tympanic bone becomes developed so that they become placed between the tympanic bone and the periotic capsule. In late foetal life they become transported completely within the tympanic cav-

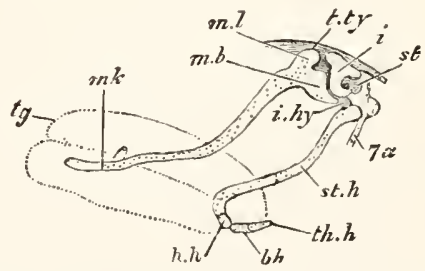

Fia. 342. Eubryo Pig, an INCh ANd a third LONG; SIDE VIEW OF MANDIBULAR ANI HYOLI ARCHES. The main hrold arch is SEeN as DISPLACED BaCKWARDS AFTER SEgMENTATION FRON THE INCUS. (From Parker.)

$t g$. tongue ; $m k$. Meckelian cartilage : $m l$. body of malleus; mb. mambrium or handle of the malleus; t.ty. termen tympani ; $i$. incus; st. stapes; i.hy. interhyal ligament; st.h. stylohyal cartilage; $h . h$. hypolyyal ; b.h. basibranchial; th.h. rudiment of first branchial arch; $7 a$. facial nerve. 
ity, though covered by a reflection of the tympanic mucous membrane.

The dorsal end of the part of the hyoid separated from the incus becomes ossified as the tympano-hyal, and is anchylosed with the adjacent parts of the periotic capsule. 'The middle part of the bar just outside the skull forms the stylo-hyal (styloid process in Man) which is attached by ligament to the anterior cornu of the hyoid (cerato-hyal).

While the account of the formation of the malleus, incus, and stapes just given is that usually accepted in this comtry, a somewhat different riew of the development of these parts has as a rule been adopted in Germany. Reichert (No. 46r) held that both the malleus and the incus were derived from the mandibular bar; and this view has been confirmed hy Giünther, Kölliker and other observers, and has recently been adopted loy Salensky (No. 462) after a careful research especially directed towards this point. Reichert also held that the stapes was derived from the hyrid bar; lut, thongh his observations on this point have been very widely accepted, they have not met with such mniversal recognition as his views on the origin of the malleus and incus. Salensky has recently arrived at a view, which is in accord with that of Parker, in so far as the independence of the stapes of both the hyoid and mandibular arches is concerned. Salensky howerer holds that it is formed from a mass of mesoblast surrounding the artery of the mandibular arch, and that the form of the stapes is due to its perforation ly the mandibular artery. A product of this artery permanently perforates the stapes in a few Mammalia, thongh in the majority it atrophies.

In view of the different aceounts of the origin of the incus the exact nature of this bone must still be considered as an open question, but shoull Reichert's view be confirmed the identification of the incus with the columella of the Amphibia and Sauropsidat nust be abandoned.

\section{Membrume bones and ossifications of the crunium.}

The membrane bones of the skull may be divided into two classes, viz. (1) those derived from dermal osseons plates, which as explained above (p. 447) are primitively formed by the coalescence of the osseous plates of scales; and $(\because)$ those formed by the coalescence of the osseous plates of teeth lining the oral cavity. Some of the bones sheathing the elge of the mouth have been formed partly by the one process and partly by the other.

In the Fishes there are fouml all grades of transition between simple dermal scutes, and true subdermal osseons plates forming an integral part of the internal skeleton. Dermal scutes are best represented in Acipenser and some Siburoid Fishes.

Where the membrane bones still retain the character of dermal plates, those on the dorsal surface of the cranium are usually arranged in a series of longitudinal rows, continuing in the region of the head the rows of dermal scutes of the trunk; while the remaining cranial scutes are connected with the visceral arches. The dermal bones on the dorsil surface of the head are very different in number, 
size, and arrangement in different types of Fishes; but owing to their linear disposition it is usually possible to find a certain number both of the paires and umpaired bones which have a similar situation in the different forms. These usually receive the same names, but both from general considerations as to their origin, as well as from a comparison of different species, it appears to me probable that there is no real homology between these bones in different species, but only a kind of greneral correspondence ${ }^{1}$.

It is not in fact till we get to the types above the Fishes that we can find a series of lomologous dorsal membrane bones covering the roof of the skull. In these types three paired sets of suc , bones are usually present, viz. from belind forwards the parietals, frontals and nasils, the latter bounding the posterior surface of the external nasal opening. Even in the higher types these bones are liable to vary very greatly from the usual arrangement.

Besides these homes there is usually present in the higher forms a lacrymal bone on the anterior margin of the orbit derived from one of a series of periorbital membrane bones frequently found in Fishes. Tarious supraorbital and postorbital bones, etc. are also frequently found in Lacertilia. etc. which are not impossibly phylogenetically indepentent of the nembrane bones inherited from Fishes; and may have been evolved as bony scutes in the subdermal tissue of the papillie of the sanropsidan scales.

The visceral arches of Fishes, especially of the Teleostei, are usually provided with a series of membrane bones. In the true branchial arches these take the form of dentigerous plates; but no such plates are found in the Amplibia or Anmiota.

The opercular thap attached to the hyoil arch is usual'y supported by a series of membrane bones, which attain their highest development in the Teleostei. One of these bones, the præopercular, is very constant and is primitively attached along the onter edge of the hyomandibular. It seems to be retained in Amphibia as a membrane bone, overlapping the attachment of the quadrate and known as the squamosal; though it is not impossible that this bone may be lerived from a superficial membrane bone, widely distributer in 'Teleostei and Ganoids, which is known as the supra-temporal. In Dipnoi the bone which appears to be clearly homologous with the squamosal would seem from its position to belong to the series of dorsal plates, and therefore to be the supra-temporal; but it is reyarled by Huxley (No. 446) as the pritopercular'.

In the Amniota the squamosal forms an integral part of the osseous roof of the skull; but in the Sauropsida it continnes, as in Amphibia, to be closely related to the quarlate.

1 For some interesting remarks on the arrangement of these bones in Fishes, vide Brilge, "On the Osteology of Polyorlon folitm." Phil. Trans., 1878.

2 It is not impossible that the solution of the difficulty about the præopercular is to be found by sumposing that the mropercular as it exists in Teleostei is derived from a dorwal iernal plate, and that in the I) ipnoi this plate retains more nearly than in Teleostei its prinitive position. 
A larger series of persistent membrane bones are related to the mandibular, and its palato-yuadrate process.

Overlying the palato-quadrate process are two rows of bones, one row lying at the edge of the mouth, on the outer side of the pterygopalatine process, and the other set on the roof of the mouth superticial to the pterygo-palatine process.

The outer row is formed of the premaxilla, maxilla, jugal, and very often quadrato-jugal. Of these bones the maxilla and premaxilla, as is more especially demonstrated by their ontogeny in the Urodela, are partly derived from dentigerous plates and partly from membrane plates out ide the mouth; while the jugal, and quadrato-jugal when present, are entirely extra-oral. In the Amphibia and Amniota the promaxillae and maxillae are the nost important bones in the facial region, and are quite independent of any cartilaginous substratum.

The second row of bones is clearly constituterl in the Dipnoi and Amphibia by the vomer in front, then the palatine, and finally the pterygoid behind. Of these bones the vomer is never related to a cartilaginous tract below, while the palatines and pterygoids usually are so. 'The position and growth of the thrce bones in many Urodela (Axolotl) is especially striking (Hertwig. No. 442). In tlie Axolotl they form a contimuous series, the vomer and palatine being eovered by teeth, but the pterygoid being without teeth. 'The vonuer and palatine originate from the united osseous plates of the bases of the teeth, while the pterygoid is in the first instance continuous with the palatine.

In Teleostei, Amia, etc, there are dentigerous plates forming a palatine and pterygoid, which in position, at any rate, closely cor. respond with the similarly named bones in Anphibia; and there is also a dentigerous vomer which may farly be considered as equivalent to that in Amplibia.

In the Amniota the three bones found in Amphibia are always present, but with a few exceptions amongst the Lacertilia and Ophidia, are no longer dentigerous. The cartilaginous bars, which in the lower types are placed below the palatine and pterygoid membrane bones, are usually imperfectly or not at all developerl.

On Meckel's cartilage important membrane bones are almost always grafted. On the outsicle and distal part of the cartilage a dentary is usually developed, which may envelope and replace the cartilage to a larger or smaller extent. Its oral edge is usually dentigerous. The splenial nembrane bone is the most important bone on the immer side of Meckel's cartilage, but other elements known as the coronoid and angular may also be added. In Mammalia the dentary is the only element present (vide p. 485).

On the roof of the mouth a median bone, the parasphenoid, is very widely present in the Amphibia and Fishes, except the Elasmobranchii and Cyclostonata, and has no doubt the same phylogenetic origin as the vomer and nembranous palatines and pterygoids. 
It is less important in the Sauropsida, and becones indistinguishably fused with the sphenoid in the adult, while in Mammalia it is no longer found.

Ossification of the Cartilaginous Cranium. In certain Fishes the cartilaginous cranium remains quite mnossified, while completely enveloped in dermal bones. Such for instance is its condition in the Selachioid Ganoids. In most instances, however, the investment of the cartilaginous cranium by nembrane bones is accompanied by a more or less complete ossification of the cartilage itself.

In the Dipnoi this occurs to the smallest extent, the only ossifications occurring in the lateral parts of the occipital region, and forming the exoceipitals.

In Teleostei and bony Ganoids, a considerably greater number of ossifications occur in the cartilage.

In the region of the occipital cartilaginous ring there appears a basioccipital and supraccipital and two exoccipitals. The basioccipital is the only bone on the floor of the skull ossifying that jart into which the notochord is prinitively continued ${ }^{1}$.

In the region of the periotic cartilage a large number of bones may appear. In front there is the prootic, which often meets the exoccipital behind; behind there is above and in close comnection with the supraoceipital the epiotic, and below in close convection with the exnccipital the opisthotic. On the dorsal side of the cartilage there is a projecting ridge composed mainly of at bone known as the pterotic, sometimes erroneously called the squamosal, and continued in front by the sphenotic. 'The pterotic, or the cartilaginous region corresponding to it, always supplies the articular surface for the hyomandibular.

In the floor of the skull, in the region of the pituitary body, there is formed a basisphenoid; while in the lateral parts of the wall of this part of the cranium, there is a bone known as the alisphenoid.

In front, parts of the lateral walls of the cranium ossify as the orbitosphenoids.

In view of the very imperfect ossification of the cartilaginous cranium of the Dipnoi, and of the fact that there is certainly no direct genetic connection between the Teleostei on the one hand, and the Amphibia and Anniota on the other, it is very difficult to believe that most of the ossifications of the cranium in the Amphibia and Amniota have more than a general correspondence with those in the Teleostei.

In the Amphibia the ossifications in the cartilage are comparatively few. In the occipital region there is a lateral ossification on each side of the exoccipital, the basioccipital region being unossified, and the supraoccipital at the utmost indurated by a calcareons deposit.

The periotic capsule is ossified by a prootic centre, which meets the exoccipital behind.

1 The notochord appears also to enter into the postcrior part of the region which oscities as the basinghenoil. 
The front part of the cartilaginous cranium is ossified by a complete ring of bone--the sphenethmoid bone-which embraces part of the ethmoid region, and of the orbitosphenoid and presphenoid regions.

In the Amphibia the cartilaginous cranium, with its centres of ossification, is easily separable from the membranous investing bones.

In the Amniota the cartilaginous craniun, whose development in the embryo has alrealy been described, becomes in the adult much more largely ossified, and the bones which replace the primitive cartilage unite with the membrane bones to form a continuous bony cranium.

The centres of ossification become again much more numerous. In the occipital segment analogous centres to those of 'l'eleostei are again found; and it is probathle that the exoccipitals are homolngous throughout the series, the supraoccipital and basioccipital bones of the ligher types being merely identical in position with the sinilarly named bones in Fishes.

In the perintic there are usually three centres of ossification, first recognised by Huxley. 'These are the prootic, the epiotic and opisthotic, the situations of which have already been defined. Of these the prootic is the must constant.

In Reptiles, the prootic and opisthotic frequently remain distinct even in the adult.

In Birds, the epiotic and opisthotic are early united with the supra- and exoccipital; and at a later period the prootic is also indistingnishably fused with the adjacent parts.

In Manmals the three ossifications fuse into a continuous wholethe periotic bone-which may be partially united with the adjacent parts.

In the pituitary region of the base of the cranium a pair of osseous centres or in the higher types a singhe centre $\left(\right.$ Parker $\left.^{1}\right)$ gives rise to the basisphenoid bone, and in front of this another basal or pair of basal ossifications forms the presphenoid, while laterally to these two centres there are formed centres of ossitication m the alisphenoid and urbitosphenoid regions, which may be extremely reduced in various Sauropsida, leaving the side walls of the skull almost entirely formed of membrane or cartilage.

In the ethmoid legion there may arise a median ossification forming the mesethmoid and lateral ossifications fonming the lateral ethmoids or prefronta's; which may assist in forming the front wa'l of the brain-case, or be situated quite externally to the brain-case and be only related to the olfactory capsules.

The labial cartilages. In most Fishes a series of skeletal structures, known as the labial cartilages, are dereloped at the front and sides of the mouth, and in connection with the olfactory capsules; and these cartilages still persist in connection with the olfactory capsules, though in a reduced

1 Accorting to Kobliker there are two centres in Man in both the basisphenoid and presplenoid. 
form, in the higher types. They are more developed in the Cyclostomata than in any other Vertebrate type.

The meaning of these cartilages is very obscure; but, fiom their being in part employed to support the lips and horny teeth of the Cyclostomata and the Tadpole, I should be inclined to regard them as remnints of a prinitive skeleton supporting the suctorial mouth, with which, on the grounds already stated (p. $26: 3)$, I believe the ancestors of the present Vertebrata to lave been provided.

\section{Bibliography.}

(+39) A. Dugès. "Recherches sur l'Ostéologie et la myologie des Batraciens à leur différents âges." Paris, Mém. sacans étromg. 1835, aud An. Sci. Nat. Vol. I. 1834 .

$(++0)$ C. Gegenbaur. Untersuchungen z. vergleich. Anat. d. Wirbelthiere, n1. Heft. Das kopfskelet d. Selochier. Leipzig, 187.2.

(4+1) Günther. Beob. ̈̈b. die Entwick.d. Gelörorgans. Leipzig, 1842.

(++2) O. Hertwig. "Ueb. d. Zahnsystem d. Amphibien n. seine Bedeutung f.

d. Genese d. Slielets d. Muudhölle." Archir f. milir. Auut., Vol. xi. 1s7t, suppl.

$(++3)$ T. H. Huxley. "On the theory of the vertebrate sliull." Proc. Royal Soc., Vol. Ix. 1858.

(t+t) T. H. Huxley. The Elements of Comparative Anatomy. Tondon, 1869.

$(++5)$ T. H. Huxley. "On the Mallens and Incus." Proc. Zool. Soc., 186 ).

(++6) T. H. Huxley. "On Ceratolus Forsteni." Proc. Zool. Soc., 1876.

$(++7)$ T. H. Huxley. "The nature of the craniofacial apparatus of Petromyzon."

Joum. of Allat. amel Phys., Vol. x. 1876.

$\left(t^{8}\right)$ T. H. Huxlcy. The Anatomy of Tertebrated Amimals. London, 1871.

$(4+9)$ W. K. Parker. "On the structure and development of the skull of the Common Fowl (Gallus Domesticus)." Phil. Trans., 1869.

$(+, 0)$ W. K. Parker. "On the structure and development of the skull of the Common Frog (Rana temporaria)." Phil. Trans., 1871.

$(+51)$ W. K. Parker. "On the structure and development of the skull in the Salmon (Salmo salar)." Bakerian Lecture, Phil. I rans., 1873.

$(+52)$ W. K. Parker. "On the structure aud derelopment of the skull in the Pig (Sus selofa)." Phil. Trans., 187t.

(453) W. K. Parker. "On the structure and development of the sliull in the Batrachia." Part 1. Plit. Trons., 1876.

$(+5+)$ W. K. Parker. "On the structure and development of the skull in the Uiodelous Amphibia." Part in. I'hil. Trans., 1877.

(455) W. K. Parker. "On the structure and development of the skull in the Common Snake (Tropidonotus natrix)." Phil. Tron., 1878.

$(+; 6)$ W. K. Parker. "On the structure and development of the sliull in Sharks and Skates." Troms. Zoolog. Soc., 1878. Vol, x. pt. Iv.

(45) W. K. Parker. "On the structure and development of the skull in the Lacertilia." Pt. I. Lacerta agili:, L. viridis and Zootoca vivipara. Phil. Trons., 1879. $(+58)$ W. K. Parker. "The development of the Green Turtle." The Zoology of the royage of H.M.S. Challenger. Vol. I. pt. v.

(459) W. K. Parker. "The structure and development of the skull in the Batrachia." Pt. 11. P',il. Trals., 1880. 1877.

(+60) W. K. Parker and G. T. Bettany. The Iorphology of the Skmll. London,

(460*) H. Fathke. Entwick. d. Natter. Könirsberg, 1839.

( 4 r r) C. B. Reichert. "Ueber die Visceralbogen d. Wirbelthiere." Mïller"s Arehiv, 1837.

(462) W. Salensky. "Beiträge z. Entwick. d. knorpeligen Gehörkn̈̈chelchen." Horphol. Jahbbuch, Vol. vi. 1880.

Vide also Kolliker (No. $29^{\circ}$ ), especially for the human and mamnalian skull; (ioitte (No. 296). 


\section{CHAP'TER XX.}

\section{THE PECTORAL AND PELVIC GIRDLES AND THE SKELETON OF THE LIMBS.}

\section{The Pectoral girdle.}

Pisces. Amongst Fishes the pectoral girdle presents itself in its simplest form in Elasmobranchii, where it consists of a bent band of cartilage on each side of the body, of somewhat variable form, meeting and generally uniting with its fellow ventrally. Its anteriur border is in close proximity with the last visceral arch, and a transverse ridge on its onter and posterior border, forming the articular smrface for the skeleton of the limb, divides it into a dorsal part, which may be called the scapula, and a ventral part which may be called the coracoid.

In all the remaining groups of Fishes there is added to the cartilaginous band, which may wholly or partially ossify, an osseous support composed of a series of membrane bones.

In the types with such membrane bones the cartilaginous parts do not continue to meet, ventrally, except in the Dipnoi where there is a ventral piece of cartilage, distinct from that bearing the articulation of the limb. The cartilage is moreover proluced into two ventral processes, an anterior and a posterior, below the articulation of the limb; which may be called, in accorkance with Gegenbaur's nomenclature, the procoracoid and coracoid. Of these the precoracoid is far the most prominent, and in the majority of cases the coracoid can hardly be recognised. The coracoid process is however well developed in the Selachioid Ganoids, and the Siluroid Teleostei. In 'Teleostei the scapular region often ossifies in two parts, the smaller of which is namer by Parker præcoracoid. though it is quite distinct from Gegenbaur's præcoracoid. The membrane bones, as they present themselves in their most primitive state in Acipenser and the Siluroids, are dermal scutes embracing the anterior edge of the cartilaginous girdle. In Acipenser there are three scutes on each side. $A$ dorsal scute known as the supra-clavicle, connected above with the skull by the post-temporal; a midele piece or clavicle, and a 
ventral or infra-clavicle (inter-clavicle), which meets its fellow below.

In most Fishes the primitive dermal scutes have become subdermal membrane bones, and the infra-clavicle is usually not distinct, but the two clavicles form the most important part of the membranous elements of the girdle. Additional membrane bones (postclavicles) are often present behind the main row.

The development of these parts in Fishes has been but little studied.

In Scyllium, amongst the Elasmobranchii, I find that each half of the pectoral girdle develops as a vertical bar of cartilage at the front border of the rudimentary fin, and externally to the muscle-plates.

Before the tissue forming the pectoral girdle has acquired the character of true cartilage, the bars of the two sides meet ventrally by a differentiation in situ of the mesoblastic cells, so that, when the girdle is converted into cartilage, it forms an undivided are, girthing the ventral side of the body. There is developed in continuity with the posterior border of this arc on the level of the fin a horizontal bar of cartilage, which is continued backwards along the insertion of the fin, and, as will be shewn in the sequel, becomes the metapterygium of the adult (figs. $3+4, b p$ and $3+8, m p)$. With this bar the remaining skeletal elements of the fin are also continuous.

The foramina of the pectoral girdle are not in the first instance formed by absorption, but by the non-development of the cartilage in the region of pre-existing nerves and vessels.

The development of these parts in Teleostei has been recently investigated by 'swirski (No. 472) who fiuds in the Pike (Esox) that the cartilarginous pectoral girdle is at first continuous with the skeleton of the fin. It forms it rod with a dorsal scapular and rentral coracoid process. An independent mass of cartilage gives rise to a precoracoid, which unites with the main mass, forming a triradiate bar like that of Acipenser or the Siluroids. The coracoid process becomes in the course of development gradually reduced.

'Swirski corrcludes that the so-called pracoracoid bar is to some extent a secondary element, and that the coracoid bar corresponds to the whole of the ventral part of the girdle of Elasmobranchii, but his investigations do not appear to me to be as complete as is desirable.

Amphibia and Amniota. The pectoral girdle contains a more or less constant series of elements throughout the Amphibia and Amniota; and the differences in structure between the shoulder girdle of these gromps and that of Fishes are so great that it is only possible to make certain general statements respecting the homologies of the parts in the two sets of types.

The generally accepted view, founded on the researches of Parker, Hnxley, and Gegenbaur, is to the effect that there is a primitively cartilaginous coraco-scapular plate, homologous with that in Fishes, and that the membrane bones in Fishes are represented by the clavicle and inter-clavicle in the Sauropsida and Mammalia, which are however usually almitted to be absent in Amphibia. 'Jhese 
views have recently been challenged by Gïtte (No. 466) and Hoftmann (No. 467), on the ground of a series of careful enbryological observations; and until the whole subject has been worked over by other observers it does not seem possible to decide satisfactorily between the conflicting views. It is on all hands admitted that the scapulo-coracoid elements of the shoulder girdle are formed as a pair of cartilaginous plates, one on each side of the body. The dorsal half of each plate becomes the scapula, which may subsequently become livided into a supra-scapula and scapula proper; while the ventral half forms the coracoid, which is not always separated from the scapula, and is usually divided into a coracoid proper, a pracoracoid, and an epicoracoid. By the conversion of parts of the primitive cartilaginous plates into membranous tissue various fenestra may be formed in the cartilage, and the bars bounding these fenestre both in the scapula and coracid regions have received special names; the anterior bar of the coracoil region, forming the pracoracoid, being especially important. At the boundary between the scapula and the coracoil, on the hinder border of the plate, is placed the glenoid articular cavity to carry the head of the humerus.

The grounds of difference between Götte and Hoffmamn and other anatomists concern especially the clavicle and inter-clavicle. The clavicle is usually regarded as a membrane bone which may become to some extent cartilaginous. By the above anatomists, and by Rathke also, it is held to be at first united with the coraco-scapular plate, of which it forms the anterior limb, free ventrally, but united dorsally with the main part of the plate; and Götte and Hoffmann hold that it is essentially a cartilage bone, which however in the majority of the Reptilia ossifies directly without passing throngh the condition of cartilage.

The interclavicle (episternum) is held by Gütte to be developed from a paired formation at the free ventral cnds of the clavicles, but he holds views which are in many respects original as to its lomologies in Mammalia and Amphibia. Even if Götte's facts are admitted, it does not appear to me necessarily to follow that his deductions are correct. The most important of these is to the effect that the dermal clavicle of Pisces has no homologue in the higher types. Granting that the clavicle in these gromps is in its first stage continuous with the coraco-scapular plate, and that it may beeome in some forms cartilaginous before ossifying, yet it seens to me all the same quite possible that it is genetically derived from the clavicle of Pisces, but that it has to a great extent lost even in development its primitive characters, though these characters are still partially indicated in the fact that it usually ossifies very early and partially at least as a membrane bone.

1 The fact of the clavicle going out of its way, so to speak, to become cartilaginous before being ossified, may perhaps be explained by supposing that its close connection with the other parts of the shoulder girdle has caused, by a kind of infection, a change iu its histological characters. 
In treating the dovelopment of the precural gindle systematically it will be convenient to begin with the Amniota, which may be considered to tix the nomenclature of the elements of the shoulder girile.

Lacertilia. The shoulder girdle is formed as two membrinous plates, from the dorsal part of the anterior border of each of which a bar projects (Rathke, Götte), which is free at its ventral end. This bar, which is usually (Gegenbarr, Parker) held to be independent of the remaining prart of the shoulder girdle, gives rise to the clavicle and interclavicle. The scapulocoracoid plate som becomes cartilaginous, while at the same time the clavicular bar ossifies directly from the membranous state. The ventral ends of the two clavicular bars enlarge to form two longitudinally placed plates, which unite together and ossify as the interclavicle.

Parker gives a very different account of the interclavicle in Angnis. He states that it is formed of two pairs of bones 'strapped on to the antero-inferior part of the presternum,' which subsequently unite into one.

Chelonia. The thoulder girdle of the Chelonia is formed (Rathke) of a triratiate cartilage on each side, with one dorsal and two ventral limbs. It is admitted on all hands that the dorsal limb is the scajular element, and the pos erior ventral limb the coracoid ; but, while the anterior ventral limb is usually held to be the precolacoid, Götte and Hoffmann nuintain that, in spite of its being formed of cartilage, it is homologrous with the anterior bar of the primitive shonlder-plate's of Lacertilia, and therefore the lomologue of the clavirle.

Parker and Huxley (doubtfully) hold that the three anterior elements of the ventral plastron (entoplastron and epiplastra) are homologons with the interclavicle and clavicles, but considering that these plates apjear to belong to a secondary system of dermal ossifications peculiar to the Chelonia, this homology does not appear to me probable.

Aves. There are very great differences of view as to the development of the pectoral arch of Aves.

About the presence in typical forms of the coraco-scapular plate and two independent clavicular bars all authors are agreed. With reference to the clavicle and interclavicle Parker (No. 468) finds that the scipular end of the clavicle attaches itself to and ossifies a mass of cartilage, which he regards as the mesoscapula, while the interclavicle is formed of a mass of tissue hetween the ends of the clavicles where they meet ventrally, which becomes the dilated plate at their junction.

Gegenbaur holds that the two primitive clavicular bar's are simply clavicles, without any element of the scapula; and states that the clavicles are not entirely ossified from membrane, but that a delicate band of cartilage precedes the osseous bars. He finds no interclavicle.

Götte and Ratlıke both state that the clavicle is at first continuous with the coraco-scapular plate, but become; early separated, and ossifies entirely as a membrane bone. Götte further states that the interclavicles are formed as outgrowths of the median ends of the clavicles, which extend themselves at an early period of development along the inner edges of the two lailves of the sternum. They soon separate from the clavicles, which subseqnently meet to form the furculum; while the interclavicular rudiments give rise, on the junction of the two halves of the sternum, to its keel, and to the ligament connectiug the furculum with the sternum. The observations of 
Götte, which tend to shew the keel of the sternum is really an interclavicle, appear to me of great importance.

A precoracoid, partially separated from the coracoid by a space, is present in Struthio. It is formed by a fenestration of a primitively continuous cartilaginous coracoid plate (Hoffmann). In Dromæus and Casuarius clavicles are present (fused with the scapula in the adult Dromaus), though alsent in other Ratita (Parker, etc.).

Mammalia. The coracoid element of the coraco-scapular plate is much rednced in Mammalia, forming at most a simple process (except in the Ornithodelphia) which ossifies however separately'.

With reference to the clavicles the same divergencies of opinion met with in other types are found here also.

The clavicie is staterl by Ratlike to be at first continuous with the coraco-scapular plate. It is however soon separated, and ossifies very early, in the lumman embryo before any other bone. Gegenbaur lowever shewed that the human clavicle is provided with a central axis of cartilage, and this ohservation has been contirmed by Kölliker, and extended to other Mammalia by Götte. The mode of o-sification is nevertheless in many respects intermediate between that of a true cartilage bone and a membrane bone. The ends of the clavicles remain for some time, or even permanently, cartilaginous, ancl have been inter'preted by Parker, it appears to me on liarlly sntficient grounds, as parts of the mesoscapula and pracoracoid. Parker's so-called mesoscapula may ossify separately. The homologies of the episternum are much disputed. Götte, who has worked out the developinent of the parts more fully than any other anatomist, finds that paired interclavicular clements grow out backwards from the ventral ends of the clavicles, and uniting together form a somewhat T-shaped interclavicle overlying the front end of the sternum. This condition is permanent in the Ornithodelphia, except that the anterior part of the sternum undergoes atrophy. Bnt in the higher forms the interclavicle becomes almost at once divirled into three parts, of which the two lateral remain distinct, while the median elenent fuses with the subjacent part of the sternmm and constitutes with it the presternum (manubrium sterni). It Gïtte's facts are to be trusted, and they have been to a large extent confirmed by Hoffmann, his homologies appear to be satisfactorily establisher. As mentioned on p. 463 Ruge (No. 438 ) holds that Götte is mistaken as to the origin of the presternum.

Gegenbaur almits the lateral elements as parts of the interclavicle, while Parker holds that they are not parts of an interclavicle but are lomologous with the omosternum of the Flog, which is lowever held by Götte to be a true interclavicle.

Amphibia. In Amplibiat the two halves of the shoulder girdle are each formed as a continuous plate, the ventral or coracoid part of which is forked, and is composed of a larger posterior and a smaller anterior bar-like process, mited dorsally. In the Urodela the two remain permanently free at their ventral ends, but in the Anura they become mited, and the space between them then forms a fenestra. The anterior process is usually

1 This process, known as the coracoid process, is held by Sabatier to be the pracoracoid; while this author also holds that the upper third of the glenoid cavity, which ossifies by a special nucleus, is the true coracoid. The absence of a pracoracoid in the Ornithodelphia is to my mind a serions difficuly in the way of Sabatier's view. 
(Gegenbaur, Parker) regarded as the præcoracoid, but Götte has pointed out that in its mode of development it strongiy resembles the clavicle of the higher forms, and behaves quite differently to the so-called pracoracoid of Lizards. It is however to be noticed that it differs from the clavicle in the fact that it is never segmented off from the coraco-scapular plate, a condition which has its only parallel in the equally doubtful case of the Chelonia. Parker holds that there is no clavicle present in the Amphibia, while Gegenbaur maintains that an ossification which appears in many of the Anura (though not in the Urodela) in the perichondrium on the anterior border of the cartilaginous bar above mentioned is the representative of the clavicle. Goitte's observations on the ossification of this bone throw doubt upon this view of Gegenbaur; while the fact that the cartilaginous bar may be completely enclosed by the bone in question renders Gegenbaur's view, that there is present both a clavicle and præcoracoid, highly improbable.

No interclavicle is present in Urodela, but in this group and in a number of the Anura, a process grows out from the end of each of the bars (prrecoracoids) which Götte holds to be the clavicles. The two processes unite in the median line, and give rise in front to the anterior unpaired element of the shoulder girdle (omosternum of Parker). They sometimes overlap the epicoracoids behiud, and fusing with them bind them together in the median line. Parker whe has described the paired origin of the so-called omosternum, holds that it is not homologous with the interclavicle, but compares it with his omosternum in Mammals.

\section{BibliograpHY.}

$\left({ }_{4}{ }_{3}\right)$ Bruch. "Ueber die Entwicklung der Clavicula und die Farbe des Blutes." Zeit.f. wiss. Zool., iv. 1853 .

(464) A. Dugès. "Recherches sur l'ostéologie et la myologie des Batraciens à leurs différens âges." Mémoires des savants étrang. Académie royale des sciences de l'institut de France, Vol. vi. 1835.

$\left({ }_{4} 5_{5}\right)$ C. Gegenbaur. Untersuchungen zur vergleichenden Anatomie der Wrirbelthiere, 2 Heft. Schultergïtel der Wirbelthiere. Brustflosse der Fische. Leipzig, 1865. (466) A. Götte. "Beiträge z. vergleich. Morphol. d. Skeletsystems d. Wirbelthiere: Brustbien u. Schultergiirtel. Archiv f. mikr. Anat. Vol. xIr. 1877.

$\left(4 \sigma_{7}\right)$ C. K. Hof fma nn. "Beiträge z. vergleichenden Anatomie d. Wirbelthiere." Niederlïndisches Archin f. Zool., Vol. v. 1879.

(468) W. K. Parker. "A Monograph on the Strueture and Development of the Shoulder-girdle and Sternum in the Vertebrata." Ray Society, 1868.

(469) H. Rathke. Ueber die Entwicklung der Schildkröten. Braunschweig, 1848. 1853.

(40) H. Rathke. Ueber den Ban und die Entwicklung des Brustbeins der Saurier,

$(+i \mathrm{I})$ A. Sabatier. Comparaison des ceintures et des membres antérieurs et postérieurs d. la Série d. Vertébrés. Montpellier, 1880.

(472) Georg 'Swirski. Untersuch. üb. d. Fntwick, d. Schultergïrtels $u$. $d$. Skelets d. Brustflosse d. Hechts. Inaug. Diss. Dorpat, 1880.

\section{Pelvic girdle.}

Pisces. The pelvic girdle of Fishes is formed of a cartilaginous band, to the outer and posterior side of which the basal element of the pelvic fin is usually articulated. This articulation divides it into a dorsal iliac, and ventral pubic section. The iliac section never articulates with the vertebral column.

In Elasmobranchii the two girdles unite ventrally, but the iliac

B. E. II. 
section is only slightly developed. In Chimæra there is a well developed iliac process, but the pubic parts of the girdle are only united by connective tissue.

In the cartilaginous Ganoids the pelvic girdle is hardly to be separated from the skeleton of the fin. It is not united with its fellow, and is represented by a plate with slightly developed pubic and iliac processes.

In the Dipnoi there is a simple median cartilage, articulated with the limb, but not provided with an iliac process. In bony Ganoids and Teleostei there is on each side a bone meeting its fellow in the ventral line, which is usually held to be the rudiment of the pelvic girdle; while Davidoff attempts to shew that it is the basal element of the fin, and that, except in Polypterus, a true pelvic girdle is absent in these types.

From my own observations I find that the mode of development of the pelvic girdle in Scyllium is very similar to that of the pectoral girdle. 'There is a bar on each side, continuous on its posterior border with the basal element of the fin (figs. 345 and 347 ). This bar meets and unites with its fellow ventrally before becoming converted into true cartilage, and though the iliac process (il) is never very considerable, yet it is better developed in the embryo than in the adult, and is at first directed nearly horizontally forwards.

Amphibia and Amniota. The primitive cartilaginous pelvic girdle of the ligher types exlibits the same rivision as that of Pisces into a dorsal and a ventral section, which meet to form the articular cavity for the femur, known as the acetabulum. The dorsal section is always single, and is attached by means of rudimentary ribs to the sacral region of the vertebral column, and sometimes to vertebræ of the adjoining lumbar or caudal regions. It always ossifies as the ilium.

The ventral section is usually formed of two more or less separated parts, an anterior which ossifies as the pubis, and a posterior which ossifies as the ischium. The space between them is known as the obturator foramen. In the Amphibia the two parts are not separated, and resemble in this respect the pelvic girdle of Fishes. They generally meet the corresponding elements of the opposite side ventrally, and form a symphysis with them. The symphysis pubis, and symphysis ischii inay be continuous (Nammalia, Amphibia).

The observations on the development of the pelvic girdle in the Amphibia and Amniota are nearly as scanty as on those of Fishes.

Amphibia. In the Amphibia (Bunge, No. 473) the two halves of the pelvic girdle are formed as independent masses of cartilage, which subsequently unite in the ventral line.

In the Urodelous Amphibia (Triton) each mass is a simple plate of cartilage divided into a dorsal and ventral section by the acetabulum. The ventral parts, which are not divided into two regions, unite in a symphysis comparatively late.

The dorsal section ossifies as the ilium. The ventral usually containe 
a single ossification in its posterior part which forms the ischinm; while the anterior part, which may be convidered as representing the pubis, usually remains curtilaginons; though Huxley (No. 475) states that it has a separate centre of ossification in Salamander, which however does not appear to be always present (Bunge). There is a small obturator foramen between the ischinm and pubis, which gives passage to the obturator nerve. It is formed by the part of the tissue where the nerve is placed not becoming converted into cartilage.

There is a peculiar cartilage in the ventral median line in front of the puhis, which is developed independently of and much later than the true parts of the pelvic girdle. It may be called the prepubic cartilage.

Lacertilia. In Lacertilia the pelvic girdle is formed as a somewhat trirudiate mass of cartilage on each side, with a dorsal (iliac) process, and two rentral (pubic and ischiad) processes. The acetabulum is placer on the onter side at the junction of the three processes, each of which may be considered to have a share in forming it. The distal ends of the pubis and ischium are close together when first formed, bat subsequently separate. Each of them mites at a late stuge with the corresponding process of the opposite side in a rentral symphysis. A centre of ossification appears in each of the three processes of the primitive cartilage.

In Birds the parts of the pelvic girdle no longer develop as a continuous cartilage (Bunge). Either the pubis may be distinct, or, as in the Duck, all the elements. The ilium early exhibits a short anterior process, but the pubis and ischium are at first placed with their long axes at right angles to that of the ilium, but gradnally become rotated so as to lie parallel with it, their distal ends pointing backwards, and not aniting veutrally excepting in one or two Struthious forms.

Mammalia. In Mammalia the pelvic girdle is formed in cartilage as in the lower forms, but in Man at any rate the pulic part of the cartilage is formed independently of the remainder (Rosenberg). There are the usual three centres of ossification, which unite eventually into a single bone-the innominate bone. The pubis and ischium of each side unite with each other ventrally, so as completely to enclose the obturator foramen.

Hnxley holds that the so-called marsupial bones of Monotremes and Marsupials, which as shewn by Gegenhaur (No. 474) are preformed in cartilage, are homologous with the prepubis of the Uroulela; but considering the great gap hetween the Urodela and Mammalia this homology can only be regarded as tentative. He further holds that the anterior prolongations of the cartilaginous ventral ends of the pubis of Crocodilia are also structures of the same nature.

\section{BibliograpHY.}

(43) A. Bunge. Ċntersuch. z. Entrick. d. Beckengirtel. d. Amphibien, Reptitien n. Vögel. Inaug. Diss. Dorpat, 1880.

(47) C. Gegenbaur. "Ueber d. Ausschluss des Schambeins von d. Pfanne d. Hüftgelenkes." Horph. Jahrinch, Vol. n1. 1876.

(475) Th. H. Huxley. "The characters of the Pelvis in Mammalia, etc." Proc. of Koy. Soc., Vol. xxv11. 1879.

$\left(47^{6}\right)$ A. Sabatier. Comparaison des ceintures et des membres antérieurs rt postêrieurs dans la Série d. Vertébrés. Montpellier, 1880. 


\section{Comparison of Pectoral and Pelvic girdles.}

Throughout the Vertebrata a more or less complete serial homology may be observed between the pectoral and pelvic girdles.

In the cartilaginous Fishes each girdle consists of a continuous band, a dorsal and ventral part being indicated by the articulation of the fin; the former being relatively undeveloped in the pelvic girdle, while in the pectoral it may articulate with the vertebral column. In the case of the pectoral girdle secondary membrane bones become added to the primitive cartilage in most Fishes, which are not developed in the case of the pelvic girdle.

In the Amphibia and Amniota the ventral section of each girdle becomes divided into an anterior and a posterior part, the former constituting the præcoracoid and pubis, and the latter the coracoid and ischium; these parts are however very imperfectly differentiated in the pelvic girdle of the Urodela. The ventral portions of the pelvic girdle usually unite below in a symphysis. They also meet each other ventrally in the case of the pectoral girdle in Amphibia, but in most other types are separated by the sternum, which has no homologue in the pelvic region, unless the præpubic cartilage is to be regarded as such. The dorsal or scapular section of the pectoral girdle remains free; but that of the pelvic girdle acquires a firm articulation with the vertebral column.

If the clavicle of the higher types is derived from the membrane bones of the pectoral girdle of Fishes, it lias no homologue in the pelvic girdle; but if, as Götte and Hoffmann suppose, it is a part of the primitive cartilaginous girdle, the ordinary view as to the serial homologies of the ventral sections of the two girdles in the higher types will need to be reconsidered.

\section{Limbs.}

It will be convenient to describe in this place not only the development of the skeleton of the limbs but also that of the limbs themselves. The limbs of Fishes are moreover so different from those of the Amphibia and Amniota that the development of the two types of limb may advantageously be treated separately.

In Fislies the first rudiments of the limbs appear as slight longitudinal ridge-like thickenings of the epiblast, which closely resemble the first rudiments of the unpaired fins.

These ridges are two in number on each side, an anterior immediately behind the last visceral fold, and a posterior on the level of the cloaca. In most Fishes they are in no way connected, but in some Elasmobranch embryos, more especially in Torpedo, they are connected together at their first development by a line of columnar epiblast cells'. 'This comnecting line of columnar epiblast is a very transitory structure, and after its disappearance the rudimentary fins become more prominent, consisting (fig. $343, b$ ) of a projecting ridge both of epiblast and mesoblast, at the outer edge of 1 F. M. Balfour. Monograph on. Elasmobranch Fishes, pp. 101-2. 
which is a fold of epiblast only, which soon reaches considerable dimensions. At a later stage the mesoblast penetrates into this fold and the fin becomes a simple ridge of mesoblast, covered by epiblast. The pectoral fins are usually considerably ahead of the pelvic fins in development.

For the remaining history it is necessary to confine ourselves to Scyllium as the only type which has been adequately studied.

The direction of the original ridge which connects the two fins of each side is nearly though not quite longitudinal, sloping somewhat obliquely downwards. It thus comes about that the attachment of each pair of limbs is somewhat on a slant, and that the pelvic pair nearly meet each other in the median ventral line a little way behind the anus.

The elongated ridge, forming the rudiment of each fin, gradually projects more and more, and so becomes broader in proportion to its length, but at the same time its actual attachment to the side of the body

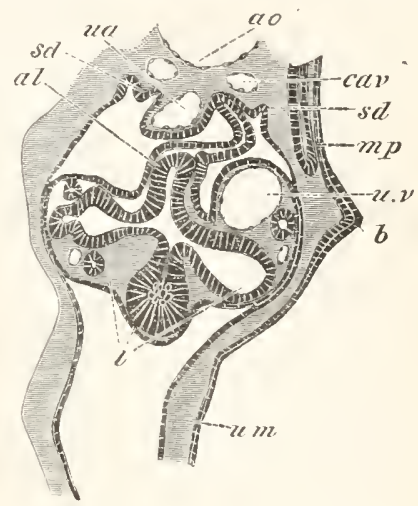

Fig. 343. Section throdgh the VENTRAL PART OF THE TRUNK OF A roung embryo of Scrllicm at the LEVEL OF THE UMBILICAL CORD.

b. pectoral fin; ao. dorsal aorta; cav. cardinal vein; ua. vitelline artery; uv. vitelline vein; al. duodenum; $l$. liver; $s d$. opening of segmented duct into the body carity; mp. muscle plate; um. umbilical canal. becomes shortened from behind forwards, so that what was originally the attached border becomes in part converted into the posterior border. This process is much more completely carried out in the case of the pectoral fins than in that of the pelvic, and the changes of form undergone by the pectoral fin in its development may be gathered from figs. $3+4$ and 348 .

Before proceeding to the development of the skeleton of the fin it may be pointed out that the connection of the two rudimentary fins by a continuous epithelial line suggests the hypothesis that they are the remnants of two continuous lateral fins ${ }^{1}$.

Shortly after the view that the paired fins were remnants of continuous lateral fins had been put forward in my memoir on Elasmobranch Fishes, two very interesting papers were published by 'Thacker (No. 489) and Mivart (No. 484) advocating this view on the entirely independent grounds of the adult structure of the skeleton of the paired fins in comparison with that of the unpaired fins ${ }^{2}$.

1 Both Maclise and Humphry (Journal of Anat. and Phys., Vol. v.) had previously suggested that the paired fins were related to the unpaired fins.

2 Davidoff in a Memoir (No. 477) which forms an important contribution to our knowledge of the structure of the pelvic fins has attempted from his obsertations to deduce certain arguments against the lateral fin theory of the limbs. His main 
The development of the skeleton has unfortunately not been as yet very fully studied. I have however made some investigations on this subject on Scyllium, and 'Swirski has also made some on the Pike.

In Scyllium the development of both the pectoral and pelvic fins is very similar.

In both fins the skeleton in its earliest stage consists of a bar springing from the posterior side of the pectoral or pelvic girdle, and running backwards parallel to the long axis of the body. The outer side of this bar is continued into a plate which extends into the fin, and which becomes very early segmented into a series of parallel rays at right angles to the longitudinal bar.

In other words, the primitive skeleton of both the fins consists of a longitudinal bar running along the base of the fin, and giving off at right angles series of rays which pass into the fin. The longitudinal bar, which may be called the basipterygium, is moreover continuous in front with the pectoral

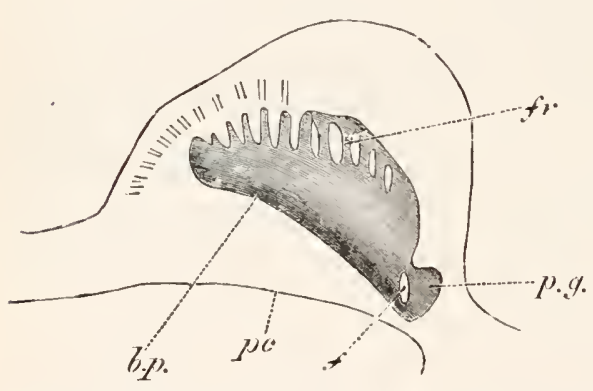

344. Pectoral fin of a young embryo of Scrllida IN LONGltudinal aNd horizontal SECTION.

The skeleton of the fin was still in the condition of embryonic cartilage.

b.p. basipterygium (eventual metapterygium); fr. fin rays; $p . g$. pectoral girỏle in transverse section; $f$. foramen in pectoral girdle; $p c$. wall of peritoneal cavity. or pelvic girdle as the case may be.

The primitive skeleton of the pectoral fin is shewn in longitudinal section in fig. $34+$, and that of the pelvic fin at a slightly later stage in fig. 345 .

A transverse section shewing the basipterygium $(m p t)$ of the pectoral fin, and the plate passing from it into the fin, is shewn in fig. 346 .

Before proceeding to describe the later history of the two fins it may be well to point out that their embryonic structure com-

argument is based on the fact that a variable but often considerable number of the spinal nerres in front of the pelvic fin are united, by a longitudinal commissure, with the true plexus of the nerves supplying the fin. From this he concludes that the pelvic fin has shifted its position, and that it may once therefore have been situated close behind the visceral arches. If this is the strongest argument which can be brought against the theory advocated in the text, there is I trust a considerable chance of its being generally accepted. For even granting that Davidoff's deduction from the character of the pelvic plexus is correct, there is, so far as I see, no reason in the nature of the lateral fin theory why the pelvic fins should not have shifted, and on the other hand the longitudinal cord connecting some of the spinal nerves in front of the pelvic fin may have another explanation. It might for instance be a remnant of the time when the pelvic fin had a more elongated form than at present, and accordingly extended further forwards.

In any case our knowledge of the nature and origin of nervous plexuses is far too imperfect to found upon their character such conclusions as those of Davidotf. 
pletely supports the view which has been arrived at from the consideration of the soft parts of the fin.

My observations shew that the embryonic skeleton of the paired fin consists of a series of parallel rays similar to those of the unpaired fins. 'These rays support the soft part of the fin which has the form of a longitudinal ridge, and are continuous at their base with a longitudinal bar, which may very probably be due to secondary development. As pointed out by Mivart, a longitudinal bar is also occasionally formed to support the cartilaginous rays of unpaired fins. The longitudinal bar of the paired fins is believed by both Thacker and Mivart to be lue to the coalescence of the bases of primitively

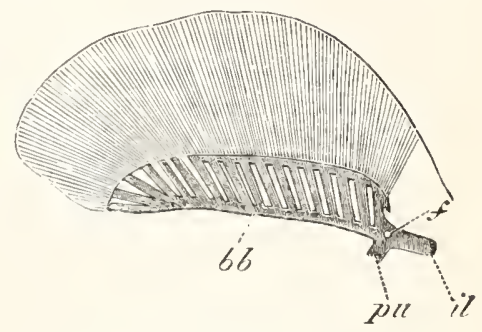

Fig, 34.5. Pelvic fin of a very youna Female EMbryo of Scyllium Stellare.

bb. hasipterygium; $p u$. pubic process of pelvic girdle; $i l$. iliae process of pelvic girdle. independent rays, of which they believe the fin to have been originally composed. 'This view is probable enough in itself, but there is no trace in the embryo of the bar in question being formed by the coalescence of rays, though the fact of its being perfectly continuous with the bases of the rays is somewhat in favour of this view ${ }^{1}$.

A point may be noticed here which may perhaps appear to be a difficulty, viz. that to a considerable extent in the pectoral, and to some extent in the pelvic fin the embryouic eartilage from which the fin-rays are developed is at first a continuous lamina, which subsequently segments into rays. I am however inclined to regard this merely as a result of the mode of conversion of the indifferent mesoblast into cartilage ; and in any case no conclusion adverse to the above view can be drawn from it, since I find that the rays of the unpaired fin are similarly segmented from a continuous lamina. In all eases the segmentation of the rays is to a large extent completed before the tissue in question is sufficiently differentiated to be called eartilage by an histologist.

Thacker and Mivart both hold that the pectoral and pelvic girdles have been evolved by ventral and dorsal growths of the anterior end of the longitudinal bar supporting the fin-rays.

There is, so far as I see, no theoretical objection to be taken to this view, and the fact of the pectoral and pelvic girdles originating continuously, and long remaining united with the longitudinal bars of their respective fins is in favour of rather than against this view.

1 Thacker more especially founds his view on the adult form of the pelvic fins in the cartilaginous Ganoids; Polyodon, in which the part which constitutes the basal plate in other forms is aivided into separate segments, being mainly relied on. It is possible that the segmentation of this plate, as maintained by Gegenbaur and Davidoff, is secondary, but Thacker's view that the segmentation is a primitive eharacter seems to me, in the absence of definite evidence to the reverse, the more natural one. 
The same may be said of the fact that the first part of each girdle to be formed is that in the neighbourhood of the longitudinal bar (basipterygium) of the fin, the dorsal and ventral prolongations being subsequent growths.

The later development of the skeleton of the two fins is more conveniently treated separately.

The pelvic fin. The changes in the pelvic fin are comparatively slight. T'he fin remains through life as a nearly horizontal lateral projection of the body, and the longitudinal bar-the basipterygium -at its base always remains as such. It is for a considerable period attached to the pelvic girdle, but eventually becomes segmented from it. Of the fin rays the anterior remains directly articnlated with the pelvic girdle on the separation of the basipterygium (fig. 347 ), and the remaining rays finally become segmented from the

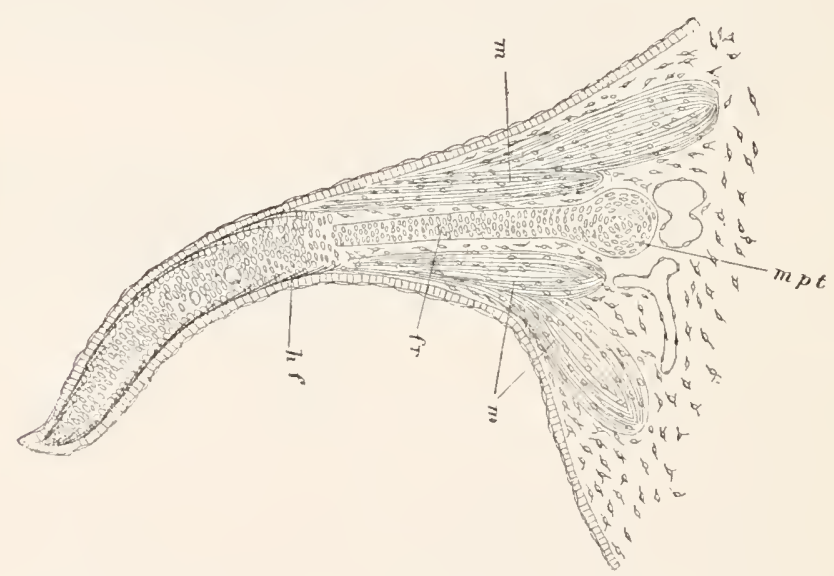

Fig. 346. Transverse section throdgh the pectoral fin of a yovag emibryo of SCrllidil stellare.

$m p t$. basipterygial bar (metapterygium); $f r$. fin ray; $m$. muscles; $h f$. horny fibres.

basipterygium, though they remain articulated with it. They also become to some extent transversely segmented. The posterior end of the basipterygial bar also becomes segmented off as the terminal ray.

The pelvic fin thus retains in all essential points its primitive arrangement.

The pectoral fin. The earliest stage of the pectoral fin differs from that of the pelvic fin only in minor points. There is the same longitudinal or basipterygial bar to which the fin-rays are attached, whose position at the base of the fin is clearly seen in the transverse section (fig. $346, m p t$ ). In front the bar is continuous with the pectoral girdle (figs. 344 and 348 ). 
The changes which take place in the course of the further develop-

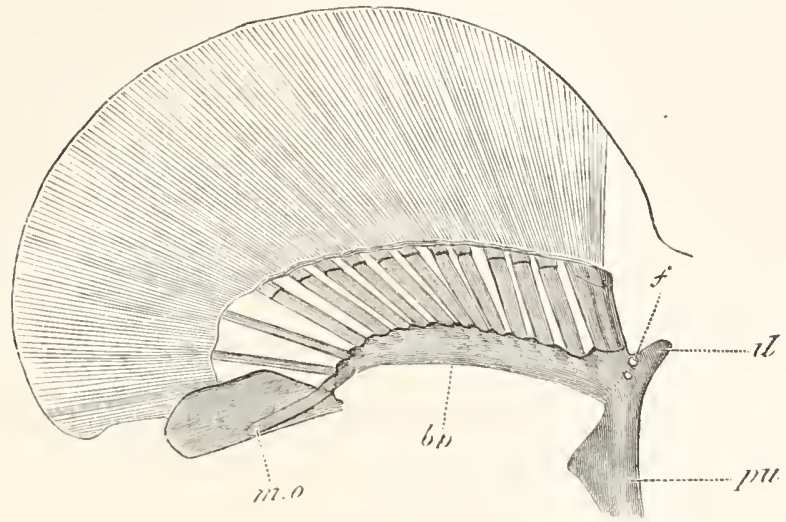

Fig. 347. Pelvic fin of a young male exbryo of Scylliual stellare.

$b p$. basipterygium; m.o. process of basipterygium continued into clasper; $i l$. iliac process of pectoral girdle; $p u$. pubis.

ment are however very much more considerable in the case of the pectoral than in that of the pelvic fin.

By the process spoken of above, by which the attachment of the pectoral fin to the body wall becomes shortened from behind forwards, the basipterygial bar is gradually rotated outwards, its anterior end remaining attached to the pectoral girdle. In this way this bar comes to form the posterior border of the skeleton of the fin (figs. 348 and $349 \mathrm{mp}$ ), constituting what Gegenbaur called the metapterygi um, and eventually becomes segmented off from the pectoral girdle, simply articulating with its hinder edge.

The plate of cartilage, which is continued outwards from the basipterygium, or as we may now call it, the metapterygium, into the fin, is not nearly so completely

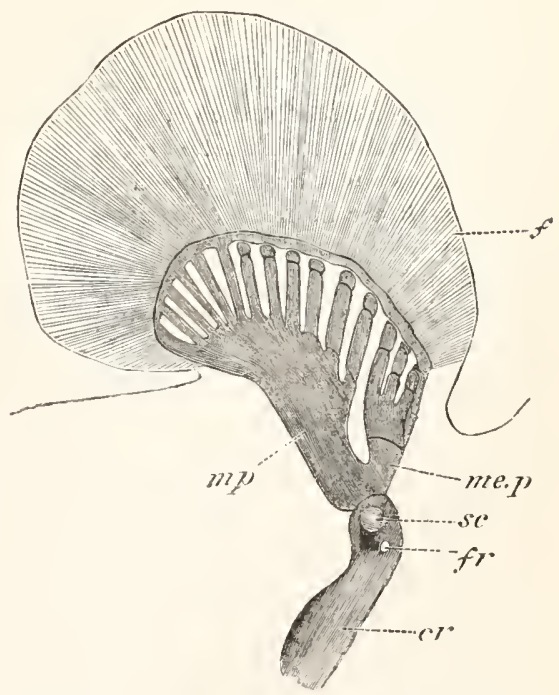

348. Pectoral fin of an exibryo of ScyLLIUU STELLARE.

$m p$. metapterygium (basipterygiam of earlier stage); me.p. rudiment of future pro- and mesopterygium; sc. cut surface of scapular process; $c r$. coracoid process; $f r$. foramen; $f$. horny fibres. 
divided up into fin-rays as in the case of the pelvic fin, and this is especially the case with the basal part of the plate. This basal part becomes in fact at first only divided into two parts (fig. 348) a small anterior part at the front end (me.p), and a larger posterior along the base of the remainder of the fin. 'The anterior part directly joins the pectoral girdle at its base, resembling in this respect the anterior fin-ray of the pelvic girdle. It constitutes the rudiment of the mesopterygium and propteryginm of Gegenbaur. It bears four fin-rays at its extremity, the anterior not being well marked. The remaining fin-rays are borne by the edge of the plate continuous with the metapterygium.

'The further changes in the cartilages of the limb are not important, and are easily understood by reference to fig. 349 representing the limb of a nearly full-grown embryo. The front end of the anterior basal cartilage becomes segmented off as a propterygium, bearing a single fin-ray, leaving the remainder of the cartilige as a mesopterygium. The remainder of the now considerably segmented fin-rays are borne by the metapterygium.

The mode of development of the pectoral fin demonstrates that, as supposed by Mivart, the metapterygium is the homologue of the basal cartilage of the pelvic fin.

From the mode of development of the fins of Scyllium conclusions may be drawn adverse to the views recently put forward on the structure of the fin by Gegenbaur and Huxley, both of whom consider the primitive type of fin to be most nearly retained in Ceratodus, and to consist of a central multisegmented axis with numerous rays. Gegenbaur derives the Elasmobranch pectoral fin from a form which he calls the archipterygium, nearly like that of Ceratodus, with a median axis and two rows of rays; but holis that in addition to the rays attached to the median axis, which are alone found in Ceratodus, there were other rays directly articulated to the shoulder-girdle. He considers that in the Elasmobranch tin the majority of the lateral rays on the posterior (median or inner according to his view of the position of the limb) side have become ahorted, and that the central axis is represented by the metapterygium; while the pro- and mesopterygium and their rays are, he believes, derived from those rays of the archipterygium which originally articulated directly with the shoulder-girdle.

Gegenbaur's view appears to me to be absolutely negatived by the facts of development of the pectoral fin in Scyllium; not so much because the pectoral fin in this form is necessarily to be regarded as primitive, but because what Gegenbaur holds to be the primitive axis of the biserial fin is demonstrated to be really the base, and it is only in the adult that it is conceivable that a second set of lateral rays could have existed on the posterior side of the metapterygium. If Gegenbaur's view were correct we should expect to find in the embryo, if anywhere, traces of the second set of lateral rays; but the fact is that, as may easily be seen by an inspection of figs. 344 and 346 , such a second set of lateral rays could not possibly have existed in a type of fin like that found in the embryo ${ }^{1}$. With

1 If, which I very much doubt, Gegenbaur is right in regarding certain rays found 
this view of Gegenbaur's it appears to me that the theory leeld by this atnatomist to the effect that the liubs are modified gill arches also falls; in that his method of deriving the limbs from gill arches ceases to be achissible, while it is not easy to see how a limb, formed on the type of the embryonic limb of Elasnobranchs, could be derived from a visceral arch with its branchial rays ${ }^{1}$.

Gegenbaur's older view that the Elasmobranch fin retains a primitive uniserial type appears to me to be nearer the truth than his more recent view on this subject; though I hold that the fuudamental point established by the development of these parts in Scyllium is that the posterior border of the adult Elasmobranch tin

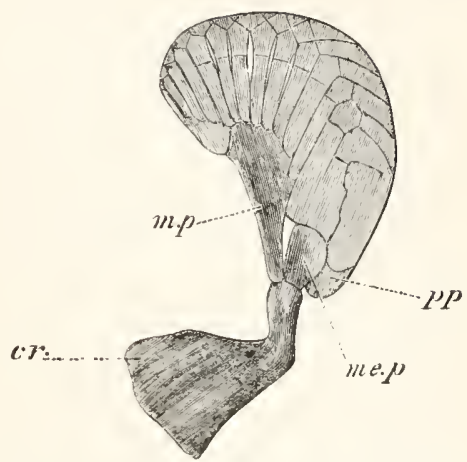

Fig. 349. Skeletoy of the pectoral fin and PART OF PECTORAL GIRILE OF A NEALLY RIPE EMBRYO of SCylliuM STELlare.

mp. metapterygium; me.p. mesopterygium; $p p$. propterygium; $c r$. coracoid process. is the primitive base line, i.e. the line of attachment of the fin to the side of the body.

Huxley holds that the mesopterygium is the proximal piece of the axial skeleton of the limb of Ceratodus, and derives the Elasmobranch fin from that of Ceratodus by the shortening of its axis and the coalescence of some of its elements. The secondary character of the mesopterygium, and its total absence in the embryo Scyllium, appears to me as conclusive against Huxley's view, as the character of the embryonic fin is against that of Gegenbaur; and I should be much more inclined to hold that the fin of Ceratodus has been derived from a fin like that of the Elasmobranchii by a series of steps similar to those which Huxley supposes to lave led to the establishment of the Elasmobranch tin, but in exactly the reverse order.

With reference to the development of the pectoral fin in the Teleostei there are some observations of 'Swirski (No. 488) which unfortunately do not throw very much light upon the nature of the limb.

'Swirski finds that in the Pike the skeleton of the limb is formed of a plate of cartilage, continuous with the pectoral girdle; which soon becomes divided into a proximal and a distal portion. The former is subsequently segmented into five basal rays, and the latter into twelve parts, the number of which subsequently becomes reduced.

in some Elasmobranch pectoral fins as rudiments of a second set of rays on the posterior side of the metapterygium, these rays will have to be regarded as structures in the act of being evolved, and not as persisting traces of a biserial fin.

1 Some arguments in favour of Gegenbaur's theory adduced by Wiedersheim as a result of his researches on Protopterus are interesting. The attachment which he describes between the external gills and the pectoral girdle is no doubt remarkable, but I would suggest that the observations we have on the vascular supply of these gills demonstrate that this attachment is secondary. 
These investigations night be regarded as tending to shew that the basipterygium of Elasmobranchii is not represented in Teleostei, owing to the fin rays not having united into a continuous basal bar, but the observations are not sufficiently complete to admit of this conclusion being founded upon them with any certainty.

\section{The cheiropterygium.}

Observations on the early development of the pentadactyloid limbs of the higher Vertebrata are comparatively scanty.

The limbs arise as simple outgrowths of the sides of the body, formed both of epiblast and mesoblast. In the Amniota, at all events, they are processes of a special longitudinal ridge known as the Wolffian ridge. In the Amniota they also bear at their extremity a thickened cap of epiblast, which may be compared with the epiblastic fold at the apex of the Elasmobranch fin.

Both limbs have at first a precisely similar position, both being directed backwards and being parallel to the surface of the body.

In the Urodela (Götte) the ulnar and fibular sides are primitively dorsal, and the radial and tibial ventral: in Mammalia however Kölliker states that the radial and tibial edges are from the first anterior.

The exact changes of position undergone by the limbs in the course of development are not fully understood. To suit a terrestrial mode of life the flexures of the two limbs become gradually more and more opposite, till in Mammalia the corresponding joints of the two limbs are turned in completely opposite directions.

Within the mesoblast of the limbs a continuous blastema becomes formed, which constitutes the first trace of the skeleton of the limb. The corresponding elements of the two limbs, viz. the humerus and femur, radius and tibia, ulna and fibula, carpal and tarsal bones, metacarpals and metatarsals, and digits, become differentiated within this, by the conversion of definite regions into cartilage, which may either be completely distinct or be at first united. These cartilaginous elements subsequently ossify.

The later development of the parts, more especially of the carpus and tarsus, has been made the subject of considerable study; and important results have been thereby obtained as to the homology of the various carpal and tarsal bones throughout the Vertebrata; but this subject is too special to be treated of here. The early development, including the succession of the growth of the different parts, and the extent of continuity primitively obtaining between them, has on the other hand been but little investigated; recently however the development of the limbs in the Urodela has been worked out in this way by two anatomists, Götte (No. 482) and Strasser (No. 487), and their results, though not on all points in complete harmony, are of considerable interest, more especially in their bearing on the derivation of the pentadactyloid limb from the piscine fin. Till lowever further investigations of the same nature have been made upon other types, the conclusions to be drawn from Götte and Strasser's observa- 
tions nust be regarded as somewliat provisional, the actual interpretation of various ontological processes being very uncertain.

The forms investigated are Triton and Salamandra. WVe may remind the reader that the hand of the Urodela has four digits, and the foot five, the fifth digit heing absent in the hand ${ }^{1}$. In 'Triton the proximal row of' carpal bones consists (using Gegenbaur's nomenclature) of (1) a radiale, and (2 and 3) an intermedium and ulnare, partially united. The distal row is formed of four carpals, of which the first often does not support the first metacarpal; while the second articulates with both the first and second metacarpals. In the foot the proximal row of tarsals consists of a tibiale, an intermedium and a fibulare. The distal row is formed of four tarsals, the first, like that in the hand, often not articulating with the first metatarsal, the second supporting the first and second metatarsals; and the fourth the fourth and fifth metatarsals.

The mode of development of the hand and foot is almost the same. The most remarkable feature of development is the order of succession of the digits. The two anterior (radial or tibial) are formed in the first instance, and then the third, fourth and fifth in succession.

As to the actual development of the skeleton Strasser, whose observattions were made by means of sections, has arrived at the following results.

The humerus with the radius and ulna, and the corresponding parts in the hind limb, are the first parts to be differentiated in the continuous plate of tissue from which the skeleton of the limb is formed. Somewhat later a cartilaginous centre appears at the base of the first and second fingers (which have already appeared as prominences at the end of the limb) in the situation of the permanent second carpal of the distal row of carpals; and the process of chondrification spreads from this centre into the fingers and into the remainder of the carpus. In this way a continuous carpal plate of cartilage is established, which is on the one hand continuous with the cartilage of the two metacimpals, and on the other with the radius and nlna.

In the cartilage of the carpus two special columns may he noticed, the one on the radial side, most advanced in development, being continuous with the radius; the other less developed column on the side of the ulna heing continuous both with the ulna and with the radius. The ulna and radius are not united with the humerus.

In the further growth the third and fourth digits, and in the foot the fifth digit also, gradually sprout out in succession from the ulnar side of the continuous carpal plate. The carpal plate itself becomes segmented from the radius and ulna, and divided up into the carpal bones.

The original radial column is divided into three elements, a proximal the radiale, a middle element the first carpal, and a distal the second carpal already spoken of. The first carpal is thus situated between the basal cartilage of the second digit and the radiale, and would therefore appear to be the representative of a primitive middle row of carpal bones, of which the centrale is also another representative.

The centrale and intermedium are the middle and proximal products of the segmentation of the ulnar column of the primitive carpus, the distal second carpal being common both to this column and to the radial columm.

1 'This seems to me clearly to follow from Götte and Strasser's observations. 
The ulnar or fibular side of the carpus or tarsus becomes divided into a proximal element-the ulnare or fibmlare - the ulnare remaining partially united with the intermedium. There are also formed from this plate two carpals to articulate with digits 3 and 4 ; while in the foot the corresponding elements articnlate respectively with the third digit, and with the fourth and fiftl digits.

Gütte, whose observations were made in a somewhat different method to those of Strasser, is at variance with him on several points. He finds that the primitive skeleton of the limb consists of a basal portion, the humerus, continued into a radial and an ulnar ray, which are respectively prolonged into the two first digits. The two rays next coalesce at the base of the fingers to form the carpus, and thus the division of the limb into the brachium, antebrachium and manus is effected.

The ulna, which is primitively prolonged into the second digit, is suhsequently separated from it and is prolonged into the third; from the side of the part of the carpus connecting the ulna with the third digit the fourth digit is eventually budied out, and in the foot the fonrth and fifth digits arise from the corresponding region. Eacl of the three columms connerter respectively with the first, second, and third digits becomes divided into three successive carpal bones, so that Götte holds the skeleton of the hand or foot to be formed of a proximal, a middle, and a distal row of carpal boncs each containing potcntially three elements. The proximal row is formed of the radiale, intermedium and ulnare; the midcle row of carpal 1, the centrale and carpal 4, and the distal of carpal 2 (consisting according to Giotte of two coalesced elements) and carpal 3.

The derivation of the Cheiropterygixm from the Ichthyopterygium. All anatomists are agreed that the limbs of the higher Vertebrata are derived from those of Fishes, but the gulf between the two types of limbs is so great that there is roon for it very great diversity of opinion as to the mode of evolution of the cheiropteryginm. The most important speculations on the subject are those of Gegenbaur and Huxley.

Gegenbaur holds that the cheiropterygium is derived from a uniserial piscine limb, and that it consists of a juimitive stem, to which a series of lateral rays are attached on one (the ulnar) sirle; while Huxley holds that the cheiropterygium is derived from a biserial piscine limb by "the lengthening of the axial skeleton, accompanied by the removal of its distal plements further away from the shoulder-girdle and by a diminution in the number of the rays."

Neither of these theories is founded upon ontology, and the only ontological evidence we have which bears on this question is that above recorder with reference to the development of the Urodele limb.

Without holding that this evidence can be considered as in any way conclusive, its tendency would appear to me to be in favour of regarding the cheiropterygium as derived from a uniserial type of fin. The humerus or femur would appear to be the basiptcrygial bars (metajterygium), which have become directed outwards instead of retaining their original position parallel to the length of the body at the base of the fin. "The anterior. (proximal) fin-rays and the pro- and mesopterygium must be supposed to have become aborted, while the radius or ulna, and tibia or fibula are two posterior fin-rays (probably each representing screral coalesced rays like the pro- and mesopterygium) which support at their distal extremities more numerous fin-rays consisting of the rows of carpal and tarsal bones. 
This view of the cheiropterygium corresponds in some respects with that put forward by Götte as a result of his investigations on the development of the Urodele limbs, though in other respects it is very different. A difficulty of this view is the fact that it involves our supposing that the rarlial edge of the limb corresponds with the metapterygial edge of the piscine fin. The difficulties of this position lave been clearly pointed out by Huxley, but the fuct that in the primitive position of the Urodele limbs the radius is ventral and the ulna dorsal shews that this difficulty is not insuperable, in that it is easy to conceive the radial horder of the fin to have become rotated from its primitive Elasmobranch position into the vertical position it occupies in the embryos of the Urodela, and then to have been further rotated from this position into that which it occupies in the adult Urodela and in all bigher forms.

\section{Bibliography of the Limbs.}

$(47 i)$ M. v. David of f. "Beiträge z. vergleich. Anat. d. hinteren Gliedmaassen d. Fische 1." Morphol. Jahrbuch, Vol. v. 1879.

$\left({ }_{4} 8\right)$ C. Gegenbaur. Untersuchangen z.vergleich. Anat. d. Wirbelthiere. Leipzig, 1864-5. Erstes Heft. Carpus u. Tarsus. Zweites Heft. Brustflosse d. Fische.

(479) C. Gegenbaur. "Ueb. d. Skelet d. Gliedmaassen d. Wirbelthiere im Allgemeinen u. d. Hintergliedmaassen d. Selachier insbesondere." Jenaische Zeitschrift, Vol. v. 1870. 1873.

(480) C. Gegenbaur. "Ueb. d. Archipterygium." Jenaische Zeitschrift, Vol.vis.

(48r) C. Gegenbaur. "Zur Morphologie d. Gliedmaassen d. Wirbelthiere." Morphologisches Jalubuch, Vol. 11. 1876.

$(482)$ A. Götte. Ueb. Entwich. u. Regeneration d. Gliedmaassenskelets d. Nolche. Leipzig, 1879.

$\left(48_{3}\right)$ T. H. Huxley. "On Ceratodus Forsteri, with some observations on the classification of Fishes," Proc, Zool. Soc. 1876.

$\left(48_{4}\right)$ St George Mivart. "On the Fins of Elasmobranchii." Zoological Trans., Vol. $\mathrm{x}$.

(45) A. Rosenberg. "Ueb. d. Entwick. d. Extremitäten-Skelets bei einigen d. Reduction ihrer Gliedmaassen charakterisirten Wirbelthiere." Zeit.f. wiss. Zool., Vol. xx111. 1873 .

(486) E. Rosenberg. "Ueb. d. Entwick. d. Wirbelsäule u. d. centrale carpi d. Menschen." Morphologisches Jahrbuch, Vol. I. 1875.

$\left({ }_{4} 8_{7}\right)$ H. Strasser. "Z. Entwick. «. Extremitätenknorpel bei Salamandern u. Tritonen." MLorphologisches Jahrbnch, Vol, v. 1879.

(488) G. 'Swirski. Untersuch. iib. d. Entuick. d. Schultergïrtels n. d. Skelets d. Brustflosse d. Hechts. Inaug. Diss. Dorpat, 1880.

$(489)$ J. K. Thacker. "Median and paired fins. A contribution to the history of the Vertebrate limbs." Trans. of the Connecticut Acad., Vol. III. 1877.

(490) J. K. Thacker. "Ventral fins of Ganoids." Trans. of the Connecticut Acad., Vol. 1v. 1877. 


\section{CHAPTER XXI.}

\section{THE BODY CAVITY, THE VASCULAR SYSTEM, AND THE VASCULAR GLANDS.}

\section{The body cavity.}

Is the Colenterata no body cavity as distinct from the alimentary cavity is present; but in the remaining Invertebrata the body cavity may (1) take the form of a wide space separating the wall of the gut from the body wall, or (2) may be present in a more or less reduced form as a number of serous spaces, or (3) only be represented by irregular channels between the muscular and connective-tissue cells filling up the interior of the body. The body cavity, in whatever form it presents itself, is probably filled with fluid, and the fluid in it may contain special cellular elements. A well developed body cavity may coexist with an independent system of serous spaces, as in the Vertebrata and the Echinodermata; the perihæmal section of the body cavity of the latter probably representing the system of serous spaces.

In several of the types with a well developed body cavity it has been established that this cavity originates in the embryo from a pair of alimentary diverticula, and the cavities resulting from the formation of these diverticula may remain distinct, the adjacent walls of the two cavities fusing to form a dorsal and a ventral mesentery.

It is fairly certain that some groups, e.g. the Tracheata, with imperfectly developed body cavities are descended from ancestors which were provided with well developed body cavities, but how far this is universally the case cannot as yet be definitely decided, and for additional information on this subject the reader is referred to pp. 294-297 and to the literature there referred to.

In the Chætopoda and the Tracheata the body cavity arises as a series of paired compartments in the somites of mesoblast (fig. 350) which have at first a very restricted extension on the ventral side of the body, but eventually extend dorsalwards and ventralwards till each cavity is a half circle investing the alimentary tract; on the dorsal side the walls separating the two half cavities usually remain 
as the dorsal mesentery, while ventrally they are in most instances

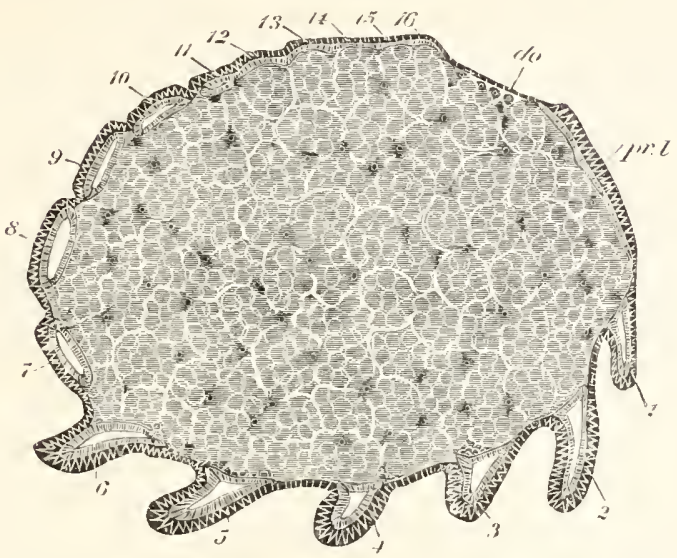

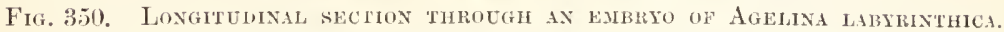

The section is taken slightly to one side of the middle line so as to slrew the relation of the mesoblastic somites to the limbs. In the interior are seen the jolk segments and their nuclei.

1-16. the segments; pr.l. procephalie lobe; do. dorsal integument.

absorbed. The transverse wal's, separating the successive compartments of the body cavity, generally become more or less perforated.

Chordata. In the Chordata the primitive body cavity is either directly formed from a pair of alimentary diverticula (Cephalochorda) (fig. 3) or as a pair of spaces in the mesoblastic plates of the two sides of the body (fig. 20 ).

As already explained (pp. $24+-249$ ) the walls of the clorsal sections of the primitive body cavity soon become separated from those of the ventral, and becoming segmented constitute the muscle plates, while the cavity within them becomes obliterated: they are dealt with in a separate chapter. The ventral part of the primitive cavity alone constitutes the permanent body cavity.

The primitive body cavity in the lower Vertebrata is at first continued forwards into the region of the head. but on the formation of the visceral clefts the cephalie section of the body cavity becomes divided into a series of separate compartments. Subsequently these sections of the body cavity become obliterated; and, since their walls give rise to muscles, they may probably be looked npon as equivalent to the dursal sections of the body eavity in the trunk, and will be treated of in comnection with the muscular system.

As a result of its mode of origin the body cavity in the trunk is at first divided into two lateral halves; and part of the mesoblast lining it soon becomes distinguished as a special layer of epithelium, known as the peritoneal epithelium, of which the part bounding the outer wall forms the somatic layer, and that bomnding the inner

I. E. II. 
wall the splanchnic layer. Between the two splanchnic layers is placed the gut. On the ventral side, in the region of the permanent gut, the two halves of the body cavity soon coalesce, the septum between them becoming absorbed, and the splanchnic layers of epithelimm of the two sides uniting at the ventral side of the gut, and the somatic layers at the median rentral line of the body wall (fig. 351).

In the luwer Vertebrata the body cavity is originally present even in the post-anal region of the trunk, but usually atrophies early, frequently before the two halves coalesce.

On the dorsal side of the gut the two halves of the boly cavity never coalesce, but eventually the splanchnic layers of epithelium of the two siles, together with a thin layer of interposed mesoblast, form a delicate membrane, known as the mesentery, which suspends the gut from the dorsal wall of the body (fig. 119) and 351). On the dorsal side the epithelium lining of the body cavity is usually more columnar

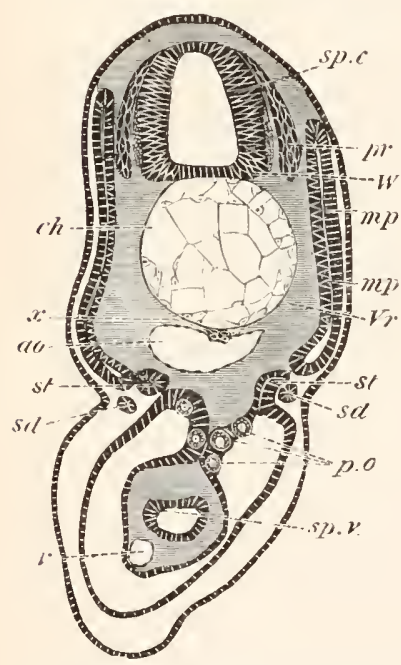

Fig. 351. SeCtiox through THE TRUNK OF A SCYLLIU⿴囗丨 EMBRTo MLIGHTLY YOUNGER THAN 28 F.

sp.c. spinal canal; $W$. white matter of spinal cord; $p r$. postei ior nerre-roots; ch. notochord; $x$. sub-notochordal rod; ao. aorta; $m p$. muscle-plate; $m p^{\prime}$. inner layer of muscle-plate already converted into muscles; Ir r. rudiment of vertebral body; st. segmental tube; sd. segmental duct; sp.v. spiral valve; $v$. subintestinal ve:n; p.o. primitive generative cells. than elsewhere (fig. $35 \mathrm{i}$ ), and its cells partly form a covering for the generative organs, and partly give rise to the primitive germinal cells. This part of the epithelinm is often known as the germinal epithelium.

Over the greater part of the body cavity the lining epithelium becomes in the adult intimately united with a layer of the subjacent commective tissue, and constitutes with it a special lining membrane for the body carity, known as the peritoneal membrane.

Abdominal pores. In the Cyclostomata, the majority of the Elasmobranchii, the Ganoidei, a few Teleostei, the Dipnoi, and some Samropsida (Chelonia and Crocodilia) the body cavity is in communication with the exterior by a pair of pores, known as abdominal pores, the external openings of which are usually situated in the cloaca $^{1}$.

The ontogeny of these pores has as yet been but very slightly investigated. In the Lamprey they are formed as apertures ieading from the body cavity into the excretory section of the primitive cloaca. This section would appear from Scott's (No. 87) observations to be derived from part of the hypoblastic cloacal section of the alimentary tract.

1 For a full account of these structures the reader is referred to T. W. Bridge, "Pori Abdominales of Vertebrata." Journal of Anat. and Physiol., Vol. xiv., 1879. 
In all other cases they are formerl in a region which appears to belong to the epiblastic region of the clorea; and from my observations on Elasmobranchs it may be certainly conchuded that they are formed thers in this group. They may appear as perforations (1) at the apices of papilliform prolongations of the hody carvity, or (2) at the ents of cloacal pits divected from the exterior towarls the body cavity, or (3) as simple slit-like openings

Considering the difference in derelopment between the abdominal pores of most types, and those of the Cyclostomata, it is open to doubt whether these two types of pmes are strictly homolugous.

In the Cyclostomata they serve for the passage outwarls of the generat tive prolucts, and they also have this function in some of the few 'T'elenstei in which they are found; and Gegenbaur and Brigge hold that the primitive mole of exit of the generative products, prior to the development of the Miillerian flucts, :as probably by means of these pores. I have elsewhere suggested that the abdominal pores are perliaps remmants of the openings of seguneutal tubes; there loes not however appear to be any definite evidence in favonr of this view, and it is more probable that they may have arisen as simple perforations of the body wall.

\section{Pericardial cavity, pleural cavities,} and diaphragm. In all Vertebrata the heart is at first placed in the body cavity (fig. 35.3 A), but the part of the botly cavity containing it afterwards beconces separated as a listinct cavity known as the pericardial cavity. In Elasmobranchii, Acipenser, etc. a prasage is however left between the pericarhial cavity and the boty cavity; and in the lamprey a sepatration between the two cavities does not occur during the Ammocote stage.

In Elasmobranchii the pericardial cavity becomes established as a distinct space in front of the body cavity in the following way. When the two ductus Cuvieri, leakling transversely from the sinus venosus to the cardinal veins, become developed, a horizontal septum, shewn on the right side in fig. $35 \%$, is formed to support them, stretching across from the splauchnic to the somatic side of the body cavity, and dividing the boty cavity (fig. 352 ) in this part into (1) at dorsal section formen of a right and left division constituting the true body cavity

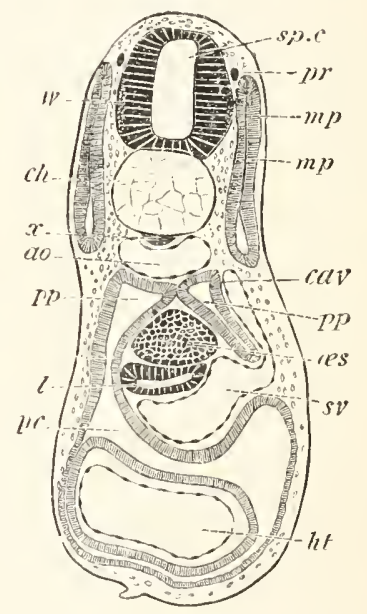

FI(. 35\%. SECTION THROUGII THE THUNK OF A S'CYLLIUM EMBRTO SLIGHTLX YOUNGER THAX $28 \mathrm{~F}$.

The figure shews the separation of the body cavity from the pericardial cavity by a horizontal sfiptum in which rums the ductus Cuvieri; on the left side is seen the narrow passage which remains connecting the two cavities.

sp.c. spinal canal; $\boldsymbol{H}$. white matter of spinal cord; $p r$. commissure connecting the posterior nerve-roots; al. notochord; $x$. sub-notochortal rod; ao. anta; $s v^{2}$ sinus renosus; crex. cardinal vein ; ht. heart; $p p$. boly cavity ; pc. pericartal curity; as. solid cesophagus; l. liver ; mp. muscleplate.

$$
3.3-2
$$


$(p p)$, and (2) a ventral part the pericardial cavity $(p c)$. The septum is at first of a very small longitudinal extent, so that both in front and behind it (fig. 352 on the left side) the dorsal and ventral sections of the body cavity are in free communication. The septum soon however becomes prolonged, and ceasing to be quite horizontal, is directed obliquely upwards and forwards till it meets the dorsal wall of the body. Anteriorly all communication is thus early shut off between the body cavity and the pericardial cavity, but the two cavities still open freely into each other behind.

The front part of the body cavity, lying dorsal to the pericardial cavity, becomes gradually narrowed, and is wholly obliterated long before the close of embryonic life, so that in adult Elasmobranch Fishes there is no section of the body cavity dorsal to the pericardial cavity. The septum dividing the body cavity from the pericardial cavity is prolonged backwards, till it meets the ventral wall of the body at the point where the liver is attached by its ventral mesentery (falciform ligament). In this way the pericardial cavity becomes completely shut off from the body cavity, except, it would seem, for the narrow communications found in the ardult. The origin of these communications has not however been satisfactorily worked out.

The septum between the pericardial cavity and the body cavity is attached on its dorsal aspect to the liver. It is at first nearly horizontal, but gradually assumes a more vertical position, and then, owing to the obliteration of the primitive anterior part of the body cavity, appears to mark the front boundary of the body cavity. 'The above description of the mode of formation of the pericardial cavity, and the explanation of its relations to the body cavity, probably holds true for Fishes generally.

In the ligher types the earlier changes are precisely the same as those in Elasmobranch Fishes. The heart is at first placed within the body cavity attached to the ventral wall of the gut by a mesocardiun (fig. $353 \mathrm{~A}$ ). A horizontal septum is then formed, in which the ductus Cuvieri are placed, diviling the body cavity for a short distance into a dorsal $(p p)$ and ventral $(p c)$ section (fig. $35.3 \mathrm{~B}$ ). In Birds and Mammals, and probably also in Reptilia, the ventral and dorsal parts of the body cavity are at first in free communication both in front of and behind this septum. This is shewn for the Chick in fig. $353 \mathrm{~A}$ and $\mathrm{B}$, which are sections of the same chick, A being a little in front of B. The septum is soon continued forwards so as completely to separate the ventral pericardial and the dorsal body cavity in frout, the pericardial cavity extending at this period considerably further forwards than the body cavity.

Since the horizontal septum, by its mode of origin, is necessarily attached to the ventral side of the gut, the dorsal part of the primitive body space is divided into two halves by a median vertical septum formed of the gut and its mesentery (fig. $353 \mathrm{~B}$ ). Posteriorly the horizontal septum grows in a slightly ventral direction along the under surface of the liver (fig. 354 ), till it incets the abdominal wall 
of the body at the insertion of the falciform ligament, and thus completely shuts off the pericardial cavity from the body cavity. The horizontal septum forms, as is obvious from the above description, the dorsal wall of the pericardial cavity ${ }^{1}$.

With the complete separation of the perieardial cavity from the body cavity, the first period in the development of these parts is completed, and the relations of the body cavity to the pericardial cavity become precisely those found in the embryos of Elasmobranchii. The later changes are howevor very different. Whereas in Fishes the right and left sections of the body cavity dorsal to the pericardial cavity soon atrophy, in the higher types, in correlation with the relatively backward situation of the heart, they rapidly become larger, and receive the lungs which soon sprout out from the throat.

The diverticula which form the lungs grow ont into the splanchnic mesoblast, in front of the body cavity; but as they grow, they extend into the two anterior compartments of the looly cavity, each attached

A

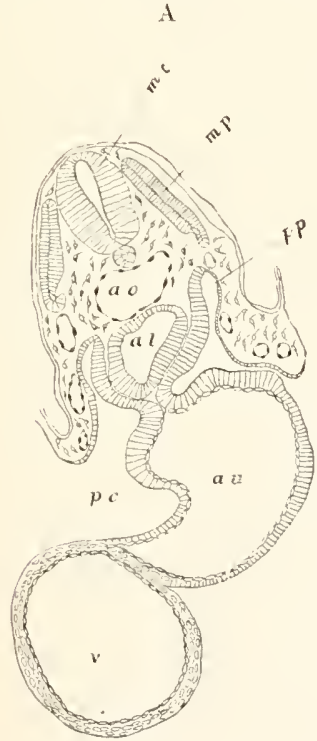

(3)

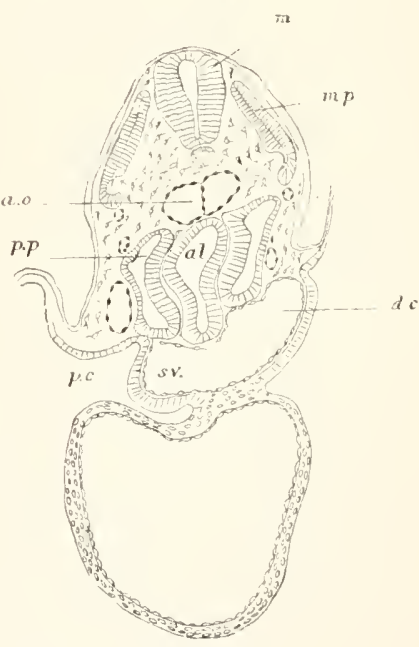

Fig. 353. Thansyerse sections thlough a Chick embryo with thenty-one MESOBLASTIC SOMITES TO SHEW THE FORMATION OF THE PERICARDIAL CAVIT, A. BEING THE ANTERIOK SECTIOX.

$p p$. body eavity; pc. pericardial eavity; al. alimentary cavity ; $a u$. auricle ; $v$. ventricle; sv. sinus venosus; dc. ductus Cuvieri; ao. aorta; mp. muscle-plate; mc. medullary cord.

1 Kölliker's account of this septum, which he calls the mesocardium laterale (No. $29^{9}$, p. 295), would seem to imply that in Mammals it is completed posteriorly even before the formation of the liver. I doubt whether this takes place quite so early as he implies, but have not yet determined its exact period by my owu observations. 
by its mesentery to the mesentery of the gut (fig. $354 l g$ ). They soon moreover extend beyoud the region

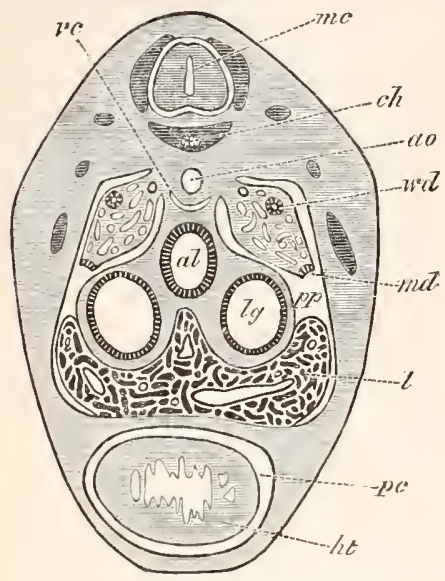

Frg. 354. Section throdgh the CARDIAC REGLN OF AN EMBRTO OF LaCERTA MURALIS OF 9 MM. TO SHEW THE MOHE OF FORMATION OF THE PERICARDLAL CAVITY.

ht. heart; pc. pericardial cavity ; al. alimentary tract; $l g$. lung; $l$. liver; $p p$. body cavity; mu. open end of Mullerian duct; $w d$. Tolftian duct; $v c$. vena cava inferior; ao. aorta; $c h$. notochord; mc. medullary cord. pericardial cavity. This proress is illustrated by fig. 35.5 , taken from an embryo Rabbit. The two dorsal sections of the body cavity $(p l \cdot p)$ finally extend so as completely to envelope the pericardial cavity (pc), remaining however separated from each other below by a lamina extending from the ventral wall of the pericardial cavity to the body wall, which forms the anterior mediastinum of human anatomy.

By these changes the pericardial cavity is converted into a closed bag, completely surrounded at its sides by the two lateral halves of the body cavity, which were primitively phaced dorsally to it. These two sections of the body carity, which in Amplibia and Sauropsida remain in free communication with the undivided peritoneal cavity behind, may, from the fact of their containing the lungs, be called the pleural cavities.

In Mammalia a further change takes place, in that, by the formation of a vertical partition acruss the body cavity, known as the diaphragm, the pleural cavities, containing the lungs, become isolated from the remainder of the body or peritoneal cavity. As shewn by their development the so-called pleura or pleural sacks are simply 
the peritoneal linings of the anterior divisions of the body cavity, shut off from the remainder of the body cavity by the diaphragm.

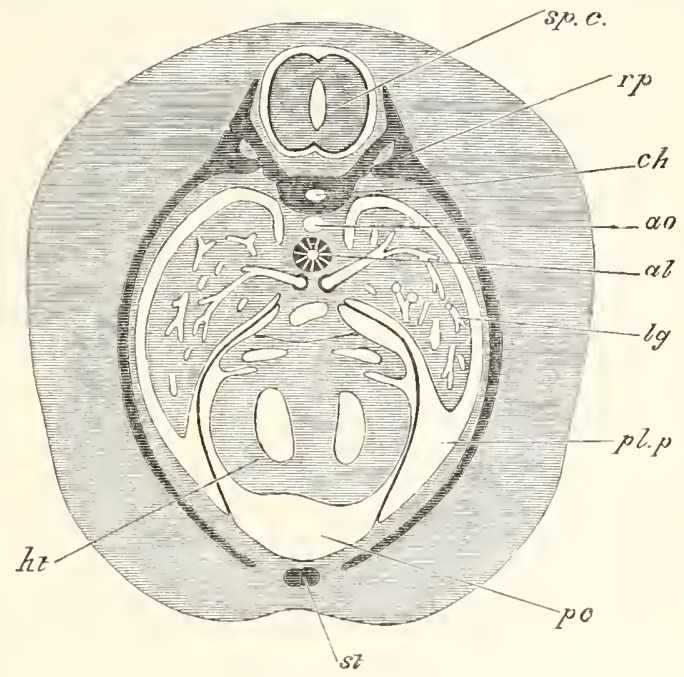

Fig. 35.5. Section through an aDyaxcel endrio of a Rabbit to shew holv thle PERICARDIAL CAVITY BECOMES SURrounded by THE PLEURAL CAVITIES.

$h t$. heart; $p c$. perieardial cavity ; $p l . p$. plenral cavity ; lg. lung; al. alimentary tract; ao. dorsal aorta; ch. notochord; rp. rib; st. sternum; sp.c. spinal cord.

The exact mode of formation of the diaphragm is not fully made out; the account of it recently given by Cudiat (No. 49I) not being in my opinion completely satisfactory.

\section{BibliogiRaphy.}

(49r) M. Cadiat. "Du développement de la partie céphalothoracique de l'embryon, de la formation du diaphragme, des pleures, du péricarde, du pharynx et de l'iesophage." Journal de l'Anatomie et de la Physiologie, Vol. xIv. 1878.

\section{Vasculur System.}

The actual observations bearing on the origin of the vasculas system, using the term to include the lymphatic system, are very scanty. It seems probable, mainly it must be arlmitted on ì miori grounds, that vatscular and lymphatic systems have originated from the conversion of indefinite spaces, primitively situated in the general connective tissue, into definite channels. It is quite certain that vascular systems have arisen independently in many types; a very striking case of the kind being the development in certain parasitic Copepoda of a closed system of vessels with a red non-corpusculated blood (E. van Beneden, Heider), not found in any other Crustacea. Parts of vascular systems appear to have arisen in some cases by a canalization of cells. 
The blood systems may either be closed or communicate with the body cavity. In cases where the prinutive body cavity is atrophied or partially broken up into separate compartments (Insecta, Mollusca, Discophora, etc.) a free communication between the vascular system and the body cavity is usually present; but in these cases the communication is no doubt secondary. On the whole it would seem probable that the vascular system has in most instances arisen independently of the body cavity, at least in types where the body cavity is present in a well-developed condition. As pointed out by the Hertwigs, a vascular system is always absent where there is not a considerable development of connective tissue.

As to the ontogeny of the vascular chammels there is still much to be marle ont both in Vertebrates and Tnvertebrates.

The smaller chammels often rise by a canalization of cells. This process has been satisfactorily studied by Lankester in the Leech ${ }^{1}$, and may easily be observed in the hilastolerm of the Chick or in the epiploon of a newly lorn Rabbit (Schäfer, Ranvier). In either case the vessels arise from a network of cells, the superficial protoplasm and part of the nuclei giving rise to the walls, and the blood corpuscles being derived either from nncleated masses set free within the ressels (the Chick) or from blood corpuscles directly differentiated in the axes of the cells (Mammals).

Larger vessels would seem to be formed from solid cords of cells, the central cells becoming converted inte the corpuscles, and the peripheral cells constituting the walls. This mode of formation has been observed by myself in the case of the Spider's heart, and by other observers in other Invertebrata. In the Vertebrata a more or less similar mode of formation appears to loold good for the larger vessels, but further investigations are still required on this subject. Götte finds that in the Frog the larger vessels are formed as longitudinal spaces, and that the walls are derived from the indifferent cells bomding these spaces, which become flattened and united into a continuous layer.

The early formation of vessels in the Verteliata takes place in the splanchnic mesoblast; but this appear's due to the fact that the circulation is at first mainly confined to the vitelline region, which is covered by splanchnic nesoblist.

\section{The Ileart.}

The heart is essentially formed as a tubular cavity in the splanchnic mesoblast, on the ventral side of the throat, immediately belind the region of the visceral clefts. The walls of this cavity are formed of two layers, an outer thicker layer, which has at first only the form of a half tube, being incomplete on its dorsal side; and an inner lamina formed of delicate flattened cells. The latter is the epithelioid lining of the heart, and the cavity it contains the true cavity of the heart. The outer layer gives rise to the muscular wall and peritoneal covering of the heart. Though at first it has only the

1 "Connective and vasifactive tissnes of the Leech." Quart. J. of Micr. Science, Vol. xx. 1880 . 
form of a half tube (fig: 356), it soon becomes folded in on the dorsal side so as to form for the heart a complete muscular wall. Its two sides, after thus meeting to complete the tube of the leart, remain at first continuous with the splanchnic mesoblast surrounding the throat, and form a provisional mesentery - the mesocardiumwhich attaches the heart to the ventral wall of the throat. The superficial stratum of the wall of the heart differentiates itself as the peritoneal covering. The imer epithelioid tube takes its origin at the time when the general cavity of the heart is being formed by the separation of the splanchnic mesoblast from the hypublast. During this process (fig. 3.57) a layer of mesoblast remains close to the hypoblast, but connected with the main mass of the mesoblast by protopliasmic processes. A second layer next becomes split from the splanchnic mesoblast, connected with the first layer by the above-nentioned protoplasmic processes. 'These two layers form together the epithelioid lining of the heart; between them is the cavity of the heart,

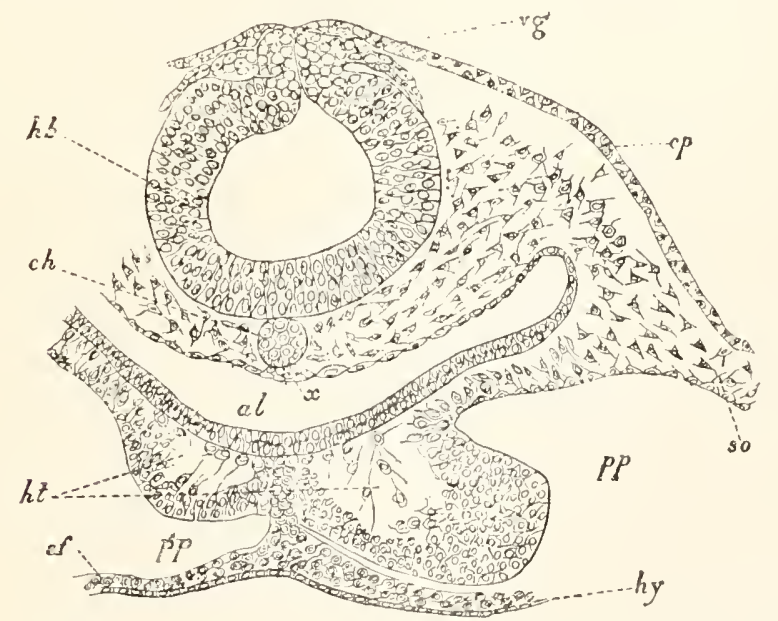

Fig. 357. Transverse section throdgh the postertor part of the HEAD OF AN EMBRYo C'MICK OF THIRTY HoURs.

$h b$. hind-brain; $v g$. vagus nerve; ep. epiblast; $c h$. notochord; $x$. thickening of hypoblast (possibly a rudiment of the sub-notochordal rod); al. throat; ht. heart; $p p$. body cavity; so. somatic mesoblast; sf. splanchnic mesoblast; hy. hypoblast. 
which soon loses the protoplasmic trabeculæ which at first traverse it. The cavity of the heart may thus be described as being formed by a hollowing out of the splanchnic mesoblast, and resembles in its mode of origin that of other large vascular trunks.

The above description applies only to the development of the heart in those types in which it is formed at a period after the throat has become a closed tube (Elasmobranchii, Amphibia, Cyclostomata, Ganoids (?)). In a number of other cases, in which the heart is formed before the couversion of the throat into a closed tube, of which the most notable is that of Mammals (Hensen, Götte, Kölliker), the lıeart arises as two independent tubes (fig. 358), which eventually coalesce into an unpaired structure.

In Mammals the two tubes out of which the heart is formed appear at the sides of the cephalic plates, opposite the region of the mid-and hindbrain (tig. 358). They arise at a time when the lateral folds which form the rentral wall of the throat are only just becoming visible. Each half of the heart originates in the same way as the whole heart in Elasmobranchii, etc.; and the layer of the splanchnic mesoblast, which forms the muscular wall for each part $(a h h)$, has at first the form of a half tnbe open below to the hypoblisst.

On the formation of the lateral folds of the splanchnic walls, the two halves of the heart become carried inwards and downwards, and eventually

A.

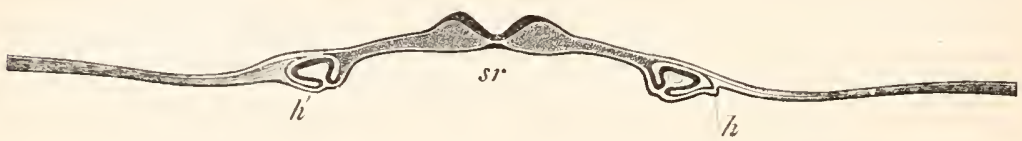

B.

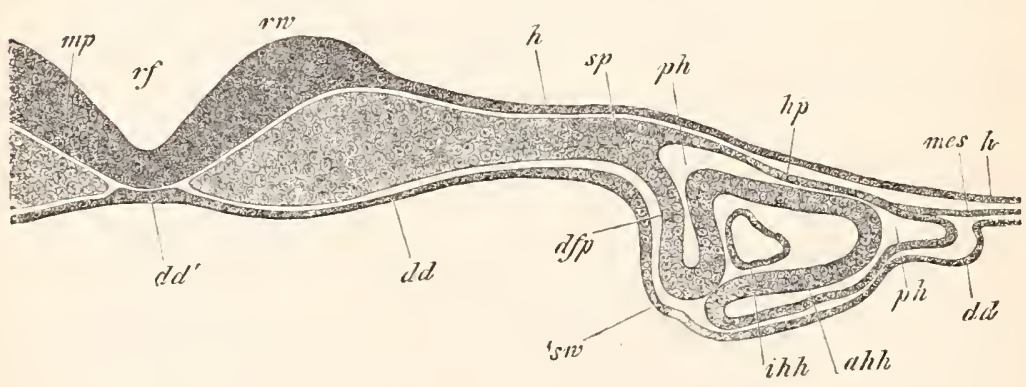

Fig. 3ǎ. Transverse section throvgh the head of a Rabbit of the saje AGE As rig. 144 B. (From Kölliker.)

$\mathrm{B}$ is a more highly magnified representation of part of A.

$r f$. medullary groove; $m p$. medullary plate; $r w$. medullary fold; $h$. epiblast; dd. hypoblast; $d d^{\prime}$. notochordal thickening of lyypoblast; $s p$. undivided mesoblast; hp. somatic mesoblast; dfp. splanchnic mesoblast; $p h$. pericardial section of bodycavity; $a h h$. muscular wall of leart; $i h h$. epithelioid layer of heart; mes. lateral undivided mesoblast; su. part of the hypoblast which will form the ventral wall of the pharynx. 
meet on the ventral side of the throat. For a short time they here remain distinct, but soon coalesce into a single tube.

In Birds, as in Mammals, the heart makes its appearance as two tubes, but arises at a period when the formation of the throat is very much more adranced than in the case of Mammals. The heart arises immediately behind the point up to which the ventral wall of the throat is established and thus has at first a $\wedge$-shiped form. At the apex of the $\wedge$, which forms the anterior end of the heart, the two halves are in contact (fig. 357), though they have not coalesced; while behind they diverge to be continued as the vitelline reins. As the folding in of the throat is continued backwards the two limbs of the heart are brought together and soon coalesce from before backwards into a single structure. Fig. 359 A and B shews the heart during this process. The two hatves have coalesced anteriorly (A) but are still widely separated behind (B). In Teleostei the heart is formed as in Birds and Manmals by the coalescence of two tubes, and it arises before the formation of the throat.

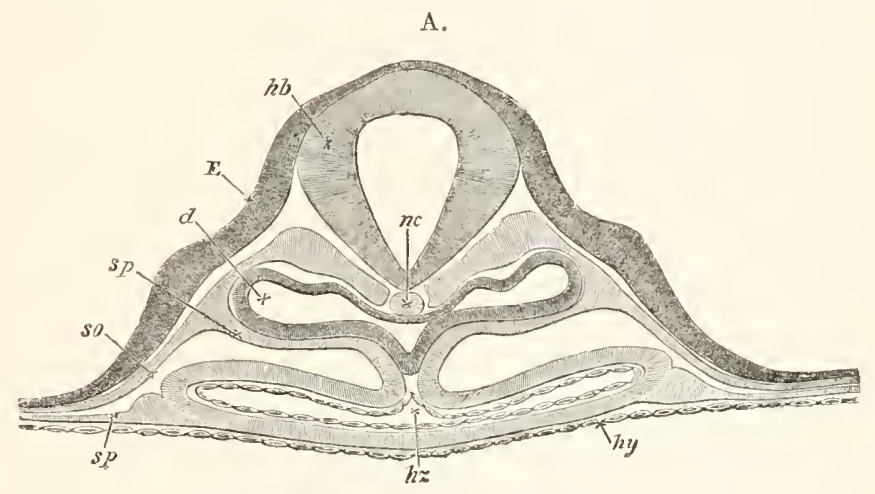

B.

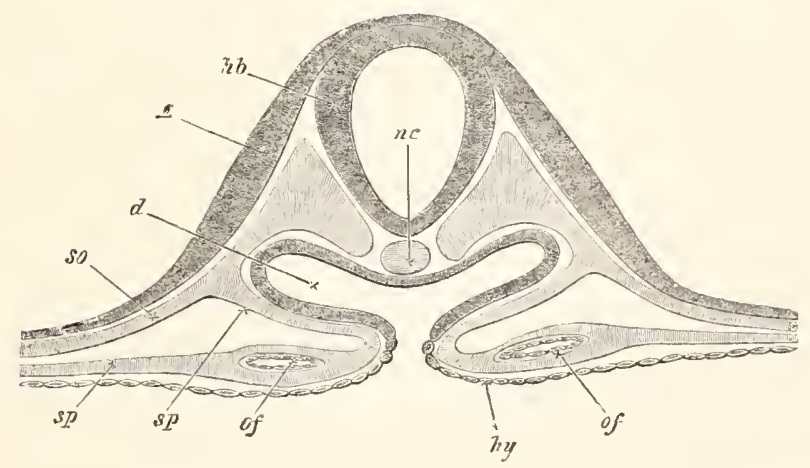

Fig. 359. Two DIAGRAMMATC SECTIONS THROUGH THE REgION OF THE HIND BRAIN OF AN EABRYO CHICK OF ABOUT 36 HOURS ILLTSTRATING THE FORMATION OF THE HEART.

hl. hind-brain; Ke. notochord; E. epiblast; so. somatopleure; sp. splanchnopleure; d. alimentary tract; hy. hypoblast; hz. heart; of vitelline veins. 
The fact that the heart arises in so many instances as a double tube might lead to the supposition that the ancestral Vertebrate had two tubes in the place of the present unpaired heart.

The following considerations appear to me to prove that this conclusion cannot be accepted. If the folding in of the splanchnopleure to form the throat were deferred relatively to the formation of the heart, it is clear that a modification in the development of the heart would occir, in that the two halves of the heart would necessarily be formed widely apart, and only eventually united on the folding in of the wall of the throat. It is therefore possible to explain the double formation of the heart without having recourse to the above hypothesis of an ancestral Vertebrate with two hearts. If the explanation just suggested is the true one the heart should only be formed as two tubes when it arises prior to the formation of the throat, and as a single tube when formed after the formation of the throat. Since this is invariably found to be so, it may be safely concluded that the formation of the heart as two cavities is a secondary mode of development, which has been brought about by variations in the period of the closing in of the wall of the throat.

'T'he heart arises continuously with the sinus venosus, which in the Amniotic Vertebrata is directly continued into the vitelline veins. Though at first it ends blindly in front, it is very soon connected with the foremost aortic arches.

The simple tubular lieart, connected as above described, grows more rapidly than the clamber in which it is contained, and is soon doubled upon itself, acquiring in this way an S-shaped curvature, the posterior portion being placed dorsally, and the anterior ventrally. A constriction soon appears between the dorsal and ventral portions.

The dorsal section becomes partially divided off behind from the sinus venosus, and constitutes the relatively thin-walled auricular section of the heart; while the ventral portion, after becoming distinct anteriorly from a portion continued forwards from it to the origin of the branchial arteries, which may be called the truncus arteriosus, acquires very thick spongy muscular walls, and becomes the ventricular division of the heart.

The further changes in the heart are but slight in the case of the Pisces. A pair of simple membranous valves becomes established at the auriculoventricular orifice, and further changes take place in the truncus arteriosus. This part becomes divided in Elasmobranchii, Ganoidei, and Dipnoi into a posterior section, called the conus arteriosus, provided with a series of transverse rows of valves, and an anterior section, called the bulbus arteriosus, not provided with valves, and leading into the branchial arteries. In most Teleostei (except Butirinus and a few other forms) the conus arteriosus is all but obliterated, and the anterior row of its valves alone preserved ; and the bulbus is very much enlarged ${ }^{2}$.

1 Vide Gegenbaur, "Zur vergleich. Anat. d. Herzens." Jenaische Zeit., Vol. Ir. 1866, and for recent important observations, J. E. V. Boas, "Ueb. Herz u. Arterienbogen bei Ceratoden u. Protopterus," and "Ueber d. conus arter. b. Butirinus, etc.," Morphol. Jahrb., Vol. vi. 1880. 
In the Dipnoi important changes in the heart are effected, as conparer with other Fishes, by the development of true lungs. Both the auricular and ventricular chamber may be imperfectly divided into two, and in the conus a partial longitudinal septum is developed in comnection with a longitudinal row of valves ${ }^{1}$.

In Amplibia the heart is in many respects similar to that of the Dipnoi. Its curvature is rather that of a serew than of a simple $S$. The truncus arteriosus lies to the left, and is continued into the ventricle which lies ventrally and more to the right, and this again into the dorsally placed auricular section.

After the heart has reached the piscine stage, the auricular section (Bombinator) becomes prolonged into a right and left auricular appendage. A septum next grows from the roof of the auricular portion of the heart obliquely backwards and towards the left, and divides it in two chambers; the right one of which remains continuous with the sinus venosus, while the left one is completely shut off fiom the siums, though it soon enters into communication with the newly established pulmonary veins. The truncus arteriosus ${ }^{2}$ is divided into a posterior coms arteriosus (pylangium) and an anterior bullus (synangimm). The former is proviled with a proximal row of valves at its ventricular end, and a distal row at its anter.ior cnd near the bulhus. It is also provided with a longitudinal septum, which is no doubt homologous with the septum in the conus arteriosus of the Dipmoi. The bulbus is well developed in many Urodela, but hardly exists in the Anura.

In the Anniota further changes take place in the heart, resulting in the abortion of the listal rows of valves of the conus arteriosus ${ }^{3}$, and in the splitting up of the whole truncus arteriosus into three vessels in Reptilia, and two in Birds and Mammals, each opening into the ventricular section of the heart, and provided with a special set of valves at its commencement. In Birds and Mammals the ventricle becomes moreover completely divided into two chambers, each communicating with one of the divisions of the primitive truncus, known in the higher types as the systemic and pulmonary aortie. 'The character of the development of the heart in the Amniota will be best understood from a description of what takes place in the Chick.

In Birds the originally straight heart (fig. 109) soon becomes doubled up upon itself. The ventricular portion becomes placed on the ventral and right side, while the auricular section is dorsal and to the left. The two parts are separated from each other by a slight constriction known as the canalis auricularis. Anteriorly the rentricular cavity is continued into the trunctus, and the renous or auricular portion of the heart is similarly con-

1 Boas holds that the longitudinal septum is formed by the coalescence of a row of longitudinal valves, but this is opposed to Lankester's statements, "On the hearts of Ceratodus, Protopterus and Chimara," etc. Zool. Trans. Vol. x. 1879.

2 For a good description of the adult heart vide Huxley, Article "Amphibia," in the Encyclopedia Britannica.

3 It is just possible that the reverse may he true, vide note on p. 526 . If however, as is most probable, the statement in the text is correct, the valves at the mouth of the ventricle in Teleostei are not homologous with those of the Amniota; the former being the distal row of the valves of the conus, the latter the proximal. 
nected helind with the sinus venosus. The auricular appendages grow ont from the auricle at a very early period. The general appearance of the heart, as seen from the ventral side on the fonth day, is shewn in fig. 360 . Although the external divisions of the heart are well marked even before this stage, it is not till the end of the third day that the internal partitions become apparent; and, contrary to what night have been anticipated from the evolution of these parts in the lower tyjes, the ventricular septum is the first to be established.

It commences on the third day as a crescentic ridge or fold springing from the convex or ventral sicle of the rounded ventricular portion of the beart, and on the fourth day grows rapidly acoss the ventricular cavity towards the concave or dorsal side. It thus forms an incomplete longitutinal partition, extending from the canalis auricularis to the commencement of the truncus arteriosus, and dividing the twisted ventricular tube into two somewliat curved canals, one more

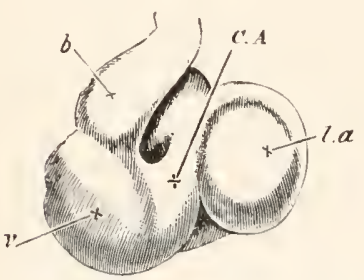

Fig. 360. Hearti of a Chick ox TIE FOURTH DAY OF INCUBATION VIEWED FROM THE VEXTRAL SURFACE.

l.a. left auricular appendage; C.A. canalis auricularis; $v$. ventricle; $b$. truncus ar teriosus. appears as the rudiment of the auricular septum, while in the canalis auricularis, which is now at its greatest length, there is also to be seen a commencement of the valvular structures tending to separite the cavity of the auricles fiom those of the ventricles.

Abont the 106th lour, a septum begins to make its appearance in the truncus arteriosus in the form of a longitudinal fold, which according to Tonge (No. 495) starts at the end of the truncus furthest removed from the leart. It takes origin from the wall of the truncus between the fourth and fifth pairs of arches, and grows downwards in such a manner as to divide the truncus into two chamnels, one of which leads from the heart to the third and fomrth pairs of arches, and the other to the fifth pair. Its course downwards is not straight but spiral, and thus the two channels into which it divides the truncus arteriosus wind spirally the one round the other.

At the time when the septum is first formed, the opening of the truncus arteriosus into the rentricles is narrow or slit-like, alparently in order to prevent the flow of the blood back into the heart. Soon after the appearance of the septum, however, semilumar valves (Tonge, No. 495) are developed from the wall of that portion of the truncus which lies between the free edge of the septum and the cavity of the ventricles ${ }^{1}$.

1 If Tonge is correct in his statement that the semilunar valves develop at some 
The ventral and the dorsal pairs of valves are the first to appear: the former as two small solid prominences separated from each other by a narrow groove; the latter as a single ridge, in the centre of which is a prominence indicating the point where the ridge will subsequently become divided into two. The outer valves appear opposite each other, at a considerably later period.

As the septum grows downwards towards the heart, it finally reaches the position of these valves. One of its edges then passes between the two ventral valves, and the other unites with the prominence on the dorsal valve-ridge. At the same time the growth of all the parts causes the valves to appear to approach the heart, and thus to be placed quite at the top of the ventricular cavities. The free edge of the septum of the truncus now fuses with the ventricular septum, and thus the division of the truncus into two separate channels, each provided with three valves, and each communicating with a separate side of the heart, is complete; the position of the valves not being very different from that in the adult heart.

That division of the truncus which opens into the fifth pair of arches is the one which communicates with the right ventricle, while that which opens into the third and fourth pairs communicates with the left ventricle. 'The former becomes the pulmonary artery, the latter the commencement of the systemic aorta.

The external constriction actually dividing the truncus into two vessels doss not begin to appear till the septum has extended some way back towards the heart.

The semilunar valves become pocketed at a period considerably later than their first formation (from the 147 th to the 165 th hour) in the order of their appearance.

A.

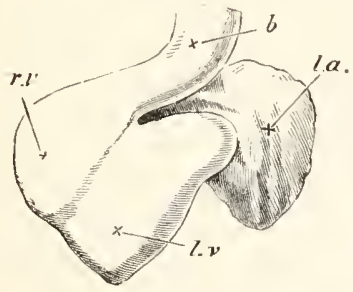

B.

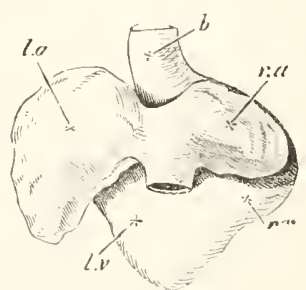

Fia. 361. Two views of the helrt of a Chick upon the Fifth day of 1NCUBATION.

A. from the ventral, B. from the dorsal side.

l.a. left auricular appendage; $r . a$. right auricular appendage; $r . x$. right ventricle; l.v. left ventricle; $b$. truncus arteriosus.

At the end of the sixth day, and even on the fifth day (figs. 361 and $362)$, the appearance of the heart itself, without reference to the vessels which come from it, is not very dissimilar from that of the adult. The

distance from the mouth of the ventricle, it would seem possible that the portion of the trumcus between them and the ventricle ought to be regarded as the embryonic conus arteriosus, and that the distal row of valves of the conus (and not the proximal as suggested above, $p .525$ ) has been preserved in the higher types. 
original protuberance to the right now forms the apex of the ventricles, and the two auricular appendages are placerl at the anterior extremity of the heart. The most noticeable difference

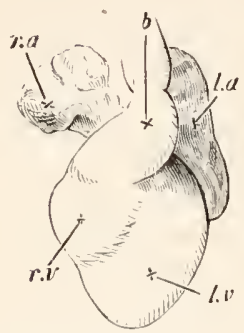

F16. 362. Heart of a Chick LPON THE SIXTH DAY OF INCUIBATION, FRON THE VENTRAL SURFACE.

l.a. left aurieular appendage ; $r . a$. right auricular appendage; $r . v$. right ventricle; $l . x$. left ventricle; $b$. truncus arteriosus. (in the ventral view) is the still externally undivided condition of the truncus arteriosus.

The subsequent changes which the heart undergoes are concerned more with its intcrnal structure than with its external shape. Indeed, duriug the next three days, viz. the eighth, ninth, and tenth, the external form of the heart remains nearly unaltered.

In the auricular portion, however, the septum which commenced on the fifth day becomes now more conspicuous. It is placed vertically, and arises from the ventral wall; commencing at the canalis auricularis and proceeding towards the opening into the sinils venosus.

This latter structure gradually becomes aborted so as to become a special alpendage of the right auricle. The inferior vena cava enters the sinus obliquely from the right, so that its blood has a tendency to flow towards the left auricle of the heart, which is at this time the larger of the two.

The valves between the ventricles and auricles are now well developed, and it is about this time that the division of the truncus arteriosus into the aorta and pulmonary artery becomes visible from the exterior.

By the eleventh to the thirteenth day the right auricle has become as large as the left, and the auricular sejtum much more complete, though there is still a small opening, the forcmen ovale, by which the two cavities communicate with each other.

The most important feature in which the development of the Reptilian heart differs from that of Birds is the division of the truncus into three vessels, instead of two. The three vessels remain bound up in a common sheath, and appear externally as a single trunk. The vessel not represented in Birds is that which is continued into the left aortic arch.

In Mammals the early stages in the development of the heart present no important points of difference from those of Aves. The septit in the truncus, in the ventricular, and in the auricular cavities are formed, so far as is known, in the same way and at the same relative periods in both groups. In the embryo Man, the Rablit, and other Mammals the division of the ventricles is made apparent extemally by a deep cleft, which, though eranescent in these forms, is permanent in the Dugring.

The attachnent of the auriculo-ventricular valves to the wall of the ventricle, and the similar attachment of the left auriculo-ventricular valves in Birds, have been especially studied by Gegenbaur and Bernays (No. 492), and deserve to be noticed. In the primitive state the ventricular walls have throughout a spongy character; and the auriculo-ventricular valves are simple membramous projectious like the auriculo-ventricular valves of Fishes. Soon however the spongy museular tissue of both the ventricular and 
anriculan walls, which at first pass uninterrupterlly the one into the othere, grows into the bases of the vilves, which thus become in the main musculat projections of the walls of the lieart. As the wall of the ventricle thickens. the museular trabeeulie, connected at one end with the valves, remain at the other end nuited with the ventricular wall, and form speeial bands passing between the two. The valves on the other hand lose their muscular attachment to the amicular walls. This is the condition permanent in Ornithorhynchus. In higher Mammalia the ends of the muscular bands inserted into the ralves become filnous, from the development of intermuscular comnective tissue, and the atroply of the muscular elements. The fibrous parts now form the chorde tendiuese, and the muscnlar the musculi papillares.

The sinus venosus in Mammals becomes completely merged into the right auricle, and the systemic division of the truncus arteriosus is apparently not homologous with that in Birds.

In the embryos of all the (raniata the heart is sitnatel very far forwards in the region of the head. This position is retaine In Amphibia the heart is moved further back, while in all the Ammiota it gradually slifts its position first of all into the region of the neck and finally passes completely within the thracic cavity. The steps in the change of position may be gathered fiom figs. 109, 111 , and 118 .

\section{Biburngriphy of the Herit.}

(402) A. C. Bernays. "Entwicklungsges hichte 1. Atrioventrienlarlilappen." Iorphol. Jahrluach, Vol. Ir. 187i.

(49.3) E, Gasser. "Ueber d. Entstehung d. Herzens beim Hähn." Arelir $f$. mikr. Anat., Vel. xiv.

$(4+)$ A. Thomson. "On the development of the vasemlar ststem of the fretus of Vertebrated Animals." Edimb. New Phil. Jomrnal, Vol. Ix. 18:30 and 1831.

(49.5) M. Tonge. "Olsservations on the development of the semilmmar valves of the aorta and pulmonary artery of the heart of the (hick." Phil. Trams. Cux. 186:t.

ride also Von Baer (291), Rathke (300), Hensen (182), Kibllikex (298), (riitte (296), and Balfour (292).

\section{Arterial System.}

In the embryos of Vertebrata the arterial system consists of a forward continuation of the truncus arteriosus, wn the ventral side of the throat (fig. 363 , abr, and $364, a$ ), which, with a few exceptions to be noticed below, divides into as many branches on each side as there are visceral arches. These branches, after traversing the visceral arches, unite on the dorsal side of the throat into a common trunk ou each side. This trunk (figs. $3(63$ and $3(64)$ after giving off one (or more) vessels to the head ( $c^{\prime}$ and $c$ ) turus backwards, and bends in towards the midlle line, close to its fellow, immediately below the notochord (figs. 21 and 116) and runs backwards in this situation towards the end of the tail. The two paral'el trunks below the notochord fuse very early into a single trunk, the dorsal aorta (figs. :3(i), $a d$, and :364, $\left.a^{\prime \prime}\right)$. There is given off from each collecting trunk from the visceral arches, or from the commencement of the clorsal aorta, a subclavian

I. E. II. 
artery to each of the anterior limbs; from near the anterior end of

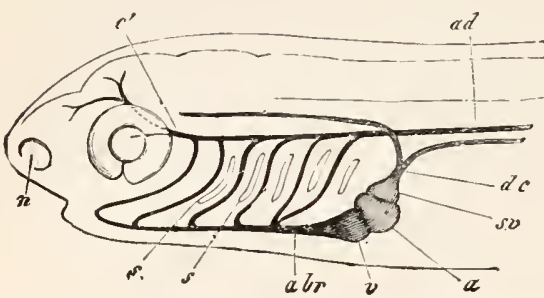

Fig. 363. Diagramatic VIEW OF the hean nf an embiro Teleosteax, with the pRimIIVE VASCULAR TRUNKs. (From Gegenbaur.)

$a$. auricle; $v$. ventricle; $a b r$. branchial artery ; $c^{\prime}$. carotid; ad. dorsal aorta ; $s$. branchiat elefts; $s v$. sinus venosus; dc. ductus Cuvieri ; n. nasal pit.

The primitive arrangement of the arterial trunks is with a few modifications retained in Fishes. With the development of the gills the vessels to the arches become divided into two parts connected by a capillary system in the gill folds, viz. into the branchial arteries bringing the blood to the gills from the truncus arteriosus, and the branchial veins transporting it to the dorsal aorta. The branchial vessels to those arches which do not bear gills, either wholly or partially atrophy; thus in Elasmobranchii the mandibular trunk, which is fully developed in the embryo (fig. 193, lav), atrophies, except for a small remnant bringing blood to the rudimentary gill of the spiracle from the branchial vein of the hyoid arch. In Ganoids the mandibular artery atrophies, but the hyoid is usually preserved. In Teleostei both mandibular and hyoid arteries are absent in the achult, except that there is usually left a rudiment of the hyoid, supplying the pseudobranch, which is similar to the rudiment of the mandibular artery in Elasmobranchii. In Dipnoi the mandibular artery atrophies, but the hyoid is sometimes preserved (Protopterus), and sometimes lost.

In Fishes provided with a well developed air-bladder this organ receives arteries, which arise sometimes from the dorsal aorta, sometimes from the celiac arteries, and sometimes from the dorsal section of the last (fourth) branchial trunk. The latter origin is found in Polypterus and Amia, and seems to have been inherited by the Dipnoi where the air-bladker forms a true lung.

The pulmonary artery of all the air-breathing Vertebrata is derived from the pulmonary artery of the Dipnoi.

In all the types above Fishes considerable changes are effected in the primitive arrangement of the arteries in the visceral arches.

1 In Mammalia the superior mesenteric artery arises from the vitelline artery, which may probably be regarded as a primitive caliaco-mesenteric artery.

2 The mandibular artery is stated by fiotte never to be developed in Teleostei, but is distinetly figured in Jereboullet (No. - i1). 
In Amphibia the piscine condition is most nearly retained ${ }^{1}$. The mandibular artery is never developed, and the hyoid artery is imperfect, being only connected with the cephalic vessels and never directly joining the dorsal aorta. It is moreover developed later than the arteries of the true branchial arches behind. The subclavian arteries spring from the common trunks which unite to form the dorsal aorta.

In the Urodela there are developed, in adlition to the liyoid, four branchial arteries. The three foremost of these at first supply gills, and in the Perennibranchiate forms continue to do so through life. The fourth does not supply a gill, and very early gives off, as in the Dipnoi, a pulmonary branch.

'The byoid artery soon sends forward a lingual artery from its ventral end, and is at first continuerl to the carotid which grows forward from the dorsal part of the first branchial vessel.

In the Caducibranchiata, where the gills atrophy, the following changes take place. The remnant of the hyoid is continued entirely into the lingual artery. The first branchial is mainly continued into the carotid and other cephalic branches, but a narrow remnant of the trunk, which originally connected it with the dorsal aorta, remains, forming what is known as a ductus Botalli. A rete mirabile on its course is the remnant of the original gill.

The second and third branchial arches are continued as simple trunks into the dorsal aorta, and the blood from the fourth arch mainly passes to the lungs, but a narrow ductus Botalli still connects this arch with the dorsal aorta.

In the Anura the same number of arches is present in the embryo as in the Urodela, all four branchial arteries supplying branchiæ, but the arrangement of the two posterior trunks is different from that in the Urodela. The third arch becomes at a very early period continued into a pulmonary vessel, a relatively narrow branch connecting it with the second arch. The fourth arch joins the pulmonary branch of the third. At the metamorphosis the hyoid artery loses its connection with the carotid, and the only part of it which persists is the root of the lingual artery. The first branchial artery ceases to join the dorsal aorta, and forms the root of the carotid : the so-called carotid gland placed on its course is the remmant of the gill supplied by it before the metamorphosis.

The second artery forms a root of the dorsal aorta. The third, as in all the Amniota, now supplies the lungs, and also sends off a cutaneous branch. The fourth disappears. The connection of the pulmonary artery with both the third and fourth branchial arches in the embryo appears to me clearly to indicate that this artery was primitively derived from the fourth arch as in the Urodela, and that its permanent connection with the third arch in the Anura and in all the Amniota is secondary.

1 In my account of the Ampluibì, Grotte (No. 296) has been followed. 
In the Amniuta the metanorphnsis of the arteries is in all cares very similar. Five arclıes, viz. the mandibular, hyoid, and three branchial arches are always developed (fig. 364), but, owing to the

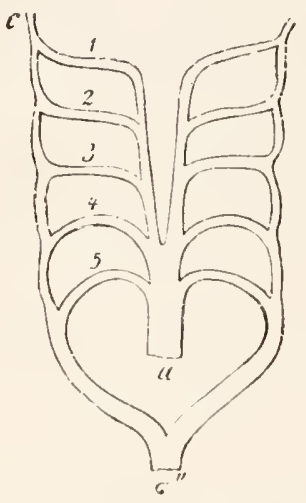

Fig, 364. Diagrat of the armangemext OF THE AR'TURIAL ARCHES IN AN EMBRYO OF ONH of trie Amsiota. (From Gegenbanr; after R.tтне.)

a. ventral aorta; $a^{\prime \prime}$. dorsal aorta; 1,2 , $3,4,5$. arterial arches; $c$. carotid artery. absence of branchie, never function as branchial arteries. Of these the main parts of the first two, connecting the truncus arteriosus with the collecting trunk into which the arterial arehes fall, always disappear, usually before the complete devolopment of the arteries in the posterior arches.

The anterior part of the collecting trumk into which these vessels fall is not obliterated when they disappear, but is on the contrary continued forwards as a vessel supplying the brain, homologous with that found in Fishes. It constitutes the internal carotid. Similarly the anterior part of the trunk from which the mandibular and hyoid arteries sprang is continued forwards as a small vessel ${ }^{1}$, which at first passes to the oral region and constitutes in Reptiles the lingual artery, homologous with the lingual artery of the Amphihia; but in Birds and Mammals becomes nole inportant, and is then known as the external carotid (tig. 12.5). By these changes the roots of the extemal and intemal carotids spring respectively from the ventral and clorsal ends of the primitive third artery, i.e. the artery of the first branchial arch (fig. $36.5, c$ and $c^{\prime}$ ); and thus this arterial arch persists in all types as the common carotid, and the basal part of the internal curotid. 'I'he trunk comnecting the third arterial arch with the system of the dorsal aorta persists in some Reptiles (Lacertilia, fig. $8666 \mathrm{~A}$ ) as a ductus Botalli, but is lost in the remaining Reptiles and in Birds and Mammals (fig. 366 B C, D). It disappears earliest in Mammals (fig. $365 \mathrm{C}$ ), later in Birds (fig. $36.5 \mathrm{~B})$, and still later in the majority of Reptiles.

The fourth arch always continues to give rise, as in the Anura, to the system of the dorsal aorta.

In all Reptiles it persists on both sides (fig. 366 A and B), but with the division of the truncus arteriosus into three vessels one of these,

1 His (No. 232) describes in Man two ventral continuations of the truncus arte. riosus, one derived from the mandibular artery, forming the external maxillary artery, and one from the hyoid artery, forming the lingual artery. The vessel from which they spring is the external carotid. These observations of His will very probably be found to hold true for other types. 
i.e. that opening furthert to the left sile of the ventrick (e and $d$ ), is continuous with the right fourth areh, and also with the common
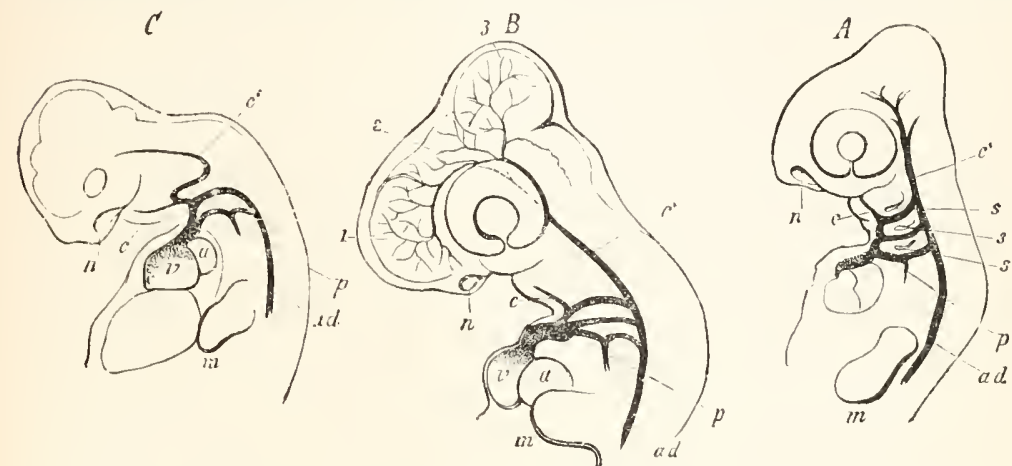

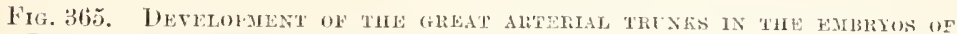
A. A Lizard; B. The comox Fowl; C. The I'ra. (From Gegenbanr; after Rathlie.)

The first two arches have disappeared in all thee. In $\mathrm{A}$ and $\mathrm{B}$ the last three are still complete, but in $\mathrm{C}$ the last two are alome complete.

p. pulmonary artery springing from the fifth areh, but still connected with the system of the dorsal aorta hy a ductus Botalli; $c$ external carotid; $c$. internal carotid; ad. dornal aorta; $a$. auricle; $r$. ventricle; $n$. nasal pit; m. rudiment of fore-limb.

carotid arteries $(c)$; while a second springing from the right side of the ventricle is continuous with the left funtth areh ( $h$ and $f^{\prime}$ ). Ther right and left divisions of the fourth arch meet however on the dorsal side of the essophagus to give origin to the dorsal aorta $(g)$.

In Birds (fig. $\left.366{ }^{C}\right)$ the left fourth arch $(h)$ loses its connection with the dorsal aorta, though the ventral part remains as the root of the left subelavian. The truncus arteriosus is moreover only divided into two parts, one of which is continuous with all the systemic arteries. 'Thus it comes about that in Birls the right fourth arch (e) alone gives rise to the dorsal anta.

In Mammals (fig. $366 \mathrm{D}$ ) the truncus arteriosus is only divided into two, but the left fourth arch (e), instead of the right, is that continuous with the dorsal aorta, and the right fourth arch $(i)$ is only continued into the right vertebral and right subclavian arteries.

'The fifth arch always gives origin to the puhnonary artery (fig. $36.5, p)$ and is continuous with one of the divisions of the truncus arteriosus. In Lizards (fig. :366 A, i), Chelonians and Birls (fig. :366 $\mathrm{C}, i$ ) and probably in Crocodilia, the right and left puhmonary arteries spring respectively from the right and left fifth arches, and during the greater part of embryonic life the parts of the fifth arches between the origins of the puhnonary arteries and the system of the dorsal aorta are preserved as ductus Botalli. These ductus Botalli persist for life in the Chelonia. In Ophidia (fig. $3(66 \mathrm{~B}, h$ ) and Mammalia (fig. $366 \mathrm{D}, m$ ) only one of the fifth arches gives origin to the two pulmonary arteries, viz. that on the right side in Opaidia, and the left in Manmalia. 
The ductus Botalli of the fifth arch (known in Man as the ductus arteriosus) of the side on which the pulmonary arteries are formed, may remain (e.g. in Man) as a solid cord comnecting the common stem of the pulmonary aorta with the systemic aorta.

The main history of the arterial arches in the Amniota has been sufficiently dealt with, and the diagram, fig. 366, copied from Ratlıke, shews at a glance the character of the metamorphosis these arches undergo in the different types. It merely remains for me to say a few words about the subclavian and vertebral arteries.

'The subclavian arteries in Fishes usually spring from the trunks connecting the branchial veins with the dorsal aorta. This origin, which is also found in Amphibia, is typically found in the embryos of the Anniota. In the Lizards this origin persists through life, but
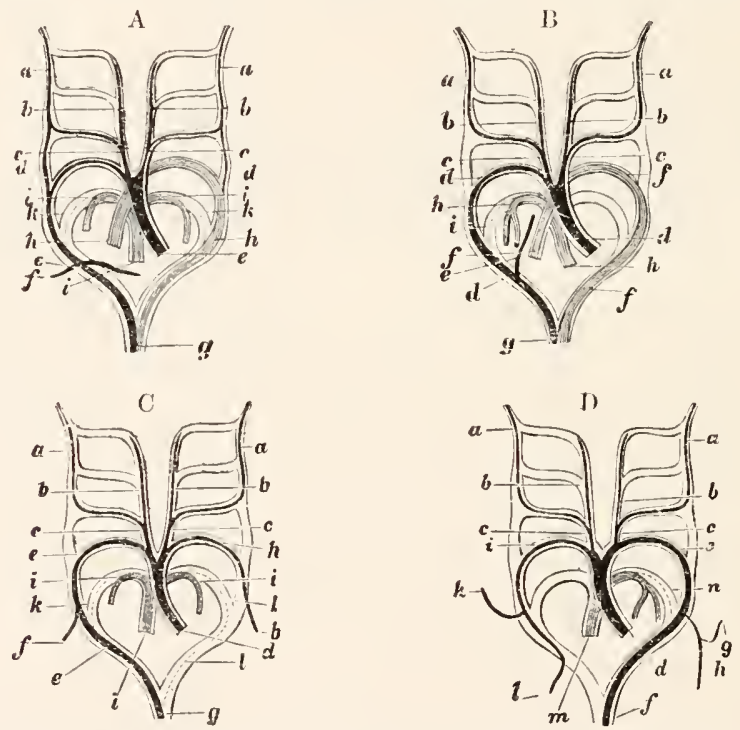

Fif. 366. Diagrams illustrating the metamorphosis of the arterial arches in a Iizard A, a Sxańe B, a Bird C and a Mammal D. (From Mivart after Rathke.)

A. a. intermal carotid ; $b$. external carotid; $c$. common carotil ; d. ductus Botalli between the third and fourth arches; $e$. right aortic trunk; $f$. subclavian; $g$. dorsal aorta; $h$. left aortic trunk; $i$. pulmonary artery; $l$. rudiment of ductus Botalli between the pulmonary artery and the system of the dorsal aorta.

B. $a$. internal carotid; $b$. external carotid; $c$. common carotid; $d$. right aortic trunk; $e$. vertebral artery; $f$. left aortic trunk of dorsal aorta; $h$. pulmonary artery; i. ductus Botalli of pulmonary artery.

C. $a$. internal carotid; b. external carotid; $c$. common carotid; $d$. systemic aorta ; $e$ fourth areh of right side (root of dorsal aorta) ; f. right subclavian; $g$. dorsal aorta; $h$. left subclavian (fourth arch of left sile); $i$. pulmonary artery; $k$. and 7 . right and left ductus Botalli of pulmonary arteries.

D. $a$. internal earotid; $b$. external carotid; $c$. common carotil ; $d$. systemic aorta; e. fourth areh of left side (root of dorsal aorta); f. dorsal aorta; $g$. left vertebral artery; $h$. left subelavian artery ; $i$. right subclavian (fourth arch of right side); $k$. right vertebral; $l$. continuation of right subclavian; $m$. pulmonary artery; $n$. duetus Ibotalli of pulmonary artery. 
both subclavians spring from the right side. In most other types the origin of the subclavians is carried upwards, so that they usually spring from a trunk common to them and the carotids (arteria anonyma) (Birls and some Mammals); or the left one, as in Man and some other Manmals, arises from the systemic aorta just beyond the carotids. Various further modifications in the origin of the subdavians of the same general nature are found in Mammalia, but they need not be specified in detail. The vertebral arteries usually arise in close connection with the subclavians, but in Birds they arise from the common carotils.

\section{Bibliography of the Arterial System.}

(496) H. Rathke. "Ueb. d. Entwick. d. Arterien w. bei d. Säugethiere von d. Bogen d. Aorta ausrehen." Müller's Archir, $18+3$.

(497) H. Rathke. "Untersuchungen üb. d. Aortenwurzeln d. Saurier." Denkschriften d. k. Aliad. Wien, Vol, xim. 1857.

ride also His (No. 232) and general works on Vertebrate Embrgology.

\section{The Tenous System.}

The venous system, as it is fonnd in the embryos of Fishes, consists in its earliest condition of a single large trunk, which traverses the splanchic mesoblast investing the part of the alimentary tract behind the heart. This trunk is directly continuous in front with the heart, and underlies the alimentary canal through both its præanal and postanal sections. It is shewn in section in fig. $367, v$, and may be called the snbintestinal vein. This vein has been found in the emb:yos of Teleostei, Ganoidei, Elasmobranchii and Cyclostomata, and runs parallel to the dorsal aorta above, into which it is sometimes continued behind (Teleostei, Ganoidei, etc.).

In Elasmobranch embryos the subintestinal vein terminates, as may be gathered from sections (fig. 368, v.cuu), shortly before the end of the tail. The same series of sections also shews that at the cloaca, where the gut enlarges and comes in contact with the skin, this vein bifurcates, the two branches uniting into a single vein both in frunt of and behind the cloaca.

In most Fishes the anterior part of this vein atrophies, the caudal section alone remaining, but the anterior section of it persists in the fold of the intestine in Petromyzon, and also remains in the spiral valve of some Elasmobranchii. In Amphioxus, moreover, it forms, as in the embryos of higher types, the main venous trunk, though even here it is usua!ly broken up into two or three parallel vessels.

It no doulst represents one of the primitive longitulinal trunks of the vermiform ancestors of the Chordata. The heart and the branchial artery constitute a specially modified anterior continuation of this vein. The dilated portal sinus of Myxine is probably also part of it; and if this is 


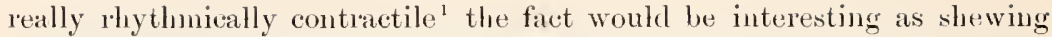
that this quality, which is now localised in the heart, was once probably common to the subintestinal vessel for its whole lengtl.

On the development of the carlinal veins (to be described below)

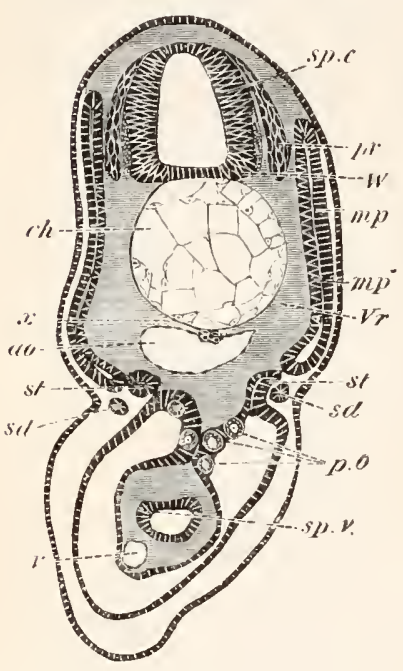

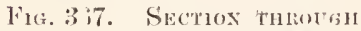

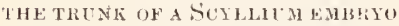
SLGHTLY IOENGER THAX 28 F.

sp.c. spinal canal; $\Pi$. white matter of spinal cord ; $p r$. poste lior nerve-roots; ch. notochord; r. sub-notuehordal sorl; acr. aorta; mp. musele plate; mp'. inner layer of musele-plate alreaty converted into muscles; $1 \%$ rudiment of vertebial body; st. segmental tube; sd. segmental duet; spor. ;piral valve; $c$ subintestinal vein; p.o. primitive gencrative cells. considerable changes are effected in the subintestinal vein. Its postanal section, which is known in the adult as the caudal vein, nnites with the cardinal veins. On this junction being effected retrogressive (hanges take place in the prapanal section of the original subintestinal vessel. It breaks up in front into a number of smaller vessels, the nost importunt of which is a special vein, which lies in the fold of the spiral valve, and which is nure conspicuons in sone Elasmobranchii than in Seyllium, in which the development of the vessel has been mainly studied. The lesser of the two branchies eomecting it romol the cloaca with the candal vein first vanishes, and then the larger; and the two posterior carlinals are left as the sole forwarl continuations of the caurlal vein. The latter then becones prolonged forwards, so that the two cardinals open into it some little distance in front of the hind end of the kidneys. By these changes, and by the lisanpearance of the postanal section of the gut, the caudal vein is made to appear as a supraintestinal and not, as it really is, a subintestinul ressel.

Fron the subintestinal vein there is given off a branch which supplies the yolk-sack. This leaves the subintestiual vein close to the liver. The liver, on its development, embraces the subintestinal vein, which then breaks up into a capillary system in the liver, the main part of its blood coming at this period from the yolk-sack.

The portal system is thus established from the subintestinal vein; but is eventually jomed by the varions visceral, and sometimes by the genital, veins as they become successively developed.

The blood from the liver is brought back to the sinus venosus by veins known as the hepatic veins, which, like the hepatic capillary system, are derivatives of the subintestinal vessel. 
There join the portal system in Myxinoids and many l'cleostei a number of veins from the anterior abdominal walls, representing a commencenent of the anterior abdominal or ejigastric vein of ligher types'.

In the higher Vertebrates the original subintestinal ressel never attains a full development, even in the embryo. It is represented by (1) the ductus renosus, which, like the true subintestinal vein, gives origin (in the Ammiota) to the vitelline veins to the yolk-salck, and (:) hy the caudal vein. Whether the partial atrophy of the subintestinal vessel was primitively catused by the development of the cardinal reins, or for some other reason, it is at any rate a fact that in all existing Fishes the curdinal veins form the main venous chanmels of the trunk.

Their hater development than the sulintestinal vessel as well as their absence in Amphioxus, probubly indicate that they hecame evolved, at any rate in their present form, within the Vertehrate phylum.

The embryonic condition of the venous system, with a single large subintestinal vein is, as has been stated, always moditied by the development of a paired system of vessels, known as the cardinal veins, which bring to the heart the greater part of the blood from the trunk.

The cardinal veins appear in Fishes as four paired longitudinal trunks (tigs. 36:3 and :369), two anterior $(j)$ and two posterior $(c)$. 'They unite isito two transverse trunks on either side, known as the ductus Cuvieri (dc), which fall into the sinus venosus, passing from the body wall
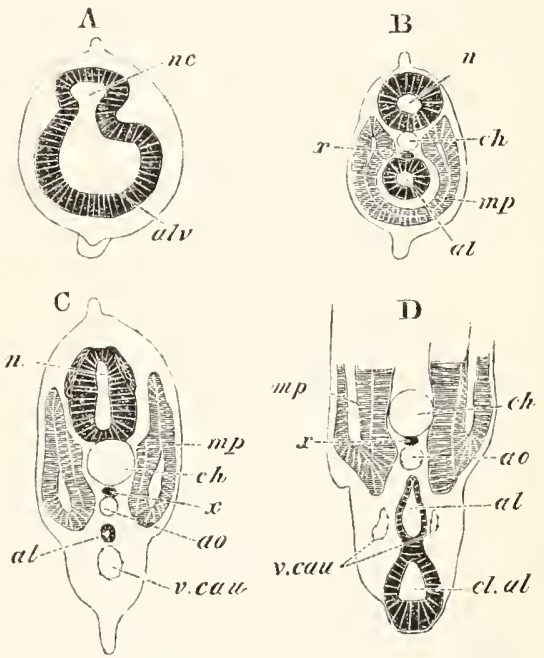

Fiti. 368. Fovr sectioxs throvghr the posi'ANAL PART OF THE TAIL OF AN EMBITO OF THE SAME AGE AS FIG. $28 \mathrm{~F}$.

$\mathrm{A}$ is the posterior section.

$n e$. neural canal; ul. post-anal gut; ulv. cau lal vesicle of post-anal gut; $x$. subnotochord rod; $m p$. muscle-plate; ch. notochord; cl.al. closea; au. aorta; r.cau. eaudal rein. to the sinus by a lateral mesentery of the heart already spoken of (p. 515, fig. 352). The anterior pair, known as the anteriur cadinal or jugular veins, bring to the heart the blood from the hear and neck. They are placed one on each side above the level of the branchial arches (tig. 299 , a.cv). The pusterior cardinal veins lie immediately dorsal 
to the mesonephros (Wolffian body), and are mainly supplied by

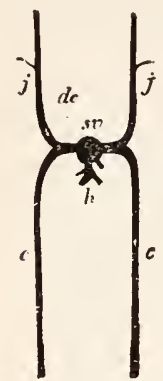

Fír. 369. DiAGRAM OF THE PAIRED VENOUS SYSTEM OF A Fisfr. (From Gegenbaur.)

j. jugular vein (anterior cardinal vein); $c$. posterior cardinal vein; $h$. hepatic veins; $s v$. sinus venosus; $d c$. ductus Cavieri.

In the embryos of all the higher forms the general characters of the venous system are at first the same as in Fishes, but with the development of the vena cava inferior the front sections of the posterior cardinal veins atrophy, and the ductus Cuvieri, remaining solely comnected with the anterior cardinals and their derivatives, constitute the superior vence cave. The inferior cava receives the liepatic veins.

Apart from the non-development of the subintestinal vein the visceral section of the venous system is very similar to that in Fishes.

The further changes in the venous system must be dealt with separately for each group.

Amphibia. In Amplibia (Gïtte, No. 296) the anterior and posterior cardinal veins arise as in Pisces. From the former the internal jugular rein arises as a braneh; the external jugular constituting the main stem. The subclarian with its large cutaneous branch also springs from the system of the anterior cardinal. The common trunk formed by the junction of these three veins falls into the ductus Curieri.

The posterior cardinal veins occupy the same position as in Pisces, and unite behind with the caudal reins, which Gütte has shewn to be originally situated below the postanal gut. The iliac reins unite with the posterior cartinal veins, where the latter fall into the caurlal vein. The original piscine condition of the reins is not long retained. It is first of all disturbed by the development of the anterior part of the important unpared venous trunk which forms in the adult the vena cava inferior. This is developed independently, but unites behind with the right posteri,n cardinal. From this point lackwards the two cardinal veins coalesce for 
sonte listance, to give rise to the posterior section of the vena cava inferior, situated between the kidneys ${ }^{1}$. The anterior sections of the cardinal veins subsequently atropliy. The posterior part of the cardinal veins, from their junction with the vena cava inferior to the caulal veins, forms a rhomboidal figure. The iline vein joins the outer angle of this figure, and is thus in direct communication with the inferior vena cava, but it is also comnected with a longitudinal vessel on the outer horder of the kidneys, which receives transverse vertebral veins and transmits their blood to the kidneys, thus forming a renal portal system. 'The anterior limbs of the rhombo d formed by the carlinal veins soon atrophy, so that the blood from the hind limbs can only pass to the inferior vena cava through the renal portal system. The posterior parts of the two cardinal veins (uniting in the Urorlela directly with the unpaired caurlal vein) still persist. The iliac veins also become directly comnected with a new vein, the anterior abdominal vein, which has meanwhile become developed. Thus the iliae veins hecome united with the system of the vena cara inferior through the vena renalis advehens on the outer border of the kidney, and with the anterior abdominal veins by the epigastric veins.

The visceral veuous system legins with the development of two vitelline veins, which at first join the sinus venosus directly. They soon become euveloped in the liver, where they break up into a capillary system, which is also joined by the other veins from the viscera. The hepatic system has in fact the same relations as in Fishes. Into this system the anterior abdominal vein also pours itself in the adult. This rein is originally formed of two ressels, which at first fall directly into the sinus venosus, miting close to their opening into the sinus with a vein from the truneus arteriosus. They become prolonged backwards, and after receiving the epigastric veins above mentioned from the iliac veins, and also veins from the allantoic bladder, unite hehind into a single vessel. Anteriorly the right vein atrophies and the left contimmes forward the unjaired posterior. section.

A secondary connection becomes established between the anterior abdominal vein and the portal system; so that the blood originally transported by the former vein to the heart becomes diverted so as to fall into the liver. A remnant of the primitive connection is still retained in the adult in the form of a small vein, the so-called vena bulbi posterior, which brings the blood from the walls of the truncus arteriusus directly into the anterior abdominal vein.

The pulmonary veins grow directly from the heart to the lungs.

For our knowledge of the development of the venous system of the Amniota we are mainly indebted to Ratlıe.

Reptilia. As an example of the Reptilia the Snake may be selected, its venous system having been fully worked out by Rathke in his important memoir on its derelopment (No. 300).

The anterior (external jugular) and posterior cardinal veins are formed in the embryo as in all other types (fig. $370, v j$ and $v c$ ) ; and the anterior cardinal, after giving rise to the anterior vertebtal and to the cephalic veins, persists with but shight modifications in the adult; while the two ductus Cuvieri constitute the superior vena cavæ.

1 This statement of Götte's is opposed to that of Rathke for the Amniota, and cannot be considered as completcly estahlished. 
The two posterior cardinals unite behind with the caudal veins. They are placed in the ustual situation on the dorsal and outer border of the kidneys.

With the development of the vena cava inferior, to be described below, the blood from the kidneys becomes mainly

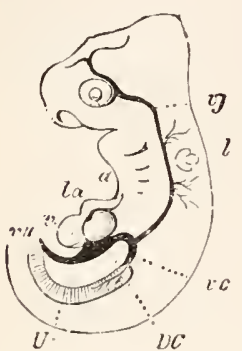

Fig. 370. ANTERtor PORTIOX OF THE VENOT'S STATEM OF AN EMBRTONIC Sxalie. (From Gegenbaur; alter Rathke.)

re. posterior cardinal vein; $v j$. jagular vein; $D C$. ductus Cuvieri ; ru. allantoic vein; $r$ ventricle; $l a$. truncus arteriosus; a. visceral clefts; $l$. auditury vesicle. transported by this ressel to the lieart; and the section of the posterior carrinals opening into the luctus Cuvieri gradually atrophies, their posterior parts remaining however on the outer border of the kidneys as the vende renales alvelientes ${ }^{1}$.

While the front part of the posterior cardinal veins is under-oing atrophy, the intercostal veins, which originally poured their blome into the posterior cardinal veins, become also connected with two longitulinal veins-the posterjor vertebral veius-which are homologous with the azyogs and hemiazygos veins of Han; and bear the sane relation to the anterior vertebral veins that the anterior and posterior cardinals do to each other.

'The:se veins ale at first conuected by transverse anastomoses with the pusterior cirdinals, but, on the disalpearance of the front part of the latter, the whole of the hlood from the intercostal veins falls into the pusterior vertebral veins. 'They are united in front with the anteriol. vertebral reins, and the connon trumk of the two veins on each sicle falls into the jugular vein.

The prosterior vartebral veins are at tirst symmetrical, hut after becoming connected by transrerne anastomoses, the right becones the more importiut of the two.

'Tlie vena tava inferior, though considerably later in its development than the cardinals, arises rairly early. It constitutes in fiont an unpaired trunk, at first very small, opening into the right alluntoic rein, close to the heart. Posteriorly it is continuous with two veins placed on the inner border of the kidneys ${ }^{2}$.

The vena cava inferior passes through the dorsal part of the liver, and in doing so receives the hejatic veins.

The portal system is at first constituted by the vitelliue vein, which is directly continuous with the venous end of the heart, and at first receives the two ductus Cuvieri, lut at a later period unites with the left ductus. It soon receives a mesenteric vein bringing the blood from the viscera, which is small at first but rapidly increases in importance.

1 Rathke's account of the vena renalis advehens is thus entirely opposed to that which Gitte gives for the Frog, but my own observations on the Lizard incline me to accept Ratlke's statements, for the Amniota at any rate.

2 The vena cava inferior does not according to liatlke's account unite behind with the posterior cardinal veins, as it is stated by Götte to do in the Anura. Götte yuestions the accuracy of liathke's statements on this head, but my own observations ace entirely in favour of liathke's observations, and lend no support whatever to Götte's views. 
The common trunk of the vitelline amd mesenteric veins, which may be called the portal vein, becomes early enveloped by the liver, and gives off branches to this organ, the blood from which passes by the hepatic reins to the venat cava inferiol. As the branches in the liver become more inportant, less and less blood is directly transported to the heart, and finally the prart of the original vitelline vein in front of the liver is alsorbed, and the whole of the blool from the portal system passes from the liver into the vena cava inferior.

The last section of the renous system to be dealt with is that of the anterior abdominal vein. There are originally, as in the Anura, two veins belonging to this system, which owing to the precocious development of the blaclder to form the allantois, constitute the allantoic veins (fix. 370, vu).

These veins, rumning along the anterior ablominal wall, are formed somewhat later than the vitelline vein, and fill into the two ductus: Cuvieri. They unite with two epigastric veins (homologous with those in the Anura), which connect them with the system of the posterior cardinal veins. The left of the two eventually atrophies, so that there is formed an unpaired allantoic vein. This vein at first receives the vena cava inferior close to the heart, hut eventually the junction of the two takes place in the region of the liver, and finally the anterior ablominal vein (as it comes to be after the atrophy of the allantois) joins the portal system and breaks "p into capillaries in the liver ${ }^{1}$.

In Lizards the iliac veins join the posterior cardinals, and so pour part of their bloud into the kilneys; they also become connecterl by the epigastric veins with the system of the anterior abdominal or allantoic vein. 'The suhclavian veins join the system of the superior' vense cave.

The venous system of Birds and Mammals differs in two important points from that of Reptilia and Amphibiar. Firstly the anterior abelominal vein is only a fortal vessel, forming during foetal life the allantoic vein; and secomlly a direct commetion is established between the vella uava inferior and the veins of the hind limbs and posterior parts of the carlinal veins, so that there is no renal portal system.

Aves. The chick may be taken to illustrate the derelopment of the venuus system in Birds.

On the third day, nearly the whole of the renous blood fiom the body of the embryo is carried back to the heart by two main renous trunks, the antrior (fig. $125,5 . C^{\prime}\left(V^{\prime}\right)$ and posterior $(C . V a)$ cardinal veins, juining on each sicle to form the short transverse ductus Cuvieri $(D C)$, both of which unite with the sinus venosus clore to the heart. As the hearl and neck continue to enlarge, and the wings become developed, the single anterion. cardinal or jugular vein (fig. $371, J$ ), of each side, is joined by two new veins: the vertekral vein (su. I.), bringing back blood from the heal and neck, and the subclitrian vein from the wing (II).

On the thind day the posterior cardinal veins are the only veins which return the blood from the hinder part of the hody of the embryo.

About the fourth or fifth day, however, the vena cava inferion (tig. 371, Y.C.I) makes its appearance. This, stating from the sinus venosus not far from the heart, is on the fifth day a short trunk rumning backward in the middle line below the aorta, and speedily losing itself in the tissues

1 The junction between the portal system and the anterior ablominal rein is apparently denied by Rathke $(\mathrm{No}, 3,300, \mathrm{p} .173)$, but this must be an error on his part. 
of the Wolffian bodius. When the true kidueys are formed it also receives blood from them, and thenceforward enlarging rapidly becomes the channel

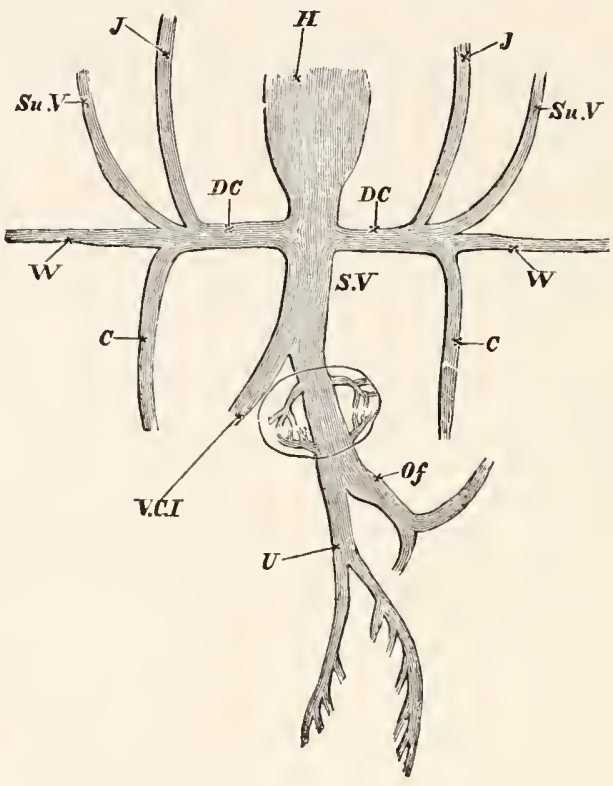

Fig. 371. Diagram of the vexous circulation in the Chick at the commencenent OF THE FIFTII DAY.

$H$. heart; $D C$. ductus Cuvieri. Into the ductus Cuvieri of each side fall $J$. the jugular vein, $S u . V$. the superior vertebral, $W^{r}$. the vein from the wing, and $C$. the inferior cardinal vein; S.V. sinus venosus; $O f$. vitelline vein; $U$. allantoic vein, which at this stage gives off branches to the body-walls; V.C.I. inferior vena cava.

by which the greater part of the blood from the hinder part of the borly finds its way to the heart. In proportion as the vena cava inferior increases in size, the posterior cardinal veins diminish.

The blood originally coming to them from the posterior part of the spinal cord and trunk is transported into two posterior vertebral veins, similar to those in Reptilia, which are however placed dorsally to the heads of the ribs, and join the anterior vertebral veins. With their appearance the anterior parts of the posterior curdinals disappear. The blood from the hind limbs bccomes trinsported directly through the kidney into the vena cava inferior, without forming a renal portal system ${ }^{1}$.

On the third day the course of the vessels from the yolk-sack is very simple. The two vitelline veins, of which the right is already the smaller, form the ductus venosus, from which, as it passes through the liver on its way to the heart, are given off the two sets of vencedvehentes and vence revehentes (fig. $37 \mathrm{l})$.

With the appearance of the allantois on the fourth day, a new fiature is introduced. From the ductus venosus there is given off a vein which

1 The morle in which this is effected requires fun ther investigation. 
quickly divides into two branches. These, running along the ventral walls

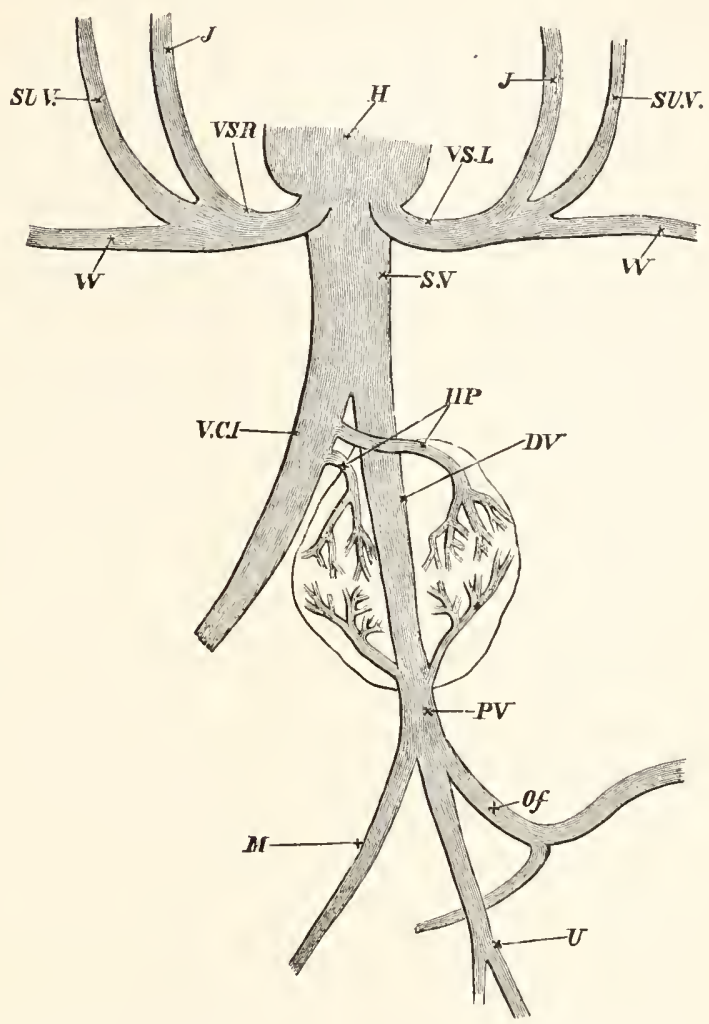

Fig. 372. Diagram of the venous circulation in the Chick durisg tile later DAYS OF INCUBATION.

II. heart; I'SR. right vena cara superior; IS.L. left vena cava superior; S.I. sinus venosus. The two vena cavæ superiores are the original 'ductus Cuvieri,' they open into the sinus venosus. $J$. jugular vein; SU.V. anterior vertebral vein; II'. subclavian; $\mathrm{I}^{Y}$.C.I. vena cava inferior; HP. hepatic veins; $D V$. ductus venosus; $P I$. portal vein; $M$. mesenteric vein bringing blood from the intestines into the portal vein ; $O f$. vitelline vein; $U$. allantoic vein. The three last mentioned veins unite together to form the portal vein.

of the body from which they receive some amount of blood, pass to the allantois. They are the allantoic veins (fig. $371, u$ ) homologous with the anterior abdominal vein of the lower types. They unite in front to form a single vein, which becomes, by reason of the rapid growth of the allantois, very long. The right branch soon diminishes in size and finally disappears. Meanwhile the left on reaching the allintois bifurcates; and, its two branches becoming large and conspicuous, there still appear to be two main allantoic veins. At its first appearance the allintoic vein seems to be but a small branch of the vitelline, but as the allantois grows rapidly, 
and the yolk-sack dwindles, this state of things is reverseal, and the losi conspicuous vitelline appears as a branch of the larger allantoic vein.

On the third day the blood retming from the walls of the intestine is insignificant in amount. As howevel the intestine becomes more and more ieveloped, it acquires a distinct renous system, and its blood is returned by veins which form a trumk, the mosenteric vein (fig. $37 \cdot 2, M)$. falling into the vitelline vein at its junction with the allantoic rein.

These three great reins, in fact, form a large common trunk, which enters at once into the liver, and which we may now call the portal voin. (fig. $372, P^{\prime} V$ ). This, at its entrance into the liver, partly breals up into the veno advehentes, and partly continues as the ductus venosus (DV) straight through the liver, energing from which it joins the veua cavat inferior. Before the estahlishment of the vena cava inferior, the vena revehentes, carrying back the blod which eirculates through the hepatic capillaries, join the ductus venosus close to its exit from the liver. By the time however that the vena cava has become a large and inportant vessel it is found that the rence revehentes, or as we may now call them the hepatic ceins, have shifted theil embouchment, and now fall directly into that vein, the ductus venosus making a separate junction rather higher up (tig. $372,11 P$ ).

This state of things continues with hut slight elumges till near the eud of incubatin, when the chick begins to breathe the air in the air-chamber of the shell, and respiration is no longer carried on by the allantois. Blool then ceases to flow aloug the allintoic vessels; they hecome obliterated. The vitelline vein, which as the yolk becomes gradually absorbed proportionately diminishes in size and importance, comes to appear as a mere lirinch of the portal vein. The ductus venosus beennes obliterated; and

$A$

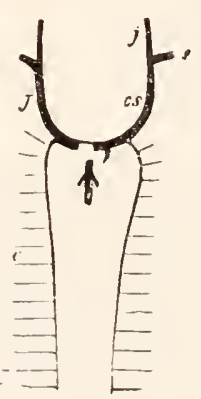

$B$

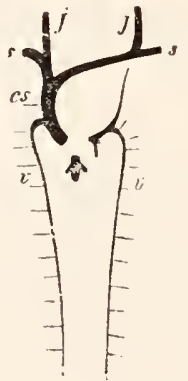

$C$

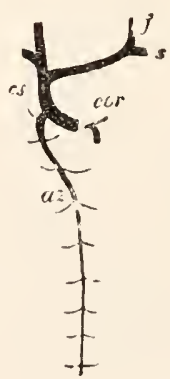

Fig. 373. Diagray of the Develophext of the pared venous sistem of Mamads (Mav). (From Gegenbaur.)

$j$. jugular rein ; $c s$. vena cava superior; s. subclavian veins ; c. posterior car inal vein ; $v$. vertebral vein; $a z$. azygos vein ; cor. coronary vein.

A. Stage in which the cardinal reins have already disappeared. Their position is indicated by dotted lines.

B. Later stage when the bloo 1 from the left jugular vein is carried into the right to form the single vena cava superior; a semnant of the left superior cava being however still left.

C. Stage after the left vertebral vein has disappeared; the right rertebral remaining as the azygos vein. The coronary rein remains as the last remnant of the left superior vena cava. 
hence the whole of the blond coming through the portal vein flows into the substance of the liver, and so by the hepatic veins into the vena cava.

Although the allantoic (anterior abdominal) vein is obliterated in the adult, there is nevertheless established an anastomosis between the portal system and the reins bringing the blond from the limbs to the vena cava inferion, in that the caudal rein and posterior pelvic reins open into a ressel, known as the coceygeo-mesenteric vein, which joins the portal vein ; while at the same time the posterior pelvic veins are connected with the common iliac veins by a vessel which unites with them close to their jumction with the cocygeo-mesenteric rein.

Mammalia. In Mammals the same venous trunks are leveloperl in the embryo as in other types (fig. $373 \mathrm{~A}$ ). The anterior carlinals or external jugulars form the primitive reins of the anterior part of the boty, and the internal jugulars and anterior vertebrals are sulsequently formed. The subclavians (fig $37: 3 \mathrm{~A}, s$ ), developed on the formation of the anterior limbs, also pour their blond into these primitive trunks. In the lower Mammalia (Monotremata, Marsupialia, Insectivora, some Rudentia, etc.) the two ductus Cuvieri remain as the two superior vence care, but more usually an anastomosis arises between the right and left immoninate veins, and eventually the whole of the blool of the left superion cava is carried to the right side, and there is left only a single suproror cava (fig. 373 $B$ and C). A smill ruliment of the left superior cava remains howerer as the sinus coronarius and receives the colonaly vein from the heart (figs. $373 \mathrm{C}$, cor and $374, c s$ ).

The posteriol carlinal reins form at first the only veins receiving the hlood from the posterior part of the trunk and kidneys; and on the development of the hind limbs receive the blool firom them also.

As in the types aheady lescriber an mupatifer rend cava inferior becomes rventually developed, and gradually carries off a larger and laroper portion of the hlowl originally returned by the posterior cardinals. It mites with the common stem of the allantric and vitelline veins in feront of the liver.

At a later period a pair of trmas is establisher hringing th. hloorl from the posterior part of the cardinal veins and the crural veins directly into the vena cava inferior (fig. $37+$, il). These vessels, whose development has not heen adequately investigated, form the common iliac veins, while the posterior ends of the corrlinal veins which $j$ in them hecone the hypogastric reins (fig. $: 37$ hy). Owing to the development of the

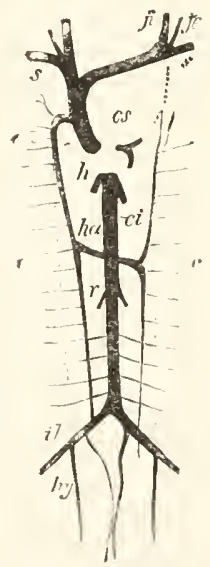

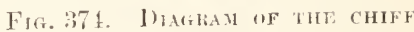
rexots Throks of Mix. (From fiegrenbatur.)

cs. rena cava superior; s. subclavian vein ; ji. internal jugular; $j e$. external jugular; az. azyoos rein ; ha. hemiazygos vein; $c$. dotted line shewing previous position of cardinal veins; ci. vena cava inferior ; r. renal reins; il. iliac; hy. hypogastric veins; $h$. hepatic veins.

The dotted lines shew the position of embryonic ressels aborted in the adult. 
common iliac veins there is no renal portal system like that of the Reptilia and Amplibia.

Posterior vertebral veins, similar to those of Reptilia and Birds, are established in connection with the intercostal and lumbar veins, and unite anteriorly with the front part of the posterior cardinal veins (fig. $373 \mathrm{~A})^{1}$.

On the formation of the posterior vertchral veins, and as the inferior vena cava becomes more important, the middle part of the posterior cardinals becomes completely aborted (fig. 374,c), the anterior and posterior parts still persisting, the former as the continuations of the posterior vertebrals into the anterior vena cava (az), the latter as the hylogastric veins $(h y)$.

Though in a few Mammalia both the posterior vertebrals persist, a transverse connection is usually established between them, and the one (the right) becoming the more important constitutes the azygos vein (fig. 37t, (tz), the persisting part of the left forming the hemiazygos vein (hct).

'The remainder of the venous system is formed in the embryo of the vitelline and allantoic veins, the former being eventually joined by the mesenteric vein so as to constitnte the portal vein.

The vitelline vein is the tirst part of this sy stem established, and divides near the lieart into two veins bringing back the blood from the yolk-sack (umbilical vesicle). The right vein soon however aborts.

The allantoic (anterior abdominal) veins are originally paired. They are developerl very carly, and at first course along the still widely open somatic walls of the body, and fall into the single vitelline trunk in front. The right allantoic vein disappears beforc long, and the common trunk formed by the junction of the vitelline and allantoic veins becomes considerably clongated. This trunk is soon enveloped by the liver.

The succeeding changes have been somewhit differently described by Kölliker and liathke. According to the former the common trunk of the allantoic and vitelline veins in its passage through the liver gires off branches to the liver, and also receives branches from this organ near its anterior exit. The main trunk is however never completely aborted, as in the embryos of other types, but remains as the ductus venosus Arantii.

With the development of the placenta the allantoic vein becomes the main source of the ductus vcnosus, and the vitelline or portal vein, as it may perhaps be now conveniently called, ceases to join it directly, but falls into one of its branches in the liver.

The vena cava inferior joins the continuation of the duetus venosus in front of the liver, and, as it beconnes more important, it receives directly the hepatic veins which originally brought back blood into the ductus venosus. The ductus venosus becomes moreover merely a small branch of the vena cava.

At the close of fortal life the allantoic vein becomes obliterated up, to its place of entrance into the liver; the ductus venosus becomes a solid cord-the so-called romnd ligament-and the whole of the venous blood is bronght to the liver by the portal vein ${ }^{2}$.

1 Rathke, as mentioned above, holds that in the Snake the front part of the posterior cardinals completely aborts. Further investigations are required to shew whether there really is a difference between Mammalia and Reptilia in this matter.

${ }^{2}$ According to Rathke the original trunk connecting the allantoic vein directly with 
Owing to the allantoic (anterior abdominal) vein having merely a foetal existence an anastomosis between the iliac reins and the portal system hy means of the anterior abdominal vein is not establisherl.

\section{Biblography of the Venous System.}

(498) J. Marshall. "On the development of the great anterior veins." Phil. Trans., 18.59.

(499) H. Rathke. "Ueb. d. Billung d. Pfortader u. d. Lebervenen b. Säugethieren." Heckel's Archiv, 1830.

(500) H. Rathke. "Ueb. d. Bau u. d. Entwick, d. Venensystems d. Wirbelthiere." Bericht. ̈̈b. d. naturh. Seminar. d. Inix. K̈̈nigsberg, 1838.

Vide also Von Baer (No. 2.9 I), Gütte (No. 296), Kölliker (No. 298), and Rathke (Nos. $299,300$, and 301$)$.

\section{Lymphatic System.}

The lymphatic system arises from spaces in the general parenchyma of the body, independent in their origin of the true body cavity, though communicating both with this cavity and with the rascular system.

In all the true Vertebrata certain parts of the system form definite trunks communicating with the venous system; and in the higher types the walls of the main lymphatic trunks become quite distinct.

But little is known with reference to the ontogeny of the lymphatic vessels, but they originate late in larval life, and have at first the form of simple intercellular spaces.

The lymphatic glands appear to originate from lymphatic plexuses, the cells of which produce lymph corpuscles. It is only in Birds and Mammals, and especially in the latter, that the lymphatic glands form definite structures.

The Spleen. The spleen, from its structure, must be classed with the lymphatic glands, thongh it has definite relations to the vascular system. It is developed in the mesohlast of the mesogastrium, usually about the same time and in close comnection with the pancreas.

According to Müller and Peremeschko the mass of mesolhast which forms the spleen becomes early separated by a groove on the one side from the pancreas and on the other from the mesentery. Some of its cells become elongated, and send out processes which uniting with like processes from other cells forn the trabecnlar system. From the remainder of the tissue are derived the cells of the spleen pulp, which frequently contain more than one nucleus. Especial accunulations of these rells take place at a later period to form the so-called Malpighian corpuscles of the spleen.

\section{Bibliography of Spleen.}

(50r) W. Müller. "The Spleen." Stricker's Histology.

(502) Peremeschko. "Ueb. d. Entwick. d. Milz." Sitz. d. Wien. Akad. Wiss., Vol. Lvi. 1867.

\section{Sinprarenal bodies.}

In Elasmobranch Fishes two distinct sets of structures are fomml, both of which have been called suprarenal bodies. As shewn in the seque]

the heart through the liver is aborted, and the ductus venosus Arantii is a secondary connection established in the latter part of fotal life. 
both of these structures probably unite in the lighler types to form the suprarenal bodies.

One of them consists of a series of paired bodies, situated on the branches of the dorsal aorta, segmentally arranged, and forming a chain extending from close behind the lieart to the hinder end of the body cavity. Each body is formed of a series of lobes, and exlibits a well-marked distinction into a cortical layer of colummar cells, and a medullary substance formed of irregular polygonal cells. As first shewn by Leydig, they are closcly comected with the sympathetic ganglia, and usually contain mumerous ganglion cells distributed amongat the proper cells of the body.

The second body consists of an unpaired column of cells placed between the dorsal aorta and unpaired candal voin, and bounded on each side by the posterior parts of the kidney. I propose to call it the interrenal body. In front it overlaps the paired suprarenal bulies, but does not unite with them. It is formed of a series of well-marked lobules, etc. In the fresh state leydig (No. 506) finds that "fit molecules form the chief mass of the body, anl one finds freely imbediled in them clear vesicular nuclei." As may easily be male out from liarlened specimens it is inrested by a tmica propria, which gives off septa dividing it into wellnurkerl areas filled with polygonal cells. 'These cells constitute the true larenchyma of the body. By the ordinary methods of hardening, the oil globules, with which they are filled in the fresh state, completcly disappear.

The paired suprarenal bodies (Balfour, No. 292, pp. 242-244) are dereloped trom the sympathetic ganglia. 'These ganglia, shewn in an carly stage in fig. 380 sy.y, become gradually divided into a ganglionic part and a glandnla. part. 'The former' constitutes the sympathetic ganghia of the adult ; the latter the true paired suprarenal bodics. The interrenal body is however developed (Balfour, No. 292, p1. 245-247) from indifferent mesoblast colis between the two kilneys, in the same situation as in the adult.

The development of the suprarenal bodies in the Ammiota lias been most fully studied by Braun (No. 503) in the Reptilia.

In Lacertilia they consist of a pair of elongated yellowish borlies, placel between the vena renalis revehens and the generative glands.

They are formed of two constituents, viz. (1) masses of brown cells placed ou the dorsal side of the organ, which stain deeply with chromic acid, like certain of the cells of the suprarenals of Mammalia, and (2) irregular cords, in prut provided with a lumen, filled with fat-like globules ${ }^{1}$, amongst which are nuclei. On treatment with cluomic acid the fat globules disappear, and the cords break up into bolies resembling columnar cells.

The dorsal masses of brown cells are developed from the sympathetic ganglia in the same way as the paired supnarenal bodies of the Elasmobranchii, while the cords filled with fat-like globules are formerl of indifferent mesoblast cells as a thickening in the lateral walls of the inferior vena cava, and the cardinal veins continuons with it. The ohservations of Brmm (No. 504) on the Click, ant Köliker (No. 29S, pp. 953-955) on the Mammal, adcl but little to those of Brann. They shew that the greater part of the gland (the cortical substance) in these two types is derived from the mesoblast, and that the glands are closely connected with sympathetic

1 These globules are not formed of a true fatty substance, and this is also probably true for the similar globules of the interrenal bodies of Elasmobranchii. 
ganglia; while Kölliker also states that the posterior part of the organ is impaired in the embryo rabbit of 16 or 17 days.

The structure and development of what I have called the interrenal body in Elasmobranchii so closely correspond with that of the mesoblastic part of the suprarenal bodies of the Reptilia, that I have very little hesitation in regatroling them as homologous's while the paired bodies in Elismobranchii, derived from the sympathetic ginglia, clearly correspond with the part of the suprarenals of Reptilia having a similar origin; although the anterior larts of the paired suprarenal bodies of Fishes have elealy become aborted in the higher types.

In Elasmobranch Fishes we thus have (1) a series of paired bodies, derived from the sympathetic ganglia, and (2) an unpaired body of mesollastic origin. In the Amniota these bodies unite to form the compound suprarenal bodies, the two constituents of which remain, however, distinct in their development. The mesoblastic constituent appears to form the cortical part of the adult suprarenal boty, and the nervous constituent the medullary part.

\section{Biblography of the Suprorenal bodies.}

(503) M. Braun. "Bau u. Entwick. d. Nebennieren bei Reptilien." Arbeit. a. d. zool.zoot. Institut Wiirzburg, Vol. v. 1879.

(504) A. v. Brunn. "Ein Beitrïg z. Kenntniss d. feinern Banes u. d. Entwick. a. Nebemnieren." Archiv f. mikr. Anat., Vol. vir. 1872.

(505) Fr. Leydig. Untersuch. ïb. Fische u. Reptilien. Berlin, 1853.

(506) Fr. Leydig. Rocken u. Itaie. Leipzig, 1852.

rille also F. M. Balfour (No. 292), Kölliker (No. 298), Remak (No. 302), ete.

1 The fact of the organ being unpaired in Elasmobranchii and paired in the Amniota is of no importance, as is shewn by the fact that part of the organ is unpaired in the Rabbit. 


\section{CHAP'TER XXII.}

\section{THE MUSCULAR STSTEM.}

Is all the Coelenterata, except the Ctenophora, the contractile elements of the body wall consist of filiform processes of ectodermal or entodermal epithelial cells (figs. 375 and $376 \mathrm{~B}$ ). The elements provided with these processes, which were first discovered by Kleinenberg, are known as myo-epithelial cells. Their contractile parts may either be striated (fig. 376) or

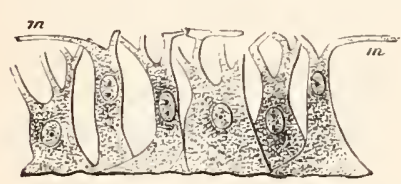

F1(i. 375. Mro-EITTHELIAL CELls of Hrora. (From Gegenbaur; after Kleinenberg.) $m$. contractile fibres. non-striated (fig. 375). In some instances the epithelial part of the cell may nearly abort, its nucleus alone remaining (fig. $376 \mathrm{~A}$ ); and in this way a layer of muscles lying completely below the surface may be established.

There is embryological evidence of the derivation of the voluntary muscular system of a large number of types from niyo-epithelial cells of this kind. The more important of these groups are the Chrtopola, the Gephyrea, the Chætognatha, the Nematoda, and the Vertebrata ${ }^{1}$.

While there is clear evidence that the muscular system of a large number of types is composed of cells which had their origin in myoepithelial cells, the mode of evolution of the muscular system of other types is still very obscure. The muscles may arise in the embryo from amøeboid or indifferent cells, and the Hertwigs ${ }^{2}$ hold that in many of these instances the muscles have also phylogenetically taken their origin from indifferent connective tissue cells. The subject is however beset with very serious difficulties, and to discuss it here would carry me too far into the region of pure histology.

1 If recent statements of Metschnikoff are to be trusted, the Echinodermata must be added to these groups. The amoboid cells stated in the first volume of this treatise to form the muscles in this group, on the authority of Selenka, give rise, according to Metschuikoff, only to the cutis, while the same naturalist states the epithelial cells of the vasoperitoneal vesicles are provided with muscular tails.

$2 \mathrm{O}$. and R. Hertwig, Die Celomtheorie. Jena, 1881. 
The voluntary muscular system of the Chordata.

The muscular fibres. The muscular elements of the Chordata undoubtedly belong to the myo-epithelial type. The embryonic
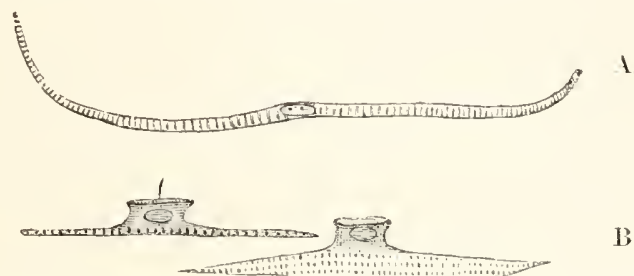

1

B

Fig. 376. Muscle-cells of Lizzia Köllikeri. (From Lankester; after O. and R. Hertwig.)

A. Muscle-cell from the circular fibres of the subumbrella.

B. Myo-epithelial cells from the base of a tentacle.

muscle cells are at first simple epithelial cells, but soon become spindle-shaped : part of their protoplasm becomes differentiated into longitudinally placed striated muscular fibrils, while part, enclosing the nucleus, remains indifferent, and coustitutes the epithelial element of the cells. The muscular fibrils are either placed at one side of the epithelial part of the cell, or in other instances (the Lamprey, the Newt, the Sturgeon, the Rabbit) surround it. The latter arrangement is shewn for the Sturgeon in fig. 57.

The number of the fibrils of each cell gradually increases, and the protoplasm diminishes, so that eventually only the nucleus, or nuclei resulting from its division, are left. The products of each cell probably give rise, in conjunction with a further division of the nucleus, to a primitive bundle, which, except in Amphioxus, Petromyzon, ete., is surrounded by a special investment of sarcolemma.

The voluntary muscular system. For the purposes of description the muscular system of the Vertebrata may conveniently be livided into two sections, viz. that of the heal and that of the trunk. The main part, if not the whole, of the muscular system of the trunk is derived from certain structures, known as the muscle-plates, which take their origin from part of the primitive mesoblastic somites.

It has already been stated (pp. 243-246) that the mesoblastic somites are derived from the dorsal segmented part of the primitive mesoblastic plates. Since the history of these bodies is presented in its simplest form in Elasmobranchii it will be convenient to commence with this group. Each somite is composed of two layers-a somatic and a splanchnic-both formed of a single row of columnar cells. Between these two layers is a cavity, which is at first directly continuous with the general body cavity, of which incleed it merely forms a specialized part (fig. 377 ). Before long the cavity becomes however completely constricted off from the permanent buily cavity. 
Very early (fig. 377) the inner or splanchnic wall of the somites loses its simple constitution, owing to the middle part of it undergoing peculiar changes. The meaning of the changes is at once shewn by longitudinal horizontal sections, which prove (fig. 378) that the cells in this situation $\left(m p^{\prime}\right)$ lave become extended in a longitudinal direction, and, in fact, form typical spindle-shaped embryonic muscle-cells, each with a large nucleus. Every musc.e-cell extends for the whole length of a somite. The imer layer of each somite, immediately within the muscle-band just described, begins to proliferate, and proluce a mass of cells, placed between the muscles and the notochord $\left(\mathrm{I}^{r}\right)$. Thiese cells form the commeneing vertebral bodies, and have at first (fig. :375) the same segmentation as the somites from which they sprang.

After the sepration of the vertebral bodies from the somites,

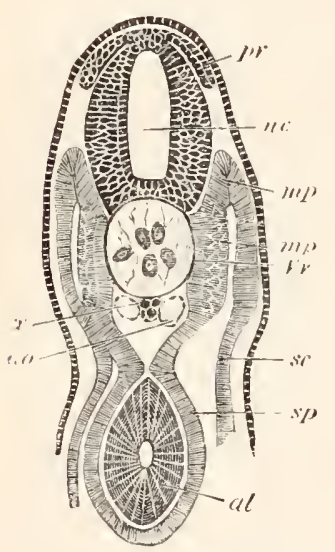

Fli. 377. Traxsvelse secTHON THROLGH THE TRTXK OF AN EMBPO SLIGHTLY OLHER THAN FIG. $20 \mathrm{E}$.

nc. neural canal; $m$. posterior root of spinal nerve; $x$. subnotuchordal rod; uo. worta; $s c$. somatic mesoblast; sp. splanchnic mesoblast; mp. muscle-plate; my'. portion of muscle-plate converted into muscle; Ir. portion of the vertebral plate which will give rise to the vertebral bodies; $a l$. alimentary tract. the remaining parts of the somites may be called muscle-plates; since they become direetly converted into the whole voluntary muscular system of the trunk (fig. :379, mp).

According to the statements of Bambeke and Giotte, the Amplibians present some noticeable peculiarities in the development of their muscular sistem, in that such distinct muscle-plites as those of other vertebrate types are not developred. Wach side-plate of intesoluast is divided into a somatic and a splanchnic lityer, continuous throughout the vertebral and parietal portions of the plate. The vertebral portions (somites) of the plates soon become separated from the parietal, and form indenendent masses of cells constituted of two layers, which were originally continuous with the somatic and splanchnic layers of the parietal plates (fig. 79). The outer or somatic layer of the vertebral plates is formed of a single row of cells, but the inner or splanchnic layer is made up of a kernel of cells on the side of the somatic laser and an inner layer. The kernol of the splanchnic layer and the outer or somatic layer together correspond to it muscle-plate of other Vertebrata, and exhilit a sinilar segmentation.

Osseous Fishes are stated to agree with Amphibians in the development of their somites and muscular system ${ }^{1}$, but further observations on this point are required.

In Birds the horizontal splitting of the mesoblast extends at first to the dorsal summit of the mesoblastic plates, but after the isolation of the

"Ehrlich, "Ueber den peripher. Theil a. Trwirbel." Arehir f. micr. A wat., Vol. xi. 
somites the split between the somatic and splanchnic layers becones to a large extent obliterated, though in the anterior soluites it appears in part to persist. The somites on the second day, as seen in a transverse section(fig. $115, P . v$.), are somew liat quadrilateral in form but broader than they ane deel.

Euch at that time consists of a somewhat thick cortex of raliating rather gramular columnar cells, enclosing a small kernel of splierical cells. They are not, as may be seen in the above figure, completely separatud from the ventral (or lateral as they are at this period) parts of the mesoblastic plate, and the dorsal and outer layer of the cortex of the somites is continnous with the somatic laver of mesoblast, the remainder of the curtex, with the

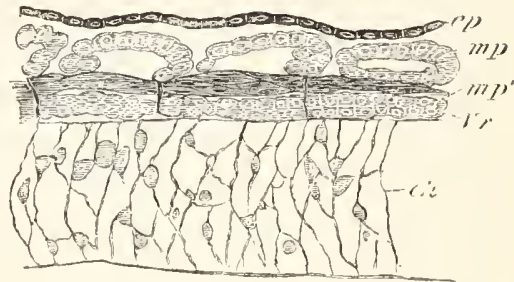

Fir. 378. Hohizoxtal SECTION THBOUgh THE TRUNK OF AN EMBRYO OF SCYLLIUM CONSHERAMLY YOUNGER THAN $28 \mathrm{~F}$.

The section is talien at the level of the notochord, and shews the separation of the cells to form the vertebral bodies from the miscle-plates.

ch. notochord; $e p$. epiblast; $\Gamma$ r. rudiment of vertebral body; mp. muscle-plate; $m p^{\prime}$. portion of muscle-plate already differentiated into longitudinal muscles. central kernel, being continuous with the splanchnic layer. Towards the end of the sicoml and begimning of the thind day the upper and outer layer of the cortex, together probably with some of the central cells of the kernel, becomes separated off as a nuscle-plate (fig. 116). The nouscle-plate when formed (fig. 117) is found to consist of two layers, an inner and an outer, whici enclose between them an almost obliterated central carity; and no sooner is the muscleplate formed than the middle portion of the immer layer hecomes converted into longitudinal muscles. The avian muscle-plates have, in fact, precisely the sime constitution as those of Elasmobranchii. The central space is clearly at remmant of the vertebrel portion of the body cuvity, which, though it wholly or partially disappears in a previous stage, reaplears again on the formation of the muscle-plate.

The remannuler of the somite, after the formation of the muscle-plate, is of very considerable hulk; the cells of the cortex belonging to it lose their distinctive charaters, and the major l art of it becomes the vertebral rudiment.

In Mammalia the history appears to be generally the same as in Elasmobranchii. The split which gives rive to the body cavity is continued to the dorsal summit of the inesurblastic plates, and the dorsal portions of the plates with their contained cavities become divided into somites, and are then separated off from the ventral. The later development of the somites has not been worked out with the requisite care, but it would seem that they form somewhat cubical bodies in which all trace of the primitive slit is lust. The further development resembles that in Birds.

The first changes of the mesolulastic somites and the formation of the muscle-plates do not, according to existing statements, take place on quite the same type throughont the Vertebrata, yet the comparison which has been instituted between Elasmobranchs and other Vertebrates appoas to prove that thre are important common 
features in their development, which may be regarled as primitive, and as baving been inherited from the ancestors of Vertebrates. These features are (1) the extension of the body cavity into the vertebral plates, and subsequent enclosure of this cavity between the two layers of the muscle-plates; (2) the primitive division of the vertebral plate into an outer (somatic) and an inner (splanchnic) layer, and the formation of a large part of the voluntary muscular system out of the inner layer, which in all cases is converted into muscles earlier than the outer layer.

The conversion of the muscle-plates into muscles. It will be convenient to commence this subject with a description of the changes

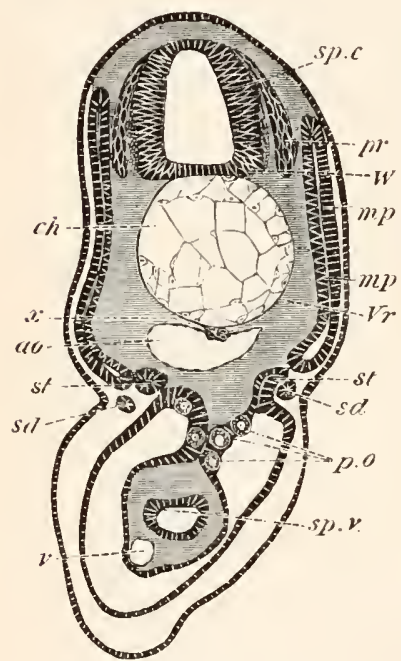

Fig, 379. Section throvgh THE TRUNK OF A SCYLLICM EMBRTO SLIGHLY YOUNGER THAN $28 \mathrm{~F}$.

sp.c. spinal canal; $W$. white matter of spinal cord; pr. posterior nerve-roots; ch. notochord; $x$. sub-notochordal rod; ao. aorta; mp. muscle-plate; $m p^{\prime}$. inner layer of muscle-plate already converted into muscles; $\mathrm{Vr}$. rudiment of vertebral body; st. segmental tube; $s d$. segmental duct; $s p . v$. spiral valve; $v$. subintestinal vein; p.o. primitive generative cells.

which take place in such a simple type as that of the Elasmobranchii.

At the time when the muscle-plates have become independent structures they form flat two-layered oblong bodies enclosing a slit-like central cavity (fig. $279, m p)$. The outer or somatic wall is formed of simple epithelial-like cells. The inner or splanchnic wall has however a somewhat complicated structure. It is composed dorsally and ventrally of a columnar epithelium, but in its midlle portion of the muscle-cells previously spoken of. Between these and the central cavity of the plates the epithelium forming the remainder of the layer commences to insert itself; so that between the first-formed muscle and the cavity of the muscle-plate there appears a thin layer of cells, not however continuous throughout.

When first formed the muscle-plates, as viewed from the exterior, have nearly straight edges; soon however they become beut in the middle, so that the erlges have an obtusely angular form, the apex of the angle being directed forwarls. They are so arrangel that the anterior edge of the one plate fits into the posterior edge of the one in front. In the lines of junction between the plates layers of connective tissue cells appear, which form the commencements of the intermuscular septa.

The growth of the plates is very rapid, and their upper ends soon extend to the summit of the neural canal, and their lower ones nearly meet in the median ventral line. 'The original band of muscles, whose growth at first is very slow, now increases with great 
rapidity, and forms the nucleus of the whole voluntary muscular system (fig. 380, $m p^{\prime}$ ). It extends upwards and downwards by the continuous conversion of fresl cells of the splanchnic layer into muscle-cells. At the same time it grows rapilly in thickness by the addition of fresh spindle-shaped muscle-cells from the somatic layer as well as by the division of the already existing cells.

Thus both layers of the muscle-plate are concemed in forming the great longitudinal lateral muscles, though the splanchnic layer is converted into muscles very much sooner than the somatic ${ }^{1}$.

Each muscle-plate is at first a continuous structure, extending from the dorsal to the ventral surface, but after a time it becomes diviled by a layer of connective tissue, which becomes developed nearly on a level with the lateral line, into a dorso-lateral and a ventrolateral section. The ends of the muscle-plates continue for a long time to be formed of undifferentiated columnar cells. The complicated outlines of the inter-muscular septa become gradually established during the later stages of development, causing the well-known appearances of the muscles in transverse sections, which require no special notice here.

The muscles of the limbs. 'T he limb muscles are formed in Elasmobranchii, coincilently witlı the cartilaginous skeleton, as two bands of longitudinal fibres on the dorsal and ventral surfaces of the limbs (fig. 346). The cells, from which these muscles originate, are derived from the muscle-plates. When the ends of the muscle-plates reach the level of the limbs they bend outwards and enter the tissue of the limbs (fig. 380). Small portions of Eeveral muscle-plates $(m p l)$ come in this way to be situated within the limbs, and are very soon segmented off from the remainder of the inuscle-plates. The portions of the muscle-plates thus introduced soon lose their original distinctness. There can however be but little doubt that they supply the tissue for the muscles of the limbs. The muscle-plates themselves, after giving off buds to the limbs, grow downwards, and soon cease to shew any trace of having given off these buds.

In addition to the longitudinal museles of the trunk just described, which are generally characteristic of Fishes, there is found in Amphioxus a peculiar transverse abdominal muscle, extending from the mouth to the abdominal pore, the origin of which has not been made out.

It has already been shewn that in all the higher Vertebrata muscle-plates appear, which closely resemble those in Eiasmobranchii; so that all the higher Vertebrata pass through, with reference to their muscular system, a fish-like stage. The middle portion of the inner layers of their muscle-plates becomes, as in Elasmobranchii, con-

1 The brothers Hertwig have recently maintained that only the inner layer of the muscle-plates is converted into muscles. In the Elasmobranchs it is easy to demonstrate the incorrectness of this view, and in Acipenser (vide fig. 57, $m p$ ) the two layers of the muscle-plate retain their original relations after the cells of both of them have become converted into muscles. 
verted into muscles at a very early period, and the onter layer for a long time remains formed of indifferent cells. That these muscleplates give rise to the main muscular system of the trunk, at any

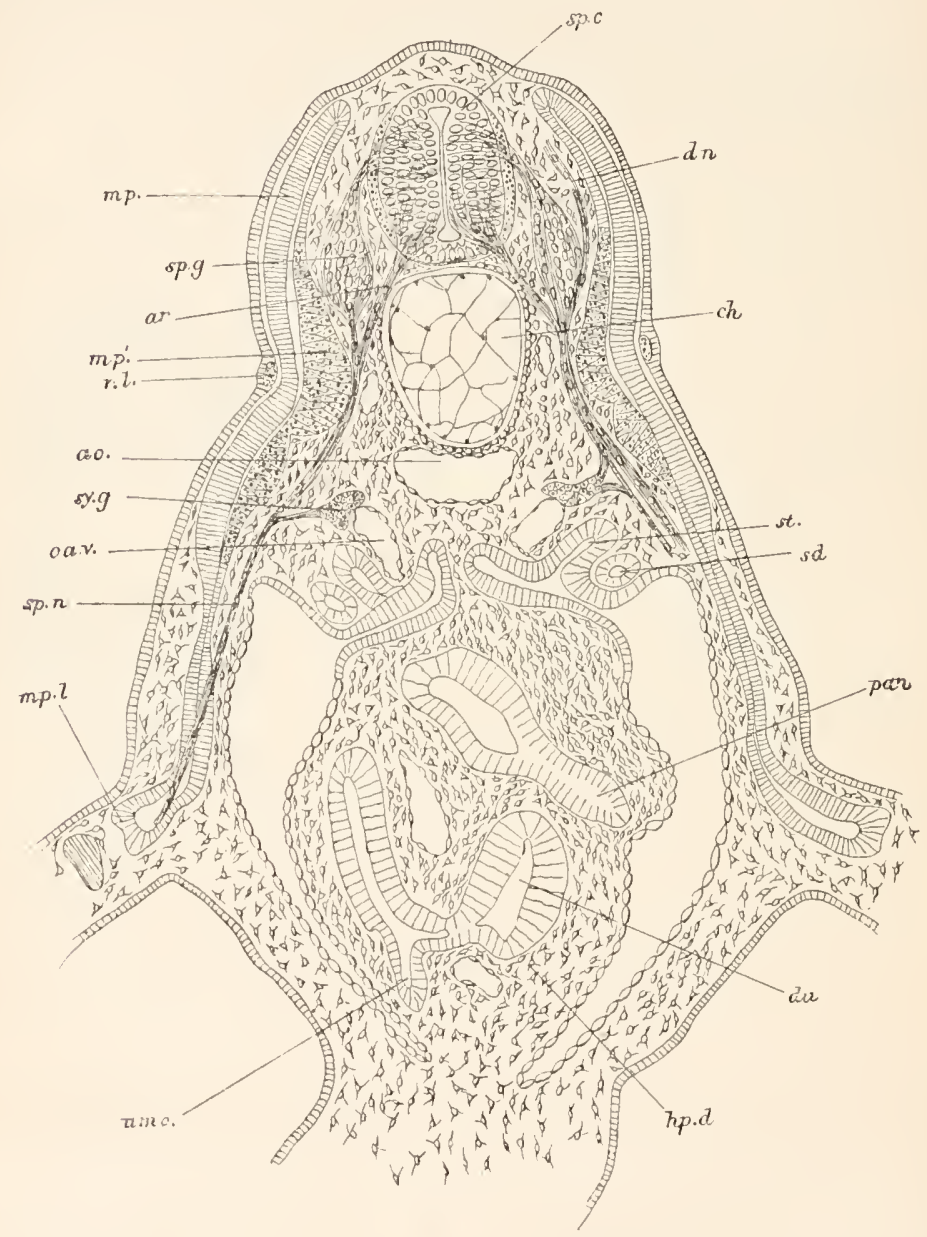

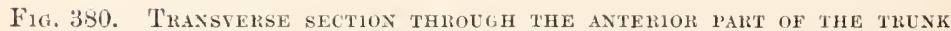
OF AN EMBryo OF SCYLLIUM SLIGHTLY OLDER THAN Fig. $29 \mathrm{~B}$.

The section is diagrammatic in so far that the anterior nerve-roots have been inserted for the whole length; whereas they join the spinal cord half-way between two posterior roots.

sp.c. spinal cord; sp.g. ganglion of posterior root; ar. anterior root; dn. dorsally cirected nerve springing from posterior root; mp. muscle-plate; $m p^{\prime}$. part of muscleplate already converted into muscles; $m . p l$. part of muscle-plate which gives rise to the muscles of the limbs; $n l$. nervus lateralis; ao. aorta; $c h$. notochord; sy. $\%$. sym. pathetic ganglion; $c a . l$. cardinal vein; sp.n. spinal nerve; sd. segmental (archinephric) luct; st. segmental tube; du. duodenum; pun. pancreas; hp.d. point of junction of hepatic duct with duodenum; wme. unbilical canal. 
rate to the episkeletal muscles of Huxley, is practically certain, but the details of the process have not been made out.

In the Perennibranchiata the fish-like arrangement of muscles is retainer through life in the tail and in the dorso-lateral parts of the trunk. Tn the tail of the Ammiotic Verteluatat the primitive arragement is also more or less retained, and the same lolds good for the rlorso-lateral trunk museles of the Lacertilia. In the other Amniota and the Aumb the dorso-lateral muscles lave hecome divided up into a series of separate muscles, which are arranged in two main layers. It is probable that the intereostal muscles belong to the same group as the dorso-literal muscles.

The aldominal muscles of the trumk, ren in the lowest Amplitia, exhibit a division into several layers. The recti aldominis are the least altered part of this system, and usually retain inclications of the primitive inter-nuscular septa, which in many Ampliblia and Licertilia are also to some extent preserved in the other albrlominal muscles.

In the Amniotic Vertelnates there is formed und rueath the vertehral column and the transverse processes a system of musches, forming part of the hyposkeletal system of Huxley, and called hy Gegenbam the subvertebral muscles. The development of this system has not heen worked out, but on the whole I am inclined to believe that it is deriver from the musele-plates. Kibliker, Huxley and other embryologists brlieve however that these muscles are independent of the muscle-plates in their origin.

Whether the muscle of the diaphragm is to he plicerl in the same category as the hyposkeletal muscles has not been made out.

It is probalile that the cutameous muscles of the trmk are deriver from the cells giren off from the muscle-plates. Kobliker lowever believes that they have an independent origin.

The limb-museles, both extrinsic and intrinsie, as may be concluded from their development in Elasmolnamchii, are derived from the muscleplates. Kleinenberg found in Lacertilia a growth of the muscle-plates into the limbs, and in Amphibia Gritte finds that the onter layer of the muscle-plates gives rise to the musches of the limbs.

In the higher Vertelirata on the other hand the entrance of the muscleplates into the limbs has not been male out (Kiilliker). It seems therefore frobable that by an embryological morlification, of which instances are so fiequent, the cells which give rise to the muscles of the limbs in the ligher Vertebrata can no longer be tracerl into a direct commection with the museleplates.

\section{The Somites and muscular system of the head.}

The extension of the somites to the anterior end of tho hody in Anphioxus clearly proves that somites, similar to those of the trunk, wer" originally present in a region, which in the higher Vertebrata has become differentiated into the hear. In the adult condition no true Vertebrate exhibits indicatious of such somites, but in the embryos of several of the lower Vertebrata structures have been foumd, which are probably equivalent to the somites of the trunk: they have been frequently alluded to in the previous chapters of this volume. These structures have been most fully worked out in Elasmobranchii. 
The mesoblast in Elasmobranch embryos becomes first split into somatic and splanchnic layers in the region of the head; and between these layers there are formed two cavities, one on each side, which end in front opposite the blind anterior extremity of the alimentary canal; and are continuous behind with the general body cavity (fig. $20 \mathrm{~A}, v p)$. I propose calling them the head-cavities. The cavities of the two sides have no communication with each other.

Coincidently with the formation of an outgrowth from the throat to form the first visceral cleft, the head-cavity on each side becomes divided into a section in front of the cleft and a section behind the cleft; and at a later period it becomes, owing to the formation of a second cleft, divided into three sections: (1) a section in front of the first or liyomandibular cleft; (2) a section in the hyoid arch between the hyomandibular cleft and the hyobranchial or first branchial cleft ; (3) a section belind the first branchial cleft.

The front section of the lead-cavity grows forward, and soon becomes divided, without the intervention of a visceral cleft, into an

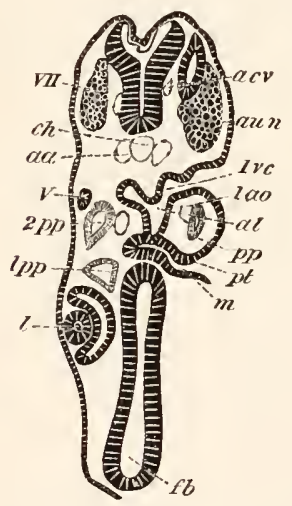

Fig. 381. Transverse section THROVGH THE FRONT PART OF THF head of a young Pristiures embro.

The section, owing to the cranial flexure, cuts both the fore- and the hind-brain. It shews the premandibular and mandibular head cavities $1 p p$ and $2 p p$, etc. The section is moreover somewhat oblique from side to side.

$f b$. fore-brain; $l$. lens of eye; $m$. mouth; pt. upper end of mouth, forming pituitary involution; $1 a o$. mandibular aortic arch; $1 p p$. and $2 p p$. first and second head cavities; 1vc. first visceral cleft; $V$. fifth nerve; aun. auditory nerve; VII. seventh nerve; aa. dorsal aorta; $a c v$. anterior cardinal vein; $c h$. notochord. anterior and posterior division. The anterior lies close to the eye, and in front of the commencing mouth involution. The posterior part lies completely within the mandibular arch.

As the rudiments of the successive visceral clefts are formed, the posterior part of the head-cavity becomes divided into successive sections, there being one section for each arch. Thus the whole head-cavity becomes on each side divided into (1) a premandibular section; (2) a mandibular section (vide fig. $29 \mathrm{~A}, p p)$; (3) a liyoid section; (4) sections in each of the branchial arches.

The first of these divisions forms a space of a considerable size, with epithelial walls of somewhat short columnar cells (fig. $381,1 p p$ ). It is situated close to the eye, and presents a rounded or sometimes a triangular figure in section. 'The two halves of the cavity are prolonged ventralwards, and meet below the base of the forebrain. The comnection between them appears to last for a considerable time. These two cavities are the only parts of the body cavity within the head which unite ventrally. The section of the head-cavity just described 
is so similar to the remaining sections that it must be considered as serially homologous with then.

The next division of the head-cavity, which from its position may be called the mandibular cavity, presents a spatulate shape, being dilated dorsally, and produced ventrally into a long thin process parallel to th hyomandibular gillcleft (fig. 20, $p p$ ). Like the previous space it is lined by a short columnar epithelium.

The mandibular aortic arch is situated close to its inner side (fig. 381, $2 p p)$. After becoming separated from the lower part (Marshall), the upper part of the cavity atrophies about the time of the appearance of the external gills. Its lower part also becomes much narrowed, but its walls of columnar cells persist. 'The outer or somatic wall becomes very thin indeed, the splanchnic wall, on the other hand,

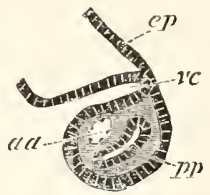

Fig. 382. Horizontal sec. TION THROUGH THE PEXULTI. MATE VISCERAL ARCH OF AN EMbryo of Pristiurus.

ep. epiblast; $v c$. pouch of hypoblast which will form the walls of a visceral cleft; $p p$. segment of body-cavity in visceral arch; aa. aortic arch. thickens and forms a layer of several rows of elongated cells. In each of the remaining arches there is a segment of the original body cavity fundamentally similar to that in the mandibular arch (fig. 382). A dorsal dilated portion appears, however, to be present in the third or hyoid section alone (fig 20 ), and even there disappears very soon, after being segmented off from the lower part (Marshall). The cavities in the posterior parts of the head become much reduced like those in its anterior part, though at rather a later period.

It has been shewn that the divisions of the body cavity in the head, with the exception of the anterior, early become atrophied, not so however their wulls. The cells forming the walls both of the dorsal and ventral sections of these cavities become elongated, and finally become converted into muscles. Their exact history has not been followed in its details, but they almost unquestionably become the musculus contrictor superficialis and musculus interbranchialis ${ }^{1}$; and probably also musculus levator mandibuli and other muscles; of the front part of the head.

The anterior cavity close to the eye remains maltered much longer than the remaining cavities.

Its further history is very interesting. In my original account of this cavity (No. 292, p. 208) I stated my belief that its walls gave rise to the eye-muscles, and the history of this process has been to some extent worked out by Marshall in his important memoir (No. 509).

Marshall finds that the ventral portion of this cavity, where its two halves meet, becomes separated from the remainder. 'The eventual

1 Vide Vetter, "Die Kiemen und Kiefermusculatur d. Fische." Jenaische Zeitschrift, Vol. vir. 
fate of this part has not however been followed. Each dorsal section acquires a cup-like form. investing the posterior and inner surface of the eye. The cells of its onter wa!l subseqnently give rise to three sets of muscles. The middle of these, partly also derived from the inner walls of the cup, becomes the rectus internus of the eye, the dorsal set forms the rectus superior, and the ventral the rectus inferior. The obliquus inferior appears also to be in part developel from the walls of this cavity.

Marshall brings evidence to shew that the rectus externus (as might be anticiputed from its nerve supply) has no connection with the walls of the premandibular hearl-cavity, and finds that it arises close to the position originally occupied by the second and third cavities. Marshall has not satisfactorily made ont the mode of development of the obliquus superior.

The walls of the cavities, whose history has just been recorded, have definite relations with the cranial nerves, an account of which has alrearly been given at p. 379 .

Heal-cavities, in the main similar to those of Elasmobranchii, have been fouml in the embryo of Petromyzon (fig. 45, hc), the Newt (Osborn and Sicott), and various Reptilia (Parker).

\section{Bibilography.}

(507) G. M. Humphry. "Muscles in Vertebrate Animals." Jomn. of Anot. and Phys., Vol, vi. 1872.

(:08) J. Miiller. "Vergleichende Anatomie d. Mrxinoiden." Part I. Ostenlogie u. Myologie." Akad. Wiss., Berlin, 1834.

$(509)$ A. M. Marshall. "On the heat cavities and associated nerves of Elasmnbranclis." Quert. .J. of Micr. Scienre, Vol, xxr. 1881.

(510) A. Selneider. “Anat. u. Entwick. d. Muskelsystems d. Wirbelthiere." Sitz. d. Oberhessischen Gesellselinft, 1s73.

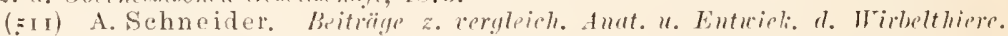
Berlin, 1879 .

I'ide also Gr̈tte (No. 290), Kölliker (No. 29\$), Balfom (No. 292), Huxley, ete. 


\section{CHAPTER XXIII.}

\section{EXCRETORY ORGANS.}

ExCRETORY organs consist of coiled or branched and often ciliated tubes, with an excretory pore opening on the outer surface of the body, and as a rule an internal ciliated orifice placed in the bodycavity. In forms provided with a true vascular system, there is a special development of capillaries arumd the glandular part of the excretory organs. In many instances the glandular cells of the crgans are filled with concretions of uric acid or some similar product of nitrogenous waste.

There is a very great morphological and physiological similarity between almost all the forms of exrretury organ found in the animal kingdom, but although there is not a little to be said for holding all these organs to be derived from some common prototype, the attempt to establish definite homologies between them is beset with very great difficulties.

Platyelminthes. Throughont the whole of the Platyelninthes these organs are constructed on a well-lefined type, and in the Rotifera excretory organs of a similar form to those of the P'atyelminthes are also present.

These organs (Fraipont. No. 513) are more or less distinctly paired, and consist of a sistem of "ide canals, often united into a network, which open on the one hand into a pair of large tubes leading to the exterior, and on the other into fine canals which terminate by ciliaterl openings, either in spaces between the connective-tissue cells (Platyelminthes), or in the body-cavity (Liotifera). 'The fine canals open directly into the larger ones, without first uniting into canals of an intermediate size.

The two large tubes open to the exterior, either by means of a median posteriorly placed contractile vesicle, or by a pair of vesicles, which liave a ventral and anterior position. The former type is characteristic of the majority of the Trematorla, Cestoda, and Rotifera, and the latter of the Nemertea and some Trematoda. In the

B. E. II. 
Turbellaria the position of the external openings of the system is variable, and in a few Cestoda (Wagner) there are lateral openings on each of the successive proglottides, in addition to the terminal openings. The mode of development of these organs is unfortunately not known.

Mollusca. In the Mollusca there are usually present two independent pairs of excretory organs-one found in a certain number of forms during early larval life only ${ }^{1}$, and the other always present in the adult.

The larval excretory organ has been found in the pulmonate Gasteropola (Gegenbaur, $\mathrm{Fol}^{2}$, Rabl), in Teredo (Hatschek), and possibly also in Paludina. It is placed in the anterior region of the body, and opens ventrally on each side, a short way behind the velum. It is purely a larval organ, disappearing before the close of the veliger stage. In the aquatic Pulmonata, where it is best developed, it consists on each side of a $Y$-shaped tube, with a dorsally-placed apex, containing an enlargement of the lumen. There is a ciliated cephalic limb. lined by cells with concretions, and terminating by an internal opening near the eye, and a non-ciliated pedal limb opening to the exterior ${ }^{3}$.

Two irreconcilable views are held as to the development of this system. Rabl (Vol. I. No. 268) and Hatschek hold that it is developed in the mesoblast; and Rabi states that in Planorbis it is formed from the anterior mesoblast cells of the mesoblastic bands. A special mesoblast cell on each side elongates into two processes, the commencing limbs of the future organ. A lumen is developed in this cell, which is continued into each limb, while the continuations of the two limbs are formed by perforated mesoblast cells.

According to Fol these organs originate in aquatic Pulmonata as a pair of invaginations of the epiblast, slightly behind the mouth. Each invagination grows in a dorsal direction, and after a time suddenly bends on itself, and grows ventralwards and forwards. It thus acquires its $\mathrm{V}$-shaped form.

In the terrestrial Pulmonata the provisional excretory organs are, according to Fol, formed as epiblastic invaginations, in the same way as those in the aquatic Pulmonata, but have the form of simple nonciliated sacks, without internal openings.

The permanent renal organ of the Mollusca consists typically of a pair of tubes, although in the majority of the Gasteropoda one of the two tubes is not developed. It is placed considerably belind the provisional renal organ.

1 I leave out of consideration an external renal organ found in many manine Gasteropod larve, vide Vol. I. p. 232.

2 H. Fol, "Etudes sur le dével. d. Mollusques." Mem. III. Archir d. Zool.expér. et gênér., Vol. vi1I.

3 The cartul observations of Fol seem to me nearly conclusive in favour of this limb having an external opening, and the statement to the reverse effect on p. 232 of Vol. I. of this treatise, made on the anthority of Rabl and Butschli, must probably be corrected. 
Each tube, in its most typical form, opens by a ciliated funnel into the pericardial cavity, and has its external opening at the side of the foot. The pericardial fumnel leads into a glandular section of the organ, the lining cells of which are filled with concretions. This section is followed by a ciliated section, from which a narrow duct learls to the exterior.

As to the development of this organ the same divergence of opinion exists as in the case of the provisional renal organ.

Rabl's careful observations on Planorbis (Vol. I. No. 268) tend to shew that it is developed from a mass of mesoblast cells, near the end of the intestine. The mass becones hollow, and, attaching itself to the epiblast on the left side of the anus, acquires an opening to the exterior. Its internal opening is not established till after the formation of the heart. Fol gives an equally preeise account, but states that the first rudiment of the oryan arises as a solid mass of epiblast cells. Lonkester finds that this organ is developed as a pairel invagination of the epiblast in Pisidium, and Bobretzky also lerives it from the epiblast in marine Prosobranchiata. In Cephalopoda on the other liand Bohretzky's observations (I conclude this from his figmes) indicate that the excretory sacks of the renal organs are derived from the mesoblast.

Polyzoa. Simple excretory organs, consisting of a pair of ciliated canals, opening between the mouth and the anus, lave been found by Hatschek and Joliet in the Entuproctous Polyzoa, and are developed, according to Hatschek, by whom they were first found in the larva, from the mesoblast.

Brachiopoda. One or rarely two (Rhynchonella) pairs of canals, with both peritoneal and external openings, are found in the Brachiopoda. They undoubtedly serve as genital ducts, but from their structure are clearly of the same nature as the excretory organs of the Chretopoda described below. Their development has not been worked out.

Chætopoda. Two forms of excretory organ have been met with in the Chatopoda. The one form is universally or nearly universally present in the adult, and typically consists of a pair of coiled tubes repeated in every segment. Each tube has an internal opening, placed as a rule in the segment in front of that in which the greater part of the organ and the external opening are situated.

There are great variations in the structure of these organs, which cannot be dealt with here. It may be noted however that the internal opening may be absent, and that there may be several internal openings for each organ (Polynoe). In the Capitellidie moreover several pairs of excretory tubes have been shewn by Eisig (No. 5 I2) to be present in each of the posterior segments.

The second form of excretory organ has as yet only been found in the larva of Polygordius, and wili be more conveniently dealt with in connection with the development of the excretory system of this form. 
'There is still considerable doubt as to the mode of formation of the excretory tubes of the Clirtopoda. Kowalevsky (No. 277), from his observations on the Oligochata, holds that they develop ats outgrowths of the epithelial layer covering the posterior side of the dissepiments, and secondarily become connceted with the epidermis.

Hatschel finds that in Criorlilus they arise from a continuous linear thickening of the sonatic mesoblast, immediately beneath the epidermis, and dorsal to the ventral band of longitudinal muscles. They break up into S-shaped cords, the anterior end of each of which is situated in front of a dissepiment, and is formed at first of a single large cell, while the posterior part is continued into the segment behind. The cords are covered by a peritoneal lining, which still envelopes them, when in the succeeding stage they are carried into the body-cavity. 'They subsequently beeome hollow, and their hinder ends acquire openings to the exterior. The formation of their interual openings has not been followed.

Kleinenberg is inclined to believe that the excretory tubes take their origin from the epiblast, but states that he las not satisfactorily worked out their development.

The observations of Eisig (Ko. 5I2) on the Capitellidæ support Kowalevsky's view that the excretory tubes originate from the lining of the peritoneal cavity.

Hatschek (No. 5I4) has given a very interesting account of the development of the excretory system in Polygordius.

The excretory system begins to be formed, while the larva is still in the trochosphere stage (fig. 38:3, $\mathrm{m}^{\prime} / \mathrm{l}$ ), and consists of a

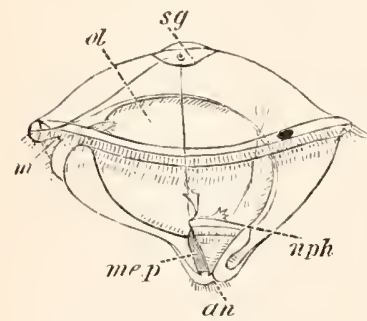

Fig. 383. Polygordit's LARva. (After Hatschek.)

$m$. mouth ; $s g$. supra-cesophageal ganglion; nph.nephridion; me.p. mesoblastic band; an. anus; ol. stomach. provisional excretory organ, which is placed in front of the future segmented part of the body, and occupies a position very similar to that of the provisional excretory organ found in some Mulluscan larve (vide p. $5(i 2)$.

Hatschek, with some show of reasin, holds that the prorisional excretory organs of Polygordius are homologous with those of the Ilollissea.

In its earliest stage the provisional excretory organ of Polrgordius consists of a pair of simple ciliated tubes, each with an anterior funuel-like opening situated in the millst of the mesoblast cells, and a posterior extemal opening. The latter is placed immediately in front of what afterwards becomes the segmented region of the embryo. While the larra is still unsegmented, a secoud internal opening is formed for each tube (fig. 38:3. ${ }^{2} / h$ ) and the two openings so formed may eventually become divided into five (fig. $38+A)$ all communicating by a single pore with the exterior. 
When the pusterior region of the embryo becomes segmenter], paired excetory organs are formed in each of the posterior segments, but the account of their development, as given by Hatschek, is so remarkable that I do not think it can be definitely accepted without further confirmation.

From the point of junction of the two main branches of the lorval kidney there grows backwarls (fig. $384 \mathrm{~B}$ ), to the hind end of the first segment, a very delicate tube, only indicated by its ciliaterl Jumen, its walls not being differentiater. Near the front end of this tube a fumnel, leading into the larval borly cavity of the hearl, is formerl, and subsequently the posterior end of the tube acquires an external opening, and the tube distinct walls. The commumication with the provisional excretory organ is then lost, and thus the excretory tube of the first segment is established.

The excretory tubes in the second and succeeding segments are formed in the same way as in the first, i.e. by the continuation of the lumen of the hind end of the excretory tube from the preceding segment, and the subsequent separation of this part as a separate tube.

The tube may be continued with a sinuous course through
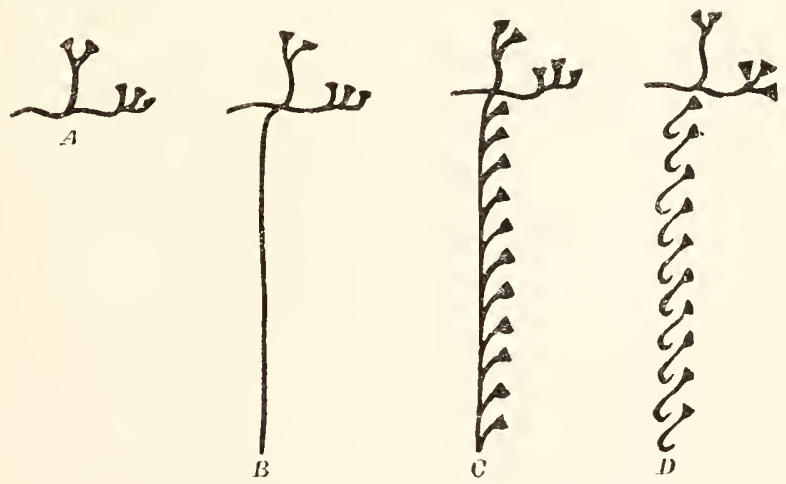

Fig. 38t. Dharam illestratixa the meveloparext of the excretury sistes of Polygondus. (After Hatschek.)

several segments without a distinet wall. The external and internal openings of the permanent excretory tubes are thus secondarily acquired. The internal openings conmunicate with the permanent body cavity. The development of the permanent excretory tubes is diagrammatically represented in fig. $384 \mathrm{C}$ and $\mathrm{I}$.

The provisional excretory orgau atrophies during larval life.

If Hatschek's account of the levelopment of the excretory system of Polygordius is correct, it is clear that important secondiury moditications must have taken place in it, because his description implies that there sprouts from the anterior excretory organ, while it has its own external opening, a posterior duct, which does not communicate either with the exterior 
or with the body cavity! Such a luct could have no function. It is intelligible either (1) that the anterior excretory organ should lead into a longitudinal duct, opening posteriorly; that then a series of seconlary openings into the body cavity should attach themselves to this, that for each internal opening an external should subsequently arise, and the whole break up into seprarate tubes; $o r^{\circ}(2)$ that behiud an anterior provisional excretory organ a series of secontary independent segmental tubes should be formed. But from Hatschek's account neither of these modes of evolution can be leduced.

Gephyrea. 'The Gephyrea may have three forms of excretory organs, two of which are found in the adult, and one, similar in position and sometimes also in structure, to the provisional exretury organ of Polygordins, has so far only been found in the larve of Echiurus and Bonellia.

In all the Gephyrea the so-called 'brown tubes' are apparently homologous with the segmented excretory tubes of Chxtopods. 'Their main function appears to be the transportation of the generative products to the exterior. 'There is but a single highly modified tube in Bonellia, forming the oviduct and uterus; a pair of tubes in the Gephyrea inermia, and two or three pairs in most Gephyrea arnata, except Bonellia. Their development has not been studied.

In the Gephyrea armata there is always present a pair of posteriorly placed excretory organs, opening in the adult into the anal extremity of the alimentary tract, and provided with numerous ciliated peritoneal fumnels. These organs were stated by Spengel to arise in Bonellia as outgrowths of the gut; but in Echiurus Hatschek (No. 5I5) finds that they are developed from the somatic mesoblast of the terminal pa:t of the trunk. They soon become hollow, and after attaching themselves to the epiblast on each sicle of the anus, acquire external openings. They are not at first provided with peritoneal funnels, but these parts of the organs become developed from a ring of cells at their inner extremities; and there is at first but a single funnel for each vesicle. 'The mode of increase of the fimuels has not been observed, nor has it been made out how the organs themselves become attached to the hind-gut.

The provisional excretory organ of Echiurus is developed at an early larval stage, and is functional during the whole of larval life. It at first forms a ciliated tube on each sile, placed in front of that part of the larva which becomes the trunk of the adult. It opens to the exterior by a fine pore on the ventral side, immediately in front of one of the mesoblastic bands, ancl appears to be formed of perforated cells. It terminates internally in a slight swelling, which represents the normal internal ciliated funnel. The primitively simple excretory organ becomes eventually highly complex by the formation of numerous branches, each ending in a slightly swollen extremity. These branches, in the later larval stages, actually form a network, and the imner end of each main branch divides into a 
bunch of fine tubes. The whole organ resembles in many respects the excretory organ of the Platyelninthes.

In the larva of Bonellia Spengel has described a pair of provisional excretory tubes, opening near the anterior end of the body, which are probably homologous with the provisional excretory organs of Echiurus (vide Vol. I., fig. $162 \mathrm{C}$, se).

Discophora. As in many of the types alrealy spoken of, permanent and provisional excretory organs may be present in the Discophora. The former are usually segmentally arranged, and resemble in many respects the excretory tubes of the Chatopoda. They may either be provided with a peritoneal fumnel (Nephelis, Clepsine) or have no internal opening (Hirudo).

Bourne ${ }^{1}$ has shewn that the cells surounding the main duct in the medicinal Leech are perforated by a very remarkable network of ductules, and the structure of these organs in the Leech is so peculiar that it is permissible to state with the reserve their homology with the excretory organs of the Chatopoda.

The excretory tubes of Clepsine are held by Whitman to be developed in the mesoblast.

There are found in the embryos of Nephelis and Hirudo certain remarkable provisional excretory organs the origin and history of which are not yet fully made out. In Nephelis they appear as one (according to Robin), or (according to Biitschli) as two successive pairs of convoluted tubes on the dorsal side of the embryo, which are stated by the latter author to develop from the scattered mesoblast cells underneath the skin. At their fullest development they extend, according to Robin, from close to the head to near the ventral sucker. Each of them is U-shaped, with the open end of the U forwards, each limb of the $U$ being formed by two tubes united in front. No external opening has been clearly made out. Fiirbringer is inclined from his own researches to believe that they open laterally. They contain a clear fluid.

In Hirndo, Lenckart has described three similar pairs of organs, the structure of which he has fully elucidated. They are situated in the posterior part of the body, and each of them commences with an enlargement, from which a convoluted tube is continued for some distance backwards; the tube then turns forwards again, and after bending again upon itself opens to the exterior. The anterior part is broken up into a kind of labyrinthic network.

The provisional excretory organs of the Leeches cannot be identified with the anterior provisional organs of Polygordius and Echiurus.

Arthropoda. Amongst the Arthropoda Peripatus is the only form with excretory organs of the type of the segmental excretory organs of the Chrtopoda2.

1 "On the Structure of the Nephridia of the Medicinal Leech." Quart.J. of Hicr. Science, Vol. xx. 1880 .

2 Ville F. M. Balfour, "On some points in the Anatomy of Peripatus Capensis." Quart. J. of Mier. Srience, Vol. XIx. 1879. 
These organs are placed at the bases of the feet, in the lateral divisions of the body cavity, shut off from the nain median division of the borly cavity by longitudinal septa of transverse musc'es.

Each finlly developed organ consists of three parts:

(1) A dilated vesicle opening externally at the base of a foot. (2) A coiled glandular tube connected with this, and subdivided again into several minor divisions. (3) A short terminal portion opening at one extremity into the coiled tube and at the other, as I believe, into the borly cavity. This section becomes very conspicuous, in stained preparations, by the intensity with which the nuclei of its walls absorb the colonring matter.

In the majority of the Tracheata the excretory organs have the form of the so-called Nalpighian tubes, which always (vide Vol. I.) originate as a pair of outgrow ths of the epiblastic proctod:um. From their mode of development they almit of comparison with the anal vesicles of the Gephyrea though in the present state of our knowledge this comparison must be regarded as somewhat hypothetical.

The antennary and shell-glands of the Crustacea, and possibly also the so-called dorsal organ of varions Crustacean larvæ appear to be excretory, and the two former have been regarded by clans and Grobber as belonging to the sane system as the segmental excretory tubes of the Chatopoda.

Nematoda. Paireal excretory tubes, rmming for the whole length of the body in the so-called lateral line, and opening in front by a common ventral pore, are present in the Nematorla. They do not aplear to communicate witl the body cavity, and their development has not been studied.

Very little is known with reference either to the structure or development of excretory mgans in the Echinodermata and the other Invertebrate types of which no mention has been so far made in this Chapter.

\section{Excretory organs and generative ducts of the Craniata.}

Although it woukl be convenient to separate, if possible, the history of the excretory organs from that of the generative ducts, yet these parts are so closely related in the Vertebrata, in some cases the same duct having at once a generative and a urinary function, that it is not possible to do so.

The excretory organs of the Vertehrata consist of three distinct glandular borlies and of their ducts. These are (1) a small glindular body, nsually with one or more ciliated fimnels opening into the body cavity, near the opening of which there projects into the body cavity a vascular glomernlus. It is situated very far forwards, and is usually known as the head-kidney, though it may perhaps be more suitably called, adopting Lankester's nomenclature, the pronephros. Its duct, which forms the basis for the generative and urinary ducts, will be called the segmentul duct. 
(2) The Wolfian body, which may be also called the mesonephros. It consists of a series of, at first, segmentally (with a few exceptions) arranged glandular canals (segmentul tubes) primitively opening at one extremity by fumnel-shaped apertures into the borly cavity, and at the other into the segmental duct. This duet becomes in many forms divided longitudiually into two parts, one of which then remains attaehed to the segmental tubes and forms the Wrolfian or mesonephric duct, while the other is known as the Mülleriun duct.

(3) The kidney proper or metunephros. This organ is only found in a completely differentiated form in the ammiotic Vertebrata. Its duet is an outgrowth from the Wolftian duct.

The above parts do not coexist in full activity in any living adult nember of the Vertebrata, though all of them are fomd together in certain embryos. They are so intimately connected that they cannot be satisfactorily realt with separately.

Elasmobranchii. The extretory system of the Elasmobranchii is by no means the most primitive known, but at the same time it forms a convenient starting point for studying the modifications of the system in other groups. The most remarkable peculiarity it presents is the absence of a pronephros. The development of the Elasmobranch excretory system has been mainly stulied by Semper and myself.

The first trace of the system makes its appearance as a knob of mesoblast, springing from the intermediate cell-mass near the level of the hind end of the heart (fig. 38.5 A, $m$ ). This knob is the mdiment of the abdominal opening of the segmental duct, and from it there grows backwards to the level of the anus a solid column of cells, which constitutes the rudiment of the segmental duct itself (fig. 38.5, B, $p d)$. The knob projects towarts the epiblast, and the column connected
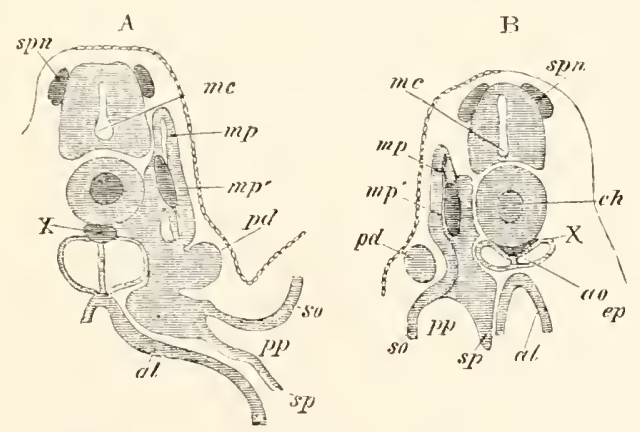

Fig. 385. Two sectioxs of a lristures embrio with three risceral clefts.

The section- illustrate the development of the segmental duct $(p d)$ or primitive duct of the pronepliros. In A (the anterior of the two sections) this appears as a solid linol, ( $p d$ ) projecting towards the epiblast. In B is seen a section of the column which has grown backwards from the knob in $\mathrm{A}$.

spm. rudiment of a spinal nerve; me. medullary eanal; ch. notochord; $X$. subnotochordal rod; $m p$. muscle-plate; $m p^{\prime}$. specially developed portion of muscle-plate; ao. dorsal aorta; $j$. segmental duct; so. somatopleure; sp. splanchnopleure; $p p$. body cavity; $\rho p$. epillast; al. alimentary canal. 
with it lies between the mesoblast and epiblast. The knob and column do not long remain solid, but the former acquires an open-

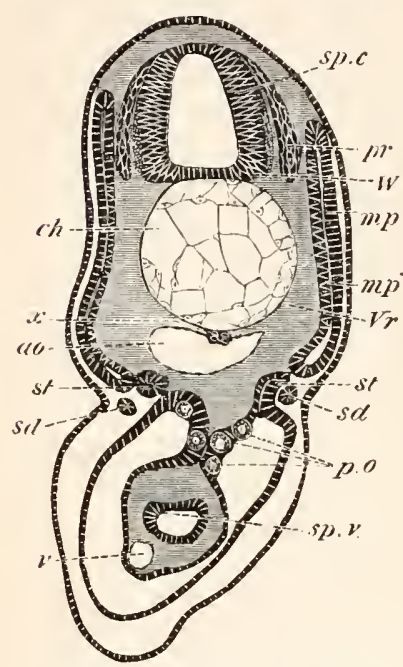

Fig. 386. Section through THE TRUNK OF A SCYLLIUN EMBRYO SLIGHTLY YOUNGER THAX 28 F.

sp.c. spinal canal; W. white matter of spinal cord; $p r$. posterior nerve-roots; $c h$. notochord; $x$. sub-notochordal rod; ao. aorta; mp.muscle-plate; $m p^{\prime}$. inner layer of muscle-plate already converted into muscles ; $V r$. rudiment of vertebral body; st. segmental tube; sd. segmental duct; sp.c. spiralvalve; $v$.subintestinal vein; p.o. primitive generative cells. ing into the body cavity (fig. $421, s d$ ) continuous with a lumen, which makes its appearance in the column (fig. 386, $s d)$. The knob forms the only structure which can be regarded as a rudiment of the pronephros.

While the lumen is gradually being formed, the segmental tubes of the mesonephros become established. They appear to arise as differentiations of the parts of the primitive lateral plates of mesoblast, placed between the dorsal end of the body cavity and the muscle-plate (fig. $386, s t)^{1}$, which are usually known as the intermediate cell-masses.

The lumen of the segmental tubes, though at first very small, soon becomes of a considerable size. It appears to be established in the position of the section of the body cavity in the intermediate cell-mass, which at first unites the part of the body cavity in the muscle-plates with the permanent body cavity. The lumen of each tube opens at its lower end into the dorsal part of the body cavity (fig. $386, s t$ ), and each tube curls obliquely backwards round the inner and dorsal side of the segmental duct, near which it at first ends blindly.

One segmental tube nakes its appearance for each somite (fig. 265), commencing with that immediately behind the abdominal opening of the segmental duct, the last tube being situated a few segments behind the anus. Soon after their formation the blind ends of the segmental tubes come in contact with, and open into the segmental duct, and each of them becomes divided into four parts. These are (1) a section carrying the peritoneal opening, known as the peritoneal funnel, (2) a dilated vesicle into which this opens, (3) a coiled tubulus proceeding from (2), and terminating in (4) a wider portion opening into the segmental duct. At the same time, or shortly before this, each segmental duct unites with and opens into one of

1 In my original account of the development I held these tubes to be invaginations of the peritoneal epithelium. Sedgwick $\left(\mathrm{No}_{0}, 5+9\right)$ was led to doubt the accuracy of my original statement from his investigations on the chick; and from a re-examination of my specimens he arrived at the results stated above, and which I am now myself inclined to adopt. 
the horus of the cloaca, and also retires from its primitive position between the epiblast and mesoblast, and assumes a position close to the epithelium lining the body cavity (fig. $380, s d$ ). The general features of the excretory organs at this period are diagrammatically represented in the woodcut (fig. 387). In this fig. pd is the segmental duct and $o$ its abdominal opening; s.t points to the segmental tubes, the finer details of whose structure are not represented in the diagram. The mesonephros thus forms at this period an elongated gland composed of a series of isolated coiled tubes, one extremity of each of which opens into the body cavity, and the other into the segmental duct, which forms the only duct of the system, and communicates at its front end with the body cavity, and behind with the cloaca.

'The next important change concerns the segmental duct, which becomes longitudinally split into two complete ducts in the female, and one complete duct and parts of a second duct in the male. The manner in which this takes place is diagrammatically represented in fig. 387 bv the clear line $x$, and in transverse section in figs. 388 and 389 . The resulting ducts are (1) the Wolffian duct or mesonephric duct $(w d)$, dorsally, which remains continuous with the excretory tubules of the mesonephros, and ventrally $(\stackrel{2}{)})$ the oviduct or Miillerian duct in the female, and the rudiments of this duct in the male. In the
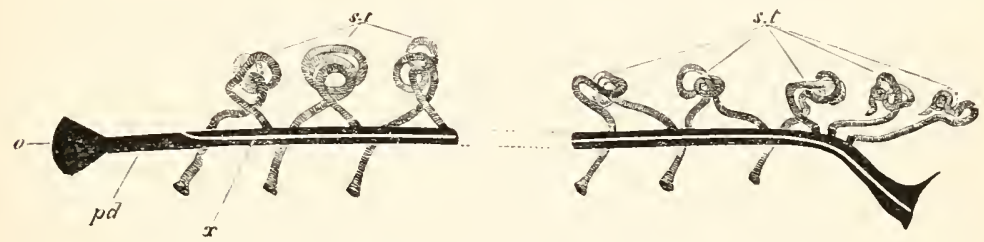

Fla. 387. Dhagrai of the primitive condition of the kidNey iN aN ELASMOBRAXCh EMBRYo.

$p d$. segmental duct. It opens at $o$ into the body cavity and at its other extremity into the cloaca; $x$. line along which the division appears which separates the segmental duct into the Wolffian duct above and the Müllerian duct below; s.t. segmental tubes. They open at one end into the body cavity, and at the other into the segmental duct.

female the formation of these ducts takes place (fig. 3s9) by a nearly solid rod of cells being gradually split off from the ventral side of all but the foremost part of the original segmental duct. This nearly solid cord is the Muillerian duct $(o d)$. A very small portion of the lumen of the original segmental duct is perhaps continued into it, but in any case it very soon acquires a wide lumen (fig. $39.9 \mathrm{~A}$ ). The anterior part of the segmental luct is not divided, but remains continuous with the Miillerian duct, of which its anterior pore forms the permanent peritoneal opening ${ }^{1}$ (fig. 387 ). The remainder of the seg-

1 Five or six segmental tubes belong to the region of the undivided anterior part of the segmental duct, which forms the front end of the Miillerian duct: but they appear to atrophy very early, without acquiring a definite attachment to the segmental duct. 
mental duct (after the loss of its anterior section, and the part split off from its ventral side) forms the Wolffian luct. The process of

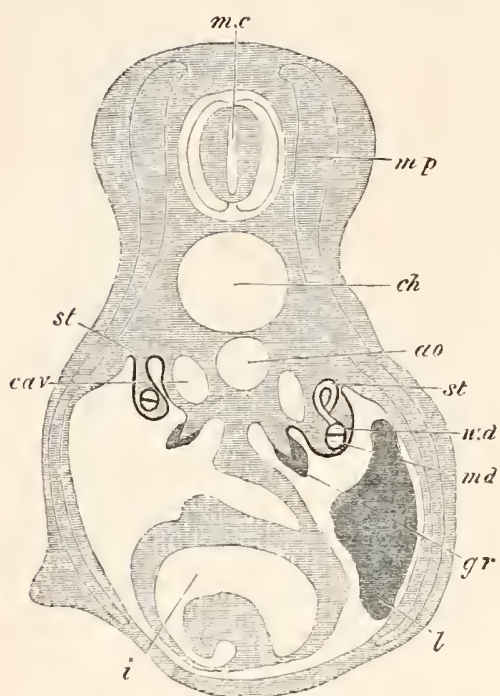

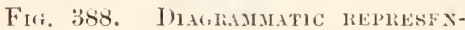
TATION OF A TRAXSUERE SECTION OF A SCYLLITM EMBRYO ILLTSTRATIXG THE FOIMation or THE WOLFian AXI MÜLlerias DUCTS IY THE LONGITTDINAL SPLITTIXG OF THE SE(BMENTAL Uイ'T.

me. melullary canal; mp. muscleplate; ch. notochord; ro. aorta; cor. cardinal vein; st. segmental tube. On the left side the section passes through the opening of a segmental tube into the body cavity. On the light this opening is represented by dotted lines, and the opening of the segmental tube into the Wolftian dnet has lyeen cut through; $w . d$. Wolffian duct: m.l. Miillerian duct. The section is taken through the point where the segmental duct and Wolftian duct have just bccome scparate; yr. the germinal vi gre with the thickencd germinal epithelinu; $l$. liver ; $i$. intestine with spiral valve.
A.

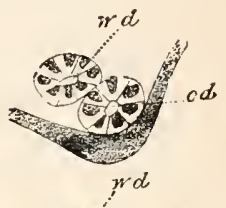

B.

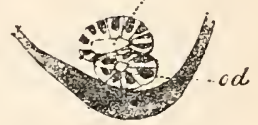

C.

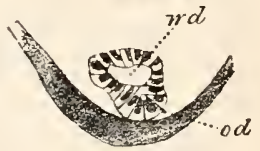

11.

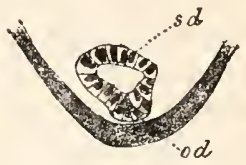

Fir. 38!\%. Fotr sectioss TIIROUGH TIE AXTEIIOR PAIT WF THE SEGMENTAL WUCT OF A F ZMALE EMBTYO OF ŚCYLIITM ('ANICULA.

The figure sliews bow the segmental duct becomes split into the Wolffian or mesoneplric duct above, and Mïllerian duct or oviduct below.

w. Wolfian or mesonephric duct; od. Müllerian duct or oviduct ; sil. segmental duct.

formation of these ducts in the male differs from that in the female chiefly in the fact of the anterior undivited part of the segmental duct, which forms the front end of the Miillerian duct, being shorter, and in the column of cells with which it is continuous being from the first incomplete.

The segmental tubes of the mesonephros undergo further important changes. The vesicle at the termination of each peritoneal funnel sends a bul forwards towards the preceding tubulus, 
which joins the fourth section of it close to the opening into the Wolffian duct (fig. $390, p x$ ). 'The remainder of the vesicle becomes converted juto a Mapighian borly $(m g)$. By the tirst of these changes a tuhe is established comnecting each pair of segments of the nesonephros, and though this tube is in part aborted (or only represented by a fibrous band) in the anterior part of the excretory organs in the alult, and most probably in the hinder part, yet it seens almost certain that the secondary and tertiary Malpighian bodies of the majority of segments are developed from its persisting blind end. Each of these secondary and tertiary Malpighian bodies is connecter with a convoluted tubulus (fig. 391 ( $m y$ ), which is also developed from the tube commecting

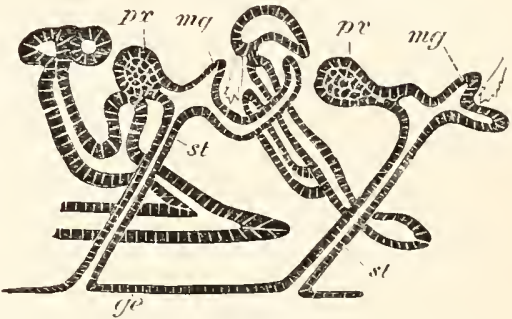

Fig. 390. Lox'HTLINAL VERTICAL SECTION THROUGH PART OF THE HESONEPHROS OF AN Eubryo of Scrluium.

The figure contains two examples of the budding of the vesicle of a segmental tube (which forms a Malpighian body in its own segment) to unite with the tubulus in the preceding segment close to its opeuing into the Wolffian (mesonephric) duct.

ge. epithelium of body-cavity; st. peritomeal fumel of segmental tube with its peritoneal opening; my. Malpighian body; p.x. bud from Malpighian body uniting with preceding segment. each pair of segmental tubes, and therefore falls into the primary tubulus close to its junction with the segmental duct. Owing to the formation of the access ry tubuli the segments of the mesonephos acquire a compound character.

The third seetion of each tubulus becomes by continuous growth, especially in the hinder segments, very bulky and convoluted.

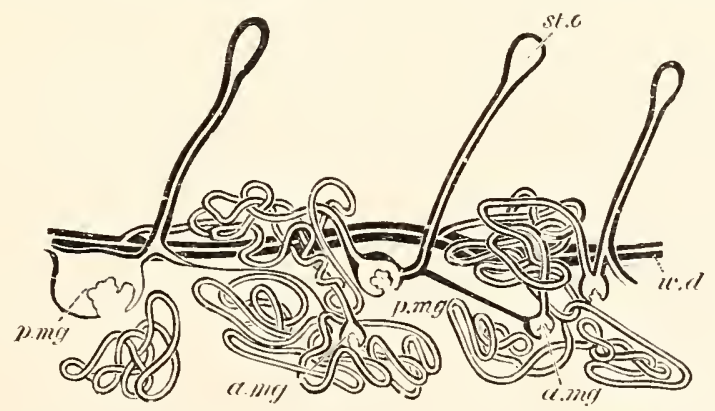

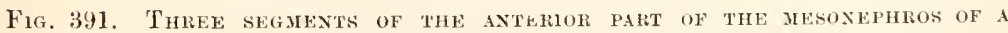
NEARLY RIPE EMBRYo OF SCYLliUM CANICULA AS A TRANSPARENT OBJEcT.

The figure shews a fibrous band passing from the prinary to the secondaly Malpighian bodies in two segments, which is the remains of the outgrowtl from the primary Malpighian body.

st.o. peritoneal funnel; $p . m g$. primary Malpizhian boly;, .mg. accessory Malpirhian body; $x, d$. mesonephric (Wolftian) duct. 
The general character of a slightly developed segment of the mesonepliros at its full growth may be gathererl from fig. 391. It commences with (1) a peritoneal opening, somewhat oval in form (st.o) and leading directly into (2) a narrow tube, the segmental tube, which takes a more or le:s oblique course backwards, and, passing superficially to the Wolfinan duct $(w . d)$, opens into (3) a Malpighian body ( $p . m g)$ at the anterior extremity of an isolated coil of glandular tubuli. This coil forms the third section of each segment, and starts from the Malpighian body. It consists of a considerable number of rather definite convolutions, and after miting with tubuli from one, two, or more (according to the size of the segment) accessory Malpighian bodies $(a . m g)$ sinaller than the one into which the segmental tube falls, eventually opens by (t) a narrowish collecting tube into the Wolffian duct at the posterior end of the segment. Each segment is probably completely isolated from the arljoining segments, and never has more than one peritoneal fumel and one communication with the IVolffian duct.

Up to this time there has been no distinction between the anterior and posterior tubuli of the mesonephros, which alike open into the Wolffian duct. The collecting tubes of a considerable number of the hindermost tubuli (ten or eleven in Scyllium canicula), either in some species elongate, overlap, and eventually open by apertures (not usually so numerous as the separate tubes), on nearly the same level, into the limdermost section of the Woltian duct in the female, or into the urinogenital cloaca, formed by the coa'esced terminal parts of the Wolffian ducts, in the male; or in other species become modified, by a peculiar process of splitting from the Wolftian duct, so as to pour their secretion into a single duct on each side, which opens in a position corresponding with the numerous ducts of the other species (fig. :392). In both cases the modified posterior kidney-segments are probably equivalent to the permanent kidney or metanephros of the amniotic Vertebrates, and for this reason the numerous collecting tubes or single collecting tube, as the cave may be, will be spoken of as ureters. The anterior tubuli of the prinitive excretory organ retain their early relation to the Wolffian duct, and form the permanent Wolftian body or mesonephros.

The originally separate terminal extremities of the Wolffian ducts always coalesce, and form a urinal cloaca, opening by a single aperture, situated at the extrernity of the median papilla behind the anus Some of the peritoneal openings of the segmental tubes in Scyllium, or in other cases all the openings, become obliterated.

In the male the anterior segmental tnbes undergo remarkable modifications, and become connected with the testes. Branches appear to grow from the first three or four or more of them (though probably not from their peritoneal openings), which pass to the base of the testis, and there uniting into a longitudinal canal, form a network, and receive the secretion of the testicular ampull:e (fig. $393, n t)$. 'These ducts, the vasa efferentia, carry the semen to the 
Wolffian body, but before opening into the tubuli of this body they unite into a canal known as the longitudinal canal of the It olftian body (l.c), from which pass off ducts equal in number to the vasa efferentia, each of which normally ends in a Malpighian corpusele. From the Malpighian corpuscles so comnected there spring the convoluted tubuli, forming the generative segments of the Wolffian borly, along which the semen is conveyed to the Wolffian duct $(c \cdot d)$. The Wolffian duct itself becomes much contorted and acts as vas deferens.

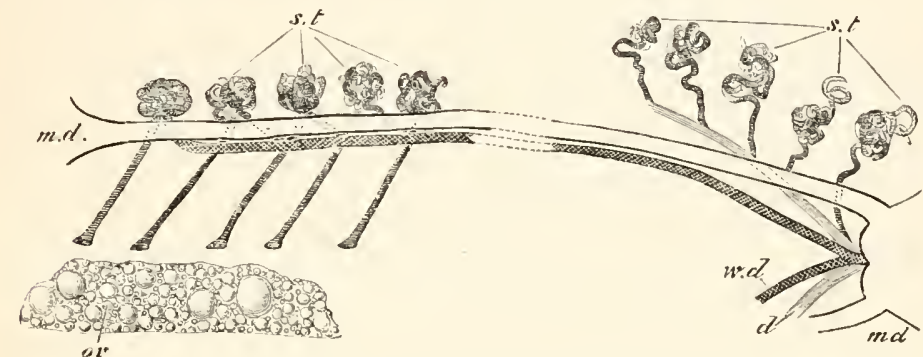

Fig. 392. Diagray of the arkangement of the urinogenital organs in aN aDUlt Femala Elasiobranch.

m.d. Müllerian duct; w.d. Wolffian duct; s.t. segmental tubes; five of them are represented with openings into the body cavity, the posterior segmental tubes form the mesonephros; ov. ovary.

Figs. 392 and 393 are diagrammatic representations of the chief constituents of the adult urinogenital organs in the two sexes. In the adult female (fig. 392), there are present the following parts :

(1) The oviduct or Miillerian duct (m.d) split off from the segmental duct of the kidneys. Each oviduct opens at its anterior extremity into the body-cavity, and behind the two oviducts have independent communications with the general cloaca.

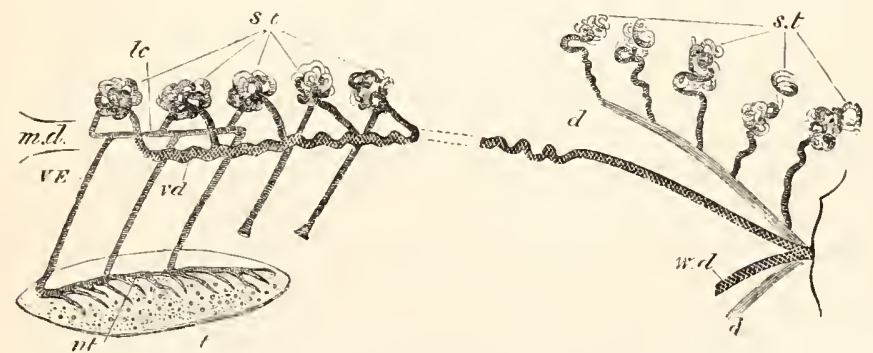

Fig. 393. Diagram of the arrangenent of the urivogental organs iN an adult male Elashobranch.

m.d. rudiment of Müllerian duct; w.d. Wolffian duct, marked $v d$ in front and serving as vas deferens; s.t. segmental tubes; two of them are represented with openings into the body cavity; $d$. ureter; $t$. testis; $n t$. canal at the base of the testis; $V F$. vasa efferentia; $1 c$. longitudinal canal of the Wolffian body. 
(2) The mesonephric ducts $(w . d)$, the wther product of the segmental ducts of the kidneys. They end in front by becoming continuous with the tubulus of the anterior persisting segment of the mesonephros on each side, and unite behind to open by a common papilla into the cloaca. The mesonephric duct receives the secretion of the anterior tubuli of the primitive mesonephros.

(3) The ureter which carries otf the secretion of the kidney proper or metanephros. It is represented in my diagram in its must rare and differentiated condition as a single duct connected with the posterior segmental tubes.

(4) The segmental tules (s.t) some of which retain their original openings into the body cavity, and others are without them. 'They are divided into two gromps, an anterior forming the mesonephros or Wolffian body, which pours its secretion into the Wolftian duct; and a posterior group forming a gland which is probably equivalent to the kidney proper of anmiotic Craniata, and is comnected with the ureter.

In the male the following parts are present (fig. :39:3):

(1) The Mïllerian duct (m.d), consisting of a small ruliment attached to the liver, representing the foremost end of the oviduct of the female.

(2) The mesoneplnic duct (u.d) which precisely corresponds to the mesonephric duct of the fenale, but, in addition to serving as the duct of the Wolffian body, also acts as a vas deferens $(c d)$. In the adult male its foremost part has a very tortuous course.

(3) The ureter $(d)$, which has the same fundamental constitution as in the female.

(t) The segmental tubes (s.t). The posterior tubes have the same arrangement in both sexes, but in the male modifications take place in connection with the anterior tubes to fit them to act as transporters of the semen.

Connecterl with the anterior tubes there are present (1) the vasi efferentia ( $\left.I^{\prime} E^{\prime}\right)$, united on the one hand with (2) the central canal in the base of the testis $(n t)$, and on the other with the longitudinal canal of the Wolffian body $(l c)$. From the latter are seen passing off the successive tubuli of the anterior segments of the Wolffian bodv, in comnection with which Malpighian bodies are typically present, though not represented in my diagram.

Apart from the absence of the pronephros the point; which deserve notice in the Elasmobranch excretory system are (1) 'The splitting of the segmental duct into Wolffian (mesonephric) and Miillerian ducts. (2) The connection of the former with the mesonephros, and of the latter with the abdoninal opening of the segmental duct which represents the pronephros of other types. (3) The fact that the Miillerian duct serves as oviduct, and the Wolffian duct as vas deferens. (4) The differentiation of a posterior section of the mesonephros into a special gland forechadowing the metanephros of the Ammiota. 
Cyclostomata. The development of the excretory system amongst the Cyclostomata has only been studied in Petromyzon (Miiller, Fiirbringer, and Scott).

The first part of the system developed is the segmental duct. It appears in the embryo of about 14 days (Scott) as a solid cord of cells, differentiater from the somatic mesoblast near the dorcal end of the body cavity. T'his cord is at first placed immediately below the epiblast, and grows backwarls by a continuous process of differentiation of fresh mesoblast cells. It soon acyures a lumen, and joins the cloacal section of the alimentary tract before the close of foetal life. Before this communication is established, the front end of the duct sends a process towards the body cavity, the blind end of which acquires a ciliated opening into the latter. A series of abont four or five successively formed untgrowths from the duct, one behind the other, give rise to as many ciliated fumnels opening into the borly cavity, and each communicating by a more or less elongated tube with the segmental duct. These funnels, which have a metameric arrange ment, constitute the pronephros, the whole of whicin is situated in the pericardial region of the body cavity.

On the inner side of the peritoneal openings of each pronephros there is formed a vascular glomerulus, projecting into the bodycavity, and covered by peritoneal epithelium. For a considerable period the pronephros constitutes the sole functional part of the excretory system.

A mesonephros is formed (Fürbringer) relatively late in larval life, as a segmentally arranged series of solid cords, derived from the peritoneal epithelium. These cords constitute the rudiments of the segmental tubes. They are present for a considerable portion of the body cavity, extending backwards from a point shortly behind the pronephros. They soon separate from the peritoneal epithelimm, become hollowed out into canals, and join the segmental duct. At their blind extremity (that originally connected with the peritoneal epithelium) a Malpighian body is formed.

The pronephros is only a provisional excretory organ, the atrophy of which commences during larval life, and is nearly completed when the Ammocote has reached $180 \mathrm{~mm}$. in length. Further changes take place in comnection with the excretory system on the conversion of the Ammocate into the adult.

The segmental ducts in the adult fall into a common urinogenital cloaca, which opens on a papilla behind the anus. 'This cloaca also communicates by two apertures (abdominal pores) with the body cavity. The generative products are carried into the cloaca by these pores; so that their transportation outwards is not performed by any part of the primitive urinary system. The urinogenital cloaca is formed by the separation of the portion of the primitive cloaca containing the openings of the segmental ducts from that connected with the alimentary tract.

The mesonephros of the Ammocote undergoes at the meta-

l. F. II. 
morphosis complete atrophy, and is physiologically replaced by a posterior series of segmental tubes, opening into the hindermost portion of the segmental duct (Schneider).

In Myxine the excretory system consists (1) of a highly developed pronephros with a bunch of ciliated peritoneal funnels opening into the pericardial section of the body cavity. The coiled and branched tubes of which the pronephros is composed open on the ventral side of the anterior portion of the segmental duct, which in old imliviluals is cut off from the posterior section of the duct. On the dorsal side of the portion of the segmental duct belonging to the pronephros there are present a small number of diverticula, terminating in glomeruli : they are probably to be regarded as anterior segmental tubes. (2) Of a mesonephros, which coumences a considerable distance behind the pronephros, and is formed of straight extremely simple segmental tubes opening into the segmental duct (fig. 385).

The excretory system of Myxine clearly

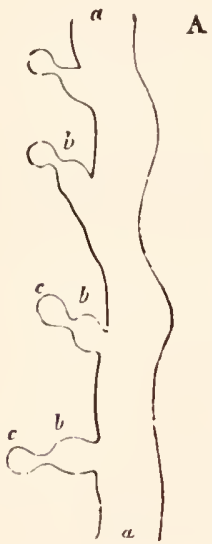

B

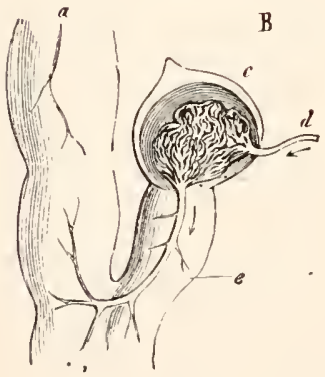

Fig. 3\%4. Portions of the Mesonephros of Mrxine. (From (iegenbaur; after J. Müller.)

$a$. segmental duct; $b$. seomental tube; $c$. glomerulus; $d$. afferent, ค. efferent artery.

$B$ represents a portion of $A$ highly magnified. retains the characters of the system as it exists in the larva of Petronizzon.

Teleostei. In most Teleostei the pronephros and mesonephros cuexist through life, and their products are carried off by a duct, the nature of which is somewhat doubtfurl, but which is probably homologons with the mesonephric duct of other types.

The system commences in the entbryo (Rosenberg, Oellacher, Götte, Fiirbringer) with the formation of a groove-like fold of the somatic layer of peritoneal epithelium, which becomes gradually constricted into a canal; the process of constriction commencing in the middle and extending in both directions. The canal does not however close anteriorly, but remains open to the borly cavity, thus giving rise to a firnnel equivalent to the pronephric fumnels of Petromyzon and Myxine. On the inner side of this fumnel there is formed a glomerulus, projecting in to the body cavity; aud at the same time that this is being formed the anterior end of the canal becomes elongated and convoluted. The above structures constitute a pronephros, while the posterior part of the primitive canal forms the segmental durct.

The portion of the body cavity with the glomerulus and peritoneal fimmel 
of the pronephros (fig. $395, \mathrm{j}$, o) soon becomes completely isolated from the remainler, so as to form a closed cavity $(g l)$. The development

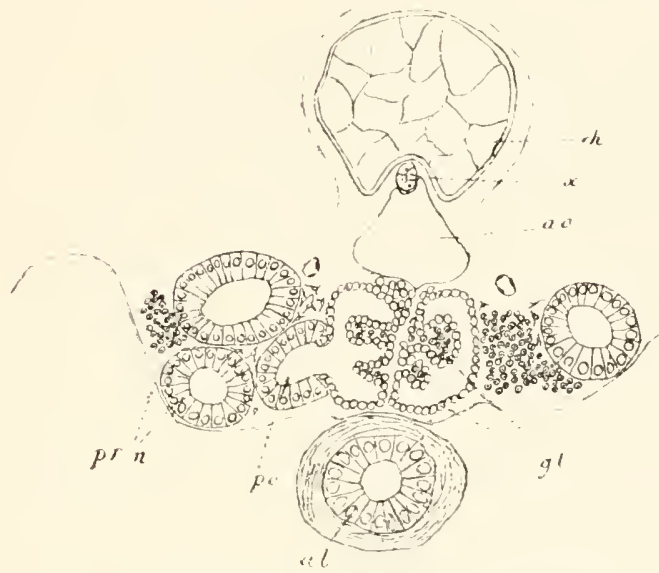

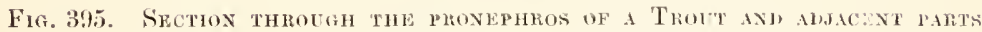
TEN DAYS BEFORE HATEHING.

pr.u. pronephros; wo. opening of pronephros into the isolated portion of the lody eavity containing the glomerulus; gl. glomerulus; al. anta; rh. notochord; $x$ subnotochordal rod; $a l$. alimentive trart.

of the mesonephros does not talke place till long after that of the pronephros. The segmental tubes which form it are stated by Firbringer to arise from solid ingrowths of peritoneal epithelium, developed successively from before backwards, hut Sedgwick informs me that they arise as differentiations of the mesoblastic cells netr the peritoneal epithelium. They soon become hollow, and mite with the sermental duct. Malpighian bodies are developerl on their median portions. They grow very greatly in length, and become much convoluted, but the letails of this process have not been followerl out.

The foremost segmental tubes are situated close behind the pronephros, while the hindermost are in many cases developed in the postanal continuations of the body cavity. The pronephos appears to form the swollen cephalic portion of the kidney of the adult, and the mesonephros the remainder; the so-called candal portion, where present, being derived (?) from the postanal segmental tubes.

In some cases the cephalic portion of the kidneys is absent in the adult, which probably implies the atrophy of the pronephos; in other instances the cephatic portion of the kidneys is the only part developed. Its relation to the embryonic pronephos requires however further elucidation.

In the adult the ducts in the lower part of the kidneys lie as a rule on their onter borkers, and almost invariably open into a urinary bladerer, which usually opens in its turn on the mringenital 
papilla immediately belind the genital pore, but in a few instances there is a common urinogenital pore.

In most Osseous Fish there are true generative ducts continuous with the investment of the generative organs. It appears to me most probable, from the analogy of Lepidosteus, to be describer in the next section, that these ducts are split off from the primitive segmental duct, and correspond with the Miillerian ducts of Elasmohranchii, etc.; though on this point we lave at present no positive embrvolugical evidence (vide general considerations at the end of the Chapter). In the female Samon and the male and female Eel the generative products are carried to the exterior by ablominal pores. It is possible that this may represent a primitive condition, though it is more probably a case of degeneration, as is indicated by the presence of ducts in the male Salmon and in forms nearly allied to the Salmonidx.

The coexistence of alxhminal pores and generative ducts in Mormyrus appears to me to demonstrate that the generative ducts in Teleostei camnot be derived from the coalescence of the investment of the generative organs with the abdominal pores.

Ganoidei. The true excretory gland of the actult Ganoidei resembles on the whole that of Tele-

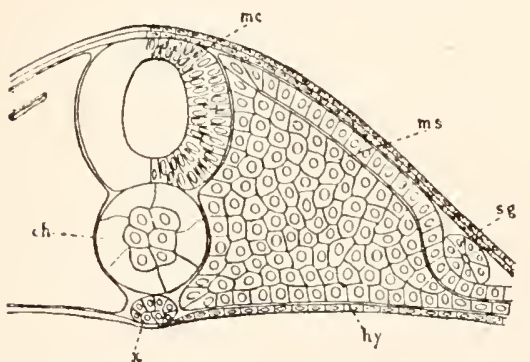

Fif. 396. SECTION THROCGH THE TRT:NK of a Lepidosteus EMBRY ON THE SIXTH DAY AFTER IMPREGNATION.

mc. medullary cord; ms. mesoblast; $s \%$. segmental duct; $c h$. notochord; $x$. subnotochordal rod; hy. hypoblast. ostei, consisting of an elongated band ou each side-the mesonephros-an anterior dilatation of which probably represents the pronephros.

There is in botl sexes a Miillerian duct, provided, except in Lepidosteus, with an abdominal funnel, which is however situated relatively very far back in the abdominal cavity. The Mällevian ducts appear to serve as generative canals in both seres. In Lepidosteus they are continuous with the investment of the generative glands, and thus a relution between the generative ducts and glands, very similar to that in Teleostei, is brought about.

Posteriorly the Millerian ducts and the ducts of the mesonephros remain united. The common duct so formed on each side is clearly the primitive segmental duct. It receives the secretion of a certuin number of the posterior mesonephric tubules, and usually unites with its fellow to form a kind of bladder, opening by a single pore into the cloaca, behind the anus. The duct which receives the secretion of the anterior mesonephric tubules is the true mesonephric or Wolffian duct.

The development of the excretory system, which has been 
partially worked ont in Acipenser and Lepidostens ${ }^{1}$, is on the whole very similar to that in the Teleostei. The first portion of the

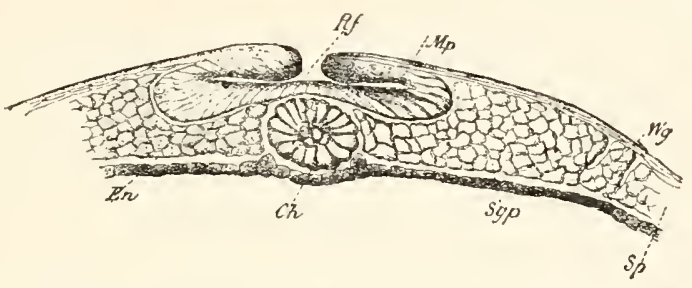

Fig, 397. Traxsverse section through the axterior patt of ax Acipexser kimpro. (After Salensky.)

Ri. medullary groove; $I_{p}$. medullary plate; H\% segmental duct; Ch. notochord; En. hypoblast; Sglp. mesublastic somite; Sp. parietal part of mesoblastic plate.

system to be formed is the segmental duct. In Lepilosteus this duct is formed as a groove-like invagination of the somatic peritoneal epithelium, precisely as in 'Teleostei, and shortly afterwards forms a duct lying between the mesoblast and the epillast (fig. $396(6, s g$ ). In Acipenser (Salensky) however it is formed as a solid ridge of the somatic mesoblast, as in Petromyzon and Elasmobranchii (fig. 397, $W g)$.

In both forms the ducts unite behind with the cloaca, and a pronephros of the Teleostean type appears to be developed. 'This gland is provicled with but one" peritoneal opening, which together with the glomerulus belonging to it becomes encapsuled in a special section of the body cavity. The opening of the pronephros of Acipenser into this cavity is shewn in fig. $39 \mathrm{~S}, \mathrm{pr} \cdot \mathrm{n}$. At this early stage of Acipenser (larva of $5 \mathrm{~mm}$.) I could find no glomernlus.

The mesonephros is formed some distance behind, and some time after the pronephros, both in Acipenser and Lepilosteus, so that in the larva of both these genera the pronephros is for a consilerable period the only excretory organ. In Lepirlostens especially the development of the mesonephros occurs very late.

The development of the mesonephros has not been worked out in Lepidostens, but in Acipenser the anterior segmental tubes become first established as (I believe) solid cords of cells, attached at one extremity to the peritoneal epithelium on each side of the insertion of the mesentery, and extending upwards and outwards round the segmental duct ${ }^{3}$. The posterior segmental tubes arise later than the anterior, and (as far as can be determined from the sections in my possession) they are formed independently of the peritoneal epithelium, on the dorsal side of the segmental duct.

1 Acipenser has been investigated by Fürbringer, Salensky, Sedgwick, and also by myself, and Lepidosteus by W. N. Parker and myself.

2 I have not fully proved this point, but have never found more than one opening.

${ }^{3}$ Whether the segmental tubes are formed as ingrowths of the peritoneal epithelium, or in situ, could not he determined. 
In later stages (larve of $7-10 \mathrm{~mm}$.) the anterior segmental tubes gradually lose their attachment to the peritoneal epithelium. The extremity near the peritoneal epithelium forms a Malpighian borly, and the other end unites with the segmental duct. At a still later stage wide peritoneal funnels are established, for at any rate a considerable number of the tubes, learling from the body cavity to the Malpighian bodies. These funnek have been noticed by Fiirbringer, Salensky and myself, but their mode of development has not, so far as I know, been male out. The fnumels appear to be no longer present in the adult. The development of the Müllerian ducts has not been worked out.

Dipnoi. The rxcretory system of the Dipnoi is myly known in the

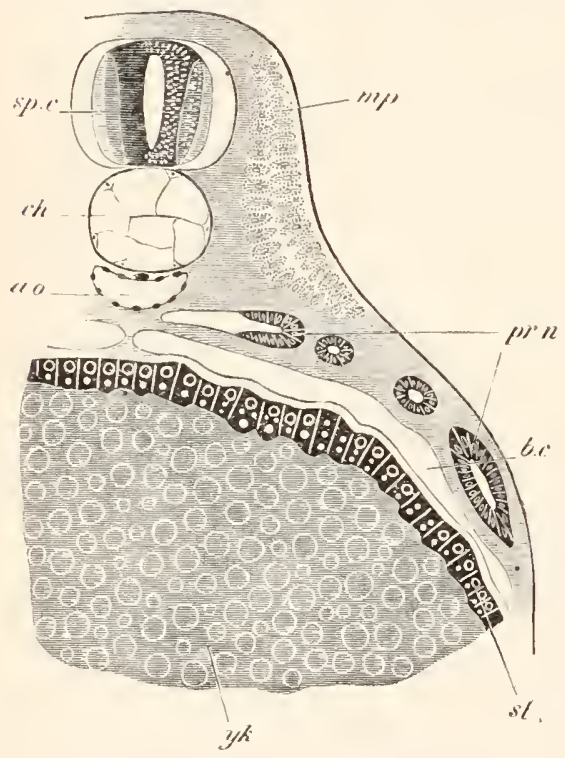

Fig. 398. Transverse sectiox throvgh THE REGLON OF THE STONACH OF A LARVA OF AchPEXSER 5 MA. IN LEXGTH.

st. epithelium of stomach; $y k$. yolk; $r h$. notochord, below which is a subnotochordal roll; $p r . n$. pronephros; ao. aorta; mp. muscleplate formed of large cells, the outer parts of which are differentiated into contractile filmes; sp.c. spinal cord; b.c. body cavity. arlult, but though in some respects intermediate in character. between that of the Cimoidei and Amplibia, it resembles that of the Ganoidei in the important feature of the Miillerian ducts serving as genital ducts in both sexis.

Amphibia. In Amphibia (Götte, Fiirloringer) the development of the excretory system commences, as in Teleostei, by the formation of the segmental duct from a groove formed by a fold of the sonatic layer of the peritoneal epithelimm, near the dorsal border of the borly cavity (fig. 399, u). The anterior end of the groove is placed immediately behind the branchial region. Its posterior part snon becomes converted into a canal by a constriction which commences a short way from the front end of the groove, and thence extends backwards. 'This canal at first ends blindly close to the cloaca, into which however it soon opens.

The anterior open part of the groove in front of the constriction (fig. 399, u) becomes differentiated into a longitudinal duct, which remains in open communication with the body cavity by two (many Uromela) three (many Aurra) or fonr (Coecilidie) canals. This constitutes the dorsal part of the pronephros. The ventral part of the 
gland is formed from the section of the duct immediately behind the longitudinal canal. This part grows in length, and, assuming an S-shaped curvature, becomes placed on the ventral side of the first formed part of the pronephros. By continuous growth in a limited space the convolutions of the canal of the pronephros becone more numerous, and the complexity of the gland is firther increased by the outgrowth of blindly ending diverticula.

At the root of the mesentery, opposite the peritoneal openings of the pronephros, a longitudinal fold, lined by peritoneal epithelium, and attached by a narrow band of tissue, makes its appearance. It soon becomes highly vascular, and constitutes a glomerulus homologous with that in Petromyzon and Teleostei.

The section of the body cavity which contains the openings of the pronephros and the glonernlus, becomes dilated, and then temporarily slrut off from the remainder. At a later period it forms a special though not complete!y isolated compartment. For a long time the pronephros and its duct form the only excretory organs of larval Amphibia. Eventually however the formation of the mesonephros commences, and is followed by the atrophy of the pronephros. The mesonephros is conposed, as in other types, of a series of segmental tubes, but these, except in Cociliidat, no longer correspond in number with the myotomes, but are in all instances more numerous. Morcover, in the posterior part of the mesonephros in the Urodeles, and through the whole length

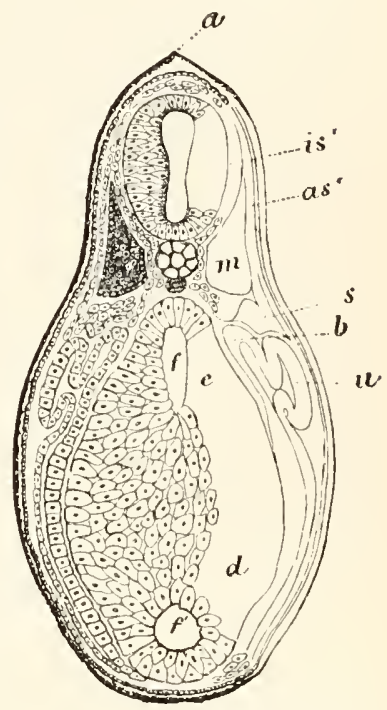

Fi(3. 3:49. Transverse secTION THROUGH A VERY YOUNG TAIPOLE OF BoMbINATOR at THE LEVEL OF THE AVTERTOR END OF THE roLk-sack. (After Götte.)

a. fold of epiblast continuous with the dorsal fin; $i s^{x}$. neural cord; $m$. lateral muscle; $a s^{\mathrm{x}}$. onter layer of muscle-plate; s. lateral plate of mesoblast; $b$. mesentery; $u$. open end of the segmental duct, which forms the pronephros; $f$. alimentary tract; $f^{\prime}$. ventral diverticulum which becomes the liver; $e$. junction of yolk cells and hypoblast cells; $d$. yolk cells. of the gland in other types, secondary and tertiary segmental tubes are formed in addition to the primary tubes.

The development of the mesonephros commences in Salamandra (Fiirbringer) with the formation of a series of solid cords, which in the anterior myotomes spring from the peritoneal epithelium on the inner side of the segmental duct, but posterionly arise independently of this epithelium in the redjoining mesoblast. Sedgwick informs me that in the Frog the segmental tubes are throughout developed in the mesoblast, independently of the peritoneal epithehium. These cords next become detached from the peritoneal epithelium (in so far as they are primitively united to it), and after first assuming a vesicular form, grow out into coiled tulhes, with a median 
limb the blind end of which assists in forming a Malyighian body, and a lateral limb which comes in contact with and opens into the segmental duct, and an intermediate portion connecting the two. At the junction of the median with the intermediate portion, and therefore at the neck of the Malpighian body, a canal grows out in a ventral direction, which meets the peritoneal epithelium, and then develops a funnel-shaped opening into the body cavity, which sulsequently becomes eiliated. In this way the peritoneal funnels which are present in the adult are establisherl.

The median and lateral sections of the segmental tubes become highly convoluted, aud the separate tubes soon come into such close proximity that their primitive distiuctness is lost.

The first fully developed segmental tube is formed in Salamandra maculata in about the sixth myotome behind the pronephiros. But in the region betwcen the two structures rudimentary segmental tubes are developed.

The number of primary segmental tubes in the separaie myotomes of Salamancha is as follows :

In the 6 th myotome (i.e. the first with a true

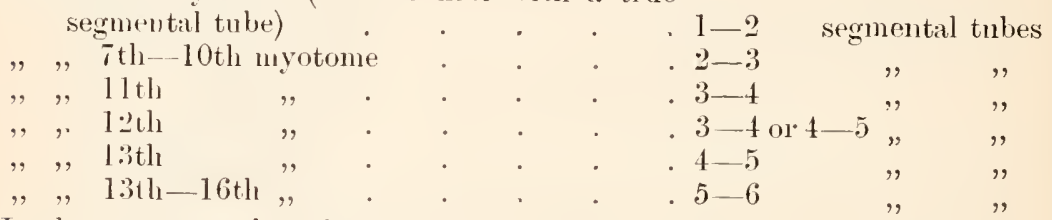

It thus appears that the segmental tubes are not only more numerous than the nyotomes, but that the number in each myotome increases from before backwarts. In the case of Salamandra there are formed in the region of the posterior (10-16) myotomes secondary, tertiary, etc. segmental tubes out of independent solid cords, which arise in the mesoblast dorsally to the tubes already established.

The secondary segmental tubes appear to develop out of these cords exactly in the same way as the primary ones, except that they do not join the segmental duct directly, but unite with the primary segmental tubes shortly before the junction of the latter with the segmental duct. In this way compound segmental tubes are established with a common collecting tube, but with numerous Malp,ighian bodies and ciliated peritoneal openings. The difference in the mode of origin of these compound tubes and of thove in Elasmobranchii is rery striking.

The later stages in the development of the segmental tubes have not been studied in the other Amphibian types.

In' Crecilidide the earliest stages are not known, but the tubes present in the aduit (spengel) a truly segmental arrangement, and in the young each of them is single, and provided with only a single peritoneal funnel. In the adult however many of the segmental organs hecome compound, and may have as many as twenty funnels, etc. Both simple and compound segmental tubes occur in all parts of the mesonephros, and are arranged in no definite order.

In the Anura (Spengel) all the segmental tubes are compound, and an enormous number of peritoneal funnels are present on the ventral surface, hut it has not yet heen definitely determined into what part of the segmental tules they open. 
Before dealing with the finther changes of the Wolffian body it is necessary to return to the segrnental duct, which, at the time when the pronephros is underguing atrophy, becomes split into a dorsal Wolffian and vential Miillerian duct. The process in Salamandra (Fiirbringer) has much the same character as in Elasmobranchii, the Miallerian duct being formed by the gradual separation, from before backwards, of a solicl row of cells from the ventral side of the sermental duct, the remainder of the duct constituting the Wolffian duct. During the formation of the Mibillerian duet its anterior purt becomes hollow, and attaching itself in front to the peritoneal epithelium acpuires an opening into the body eavity. The process of h.llowing is continued back wards pari passu with the splitting of the segmental duct. In the female the process is continued ti'l the Miillerian duct opens, close to the Wolffian dnet, into the cloaca. In the male the dnct usually ends blindly. It is inmportant to notice that the abdominal opening of the Hiillerian dinct in the Amphibia (Salamandra) is a formation independent of the pronephros, and placed slightly behind it; and that the undivided anterior part of the segnental duct (with the pronephros) is not, as in Elasmobranchii, uniter with the Mibllerian duet, but remains connected with the Wolftian duct.

The development of the Miillerian durt has not heen satisfactmily studied 'in other forms besides salamaudra. In C'œciliide its abdominal opening is on a level with the anterior ent of the Wolffim borly. In other forms it is ustually placed very far torwards, close to the root of the lungs (except in Proteus and Batrachoseps, where it is placed somewhat further back), and some distance in front of the Wolftian body.

The Miillerian duct is always well developer in the female, and serves as oviduct. In the male it does not (except possibly in Alytes) assist in the transportation of the genital prolucts, and is always more or less rondimentary, and in Anura may be completely absent.

After the formation of the Hiillerian luct, the Wolffian duct remains as the excretory channel for the Wolffian body, and, till the atrophy of the pronephros, for this gland also. Its anterior section, in front of the Wolftian body, undergoes a more or less complete atrophy.

The further changes of the excretory system concem /1) the junction in the male of the anterior part of the Wolffian body with the testis; (2) certain changes in the collecting tubes of the posterior part of the mesonephros. The first of these processes results in the division of the Wolffian borly into a rexual and a non-sexual part, and in Salamandra and other Urodeles the division corresponds with the distribution of the simple and compound segmental tubes.

Since the development of the canals connecting the testes with the sexual part of the Wolffian body has not been in all points satisfactorily elucidated, it will be convenient to conmence with a deseription of the adult arrangement of the parts (fig. $4(00 \mathrm{~B}$ ). In most instances a non segmental spotem of malnals-the vasa efferentia 
(ve) - coming from the testis, fall into a canal known ats the longitudinal canal of the Wolftian body, from which there pass off transverse canals, which fall into, and are equal in number to, the primary Malpighian bodies of the sexual part of the gland. The spermatozoa, brought to the Mrlpighian bodies, are thence transported along the segmental tubes to the Wolffian duct, and so to the exterior. The system of canals connecting the testis with the Malpighian bodies is known as the testicular network. The number of segmental tubes connected with the testis varies very greatly. In Siredon there are as many as from 30-32 (spenge!).

The longitudinal canal of the Wolftian body is in rare instances (Spelerpes, etc.) alssent, where the sexual part of the Wolftian boty is slightly developed. In the Urodela the testes are minter with the anterior part of the Wolffian body. In the Ceciliida the junction takes place in an homologous part of the Wolfhim body, but, owing to the development of the anterior segmental tubes, which are rudinentary in the Urodela, it is situated some way behind the front end. Amongst the Anura the connection of the testis with the tubules of the Woltian borly is subject to considerable variations. In Bufo cinereus the normat Urodele type is preserver, and in Bombinator the same arrangement is foum in a rudimentary condition, in that there are transverse trunks from the longitudinal canal of the Wolttian borly, which end blindly, while the semen is carried into the Wolffian duct by catnals in front of the Wolffian hody. In Alytes and Tiscoglossus the semen is carriet away by a similar direct continuation of the longitudinal canal in front of the Wolftim bolly, but there are 110 rudinentary transverse canals passing into the Wolftian body, as in Bombinator. In Rima the trinsverse ducts which pass off' from the longiturlinal canal of the Wolffian borly, after dilating to form (?) rullimentary Malpighian horlies, enter directly into the collecting tubes near their opening into the Woltfian duct.

In most Urodeles the peritoneal openings connected with the primary generative Malpighian bodies atmolhy, but in spelerpes they persist. In the Creciliidie they also remain in the aldult state.

With reference to the development of these parts little is known except that the testicular network grows out from the primary Malpighian bodies, and becomes united with the testis. Embryological evidence, as well as the fact of the persistence of the peritoneal funnels of the generative region in the adults of some forms. proves that the testicular network is not developed from the peritoneal funnels.

Rudiments of the testicular network are form in the female Cceciliide and in the females of many Urodela (Salamandra, Triton). These rudiments may in their fullest development consist of a longiturlinal canal and of transverse canals passing from this to the Malpighian boclies, together with some branches passing into the mesovarium.

Amongst the Urodela the collecting tubes of the hinder non-sexual part of the Wwitian body, which probably represents a rudimentary metdnephros, undergo in the male sex a change similar to that which they usually unlergo in Elasmohranchii. Their points of junction with the Wolffian duet are carried back to tlie hindermost end of the duct (fig. 
400 B), and the collecting tubes themselves unite together into one or more short ducts (ureters) before joining the Wolffin duct.

In Batrachoseps only the first collecting tube becomes split off in this way; and it forms a single elongated ureter which receives all the collecting tubes of the posterior segnental tubes. In the female and in the male of Proteus, Menobranchus, and siren the collecting tulies retain their primitive transverse course and open laterally into the Wolftian duct. In rate cases (Ellipsoglossus, Spengel) the meters open directly into the cloalca.

The urinary bladiler of the Amphibia is an outgrowth of the ventral wall of the cloacal section of the alimentary tract, and is homologons with the allantois of the ammiotic Vertebrata.

The subjoined diagram (fig. too) of the urogenital system of 'Triton illustrates the more important points of the preceding description.

In the female (A) the following parts are present:

(1) The Miillerian duct or oviduct (orl) derived from the splitting of the segmental duct.

(2) 'The Wulffian duet (sug) constituting the portion of the segmental duct left after the formation of the Miillerian duct.

(3) 'The me sonephros $\left(r^{\circ}\right)$, divided into an anterior sexual part comnected with a rulimentary testicular network, and a posterior part. The collecting tubes from both parts fall transversely into the Wolffian duet.

(4) The ovary (ox).

(.5) The rudimentary testicular network.

In the male (B) the following parts are present :

(1) The finctionless though fairly developed Miillerian duct (m).

(2) The Wolffian duct (sug).

(3) The mesonephros (r) divided into a true sexual part, through the segmental tubes of which the semen passes, and a non-sexual part. The collecting tubes of the latter do not enter the Wolffian duct directly, but bend obliquely backwards and only fall
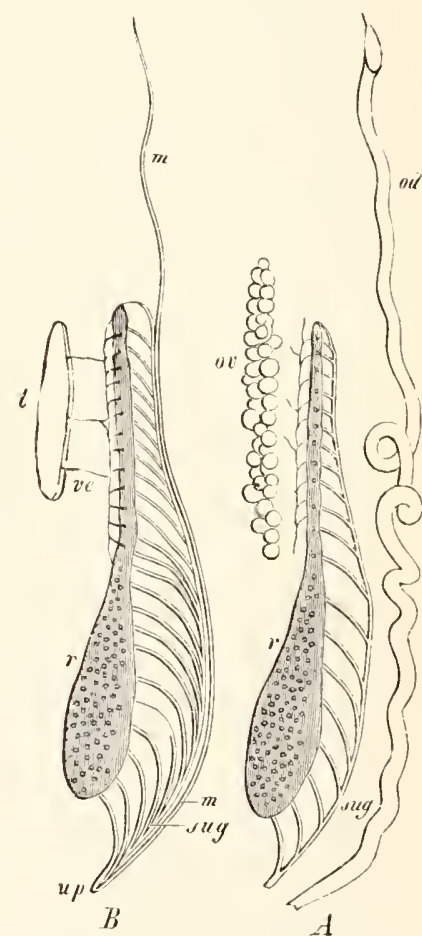

Fig. 400. Diagray of the trinogenteal sistem of Triton. (From Gegenbaur; after Spengel.)

A. Female. B. Hale.

$r$ mesonephros, on the surface of which numerous peritoneal funnels are visible; sug. mesonephric or Wolffian duct; od. ovidnet (Miillerian duct); m. Miillerian duct of male; re. vasa efferentia of testis; $t$. testis; ov. ovary; $u p$. minogenital pore. 
into it close to its cloacal aperture, after uniting to form one or two primary tubes (ureters)

(4) The testicular network (ve) consisting of (1) transverse ducts from the testes, falling into (2) the longitudinal canal of the Wolffian bolly, from which (3) transverse canals are again given off to the Malpighian bollies.

Amniota. The amniotic Vertehrata agree, so far as is known, very closely amongst themselves in the formation of the urinogenital system.

'The most characteristic feature of the system is the full devel pment of a metanephros, which constitntes the functional kidney on the atrophy of the mesonephros or Wolftian body, which is a purely embryonic organ. The first part of the system to develop is a duct, which is usually spoken of as the Wolffian duct, but which is really the homologne of the segmental duct. It apparently develops in all the Amniota nearly on the Elasmobranch type, as a solid rod, frimarily derived from the somatic mesoblast of the intermediate cell mass (fig. $\left.401 W^{\prime} . d\right)^{1}$.

The first trace of it is vissble in an embryo Chick with eight somites, as a rilge projecting from the intermediate cell mass towards the epiblast in the region of the seventh somite. In the course of further development it continues to constitute such a ridge as far as the eleventh sonite (Sedgwick), bnt from this point it grows backwards in the space between the epiblast and mesoblast. In an embryo with fourteen somites a small lumen has appeared in its mirdle part and in front it is connected with rudimentary Wolffian tubules, which develop in continnity with it (Sedgwick). In the succeering stages the himen of the duct gratually extends backwards and forwards, and the duct itnelf also passes inwards relatively to the epiblast (fig. 4(12). Its hind end elongates till it comes into connection with, and opens into, the cloacal section of the hind-gut ${ }^{2}$.

It might have been anticipated that, as in the lower types, the anterior end of the segmental duct would either open into the boly cavity, or come into connection with a pronephros. Neither of these ocrurrences take place, though in some types (the Fowl) a strncture, which is probably the rutiment of a pronephros, is developerl; it does not lowever appear till a later stage, and is then uncomnected with the segmental thet. The next part of the system to appear is the mesonephros or Wolffian body.

This is formed in all Anniota as a series of segmental tubes, which in Lacertilia(Braun) correspond with the myotomes, but in Birds and Mammatia are more numerous.

1 Dansky and Kostenitsch (No. 5+3) describe the Wolftian duct in the Click as developing from a groove opening to the peritoneal eavity, which subsequently becomes constricteI into a duct. I have never met with specimens such as those figured by these authors.

2 The foremost extremity of the segmental duct presents, according to Gasser, curious irremularities and an anterior completely isouted portion is often present. 
In Reptilia (Braun, No. 542), the mesoneplurie tubes develop as seumentally-arranged masses on the immer side of the Wolthan duct, and

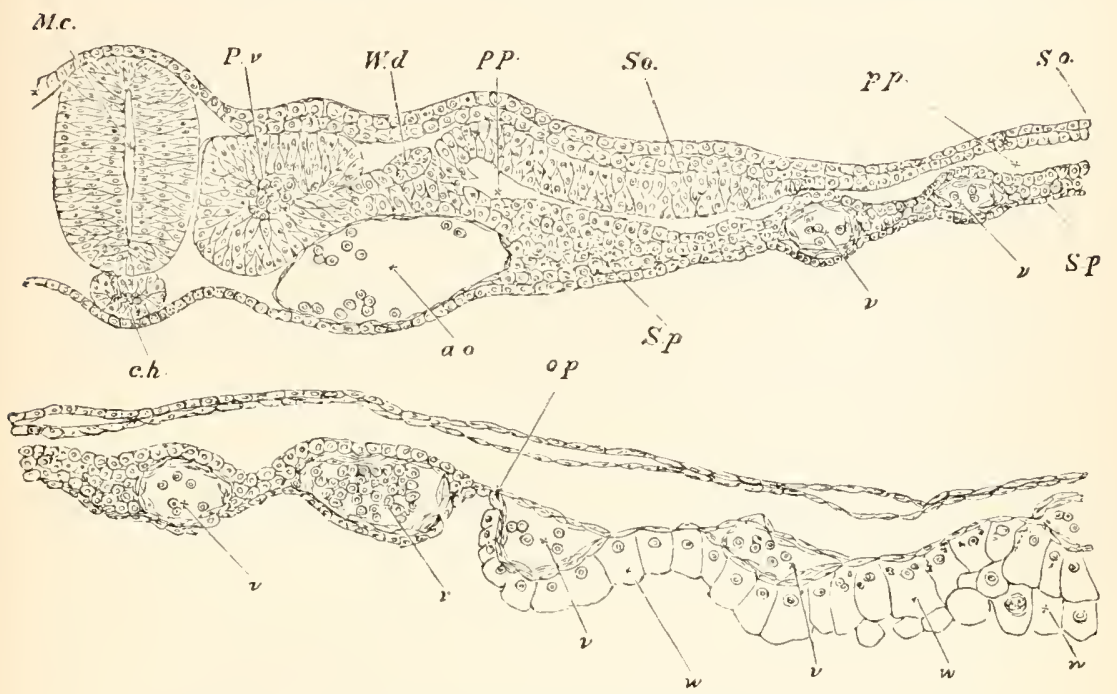

Fig. 401. Transvelise section throvgh the dorsal region of aN EMBRYO CHICK OF 45 HOURs.

M.e. medullary canal; P.x. mesoblastic somite; W.d. Wolffian duct which is in contact with the intermerliate cell mass; So. somatopleure; S.p. splanchnopleure; p.p. pleuroperitoneal cavity; ch. notochord; op. bonndary of area opaca; $v$. blood. vessel.

appear to be at first united with the peritoneal epithelium. Each mass sonn becomes an oval vesicle, probathly opening for a very short period into the peritoneal cavity by a peritoneal fumel. The vesicles become verv arly detached from the peritoneal epithelimn, and lateral outgrowths from them give rise to the main parts of the segmental tubes, which soon unite with the segmental duct.

In Birds the development of the segnental tubes is more complicated ${ }^{1}$.

The tubules of the Wolffian body are derived from the intermediate cell mass, shewn in fig. 401, between the upper end of the borly cavity and the muscle-plate. In the Chick the morle of development of this mass into the segmental tubules is different in the regions in front of and behind about the sixteenth segment. In front of about the sixteenth segment the intermediate cell mass becomes detached from the peritoneal epithelium at certain points, remaining attached to it at other points, there being several such to each segment. The parts of the intermediate cell mass attached to the peritoneal epithelium becone converted nito S-shaped cords (fig. 402, st) which soon unite with the segmental duct (wod). Into the commencement of each of these cords the lmmen of the body cavity is for a short distance prolonged, so that this part constitutes a

1 Correct figures of the early stages of these structures were first given by Kölliker, but the correct interpretation of them, and the first satisfactory accomt of the development of the excretory organs of Birds was given hy Selgwick (No. $z+9$ ). 
rudimentary peritoneal funnel. In the Duck the attachment of the intermediate cell mass to the peritoneal epithelium is prolonged further back than in the Chick.

In the formost segmental tubes, which never reach a very complete development, the peritoneal fumnels widen considerably, while at the same time they acquire a distinct lumen. The section of the tube arjoining the wisle peritoneal fumnel becomes partially invaginated by the formation of a glomerulus, and this glomerulus soon grows to such an extent as to project through the peritoneal finnel, the neck of which it completely fills, into the body cavity (fig. $403, y l$ ). There is thus formed a series of free peritoneal gloneruli belonging to the anterior Wolttian tubuli ${ }^{1}$. These tubuli becone however early aborted.

In the case of the remaining tubules reveloped from the S-shaped cords the attachment to the peritoneal epithelium is rery som lost. The cords acquire a lumen, and open into the segmental duct. Their blind extremities constitute the rudiments of Malpighian bodies.

In the posterior part of the Wolttian boly of the Chick the intermeriate cell mass becomes very early detached foom the peritoneal epithelium, and at a considerably later period breaks up into oval vesicles

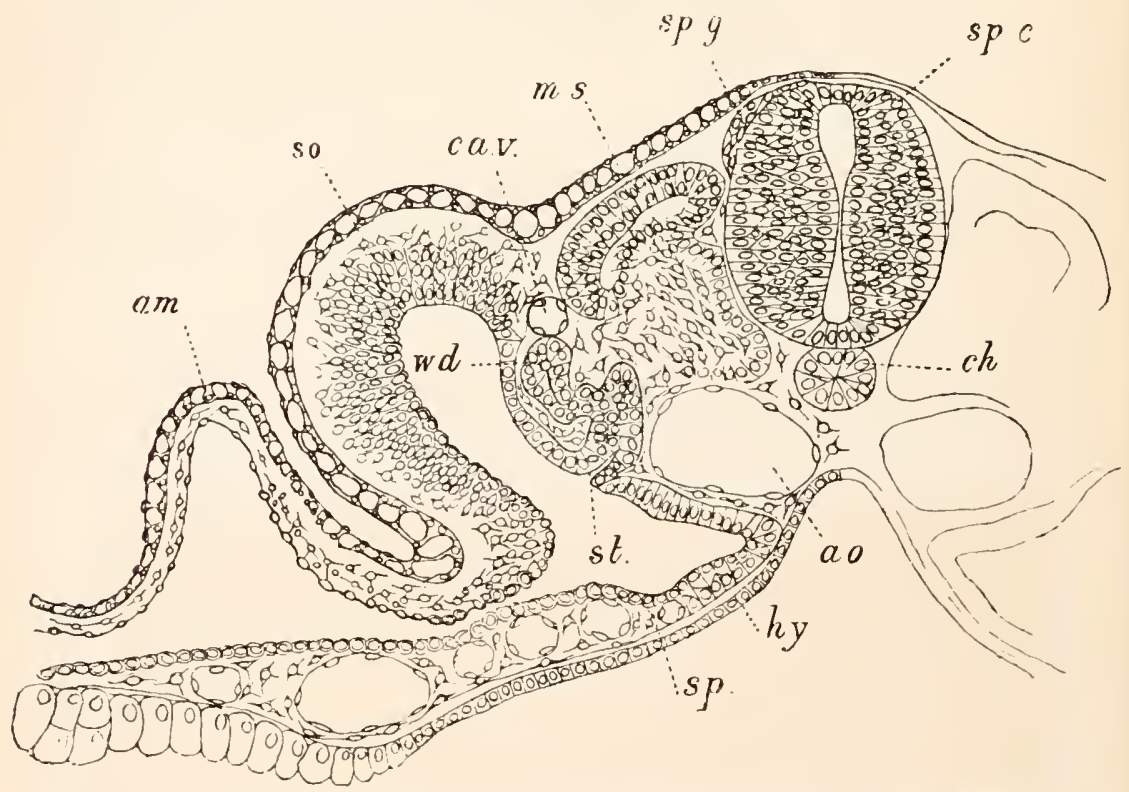

Fig, 402. Traxsuerse section throdgh the trunk of a Duck embrio with ABOUT TWENTY-FOUR MESOBIASTIC SOMITES.

am. amnion; so. somatopleure; sp. splanchnopleure; $u d$. Wolffian duct; st. segmental tule; $c a . r$. cardinal vein; m.s. muscle-plate; sp.y. spinal gauglion; sp.c. spinal cord; ch. notochord; lo. aorta; hy. lrypoblast.

1 These external glomeruli were originally mistaken hy me (No.539) for the glomerulus of the pronepliros, from their resemblance to the glomerulus of the Amphibian pronephros. Their true meaning was made out by Serlgwick (No. 5.;0). 
similar to those of the Reptilia, which form the rudiments of the segmental tubes.

Secondary and tertiary segmental tubules are formed in the Chack, on the dorsal side of the primiry tubules, as direct differentiations of the mesoblast. 'They open independently into the Woltitian duet.

In Mammalia the segmental tubules (Egli) ar'e formed as solid masses in the same situation as in Birds and Reptiles. It is not known whether they are united with the peritoneal epithelium. They soon become oval vesicles, which develop into complete tubules in the manner already indicated.

After the establishment of the Wultian body there is formed in both sexes in all the Ammiota a duct, which in the fomale becomes the oviduct, but which is finctionless and lisappears more or less completely in the male. This duct, in spite of certain peculiarities in its development, is without doubt homologous with the Miillerian duct

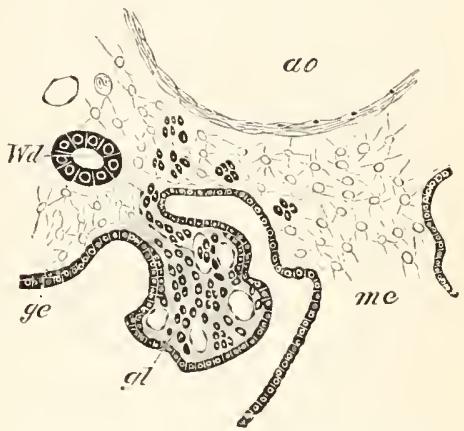

F19. 403. SEcTION THRovgh the EXTERNAL ALOMHULUS OF ONE OF THE ANTERIOIR SEGMENTAI, TUBES OF AN EMIBHYO CHICK OF ABOUT $100 \mathrm{H}$.

$g l$. glomeruhus; gr. peritoneal epithelium; Wd. Wolftian duct; ao. aorta; me. mesentery. The segmental tube, and the connection between the external and internal parts of the glomerulus are not sliew $n$ in this figure. of the Ichthyopsida. In comnection with its anterior extremity certain structures have been found in the Fowl, which are probably, on grounds to be hereafter stated, homologous with the pronephros (Balfour and Sedgwick).

The pronephros, as I shall call it, consists of a sliglitly convoluted longitudinal canal with three or more peritoneal openings In the earliest conclition, it consists of three suecessive open in-

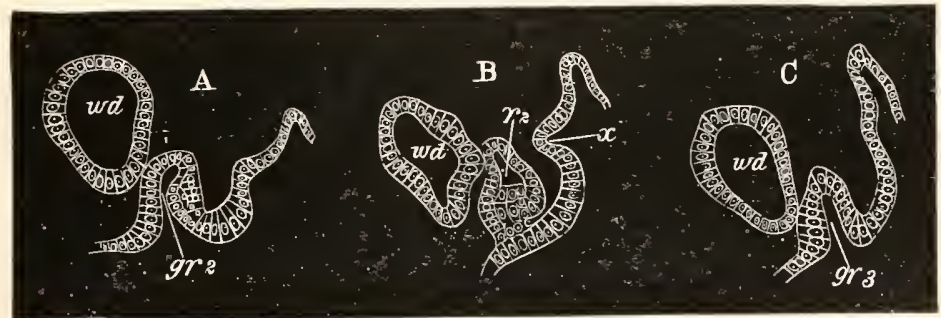

Fig. 404. Sectlons shewlNg two of the peritoneal 1XVagiNations Which give rise to the anterior part of ihe Müllerian wuet (proneinros). (After Balfoux and Serlgwick.)

$$
\begin{aligned}
& \mathrm{A} \text { is the } 11 \text { th section of the series. } \\
& \mathrm{B},, 15 \text { th , }
\end{aligned}
$$

gr 2. second groove; $g r$ 3. third groove; $r 2$. secosd ridge: $u d$. Wolftian duct. 
volutions of the peritoneal epitbelium, connected together by more or less well-defined ridge-like thickenings of the epithelium. It takes its origin from the layer of thickened peritoneal epitheliun situated near the dorsal angle of the body cavity, and is situated some considerable distance behind the front end of the Wolffian duct.

In a slightly later stage the ridges commecting the grooves become partially constricted off from the peritoneal epithelium, and develop a lumen. The condition of the structure at this stage is illustrated by fig. $40 \mathrm{H}$, representing three transverse sections through two grooves, and throngh the ridge connecting them.

The pronephros may in fact now be deseribed as a slightly convoluted duct, opening into the bouly cavity by three groove like apertures, and continuous behind with the rudiment of the true Mïillerian duct.

The stage just described is that of the fullest development of the pronephros. In it, as in all the previous stages, there appear to be only three main openings into the borly cavity; but in some sections there are indications of the possible presence of one or two additional rudimentary grooves.

In an embryo not very much older than the one last describerl the pronephros atrophies as such, its two posterior openings vanishing, and its anterior opening remaining as the permanent opening of the Müllerian duct.

The pronephros is an extremely transitory structure, and its development and atrophy are completed between the 90th and 120th hours of incubation.

The position of the pronephros in relation to the Wolffian body is shewn in fig. 40.5, which probably passes through a region between two of the peritoneal openings. As long as the pronephros persists, the Miillerian duct consists merely of a very small rudiment, contimuous with the hindermost of the three peritoneal openings, and its solid extremity appears to unite with the walls of the Wolffian duct.

After the atrophy of the pronephros, the Miillerian duct commences to grow rapidly, and for the first part of its course it appears to be split off as a solid rod from the outer or ventral wall of the Wolffian duct (fig. 406). Into this rod the lumen, present in its front part, subsequently extenrls. Its mode of development in front is thus precisely similar to that of the Miillerian duct in Elasmobranchii and Amphibia.

This mode of development only oceurs however in the anterior part of the duct. In the posterior part of its course its growing point lies in a bay formed by the outer walls of the Wolffian duct, but does not become definitely attached to that duct. It seems however possible that, although not actually split off from the walls of the Wolffian iluct, it may grow backwards from cells derived from that duct. 
The Müllerian duct finally reaches the cloaca though it does not

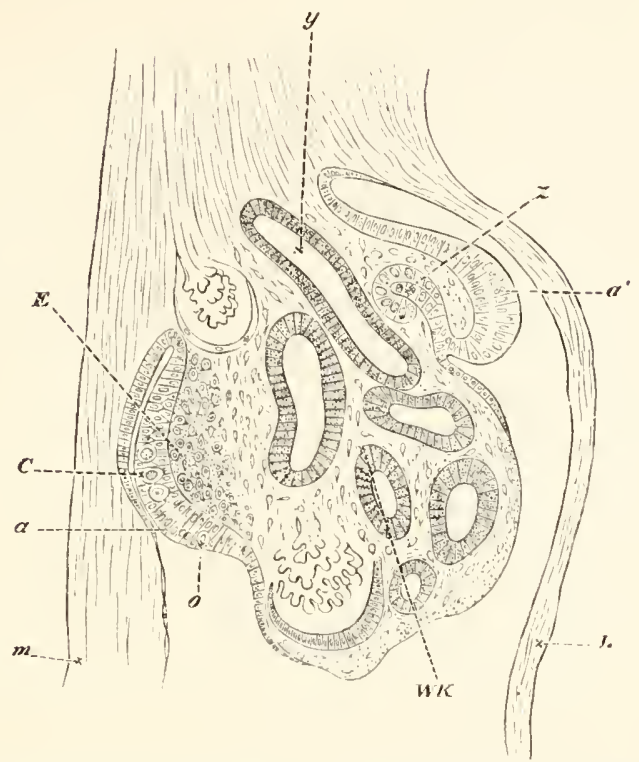

Fig, 40J. SECTION OF THE WOLFFIAN BODY DEVELOPING PRONEPHROS ANI) aentral glaNd of the Focrth iar, (After Waldeyer,) Magnified 160 times.

$m$. mesentery; $L$. somatopleure; $a^{\prime}$. portion of the germinal epithelium from which the involution $(z)$ to form the pronephros (anterior part of Müllerian duct) takes place; a. thickened portion of the germinal epithelium in which the primitive germinal cells $C$ and o are lying; $E$, modified mesoblast which will form the stroma of the ovary: $W K$. Wolfhian body; $y$. Wolffian duet.

in the female for a long time open into it, and in the male never does so.

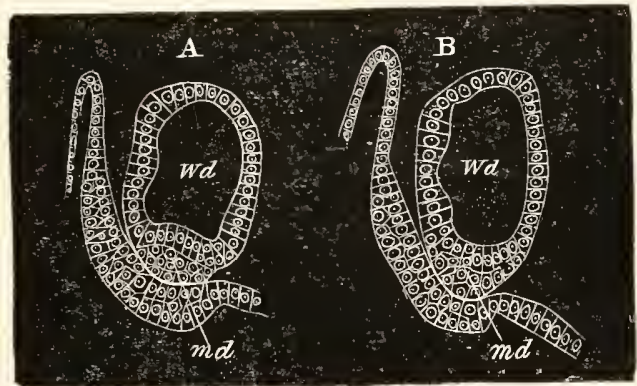

Fig. 406. TWO SECTIONS SIHWING THE JUNCTION OF THE TERMINAL SOLID PORTION

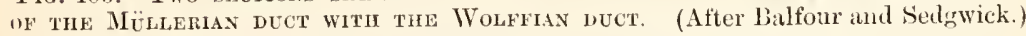

In $\mathbf{A}$ the terminal portion of the duct is quite distinct; in B it has united with tho walls of the Wolffian duet.

mel. Miillerian duet; Wil. Wolftian duct.

13. I. II 
The mode of growth of the Müllerian duct in the posterior part of its course will best be understood from the following description quoted from the paper by Sedgwick and myself.

"A few sections before its termination the Müllerian duct appears as a well-defined oval duct lying in contact with the wall of the Wolffian duct on the one hand and the germinal epithelium on the other. Gramlually, however, as we pass backwards, the Miillerian duct dilates; the external wall of the Wolftian duct adjoining it becomes greatly thickened and pushed in in its middle part, so as ahmost to touch the opposite wall of the luct, and so form a bay in which the Müllerian ruct lies. As soon as the Miillerian duct has come to lie in this bay its walls lose their previous distinctness of outline, and the cells composing them assume a curious vacuolated appearance. No well-defined line of separation can any longer he traced between the walls of the WVoltiin duct and those of the Miillerian, but between the two is a narrow clear space traversed by an irregular network of fibres, in some of the meshes of which nuclei are present.

The Miillerian duct may be traced in this condition for a considerable number of sections, the peculiar features above described becoming more and more marked as its termination is approached. It continues to dilate and attains a maximum size in the section or so before it disappears. A lumen may be observed in it up to its very end, but is nsually irregular in outline and frequently traversed by strands of jrotoplasm. The Miillerian duct tinally terminates quite sudrlenly, and in the section inmediately behind its termination the Wolffian duct assumes its normal appearance, and the part of its outer wall on the level of the Iüllerian duct comes into contact with the germinal epithelium."

Before describing the development of the Miillerian duct in other Amniotic types it will be well to say a few words as to the identifications above arlopterl. The identification of the duct, usually called the Wolffian duct, with the segmental dinct (exchsive of the pronephros) appears to be mor phologically justified for the following reasons: (1) that it gives rise to prat of the Miilierian duct as well as to the duct of the Wolftian body; bellaving in this respect precisely as does the segmental duct of Elasmohranchii and Amplibia. (2) That it serves as the duct for the Wolffian hody, before the Müllerian duct originates from it. (3) That it develops in a manner strikingly similar to that of the segmental duct of various lower forms.

With reference to the pronephros it is obvions that the organ identified as such is in many respects similar to the pronephros of the Amphibia. Both consist of a somewhat convoluted longitudinal canal, with a certain number of peritoneal openings ;

The main difficulties in the lomology are:

(1) the fact that the pronephros in the Bird is not mited with the segmental duot;

(2) the fact that it is situated helind the front end of the Wolffian body.

It is to be remembered in comnection with the first of these difficulties that in the formation of the Miullerian duct in Elasmobranchii the anterior undivided extremity of the prinitive segmental duct, with the peritoneal opening, which probably represents the pronephros, is attached to the Mülleriun duct, and not to the Wolfian duct; though in Amphibia the reresse is the case. To explain the discontinuity of the pronephros with the segmental duct it is only necessary to suppose that the segmental duct and 
pronephros, which in the Ichthyopsidir develop as a single formation, develop in the Bird as two independent structures-a far from extravagant supposition, considering that the pronephros in the Bird is undoubtedly quite functionless.

With reference to the posterior position of the pronephros it is only necessary to remark that a change in position might easily take place after the acquirement of an independent development, and that the shifting is probably correlated with a shifting of the abdominal opening of the Miillerian duct.

The promephros has only been observed in Birds, and is very possibly not developed in other Amniota. The Miillerian luct is also usually stated to develop as a groove of the peritoneal epithelium, shewu in the Lizard in fig. $3.5 \mathrm{t}$, md., which is continued backward as a primitively solid rod in the space between the Wolffian duct and peritoneal epithelium, withont becoming attached to the Wolffian duet.

On the formation of the Miillerian duct, the duct of the mesonephros becomes the true mesonephric or Wolftian duet.

After these changes have taken place a new organ of great importance makes its appearance. This organ is the permanent kidney, or metanephros.

Metanephros. The mode of development of the metanephros has as yet only been satisfactorily elucidated in the ('hick (Sedgwick, No. 549). The ureter and the collecting tubes of the kiducy are developed from a dorsal outgrowth of the hiuder part of the Wolftian duct. The outgrowth from the Wolffian duct grows forwards, and extends along the outer side of a mass of mesoblastic tissue which lies mainly behind, but somewhat overlaps the dorsal aspect of the Wolffian body.

This mass of mesoblastic cells may be called the metanephric blastema. Selgwick, of the accuracy of whose account I have satisfied myself, has shewn that in the Chick it is derived from the intermediate cell mass of the region of about the thirty-first to the thirty-fourth somite. It is at first continnous with, and indistinguishable in structure from, the portion of the intermediate cell mass of the region immediately in frout of it, which breaks up into Wolffian tubules. The metanephric blastema remains however quite passive during the formation of the Wolffian tubules in the adjoining blastema; and on the formation of the ureter breaks off from the Wolffian body in front, and, growing forwards and torsalwards, places itself on the inner side of the ureter in the position just described.

In the subsequent development of the kidney collecting tubes grow out from the ureter, and become continuous with masses of cells of the metanephric blastema, which then differentiate thenselves into the kidney tubules.

The process just described appears to me to prove that the fidney of the Amniota is a specially differentiated posterior section of the primitive mesonephros. 
Aceording to the view of Remak and Köliker the outgrowthis from the ureter give rise to the whole of the tubuli uriniferi and the capsules of the Malpighian bolies, the mesolylast around them forming blood-vessels, etc. On the other hanl some observers (Kupffer, Bornhaupt, Braun) maintain, in accordance with the aceount given above, that the outgrowths of the ureter form only the eollowting tubes, and that the secreting tubuli, etc. are formed in situ in the aljacent mesollast.

Braun (No. 5+2) has arrived at the conclusion that in the Lacertilia the ti-sue, out of which the tubuli of the metanephos are formed, is derived fron inegular solis ingrowths of the peritonteal eprithelium, in a region behind the Wolthim body, but in a position corresponding to that in which the segmental tubes take their origin. These ingrowths, after separating from the peritoneal epithelium, mite together to form a cord into which the ureter sends the lateral ontgrowths aheady described. These outgrowths unite with seereting tubuli and Malpighian bodies, formed in situ. In Lacentilia the blastema of the kilney extends into a postanal region. Brann's account of the origin of the metanephric blastema loes not appear to me to be satinfactorily demonstrated.

The ureter loes not long remain attached to the Wolffian duct, but its opening is gradually carried back, till (in the Chick between the 6th and 8th day) it opens independently into the cloaca.

of the further changes in the excretory system the most inportant is the atroplyy of the greater part of the Wolffian body, and the conversion of the Woltian duct in the ma!e sex into the vas deferens, as in Amphibia and the Elasmobranchii.

The mode of comnection of the testis with the Wolffian duct is very remarkable, but may be derived from the primitive arrangement characteristic of Elasmolranchii and Amphibia.

In the structures connecting the testis with the Wolffian body two parts have to be distinguished, (1) that equivalent to the testicular network of the luwer types, ( $)$ ) that derived from the segmental tubes. 'The former is probalily to be found in peculiar untgrowths from the Mahpighian bodies at the base of the tentes:

These were first discovered by Braun in Reptilia, and consist in this group of a series of outgrowths from the primary (?) Malpighian bodies along the base of the testis: they unite to form an interrupted cond in the substanee of the testis, from which the testicular tubuli (with the exception of the seminiferous cells) are subsequently differentiated. These outgrowths, with the exception of the first two or three, become detached from the Malpighian bodies. Outgrowths similar to those in the male are fonnd in the female, but subsequently atrophy.

Ontgrowths homologous with those found by Braun have been detected by myself ( $Y 0.555$ ) in Mlammals. It is not certain to what parts of the testicular tubuli they give rise, but they probably form it any rate the vasa recta and rete vasculosum.

In Mammals they also occur in the female, and give rise to cords of tissue in the ovary, which may persist through life.

'The comparison of the tubuli, formed out of these structures, with 
the Elasmobranch and Amphibian testicular network is justified in that both originate as ontgrowths from the prinary Malpighian bodies, and thence extend into the testis, and come into connection with the true seminiferous stroma.

As in the lower types the semen is transported from the testicular network to the Wolftian duct hy parts of the glandular tubes of the Wolftian body. In the case of Reptilia the anterior two or three segmental tubes in the region of the testis probably have this function. In the case of Mammalia the vasa efferentia, i.e. the coni vasculosi, appear, according to the usually accepted view, to be of this nature, though Banks and other investigators believe that they are independently developed struciures. Further investigations on this point are required. In Birds a connection between the Wolfiam body and the testis appears to be established as in the other trpes. Thie Wolffian duct itself becomes, in the males of all Amniotit, the vas deferens and the convoluted canal of the epididymis-the latter structure (except the head) being entirely derived from the II olftian duct.

In the female the Woltian duct atrophies nore or less completely.

In Snakes (Braun) the posterior part remains as a functionless canal, commencing at the ovary, and opening into the cloaca. In the Gecko (Bram) it remains as a small canal joining the ureter; in Blindworms a considerable part of the canal is left, and in Lacerta (Brann) only interrupted portions.

In Mammalia the middle part of the duct, known as Gartner's canal, persists in the females of some monkeys, of the pig and of many ruminiants.

The Wolffian body atrophies nearly completely in both sexes; though, as described above, part of it opposite the testis persists as the head of the epididymis. 'The posterior part of the gland from the level of the testis may be called the sexual part of the gland, the anterior part forming the non-sexual part. The latter, i.e. the anterior part, is first absorbed; and in some Reptilia the posterior part, extending from the region of the genital glands to the permanent kidney, persists till into the second year.

Various remnants of the Wolffian boly are found in the adults of both sexes in different types. The most constant of them is perlaps the part in the female equivalent to the head of the epididymis and to prarts also of the coiled tube of the epididymis, which may be called, with Waldeyer, the epoophoron ${ }^{1}$. 'This is found in Reptiles, Birls and Mammals; though in a very rudimentary form in the first-named group. Remnants of the anterior non-sexual prit of the Wolthian bodies have been called by Waldeyer parepididymis in the male, and paroophoron in the female. such remmants are not (Braun) found in Reptilia, but are stated to be found in both male and female Birds, as a small organ consisting of blindly ending tubes with yellow pigment. In some male Mammals (including

1 This is also called parovarium (His), and Rosenmüller's organ. 
Man) a parepididymis is found on the upper side of the testis. It is usually known as the organ of Giraldes.

The Müllerian duct forms, as has been stated, the oviduct in the female. The two ducts originally open independently into the cloaca, but in the Mammalia a subsequent modification of this arrangement occurs, which is dealt with in a separate section. In Birds the right oviluct atrophies, a vestige being sometimes left. In the male the ITiillerian ducts atrophy more or less completely.

In most Reptiles and in Birds the atrophy of the Miillerian ducts is complete in the male, but in Lacerta and Angris a rudiment of the anterior part has been detected by Leydig as a convoluted canal. In the Pabbit (Kölliker) ${ }^{1}$ and probably other Mammals the whole of the ducts probably disappears, but in some Manmals, e.g. Man, the lower fused ends of the Miillerian ducts give rise to a pocket opening into the urethra, known as the uterus masculinus; and in other cases, e.g. the Beaver and the Ass, the rudiments are more considerable, and naty be continued into horns homologous with the horns of the uterus (Weber).

The hydatid of Morgani in the male is supposed (Waldeyer) to represent the abdominal opening of the Fallopian tube in the female, and therefore to be a remnant of the Miillerian duct.

\section{Changes in the lower parts of the urinogenital ducts in the Amniota.}

The genital cord. In the Monodelphia the lower part of the Wolffian ducts becomes enveloped in both sexes in a special cord of tissue, known as the genital cord (fig. 407, gc), within the lower part of which the Miullerian ducts are atso encloserl. In the male the Muillerian ducts in this cord atrophy, except at their distal end where they unite to form the uterus masculinus. The Wolffian ducts, after becoming the vasa deferentia, remain for some time enclosed in the common cord, but afterwards separate from each other. The seninal vesicles are outgrowths of the vasa deferentia.

In the female the Wolftian ducts within the genital cord atrophy, though rudiments of them are for a long time visible or even permanently persistent. The lower parts of the Müllerian ducts unite to form the vagina and body of the uterus. The junction commences in the iniddle and extends forwards and backwards; the stage with a median junction being retained permanently in Marsupials.

The urinogenital sinus and external generative organs. In all the Amniota, there open at first into the common cloaca the alimentary canal dorsally, the allantois ventrally, and the Wolffian and Miillerian ducts and ureters laterally. In Reptilia and Ares the embryonic condition is retained. In both groups the allantois serves as an embryonic urinary bladder, but while it atrophies in Aves, its stalk dilates to form a permanent urinary bladder in Reptilia. In

1 Weber (No. 553) states that a uterus masculinus is present in the Rabbit, but his account is by no means satisfactory, and its presence is distinctly denied by Kölliker. 
Mammalia the dorsal part of the cloaca with the alimentary tract becomes tirst of all partially constricted off from the ventral, which then forms a urinogenital sinus (fig. $407, u g)$. In the course of development the urinogenital sinus becomes, in all Mammalia but the Ornithodelphia, completely separated from the intestinal cloaca, and the two parts obtain separate extemal openings. The ureters (fig. 407,3 ) open ligher up than the other ducts into the stalk of the allantois which dilates to form the bladiler (t). The stalk connecting the bladder witlı the ventral wall of the body constitutes the urachus, and loses its lumen before the close of embryonic life. 'The part of the stalk of the allantois below the openings of the ureters narrows to form the urethra, which opens together with the Wolffian and Müllerian ducts into the urinogenital cloaca.

In front of the urinogenital cloaca there is formed a genital prominence (fig. $407, c p$ ), with a groove continued from the urinogenital opening; and on each side a genital fold $(l s)$. In the male the sides of the groove on the prominence coalesce together, embracing between them the opening of the urinogenital cloaca; and the prominence itself gives rise to the penis, along which the common urinogenital

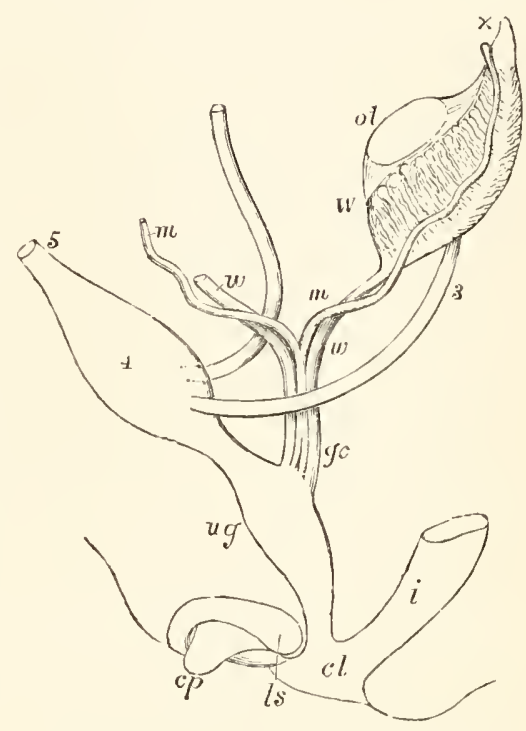

Fig. 407. Diagray of the urinogenital organs of a Mamal at an early stage. (After Allen Thomson; from Quain's Anutomy.)

The parts are seen chiefly in profile, but the Miallerian and Wolftian ducts are seen from the front.

3. ureter; 4. urinary bladder; 5. urachus; ot. genital ridge (ovary or testis); $W$. left Wolffian body; $x$. part at apex from which coni vasculosi are afterwards developed; $w$. Wolffian duct. $m$. Müllerian duct; gc. genital cord consisting of Wolffian and Iï̈llerian ducts bound up in a common sheath; $i$. rectum; $u g$. urinogenital sinus; $c p$. elevation which becomes the clitoris or penis; $l s$. ridge from which the labia majora or scrotum are cleveloped. passage is continued. The two genital folds unite from behind forwards to form the scrotum.

In the female the groove on the genital prominence gradually disappears, and the prominence remains as the clitoris, which is therefore the homologne of the penis: the two genital folds form the labia majora. The urethra and vagina open independently into the common urinogenital sinus. 


\section{General conclusions and Summary.}

Pronephros. Sedgwick has pointed ont that the pronephros is always present in types witl a larval development, and either absent or imperfectly developed in those types which indergo the greater part of their development within the egg. Thus it is practically absent in the embryos of Elasmobranchii and the Amniota, but present in the larve of all other forms.

This coincidence, on the principles already laid down in a previous chapter on larval forms, affords a strong presumption that the pronephros is an ancestral organ; and, coupled with the fact that it is the first part of the execretory system to be developed, and often the sole excretory organ for a considerable period, points to the conclusion that the pronephros and its duct-the segmental duct-are the most primitive parts of the Vertebrate excretory system. This conclusion coincides with that arrived at by Gegenbaur and Fürbringer.

The duct of the pronephros is al ways developed prior to the gland, and there are two types according to which its development may take place. It may either be formed by the closing in of a continuous groove of the somatic peritoneal epithelium (Amphibia, Teleostei, Lepidosteus), or as a solid knob or rod of cells derived from the somatic mesoblast, which grows backwards between the epiblast and the mesoblast (Petromyzon, Elasmobranchii, and the Amniota).

It is quite certain that the second of these processes is not a trine record of the evolution of the dnct, and though it is more possible that the process observable in Amphibia and the Teleostei may afford some indications of the manner in which the duct was established, this cannot be regarded as by any means certain.

The mode of development of the pronephros itself is apparently partly dependent on that of its duct. In Petromyzon, where the duct does not at first communicate with the body cavity, the pronephros is formed as a series of outgrowths from the duct, which meet the peritneal epithelium and open into the body cavity; but in other instances it is derived from the anterior open end of the groove which gives rise to the segmental duct. The open end of this groove may either remain single ('Teleostei, Ganoidei) or be divided into two, three or more apertures (Amplibia). 'The main part of the gland in either case is formed by convolutions of the tube connected with the peritoneal fumel or funnels. The peritoneal funnels of the pronephros appear to be segmentally arranged.

The pronephros is distinguished from the mesonephros by developmental as well as structural features. The most important of the former is the fact that the glandular tubules of which it is formed are always outgrowths of the segmental duct; while in the mesonepliros they are always or almost always ${ }^{1}$ formed independently of the duct.

1 According to Sedgrick some of the anterior segmental tubes of Aves form an exception to the general rule that there is no outgrowth from the segmental or metanephric duct to meet the segmental tubes. 
The chief structural peculiarity of the pronephros is the absence from it of Malpighian borties with the same relations as those in the meso- and metanephros; unless the structures found in Myxine are to be regarded as such. Functionally the place of such Malpighian bodies is taken by the vascular peritoneal ridge spoken of in the previous pages as the glomerulus.

That this botly is really related functionally to the pronephros appears to be indicated (1) by its constant occurrence with the pronephros and its position opposite the peritoneal openings of this body ; (2) by its atrophy at the same time as the pronephros; (3) by its enclosure together with the pronephridian stoma in a special compartment of the body cavity in Teleostei and Ganoids, and its partial enclosure in such a compartment in Amphilia.

The pronephros atrophies more or less completely in most types, thongh it probably persists for life in the Teleostei and Ganoids, and in some members of the former group it perhaps forms the sole alult organ of excretion.

The cause of its atrophy may perhaps be related to the fact that it is situated in the pericardial region of the body cavity, the dorsal part of which is aborted on the formation of a closed pericardium; and its preservation in Teleostei and Ganoirls may on this view be due to the fact that in these types its peritoneal funnel and its glomerulus are early isolated in a special cavity.

Mesonephros. The mesonephros is in all instances composed of a series of tubules (segmental tubes) which are developed independently of the segmental duct. Each tubule is typically formed of (1) a peritoneal fumnel opening into (2) a Malpighian body, from which there proceeds (3) a coiled glandular tube, finally opening by (t) a collecting tube into the segmental duct, which constitutes the primitive duct for the mesonephros as well as for the pronephros.

The development of the mesonephridian tubules is subject to considerable variations.

(1) They may be formed as differentiations of the intermediate cell mass, and be from the first provided with a lumen, opening into the body cavity, and directly derived from the section of the bodycavity present in the intermediate cell mass; the peritoneal funnels often persisting for life (Elasmobranchii).

(2) They may be formed as solid cords either attached to or independent of the peritoneal epithelium, which after first becoming independent of the peritoneal epithelium subsequently send downwarls a process, which unites with it and forms a peritoneal funnel, which may or may not persist (Acipenser, Amphibia).

(3) They may be formed as in the last case, but acquire no secondary connection with the peritoneal epithelium (Teleostei, Amniota). In connection with the original attachment to the peritoneal epithelium, a true peritoneal fumnel may however be developed (Aves, Lacertilia). 
Physiological considerations appear to shew that of these three methods of development the first is the most primitive. The development of the tubes as solid cords can hardly be primary.

A question which has to be answered in reference to the segmental tubes is that of the homology of the secondarily developed peritoneal openings of Amphilia, with the primary openings of the Elasmoliranchii. It is on the one hand difficult to understand why, if the openings are homologous in the two types, the original peritoneal attachment should be obliterated in Amphibia, only to be shortly afterwards reacquired. On the other hand it is still more difficult to understand what physiological gain there could be, on the assumption of the non-homology of the openings, in the replacement of the primary opening by a secondary opening exactly similar to it. Considering the great variations in development which occur in undoubtedly homologous parts I incline to the view that the openings in the two types are homologous.

In the majority of the lower Vertebrata the mesonephric tubes have at first a segmental arrangement, and this is no doubt the primitive condition. The coexistence of two, three, or more of them in a single segment in Amphibia, Aves and Mammalia has recently been shewn, by an interesting discovery of Eisig, to have a parallel amongst Chætopods, in the coexistence of several segmental organs in a single segment in some of the Capitellidæ.

In connection with the segmental features of the mesonephros it is perhaps worth recalling the fact that in Elasmobranchii as well as other types there are traces of segmental tubes in some of the postanal segments. In the case of all the segmental tubes a Malpighian body becomes established close to the extremity of the tube aljoining the peritoneal opening, or in an homologous position in tubes without such an opening. The opposite extremity of the tube always becomes attached to the segmental duct.

In many of the segments of the mesonephros, especially in the hinder ones, secondary and tertiary tubes become developed in certain types, which join the collecting canals of the primary tubes, and are provided, like the primary tubes, with Malpighian bodies at their blind extremities.

There can it appears to me be little or no doubt that the secondary tubes in the different types are homodynamous if not homologons. Under these circumstances it is surprising to find in what different ways they take their origin. In Elasmobranchii a bud sprouts out from the Malpighian body of one segment, and joins the collecting tube of the preceding segment, and subsequently, becoming detached from the Malpighian body from which it spronted, forms a fresh secondary Malpighian body at its blind extremity. Thus the secondary tubes of one segment are formed as buds from the segment behind. In Amphibia (Salamandra) and Aves the secondary tubes develop independently in the mesoblast. These great differences in development are important in reference to the homology of the metanephros or permanent kidney, which is discussed below. 
Before leaving the mesonephros it may be worth while putting forward some hypothetical suggestions as to its origin and relation to the pronephros, leaving however the difficult questions as to the homology of the segmental tubes with the segmental organs of Chretopods for subsequent discussion.

It is a peculiarity in the development of the segmental tubes that they at first end blindly, though they subsequently grow till they meet the segmental duct with which they unite directly, without the latter sending out any offshoot to meet them ${ }^{\mathrm{I}}$. It is difficult to believe that peritoneal infundibula ending blindly and unprovided with some external orifice can liave had an excretory function, and we are therefore rather driven to suppose that the peritoneal infundilula which become the segmental tubes were either from the first provided each with an oritice opening to the exterior, or were united with the segmental duct. If they were from the first provided with external openings we may suppose that they became secondarily attached to the duct of the pronephros (segmental duct), and then lost their external openings, no trace of these structures being left, even in the ontogeny of the system. It would appear to me more probable that the pronephros, with its duct opening into the cloaca, was the only excretory organ of the unsegmented ancestors of the Chordata, and that, on the elongation of the trunk and its subsequent segmentation, a series of metameric segmental tubes became evolved opening into the segmental dict, each tulve being in a sort of way serially homologous with the primitive pronephros. With the segmentation of the trunk the latter structure itself may have acquired the more or less definite metameric arrangement of its larts. $^{\text {rarts }}$

Another possible view is that the segmental tubes may be modified derivates of posterior lateral branches of the pronephros, which may at first lave extended for the whole length of the hody cavity. If there is any truth in this hypothesis it is necessary to suppose that, when the unsegmented ancestor of the Chordata became segmented, the prosterior branches of the primitive excretory organ became segmentally arranged, and that, in accordance with the change thus gradually introduced in them, the time of their development became deferred, so as to accord to a certain extent with the time of formation of the segments to which they belonged. The change in their mode of development which would be thereby introduced is certainly not greater than that which las taken place in the case of segmental tubes, which, having originally developed on the Elasmobranch type, have come to develop as they do in the posterior part of the mesonephros of Salamandra, Birds, etc.

Genital ducts. So far the origin and development of the excretory organs have been considered without reference to the modifications introduced by the excretory passages coming to serve as generative ducts. Such an unmodified state of the excretory organs is perhaps found permanently in Cyclostomata ${ }^{2}$ and transitorily in the embryos of most forms.

1 As mentioner in the note on p. 600 Sergwick maintains that the anterior segmental tubes of the Chick form an exception to this general statement.

2 It is by 110 means certain that the transportation outwards of the genital products by the abdominal pores in the Cyelostomata may not be the result of degeneration. 
At first the generative products seem to have been discharged freely into the body cavity, and transported to the exterior by the abdominal pores (vide p. 51.5).

The secondary relations of the excretory ducts to the generative organs seem to have been introduced by an opening commected with the pronephridian extremity of the segmental duct having aepuired the function of admitting the generative products into it, and of carrying them outwards; so that primitively the segmentul duct must lave served as efferent duct both for the generative products and the proneplwic secretion (just as the Wolffan duct still does for the testicular products and secretion of the Wolttian body in Elasmobranchii and Amplibia).

The opening by which the generative products entered the segmental duct can harlly have been specially developed for this purpose, but must almost certainly have been one of the peritoneal openings of the pronephros. As a consequence (by it process of natural selection) of the segmental duct having both a generative and a urinary function, a further differentiation took place, by which that duct became split into two-a ventral Miillerian duct and a dorsal Wolffian duct.

The Miillerian duct was probably continuous with one or more of the abdonimal openings of the pronephros which served as generative pores. At first the segmental duct was probably split longitndinally into two equal portions, and this mode of splitting is exceptionally retained in some Elasmobranchii; but the generative function of the Miillerian duct gradually impressed itself more and more upon the enbryonic development, so that, in the course of time, the Mitlerian duct developed less and less at the expense of the Wolffian duct. This process appears partly to have taken place in Elasmobranchii, and still more in Amplibia, the Amphibia offering in this respect a less primitive condition than the Elasmobranchii; while in Aves it has been carried even further, and it seems possible that in some Ammiota the Miillerian and segmental dluets may actua'ly develop independently, as they do exceptionally in individual specimens of Salanandra (Fübringer). The abdoninal openiug no doubt also became specialiserl. At first it is quite possible that more than one pronephric abdominal fumnel may have served for the entrance of the generative products; this function being, no doubt, eventually restricted to one of then.

Three different types of development of the abdominal opening of the Miillerian duct have been observed.

In Amphibia (Salamandra) the permanent opening of the Miillerian duct is formed independently, sone way behind the pronephros.

In Elasmobranchii the original opening of the segmental duct forms the permanent opening of the Miillerian duct, and no true pronephros appears to be formed.

In Birds the anterior of the three openings of the rudimentary pronephros remains as the permanent opening of the Miillerian duct. 
These three modes of develnment very probably represent specialisations of the primitive state along three different lines. In Amphibia the specialisation of the opening appears to have gone so far that it no longer has any relation to the pronephros. It was probably originally one of the posterior openings of this gland.

In Elasmobranchii, on the other hand, the functional opening is formed at a period when we should expect the pronephros to tevelop. This state is very possibly the result of a differentiation by which the pronephros grarlually ceased to become developed, but one of its peritomeal openings remained as the abdominal aperture of the Miillerian (luet. Aves, finally, appear to have become differentiated along a third line; since in their ancestors the anterior (?) pore of the head-kihney appears to have become specialised as the permanent opening of the Miillerian duct.

The Müllerian duct is usually formed in a more or less complete mamner in both sexes. In Ganoids, where the separation between it and the Wolffian duct is not completed to the cloaca, and in the Dipnoi, it probably serves to carry off the generative products of both sexes. In other cases however only the female products pass ont by it, and the partial or complete formation of the Miillerian dnet in the male III these cases needs to be explained. 'This may be done either by supposing the Ganoid arrangement to have been the primitive one in the ancestors of the other forms, or, by supposing characters acquired primitively by the female to have become inherited by both sexes.

It is a question whether the nature of the generative ducts of Teleostei can be explained by comparison with those of Ganoids. The fact that the Miillerian duets of the Teleostean Ganoid Lepidostens attach themselves to the generative organs, and thus acquire a resemblance to the generative duets of 'Teleostei, affords a powerful argument in favour of the view that the generative ducts of both sexes in the Teleostei are modified Miullerian ducts. Embryology can however alone definitely settle this question.

In the Elasmobranchii, Amphibia, and Amniota the male prolucts are carried off' by the Wolffian duct, and they are transported to this duet, not by open peritoneal fumnels of the mesonephros, but by a network of ducts which sprout either from a certain number of the Malpighian bodies opposite the testis (Amphibia, Amniota), or from the stalks connecting the Malpighian bodies with the open funnels (Elasmobranchii). After traversing this network the semen passes (except in certain Anura) through a variable number of the segmrental tubes directly to the Wolffian duct. The extent of the connection of the testis with the Wolffian body is sulject to great variations, but it is usually more or less in the anterior region. Rucliments of the testicular network have in many eases becone inherited by the female.

The origin of the comnection between the testis and Wolffian body is still rery obscure. It would be easy to understand how the testicular products, 
after falling into the body cavity, might be taken up by the open extremities of some of the peritoneal funnels, and how such open funnels might have groove-like prolongations along the mesorchinm, which might eventually be converted into ducts. Ontogeny does not however altogether favour this view of the origin of the testicular network. It seems to me nevertheless the most probable view which has yet been put forwarl.

The mode of transportation of the semen by means of the mesonephric tubules is so peculiar as to render it highly improbable that it was twice acquircd, it becomes therefore necessary to suppose that the Amphibia and Amniota inherited this mode of transportation of the semen from the same ancestors as the Elasmoloranchii. It is remarkable therefore that in the Ganoidei and Dipnoi this arrangement is not found.

Either (1) the arrangement (found in the Gano:dei and Dipnoi) of the Müllerian duct serving for both sexes is the primitive arrangement, and the Elasmobranch is secondary, or (2) the Ganoid arrangement is a secondary condition, which has originated at a stage in the evolution of the Vertebrata when some of the segmental tubes had begun to serve as the efferent ducts of the testis, and has resulted in consequence of a degeneration of the latter structures. Although the second alternative is the more easy to reconcile with the affinities of the Ganoid and Elasmobranch types, as indicated by the other features of their organization, I am still inchined to accept the former ; and consider that the incomplete splitting of the segmental duct in Ganoidei is a strong argument in favour of this view.

Metanephros. With the employment of the Wolffian duct to transport the semen there seems to be correlated (1) a tendency of the posterior segmental tubes to have a duct of their own, in which the seminal and urinary fluids cannot become mixed, and (2) a tendency on the part of the anterior segmental tubes to lose their excretory function. The posterior segmental tubes, when comnected in this way with a more or less specialised duct, have been regarded in the preceding pages as constituting a metanephros.

This differentiation is hardly marked in the Anura, but is well developed in the Urodela and in the Elasmolranchii; and in the latter group has become inherited by both sexes. In the Ammiota it culminates, according to the view independently arrived at by Semper and myself, (1) in the formation of a completely distinct inetanephıros in both sexes, formed however, as shewn by Sedgwick, from the same blastema as the Wolffian body, and (2) in the atrophy in the adult of the whole Wolffian body, except the part uniting the testis and the Wolffian duct.

The homology betwern the posterior metanephridian section of the Wolffian boly, in Elismobranchii and Urodelat, and the kidney of the Amniota, is only in my opinion a general one, i.e. in loth cases a common cause, viz. the Wolftian duct acting as vas deferens, has resulted in a more or less similar differentiation of parts.

Fürbringer has urged against Semper's and my view that no satisfactory proof of it his yet been offered. This proof has however, since Fürbringer wrote his paper, been supplied by Sedgwick's observations. The development of the kidney in the Ammiota is no doubt a direct as 
opposed to a phylogenetic development; and the substitution of a direct for a phylogenetic development has most probably been rendered possible by the fact that the anterior part of the mesonephros continued all the while to be unaffected and to remain as the main excretory organ during fotal life.

The most serious difficulty med by Fürbringer against the homology is the fact that the ureter of the metanephros develops on a type of its own, which is quite distinct from the mode of development of the ureters of the metanephros of the Ichthyopsidan forms. It is however quite possible, though far from certain, that the ureter of Amniota nay be a special formation confined to that group, and this fact would in no wise militate against the homology I have been attempting to establish.

\section{Comparison of the Excretory orguns of the Chordata and Invertebrutu.}

The structural characters and development of the various forms of excretory organs described in the preceding pages do not appear to me to be sufficiently distinctive to render it possible to establish homologies between these organs on a satisfactory basis, except in closely related groups.

The excretory organs of the Platyelminthes are in many respects similar to the provisional excretory organ of the trochosphere of Polygordius and the Gephyrea on the one hand, and to the Vertebrate pronephros on the other; and the Platyelminth excretory organ with an anterior opening might be regarded as having given origin to the trochosphere organ, while that with a posterior opening may have done so for the Vertebrate pronephros ${ }^{1}$.

Hatschek has compared the provisional trochosphere excretory organ of Polygordius to the V'ertebrate pronephros, and the posterior Chrotopod segmental tubes to the mesonephric tubes; the latter homology having been already suggested independently by both Semper and myself. With reference to the comparison of the pronephros with the provisional excretory organ of Polygordius there are two serious difficulties:

(1) The pronephric (segmental) duct opens directly into the cloaca, while the duct of the provisional trochosphere excretory organ opens anteriorly, and directly to the exterior.

(2) The pronephros is situated within the segmented region of the trunk, and has a more or less distinct metameric arrangement of its parts; while the provisional trochosphere organ is placed in front of the segmented region of the trunk, and is in no way segmented.

The comparison of the mosonephric tubules with the segmental excretory organs of the Chrtopoda, though not impossible, cannot be satisfactorily admitted till some light has been thrown upon the loss of the supposed external openings of the tubes, and the origin of their secondary connection with the segmental duct.

Confining our attention to the Inverteluata it appears to me fairly clear that Hatschek is justitied in holding the provisional trochosplere excretory organs of Polygordins, Echimus and the Mollusca to be homologous. The atrophy of all these larval organs may perhaps be due to the prescnce of a well-developed trunk region in the adult (absent in the larva), in which excretory urgans, probably serially homologous with those present in the

1 This snggestion has I believe been made by Fïrbringer. 
anterior part of the larva, became developed. The excretory organs in the trunk were probably more conveniently situated than those in the hear, and the atrophy of the latter in the adult state was therefore brought about, while the trunk organs became sufficiently enlarged to serve as the sole excretory organs.

\section{Biblography of the Excretory Organs.}

\section{Invertebrata.}

(5I2) H. Eisig. “Die Segmentalorgane d. Capitelliden." Mitth. a. d. zocl. Stat. z. Neapel, Vol. 1. 1879.

(513) J. Fraipont. "Recherehes s. l'appareil exeréteur des Trematodes et d. Cestoïdes." Archives de Biologie, Vol. I. 1880.

(, It) B. Hatschek. "Studien üb. Entwick. d. Anneliden." Arbeit. a. d. zool. Instit. Wien, Vol. I. 1878.

(5 I5) B. Hatschek. "Ueber Entwick, von Eehiurus," ete. Arbeit. a. d. zool. Instit. Wien, Vol. III. 1880.

\section{Excretory Organs of Veirtebrata.}

\section{General.}

(516) F. M. Balfour. "On the origin and history of the urinogenital organs of Vertebrates." Joumal of Anat. and Phys., Vol. x. 1876.

(517) Max. Fïrloringer ${ }^{1}$. "Zur vergleichenden Anat. u. Entwiek. d. Exeretionsorgane d. Vertebraten." Morphol. Jahrluch, Vol. Iv. 1878.

$(518)$ H. Meckel. Zur Horphol. d. Harn- ". Geschlechtsucerliz. d. Wirbelthiere, etc. Halle, 1818.

$(519)$ Joh. Miiller. Bildmngsgeschichte d. Genitulien, etc. Diisseldorf, 1830.

$(520)$ H. Ratlike. "Beobaehtumgen u. Betraehtungen ii. d. Entwieklung d. Geschlechtswerkzenge bei den Wirbelthieren." N. Schriften d. notmf. Ge'sell. in Dantzig, Bd. I. 1825.

(521) C. Semper'. "Das Urogenitalsystem d. Plagiostomen u. seine Bedeutung f. d. iibrigen Wirbelthiere." Arb.a. d. zool.-zoot. Instit. Würzburg, Vol. 11. 1875.

$(522)$ W. Waldeyer ${ }^{1}$. Eierstock u. Ei. Leipzig, 1870.

\section{Elasmobranchii.}

(523) A. Sehultz. "Zur Entwick. d. Selachiereies." Archin f. mikr. Anat., Vol. XI. 1875 .

Vidr also Semper (No. 52r) and Balfour (No. 29z).

\section{Cyclostomatet.}

$(\Sigma 24)$ J. Müller. "Untersuchungen ii. d. Eingeweide d. Fische." Alh. $d . k$. Ak. Wiss. Berlin, 1815.

(525) W. Mïller. "Ueber d. Persistenz d. Unniere b. Myxine glutinosa." Incieische Zitsclirift, Vol, vII, 1873.

$(=26)$ W. Miilier. "Ueber d. Ulogenitalsystem d. Amphioxus u. d. Cyelostomen." Jemaische Zeitschrift, Vol. $1 \mathrm{x} .1875$.

(527) A. Schineider. Beiträge z. vergleich. Anat. ". Entwick. d. Wirbelthiere. Berlin, 1879 .

(528) W. B. Seott. "Beiträge z. Entwick. d. Petromyzonten." Morphol. Jahrbuch, Vol. vi1. 1881.

\section{Teleostei.}

(329) J. Hyrtl. "Das uropoetịsehe System d. Knochenfische." Denlisclu. $d$. k. li. Akad. Wiss. Wien, Vol. 11. 1850.

(5.30) A. Rosenberg. Untersnchungen ïb. die Entwicklung d. Telcostiermiere. Dorpat, $1<67$.

ride also Oellaeher (No. 72 ).

1 The papers of Fürbringer, Semper and Waldeyer contain full referenees to the literature of the Vertebrate exeretory organs. 


\section{Ampleibice.}

(53) F. H. Bidder. Trorgleichend-anntomische u. histologische Untersnchungen ï. die mönulichen Geschlechts-und Harnwerkzenge d. nackten Amphibien. 1)orpat, 1816.

- (532) C. J. Duvernoy. "Fragments s. les Organes genito-urinaires des Reptiles," ete. IIćm. Acal. Sciences. Paris. Vol. xi. 1851, pp. 17-95.

(5.33) M. Fiirbringer. 'Zu' Entwicklung d. Amphibiemiere. Heilelberg, 1877.

$(5,3+)$ F. Leydig. Anatomie d. Amphibien u. Reptilien. Berlin, 1853.

(535) F. Jueydig. Lehrbuch d. Histologie. Hamm, 1857.

$(536)$ F. M eyer. "Anat. d. Urogenitalsystems d. Selachier u. Amphibien." Sitz, d. naturfor. Gesellsch. Leipzig, 1875.

(537) J. W. S'pengel. "Das Urogenitalsystem d. Amphibien." Arb. a. d. zool. zoot. Instit. Wiurzburg. Vol. I11. 1876.

$(538)$ Von Wittieh. "Harn- u. Gesehleehtswerkzeuge d. Amphibien." Zeit. $f$. wiss. Zool., Vol. Ir.

Vide also Götte (No. 296).

\section{Amiota.}

(.539) F. M. Balfour and A. Sedgwiek. "On the existence of a head-kidney in the embryo Chick," ete. Quart. J. of Hicr. Scienee, Vol. xix. 1878.

$(5+0)$ Banks. On the Wolfin bodies of the foetus and their remains in the adult. Edinburgh, 1864.

$(\overline{+1})$ Th. Bornlıapt. Tntersuchungen ̈̈b. die Entucicklungd. Urogcnitalsystems beim Ḧ̈hnchen. Inang. Diss. Riga, 1867.

$(5+2)$ Max Braun. "Das Urogenitalsystem d. einheimischen Reptilien." Arbcitcu a. d. zool.-zoot. Instit. Würzburf. Vol. 1v. 1877.

$(5+3)$ J. Dansky 1. J. Kostenitsch. "Ueb. d. Entwick. d. Keimblätter n. d. Wolff'schen Ganges im Hühnerei," Mém. Acarl. Imp. Pétersboury, vir. Series, Vol. xxv11. 1880.

$(5+4)$ Th. Egli. Beiträge zur Anat. nud Entwick. d. Geschlechtsorgame. Inaug. Diss. Ziirich, 1876.

$(5+5)$ E. Gasser. Beiträge zur Entuicklungsgcsehichtc A. Allantois, der Müller'schen Gänge u. des Afters. Frankfurt, 1874.

$(5+6)$ E. Gasser. "Beob. iib. d. Entstehung d. Wolff'schen Ganges bei Embryonen von Hïhnern u. Gänsen." Arch. für mikr. Anat., Vol. xıv. 1877.

$(5+7)$ E. Gasser. "Beiträge z. Entwicklung d. Urogenitalsystems d. Hiihnerembryonen" Sitz. r. Gescll. zur Befinderung d. gesam. Naturwiss. Marburg, 1879.

$(5+8)$ C. Kupffer. "Untersuchung iiber die Entwicklung des Harn- und Geschlechtssystems." Arehiv, fuir mikr. Anat., Vol. 11. 1866.

$(5+9)$ A. Sedgwick. "Development of the kidney in its relation to the Wolffian body in the Click." Quart. J. of Hicros. Scienee, Vol. xx. 1880.

$(5,0)$ A. Sedgwick. "On the development of the structure known as the glomerubus of the head-kidney in the Chick." Quart. J. of Micros. Science, Vol. xx. 1880.

(551) A. Sedgwiek. "Early development of the Wolftian duct and anterior Wolffian tubules in the Chick; with some remarks on the vertebrate excretory system." Quut. J. of Micros. Science, Vol. xxı. 1881.

$(5=2)$ M. Watson. "The homology of the sexual organs, illustrated by comparative anatomy and pathology." Joumal of Anat. and Phys., Vol. xiv. 1879.

$(5.53)$ E. H. Weber. Zusätzc z. Lehre von Baue u. d. Verrichtungen d. Geschleehtsorgane. Jeipzig, 1846.

Tille also Remak (No. 302), Foster and Balfour (No. 295), His (No. 297), Kölliker (No. 29s). 


\section{CHAP'TER XXIV.}

\section{GENERATIVE ORGANS AND GENITAL DUCTS.}

\section{Generative organs.}

THE structure and growth of the ovmu and spermatozoon were given in the first chapter of this work, but their derivation from the germinal layers was not touched on, and it is this subject with which we are here concerned. If there are any structures whose identity throughout the Metazon is not open to doubt these structures are the ovum and spermatozoon; and the constancy of their relations to the greminal layers would seem to be a crucial test as to whether the latter have the morphological importance usually attributed to then.

The very fragmentary state of our knowledge of the origin of the generative cells has however prevented this test being so far very generally applied.

Porifera. In the Porifera the researches of Schulze have clearly demonstrated that both the ova and the spermatozoa take their origin from indifferent cells of the general parenchyma, which may be called mesoblastic. The primitive germinal cells of the two sexes are not distinguishable; but a germinal cell by enlarging and becoming spherical gives rise to an ovunn; and by subdivision forms a sperm-morula, from the constituent cells of which the spermatozoa are directly developed.

Ccelenterata. The greatest confusion prevails as to the germinal layer from which the male and female products are derived in the Coelenterata ${ }^{1}$.

The following apparent modes of origin of these products have been observed.

(1) The generative products of both sexes originate in the ectoderm (epiblast): Hyclra, Cordylophora, Tubularia, all (?) free Gonophores of Hydromedusæ, the Siphonophora, and probably the Ctenophora.

1 E. vau Beneden (No. 556) was the first to discover a different origin for the generative products of the two sexes in Hydractinia, and his observations have led to numerous subsequent researches on the subject. For a summary of the observations on the Hydroids vide Weismann (No. 560 ). 
(2) The generative prolucts of both sexes originate in the entoderm (hypoblast): Plumularia and Sertularella, amongst the Hydroids, and the whole of the Acraspeda and Actinozoa.

(:) The ma!e cells are formen in the ectoderm, and the female in the entoderm: Gonothyra, Campauularia, Hydractinia, Clava.

In view of the somewhat surprising results to which the researches on the origin of the genital products amomgst the Coelenterata have led, it would seem to be necessary either to hold that there is 110 definite homology between the germinal layers in the lifferent forms of Colenterata, or to offer some satisfactory explanation of the behavion of the genital products, which would not involve the acceptance of the first alternative.

Though it can hardly be sail that such an explanation has yet been offered, sume observations of Kleiuenberg (No. 557) undonbtedly point to such an explanation being possible.

Kleinenberg has shewn that in Eudendrium the ova migrate freely from the ectoderm into the endodern, and vice versa; but he has given strong grounds for thinking that they ariginute in the ectodern. He has further shewn that the migration in this type is by no means an isolated phenomenon.

Since it is usually mly possible to recognise-generative elements after they have advanced considerably in development, the mere position of a generative cell, when first obselved, can aftord, after what Kleinenberg has shewn, no absolute proof of its origin. Thus it is quite possible that there is really only one type of origin for the generative cells in the Coelenterata.

Kleinenberg has given reasons $\left.f^{\prime}\right)^{\circ}$ thinking that the migration of the ova into the entoderm may have a nutritive ohject. If this be so, and there are numerous facts which shew that the position of generative cells is often largely influenced by their nutritive requirements, it seems not impossible that the endodermal position of the generative organs in the Actinozoa and acraspedote Medusa may have arisen by a continuously earlier migration of the generative cells from the ectoderm into the endoderm; and that the migration may now take place at so early a period of the develop. ment, that we should be justified in formally holding the generative products to be endodermal in or igin.

We might perhitps, on this view, fornulate the origin of the generative products in the Coelenterata in the following way :-

Both ova and spermatozoa primitively originated in the ectoderm, but in order to secure a more complete nutrition the cells which give rise to them exhibit in certain groups a tendency to migrate into the endoderm. This migration, which may concern the generative cells of one or of both the sexes, takes place in some cases after the generative cells have become recognisable as such, and very probably in other cases at so early a period that it is impossible to distinguish the generative cells from indifferent embryonic cells.

Very little is known with reference to the origin of the generative cells in the triploblastic Invertebrata. 
Chætopoda and Gephyrea. In the Chxtopoda and Gejhyrea, the germinal cells are always developed in the adult from the epithelial lining of the body cavity; so that their origin frum the mesoblast seems fairly established.

If we are justified in holding the body cavity of these forms to be a derivative of the primitive archenteron (vide pp. 294 and 29.5) the generative cells may fairly be held to originate fiom a layer which corresponds to the endoderm of the Colenterata ${ }^{2}$.

Chætognatha. In Sagitta the history of the generative cells, which was first worked out by Kowalevsky and Bütschli, has been recently treated with great detail by $\mathrm{O}$. Hertwig ${ }^{2}$.

The generative cells appear during the gastrula stage, as two large cells with conspicuous nuclei, which are placed in the hypoblast lining the archenteron, at the pole opposite the blastopore. 'These cells soon divide, and at the same time pass out of the hypoblast, and enter the archenteric cavity (fig. $408 \mathrm{~A}, g e$ ). The division

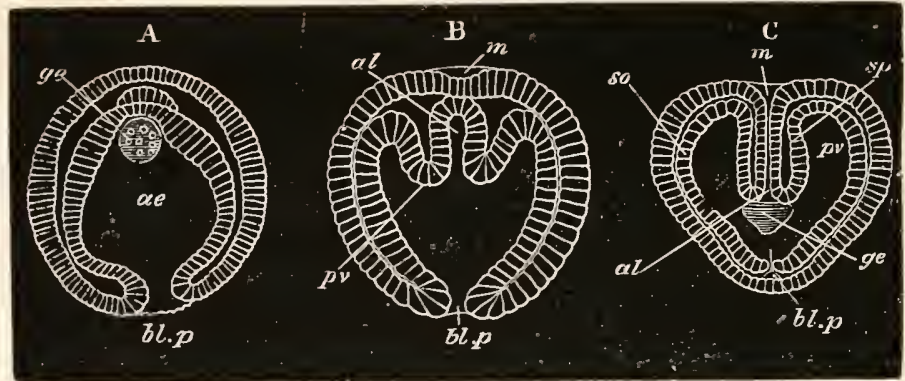

Fig, 408. Thref stages in the development of Sagitta. (A and C after Bütschli, and B after Kowalevsky.)

The three embryos are represented in the same positions.

A. Represents the gastrula stage.

B. Represents a succeeding stage, in which the primitive archenteron is commencing to be divided into three.

C. Represents a later stage, in which the mouth involution $(m)$ has become continuous with the alimentary tract, and the blastopore is closed.

$m$. mouth; al. alimentary canal; ae. archenteron; bl.p. blastopore; $p v$. perivisceral cavity; sp. splanchuic mesoblast; so. somatic mesoblast; ge. generative organs.

into four cells, which is not satisfactorily represented in my diagram, takes place in such a way that two cells are placed wearer the median line, and two externally. The two inner cells form the eventual testes, and the outer the ovaries, one half of each primitive cell thus forming an ovary, and the other a testis.

1 The Hertwigs (No. $27 \mathrm{I}$ ) state that in their opinion the generative cells arise from the lining of the body cavity in all the forms whose body cavity is a product of the archenteron. We do not know anything of the embryonic development of the generative organs in the Echinodermata, but the adult position of the generative organs in this group is very unfavourable to the Hertwigs' view.

30 . Hertwig, Die Chatognathen. Jena, 1880. 
When the archenteric cavity is divided into a median alimentary tract, and two lateral sections forming the body cavity, the generative organs are placed in the common vestibule into which both the body cavity and alimentary cavity at first open (fig. 40S).

The generative organs long retain their character as simp!e cells. Eventually (fig. 409) the two ovaries travel forwards, and apply themselves to the body walls, while the two testes also become separated by a backward prolongation of the median alimentary tract.

On the formation of the transverse septum divilling the tail from the borly, the ovarian cells lie immediately in front of this septum, and the testicular cells in the region behind it.

Polyzoa. In Pedicellina amongst the entcproctous Polyzon, Hatschek finds that the generative organs originate from a pair of specially large mesoblast cells, situated in the

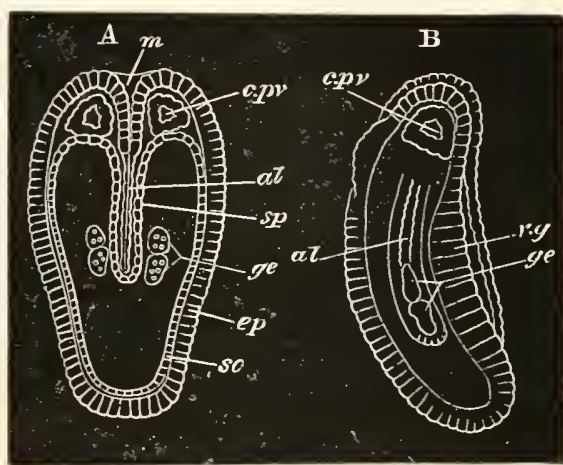

Fig. 409. Two views of a Late EMBRYo of SagitTa. A, from the dorsal suiface. $B$, from the side. (After Biitschli.)

$m$. mouth; al. alimentary canal; $\imath . g$. ventral ganglion (thickening of epiblast); ep. epiblast; c.pv. cephalic section of body cavity; so. somatopleure; $s p$. splanchnopleure; ge. generative organs.

space between the stomach and the floor of the vestibule. The two cells undergo changes, which have an obvious resemblance to those of the generative cells of the Chatognatha. They become surrounded by an investment of mesoblast cells, and divide so as to form two niasses. Each of these masses at a later period separates into an anterior and a posterior part. The former becomes the ovary, the latter the testis.

Nematoda. In the Nematoda the generative organs are derived from the division of a single cell which would appear to be mesoblastic ${ }^{\prime}$.

Insecta. The generative cells have been observed at a very early embryonic stage in several insect forms ( $V_{0}$. I. p. 34t), but the observations so far recorded with reference to them do not enable us to determine with certainty from which of the germinal layers they are derived.

Crustacea. In MIoina, one of the Cladocera, Grobben ${ }^{2}$ has shewn that the generative organs are derived from a single cell, which

1 Vide Vol. I. p. 309; also Götte, Zool. Anzeiger, No. So, p. 189.

2 C. Grobben. "Die Entwick. d. Moina rectirostris." Arleit. a. d. zool. Instit. Wien. Vol. II. 1879. 
becomes differentiated during the segmentation. This cell, which is in close contiguity with the cells from which both the mesoblast and hypoblast originate, subsequently divides; but at the gastrula stage, and after the mesoblast has become formed, the cells it gives rise to are enclused in the epiblast, and do not migrate inwards till a later stage. The products of the division of the generative cell subsequently divide into two masses. It is not possible to assign the generative cell of Moina to a definite germinal layer. Grobben, however, thinks that it originates from the division of a cell, the remainder of which gives rise to the hypoblast.

Chordata. In the Vertebrata, the primitive generative cells (often known as prinitive ova) are early distinguishable, being imbedded amougst the cells of two linear streaks of peritoneal epithelium, placed on the dorsal side of the body cavity, one on each side of the mesentery (figs. $405 \mathrm{C}$ and 410, po). They appear to be derived from the epitheliat cells amongst which they lie; and are characterized by containing a large granular nucleus, surrounded by a considerable body of protoplasm. The peritoneal epithelium in which they are placed is known as the germinal epithelium.

It is at first impossible to distinguish the gerninal cells which will become ova from thuse which will become spermatozoa.

The former however remain within the peritoneal epithelium (fir. 411), and hecome converted into ova in a manner more particularly described in Vol. I. pp. $4: 3-47$.

The listory of the primitive germinal cells in the male has not been so adequately workerl ont as in the female.

The fullest history of them is that given by Semper (No. 559) for the Elasmobranchii, the general accuracy of which I can fully support; though with reference to certain stages in the history further researches are still required ${ }^{1}$.

In Elasmobranchii the male germinal cells, instead of remaining in the germinal epithelium, migrate into the adjacent stroma, accompanied I believe

I Balbiani (No. 5.54) has also recently dealt with this subject, but I cannot bring my own observations into accord with his as to the structure of the Elasmobrauch testis. 
by some of the indifferent epithelial cells. Here they increase in number, and give rise to masses of variable form, composed partly of true germinal cells, and partly of smaller cells with deeply staining nuclei, which are, I believe, derived from the germinal epithelium.

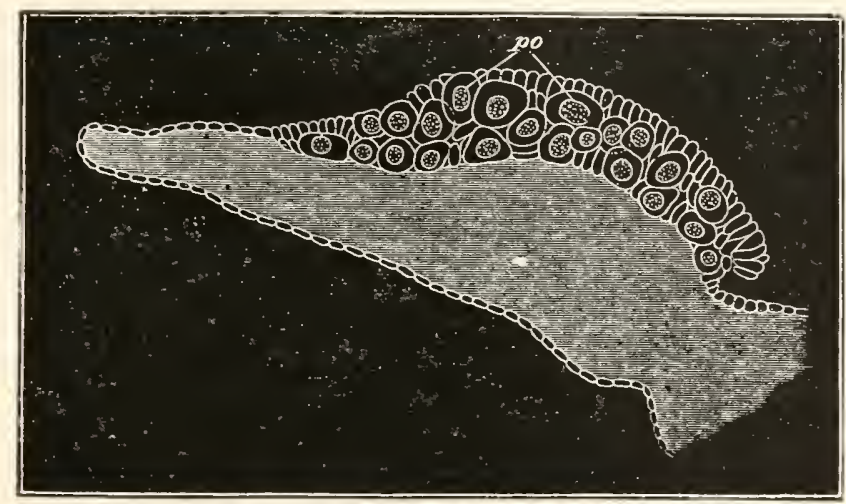

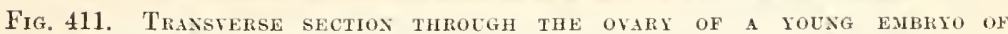

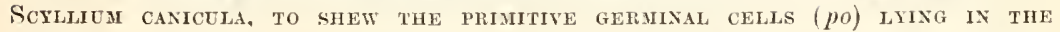
(WERINAL EPITHELIUA ON THE OUTER SIDE OF THE OYARIAN RIDGE.

These masses $n\lrcorner x t$ break up into ampullix, mainly formed of germinal cells, and each proviled with a central lumen; and these ampullæe attach themselves to tubes derived from the smaller cells, which are in their turn continuous with the testicular network. The spermatozoa are developed from the cells forming the walls of the primitive ampulla; but the process of their formation does not concern us in this chapter.

In the Reptilia Braun has traced the passage of the primitive germinal cells into the testicular tubes, and I am able to confirm his observations on tlis point: he has not however traced their further history.

In Mammalia the evidence of the origin of the spermatospores from the germinal epithelium is not quite complete, but there can be but little doubt of its occurrence ${ }^{1}$.

In Amphioxus Langerhans has shewn that the ova and spermatozoa are derived from similar germinal cells, which may be compared to the germinal epithelium of the Vertebrata. These cells are however segmentally arranged as separate masses (vide Vol. I. 1. 43).

\section{BIBLIOGRAPHY.}

* $\left(55_{4}\right)$ G. Balbiani. Leçons s. la génération des Vertébrés. Paris, 1879.

(55.) F. M. Balfour. "On the structure and development of the Vertebrate ovary," Quart. J. of Nicr. Science, Vol. xvir.

1 An entirely different view of the origin of the sperm cells has been adopted by Balbiani, for which the reader is referred to his Memoir (No. 554). 
(556) E. van Beneden. "De la distinction originelle du tecticule et de l'ovaire, etc." Bull. Ac. roy. belgique, Vol. xxxvir. 1874.

$(557)$ N. Kleinenberg. "Ueb. d. Entstehung d. Eier b. Eudendrium." Zeit. $f$. wiss. Zool., Vol. xxxv. 1881.

(558) H. I ud wig. "Ueb. d. Eibildung im Theirreiche." Arbeit. a. d. zool.-zoot. Instit. Wiirzburg, Vol. I. 1874.

(559) C. Semper. "Das Urogenitalsystem d. Plagiostomen, etc." Arbeit. $a . d$. zool.-zoot. Instit. Wï̈zburg, Vol. II. 1875.

(560) A. Weismanu. "Zur Frage nach dem Ursprung d. Geschlechtszellen bei den Hydroiden." Zool. Anzeiger, No. 55, 1880.

Vide also O. and R. Hertwig (No. 271), Kölliker (No. 298), ete.

\section{Genital Ducts.}

The development and evolution of the generative ducts is as yet very incompletely worked out, but even in the light of our present knowledge a comparative review of this subject brings to light features of considerable interest, and displays a fruitful field for future research.

In the Coelenterata there are no generative ducts.

In the Hydromedusa and Siphonophora the generative products are liberated by being dehisced directly into the surrounding medium; while in the Acraspeda, the Actinozoa and the Ctenophora, they are dehiseed into parts of the gastrovascular system, and carried to the exterior through the month.

The arrangement in the latter forms indicates the origin of the methods of transportation of the genital products to the exterior in many of the ligher types.

It has been already pointed out that the body cavity in a very large number of forms is probably derived from parts of a gastrovascular system like that of the Actinozoa.

When the part of the gastrovascular system into which the generative prolucts were dehisced became, on giving rise to the body cavity, shut off from the exterior, it would be essential that some mode of transportation outwards of the generative products should be constituted.

In some instances simple pores (probably already existing at the time of the establishment of a closed body cavity) become the generative ducts. Such seems probably to have been the case in the Chætognatha (Sagitta) and in the primitive Chordata.

In the latter forms the generative products are sometimes dehisced into the peritoneal cavity, and thence transported by the abdominal pores to the exterior (Cyclostomata and some Teleostei, vide p. 514). In Amphioxus they pass by dehicence into the atrial cavity, and thence through the gill slits and by the mouth, or by the abdominal pore (?) to the exterior. The arrangement in Amphioxus and the Teleostei is 110hably secourlary, as possibly also is that in the Cyclostomata; so that the primitive mode of exit of the generative products in the Chordata is still uncertain. It is highly improbahle that the generative ducts of the Tunicata are primitive structures. 
A hetter established and more frequent mode of exit of the generative prorhets when dehisced into the body cavity is by means of the excretory organs. The generative products pass from the body cavity into the open peritoneal funnels of such organs, and thence through their ducts to the exterior. 'This mode of exit of the generative products is characteristic of the Chatopoda, the Gepliyrea, the Brachiopoda and the Vertebrata, and probably also of the Mollusca. It is moreover quite possible that it occurs in the Polyzoa, some of the Arthroporla, the Platyelmintlies and some other types.

The simple segmental excretory organs of the Polychita, the Gephyrea and the Brachiopoda serve as generative canals, and in many instances they exhibit no modification, or but a very slight one, in connection with their secondary generative function; while in other instances, e.g. Bonellia, such modification is very considerable.

The generative ducts of the Oligochreta are probably derived from excretory organs. In the Terricola ordinary excretory organs are present in the generative segments in adlition to the generative ducts, while in the Linicola generative ducts alone are present in the adult, but before their levelopment excretory organs of the usual type are found, which undergo atrophy on the appearance of the generative ducts (Veiljovsky).

From the analogy of the splitting of the segmental duct of the Vertebrata into the Miillerian and Wolftian dncts, as a result of a combined generative and excretnry function (vide p. 600), it seems probable that in the generative segments of the Oligochieta the excretory organs had at first both an excretory and a generative function, and that, as a secondary result of this clouble function, each of them lias become split into two parts, a generative and an excretory. The generative part has undergone in all forms great moditications. The excretory parts remain unmodified in the Earthworms (Terricola), but completely abort on the development of the generative ducts in the limicola. An explanation may probably be given of the peculiar arrangements of the generative ducts in Siccocirrus amongst the Polychreta (vide Marion and Bobretzky), analogons to that just offered for the Oligochieta.

The very interesting modifications produced in the excretory organs of the Vertebrata by their serving as generative ducts were fully described in the last chapter; and with reference to this part of our subject it is only necessary to call attention to the case of Lepidosteus and the 'Teleostei.

In Lepidusteus the Miillerian duct appears to have become attached to the generative organs, so that the generative products, instear of falling directly into the body cavity and thence entering the open end of a peritoneal funnel of the excretory organs, pass directly into the Miillerian duct withont entering the body cavity. In most T'eleostei the modification is more complete, in that the grenerative duets in the adult have no obvious connection with the excretory organs.

The transportation of the male products to the exterior in all the higher Vertebrata, without passing into the body cavity, is in priuciple similar to the arrangement in Lepidosteus.

The above instances of the peritoneal funuels of an excretory 
organ becoming continuous with the generative glands, render it highly probable that there may be similar instances amongst the Invertebrata.

As has been already pointed out by Gegenbaur there are many features in the structure of the genital ducts in the more primitive Mollusca, which point to their having been derived from the excretory organs. In several Lamellibranchiata ${ }^{1}$ (Spondylus, Lima, Pecten) the generative ducts open into the excretory organs (organ of Bojanus), so that the generative products have to pass through the excretory organ on their way to the exterior. In other Lamellibranchiata the genital and excretory organs open on a common papilla, and in the remaining types they are placed close together.

In the Cephalopoda again the peculiar relations of the generative organs to their ducts point to the latter having primitively had a different, probably an excretory, function. The glands are not continuous with the ducts, but are placed in special capsules from which the duct: proceed. The genital products are dehisced into these capsules and thence pass into the ducts.

In the Gasteropoda the genital gland is directly continuous with its duct, and the latter, especially in the Pulmonata and Opisthobranchiata, assumes such a complicated form that its origin from the excretory organ would hardly have been suspected. The fact however that its opening is placed near that of the excretory organ point. to its being homologous with the generative ducts of the more primitive types.

In the IDiscophora, where the generative ducts are continuous with the glands, the structure both of the generative glands and ducts point. to the latter having originated from excretory organs.

It seems, as already mentioned, very possible that there are other types in which the generative ducts are derived from the excretory organs. In the Arthroporla for instance the generative ducts, where lrovided with anteriorly placed openings, as in the Crustacea, Arachnida and the Chiloguathous Myriapoda, the Pocilopoda, ete., may possibly be of this nature, but the data for deciding this point are so scanty that it is not at present possible to do more than frame conjectures.

The ontogeny of the generative ducts of the Nematoda and the Insecta appears to point to their having originated independently of the excretory organs.

In the Nematola the generative organs of both sexes originate from a single cell (Schneider, Vol. I. No. 390).

This cell elongates and its nuclei multiply. After assuming a somewhat columnar form, it divides into (1) a superficial investing layer, and (2) an axial portion.

In the female the superficial layer is only developed distinctly in

1 For a summary of the facts on this subject rile Broan, Klassen $u$. Ordnungen $d$. Thierreirhs, Vol. 1I. p. 404. 
the nodian part of the colmmu. In the course of the further development the two emrls of the colnmin liceome the blind ends of the ovary, and the axial tissue they contain forms the rerminal tissue of nucleated protoplasm 'The superficial layer gives rise to the epithelium of the uterus and oviduct. 'The germinal tissue, which is originally continuous, is interrupted in the midlle part (where the superficial laver gives rise to the uterus and oviduct), and is confined to the two lind extremities of the tube.

In the male the superficial layer, which gives rise to the epithelium of the vas deferens, is only formed at the hinder end of the original column. In other respects the development takes place as in the female.

In the Insecta again the evidence, though somewhat conflicting, indicates that the generative ducts arise very much as in Nematoles. from the same primitive mass as the generative organs. In both of these types it would seem probable that the generative organs were primitively placed in the body cavity, and attached to the epidermis, through a pore in which their products passed out; and that, acquiring a tubular form, the peripheral part of the gland gave rise to a ciuct, the remainder constituting the true generative gland. It is quite possible that the generative duets of such forms as the Platyelminthes may have had a similar origin to those in Inserta and Nematoda, but from the analogy of the Mollusea there is nearly as much to be said for regarding them as molified excretory organs.

In the Echinodermata nothing is unfortunately known as to the outogeny of the generative organs and ducts. 'The structure of these orgaus in the adult would however seem to iudicate that the most primitive type of echinodern generative organ consists of a blind sack, projectiug into the body cavity, and opening by a pore to the exterior. The sack is lined by an epithelinm, continuous with the epidermis, the cells of which give rise to the ova or spermatozoa. The duct of these organs is obviously harlly differentiated from the glaud; and the whole structure might easily be derived from the type of generative organ characteristic of the Hydromedusa, where the generative cells are developed from special areas of the ectolern, and, when ipe, pass directly into the surrounding medium.

If this suggestion is correct we may suppose that the generative ducts of the Echinodermata have a different origin to those of the majority of the remaining tiploblastica

Their ducts have been evolved in forms in which the generative products continued to be liberated directly to the exterior, as in the Hydromeduse; while those of other types have been evolved in forms in which the generative products were first transported, as in the Actinozoa, into the gastrovascular canals ${ }^{2}$.

It would be interesting to have further information about Balanoglossus.

2 These views fit in very well with those aheady put forward in Chapter xin. on the affinities of the Echinodermata. 


\section{CHAPTER XXV.}

\section{TIIE ALIMENTARY CANAL AND ITS APPENDAGES, IN THE CHORDATA.}

THE alimentary canal in the Chorlata is always formed of three sections, analogous to those so universally present in the Invertebrata. These sections are (1) the mesenteron lined by hypoblast; (2) the stomodicum or month lined by epibiast, and (3) the proctodrum or anal section lined like the stomodæum by epiblast.

\section{Mesenteron.}

The early development of the epithelial wall of the mesenteron has alreaty been described (Chapter XI.). It forms at first a simple hypoblastic tube extending from near the front end of the body, where it terminates blindly, to the hinder extremity where it is uniter with the neural tube by the neurenteric canal (fig. $420, n e$ ). It often remains for a long time widely open in the middle towards the yolk-sack.

It has already been shewn that from the dorsal wall of the mesenteron the notochord is separated off nearly at the same time as the lateral plates of mesoblast (pp. 24:3-249).

The subnotochordal rod. At a period slightly subsequent to the formation of the notochord, and before any important differentiations in the mesenteron have become apparent, a remarkable rorl-like body, which was first discovered by Götte, becomes split off from the dorsal wall of the alimentary tract in all the Ichthyopsida. 'This borly, which has a purely provisional existence, is known as the subnotochordal rod.

It develops in Elasmobranch embryos in two sections, one situated in the heal, and the other in the trunk.

The section in the trunk is the first to appear. The wall of the alimentary canal becomes thickened along the median dorsal line (fig. $412, x)$, or else produced into a ridge into which there penetrates a narrow prolongation of the lumen of the alimentary canal. In either case the cells at the extreme summit become gralually constricted off as a rod, 
which lies immediately dorsal to the alimentary tract, and ventral to the notochord (fig. $413, x$ ).

In the hindermost part of the body its morle of formation differs somewhat from that above described. In this part the aliment:ury wall is very thick, and undergoes no special growth prior to the formation of the sul,notochordal rod; on the contrary, a small linear portion of the wall becomes scooped out alomg the median dorsal line, and eventually separates from the remainder as the rod in question. In the trunk the splitting off of the rod takes place from before backwards, so that the anterior part of it is formed before the posterior.

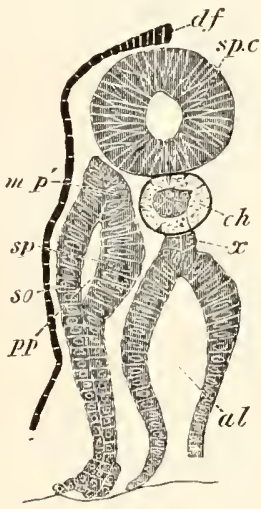

Fig. 412. Transverse sectiox throvgh the tail region of a PristiURUS EMBryo OF the SAME AGE as Fig. $2 s \mathrm{E}$.

df. dorsal fin; sp.e. spinal cord; $p p$. body cavity; sp. splanchnic layer of mesoblast; so. somatic layer of mesoblast; $m p^{\prime}$. portion of splanclunic mesoblast commencing to be differentiated into muscles; $c h$. notochord; $x$. subnotochordal rod arising as an outgrowth of the dorsal wall of the alimentary tract; al. alimentary tract.

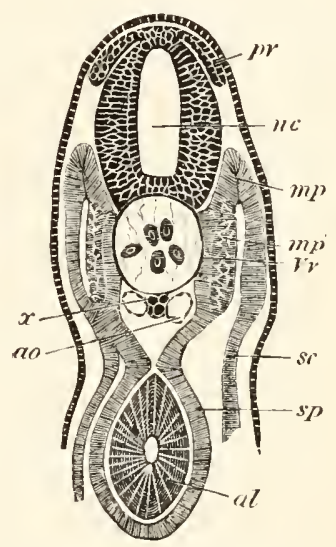

Fig. 413. Transverse secTION THROUGH TIE TRUNK OF AN EABRYO SLIGHTLY OLDER THAN F1G. 28 E.

ne. neural canal; pr. posterior root of spinal nerve; $x$. subnotochordal rod; ao. aorta; sc. somatic mesoblast; sp. splanchnic mesoblast; mp. muscle-plate; $m p^{\prime}$. por tion of muscle-plate converted into muscle; $r \because$ portion of the vertebral plate which will give rise to the vertebral bodies; $a$. alimentary tract.

The section of the subnotochordal rod in the head would appear to derelop in the same way as that in the trunk, and the splitting off from the throat proceeds from before backwards.

On the formation of the dorsal aorta, the subnotochordal rod heconies separated from the wall of the gut and the aorta interposed between the two (fig. $367, x$ ).

When the submotochordal rod attains its fullest development it terminates anteriorly some way in front of the auditory vesicle, though a little behind the end of the notochord; posteriorly it extends very nearly to the extremity of the tail and is almost co-extensive with the postanal section of the alimentary tract, though it does not reach quite so far back as 
the catudal vesicle (fig. $4 \mathscr{2} 4, h x$ ). Very shortly after it has attainer its maximum size it begius to atrophy in front. We may therefore conclude that its atrophy, like its development, takes place from before backwards. During the later embryonic stages not a trace of it is to be seen. It has also been met with in Acipenser, Lepidosteus, the Teleostei, Petromyzon, and the Ampluibia, in all of which it appears to develop in findamentally the same way as in Elasmobranchii. In Acipenser it appears to persist in the adult as the subvertebral ligament (Bridge, Salensky). It has not yet been found in a fully developed form in any amniotic Vertebrate, though a thickening of the hypoblast, which may perhaps be a rudiment of it, has been found by Marshall and myself in the Chick (fig. $110, x$ ).

Eisig has institnted an interesting comparison between it and an organ which he has found in a family of Chetopods, the Capitellide. In these forms there is a tuhe underlying the alimentary tract for nearly its whole length, and opening into it in front, and probably behind. A remnant of such a tuive might easily form a rudiment like the subnotochordal rod of the Ichthyopsida, and as Eisig points out the prolongation into the latter during its formation of the lumen of the alimentary tract distinctly favours such a view of its original natme. We can however hardly suppose that there is anv direct genetic comnection between Eisig's organ in the Catpitellide and the subnotochordal rod of the Cliordata.

Splanchnic mesoblast and mesentery. The nesenteron consists at first of a simple liypoblastic tube, which however becomes enveloped by a layer of splanchnic mesoblast. This layer, which is not at first continued over the clorsal side of the mesenteron, gradually grows in, and interposes itself between the hypoblast of the mesenteron, and the organs above. At the same time it becomes differentiated into two layers, viz. an outer epithelioid layer which gives rise to part of the peritoneal epithelium, and an inner layer of undifferentiated cells which in time becomes converted into the connective tissue and muscular walls of the mesenteron. The connective tissue layers become first formed, while of the muscular layers the circular is the first to make its appearance.

Concidently with their differentiation the connective tissue stratum of the peritoneum becomes established.

The Mesentery. Prior to the splanchnic mesoblast growing round the alimentary tube above, the attachment of the latter structure to the dorsal wall of the body is very wile. On the completion of this investment the layer of mesoblast suspending the alimentary tract becomes thinner, and at the same time the alimentary canal appears to be drawn downwards and away from the vertebral column.

In what may be regarded as the thoracic division of the general pleuroperitoneal space, along that part of the alimentary canal which will form the cesophagns, this withdrawal is very slight, but it is very marked in the abdominal region. In the latter the at first straight digestive canal comes to be suspended from the body above by a narrow flattened band of mesoblastic tissue. This flattened band is the mesentery, shewn commencing in fig. 117, and mucl, 
more atvanced in fig. $119, M$. It is covered on either side hy a layer of that cells, which form part of the general peritoneal epithelioid lining, while its interior is composed of indifferent tissue.

The primitive simplicity in the arrangement of the mesentery is usually afterwards replaced by a more complicated disposition, owing to the subsequent elongation and consequent convolution of the intestine and stomach.

The layer of peritoneal epithelimm on the ventral sicle of the stomach is continued over the liver, and after embracing the liver, becomes attacherl to the ventral ablominal wall (fig. 380). Thus in the region of the liver the body cavity is divided into two halves by a membrane, the two sides of which are covererl by the peritoneal epithelium, and which encloses the stomach dorsally and the liver ventrally. 'The part of the membrane between the stomach and liver is narrow, and constitutes a kind of mesentery suspending the liver from the stomach: it is known to human anatomists as the lesser omentum.

The part of the membrane connecting the liver with the anterior abdominal wall constitutes the falciform or suspensory ligament of the liver. It arises by a secondary fusion, and is not a remnant of a primitive ventral mesentery (vide pp. 513 and 514).

'The mesentery of the stomach, or mesogastrium, enlarges in Mammalia to form a peculiar sack known as the greater omentum.

'The mesenteron exhibits very early a trifold division. An anterior portion, extending as far as the stomach, becomes separated off as the respiratory division. On the formation of the anal invagination the portion of the mesenteron behind the anus becomes marked off as the postanal division, and between the postanal section and the respiratory division is a middle portion forming an intestinal and cloacaldivision.

\section{The respiratory division of the mesenteron.}

This section of the alimentary canal is distinguished by the fact that its walls send out a series of paired diverticula, which nieet the skin, and after a perforation bas been effected at the regions of contact, form the branchial or visceral clefts.

In Amphioxus the respiratory region extends close up to the opening of the hepatic diverticulum, and therefore to a position corresponding with the commencenent of the intestine in higher types. In the craniate Vertebrata the number of visceral clefts has become reduced, but from the extension of the visceral clefts in Amphioxus, combined with the fact that in the higher Vertebrata the vagus nerve, which is essentially the nerve of the branchial pouches, supplies in addition the walls of the oesophagus and stomach, it may reasonably be concluded, as has been pointed out by Gegenbaur, that the true respiratory region primitively included the region which in the higher types forms the cestophagus and stomach. 
In Ascilians the respiratory sack is homologous with the respiratory tract of Amplioxus.

The details of the development of the branchial clefts in the different gromps of Vertebrata liave already been described in the systematic part of this work.

In all the Ichthyopsida the walls of a certain number of clefts become folded; and in the mesoblast within these folds a rich capillary network, receiving its blood from the branchial arteries, becomes established. These folds constitute the true internal gills.

In adlition to internal gills external brunchial processes covered by epiblast are placed on certain of the visceral arches in the larva of Polypterus, Protopterus and many Amplibia. The external gills have probably no genetic connection with the internal gills.

The so-called external gills of the embryos of Elasmobranchii are merely internal gills prolonged ontwards through the gill clefts.

The posterior part of the primitive respiratory division of the mesenteron becomes, in all the higher Vertebrata, the resoplagus and stomach. With reference to the development of these parts the only point worth especially noting is the fact that in Elasmobranchii and 'T'eleostei their lumen, though present in very young embryos, becomes at a later stage completely filled up, and thus the alimentary tract in the regions of the osophagus and stomach becomes a solid cord of cells (fig. $23 \mathrm{~A}, \infty \mathrm{s}$ ): as already suggested (p. 50) it seens not impossible that this feature may be connected with the fact that the asophageal region of the throat was at one time perforated by gill clefts.

In adlition to the gills two important organs, viz. the thyroid body and the lungs, take their origin from the respiratory region of the alimentary tract.

Thyroid body. In the Ascidians the origin of a groove-like diverticulum of the ventral wall of the branchial sack, bounded by two lateral folds, and known as the endostyle or hypopharyngeal groove, has already been described (p. 15). This groove remains permanently open to the pharyngeal sack, and would seem to serve as a glandular

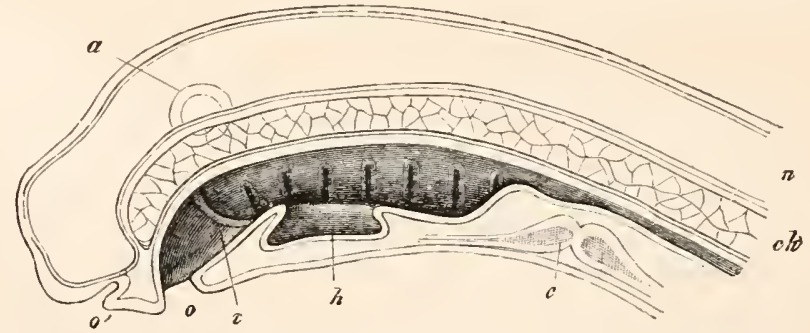

F1g. 114. Diaframatic vertical sectiox of a jest-hatchen laria of Petromizon. (From (iegenbaur; after Calberla.)

o. moutlı; $o^{\prime}$. olfactory pit; $v$. septum between stomodxum and mesenteron; h. thyroid involution; $n$. spinal cord; $c h$. notochord; $c$. heart; $a$. auditory vesicle. 
organ secreting mucus. As was first pointed ont by IV. Miiller there is present in Amphioxus a very similar and probably homologins organ, known as the hypopharyngeal groove.

In the higher Vertebrata this organ never retains its primitive condition in the adult state. In the lava of Petromyzon there is however, present a ventral groove-like diverticulum of the throat, extending from about the second to the fourth visceral cleft. This organ is shewn in longitudinal section in fig. $414, h$, and in transverse section in fig. 415, and has been identified by W. Niiller (Nos. 565 and 566) with the hypopharyngeal groove of Amphioxus and Ascidians. It does not, however, long retain its primitive condition, but its opening becomes gralually reduced to a pore, placerl between the third and fourth of the permanent clefts (fin. 416 , th). This opening is retained throughout the Ammocote condition, but the organ becomes highly complicated, with paired anterior and posterior horns and a median spiral portion. In the adult the

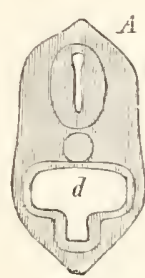

Fig, 115.
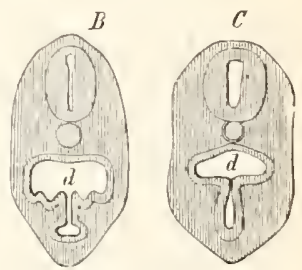

Dharamatic TRANS. VERSE SECTIONS THROUGII THE BRANCHIAI REgION OF YOUNG LARVe OE PetroyizoN. (From Gegenbaur; after Calberla.) a. branchial region of throat. connection with the pharyux is obliterated, and the organ is partly absorbed and partly divided np into a series of glandular tollicles, and eventually forms the thyroid borly.

From the consideration of the above facts W. Miiller was led to the conclusion that the thyroid body of the Craniata was derived firom the endostyle or hypopleryngeal grooce. In all the higher Vertebrata

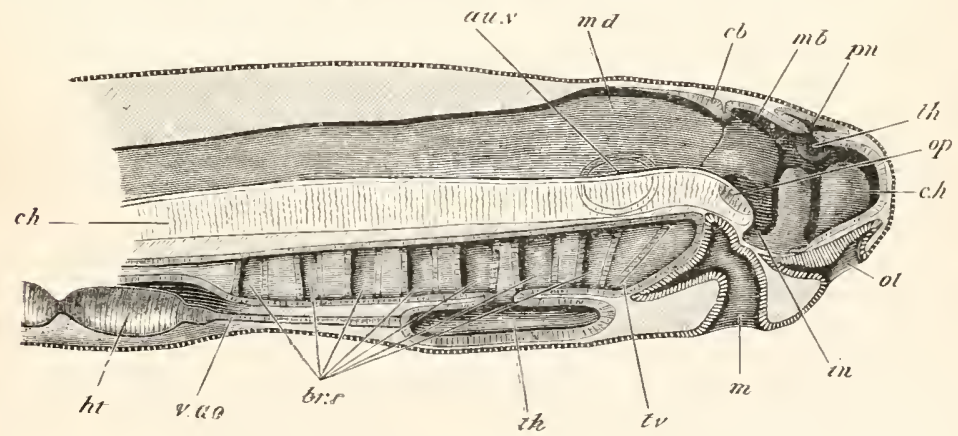

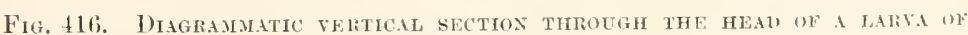
I'ETROAYZON.

The larva har been hatehed three days, and was $4.8 \mathrm{~mm}$. in length. The optic and auditory vesicles are supposed to be seen through the tissues. The letter to lointingy to the base of the velum is where Scott believes the hyomandibular cleft to be situated.

c.h. cerebral hemisphere; th. optic thal:umus; in. infundibulmo $p n$. pineal glime; mb. mid-brain; cb. cercbellum; md. medulla oblongata; an.r. anditory vesicle; op. optic vesicle; ol. olfactory pit; $m$. mouth; lu.e. branchial poncles; th. thyroid inrohution; $v .(u o$. ventral aorta; $h t$. ventricle of heart; $r h$. notochord.

I3. E. II. 
the thyroid body arises as a diverticulum of the ventral wall of the throat in the region either of the mandibular or hyoid arches (fig. 417, $T h$ ), which after being segmented off becomes divided up into follicles.

In Elasmobranch embryos it appears fairly early as a diverticulum from the ventral surface of the throat in the region of the mandibular arch, extending from the border of the mouth to the point where the ventral aorta divides into the two aortic branches of the mandibular arch (fig. $417, T \%$ ). Somewhat later it becomes in Scyllium and Torpedo solid, though still retaining its attachment to the wall of the cesophagus. It continues to grow in length, and becomes divided up into a number of solid branched lohules separated by comnective tissue septa. Eventually its comnection with the throat becones lost, and the lohules develop a lumen. In Acanthias the lumen of the gland is retained (W. Müller) till after its detachment from the throat. It preserves its embryonic position through life. In Amplhibia it originates, as in Elasmolnanchii, from the region of the mandibular arch ; but when first visible it forms a double epithelial wall connecting the throat with the nervous layer of the epidermis. It subsequently becomes detached from the epidermis, and then has the usual form of a diverticulum from the throat. In most Amphibians it becomes divided into two lobes, and so forms a praired body. The preculiar connection between the thyroid diverticulum and the epidermis in Amphibia has been noted by Giitte in Bombinator, and by Scott and Osborn in Triton. It is not very eacy to see what meaning this connection can have.

In the Fowl (W. Miuller) the thyroid body arises at the end of the second or begimning of the third day as an outgrowth from the hypoblast of the throat, opposite the point of origin of the anterior arterial arch. This outgrowth becomes by the fourth day a solid mass of cells, and hy the fifth ceases to be connected with the epithelium of the throat, becoming at the same time lilobed. By the seventh day it has travelled somewhat l,ackwards, and the two lobes have completely separated from each other. By the ninth day the whole is invested by a capsule of connective tissue, which sends in septa dividing it into a number of lobes or solid masses of cells, and by the sixteenth day it is a paired body composed of a number of hollow branched follicles, each with a 'membrana propria,' and separated from each other by septa of comnective tissue. It finally travels back to the point of origin of the caroticls.

Amongst Mammalia the thyroid arises in the Rabbit (Kölliker) and Man (His) as a hollow diverticulum of the throat at the bifurcation of the foremost pair of aortic arches. It soon however becomes solid, and is eventually detached from the throat and comes to lie on the ventral side of the larynx or windpipe. The changes it undergoes are in the main similar to those in the lower Vertebrata. It becomes partially constricted into two lobes, which remain however mnited by an isthmus'. The fact

1 Wölfler (Nc. 5.I ) states that in the Pig and Calf the thyroid body is formed as a pair of epithelial resicles, which are developed as outgrowths of the walls of tlee first pair of visceral clefts. He attempts to explain the contradictory observations of other embryologists by supposing that they have mistaken the ventral ends of visceral pouches for an unpaired outgrowth of the throat. Stieda (No. 569) also states that in the Pig and Sheep the thyroid arises as a paired body from the epithelium of a pair of visceral alefts, at a much later period than would appear from the observations of 
that the thyroil sometimes arises in the region of the first and sometimes in that of the second cleft is probably to be explained by its rudimentary character.

The Thymus gland. The thymus gland may conveniently be dealt with here, although its origin is nearly as obscure as its function. It has usually been held to be connected with the lymphatic system. Kölliker was the first to shew that this riew was probably erroneous, and he attempted to prove that it was derived in the Rabbit from the walls of one of the visceral clefts, mainly on the groum of its presenting in the embryo an ejithelial character.

Stieda (No. 569) has recently verified Kölliker's statements. He finds that in the rig and the sheep the thymus arises as a paired outgrowth from the epithelial remnants of a pair of visceral clefts. Its two lobes may at first be either hollow (Sheep) or solid (Pig), but eventually beeome solid, and tmite in the median line. Stieda and His hold that in the adult gland, the socalled corpuscles of Hassall are the remnants of the embry onic epithelial part of the gland, and that the lymphatic part of it is of mesoblastic origin; but Kiblliker believes the lymphatic cells to be direct products of the embryonic epithelial cells.

'The posterior visceral clefts in the course of their atrophy give rise to various more or less conspictous bodies of a pseudo. glandular nature, which have been chiefly studied by Remak ${ }^{1}$.

Swimming bladder and lungs. A swimming bladder is present in all Ganoids and in the vast majority of 'T'eleostei. Its development however is only imperfectly known.

In the Salmon and Carp it arises, as was first shewn by Von Baer, as an outgrowth of the alimentary tract, shortly in front of the liver. In these forms it is at first placed on the dorsal side and slightly to the right, and grows backwards on the dorsal side of the gut, between the two folds of the mesentery.

The absence of a pneumatic dnet in the Physoclisti would appear to be due to a post-larval atrophy.

His and Kölliker. In view of the comparative development of this organ it is difficult to accept either Wölfler's or Stieda's account. Wölfler's attempt to explain the supposed errors of his predecessors is certainly not capable of being applied in the case of Elasmobranch Fishes, or of Petromyzon; and I am inclined to think that the method of investigation by transverse sections, which has been usually employed, is less liable to error than that by longitudinal sections which he has adopted.

1 For details on these organs vid, Kölliker, Entwirlilun!ssteschichte, p. 881. 
In Lepidosteus the air-bladder appears to arise, as in the Teleostei, as an invagination of the dorsal wall of the oesophagus.

In advanced embryos of Galens, Mustelus and Acanthias, MikluchoMaclay detected a small diverticulum opening on the dorsal side of the wsophagus, which he regards as a rudiment of a swimming bladder. This interpretation must however be regarded as somewlat doubtful.

The lungs. The lungs originate in a nearly identical way in all the Vertebrate forms in which their development has been observed. They are essentially buds or processes of the ventral wall of the primitive osophagus.

At a point inmediately behind the region of the visceral clefts the cavity of the alimentary canal becomes compressed laterally, and at the sane time constricted in the midule, so that its transverse section (fig. $418 \mathrm{l}$ ) is somewhat hourglass-shaped, and shews an upper or dorsal chamber $d$, joining on to a lower or ventral chamber $l$ by a short narrow neek.

The hinder end of the lower tube enlarges (fig. $41 \mathrm{~S}_{2}$ ), and then becomes partially diviled into two lobes (tig. $418_{3}$ ). All these parts at first freely communicate, but the two lubes, partly by their own growth, and partly by a process of constriction, soon become isolated posteriorly ; while in fiont they open into the lower chamber of the nesophagus (fig. 4.22).

By a contimuation forwards of the process of constriction the lower chamber of the œsophagus, carrying with it the two lobes alove mentioned, becomes gradually transformed into an independent tube, opening in front by a narrow slitlike aperture into the resophagus. The single tube in front is the rudiment of the trachea and larynx, while the two diverticula behind become (fig. $419, \lg$ ) the bronchial tubes and lungs.

While the above changes are taking place in the hypoblastic walls of the alimentary tract, the splanchuic mesoblast surrounding these structures becomes very much thickened; but other"vise hears no marks of the interua! changes which are going (1), so that the
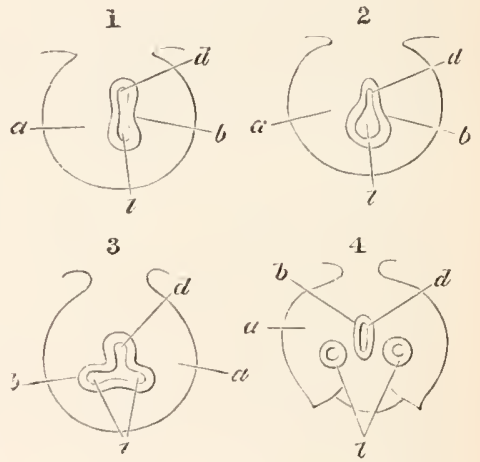

Fig. 418. Four Diagras ILLUSTra. TING THE FORMATION OF THE LUNGS. (After Götte.)

$a$. mesoblast; $b$. hypoblast; $d$. cavity of digestive canal; $l$. eavity of the pulmonary diverticulum.

In (1) the digestive canal has commenced to be constricted into an upper and lower canal; the former the true alimentary canal, the latter the pulmonary tube; the two tubes communicate with each other in the centre.

In (2) the lower (pulmonary) tube has become expanded.

In (3) the expanted portion of the tube has become constricted into two tubes, still communicating with each other and with the digestive canal.

In (1) these are completely separated from each other and from the digestive canal, anil the mesoblast has also begun to exhibit externally changes corresponting to the internal changes which have been going on. 
above formation of the lungs and trachea cannot be seen from the surface. As the paired diverticula of the lungs grow backwards, the mesoblast around them takes however the form of two lobes, into which they gradually bore their way.

There do not seem to be any essential differences in the mode of formation of the above structures in the types so far observed, riz. Amphibia, Aves and Mammalia. Writers differ as to whether the lungs first arise as paired direrticula, or as a single diverticulum ; and as to whether the rudiments of the lungs are established hefore those of the trachea. If the above account is correct it would appear that any of these positions might be naintained. Phylogenetically interpreted the ontogeny of the lungs applears however to inply that this organ wils first an mpraired structure and has become secondanily paired, and that the trachea was relatively late in appearing.

The further development of the lungs is at first, in the higher types at any rate, essentially similar to that of a racemose gland. From each primitive diverticulum numerous branches are given off. In Ares and Manmolia (fig. 35.5) they are mainly confined to the dorsal and lateral parts. These branches penetrate into the surrounding mesoblast and contimue to give rise to secondary and tertiary branches. In the mesoblast around them numerous capillaries

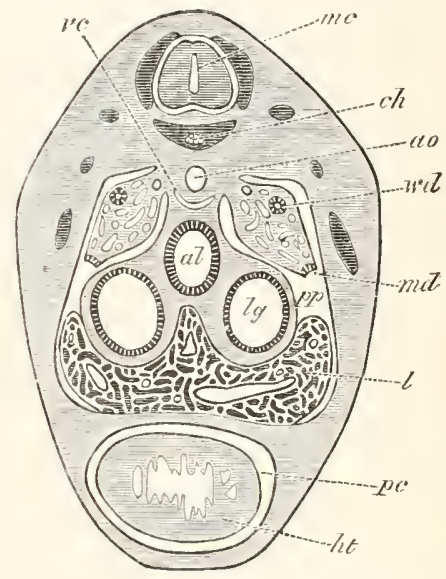

Fig. 419. Section throvgh the CARDIAC RELION OF AN EMBRYO OF LACERTA MUPALIS OF 9 MA. TO SHEW THE MODE OF FORMATION OF THE PERICARDIAL CATITY.

lit. heart; pe. pericardial cavity ; al. alimentary tract; lo. lung; 7 . liver; pp. body cavity; md. open end of IIullerian duct; $u d$. Wolffian duct; rc. vena cara inferior; ao. aorta; w. notochord; me. medullary cord.

make their appearance, and the further growth of the bronchial tubes is supposed by Boll to be due to the nutual inte: action of the hitherto passive mesoblast and of the hypoblast.

The further changes in the lungs vary somewhat in the different forms.

The air sacks are the most characteristic structures of the avian lung. They are essentially the dilated ends of the primitive diverticulat or of their main branches.

In Miammalia (Fölliker, No. 298) the ends of the bronclial tubes become dilated into resicles, which may be called the primary air-cells. At first, owing to their development at the ends of the bronchial branches, these are contined to the surface of the lungs. At a later period the primary air-cells divide each into two or three parts, and give rise to secondiny air cells, while at the same time the smallest bronchial tules, which continue all the while to divide, give rise at all points to firesh aircells. Finally the bronehial tubes cease to become more branched, and the 
air-cells belonging to each minute lobe come in their further growth to open into a common chamber. Before the lungs assume their function the embryonic air-cells undergo a considerable dilatation.

The trachea and larym. The development of the trachea and larynx does not require any detailed description. The larynx is formed as a simple dilatation of the trachea. The cartilaginous structures of the larynx are of the same nature as those of the trachea.

It follows from the above account that the whole pulmonary structure is the result of the growth by budding of a system of branched liypoblastic tubes in the midst of a mass of mesoblastic tissue, the hypoblastic elements giving rise to the epithelium of the tubes, and the mesoblast providing the elastic, muscular, cartilaginous, vascular, and other connective tissues of the tracheal and bronchial walls.

There can be no doubt that the lungs and air-bladder are homologous structures, and the very interesting memoir of Eisig on the air-bladder of the Clixtopoda ${ }^{1}$ shews it to be highly probable that they are the divergent modifications of a primitive organ, which served as a reservoir for gas secreter in the alimentary tract, the gas in question being probably employed for respiration when, for any reason, ordinary respiration by the gills was insufficient.

Such an organ might easily become either purely respiratory, receiving its air from the exterior, and so form a true lung; or mainly hydrostatic, forming an air-bladder, as in Ganoidei and Teleostei.

It is probable that in the Elasnobranchii the air-bladder has become aborted, and the organ discovered by Micklucho-Maclay may perhaps be a last remnant of it.

The middle division of the mesenteron. 'The middle division of the mesenteron, forming the intestinal and cloacal region, is primitively a straight tube, the intestinal region of which in most Vertebrate embryos is open below to the yolk-sack.

Cloaca. In the Elasmobranchii, the embryos of which probably retain a very primitive condition of the mesenteron, this region is not at first sharply separated from the postanal section behind. Opposite the point where the amus will eventually appear a dilatation of the meseuteron arises, which comes in contact with the external skin (fig. $28 \mathrm{E}, \mathrm{an}$ ). This dilatation becomes the hypoblastic section of the cloaca. It communicates behind with the postanal gut (fig. 424 D), and in front with the intestine; and may be defined as the dilated portion of the alimentary tract which receives the genital and urinary ducts and opens externally by the proctodaum.

In Acipenser and Amphibia the cloacal region is indicated as a rentral diverticulum of the mesenteron even before the closure of the blastopore. It is shewn in the Amphibia at an early stage in fig. 73, and at a later period, when in contact with the skin at the point where the anal invagination is about to appear, in fig. 420 .

1 H. Eisig, "Ueb. d. Vorkommen eines schwimmblasenähnlichen Organs bei Anneliden." Vittheil. a. l. zool. Station z. Neapel, Tol. Ir. 1881. 
In the Suuropsida and Mammalia the cloaca appears as a dilatation of the mesenteron, which receives the opening of the allantois almost as soon as the posterior part of the inesenteron is established.

The eventual changes which it undergoes have been already dealt with in connection with the urinogenital organs.

Intestine. The region in front of the cloaca forms the intestine. In certain

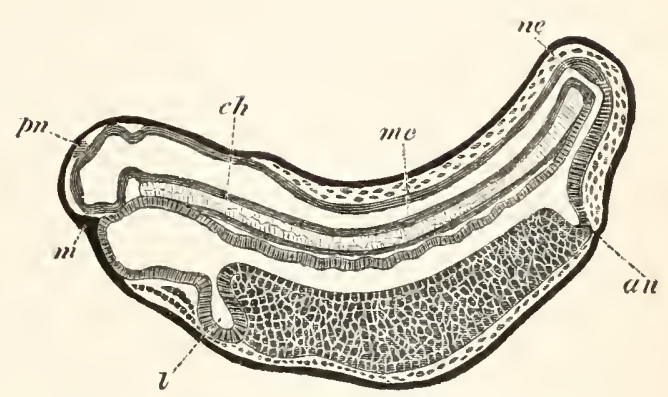

Fit. 420. Loxglevidial section throvgh an at). vanced embryo of Bombinator. (After Götte.)

$m$. mouth; an. anus; l. liver; ne. neurenteric canal; me. medullary canal; $c h$. notochord; $p n$. pineal gland.

Vertebrata it nearly

retains its primitive character as a straight tube; and in these types its anterior part is characterised by the presence of a peculiar fold, which in a highly specialised condition is known as the spiral valve. 'This structure appears in its simplest form in Anmocotes. It there consists of a fold in the wall of the intestine, giving to the lumen of this canal a semilunar form in section, and taking a half spiral.

In Elasmobranchii a similar fold to that in Ammocotes first makes its appearance in the embryo. This fold is from the first not quite straight, but winds in a long spiral round the intestine. In the course of development it becomes converted into a strong ridge projecting into the lumen of the intestine (fig. 38s, l). The spiral it makes becomes much closer, and it thus acquires the form of the adult spiral valve. A spiral valve is also found in Chimara and Ganoids. No rudiment of such an organ is found in the Teleostei, the Amphibia, or the higher Vertebrata.

The presence of this peculiar organ appears to be a very primitive Vertebrate character. The intestine of Ascidians exhibits exactly the same peculiarity as that of Ammocotes, and we may probably conclude from enibryology that the ancestral Chordata were provided with a straight intestine having a fold projecting into its lumen, to increase the area of the intestinal epithelium.

In all forms in which there is not a spiral valve, with the exception of a few Teleostei, the intestine becomes considerably longer than the cavity which contains it, and therefore necessarily more or less convoluted.

The posterior part usually becomes considerably enlarged to form the rectum or in Mammalia the large intestine.

In Elasmobranchii there is a peculiar gland opening into the 
dorsal side of the rectum, and in many other forms there is a cacum at the commencement of the rectun or of the large intestine.

In 'Teleostei, the Sturgeon and Lepidosteus there opens into the frunt end of the intestine a number of cueal pouches known as the pancreatic caca. In the adult Sturgeon these pouches unite to form a compract gland, but in the embryo they arise as a series of isoliated outgrowths of the duodenum.

Commeted with the anterior portion of the middle region of the alimentary canal, which may be called the duodenum, are two very important and constant glandular organs, the liver and the pancreas.

The liver. The liver is the earliest formed and largest glandular wgan in the embryo.

It appears in its simplest form in Amphioxus as a single unbranched diverticulum of the alinentary tract, immediately behind the respiratory region, which is directed forwards and placed on the left sille of the body.

In all true Vertebrata the gland has a much more complicated structure. It arises as a ventral outgrowth of the duodenum (fig. $+20, l)$. 'llis outgrowth may be at first single, and then grow out into two lobes, as in Elasmobranchii (fig. 4.21) and Amphibia, or have from the first the form of two somewhat unequal diverticula, as in Birls (fig. 4.22), or again as in the Rabbit (Kölliker) one diverticulum may be first formed, and a second one appear somewhat later. The

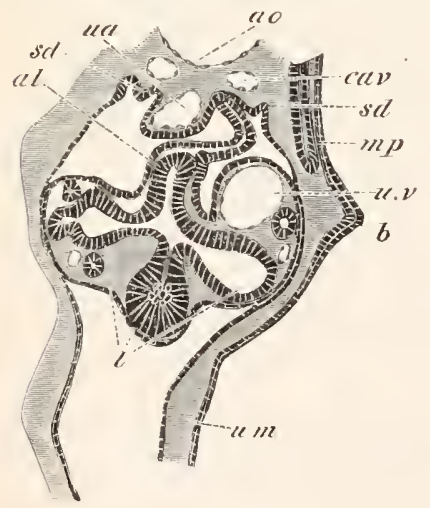

Fig. 421. Section thiovgh the VEXTRAL PART OF THE TRUNK OF A YOUNG EMBITO OF SEYLALM AT THI LEVEL OF THE UMBHLAL CORD.

b. pectoral fin; ao. dorsal aorta; cav. cardinal rein; ua. vitelline artery; uv. vitelline vern mited with subintestinal vein; al. duodenum; 7. liver; sd. opening of segmental duct into the boly-cavity ; mp. musele-piate; um. umbilical canal. hepatic diverticula, whatever may be their prinitive form, grow into a special thickening of the splanchnic mesoblast.

From the primitive diverticula there are soon given off a number of hollow buds (fig. 421 ) which rapidly increase in length and number, and form the so-called hepatic cylinders. They soon anastomose and unite together, and so constitute an irregular network. Coincidently with the formation of the hepatic network the united vitelline and visceral vein or veins $(u, v)$, in their passage through the liver, give off numerous branches, and gradually break up into a plexus of channels which form a sceondary network amongst the hepatic cylinders. In Amphibia these channels are stated by Götte to be lacunar, but in Elasmobranchii, and probably Vertebrata generally, they are from the first provided with distinct though delicate walls. 
It is still doubtful whether the lopatic cylinders are as a rule hollow or solid. In Elasmobranchii they are at first provided with a large lumen, which though it becomes gradually smaller never entirely vamishes. The sime seems to holel good for Amphibia and some Manmalia. In Aves the lumen of the cylinders is even from the first much more difficult to see, and the cylinders are stated by liemak to be solid, and lie luas been followed in this natter by Kölliker. In the Rabbit also Kölliker finds the cylinders to be solid.

The embryonic hepatic network gives rise to the parenchyma of the alult liver, with which in its general arrangement it elosely agrees. The blood-channels are at first very large, and have a very irregnlar arrangement; and it is not till comparatively late that the hepatic lobules with their characteristic vascular structures beconne establisherl.

The biliary ducts are formed either from some of the primitive hepatic cylinders, or; as would seem to be the case in Elasmobranchii and Birds (tig. 4.2.), from the larger diverticula of the two primitive outgrowths.

The gall-bladder is so inconstant, and the arrangement of the duets opening into the intestine so variable, that no general statements can be made about them. In Elasmobranchii the primitive median diverticulum (fig. 42!) gives rise to the ductus choledochus. Its anterior end lilates to form a gall-bladder.

In the Rabbit a ductus choledochus is forned by a diverticulum from the intestine at the point of insertion of the two primitive lubes. The gall-bladder arises as a diverticulum of the right primitive lobe.

'The liver is relatively very large during embryonic life and has, 110 doubt, important functions in connection with the cireulation.

The pancreas. So far as is known the development of the pancreas takes place on a very constant type throughout the series of craniate Vertehrata, thongh absent in sone of the Tuleostean fishes and Cyclostomata, and very much reduced in most Teleostei and in Petroniyzon.

It arises nearly at the same time as the liver in the form of a hollow outgrowth from the dorsal sile of the intestine nearly opposite but slightly behind the hepatic outgrowth (fig. $422, p$ ). It soon assunes, in Elasmobranchii and Mammalia, somewhat the form of in inverted funnel, and from the expanded dorsal part of the funnel 
there grow out numerous hollow diverticula into the passive splanchnic mesoblast.

As the ductules grow longer and become branched, vascular processes grow in between them, and the whole forms a compact glandular body in the mesentery on the dorsal side of the alimentary tract. The funnel-shaped receptacle loses its original form, and elongating, assumes the character of a duct.

From the above mode of development it is clear that the glandular cells of the pancreas are derived from the hypoblast.

Into the origin of the varying arrangements of the pancreatic ducts it is not possible to enter in detail. In some cases, e.g. the Rabbit (Kölliker), the two lobes and ducts arise from a division of the primitive gland and duct. In other cases, e.g. the Bird, a second diverticulum springs from the alimentary tract. In a large number of instances the primitive condition with a single duct is retained.

Postanal section of the mesenteron. In the embryos of all the Chordata there is a section of the mesenteron placed behind the anus. This section invariably atrophies at a comparatively early period of embryonic life; but it is much better developed in the lower forms than in the higher. At its posterior extremity it is primitively continuous with the neural tube (fig. 420), as was first shewn by Kowalevsky.

The canal connecting the neural and alimentary canals has alrearly been described as the neurenteric canal, and represents the remains of the blastopore.

In the Tunicata the section of the mesenteron, which in all probability

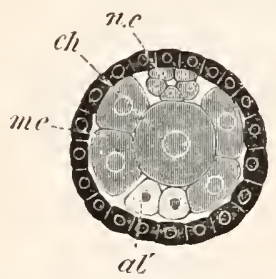

Fig. 423. Transverse optical SECTION OF THE TAIL OF AN EM. mrxo of Phallusia mammilata. (After Kowalevsky.)

The section is from an embryo of the same age as fig. $8 \mathrm{Iv}$.

ch. notochord; n.c. neural canal; me. mesoblast; al'. hypoblast of tail. corresponds to the postanal gut of the $V$ ertebrata, is that immediately following the dilated portion which gives rise to the branchial cavity and permanent intestine. It has alleady been shewn that from the dorsal and lateral portions of this section of the primitive alimentary tract the notochord and muscles of the Ascidian tadpole are derived. The remaining part of its walls forms a solid cord of cells (fig. 423, $a l^{\prime}$ ), which either atrophies, or, according to Kowalevsky, gives rise to blood-vessels.

In Amphioxus the postanal gut, thougl distinctly developed, is not very long, and atrophies at a comparatively early period.

In Elasmolnanchii this section of the alimentary tract is very well developed, and persists for a considerable period of embryonic life. The following is a history of its development in the genus Scyllium.

Shortly after the stage when the anns has become markerl out by the alimentary tract sending down a papilliform precess towards the skin, the 
postanal gut begins to develop a terminal dilatation or vesicle, comnecter with the remainder of the canal by a narrower stalk.

The walls both of the resicle and stalk are formed of a fairly columnar epithelium. The vesicle communicates in front by a narrow passage with the neural canal, and belind is continued into two horns corresponding with the two caudal swellings previously spoken of (p. 45). Where the canal is continued into these two horns, its walls lose their distinctness of outline, and become continuous with the adjacent mesoblast.

In the succeeding stages, as the tail grows longer and longer, the postanal section of the alimentary tract grows with it, without however undergoing alteration in any of its essential characters. At the period of the maximun development, it has a length of about $\frac{1}{3}$ of that of the whole alimentary tract.

Its features at a stage shortly before the external gills have become prominent are illustrated by a series of transverse sections through the tail (fig. 424). The four sections have been selected for illustration out of a fairlycomplete series of about one hundred and twenty.

Posteriorly (A) there is present a terminal vesicle (alv) $.25 \mathrm{~mm}$. in diameter, which communicates dorsally by a narrow opening witl the neural canal (ne); to this is attached a stalk in the form of a tube, also lined by columnar epithelium, and extending through about

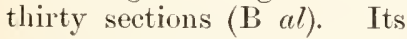
average diameter is about $.084 \mathrm{~mm}$., and its walls are very thick. Overlying its front end is the sulnotochordal rod $(x)$, but this does not extend as far back as the terminal vesicle.

The thick-walled stalk of the resicle is connected with the cloacal section of the alimentary tract by a very narlow thin-walled tube $(\mathrm{C} a l)$. This for the most part has a
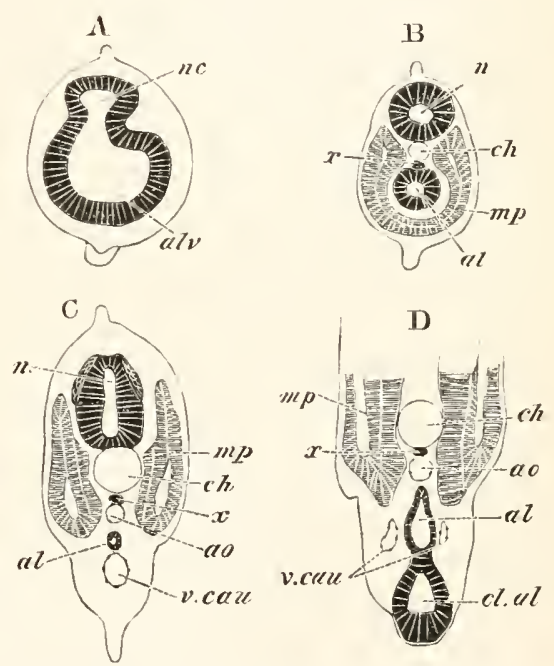

Fiti, 424. Foer sectrons throvgh the postANAL PART OF THE TAH OF AN EMBRYO OF THE SAME AGE AS FIG. 28 F.

$\mathrm{A}$ is the posterior section.

ne. neural canal; al. post-anal gut; ale. caudal vesicle of post-anal gut ; $x$. subnotochord rod; mp. muscle-plate; ch. notochord; $c l$. al. cloaca; ao. aorta; v. cau. caudal vein. fairly miform calibre, and a diameter of not more than $035 \mathrm{~mm}$. Its walls are formed of flattened epithelial cells. At a point not fir from the cloaca it becomes smaller, and its diameter falls to $03 \mathrm{~mm}$. In front of this point it rapidly dilates again, and, after hecoming fairly wide, opens on the dorsal side of the cloacal section of the alimentary canal just behind the anus (D rl).

Very shortly after the stage to which the above figures belong, at a 
point a little behind the anus, where the postanal section of the canal

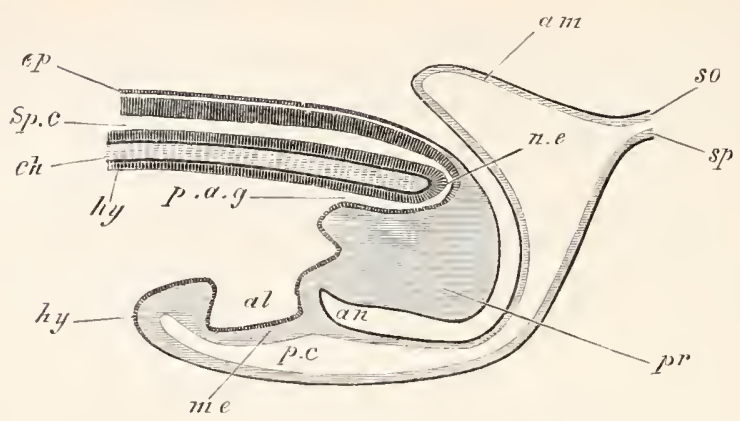

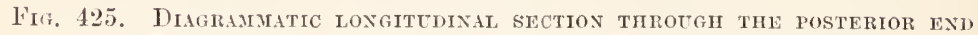
of an endrio limd at the time of the formation of the Allantois.

ep. epiblast; Sp.e. sipinal canal; ch. notochord; n.e. neurenteric eanal; hy. hypoblast; p.a.g. postanal gut; $p r$. remains of primitive streak folded in on the ventral sile; al. allantois; me. splanchnic mesoblast; an. point where anus will be formed; p.c. perivisceral cavity; am. amnion; so. somatopleure; sp. splanchnopleure.

was thinnest in the previous stage, it becomes solis, and a rupture liere vecurs in it at a slightly later perior.

The atroply of this part of the alimentary tract having once commenced proceeds rapidiy. The prosterior part first becomes reduced to a smatl rudiment near the end of the tail. There is no longer a terminal vesicle, nor a nementeric canal. The portion of the postanal section of the alimentary tract, just behind the cloaca, is for a short time represented by a small rudinent of the dilated part which at an earlier period opened into the cloaca.

In Teleostei the vesicle at the end of the tail, diseovered by Kupffer, (fig. $34, h y e)$ is probably the equivalent of the vesicle at the eurl of the postanal gut in Elasmoliranchii.

In Petronyzon and in Amphibia there is a well-developed postanal gut comeeted with a nementeric camal which gradually atroplies. It is shewn in the embryo of Bombinator in fig. $4: 0$.

Amongst the ammintic Vertebrata the postanal gut is less developed than in the Ichthynssida. A nementeric canal is present for a short periol in rarious binds (Gasser, ete.) and in the Lizard, but disappears very early. There is however, as has been pointed out by Kölliker, a well marked postanal gut continued as a narow tube from behind the cloaca into the tail both in the Bird (fig. 425, p.a.g.) and Mammals (the Rabbit), but especially in the latter. It atrophies early as in lower forms.

The morphological significance of the postanal gut and of the neurenteric canal has already been spoken of in Chapter xir., p. 267.

\section{The Stomoderum.}

The anterior section of the permanent alimentary tract is formed by an invagination of epiblast, cmstituting a more or less considerable pit, with its immer wall in contact with the blind anterior catremity of the alimentary tract. 
In Ascidians this pit is placed on the dorsal surface (fig. 9, o), and becomes the permanent oral cavity of these forms. In the larva of Amphioxus it is stated to be formed unsymmetrically (vide p. 5), but further observations on its development are requirel.

In the true Vertebrata it is always formed on the ventral surface of the head, immediately behind the level of the fore-brain (fig. 4.26), and is deeper in Petromyzon (fig. $416, m$ ) than in any other known form.

From the primary buccal cavity or stomodeum there grows unt the pituitary pit (fig. $42(i, p t)$, the development of which has already been described (p. 3.58).

The wall separating the stomodrum from the mesenteron always becomes perforated, usually at an early stage of development, and though in Petronyzon the boundary between the two cavities remains indicated by the velum, yet in the higher Vertebrata all trace of this boundary is lost, and the original linits of the primitive buccal cavity become obliterated; while a secondary buccal cavity, partly linerl by hypoblast and partly by epiblast, becomes established.

This cavity, apart from the organs which belong to it, presents important variations in structure. In most Pisces it retains a fairly simple character, but in the Dipnoi its outer boundary becomes extended so as to enclose the ventral opening of the nasal sack, which thence-

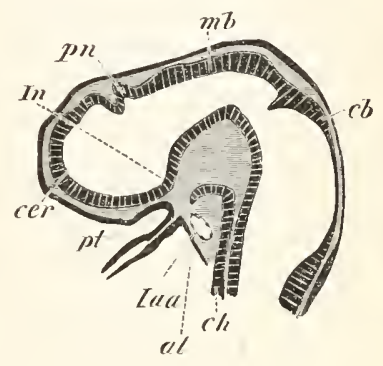

Fig. 426. Loxituminat secTION THROUGH THE BRAIN OF A young Pristiures embrio.

cer. umpaired rudiment of the cerebral hemispheres; $m$. pineal gland; In. infundibulum; $p t$. ingrowth from mouth to form the pituitary boly; mb. midbrain; $c b$. cerebellum; ch. notochord; al. alimentary tract; Iat. artery of mandibular arch. forward constitutes the posterior nares.

In Amphibia and Amniota the posterior nares also open well within the boundary of the buccal cavity.

In the Amniota further important changes take place

In the first place a plate grows inwards from each of the superior maxillary processes (fig. $427, p$ ), and the two plates, meeting in the middle line, form a horizontal septum diviling the front part of the primitive buccal cavity iuto a dorsal respiratory section (n), containing the opening of the posterior nares, and a ventral cavity, forming the permanent mouth. The two divisions thus formed open into a common cavity behind. The horizontal septum, on the development within it of an osseous p'ate, coustitutes the harl palate.

An interuasal septum (fig. $427, e$ ) may more or loss completely divide the dorsal cavity into two canals, continuous respectively with the two nasal cavities.

In Mammalia a posterion prolongation of the palate, in which an osseous plate is not formed constitutes the soft palate. 
The second change in the Amniota, which also takes place in some Amphibia, is caused by the section of the mesenteron into which the branchial pouches open, be-

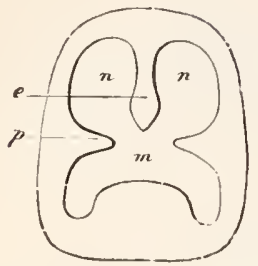

Fig. 427. Diagram shewing THE DIVISION OF THE PRINITIVE BUCCAL CAVITY INTO THE RESPIRATORY SECTION ABOVE AND THE TRUE MOUTI BELOW. (From Gegenbaur.)

$p$. palatine plate of superior maxillary process; $m$. permanent mouth; $n$. posterior part of nasal passage; $c$. internasal septum. coming, on the atrophy of these structures, converted into the posterior part of the buccal cavity.

The organs derived from the buccal cavity are the tongue, the various salivary glands, and the teeth; but the latter alone will engage our attention here.

The teeth. The teeth are to be regarded as a special product of the oral mucous membrane. It has been shewn by Gegenbaur and Hertwig that in their mole of development they essentially resemble the placoid scales of Elasmobranchii, and that the latter structures extend in Elasmobranchii for a certain distance into the cavity of the mouth.

As pointed out by Gegenbaur, the teeth are therefore to be regarded as more or less specialised placoid scales, whose presence in the mouth is to be explained by the fact that the latter structure is lined by an invagination of the epidermis. The nost important developmental point of difference between teeth and placoid scales consists in the fact, that in the case of the former there is a special ingrowth of epilhast to meet a connective tissue papilla which is not found in the latter.

Although the teeth are to be regarded as primitively epiblastic structures, they are nevertheless found in Teleostei and Gamoidei on the hyoid and branchial arches; and very possibly the teeth on some other parts of the mouth are developed in a true hypoblastic region.

The teeth are formed from two distinet organs, viz. an epithelial cap and a connective tissue papilla.

The general mode of development, as has been more especially shewn hy the extended researches of Tomes, is practically the same for all Vertelirata, and it will be convenient to rescribe it as it takes place in Mammalia.

Along the line where the teeth are about to develop, there is formed an epithelial ridge projecting into the subjacent comnective tissue, and derived from the immermost columnar layer of the oral epithelium. At the points where a tooth is about to be formed this ridge undergoes special changes. It becomes in the first place somewhat thickened by the development of a number of rounder cells in its interior; so that it becomes constituted of (1) an external layer of columnar cells, and (2) a central core of rounded cells; both of an epithelial nature. In the second place the organ gradually assumes a dome-shaped form (fig. $428, e$ ), and covers orer a papilla of the subepithelial connective tissue $(p)$ which has in the meantime been developed. 
From the above epithelial structure, which may be called the enamel organ, and from the papilla it covers, which niay be spoken of as the dental papilla, the whole tooth is developed. After these parts have become established there is former round the rudiment of each tooth a special connective tissue capsule; known as the dental capsule.

Before the dental capsule has become definitely formed the enamel organ and the dental papilla undergo important changes. 'T'he rounded epithelial cells forming the core of the enamel organ undergo a peculiar transformation into a tissue closely resembling ordinary embryonic comnective tissue, while at the same time the epithelium adjoining the dental papilla and covering the inner surface of the enamel organ, açuires a somewhat different structure to the epithelium on the outer sile of the organ. Its cells hecome very markedly colummar, and form a verv regular cylindrical epithelium. This layer alose is concerned in forming the enamel. 'The cells of the outer epithelial layer of the enamel organ become somewhat flattened, and the surface of the layer is raised into a series of short papilla which project into the highly vascular tissue of the dental sheath. Between the epithelium of the enamel organ and the adjoining connective tissue there is everywhere present a delicate menbrane known as the membrana praformativa.

The dental papilla is formed of a lighly vascular core and a non-vascular superficial layer adjoining the inner epithelium of the

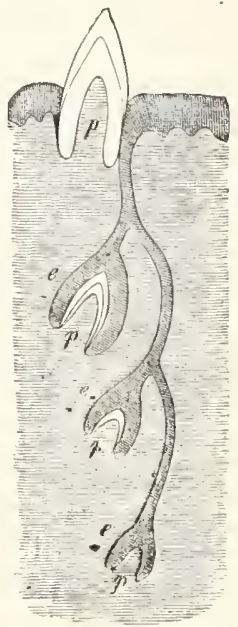

Fyg. 428. Diagrais shewing THE DEVELOPMENT OF THE TEETH. (From Gegenbaur.)

p. dental papilla; $e$. enamel organ.

enamel organ. The cells of the superficial layer are arrangerl so as almost to resemble an epithelium.

The first formation of the hard structures of the tooth commences at the apex of the dental papilla. A calcification of the outermost layer of the papilla sets in, and results in the formation of a thin layer of dentine. Nearly sinultaneously a thin layer of enamel is deposited over this, from the inner epithelial layer of the enamel organ (fig. 428). Both enamel and dentine continue to be deposited till the crown of the tooth has reached its final form, and in the course of this process the enamel organ is reduced to a thin layer, and the whole of the outer layer of the dental papilla is transformed into dentine-while the inner portion remains as the pulp.

The root of the tooth is formed later than the crown, but the enamel organ is not prolonged over this part, so that it is only formed of dentine.

By the formation of the root the crown of the tooth becomes pushed outwards, and breaking through its sack projects freely on the surface.

The part of the sack which surrounds the root of the tooth gives rise to the cement, and becomes itself converted into the periosteum of the dental alveolus.

The general development of the enamel organs and dental papille is 
shewn in the diagram (fig. 428). From the epithelial ridge three enamel organs are represented as being developed. Such an arrangement may occur when teeth are successively replaced. The lowest and youngest enamel organ (e) has assumed a cap-like form enveloping a dental papilla, but no calcification has yet taken place.

In the next stage a cap of dentine has become formed, while in the still older tooth this has become covered by a layer of enamel. As may be gathered from this diagram, the primitive epithelial ridge from which the enamef organ is formed is not necessarily a!sorbed on the formation of a tooth, but is capable of giving rise to fresh enamel organs. When the enamel organ has reached a certain stage of development, its connection with the epithelial ridge is ruptmed (fig. 428).

The arrangenent represented in tig. 428, in which successive enamel organs are formed from the same epithelial ridge, is found in most Vertebrata except the Teleostei. In the Teleostei, however (Tomes), a fresh enamel organ grows inwards from the epithelium for each successively formed tooth.

\section{The Proctodeum.}

In all Vertebrata the cloacal section of the alimentary tract which receives the urinogenital ducts is placel in communication with the exterior by means of an epiblastic invagination, constituting a proctodreum.

'This invagination is not usually very deep. and in most instances the boundary wall between it and the hypoblastic cloaca is not perforater till considerably after the perforation of the stomodienm; in Petromyzon, however, its perforation is effected before the mouth and plarynx are placed in communication.

The mode of formation of the proctolisum, which is in general extremely simple, is illustrated by fig. 4:20 $\mathrm{cm}$.

In most forms the original boundary between the epiblast of the proctodienm and the hypoblast of the primitive cloaca becomes obliterated after the two have become placed in free communication.

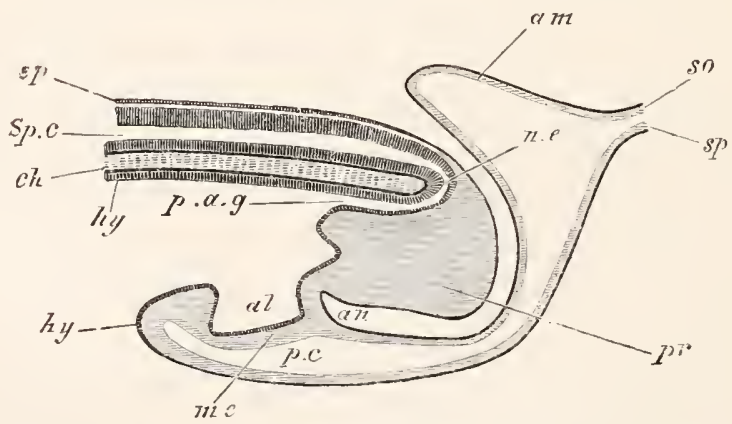

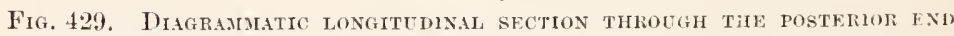
of an exbrio Bren at the time of thl Formation of the Aldantols.

ep. epiblast; Sp.c. spinal canal; ch. notochord; n.e. neurenteric canal; hy. hypoblast; $p . a . q$. postanal gut; $p r$. lemains of pimitive streak folded in on the ventral side; al. allantois; me. mesoblast; an. point where anus will be formed; p.c. periviscrial cavity; am. ammion; so. somatopleure; sp. splanchnopleme. 
In Birds the formation of the proctodæum is somewhat more complicated than in other types, owing to the outgrowth from it of the bursa Fabricii.

The proctodreum first appears when the folding off of the tail end of the embryo commences (fig. 429, an ) and is placed near the front (originally the apparent hind) end of the primitive streak. Its position marks out the front border of the postanal section of the gut.

The bursa Fabricii first appears on the seventh day (in the chick), as a dorsal outgrowth of the proctodieum. The actual perforation of the septum between the proctodieum and the cloacal section of the alimentary tract is not effected till about the fifteenth day of foetal life, and the approximation of the epithelial layers of the two organs, preparatory to their absorption, is partly effected by the tumneling of the mesoblastic tissue between them by numerous spaces.

The hypoblastic section of the cloaca of birds, which receives the openings of the urinogenital ducts, is permanently marked off by a fold from the epiblastic section or true proctodreum, with which the bursa Fabricii communicates.

\section{Biblography.}

\section{Alimentary Canal and its appendeges.}

(56r) B. Afanassiew. "Ueber Bau u. Entwicklung d. Thymus d. Säugeth." Archiv f. mikr. Anat. Bd. xIv. 1877.

(562) Fr. Boll. Das Princip d. Wachsthums. Berlin, 1876.

(563) E. Gasser. "Die Entstehung d. Cloakenöffnung bei Hühnerembryonen." Archiv f. Anat. u. Physiol., Anat. Abth. 1880.

(564) A. Götte. Beiträgc zur Entwicklungsgeschichted. Darmkanals im Hïhnchcn. 1867.

(565) W. Mïller. "Ueber die Entwickclung der Schilddrüse." Jenaische Zeit schrift, Vol. vi. 1871.

(5.6) W. Müller. "Die Hypobranchialrinne d. Tunicaten." Jenaische Zeit. schrift, Vol. viI. 1872.

(567) S. L. Schenk. "Die Banchspeicheldrüse d. Embryo." Anatomisch-physiologische Untersuchungen. 1872.

(568) E. Selenka. "Beitrag zur Entwicklungsgeschichte d. Luftsäcke d. Huhns." Zeit.f. wiss. Zool. 1866.

(569) L. Stieda. Untersuch. ̈̈b. d. Entwick. d. Glandula Thymus, Glandula thyroidea, $u$. Glandula carotica. Leipzig, 1881.

( 570$)$ C. Fr. Wolff. "De formatione intestinorum." Nov. Comment. Akad. Petrop. 1766.

(57r) A. Wölfler. Ueb. d. Entwick. u. d. Bau d. Schilddrüse. Berlin, 1880.

Vide also Kölliker (298), Götte (296), His (232 and 297), Foster and Balfour (295), Balfuur (292), Remak (302), Schenk (303), etc.

\section{Teeth.}

(572) T. H. Huxley. "On the enamel and dentine of teeth." Quart. J. of Micros. Science, Vol. III. 1855.

(573) R. Owen. Odontography. London, 1840-1845. 1876 .

(574) Ch. S. Tomes. Mamal of dental anatomy, human and comparative. London,

(575) Ch. S. Tomes. "On the development of teeth." Quart. J. of Micros. Science, Vol. xvi. 1876.

$(5 ; 6)$ W. Waldeyer. "Structure and development of teeth." Stricker's His. tology. 1870.

Vide also Kölliker (298), Gegenbaur (294), Hertwig (306), ete.

B. E. II 



\section{INDEX 'TO VOLUME II.}

Abdominal muscles, 557

Abdominal pore, 514,616

Acipenser, development of, 81; aftinities of, 98 ; comparison of gastrula of, 233 ; pericardial cavity of, $\check{5} 15$

Actinotrocha, 307

Air-bladder of Teleostei, 63; Lepidostens, 97 ; blood supply of, 530; general account of, 627 ; liomologies of, 630

Alciope, eyc of, 394

Alisphenoid region of skull, 469

Alimentary canal and appendages, development of, 620

Alimentary tract of Ascidia, 15; Molgula, 18; Pyrosoma, 20; Salpa, 26; Elasmobranchii, 43; Teleostei, 60; Petromyzon, 77, 79; Acipenser, 91; Amphibia, 107, 112 ; Chick, 139; respiratory region of, 623 ; temporary closure of cesophngcal region of, 624

Allantois,development of in Chick, $159, \mathbf{1 6 4}$; blood-vessels of in Chick, 160; Laccrta, 170,173 ; early decrelopment of in Riabit, 190, of Guinea-pig, 220 ; origin of, 257. See also 'Placenta' and 'Bladder.'

Alternation of generations in Ascidians, origin of, 29; in Botryllus, 29; Pyrosoma, 30; Salpa, 30; Doliolum, 30

Alytes, branchial chamber of, 112 ; yolksack of, 115; branchiæ, 116 ; Miillcrian duct of, 585

Amblystoma, ovum of, 99; larva of, 117, 118

Amia, ribs of, 463

Ammocotes, 78; metamorphosis of, 81 ; eye of, 409

Amnion, early development of in Chick, 154; later history of in Chick, 163 ; Lacerta, 169, 173; Rabbit, 190; origin of, 255,257

Amphibia, development of, 99 ; viviparous, 100 ; gastrula of, 231 ; suctorial mouth of, 263 ; cerebellum of, 350 ; infundibulum of, 355 ; pineal gland of, 357 ; cerebrum of, 361 ; olfactory lobes of, 366 ; nares of, 439 ; notochord and its slieath, 452 ; vertcbral column of, 456 ; xibs of, 463 ; branchial arches of, 473 ; mandibular and hyoid arches of, 479 columella of, 479 ; pectoral girdlc of, 496 ; pelvic girdle of, 498; limbs of, 509 ; heart of, 525 ; arterial systcm of, 531 ; venous system of, 538 ; excretory system of, 582 ; vasa efferentia of, $586^{\circ}$; liver of, 632 ; postanal gut of, 636 ; stomodreum of, 639

Amphiblastula larva of Porifera, 285

Amphioxus, development of, 1 ; gastrula of, 229 ; formation of mesoblast of, 243 ; development of notochord of, 243 ; head of, 260 ; spinal nerves of, 380 ; olfactory organ of, 438; venous system of, 535; transverse ablominal muscle of, 555 ; gencrative cells of, 615 ; liver of, 632 ; postanal gut of, 634 ; stomodæum of, 639

Amphistylic skulls, 476

Angular bone, 488

Anterior abdominal vein, 537

Anura, development of, 100 ; epiblast of, 103; mesoblast of, 105; notochord of, 105 ; hypoblast of, 107 ; general growth of embryo of, 108 ; larva of, 111 ; vertebral column of, 458 ; mandibular arch of, 481

Anus of Amphioxus, 6; Ascidia, 15; Pyrosoma, 23; Salpa, 26; Elasmobranchii, 47; Amphibia, 108, 109; Chick, 139 ; primitive, 268

Appendicularia, development of, 28

Aqueductus vestibuli, 427

Aqueous humour, 409

Arachnida, nervous system of, 337; eye of, 396

Area, embryonic, of rabbit, 180 ; epiblast of, 181 ; origin of cmbryo from, 188 area opaca of Chick, 12.1 ; epillast, hypoblast, and mesoblast of, 132 area pellucida of Chick, 124 ; of Lacerta, 167

area vasculosa of Chick, 161 ; mesoblast of, 133; of Lizard, 173; Rabbit, 188, 190

Arteria centralis retinæ, 414 
Arterial system of Petromyzon, 80 ; constitnition of in embryo, 529; of Fishes, 530 ; of Amphibia, 531; of Amniota, 532

Arthropoda, head of, 260 ; nervous system of, 337 ; eye of, 395 ; excretory organs of, 567

Artieular bone of Teleostei, 478 ; of Sauropsida, 484

Ascidia, development of, 8

Ascidians. See 'Tunicata'

Ascidiozooids, 21

Atrial carity of Amphioxus, 6; Ascidia, 15; Pyrosoma, 20

Atrial pore of Amphioxus, 6; Ascidia, 17 ; Pyrosoma, 23; Salpa, 27

Auditory capsules, ossifications in, 489, 490

Auditory involution of Elasmobranchii, 47 ; Tंeleostei, 59; Petromyzon, 73, 76; Acipenser, 87; Lepidosteus, 94; Amphibia, 105; Chick, 141

Auditory nerve, development of, 377

Auditory organs, of Ascidia, 13; of Salpa, 26 ; of Ammoccetes, 80; Ganoidei, 89, 94; of Amphibia, 105; of Aves, 141; general development of, 422 ; of aquatic forms, 422 ; of land forms, 423; of Coelenterata, 423; of Mollusea, 424; of Crustacea, 425; of Vertebrata, 425; of Cyclostomata, 73, 76, 426 ; of Teleostei, Lepidostens and Amphibia, 426; of Mammalia, 427 ; accessory structures of, 435 ; of Tunicata, 436

Auriculo-rentricular valves, 528

Antostylic skulls, 476

Aves, development of, 120 ; cerebellum of, 351 ; midbrain of, 352 ; infundibulum of, 355 ; pineal gland of, 357 ; pituitary body of, 359 ; cerebrum of, 361 ; ol. factory lobes of, 366 ; spinal nerves of, 374 ; cranial nerves of, 374 ; vagus of, 377 ; glossopharyngeal of, 377 ; vertebral column of, 459 ; ossification of vertebral column of, 460 ; branchial arches of 472,473 ; pectoral girdle of, 495 ; pelric girdle of, 499 ; heart of, 523 ; arterial system of, 532 ; venous system of, 541 ; muscle-plates of, 552 ; excretory organs of, 588 ; mesonephros of, 589 ; pronephros of, 591 ; Miillerian duct of, 591,593 ; nature of prone. phros of, 594 ; connection of Mixllerian duct with Wolffian in, 594; kidney of, 595 ; lungs of, 629 ; liver of, 632 ; postanal gut of, 636

Axolotl, 117, 118; orum of, 99 ; midbrain of, 352 ; mandibular arch of, 479

Basilar membrane, 432

Basilar plate, 466

Basipterygium, 502

Basisphenoid region of skull, 469

Bilateral symmetry, origin of, 308-310
Bile duct, 633

Bladder, Amphibia, 108; of Amniota, 598

Blastodermic vesicle, of Rabbit, first development of, 179 ; of 7 th day, 183 ; Guinea-pig, 219; meaning of, 242

Blastoderm of Pyrosoma, 20; Elasmobrauchii, 34; Chick, 124; Lacerta, 167

Blastopore, of Amphioxus, 2; of Ascidia, 9 ; Elasmobranchii, 35, 44, 51; Petromyzon, 71; Acipenser, 86; Amphibia, 103, 108; Chick, 127; Rabbit, 178; true Mammalian, 187; comparative history of closure of, 236,240 ; summary of fate of, 281; relation of to primitive anns, 268

Blood-ressels, development of, 520

Body cavity, of Ascidia, 18; Molgula, 18; Salpa, 26; Elasmobranchii, 39; of Teleostei, 60; Petromyzon, 77; Chick, 140; development of in Chordata, 269; views on origin of, $294-297,310$; of Invertebrata, 512; of Chordata, 513; of head, 557

Bombinator, branchial chamber of, 112; rertebral column of, 458

Bonellia, excretory organs of, 567

Bones, origin of cartilage bones, 447; origin of membrane bones, 447 ; develop. ment of, 148; homologies of membrane bones, 487; homologies of eartilage bones, 489

Brachiopoda, excretory organs of, 563; generative ducts of, 617

Brain, of Ascidia, 10, 13; Elasmobranchii, 46, 49, 49; Teleostei, 62; Petromyzon, 73, 76; Acipenser, 87; Lepidosteus, 93 ; early development of in Chick, 141; flexure of in Chick, 145; later development of in Chick, 146; Rabbit, 190; general account of development of, 345 ; flexure of, 346 ; histogeny of, 347

Branchial arches, præoral, 470; disappearance of posterior, 472 ; dental plates of in Teleostei, 473; relation of to head cavities, 471 : see 'Visceral arches' Branchial chamber of Amphibia. 112

Branchial clefts, of Amphioxus, 6; of Ascidia, 15, 17; Molgula, 19; Salpa, 27 ; of Elasmobranchii, 47, 48, 49, 50; Teleostei, 62; Petromyzon, 74, 79; Acipenser, 87; Lepidosteus, 94, 96; Amphibia, 109, 110; Chick, 147; Rabbit, 191; præoral, 259, 265; of Inverte. brata, 270 ; origin of, 270

Branchial rays, 473

Branchial skeleton, development of, 471, 486; of Petromyzon, 79, 259, 471; of Ichthyopsida, 472; dental plates of in Tele. ostei, 473; relation of to head cavities, 471

Branchiæ, external of Elasmobranchii, 50, 51; of Teleostei, 62; Acipenser, 88; Amphibia, 105, 110, 112 
Brood-ponch, of Salpa, 24; Teleostei, 55; Amphibia, 100

Bromn tubes of Gephyrea, 566

Bulbus arteriosus, of Fishes, 524; Amphibia, 525

Bursa Fabricii, 139, 641

Canalis auricularis, 525

Canalis reuniens, 429

Capitellidæ, excretory organs of, 563

Carcharias, placenta of, 51

Cardinal vein, 5536

Carnivora, placenta of, 207

Carpus, development of, 509

Cartilage bones of skull, 489 ; lomologies of, 489

Cat, placenta of, 207

Caudal swellings of Elasmobranchii, 38, 45; Teleostei, 5s; Chick, 135, 141

Cephalic plate of Elasmobranchii, 45

Cephalochorda, derelopment of, 1

Cephalopoda, eyes of, $3 ; 9$

Cerebellum, Petromyzon, 76; Chick, 146; general account of development of, 349 , 350

Cerebrum of Petromyzon, 76, 81; Chick, 145 ; general development of, 353,360 ; transverse fissure of, 364

Cestoda, excretory organs of, 561

Cetacea, placenta, 212

Chrtognatha, nerrous system of, 289; eye of, 394; generative organs of, 612 ; generative ducts of, 616

Chætopoda, head of, 260; eyes of, 394 ; excretory organs of, 563; generative organs of, 612; generative ducts of, 617

Charybdiea, eye of, $3>8$

Cheiroptera, placenta of, 202

Cheiropterygium, 508; relation of to ichthyopterygium, 510

Chelonia, development of, 174 ; pectoral girdle of, 495 ; arterial system of, 533

Chick, development of, 120 ; general grow th of embryo of, 141 ; rotation of embryo of, 143 ; feetal membranes of, 154 ; epiblast of, 124, 133; optic nerve and choroid fissure of, 411

Chilognatha, eye of, 395

Chilopoda, eye of, 395

Chimæra, lateral line of, 444 ; vertebral column of, 452 ; nares of, 439

Chiromantis, oriposition of, 100

Chorda tympani, development of, 378

Chordata, ancestor of, 258; branchial system of, 259; evidence from Ammoccetes, 259; head of, 260 ; mouth of, 264 ; table of phylogeny of, 271

Chorion, 197; villi of, 197,215

Choroid coat, Ammocotes, 81; general account of, 401

Choroid fissure, of Vertebrate eye, 400, 406; of Ammocotes, 410; comparative development of, 411; of Chick, 412 ; of Lizards, 413; of Elasmobranchii,
413; of Teleostei, 414; Amphibia, 414; Mammals, 414, 416

Choroid gland, 265

Choroid pigment, 403

Choroid plexus, of fourth ventricle, 350 ; of third rentricle, 356 ; of lateral rentricle, 364

Ciliated sack of Ascidia, 15; Pyrosoma, 22 ; Salpa, 26

Ciliary ganglion, 379

Ciliary muscle, 403

Ciliary processes, 402; comparative de. relopment of, 416

Clavicle, 492

Clitoris, development of, 599

Clinoid ridge, 469

Cloaca, 630

Coccygeo-mesenteric rein, 545

Cochlear canal, 427

Coecilia, derelopment of, 118; pronephros of, 582; mesonephros of, 584; Miiillerian duct of, 585

Coelenterata, larvæ of, 303 ; eyes of, 388 ; auditory organs of, 423 ; generative organs of, 610

Columella auris, 436; of Amplibia, 479; of Sauropsida, 483

Commissures, of spinal cord, 343 ; of brain, $355,356,361,365$

Coni vasculosi, 597

Conus arteriosus, of Fishes, 524; of Am. phibia, 525

Coracoid bone, 492

Cornea, of Ammocnetes, 81; general development of, 407; corpuscles of, 408 ; comparative development of, 411 ; of Hammals, 411

Coronoid bone, 488

Corpora geniculata interna, 353

Corpora quadrigemina, 352

Corpora striata, development of, 360

Corpus callosum, development of, 365

Corti, organ of, 430 ; strueture of, 432 ; fibres of, 433 ; development of, 434

Cranial flexure, of Elasmobranchii, 48, 49 ; of Teleostei, 62; Petromyzon, 76, 77 ; of Amphibia, 108, 109; Chick, 145; Rabbit, 191; characters of, 266; significance of, 267

Cranial nerves, development of, 374 ; relation of to head cavities, 379 ; anterior roots of, $380-382$; view on position of roots of, 383

Crocodilia, arterial system of, 533

Crura cerebri, 353

Crustacea, nervous system of, 338 ; eye of, 396 ; auditory orgaus of, 425 ; generative cells of, 613 ; generative ducts of, 618

Cupola, 432

Cutaneous muscles, 557

Cyathozooid, 21

Cyolostomata, auditory organs of, 426 ; olfactory organ of, 439 ; notochord and vertebral column of, 450,453 ; abdo- 
minal pores of, 515 ; segmental duct of, 577; pronephros of, 577; mesonephros of, 577; generative ducts of, 603,616 ; venous system of, 535 ; excretory organs of, 577

Cystignathus, oviposition of, 100

Dactylethra, branchial chamber of, 112 ; branchise of, 112 ; tadpole of, 115

Dccidua reflexa, of Rat, 200; of Inscetivora, 202; of Man, 203

Deiter's cells, 433

Dental papilla, $6 \pm 1$

Dental capsule, 641

Dentary bone, 488

Dentine, 641

Descemet's membrane, 108

Diaphrarm, 518; muscle of', 557

Dipnoi, nares of, 440 ; vertebral column of, 452 ; membrane bones of sliull of, 487; heart of, 525 ; arterial system of, 530 ; excretory system of, 582 ; stomodieum of, 639

Diptera, eye of, 395

Discophora, excretory organs of, 567

Dog, placenta of, 206

Dohru, on relations of Cyclostomata, 69 ; on ancestor of Chordata, 258, 264

Doliolum, development of, 23

Ductus arteriosus, 533

Dnctus Botalli, 532

Ductus Cuvieri, 537

Dnctus venosns Arantii, 547

Dugong, heart of, 528

Dysticus, eye of, 395

Ear', see 'Auditory organ'

Echinodermata, secondary symmetry of larra of, 313 ; excretory organs of, 568 ; generative ducts of, 619

Echinorhinus, lateral line of, 444 ; rertebral columin of, 452

Echiurus, cxcretory organs of, 566

Ectostosis, 448

Eclentata, placenta of, 205, 207, 213

Eel, generative dncts of, 580

Egg-shell of Elasmobranchii, 33; Chick, 121

Elasmobranchii, development of, 33 ; viviparous, 33; general features of development of, 45 ; gastrula of, 233 ; development of mesoblast of, 244; notochord of, 214 ; meaning of formation of mesoblast of, 245; restiform tracts of, 350 ; optic lobes of, 352 ; cerebellum of, 350 ; pineal gland of, 356 ; pituitary body of, 359 ; cerebrum of, 361 ; olfactory lobes of, 366 ; spinal nerres, 369 ; cranial nerres of, 376 ; sympathetic nervons system of, 384 ; nares of, 439 ; lateral line of, 444 ; rertebral column of, 453 ; ribs of, 462 ; parachordals of, 467 ; mandibular and hyoid arehes of, 474 ; pectoral girdle of, 493 ; pelric girdle of,
498; limbs of, 500; pericardial cavity of, 515 ; arterial system of, 530 ; venous system of, 535; muscle-plates of, 551; excretory organs of, 569; constitution of excretory organs in adult of, 575 ; spermatozoa of, $61 \mathrm{~J}$; swimming-bladder of, 628 ; intestimes of, 631 ; liver of, 632 ; postanal gnt of, 634

Elieoblast of Pyrosoma, 23; Salpa, 25

Elcpliant, placenta of, 207

Embolic formation of gastrula, 276

Enamel organ, 641

Endolymph of ear, 430

Endostosis, 448

Endostyle of Ascidia, 15, 624; Pyrosoma, 21 ; Salpa, 27

Epiblast, of Elasmobranchii, 38; Telcostei, 57, 60 ; Pctromyzon, 71; Lepidosteus, 92; Amplibia, 101, 103; Chick, 124, 138 ; Lacerta, 168; Rabbit, 179, 181 ; origin of in Rabbit, 184; comparative account of development of, 249

Epibolic formation of gastrula, 277

Epichordal formation of vertebral column, 458

Fpicrium glutinosum, 118

Epidermis, in Colenterata, 325; protective structures of, 325

Epididymis, 597

Epigastric vein, 537

Episkeletal muscles, 557

Episternum, 494

Epoophoron, 597

Fthmoid bone, 490

Ethmoid region of sknll, 470

Ethmopalatine ligament of Elasmobranchs, 475

Euphausia, eye of, 398

Eustachian tube, of Amphibia, 111; Chick, 149 ; Rabbit, 192 ; general development of, 435

Excretory organs, general constitution of, 561 ; of Platyelminthes, 561; of Mollusea, 562 ; of Polyzoa, 563 ; of Brachiopoda, 563; of Chretopoda, 563; of Gepliyrea, 566; of Discophora, 567; of Arthropoda, 567; of Nematoda, 568; of Echinodermata, 568; constitution of in Craniata, 568; of Elasmobranclii, 569; constitution of in adult Elasmobranch, 575 ; of Petromyzon, 577 ; of Myxine, 578 ; of Teleostei, 578 ; of Ganoidei, 580 ; of Dipnoi, 582; of Amphibia, 582; of Amniota, 588 ; comparison of Vertebrate and Invertebrate, 607

Excretory system, of Elasmobranchii, 40; Teleostei, 63; Petromyzon, 78, 81; Acipenser, 91 ; Amphibia, 110

Exoccipital bone, 489

Exoskeleton, dermal, 325-327; epidermal, $325-328$

External generative organs, 5.9

Extra-branchial skeleton, 471

Eye, of Asciclia, 14; Salpa, 26 ; Elasmo- 
branchii, 46, 47, 48; Teleostei, 59; Petromyzon, 76, 80; Aves, 141; Rabbit, 190 ; general development of, 387 ; evolution of, 387,388 ; simple, 395 ; compound, 396; aconous, 396 ; pseudoconous, 396 ; of Invertebrata, 388 ; of Vertebrata, 398 ; comparative development of Vertebrate, 409 ; of Ammocoetes, 409; of Tunicata, 418; of Chordata, general views on, 419 ; accessory eyes of Fishes, 420 ; muscles of, 558

Eyelids, development of, $\mathbf{4 1 6}$

Falciform ligament, 623

Falx cerebri, 361

Fasciculi teretes, of Elasmobranchii, 350

Feathers, development of, 327

Fenestra rotunda and ovalis, 436

Fertilization, of Amplioxus, 2 ; of Urochorda, 8; Salpa, 24; Elasmobranchii, 33; of Teleostei, 55; Petromyzon, 69; Amphibia, 99; Chick, 121; Reptilia, 167 ; meaning of, $27 \pm$

Fiftl nerve, development of, 378

Fifth ventricle, 365

Fins, of Elasmobranchii, 51; Teleostei, 63; Petromyzon, 77, 78; Acipenser, 89 ; Lepidosteus, 97 ; relation of paired to unpaired, 501, 503; development of pelvic, 504; development of pectoral, 504 ; views on nature of paired tins, 506

Fissures of spinal cord, 34.4

F $\propto$ tal development, 297 ; secondary variations in, 298

Foot, 508

Foramen of Munro, 3 54,360

Foramen ovale, 528

Forebrain, of Elasmobranchii, 46, 48, 49; Petromyzon, 76 ; general development of, 353

Formative cells, of Chick, 124

Fornix, development of, 365

Fornix of Gottsche, 352

Fourth nerve, 382

Frontals, 487

Fronto-nasal process, of Chick, 149

Gaertner's canals, 597

(iall-bladder, 633

Ganoidei, development of, 84 ; relations of, 98 ; nares of, 140 ; notochord of, 450 ; vertebral column of, 450,456 ; ribs of, 462 ; pelvic girdle of, 498 ; arte. rial system of, 530 ; excretory organs of, 580 ; generative ducts of, 605

Gastropoda, eye of, 389

Gastrula, of Amphioxus, 2; of Ascidia, 9; Elasmobranchii, 35, 36; Petromyzon, 70; Acipenser, 85; Amplibia, 102 ; comparative development of, in Inver. tebrata, 229; comparison of Mammalian, 242 ; phylogenetic meaning of, 275 ; ontogeny of (general), 276 ; phylogeny of, $2 \circ 0-285$; secondary types of, 282
Geckos, vertebral column of, 459

Generative cells, development of, 610 ; origin of in Colenterata, 610 ; of Invertebrata, 612 ; of Vertebrata, 614

Generative ducts, of Teleostei, 580, 605; of Ganoids, 580 ; of Cyclostomata, 603 ; origin of, 604 ; of Lepidosteus, 605 , 617; development and evolution of, 616 ; of Colenterata, 616 ; of Sagitta, 616; of Tunicata, 616; Chætopoda, Gephyrea, etc., 617 ; of Mollusca, 618 ; of Discophora, 618; of Echinodermata, 619

Generative system of Elasmobranchii, 42

Gephyrea, nervous system of, 340 ; excretory organs of, 566 ; generative cells of, 612 ; genera tive lucts of, 617

Germinal disc, of Elasnobranchii, 33; Teleostei, 55; Chick, 122

Germinal epithelium, 614

Germinal layers, summary of organs derived from, in Vertebrata, 252; historical account of views of, 275 ; homologies of in the Netazoa, 285

Germinal wall of Chick, 126,132 ; structure and changes of, 133

Geryonia, auditory organ of, 424

Gill of Salpa, 26

Giraldes, organ of, 598

Glands, epidermic, development of, 328

Glomerulus, external, of Chick, 590

Glossopharyngeal nerve, development of, 375,376

Grey matter of spinal cord, 313 ; of brain, 348

Growth in length of Vertebrate embryo, 251

Guinea-pig, primitive streak of, 186 ; notochord of, 187; placenta of, 201; development of, 218

Gymmophiona, see 'Cocilia'

Habenula perforata, 432

Hairs, development of, 328

Halichrerus, placenta of, 207

Hand, 508

Head, comparative account of, 260; segmentation of, 261

Head cavities, of Elasmobranchii, 41 ; Petromyzon, 74, 79; Amphibia, 105; general development of, 558

Head-fold of Chick, 130, 139

Head-kidney, see 'Promephros'

Heart, of Pyrosoma, 21; Elasmobranchii, 42, 48; Petromyzon, 77, 80; Acipenser, 87; Chick, 141; first appearance of in Rabbit, 190; general development of, 520 ; of Fishes, 522, 524; of Mammalia, 522; of Birds, 523, 525; meaning of development of, 524 ; of Amphibia, 525; of Amniota, 525; change of position of, 529

Hind-brain, Elasmobranchii, 46, 48, 49 ; Petromyzon, 76 ; general account of, 348 
Hippocampus major, development of, 363 Hirudo, development of blood-ressels of, 520 ; excretory organs of, 567

Horse, placenta of, 210

Hyaloid membrane, 405

Hylodes, oviposition of, 100 ; metamor. phosis of, 114

Hyobranchial cleft, 471

Hyoid arch, of Chick, 149; general account of, 471,474 ; modifications of, 472,475 ; of Elasmobranchii, $17 \pm$; of Teleostei, 477 ; of Amphibia, 479 ; of Sauropsida, 483 ; of Mammalia, 484

Hyomandibular bar of Elasmobranchii, 474,475 ; of Teleostei, 477; of Amphibia, 479

Hyomandibular eleft, of Petromyzon, 74; Chick, 149 ; general accomnt of, 471

Hyostylic skulls, 475

Hypoblast of Elasmobranchii, 42 ; Teleostei, 57, 60; Petromyzon, 70; Acipenser, 86 ; Lepidosteus, 93 ; Amphibia, 101 , 107; Chick, 125, 138; Lacerta, 168; Rabbit, 178, 179, 181; origin of in Rab. bit, 182

Hyposkeletal museles, 557

Hyrax, placenta of, 207

Incus, 436,484

Infraclavicle, 493

Infundibulum of Petromyzon, 76 ; Click, 145; general development of, 354

Insectivora, placenta of, 202

Insects, nerrous system of, 338; eye of, 396 ; generative organs of, 613 ; generative ducts of, 618

Intercalated pieces of vertebral column, 454

Interclavicle, homologies of, 194

Intermediate cell-mass of Chick, 152

Intermuscular septa, 551

Interorbital septum, 469

Interrenal bodies, 548

Iris, 402; comparative development of, 416

Iris of Anmocoetes, 81

Island of Reil, 366

Jacobson's organ, 412

Jugal bone, 488

\section{Kidney, see 'Metanephros'}

Labia majora, development of, 599

Labial cartilages, 490

Labium tympanicum, 432 ; vestibulare, 432

Lacertilia, general development of, 167 ; nares of, 442 ; pectoral girdle of, 495 ; pelvic girdle of, 499 ; arterial system of, 533

Lacrymal bone, 487

Lacrymal duct, $\mathbf{4 1 7}$

Lacrymal glands, 417
Læmargus, vertebral column of, 452

Lagena, 432

Lamina spiralis, 432

Lamina terminalis, 361

Larva of Amphioxus, 2 ; of Ascidia, 12 18; Teleostei, 65; Petromyzon, 73, 78; Lepidosteus, 96, 263 ; Amphibia, 111, 116; types of, in the Invertebrata, 299

Larra, nature, origin, and affinities of, $297-318$; secondary variations of less likely to be retained, 299; ancestral history more fully recorded in, 299 ; secondary variations in development of, 300 ; ontogenetic record of secondary variations in, 298; of freshwater and land animals, 299; types of, 299 ; phosphorescence of, 301 ; of Coelenterata, 303 ; table of, 301 ; of Invertebrata, 303 et seq.

Lalynx, 630

Lateral line sense organs, 443 ; comparison of, with invertebrate, 413 ; development of, in Teleostei, 444; development of, in Elasmobranchii, 144

Lateral ventricle, 360 ; anterior cornu of, 362 ; descending cornu of, 362 ; choroid plexus of, 361

Layers, formation of, in Elasmobranchii, 34, 46; Teleostei, 57; Petromyzon, 70; Acipenser, 84; Lepidosteus, 92; Am phibia, 101; Chick, 121, 126; Lacerta, 167; Rabbit, 178-183; comparison of Mammalia with lower forms, 187, 240; comparison of formation of in Vertebrata, 229; origin and homologies of, in the Metazoa, 274

Leech, see 'Hirudo'

Lemuridæ, placenta, 213

Lens, of Elasmobranchii, 47, 48; Petromyzon, 76, 81 ; Acipenser, 87 ; Lepidosteus, 95; Amphibia, 105; Chich, 146; of Vertebrate eyes, 399 ; general account of, 406; capsule of, 106 ; comparative development of, 411; of Amphibia, Teleostei, Lepidosteus, 411

Lepidosteus, development of, 91 ; larva of, 96 ; relations of, 98 ; spinal nerves of, 374 ; ribs of, 463 ; generative ducts of, 580,605 ; swimming-bladder of, 628

Ligamentum pectinatum, 403

Ligamentum suspensorium, 459,460

Ligamentum resicæ medium, 198

Limbs, of Elasmobranchii, 48; Teleostei, 61 ; first appearance of in Chick, 152; Rabbit, 192 ; muscles of, 555 ; of Fishes, 500 ; relation of, to unpaired fins of Fishes, 501, 503; of Amphibia, 508

Liver of Teleostei, 63; Petromyzon, 78, 79; Acipenser, 90, 91; Amphibia, 107; general account of, 632

Lizard, development of, 167 ; general growth of embryo of, 172 : Miillerian duet of, 595

Lizzia, eye of, 388 
Lobi inferiores, 355

Lungs of Amphibia, 113; development of, 628; homology of, 630

Lymphatic system, 547

Malleus, 436,485 ; views on, 486

Malpighian bodies, development of accessory in Elasmobranchs, 573

Mammalia, development of, 177; comparison of gastrula of, 242 ; cerebellum of, 350 ; infundibulum of, 355 ; pineal gland of, 357 ; pituitary body of, 359 ; cerebrum of, 361 ; spinal nerres of, 369 ; sympathetic of, 384 ; vertebral column of, 460 ; branchial arches of, 472,473 ; mandibular and hyoid arches of, 484; pectoral girdle of, 496 ; pelvic girdle of, 499; heart of, 522; arterial system of, 532 ; venous system of, 545 ; muscleplates of, 553; mesonephros of, 589; testicular network of, 596 ; urinogenital sinus of, 599 ; spermatozoa of, 615 ; lungs of, 629 ; intestines of, 631 ; liver of, 632 ; postanal gut of, 636 ; stomodxum of, 639

Mammary gland, development of, 329

Man, placenta of, 202; general account of development of, 221 ; eharacters of embryo of, 225

Mandibular arch of Elasmobranchii, 51, 474; Petromyzon, 75; Acipenser, 87, 6; Chick, 14s; general account of, 471 , 474 ; modification of to form jaws, 472, 474 ; of Teleostei, 477; of Amphibia, 479; Sauropsirla, 483; Mammalia, 484

Mandibular bar, evolution of, 259, 266

Manis, placenta of, 213

Marsupial bones, 499

Marsupialia, foetal membranes of, 198 ; cerebellum of, 351 ; corpus callosum of, 365 ; uterus of, 598

Maxilla, 488

Meatus auditorius externus, of Chick, 150; development of, 435

Meckelian cartilage, of Elasmobranchii, 474 ; of Teleostei, 47s; of Amphibia, 480,481 ; of Sauropsida, 481 ; of Mam. malia, 485

Mediastinum anterior and posterior, 518

Medulla oblongata, of Chick, 146 ; general development of, 349

Medullary plate of Amphioxus, 3, 4; of Ascidia, 9; Elasmobranchii, 36, 39, 45; Teleostei, 58; Petromyzon, 72; Acipenser, 85; Lepidosteus, 92 ; Amphibia, 104, 105, 108; Chick, 131; Lacerta, 168; Rabbit, 185, 188, 190; primitive bilobed character of, 251,263

Medusæ, auditory organs of, 423

Membrana capsulo-pupillaris, 407, 415. 418

Membrana elastica externa, 450

Nembrana limitans of retina, 404

Jembrana tectoria, 430,432
Membrane bones, of Amphibia, 479; of Sauropsida, 484; of Mammalia, 485 ; of mandibular arch, 488; of pectoral girdle, 492, 494; origin of, 486 ; homologies of, 487

Membranous labyrinth, derelopment of in Man, 427

Menobranchus, branchial arches of, 117

Mesenteron of Elasmobranchii, 35; Teleostei, 60; Petromyzon, 70; Acipenser, 85; Amphibia, 101, 102, 107; Chick, 139 ; general account of, 620

Mesentery, 51t, 622

Mesoblast, of Amphioxus, 5 ; Ascidia, 14, 17; Pyrosoma, 20; Salpa, 25; Elasmobranchii, 36, 39; Teleostei, 60; Petromyzon, 71; Acipenser, 86; Lepidosteus, 93; Amphibia, 103, 105, 106 ; of Chick, 127, 138; double origin of in Chick, 128, 130, 131; origin of from lips of blastopore in Chick, 131 ; of area vasculosa of Chick, 133; Lacerta, 168; origin of in Rabbit, 180,185 ; of area vasculosa in Rabbit, 188; comparative account of formation of, $2+3$; discussion of development of in Vertebrata, 247; meaning of derelopment of in Amniota, 247 ; phylogenetic origin of, 286 ; summary of ontogeny of, $289-292$; views on ontogeny of, $292-297$

Mesoblastic somites, of Amphioxus, 5; Elasmobranchii, 40, 45; Petromyzon, 72; Acipenser, 87; Lepidosteus, 94; Amphibia, 106, 108; Chick, 134, 151; Rabbit, 189; development of in Chordata, 269 ; meaning of derelopment of, 274 ; of head, 557

Mesogastrium, 623

Mesonephros, of Teleostei, 63, 579; Petromyzon, 78, 81, 577; Acipenser, 91, 581; Amphibia, 111, 583; Chick, 152, 588; general account of, 569; development of in Elasmobranchs, 570 ; of Cyclostomata, 577; Ganoidei, 581; sexual and non-sexual part of in Amphibia, 585; of Amniota, 588, 597; summary and general conclusions as to, 601 ; relation of to pronephros, 603

Mesopterygium, 506

Metagenesis of Ascidians, 2.3

Metamorphosis of Amphibia, 113, 116

Metanephros, 569; development of iu Elasmobranchii, 574; of Amphibia, 586; of Amniota, 588; of Chick, 595 ; of Laecrtilia, 596 ; phylogeny of, 606

Metapterygium, 505

Ietapterygoid, of Elasmobranchii, 474, 475 ; of Teleostei, 478

Netazoa, evolution of, 280, 283; ancestral form of, 275,285

Mid-brain, of Elasmobranchii, 46, 48, 49; Petromyzon, 76 ; general account of development of, 352

Moina, generative organs of, 613 
Molgula, development of, 18

Mollusca, nervous system of, 341 ; eyes of, 388 ; auditory organs of, 424 ; excretory organs of, 562

Monotremata, fotal membranes of, 198; cerebellum of, 351 ; corpus callosum of, 365 ; cerebrum of, 365 ; urinogenital sinus of, 599

Mormyrus, generative ducts of, 580

Mouth, of Amphioxus, 6 ; of Ascidia, 15; Pyrosoma, 22; Salpa, 26; Elasmobranchii, 47, 50, 51, 52; Petromyzon, 74, 77, 78, 81 ; Acipcnser, 88; Lepidosteus, 98; Amphibia, 107, 109, 111; Rabbit, 191 ; origin of, 263

Mouth, suctorial, of Petromyzon, 81 ; Acipenser, 88; Lepidosteus, 95,263 ; Amphibia, $109,116,263$

Miillerian duct, 569; of Elasmobranchs, 571 ; of Ganoids, 580; of Amphibia, 585; of Aves, 591, 593; opening of into cloaca, 598; origin of, 604 ; summary of development of, 604; relation of to pronephros, 604

Muscle-plates, of Amphioxus, 5; Elasmobranch.̈, 40, 551; Teleostci, 552; Petromyzon, 77; Chick, 151, 552; general development of, 551; of Amphibia, 552; Aves, 552 ; of Mammalia, 553 ; origin of muscles from, 554

Muscles, of Ascidia, 10, 14; development of from muscle-plates, $5 \check{5} 4$; of limbs, 555 ; of head, 557 ; of branchial arches, $559 ;$ of eye, 559

Muscular fibres, epithelial origin of, 550

Muscular system, development of, 550; of Chordata, 551

Mustelus, placenta of, 51

Iyoepithelial cells, 550

Mysis, a uditory organ of, 425

Myxine, ovum of, 82 ; olfactory organ of, 439 ; portal sinus of, 535 ; excretory system of, 578

Nails, development of, 323

Nares, of Acipenser, 89 ; of Ichthyopsida, 440; development of in Click, 441; development of in Lacertilia, 442 ; development of in Amphibia, 443

Nasal bones, 487

Nasal pits, Acipenser, 89; Chick, 146; general developnent of, 438

Nematoda, excretory organs of, 5 c8 ; generative organs of, 613 ; generative ducts of, 618

Nemertines, nervous system of, 258 ; excretory organs of, 561

Nerve cor $d$, origin of ventral, 312

Ncrves, spinal, 369 ; cranial, 374-383

Nervous system, central, general account of development of in Vertebrata, 342; conclusions as to, 366 ; sympathetic, 384
Nervous system, of Amphioxus, 3 ; Ascidia, 13, 14; Molgula, 18; Pyrosoma, 20, 21; Salpa, 25, 26; Elasmobranchii, 36; Teleostei, 62 ; Petromyzon, 73, 76; Acipenser, 87; Amphibia, 104; comparative account of formation of central, 250; of Sagitta, 289; origin of in Colenterata, 289 ; of prooral lobe, 311,313 ; evolution of, 330-335; development of in Invertebrates, 335; of Arthropoda, 337; of Gephyrea, 340 ; Mollusca, 341

Neural canal, of Ascidia, 9 ; Teleostei, 58; Petromyzon, 72 ; Acipenser, 86 ; Lepidosteus, 94; Amphibia, 104, 108; Chick, 138, 141; Laccrta, 172; closure of in Frog and Amphioxus, 233; closure of in Elasmobranchii, 236; phylogenetic origin of, 262

Neural crest, $369,374,375$

Neurenteric canal, of Amplioxus, 3, 4; Ascidia, 9 ; Elasmobranchii, 44 ; Petromyzon, 72; Acipenser, 86 ; Lepidosteus, 93 ; Aves, 135 ; Lacerta, 168, 170 ; general account of, 267 ; meaning of, 268

Newt, ovum of, 99; development of, 103 ; general growtl of, 116

Notidanus, vcrtebral column of, 452 ; branchial arches of, 472

Notochord of Amphioxus, 5; Ascidia, 10, 14; Elasmobranchii, 42; Teleostei, 60; Petromyzon, 71, 77; Acipenser, 86; Lepidosteus, 93; Ampliibia, 105, 106 ; Chick, 130; canal of, in Chick, 135; Laccrta, 168, 169; Guinea-pig, 187; comparative account of formation of, 243 , 269 ; sheath of, 449 ; later histological changes in, 449; cartilaginous sheatl of, 451; in head, 467; absence of in region of trabeculæ, 468

Notodclpliys, brood-pouch of, 100 ; brancliix of, 116

Nototrema, brood-pouch of, 100

Nucleus pulposus, 460

Oceania, eye of, 388

Occipital bone, 489

Esophagus, solid, of Elasmobranchii, 50, 624 ; of Teleostei, 63

Olfactory capsules, 470

Olfactory lobes, development of, 366

Olfactory nerves, Ammoccetes, 81; gene. ral development of, 382

Olfactory organ, of aquatic forms, 438; Insects and Crustacea, 438; of Tunicata, 438; of Amphioxus, 438; of Vertebrata, 438; Petromyzon, 439 ; of Myxine, 439

Olfactory sacks, of Elasmobranchii, 49,50 ; Teleostei, 59; Petromyzon, 76, 79; Acipenser, 87, 89; Lepidosteus, 95; Chick, 146

Oligochrta, excretory organs of, 564

Olivary bodies, 350

Omentum, lesser and greater, 623 
Onchidium, eye of, 394

Opereular bones, 487

Operculum, of Teleostei, 62; Acipenser, 88; Lepidosteus, 96, 98 ; Amphibia, 111

Ophidia, development of, 173; arterial system of, 533 ; venous system of, 539

Optic ehiasma, 35̃4, 405

Optic cup, retinal part of, 402 ; ciliary portion of, 403

Optic lobes, 352

Optic nerve, development of, 405; comparative development of, 411

Optic thalami, development of, 355

Optic vesicle, of Elasmobranchii, 46-48; Teleostei, 59, 410; Petromyzon, 73, 76; Acipenser, 87; Lepidosteus, 94; Chick, 141; Rabbit, 190; general development of, 353; formation of secondary, 401 . obliteration of cavity of, 402 ; comparative development of, 410 ; of Lepidosteus and Teleostei, 410. Sce also 'Eye'

Ora selrata, 402

Orbitosphenoid region of skull, 470

Organs, classification of, 323; derivation of from germinal layers, 321

Orycteropus, placenta of, 207

Otic process, of Axolotl, 480; of Frog, 481 et seq.

Otoliths, 422

Oviposition, of Amphioxus, 1; Elasmobranchii, 33; Teleostei, 55; Petromyzon, 69; Amphibia, 100; Reptilia, 167

Orum, of Amplioxus, 1; Pyrosoma, 19; Elasmobranchii, 33; Teleostei, 55; Petromyzon, 68; Myxine, 82; Acipenser, 84; Lepictosteus, 91; Amphibia, 99; Chick, 121; Reptilia, 167; Mammalia, 177 ; of Porifera, 610 ; migration of in Colenterata, 611; Vertebrata, 614

Palatine bone, of Teleostei, 478; origin of, 488

Pancreas, Acipenser, 91; general development of, 633

Pancreatic exca, of Teleostei, etc. 632

Papilla, oral, of Acipenser, 89; Lepidosteus, 95

Parachordals, 466

Parasphenoid bone, 488

Parepididymis, 597

Parietal bones, 487

Parooploron, 597

Parovarium, 597

Pectoral girdle, 492; of Elasmobranchs, 493; of 'Teleostei, 493; of Amplibia and Amniota, 493 ; comparison of with pelvic, 500

Pecten, eye of, 394

Pccten, of Ammocoetes, 410; of Chick, 412; Lizard, 413; Elasmobranclss, 413

Pedicle, of Axolotl, 480; of Frog, 481

Pelobates, branchial apertures of, 112; vertebral column of, $45 \mathrm{~s}$
Pelodytes, branchial chamber of, 112

Pelvic girdle, 497; of Fishes, 497; Amphibia and Amniota, 498; of Lacertilia, 499; of Mammalia, 499 ; comparison with pectoral, 500

Penis, development of, 599

Peribranchial cavity, of Amphioxus, 6 ; of Ascidia, 15; Pyrosoma, 20

Perieardial cavity, of Pyrosoma, 21; Elasmobranchii, 40; Petromyzon, 77 ; general account of, 514 ; of Hishes, 516 ; of Amphibia, Sauropsida and Mammalia, 517

Perichordal formation of vertebral column, 458

Perilymph of ear, 430

I'eriotic capsules, ossifications in, 489, 490

Peripatus, nervous system of, 337; eye of, 395 ; excretory organs of, 567

Peritoneal membrane, 514

Petromyzon, development of, 6s; affinities of, 68, 69; general development of, 72; hatching of, 73; comparison of gastrula of, 233; branchial skeleton of, 259, 471; cerebellum of, 350; pineal gland of, 357 ; pituitary boly of, 359 ; cerebrum of, 361 ; auditory organ of, 426 ; olfactory organ of, 439 ; comparison of oral skeleton of with Tadpole, 482; pericardial cavity of, 515; abdominal pores of, 515 ; venous system of, 535; excretory organs of, 577; segmental duct of, 577 ; pronephros of, 577 ; mesonephros of, 577; thyroid body of, 625 ; postanal gut of, 636 ; stomodeum of, 639

Phosphorescence of larve, 301

Phylogeny, of the Chordata, 271; of the Metazoa, 316

Pig, placenta of, 209; mandibular and liyoid arches of, 484

Pineal gland, of Petromyzon, 76; Chick, 145 ; general development of, 356 ; nature of, 356,358

Pipa, brood-pouch of, 100 ; metamorphosis of, 114 ; yolk-sack of, 115 ; vertebral column of, 458

Pituitary body, of Liabbit, 191; general development of, 358 ; meaning of, 359

Placenta, of Salpa, 24; Elasmobranchii, 54; of Mammalia, 193 ; villi of, 195 ; deciduate and non-deciduate, 198; comparative account of, $198-216$; characters of primitive type of, 199 ; zonary, 205 ; non-decidtuate, 207; histology of, 215 ; evolution of, 216

Placoid scales, 326

Planorbis, excretory organs of, 562

Planula, structure of, 303

I'leural cavities, 518

I'leuronectidx, development of, 65

Pneumatocela, characters of, 271 
Polygordius, excretory organs of, 564

Polyophthalmus, eye of, 394

Polypedates, brood-pouch of, 100

Polyzoa, excretory organs of, 563 ; generative cells of, 613 ; generative ducts of, 618

Pons Varolii, 3.51, 352

Pori abdominales, Ammocotes, 81

Porifera, ancestral form of, 285 ; development of generative cells of, 610

Portal vein, 536

P'ostanal gut of Elasmobranchii, 47, 48, 49; Tcleostei, 61 ; Chick, 140 ; general account of, 267,634

Premaxilla, 488

Prieopercular bone, 487

l'ræoral lobe, ganglion of, 311, 313

Prefrontals, 490

Presphenoid region of skull, 470

Prinitive groove of Chick, 128

Primitive streak, of Chick, 126, 134; meaning of, 127 ; origin of mesoblast form in Chick, 127, 128; continuity of hypoblast with epiblast at anterior end of, in Chick, 129 ; comparison of with blastopore, 1:37; fate of, in Chick, 137; of Lacerta, 168 ; of Rabbit, 184 ; of Guineapig, 186; fusion of layers at, in Rabbit, 186 ; comparison of with blastopore of lower forms, 187, 238; of Mammalia, 241

Processus falciformis of Ammoccetes, 410 ; of Elasmobranch, $\mathbf{4 1 3}$; of Teleostei, $\mathbf{4 1 4}$

Proctodxum, 6.2

Pronephros, of Teleostei, 63, 578 ; Petromyzon, 78, 81, 577; Acipenser, 88, 91; Amphibia, 110, 582; general account of, 568; of Cyclostomata, 577; of Myxine, 578; Ganoidei, 581; of Amniota, 588; of Chick, 591; summary of and general conclusions as to, 600 ; relation of, to mesonephros, 603; cause of atrophy of, 601

Prootic, 489, 490

Propterygium, 506

Proteus, branchial arches of, 117

Protochordata, characters of, 271

Protoganoidei, characters of, 272

Protognathostomata, characters of, 271

Protopentadactyloidei, characters of, 272

Protovertcbrata, characters of, 271

Pseudis, Tadpole of, 115 ; vertebral column of, 458

Pseudophryne, yolk-sack of, 115 ; Tadpole of, 116

Pterygoid bone, of Teleostei, 478; origin of, 488

Pterygoquadrate bar, of Elasmobranchii, 474; of Teleostei, 478; Axolotl, 40 ; Frog, 481; of Sauropsida, 484; of Mammalia, 484

Pulmonary artery, origin of, 530 ; of Amphibia, 531; of Amniota, 533
Pulmonary vein, 538

Pupil, 402

Pyrosoma, development of, 19

Quadrate bone of Teleostei, 478 ; of Axolotl, 480 ; Frog, 481 ; Sauropsida, 484

Quadratojugal bone, 488

Rabbit, development of, 177; general growth of embryo of, 188; placenta of, 199

Radiate symmetry, passage from to bilateral symmetry, $308-310$

Raja, caudal vertebræ of, 455

Rat, placenta of, 200

liecessus labyrinthi, 427

Reissner's membrane, 432

Reptilia, development of, 167 ; viviparous, 167 ; cerebellum of, 350 ; infundibulum of, 355 ; pituitary body of, 359 ; cerebrum of, 361 ; rertebral column of, 458; arterial system of, 532 ; venous system of, 539; mesoncphros of, 588; testicular network of, 596 ; spermatozoa of, 615

Restiform tracts of Elasmobranchii and Teleostei, 350

Retina, histogenesis of, 404

Retinulæ, 396

Rhabdom, 396

Rhinoderma, brood-pouch of, 100 ; metamorphosis of, 115

Ribs, development of, 462

Rosenmiiller's organ, 597

Rotifera, excretory organs of, 561

Round ligament of liver, 546

Ruminantia, placenta of, 211

Sacci vasculosi, 355

Sacculus hemisphericus, 427 ; of Mammals, 428,429

Sagitta. See 'Chætognatha'

Salpa, sexual development of, 24 ; asexual development of, 28

Salamandra, larva of, 117; vertebral column of, 456 ; limbs of, 509 ; mesonephros of, 583 ; Miullerian duct of, 585

Salmonidx, hypoblast of, 57 ; generative ducts of, 580

Sauropsida, gastrula of, 238; meaning of primitive streak of, 239 ; blastopore of, 240 ; mandibular and hyoid arches of, 483 ; pectoral girdle of, 493

Scala, restibuli, 430 ; tympani, 430 ; media, 430

Scales, general development of, 327 ; development of placoi 1 scales, 326

Scapula, 492

Sclerotic, 401

Scrotum, development of, 599

Scyllium, candal vertebræ of, 455 ; mandibular and hyoid arches of, 476 ; pectoral 
girdle of, 493 ; limbs of, 501 ; pelvic fin of, 504 ; pectoral fin of, 504

Segmental duct, 568 ; development of in Elasmobranchs, 569 ; of Cyclostomata, 577 ; of Teleostei, 578 ; of Ganoidei, 580 , 581 ; of Amplibia, 582; of Amniota, 588

Segmental organs, 563

Segmental tubes, 569 ; development of in Elasmobranchs, 570 ; rudimentary anterior in Elasmobranchs, 571 ; development of secondary, 602

Segmentation cavity, of Elasmobranchii, $34-36$; Teleostei, 56, 69, 70; Anmphibia, 100,103

Segmentation, meaning of, 274

Segmentation of ovum, in Amphioxus, 2 ; Ascidia, 8; Molgula, 18 ; Prrosoma, 19; Salpa, 25; Elasmobranchii, 33 ; Teleostei, 56 ; Petromyzon, 69; Acipenser, 84 ; Lepidosteus, 92 ; Amphibia, 100, 102; Newt, 103; Chick, 121; Lizard, 167 ; Rabbit, 177

Semicircular canals, $\$ 27$

Sense organs, comparative account of development of, 252

Septum lncidum, 36.

Serous membrane, Lacerta, 172 ; of Rabbit, 196

Serenth nerve, development of, 377

Shell-gland, of Crustacea, 568

Shield, embryonic, of Chick, 125; of Lacerta, 167

Simiadx, placenta of, 205

Sinus rhomboidalis, of Chick, 131

Sinus venosus, 524

Sirenia, placenta of, 212

Sixth nerve, 381

Skate, mandibular and hyoid arches of, 175

Skeleton, elements of found in Vertebrata, 447

Skull, general development of, 465 ; historical account of, 465 ; derelopment of cartilaginous, 466 ; cartilaginous walls of, 470 ; composition of primitive cartilaginous cranium, 466

Somatopleure, of Chick, 141

Spelerpes, branchial arches of, 117

Spermatozoa, of Porifera, 612 ; of Tertebrata, 614

Sphenoid bone, 489

Sphenodon, hyoid arch of, 483

Spinal corl, general account of, 342 ; white matter of, 342 ; central canal of, 343,345 ; commissures of, 343 ; grey matter of, 343 ; fissures of, 341

Spinal nerves, posterior roots of, 369 ; anterior roots of, 372

Spiracle, of Elasmobranchii, 50 ; Acipenser, 87; Amphibia, 112

Spiral valve. See "Valve"

Spleen, 547
Splenial bone, 488

Squamosal bone, 487

Stapes, 436; of Mammal, 485

Sternum, development of, 463

Stolon of Doliolum, 24 ; Salpa, 28

Stomodxum, 636

Stria vascularis, 431

Styloid process, 486

Sub-intestinal rein, 535; meaning of, 535

Syugnathus, brood-pouch of, 55

Subnotochordal rod, of Elasmobranchii, 45 ; Petromyzon, 77 ; Acipenser, 91 ; Lepidosteus, 95 ; general account of, 620 ; comparison of with siphon of Chætopods, 622

Subzonal membrane, 196 ; villi of, 195

Sulcus of Mumro, 355

Supraclaricle, 492

Suprarenal bodies, 547

Supra-temporal bone, 497

Swimming bladder, see Air bladder.

Sylvian aqueduct, 352

Sylvian fissure, 36.5

Sympathetic ganglia, development of, 381

Tadpole, 111. 114, 115; phylogenetic meaning of, 113; metamorphosis of, 113; meaning of suctorial mouth of, 481

Tail of Teleostei, 64; Acipenser, 89 ; Lepidosteus, 97; Amphibia, 109

Tarsus, development of, 509

Teeth, horny provisional, of Amplibia, 112 ; general derelopment of, 610 ; origin of, 640

Teleostei, development of, 5.5 ; viviparous, 55 ; comparison of formation of layers in, 238 ; restiform tracts of, 350 ; mid-brain of, 352 ; infundibulum of, 355 ; cerebrum of, 361 ; nares of, 440 ; lateral line of, 414 ; notochord and membrana elastica of, 452 ; vertebral column of, 456 ; ribs of, 463 ; hyoid and mandibular arches of, 476 ; pectoral girdle of, 493 ; pelric girdle of, 498 ; limbs of, 507 ; heart of, 523 ; arterial system of, 530 ; muscleplates of, 552 ; excrctory organs of, 578 ; generative ducts of, $580,605,616$; swimming bladder of, 627 ; postanal gut of, 636

Teredo, nerrous system of, 341

Test of Ascidia, 12; Salpa, 26

Testicular network, of Elasmobranchs, 574 ; of Amphibia, 586; Reptilia, 596; of Mammals, 596

Testis of Vertebrata, 614

Testis, connection of with Wolffian body, in Elasmobranchii, 574; in Amphibia, 585 ; in Amniota, 596 ; origin of, 605

Thalamencepha? $n$ of Chick, 145 ; general development of, 351 
Third nerve, development of, 379

Thymus gland, 627

Thyroid gland, Petromyzon, 75; general account of, 624 ; nature of, 625 ; dc. velopment of iu Vertebrata, 626

Tooth. Sce 'Teeth'

'Tori semicirculares, 352

Tornaria, 307

Trabeculie, 466,468 ; nature of, 468

'Trachea, 630

Trematoda, excretory organs of, 561

Triton alpestris, sexual larva of, 118

Triton, development of limbs of, 509 ; urinogenital organs of, 587

Truncus arteriosus, 524; of Amphibia, 525 ; of Birds, 526

'Tunicata, development of mesoblast of, 243 ; test of, 326 ; eye of, 418 ; auditory organ of, 436; olfactory organ of, 438; generative duct of, 616; intestine of, 631 ; postanal gut of, 634 ; stomodæum of, 639

Turbellaria, cxeretory organs of, 561

Tympanic annulus of Frog, 483

Tympanic cavity, of Amphibia, 111 ; Chick, 149 ; Rabbit, 192 ; general development of, 435 ; of ITammals, 485

Tympanic membrane, of Chick, 150 ; gene. ral development of, 435

Tympanohyal, 486

Umbilical canal of Elasmobranchii, 45, $47,48,49$

Umbilical cord, 197 ; vessels of, 198

Ungulata, placenta of, 208

Urachus, 19s, 599

Ureters, of Elasmobranchii, 574 ; development of, 596

Urethra, 599

Urinary bladder of Amphibia, 587; of Amniota, 598

Urinogenital organs, see Excretory organs.

Urinogenital sinus of Petromyzon, 577; of Sauropsida, 598; of Mammalia, 599

Urochorda, development of, 8

Uterus, development of, 598 ; of Marsupials, 598

Uterus masculinus, 598

Utriculus, 427

Uvea of iris, 403

Vagus nerve, development of, 374,376 ; intestinal branch of, 376 ; branch of to lateral line, 377

Valve, spiral, of Petromyzon, 79; Acipenser, 91 ; general account of, 631

Talves, semilunar, 527; a uriculo-ventricular, 528

Vasa efferentia, of Elasmobranchs, 574; of Amphibia, 586; general origin of, ธ997

Vascular system, of Amphioxus, 7 ; Petro- myzon, 80; Lepidosteus, 96 ; general development of, 519

Vas defcrens, of Elasmobranchii, 575; of Amniota, 596

Vein, sub-intestinal of Petromyzon, 80 ; Acipenser, 91 ; Lepidosteus, 96

Velum of Petromyzon, 74

Vena cava inferior, development of, 538

Venous system of Petromyzon, 80 ; general development of, 535 ; of Fishes, 535 ; of Amphibia and Amniota, 538; of Reptilia, 539; of Ophidia, 539 ; of Aves, 541 ; of Mammalia, 545

Ventricle, fourth, of Chick, 146 ; history of, 349

Ventricle, lateral, 360,362 ; fiftll, 365

Ventricle, thircl, of Chick, 145

Vertebral bodies, of Chick, 151

Vertebral column, development of, 449, 453; epichordal and perichordal development of in Amphibia, 458

Vespertilionidæ, early development of, 179

Vieussens, valve of, 351

Villi, placental, of zona radiata, 195 ; subzonal membrane, 195; chorion, 197; Nan, 204 ; comparative account of, 215 ; of young human ovum, 221, 225

Visceral arches, Amphioxus, 6; Elasmobranchii, 47-50; Teleostei, 62 ; Acipenser, 87; Lepidosteus, 96 ; Amphibia, 109, 110; Chick, 147; Rabbit, 191; preoral, 470 ; relation of to head cavities, 471 ; disappearance of posterior, 472; dental plates of in 'Teleostei, 473

Visual organs, evolution of, 387

Vitelline arteries, of Chick, 162

Vitelline veins, of Chick, 162

Vitreous humour, of Ammocotes, 81; general development of, 407; blood. ressels of in Mammals, 414; mesoblastic ingrowth in Mammals, 414

Vomer, 488

White matter, of spinal cord, 342; of brain, 348

Wolffian body, see 'Mesonephros'

Wolffian duct, first appearance of in Chick, 152; general account of, 569 ; of Elasmobranchs, 571 ; of Ganoids, 580 ; of Amphibia, 585; of Amniota, 5-8; atrophy of in Amniota, 597

Wolftian ridge, 153

Yolk blastopore, of Elasmobranchii, 52

Yolk, folding off of embryo from, in Elasmobranchii, 45; in Teleostei, 62; Acipenser, 87 ; Chick, 139, 141

Yolk nuclei, of Elasmobranchii, 34, 44; Teleostei, 56, 61

Yolk, of Elasmobranchii, 33; Teleostei, 55; Petromyzon, 79; Acipenser, 90; Amphibia, 101, 107; Chick, 121; influence of on formation of layers, 230 ; 
influence of on early development, 282,283

Yolk-sack, Amphibia, 108, 115, 116; enclosure of, 101

Yolk-sack, development of in Rabbit, 188; of Mammalia reduced, 188; circulation of in Rabbit,'193; "enclosure of in Sauropsida, 240

Yolk-sack, enclosure of, Petromyzon, 70

Yolk-sack, Lepidosteus, 97

Yolk-sack of Chick, enclosure of, 133 ; stalk of, 142 ; general account of, 161 ; circulation of, 162 ; later history of, 164

Yolk-sack of Elasmobranchii, enclosure of, 51,236 ; circulation of, 52

Yolk-sack of Lacerta, 173; circulation of, 173

Yolk-sack, Teleostei, 61, 6õ; enclosure of, 60 ; circulation of, 66

Zona radiata, villi of, 195

Zonula of Zinn, 407 



\section{BIBLIOGRAPHY.}

\section{('EPHALOCIIORDA.}

(I) A. Kowalersky. "Entwicklungsgeschichte des Amphioxus lanceolatus." Mém. Acad. Impêr. des sciences de St Pétersbourg, Series vir. 'Tom. xı. 1867.

(2). A. Kowalevsky. "Weitere Studien iiber die Entwicklungsgeschichte des Amphioxus lanceolatus." Archiv f. mikr. Anut., Vol. xıI. 1877.

(3) Lenckart u. Pagenstecher. "Untersuchungen über niedere Seethiere." Müller's Arctive, 1858.

(4) Max Schultzc. "Beobachtung junger Exemplare von Amphioxus." Zeit. f. wiss. Zool., Bd. 1II. 1851.

(5) A. M. Marshall. "On the mode of Oviposition of Amphioxus." Jour. of Anat. and P'hys., Vol. x. 1876.

\section{UROCHORDA.}

(6) P.J. van Beneden. "Recherehes s. lFmbryogénie, l'Anat, et la P'hysiol. des Ascidies simples." Mém. Acal. Roy. de Pelgique, Tom. xx.

(7) W. K. Brooks. "On the development of Salya." Int7. of the Huseum of Comp. Anat. at Harratd College, Cambridge, Mass.

(8) H. Fol. F́tudes sur les Appendiculaires du détroit de Messine. Genìve t Bâle, $1>7 \%$.

(9) Ganin. "Neue Thatsachen a. d. Entwicklungsgeschichte d. Ascidien." Zrit. f. uiss. Zool., Vol. xx. 1870.

(ro) C. Gegenbaur. "Ueber clen Entwicklungscyclus ron Doliolum nebst Bemerkungen über die Larven ,lieser Thicre." Zcit. f. viš. Zool., Bł. v11. 15ō6.

(i ) A. Giard. "Études critiques des travaux d'embryogénie relatif́s à la parenté des Vertébrés et des Tuniciers." Archir. Zoot. expériment., Vol. I. 1872. 1872

(1 2) A. Giard. "Recherches sur les Synaseidies." Archir. Zool. expér., Tol. I.

(rз) O. Hertwig. "Untersuchungen ïb. d. Bau u. ג. Entwicklung des CelluloseMantels d. Tumicaten." Jenaische Kaitsefrift, Bd. nIr. 1873.

(i f) Th. H. Huxley. "Remarks upon Appendicularia and Doliolum." Phit. Trans., 1851.

(I5) Th. H. Huxley, "Observations on the anatomy and pliysiology of Salpa and Pyrosoma." Phit. T'rans., 1851.

(i6) Th. H. Huxley. "Anatomy and development of Pyrosoma." Limean Trans., 1860, Vol. xsin.

(1 7$)$ Keferstein u. Ehlers. Zoologische Beiträge, 1861. Doliolum.

(IS) A. Kowalevsky. "Entwicklungsgeschichte d. einfachen Ascidien." Hém. Acal. Pétersbourg, viı. série, T. x. 1866.

(I9) A. Kowalevsky. "Beitrag z. Entwick. d. Tunicaten." Nachrichten d. königl. Gesell. zu Gïttingen. 1868.

(20) A. Kowalevsky. "Wcitere Stulicn üb. d. Entwicklung d. einfachen Ascidien." Arefhir f. mikr. Anat., Vol. vir. 1871.

(2r) A. Kowalersky. "Ueber Knospung d. Ascidien." Archir f. mitir. Anat,, Vol.x. 1874.

(22) A. Kowalersky. "Ueber die Entwicklungsgeschichte d. Pyrosoma." Arehir f. mikr. Anat., Vol. xi. 1875.

(23) A. Krohn, "Ueber dic Gattung Doliolum u. ihre Arten." Archir $f$. Naturgeschichte, Bd. xтпr. 1,52.

B. E. II. 
(24) A. Krolnn. "Ueber die Entwicklung d. Ascilien." Miiller"s Archir, 1852.

(25) A. Krohn. "Ueber die Fortptlanzungsverhältnisse d. Botrylliden." A tchir f. Niturgesehichte, Vol. xxxv. 1869.

(26) A. Kroln. "Ueber die früheste Bildung d. Botryllenstöcke." Archir $f$. Naturyeschichte, Vol, xxxv. 1869.

(27) C. Kupffer. "Die Stammverwandschaft $z$ wischen Ascidien u. Wirbelthieren." Archie f. mikr. Anat., Vol. vi. 1870.

(28) C. Kulfer. "Zur Entwicklung d. einfachen Ascilien." Avchir f. mikr. Anat., Vol. rin. 1872.

(29) H. Lacaze Duthiers. "Recherches sur l'organisation et l'Embryogénie des Ascidies (Molgula tubulosa)." Comptes rendus, May 30, 1870, p. 1154.

(30) H. Lacaze Duthiers. "Les Ascidics simples des Côtes de France (Development of Molgula)." Archir. Zool. expér., Vol. III. 187 t.

(3I) R. Lenckart. "Salpa u. Verwandte." Zoologische Untersuchungen, Heft II.

(32) E. Metschnikoff. "Observations sur le développement de quelques animaux (Botryllus and Simple Ascidians)." Buil. d. l'Aead. Pétersbon'g, Vol. xnI. 1869.

(33). H, Milnc-Edwards. "Observations s. l. Ascidies composées des côtes de la Manche." Mémoires d. l'Iustitut, T. xvir. 1812.

(3+) W. Salensky. "Ueber d, embryonale Entwicklungsgeschichte der Salpen." Zeit. f. wiss. Zool., B. xxvir. 1877.

(3:) W. Salensky. "Ueber die Knospung d. Salpen." Horphol. Jahrbuch, Bd. 1II. 1877.

(36) W. Salensky. "Teber dic Entwicklung d. Hoden u. über den Generationswechsel d. Salpen." Žeit. f. wiss. Zool., Bd. xxx. Suppl. 1878.

(37) C. Scmper. "Teber die Entstehung d. geschichteten Cellulose-Epidernis d. Ascidicn." Arbeit. a. d. zool.-zoot. Instit. Wiirzburg, Vol. II. 1875.

(38) Fr. Todaro. Sopra lo sviluppo e l'anatouia delle Salpe. Roma, 1875.

(39) Fr. T'odaro. "Sui primi fenomeni dcllo sviluppo delle Salpe." Reale Accudemia dei Lincei, Vol. 1\%. 1880.

\section{ELASHOBRANCHII.}

(to) F. M. Balfour. "A preliminary account of the development of the Elasmobranch Fishes." Quart. J. of licr. Sicicuce, Vol. xiv. 1\$76.

( +1$)$ F. M. Balfour. "A Monograph on the development of Elasmoloranch Fishes." Jondon, 1878. Reprinted from the Jomual of A uat. and Physiol. for 1876, 1877. an 1878 .

(+2) Z. Gerbe. "Recherches sur la segmentation de la cicatrule et la formation des: produits adrentifis de l'aruf des Plagiostomes et particulierement des Raies." Vide also Journal de l'Anetomie te de la Physiologie, 1872.

(+.3) W. His. "Leb. d. Bildung v. Haifischenembryonen." Zeit. fuir Anat. u. Enticick., Vol. 11. 1877.

(44) A. Kowalevsky. "Development of Acantlias vulgaris and Mustelus levis." (Russian.) Transuctions of the Kiew Socirty of Naturalists, Fol. I. 1870.

(45) R. Leuckart. "Ueber die allmählige Bildung d. Körpergentalt bei d. Rochen." Zeit.f. wiss. Zool., Bd. 11., p. 258.

(4) Fr. Leydig. Lochen u. Haie. Leinzig, 1852.

(47) A. W. II lm. "Bidrag till kinnedom om utvecklingen af Rajo." Kongl. retenskaps aliademiens firhandliugar. Stockholm, 1876.

(+8) Joh. Müllcr. Glatter IIaie des Aristoteles und iiber die Verschiedcuheiten unter den IIaifischen und Rochen in der Entwichluug des Eies. Berlin, 1:40.

(49) S. L. Schenk. "Die Eier von Raja quadrimaculata inncrhalb der Eileiter." Sitz. der k. Akad. Wien, Vol. Lxim. 1s73.

(50) Alex. Schultz. "Zur Entwicklungsgeschichte des Selachiereies." Areliv fiir micro. Alut., Vol. xI. 1875.

(5i) Alex. Schultz. "Beitrag zur Entwiclinugsgeschichte d. Knorpelfische." Arehir fïr wirco. Anat., Vol. xiIr. 1877.

(52) C. Semper. "Die Stammesverwandschaft đ. Wirbelthiere n. Wirbellosen." Arbeit. a. d. zool.-zoot. Instit. Wiirzburq, Vol. I1. 1s75.

(5.3) C. Semper. "Das Urogenitalsystem d. Plagioztomen, ete." Arbeit. a. d. zool.-zoot. Instit. Wiìzlurg, Vol. II. 1875.

(5t) Wyman. "Observations on the Development of Raja batis." Memoirs of the Auerican Academy of Arts aud Sciences, Vo!. Ix. 1864. 


\section{Telenostei.}

(55) Al. Agassiz. "On the young Stages of sone Osseons Fishes. I. Development of the Tail" Procestings of the American Academy of Ats and Sciences, Vol. xırl. Presenter Oet. 11, 1877 .

(56) Al. Agassiz. "II. Development of the Flommers." Proccedings of the American Acal. of Arts aud Sciences, Vol. xiv. Presented June, 187s.

$(5 ;)$ K. E. v. Baer. Intersuchungen ïber die Entwichlungsgeschichte der Fische. Leipzig, 1835.

(58) Cli. van Bambelie. "Premiers effets de la féeondation snr les a'ufs de Poissons: sur l'origine et la signification du fenillet muquenx on glandulaire chez les l'oissons Ossenx." Couptes Rendus des Séances de l'Académie des Sciences, Tome Lxxiv. 1872 .

(50) Ch. van Bambeke. "Recherehes sur lEmbryologie des Poissons Ossenx."

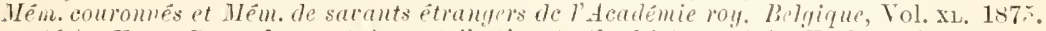

(6o) E. v. Beneden. "A contribution to the listory of the Embryonic development of the Teleosteans." Quact. J. of Hice. Sci., Vol. xin11. 1878.

(6 г) E. Calberla. "Zur Entwieklung des Malullarohres u. d. Chorda dorsalis d. Teleostier i. d. Tetromyzonten." Morpholoyisches Jahbueh, Vol, 111, 1877.

(62) A. Gïtte. "Beiträge zur Entwicklungsgeschichte der Wirbelthiere." Archiv f. mikt. Anat., Tol. 1x. 1873.

$\left(6_{3}\right)$ A. Götte. "Ueber d. Entwieklungd. Central-Nervensrstems der Teleostier." Archiv f. mikl. Aluat., Vol. xr. 1878.

$\left(6_{4}\right)$ A. Götte. "Entwiek, d. Teleostierkeime." Zoologischer Anzciger, No. 3.

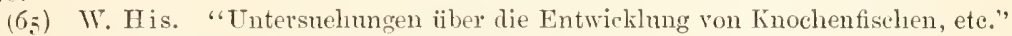
Keit. f. Anat. u. Entuichlungsgeschichte, Tol. 1. 1876.

(66) II. His. "Untersnehungen ïher die Bildung des Knochenfischembryo (Salmen)." Archir f. Auat. u. Physiol., 187ז.

$\left(6_{7}\right)$ E. Klein. "Observations on the early Development of the Common Trout." Quat. I. of Hice. Seicuce, Vol. xv1. 1876.

(68) C. Kupffer. "Beobaelıtungen über die Entwicklung der Knoehenfiselıe." Archiv f. miki. Anat., Bd. $1 \mathrm{v} .1868$.

(5y) C. Kupffer. Teber Laichen u. Entuickluu! des Ostscc-Herings. Berhin, 1878.

(;o) M. Lereboullet. "Lecherches sur le développement du broelict de la perelie et de l'éerevisse." Ammales des Sciencen Nat., Vol. 1., Selies 1V. 185t.

(71) M. Lereboullet, "Reeherehes d'Embryologie comparée sur le développement de la Truite." An. Sci. Nat., quatrieme série, Tol. xvi. 1861.

(72) T. Oellaclier. "Beitrïge zur Entwieklungsgeschiehte der Knoelienfische naeh Beobaehtungen am Bachforellenei." Zeit.f. wiss. Zool., Vol. xx11., 1872, and Vol. xxi11., 1873.

$\left(\sigma^{*}\right)$ H. Rathke. Abh. z. Bildung u. Entuick. d. Mensehen u. Thicre. Leipzig, 183:-3. Part 11. Blennins.

(73) Rieneek. "Ueber die Schichtnng des Forellenkeims." Archir f. mikr. Anat., Bl. v. 1869.

$(74)$ S. Strieker. "Untersuchungen über die Entwieklung der Bachforelle." Sitzungsberichte der Wiener $k$. Akad. d. Wiss., 1865. Tol. Lr. Abth. 2.

(75) Carl Vogt. "Embryologie des Sahmones." Histoice Naturlle des I'oissons de l'Europe Ceutrale. L. Agassiz. 1812.

$(-6)$ C. Weil. "Beiträge zur Kenntniss der Knochentisehe." Sit:unguec. de" Hiener kais. Aliad, der Wriss., Bd, Lxw, 1872.

\section{C'rclostomata.}

(77) E. Calberla. "Der Befruchtmgsvorgang beim Petromyzon P'laneri." Zeit. f. wiss. Kool. Vol. xxx. 1877.

(;8) E. Calberla. "Ueb. d. Entwicklung d. Medullarrohres u. d. Chorda dorsalis d. Teleostier u. d. Petromyzonten." Morpholog. Jahrbuch, Vol. 11. 1877.

(79) C. Kupffer n. B. Benecke. Der Vorgang d. Befruchtung am Ei d. Neunaugeu. Königsberg, 1878. 1856 .

(8o) A ug. Mïller. "Ueber die Entwicklung d. Nemangen." Müller's Achir,

(8r) Ang. Müller. Beobachtungen iib. d. Befochtungserscheinungen in Ei d. Nemaugen. Königsberg, 1861. 
(82) W. Müller. "Das Urogenitalsystem d. Amphioxus u. d. Cyclostomen." Jenaische Zeitsehrift, Vol. 1x. 1875.

(83) Ph. Owsjannikoff. "Die Entwick. von d. Flussneunaugen." Vorläuf. Mittheilung. Mélanges biologiques tirés dn Bulletin de l'Acad. Imp. St Pétersbonrg, Vol. vil. 1870.

(8f) Ph. Owsjannikoff. On the derelopment of Petromyzon fluviatilis (Tinssian).

(85) Anton Schneider. Beiträge z. vergleich. Anat. n. Entwick. d. Wirbelthiere. Quarto. Berlin, 1879.

(86) M. S. Schultze. "Dic Entwickl. v. Petromyzon Planeri." Geliönte Preisschrift. Haarlem, 1856.

$\left(8_{7}\right)$ W. B. Scott. "Vorläufige Mitheilung üb. d. Entwicklungsgeschichte d. Petromyzonten." Zoologischer Anzeiger, Nos. 63 and 6t. I11. Jahrg. 1880.

\section{GANOIDEI.}

\section{- Acipenseridu.}

(88) Knock. "I)ie Beschr. d. Reise z. Wolga Belunfs d. Sterlettbefruclitung." Bull. Soe. Nat. Moscow, 1871.

(Sy) A. Kowalevsky, Ph. Owsjannikoff, and N. Wagner. "Die Entwick. 1. Sitöre." Vorliuf. Mittheilung. Mélanges Biologiqnes tirés dn Bulletin d. l'Acad. Imp. S't Pétershoura, Vol. vi1. 1870.

(90) W. Salensky. "Development of the Sterlet (Acipenser ruthenus)." 2 Parts. Proceedings of the Society of Naturalists in the imperial Tniversity of hisan. 1878 and ? (Russian). Part I., abstracted in Hoffmanu and Schwalbe's Jahresbrieht for 1878.

(91) W. Salensky. "Zur Embryologie d. Ganoiden (Acipenser)." Zoologischer Anzeiger, Vol. I., Nos. 11, 12, 13.

\section{Lepidosteide.}

(92) Al. Agrasiz. "The development of Jepidostens." Proc. Amer. Acad. of Arts and Sciences, Vol. xi11. 1878.

\section{Anphibia.}

(93) Ch. van Bambeke. "Recherches sur le développement du Pélobatc brun." Mémoires conronnés, etc. de r'Acad. roy. de Belgique, 1868.

(94) Cli. van Bambeke. "Tiecherches sur l'embryologie des Batracions." Bulletin de l'Acad. roy. de Belgique, 1875.

(95) Ch. van Bambeke. "Nourelles recherches sur l'embryo'ogie des Batraciens." Archices de Biologie, Vol. 1. 1880.

(96) K. E. von Baer. "Die Metamorphose des Eies der Batrachier." MÏ̈ller's Arehiv, 1834.

(97) B. Benecke. "Ueber die Entwicklung des Erdsalamanders." Zoologischer Anzeiger, 1880.

(9) S. F. Clarke. "Development of Amblystoma punctatum," Part I., External. Studies from the Biological Laboratory of the Johns Ilopkins University, No. 1I. 1880.

(99) H. Cramer. "Bemerkmngen üb. d. Zellenleben in d. Entwick. d. Froscheies." Müller's Arehir, 1818.

( 100$)$ A. Ecker. Teones Physiolog. 1851-1859.

(Iог) A. Götte. Die Entwieklungsgeschichte der Unke. Leipzig, 1875.

(102) C. K. Hoffmann. "Amphibia." Iizassen u. Ordnminen d. Thiemeichs, $1873-1879$.

(103) 'T. H. Huxley. Article "Amphibia" in the Encycioparlia Britannica.

(rof) A. Moquin-Tandon. "Déreloppement des Batraciens anures." Aunates des Seiences Naturelles, 11. 1875.

(105) G. Newport. "On the impregnation of the Orum in Amphibia" (three memoirs). Phil. Trans. 1851, 1853, and 1854.

(106) W. K. Parker. "On the structure and development of the Skull of the common Frog." Phil. Trans., cLxi. 1871.

(107) W. K. Parker. "On the structure and development of the Skull of the Batrachia." Phil. Trans., Vol, cxuvi., Part 2. 1876. 
(108) W. C. H. P'eters. "Ueber die Entwicklung der Coecilien und besonders ron Coecilia compressicanda." Berlin. Monatsbericht, p. 40, 1874.

(109) W. C. H. Peters. "Ueber die Entwicklung der Coecilien." Berl. Monatsbericht, p. 483,1875 .

(1 10) J. L. Prevost and J. B. Dumas. "Deuxième Mém. s. 1. génération.

Développement de l'cuf d. Batraciens." Ann. Sci. Yat. 11. 1821. 1858 .

(11 I) R. Hemak. Untersuchungen ̈̈ber die Entwicklung der Irirbelthiere, 1850-

(ir2) I. Rusconi. Déreloppement de la grenouille commune depnis le moment de sa naissance jusqu à son étut parait, 1826.

(113) M. Rusconi. Mistoire nuturelle, développement et mótrmorphose de la Salumandie terrestre, 1854.

(irt) W. B. Scott and H. F. Osborn. "On the early development of the common Newt." Quart. J. of Hicr. Science, Vol. xxrx. 1879.

(115) S. Stricker. "Entwicklungsgeschichte von Bufo cinerens." Sitzb. der kaiserl. Acal. zn IIien, 186 ?.

(116) S. Stricker. "Untersuchungen iiber die erston Anlagen in BatrachierEiern." Zeitsc'rift f. wiss. Zoologie, Bu. xr. 1861.

\section{Ares.}

(и7) K. E. von Baer. "Leb. Entuchlungsgezchichte d. Thiere." Königsherg, $1828-1837$.

(118) F. II. Balfour. "The development and growth of the layers of the Blastoderm," and "On the disappearance of the Primitive Groove in the Embryo Chick." Quart. J. of Nlicros. Sicience, Vol. x111. 1873.

(119) M. Braun. "Die Entwicklung d. Wellenpapagei's." Part I. Arbeit. d. zool.-zoot. Instit. Würzburg, Vol. v. 1879.

(120) M. Braun. "Aus d. Entwick. d. Papageien; I. Räckenmark; II. Entwicklung d. Mesolerms; III. Die Terbindunen zwischen Rïckcnmark u. Darm bei

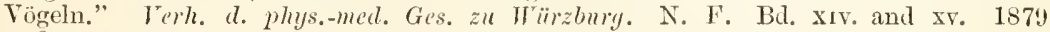
and 1880 .

(เ21) J. Disse. "I)ie Entwicklung des mittleren Keimblattes im Hühnerei." Areliv fiir mikr. Anat. Tol. xv, 1878.

(122) J. Disse. "Die Entstehung d. Blutes u. d. ersten Gefïsse im Hülnnerei." Arehir t. mikr. Anat., Vol. xri. 1879.

(I23) Fr. Durante. "Sulla struttura della macula germinativa delle uova di Gallina." Ricerehe nel Laboratorio di Automia drlla R. Universiti di Roma.

(12t) E. Dursy. Der, Primitiostreif des Hïhnchens. 1867.

(125) M. Duval. "Cinde sur la ligne primitive de l'embryon de Poulet." Annales des Sciences Nuturelles, Vol. vi1. 1879.

(126) M. Foster and E. M. Balfour. Elements of Embryology. Part I. London, 1874 .

(I27) Gasser. "Der Primitivstreifen bei Vogelembryonen." Schriften $d$. Gesell. zur Beförl. d. gesammten Naturwiss. zu Narburg, Vol. II. Supplement 1. 1879.

(128) A. Götte. "Beiträge zur Entwicklungsgeschichte d. Wirbelthiere. II. Die Bildung d. Keimblatter u. d. Blutes im Hiihnerei." Archin für mikr. Anat., Tol, x. 1874 .

(129) T. Hensen. "Embryol. Mitth." Arehir f. mikr. Anat., Vol. In. 1867. 1868 .

(130) W. His. Untersuch. iib. d. e'ste Anlage d. Mrirbetthierleibes. Leipzig.

(131) W. His. Unsere K̈̈̈perform und des physiol. Problem ilirer Entstehung. Leipzig, 1875 .

(132) W. His. "Der Keimwall des Hühnereies u. d. Entstehung d. parablastischen Zellen." Zeit. f. Anat. u. Entwickhungsgeschichte. Bd. 1. 1876.

(133) W. His. "Neue Untersuchungen ïb. die Bildung des Hïhnerembryo I." Archiv f. Anat. u. Phys. 1877.

(134) E. Klein. "Das mittlere Keimblatt in seiner Beziel. z. Entwick. d. crs. Blntgefässe und Blutkörp. im Höhnerembryo." Sitzungsber. Mien. Aliad., Tol, Lxm. 1871.

(135) A. Kölliker. Entwicklungsgeschichte d. Menschen u. d. höheren Thiere. Leipzig, 1879. 
(136) C. Kupffer. "Iie Eutstelı. d. Allantois u. d. Gastrula d. Wirbelth." Zoolog. Anzoiger, Vol. 1r. 1879, pp. 520, 593, 612.

(I37) C. Kupfer and B. Benecke. "Photogramme z. Ontogenie d. Vögel." Nov. Act. d. k. Leop.-Carol.-1)entschen Akad. d. Naturforscher, Vol. xu. 1879.

(1 $3^{8)}$ J. Oellacher. "Untersnchungen über die Furchung u. Blatterbildung im Hühnerei." Stricker's Studien. 1870. 1817.

(139) C. H. Pander. Beiträge z. Fntrick. d. Hïnchens im Eie. Würzburg,

(I \&o) A. Tauber. "Ueher die Embryon alanlage des Hülmchens." Centralblatt fiir d. medic. Wissenschaften. 1874-75.

(I +1$)$ A. Rauber. Ueber die Stellung des Hühnehens im Entwicklungsplan. 1876.

$(1+2)$ A. Rauber. "Primitivrime und Urmunl. Beiträge zur Entwicklungsgeschichte des Hühnchens." Horphol. Jahrbach, B. 1r. 1876.

$\left(I_{+3}\right)$ A. Rauber. Primitirstreifen und Nemula der Wirbelthiere in normaler und pathologischer Beziehung. 1877.

(I+4) R. Remak. Untersuch. ̈̈b. d. Entwicklung d. Wirbelthiere. Berlin, 1850_55.

$(1+5)$ S. L. Schenk. "Beiträge z. Lehre v. d. Organanlage im motorischen Keimhlatt." Sitz. W'ien. Alarl., Vol. Lvir. 1860.

( f $^{6}$ S. L. Schenk. "Beiträge z. Lehre v. Amvion." drchir f. mikr. Anat., Vol. viI. 1871 .

1874 .

$(1+7)$ S. L. Schenk. Lehrbuch d. veryleich. Embryol. d. Wirbelthiere. Wien,

(148) S. Stricker. "Mittheil. üb. d. selbstständigen Bewegungen embryonaler

Zellen." Sitz. Wien. Akad., Vol. xuIx. 1864.

( +9 ) S. Stricker. "Beiträge zur Kemtniss des Hühnereies." Wriener Sitzungsber., Vol. L1Y. 1866 .

(I50) H. Tirchow. Teber d. Epithel d. Dottersackes im Hïhnerei. Inaug. Diss. Berlin, 1875.

(151) W. Waldeyer. "Ueber die Keimblätter und den Primitivstreifen bei der Entwicklung des Hühnerembryo." Zeitschrift für rationelle Yedicin. 1869.

(I52) C. F. Wolff. Theoria generationis. Hala, 1759.

(153) C. F. Wolff. Ueb. d. Bildung d. Darmcanals im bebrïteten Hünchen. Halle, 1812.

\section{Reptilia.}

(15, C. Kupferer and Benecke. Die erste Entwicklung am Ei d. Reptitien. Königsberg, 1878 .

(155) C. Kupffer. "Die Entstehung d. Allantois u. d. Gastrula d. Wirbelthiere." Zoolegischer Anzeiger, Vol. 1r. 1879, p1. 520, 593,612.

\section{Lacertilia.}

$(1 ; 6)$ I'. M. Balfour. "On the early Development of the Lacertilia, together with some observations, ete." Quart. J. of Hicr. Science, Vol. xIx. 1879.

(15i) Emmert u. Hochstetter. "Untersuchung üb. d. Entwick. d. Eidechsen in ihren Eiern." Reil's Arehix, Vol. x. 1811.

$(1 ;-8)$ M. Le reboullet. "Développement de la Truite, du Lézard et du Limmée. II. Lmbryologie du Lézard." An. Sci. Nat., Ser. rv., Vol. xxvir. 1862.

( 59 ) W. K. Parker, "Structure and Devel. of the Skull in Lacertilia." Phil. Trans., Vol. 170, p. 2. 1879.

(r6o) H. Strahl. "Ueb. d. Canalis myeloentericus d. Eidechse." Schrift. $\boldsymbol{l}$. Gesell. 2. Beför. d. gescm. Naturwiss. Marburg. July 23, 1880.

\section{Oplidia.}

(161) H. Introchet. "Recherches s. 1. enveloppes du fuetus." Mêm. $d$. Soc. Méd. d'Emulation, Paris, Tol. vin. 1816.

(i6z) W. K. Parker. "On the skull of the common Snake." Phil. Trans., Tol. 169, Part II. 1878.

(163) H. Rathke. Entwick. d. Natter. Königsberg, 1839.

\section{Chelonia.}

(164) L. Agassiz. Contributions to the Natural Itistory of the United States. Vol. 11. 1857. Embryology of the Turtle. 
(165) W. K. Parker. "On the development of the skull and nerves in the green Turtle." Proe. of the Roy. Soc., Vol. xxvir. 1879. Tide also Nuture April 14, 1879, and Challewger Reports, Vol. 1. 1880.

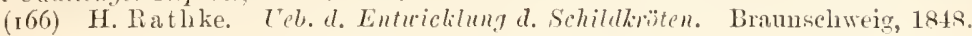

\section{Cirocodilia.}

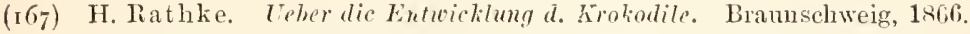

\section{MAIMALIA.}

1837.

(168) K. E. von Bacr. Teb. Entwicklnngsgeschichte d. Jhiere. Königsberg, 1828 -

(i6y) Barry. "Researches on Embryology." First Scries. Philosophical Transactions, 1838, Part II. Second Series, Ibid, 1839, Part II. Third Series, Ibid. 1840.

(izo) Ed. van Bencden. La maturution de l'auf, la fécondution et les premières phases du déreloppement embryonuire d. Mammifères. Bruxelles, 1875.

(i $\mathbf{1}$ ) Ed. van Beneden. "Recherches sur l'embryologie des Mammifères." Arrhiies de Biologie, Tol. 1. 1880.

(r 7 ) Ed. v. Beneden and Ch. Julin. "Observations sur la maturation ete. de l'cuf chez les Cheiroptires." Archives de Biologie, Vol. 1. 1880.

(173) Th. L. W. Bischoff. Entwicklungsgesehiehted. Säugethiere u. des Menschen. Leipzig, 18\$2.

$(\mathbf{I t})$ Th. L. W. Bischoff. Entuchlungsgeschichte des Kanincheneies. Bram. schweig, 1842.

(175) Th. L. W. Bischoff. Entwichlungsgeschichte des Hundeeies. Bramnschwein, 1845.

$(\mathrm{I} ; 6)$ Th. I. W. Bischoff. Entwiclihngsgeschichte des Meerschwinchens. Giessen. 1852.

(i -7) Th. L. W. Bischoff. Entwieklungsgeschichte des Rehes. (riessen, 1854

$(1,-5)$ T'h. L. IT. Bisclioff, "Nene Beobachtungen z. Entwicklungsigeselı, de Meerschweinchens." Abh. a. bayr. Aliad., Cl. I1. Tol. x. 1866.

( 79$)$ Th. L. W. Bischoff. Historisch-livitische Bemertunten z. d. neuesten Mittheilungen ïb. d. erste Entwick. d. Sïugethiereier. MIünchen, 1877.

(Iso) M. Coste. Embryogénie comparé. Paris, 1837. 1874.

( s1) E. Haeckel. Anthropogenie, Entuichlnngsgeschichte des Henschen. Leipzig.

(is2) V. Hensen. "Beobachtungen üb. d. Befrucht. u. Entwick. d. Kanine'uens 11. Meerschweinchens." Zeit. f. Anat. u. Entuicl., Tol, 1. 1s76.

(183) A. Kölliker. Entuicklungsgeschichte d. Mensehen $u$. höheren Thiere. Leipzig, 1879 .

(184) A. Kölliker. "Die Entwick. d. Ke:mblätter des Faninclıens." Zoologischer Anzeiger, Tos. 61, 62, Tol. I1I. 1880.

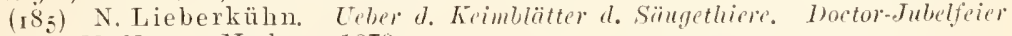
d. Herin 11. Nasse. Marburg, 1879.

(r\&6) N. Lieberkïhn. "Z. Lehre von d. Keimblättenn d. Sängethicre." Sitz. d. Gesell.z. Beförd. d. gesam. Naturuiss. Marbug, No. :3. 1381.

(г $\left.\mathbf{S}_{7}\right)$ Jiauber. "Die erste Entwicklung d. Kaninchens." Sitzungsber. d. naturfor. Gesell.z. Leipzig. 1875.

( 88$)$ C. B. Reichert. "Entwicklung des Meerschweinchens." Abh. der Berl. Alial. 1862.

$\left(\mathrm{r} \mathrm{S}_{9}\right) \mathrm{E}$. A. Schäfer. "Description of a Mammalian ovm in an carly condition of development." I'roc. Roy. Soc., No. 16s. 1876.

(rgo) E. A. Schäfer. "A contribution to the history of development of the guinea-pig." Jommal of Anat. and Phys., Tol x. anl xi. 1876 and 1877.

\section{Fotul Membranes and Placentu of Mammalit.}

(19r) John Anderson. Anatomical and Zoological reseureles in Western Yunnan. London, 1878.

(192) K. E. von Baer. Intesuclungen über die Gefïssterbindung zuischen Mutter und Frucht, 1828. 
(193) C. G. Carus. Tabulae anatomiam comparativam illustrantes. 18:31, 1840.

(i9t) H. C. Cliapman. "The placenta and generative apparatus of the Elephant." Journ. Aeal. Nut. Sc., Philadelphia. Vol. virr. 1880.

(195) C. Creighton. "On the formation of the placenta in the guinea-pig." Journal of Anut. and Phys., Vol. xir. 1878.

(196) Ecker. Icones Physiologicae. 1852-18.59.

(I97) G. B. Ercolani. The ntricular glands of the uterus, ete., translated from the Italian under the direction of $\mathrm{H}$. O. Marey. Boston, 1880. Contains translation. of memoirs published in the Mem. dell' Accad. 1. Scienze d. Bologna, and additional matter written specially for the translation.

(rgs) G. B. Ercolani. Nuoce ricerehe sulla placenta nei pesei eartilaginosi e nei manumiferi. Bologna, 1830.

(I99) Eschricht. De organis quae respirationi et mutritioni fotus Mammalium inserviunt. Hafniae, 1837.

(200) A. H. Garrod and W. Turner. "The gravid uterus and placenta of Hyomoschus aquaticus." Proe. Kool. Soc., London, 1878.

(201) P. Harting. Itet ei en de placenta van Iralicore Dugong. Inaug. diss. Utrecht. "On the ovum and placenta of the Dugong." Abstract by Prof. Turner. Jourual of Anot. and Phys., Vol. xirr.

(202) Th. H. Huxley. The Elements of Comparative Anatomy. London, 1864.

$(203)$ A. Kïlliker. "Ueber die Placenta der Gattung Tragulus." Terh. der Wiirzb. phys,-med. Gesellsehaft, Bil. x.

$\left(20_{+}\right)$C. 1). Meigs. "On the reproduction of the Opossum (Didelphis Virginiana)." Amer. Phil. Soc. Truts., Vol. x. 1853.

$(205)$ H. Milne-Edwards. "Sur la Classification Naturelle." Amn. Sciences

Nat., Sér. 3, Vol. I. 1844.

(206) Alf. Milne-Edwards. "Recherches sur la famille des Chevrotains." Ann. des Sciences Nat., Series v., Vol. Ir. 1864.

(207) Alf. Milne-Edwards. “Olservations sur quelques points de l'Embryologie des Lemuriens, etc." Ann. Sci. Nat., Ser. v., Vol. xv. 1872.

(208) Alf. Milne-Edwards. "Sur la conformation du placenta chez le Tamandua." Aim. des Sé. Nat., xv. 1872.

(200) Alf. Milne-Edwards. "Recherches s. l. enveloppes foetales du Tatou ì neuf bandes." Ann. sci. Nut., Ser. vi., Vol. vir. 1878.

(2ro) R. Owen. "On the generation of Mrrsupial animals, with a description of the impregnated uterus of the Kangaroo." Phil. Thuns., 1834.

(2xi) R, Owen. "Description of the membranes of the uterine foetus of the

Kangaroo." Mag. Nat. Hist., Vol. I. 1837.

(212) R. Owen. "On the existence of an Allantois in a foetal Kangaroo (Macropus major)." Zool. Soe. Proc., v. 1837.

(2r3) R. Owen. "Description of the fotal membranes and placenta of the Ele-

phant." Phil. Trans., 1857.

(2I+) R. Owen. On the Anatony of Tertebrates, Vol. III. Iondon, 1868.

(2r G) G. Rolleston. "Placental structure of the Tenrec, etc." Trausactions of

the Zoologieal Society, Vol. v. 1866.

(2i6) W. Turner. "Observations on the structure of the human placenta." Journal of Anat. and Phys., Vol. vir. 1868.

(217) W. Turner. "On the placentation of the Cetacea" Trans. Roy. Soe. Erliub., Vol. Xxчr. 1872.

(218) W. Turner. "On the placentation of Sloths (Choløpus Hoffmanni)." Trans. of R. Society of Edinburgh, Tol. xxvir. 1875.

(219) W. Turner. "On the placentation of Seals (Halichorus gryphus)." Trans. of R. Society of Ediuburgh, Vol, xxvir. 1875.

(220) W. Turner. "On the placentation of the Cape Ant-eater (Orycteropus capensis)." Journal of Anat. and Phys., Tol. x. 1876.

(2zI) W. Turner. Lectures on the duatomy of the Placenta. First Series. Edimburgh, 1876.

(222) W. Turner. "Some general observations on the placenta, with spec:al reference to the theory of Evolution." Journal of Anat. aud. Phys.s., Vol. xi. 1877.

(223) W. Turner. "On the placentation of the Lemurs." Phil. Trans., Vol.

166, p.2. 1877.

(22t) W. Turner. "On the placentation of Apes." Phil. Trans., 1878.

(225) W. Turner. "The cotyledonary and diffused placenta of the Mexican deer (Cervus Americanus)." Jourual of Anat. and Phys., Vol. xin. 1879. 


\section{Humun Embrijo.}

(226) Fried. Ahlfeld. "Beschreibung eines selı kleinen menschlichen Eies." Arehiv f: Gynaekologie, Bd. xı11. 1878.

(227) Herm. Beigel und Ludwig Loewe. "Beschreibung eines menschlichen Eichens aus der zweiten bis dritten Woche der Schwangerschaft." Archir f. Gynackologie, Bd. X1I. 1877.

(228) K. Breus. "Ueber ein menschliches Ei ans der zwciten Woche der Gravidität." Wiener medicinische Wochenschrift, 1877.

(229) NI. Coste. Histoire générale ét particulière du dévclippement dcs corps organisês, $1847-59$.

(230) A. Ecker. Leones Physiologicae. Leipzig, 1851-1859.

(23r) V. Hensen. "Beitrag z. Morphologie d. Körperform u. d. Gehirns d. mellschlichen Embryos." Archiv f. dnat. u. Phiss., 1877.

(232) W. His. Anatomie menschlicher Embryonen, Part I. Embryonen d. ersten Monats. Leipzig, 1880.

(233) J. Kollmann. "Die menschlichen Eier von 6 III. Grössc." Archiv $f$. Anat. und Phys., 1879.

(234) W. Krause. "Ueber d. Allantois d. Menschen." Archiv f. Anat. und Phys., 1875.

(2.35) W. Krause. "Ueber zwei frihzeitige menschliche Embryonen." Zeit.f. wiss. Zool., Vol. xxxr. 1880.

(236) I. Loewe. "Im Sachen der Eihäute jüngster monschlicher Eier." Arthiv fiir Gynaekologie', Bd. xrv. 1879.

(237) C. B. Reichert. "Beschrcibung einer frühzeitigen menschlichen Frucht im bläschenförmigen Billungszustande (sackförmiger Feim von Bacr) nebst vergleichenden Untersuchungen über die bläschenförmigen Frïchte cler Sängethiere und des Ifenschen." Abhandlungen der kïnigl. Alad. d. Miss. zu Berlin, 1873.

(238) Allen Tlomson. "Contributions to the history of the structure of the human orum and embryo betore the third week after conception; with a description of some early ova." Edinburgh $1 \mathrm{Hed}$. Surg. Journal, Vol. L11. 1839.

\section{COMPARISON OF THE FORMATION OF THE GERMINAL LAYERS IN THE Vertebrata.}

(239) F. II. Balfour. "A comparison of the early stages in the development of Vertebiates." Quart. J. of Hicr. Science, Vol. xv. 1875.

$(2+0)$ F. M. Balfour. "A monograph on the devel pment of Elasmobranch Fishes." London, 1878.

$(2+1)$ F. II. Balfour. "On the early derelopment of the Lacertilia together witl some observations, etc." Quart. J. of Hicr. Science, Vol, xix. 1879.

$(2+2)$ A. Götte. Die Entwichlungsyeschichte d. C'nke. Leipzig, 1875.

$(2+3)$ W. His. "Ueb. d. Bildung d. Haitischembryonen." Zeit. f. Anat. u. Entwick., Vol. 11. 1877. Cf. also His' papers on Teleostei, Nos. 6 . and 66.

(2+t) A. Kowalevsky. "Entwick, d. Amphioxus lanceolatus." Hém. Acud. dis Sciences St Pétersbourg, Ser. vir. Tom. xı. 1 w67.

$(2+5)$ A. Kowalersky. "Weitere Studien ïb. d. Entwick. d. Amphioxus lanceolatus." Archivf.mikr. Anat., Vol. xu1r. 1877.

(2+6) C. Kupfter. "Die Entsteliung d. Allantois u. d. Gastrula d. Wirbelthiere." Zool. Anzeiger, Vol. II. 1879, pp. 520, 593, 612.

$(2+7)$ R. Femak. Untersuchungen äb. d. Entwicklung d. Wivbelthiere, 1850-1858.

(24\$) A. Rauber. Primitiestreifen $n$. Nenrula d. Wirbelthiere. Leipzig, 1877.

\section{Phylogery of the Chordata.}

(249) F. II. Balfour. A IIonograph on the development of Elusmobraneh Fishes, London, 1878.

(250) A. Dohrn. Der Ursprung d. Wirbelthiere und d. Princip. d. Functionswechsel. Leipzig, 1875.

(25I) E. Haeckel. Schöpfungsgeschichte. Leipzig. Tride also Translation. The History of Creation. Fing and Co., London. 1876.

(252) E. Haeckel. Anthropogcnie. Leipzig. Fide also Tramslation. Anthropogeny. Kegan Paul and Co., London, 1878.

B. E. II. 
(253) A. Kowalevsky. "Entwicklungsreschichte d. Amphioxus lanceolatus.' Mém. Aead. d. Séen. St Pétersbonry, Ser. VII. Tom. xI. 1867, and Arehiv $\dot{f}$. mikr. A uut., Vol. xil1. 1877.

$(25+)$ A. Kowalevsky. " "Weitcre Stud. ïb. d. Entwick. d. einfachen Ascidien." Arehiv f. mikr. Anat., Vol. v11. 1871.

$(255)$ C. Semper. "Die Stammesverwand chaft d. Wirbelthiere u. Wirbellosen." Arbeit. a. d. zool.-zoot. Instit. Iiirzhurg, Vol. 11. 1875.

$(256)$ C. Semper. "Die Verwandschaftbeziehungen d. gegliederten Thiere." drbeit. a. d. zool.-zoot. Instit. Wïrzburg, Vol. I1. 1876-1877.

\section{General works on Embriologr.}

(257) Allen Thomson. British Association Address, 1877.

(258) A. Agassiz. "Embryology of the Ctenophoræ." Mem. Amer. Aead. of Arts and Sciences, Vol. x. 1874.

(259) K. E. von Baer. Ueb. Entwickhungsgesehiehte d. Thicre. Königsberg, $182 \div-1 \leqslant 37$.

(260) F. Mr. Balfour. "A Comparison of the Early Stages in the Development of Vertebrates." (quart. Journ. of Mier. Sci., Vol. xv. 1875. 1874 .

(261) C. Claus. Die Typentehe u. F IIaeckel's sg. Gastrea-theorie. Wien,

(262) C. Claus. Grundzïge d. Zoologie. Marburg und Leipzig, 1879.

(263) A. Dohrn. Der Ursprung d. W'irbetthiere $u$. d. Princip des Funetions. weehsels. Leipzig, 1875.

(264) C. Gegenbaur. Grundriss d. vergleiehenden Anatomie. Leipzig, 1878. Vide also Translation. Elements of Comparative Anatomy. Macmillan \& Co. 1878.

(265) A. Götte. Entwicklungsgeschiehte d. Lnke. Leipzig, 1874.

(266) E. Haeckel. Studien z. Gastrca-theorie, Jena, 1877; and also Jenaisehe Zeitschrift, Vols, viı. and Ix. 1874-5.

$(267)$ E. Haeckel. Schöpfungsgesehichte. Leipzig. Vide also Translation.

The Itistory of Creation. King \& Co., London, 1878.

(268) E. Haeckel. Authropogenie. Leipzig. Vide also Translation. Anthropogeny. Kegan Paul \& Co., London, 1878.

(269) B. Hatschek. "Studien ïb. Entwicklungsgeschichte d. Anneliden." Arbeit. a. d. zool. Instit. d. Univer. W'ien. 1878.

$(270)$ O. and R. Hertwig. "Die Actinien." Jenaisehe Zeitselerift, Vols. xIII. and XIV. 1879.

(27I) O. and R. Hertwig. Die Colomtheorie. Jena, 1881.

(272) O. Hertwig. Die Chetognathen. Jena, 1880.

(273) R. Hertwig. Uel. d. Ban d. Ctenoplorem. Jena, 1880.

$(27+)$ T. H. Huxley. The Anutomy of Invertebrated Animals. Churchill, 1877.

$\left(27+^{*}\right)$ T. H. Huxley. "On the Classification of the Animal Kingdom." Qnart. J. of Hicr. Seience, Vol. xv. 1875.

(275) N. Kleinenberg. Inydra, eine anatomiseh-entwieh/ungsgesehichte Untersuelung. Leipzig, 1872.

$(276)$ A. Kölliker. Entwieklungsgesehiehte d. Mensehen u. d. hoh. Thiere. Leipzig, 1879.

(277) A. Kowalevsky. "Embryologische Studien an Wïrmern u. Arthropoden." Mém. dead. Pétersbourg, Series viı. Vol. xv1, 1871.

$(278)$ E. R. Lankester. "On the Germinal Layers of the Embryo as the Basis of the Genealogical Classification of Animals." A mn. and Mag. of Nat. Hist. 1873.

(279) E. L. Lankester. "Notes on Embryology and Classification." Quart. Joum. of Jicr. Sci., Vol. xvı. 1877.

(280) E. Metschnikoff. "Zur Entwicklungsgeschichte d. Kalkschwämme." Zeit.f. wiss. Zool., Vol. xxiv. 1874.

(28I) E. Metschnils off. "Spongiologische Studien." Zeit. f. wiss. Zool., Vol. хxх11. 1879.

$(28 z)$ A. S. P. Packard. Life Itistories of Animals, including Man, or Outlines of Comparative Embryology. Holt and Co., New York, 1876.

$(283)$ C. Rabl. "Ueb. d. Entwick. d. Malermuschel," Jenaische Zeitseh., Vol. х. 1876 .

$(28+)$ C. Rabl. "Ucb. d. Entwicklung. d. Tellerschneke (Planorbis)." Norph. Jahrlueh, Vol. v. 1879. 
(285) H. Rathke. Abhandlungen z. Bildung und Entwicklungsgeseh. d. Menschen n. d. Thiere. Leipzig, 1833 .

1829

(286) H. Rathke. Ueber die Bildung n. Entwicklungs. d. Flusskrebses. Leipzig,

(287) R. Remak. Untersuch. ̈̈b. d. Entwick. d. Wirbelthiere. Berlin, 185.

(288) Salensky. "Bemerkungen üb. Haeckels Gastra-theoric." Archiv $f$. Naturgeschicht, 1871.

$\left(2 S_{9}\right)$ E. Schäfer. "Some Teachings of Development." Qnart. Journ. of Micr. Science, Vol. xx. 1880.

(200) C. Semper. "Die Verwandtschaftbezielıngen d. gegliederten Thiere.' Arbeiten a. d. zool.-zoot. Instit. Wiirzburg, Vol. I11. 1876-7.

\section{General works DeAling with the Developanent of the ORGANS OF THE CHORDATA.}

(291) K. E. von Baer. Ueber Entwichlungsgesehichte d. Thiere. Königsberg, $1828-1837$.

(292) F. M. Balfour. A Honograph on the development of Elasmobranch Fishes. London, 1878 .

(29.3) Th. C. W. Bisch of f. Entwieklungsgesch. d. Sängethiere n. d. Mensehen. Leipzig, 1812.

(29+) C. Gegenbaur. Grundriss d. vergleichenden Anatomie. Leipzig, 1878. Vide also English translation, Elements of Comp. Anatomy. London, 1878.

(295) M. Foster and F. M. Balfour. The Elements of Embryology. Part I. London, 1874.

(296) Alex. Götte. Entwicklnngsgeschichte d. Unke. Ieipzig, 1875.

1868.

(297) W. His. Untersneh. $\ddot{b}$. d. crste Anlage d. Wirbelthierleibes. Leipzig,

(298) A. Kölliker. Entwicklungsgeschichte d. Menschen n. der hïheren Thiere. Leipzig, 1879.

(299) H. Rathke. Abhandlungen ̈̈. Bildung und Entwichmngsgeschichte d. Menschen n. d. Thiere. Leipzig, 1838.

(300) H. Rathke. Entwicklungs. d. Natter. Königsberg, 1839.

(301) H. Rathke. Entwieklungs. d. Wirbelthiere. Leipzig, 1861.

(302) R. Remak. Untersuchungen üb. d. Entwicklnng d. Wirbelthicre. Berlin, $1850-1855$. 1874 .

(303) S. L. Schenk. Lehbueh d. vergleich. Embryologie a. Wirbetthiere. Wien,

\section{EPIDERMIS AND ITS DERIVATIVES.}

\section{General.}

(30+) T. H. Huxley. "Tegumentary organs." Tord's Cyclopedia of Anat. and Physiol.

(305) P. Z. Unna. "Histol. u. Entwick. d. Oberhaut." Archiv f. milk. Anat. Vol. xv. 1876. Vide also Kölliker (No. 298).

\section{Scales of the Pisces.}

(305) O. Hertwig. "Ueber Bau u. Entwicklung d. Placoidschuppen u. d. Zähne d. Selachier." Jenaisehe Zeitschrift, Vol. vin. 1874.

(307) O. Hertwig. "Ucber d. Hautskelet d. Fische." Morphol. Jahrbuch, Vol. 11. 1876. (Siluroiden u. Acipenseridæ.)

(3с8) O. Hertwig. "Ueber d. Hautskelet d. Fische (Lepidosteus u. Polypterus)." Morph. Jahrbuch, Vol.v. 1879.

\section{Feathers.}

(309) Th. Studer. Die Fntwick. d. Federn. Inaug. Diss. Beru, 1873. xxx. 1878 . 
Surect-glands.

(3i1) M. S. Ranvier. "Sur la strueture des glantes suloripares." Comptes Rendus, Hec. 2:), 1879.

\section{Matmmary glands.}

(312) C. Crein'ston. "On the devel. of the Mamma and the Mammary function." Joul'. of Anut. and 'hlys.s. Vol. xi. 1877.

(з3) C. (iegenbaur. "Bemerkimgen iib. d. Milehdrisen-Papillen d Sängethiere." Jemaische \%eit., Vol. vis. 1873.

(3r) M. Huss. "Beitr. z. Entwick. d. Milehdrisen b. Menschen u. b. Wiederkäuetn." Jentrische Zıit., Tol. v1. 1873

(315) (. Langer. "Ueber d. Bau u. d. Entwicklung d. Milchdrüsen." Denk. d. k. Alutd. Wiss. Wien, Vol. ni. $18 j 1$.

\section{The Nervors Srgtem.}

\section{Evolution of the Nervous System.}

(316) F. M. Balfour. "Ad hress to the Department of Anat. and Plysiol. of the British Assocition." 1880.

(3г-) ('. Clans. "Studien äb. Polypen u, Quallen d. Adria. I. Acalephen, Discomedusen." Inenk. d. math.-naturmiss. Classe d. k. Akat. Wiss. Wien, Vol. xxxvin. 1877.

(319) Th. Eimer. Zoolugische Studien a. C'apri. I. Veber Beroë oratus. Ein Beitra! z. Amat. d. Rippenquall'n. I eipzi

(3rg) T. Hensen. "Zur Entwicklung d. Nerrensystems." Tirchow's Archir, Vol. xxx. $1 \times(i)$.

(320) O. and R. Hertwig. Das Nemensystem u. d. Simesorgane d. Mednsen. Le:prig, $187 \delta$.

(.32 I) O. and R. Hertwig. "Die Actinion anat. u. histol. mit besond. Beriicksichtigung d. Nervemmuskelsystem untersueht." "Jenaische Zeit., Vol. xur. 1879.

(322) R. Hertwig. "Üeb. d. Bau d. Ctenophoren." Jenaische Zeitschrift, Vol. x15. 1880.

(323) A. W. Hulrecht. "The Peripheral Nervous System in Palæo- and Schizonemertini, one of the layers of the body-wall." Qnart. J. of Micr. Scirnce, Vol. xx. 1820.

(324) N. Kleinenherg. Hydra, eine anatomisch-entwicklungsgeschichtliche Untersuchun\%. Jeeipzig, 187\%.

(325) A. Kowalevsky. "Embryologisehe Stulien an Wïmern u. Arthropoden."

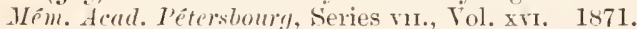

(326) E. A. Seliafier. "Observations on the nerrous system of Aurelia aurita." Phil. Truns. 1878.

\section{Nervous System of the Invertebratct.}

(327) F. M. Balfour. "Notes ou the develo")ment of the Araneina." Quart. J.of Micr. Srience, Vol. xx. 1880.

(328) B. Hatsehek. "Beitr. z. Entwi klung d. Lepidcpteren." Jenaische Zeitschrift, Vol. xi. 187\%.

(329) N. Kleinenberg. "The development of the Earthworm, Lumbricus Trapezoides." Quart. et. of Hicr. Science, Vol, xIx. 1879.

(330) A. Kowalevsky. "Embryolozisehe Studien an Würmern u. Arthropolen." Mém. Acad. Pétersbourı, Series vir., Vol. xvi. 1871.

(3.3I) H. Reichenbaeh. "Die Embryonalanlare u, erste Entwick. d. Flusslirebses." Zeit. f. wiss. Zool., Vol. xxix. 1877.

\section{Centiol Nerrous System of the Vertebrata.} 1814.

(.3.32) C. J. Carus. Tersuch einer luorstellung d. Nertensystems, etc. Lejpzig, 
(333) J. J. Clark. "Researclies on the development of the spinal cord in Man, Manmalia and Birds." Phil. Trans., 1862.

(33+) E. I) ursy. "Beiträge zur Entwicklmmgsgeschichte des Himanhanges." Centedblatt f. d. med. Wissensclueften, 1868. Nr. 8.

(.335) E. Dursy. Zur. Entwicklungsgeschichte des Kopfes des Hensehen und der höheren Wirbelthiere. Tübingen, 1869.

(336) A. Ecker. "Zur Entwicklungsgeschichte der Furchen und Windungen der Grosshim-Hemisphären im Foetus des Menschen." Arehir f. Anthropologie, v. Echer und Lindenselımiat. Tol, 11.1868.

(337) E. Ehlers. "Die Epiphyse am Gehim d. Plagiostomen." Zeit. f. uiss. Zool. Tol. xxx., suppl. 1878.

(338) P. Flechsig. Wie Leitungsb then iul Gehim und Rüickenmark des IIenschen. A uf Grund entuicklungsgeschichtheher Ĺutersuchungen. Leipzig, 1876.

(.339) V. Hensen. "Zur Entwicklung des Nervensystems." Tirehow" Archir, Bd. xxx. 1864

(3fo) L. I̋̈we. "Beiträge z. Anat. u. z. Entwick, d. Nerrensystems d. Säugethiere u. d. Menschen." Berlin, 1880.

$(3+\tau)$ L. Löwc. "Beiträge z. verglcish. Morphogenesis d. centralen Nervensystems d. Wirbelthiere." Nittheil. a. d. embryol. Instit. Wien, Vol. n. 1880.

(3+2) A. M. Marshall. "The Morphology of the Vertebrate Olfactory organ." Quart. J. of Mier. Science, Vol, xix, 1879.

$(3+3)$ V. r. Mihalkovies. Eutrieklungsgesehichte d. Gehims. Leipzig, 1877.

(3++) W. Mïller. "Ueber Entwicklung und Bau der Hypophysis und des Frocessus infundibuli cerebri." Jenaische Zeitsehritt. Bd. v. 1871.

$(3+5)$ H. Rahl-R iickhard. "Die gegenseitigen Terhältnisse d. Chorda, Hypophysis ete. bei Haifischembryonen, nebst Bemerkungen üb. d. Deutung d. einzclnen 'I'heile d. Fisshgehims." Morphol. Juhrbuch, Vol, r1. 1880.

(3+6) H. Pathke. "Ueber die Entstehung der glandula pituitaria." Muiller's Arehir, Anat. und Pliysiol., Bt. v. 1838.

1861 .

$(3+7)$ C. B. Reichert. Der Ban des menschliehen Gehirns. Leipzig, 1859 u.

$(3+8)$ F. Schmidt. "Beiträge zur Entwicklungsgeschichte des Gehirns." Zeitschrift f. wiss. \%oologie, 1862. Bi. xI.

(3+9) G. Schwalbe. "Beitrag z. Entwick. d. Zwischenhirns." Sitz. d. Jenaisehen Gesill. f. Med. n. Nuturuiss. Jan. 23, 1880.

$(350)$ Fried. Tiedemann. Anatomie und Bildungsgeschichte des Gehims in Foetus des Henschen. Nürnberg, 1816.

\section{Peripheral Nerrouts System of the Tertebrata.}

(351) F. M. Balfour. "On the development of the spinal nerves in Kasmobranch Fishes." Philosophieal Transaetions, Vol. CLXv1. 1876; vide also, A monograph on the development of Elasmobruneh Fishes. London, 1×78, pp. 191-216.

(352) W. His. "Ueb. d. Anfänge d. peripherisehen Nervensystems." Archiv $f$. Anat. 1. Physiol., 1879.

(35.3) A. M. Marshall. "On the early stares of development of the nerres in Birls." Jourual of Anat. and Phys., Tol. x1. 1877.

$(35+)$ A. M. Marshall. "The development of the cranial nerves in the Chick." Quurt. J. of Hier. Science, Vol. xrm1. 1878.

(355) A. M. Marsliall. "The morplology of the vertebrate olfactory organ." Quat. J. of Hicr. Scienee, Vol. xix. 1879.

$(3: 6)$ A. M. Marshall. "On the head-cavities and associated nerres in Elasmobranchs." Quart. J. of Hier. Scienee, Yol. xx1. 1881.

(357) C. Schwalbe. "Das Ganglion oculomotorii." Jenaische Zeitsehrift, Vol. xill. 1879

\section{Sympathetic Nervous System.}

(360) F. M. Balfour. Honograph on the development of Elasmobranch Fishes. Lonton, 1878, p. 173.

(36r) S. L. Schenk and W. R. Birdsell. "Ueb. d. Lehre ron d. Entricklung d. Ganglien 1. Sympatheticus," Hittleil. a. d. embryologisehen Instit. Wien. IIft 11. $1 ऽ 79$. 


\section{The Eye.}

\section{Eye of the Mollusca.}

(.362) N. Bobretzky. "Observations on the development of the Cephalopoda" (Russian). Nachriehten d. Kuiserlichen Gesell. d. Freunde der Naturuiss. Anthropolog. Ethnogr. bei l. Unirersität Moskm.

$\left(3^{6}, 3\right)$ H. Grenacher. "Zur Entwicklungsgeschichte d. Cephalopoden." Zeit. $f$. wiss. $/$ ool., Bd. xxrv. 1874.

$\left(3^{6}\right)$ V. Hensen. "Ueber d. Ange einiger Cephalopoden." Zeit.f. wiss. Zool., Tol. xv. 1865.

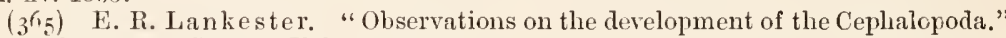
Quart. J. of Hier. Seienee, Vol. xv. 1875. 1877 .

${ }_{3}^{660)}$ C. Semper. Ueber Sehorgane von Typus d. Wirbelthieraugen. Wiesbaden,

\section{Eye of the Arthropoda.}

(36-) N. Bobretzky. Derelopment of Astaens and Palaemon. Kiew, 1973.

$\left(3^{68}\right)$ A. Dohrn. "Untersuchungen ib. Bau u. Entwicklung d. Arthopoden. Palimus und scyllarus." Zeit. f. wiss. Zool., Bd. xx. 1870, p. 26t et seq.

(369) E. Claparède. "Morplologie d. zusammengesetzten Auges bei den Arthropolen." Zeit. f. "riss. Zool., Bd. x. 1860.

(370) H. Grewacher. Untersuchungen ïl. d. Sehorgane d. Arthopoden. Göttingen, 1879.

\section{The Vertebrate Eyye.} $187 i$.

(37 I) J. Arnold. Beiträge zur Entwieklungsgeschiehte des Auges. Heidelberg,

$\left(37^{2}\right)$ Babuchin. "Beitrïge zur Entwicklungsgeschichte des Auges." Würzburger naturwissenschaftliche Zetsehrift, Bi. 8.

(37.3) L. Kessler. Zur Entwicliung d. Auges d. Wirbelthiere. Leipzig, 1877.

$(37+)$ N. Lieberkïhn. Veber dus Auge des Hirbelthierembryo." Cassel, 1872.

$(375)$ N. Lieberkülın. "Beiträge z. Anat. d. embryonalen Auges." Archiv f. Aurt. und Phys., 1879.

$(3-6)$ L. Löwe. "Beiträge zur Anatomie des Auges" and "Die Histogenese der Retina." Arehiv f. mikr. Allat., Vol. xv. 1878.

(.37) V. Mihalkowics, "Untersuchungen z̈ber den Kamm des Vogelauges." Arelie f. mikr. Anat., Vol. Ix. 1873.

(378) W. Mïller. "Ueber die Stammesentwickelung des Sehorgans der Wirbelthiere." Festyabe Carl Luduig. Leipzig, 1874.

(379) S. L. S'chenk. "Zur Entwickelungsgeschichte des Auges der Fische." Hiener Sitzunglerichle, Bd. Lv. 1867.

\section{Accessory organs of the Vertebrate Eye.}

(380) G. Born. "Die Nasenhöhlen u. d. Thränennasengang d. Amphibien." Morphologisehes Juhrbueh, Bd. 11. 1876.

$\left(\mathrm{S}_{\mathrm{I}}\right)$ G. Born. "1) Nasenhöhlen 11. d. Thränennasengang d. amnioten Wirbelthiere. I. Lacertilia, II. Aves." Horphologisehes Jahrbueh, Bd. v. 1879.

\section{Eye of the Tunicata.}

$\left({ }_{i} S_{2}\right)$ A. Kowalevsky. "Weitere Studien iib. d. Entwicklung d. einfachen Ascidien." Archiv f. mikr. Anat., Vol. vn. 1871.

$\left(3^{\mathrm{S}} 3\right)$ C. Kupffer. "Zur Entwicklung d. einfachen Ascidien." Archiv f. mikr. Aluat., Vol. vil. 1872 .

\section{Auditory Organs.}

\section{Auditory organs of the Invertebrata.}

$\left(3 s_{4}\right)$ V. Hensen. "Studien üb. d. Gehörorgan d. Decapoden." Zeit.f. wiss. zool., Tol. xi11. 1863.

$\left(3_{5}^{8}\right)$ O. and R. Hertwig. Das Nerrensystem u. d. Simesorgane d. Medusen. Leipzig, 1878 . 


\section{Auditory organs of the Vertebrata.}

(386) A. Boetteher. "Bau u. Entwicklung d. Schnecke." Denkschriften $d$. kaiserl. Leop. Carol. Alkal. d. Wissensehuft., Vol. xxxv.

$\left(3_{7}\right)$ C. Hasse. Die rergleich. Morphologie u. Histologie d. hïntigen Gehörorgane a. Nirbelthiere. Leipzig, 1×73.

(388) V. Hensen. "Zur Morphologie d. Schnecke." Zeit. f. wiss. Zool., Vol. x 111.1863.

(38y) E. Huschke. "Ueb. d. erste Bildungsgeschichte d. Auges u. Ohres beim bebrüteten Küchlein." Isis von Oken, 1831, and Meckel's Arehir, Vol. v.

(390) Reissner. De duris internce formatione. Inang. Diss. Dorpat, 1851.

\section{Accessory parts of Iertebrate Eur.}

(391) David Hunt. "A comparative sketch of the development of the ear and eye in the Pig." Transactions of the International Otological Congress, 1876.

(392) W. Moldenhaner. "Zur Entwick. d. mittleren u. äusseren Olıres." Iforphol. Jahrbueh, Vol. 111. 1877.

(39.) V. Urbantschitsch. “Ueb. d. erste Anlage d. Mittelohres u. d. Trommelfelles." Mittheil. a. d. embryol. Instit. Wien, Heft I. 1877.

\section{Olfactory Organ.}

(394) G. Born. "Die Nasenhöhlen u. d. Thränennasengang d. amnioten Wirbelthiere." Parts 1. and 11. Morphologisches Jahrbuch, Bd. v., 1879.

(395) A. Kölliker. "Ueber die Jacobson'schen Organe des Nenschen." Festschrift f. Rienecker, 1877.

(396) A. M. Marshall. "Morphology of the Vertebrate Olfactory Organ." Quart. Journ. of Hier. Science, Vol. xix., 1879.

\section{SExSE-ORGANS OF THE LATERAL LINE.}

(397) F. M. Balfour. A Honograph on the development of Elasmolraneh Fishes, pp. 141-146. London, 1878.

(398) H. Eisig. "Die Segmenta'organe d. Capitelliden." Mittheil. a. d. zool. Station zu Neapel, Vol. I. 1879.

(399) A. Götte. Entwichlungsgeschiehte d. Unke. Leipzig, 1875. 1857

$(+\infty)$ Fr. Leydig. Lehrbuch d. Histologie des Menschen 1. d. Thicre. Hamm.

(+or) Fr. Leydig. Nene Beitrïye z. anat. Kenntniss d. IIantdecke u. IIutsinnesorgane \%. Fische. Halle, 1879.

$(+02)$ - F. E. Schulze. "Ueb. d. Simnesorgane d. Seitenlinie bei Fischen und Amphibien." Areliv f. milir. Anat., Vol. vi. 1870.

$\left({ }_{+} 03\right)$ C. Semper. "Das Urogenital system d. Selachier." Arbeit. a. d. zool.zoot. Instit. Würzlurg, Vol, 1 .

(404) B. Solger. "Neue Untersuchungen zur Anat. d. Seitenorgane d. Fische." drehiv $f$ mikr. Anat., Vol. xvil. and xvm. 1879 and 1880.

\section{Origin of the Skeletox.}

(405) C. Gegenbaur. "Ueb. primäre u. secundäre Knochenbildung mit besonderer Beziehung auf d. Lehre von dem Primordialeranium." Jenaische Zeitschrift, Vol. 11I. 1867.

(406) O. Hertwig. "Ueber Bau u. Entwicklnng d. Placoiłschuppen u. d. Zähne d. Selachier." Jenaische Zeitschrift, Vol. vin. 1874.

$\left({ }_{407}\right)$ O. Hertwig. "Ueb. d. Zahnsystem d. Amphibien u. seine Bedentung f. d. Genese d. Skelets d. Iundhöhle." Archiv f.mikr. Anat., Vol. xı. Supplementheft, 1874.

(†o8) O. Hertwig. "Ueber d. Hautskelet d. Fische." Morphol. Jahrbuch, Vol.

II. 1876. (Siluroiden u. Acipenseriden.)

(+o9) O. Hertwig. "Ueber d. Hautskelet d. Fische (Lepidosteus u. Polypterus)" Morph. Jahruch, Vol. v. 1879. 
(4 Io) A. Kölliker. “Allg€meine Betrachtungen üb, die Entstehung d. knöchernen Schädels d. Wirbelthiere." Berichte v. d. königl. zoot. Anstalt z. W'ïrzbmr, 1849.

(4II) Fr. Leydig. "Histologische Bemerkungen üb. d. Polypterus bichir." Zeit.f. wiss. Zool., Vol. v. 1858.

( 1 i 2) H. II üller. "Ueber d. Entwick. d. Knoehensubstanz nebst Bemerkungen, ete." Zeit. f. wiss. Zool., Vol. Ix. 1859.

$(+1,3)$ Williamson. "On the structure and derelopment of the Scales and Bones of Fishes." Phil. Trans., 1851.

$\left(t^{r}+\right)$ Vrolik. "Studien üb. d. Verknöcherung u. die Knoehen d. Schädels d. Teleostier." Niederlündisches Archiv f. Zoologie, Vol. I.

\section{Notochord and Vertebral Column.}

(+15) Cartier. "Beiträge zur Entwicklungsgesehichte der Wirbelsäule." Zeitsehrift für wiss. Zool., Bd. xxv. Suppl. $1>75$.

(46) C. Gegenbaur. Untersuchnngen zur vergleichenden Anutomie der Virbelsïnle der Anthibien und Reptilien. Leipzig, 1862.

$(+5)$ C. Gegenbaur. "Ueber die Entwickelung der Wirbelsäule cles Lepidosteus mit vergleichend anatomisehen Lemerkungen." Jenaisehe Zeitschrift, Bd. III. 1863.

(4 I8) C. Gegenbaur. "Ueb. d. Skeletgewebe d. Cyclostomen." Jenoische Zeitsclnift, Vol. v. 1870.

(+19) Al. Götte. "Beiträge zur vergleich. Morphol. des Skeletsystems d. Wirbelthiere." II. "Die Winbclsänle u. ilıre Anlä̈nge." A rchiv f. mikr. Anut., Vol. xv. 1878 (Cyelostomen, Ganoiden, Plagiostomen, Climaera), and Vol. xrr. 1879 ('Teleostier).

$(+20)$ Hasse und Schwarck. "Studien zur vergleichenden Anatomie der Wirbelsäule u. s. w." Hasse, Anatomisehe Studien, 1872.

$(+21)$ C. Hasse. Das natiirliche System d. Elasmobranchier anf Grmullage d. Ban.u. d. Entuick. ilırer Wirbelsäule. Jena, 1879.

$(+22)$ A. Kölliker. "Ueber die Beziehungen der Chorda dorsalis zur Bildung der Wirbel der Selachier und einiger anderen Fische." Verhamdlungen der physical. medicin. Gesellsehaft in I"̈̈izlurg, Bd. x.

$(+2.3)$ A Kölliker. "Weitere Beobachtungen über die Wirbel der Sclachier insbesondere ïber die Wirbel der Lamnoidei." Ablundlungen der senkenbergischen naturforsehenden Gesellschaft in Frankfurt, Bd. v.

$(+2 t)$ H. Leboucy. "Recherches s. l. mode de disparition de la eorde dorsale ehez les vertébrés supérieurs." Archires de Biologie, Vol. 1. 1880.

$(+25)$ Fr. Leydig. Anatomisch-histologische Untersuchnngen über Fische and Reptilien. Berlin, 1853.

(+26) Ang. Miiller. "Beobachtungen zur vergleichenden Anatomie der Wirbelsaiile." Miiller's Archir. 18.33.

$(+27)$ J. I iiller. "Vergleichende Anatomie der Myxinoiden u. der Cýlilostomen mit durchbohrtem Ganmen, I. Osteologie und IYyologie." Abhandlungen "der hirniglichen Akademie der Wissenschaften zu Berlin. 1834.

$(+28)$ W. Miiller. "Beobachtungen des patholorischen Instituts zu Jena, I. Ueber den Ban der Chorda dors lis." Jemaisehe Ze itseh ift, Bd. vi. 1871.

$(+29)$ A. Schneider. Beitrïge z. vergleich. Anat. n. Entwick. d. Wirbelthicre. Berlin, 1879.

\section{Ribs ANd Sternum.}

(430) C. Claus. "Beiträge z. vergleieh. Osteol. d. Vertebraten. I. Rippen u. unteres Bogensystem." Sitz. d. kaiser. dkad. Wiss. Mirn, Vol. Lxxiv. 1876.

(+3I) A. E. Fick. "Zur Entwicklungsgeschichte d. Rippen und Querfortsätze." Archiv f. Aluat. und Physiol. 1879.

(+32) C. Gegenbaur. "Zur Entwick. d. Wirbelsäule des Lepidosteus mit vergleich. anat. Bemerk." Jemuische Zeit., Vol. In. 1867.

(+33) A. Götte. "Beiträge z. vergleich. Morphol. d. Skeletsystems d. Wirbel. thiere Brustbi in u. Schultergürtel." Arehir $f$. mikr. Anut., Vol. xIv. 1877.

(+34) C. Hasse u. G. Born. "Bemerkungen üb. d. Morphologie d. Rippen." Zoologischer Auzriger, 1879.

(435) C. K. Hof fmann. "Beiträge z. vergl. Anat. d. Wirbelthiere." Niederländ. Archiv Zool., Vol. rv. 1878. 
(+36) W. K. Parker. "A monograph on the structure and development of the shonlder-girdle and sternum." limy soc. 1867.

(437) H. Rathke. Leb. d. Bum u. l. Entwicklung d. Brustbeins d. Sanrier. 18.53.

$(+38)$ G. Ruge. "Untersuch. üh. Entwiek. am Brustbeine d. Nenschen." Morplool. Jahrbueh., Vol. v1. 1880.

\section{THE SKTLL.}

(+39) A. Dugès. "Recherches sur l'Ostéologie et la myologie des Batraciens ì leur différents âges." Paris, Mém. sarans étrang. 183ð, and An. Sci. Nat. Yol. 1. 1834 .

$(++0)$ C. Gegenbaur. Untersuchungen z. vergleich. Anat. d. Wirbelthiere, III. Iheft. Das hoptskelet d. Selachier. Leipzin, 1872.

(t+1) Gïnther. Beob. ̈̈b. die Entwicli.d. Gehimorgans. Leipzig, 1812.

$(4+2)$ O. Hertwig. "Ueb. d. Zahnsystem d. Amphibien u. scine Bedentung f. d. Genese d. Skelets d. Mnndhöhle." Arclin f. mikr. Anat., Vol. xi. 187t, suppl,

$(++3)$ T. H. Hnxley. "On the theory of the vertebrate skull." Proc. Royal Soc., Vol. Ix. 1858.

(+4t) T. H. Huxley. The Elements of Comparatice Anatomy. London, 1869 .

$(++5)$ T. H. Huxley. "On the Malleus and Incus." Proe. Zool. Soc., 1869.

(4+6) T. H. Huxley. "On Ceratodus Forsteri." Proe. Zool. Soc., 1876.

$(+t i)$ T. H. Huxley. "The nature of the craniofacial apparatus of Petromyzon."

Joun n. of Anat. and P'yys, Vol. x. 1876.

$(+48)$ T. H. Huxley. The Anutomy of Tertebrated Animals. London, 1871.

$(+49)$ W. K. Parlier. "On the strueture and derelopment of the slubll of the Common Fowl (Gallus Domestieus)." Phil. Trans., 1869.

$(+50)$ W. K. Parker. "On the strueture and development of the skull of the Collmon Frog (Rana temporaria)." Phil. 'Trans., 1871.

$(+51)$ W. K. Parker. "On the structure and development of the skull in the Salmon (Salmo salar)." Bakerian Leeture, Phil. Trans., 1873.

$(+, 52)$ W. K. Parker. "On the structure and development of the skull in the Pig (Sus serofa)." Plit. Trans., $187 t$.

$(+53)$ W. K. Parker. "On the structure and development of the sliull in the Batrachia." Part II. Phil. Trans., 1876.

$(+5+)$ W. K. l'arlier. "On the structure and development of the skull in the Urodelous Amphibia." Part In. Phil. Trans., 1877.

(45) IV. K. Parker. "On the strncture and derelomment of the sknll in the Common Snake (Tropidonotns natrix)." Phil. Troms, 1878.

$(+; 6)$ IV. K. Parker. "On the strueture and development of the skull in Sharks and skates." Trams. Zoolog. Soe., 1878. Vol. x. pt. Iv.

$(45)$ W. K. Parker. "On the structure and development of the skull in the Laeertilia." Pt. I. Lacerta agili-, L. viridis and Zootoea vivipara. Phil. Trons., 1879. $(458)$ W. K. Parker. "The derelopment of the Gireen Turtle." The Koolog!n of the loyage of H.ul.S. Challenyer. Vol. I. pt. v.

$(+59)$ W. K. Parker. "The structure and development of the skull in the Batrachia." Pt. III. Phil. Trans., 1880. 1877 .

$(+60)$ W. K. Parker and (i. T. Bettany. The Morphology of the Sliull. London,

$\left(+60^{*}\right)$ H. Rathke. Entuick, d. Nutter. Königsherg, 1839.

( $6 r)$ C. B. Reichert. "Ueber die Visceralbogen d. Wirbelthiere." Miller's Archiv, 1837.

(+62) W. Salensky. "Beiträge z. Entwick. d. linorpeligen (ielıörkn̈̈chelehen." Jorphol. Jahrbuch, Vol. vi. 1890.

Vide also Külliker (No. 29 \$), cspecially for the human and mammalian skull; (iötte (No. 29 ).

\section{The Pectoral, Girdel.}

$\left(4^{\sqrt{3}} 3\right)$ Brueb. "Ueber die Entwicklung der Clavienla und die Farbe des Blutes." Zeit. f. wiss, Zool., nv. 1853.

$\left(4^{6}+\right)$ A. Dugès. "Riecherc'les sur l'ostéologie et la mrologie des Batraciens ì

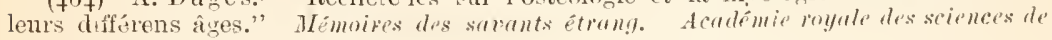
liisstitut de France, Vol. vi. 183 \%

B. E. II. 
(465) C. Gegenbaur. Untersuehungen zur vergleiehenden Auatomie der Wirb? thieve, 2 Heft. Sehultergürtel der Wrirbelthiere. Brustfosse der Fisehe. Leipzig, 186is. (466) A. Gütte. "Beiträge z. vergleich. Morphol. d. Skeletsystems d. Wirbelthiere: Brustbien u. Schultergiirtel. A rehiv f. mikr. Anat. Vol. xıv. 1877.

$\left(4^{6} 7\right)$ C. K. Hof fmann. "Beiträge z. vergleichenden Anatomie d. Wirbelthiere." Niederlïndisehes Arehin f. Zool., Vol. v. 1879.

( $f(6)$ IV. K. Parker. "A Monograph on the Strueture and Development of the Shoulder-girdle and Stermum in the Vertebrata." Roy Society, 1868.

$(450)$ H. Rathke. Ueber die Entwicklnug der Sehildkröten. Braunsehweig, 18ts. 1853.

(40) H. Rathke. Ueber den Ban und die Entwicklung des Brustbeins der Saurier,

$(+i r)$ A. Sabatier. Comparaison des ceintures et des membres antérieurs et postérieurs d. la Série d. I'ertébrés. Montpellier, 1880.

$(+72)$ Georg 'Swirski. Untersueh. $\ddot{b}$. d. Entwick. d. Sehultergürtels $u$. d. Skelets d. Brustflosse d. Heehts. Inang. Diss. Dorpat, 1880.

\section{The Pelvic Girdee.}

(473) A. Bunge. Untersueh. z. Entwick. a. Beekengürtels d. Amphilien, Reptilien u. Vögel. Inaug. Diss. Dorpat, 1880.

$(+\vec{i})$ C. Gegenbaur. "Ueber d. Aussehluss des Sehambeins von d. P'fanme d. Hüftgelenkes." Morph. Jahluuch, Vol. 1I. 1876.

(45) Th. H. Huxley. "The elharacters of the Pelvis in Mammalia, ete." Pror. of hoy. Soe., Vol. xxvit. 1879.

$(+76)$ A. Sabatier. Comparaison des ceintures et des membres antérions ot postérieurs dans lo Série d. Vertélués. Montpellier, 1880.

\section{SRELETON OF THE Liniss.}

(47) M. v. David off. "Beiträ̀ge z. vergleieh. Anat. d. hinteren Gliedmaassen d. Fiselie I." Morphol. Jahrlueh, Vol. v. 1879.

$(4-8)$ C. Gegenbaur. Untersuchungen z. vergleieh. Auat. d. Wirbelthiere. Leipzig, 1864-5. Erstes Heft. Carpus u. Tarsus. Zweites Heft. Brustflosse d. Fisehe.

(479) C. Gegenbaur. "Ueb. d. Skielet d. Gliedmaassen d. Wirbelthiere im Allgemeinen u. d. Hintergliedmaassen d. Selachier insbesondere." Jenaische Zeitschrift, Vol. v. 1870. 1873.

(480) C. Gegenbaur. "Ueb. d. Arehipterygium." Jenaische Zeitsehrift, Vol. vir.

(48I) C. Gegenbaur. "Zur Morphologie d. Gliedmaassen d. Wirbelthiere." Morphologisches Jahrbuch, Vol. 11. 18;6.

(482) A. Götte. Ueb. Entrick. u. Regeneration d. Gliedmaasseuskelets d. Molche. Leipzig, 1879.

$\left({ }_{4} \mathrm{~s}_{3}\right)$ T. H. Huxley. "On Ceratodus Forsteri, with some observations on the classifieation of Fishes." Proe. Zool. Soc. 1876.

$\left({ }_{4}\right)$ St George Mivart. "On the Fins of Elasmobranchii." Zoological Trans., Vol. $\mathrm{x}$.

( 48 ;) A. Rosenberg. "Ueb. d. Entwiek, d. Extremitäten-Skelets bei einigen d. Rednction ihrer Gliedna.assen eharakterisirten Wirbelthiere." Zeit.f. wiss. Zool., Vol. xxIII. 1873.

(486) E. Rosenberg. "Ueb. d. Entwick. d. Wirbelsäule u. d. eentrale carpi d. Menschen." Morphologisches Jahrbueh, Vol, I. 1875.

$\left({ }^{8} 87\right)$ H. Strasser. "Z. Entwiek. d. Extremitätenknorpel bei Salamandern u. Tritonen." Norphologisches Jahrbuch, Vol. v. 1879.

(488) G. 'Swirski. Untersuch. üb. d. Entwiek. d. Schultergürtels u. d. Skelets d. Brustflosse d. Hechts. Inang. Diss. Dorpat, 1880.

(489) J. K. Thacker. "Median and paired fins. A enntribution to the history of the Vertebrate limbs." Trans. of the Commenticut Acarl., Vol. I11. 1877.

(490) J. K. Thacker. "Ventral fins of Ganoids." Trans. of the Connectiont Aead., Vol. 1v. 1877. 


\section{Pleural and pericardial Cavities.}

(49r) M. Cadiat. "Du développement de la partie céphalothoracique de l'embryon, de la formation du diaphragme, des pleures, du péricarde, du plaryns et de l'usophage." Journal de l'Anatomie et de la 1'hysiologie, Vol. siv. 1878.

\section{Vascular System.}

\section{The IIeart.}

(492) A. C. Bernays. "Entwicklungsgeschichto d. Atrioventricularklappen." Morphol. Jahibuch, Vol. II. 1876.

(+93) E. Gasser. "Ueber d. Entstehung d. Herzens beim Hülnn." Archiv $f$. mikir. Anat., Vel, xiv.

(494) A. Thomson. "On the development of the vascular system of the futus of Vertebrated Animals." Ellinb. New Phil. Journal, Vol. Ix. 1830 and 1 S31.

(495) M. Tonge. "Observations on the development of the semilunar valves of the aorta and pulmonary artery of the heart of the Chick." Phil. Trans. curx. 1869.

Vide also Von Baer (291), Rathke (300), Hensen (IS2), Kölliker (298), Götte (296), and Balfour (292).

\section{The Arterial System.}

(496) H. Rathke. "Ueb. d. Entwick. d. Arterien w. bei d. Säugethiere von d. Bogen d. Aorta ausgehen." Müller's Arehiv, 1813.

(+97) H. Rathke. "Untersuchungen üb. d. Aortenwurzeln d. Saurier." Denkschriften d. k. Akud. Irien, Vol. xir. 1857.

Vide also His (No. 232) and general works on Vertebrate Embryology.

\section{The Venous System.}

$\left(49^{8)}\right.$ J. Marsliall. "On the development of the great anterior veins." Phil. Trans., 1859.

(499) H. Rathke. "Ueb. d. Bildung d. Pfortader u. d. Lebervenen b. Sängethieren." Jeckel's Archiv, 1830.

(500) H. Rathke. "Ueb. d. Bau u. d. Entwick. d. Venensystems d. Wirbelthiere." Bericht. ̈̈b. d. naturh. Seminar. d. Unie. Kï̈nigsberg, 1838.

Vide also Von Baer (No. 29r), Götte (No. 296), Kölliker (No. 299), and Rathke (Nos. 299, 300, and 301).

\section{The Spleen.}

(501) W. Mïller. "The Spleen." Stricker's IIistology!.

(502) Peremeschko. "Ueb. d. Entwick. d. Milz." Sitz. d. Wien. Akad. Wiss., Vol. LYI. 1867.

\section{The Suprarenal Bodies.}

(„o3) I. Braun. "Bau u. Entwick. d. Nebemnieren bei Reptilieu." Arbeit. a. d. zool-zoot. Institut Wiirzburg, Vol. v. 1879.

(5०4) A. v. Brunu. "Ein Beitrïg z. Kenntniss d. feinern Baues u. d. Entwick.

d. Nebennieren." Archiv f. mikr. Anat., Vol, vili. 1872.

(5о5) Fr. Leydig, Unter'such. ̈̈b. Fische u. Reptilien. Berlin, 1853.

$(506)$ Fr. Leydig. Rochen u. IIaie. Leipzig, 1852.

I'ide also F. II. Balfour (No. 292), Kölliker (No. 298), Remak (No. 302), etc. 


\section{'The Muscelar System of the Vertebrata.}

(507) G. M. Humphry. "Museles in Vertebrate Animals." Journ. of Anat. and Phys., Tol. vi. 1872.

(.08) J. Mïller. "Vergleiehende Anatomie d. Myxinoiden." Part I. Osteologie u. Myologie." Aknd. Wiss., Berlin, 1834.

(509) A. M. Marshall. "On the head eavities and associated nerves of Elasmobranehs." Quart. J. of Micr. Science, Vol. xxi. 1881.

(510) A. Sehneider. “Anat. u. Entwick. d. Muskelsystems d. Wirbelthiere." Sitz. d. Oberhessischen Gesellschatt, 1873.

(=ir) A. Schneider. Beitrïge z. vergleich. Anat. u. Entuicl. d. Wirbelthiere. Berlin, 187!).

I'ide also Götte (No. 296), Kölliker (No. 298), Balfour (No. 292), Huxley, cte.

\section{ExcRETORY ORgaNs.}

\section{INYERTEBRATA.}

(512) H. Eisig. “Die Sermentalorgane d. Capitelliden." Mittl. a. l. zol. Strit. $z$. Neapel, Vol. I. 1879.

(513) J. Fraipont. "liecherches s. l'appareil exeréteur des Trematodes et $\mathbf{d}$ Cestödes." Arrices de Biologir, Vol. I, 1880.

(., $\left.{ }_{+}\right)$B. Hatschek. "Studien ïb. Entwiek. d. Ameliden." Arbeit. a. a. zool. Instit. Wien, Vol. I. 1878.

(5I5) B. Hatschek. "Ueber Entwiek, von Echiurus," etc. Arbeit. a. d. zool. Instit. Wicn, Vol. 1II. 1880.

\section{VERTEBRATA.}

\section{Generul.}

(516) F. M. Balfour. "On the origin and history of the urinogenital organs of Vertebrates." Journal of Anat, and Phys., Vol. x. 187t.

(5г7) Max. Fiirbringer"1. "Zn' vergleichenden Anat. u. Entwick. d. Exeretionsorgane d. Vertebraten." Morphol. Jahrbach, Vol. Iv. 1878.

(5i8) H. Meckel. Zur Morphol. d. IIarn-u. Geschlechtswerliz. d. Wirbelthiere, etc. Halle, 1848.

(5rg) Joh. Miiller. Bildungsgeschichte d. Genitnlien, ete. Diisseldorf, 1830.

(520) H. Rathke. "Beobatchtungen u. Betrachtmngen ü. d. Entwieklung d. Geschlechtswerkzeuge bei den Wirbelthieren." N. Schriften d. uaturf. Gescll. in Dantzig, Bi. I. 1525 .

(521) C. Semper1. "Das Urogenitalsystem d. Plagiostomen 1l. seine Bedeutung f. d. uibrigen Wirhelthiere." A rb. a. d. zool.-zoot. Instit. Wiirzburg, Vol. Ir. 1875.

(522) W. Waldeyer ${ }^{1}$. Eierstock u. Ei. Leipzig, 1870.

\section{Elasmobranchii.}

$(52.3)$ A. Schultz. "Zur Eutwiek. d. Selachiereies." Archiv f. mikr. Anat., Vul, x1, 1575 .

ride also Semper (No. $52 \mathrm{I})$ and Balfour (No. 292).

\section{Cyclostometet.}

$(\$ 2 t)$ J. Miiller. "Untersuehungen i. d. Eingeweide d. Fisehe." Abh, $d . k$. Ak. Wiss. Berlin, 1845.

(525) W. M üller. "Ueber d. Persistenz d. Urniere b. Myxine glutinosa." Jenuische Zeitschrift, Vol, v1I. 1873.

(526) W. M ïller. "Ueber d. Urogenitalsystem d. Amphioxns u. d. Cyclostomen." Jenaische Zeitschrift, Vol. Ix. 1875.

1 The papers of Fibrbinger, Semper and Walcleyer contatin full references to the literature of the Vertebrate excretory organs. 
(527) A. Schneider. Bciträge z. rergleich. Aut. u. Eutvick. d. Wirbethicese Berlin, 1879 .

(.2S) W. B. Scott. "Beiträge z. Entwick. d. Petromyzonten." IIorphol. Jahibach, Vol. vi1. 1881.

\section{Teleostei.}

(329) J. Hyrtl. "Das mopoetische System d. Knochenfische." Denkschr. d. $k$. k. Akial. Wiss. Wien, Vol. In. 1850.

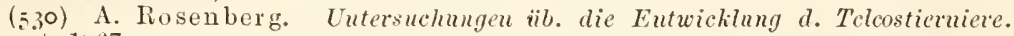
Dorpat, $1<67$.

Vide also Oellacher (No. 72 ).

\section{Amplibice.}

(5.31) F. H. Bidder. Vergleichend-auatomische u. histologische Untersuchnngen ii. die miinulichen Geschlechts- und Harnwerlizenge d. nackten Amphibien. Dorpat, 18t6.

(532) C. L. Duvernoy. "Fragments s. les Organes genito-urinaires des Reptiles," ete. Mém. Acul. Sciences. Paris. Vol. xr. 1851, pp. 17-95.

(533) M. Fii rbringer. Kur Éntwicklung d. Amphibienciere. Heidelberg, 1877.

(53.) F. Leydig. Anatomie d. Anphibien u. Reptilieu. Berlin, 1853.

(535) F. Leylig. Lehrbuch d. Histologie. Hamm, 1857.

(536) F'. M eyer. "Anat. d. Urogenitalsystems d. Selachier u. Amphibien." Sitz. d. maiurfor. Gesellsch. Leipzig, 1875.

(537) J. W. Spengel. "Das Urogenitalsystem d. Amphibieu." Arb. a. d. zool.zoot. Instit. W"ïrzburg. Vol. 11. 1876.

(..38) Von Wittich. "Harn- u. Gesehlechtswerkzenge d. Amphibien." Zeit.f. wiss. Zool., Vol. Ir.

$$
\text { ride also Gütte (No. 296). }
$$

\section{Aminiotu.}

(539) F. M. Balfour and A. Sedgwick. "On the existence of a head-kidney in the embryo Chick," etc. Qunt. J. of Hicr. Science, Vol, xix, 1878.

$(5+0)$ Banks. On the Wolfitan bodies of the fotns and their remaius in the adult. Edinburgh, 1864 .

$(\Sigma+1)$ Th. Bornhanpt. Untersuchangen ïb. die Eutuichlung d. Urogcnitalsystems bcin Hïhnchen. Inang. Diss. Riga, 1867.

$(5+2)$ Max Brann. "Was Urogenitalsystem d. einheimischen Reptilien." Arbeiteu a. d. zool.-zoot. Instit. Wiirzburg. Vol. Iv. 1877.

(5+3) J. Dansky u. J. Kostenitsch. "Ueb. d. Entwick. d. Keimblätter u. d. Wolff'schen Ganges im Hühnerei." Hém. Acal. Imp. Pétersbourg, vir. Series, Vol. xxVII. 1880.

(5+4) 'Th. Egli. Beiträge zur Anat. und Entwich. d. Geschlechtsorgune. Inaug. Diss, Zürich, 1876 .

$(5+5)$ E. Gasser. Beiträge zur Entucichingsgeschichte d. Allantois, der Hiiller'schen Gïnge u. des Afters. Frankfurt, 1874.

$(5+6)$ E. Gasser. "Beob. iib. đ. Entstehung d. Wolff'schen Ganges bei Embryonen von Hïhnern u. Gä̈nsen." Arch. für mikr. Auat., Vol. xiv. 1877.

$(5+7)$ E. Gasser. "Beiträge z. Entwicklung d. Urogenitalsystems d. Hüihuerembryonen" Sitz. d. Gesell. zur Beförderung d. gesum. Natnrtiss. Larburg, 1879.

$\left(54^{8}\right)$ C. Kupffer. "Untersuchung iiber die Entwicklung des Harn- und Geschlechtssystems." Archiv fiir milir. Anat., Vol. Ir. $1 \times 66$.

$(5+9)$ A. Sedgwick. "Development of the kilney in its relation to the Wolffian body in the Chick." Quart. J. of Micros. Science, Vol. xx. 1880.

$(550)$ A. Sedgwick. "On the development of the structure known as the glomeralus of the head-kidney in the Chick." Quart. J. of Hicrus. Science, Vol. xx. 18s0.

(.51) A. Sedgwick. "Early development of the Wolftian duct and anterior" Wolftian tubules in the Chick; with some remarks on the vertebrate excretory systcm." Quart. J. of Micros. Science, Vol. Xxi. 1881.

$(5,2)$ M. Watson. "The homology of the sexual organs, illustrated by comparative anatomy and pathology." Journal of Anat. and Phys., Vol. xiv. 1879.

$(553)$ E. H. Weber. Zusätze z. Lehre von Baue u. d. Verrichtungen d. Geschlechtsorgane. Leipzig, 1846.

I'ide also Remak (No. 302), Foster and Balfour (No. 295), His (No. 297), Kölliker (No. 298). 


\section{Generative Organs.}

(554) G. Balbiani. Lerons s. la génération des Vertébrés. Pari, 1879.

$(555)$ F. M. Balfour. "On the structure and development of the Vertebrate ovary." Quart. J. of Wicr. Science, Vol. sinn.

(556) E. van Beneden. "De la distinction originelle du tecticule et de l'ovaire, etc." Bull. dc. roy. bclgiqne, Vol. xxxviı. 1874.

(5.5) N. Kleinenberg. "Ueb. d. Entstehung d. Eier b. Eudendrium." Zcit. $f$. wiss. ZZool., Vol. xxxv. 1881.

$(5,5)$ H. Ludwig. "Ueb. d. Eibildung im Theirreiche." Arbcit. a. d. zool.-zoot. Instit. Wïrzburg, Vol. I. 1874.

(559) C. Semper. "Das Urogenitalsystem d. Plagiostomen, etc." Arbeit. a. $d$. zool.-zoot. Instit. Wï̈zburg, Vol. 11. 1875.

(560) A. Weismann. "Zur Frage nach dem Ursprung d. Geschlechtszellen bei den Hydroiden." Zool. Anzeiger, No. 55, 1880.

Iide also O. and R. Hertwig (No. 2ך1), Kölliker (No. 298), etc.

\section{Alimentary Canal and its Appendages.}

(561) B. Afanassiew. "Ueber Bau u. Entwicklung d. Thymus d. Säugeth." Archiv f. mikr. Anat. Bd. xiv. 1877.

(562) Fr. Boll. Das Princip d. Wachsthums. Berlin, 1876.

(563) E. Gasser. "Die Entstehung d. Cloakenöffnung bei Hühnerembryonen." Archin f. Anat. n. Physiol., Anat. Abth. 1880. 1867.

(564) A. Götte. Bciträge zur Entwicklungsgeschichted. Darmkanals im Hühnchen.

(565) W. Irüller. "Ueber die Entwickelung der Schilddrüse." Jenaische Zeitschrift, Vol. vi, 1871.

(5 6) W. Mïller. "Die Hypobranchialrimne d. Tunicaten." Jcnaische Zcit. schrift, Vol. vir. 1872.

$(567)$ S. L. Schenk. "Die Bauchspeicheldrüse d. Embryo." Anatomisch-physiologische Untersuchungen. 1872.

(568) E. Selenka. "Beitrag zur Entwicklungsgeschichte d. Luftsäcke d. Huhns." Zcit. f. wiss. Zonl. 1866.

(560) L. Stieda. Untersuch. üb. d. Enturick. d. Glandula Thymus, Glandula thyroidea, u. Glandula carotica. Leipzirg, 1881.

$(570)$ C. Fr. Wolff. "De formatione intestinorum." Nov. Comment. Akad. Petrop. 1766.

(5;1) A. Wölfler. Ucb. d. Eutuick. u. d. Ban d. Schilddrüse. Berlin, 1880.

lide also Kölliker (298), Götte (296), His (232 and 297), Foster and Balfour (295), Balfuur (292), liemak (302), Schenk (303), etc.

\section{Teeth.}

(572) T. H. Huxley. "On the enamel and dentine of teeth." Quart. J. of Micros. Science, Vol. III. 1855.

(573) R. Owen. Odoutography. London, 1840-1845.

(57t) Cl. S. Tomes. Hannal of dental anatomy, human and comparative. London, 1876 .

(5;5) Ch. S. Tomes. "On the development of tceth." Qnart. J. of Micros. Science, Vol. xvi. 1876.

$(5 ; 6)$ W. Waldeyer. "Structure and development of teeth." Stricker's Histology. 1870.

Iride also Kölliker (298), Gegenbaur (29t), Hertwig (306), etc. 




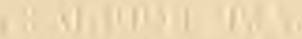

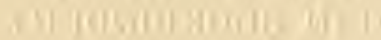

(i) 1 1940 


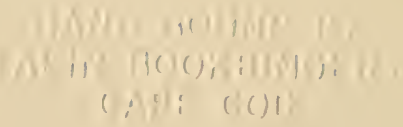



